UNIVERSIDAD POLITÉCNICA DE MADRID

FACULTAD DE INFORMÁTICA

Departamento de Lenguajes y Sistemas Informáticos e

Ingeniería del Software

TESIS DOCTORAL

\title{
PROCESO DE REVISIÓN SISTEMÁTICA DE EXPERIMENTOS EN INGENIERÍA DEL SOFTWARE
}

AUTORA:

TUTORES:
ANNA GRIMÁN PADUA

NATALIA JURISTO

(Universidad Politécnica de Madrid)

OSCAR DIESTE

(Universidad Politécnica de Madrid)

Madrid, Junio 2017 



\section{Resumen}

En el contexto profesional, la necesidad de tomar mejores decisiones obliga cada vez más a los líderes y gerentes a incorporar conocimiento que haya sido comprobado empíricamente, como una manera de reducir el grado de incertidumbre. Es así como los estudios empíricos han llegado a cumplir un rol importante en el proceso de toma de decisiones. Entre ellos, los experimentos controlados son el tipo de estudio más ampliamente aceptado en el contexto académico e industrial.

En Ingeniería del Software (IS) la conducción de experimentos controlados comienza a tomar auge en la última década. Tales experimentos han buscado comprobar, de una manera mucho más rigurosa, las ventajas de ciertas tecnologías frente a otras; o la utilidad de una tecnología particular en una situación dada. A pesar de esto, no podemos afirmar aún que la Ingeniería de Software Experimental sea una disciplina madura. Por el contrario, existen serias debilidades en cuanto a la cantidad y calidad de los experimentos individuales que podemos localizar, así como restricciones para recuperar los mismos utilizando los medios electrónicos disponibles. Todo lo anterior nos presenta limitaciones cuando pretendemos tomar decisiones basadas en las evidencias obtenidas de los experimentos individuales. Una manera de aumentar la validez de tales evidencias es combinar los resultados individuales por medio de métodos cuantitativos o cualitativos. Es así como surgen los estudios secundarios, tales como las Revisiones Sistemáticas (RS), que combinan los resultados de los estudios primarios previamente conducidos.

A pesar de que han sido propuestos lineamientos para la conducción de RS en la IS, éstos presentan debilidades y carencias, motivado por la fuerte influencia que han recibido de propuestas equivalentes que se encuentran en uso en otras disciplinas; sin considerar un conjunto de características que son particulares a la IS (p.e. una base experimental escasa y de calidad muy diversa). Esto lleva a que las RS en IS sean muy complejas y costosas. Frecuentemente, los revisores tienen que resolver de manera intuitiva dificultades de diferente naturaleza que impiden aprovechar la base de experimentos existentes. En otras ocasiones, los resultados que se obtienen no llegan a ser significativos, como consecuencia de un número muy pequeño de experimentos y sujetos. Finalmente, esto tiene un impacto negativo en la transferencia de razonamientos empíricamente comprobados a los tomadores de decisiones en el ámbito industrial.

En esta investigación se propone un proceso de revisión de experimentos que define cinco fases y establece lineamientos y recomendaciones para cada una de ellas; considerando las características específicas de la IS. Este proceso de RS se caracteriza por: 1) maximizar la cantidad de la evidencia primaria utilizada; 2) facilitar la definición del objetivo de revisión en aquellos casos de alto grado de incertidumbre; 3) resolver los problemas derivados de la diversidad de terminología; 4) manejar la condición de heterogeneidad de los experimentos, facilitando las actividades de lectura, extracción de datos y síntesis; 5) uso de diversas técnicas de meta-análisis que permiten aprovechar estudios con 
limitaciones de disponibilidad de datos; 6) uso de una escala validada para la evaluación de la calidad de experimentos. Además, se prescriben actividades, tareas y artefactos de manera sistemática; permitiendo que el proceso propuesto sea repetible, gestionado y documentado; promoviendo así su efectividad. Finalmente, todo esto contribuye al aprovechamiento de la mayor y mejor evidencia disponible para la agregación y generación de nuevo conocimiento. 


\section{Abstract}

In the professional context, the need to make better decisions forces leaders and managers more and more to incorporate knowledge that has been empirically proven, as a way to reduce the degree of uncertainty. This is how empirical studies have come to play an important role in the decision-making process. Among them, controlled experiments are the most widely accepted type of study in the academic and industrial context.

In Software Engineering (SE) the conduction of controlled experiments begins to take shape in the last decade. Such experiments have sought to verify, in a much more rigorous way, the advantages of certain technologies over others; or the utility of a particular technology in a given situation. In spite of this, we cannot yet claim that Experimental Software Engineering is a mature discipline. On the contrary, there are serious weaknesses in the quantity and quality of the individual experiments that we can locate, as well as restrictions to recover them using the available electronic means. All of the above presents limitations when we intend to make decisions based on the evidence obtained from the individual experiments. One way to increase the validity of such evidence is to combine individual results by quantitative or qualitative methods. This is how secondary studies arise, such as Systematic Reviews (SR) that combines the results of the previously conducted primary studies.

Although there are guidelines that have been proposed for the conduction of SR in SE, they present weaknesses and deficiencies, motivated by the strong influence they have received from equivalent proposals that are in use in other disciplines; without considering a set of characteristics that are particular to SE (e.g. a scarce experimental base of very diverse quality). This leads to SR in SE to be very complex and expensive. Often, reviewers have to intuitively solve difficulties of different nature that prevent taking advantage of the existing base of experiments. At other times, the results obtained do not become significant, as a consequence of a very small number of experiments and subjects. Finally, this has a negative impact on the transfer of empirically proven reasoning to industrial decision makers.

This research proposes a review process of experiments that defines five phases and establishes guidelines and recommendations for each one of them; considering the specific characteristics of SE. This SR process is characterized by: 1) maximizing the amount of primary evidence used; 2) facilitating the definition of the review objective in cases of high degree of uncertainty; 3) solving problems arising from the diversity of terminology; 4) to manage the heterogeneity condition of the experiments, facilitating the activities of reading, data extraction and synthesis; 5) use of various techniques of meta-analysis that allow to take advantage of studies with limitations of availability of data; and 6) use of a validated scale for the evaluation of the quality of experiments. In addition, activities, tasks and artifacts are systematically prescribed; allowing the proposed process to be repeatable, managed and documented; thus, promoting 
its effectiveness. Finally, all this contributes to the use of the greater and better available evidence for the aggregation and generation of new knowledge. 



\section{Índice General}

Acrónimos y Abreviaciones 1

PARTE I - DESCRIPCION DEL PROBLEMA DE INVETIGACIÓN 3

CAPÍTULO 1. INTRODUCCIÓN

1.1. Área de Investigación 4

1.2. Identificación del problema 7

1.3. Importancia del problema de investigación 8

1.4. Objetivo del trabajo 10

1.5. Aproximación a la solución 11

CAPÍTULO 2. ESTADO DE LA CUESTIÓN 15

2.1. Estado de la cuestión sobre procesos de revisión sistemática 15

CAPÍTULO 3. PLANTEAMIENTO DEL PROBLEMA 79

3.1. Descripción de la solución propuesta 79

3.2. Hipótesis de trabajo 79

3.3. Descripción de la solución propuesta 80

CAPÍTULO 4. METODOLOGÍA 82

4.1. Selección del Método de Evaluación 85

PARTE II - RESOLUCIÓN 92

CAPÍTULO 5. VISIÓN GENERAL DE PROCESO 93

5.1. Características de la IS que provocan variaciones en el proceso de RS 94

5.2. Aproximación a la solución 102

5.3. Proceso propuesto 109

CAPITULO 6. FASE DE BÚSQUEDA 120 
6.1. Características específicas de la IS que provocan variaciones en la Fase de Búsqueda

6.2. Aproximación a la solución 129

6.3. Actividades propuestas para la Fase de Búsqueda 131

CAPÍTULO 7. FASE DE EXTRACCIÓN DE DATOS 177

7.1. Características específicas de la IS que provocan variaciones en la Fase de Extracción de Datos 178

7.2. Aproximación a la solución 181

7.3. Actividades propuestas para la Fase de Extracción de Datos 182

CAPÍTULO 8. FASE DE VALORACIÓN DE LA CALIDAD 234

8.1. Características específicas de la IS que provocan variaciones en la Fase de Valoración de la Calidad 235

8.2. Aproximación a la solución 239

8.3. Actividades propuestas para la Fase de Valoración de la Calidad 248

CAPITULO 9. FASE DE SÍNTESIS DE DATOS 255

9.1. Características específicas de la IS que provocan variaciones en la Fase de Síntesis de Datos 256

9.2. Aproximación a la solución 259

9.3. Actividades propuestas para la Fase de Síntesis de Datos 262

CAPÍTULO 10. FASE DE REPORTE 302

10.1. Presentar una Introducción a la RS. 302

10.2. Presentar un resumen de los datos procesados durante la RS. 302

10.3. Presentar las evidencias obtenidas. 302

10.4. Presentar las hipótesis establecidas y las restricciones de la RS en función de las condiciones no ensayadas por los estudios. 303

PARTE III - VALIDACIÓN 308

CAPÍTULO 11. EVALUACIÓN DE LA PROPUESTA 309 
11.1. ANÁLISIS DE CARACTERÍSTICAS POR CASO DE ESTUDIO 309

11.2. DEFINICIÓN Y PRIORIZACIÓN DE LAS CARACTERÍSTICAS REQUERIDAS 310

11.3. SELECCIÓN DE EVALUADORES Y PROYECTOS 317

11.3. CASO DE ESTUDIO 1 (PROGRAMACIÓN EN PAREJA) 320

11.4. CASO DE ESTUDIO 2 (INSPECCIÓN DE SOFTWARE) 333

CAPÍTULO 12. IMPACTO DE LA EVALUACIÓN 356

12.1. ANÁLISIS DE LAS LIMITACIONES DEL PROCESO 356

12.2. IMPLEMENTACIÓN DE MEJORAS 362

CAPÍTULO 13. CONCLUSIONES Y TRABAJOS FUTUROS 369

13.1. Conclusiones 369

13.2. Futuras líneas 371 



\section{Índice de Figuras}

Figura 4.1. Enfoque metodológico. Adaptado de (Pérez, Grimán, Mendoza, \& Rojas, 2004) 83

Figura 5.1. Visión general del proceso de revisión 110

Figura 6.1.a. Actividades de la Fase de Búsqueda exclusivas al escenario "Objetivo a alto nivel" 131

Figura 6.1.b. Actividades de la FASE DE BÚSQUEDA comunes a ambos escenarios 132

Figura 6.2. Tareas relacionadas con la Determinación del tema de revisión 135

Figura 6.3. Tareas relacionadas con la Búsqueda preliminar de experimentos 138

Figura 6.4. Tareas relacionadas con el DESCARTE DE ARTÍCULOS IRRELEVANTES 150

Figura 6.5. Tareas relacionadas con la Selección de estudios a agregar 156

Figura 6.6. Tareas relacionadas con Ia DECLARACIÓN DEL OBJETIVO DE REVISIÓN 160

Figura 6.7. Tareas relacionadas con la actividad BÚSQUEDA Y LECTURA DE ANTECEDENTES 164

Figura 6.8. Tareas relacionadas con la actividad BÚSQUEDA REFINADA 168

Figura 6.9. Tareas relacionadas con la BÚSQUEDA ITERATIVA 171

Figura 6.10. Tareas relacionadas con el DESCARTE DE ARTÍCULOS IRRELEVANTES 174

Figura 6.11. Tareas relacionadas con la Definición de grupos candidatos a agregar 175

Figura 7.1. Actividades de la Fase de Extracción de datos 184

Tabla 7.1. Ejemplo de grupo candidato y factor principal. Caso de estudio: inspección de software 191

Figura 7.2. Tareas de la actividad LECTURA EN PROFUNDIDAD 201

Figura 7.3. Pasos de la tarea PLANIFICAR LA LECTURA 205

Figura 7.4. Tareas de la actividad ORGANIZACIÓN DE LOS DATOS 212

Figura 7.5. Tareas de la actividad Identificar GPAs __ 226

Figura 8.2. Actividades de la Fase de Evaluación de la calidad ___ 249

Figura 8.3. Formato de Evaluación de Calidad ___ 250

Figura 9.1. Actividades de la Fase de Síntesis de datos ___ 264

Figura 9.2. Plantilla para la agregación del grupo de estudios __ 266

Figura 9.3. Datos y condiciones de los estudios de A01 en la Plantilla de agregación ___ 270

Figura 9.4. Plantilla para la agregación del grupo de estudios A01__ 279

Figura 9.6. Plantilla para la agregación del grupo de estudios A01_1___ 285

Figura 9.7. Plantilla para la agregación del grupo de estudios A01_2_286

Figura 9.12. Jerarquía de técnicas para la RS sobre inspección de software___ 296

Figura 9.13. Jerarquía de VR y métricas para la RS sobre inspección de software __ 297 



\section{Índice de Tablas}

Tabla 4.1. Métodos de evaluación incluidos en DESMET (B. Kitchenham, 1996) 85

Tabla 4.4. Resumen de métodos candidatos 88

Tabla 4.5. Resumen de criterios prácticos (B. Kitchenham, 1996) 89

Tabla 5.1. Hitos del proceso de revisión 114

Tabla 5.2. Roles propuestos para el equipo de RS y actividades asociadas 115

Tabla 6.1. Ejemplo de Declaración del tema de revisión 137

Tabla 6.2. Ejemplo de documentación de una estrategia de búsqueda 146

Tabla 6.3. Ejemplo de registro de artículos recuperados 148

Tabla 6.4. Ejemplo de resumen de artículos relevantes 153

Tabla 6.5. Ejemplo de estadísticas de búsqueda 155

Tabla 6.6. Ejemplos de sub-temas de inspección de software 158

Tabla 6.7. Artículos agrupados por sub-tema 159

Tabla 6.8. Grupos candidatos a agregación 159

Tabla 6.9. Ejemplo de enunciado y justificación de un objetivo de revisión en el formulario B07 161

Tabla 6.10. Ejemplo de los componentes de la pregunta de revisión en el formulario B07 162

Tabla 6.11. Ejemplo de los criterios de I/O en el formulario BO7 163

Tabla 7.2. Ejemplo Agrupamiento por tarea. Caso de estudio: inspección de software 191

Tabla 7.3. Ejemplo Agrupamiento por tipo de sujeto. Caso de estudio: inspección de software 192

Tabla 7.4. Ejemplo de resumen de datos del experimento ART_27. Caso de estudio: inspección de software

Tabla 7.5. Ejemplo de Agrupamiento de Replicaciones. Caso de estudio: inspección de software 194

Tabla 7.6. Ejemplo de Agrupamiento de Replicaciones. Caso de estudio: inspección de software 195

Tabla 7.7. Ejemplo de representación tabular 196

Tabla 7.8. Ejemplo de representación de los estudios del grupo Requisitos - Estudiantes 196

Tabla 7.9. Ejemplo de re-organización de los estudios del grupo Requisitos - Estudiantes 197

Tabla 7.10. Ejemplo de representación tabular agrupando en clusters 197

Tabla 7.11. Ejemplo de representación tabular: Requisitos - Estudiantes 198

Tabla 7.12. Ejemplo de representación tabular: Código - Estudiantes 198

Tabla 7.13. Ejemplo de agrupamiento: Diseño - - Estudiantes 199

Tabla 7.14. Ejemplo de agrupamiento: Diseño con UML - Estudiantes 199

Tabla 7.15. Ejemplo de re-estructuración: Requisitos-Estudiantes 202

Tabla 7.16. Ejemplo de re-estructuración: Código - Estudiantes ___ 203

Tabla 7.17. Ejemplo de re-estructuración: Diseño - - Estudiantes ___ 203

Tabla 7.18. Ejemplo de re-estructuración: Diseño con UML - Estudiantes ___ 203 
Tabla 7.19. Ejemplo de Orden de lectura para los grupos relacionados con inspección de software 207

Tabla 7.20. Ejemplo de Codificación de estudios 213

Tabla 7.21. Ejemplo de Codificación de factores 213

Tabla 7.22. Ejemplo de Codificación de Variables Respuesta 214

Tabla 7.23. Ejemplo de Codificación de métricas 214

Tabla 7.24. Ejemplo de Resumen de datos cuantitativos 217

Tabla 7.25. Ejemplo de Resumen de contexto experimental 220

Tabla 7.26. Ejemplo de Resumen de resultados experimentales y observaciones por estudio 223

Tabla 7.27. Ejemplo de Resumen de densidad de estudios por métrica 227

Tabla 7.28. Formato para el análisis de densidad de estudios por métrica y tarea-tipo de sujeto_ 229

Tabla 7.29. Formato para el análisis de densidad de estudios por métrica M01 y tarea-tipo de sujeto _ 230

Tabla 7.30. Ejemplo de densidad de estudios para la métrica M01 y la tarea Requisitos 230

Tabla 7.31. Ejemplo de densidad de estudios para la métrica M03 y la tarea Código 231

Tabla 7.32. Ejemplo de densidad de estudios para la métrica M01 y la tarea Diseño 231

Tabla 7.33. Grupos potencialmente agregables para el caso de estudio según el factor Técnica 232

Tabla 8.1. Condiciones de los niveles de calidad de un experimento 252

Tabla 8.2. Relación de preguntas y niveles de calidad de un cuasi-experimento 253

Tabla 9.1. Resumen de Datos cuantitativos del grupo A01 270

Tabla 9.2. Resumen de datos requeridos por cada técnica de meta-análisis 273

Tabla 9.4. Listado de Evidencias 291

Tabla 9.4. Ejemplo de Listado de evidencias 291

Tabla 9.5. Listado de Hipótesis 292

Tabla 9.6. Resumen de hipótesis 293

Tabla 9.7. Niveles de confianza 295

Tabla 9.8. Interpretación de los niveles de confianza 295

Tabla 6. Ejemplo de Relación de evidencias con cada nivel/métrica para el caso de inspección de software

Tabla 7. Ejemplo de resumen de evidencias por nivel 299

Tabla 9.10. Ejemplo de resumen de evidencias por métrica 300

Tabla 11.1. Características a ser evaluadas 301

Tabla 11.2. Sub-características a evaluar 312

Tabla 11.3. Ejercicios de evaluación realizados sobre el proceso de RS 312

Tabla 11.4. Ejercicios de evaluación realizados sobre el proceso de RS 320

Tabla 11.5. Tareas genéricas relacionadas con las fases de Búsqueda y Extracción 320

Tabla 11.6. Resultados más relevantes obtenidos de ambos procesos 321

Tabla 11.7. Problemas identificados en ambos procesos 322

Tabla 11.8. Comparación de los procesos Grimán y Kitchenham versus (Hannay et al., 2009) 324

Tabla 11.9. Evaluación de características con base en el caso de estudio 1 325 
Tabla 11.10. Fases y actividades genéricas para la comparación

Tabla 11.11. Resultados obtenidos para las actividades genéricas de la fase de Búsqueda en los procesos comparados. 337

Tabla 11.12. Resultados obtenidos para las actividades genéricas de la fase de Extracción en los procesos comparados.

Tabla 11.13. Resultados obtenidos para las actividades genéricas de la fase de Síntesis en los procesos comparados. 342

Tabla 11.14. Comparación de estudios recuperados y agregados en ambos procesos 345

Tabla 11.15. Análisis de artículos no incluidos en el caso de estudio 347

Tabla 11.16. Evaluación de características con base en el caso de estudio 2 351

Tabla 12.1. Limitaciones encontradas durante la validación del proceso 356

Tabla 12.2. Mejoras incorporadas al proceso y su relación con las características evaluadas 367 



\section{Acrónimos y Abreviaciones}

\begin{tabular}{|c|c|}
\hline ARCHE & Alberta Research Centre For Child Health Evidence \\
\hline $\mathrm{C} 2$ & Campbell Collaboration \\
\hline C2-RIPE & $\begin{array}{l}\text { Campbell Collaboration Reviews of Intervention and Policy Effectiveness } \\
\text { gister }\end{array}$ \\
\hline $\mathrm{CC}$ & Cochrane Collaboration \\
\hline CDR & Centre for Reviews and Dissemination \\
\hline CEBC & Centre for Evidence-based Conservation \\
\hline EPPI & Evidence for Policy and Practice Initiative Centre \\
\hline EBSE & Empirical Software Engineering \\
\hline $\mathrm{GCl}$ & Grupo de Colaboración en Investigación \\
\hline GR & Grupo de Revisión \\
\hline GRSB & Grupo de revisions sistemáticas de la Universidad de Berkley \\
\hline HANAH & The Housing and Neighbourhoods and Health Project \\
\hline HuGE & Human Genome Epidemiology Network \\
\hline$J \mathrm{BI}$ & Joanna Briggs Institute \\
\hline IS & Ingeniería de Software \\
\hline ISE & Ingeniería de Software Experimental \\
\hline LRSIS & Lineamientos para Revisiones Sistemáticas en Ingeniería de Software \\
\hline MOOSE & Meta-analysis Of Observational Studies in Epidemiology \\
\hline NCVER & National Centre for Vocational Education Research \\
\hline NHMRC & National Health and Medical Research Council \\
\hline NICE & National Institute for Health and Clinical Excellence \\
\hline QUOROM & Quality Of Reporting Of Meta-analyses \\
\hline $\mathrm{RCT}$ & Randomized cotrolled trial \\
\hline RS & Revisión Sistemática \\
\hline RSC & Revisión Sistemática Cochrane \\
\hline
\end{tabular}




\section{SIGN \\ Scottish Intercollegiate Guidelines Network}

UFRJ

Universidad Federal de Río de Janeiro 


\section{PARTE I - DESCRIPCION DEL PROBLEMA DE INVETIGACIÓN}




\section{CAPÍTULO 1. INTRODUCCIÓN}

\section{1. Área de Investigación}

La Medicina Basada en la Evidencia (MBE) ha sido adoptada por varios otros dominios, incluyendo la Ingeniería de Software; donde el mecanismo normal para la identificación y la agregación de evidencia es la revisión sistemática de la literatura; dando origen a lo que se conoce, por analogía con Medicina, como Ingeniería de Software Basada en la Evidencia (IBSE), la cual puede definirse como una aproximación a los estudios empíricos en la que el investigador busca identificar e integrar la mejor evidencia disponible con la experiencia de campo para informar sobre prácticas y formulación de políticas (B. A. Kitchenham et al., 2004).

ISBE tiene como objetivo principal mejorar la toma de decisiones relacionadas con el desarrollo y mantenimiento de software mediante la integración de la mejor evidencia actual de Investigación con la experiencia práctica y los valores humanos (Dyba et al., 2005). Para comprender mejor esta aproximación, es necesario definir los diferentes tipos de evidencia que pueden localizarse en ISBE:

1. Ensayo clínico o Experimento controlado aleatorizado (RCT): Es una forma de estudio primario. Se refiere a un estudio en el que es controlada deliberadamente una intervención (es decir, un tratamiento) para observar sus efectos (Shadish, Cook, \& Campbell, 2002)

2. Cuasi-experimento: Un experimento en el que las unidades no son asignadas al azar para las intervenciones (Shadish et al., 2002).

3. Caso de Estudio: Una forma de estudio primario que incluye la investigación de algún fenómeno en un contexto de la vida real. Los casos de estudio se utilizan normalmente para fines explicativos, exploratorios y descriptivos. Las dos principales formas son Caso de estudio único: que puede ser apropiado cuando se estudia un caso representativo o un caso especial, pero será menos confiable que la forma de Múltiples casos, donde la replicación se emplea para ver el número de veces que casos muy diferentes pueden predecir los mismos resultados. Debe tenerse en cuenta que el termino Caso de estudio se utiliza a veces en otras disciplinas en el sentido de una narrativa que describe un ejemplo de interés (Yin, 2003) (Oates, 2006)

4. Encuesta: Método de investigación global de recopilación de información para describir, comparar o explicar los conocimientos, las actitudes y el comportamiento. El propósito de la encuesta es recoger información de un gran grupo de personas de una manera estándar y sistemática, y luego a buscar patrones en los datos resultantes que pueden generalizarse a la población en general (Budgen, 2007) .Las encuestas pueden ser: 
a. Descriptivas: El objetivo es averiguar cuáles son los atributos de un fenómeno particular.

b. Explicativa: El propósito aquí es explicar por qué se produce un fenómeno particular.

c. Exploratoria: Aquí el estudio exploratorio se utiliza para "delimitar" un problema y garantizar luego que un estudio (más completo) no omita cualquier asunto de importancia.

5. Revisión sistemática de la literatura: esta es una forma particular de estudio secundario y tiene como objetivo proporcionar un enfoque objetivo e imparcial a la búsqueda de estudios primarios relevantes, y para la extracción y la agregación de los datos de los mismos (B. Kitchenham \& Charters, 2007).

6. Estudios Observacionales: en un estudio observacional, el investigador observa el comportamiento de interés directamente, los estudios observacionales proporcionan una riqueza de descripción que falta en los métodos más estructurados de recolección de datos, como los experimentos y encuestas (BERENSON \& LEVINE, 1996).

7. Estudios de Cohorte: son un procedimiento epidemiológico analítico de carácter longitudinal, basado en la observación a largo plazo del tiempo de dos grupos de individuos; uno constituido por individuos expuestos a un fenómeno (Cohorte expuesta) y otro, compuesto por individuos no expuestos a dicho fenómeno (García \& González, 2000).

Entre los tipos de estudios descritos, es de interés para esta investigaciónlas las revisiones sistemáticas de ensayos clínicos o experimento controlados aleatorizados (RCT). No obstante, otros tipos de estudios serán de interés para trabajos futuros.

Dentro de la investigación por revisión de la literatura se conocen dos tipos diferentes: las revisiones sistemáticas y las revisiones narrativas. La revisión narrativa fue tradicionalmente el método de integración de la literatura. Sin embargo, presenta al menos dos debilidades claras: 1) no se establece una norma sobre cómo conseguir los datos primarios ni cómo sintetizarlos, sino que aplica el criterio subjetivo del revisor; y 2) no se combinan los datos primarios de manera cuantitativa (Beltrán, 2005). Por lo tanto, las revisiones narrativas corren el riesgo de obtener resultados imprecisos y sesgados.

Por el contrario, una RS da respuesta a una pregunta que ha sido claramente formulada por el revisor y utiliza métodos sistemáticos y explícitos para identificar, seleccionar, y evaluar tales evidencias; así como extraer y analizar los datos proporcionados por éstas (Khan et al., 2001). Una RS es un estudio integrativo, observacional, retrospectivo, secundario, en el cual se combinan estudios primarios que examinan la misma pregunta (Beltrán, 2005). Dentro de la RS pueden existir dos formas (Beltrán, 2005):

- Cuantitativa o meta-análisis

- Cualitativa u overview

Proceso de RS de experimentos en IS 
Propuesta de un proceso de revisión de estudios empíricos en Ingeniería del Software

Las diferencias están dadas por el uso de métodos estadísticos que permiten la combinación y análisis cuantitativo de los resultados obtenidos en cada uno de los estudios primarios. El método cuantitativo clásico consiste en el meta-análisis, el cual incluye el análisis estadístico de una amplia serie de resultados individuales correspondientes a los estudios primarios, con el objeto de integrar sus hallazgos (G. Glass, 1976) .

Las RS tuvieron su origen en Medicina (Pearson, 1904). Las RS también se han aplicado durante años en Educación, Psicología y otros campos de las Ciencias Sociales y de la salud, para la generación de evidencias que soporten la toma de decisiones en su práctica profesional. En tales disciplinas existen metodologías reconocidas, que orientan en la realización de estos procesos y el reporte de sus resultados.

A diferencia de lo ocurrido en tales disciplinas, el nacimiento de las RS en IS es muy reciente. Prueba de ello es que en (R. L. Glass, Vessey, \& Ramesh, 2002) se examinaron 369 artículos publicados en el período 19951999 en seis revistas de reputación del área, encontrando que sólo un $1.1 \%$ de los artículos analizados utilizaron revisiones o análisis de la literatura como método de investigación, ninguno de los cuales utilizó el meta-análisis.

No obstante, a finales de los años 90 pueden ubicarse algunos trabajos que ponen el Meta-análisis en el contexto de la IS. Ejemplos de ello son los trabajos de (Brooks, 1997), (Pickard, Kitchenham, \& Jones, 1998) y (Hayes, 1999) quienes presentan las ventajas de su aplicación en esta área. Mientras que (Miller, 1999) (J. Miller, 2000) pone en evidencia las deficiencias de esta técnica para alcanzar resultados confiables.

A comienzos del siglo XXI aparecen las primeras revisiones, aunque con un fuerte énfasis en el uso del Meta-análisis: (Döring, 2002) presenta una RS sobre treinta estudios relacionados con el desarrollo de sitios Web personales; (Whitten \& Stephens, 2002) describen el análisis utilizado para producir nuevo conocimiento acerca de las funciones infomediarias; (Premkumar, 2003) evalúa el impacto de ciertos factores en la adopción de tecnologías de comunicación basadas en el ordenador; finalmente, destaca en este período el trabajo de (C. Wohlin, Peterson, \& Aurum, 2003) en el que realizó la combinación de 30 grupos de datos para evaluar la influencia de varios aspectos diferentes, incluyendo técnicas de lectura, tamaños de equipo y perfil de los sujetos (profesionales versus estudiantes). Sin embargo, no fue sino hasta que aparece la propuesta de (B. Kitchenham, 2004) que se comienza a hablar de una propuesta de lineamientos para RS en IS.

Posteriormente se han producido otras revisiones, aunque de manera muy conservadora. Por ejemplo, (Cruzes \& Dyba, 2010) encontraron un conjunto de 31 revisiones en el período 2004-2009. De la misma manera, en (B. Kitchenham, Pretorius, et al., 2010) (B. Kitchenham, Pretorius, et al., 2010)se localizaron 33 RS en el período 2004-2010. La mayoría de las RS documentadas en IS están inspiradas en el procedimiento propuesto por (B. Kitchenham, 2004).

Al mismo tiempo que se dan estas revisiones, aparecen también publicados otros trabajos relacionados con aspectos que influyen en los resultados de una RS; por ejemplo, varias iniciativas de estandarización fueron publicadas en (A. Jedlitschka \& D. Pfahl, 2005; B. Kitchenham et al., 2006; B. Kitchenham, Pfleeger, 
Pickard, Jones, Hoaglin, Emam, et al., 2002) que intentan mejorar y estandarizar el reporte de estudios empíricos en esta área.

También en IS se encuentran intentos de sentar las bases de una disciplina basada en la evidencia. Es así como se ubican los primeros trabajos (T. Dybå, Kitchenham, \& Jørgensen, 2005; B. Kitchenham, Budgen, Brereton, \& Linkman, 2005; B. Kitchenham, Dybå, \& Jørgensen, 2004; Rainer, Jagielska, \& Hall, 2005) que establecieron los beneficios y limitaciones de la IS basada en Evidencia (EBSE, por su acrónimo inglés Evidencebased Software Engineering) y establecieron que el propósito de esta práctica es soportar, con teorías basadas en evidencias empíricas, el proceso de toma de decisiones de los profesionales de la IS.

\subsection{Identificación del problema}

La toma de decisiones es la esencia de la gestión, donde las decisiones que están respaldadas por datos y análisis suelen ser mejores que las decisiones tomadas sobre la base del instinto, el folklore o la evidencia anecdótica informal (Tingling \& Brydon, 2010). Según (Tingling \& Brydon, 2010), mucho se ha escrito en los años recientes acerca de cómo mejorar el proceso de toma de decisiones basado en evidencia o basado en hechos; ejemplo de ello son los trabajos presentados en (Davenport \& Harris, 2007 ), (Lewis, 2003) y (Ayres, 2008) quienes describen las virtudes del análisis de datos para mejorar la toma de decisiones.

La IS es un área donde el proceso de toma de decisiones involucra situaciones como la evaluación de costos, límites, calidad, y riesgos inherentes a un proyecto. Los ingenieros de software pueden tomar decisiones incorrectas, tales como la adopción de nuevas técnicas, si no consideran evidencia científica acerca de la eficacia de tales técnicas (Dyba, Kitchenham, \& Jorgensen, 2005).

Para que el proceso de toma de decisiones pueda ser soportado por la evidencia científica, es necesario conducir estudios secundarios, como las revisiones sistemáticas, que permitan obtener nuevo conocimiento validado a través de los estudios primarios. Como veremos más adelante esto ha supuesto un reto en nuestra disciplina.

Puede observarse en la literatura como las metodologías que están en uso en otras disciplinas, han demostrado ser muy efectivas en sus respectivos contextos. Como ejemplo se puede mencionar el catálogo de la Cochrane que cuenta con más de 12000 revisiones del área de Medicina. En tales disciplinas existen metodologías reconocidas, tales como (EPPI-CENTRE, 2002; EPPI-CENTRE, 2003; Higgins, 2006; Khan et. al, 2001; NHMRC, 2000; Pai et. al, s/f), que orientan en la realización de estos procesos y el reporte de sus resultados.

Es comprensible que en las propuestas actuales en IS es notoria la influencia de las metodologías para RS de Medicina. Sin embargo, dichas metodologías no son necesariamente extrapolables a otras áreas del conocimiento y en particular a la IS.

Proceso de RS de experimentos en IS 
Propuesta de un proceso de revisión de estudios empíricos en Ingeniería del Software

Encontramos en la práctica que existen problemas para la aplicación de tales metodologías, ya que la IS presenta diferencias importantes con las disciplinas de las Ciencias de la Salud. La experiencia recogida en (Davis et. al, 2006; Fernández, 2007) nos permitió identificar las características de la IS que la diferencian de Medicina en cómo se conduce una RS:

- La motivación se deriva del interés por conocer el estado de madurez del conocimiento sobre una tecnología (por ejemplo, ¿qué sabemos sobre técnicas de prueba?). Como consecuencia no se puede definir un objetivo con suficiente precisión desde el comienzo de la RS (Higgins, 2006), y es muy difícil realizar un desarrollo temprano del protocolo de revisión.

- En relación a la búsqueda, vemos que en IS la exhaustividad en las búsquedas es necesaria debido a que se cuenta con un número reducido de experimentos. Debido a que la terminología utilizada en el área no es estándar, el proponer cadenas de búsqueda predefinidas es imposible.

- La Síntesis de datos se ve afectada por la falta de estandarización. Experimentos que analizan los mismos factores y variables respuesta los pueden reportar de manera diferente, creando confusión al agregarlos.

- La extracción de datos no es sencilla ya que también se ve afectada por la falta de estandarización del vocabulario y la baja calidad de los reportes.

- Los aspectos de un estudio (por ejemplo, ocultamiento, enmascaramiento, etc.) que influyen en su calidad no son claros. Esto que ha resultado evidente en nuestros resultados preliminares, también ha sido ampliamente discutido en el caso de otras disciplinas (Concato and Horowitz, 2004) (Feinstein and Horowitz, 1977) (Lawlor et. al, 2004), en las que tampoco se tiene claro qué aspectos pueden influir directamente en los resultados del estudio.

- El contar con un número muy pequeño de experimentos, que incluyen pocos sujetos, afecta al nivel de certeza de los resultados obtenidos a través de meta-análisis tradicional (especialmente si el tamaño del efecto estudiado es muy pequeño). Además de esto, existen diferentes variables moderadoras que pueden influir en los resultados de cada experimento llevando muchas veces a obtener resultados muy heterogéneos, incluso contradictorios.

En las características anteriores podemos observar que más que aplicar metodologías importadas de otras disciplinas se requiere un proceso particular de RS para IS. La ausencia de tal proceso provoca que la Síntesis de resultados experimentales sea muy difícil y que no sea posible generar piezas de conocimiento que soporten adecuadamente la toma de decisiones en esta disciplina.

\subsection{Importancia del problema de investigación}

No es desconocida para la mayoría de los profesionales y adémicos vinculados a la IS, la complejidad que caracteriza los proyectos que se llevan a cabo en esta disciplina. Observándose sobretodo una tasa de 
incumplimiento alta en relación a los tiempos y presupuestos. Tanto que nos ha llevado a hablar durante casi 50 años acerca de una crisis del software. Por otra parte, nos enfrentamos a retos continuos en cuanto al uso de las tecnologías de información y comunicación (TIC) con el fin de proveer mayores beneficios y prestaciones a los clientes y usaurios finales.

Todo lo anterior ha llevado a que continuamente se propongan nuevas tecnologías de desarrollo (por ejemplo; lenguajes, marcos de desarrollo, bases de dato, tipos de datos, etc.) asi como técnicas, métodos y metodologías conducentes a resolver los problemas inherentes al desarrollo de software, especialmente en prácticas como la estimación, la elicitación de requisitos, la planificación, entre otros. De esta manera, las tecnologías propuestas suponen una serie de beneficios, pero también desventajas para los desarrolladores. Existe además una tendencia general a generar propuestas con escasa o ninguna validación. Así mismo tales propuestas carecen de la articulación respecto a un determinado contexto; por ejemplo, las metodologías de desarrollo no incluyen necesariamente métodos específicos para su adopción (técnicas de prueba, técnicas de elicitación de requisitos, etc.), las técnicas recomendadas no son vinculadas con un determinado perfil del analista o desarrollador, se desconoce si las mismas funcionan igual de bien para diferentes dominios, etc.

En este sentido, (Hammersley, 2001), señala que la investigación en IS es falible, que se basa en generalizaciones que pueden ser difíciles de interpretar, y que es a menudo insuficiente para determinar los medios adecuados para la entrega de la mejor práctica.

Como lo describen (Wallace y Binkley, 2003), los profesionales y gerentes de software que buscan la calidad de su desarrollo de software suelen adoptar nuevas tecnologías sin pruebas suficientes. Estos gestores y profesionales de software a menudo tienen que tomar decisiones acerca de diversos procesos. Las compañías de software están a menudo bajo presión de adoptar tecnologías inmaduras, debido a las presiones del mercado y de gestión.

Esta complejidad de la IS, sumada a la proliferación de propuestas más o menos aisladas y de las cuales se cuenta con poca información y aplicación, genera interés en ámbitos distintos.

En primer lugar, en el ámbito académico surge la preocupación por validar tales propuestas desde un punto de vista empírico; comparando el uso de estas tecnologías entre sí, o el uso de una tecnología en particular versus no utilizar ninguna tecnología. Lo cual lleva a la conducción tanto de estudios primarios (tales como experimentos controlados) como estudios secundarios, como las revisiones sistemáticas. Éstos últimos, son especialmente importantes ya que permiten lidiar con las limitaciones de los estudios primarios, los cuales suelen contar con pocos sujetos.

Sin embargo, la experiencia revela que la conducción de RS enfrenta diversas dificultades que limitan su aplicación en la IS. Es por ello que mientras que encontramos una cantidad creciente de estudios de mapeo, el número de RS no ha crecido considerablemente en la última década.

Proceso de RS de experimentos en IS 
Los revisores en el ámbito académico encuentran difícil la aplicación de los métodos tradicionalmente usados en Medicina, bajo las condiciones particulares de la IS. Se requiere entonces de orientaciones metodológicas que permitan obtener nuevas evidencias con ciertas garantías y que alimenten la base de conocimiento acerca de las nuevas tecnologías o, incluso, sobre las tecnologías existentes.

Mientras tanto, en el ámbito industrial la necesidad de evidencias que soporten la selección de las tecnologías más adecuadas para un determinado proyecto, es una constante que incide directamente en la rentabilidad del negocio y genera continuas presiones para los gerentes. Más aún cuando observamos que en la actualidad, con el avance acelerado de la tecnología, el cierre de las brechas digitales, y el dinamismo de las organizaciones, el proceso de toma de decisiones cobra una importancia crítica.

Sin embargo, a menudo los miembros de las organizaciones toman decisiones sin la información suficiente como para soportar su elección (Akdere, 2011).

Vemos entonces como la toma de decisiones es de vital importancia en la innovación de una organización. Usando el proceso de toma de decisiones adecuadamente, se pueden obtener productos de mayor calidad, con un costo menor y de manera más rápida (Levesque \& Walker, 2007).

\subsection{Objetivo del trabajo}

El objetivo general de esta investigación es desarrollar un proceso de revisión sistemática adaptado a la Ingeniería del Software, considerando las características que la hacen particular y que establecen limitaciones para la aplicación de los procesos propuestos en otras disciplinas.

Con base en la experiencia previa se han identificado limitaciones para el uso de los procesos actuales, en cuanto a aspectos inherentes a la búsqueda, extracción de datos, valoración de la calidad, síntesis de datos, y reporte.

Se espera realizar una propuesta que no necesariamente incorpora nuevas fases al proceso de RS; considerando que las fases mencionadas son las que recurrentemente aparecen en los procesos que han sido analizados en estado de la cuestión, bien sea que se encuentran en uso en otras disciplinas o en la IS. Sin embargo, para cada una de estas fases se deberán analizar las características particulares de la IS que promueven cambios en las prácticas actualmente propuestas.

Por otra parte, se deberá establecer una manera de integrar estas fases, incluyendo los artefactos que se deben generar en cada uno de ellas como insumo a otras fases o como conocimiento que debe ser capitalizado para una mejor gestión del proceso.

Por lo anterior, se busca proponer un proceso que cumpla con las siguientes características:

- Sistemático: el proceso deberá prescribir el conjunto de actividades y pasos que deben ser acometidos para alcanzar el objetivo, la generación de evidencia confiables sobre el tema de revisión establecido. 
- Documentado: se requiere que el proceso genere información suficiente a manera de informe de la revisión realizada, lo que permitirá tomar decisiones en relación a mejoras del proceso, criterios, cadenas de búsqueda, etc.

- Repetible: el proceso a proponer debe presentar información detallada que permita su ejecución tanto por revisores experimentados como noveles.

- Eficiente: dado los costos elevados en tiempo y esfuerzo de una RS, es necesario que el proceso a proponer mantenga la coste-efectividad; permitiendo obtener los mejores resultados con el menor esfuerzo posible.

\subsection{Aproximación a la solución}

En esta investigación hemos aplicado el método Investigación-Acción para proponer nuestra solución. Esto nos ha llevado desde el análisis de diferentes propuestas que se encuentran en uso en otras disciplinas, así como en la Ingeniería de Software; hasta la aplicación de las fases y actividades propuestas en dos casos de estudio.

Para satisfacer el objetivo general planteado, se propone un proceso de RS de experimentos que incluye las fases de Búsqueda de experimentos, Extracción de datos, Valoración de la Calidad, Síntesis de Datos y Reporte de la revisión; tal como se ha identificado en la mayoría de los procesos en el Estado de la cuestión. No obstate, cada una de estas fases ha requerido de una serie de ajustes y recomendaciones, que pueden ser resumidos como sigue.

- La FASE DE BÚSQUEDA incluyó recomendaciones sobre la estrategia de búsqueda que se debe seguir para la localización de experimentos, con el fin de maximizar la recuperación de experimentos reduciendo el esfuerzo de descarte de artículos irrelevantes. Esta estrategia incluye no sólo los campos en los cuales se debe realizar la búsqueda sino también recomendaciones para la definición de cadenas de búsquedas óptimas relacionadas con los tratamientos, las métricas y el tipo de estudio que se quiere localizar.

- Para sobrellevar la escasez de estudios se incorporó no sólo experimentos controlados aleatorizados (RCT) sino también cuasi-experimentos.

- Para evitar la lectura de material irrelevante, la lectura durante la EXTRACCIÓN DE DATOS se realiza en dos ciclos: una lectura superficial que extraiga sólo los datos necesarios para formar grupos de experimentos similares en cuanto a niveles y mediciones, y otra lectura en profundidad que debería concentrarse en aquellos grupos de experimentos que sean más parecidos y, por lo tanto, con posibilidades de ser agregados más adelante.

- Desde el punto de vista de la SínTESIS DE DATOS, se busca es agregar la mayor cantidad de experimentos que sea posible, siempre siguiendo el criterio de máxima similitud entre ellos. Durante la ExTRACCIón

Proceso de RS de experimentos en IS 
DE DATOS se identifican aquellos experimentos que son más compatibles en cuanto a los niveles que ensayan y las variables que son medidas.

- Al identificar durante la extracción grupos de experimentos compatibles que pueden considerarse como grupos potencialmente agregables, es posible que la agregación se concentre en aquellos grupos que cumplan con las condiciones mínimas de número de experimentos y similitud de niveles y variables respuesta.

- Durante la FASE DE BúSQUEDA se incluyó un conjunto de actividades y recomendaciones para la conducción de una búsqueda preliminar (búsqueda de alcance o estudio de mapeo) que permita conocer la base de experimentos disponibles antes de acometer las actividades propias de la RS. Esta búsqueda preliminar permite generar una categorización de los experimentos localizados en grupos candidatos a agregación entre los cuales se seleccionará aquél que resulte de interés para los revisores. Con base en el grupo seleccionado se podrá definir la pregunta de revisión.

- Se propone que el protocolo de revisión sea documentado al final del proceso, en lugar de establecerlo al inicio sin haber explorado lo que existe acerca de la tecnología. De esta manera, el protocolo de revisión pasa a ser el artefacto que documenta las decisiones tomadas durante la RS, y que puede ser usado para determinar si el proceso ha sido conducido adecuadamente.

- Se incluyen recomendaciones para la selección de la base de datos bibliográfica más adecuada. Por otra parte, se han analizado estrategias en los distintos campos de búsqueda que proporcionan estas bases de datos, y se ha comparado el desempeño de los resultados para varios de las bases de datos disponibles en IS. Con base en lo anterior, es posible proporcionar un conjunto de recomendaciones que, si bien no resuelven el problema de no contar con bases de datos especialmente destinadas al registro de experimentos, permitirán reducir el esfuerzo de localización de los experimentos en IS tratando al mismo tiempo de maximizar la recuperación de los mismos.

- Se proponen recomendaciones para construir cadenas de búsqueda óptimas, que permitan recuperar la mayor cantidad posible de experimentos, con el menor esfuerzo necesario para el descarte de artículos irrelevantes. Estas recomendaciones se han obtenido luego de analizar diferentes estrategias de búsqueda en las bases de datos bibliográficas disponibles en IS.

- Se propone el agrupamiento de aquellos conceptos que sean similares pero que aparezcan reportados con una terminología distinta. Se recomienda que esta uniformización de la terminología se inicie durante la lectura de los experimentos y sea mantenida durante todo el proceso.

- Se proponen agrupar los experimentos con base en los niveles que ensayan y las variables respuesta que miden, y organizar la lectura según la similitud de los experimentos en cuanto a estas características. 
- Se propone que las evidencias que son obtenidas a este nivel (métrica) sean resumidas junto con otras métricas relacionadas con la misma variable respuesta.

- Se propone recolectar no sólo los datos de tipo cuantitativo (medias y varianzas) sino también aquella información de tipo cualitativa $(a>b)$ que permita realizar la agregación utilizando técnicas no paramétricas.

- Se propone la incorporación de técnicas de agregación que permitan la combinación de experimentos que no presenten todos (o ninguno) de los datos cuantitativos, pero para los cuales se cuente con información cualitativa relacionada con el efecto y su dirección.

- Se propone descartar aquellos experimentos y cuasi-experimentos que posean una calidad pobre. Esto discriminar entre los estudios de calidad media y alta.

- Se ha propuesto el agrupamiento por distintos criterios que se relacionan con el contexto: 1) agrupamiento de experimentos por tipo de sujeto, 2) agrupamiento de experimentos por tarea, y 3 ) agrupamiento de experimentos por niveles y variables respuesta. Como resultado, se presentan los experimentos resumidos por contexto, incluyendo otras características como el ambiente y el objeto.

- Se propone realizar la agregación de los experimentos por niveles y métrica bajo condiciones de igual sujeto y tarea. Adicionalmente se realiza un análisis de la heterogeneidad, no sólo desde el punto de vista de los parámetros estadísticos, sino también gráfico, procurando mantener los grupos de experimentos más homogéneos posibles. Finalmente, cuando se genera una evidencia para un grupo homogéneo de experimentos, se registran las condiciones para las cuales ha sido obtenida.

- Se propone una escala minimalista, donde los elementos que han sido incluidos son aquellos que han aparecido en nuestro estudio fuertemente relacionados con la calidad; pareciendo ser buenos predictores del mismo.

Proceso de RS de experimentos en IS 
Propuesta de un proceso de revisión de estudios empíricos en Ingeniería del Software 


\section{CAPÍTULO 2. ESTADO DE LA CUESTIÓN}

Luego de su aparición en el campo de la Medicina, las RS se han extendido a distintas disciplinas; con el propósito de soportar la práctica profesional y la toma de decisiones con la mejor evidencia disponible. Es así como han surgido diversos procesos o metodologías, en áreas como las Ciencias Sociales y Educación, las Ciencias de la Salud, y la Ingeniería; disciplinas que a simple vista lucen muy diferentes. Sin embargo, luego de la lectura de este capítulo, se encontrará que los procesos utilizados en ellas para conducir RS son mucho más estándar de lo que se podría esperar en un principio con base en tales diferencias. También se podrá observar que la cantidad de propuestas en la IS es considerablemente menor en comparación con el número de procesos que han sido propuestos en otras áreas.

En este capítulo se presentan diecisiete (17) de estas metodologías. Describiendo en primer lugar aquellas propuestas más ampliamente utilizadas en la IS; para posteriormente introducir aquellas que son más reconocidas en el campo de las Ciencias de la Salud y las Ciencias Sociales. La documentación existente de cada una de ellas en la mayoría de los casos es extensa y se encuentra disponible. Es por ello que en este capítulo se describen de manera resumida sus principios, fases y actividades buscando hacer énfasis en su contribución en relación a otros trabajos relacionados.

\subsection{Estado de la cuestión sobre procesos de revisión sistemática}

En esta sección se describen las propuestas encontradas en la revisión bibliográfica en relación a procesos para RS en diferentes disciplinas; comenzando por la Ingeniería del Software e incluyendo posteriormente otras disciplinas.

\subsubsection{Ingeniería del Software}

Durante la revisión de antecedentes se encontraron pocos trabajos previos en esta área, que establezcan propuestas para la conducción de RS en esta disciplina.

El trabajo pionero es el presentado por (B. Kitchenham, 2004) (Kitchenham. B.A. \& Charters, 2007), siendo el más ampliamente utilizado por los revisores. El otro antecedente relevante en esta disciplina es el propuesto por (J. Biolchini, Mian, Natali, \& Travassos, 2005) que incluye una mejora en cuanto a la conducción de la RS y el desarrollo del protocolo de revisión con base en (B. Kitchenham, 2004).

Por último, aunque no se trata de una propuesta orientada a las RS sino a estudios de mapeo, se presenta el trabajo de (Petersen, Feldt, Mujtaba, \& Mattsson, 2008) (Petersen, Vakkalanka, \& Kuzniarz, 2015), ya que

Proceso de RS de experimentos en IS 
éste constituye un referente importante y se trata de un trabajo ampliamente utilizado en el área, en la cual abundan las revisiones de este tipo. Por otra parte, este trabajo incluyó lineamientos aplicables a las RS con base en el análisis comparativo que los autores realizaron en relación a ambos tipos de estudios.

\subsubsection{Lineamiento para revisiones sistemáticas en Ingeniería de Software (LRSIS) -} Universidad de Keele

La propuesta presentada en (B. Kitchenham, 2004) constituyó la primera aproximación de Lineamientos Metodológicos para conducir RS en Ingeniería de Software (LRSIS), y se ha mantenido hasta la actualidad como el marco de conducción de RS más ampliamente utilizado.

Al analizar en profundidad la propuesta presentada por estos autores, donde su versión más reciente fue desarrollada en (Kitchenham. B.A. \& Charters, 2007), puede observarse una marcada influencia de metodologías propuestas en el área de Medicina, más específicamente por el NHS - Centro para Revisiones y Diseminación (CDR, por su acrónimo inglés) (K. Khan et al., 2001), aunque también se observa una influencia directa de los métodos sugeridos por la Cochrane Collaboration.

Se observa, sin embargo, que no presenta un grado importante de adecuación de las prácticas utilizadas en Medicina, considerando las diferencias entre esa área de las ciencias y la Ingeniería del Software.

En (Kitchenham. B.A. \& Charters, 2007) los autores establecen tres (3) etapas:

1. Planificación de la revisión

2. Conducción de la revisión, y

3. Reporte de los resultados de la revisión.

El objetivo de la etapa I es identificar el problema y definir el protocolo de revisión, el cual establece todos los métodos a utilizar durante la etapa II de Conducción. La etapa II incluye todas las actividades necesarias para localizar la evidencia primaria, realizar la evaluación crítica de la misma, extraer los datos y realizar la síntesis de los mismos. La última etapa tiene por objetivo documentar los resultados de la revisión. Más adelante se podrá observar la coincidencia de tales etapas y actividades con las etapas y actividades tradicionales en Medicina y otras ciencias, siendo de especial mención el uso del protocolo de revisión.

Por otra parte, esta propuesta incluye algunos lineamientos particulares que son relevantes de mencionar para una mejor comprensión de su contribución.

En primer lugar, propone una caracterización de las preguntas de investigación para Ingeniería de Software. Para ello plantea una serie de preguntas sugeridas (o preguntas tipo) que incluyen, por ejemplo, evaluar el efecto de una tecnología; evaluar la frecuencia o índice de un factor de desarrollo de un proyecto (p.e. la adopción de una tecnología) o la frecuencia o índice de éxito/fracaso de un proyecto; identificar los 
factores de costo y riesgo asociados con una tecnología; identificar el impacto de las tecnologías en los modelos de confiabilidad; desempeño y costo; y análisis de costo-beneficios de las tecnologías de software, entre otros.

Por otra parte, es interesante que los autores reconocen la necesidad de protocolos para la agregación de información de estudios de tipos (o diseños) ampliamente diferentes. Esto es, la necesidad de incorporar tanto estudios del tipo RCT como otro tipo de estudios observacionales. Para ello propone una jerarquía de diseños propia a la Ingeniería de Software, que va desde la evidencia obtenida de una opinión de experto basada en la teoría o el consenso (nivel 5) hasta la evidencia obtenida de al menos un RCT diseñado apropiadamente (nivel I). En cuanto a la aplicabilidad de estos diseños a la Ingeniería de Software, (Kitchenham. B.A. \& Charters, 2007) afirma que existe más elementos en común con los estudios en las Ciencias sociales que en el campo de la Medicina.

2.1.1.2. Enfoque para revisiones sistemáticas en Ingeniería de Software - Universidad Federal de Río de Janeiro

El trabajo realizado en la Universidad Federal de Río de Janeiro (UFRJ) por (J. Biolchini et al., 2005) propuso una metodología inspirada en (B. Kitchenham, 2004), pero enfocada en mejorar los aspectos referentes al Protocolo de Revisión.

El proceso comienza con la planificación de la revisión, donde se genera y debe ser aprobado tal protocolo. Posteriormente, se ejecuta la revisión (lo cual incluye la búsqueda, selección y evaluación de estudios, así como la extracción de los datos) y, finalmente, se analizan los datos obtenidos a través de métodos de metaanálisis. De manera concurrente, durante todo el proceso, los resultados que se obtienen son "empaquetados" en una base de datos.

La metodología UFRJ propone dos hitos en los cuales se evalúan los resultados obtenidos para decidir la continuidad del proceso o una próxima iteración. De la misma manera, propone que algunas de las fases (p.e. la definición de los criterios de inclusión/exclusión, la extracción de datos, y la síntesis de datos) sean iterativas; esto quiere decir que las actividades son iniciadas durante el desarrollo del protocolo y revisadas mientras se conduce la RS.

En su trabajo (J. Biolchini et al., 2005) además establecen algunas diferencias entre las RS de estudios en Medicina y en Ingeniería de software. En primer lugar, los autores consideran que es imposible el enmascaramiento (blinding) en los estudios en Ingeniería de software, debido a que los métodos y técnicas utilizadas en esta área incluyen tareas con alta participación humana y requieren de profesionales experimentados que estén conscientes de las técnicas y métodos que están siendo aplicados.

Proceso de RS de experimentos en IS 
Por otra parte, afirman que el efecto de una técnica difícilmente puede ser aislado, debido a que la mayoría de los métodos y técnicas afectan una parte completa del ciclo de vida. De tal manera, las técnicas estudiadas interactúan con muchas otras técnicas y procedimientos. En general, establecen que es difícil determinar un enlace causal-lineal entre una técnica particular y un resultado esperado de un proyecto.

Por último, plantean el hecho de que la evidencia disponible no se encuentra centralizada, como ocurre en Medicina con la CC. Al mismo tiempo, la evidencia disponible es fragmentada y limitada, no se encuentra apropiadamente integrada, y no está estandarizada.

El principal aporte de este trabajo es que propone una plantilla para el desarrollo del protocolo de revisión, el cual establece la información que debe ser proporcionada en una fase temprana del proceso (formulación de la pregunta, selección de fuentes, selección de estudios, extracción de información, y resumen de resultados).

\subsubsection{Estudios sistemáticos de mapeo en Ingeniería del Software}

Inicialmente el trabajo de (Petersen et. al, 2008) (Petersen et. al, 2015) está orientado a describir los pasos que se deben seguir para realizar un estudio de mapeo sistemático.

Los autores proponen cinco (5) pasos que deben ser conducidos de manera sistemática, siendo algunos de ellos iterativos. Estos pasos son:

Definir la pregunta de investigación.

Conducir búsqueda de estudios primarios.

Exploración de artículos.

Clasificación utilizando resúmenes.

Extracción de datos y proceso de mapeo.

En cuanto a la primera tarea, se enfoca en el objetivo de la revisión, el cual puede estar orientado a obtener un mapa de clasificación por frecuencias de publicación, áreas de publicación, métodos, entre otros. En segundo lugar, proponen utilizar cadenas de búsqueda para bases de datos científicas o recurrir a la búsqueda manual de actas de congresos y revistas. Para ello los autores proponen el uso de los siguientes componentes: población, intervención y resultado (PICO). Una diferencia importante entre los estudios de mapeo y las revisiones sistemáticas, es que no se utiliza el tipo de estudio o diseño como un criterio de inclusión/exclusión de la búsqueda. Por el contrario, el proceso de mapeo busca recolectar una gran variedad de estudios.

Posteriormente, se lleva a cabo un proceso sistemático de clasificación de artículos incorporando los criterios de inclusión/exclusión para determinar los artículos relevantes. Para la elaboración del esquema de 
clasificación proponen el uso de los tipos de investigación, proponiendo para ello 6 tipos previamente definidos (validación, evaluación, propuesta de solución, artículos filosóficos, de opinión y de experiencia).

Finalmente, en cuanto a la extracción de datos y el mapeo de estudios, utiliza el esquema de clasificación producido en el paso anterior para realizar el ordenamiento de los estudios. Todo ello en el marco de un proceso cíclico de refinamiento. Los resultados se enfocan principalmente en presentar las frecuencias de publicación por cada una de las categorías del esquema de clasificación. Esta información puede ser presentada con valores estadísticos.

Adicionalmente, en este trabajo los autores proponen un conjunto de lineamientos tanto para la conducción de estudios de mapeo como RS, las cuales incluyen:

Uso como métodos complementarios: propone la utilización de los estudios de mapeo como una etapa inicial de las RS. De esta manera, los tópicos del área son estructurados y los revisores pueden seleccionar el tópico específico que sea de interés.

Profundidad de lectura adaptable para la clasificación: esto supone el uso no sólo de la lectura de resúmenes sino también de la lectura en profundidad cuando sea necesario, yendo hacia aquellas partes del artículo en las que se cuenta con información relevante; buscando un esfuerzo óptimo de recuperación de la información.

Clasificar artículos basado en la evidencia y la novedad: propone que en el nivel más alto del esquema de clasificación se consideren los métodos de investigación, incluyendo aquellos no empíricos.

Datos visuales: este lineamiento propone el uso de métodos de presentación visual de los resultados de clasificación, por ejemplo, incorporando el uso de gráficos de burbuja (del inglés, bubble plots); así como herramientas que apoyan el uso de este tipo de presentaciones, tales como las herramientas de visualización de Google.

\subsubsection{Otras disciplinas}

En contraste con las escasas propuestas en el área de Ingeniería de Software, la mayoría de los procesos encontrados se encuentran en el mundo de las Ciencias Sociales y las Ciencias de la Salud, como se describe a continuación.

Es posible identificar la similitud de sus actividades. No obstante, cada una de ellas ha incorporado algún elemento diferenciador que resulta interesante de destacar. A continuación, cada una de estas metodologías es descrita con base en sus actividades, haciendo énfasis en las características que las hacen particulares dentro de su área.

Proceso de RS de experimentos en IS 


\subsubsection{Metodología para RS de intervenciones de la Colaboración Cochrane}

Sin duda el proceso más ampliamente utilizado en las RS en Medicina (y otras áreas de la Salud) es el propuesto por la Colaboración Cochrane (CC) (J. P. T. Higgins \& S. Green, 2006). El objetivo de la CC es ayudar a las personas a tomar decisiones bien fundamentadas al preparar, mantener y promover la accesibilidad de $R S$ de los efectos de las intervenciones en todas las áreas de la asistencia sanitaria.

La CC es soportada por los grupos colaboración en investigación (GCls) y por cientos de organizaciones alrededor del mundo, incluyendo proveedores de servicios de salud, agencias de financiación de investigación, departamentos de salud, organizaciones internacionales y universidades. Actualmente, existen más de 10.000 personas contribuyendo al trabajo de la CC en 80 países.

Para soportar el logro del objetivo antes descrito, la CC cuenta con una extensa librería de RS (la Base de Datos Cochrane de Revisiones Sistemáticas - BDRS) en la que son publicadas todas aquellas RS que cumplan con los estándares y procedimientos establecidos en la metodología.

El primer requisito que debe ser cumplido para realizar una RS, siguiendo la metodología Cochrane, que se desee publicar en la BDSR es proponer un protocolo de revisión, en el cual se establece de manera temprana el objetivo, los métodos y las intervenciones que serán estudiadas. Una vez que el protocolo es aprobado por los $\mathrm{GCls}$, es posible poner en marcha la RS.

III.1.1. Fundamentos del proceso de RS de la CC

Los fundamentos del proceso CC pueden ser resumidos como sigue:

- Está enfocado en las RS de experimentos controlados aleatorizados (RCT, según su acrónimo inglés): Para la CC, los RCTs proporcionan información más confiable que otras fuentes de evidencia, acerca de los efectos diferenciales de las distintas alternativas de una intervención en materia de salud. La aleatorización es considerada como la única manera de distribución de los participantes, que controla tanto los elementos de distorsión conocidos y mensurables, como aquellos que no lo son.

- $\quad$ Las revisiones poseen un formato estándar: De esta manera se garantiza que los usuarios de las RS publicadas en la librería Cochrane encuentren información completa y consistente. Para ello, la CC propone un conjunto de lineamientos sobre los contenidos a ser incluidos en el reporte de la RS.

- Propone una planificación inicial: Antes de ejecutar una RS Cochrane (RSC), los revisores deben: 1) desarrollar un protocolo que resume los antecedentes y objetivos, junto con el planteamiento de los métodos de búsqueda propuestos y los planes para la recolección y 
análisis de los datos; 2) registrar el protocolo; 3) conformar el equipo de revisión (incluyendo grupos de supervisión - profesionales, metodólogos, usuarios, decisores, etc.); 4) seleccionar las herramientas software para apoyar el proceso; 5) realizar el entrenamiento; 6) determinar los recursos necesarios para la RS; y 7) obtener financiación.

Al proponer un protocolo de revisión a priori, los revisores logran un acuerdo respecto al tópico de la revisión en el marco de las colaboraciones existentes, planifican los recursos necesarios y, sobretodo, reciben apoyo y sugerencias de los $\mathrm{GCl}$ acerca de los métodos a utilizar.

- La principal motivación de la CC es recopilar y ayudar a las personas a entender la evidencia: En este sentido, las RSC requieren comenzar el proceso con una clara motivación e independencia de los intereses de los revisores. En la mayoría de los casos, la CC recomienda realizar una RS solamente sobre aquellos tópicos que son de interés para la comunidad médica.

- Promueve el trabajo en equipo en cada RS: Debido particularmente a la necesidad de prevenir los sesgos y detectar errores, la metodología de la CC propone que al menos dos revisores sean involucrados en las mismas tareas de manera independiente; así mismo, pone especial énfasis en involucrar a los usuarios de la RS (usuarios, médicos, etc.) para conocer sus puntos de vista (p.e. intereses, prioridades, etc.).

- Previene diferentes tipos de sesgo. Con la finalidad de obtener resultados válidos, la metodología de la CC propone diferentes técnicas para prevenir aquellos sesgos que pueden distorsionar los resultados, éstos son: sesgo de selección, sesgo de desempeño, sesgo de pérdidas o exclusión y sesgo de detección.

\section{III.1.2. Visión general del proceso CC}

En la Figura III.1 se muestra la secuencia de actividades propuestas por la CC. Nótese que el proceso que subyace en la metodología de la CC evidencia claramente dos fases: una de revisión y otra de síntesis.

La fase de revisión está caracterizada por actividades que van desde la formulación del problema hasta la recolección de los datos, pasando por la localización de los estudios primarios y la valoración de su calidad; mientras que la fase de síntesis está enfocada en el análisis e interpretación de los datos (utilizando, principalmente, meta-análisis). De la misma manera, pueden observarse dos escenarios: aquel donde se desarrolla una RS por primera vez; el otro, relacionado con la mejora o actualización de una RS ya existente, por efecto de la aparición de nueva evidencia válida. Seguidamente se describen cada una de las actividades señaladas en la Figura III.1.

Proceso de RS de experimentos en IS 


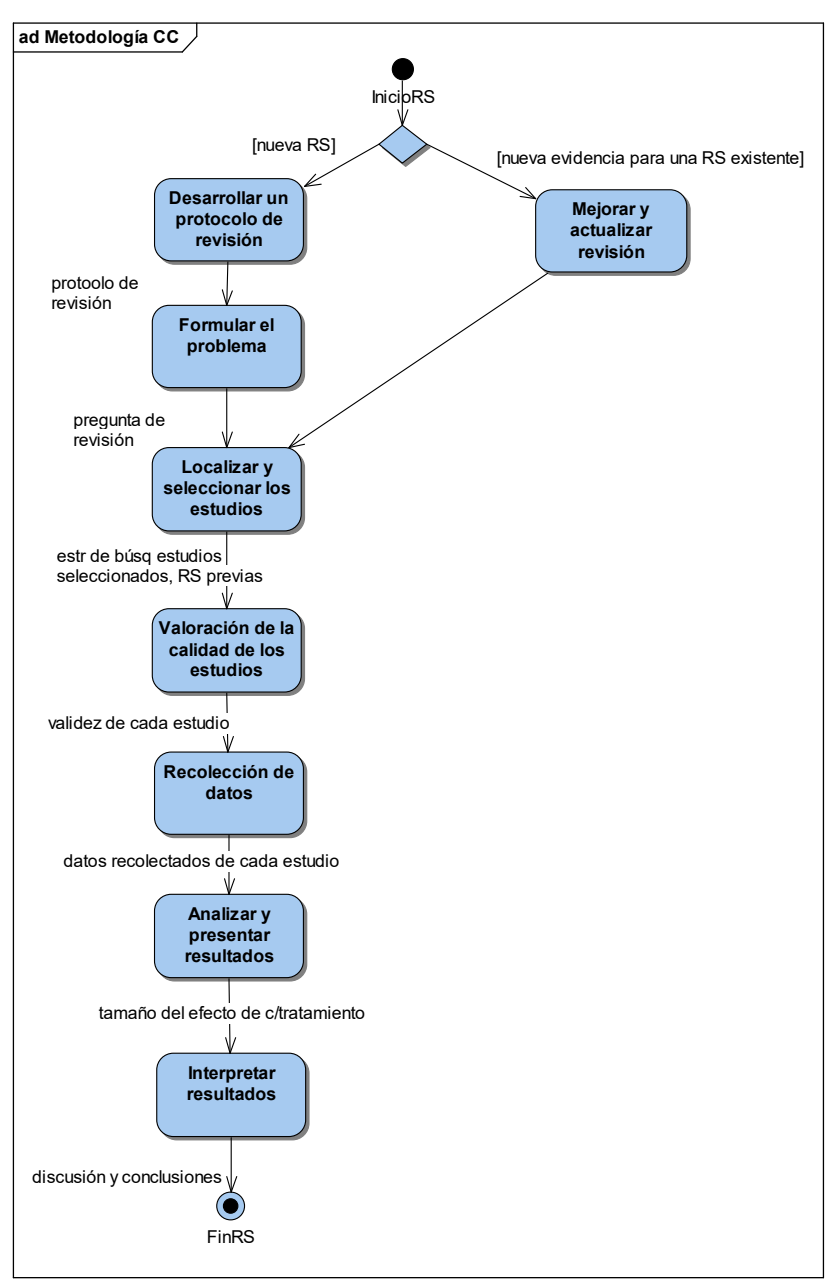

Figura III.1. Actividades de la metodología de la CC.

\section{III.1.2.1. Desarrollar un protocolo de revisión}

El objetivo de esta actividad es gerenciar la complejidad del proceso y establecer los juicios, decisiones y recursos necesarios para la RS. No obstante, el desarrollo del protocolo exige que muchas de las decisiones relativas a los criterios y métodos a utilizar durante la RS, sean establecidos antes de conocer la disponibilidad de estudios relacionados con el tema de interés. En esta etapa del proceso, el protocolo de revisión puede ser visto como un medio para lograr un acuerdo con el $\mathrm{GCl}$ acerca del tópico de la revisión y los otros aspectos antes señalados; en el marco de las colaboraciones existentes y las RS publicadas y/o en desarrollo.

Debido al gran número de iniciativas que son manejadas por la CC, y como parte del soporte brindado a los revisores, cada protocolo de revisión que se someta debe ser evaluado por los $\mathrm{GCls}$; el equipo editorial de los GCls evalúa y da recomendaciones a cada protocolo antes de que la RS sea conducida. El protocolo también será publicado en la BDRS y puede ser objeto de comentarios y críticas. 
En una RSC, el protocolo debe considerar los siguientes aspectos: opciones prácticas incluidas en las preguntas, estudio de resultados significativos (no triviales) para la toma de decisiones en asistencia sanitaria, manejo de los efectos adversos y los beneficios de las intervenciones, métodos de revisión óptimos, manejo de la evidencia no confiable, manejo del sesgo de la evidencia, y perspectiva internacional.

Cada protocolo aprobado guiará el desarrollo de la RS y no deberá sufrir cambios; aunque esto sea difícilmente logrado, por la naturaleza retrospectiva de la RS. En cualquier caso, toda modificación post-hoc del protocolo de revisión debería ser documentado.

La salida de esta actividad es un protocolo de revisión predeterminado: objetivos y antecedentes (contexto y razones), criterios para la selección de estudios, estrategia de búsqueda, métodos de recolección y análisis de los datos, resultados más importantes, y conclusiones de los autores.

\section{III.1.2.2. Formular el problema}

Como se vio anteriormente, el punto de partida de una RSC exige que los revisores tengan mucha claridad y precisión del problema al que se desea responder. Esto será relativamente sencillo en el marco de una revisión Cochrane ya que colaboradores (GCls), experimentadores (autores de los estudios primarios), revisores (autores de las RS) y usuarios (políticos, practicantes, proveedores de servicios sanitarios, etc.) cuentan con intereses bien definidos dentro de su área.

En un contexto como éste, el foco de la RS puede ser establecido tempranamente para determinar la estructura de la revisión, incluir estrategias para la localización y selección de estudios o datos, evaluar críticamente su relevancia y validez, y para analizar las variaciones entre sus resultados. En resumen, esta actividad tiene como objetivo establecer tempranamente las decisiones acerca de qué investigación incluir y cómo resumirla. Desde el punto de vista del lector de la RS, el problema es utilizado para una evaluación inicial de la relevancia de la RS.

- La salida de esta actividad es la pregunta de revisión, la cual debe especificar varios componentes:

- $\quad$ tipos de personas o participantes (decidir las enfermedades o condiciones que son de interés, así como la población y contexto de interés);

- tipos de intervenciones o exposiciones (decidir sobre las intervenciones que son de interés y las intervenciones contra las cuales éstas serán comparadas -grupos de control-);

- tipos de resultados (criterios para decidir sobre la importancia de las salidas y los datos de un estudio, para decidir su inclusión/descarte);

- $\quad$ tipos de estudios (decidir sobre los tipos de diseño de estudios que son relevantes para responder las preguntas de la RS).

Proceso de RS de experimentos en IS 


\section{III.1.2.3. Localizar y seleccionar los estudios}

Una estrategia de búsqueda es una manera de prevenir el sesgo de selección y diferenciar una RS de una revisión tradicional. La estrategia de búsqueda se ejecuta dentro de un proceso iterativo que busca aumentar la recuperación de estudios sin perjudicar la precisión de la búsqueda.

Debido a que en la RSC se asume que debe existir un problema claramente formulado (esto es, una pregunta definida tempranamente), la estrategia de localización y selección de estudios está fundamentada en los componentes clave de la pregunta planteada. La mayoría de las búsquedas en las RSC son ampliamente facilitadas por la disponibilidad de registros especializados compilados por los GCls, aunque pueden ser necesarias búsquedas adicionales. De esta manera, en el campo de Medicina la localización de estudios es facilitada por las bases de datos especializadas (p.e. MEDLINE, EMBASE, AIDSLINE, LILACS, CINAHL, etc.) que poseen términos de indexación estandarizados, así como bases de datos específicas para la localización de RCTs (p.e. CENTRAL).

Debido a la creencia común, en el campo de la Medicina, según la cual los RCTs proporcionan las estimaciones más confiables acerca de los efectos, las estrategias de búsqueda en una RSC se basan en la búsqueda de este tipo de estudios. Una vez que se han recuperado los estudios, sus títulos y resúmenes son leídos para determinar aquellos que son potencialmente elegibles y los que cumplen con los criterios de inclusión para la RS.

Pasos involucrados con la actividad

Los pasos a seguir para desarrollar y documentar una estrategia de búsqueda de estudios y organizar los resultados de la búsqueda, son:

- Búsqueda en las base de datos electrónica

- Búsqueda manual

- Chequear las listas de referencias

- Chequear otras revisiones

- Revisar versiones impresas de BD electrónicas

- Identificar estudios no publicados

- Investigar evidencias sobre efectos adversos

- Documentar la estrategia de búsqueda

- Seleccionar estudios

- Realizar seguimiento de los estudios identificados 
La salidas de esta actividad son:

- La estrategia de búsqueda documentada, incluyendo: título de la base de datos buscada, nombre del host, fecha de la búsqueda, años cubiertos por la búsqueda, términos de búsqueda (que incluye típicamente tres partes: los términos relacionados con la condición médica de interés, los términos relacionados con las intervenciones evaluadas, y los términos relacionados con los tipos de diseño de estudios a ser incluidos) y las restricciones de lenguaje.

- $\quad$ Los estudios seleccionados y las RS previas.

III.1.2.4. Valoración de la calidad de los estudios

La evaluación de la calidad de los estudios individuales que son recuperados por las búsquedas realizadas en una RS, es una actividad necesaria para limitar el sesgo al conducir el proceso, comprender muy bien las comparaciones potenciales y guiar la interpretación de los resultados (J. P. T. Higgins \& S. Green, 2006).

Los factores que justifican la evaluación de la calidad son aquellos relacionados con: la validez externa de los resultados, la validez interna de los estudios individuales y ciertas características del diseño que afectan la interpretación de los resultados.

La validez externa de una RS (una estrategia de intervención o un resultado) respecto a una población particular, es dependiente de los estudios seleccionados para la RS y de cómo los participantes, las intervenciones y los resultados de interés fueron definidos por estos estudios y por los revisores. Por otra parte, la interpretación de los resultados es dependiente de la validez de los estudios incluidos y de otras características. La variación en la validez puede explicar la variación en los resultados de los estudios incluidos en una RS. Adicionalmente, el análisis cuantitativo de estudios de distinta validez puede resultar en conclusiones del tipo falso positivo o falso negativo.

La evaluación de la validez puede entonces ser usada en la RS como: un umbral para la inclusión de estudios, una posible explicación para las diferencias en los resultados de los estudios, en el análisis de sensibilidad, como pesos en el análisis estadístico de los resultados de los estudios.

Debido a la naturaleza de los participantes y las intervenciones utilizadas en RS en Medicina, en una RSC la valoración de la calidad está enfocada en prevenir los cuatro tipos de sesgos antes mencionados (sesgo de selección, sesgo de desempeño, sesgo de pérdidas o exclusión y sesgo de detección). Para ello, los siguientes criterios son evaluados en cada estudio: enfoque de ocultamiento (allocation concealment) en la asignación de los participantes a los grupos de comparación (relacionado con el sesgo de selección), el enmascaramiento (blinding) utilizado después de la distribución de la intervención (relacionado con los sesgos de desempeño y detección), y el enfoque para manejo de pérdidas (relacionado con el sesgo de exclusión).

Proceso de RS de experimentos en IS 
Para ello, la metodología CC propone tres tipos de enfoques de evaluación:

- Enfoques simples: recomienda utilizar criterios individuales (p.e. adecuación del ocultamiento) en un análisis de sensibilidad; y valorar los criterios individuales como "cumple", "no cumple" o "difuso". Si varios criterios explícitos son utilizados, la CC propone producir una valoración global de cuán válido son los resultados de cada estudio. Por ejemplo, utilizar tres categorías de riesgo de sesgo (bajo, moderado o alto).

- Escalas de calidad y listas de chequeo: reconoce que existen diversas escalas y listas de chequeo que han sido utilizadas para determinar la validez y calidad de los RCTs. Éstas pueden responder a un cálculo más o menos complejo de la puntuación final, pero no han demostrado ser más confiables que los métodos simples para determinar la validez del estudio.

- Criterios para la evaluación de estudios observacionales: aunque las revisiones Cochrane están enfocadas en los estudios del tipo RCT, reconoce que la principal diferencia entre éstos y los estudios observacionales radica en el sesgo de selección y la necesidad de identificar y contabilizar los elementos de distorsión potenciales en los estudios obsevacionales. Para ello, los revisores deben realizar juicios sobre qué elementos de distorsión son importantes y hasta dónde ellos pueden ser medidos y controlados.

Pasos involucrados con la actividad

Las tareas relacionadas con la evaluación de la calidad son:

- Determinar el número de revisores que realizarán la evaluación.

- Determinar y aplicar los criterios de evaluación a utilizar, según el tipo de estudio.

- Incorporar a la revisión la valoración de la validez de los estudios.

- La salida de esta actividad es la validez asignada a cada estudio.

\section{III.1.2.5. Recolección de datos}

Una vez que se han seleccionado los artículos y se ha determinado la validez de sus resultados, se extrae de los estudios la información relevante para la RS. En este momento, la recolección de datos se convierte en el puente entre lo que los experimentadores han reportado en los estudios primarios (artículos publicados en revistas o actas de congresos, comunicaciones personales, etc.) y lo que finalmente es reportado por el revisor.

Debido a que en Medicina la pregunta de revisión puede ser establecida en el inicio del proceso, los componentes de la pregunta pueden ser enlazados directamente con la recolección de datos. En este caso, la pregunta guiará la determinación de los criterios finales que serán utilizados para la selección de los estudios apropiados para la RS, así como los datos que serán extraídos de estos estudios para satisfacer tales criterios 
de selección. La pregunta de revisión también puede ser relacionada con la manera en que se presentan y analizan los datos.

El formulario de recolección de datos cumple entonces con, al menos, tres funciones: 1) se enlaza directamente con la pregunta de revisión formulada y la evaluación de los estudios incluidos; además, proporciona un representación visual de éstos; 2 ) es un registro histórico de las múltiples decisiones (y sus cambios) que ocurren dentro del proceso; 3) es un repositorio del cual emerge el análisis.

Otra característica de la recolección de datos en este campo es que existen estándares desarrollados por los GCls, acerca de las características que deberían ser recolectadas de un estudio en una RS. Esto se debe a que los aspectos que pueden afectar los resultados de la RS o ayudar a los revisores a evaluar la aplicabilidad de éstos, se encuentran bien tipificados en Medicina (p.e. la población étnica, el entorno, etc.); por lo tanto, están bastante claras aquellas características del estudio que deben ser recolectadas.

Pasos involucrados con la actividad

Las tareas relacionadas con esta actividad son:

- Utilizar un formulario de recolección de datos (electrónica o en papel) para la identificación de: métodos, participantes, intervenciones, medidas de los resultados.

- $\quad$ Si es necesario, contactar a los investigadores originales.

- En caso de recolección electrónica y procesos de doble-abstracción, determinar la reconciliación de las diferencias entre ambos resultados.

- En el caso de recolección de datos por múltiples revisores, lograr consenso acerca de las diferencias.

- Verificar la elegibilidad del estudio

- Verificar la confiabilidad de los datos recolectados.

La salida de esta actividad es el formulario de recolección con los datos recolectados de cada estudio (p.e. métodos, participantes, intervenciones, medidas de los resultados).

\section{III.1.2.6. Analizar y presentar resultados}

Una vez que han sido recolectados los datos de los estudios primarios seleccionados, la actividad de análisis debe realizar comparaciones entre pares de intervenciones: una intervención experimental versus una intervención de control, o entre dos intervenciones experimentales. El objetivo del análisis es responder

Proceso de RS de experimentos en IS 
acerca del contraste entre los resultados de dos grupos tratados diferentemente (conocido como efecto o efecto del tratamiento).

El análisis puede ser narrativo (un resumen o discusión estructurada de las características de los estudios y sus resultados) o cuantitativo (involucra un análisis estadístico). El meta-análisis, la combinación estadística de resultados de dos o más estudios separados, es la técnica estadística más comúnmente usada en las RS en Medicina. Esto se debe a que en este campo se cuenta con un número significativo de estudios similares (particularmente, RCTs) lo cual permite contar con poca diversidad de estudios para el momento del análisis. Esto es importante porque usar el meta-análisis para describir el tamaño del efecto puede no ser significativo si las implementaciones de los estudios son tan diversas que la estimación de un efecto no puede ser interpretado en un contexto específico.

El meta-análisis es básicamente un proceso de dos etapas: 1) se calcula un resumen estadístico para cada estudio, y 2) se estima el promedio ponderado de los efectos de los tratamientos de los estudios individuales. El método a utilizar en el meta-análisis es dependiente del tipo de datos que se requiera manejar (p.e. dicotómicos, continuos, ordinales, contadores y tasas, tiempo_para_evento, etc.) pero también lo es de la heterogeneidad de los estudios, el número de estudios o de eventos en cada estudio. Por ello, los resultados de realizar un meta-análisis pueden ser sesgados debido a estudios muy heterogéneos, o un número pequeño de estudios (o estudios pequeños).

Independientemente del método utilizado para la síntesis, durante esta actividad deberán responderse a las siguientes preguntas: ¿cuál es la dirección del efecto?, ¿cuál es el tamaño del efecto?, ¿es el efecto consistente a través de los estudios?, ¿cuál es la solidez de la evidencia para el efecto?

Pasos involucrados con la actividad

Los pasos involucrados en la realización de la síntesis son:

- Decidir cuáles comparaciones hacer: identificar los tipos de datos y las medidas de los efectos para cada tipo de dato.

- Extracción de los resultados de los estudios: preparar resúmenes tabulares de las características y resultados de los estudios que son incluidos en cada comparación.

- Derivar estimaciones de los estudios de una manera sistemática para medir e investigar las diferencias entre los estudios (meta-análisis).

- Medir e investigar las diferencias entre los estudios (heterogeneidad).

- Interpretar los resultados y concluir cuánta confianza puede ser asignada a ellos.

- Realizar un análisis de sensibilidad: cambiar los criterios de inclusión para los tipos de estudios, participantes, intervenciones o resultados; incluir/excluir estudios; y reanalizar los datos. 
- La salida de esta actividad es la dirección y tamaño del efecto de cada tratamiento.

\section{III.1.2.7. Interpretar resultados}

Debido a la trascendencia y el número de usuarios de las RS Cochrane, los resultados alcanzados en el análisis deben ser acompañados por una discusión acerca de solidez de los estudios primarios y la aplicabilidad de los resultados de la RS. En una RS Cochrane, puede consultarse a los GCls para seleccionar un enfoque que resuma la solidez de la evidencia que sería apropiada para la pregunta que se quiere responder.

La discusión y conclusión sobre los aspectos de la RS tienen como objetivo ayudar a las personas en la toma de decisiones y entender las implicaciones de la evidencia en relación a las decisiones prácticas. Tales aspectos incluyen: la solidez de la evidencia, la aplicabilidad de los resultados, consideraciones de costo y práctica actual, y la clarificación de cualquier compensación importante entre los beneficios esperados, daños y costos de las intervenciones.

Pasos involucrados con la actividad

Los pasos involucrados en esta actividad son:

- Discutir sobre la solidez de la evidencia: cualesquiera limitaciones metodológicas importantes de los ensayos incluidos y los métodos utilizados en la revisión, que podrían afectar las decisiones prácticas acerca de la Asistencia sanitaria o la investigación futura.

- Discutir sobre la aplicabilidad: establecer el espectro de circunstancias para las cuales la evidencia será aplicable, y la variación predecible de los efectos en diferentes circunstancias.

- Discutir sobre los efectos adversos: evaluar y establecer relaciones causales de un efecto adverso para una intervención particular.

- Advertir sobre las compensaciones necesarias: concluir acerca de la utilidad práctica de las intervenciones; las compensaciones, implícitas o explícitas, entre los beneficios y los costos (y daños) estimados.

- $\quad$ Proporcionar otras informaciones relevantes.

- La salida de esta actividad es la Discusión y conclusiones acerca de los aspectos relevantes de los estudios incluidos y los resultados de la RS.

Proceso de RS de experimentos en IS 
III.1.2.8. Mejorar y actualizar revisión

El objetivo de esta actividad es proporcionar información actualizada, transparente y confiable a aquellos encargados de la toma de decisiones.

En otro escenario del proceso Cochrane, la realización de esta actividad implica repetir en intervalos periódicos, los pasos involucrados en la RS original. En el caso de las RS en Medicina esto puede ser fundamental en el avance del conocimiento relacionado con los tratamientos estudiados.

El aspecto que es más propenso a requerir actualización en una RS es la identificación de nuevos estudios; en consecuencia, el resto de las actividades deberá ser revisado. También los autores deberán dar respuesta a todas las críticas que sean sometidas a la RS que se encuentra publicada.

La salida de esta actividad es: una RS actualizada o mejorada.

\subsubsection{Guía para revisiones sistemáticas de investigaciones sobre efectividad - Centro para} revisiones y diseminación

Una metodología que tiene un fuerte impacto en la investigación sobre asistencia sanitaria y bienestar social, es la propuesta por el NHS Centro para revisiones y diseminación (CDR, por su acrónimo inglés) (K. Khan et al., 2001), de la Universidad de York. Ésta fue producida por primera vez en 1996 y tiene como propósito proveer información basada en la investigación acerca de los efectos de las intervenciones usadas en tales campos. El CDR trabaja en equipo con un gran número de otras organizaciones de investigación e información, así como con redes internacionales, tales como las colaboraciones Cochrane y Campbell.

\section{III.2.1. Fundamentos del proceso para RS del CRD}

Algunos de los fundamentos de la metodología de CDR son descritos a continuación:

- $\quad$ Requiere establecer la necesidad de una revisión: Al igual que en el caso de Cochrane, este aspecto debe ser establecido antes de encargar o dar comienzo el trabajo de revisión. Una vez que se establece el objetivo de la RS, se realiza una convocatoria para aquellos revisores interesados en llevar a cabo el proceso y responder a las preguntas planteadas por el grupo de promotores, los cuales deben someter una propuesta de revisión.

- Una vez aprobada una propuesta de revisión, se mantiene el planteamiento de Cochrane de establecer un protocolo de revisión muy tempranamente para hacer seguimiento de los métodos que son utilizados.

- $\quad$ Considera cuatro tipos de estudios a ser incluidos en una RS: estudios de efectividad de las intervenciones (principalmente los RCTs, aunque también estudios observacionales), estudios de investigación cualitativa (relacionadas con aspectos sociales, emocionales y experimentales de salud), estudios de precisión de pruebas (relacionadas con intervenciones de monitoreo y diagnosis), y estudios de evaluaciones 
económicas (estudios sobre la eficiencia de las intervenciones). En general, los tipos de estudios mencionados pueden ser utilizados de manera complementaria dentro de una revisión de efectividad de intervenciones.

- La comunicación es explícita dentro del proceso: Para ello se proponen agendas de reuniones que permiten la comunicación entre los diferentes participantes así como la planificación y el seguimiento del trabajo para asegurar que los objetivos sean alcanzados.

- $\quad$ Propone una jerarquía de diseños: para la evaluación de la calidad de los estudios primarios utiliza una jerarquía de diseños que puede ser combinada con otros aspectos de calidad, aplicados a través de un instrumento (p.e. lista de chequeo).

- $\quad$ Síntesis de datos: Al igual que en el proceso Cochrane, plantea utilizar en lo posible el análisis cuantitativo (meta-análisis); sin embargo, no descarta el uso del análisis narrativo (no cuantitativo).

- Estrategia de diseminación: Es muy importante para la metodología CDR presentar los resultados de la revisión en un reporte que sea diseminado a las audiencias relevantes. Igualmente, es considerado importante la actualización de la revisión.

\section{III.2.2. Visión general del proceso CRD}

Como se muestra en la Figura III.2(a) y (b), el CDR propone un proceso conformado por tres etapas: la planificación, la revisión, y la diseminación. Aunque el proceso parece reflejar una cronología estricta, tal cronología no siempre puede ser seguida en la práctica. En muchos casos, es necesario realizar varias etapas simultáneamente para ganar eficiencia en el proceso de revisión. Como puede observarse en las siguientes secciones, el proceso propuesto por el CDR no se diferencia marcadamente del propuesto por la CC.

\section{III.2.2.1. Etapa I: Planificación de la revisión}

A diferencia del proceso de revisión Cochrane, el proceso CDR comienza con la identificación de revisiones previas o en progreso, para establecer la necesidad de una revisión. Una vez que la necesidad es establecida, se prosigue con una convocatoria para que los revisores interesados sometan una propuesta con base en la necesidad identificada y las preguntas que dirigirán la RS. La propuesta debe presentar una evaluación preliminar de los componentes disponibles para el desarrollo de la revisión. También debe demostrar que el equipo de revisores ha entendido las preguntas planteadas por los promotores, y que es capaz de desarrollar el trabajo de revisión, y que los métodos propuestos son factibles. Esta etapa incluye tres fases que se orientan a proporcionar calidad a la RS:

Proceso de RS de experimentos en IS 

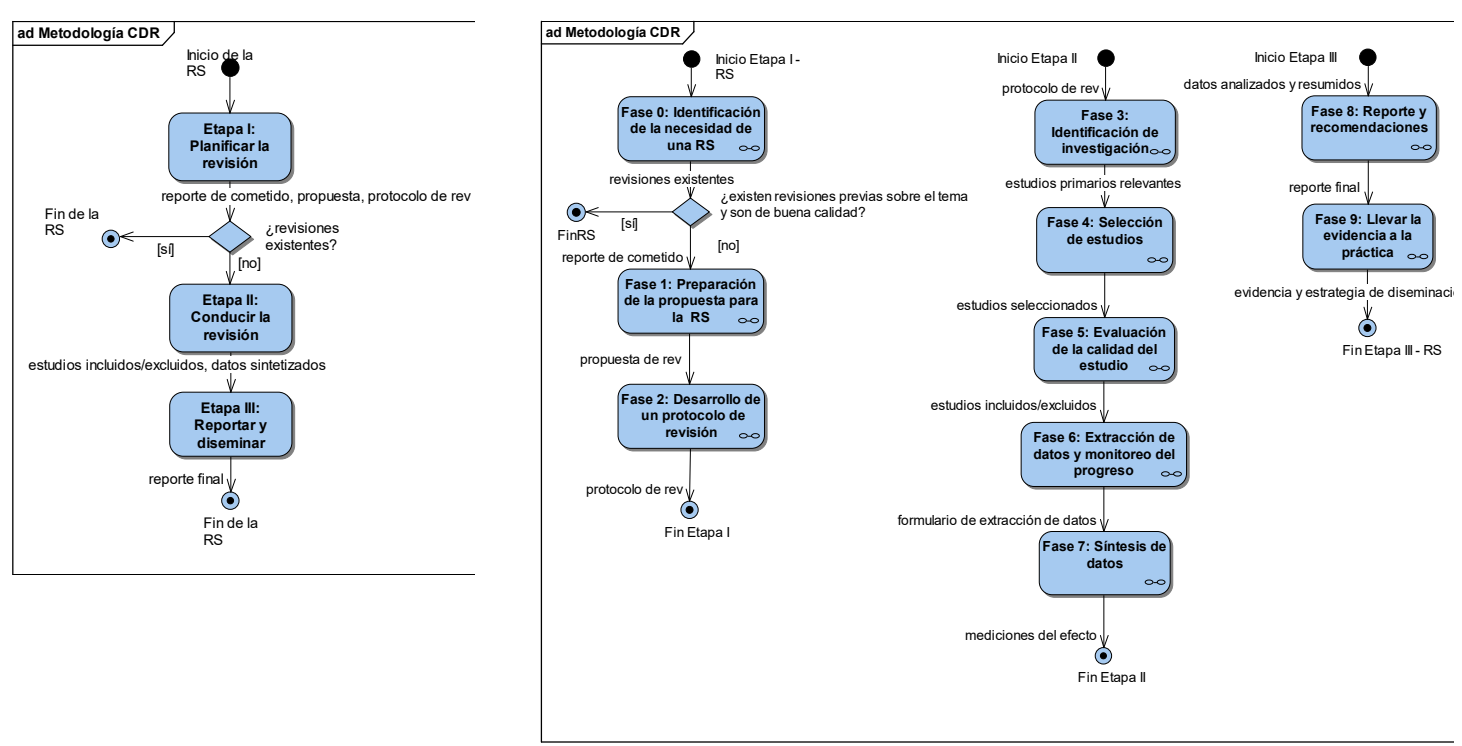

Figura III.2. (a) Etapas de la metodología CDR, (b) Fases por etapa en la metodología CDR

Fase 0: Identificación de la necesidad de una RS

Esta fase es necesaria para evitar la duplicidad en las revisiones realizadas; con ella se busca asegurar que cada nueva revisión se oriente a una investigación original en el campo de la salud y la atención sanitaria, al no existir una RS de buena calidad en el mismo tópico de interés. Si se encontrarán revisiones sobre el mismo tópico que presentaran poca calidad o no estuvieran actualizadas, podría considerarse necesario actualizarla o conducir una nueva revisión. La búsqueda de RS existentes debe realizarse sobre las bases de datos reconocidas y por contacto directo con expertos en el área.

La metodología CDR propone una lista de chequeo compuesta por una decena de preguntas que orientan en la evaluación de RS (véase Anexo \#\#). En resumen, la lista de chequeo evalúa los siguientes aspectos de la RS: objetivo, fuentes de los estudios primarios, criterios de inclusión/exclusión, criterios de evaluación de los estudios primarios, métodos de extracción de datos, y métodos de síntesis de datos.

Si en el análisis inicial de la literatura se determina que no hay RS de calidad sobre el tema, los organismos de financiación deberían desarrollar un documento de reporte de cometido que proporcione la información general de los objetivos de la revisión propuesta, el razonamiento para llevar a cabo la revisión y los antecedentes del problema clínico que se quiere tratar (la tecnología relacionada, sus alternativas, etc.).

La salida de esta actividad es el reporte de cometido.

Fase 1: Preparación de la propuesta para la RS 
Esta fase también distingue el proceso propuesto por CDR del proceso de la CC. En ella se toma en consideración el proceso mediante el cual los diferentes programas y organismos financiadores, interesados en acometer una RS, invitan al envío de propuestas a través de revistas, sitios Web y contactos personales.

El objetivo de los miembros de la comisión es asegurarse de que al completar la RS se alcanzarán resultados de investigación válidos. Para ello elaboran el reporte de cometido con la información general necesaria para que sean comprendidos los objetivos de la revisión. Entonces, una propuesta de revisión es elaborada para satisfacer los requerimientos plasmados en este reporte. Cuando los miembros de la comisión evalúan una propuesta, buscan determinar la factibilidad de la metodología a utilizar para satisfacer los objetivos de la RS.

La propuesta de investigación debe estar fundamentada en la evaluación preliminar de la literatura potencialmente relevante y su tamaño. Esto se logra a través de búsquedas de alcance realizadas en un grupo pequeño de bases de datos para estimar el tamaño de la literatura que incluye revisiones existentes y estudios primarios. Estas búsquedas preceden las búsquedas más completas y detalladas que se realzarán posteriormente.

En esta fase, las preguntas de investigación incluidas en la propuesta pueden no estar definidas de manera precisa, siempre que los objetivos de la RS se encuentren claramente identificados. Las preguntas de revisión deberán ser detalladas en el protocolo de revisión.

- La salida de esta actividad es la propuesta de revisión, cuyos componentes típicamente incluyen: 1) título del proyecto, 2) antecedentes, 3) preguntas de revisión, 4) métodos de la revisión (criterios de inclusión/exclusión, estrategia general de búsqueda de las investigaciones publicadas y no publicadas, métodos para la selección de estudios y evaluación de la calidad, y métodos para la extracción y síntesis de datos), 5) hitos de la revisión (planificación), 6) experiencia del equipo de revisión, 7) estrategia de diseminación, 8) justificación del presupuesto y los detalles del soporte requerido, las referencias, y 9) CV de los aplicantes.

Fase 2: Desarrollo de un protocolo de revisión

Al igual que en la metodología CC, el protocolo de revisión contiene la información de los antecedentes, la especificación del problema y la metodología de la revisión. El protocolo especifica el plan que seguirá la RS para identificar, evaluar y recolectar la evidencia. El primer hito del proceso CDR (similar al proceso Cochrane) es el desarrollo y aprobación del protocolo.

Los componentes del protocolo de revisión CDR son los mismos que en la metodología Cochrane, con la única excepción de que CDR incluye la planificación del proyecto. La razón para realizar un protocolo de

Proceso de RS de experimentos en IS 
revisión en el proceso CDR es el mismo que en Cochrane: minimizar el riesgo de sesgos durante el desarrollo de la RS.

- La salida de esta actividad es un protocolo de revisión, conteniendo los siguientes componentes: 1) antecedentes, 2) preguntas de revisión, 3) estrategia de búsqueda (incluyendo los términos y fuentes para la búsqueda), 4) criterios y procedimientos para la selección de estudios, 5) estrategia de extracción de datos, 6) síntesis de la evidencia extraída, y 7) planificación del proyecto.

\section{III.2.2.2. Etapa II: Conducción de la revisión}

Esta etapa presenta fases y actividades muy similares a las propuestas por la metodología CC. Se basa igualmente en una búsqueda exhaustiva y documentación de la estrategia utilizada para ella. Posteriormente, los estudios localizados son evaluados respecto a su calidad, y sus datos son extraídos para la síntesis. A continuación se describen las fases involucradas en esta etapa.

Fase 3: Identificación de investigación

Esta fase consiste en la identificación de estudios primarios relevantes a través de una estrategia exhaustiva y no sesgada. La rigurosidad en esta actividad es crucial para conseguir resultados válidos de la RS.

A diferencia de la CC, el CDR propone explícitamente considerar los atributos de una búsqueda, éstos son: sensibilidad o recuperación (la habilidad de identificar artículos relevantes) y especificidad o precisión (la habilidad de excluir artículos irrelevantes).

En el proceso se proponen algunas heurísticas para el desarrollo de estrategias adecuadas a la búsqueda de estudios relevantes. La más importante de ellas consiste en dividir la pregunta de revisión en cuatro partes (población, intervenciones, resultados y diseño de estudio) y luego proponer y probar términos para cada una de ellas. Según el proceso CDR, la estrategia final será desarrollada de manera iterativa.

La salida de esta actividad es un conjunto de estudios primarios relevantes.

Fase 4: Selección de estudios

Una vez que se ha completado la búsqueda de estudios, éstos deben ser evaluados para determinar su relevancia respecto a la pregunta de investigación propuesta. Esta tarea debería entonces ser explícita y conducirse de manera paralela e independiente, para reducir el riesgo de cometer errores de juicio.

Al igual que en el proceso propuesto por la CC, la selección de estudios es realizada con base en los criterios de inclusión/exclusión establecidos en el protocolo, esto permite evitar que se introduzcan sesgos originados por opiniones preconcebidas. Los criterios deberían ser planteados con base en los cuatro 
componentes de la pregunta: la población, las intervenciones, los resultados y el diseño de los estudios que son de interés.

El proceso propuesto por CDR establece que la selección de estudios es un proceso multi-etapas: es aplicado tempranamente en el proceso, una vez que se han recuperado los estudios a través de una estrategia de búsquedas; posteriormente, los criterios pueden ser aplicados cuando se ha analizado el texto completo de los artículos pre-seleccionados a partir de la búsqueda; finalmente, algunos artículos pueden ser excluidos en el momento de aplicar el meta-análisis para la síntesis de los datos. En el reporte final de la RS debería incluirse un diagrama de flujo o una tabla detallando los estudios incluidos y excluidos de la revisión.

- La salida de esta actividad es un conjunto de estudios seleccionados (incluidos).

Fase 5: Evaluación de la calidad del estudio

La información que se obtiene de la evaluación de la calidad es crucial para determinar la fortaleza de las inferencias y asignar grados a las recomendaciones generadas en la RS. Algunas razones para evaluar la calidad de los estudios son las siguientes:

- Determinar un umbral mínimo para la selección de los estudios primarios.

- Explorar las diferencias en la calidad, como una manera de explicar la heterogeneidad en los resultados de los estudios.

- Asignar un peso a los resultados de los estudios, proporcional a la calidad, durante el meta-análisis.

- $\quad$ Orientar en la interpretación de los resultados y ayudar a determinar la fortaleza de las inferencias.

- Orientar las recomendaciones para investigaciones futuras.

En el proceso de RS del CDR, la evaluación de la calidad del estudio está enfocada principalmente en la evaluación de la calidad interna de los estudios. Los tipos de sesgos considerados en la evaluación de la calidad de los estudios que propone CDR, son los mismos que en el proceso Cochrane (sesgo de selección, ejecución, medición y exclusión).

Según este proceso, la evaluación basada simplemente en el diseño del estudio es suficiente para garantizar un mínimo nivel de calidad. En este sentido, el umbral para la calidad de los estudios primarios puede ser determinado generando una jerarquía de diseños de estudio y fijando un límite inferior para la selección de los estudios. La jerarquía de diseños de estudio propuesta por el proceso CDR se muestra en la Tabla III.1.

Proceso de RS de experimentos en IS 
Tabla III.1. Jerarquía de diseños de estudio del CDR (K. Khan et al., 2001)

\begin{tabular}{|c|c|}
\hline ivel & Estudios \\
\hline 1 & Estudios experimentales (p.e. RCT con asignación oculta) \\
\hline 2 & Estudios cuasi-experimentales (p.e. estudio experimental sin aleatorización) \\
\hline \multirow[t]{3}{*}{3} & Estudios observacionales controlados \\
\hline & 3a. Estudios de cohorte \\
\hline & 3b. Estudios de control de casos \\
\hline 4 & Estudios observacionales sin grupos de control \\
\hline 5 & $\begin{array}{l}\text { Opinión de expertos basadas en investigaciones de parámetros pato-fisiológicos o } \\
\text { en consenso }\end{array}$ \\
\hline
\end{tabular}

Por otra parte, cada estudio debe ser evaluado a través de un instrumento que considere diferentes aspectos de calidad del estudio con base en su diseño. Otros aspectos y jerarquías de calidad son propuestos para las RS de estudios de precisión de pruebas, investigación cualitativa y evaluaciones económicas sanitarias.

Los pasos necesarios para desarrollar un instrumento de evaluación de la calidad son:

- $\quad$ Definir el constructor de calidad (p.e. validez interna, validez externa, análisis estadístico, etc.).

- Definir el alcance y propósito de la evaluación de la calidad (considerar los tipos de diseño de los estudios y las preguntas que están siendo planteadas en la RS).

- Desarrollar el instrumento (lista de chequeo).

- Determinar las propiedades de medición del instrumento (la confiabilidad de la lista de chequeo).

El CDR propone algunas listas de chequeo estándar que pueden ser aplicados para evaluar la calidad de diferentes diseños de estudio (véase Anexo \#\#). Una vez que se establece el nivel de calidad de cada estudio, pueden agruparse estudios de similar calidad asignándosele un peso proporcional al nivel de calidad correspondiente. De esta manera, los diferentes grupos de estudios serán tratados de manera separada durante el meta-análisis.

La salida de esta actividad es el conjunto de artículos incluidos junto con su nivel de calidad. 
Fase 6: Extracción de datos y monitoreo del progreso

Como se ha indicado anteriormente, la extracción de datos es una actividad propensa a errores, esto puede ser minimizado al diseñar formularios de extracción de datos con instrucciones y reglas de decisión claras acerca de la codificación de datos y el uso de más de un asesor.

El objetivo de esta fase es diseñar los formularios de extracción de datos para recolectar de manera precisa la información de las características relevantes y los resultados de los estudios seleccionados. Este proceso debe realizarse en relación con la pregunta de revisión, la evaluación de la calidad y el análisis planificado.

CDR presenta una propuesta de componentes generales y específicos que deben ser incluidos en el formulario de extracción de datos para diferentes tipos de estudios (véase Anexo \#\#). Será necesario incluir información específica sobre la población de estudio, la forma exacta y entrega de la intervención, las medidas de los resultados y el diseño del estudio. Esta información, re-verifica la elegibilidad del estudio en el momento de la extracción de datos.

Para aumentar la confiabilidad en la extracción de datos, CDR recomienda realizar pruebas pilotos en una etapa temprana del proceso de extracción. También, con el objetivo de aumentar la confiabilidad del proceso, recomiendan la participación de al menos dos revisores independientes durante el proceso de extracción. Las discrepancias entre los revisores deberán ser resueltas por consenso o por arbitraje.

- La salida de esta actividad son los formularios de extracción de datos de los estudios incluidos en la RS.

Fase 7: Síntesis de datos

El objetivo de esta fase es recolectar y resumir los datos extraídos de los estudios primarios incluidos en la RS. Consiste en la tabulación de las características de los estudios y sus resultados (síntesis no cuantitativa) y el uso de métodos estadísticos en aquellos casos en que sea apropiado (síntesis cuantitativa o meta-análisis).

Además de generar un resumen de los efectos de las intervenciones, el proceso de síntesis debe investigar si los efectos son consistentes a través de todos los estudios incluidos (o sobre las razones de las aparentes diferencias).

La evaluación cualitativa de la evidencia, es complementada con la síntesis cuantitativa (el uso de los métodos estadísticos para evaluar las variaciones de los resultados y generar los resultados recopilados). Los resultados de las investigaciones cualitativas son entonces utilizados en este enfoque para ayudar en la interpretación de los resultados cuantitativos. Esto permite sobrellevar las limitaciones del meta-análisis:

- El meta-análisis no es posible cuando no se pueden obtener los datos necesarios.

- Por otra parte, no es apropiado cuando los datos son escasos o cuando los estudios son demasiado heterogéneos como para ser adecuadamente combinados.

Proceso de RS de experimentos en IS 
Cuando se cuenta con una heterogeneidad substancial, una síntesis no cuantitativa puede explorar informalmente cómo las diferencias entre los estudios afectan sus resultados.

Adicionalmente, el proceso propuesto por el CDR también considera cuatro tipos de síntesis de datos con base en los estudios de interés en la revisión, los cuales ameritan métodos de síntesis diferentes: síntesis de datos de estudios de efectividad, síntesis de datos de estudios de precisión de pruebas, síntesis de datos de investigación cualitativa, y síntesis de datos de evaluaciones económicas.

La salida de esta actividad son las mediciones de los efectos de las intervenciones (o tratamientos).

\section{III.2.2.2. Etapa III: Reporte y difusión}

El proceso de RS culmina con la preparación de un reporte que permita a los lectores juzgar la validez y las implicaciones de los resultados de la RS. También debe desarrollarse una estrategia de diseminación que apunte efectivamente a los usuarios y partes interesadas. De esta manera, los responsables de las políticas y prácticas se mantienen informados de la evidencia contenida en la RS. Para lograr un cambio efectivo en las prácticas, será también necesario desarrollar estrategias de implementación que permitan alcanzar esta meta. A continuación se describen las fases de esta etapa.

\section{Fase 8: Reporte y recomendaciones}

Esta fase es importante para estructurar los resultados de la RS de manera que sean recibidos e implementados apropiadamente por sus usuarios potenciales (aquellos que toman decisiones clínicas y hacen política sanitaria). El reporte final debe cubrir los objetivos, métodos, resultados e implicaciones de la RS. Como parte de una estrategia efectiva de diseminación, el reporte deberá satisfacer los requerimientos del lector al cual se encuentra dirigido, al mismo tiempo que presenta información científica de una manera clara, detallada y balanceada.

CDR sugiere una estructura para este reporte, en la cual se presenta: un sumario ejecutivo o resumen estructurado, el contexto (la necesidad que motivó la RS), las preguntas dirigidas por la RS (hipótesis probadas), los métodos de revisión, los detalles de los estudios incluidos/excluidos, los resultados de la revisión, la discusión (resultados de la RS, fortalezas y debilidades, significado de los resultados y recomendaciones) y las conclusiones (recomendaciones e implicaciones). Finalmente, propone en su proceso un enfoque para generar recomendaciones prácticas clasificadas con base en el nivel de evidencia revisada.

La salida de esta actividad es un reporte de la RS.

Fase 9: Llevar la evidencia a la práctica 
Es importante que los resultados de una RS sean diseminados a las audiencias relevantes de manera que las políticas y prácticas puedan ser consideradas a la luz de la evidencia contenida en la revisión. Para ello, CDR utiliza un enfoque de diseminación cuyo elemento clave está basado en el mercado de relaciones. Según este enfoque, los individuos dentro de NHS, con el soporte del CDR, distribuyen boletines dentro de su organización tan efectivamente como sea posible. También se transfiere la evidencia a los pacientes y al público en general a través de sitios Web, material escrito y artículos en medios de comunicación masivos.

La salida de esta actividad es un reporte con la evidencia generada y la estrategia de diseminación.

\subsubsection{Metodología para la identificación y revisión sistemática de literatura científica - Consejo nacional de investigación médica y de la salud}

El Consejo Nacional de Investigación Médica y de la Salud (NHMRC, por su acrónimo inglés) es la más reconocida iniciativa en Australia para brindar soporte a la investigación científica y sanitaria; para desarrollar asesoramiento en salud a la comunidad australiana, médicos y gobernantes; y para proporcionar asesoramiento ético en materia de salud y de investigación médica. El principal soporte ofrecido por el NHMRC es el desarrollo de lineamientos basados en la evidencia obtenida a través de RS (NHMRC, 2000b). Para ello, un comité de desarrollo de lineamientos delega o desarrolla una RS de la literatura científica existente sobre las intervenciones de interés.

\section{III.3.1. Fundamentos del proceso NHMRC}

Algunos aspectos que fundamentan el proceso NHMRC y permiten entender los métodos propuestos, son los siguientes:

- $\quad$ Al igual que en la metodología CC, establece el desarrollo de un protocolo de revisión temprano.

- $\quad$ Todo el proceso se encuentra determinado por el tipo de pregunta que se desea responder. Los seis tipos de preguntas consideradas son las siguientes: intervenciones (i.e.cicuáles son los efectos de una intervención?), frecuencia o tasa de una condición o enfermedad (i.e. ¿cuán común es una condición o enfermedad particular en un grupo específico en la población?), desempeño de pruebas de diagnóstico (i.e. ¿cuán preciso en un signo, síntoma o prueba de diagnóstico en predecir la verdadera categoría de un paciente?), etiología y factores de riesgo (i.e. ¿hay factores conocidos que aumenten el riesgo de que se produzca una enfermedad o un resultado adverso?), predicción y prognosis (i.e. ¿puede predecirse el riesgo para un paciente?), y economía (i.e. ¿cuáles son los costos totales de utilizar el procedimiento?).

\section{III.3.2. Visión general del proceso NHMRC}

Proceso de RS de experimentos en IS 
Como se muestra en la Figura III.3, el proceso propuesto por el NHMRC no difiere de los procesos antes descritos. Por lo tanto, solamente se hará énfasis en aquellos aspectos novedosos presentados por la metodología, ya que muchas de las actividades propuestas tienen una fuerte influencia de la metodología Cochrane, ampliamente descrita al comienzo de este capítulo.

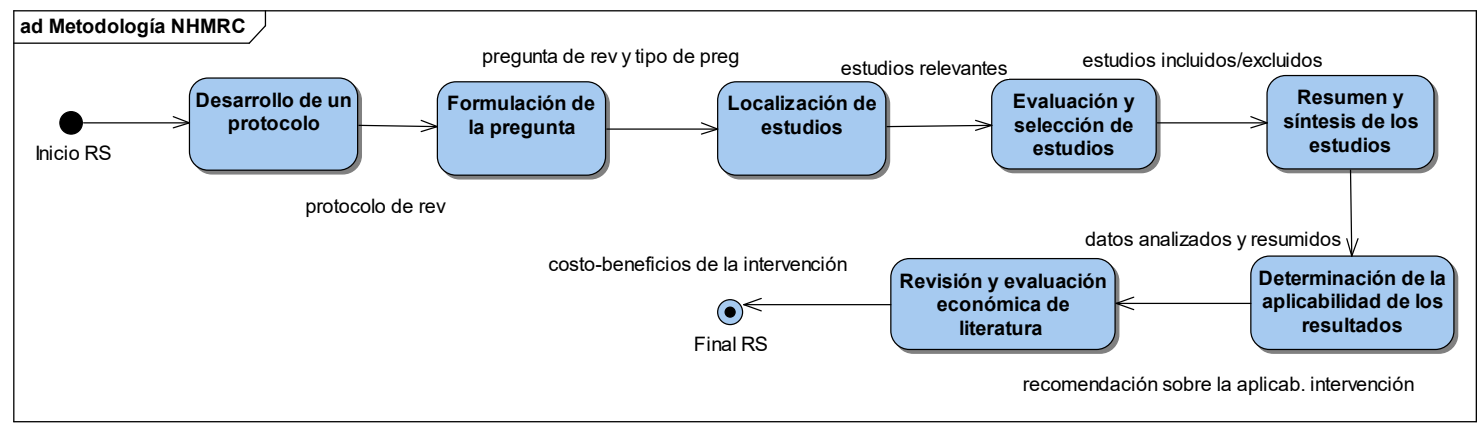

Figura III.3. Actividades de la metodología del NHMRC

A continuación se describen brevemente estas actividades haciendo énfasis en sus artefactos y su justificación dentro del proceso.

\section{III.3.2.1. Desarrollo de un protocolo}

Esta actividad adopta la propuesta por la metodología de la CC. Su objetivo es establecer, antes de llevar a cabo la revisión, los métodos que se incluirán en la revisión con base en la pregunta que debe ser respondida a través de ésta.

- La salida de esta actividad es un protocolo de revisión, con los mismos componentes que el protocolo de la CC.

\section{III.3.2.2. Formulación de la pregunta}

La metodología reconoce seis tipos de preguntas, asociadas con los siguientes aspectos: intervenciones, frecuencia o tasa de una condición o enfermedad, desempeño de pruebas de diagnóstico, etiología o factores de riesgo, predicción y prognosis, y economía.

Responder a cada tipo de pregunta requiere de distintos diseños de estudios y, consecuentemente, diferentes métodos para la RS. De esto dependerán los procesos de búsqueda, evaluación y síntesis de los estudios en la literatura. 
La metodología propone para cada tipo de pregunta los tipos de estudio ideales y los principales aspectos de evaluación que deben ser utilizados. Es de notar que solamente para el caso de las preguntas relacionadas con intervenciones, se indican los RCTs como ideales, siendo la aleatorización, el seguimiento completo y el ocultamiento de los pacientes los principales aspectos de calidad a ser evaluados en tales estudios.

Para cada diseño de estudio es asignado un nivel de evidencia que es utilizado posteriormente para la selección de estudios y la evaluación de la aplicabilidad de los resultados de la RS. Los niveles propuestos son mostrados en la Tabla III.2.

Las salidas de esta actividad son la pregunta de revisión y el tipo de pregunta seleccionada.

Tabla III.2. Designación de niveles de evidencia (NHMRC, 2000c)

\begin{tabular}{|c|c|}
\hline $\begin{array}{l}\text { Nivel de } \\
\text { evidencia }\end{array}$ & Diseño de estudio \\
\hline & Evidencia obtenida de: \\
\hline 1 & RS de todos los RCTs relevantes \\
\hline II & Al menos un RCT diseñado apropiadamente \\
\hline III-1 & Pseudos-RCTs bien diseñados \\
\hline III-2 & $\begin{array}{l}\text { Estudios comparativos (incluyendo RS) con controles concurrentes y asignación no } \\
\text { aleatorizada, estudios de cohorte, estudios de control de casos, series de tiempo } \\
\text { interrumpido con un grupo de control }\end{array}$ \\
\hline III-3 & $\begin{array}{l}\text { Estudios comparativos con control histórico, dos o más estudios simples, o series de } \\
\text { tiempo interrumpido sin un grupo de control paralelo }\end{array}$ \\
\hline IV & Series de casos, post-test o pre-test/post-test \\
\hline
\end{tabular}

III.3.2.3. Localización de estudios

Comprende tanto la búsqueda de RS previas como la búsqueda de estudios primarios publicados y no publicados. Propone términos y sinónimos para la búsqueda de los estudios primarios en las bases de datos electrónicas. No presenta aportes importantes que le diferencien de lo propuesto en el proceso Cochrane para la localización de estudios.

La salida de esta actividad es un conjunto de estudios relevantes.

Proceso de RS de experimentos en IS 
III.3.2.4. Evaluación y selección de estudios

Las conclusiones de la RS deben basarse en la evidencia de más alto nivel que se encuentre disponible. Al igual que en las metodologías previamente descritas, NHMRC propone el uso de un procedimiento estandarizado que permita seleccionar solamente aquellos estudios de calidad relevante y aceptable. De esta manera, el proceso busca garantizar la fortaleza de la evidencia utilizada para generar las recomendaciones a partir de la RS. La recomendación de la metodología NHMRC es realizar una evaluación estructurada de cada estudio, dependiendo del tipo de pregunta que se haya seleccionado para la RS. Luego que la evaluación ha sido aplicada, se puede utilizar uno de los siguientes enfoques:

- Agrupar u ordenar los estudios por su diseño y/o calidad y realizar luego una comparación de los resultados obtenidos al analizar cada grupo por separado. Ésta es la opción recomendada en esta metodología.

- Meta-regresión de elementos de calidad. Ésta alternativa es propuesta como opcional en la metodología. No obstante, esta técnica no es recomendada cuando se cuente con un pequeño número de estudios.

- Asignar un peso con base en la calidad. Ésta opción es considerada como no recomendable por la metodología, debido a que no elimina el sesgo de los estudios con poca calidad sino que apenas lo reduce ligeramente.

- La salida de esta actividad es el listado de estudios incluidos y excluidos para la RS, y el nivel de calidad asignada.

III.3.2.5. Resumen y síntesis de los estudios

No son propuestas en la metodología heurísticas específicas para la extracción de datos. En términos generales, su principal énfasis está en la presentación de los resultados de los estudios incluidos (de manera tabular o gráfica) y en la determinación de sus mediciones.

NHMRC propone un resumen de mediciones de resultados de los efectos de estudios y una aproximación para la estimación de la heterogeneidad. El propósito de evaluar la heterogeneidad de los estudios es determinar cualquier inconsistencia que proporcione la oportunidad de explorar las fuentes de variación y alcanzar un entendimiento más profundo de sus causas y controles.

Por otra parte, la metodología proporciona métodos de síntesis específicos dependiendo del tipo de pregunta que se maneje en la RS.

La salida de esta actividad es el conjunto de datos analizados y resumidos (efectos).

III.3.2.6. Determinación de la aplicabilidad de los resultados

Una vez que se han completado los componentes sistemáticos de la revisión, los revisores deben volver nuevamente a la pregunta originalmente planteada y evaluar cuán satisfecha ha sido con la evidencia 
generada. Para ello, el NHMRC propone un conjunto de pasos que comienzan con la evaluación de la evidencia obtenida en la RS con base en tres dimensiones (fortaleza de la evidencia, tamaño del efecto y relevancia); posteriormente, la evidencia es aplicada a individuos y se concluye acerca de los beneficios y perjuicios producidos por la intervención; finalmente, la evidencia es presentada resaltando los beneficios y perjuicios relevantes, y las estimaciones de los efectos relativos y absolutos. Estos pasos generan una recomendación sobre aquellos pacientes a los cuales debería ser ofrecida la intervención (NHMRC, 2000c).

Si se determina la necesidad de investigaciones adicionales, deben entonces proporcionarse sugerencias específicas acerca de las características de diseño necesarias, más que una simple solicitud de datos adicionales.

- La salida de esta actividad es un conjunto de recomendaciones sobre la aplicabilidad de la intervención.

\section{III.3.2.7. Revisión y evaluación económica de literatura}

Una evaluación económica es un análisis sistemático y explícito de opciones alternativas, evaluadas en términos de costos y consecuencias. En el campo de la asistencia sanitaria, una evaluación económica proporciona un marco de referencia y un conjunto de técnicas que permiten a los decisores incorporar criterios económicos dentro de las decisiones sobre la asignación de recursos escasos a opciones particulares en materia de salud (NHMRC, 2001).

El objetivo de esta actividad es comparar los costos-beneficios de las intervenciones en el área de asistencia sanitaria. Esta es una actividad importante si se quiere conducir una evaluación económica para generar lineamientos clínicos prácticos.

La salida de esta actividad es un reporte de costos-beneficios de la intervención.

\subsubsection{Lineamientos y marco de trabajo para la conducción de RS - Centro Alberta de investigación para la evidencia en pediatría}

El Centro Alberta de Investigación Para la Evidencia en Pediatría (ARCHE, por su acrónimo inglés) es un centro de investigación dedicado a desarrollar (y asesorar en el desarrollo de) revisiones sistemáticas en aspectos prioritarios de la pediatría, y evaluar métodos que permitan minimizar los sesgos cuando se conducen RS (ARCHE, 2007). Como se muestra en la Figura III.4 ARCHE sigue los lineamientos y el marco de trabajo propuesto por la CC.

El proceso comienza con la formulación de una pregunta (basada en tres componentes: participantes, intervenciones y resultados); posteriormente, se desarrolla un protocolo de revisión, similar al propuesto por la CC, y se conduce la búsqueda de estudios. La selección de estudios es realizada en dos etapas: primero, los

Proceso de RS de experimentos en IS 
artículos recuperados durante la búsqueda son evaluados con base en los títulos y resúmenes, para determinar la posible inclusión en la revisión; luego, el texto de los artículos seleccionados en la primera etapa es evaluado para determinar si cumplen los criterios de inclusión/exclusión.

La siguiente actividad implica que dos revisores evalúen la calidad de los artículos elegidos (resolviendo sus discrepancias a través de la discusión o el consenso). La extracción de datos es entonces conducida por dos revisores de manera independiente, comparando y reconciliando los resultados cuando sea necesario. En ARCHE, el análisis de los datos y la interpretación de los resultados y preparación del reporte son equivalentes a las dos últimas actividades de la metodología CC.

De la misma manera, ARCHE incluye una actividad para actualizar el reporte de la revisión, con base en el protocolo del GCl Cochrane.

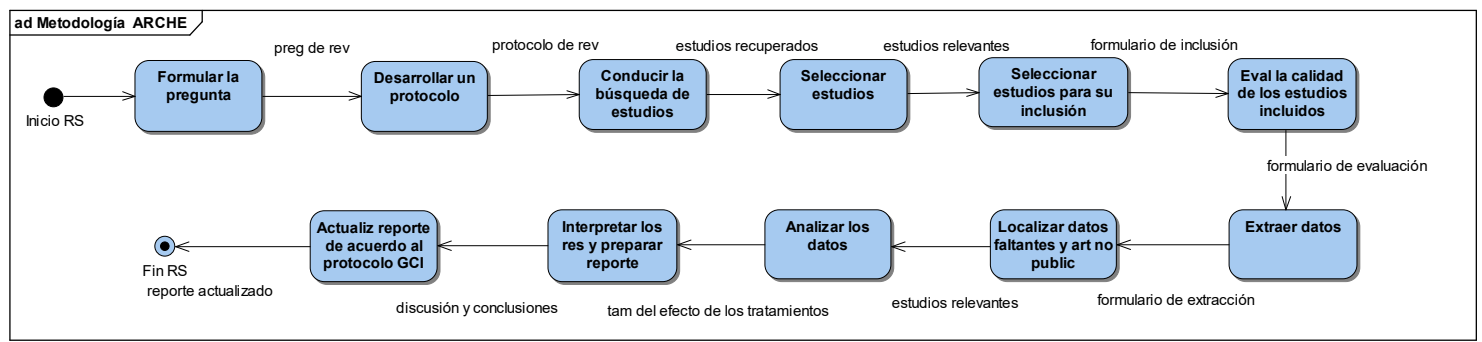

Figura III.4. Actividades de la metodología aplicada por ARCHE

Haciendo un análisis más profundo, el proceso utilizado por el ARCHE presenta un conjunto de elementos que le diferencian del propuesto por CC (ARCHE, 2007):

- En la actividad Seleccionar estudios para su inclusión, ARCHE propone la incorporación de un formulario de inclusión que evalúa los cuatro componentes de la pregunta de revisión (diseño de estudio, intervenciones, población y resultados) y documenta la decisión de incluir o no el estudio en cuestión (véase el Anexo \#\#). Cabe destacar que en cuanto al diseño del estudio se consideran solamente los RCTs.

- Otro elemento diferenciador del proceso aplicado por ARCHE se encuentra en la evaluación de la calidad de los estudios incluidos. ARCHE evalúa la calidad de los RCTs de dos maneras: la primera utiliza la escala de cinco puntos de (A.R. Jadad et al., 1996); el segundo método es la evaluación del ocultamiento de la asignación (Schultz, Chalmers, Hayes, \& Altman, 1995). La aplicación de estos dos métodos es resumida en un formulario de evaluación (véase el Anexo \#\#).

- Para la evaluación de estudios no-RCT, ARCHE aplica un formulario de 27 preguntas divididas en los siguientes aspectos: reporte, validez externa, validez interna-sesgo, validez interna-sesgo de selección, y poder (véase el Anexo \#\#). 
- También en la actividad Extracción de datos, ARCHE propone un formulario compuesto por aspectos relacionados con las características del estudio, las intervenciones, los pacientes, y los resultados de los estudios (véase el Anexo \#\#).

\subsubsection{Enfoque para la revisión sistemática de la evidencia - Instituto Joanna Briggs}

El Instituto Joanna Briggs (JBI, por su acrónimo inglés) es un centro reconocido de desarrollo de RS en el área de la salud, específicamente en las especialidades de Medicina, Enfermería, Psico-terapia, Terapia ocupacional, Podología, y Nutrición y dietética. El JBI sigue el proceso de desarrollo de RS de la CC e incorpora el enfoque de diseminación del NHS-CDR antes descrito (JBI, s/f). Esto último, determina que cada revisión JBI sea conducida por un consultor, quien reporta a un panel de revisión, y el proceso de revisión sea confinado a un período de seis meses. Adicionalmente, cada RS es actualizada cada cinco años (o antes, si es requerido).

Aunque el JBI sigue el proceso de la CC para conducir RS, le ha aportado a éste un conjunto de nuevos elementos:

- Un aspecto fundamental en este proceso es la revisión por pares de cada protocolo. El JBI coordina todas sus RS a través de un programa que evita la duplicidad de actividades y mantiene niveles adecuados de calidad.

- $\quad$ La síntesis de datos puede realizarse sobre cuatro tipos de resultados:

a. Síntesis de resultados de investigación cualitativos: para ello utiliza el Instrumento de Evaluación y Revisión Cualitativa (JBI QUARI) (véase el Anexo \#\#\#); generando un conjunto de afirmaciones que son categorizadas con base en su credibilidad y su similitud en significado. Estos resultados son también sometidos a una meta-síntesis para producir un conjunto único (integrado) de resultados que pueden ser usados como base para la práctica basada en evidencia.

b. Síntesis de resultados de investigación cuantitativa: utiliza el Instrumento para la Evaluación y Revisión Estadística (JBI MAStARI) (véase el Anexo \#\#\#) y aplica el meta-análisis siempre que sea posible.

c. Síntesis de resultados de investigación económica: los resultados de la evaluación crítica y la extracción de datos son presentados tanto en tablas estructuradas como en un resumen narrativo. Cada estudio es categorizado con base en su costo-efectividad y de la magnitud de su efectividad clínica.

Proceso de RS de experimentos en IS 
d. Síntesis de las conclusiones de opinión y otros textos: utiliza el instrumento para la Evaluación y Revisión de texto, opiniones y narrativa (JBI NOTARI) (véase el Anexo \#\#\#) y aplica la meta-síntesis de texto cuando sea posible. Esto implica la agregación o síntesis de conclusiones para generar un conjunto de afirmaciones sobre la base de la similitud en su significado. Estos resultados son también sometidos a una meta-síntesis para producir un conjunto único (integrado) de resultados que pueden ser usados como base para la práctica basada en evidencia. Cuando la

- Propone niveles de evidencia para la evaluación de la calidad de los estudios primarios, que incluyen investigación cualitativa como una buena práctica, particularmente la opinión de expertos, tal como se muestra en la Tabla III.3.

Tabla III.3. Niveles de evidencia propuestos por el JBI (JBI, s/f).

\begin{tabular}{|c|c|c|c|c|c|}
\hline $\begin{array}{l}\text { Nive } \\
\text { evidenci } \\
\text { a }\end{array}$ & $\begin{array}{l}\text { Factibilidad } \\
F(1-4)\end{array}$ & $\begin{array}{l}\text { Adecuació } \\
\text { n A (1-4) }\end{array}$ & $\begin{array}{l}\text { Significado } \\
\text { S (1-4) }\end{array}$ & $\begin{array}{l}\text { Efectividad } \\
\text { E (1-4) }\end{array}$ & $\begin{array}{l}\text { Evidencia económica EE } \\
(1-4)\end{array}$ \\
\hline 1 & $\begin{array}{l}\text { RS de } \\
\text { investigación } \\
\text { con } \\
\text { inequívocos } \\
\text { resultados } \\
\text { sintetizados }\end{array}$ & $\begin{array}{l}\text { RS de } \\
\text { investigación } \\
\text { con } \\
\text { inequívocos } \\
\text { resultados } \\
\text { sintetizados }\end{array}$ & \begin{tabular}{l}
\multicolumn{1}{c}{ RS de } \\
investigación \\
con \\
inequívocos \\
resultados \\
sintetizados
\end{tabular} & $\begin{array}{l}\text { RS (con } \\
\text { homogeneida } \\
\text { d) de estudios } \\
\text { experimentale } \\
\text { s (p.e. RCTs) o } \\
\text { uno o más } \\
\text { estudios } \\
\text { experimentale } \\
\text { s grandes con } \\
\text { intervalos de } \\
\text { confianza } \\
\text { pequeños }\end{array}$ & $\begin{array}{l}\text { RS (con homogeneidad) } \\
\text { de evaluaciones de } \\
\text { intervenciones alternativas } \\
\text { importantes comparando } \\
\text { todos los resultados } \\
\text { clínicamente relevantes } \\
\text { contra las medidas } \\
\text { apropiadas de costo, e } \\
\text { incluyendo un análisis de } \\
\text { sensibilidad clínicamente } \\
\text { sensible }\end{array}$ \\
\hline 2 & $\begin{array}{l}\text { RS de } \\
\text { investigación } \\
\text { con creíbles } \\
\text { resultados } \\
\text { sintetizados }\end{array}$ & $\begin{array}{l}\text { RS de } \\
\text { investigación } \\
\text { con creíbles } \\
\text { resultados } \\
\text { sintetizados }\end{array}$ & $\begin{array}{l}\text { RS de } \\
\text { investigación } \\
\text { con creíbles } \\
\text { resultados } \\
\text { sintetizados }\end{array}$ & $\begin{array}{l}\text { Estudios } \\
\text { cuasi- } \\
\text { experimentale } \\
\text { s (p.e. sin } \\
\text { aleatorización) }\end{array}$ & $\begin{array}{l}\text { Evaluaciones de } \\
\text { intervenciones alternativas } \\
\text { importantes comparando } \\
\text { todos los resultados } \\
\text { clínicamente relevantes } \\
\text { contra las medidas } \\
\text { apropiadas de costo, e } \\
\text { incluyendo un análisis de }\end{array}$ \\
\hline
\end{tabular}


Introduccióin

\begin{tabular}{|c|c|c|c|c|c|}
\hline & & & & & $\begin{array}{l}\text { sensibilidad clínicamente } \\
\text { sensible }\end{array}$ \\
\hline 3 & $\begin{array}{l}\text { RS de } \\
\text { texto/opinión } \\
\text { con creíbles } \\
\text { resultados } \\
\text { sintetizados }\end{array}$ & $\begin{array}{l}\text { RS de } \\
\text { texto/opinión } \\
\text { con creíbles } \\
\text { resultados } \\
\text { sintetizados }\end{array}$ & $\begin{array}{l}\text { RS de } \\
\text { texto/opinión } \\
\text { con creíbles } \\
\text { resultados } \\
\text { sintetizados }\end{array}$ & $\begin{array}{l}\text { 3a. } \\
\text { Estudios de } \\
\text { cohorte (con } \\
\text { grupo de } \\
\text { control) } \\
\text { 3b. Caso } \\
\text { controlado } \\
\text { 3c. } \\
\text { Estudios } \\
\text { observacional } \\
\text { es sin grupo } \\
\text { de control }\end{array}$ & $\begin{array}{l}\text { Evaluaciones de } \\
\text { intervenciones alternativas } \\
\text { importantes comparando } \\
\text { un número limitado de } \\
\text { resultados contra las } \\
\text { medidas apropiadas de } \\
\text { costo, e incluyendo un } \\
\text { análisis de sensibilidad } \\
\text { clínicamente sensible }\end{array}$ \\
\hline 4 & $\begin{array}{l}\text { Opinión de } \\
\text { expertos sin } \\
\text { evaluación } \\
\text { crítica explícita }\end{array}$ & $\begin{array}{l}\text { Opinión de } \\
\text { expertos sin } \\
\text { evaluación } \\
\text { crítica explícita }\end{array}$ & $\begin{array}{l}\text { Opinión de } \\
\text { expertos sin } \\
\text { evaluación } \\
\text { crítica explícita }\end{array}$ & $\begin{array}{l}\text { Opinión de } \\
\text { expertos sin } \\
\text { evaluación } \\
\text { crítica } \\
\text { explícita, o } \\
\text { comparación } \\
\text { de } \\
\text { investigación } \\
\text { o consenso }\end{array}$ & $\begin{array}{l}\text { Opinión de expertos sin } \\
\text { evaluación crítica explícita, } \\
\text { o basada en teoría } \\
\text { económica }\end{array}$ \\
\hline
\end{tabular}

- El JBI también propone el esquema presentado en la Tabla III.4 para agrupar las recomendaciones con base en sus implicaciones para la práctica.

Tabla III.4. Esquema de agrupamiento de recomendaciones (JBI, s/f).

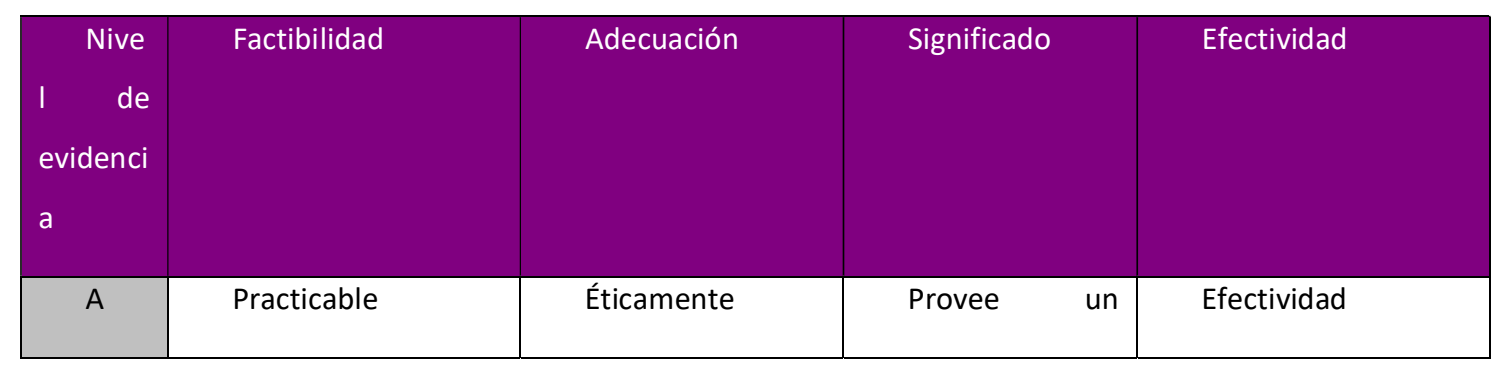

Proceso de RS de experimentos en IS 


\begin{tabular}{|c|c|c|c|c|}
\hline & inmediatamente & $\begin{array}{l}\text { aceptable } \\
\text { justificable }\end{array}$ & $\begin{array}{l}\text { razonamiento } \\
\text { fuerte para el } \\
\text { cambio práctico }\end{array}$ & $\begin{array}{l}\text { establecida a un grado } \\
\text { que amerita aplicación }\end{array}$ \\
\hline B & $\begin{array}{l}\text { Practicable con un } \\
\text { entrenamiento limitado } \\
\text { y/or recursos } \\
\text { adicionales moderados }\end{array}$ & $\begin{array}{l}\text { Aceptación ética } \\
\text { no es clara }\end{array}$ & $\begin{array}{l}\text { Provee un } \\
\text { razonamiento } \\
\text { moderado para el } \\
\text { cambio práctico }\end{array}$ & $\begin{array}{l}\text { Efectividad } \\
\text { establecida a un grado } \\
\text { que sugiere aplicación }\end{array}$ \\
\hline C & $\begin{array}{l}\text { Practicable con } \\
\text { entrenamiento } \\
\text { adicional y/o recursos } \\
\text { significativos }\end{array}$ & $\begin{array}{l}\text { Algunos } \\
\text { conflictos con } \\
\text { principios éticos }\end{array}$ & $\begin{array}{l}\text { Provee un } \\
\text { razonamiento } \\
\text { limitado para el } \\
\text { cambio práctico }\end{array}$ & $\begin{array}{l}\text { Efectividad } \\
\text { establecida a un grado } \\
\text { que justifica la } \\
\text { consideración de } \\
\text { aplicar los resultados }\end{array}$ \\
\hline D & $\begin{array}{l}\text { Practicable con } \\
\text { entrenamiento } \\
\text { adicional y/o recursos } \\
\text { extensivos }\end{array}$ & $\begin{array}{l}\text { Conflictos } \\
\text { considerables con } \\
\text { principios éticos }\end{array}$ & \begin{tabular}{l}
\multicolumn{1}{c}{ Provee un } \\
razonamiento \\
mínimo para \\
recomendar el \\
cambio
\end{tabular} & $\begin{array}{l}\text { Efectividad } \\
\text { establecida a un grado } \\
\text { limitado }\end{array}$ \\
\hline$E$ & Impracticable & $\begin{array}{l}\text { Éticamente } \\
\text { inaceptable }\end{array}$ & $\begin{array}{l}\text { No hay } \\
\text { razonamiento para } \\
\text { soportar el cambio } \\
\text { en la práctica }\end{array}$ & $\begin{array}{l}\text { Efectividad } \\
\text { establecida }\end{array}$ \\
\hline
\end{tabular}

\subsubsection{Método para el desarrollo de lineamientos - Instituto nacional para la excelencia clínica}

El Instituto Nacional para la Excelencia Clínica (NICE, por su acrónimo inglés), es parte del NHS y su rol es proporcionar lineamientos confiables e independientes para la promoción de la buena salud y la prevención y tratamiento de enfermedades. NICE ha desarrollado su misión a través de lineamientos clínicos, evaluaciones tecnológicas, procedimientos de intervención y programas de trabajo en salud pública (NIHCE, 2007).

Como se muestra en la Figura III.5, el proceso para el desarrollo de lineamientos clínicos, comienza con el establecimiento del alcance (dimensionamiento) del lineamiento, lo cual incluye realizar búsquedas preliminares e identificar aspectos clave. Posteriormente, se prepara un plan de trabajo incluyendo los costos, tiempos y el Grupo de Desarrollo del Lineamiento (GDL) que será luego conformado y cuyo funcionamiento se regirá por las reglas que se establecen en las actividades iniciales del proceso.

Una vez que se ha establecido el alcance del lineamiento y se ha preparado el plan de trabajo, NICE utiliza un proceso de RS de la evidencia (corresponden a las actividades 5-8 en la Figura III.5) que incluye actividades 
similares a las propuestas por la CC: formulación de las preguntas clínicas (estructurada en: pacientes, intervenciones, comparaciones y resultados), identificar la evidencia (desarrollar y ejecutar estrategias de búsqueda), revisar y agrupar la evidencia (seleccionar los estudios relevantes, evaluar su calidad, sintetizar los resultados a través de meta-análisis y agrupar la evidencia), y crear recomendaciones para el lineamiento con base en la evidencia (desarrollar y priorizar recomendaciones). Las últimas cuatro actividades del proceso, corresponden a la aprobación y publicación del lineamiento.

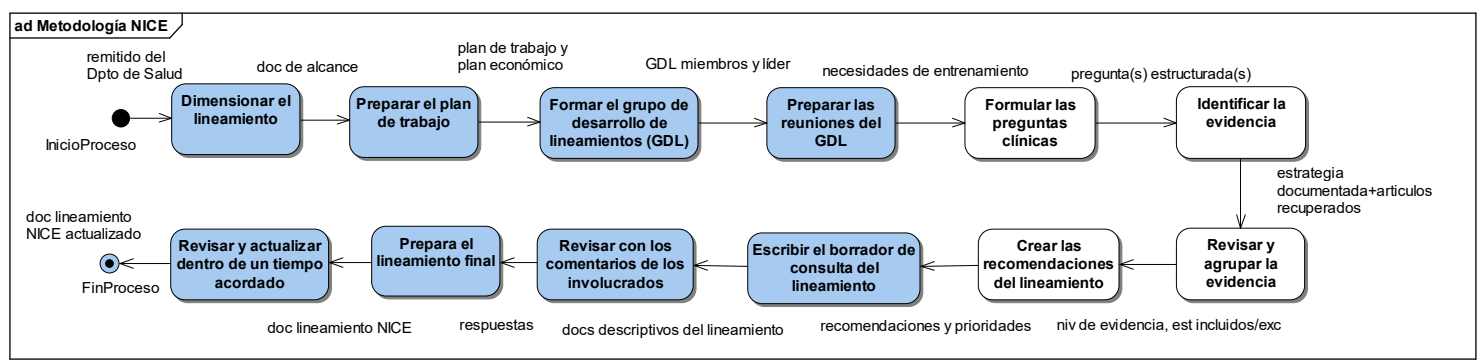

Figura III.5. Actividades relacionadas con el proceso de creación de lineamientos clínicos de NICE

Algunos elementos que ha aportado NICE al proceso de RS heredado de sus predecesores, son los siguientes (NIHCE, 2007):

- Propone un algoritmo para determinar de manera simple el diseño del estudio durante la evaluación de la calidad (véase el Anexo \#\#\#). Este algoritmo permite diferenciar estudios no comparativos (series de casos y estudios de casos) de los estudios experimentales y observacionales. Los estudios experimentales son clasificados en: RCTs, no-RCTs, pruebas aleatorizadas de grupo, y pruebas aleatorizadas individuales. El algoritmo también permite clasificar los estudios observacionales en: estudios pre-post/series de tiempo interrumpidas, estudios multi-grupales, estudios de cohorte y estudios de caso-control.

- $\quad$ NICE recomienda las listas de chequeo propuestas por SIGN (SIGN, 2004). Estas listas de chequeo pueden ser utilizadas para evaluar la validez interna de los estudios seleccionados con base en las características de calidad más importantes para cada tipo de diseño (RS y meta-análisis, RCTs, estudios de cohorte, estudios de caso-control, estudios de diagnóstico, evaluaciones económicas, y estudios cualitativos) (véase el Anexo \#\#\#).

- Propone el uso de tablas de evidencia para recolectar los datos obtenidos de los estudios seleccionados, asimismo propone una plantilla para esta tabla con los datos que deberían ser incluidos (véase el Anexo \#\#\#). 


\subsubsection{Método de desarrollo de lineamientos - Red escocesa inter-universitaria de} lineamientos

La red escocesa inter-universitaria de lineamientos (SIGN, por su acrónimo inglés) es una red dedicada a producir lineamientos en el área de la salud, que son generados directamente por una RS. SIGN trabaja con un grupo de desarrolladores cercanamente relacionados con el desarrollo de síntesis de la base de evidencia, permitiéndoles aplicar sus juicios cuando tienen que derivar recomendaciones.

La red involucra a un gran número de especialistas de la salud, gerentes de servicios de salud, servicios sociales e investigadores (SIGN, 2004). Como se observa en la Figura III.6 el proceso seguido por el SIGN es, en esencia, similar al utilizado por NICE y aún mucho más cercano al propuesto por la CC.

El proceso comienza con la definición de una o varias preguntas claves (estructurada con base en los pacientes, intervenciones, comparaciones y resultados); posteriormente, se realiza una búsqueda sistemática de la literatura que incluye la identificación de RS previas. El resultado de esta búsqueda es un listado de resúmenes que es entregado al GDL quien selecciona los artículos aplicando criterios de inclusión/exclusión explícitos.

Una vez que se han identificado los artículos que son fuentes posibles de evidencia, éstos son evaluados en dos dimensiones (calidad de su metodología y validez de sus resultados). Los artículos aceptados pasan a constituir la base de evidencia y resumidos en una tabla de evidencia. Finalmente, con base en la tabla de evidencia elaborada, el GDL produce sus recomendaciones aplicando diferentes juicios cuando sea necesario.

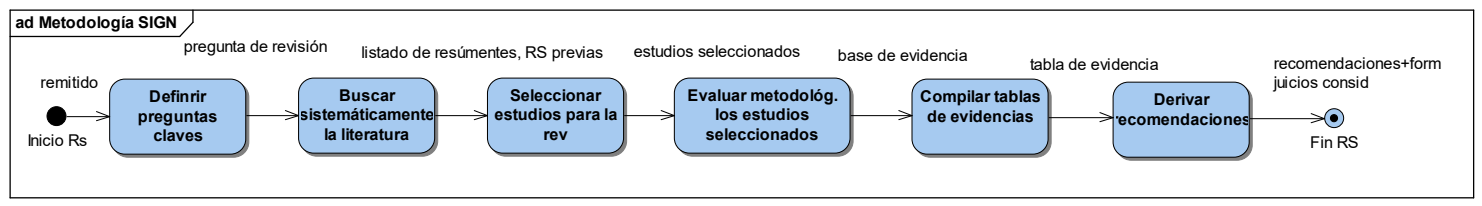

Figura III.6. Actividades de la metodología de SIGN

Los siguientes son aspectos que SIGN ha adaptado a las necesidades de su metodología:

- Utiliza listas de chequeo particulares durante la Evaluación metodológica del estudio (SIGN, 2004). Incluye seis listas de chequeo para determinar la validez interna de cada estudio, para los siguientes tipos: revisiones sistemáticas, RCTs, estudios de cohorte, estudios de casos controlados, estudios de diagnóstico, y evaluaciones económicas (véase el Anexo \#\#\#).

- Una vez que los estudios son evaluados, un nivel de calidad es asignado a cada uno de ellos. De esta manera, la generación de recomendaciones se realiza de manera agrupada por niveles de evidencia. EI nivel de evidencia está determinado a su vez por el diseño del estudio y la calidad metodológica establecida en la evaluación del estudio. La jerarquía utilizada por SIGN es presentada en la Tabla III.5. 
Tabla III.5. Jerarquía de niveles de evidencia de SIGN (SIGN, 2004)

\begin{tabular}{|c|c|}
\hline $\begin{array}{r}\text { Nive } \\
\text { evidenci } \\
\text { a }\end{array}$ & Estudio \\
\hline $1++$ & Meta-análisis de alta calidad, RS de RCTs o RCTs con muy bajo riesgo de sesgo \\
\hline $1+$ & Meta-análisis bien conducido, RS, o RCTs con un bajo riesgo de sesgo \\
\hline 1- & Meta-análisis, RS, o RCTs con un alto riesgo de sesgo \\
\hline $2++$ & $\begin{array}{l}\text { RS de alta calidad de estudios observacionales } \\
\text { Caso controlado o estudios de cohorte con un muy bajo riesgo de sesgo o } \\
\text { confusores y una alta probabilidad de que la relación sea causal }\end{array}$ \\
\hline $2+$ & $\begin{array}{l}\text { Caso control bien conducido o estudios de cohorte con un bajo riesgo de sesgo } \\
\text { o confusores y una moderada probabilidad de que la relación sea causal }\end{array}$ \\
\hline $2-$ & $\begin{array}{l}\text { Caso control o estudios de cohorte con un alto riesgo de confusores o sesgo y } \\
\text { un riesgo significativo de que la relación no sea causal }\end{array}$ \\
\hline 3 & Estudios no experimentales, p.e. reportes de casos, series de casos \\
\hline 4 & Opinión de expertos \\
\hline
\end{tabular}

- La metodología propone una tabla de evidencia para resumir los resultados de las evaluaciones (véase el Anexo \#\#\#), ésta servirá de base al GDL para aplicar sus juicios considerados completando el cuerpo de evidencia que permitirá llegar a un conjunto agrupado de recomendaciones. Para ello se utiliza un formulario de juicios considerados que documenta el volumen de la evidencia, la aplicabilidad, la generalidad, la consistencia, implicaciones de servicio, implicaciones de recursos, y el nivel de la base de evidencia (véase el Anexo \#\#\#).

- Una vez que un nivel general de evidencia ha sido asignado, se pueden generar las recomendaciones agrupadas (o la serie de recomendaciones) de acuerdo a la Tabla III.6.

Tabla III.6. Jerarquía de niveles de evidencia de SIGN (SIGN, 2004)

Proceso de RS de experimentos en IS 


\begin{tabular}{|c|c|}
\hline $\begin{array}{l}\text { Nive } \\
\text { evidenci } \\
\text { a }\end{array}$ & Estudio \\
\hline A & $\begin{array}{l}\text { Al menos un meta-análisis o RS o RCT de nivel 1++ y directamente aplicable a la } \\
\text { población objetivo } \\
\text { Una RS de RCTs o un cuerpo de evidencia que consista principalmente de estudios } \\
\text { del tipo } 1+\text {, directamente aplicable a la población objetivo y que demuestre una } \\
\text { consistencia general de los resultados }\end{array}$ \\
\hline B & $\begin{array}{l}\text { Un cuerpo de evidencia incluyendo estudios del tipo } 2++ \text {, directamente aplicable a } \\
\text { la población objetivo y que demuestre una consistencia general de los resultados; o } \\
\text { evidencia extrapolada de estudios del tipo } 1++ \text { o } 1+\end{array}$ \\
\hline C & $\begin{array}{l}\text { Un cuerpo de evidencia incluyendo estudios del tipo } 2+\text { directamente aplicable a } \\
\text { la población objetivo y que demuestre una consistencia general de los resultados; o } \\
\text { evidencia extrapolada de estudios del tipo } 2++\end{array}$ \\
\hline D & Evidencia de nivel 3 ó 4, o evidencia extrapolada de estudios del tipo 2+ \\
\hline
\end{tabular}

\subsubsection{Proceso de conducción de revisiones sistemáticas - Grupo de revisiones sistemáticas de} la Universidad de Berkeley

El grupo de revisiones sistemáticas de Berkeley (GRSB) propone un proceso de RS de evaluaciones de pruebas de diagnostico que consta de cinco pasos principales tomados de las metodologías CC y CDR (Pai et al., 2004) (véase Figura III.7).

La metodología comienza definiendo una pregunta de revisión enfocada en los cuatro componentes antes vistos, en esta actividad se revisan los lineamientos para RS, se prepara un protocolo, y se identifican las fuentes y bases de datos apropiadas donde se correrán posteriormente las búsquedas. Los títulos y resúmenes de los artículos recuperados en las búsquedas son analizados por dos revisores que seleccionan aquellos que consideran elegibles.

Una vez que se cuenta con un conjunto elegible de artículos, dos revisores extraen los datos y evalúan la calidad de cada estudio; los datos obtenidos son almacenados en una base de datos. Seguidamente, los datos son importados para realizar su análisis utilizando un software meta-analítico. Los resultados son interpretados, discutidos y reportados (incluyendo su aplicabilidad y las limitaciones de la revisión) para, finalmente, generar recomendaciones para la práctica o la política, y la investigación. 


ad Metodología GRSB

Figura III.7. Actividades de la metodología de GRSB

Como elementos diferenciadores, el proceso de GRSB agrega los siguientes aspectos particulares (Pai et al., 2004):

- Un conjunto de características de calidad para la evaluación la validez de estudios con base en su diseño: terapia, diagnóstico, perjuicios, y prognosis (véase el Anexo \#\#).

- $\quad$ El uso de dos lineamientos para el reporte de los resultados: QUOROM para el reporte de meta-análisis de RCTs y MOOSE para el reporte de meta-análisis de estudios observacionales (véase el Anexo \#\#\#).

\subsubsection{Metodología para revisión sistemática - Proyecto de hábitat y salud}

El propósito del Proyecto de hábitat y salud (HANAH) es desarrollar la colaboración entre científicos de la Universidad de Gales, en áreas multi-disciplinares como: Arquitectura, Medio ambiente, Salud pública, Sociología e Información, para estudiar el efecto de las modificaciones del medio ambiente en la salud pública (Williams et al., 2001).

En las Figura III.8 (a) y (b), se muestra el proceso detallado seguido en HANAH. Aunque en esencia estas actividades reproducen el proceso propuesto por la CC, la metodología $\mathrm{HANAH}$ incluye algunas diferencias. EI proceso comienza con la identificación de áreas temáticas para realizar las búsquedas y establecer el título de la revisión (etapa I). Posteriormente (en las etapas II y III), se realizan las búsquedas (comenzando por búsquedas preliminares para determinar el alcance de la evidencia disponible), selección de estudios y registro de la evidencia. Si no existen RS disponibles, se realiza la evaluación de los estudios seleccionados para su inclusión. En caso contrario, la RS es terminada.

En la etapa IV, los resultados obtenidos son combinados a través de meta-análisis y se identifica la evidencia de baja calidad. Finalmente, en la etapa $V$ el primer borrador es sometido al GR; en caso de que se considere necesario, el proceso podría repetirse desde la etapa II para incorporar más evidencia.

Otros aspectos a resaltar de este proceso son (Williams et al., 2001):

- Propone una clasificación de tipos de estudios para la selección y evaluación de los estudios primarios, como se muestra en la Tabla III.7.

Tabla III.7.Clasificación de tipos de evidencia en el proceso HANAH (Williams et al., 2001)

Proceso de RS de experimentos en IS 


\begin{tabular}{|c|c|}
\hline $\begin{array}{l}\text { Nivel } \\
\text { de } \\
\text { evidencia }\end{array}$ & Estudio \\
\hline S1 & $\begin{array}{l}\text { Evidencia de RS completas que contenga al menos un RCT y un resumen de los } \\
\text { estudios incluidos }\end{array}$ \\
\hline S2 & Evidencia de otras RS \\
\hline T1 & Evidencia de RCTs bien diseñados y tamaños apropiados \\
\hline $\mathrm{T} 2$ & Evidencia de RCTs bien diseñados sin aleatorización \\
\hline T3 & Evidencia de pruebas pre/post bien diseñadas \\
\hline O1 & Evidencia de estudios de cohortes bien diseñados y tamaños apropiados \\
\hline $\mathrm{O} 2$ & Evidencia de estudios de control de casos bien diseñados y tamaños apropiados \\
\hline $\mathrm{O} 3$ & $\begin{array}{l}\text { Evidencia de estudios longitudinales y de diferentes grupo bien diseñados y } \\
\text { tamaños apropiados }\end{array}$ \\
\hline $\mathrm{O} 4$ & $\begin{array}{l}\text { Evidencia de estudios bien diseñados y de tamaño apropiado, solamente } \\
\text { usando métodos cualitativos }\end{array}$ \\
\hline $\mathrm{O5}$ & Evidencia de estudios de caso bien diseñados \\
\hline $\mathrm{X} 1$ & $\begin{array}{l}\text { Opinión de consenso de uno o más grupos profesionales, representados por } \\
\text { cuerpos respetados internacionalmente }\end{array}$ \\
\hline $\mathrm{X} 2$ & Otras opiniones \\
\hline
\end{tabular}

- Proponen listas de chequeo para la evaluación crítica de los estudios seleccionados con base en cada diseño de estudio incluido en la Tabla III.7 (véase el Anexo \#\#\#). 


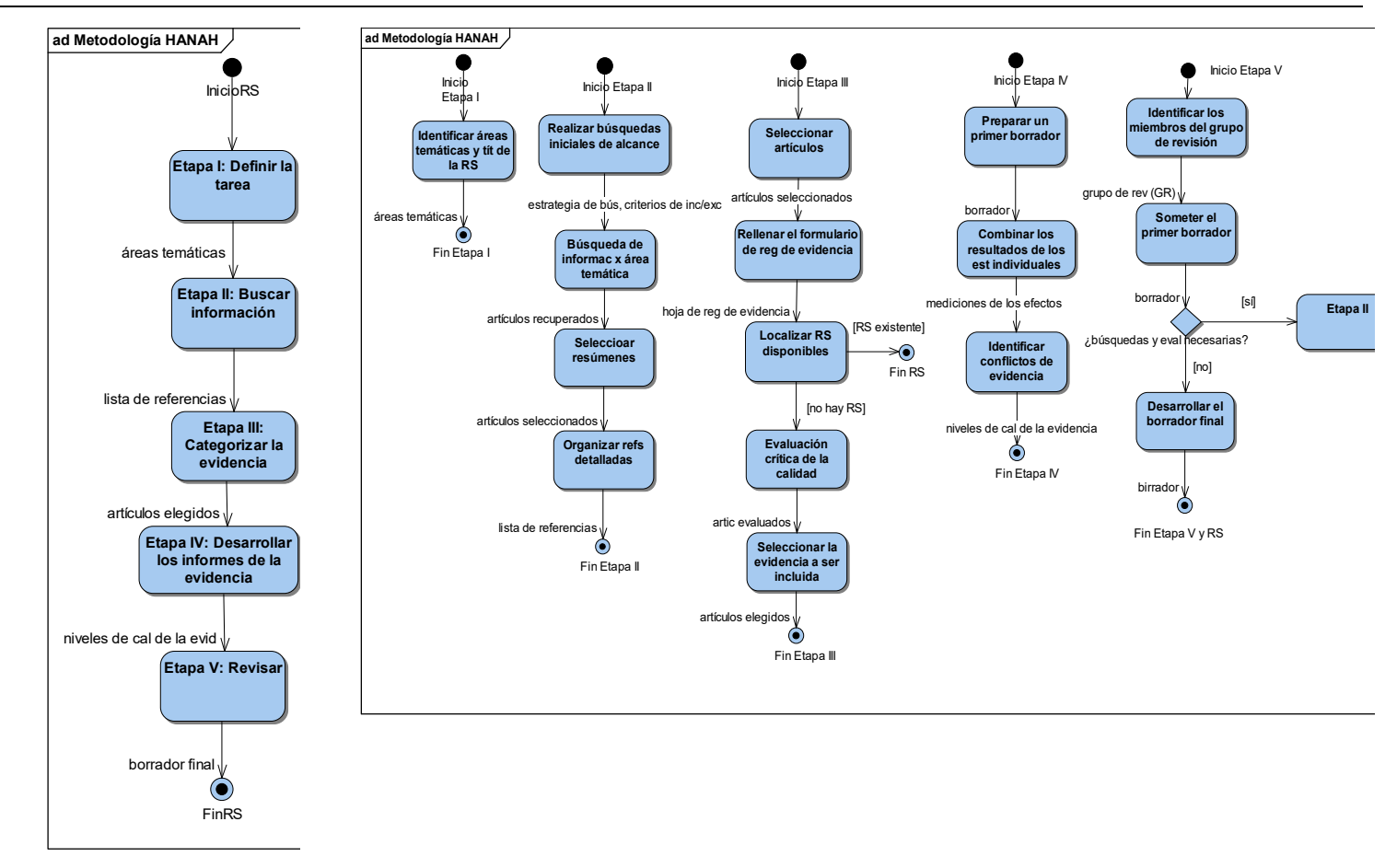

Figura III.8. (a) Etapas de la metodología HANAH, (b) Actividades de cada etapa

\subsubsection{Metodología de revisiones sistemáticas y meta-análisis - Proyecto HuGE Net}

Las revisiones HuGE fueron introducidas como un medio para integrar evidencia de estudios epidemiológicos del genoma; esto es, estudios basados en la población, acerca del impacto de la variación genética humana en la salud y las enfermedades (Little \& Higgins, 2006).

Como se muestra en la Figura III.9 el proceso HuGe contiene en esencia las mismas actividades que el propuesto por CC. La metodología plantea como actividad inicial el desarrollo de un protocolo; posteriormente, se planifica la revisión, lo cual consiste en estructurar la pregunta de revisión. Las actividades siguientes corresponden a la búsqueda y selección de estudios, recolección de datos, evaluación de sesgos potenciales (evaluación de la calidad), síntesis de datos, y presentación e interpretación de resultados.

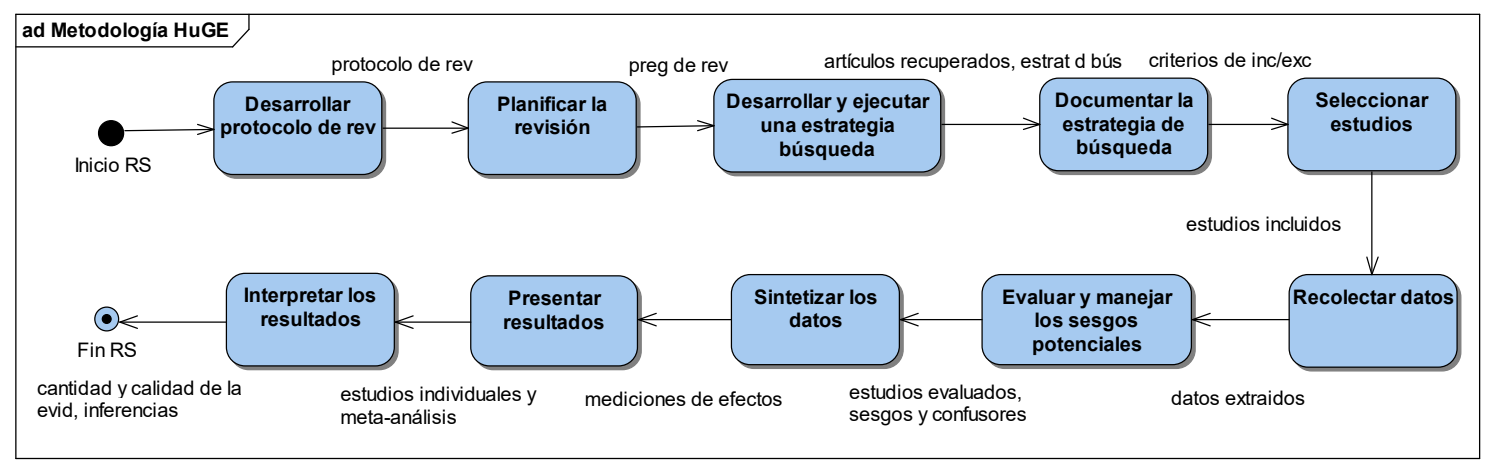

Proceso de RS de experimentos en IS 
Figura III.9. Actividades de la metodología HuGE

Sin embargo, debido a la naturaleza de la disciplina, principalmente los estudios de interés para las revisiones HuGE serán: estudios observacionales de asociaciones enfermedad-genética y estudios de interacciones. Esto determina que aspectos especiales sean introducidos dentro del proceso, que lo diferencian de los procesos antes descritos (incluso del proceso Cochrane) (Little \& Higgins, 2006):

- Los resultados de interés al plantear la pregunta de revisión podrían no estar limitados a resultados finales obtenidos en los estudios, sino que también son de interés los resultados intermedios que juegan un rol importante en la asociación del genoma y la enfermedad.

- Debido a que es necesario incluir estudios observacionales, es necesario realizar inferencia causal para establecer las asociaciones e interacciones entre el genoma y la enfermedad.

- Se incorporan sesgos particulares, diferentes a los antes mencionados, que guardan relación directa con el tipo de estudios analizados. Estos sesgos son: sesgo de información (p.e. el riesgo de una clasificación errónea del gen estudiado), sesgo de severidad (riesgo de seleccionar solamente enfermedades extremas), sesgo de reporte (riesgo de realizar inferencias causales no válidas).

- Por otra parte, durante la síntesis de datos, el enfoque se concentra en examinar la heterogeneidad más que en la producción automática de estimaciones combinadas de efectos.

- Por último, como una característica particular de las revisiones realizadas por HuGE, debido a la ausencia de un cuerpo sustancial de evidencia, la metodología sugiere utilizar criterios de inclusión que no limiten los estudios respecto al diseño, el tamaño de la muestra o la susceptibilidad al sesgo. En contraparte, proponen manejar las diferencias entre las características metodológicas de los estudios en una etapa posterior, a través de un análisis de sensibilidad para evaluar la robustez de las conclusiones, o llevar a cabo una meta-regresión o un análisis por sub-grupos.

\subsubsection{Metodología para revisiones sistemáticas - Colaboración Campbell}

La Colaboración Campbell (C2) es una organización internacional dedicada a preparar, mantener y diseminar RS de estudios de efectividad de alta calidad. La C2 intenta contribuir en las decisiones prácticas, políticas y el entendimiento público. Una RS Campbell revisa y sintetiza evidencia de intervenciones sociales y del comportamiento y de política pública, incluyendo educación, justicia criminal, y bienestar social, entre otras áreas. La C2 trabaja estrechamente con la CC, de allí que, como se muestra en la Figura III.10, presenta actividades en su proceso de RS muy similares a las de la CC, aunque también incorpora elementos de CDR (TheCampbellCollaboration, $s / f$ ). 
Una revisión Campbell debe pasar por un flujo de trabajo antes de ser conducida. Este flujo comienza cuando un revisor o Comité Coordinador define una pregunta de investigación o tópico y somete un protocolo de revisión a un Supervisor principal, éste (junto con un Equipo Editorial y evaluadores externos) aprueban el protocolo que dirigirá la RS. A partir de este momento las actividades de la revisión son similares a las descrita en los casos anteriores; incluyendo el uso del meta-análisis, cuando sea posible, para determinar el efecto principal y entender la influencia de los factores de estudios (y la variabilidad entre estudios). Una vez que la revisión es llevada a cabo, la versión final es sometida al Equipo Editorial para su publicación en el repositorio de RS de la C2 (C2-RIPE).

La estructura de la C2 presenta una serie de Grupos de métodos que trabajan en conjunto con los Grupos de métodos de la CC en el desarrollo de lineamientos equivalentes. Tales grupos trabajan en la mejora de la metodología de síntesis de investigación y en la diseminación del estado del arte de los métodos de revisión. Las principales aportaciones de los Grupos de métodos dedicados a mejorar la metodología se orientan a aspectos como: revisores, equipos editoriales, entrenamiento para los revisores, localización de estudios, evaluación de la calidad de los estudios, resumen e integración de los resultados de los estudios, e interpretación y presentación de los resultados.

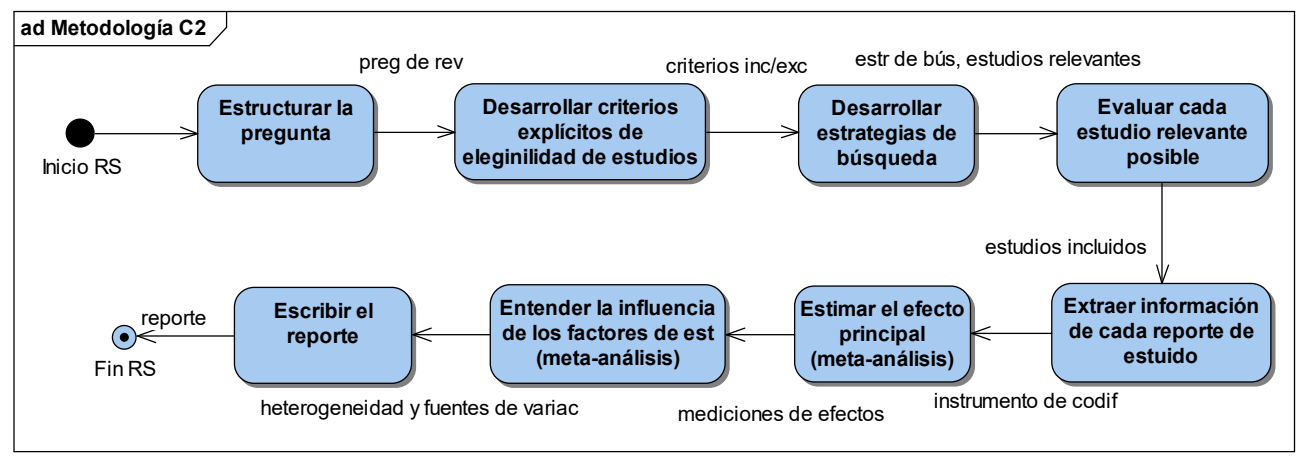

Figura III.10. Actividades involucradas con la revisión C2

Algunos aspectos que son particulares a una revisión C2 son los siguientes (TheCampbellCollaboration, s/f):

- Puede incluir evidencia de estudios de implementación de una intervención. Estos estudios pueden identificar factores que impiden o facilitan el proceso de implementación y pueden describir la experiencia subjetiva de las personas que proporcionan o reciben la intervención o el proceso de implementación de una intervención particular. Por lo tanto, la evidencia puede derivar de estudios que utilizan un amplio rango de métodos e incluir tanto datos cualitativos como cuantitativos.

- Otro tópico metodológico importante, tiene que ver con los criterios que utilizan los revisores para manejar las instancias en las cuales una evaluación simple de la efectividad proporciona datos sobre

Proceso de RS de experimentos en IS 
múltiples mediciones de resultados. Esto puede ocurrir porque varios tipos de resultados son medidos dentro del mismo estudio y/o porque el mismo resultado es medido en múltiples puntos en el tiempo.

- Por último, en el contexto de una revisión Campbell, los estudios cualitativos pueden (a) contribuir al desarrollo de una intervención más robusta, al ayudar a definir una intervención de manera más precisa, (b) apoyar en la selección de las medidas de los resultados y en el desarrollo de preguntas de investigación válidas, y (c) ayudar a entender resultados heterogéneos de los efectos en los estudios.

\subsubsection{Métodos para revisiones sistemáticas - Centro de Evidencia para la Política e Iniciativa}

\section{Práctica}

El Centro de Evidencia para la Política e Iniciativa Práctica (EPPI-Centre) fue fundado por el gobierno del Reino Unido para dar soporte a las RS de evidencia de investigación en áreas relacionadas con escuelas y estudiantes menores de 18 años. El centro está basado en la Unidad de Investigación en Ciencias Sociales del Instituto de Educación de Londres. El EPPI-Centre trabaja en asociación con Grupos de Revisión (GR) distribuidos por el Reino Unido. Los GR aseguran que el trabajo que se quiere realizar es de relevancia para un gran número de involucrados. Tales grupos incluyen políticos, educadores, investigadores académicos, etc.

El EPPI-Centre conduce RS en diversos tópicos: educación, promoción de la salud, empleo, bienestar social, y crimen y justicia. Este centro ha adaptado el modelo de síntesis sistemática de investigación que ha sido ampliamente desarrollado para las Ciencias de la salud, para orientar un mayor rango de preguntas y metodologías relevantes a la investigación en política pública, tales como: síntesis estadística, narrativa y conceptual (EPPI-Centre, 2002).

En la Figura III.11 se presentan las actividades involucradas en la metodología del EPPI-Centre. Nótese que la mayoría de las actividades son similares a las descritas en los casos anteriores. El proceso comienza con una consulta a los miembros del GR para desarrollar y refinar la pregunta de revisión. Posteriormente, se establecen los criterios de inclusión y exclusión que serán utilizados, para elegir los estudios que participarán en la RS. El resto de los métodos que serán utilizados son definidos en un protocolo de revisión.

Luego de buscar y seleccionar los estudios, éstos son categorizados utilizando un conjunto de palabras claves de EPPI, generando posteriormente un mapa sistemático del área con la que se corresponden los trabajos. En la siguiente actividad, el GR es nuevamente consultado sobre las áreas del mapa sistemático que deben ser exploradas en detalle. Con base en esta pregunta detallada, se realiza la extracción de datos (incluyendo los juicios acerca de la calidad), y finalmente, se produce el reporte (el cual incluye presentar la síntesis de los resultados de calidad media-alta junto con el procedimiento de revisión) y se publican los resultados. 


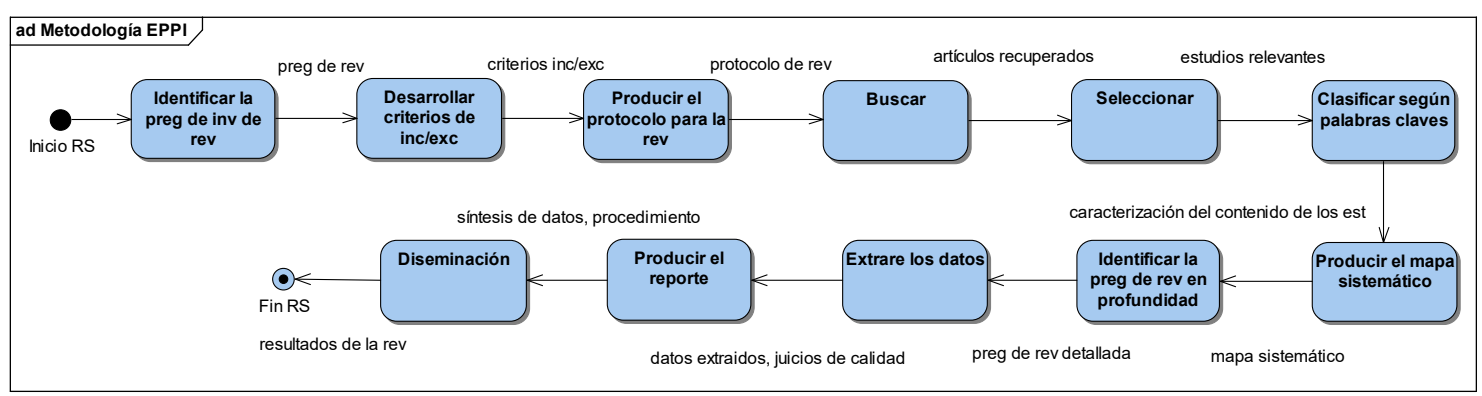

Figura III.11. Actividades de la metodología EPPI-Centre

A continuación se señalan algunos aspectos particulares presentes en las RS del EPPI-Centre (EPPI-Centre, 2002):

- Mientras que otros procesos de revisiones aplican casi exclusivamente el meta-análisis de los resultados de estudios experimentales (RCTs), el EPPI-Centre trata de incluir estudios con una mayor variedad de diseños de estudio. Por consiguiente, la síntesis de resultados puede ser tanto cuantitativa como cualitativa.

- Para realizar la clasificación según palabras claves, se codifica cada estudio contra una lista de palabras pre-establecida por EPPI. Para ello EPPI propone dos conjuntos de palabras claves: 1) una serie de palabras claves genéricas aplicadas a todos los estudios en todas las revisiones EPPI (fuente, enfoque, país, tópico, población, edad de los estudiantes, ambiente educacional, estrategia de investigación), 2) una serie de palabras claves específicas a la revisión, desarrolladas por el GR que corresponde al tópico de la revisión. Esta actividad puede realizarse de manera manual o automática, idealmente debería ser realizada por dos personas.

- El proceso propuesto por el EPPI-Centre incluye una fase de codificación más detallada en la cual se identifican las características clave de los estudios para proporcionar una perspectiva general de trabajo en el área que se está considerando. Esto implica responder un cuestionario de 100 preguntas (desarrollado por EPPI) acerca de cada estudio (véase Anexo \#\#).

- Una vez que se establece la clasificación por palabras clave, se genera un mapa sistemático del área de investigación que resume el trabajo realizado y agrupa los estudios de acuerdo a sus características principales. El mapa está basado en categorías de los dos conjuntos de palabras claves y contiene tanto información descriptiva simple (p.e. fuente de los datos, país de origen del reporte, etc.) como datos más sofisticados (p.e. relaciones entre la naturaleza de la intervención y los resultados reportados, entre otros).

Proceso de RS de experimentos en IS 
- Otra característica diferenciadora de la metodología EPPI es que al culminar la revisión detallada se deben aplicar cuatro juicios sobre la calidad del peso de la evidencia en el estudio (resultados, adecuación, relevancia y calidad global), basado en las respuestas a las preguntas previas. Cada uno de estos juicios involucra una decisión acerca de si el peso de la evidencia en el artículo es alta, media o baja. Este valor será considerado durante la síntesis de los resultados.

\subsubsection{Lineamientos para revisiones sistemáticas en conservación y gerencia ambiental - Centro para la Conservación basada en evidencia}

La metodología propuesta por el Centro para la Conservación basada en evidencia (CEBC, por su acrónimo inglés) está inspirada principalmente en las metodologías del CDR y CC (CEBC, 2006). Como se puede apreciar en las Figuras III.12 (a) y (b), las actividades involucradas en la metodología son bastante similares a las acometidas en Medicina. La metodología plantea tres etapas, donde la primera de ellas es responsable por estructurar la pregunta, establecer el alcance y el protocolo de revisión, y desarrollar la estrategia de búsqueda. En la segunda y tercera etapa, la revisión es conducida y reportada, respectivamente; utilizando para ello, básicamente, las actividades de la CC. No obstante, el proceso reconoce un conjunto de diferencias, tal y como se describe a continuación (CEBC, 2006):

- Recomienda realizar una búsqueda de dimensionamiento que permita: 1) evaluar la probabilidad de llevar a cabo la revisión, 2) identificar el potencial de la revisión para llenar las brechas de conocimiento, 3) identificar el potencial de la revisión para ser meta-analizable, 4) identificar revisiones sobre el mismo tópico, 5) identificar fuentes de datos, y 6) identificar involucrados y expertos.

- La formulación de la pregunta está usualmente limitada por la disponibilidad y complejidad de la información, requiriendo un balance entre holismo (más realismo) y reduccionismo (más estudios).

- La participación de los involucrados puede ser crítica porque las acciones sobre conservación frecuentemente presentan conflictos de objetivos.

- Debido a que en la disciplina de conservación no se cuenta con la infraestructura presente en Medicina, la metodología recomienda estrategias de búsqueda particulares (alta recuperación y baja especificidad) para reducir el sesgo e incrementar la repetibilidad. 

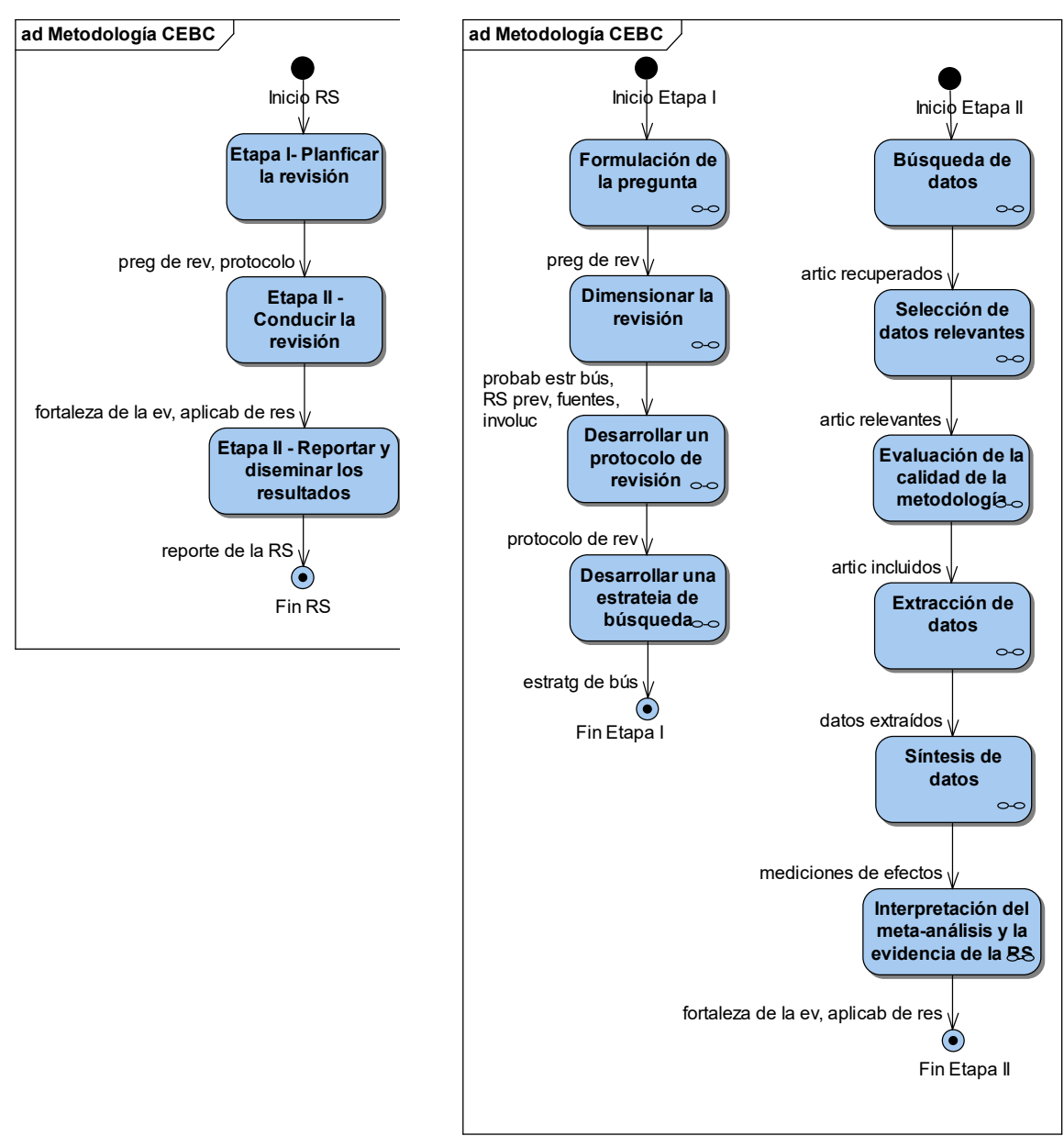

Figura III.12. (a) Etapas involucradas en la metodología CEBC, (b) Actividades de cada etapa

- En cuanto a la evaluación de la calidad de la metodología, la jerarquía de diseños de estudio propuesto en Medicina debe ser adaptada a la Ecología. Una aplicación rígida de esta jerarquía (claramente enfocada a los RCTs) no reconoce la importancia de las diferentes dimensiones metodológicas dentro de un estudio, dependiendo de la intervención que esté siendo aplicada. Para ello, utiliza la jerarquía propuesta en (Andrew \& Teri, 2003), la cual se muestra en la Tabla III.8.

- Lo anterior determina que deba utilizarse una asignación pragmática de pesos y análisis de sensibilidad para mejorar la evaluación por jerarquía de diseños de estudio, particularmente cuando se combinan datos de distintos niveles de calidad para incrementar el tamaño de la muestra. Por otra parte, el sesgo de ejecución y de detección introducidos por el diseño experimental son especialmente difíciles de evaluar de una manera estandarizada, necesitando de coeficientes de ponderación de calidad específicos a la revisión. El enmascaramiento (blinding) generalmente no es posible en ecología.

Proceso de RS de experimentos en IS 
Tabla III.8. Jerarquía de diseños adaptada para su uso en Conservación (CEBC, 2006)

\begin{tabular}{|c|c|}
\hline Catego & Estudio \\
\hline 1 & $\begin{array}{l}\text { Evidencia contundente obtenida de al menos un RCT bien diseñado y de } \\
\text { tamaño apropiado }\end{array}$ \\
\hline II-1 & $\begin{array}{l}\text { Evidencia obtenida de un experimento controlado sin aleatorización, bien } \\
\text { diseñado }\end{array}$ \\
\hline II-2 & $\begin{array}{l}\text { Evidencia obtenida de una comparación de diferencias entre sitios con y } \sin \\
\text { (controles) especies o comunidad deseadas }\end{array}$ \\
\hline II-3 & $\begin{array}{l}\text { Evidencia obtenida de múltiples series de tiempo o de resultados dramáticos en } \\
\text { experimentos no controlados }\end{array}$ \\
\hline III & $\begin{array}{l}\text { Opiniones de autoridades respetadas basadas en evidencia de campo } \\
\text { cualitativa, estudios descriptivos o reportes de comités expertos }\end{array}$ \\
\hline IV & $\begin{array}{l}\text { Evidencia inadecuada originada en problemas metodológicos, p.e. tamaño de la } \\
\text { muestra, longitud o amplitud del monitoreo, o conflictos de evidencia }\end{array}$ \\
\hline
\end{tabular}

- No es posible utilizar listas de chequeo "preestablecidas" para la evaluación de la calidad, por ello son necesarios criterios a priori específicos de revisión, preferiblemente validados por consenso con los involucrados. La metodología CEBC propone utilizar los siguientes componentes de evaluación: métodos, población, intervenciones y co-intervenciones, resultados, diseño del estudio, línea base de comparación, variación intra-tratamiento, y replicación y parámetro de abundancia. También CEBC recomienda un análisis kappa para asegurar que las decisiones sobre la relevancia de los estudios recuperados por los diferentes revisores son comparables.

- La extracción de datos es especialmente compleja respecto a las mediciones de varianza para la asignación de pesos. Deben desarrollarse reglas a priori para poder extraer los datos de una manera repetible y estandarizada, a pesar de la independencia y la (pseudo)replicación, que son comúnmente problemáticas.

- En cuanto a la síntesis de datos (meta-análisis), los modelos de efectos aleatorios son generalmente más útiles que los modelos fijos, ya que las complejas interacciones en ecología generalmente resultan en heterogeneidad ecológicamente importante entre los estudios.

- Por último, la variación del contexto ecológico y la localización geográfica limita la aplicabilidad de los resultados, los revisores deben prestar especial atención a la escala de tiempo en los estudios incluidos, la cual puede ser insuficientemente corta para hacer predicciones a largo plazo. 


\subsubsection{Metodología para revisiones sistemáticas de investigación - Centro Nacional para la} investigación en Educación Vocacional

El Centro Nacional para la investigación en Educación Vocacional (NCVER, por su acrónimo inglés) propone una metodología para el desarrollo de investigación secundaria, a través de RS, que apoyen la política y práctica de la información en el sistema de adiestramiento de Australia (Bowman \& Hayman, 2004).

La metodología, como puede observarse en la Figura III.13, presenta actividades similares a las propuestas por los procesos anteriormente descritos; comenzando con la identificación de la pregunta (con base en los cuatro componentes vistos en los casos anteriores), lo cual da paso al desarrollo de un marco de trabajo que establece el significado de los términos y los criterios de inclusión que orientan la posterior búsqueda y selección de estudios. Los pasos siguientes incluyen la evaluación de la calidad, la síntesis, presentación y diseminación de los resultados.

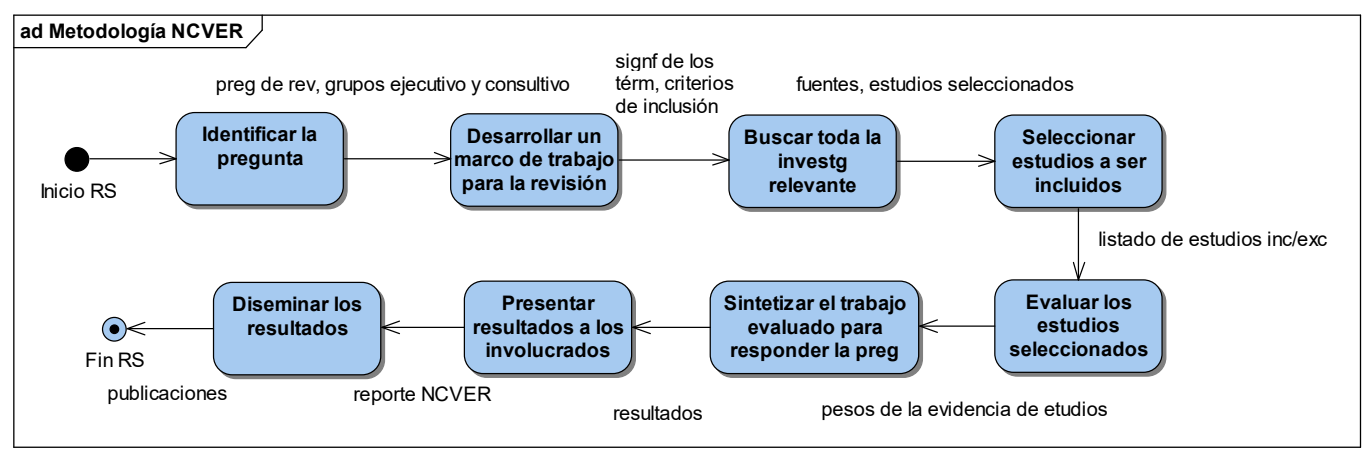

Figura III.13. Actividades involucradas en la metodología del NCVER

Las principales diferencias de la propuesta del NCVER son:

- Proponen dos dimensiones para la evaluación de los estudios seleccionados: relevancia del enfoque del estudio para responder a la pregunta de revisión y calidad del estudio en términos de la confianza que puede ser puesta en sus resultados. Los criterios de evaluación relacionados con la relevancia de la evidencia (población, intervención, y resultados) y con su calidad (validez, autenticidad, fiabilidad, actualidad y suficiencia) son presentados en una matriz y ponderados con valores del tipo Bajo(B), Medio $(M, M-, M+)$, y Alto (A); posteriormente, se realiza una selección del rango de los estudios de interés.

- Proponen una codificación para los estudios incluidos que permite extraer: datos bibliográficos, metodológicos, geográficos, temporales, poblacionales, resultados, barreras o facilitadores, y hallazgos.

Proceso de RS de experimentos en IS 


\subsection{Resumen y discusión sobre el estado del arte}

Durante el desarrollo de este capítulo, se ha presentado un conjunto de metodologías que cubren diferentes áreas de las Ciencias sociales, Medicina y otras disciplinas. En resumen, se han presentado dieciséis metodologías aplicadas a las siguientes áreas:

- Medicina y otras áreas de la Salud: se observa un número significativo de iniciativas, tanto de carácter generalista (p.e. CC, CDR, NHMRC y GRSB) como de carácter especializado, tales como: JBI (enfermería), ARCHE (pediatría), NICE y SIGN (políticas de salud), HANAH (relación salud-medio ambiente), y HuGE (genética).

- Educación y Ciencias sociales: se observó un número menor de metodologías; no obstante, aquellas existentes cuentan con reconocimiento en ésta y otras disciplinas de las Ciencias sociales. Las metodologías aplicables a este campo son: C2, EPPI-Centre y NCVER.

- Conservación del medio ambiente: siendo que la práctica basada en la evidencia para el campo de la conservación del medio ambiente es bastante joven, solamente se ha localizado una iniciativa importante para la conducción de RS, la metodología CEBC.

- Ingeniería del Software: también es una disciplina cuya práctica basada en la evidencia es bastante reciente, dos contribuciones principales han sido identificadas en esta área: LRSIS y UFRJ.

Sintetizando la revisión que se ha realizado hasta el momento, en la Tabla III.10 se presenta una comparación de las actividades planteadas por las metodologías antes descritas. En esta comparación se pueden observar las coincidencias entre las actividades propuestas por las metodologías analizadas, respecto a las actividades propuestas, especialmente, por la CC y, en menor medida, por el CDR.

Nótese que todas ellas se componen prácticamente de las mismas actividades (aunque éstas pueden poseer nombres distintos), diferenciándose solamente en unas pocas tareas concretas. Ha quedado también claro que dichas tareas diferenciales se deben a particularidades de la disciplina o al particular objetivo de la institución que promueve el proceso de RS. En otras palabras, puede afirmarse que las RS se realizan esencialmente de la misma forma, independientemente de la disciplina (lo cual se manifiesta en el gran número de tareas comunes), y sólo se diferencian en una serie de características idiosincrásicas de la disciplina, las cuales se materializan en tareas diferenciales.

Esta homogeneidad permite abstraer las actividades comunes en un proceso genérico de RS que puede servir de base para la construcción de un proceso adaptado a la Ingeniería de Software. En la columna final de la Tabla III.10, se han propuesto actividades abstractas con base en las actividades que aparecen recurrentemente (al menos dos) en las metodologías comparadas. Otras actividades, que sólo tuvieron una ocurrencia, fueron descartadas por resultar demasiado específicas para la disciplina en la que son aplicadas o la institución que conduce el proceso. 
Al realizar esta abstracción del proceso, se pretende establecer un proceso genérico para la conducción de RS que será utilizado en análisis posteriores para lograr una aproximación a la solución deseada. No obstante, debe tomarse en cuenta que, aunque en un alto nivel una misma actividad es presentada por varias metodologías, en la mayoría de los casos la implementación de la actividad presenta características y aspectos particulares a la disciplina a la que corresponde (variaciones, adecuaciones o aportaciones particulares al área). Las distintas maneras en que tales actividades son implementadas por cada una de estas metodologías, pueden resultar orientadoras en la propuesta de la solución que se persigue con esta investigación, y serán analizadas más adelante.

Una vez que estas actividades han sido definidas ampliamente a lo largo de este capítulo, al presentar las distintas metodologías de RS, no se considera necesario describirlas nuevamente en este punto del análisis. Posteriormente, cuando se analiza su aplicabilidad a la Ingeniería de Software, el propósito de cada una de ellas es nuevamente revisado para orientar adecuadamente el análisis.

Proceso de RS de experimentos en IS 
Tabla III.10. Comparación de actividades entre las metodologías descritas

\begin{tabular}{|c|c|c|c|c|c|c|c|c|c|c|c|c|c|c|c|c|}
\hline $\mathrm{CC}$ & CDR & $\begin{array}{l}\text { NHMR } \\
\text { C }\end{array}$ & $\begin{array}{r}\mathrm{A} \\
\mathrm{RCHE}\end{array}$ & $\mathrm{JBI}$ & $\mathrm{CE}^{\mathrm{NI}}$ & $\begin{array}{l}\mathrm{SI} \\
\mathrm{GN}\end{array}$ & $\begin{array}{r}\mathrm{G} \\
\mathrm{RSB}\end{array}$ & $\begin{array}{l}\text { HAN } \\
\mathrm{AH}\end{array}$ & $\begin{array}{l}\mathrm{Hu} \\
\mathrm{GE}\end{array}$ & $2^{C}$ & $\begin{array}{ll} & \text { EP } \\
\text { PI } & \end{array}$ & $\mathrm{BC}^{\mathrm{CE}}$ & $\begin{array}{l}\text { NC } \\
\text { VER }\end{array}$ & $\begin{array}{l}\text { U } \\
\text { FRJ }\end{array}$ & LRSIS & $\begin{array}{l}\text { Abstracció } \\
\mathrm{n}\end{array}$ \\
\hline & & & & & & & & $\begin{array}{l}\quad 1 . \text { Id } \\
\text { enitif } \\
\text { áreas } \\
\text { tem. }\end{array}$ & & & & & & & & \\
\hline & $\begin{array}{l}\text { 1.Iden } \\
\text { tificac de } \\
\text { la } \\
\text { necesidad }\end{array}$ & & & & & & & & & & & & & & $\begin{array}{l}\text { 1.Ide } \\
\text { ntif la } \\
\text { neces } \\
\text { de la rev }\end{array}$ & $\begin{array}{l}\text { Identificar } \\
\text { la necesidad } \\
\text { de una } \\
\text { revisión }\end{array}$ \\
\hline & $\begin{array}{l}\text { 2.Prep } \\
\text { arar ppta } \\
\text { para la RS }\end{array}$ & & & & & & & & & & & & & & & \\
\hline $\begin{array}{l}\text { 1.Desarr } \\
\text { ollar } \\
\text { Protocolo de } \\
\text { rev }\end{array}$ & $\begin{array}{l}\text { 3.Desa } \\
\text { rrollo de } \\
\text { prot de } \\
\text { rev }\end{array}$ & $\begin{array}{l}\text { 1.Desa } \\
\text { rrollo de } \\
\text { un } \\
\text { protocolo }\end{array}$ & $\begin{array}{l}2 . \\
\text { Desar } \\
\text { rollar } \\
\text { un } \\
\text { proto }\end{array}$ & $\begin{array}{l}\text { 1.D } \\
\text { es } \\
\text { Prot } \\
\text { ocol de }\end{array}$ & & & & & $\begin{array}{l}1 . \\
\text { Des } \\
\text { prot } \\
\text { de rev }\end{array}$ & & $\begin{array}{l}3 . \\
\text { Produ } \\
\text { c un } \\
\text { proto } \\
\text { c }\end{array}$ & $\begin{array}{l}\quad 3 . \\
\text { Des } \\
\text { un } \\
\text { Prot. } \\
\text { De rev }\end{array}$ & $\begin{array}{l}\text { 2.D } \\
\text { es un } \\
\text { marco } \\
\text { de trab } \\
\text { para la }\end{array}$ & $\begin{array}{r}1 \\
. \text { Plan } \\
\text { ificar } \\
\text { rev }\end{array}$ & $\begin{array}{l}\text { 2.De } \\
\text { s un } \\
\text { protoc } \\
\text { de rev }\end{array}$ & $\begin{array}{l}\text { Desarrolla } \\
\text { r un Protocolo } \\
\text { de revisión }\end{array}$ \\
\hline
\end{tabular}




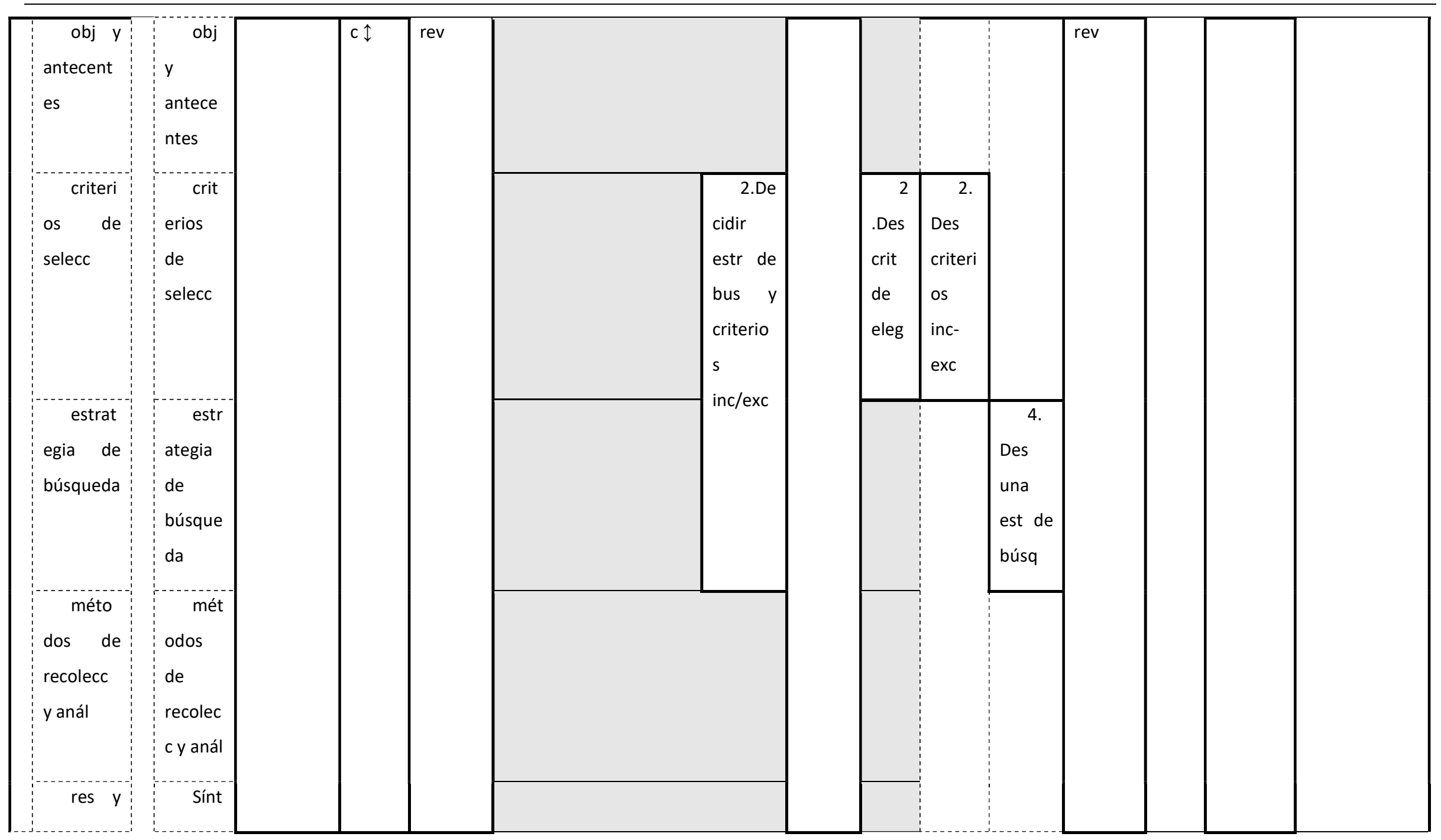




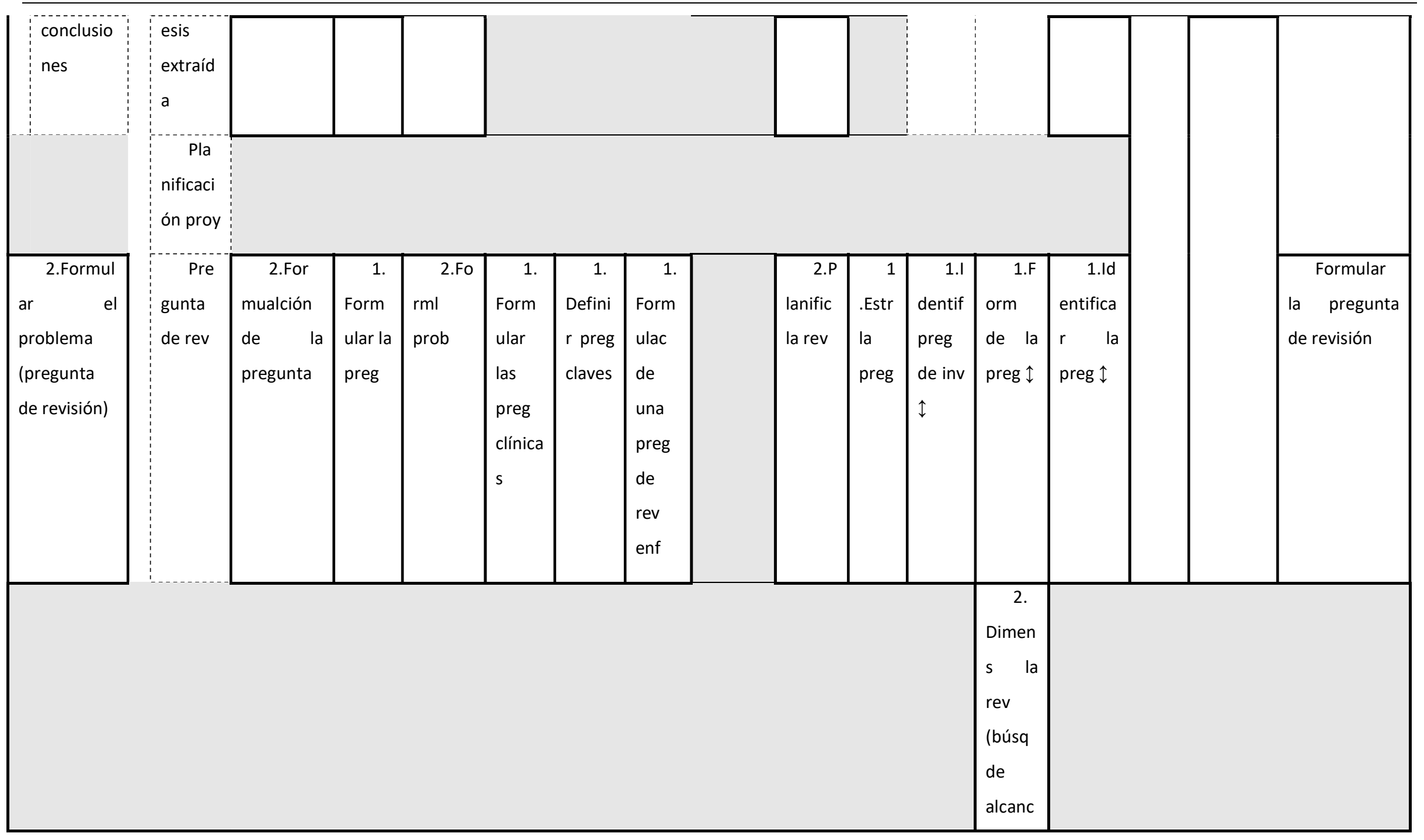




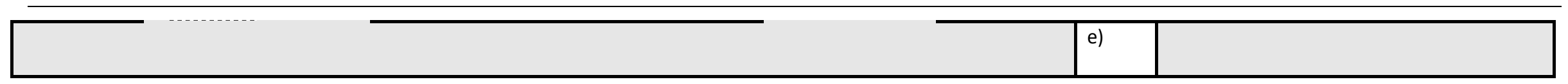

Leyenda:

\begin{tabular}{|l|l|}
\hline & $\begin{array}{c}\text { La actividad es realizada por la } \\
\text { metodología }\end{array}$ \\
\hline & $\begin{array}{c}\text { La actividad no es realizada por la } \\
\text { metodología }\end{array}$ \\
\hline & La actividad compone a otra mayor \\
\hline
\end{tabular}

Tabla III.10. Comparación de actividades entre las metodologías descritas (continuación).

\begin{tabular}{|c|c|c|c|c|c|c|c|c|c|c|c|c|c|c|c|c|}
\hline $\mathrm{CC}$ & CDR & $\begin{array}{l}\text { NHMR } \\
\text { C }\end{array}$ & $\begin{array}{r}\mathrm{A} \\
\mathrm{RCHE}\end{array}$ & $\mathrm{JBI}$ & $\mathrm{CE}^{\mathrm{NI}}$ & $\begin{array}{l}\text { SI } \\
\text { GN }\end{array}$ & $\begin{array}{c}\mathrm{G} \\
\mathrm{RSB}\end{array}$ & $\begin{array}{l}\text { HAN } \\
\mathrm{AH}\end{array}$ & $\mathrm{GE}^{\mathrm{Hu}}$ & $2^{C}$ & $\begin{array}{l}\text { EP } \\
\text { PI }\end{array}$ & $\begin{array}{l}\text { CE } \\
\mathrm{BC}\end{array}$ & $\begin{array}{l}\text { NC } \\
\text { VER }\end{array}$ & $\begin{array}{l}\text { U } \\
\text { FRJ }\end{array}$ & LRSIS & $\begin{array}{l}\text { Abstracció } \\
\text { n }\end{array}$ \\
\hline $\begin{array}{l}\text { 3.Localiz } \\
\text { ar y } \\
\text { seleccionar } \\
\text { estudios }\end{array}$ & & $\begin{array}{l}\text { 3.Local } \\
\text { ización de } \\
\text { estudios }\end{array}$ & & $\begin{array}{l}\text { 3.Lo } \\
\text { calizar } \\
\text { y } \\
\text { seleccio }\end{array}$ & & & & & & & & & & & & \multirow[t]{2}{*}{$\begin{array}{c}\text { Buscar } \\
\text { sistemáticam } \\
\text { ente estudios }\end{array}$} \\
\hline $\begin{array}{l}\text { Búsqu } \\
\text { eda }\end{array}$ & $\begin{array}{l}\text { 4.Iden } \\
\text { tificación }\end{array}$ & & $\begin{array}{r}3 . \\
\text { Cond }\end{array}$ & $\begin{array}{l}\text { nar } \\
\text { estudio }\end{array}$ & $\begin{array}{r}2.1 \\
\text { dentif }\end{array}$ & $\begin{array}{r}2 . \\
\text { Busca }\end{array}$ & $\begin{array}{r}2 . \\
\text { Busq }\end{array}$ & $\begin{array}{r}3 . B u \\
\text { sq de }\end{array}$ & $\begin{array}{c}3 . \\
\text { Desarr }\end{array}$ & $\begin{array}{r}3 \\
. \text { Des }\end{array}$ & $\begin{array}{r}4 . \\
\text { Busca }\end{array}$ & $\begin{array}{l}5 . B \\
\text { uscar }\end{array}$ & $\begin{array}{r}\text { 3.B } \\
\text { uscar la }\end{array}$ & $\begin{array}{r}2 \\
. \text { Revi }\end{array}$ & $\begin{array}{l}\text { 3.Ide } \\
\text { ntificar }\end{array}$ & \\
\hline
\end{tabular}


Proceso de RS de experimentos en IS

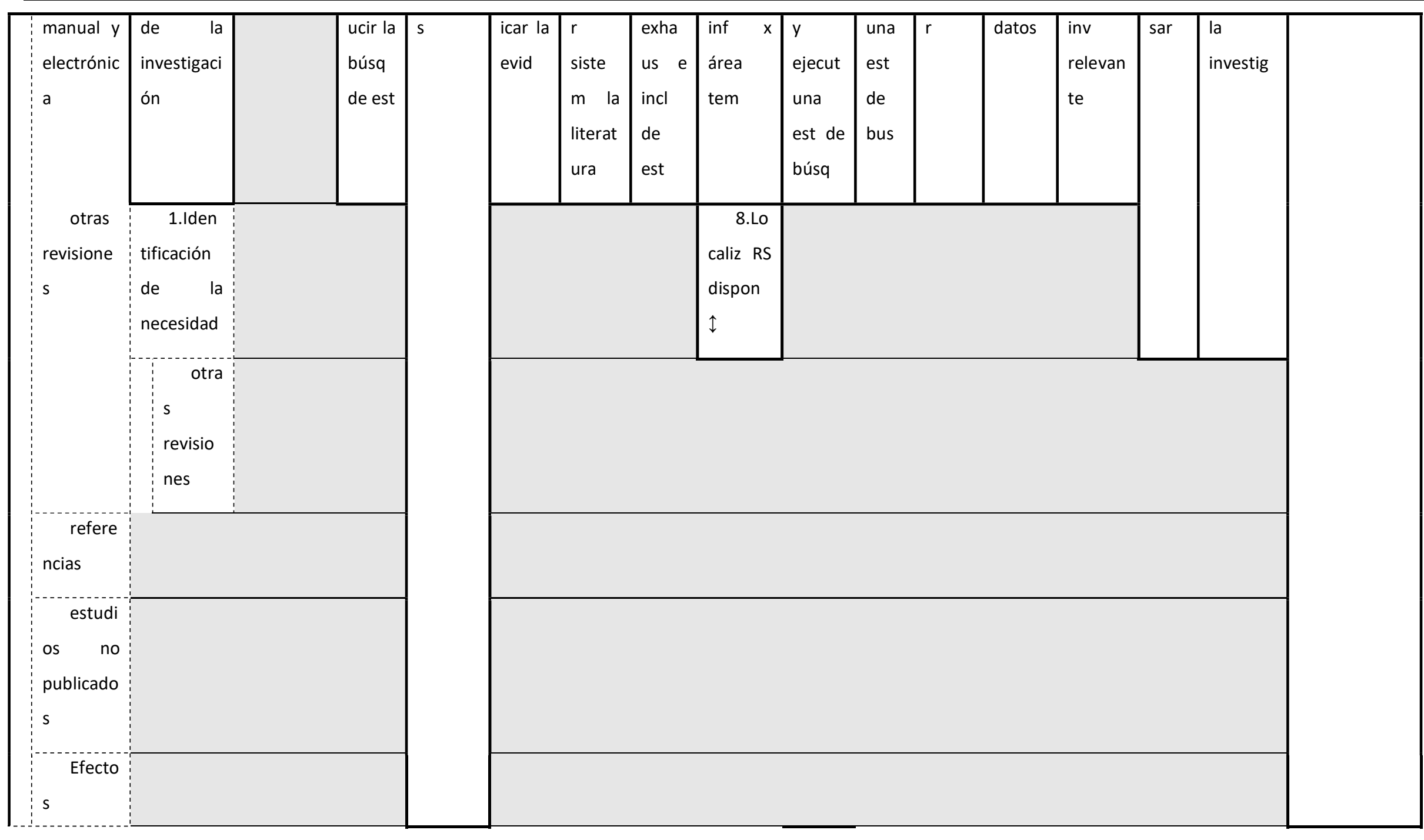


Introduccióin

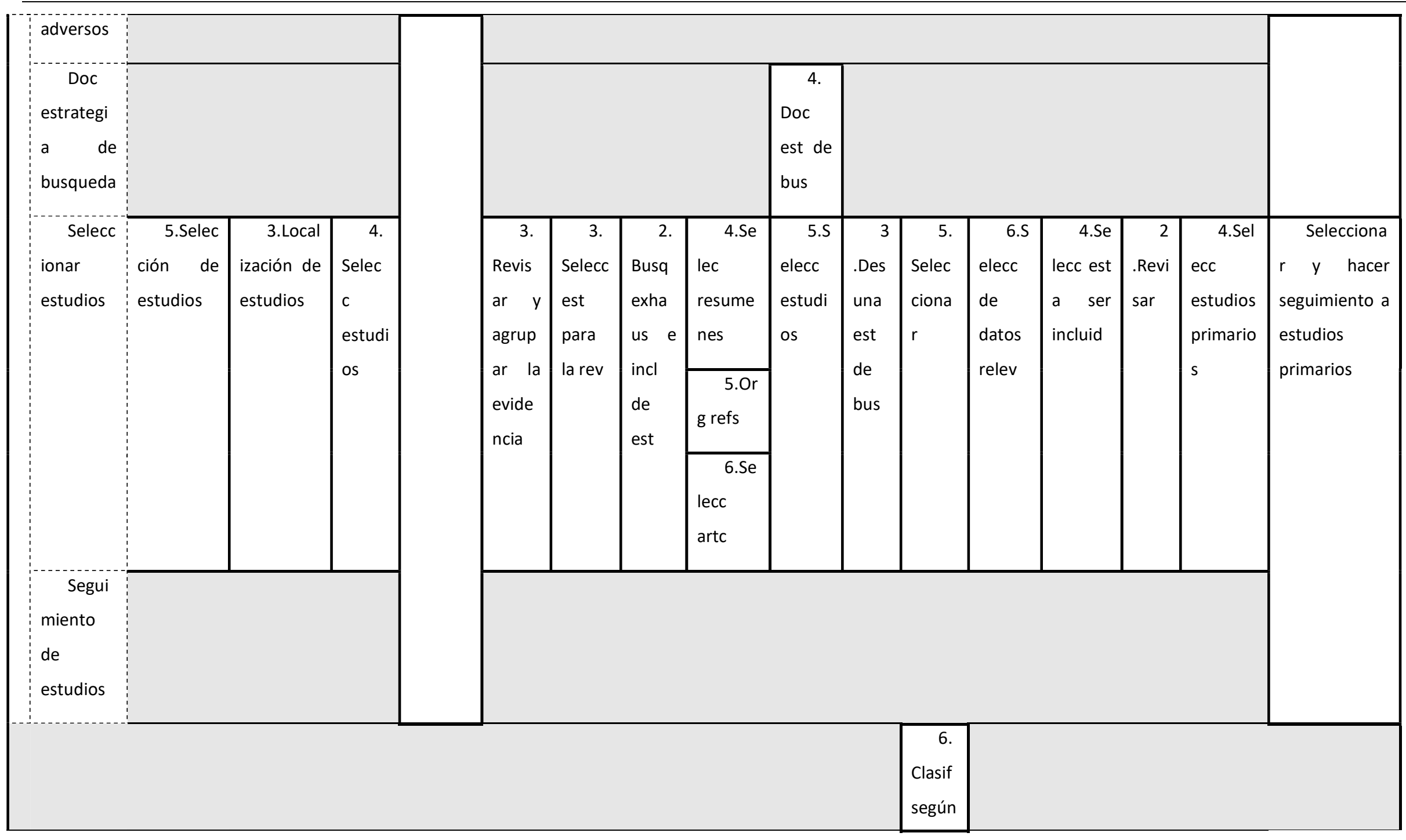




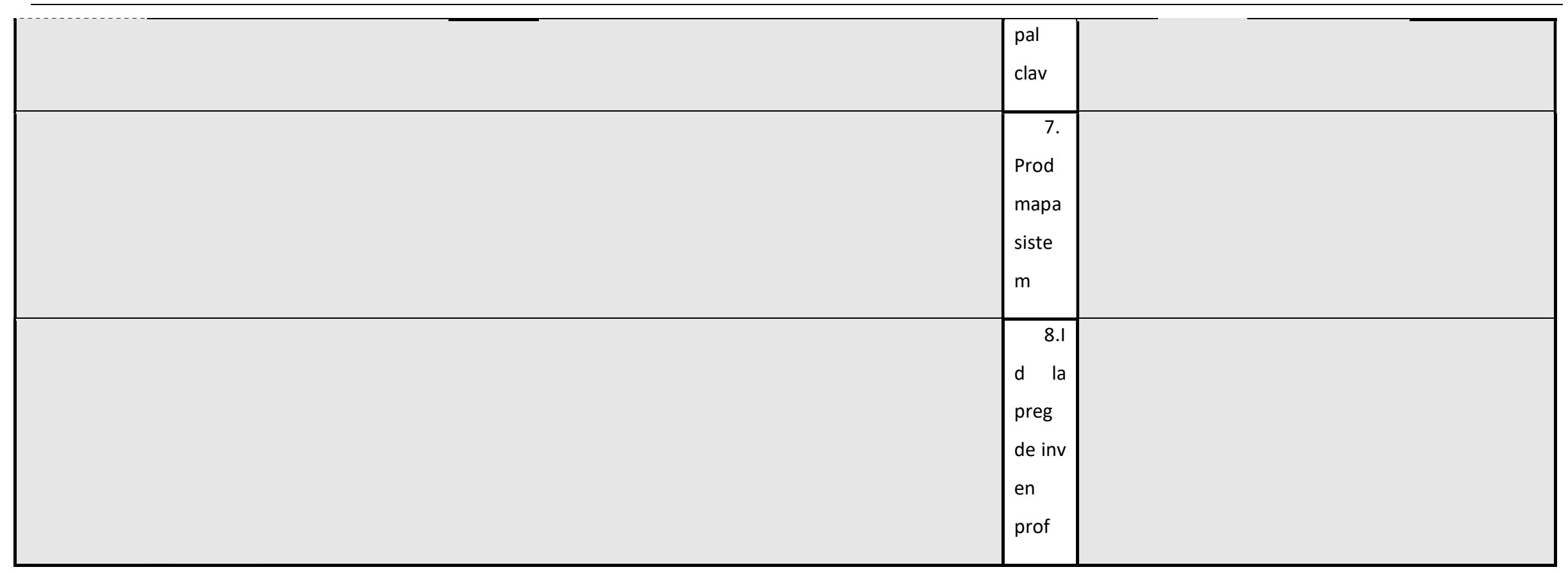

Tabla III.10. Comparación de actividades entre las metodologías descritas (continuación).

\begin{tabular}{|c|c|c|c|c|c|c|c|c|c|c|c|c|c|c|c|c|}
\hline $\mathrm{CC}$ & CDR & $\mathrm{NH}$ & $\mathrm{ARCHE}$ & $\mathrm{JBI}$ & $\mathrm{NI}$ & SI & G & HAN & $\mathrm{Hu}$ & $\mathrm{C}$ & EP & CE & $\mathrm{NC}$ & U & LRSIS & Abstracció \\
\hline
\end{tabular}


Introduccióin

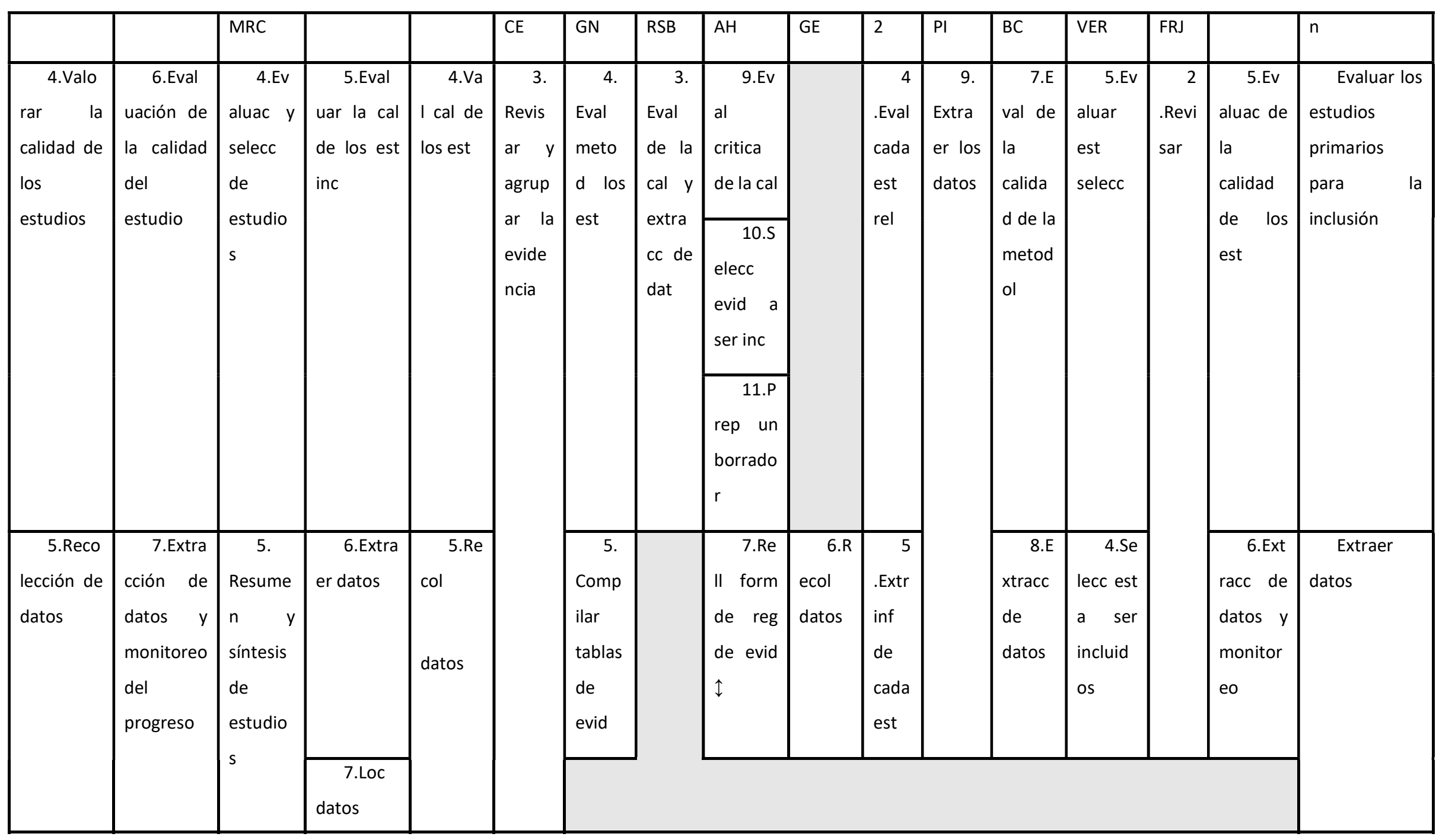




\begin{tabular}{|c|c|c|c|c|c|c|c|c|c|c|c|c|c|c|}
\hline & & $\begin{array}{l}\text { faltantes } y \\
\text { art no- } \\
\text { pub }\end{array}$ & & & & & & & & & & & & \\
\hline $\begin{array}{l}\text { 6.Anali } \\
\text { zar y } \\
\text { presentar } \\
\text { res }\end{array}$ & $\begin{array}{l}\text { 8.Sínte } \\
\text { sis de } \\
\text { datos }\end{array}$ & $\begin{array}{l}\text { 8.Anali } \\
\text { z los datos }\end{array}$ & $\begin{array}{l}\text { 6.A } \\
\text { nal } y \\
\text { pres res }\end{array}$ & $\begin{array}{l}\quad 6 . \\
\text { Consi } \\
\text { derar } \\
\text { las } \\
\text { implic }\end{array}$ & $\begin{array}{l}4 . \\
\text { Sinte } \\
\text { sde } \\
\text { res } \\
\text { est }\end{array}$ & $\begin{array}{r}12 . C \\
\text { ombina } \\
\text { r los res }\end{array}$ & $\begin{array}{l}7.5 \\
\text { intetiz } \\
\text { los } \\
\text { datos }\end{array}$ & $\begin{array}{l}6 \\
\text {.Esti } \\
m \text { el } \\
\text { efec } \\
\text { to }\end{array}$ & $\begin{array}{l}10 \\
\text {.Prod } \\
\text { el } \\
\text { repor } \\
t\end{array}$ & $\begin{array}{l}9.5 \\
\text { íntesis } \\
\text { de } \\
\text { datos }\end{array}$ & $\begin{array}{l}\text { 6.Si } \\
\text { ntetiz } \\
\text { el trab } \\
\text { evalua } \\
\text { do }\end{array}$ & $\begin{array}{r}3 \\
. \text { Ana } \\
\text { lizar } \\
\text { dato } \\
\text { s }\end{array}$ & $\begin{array}{l}\text { 7.Sín } \\
\text { tesis de } \\
\text { datos }\end{array}$ & \begin{tabular}{l}
\multicolumn{2}{c}{ Sintetizar } \\
datos y \\
presentar \\
resultados
\end{tabular} \\
\hline $\begin{array}{c}\text { a- Met } \\
\text { análisis } \\
\text { erogen } \\
\text { eidad } \\
\text { Anet de } \\
\text { sensibil } \\
\text { idad }\end{array}$ & $\begin{array}{l}\text { Met } \\
\text { a- } \\
\text { análisis } \\
\text { Aná } \\
\text { lisis } \\
\text { cualitat } \\
\text { ivo }\end{array}$ & & & & & & $\begin{array}{l}8 . P \\
\text { res } \\
\text { result } \\
\text { ad }\end{array}$ & & & & & & & \\
\hline
\end{tabular}


Tabla III.10. Comparación de actividades entre las metodologías descritas (continuación).

\begin{tabular}{|c|c|c|c|c|c|c|c|c|c|c|c|c|c|c|c|c|}
\hline CC & CDR & $\begin{array}{c}\mathrm{NH} \\
\mathrm{MRC}\end{array}$ & ARCHE & $\mathrm{JBI}$ & $\mathrm{CE}^{\mathrm{NI}}$ & ${ }_{\mathrm{GN}}^{\mathrm{SI}}$ & $\begin{array}{c}{ }^{G} \\
R S B\end{array}$ & $\begin{array}{l}\text { HAN } \\
\mathrm{AH}\end{array}$ & $\mathrm{GE}^{\mathrm{Hu}}$ & $2^{C}$ & $\begin{array}{l}\text { EP } \\
P I\end{array}$ & ${ }_{\mathrm{BC}}{ }^{\mathrm{CE}}$ & $\begin{array}{l}\quad N C \\
\text { VER }\end{array}$ & ${ }_{\text {FRJ }}^{U}$ & LRSIS & $\begin{array}{l}\text { Abstracció } \\
\text { n }\end{array}$ \\
\hline
\end{tabular}


Proceso de RS de experimentos en IS

Metodología

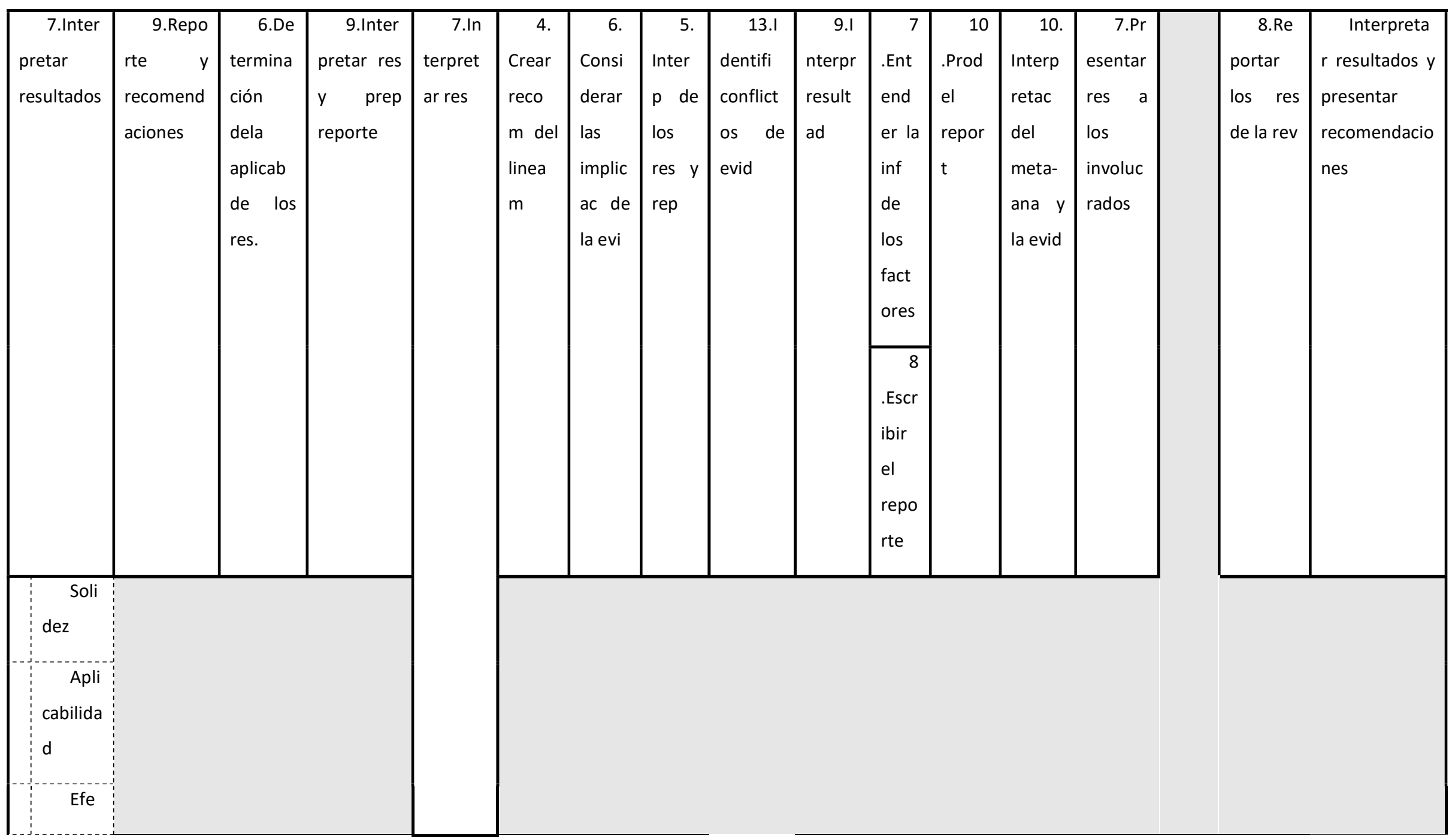


Introduccióin

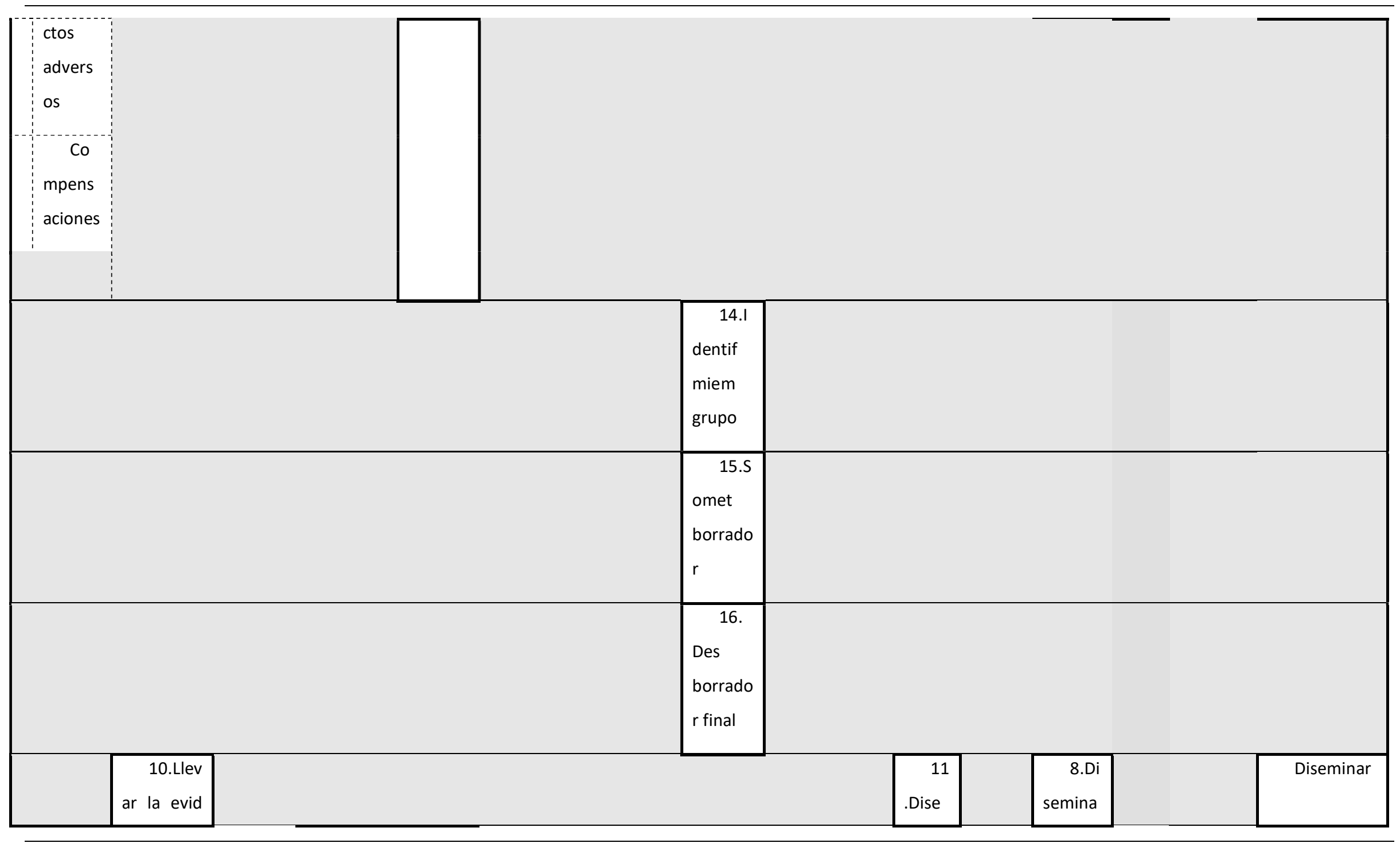


Proceso de RS de experimentos en IS

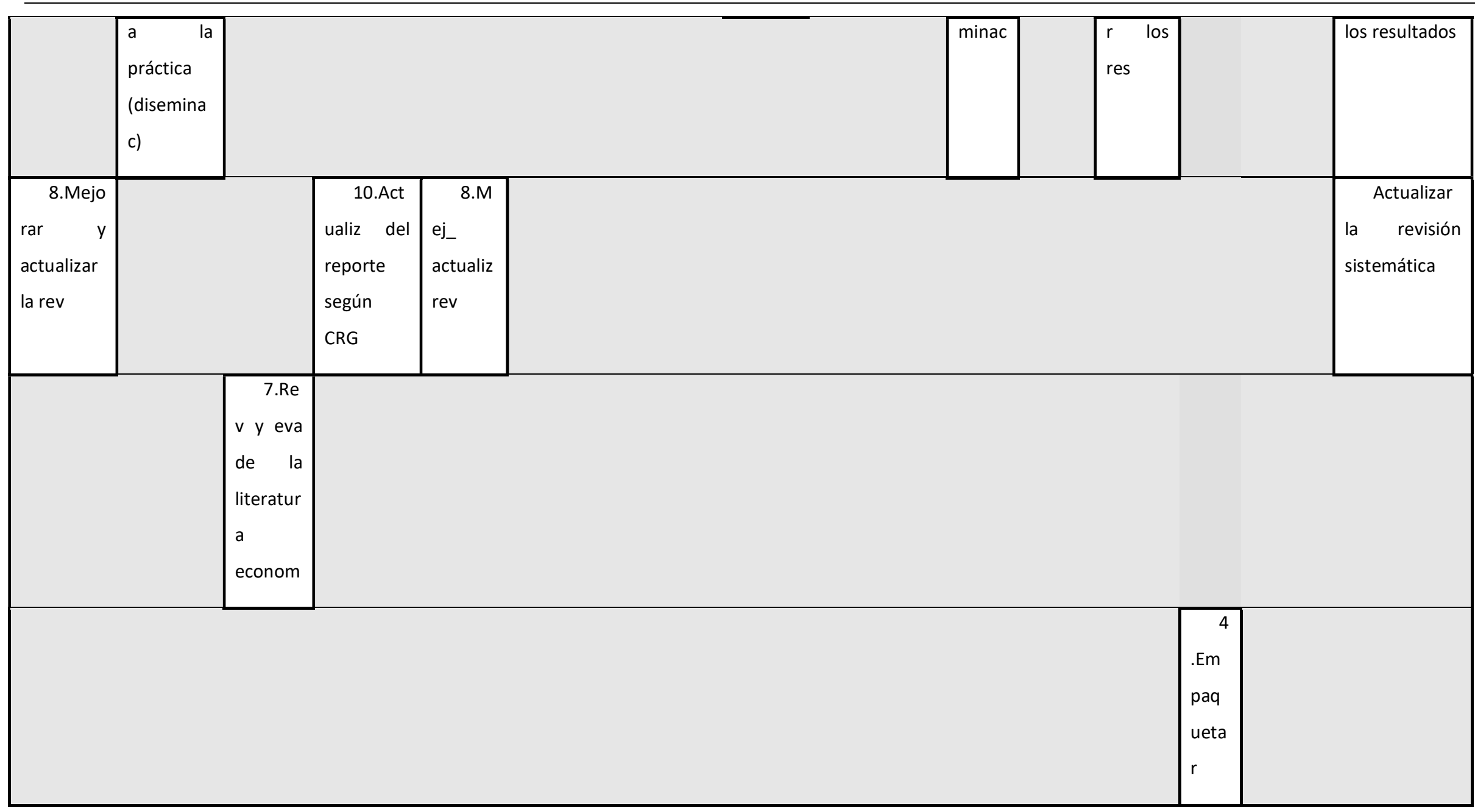

\section{Metodología}

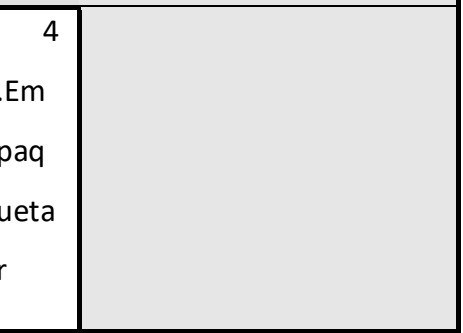




\section{CAPÍTULO 3. PLANTEAMIENTO DEL PROBLEMA}

\subsection{Descripción de la solución propuesta}

Con base en la experiencia se han identificado una serie de características de la IS que no pueden ser satisfechas por los procesos de RS propuestos actualmente; llevando a considerar variaciones en las diferentes fases del proceso que deben ser abordadas a través de heurísiticas, actividades, tareas y documentación.

Las características específicas a la IS que promueven tales variaciones pueden ser resumidas como sigue:

- $\quad$ Experimentos escasos y con pocos sujetos

- Dificultad para establecer una pregunta de revisión temprana

- Dificultad para establecer un protocolo de revisión

- $\quad$ Dificultad para localizar los experimentos existentes debido a BD inadecuadas

- $\quad$ Falta de una terminología estandarizada

- $\quad$ Diversidad de variables respuesta y métricas

- Baja calidad de reporte de los experimentos

- Grupos de experimentos con contextos heterogéneos

- Factores particulares que afectan la calidad del experimento, como p.e. el enmascaramiento (blinding).

- Definición de Calidad poco clara

- Naturaleza de los sujetos y objetos experimentales

- Escaso número de instrumentos de evaluación de la calidad y falta de validación de los mismos.

- Amplio rango de calidad en los experimentos

\subsection{Hipótesis de trabajo}


Del análisis de Antecedentes se desprende, como una conclusión directa, que ninguna de las metodologías encontradas en la literatura es actualmente adecuada para la conducción de RS en Ingeniería de Software. Incluso las metodologías que han sido particularmente propuestas para esta área (LRSIS y UFRJ) no permiten cubrir las brechas que se describen a continuación.

Esto lleva la presente investigación a plantear un proceso de RS que incorpore las mejores prácticas identificadas en el análisis, y que permita resolver los problemas presentes actualmente en las metodologías existentes, en virtud de las características tan específicas del área en cuestión.

Para el desarrollo del proceso que se desea propone se ha definido una Hipótesis general que puede ser descumpuesta en varias Hipótesis específicas:

HG: Es factible definir un proceso de RS de experimentos que responda a las necesidades y características específicas que plantean cada una de las Fases de este tipo de procesos; incorporando variaciones sobre las prácticas tradicionalmente usadas en otras disciplinas.

Esta HG puede ser descompuesta de la siguiente manera:

- HE1: es posible proponer una estrategia eficiente de búsqueda de experimentos.

Tal estrategia debe permitir la recuperación de la mayor cantidad posible de estudios relevantes para la RS con el menor esfuerzo de selección, maximizando de esta manera la cantidad de resultados experimentales disponibles para la Síntesis.

- HE2: es viable definir y aplicar un método de extracción de datos que resuelva los problemas de falta de estandarización.

Este método de recolección de resultados experimentales de los estudios primarios, debe lidiar con la falta de estandarización de términos por parte de los experimentadores y la falta de datos suficientes para la Síntesis.

- HE3: es factible definir un mecanismo para la caracterización y valoración de la calidad de experimentos.

Este mecanismo ddebe permitir establecer cómo y en qué medida los resultados de cada estudio pueden contribuir a la posterior Síntesis y derivación de piezas de conocimiento.

- HE4: es viable definir y proponer una estrategia para seleccionar el método de agregación más adecuado.

Se debe identificar el método más adecuado dentro de un conjunto de métodos de agregación de los resultados experimentales individuales.

\subsection{Descripción de la solución propuesta}


Para poder dar respuesta adecuadamente a estas características es necesario analizar su impacto en cada una de las fases del proceso de RS y proponer soluciones que abarquen todas las fases involucradas.

Estas soluciones deben ser implementadas a través de elementos metodológicos concretos, en forma de actividades, documentación o recomendaciones.

Las actividades propuestas deberán ser acometidas por los revisores mientras juegan distintos roles dentro del proceso, que requieren de conocimientos y experiencias particulares, dependiendo del tipo de actividad.

Debido a que el proceso de RS es costoso, y la inversión de tiempo y recursos debe estar bien justificada, existen puntos a lo largo del proceso en donde debe evaluarse que un determinado objetivo ha sido alcanzado, al mismo tiempo esto llevará a considerar la continuidad del proceso; esto es, decidir si es conveniente o no cancelar la RS.

Una RS puede llegar a ser muy costosa en tiempo y recursos, por lo que es importante contar con una metodología de RS adecuada, bien definida y que promueva la coste-efectividad del proceso. Lo anterior se traduce en una metodología que: 1) utilice métodos adecuados, que minimicen el riesgo de incurrir en sesgos; 2) combine evidencias primarias con una calidad mínima aceptable.

Esta investigación persigue proponer un proceso de RS que resuelva aquellas características de la IS que hacen que las metodologías o procesos actuales no sean aplicables de manera efectiva 


\section{CAPÍTULO 4. METODOLOGÍA}

De acuerdo con (Jonker \& Pennink, 2010) conducir una investigación implica la búsqueda deliberada y metodológica de (nuevo) conocimiento y puntos de vista, en la forma de respuestas a preguntas que han sido previamente formuladas. Conducir una investigación "es una manera específica de actuar orientado a una meta".

Según estos autores, una investigación aplicada, por definición, comienza con una pregunta acerca de una situación organizacional problemática. La naturaleza de esta pregunta será la que guíe el proceso de investigación.

Por otra parte, (Jonker \& Pennink, 2010)) afirman que una metodología no trata sólo de investigar sino también de actuar.

Es por ello que para alcanzar los objetivos planteados en este proyecto de investigación, no sólo es necesario basarse en teorías conocidas sino que también se requiere del aprendizaje que se pueda obtener al aplicar la propuesta a la realidad. Esto hace que los métodos de investigación clásicos, incluso exploratorios, sean difíciles de adaptar al tipo de investigación que se va a desarrollar.

En consecuencia, para el logro de los objetivos planteados en el Capítulo XX, se ha propuesto un enfoque metodológico basado en investigación-acción (I-A) (Creswell, 2002).

De acuerdo con (Baskerville \& Wood-Harper, 1996) el domino ideal de la I-A está caracterizado por una configuración social donde la investigación es un proceso (generalmente cíclico) que enlaza la teoría con la práctica. En la Figura 99.1 se muestra un resumen de las fases y actividades propuestas. 


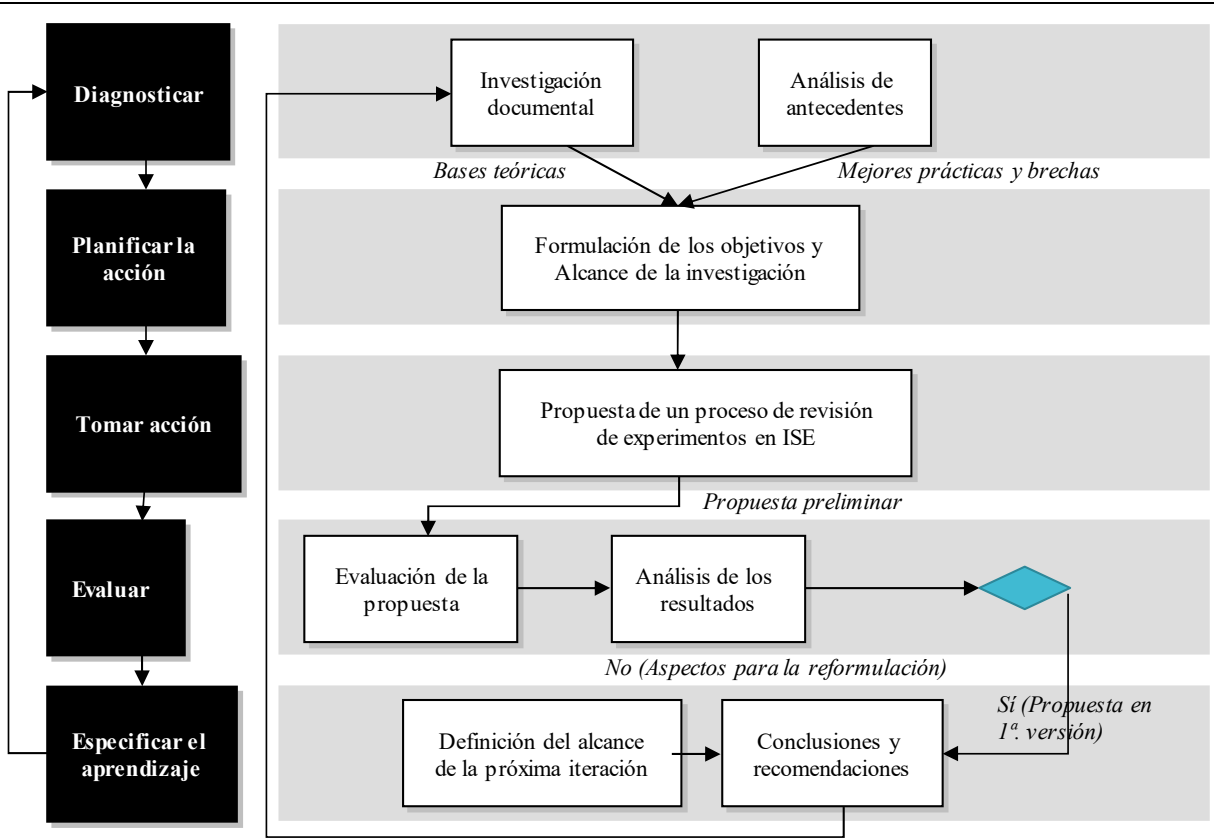

Figura 4.1. Enfoque metodológico. Adaptado de (Pérez, Grimán, Mendoza, \& Rojas, 2004)

En primer lugar, la fase de Diagnosticar identifica los problemas primarios que se traducen en las razones por las cuales la organización desea cambiar. En el caso específico de este proyecto de investigación se considera como organización a cualquier comunidad de IS, bien sea de carácter investigador o profesional, en el que se requiera llevar a cabo RS de experimentos. Sin embargo, algunos de los problemas identificables en esta disciplina pueden ser de comunes a otros dominios. Las actividades asociadas a esta fase son las siguientes:

1. Investigación documental: se refiere a la revisión de la bibliografía relacionada con RS y experimentación, para establecer un marco teórico. Implica la extracción desde fuentes diversas (incluidas las fuentes electrónicas) con el fin de construir la base conceptual que servirá de referencia a la investigación. Los productos a obtener incluyen un conjunto de conceptos, así como aspectos sociales, tecnológicos y organizacionales a ser considerados durante la investigación.

2. Análisis de antecedentes: se refiere al estudio del Estado de la Cuestión relativo al tema que es objeto de estudio: Revisiones Sistemáticas. Incluye la recolección y revisión de métodos, procesos o marcos de referencia para la conducción de RS en IS y otras disciplinas con experiencia en las prácticas empíricas. Durante esta actividad se busca establecer tareas recurrentes, ventajas/desventajas de los trabajos previos y buenas prácticas; así mismo, identificar problemas abiertos que guíen la definición de objetivos de la investigación. 
La siguiente fase, Planificar la acción, establece las acciones a través de las cuales deberían ser eliminados o mejorados los problemas principales que fueron identificados en la etapa anterior. Esta fase incluye una única actividad:

3. Formulación de los objetivos y alcance de la investigación: durante esta actividad se formula el alcance de la investigación; utilizando como entradas los resultados de las actividades precedentes.

Posteriormente, se debe acometer la fase de Tomar la acción, en la cual se implementa la acción planificada. Los participantes e investigadores colaboran en una intervención activa en la organización, canalizando los cambios. Para ello, la actividad principal es:

4. Propuesta de un proceso de RS para IS: esta actividad busca directamente la satisfacción de los objetivos establecidos en la fase anterior. El resultado esperado en el contexto de esta investigación es un proceso de RS para experimentos en IS en versión beta (prueba) junto con las consideraciones del contexto en el cual debería ser aplicado.

Durante la Evaluación, los investigadores y participantes evalúan los resultados para determinar si los efectos teóricos de la acción fueron logrados y si estos efectos solventaron el problema. Para cubrir esta fase las actividades que se deben acometer son las siguientes:

5. Evaluación de la propuesta: para determinar la mejor manera de validar el proceso propuesto, se utilizará el método DESMET propuesto por (B. Kitchenham, 1996), el cual proporciona una manera sistemática y objetiva para seleccionar un método de evaluación para herramientas y métodos en IS. Dado el carácter genérico de los métodos cualitativos y cuantitativos considerados por DESMET, se considera que éste puede ser utilizado sin riesgo para la selección del método de evaluación adecuado a este proyecto de investigación.

6. Análisis de resultados: durante esta actividad se estudian los resultados con base en los objetivos establecidos inicialmente y la evaluación previamente realizada, en términos de los productos tangibles alcanzados y los cambios producidos en el ambiente. Posteriormente, los cambios que surjan de este análisis pueden ser incorporados en una segunda versión (formal) del proceso propuesto, la cual será utilizada en futuras iteraciones de la investigación. En caso de que los resultados no fueran satisfactorios respecto a los objetivos deberá acometerse la siguiente actividad para revisar el diseño del proceso de RS o los objetivos planteados. Sin embargo, en virtud de las restricciones de tiempo establecidas en el proyecto, puede decidirse llevar a cabo un único ciclo metodológico, al final del cual los cambios requeridos por el proceso no sean acometidos 
Finalmente, al Especificar el aprendizaje los investigadores deben especificar el conocimiento adquirido, basados en la evaluación. Para ello, las actividades que se realizarán son:

7. Definición del alcance de la próxima iteración: esta actividad tomará lugar en caso de que los resultados de la evaluación realizada durante la fase anterior no sean satisfactorios. De esta manera, se establece la estructura de una nueva iteración del ciclo de I-A.

8. Conclusiones y recomendaciones: en caso de que los resultados obtenidos sean satisfactorios, se establecen las conclusiones sobre el proceso de RS ya aplicado; en caso contrario, se refuerza el alcance de la próxima iteración del ciclo de I-A.

Debido a la importancia que implica la evaluación del resultado obtenido en la fase Tomar la acción, se debe escoger cuidadosamente el método por el cual se realizará tal evaluación. Para apoyar tal decisión se recurre a DESMET (B. Kitchenham, 1996), el cual proporciona un marco de referencia para la selección razonada de un método de evaluación.

\subsection{Selección del Método de Evaluación}

El propósito de DESMET es ayudar a un evaluador en una organización particular a planear y ejecutar un ejercicio de evaluación de manera no sesgada y confiable (por ejemplo, maximizar la probabilidad de identificar el mejor método/herramienta) (B. Kitchenham, 1996). Aunque DESMET ha sido desarrollado para soportar la selección de métodos y herramientas en el marco de organizaciones desarrolladoras de software, incluye criterios y métodos de evaluación suficientemente genéricos como para que su uso pueda ser extendido a cualquier proceso de evaluación/selección dentro de una organización. Incluye los siguientes 9 métodos distintos de evaluación, tanto cualitativos como cuantitativos:

Tabla 4.1. Métodos de evaluación incluidos en DESMET (B. Kitchenham, 1996)

\begin{tabular}{|l|l|l|}
\hline Tipo & Método de evaluación & Descripción \\
\hline \multirow{3}{*}{ Cuantitativos } & Experimento formal & $\begin{array}{l}\text { Investigación del impacto cuantitativo de métodos o } \\
\text { herramientas organizado como un experimento formal }\end{array}$ \\
\cline { 2 - 3 } & Estudio de caso & Evaluación utilizando un proyecto real \\
\cline { 2 - 3 } & Encuesta & $\begin{array}{l}\text { Los usuarios de los métodos/herramientas son consultados sobre } \\
\text { propiedades de interés de los métodos/herramientas }\end{array}$ \\
\hline \multirow{3}{*}{ Cualitativos } & Pre-selección documental & $\begin{array}{l}\text { La evaluación está basada en la literatura que describe los } \\
\text { métodos/herramientas más que en el uso real de las mismas }\end{array}$ \\
\cline { 2 - 3 } & Experimento & $\begin{array}{l}\text { Utiliza el enfoque de análisis de características pero organizando } \\
\text { la actividad de evaluación como un experimento }\end{array}$ \\
\cline { 2 - 3 } & Caso de estudio & Una evaluación basada en características llevada a cabo después \\
\hline
\end{tabular}




\begin{tabular}{|l|l|l|}
\hline \multirow{2}{*}{ Híbridos } & $\begin{array}{l}\text { de que un método/herramienta ha sido usado en la práctica en } \\
\text { un proyecto real }\end{array}$ \\
\cline { 2 - 4 } & $\begin{array}{l}\text { Encuesta } \\
\text { de expertos) }\end{array}$ & $\begin{array}{l}\text { Una evaluación basada en características hecha por personas } \\
\text { que han tenido experiencia de uso o han estudiado los } \\
\text { métodos/herramientas de interés. }\end{array}$ \\
\cline { 2 - 3 } & Benchmarking & $\begin{array}{l}\text { Provee una evaluación subjetiva de los efectos cuantitativos de } \\
\text { métodos o herramientas }\end{array}$ \\
\hline
\end{tabular}

Con la excepción de los experimentos formales, las evaluaciones de DESMET son dependientes del contexto. Para seleccionar el método más adecuado a las condiciones específicas de cada evaluación, (B. Kitchenham, 1996) propone los siguientes Criterios técnicos (véase Tabla 4.2):

Tabla 4.2. Criterios técnicos de selección

\begin{tabular}{|c|c|c|}
\hline Criterio & Escenarios & Métodos recomendados \\
\hline \multirow[t]{4}{*}{ Contexto } & $\begin{array}{l}\text { Selección de un conjunto de métodos para } \\
\text { un proyecto individual }\end{array}$ & $\begin{array}{l}\text { Opinión de experto basada en Análisis } \\
\text { de efectos }\end{array}$ \\
\hline & $\begin{array}{l}\text { Evaluación inicial de muchas alternativas } \\
\text { seguida de una evaluación detallada de } \\
\text { unas pocas }\end{array}$ & $\begin{array}{l}\text { Análisis de características Modo Pre- } \\
\text { selección }\end{array}$ \\
\hline & $\begin{array}{l}\text { Evaluación del efecto de adoptar un nuevo } \\
\text { método en una organización }\end{array}$ & $\begin{array}{l}\text { Encuesta Cuantitativa } \\
\text { Análisis de características por Encuesta }\end{array}$ \\
\hline & $\begin{array}{l}\text { Evaluar un método para re-venta como } \\
\text { parte de un gran producto o línea de } \\
\text { producto }\end{array}$ & Análisis de Características \\
\hline \multirow{2}{*}{$\begin{array}{l}\text { Naturaleza del impacto } \\
\text { esperado del uso del método }\end{array}$} & Cuantitativo & Métodos cuantitativos \\
\hline & Cualitativo & Métodos cualitativos \\
\hline \multirow[t]{3}{*}{$\begin{array}{l}\text { Naturaleza del objeto a ser } \\
\text { evaluado }\end{array}$} & Herramienta & $\begin{array}{l}\text { Análisis de características } \\
\text { Benchmarking }\end{array}$ \\
\hline & Método & Indiferente \\
\hline & Método genérico & Análisis de efectos \\
\hline \multirow[t]{2}{*}{ Alcance del impacto } & $\begin{array}{c}\text { Granularidad del producto } \\
\text { - } \quad \text { Producto completo } \\
\text { - } \quad \text { Producto parcial }\end{array}$ & $\begin{array}{l}\text { Producto completo } \rightarrow \text { limitados casos } \\
\text { de estudio cuantitativos } \\
\text { Para ver el efecto a nivel de producto, } \\
\text { un caso de estudio cuantitativo } \\
\text { necesitaría tener un baseline externo } \\
\text { para propósitos de comparación (p.e. } \\
\text { valores de un proyecto "hermano" } \\
\text { usando otro método/herramienta). }\end{array}$ \\
\hline & Extensión del impacto. Efecto aplica a: & fases $\rightarrow$ Experimento \\
\hline
\end{tabular}




\begin{tabular}{|c|c|c|}
\hline & $\begin{array}{l}\text { - Una actividad de una etapa, } \\
\text { medible/observable } \\
\text { inmediatamente como una salida } \\
\text { de la actividad } \\
\text { - Dos o más etapas } \\
\text { - Una fase completa del proceso } \\
\text { - El ciclo de vida completo } \\
\text { - A otros productos }\end{array}$ & $\begin{array}{l}\text { cuantitativo/Caso de estudio } \\
\text { Ciclo de vida completo } \rightarrow \text { Encuesta } \\
\text { cuantitativa }\end{array}$ \\
\hline \multirow[t]{3}{*}{ Madurez } & $\begin{array}{l}\text { No en uso en proyectos comerciales (aún } \\
\text { en desarrollo) }\end{array}$ & Benchmarking \\
\hline & $\begin{array}{l}\text { En uso en unos pocos proyectos en la } \\
\text { organización }\end{array}$ & \\
\hline & Usado ampliamente en la organización & Encuesta cuantitativa/cualitativa \\
\hline \multirow[t]{2}{*}{$\begin{array}{lll}\text { Curva de } & \text { aprendizaje } \\
\text { asociado } & & \end{array}$} & $\begin{array}{l}\text { Tiempo requerido para entender los } \\
\text { principios subyacentes }\end{array}$ & $\leq 1$ día $\rightarrow$ experimento \\
\hline & $\begin{array}{l}\text { Tiempo requerido para utilizarlo de manera } \\
\text { proficiente }\end{array}$ & $\leq 2-3$ días $\rightarrow$ experimento \\
\hline \multirow{4}{*}{$\begin{array}{l}\text { Capacidad de medición de la } \\
\text { organización }\end{array}$} & Severamente limitado & Benchmarking \\
\hline & Capacidad de evaluación cualitativa & $\begin{array}{l}\text { Métodos cualitativos } \\
\text { Benchmarking }\end{array}$ \\
\hline & $\begin{array}{l}\text { Capacidad de evaluación cualitativa y } \\
\text { cuantitativa }\end{array}$ & $\begin{array}{l}\text { Métodos cuantitativos y cualitativos } \\
\text { Benchmarking }\end{array}$ \\
\hline & Capacidad de evaluación completa & $\begin{array}{l}\text { Métodos cuantitativos y cualitativos } \\
\text { Benchmarking }\end{array}$ \\
\hline
\end{tabular}

Nótese que algunos criterios funcionan como filtros para descartar incluso un conjunto de métodos. Es el caso del criterio Naturaleza del impacto esperado del uso del método, el cual reduce los métodos candidatos al conjunto de métodos cualitativos o cuantitativos. A continuación se evalúa cada uno de estos criterios para el caso particular que nos ocupa, la selección de un método que permita evaluar el proceso de RS. La Tabla 99.3 muestra los métodos candidatos junto con la valoración de los criterios anteriores (indicando si tal condición está presente en este proyecto).

Tabla 4.3. Resumen de criterios técnicos (B. Kitchenham, 1996)

\begin{tabular}{|l|l|l|}
\hline Método de evaluación & Condiciones que favorecen el método & Presente \\
\hline Experimento cuantitativo & Beneficios claramente cuantificables & $\mathrm{N}$ \\
\cline { 2 - 3 } & Personal disponible para tomar parte en el experimento & $\mathrm{N}$ \\
\cline { 2 - 3 } & Método/herramienta relacionado con una tarea/actividad simple & $\mathrm{N}$ \\
\cline { 2 - 3 } & Beneficios directamente medibles a través de la salida de una tarea & $\mathrm{S}$ \\
\cline { 2 - 3 }$\quad \begin{array}{l}\text { Tiempo de aprendizaje relativamente pequeño } \\
\end{array}$ & $\begin{array}{l}\text { Deseo de realizar evaluaciones de métodos/herramientas } \\
\text { independientes del contexto }\end{array}$ & $\mathrm{N}$ \\
\hline
\end{tabular}




\begin{tabular}{|c|c|c|}
\hline \multirow[t]{5}{*}{ Estudio de caso cuantitativo } & Beneficios cuantificables en un sólo proyecto & $\mathrm{N}$ \\
\hline & Beneficios cuantificables antes del retiro del producto & $\mathrm{N}$ \\
\hline & Procedimientos de desarrollo estable & N/A \\
\hline & Personal con experiencia en mediciones & S \\
\hline & $\begin{array}{l}\text { Escalas de tiempo para la evaluación compatibles con el tiempo total de } \\
\text { los proyectos estándar de la organización }\end{array}$ & $\mathrm{N}$ \\
\hline \multirow[t]{3}{*}{ Encuesta cuantitativa } & Beneficios no cuantificables en un sólo proyecto & $\mathrm{N}$ \\
\hline & $\begin{array}{l}\text { Base de datos existente de logros de proyectos incluyendo } \\
\text { productividad, calidad, datos de la herramienta/método }\end{array}$ & $\mathrm{N}$ \\
\hline & Proyectos con experiencia de utilizar el método/herramienta & $\mathrm{N}$ \\
\hline \multirow{2}{*}{$\begin{array}{l}\text { Análisis de característica - } \\
\text { Modo Pre-selección }\end{array}$} & Gran número de herramientas/métodos a evaluar & $\mathrm{N}$ \\
\hline & Escalas de tiempo pequeñas para el ejercicio de evaluación & $\mathrm{N}$ \\
\hline \multirow{5}{*}{$\begin{array}{l}\text { Análisis de característica - } \\
\text { Estudio de caso }\end{array}$} & Beneficios difíciles de cuantificar & S \\
\hline & Beneficios observables a través de la salida de una tarea & S \\
\hline & Procedimientos de desarrollo estable & N/A \\
\hline & Población de usuarios limitada & S \\
\hline & $\begin{array}{l}\text { Escalas de tiempo para la evaluación compatibles con el tiempo total de } \\
\text { los proyectos estándar de la organización }\end{array}$ & S \\
\hline \multirow{4}{*}{$\begin{array}{l}\text { Análisis de característica - } \\
\text { Experimento }\end{array}$} & Beneficios difíciles de cuantificar & $\mathrm{S}$ \\
\hline & Beneficios directamente observables a través de la salida de una tarea & S \\
\hline & Tiempo de aprendizaje relativamente pequeño & $\mathrm{N}$ \\
\hline & Población de usuarios muy variada & $\mathrm{N}$ \\
\hline \multirow{4}{*}{$\begin{array}{l}\text { Análisis de característica - } \\
\text { Encuesta }\end{array}$} & Beneficios difíciles de cuantificar & $\mathrm{S}$ \\
\hline & Población de usuarios muy variada & $\mathrm{N}$ \\
\hline & Beneficios no observables en un solo proyecto & $\mathrm{N}$ \\
\hline & $\begin{array}{l}\text { Proyectos con experiencia de usar el método/herramienta, o proyectos } \\
\text { preparados para aprender acerca de él }\end{array}$ & $\mathrm{N}$ \\
\hline \multirow[t]{4}{*}{$\begin{array}{lll}\begin{array}{l}\text { Análisis de } \\
\text { cualitativos }\end{array} & & \\
\end{array}$} & $\begin{array}{l}\text { Disponibilidad de evaluaciones por opinión de expertos acerca del } \\
\text { método/herramienta }\end{array}$ & S \\
\hline & Falta de procedimientos de desarrollo estables & N/A \\
\hline & Requerimientos para combinar métodos/herramientas & S \\
\hline & Interés en evaluación de métodos/herramientas genéricos & $\mathrm{S}$ \\
\hline \multirow[t]{2}{*}{ Benchmarking } & Método/herramienta no humano-intensiva & $\mathrm{N}$ \\
\hline & $\begin{array}{l}\text { Salidas del método/herramienta capaces de ser jerarquizados en } \\
\text { términos de algunos criterios de "bondad" }\end{array}$ & $\mathrm{N}$ \\
\hline
\end{tabular}

El resultado de la evaluación anterior se puede resumir de la siguiente manera:

Tabla 4.4. Resumen de métodos candidatos 


\begin{tabular}{|l|l|}
\hline Método de evaluación & Condiciones favorables \\
\hline Experimentos cuantitativos & $17 \%$ \\
\hline Estudios de caso cuantitativos & $25 \%$ \\
\hline Encuestas cuantitativas & $0 \%$ \\
\hline Análisis de característica - Modo Pre-selección & $50 \%$ \\
\hline Análisis de característica - Estudio de caso & $100 \%$ \\
\hline Análisis de característica - Experimento & $50 \%$ \\
\hline Análisis de característica - Encuesta & $25 \%$ \\
\hline Análisis de efectos cualitativos & $100 \%$ \\
\hline Benchmarking & $0 \%$ \\
\hline
\end{tabular}

Nótese que los métodos mejor valorados en la evaluación anterior son: Análisis de Características por Estudio de caso y Análisis de efectos cualitativos. Aunque ambos métodos presenta el $100 \%$ de las condiciones que lo califican como favorable, la selección del método debe considerar también otros criterios prácticos propuestos por DESMET, como complemento a los criterios técnicos antes evaluados. Como se observa en la Tabla 4.5, el método de Análisis de efectos cualitativos requiere un tiempo muy corto para su aplicación; no obstante, esto no es especialmente importante en este proyecto de investigación, debido a que se dispone de un tiempo medio-largo para la evaluación de la propuesta. En cambio, el riesgo asociado a los resultados es muy alto en el caso del Análisis de efectos cualitativo, siendo ligeramente mejor para el Estudio de caso. Por último, el coste de la evaluación es tomada en cuenta. De los dos métodos pre-seleccionados, el Estudio de caso es el que implica un coste mayor; sin embargo, se considera que en este proyecto se puede asumir un coste de evaluación medio siempre que se reduzca el riesgo asociado a resultados poco confiables.

Tabla 4.5. Resumen de criterios prácticos (B. Kitchenham, 1996)

\begin{tabular}{|l|l|l|}
\hline Criterio & Escala & Método candidato \\
\hline Tiempo estimado para la evaluación & Largo & $\begin{array}{l}\text { Estudio de caso (cuantitativo o análisis de } \\
\text { características) }\end{array}$ \\
\cline { 2 - 3 } & Medio & Análisis de características por encuesta \\
\cline { 2 - 3 } & Corto & $\begin{array}{l}\text { Experimento (cuantitativo o análisis de características) } \\
\text { Benchmarking } \\
\text { Análisis de características por Modo pre-selección }\end{array}$ \\
\cline { 2 - 3 } & Muy corto & $\begin{array}{l}\text { Encuesta cuantitativa } \\
\text { Análisis de efectos cualitativo }\end{array}$ \\
\hline
\end{tabular}




\begin{tabular}{|c|c|c|}
\hline \multirow[t]{5}{*}{ Riesgo } & Muy alto & $\begin{array}{l}\text { Análisis de efectos cualitativos } \\
\text { Análisis de características por Modo Pre-selección }\end{array}$ \\
\hline & Alto & $\begin{array}{l}\text { Estudio de caso cuantitativo con comparación de dos } \\
\text { proyectos } \\
\text { Análisis de características por estudio de caso }\end{array}$ \\
\hline & Medio & $\begin{array}{l}\text { Estudio de caso cuantitativo con la organización como } \\
\text { base } \\
\text { Análisis de características por encuesta }\end{array}$ \\
\hline & Bajo & $\begin{array}{l}\text { Estudio de caso con replicación interna } \\
\text { Análisis de características por experimento } \\
\text { Encuesta cuantitativa }\end{array}$ \\
\hline & Muy bajo & Experimento cuantitativo \\
\hline \multirow[t]{4}{*}{ Costo de la evaluación } & Alto & Experimento \\
\hline & Medio & $\begin{array}{l}\text { Estudio de caso } \\
\text { Análisis de característica por Encuesta } \\
\text { Benchmarking } \\
\text { Análisis de característica Modo Pre-selección }\end{array}$ \\
\hline & Bajo & Encuesta cuantitativa \\
\hline & Muy bajo & Análisis de efectos cualitativos \\
\hline
\end{tabular}

Por lo anterior, el método seleccionado para la evaluación del proceso de RS a proponer es el método de Análisis de características por Estudio de caso. Este método incluye los siguientes pasos:

1. Decidir las características o propiedades del ítem a ser evaluado.

2. Priorizar estas características o propiedades con respecto a los requerimientos de los usuarios del método/herramienta.

3. Decidir el nivel de confianza que es requerido en los resultados y seleccionar el nivel de rigor requerido del análisis.

4. Establecer un sistema de escala que pueda ser aplicado a todas las características.

5. Asignar las responsabilidades de ejecutar la evaluación.

6. Ejecutar la evaluación para determinar cuánto satisface el producto evaluado los criterios que han sido establecidos.

7. Analizar e interpretar los resultados.

8. Presentar los resultados. 
Una vez presentada la metodología a ser utilizada en esta investigación, desde su definición hasta su evaluación, los capítulos siguientes tienen como propósito presentar los resultados más relevantes una vez acometidas estas actividades. 


\section{PARTE II - RESOLUCIÓN}




\section{CAPÍTULO 5. VISIÓN GENERAL DE PROCESO}

En este capítulo se presenta el proceso de RS propuesto en esta investigación. Como se ha descrito en el ESTADO DE LA CUESTIÓN, una RS constituye un proceso no trivial que, de manera general, involucra actividades de recuperación de información, recolección de datos, evaluación de estudios, y agregación a través de técnicas estadísticas. Cada una de estas actividades encierra a su vez una gran complejidad y requiere de un esfuerzo importante para lograr finalmente generar nuevas evidencias que sean confiables y, por tanto, útiles para los profesionales de IS.

Las metodologías analizadas en el ESTADO DE LA CUESTIÓN, que están en uso en otras disciplinas, han demostrado ser muy efectivas en sus respectivos contextos. Precisamente por su éxito en disciplinas como Medicina, algunas de estas metodologías, específicamente (J. P. T. Higgins \& S. Green, 2006) y (CRD, 2009), han sido la base para los lineamientos y metodologías propuestos para IS (Kitchenham. B.A. \& Charters, 2007) (J. Biolchini et al., 2005). Sin embargo, existen problemas para la aplicación de tales metodologías, ya que en la práctica la IS presenta diferencias importantes con las disciplinas de las Ciencias de la Salud. Como se analizará en este capítulo, incluso en algunas características que son similares, la IS requiere de un tratamiento particular. El análisis de estas características es presentado en la sección 5.1. CARACTERÍSTICAS DE LA INGENIERÍA DE SOFTWARE QUE PROVOCAN VARIACIONES EN EL PROCESO DE RS.

Para poder dar respuesta adecuadamente a estas características es necesario analizar su impacto en cada una de las fases del proceso de RS y proponer soluciones que abarquen todas las fases involucradas, tal como se presenta en la sección 5.2. APROXIMACIÓN A LA SOLUCIÓN, donde se plantea el enfoque general de las soluciones propuestas. Sin embargo, estas soluciones deben ser implementadas a través de elementos metodológicos concretos, en forma de actividades, documentación o recomendaciones. Por ello en la sección 5.3. PROCESO DE RS PROPUESTO, se presenta una primera definición y descripción del proceso. Este proceso constará de cinco fases, en consonancia con los procesos analizados en el ESTADO DE LA CUESTIÓN: Búsqueda, Extracción de Datos, Valoración de la calidad, Síntesis de Datos y Reportes. Cada una de las cuales es de desarrollada en los capítulos siguientes (capítulos 6-10).

Las actividades propuestas deberán ser acometidas por los revisores mientras juegan distintos roles dentro del proceso, que requieren de conocimientos y experiencias particulares, dependiendo del tipo de actividad. Estos roles son descritos en la sección 5.4. ROLES DEL PROCESO DE RS.

Debido a que el proceso de RS es costoso, y la inversión de tiempo y recursos debe estar bien justificada, existen puntos a lo largo del proceso en donde debe evaluarse que un determinado objetivo ha sido alcanzado, al mismo tiempo esto llevará a considerar la continuidad del proceso; esto es, decidir si es conveniente o no cancelar la RS. En la sección 5.5 HITOS DEL PROCESO se establece los puntos del proceso de RS propuesto donde una decisión de continuar/parar debería ser tomada. 


\subsection{Características de la IS que provocan variaciones en el proceso de RS}

Una RS puede llegar a ser muy costosa en tiempo y recursos, por lo que es importante contar con una metodología de RS adecuada, bien definida y que promueva la coste-efectividad del proceso. Lo anterior se traduce en una metodología que: 1) utilice métodos adecuados, que minimicen el riesgo de incurrir en sesgos; 2 ) combine evidencias primarias con una calidad mínima aceptable.

Las metodologías y procesos que han sido descritos en el CAPÍTULO 2- ESTADO DE LA CUESTIÓN han probado ser efectivas en sus respectivas disciplinas, especialmente aquellas que son utilizadas más popularmente en las Ciencias de la Salud (CRD, 2009; J. P. T. Higgins \& S. Green, 2006; NHMRC, 2000a; NIHCE, 2007) y que han sido practicadas y mejoradas durante años.

Sin embargo, las características de las disciplinas relacionadas con las Ciencias de la salud (Medicina, Psiquiatría, Enfermería, etc.) parecieran distar bastante de las características de la IS. Esto hace suponer que las metodologías que se encuentran actualmente en uso en tales disciplinas no sean completamente aplicables a la IS. Otras metodologías han sido propuestas específicamente para la IS, como (B. Kitchenham, Brereton, Budgen, Turner, et al., 2009) y (J. Biolchini et al., 2005) están fuertemente inspiradas en las anteriores, por lo que presentan las mismas limitaciones para su aplicación en la IS.

Esta investigación persigue proponer un proceso de RS que resuelva aquellas características de la IS que hacen que las metodologías o procesos actuales no sean aplicables de manera efectiva. Por lo tanto, antes de definir la propuesta realizada en esta investigación, es necesario analizar las características particulares de la IS que afectan al proceso de RS. Las características que han sido identificadas en este trabajo son las siguientes:

- Debido a que la ISE es una disciplina reciente, los experimentos son escasos. Puesto que son conducidos generalmente en ambientes académicos, típicamente incluyen pocos sujetos.

- Generalmente los revisores desconocen si existen experimentos disponibles acerca de un tema de interés por lo que es difícil establecer, en una etapa temprana, una pregunta de revisión cuya respuesta sea viable en virtud de que se cuente con evidencia primaria para soportarla.

- Como consecuencia de la característica anterior, es difícil establecer un protocolo de revisión al comienzo del proceso de RS.

- Es difícil localizar los experimentos existentes debido a bases de datos bibliográficas disponibles en IS son inadecuadas.

- No se cuenta con una la terminología estandarizada en relación con la tecnología bajo estudio o las mediciones que son realizadas sobre éstas.

- Típicamente, aún los experimentos que ensayan una misma tecnología, evalúan diversas variables respuesta y métricas. 
- Apenas algunos experimentos recientes reportan adecuadamente los datos y resultados del estudio; la mayoría de experimentos presenta una baja calidad de reporte.

- Los experimentos son conducidos en contextos muy diversos por lo que los grupos de experimentos suelen ser muy heterogéneos.

- Debido a que la conducción de los experimentos se realiza de manera diferente a otras disciplinas relacionadas con las Ciencias de la Salud, no todos los factores que afectan la calidad de un experimento en tales disciplinas pueden ser considerados en IS.

El impacto de las características anteriores en el proceso de RS es analizado a continuación. Es de hacer notar que cada una de estas características puede afectar a una o más fases del proceso de RS. En los capítulos siguientes (Capítulos 6 a 10), dedicados a describir en detalle cada una de las fases, se analizan más detenidamente los cambios que son provocados por las características de la IS.

\subsubsection{Experimentos escasos y con pocos sujetos}

En las disciplinas relacionadas con las Ciencias de la Salud (como Medicina, Psiquiatría, Enfermería, etc.) y con las Ciencias Sociales (como Educación), que cuentan con una larga experiencia en experimentación, se pueden encontrar una gran cantidad de estudios empíricos, y más específicamente experimentos controlados aleatorizados (conocidos también como RCT, por su acrónimo inglés). Esto hace posible que al momento de realizar una RS se disponga de un gran número de experimentos potencialmente agregables para responder a la pregunta de revisión planteada. Por lo tanto, las actividades prescritas por estas metodologías o procesos parten de la base de que se dispondrá de estudios primarios suficientes como para soportar las conclusiones que se obtengan; lo cual determina, por ejemplo, que exista una preocupación mayor por la calidad que por la cantidad de evidencias primarias que son incluidas en la revisión.

Al contar con un volumen considerable de experimentos, los revisores pueden permitirse ser muy estrictos en la selección de los mismos; utilizando para ello diversos criterios de exclusión de experimentos; por ejemplo, relacionados con los sujetos, los tratamientos, los tipos de estudio o las variables respuesta.

La ISE es, en cambio, una disciplina muy reciente; por lo que no se dispone de una gran base de estudios empíricos. De los estudios empíricos disponibles, una parte considerable son estudios observacionales o casos de estudio; siendo los experimentos un tipo de estudio muy escaso en esta disciplina (J. C. Biolchini, Mian, Natali, Conte, \& Travassos, 2007; Sjøberg et al., 2005). Por otra parte, la mayoría de los experimentos existentes han sido conducidos en ambientes académicos por lo que, típicamente, cuentan con un número pequeño de sujetos (T. Dybå, Kampenes, \& Sjoberg, 2006). 
Esta situación dentro de la IS, afecta directamente la validez de las evidencias que puedan ser obtenidas en una RS ya que el tamaño de la muestra es uno de los factores que determinan el poder estadístico de una agregación (Cohen, 1977). Como resultado de esto, frecuentemente durante la agregación es difícil detectar los efectos entre los niveles que están siendo comparados; por otra parte, cuando se obtienen evidencias, éstas tienden a estar soportadas por un número muy pequeño de estudios, como puede observarse en (O. Dieste \& Juristo, 2011). A pesar de lo anterior, esta limitante en el número de experimentos y el número de sujetos no es abordada en las metodologías de RS propuestas para esta disciplina.

\subsubsection{Dificultad para establecer una pregunta de revisión temprana}

Típicamente, la pregunta de revisión está determinada por 4 componentes básicos: participantes, intervenciones, diseños de estudios y resultados (Counsell, 1997; CRD, 2009; J. P. T. Higgins \& S. Green, 2006; Richardson, Wilson, Nishikawa, \& Hayward, 1995). Dichos componentes permiten planificar y plasmar en un protocolo de revisión las actividades y las decisiones principales acerca de la investigación a realizar.

Como se observa en el ESTADO DE LA CUESTIÓN, prácticamente todas las metodologías presentadas parten de la formulación de una pregunta de revisión bastante precisa. Esto tiene sentido en disciplinas experimentales maduras y que cuentan con una amplia base de experimentos, ya que es fácil conocer de antemano la disponibilidad de experimentos relacionados con los tratamientos de interés.

Tal como se describió en la característica 5.1.1, éste no es el caso de la IS. Por lo tanto, establecer una pregunta de revisión al comienzo del proceso frecuentemente provoca que los revisores realicen un esfuerzo inútil al intentar localizar experimentos relacionados con la pregunta de revisión.

Por lo anterior, es frecuente que los revisores (especialmente los que realizan una RS por primera vez) comiencen el proceso de RS con un objetivo exploratorio (B.A. Kitchenham, Budgen, \& Brereton, 2011), con la intención de detectar posibles preguntas de revisión. Sólo aquellos revisores que ya han explorado y analizado la base de estudios empíricos disponibles cuentan con suficiente información como para plantearse una pregunta de revisión que eventualmente pudiera ser respondida.

Aunque actualmente existen algunas recomendaciones para sobrellevar la dificultad de establecer la pregunta de revisión, tales como realizar estudios de mapeo (B.A. Kitchenham et al., 2011) o búsquedas de alcance (CRD, 2009), los autores de estas propuestas no proporcionan suficiente detalle sobre cómo llevarlas a cabo dentro del marco del proceso general de RS.

\subsubsection{Dificultad para establecer un protocolo de revisión}


En el ESTADO DE LA CUESTIÓN puede observarse que en casi todas las metodologías analizadas, incluyendo a LRSIS y UFRJ (desarrolladas específicamente para la IS), establecen que en una etapa inicial del proceso se desarrolle un protocolo de revisión, que contribuya a gerenciar la complejidad del proceso y establecer los juicios, decisiones y recursos necesarios para la RS.

El desarrollo del protocolo de revisión exige que muchas de las decisiones relativas al objetivo a alcanzar, así como los criterios y métodos a utilizar durante la RS, sean establecidos antes de conocer la disponibilidad de experimentos relacionados con el tema de interés (J. P. T. Higgins \& S. Green, 2006). Por lo tanto, las metodologías mencionadas parten de la premisa de que los revisores cuentan con un objetivo preciso desde el comienzo de la revisión, lo cual les permite establecer tempranamente tal protocolo.

Como se explicó anteriormente, debido a la escasez de experimentos en IS, frecuentemente es muy difícil conocer anticipadamente de qué experimentos se dispone; por lo que la mayoría de las revisiones tienen un objetivo exploratorio (p.e. ¿qué sabemos acerca de inspecciones de software?) (B.A. Kitchenham et al., 2011), puesto que se desconoce si sería posible localizar experimentos relacionados con tratamientos y variables respuesta específicos. Ejemplos de ello son las revisiones realizadas por (Lisboa et al., 2010; Lucas, Molina, \& A., 2009; Morais, Burity, \& Elias, 2009; Zhang, Kitchenham, \& Pfahl, 2008). Nótese que aunque tales revisiones son presentadas como RS, en realidad se trata de revisiones de alcance, estudios exploratorios o de mapeo.

Como resultado, de la misma manera que pierde sentido en IS establecer una pregunta de revisión muy tempranamente; es cuando menos discutible establecer un protocolo de revisión cuando aún se desconoce qué tratamientos, variables respuesta, tipos de estudio y tipos de sujetos podrán ser localizados.

Este problema es abordado de manera tímida en algunas metodologías que proponen que el protocolo de revisión sea desarrollado de manera iterativa (J. Biolchini et al., 2005) o de manera retrospectiva (J. P. T. Higgins \& S. Green, 2006).

\subsubsection{Dificultad para localizar los experimentos existentes debido a BD inadecuadas}

En Medicina, cuando los revisores requieren localizar estudios primarios, pueden consultar las bases de datos bibliográficas especializadas de las cuales disponen; tales como: PubMed, MEDLINE, CENTRAL, EMBASE, AMED, CINAHL y PsycINFO, entre otras (Pilkington, 2007; Sampson et al., 2011). Estas bases de datos brindan servicios que incluyen desde la indexación de artículos que reportan experimentos hasta la facilidad de realizar búsquedas por características muy específicas del experimento (p.e. tipo de estudio, condiciones, intervenciones, mediciones, localidad); pasando por la clasificación de experimentos por tópico.

A diferencia de Medicina, en IS no existen bases de datos bibliográficas especialmente destinadas al registro de estudios empíricos realizados en el área. Existen algunas iniciativas de coleccionar estudios 
primarios en un único sitio (como la web Evidence-based Software Engineering ${ }^{1}$ ); sin embargo, esto dista mucho de una base de datos como las que han sido citadas. Por lo tanto, los revisores en IS se ven limitados a utilizar bases de datos bibliográficas de carácter generalista (tales como ACM, Google Scholar, IEEE Xplore, Science Direct o Web of Science).

Debido a que estas bases de datos no son específicas para el registro de estudios empíricos, la localización de experimentos se hace compleja y costosa, ya que para obtener todos los artículos que reportan efectivamente experimentos relacionados con la pregunta de revisión, se debe invertir tiempo y esfuerzo considerables en descartar otros artículos que, habiendo sido recuperados durante la búsqueda, reportan ciertamente experimentos o, si lo hacen, éstos no se corresponden con el objetivo de los revisores. Además, en (Bailey, Zhang, \& Budgen, 2007; Brereton, Kitchenham, Budgen, Turner, \& Khalil, 2007 ; O. Dieste, Grimán, \& Juristo, 2009; T. Dybå, Arisholm, Sjoberg, Hannay, \& Shull, 2007) se han reportado diferentes problemas de cobertura y desempeño de estas bases de datos .

Todo lo anterior hace pensar que se requiere de criterios para la selección de las bases de datos a utilizar durante la RS, a fin de que la búsqueda se realice de la manera más coste-efectiva posible. Sin embargo, estas limitaciones que afectan la búsqueda de experimentos en IS no son abordadas por las metodologías que han sido propuestas para esta disciplina.

\subsubsection{Falta de una terminología estandarizada}

En aquellas disciplinas donde se cuenta con una larga trayectoria, como Medicina, es posible observar una gran madurez en el uso del vocabulario o la terminología utilizada. De hecho, en Medicina se ha desarrollado un vocabulario controlado que es utilizado para estandarizar la información a fines de su captura, almacenamiento, intercambio, búsqueda y análisis de datos. Esto incluye palabras o frases seleccionadas y autorizadas que son utilizadas para etiquetar las unidades de información con el propósito de facilitar la recuperación cuando se realizan búsquedas. Algunos ejemplos de aplicaciones de vocabulario controlado en Medicina son: la nomenclatura sistematizada de términos clínicos para Medicina (SNOMED $\mathrm{CT}^{\circledR}$ ), el sistema universal de códigos para identificar las observaciones clínicas y de laboratorio $\left(\operatorname{LOINC}^{\circledR}\right)$, el sistema de código multi-lenguaje basado en ordenador para Medicina (OpenGALEN) y el sistema de lenguaje médico unificado (UMLS $\left.{ }^{\circledR}\right)$.

A diferencia de Medicina, IS es una disciplina joven. Sin embargo, debido al avance tecnológico acelerado, se ha producido un crecimiento descontrolado de la terminología. Aunque existen algunas iniciativas que intentan estandarizar el vocabulario y los conceptos relacionados con la disciplina, tales como (ACM, 1998;

${ }^{1}$ http://www.dur.ac.uk/ebse/ 
IEEE, 1990, 2004a), aún no se cuenta con un vocabulario controlado que pueda ser realmente de utilidad en el manejo de la información. De esta manera, se observan los siguientes problemas:

- Ambigüedad inherente al lenguaje humano natural (por ejemplo, método de inspección, técnica de inspección y técnica de lectura pueden significar lo mismo o estar relacionados para los expertos, pero esto es difícil de interpretar para el ordenador).

- $\quad$ Dificultades en el intercambio de información entre proveedores, investigadores, profesionales, etc.

- $\quad$ Inconsistencias en el registro de la información de un lugar a otro.

- Dificultad para clasificar la información.

- $\quad$ Dificultad para la manipulación simbólica de los datos; esto es, búsquedas por análisis específico.

Esta característica puede limitar fuertemente la búsqueda de estudios primarios, así como la extracción correcta de los datos; por lo que requiere especial Interés. En el caso de la búsqueda, la recuperación de toda la evidencia primaria disponible acerca de una pregunta de revisión es prácticamente imposible, ya que se requeriría conocer todos los términos equivalentes utilizados por los experimentadores para referirse a la tecnología que está siendo ensayada. En el caso de la extracción de datos, es muy difícil garantizar que los datos sean extraídos de manera correcta; lo cual finalmente terminará por afectar la síntesis de datos, al combinar resultados de métricas distintas o dejar por fuera resultados de métricas equivalentes.

A pesar de que esta característica afecta el propósito de la RS, ningunas de las metodologías o guías analizados en el ESTADO DE LA CUESTIÓN propone una solución para ello.

\subsubsection{Diversidad de variables respuesta y métricas}

En algunas disciplinas, como Medicina o Física, los experimentos que comparan los mismos fenómenos utilizan comúnmente la misma manera de evaluarlos; esto se traduce en que típicamente las respuestas a los tratamientos son medidas utilizando las mismas métricas. Por ello, contar con un número considerable de experimentos que soporten las evidencias relacionadas con una métrica, no es una preocupación para las metodologías de RS en estas disciplinas.

En cambio, en IS es común encontrar experimentos que miden una misma variable respuesta a través de métricas distintas; por ejemplo, la variable respuesta eficiencia del método de inspección podría ser medida en un experimento como la tasa de detección de fallos por unidad de tiempo $\left(m_{1}\right)$, mientras que en otro experimento podría estar siendo medida como el tiempo transcurrido hasta encontrar un fallo $\left(m_{2}\right)$. Nótese que ambas métricas son diferentes no sólo en la unidad en que son medidas (número de fallos, en el caso de $\mathrm{m}_{1}$; y minutos, en el caso de $\mathrm{m}_{2}$ ) sino también en la interpretación de la dirección del efecto; es decir, si el valor de $\mathrm{m}_{1}$ es mayor para un método, puede interpretarse que tal método es más eficiente que el otro (detecta más fallos por cada unidad de tiempo), mientras que cuando el valor de $\mathrm{m}_{2}$ 
sea mayor para un método deberá interpretarse que éste es menos eficiente (toma más tiempo encontrar cada fallo). Por lo anterior, $\mathrm{m}_{1}$ y $\mathrm{m}_{2}$ no podrían ser agregadas estadísticamente.

La situación anterior es bastante común en IS; trayendo como consecuencia que para conocer el comportamiento de una determinada tecnología se tengan que recopilar las evidencias disponibles acerca de múltiples métricas, las cuales son soportadas por muy pocos experimentos. Sin embargo, estas limitaciones no han sido abordadas aún desde el punto de vista metodológico.

\subsubsection{Baja calidad de reporte de los experimentos}

Es frecuente que un experimento, aún estando adecuadamente diseñado y habiendo sido conducido apropiadamente, sea excluido de la revisión en virtud de que no reporta toda la información necesaria. En algunas ocasiones, estás deficiencias en el reporte del experimento puede ser solventadas por los revisores comunicándose con los autores del experimento. Sin embargo, muchas veces se trata de experimentos antiguos de los cuales los mismos investigadores que condujeron el experimento no guardan los datos originales.

Estas deficiencias limitan no sólo la calidad desde el punto de vista del reporte; sino que, la mayoría de las veces, afecta también su calidad como estudio, ya que es común que los revisores respondan a los criterios de valoración de la calidad con base en la información (por ejemplo, aleatorización del experimento, ocultamiento, etc.) que es suministrada en el reporte del experimento. Finalmente, será la SÍNTESIS DE DATOS la que más se vea perjudicada, ya que para aplicar las técnicas de meta-análisis más efectivas para la agregación, es necesario contar con un conjunto de datos cuantitativos (número de sujetos, medias y varianza). Al no contar con estos datos, otras técnicas pueden ser aplicadas, no sin comprometer la confiabilidad de las evidencias obtenidas.

La falta de adherencia a los estándares para el reporte de experimentos no es una situación particular a la IS. Incluso en disciplinas como Medicina, donde existen estándares propuestos desde hace casi dos décadas, como los lineamientos CONSORT (Begg et al., 1996), los revisores han reportado poco cumplimiento de estos estándares (Agha, Cooper, \& Muir, 2007; Areia, Soares, \& Dinis-Ribeiro, 2010; Ziogas \& Zintzaras, 2009).

Los revisores en IS también han padecido el problema de la baja calidad de reporte de los experimentos (Ciolkowski, 2009; O. Dieste \& Juristo, 2011; T. Dybå et al., 2006). Esto ha motivado que se desarrollen un conjunto de recomendaciones (A. Jedlitschka \& D. Pfahl, 2005) basadas en las existentes en Medicina (específicamente en CONSORT); aunque no tan detalladas y específicas como aquellas (B. Kitchenham et al., 2008). No obstante, esta iniciativa de recomendaciones es aún muy reciente y su impacto en la calidad de reporte de los experimentos aún no es apreciable.

Aunque parece ser común a varias disciplinas, el problema de la baja calidad de reporte en IS se suma al problema de la escasez de experimentos haciendo su impacto más dramático en la SínTESIS DE DATOS, como 
puede apreciarse en (O. Dieste \& Juristo, 2011). Por ello es necesario que el proceso de RS que se siga en esta disciplina busque lidiar con la escasez de experimentos reportados adecuadamente o de manera incompleta.

\subsubsection{Grupos de experimentos con contextos heterogéneos}

El contexto de un experimento incluye todas aquellas variables que pueden afectar la generalización y la utilidad de su evidencia (A. Jedlitschka \& Ciolkowski, 2004). En Medicina, este concepto es definido con base en la pregunta de investigación; generalmente incluyendo: los sujetos, las mediciones y el ambiente (Cronbach, 1982).

En IS la conducción de un experimento presenta condiciones que lo diferencian de un experimento en Medicina:

- Los sujetos aplican los tratamientos (en lugar de recibirlos). Para ello, los sujetos deben aplicar una técnica o método relacionado con alguna etapa del proceso de desarrollo.

- $\quad$ El método o técnica es aplicado a un artefacto (objeto).

- Generalmente, los resultados son medidos sobre los objetos.

Por lo anterior, otros factores, además de los indicados por (Cronbach, 1982), deben ser tomados en cuenta en IS para establecer el contexto del experimento (Conradi \& Wang, 2003; Sjøberg et al., 2005; C. Wohlin et al., 2000), ya que los mismos podrían afectar la generalización de los resultados y su aplicabilidad. Uno de estos factores particulares a la IS se refiere a la Tarea experimental que es realizada por los sujetos durante una etapa del proceso de desarrollo; y durante la cual son aplicados los tratamientos. Por otra parte, se tiene también al Objeto experimental, que se refiere al artefacto al que está siendo aplicada la técnica. Estos factores pueden afectar la SíNTESIS DE DATOS al producir variaciones en los resultados de un grupo de experimentos.

\subsubsection{Definición de calidad poco clara y limitaciones en las escalas de calidad}

Aunque en otras disciplinas el tema de la calidad de los experimentos sigue siendo controvertido, existen gran cantidad de estudios y propuestas que van desde la jerarquía de las evidencias hasta las listas de chequeo, donde muchas de ellas incluyen gran cantidad de ítems. Muchas de estas propuestas giran en torno a un conjunto de elementos que parece ser consensuado entre los revisores y experimentadores.

Por el contrario, en la IS no existe mucha madurez en relación a la experimentación y más aún en relación a lo que puede definirse como un experimento de calidad. Ante este vacío los revisores suelen 
importar directamente de Medicina las escalas existentes, sin hacer mucha adecuación de las mismas antes de su uso en esta disciplina.

Se requiere entonces de un estudio donde los factores que inciden en la calidad de un experimento en IS sean analizados, considerando quizás aquellos que han sido tradicionalmente utilizados en otras disciplinas, pero sin perder de vista las características propias de los experimentos que se realizan en ésta. Por ejemplo, en los experimentos que son conducidos en la IS encontramos que el enmascaramiento llega a ser una variable difícil de manejar, ya que supone que el sujeto no conozca del tratamiento que está siendo aplicado; sin embargo, la propia naturaleza de la tarea experimental lleva a que esto no sea posible, ya que el sujeto es el responsable de aplicar el tratamiento que se está comparando.

Por último, se tiene que mientras en otras disciplinas abundan las escalas de calidad y listas de verificación, en IS la cantidad de estos instrumentos es escaso; siendo que algunas de ellas contienen gran número de itens y deben ser seleccionados para cada revisión con muy pocas orientaciones para ello; o en cambio no han sido propuestos expecíficamente para experimentos controlados.

A continuación, se describen las respuestas a las características anteriores.

\subsection{Aproximación a la solución}

Luego de describir las características de la IS que provocan cambios en el proceso o metodología a seguir, se presenta un resumen de las respuestas propuestas a cada una de ellas. Nótese que, aunque han sido descritas de manera individual, algunas de las características presentadas en la sección 5.1 mantienen una estrecha relación; llegando, en algunos casos, a una relación causa-efecto (por ejemplo, la escasez de experimentos puede considerarse la causa de la dificultad para establecer una pregunta de revisión temprana, la cual es, al mismo tiempo, la causa de la dificultad para establecer un protocolo de revisión al inicio del proceso de RS). Por lo tanto, las soluciones propuestas pueden abordar más de una característica. Al mismo tiempo, las soluciones propuestas pueden no estar limitadas a una única fase de la RS, sino que establecen actividades o recomendaciones para diferentes fases.

A continuación se describen de manera resumida las respuestas a las características presentadas en la sección 5.1. Estas soluciones serán descritas en detalle más adelante, representadas a través de actividades o recomendaciones.

\subsubsection{Experimentos escasos y con pocos sujetos}

Como se indicó en la sección 5.1, en IS no existen muchos RCTs que hayan sido conducidos. Esto afecta directamente la SíNTESIS DE DATOS puesto que se cuenta con poco soporte para la generación de evidencias. Por otra parte, afectará también de manera indirecta la búsqueda de experimentos pues es la fase 
responsable de la localización de estudios primarios. Por otra parte, afecta la EXTRACCIÓN DE DATOS ya que ésta es la fase más temprana en la que se puede determinar si un experimento es comparte características con otros, lo suficiente como para ser agregados durante la Síntesis de datos. A continuación, se describe la solución propuesta para afrontar esta característica:

- El problema de la escasez de experimentos debe ser abordado desde la fase más temprana del proceso de RS. Para ello la FASE DE BúSQUEDA debe incluir recomendaciones sobre la estrategia de búsqueda que se debe seguir para la localización de experimentos, con el fin de maximizar la recuperación de experimentos reduciendo el esfuerzo de descarte de artículos irrelevantes. Esta estrategia incluye no sólo los campos en los cuales se debe realizar la búsqueda sino también recomendaciones para la definición de cadenas de búsquedas óptimas relacionadas con los tratamientos, las métricas y el tipo de estudio que se quiere localizar.

- La limitación en cuanto a la disponibilidad de experimentos en IS afecta también la selección del tipo de estudios durante la BúsquedA. Dentro de las disciplinas relacionadas con las Ciencias de la Salud se considera a los RCT como los estudios de más alta calidad en la jerarquía de diseño de estudios; por lo que la incorporación de otro tipo de estudios es una posición muy controvertida (J. P. T. Higgins \& S. Green, 2006). En esta investigación se asumirá una posición intermedia en cuanto a este tipo de estudio; incorporando no sólo experimentos controlados aleatorizados (RCT) sino también cuasiexperimentos. Algunos autores, como (Shadish, Cook, \& Campbell, 2002), afirman que, siendo apropiadamente conducidos, los cuasi-experimentos pueden aportar evidencias tan válidas como un RCT.

- Puesto que no todos los experimentos participarán en la SínTESIS DE DATOS, en virtud de que algunos de ellos son únicos en ensayar ciertos niveles o evaluar una determinada métrica; debería evitarse el esfuerzo de leer a profundidad aquellos experimentos que no tienen posibilidades de ser agregados con otros. Esto requiere que la lectura durante la EXTRACCIÓN DE DATOS se realice en dos ciclos: una lectura superficial que extraiga sólo los datos necesarios para formar grupos de experimentos similares en cuanto a niveles y mediciones, y otra lectura en profundidad que debería concentrarse en aquellos grupos de experimentos que sean más parecidos y, por lo tanto, con posibilidades de ser agregados más adelante.

- Desde el punto de vista de la SínTESIS DE DATOS, lo que se busca es agregar la mayor cantidad de experimentos que sea posible, siempre siguiendo el criterio de máxima similitud entre ellos. Como se explicó en el punto anterior, se requiere que durante la EXTRACCIÓN DE DATOS se identifiquen aquellos experimentos que sean más compatibles en cuanto a los niveles que ensayan y las variables que son medidas. En esta investigación se ha considerado que, al identificar durante la extracción grupos de experimentos compatibles que pueden considerarse como grupos potencialmente agregables, es posible que la agregación se concentre en aquellos grupos que cumplan con las condiciones mínimas de número de experimentos y similitud de niveles y variables respuesta. Aunque la agregación debe 
ser realizada a nivel de métrica, por requerimiento de las técnicas de agregación, se recomienda resumir las evidencias de aquellas métricas que se encuentren relacionadas para evitar el problema de generar evidencias soportadas por muy pocos experimentos.

\subsubsection{Dificultad para establecer una pregunta de revisión temprana}

Como se comentó anteriormente, el problema de la escasez de experimentos determina que muchas veces sea imposible establecer la pregunta de revisión, ya que se desconoce si existirán suficientes experimentos disponibles sobre la tecnología de interés. Por lo tanto, éste es un problema que concierne a la BúSQUEDA, ya que es la fase en la que se puede proporcionar información acerca de los experimentos disponibles. La solución propuesta a esta característica es la siguiente:

- Durante la FASE DE BúSQUEDA debe incluirse un conjunto de actividades y recomendaciones para la conducción de una búsqueda preliminar (búsqueda de alcance o estudio de mapeo) que permita conocer la base de experimentos disponibles antes de acometer las actividades propias de la RS. Esta búsqueda preliminar permite generar una categorización de los experimentos localizados en grupos candidatos a agregación entre los cuales se seleccionará aquél que resulte de interés para los revisores. Con base en el grupo seleccionado se podrá definir la pregunta de revisión.

\subsubsection{Dificultad para establecer un protocolo de revisión}

En general, el protocolo de revisión busca establecer lo más pronto posible, el conjunto de métodos o criterios que serán seguidos durante la conducción de la RS. Esto responde a una necesidad de lograr un acuerdo acerca del objetivo y la justificación de la RS así como la manera de conducir la misma. El protocolo de revisión guarda estrecha relación con la definición de la pregunta de revisión; por lo tanto, se ve igualmente afectado por la escasez de experimentos. Todo ello afecta la manera en que son definidos los métodos y criterios a ser utilizados durante la RS. La siguiente es la solución planteada en esta investigación:

- La definición temprana del protocolo de revisión pierde sentido en IS cuando se desconoce tempranamente la pregunta de revisión. Ésta puede ser definido únicamente cuando se cuente con suficiente información para ello. En esta investigación se ha considerado que el definir los métodos a utilizar de manera prospectiva perjudica el enfoque contextual que debería utilizar un proceso de RS cuando es aplicado en IS, ya que las condiciones de esta disciplina obligan a que muchas de las decisiones relacionadas con los métodos a seguir sean tomadas a medida que se avanza en el proceso y se obtiene conocimiento acerca de los experimentos de los que se dispone. Por ejemplo, los

métodos de síntesis de datos deberían ser definidos lo más tarde posible, cuando se conozca el número definitivo de experimentos seleccionados y la extracción de datos haya proporcionado información acerca de la homogeneidad de tales experimentos. De otra manera, los métodos 
establecidos en un protocolo temprano, seguramente serían cambiados durante el desarrollo de la revisión, en virtud de las características de los experimentos que finalmente participen en la revisión. Se propone que el protocolo de revisión sea documentado al final del proceso, en lugar de establecerlo al inicio sin haber explorado lo que existe acerca de la tecnología. De esta manera, el protocolo de revisión pasa a ser el artefacto que documenta las decisiones tomadas durante la RS, y que puede ser usado para determinar si el proceso ha sido conducido adecuadamente. Este enfoque no debería suponer una limitación metodológica ya que, según (Higgins \& Green, 2006), a pesar de lo que establecen las metodologías existentes, incluso en Medicina los proyectos de RS tienden a ser evolutivos; lo que significa que frecuentemente no es posible precisar a priori aspectos como: los criterios para la selección de los estudios, la definición de la pregunta, las intervenciones y los grupos de participantes evaluados, etc., teniendo que realizar su definición de manera progresiva durante todo el proceso. Esto es posible porque la motivación para el protocolo de revisión no es la repetibilidad sino garantizar que se han tomado las medidas para evitar el sesgo.

\subsubsection{Bases de datos inadecuadas}

Como se explicó en la sección 5.1, en IS actualmente sólo se cuenta con bases de datos bibliográficas de carácter generalista, destinadas a la indexación de publicaciones de tipo científico en general y casi siempre para diferentes áreas del conocimiento. Esta limitación afecta directamente la BúsQUEDA de experimentos. La respuesta debe contribuir a conducir esta actividad en las condiciones actuales de tecnología de la IS. La siguiente es la solución planteada en esta investigación:

- Desde el punto de vista de la BúsQuedA, cualquier solución debe apuntar a lograr la máxima recuperación de experimentos sin un elevado coste de tiempo y esfuerzo. Como respuesta a esta característica se incluyen recomendaciones para la selección de la base de datos bibliográfica más adecuada. Por otra parte, debido a que las bases de datos con las que se dispone en IS no pueden proporcionar búsquedas por campos relacionados con las características de un experimento (tratamientos, contexto, variables respuesta, etc.), se han analizado estrategias en los distintos campos de búsqueda que proporcionan estas bases de datos, y se ha comparado el desempeño de los resultados para varios de las bases de datos disponibles en IS. Con base en lo anterior, es posible proporcionar un conjunto de recomendaciones que, si bien no resuelven el problema de no contar con bases de datos especialmente destinadas al registro de experimentos, permitirán reducir el esfuerzo de localización de los experimentos en IS tratando al mismo tiempo de maximizar la recuperación de los mismos.

\subsubsection{Falta de estandarización de la terminología}


Esta característica afecta prácticamente todo el proceso de RS, ya que todas las actividades requieren, en mayor o menor medida, de la precisión de ciertos datos de los experimentos (por ejemplo, tratamientos y métricas). En cuanto a la BúSQUEDA, se hace imposible recuperar todos los experimentos relacionados con una tecnología. Desde el punto de vista de la EXTRACCIÓn y la SíNTESIS DE DATOS, el problema de la falta de un vocabulario controlado tiene su impacto en la precisión del registro de los datos y en los experimentos que son agregados en relación a una misma métrica. A continuación, se indica la solución planteada en esta investigación:

- Desde el punto de vista de la Búsqueda de experimentos, lo que se busca es lograr maximizar los resultados relevantes de una cadena de búsqueda. Sin embargo, sería imposible llegar a definir una cadena de búsqueda que incluya todos los sinónimos utilizados para referirse a un tratamiento o variable respuesta en IS. Debido a que los dos componentes más comunes en la cadena de búsqueda son el tipo de estudio (en este caso, experimento) y los tratamientos (el factor y sus niveles), en esta investigación se proponen recomendaciones para construir cadenas de búsqueda óptimas, que permitan recuperar la mayor cantidad posible de experimentos, con el menor esfuerzo necesario para el descarte de artículos irrelevantes. Estas recomendaciones se han obtenido luego de analizar diferentes estrategias de búsqueda en las bases de datos bibliográficas disponibles en IS.

- En relación a la EXTRACCIÓn y la SínTESIS DE DATOS, se busca resolver los conflictos de vocabulario que afectan la identificación de niveles y métricas. Para ello se debe uniformizar la terminología con base en un estándar conocido o simplemente según el vocabulario manejado por los revisores. Para resolver esta situación se propone el agrupamiento de aquellos conceptos que sean similares pero que aparezcan reportados con una terminología distinta. Se recomienda que esta uniformización de la terminología se inicie durante la lectura de los experimentos y sea mantenida durante todo el proceso.

\subsubsection{Diversidad de variables respuesta y métricas}

Como se indicó en la sección 5.1, esta característica afecta directamente la SíNTESIS DE DATOS; al promover que se generen múltiples métricas distintas asociadas con una tecnología, que son soportadas por muy pocos experimentos. Por otra parte, afecta en menor medida la EXTRACCIÓN DE DATOS; ya que es la fase donde se identifican las métricas que son comparadas en cada experimento. Como solución se plantea lo siguiente:

- Desde el punto de vista de la EXTRACCIÓN DE DATOS, se persigue garantizar la comprensión de los experimentos para registrar adecuadamente sus datos. Ello sugiere realizar la lectura conjunta de los experimentos que sean más parecidos. Debido a la gran diversidad de métricas identificadas, se recomienda utilizar la variable respuesta como un nivel más abstracto que engloba diferentes métricas. De esta forma, se proponen agrupar los experimentos con base en los niveles que ensayan 
y las variables respuesta que miden, y organizar la lectura según la similitud de los experimentos en cuanto a estas características.

- Desde el punto de vista de la SínTESIS DE DATOS, se busca obtener evidencias soportadas por la mayor cantidad de experimentos. Debido a los requerimientos de las técnicas de agregación, los experimentos deberán ser agregados por métrica; sin embargo, se propone que las evidencias que son obtenidas a este nivel (métrica) sean resumidas junto con otras métricas relacionadas con la misma variable respuesta.

\subsubsection{Baja calidad de reporte de los experimentos}

Esta característica afecta prácticamente todas las fases de la RS; pero muy especialmente la EXTRACCIÓN DE DATOS, ya que durante esta fase se recolectan los datos que son necesarios para la agregación y para asignar un nivel de calidad al experimento. Si la extracción no logra recopilar los datos necesarios, todo el proceso se ve comprometido: si no se cuenta con los datos cuantitativos necesarios para la agregación se hace más difícil la obtención de evidencias durante la SíNTESIS DE LOS DATOS; por otra parte, durante la VALORACIÓN DE LA CALIDAD no es posible asignar una calificación al experimento si no se conocen los detalles de su diseño y conducción. Por lo tanto, la solución presenta varias aristas:

- Desde el punto de vista de la ExTRACCIón se busca obtener datos que permitan agregar el experimento a través de alguna de las técnicas disponibles. Por lo tanto, se propone recolectar no sólo los datos de tipo cuantitativo (medias y varianzas) sino también aquella información de tipo cualitativa (a > b) que permita realizar la agregación utilizando técnicas no paramétricas. Es también responsabilidad de esta fase excluir aquellos experimentos que presenten una calidad muy baja de reporte, por ejemplo, aquellos que no proporcionan ningún tipo de datos o información que le permita ser agregado durante la síntesis.

- En relación a la SíNTESIS DE DATOS, como complemento a la solución propuesta para la extracción, se propone la incorporación de técnicas de agregación que permitan la combinación de experimentos que no presenten todos (o ninguno) de los datos cuantitativos, pero para los cuales se cuente con información cualitativa relacionada con el efecto y su dirección.

- En lo que respecta a la VALORACIÓN DE LA CALIDAD, se propone descartar aquellos experimentos y cuasiexperimentos que posean una calidad pobre. Esto discriminar entre los estudios de calidad media y alta.

\subsubsection{Experimentos conducidos en diversos contextos}

A menos que se trate de replicaciones de experimentos, es frecuente encontrar contextos distintos dentro de un mismo grupo de experimentos, esto afectará directamente la SíNTESIS DE DATOS, pues el propósito de 
ésta es la agregación de experimentos homogéneos. Al mismo tiempo, esto afecta indirectamente la extracción ya que es la fase más temprana en la que se conocen los detalles acerca de la conducción del experimento. Esto implica que la solución debe atender a dos objetivos:

- En primer lugar, durante la EXTRACCIÓN DE DATOS se busca determinar la compatibilidad y homogeneidad de los experimentos. Para ello se ha propuesto el agrupamiento por distintos criterios que se relacionan con el contexto: 1) agrupamiento de experimentos por tipo de sujeto, 2) agrupamiento de experimentos por tarea, y 3) agrupamiento de experimentos por niveles y variables respuesta. Como resultado, se presentan los experimentos resumidos por contexto, incluyendo otras características como el ambiente y el objeto.

- Posteriormente, durante la SínTESIS DE DATOS, se busca realizar la agregación de experimentos dentro de un contexto homogéneo. Por lo tanto, con base en el agrupamiento que se propone en la solución anterior, se realizará la agregación de los experimentos por niveles y métrica bajo condiciones de igual sujeto y tarea. Adicionalmente se realiza un análisis de la heterogeneidad, no sólo desde el punto de vista de los parámetros estadísticos, sino también gráfico, procurando mantener los grupos de experimentos más homogéneos posibles. Finalmente, cuando se genera una evidencia para un grupo homogéneo de experimentos, se registran las condiciones para las cuales ha sido obtenida.

\subsubsection{Definición de calidad poco clara y limitaciones en las escalas de calidad}

Como respuesta a esta condición particular de nuestra disciplina, se ha buscado mantener un equilibrio entre la necesidad de incorporar la mayor cantidad posible de estudios, y la necesidad de generar evidencias con un alto grado de confiabilidad.

Se propone en este sentido utilizar una escala de calidad cuyos elementos son validados a través de un estudio de correlación, donde se ha utilizado como referente el sesgo. De esta manera se propone una escala minimalista, donde los elementos que han sido incluidos son aquellos que han aparecido en nuestro estudio fuertemente relacionados con la calidad; pareciendo ser buenos predictores del mismo.

Una vez se han identificado los elementos de calidad a ser considerados, se ha establecido aquellos que son determinantes de una calidad media y alta tanto para un experimento como para un cuasiexperimento. Esto permite, a través del uso de una escala de calidad simple, obtener un nivel de calidad que sirva de entrada para la fase de Síntesis, a fin de matizar las evidencias obtenidas.

A continuación, se presenta el proceso de RS que se propone en esta investigación, como implementación de las soluciones descritas en esta sección. 


\subsection{Proceso propuesto}

El propósito del proceso de RS que se propone a continuación es la generación, a través de técnicas de meta-análisis, de nuevas evidencias a partir de resultados obtenidos de experimentos adecuadamente conducidos en el domino de la IS. Este proceso busca abordar las limitaciones que, dentro del contexto de la IS, presentan los procesos y pautas disponibles actualmente; al incorporar las soluciones descritas en la sección 5.2 .

Tal y como se ha visto hasta ahora, una RS es un proceso complejo, expuesto además a diversos tipos de errores o sesgos que comprometen el resultado final (J. P. T. Higgins \& S. Green, 2006); ejemplos de tales sesgos son el sesgo de publicación y las distorsiones producidas por evidencias obtenidas a través de métodos inadecuados (por ejemplo, estudios primarios heterogéneos o de poca calidad, o métodos de agregación distintos al meta-análisis) (Mignini \& Khan, 2006). Tales sesgos podrían invalidar los estudios seleccionados, los datos obtenidos y la generación de conclusiones. Por esta razón, el proceso de revisión propuesto incluye diversos aspectos que cooperan en la reducción del riesgo de distorsión de los resultados, tales como: la búsqueda exhaustiva de experimentos utilizando múltiples bases de datos y universos de búsqueda no restringidos, la estandarización de la terminología, la codificación de los datos y la tabulación de resultados, la evaluación de los estudios primarios para asignar niveles de confianza a las evidencias, la selección de técnicas de meta-análisis para la agregación de los estudios primarios con base en criterios de fiabilidad y poder estadístico, y la agregación de experimentos bajo criterios de homogeneidad.

Dado que una revisión es un proceso complejo, ésta debe ser realizada a través de varias fases. EI proceso que se propone en esta investigación ha tomado como inspiración las fases que resultaron ser predominantes en las metodologías existentes: Búsqueda, Extracción de datos, Valoración de la Calidad, Síntesis de datos y Reportes. No obstante, se han incorporado las modificaciones necesarias a fin de implementar las soluciones descritas en el apartado anterior.

Una visión general del proceso de revisión propuesto se muestra en la Figura 5.1. En ella puede observarse que el proceso propuesto se compone de cinco fases, algunas de las cuales pueden ser acometidas de manera concurrente o iterativa. A continuación, se presenta una descripción breve de estas fases, dejando el detalle de las mismas para los capítulos subsiguientes. 


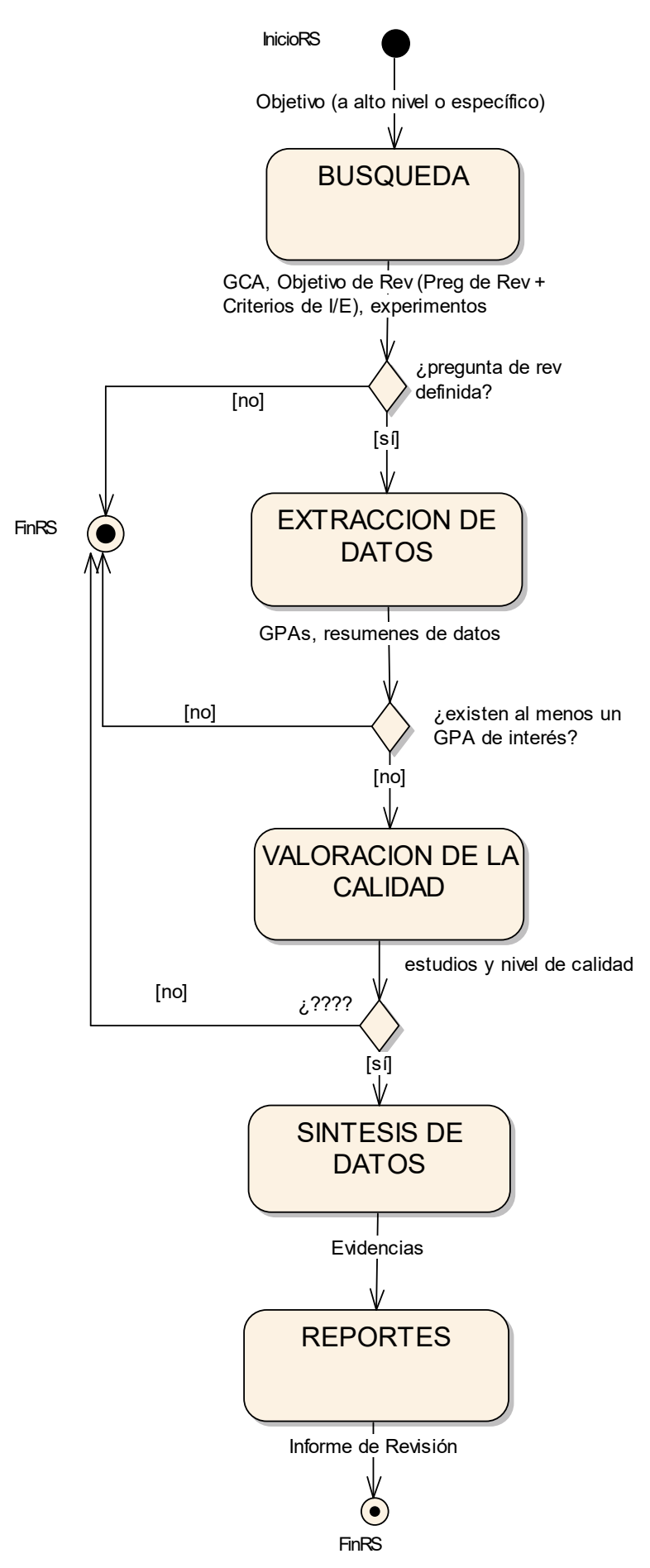

Figura 5.1. Visión general del proceso de revisión 


\subsubsection{Fase de Búsqueda}

Esta primera fase tiene como propósito localizar los experimentos disponibles en IS acerca de un tópico de interés, con el fin de que el revisor pueda establecer una pregunta de revisión. Una vez que el revisor cuenta con una pregunta de revisión establecida, esta fase se ocupa de localizar la mayor cantidad de experimentos relacionados con los tratamientos, variables respuesta y tipos de estudios de interés para la revisión.

En un primer escenario de esta fase, cuando el revisor desconoce los experimentos disponibles acerca de un tema de interés y sólo posee un objetivo a alto nivel, se realiza una búsqueda preliminar (búsqueda de alcance o estudio de mapeo) que permite localizar los experimentos disponibles y categorizarlos por tópico y tipo de estudio. Esto se conocerá en adelante como grupos candidatos a agregación (GCA). Una vez que los revisores seleccionan un GCA, es posible definir la pregunta de revisión y los criterios de inclusión/exclusión, pues existen experimentos que eventualmente permitirán dar respuesta a esta pregunta. En este escenario se realizan las siguientes actividades: DETERMINACIÓN DEL TEMA, BúSQUEDA PRELIMINAR DE EXPERIMENTOS POR TEMA, DESCARTE DE ARTíCULOS IRRELEVANTES, SELECCIÓN DE ESTUDIOS A AGREGAR.

En otro escenario de la fase, cuando el revisor ha realizado anteriormente (no necesariamente en el mismo momento) una búsqueda preliminar de experimentos acerca de un tema y cuenta con información acerca de los posibles GCA y un objetivo de revisión específico, se cuenta con las actividades necesarias para realizar una búsqueda refinada y exhaustiva que permite localizar tantos experimentos como sea posible acerca de la pregunta de revisión. En este escenario se incluyen las siguientes actividades: DECLARACIÓN DEL OBJETIVO DE REVISIÓN, BÚSQUEDA Y LECTURA DE ANTECEDENTES, BÚSQUEDA REFINADA, BúSQUEDA POR REFERENCIAS, DESCARTE DE ARTíCULOS IRRELEVANTES, Y DEFINICIÓN DE GRUPOS POTENCIALMENTE AGREGABLES.

Entre las recomendaciones incluidas en esta fase, se encuentra un conjunto de recomendaciones sobre cómo utilizar estrategias de búsqueda óptimas, que incluyen recomendaciones para: seleccionar las bases de datos bibliográficas, seleccionar los campos de búsqueda, establecer el universo de búsqueda y definir la cadena de búsqueda.

Las salidas finales de esta fase son: los GCA conteniendo el conjunto de artículos relacionados con la pregunta de revisión, la estrategia de búsqueda documentada y las estadísticas de búsqueda.

\subsubsection{Fase de Extracción de Datos}

El propósito de esta fase es recolectar los datos más relevantes de los experimentos que se encuentran incluidos en un GCA seleccionado al final de la fase de BúSQUEDA. Para alcanzar este objetivo, la extracción de datos incluye dos tipos de lectura: 
- Un ciclo de lectura que busca identificar únicamente los datos relacionados con la tarea, el tipo de sujeto, los niveles y variables respuesta de los experimentos. Con estos datos, es posible agrupar en clusters de lectura los experimentos que son más parecidos.

- Uno o más ciclos de lectura donde el revisor se concentra en aquellos clusters que posean suficientes experimentos, para extraer el resto de los datos relevantes para la revisión.

Para acometer estos ciclos de lectura la fase incluye las siguientes actividades: LECTURA SUPERFICIAL,

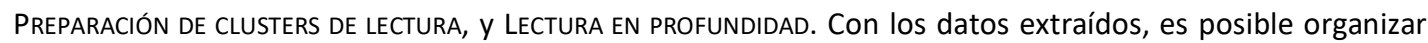
los experimentos en grupos muy similares en cuanto al tipo de sujeto, la tarea experimental, los tratamientos ensayados y la métrica evaluada. Esta similitud entre los experimentos determina grupos potencialmente agregables (GPA), ya que estos grupos son prometedores para la agregación. Durante la fase de SíNTESIS DE DATOS los GPAs seleccionados por los revisores serán agregados para obtener las evidencias. Debido a que la agregación requiere conocer los resultados cuantitativos y cualitativos de los experimentos contenidos en un GPA, durante la fase de extracción se realiza la ORGANIZACIÓN DE LOS DATOS, donde se resumen los resultados requeridos, así como el contexto de los experimentos.

Al mismo tiempo que se realiza la lectura de los experimentos, la fase incluye también actividades que tienen como propósito lograr la estandarización de la terminología. Para ello se realiza la DESCRIPCIÓN Y AGRUPAMIENTO DE CONCEPTOS, a fin de establecer un vocabulario o terminología común para todos los experimentos.

La salida final de esta fase está compuesta por los GPAs identificados y los resúmenes de datos y contexto de los experimentos.

\subsubsection{Fase de Valoración de la Calidad}

El propósito de esta fase es asignar un valor de calidad a cada uno de los estudios obtenidos durante la búsqueda, con el fin de tomar decisiones acerca de su participación y su contribución en la Síntesis de Datos. La asignación del nivel de calidad de un estudio se basa en las siguientes premisas generales:

- Los experimentos controlados que no presenten los datos requeridos para la agregación, serán eliminados durante la Fase Búsqueda o Extracción de datos. Por lo tanto, el nivel de calidad Baja será reservado para los cuasi-experimentos.

- La valoración del nivel de calidad se realizará sobre la base de las variables que resultaron fuertemente correlacionados con la calidad en el estudio realizado en esta investigación.

Como resultado final, se obtendrá un formulario con los ítems de calidad evaluados y el nivel de calidad asignado 


\subsubsection{Fase de Síntesis de Datos}

Esta fase tiene como propósito obtener nuevas evidencias a partir de los experimentos incluidos en un GPA. Para ello, los experimentos de cada GPA seleccionado son agregados utilizando la técnica de agregación más adecuada a las características del grupo, con base en los datos disponibles, y en la fiabilidad y el poder estadístico de cada una de las técnicas para el conjunto de datos que se desea agregar.

Debido a que durante la síntesis se debe lidiar con la heterogeneidad entre los experimentos, la fase propone re-agrupar los experimentos de un GPA en sub-grupos homogéneos, con base en indicadores estadísticos (tales como $\mathrm{Q}$ e $\mathrm{I}^{2}$ ) y en el análisis gráfico de la consistencia entre los efectos individuales y el efecto combinado. Una vez que se cuenta con un grupo de experimentos homogéneos, es posible generar una evidencia acerca del efecto de los tratamientos, y las condiciones para la misma. Cada agregación es registrada en una Plantilla de agregación.

Para llegar a obtener las evidencias asociadas a un GPA, las actividades a seguir en esta fase incluyen: Seleccionar el GPA a Agregar, Seleccionar el método de Agregación, y Agregar estudios usando el método.

Para que las evidencias obtenidas puedan ser útiles, éstas deben ser clasificadas según su nivel de confianza; la cual estará determinada por la calidad de los estudios y la fiabilidad/poder estadístico del método utilizado para la agregación. Esta clasificación es realizada a través de la actividad CoNSOLIDAR Y CLASIFICAR LAS EVIDENCIAS OBTENIDAS.

Si bien, por requerimiento de las técnicas de agregación, las evidencias generadas para un GPA están relacionadas con el efecto de dos tratamientos (niveles) sobre una métrica específica, la diversidad de métricas de la que se habló en la sección 5.1 puede llevar a que se generen un gran número de evidencias difíciles de relacionar; por ello se propone una actividad para COMBINAR EVIDENCIAS que genere un resumen de las evidencias obtenidas para todas las métricas relacionadas con una misma variable respuesta.

La salida de esta fase son las evidencias resumidas por nivel o variable respuesta, acompañadas por un nivel de confianza.

\subsubsection{Fase de Reportes}

El propósito de esta fase es generar el informe de la RS. Para ello se tomarán los resultados generados en cada una de las fases conducidas durante el proceso.

La salida de esta fase es el informe de revisión, el cual resume los criterios utilizados y los resultados obtenidos. 
Una vez definidas las fases del proceso propuesto, es conveniente definir quién será responsable de las actividades involucradas y cuáles deben ser sus características.

En la próxima sección se describen los criterios a aplicar en cada una de las fases descritas en esta sección para decidir acerca de la continuidad del proceso.

\subsubsection{Hitos del proceos}

Como se ha descrito en el MARCO TEÓRICO y el ESTADO DE LA CUESTIÓN, UNA RS debe incluir métodos y actividades que garanticen la obtención de resultados no sesgados; por otra parte, esto implica una inversión considerable de tiempo y otros recursos. Los revisores deben ser capaces de justificar el esfuerzo de continuar con la revisión en determinados puntos del proceso o si se incurre en ciertas condiciones que no aseguren que se cumpla el objetivo.

Por lo anterior, en esta investigación se propone un conjunto de hitos en los cuales se debería evaluar el cumplimiento de un determinado objetivo asociado a la fase en la que se encuentra el proceso, o alguno de sus entregables. Cada hito involucra uno o más criterios que deben ser evaluados para decidir si continuar con el proceso o cancelarlo (véase Tabla 5.2). Estos hitos son representados en el proceso como decisiones que llevan a continuar con la siguiente actividad/fase o llevan a la finalización del proceso (véase Figuras 5.1, 6.1, 7.1, 8.1, y 9.1).

Tabla 5.1. Hitos del proceso de revisión

\begin{tabular}{|c|c|c|c|}
\hline Fase & & Hito & Criterios de continuidad/parada del proceso \\
\hline Búsqueda & $\boldsymbol{\Delta}$ & $\begin{array}{lrr}\text { Pregunta } & \text { de } & \text { Revisión } \\
\text { definida } & \text { y } & \text { GCA } \\
\text { disponibles } & & \\
\end{array}$ & $\begin{array}{l}\text { - Al finalizar la actividad de DESCARTE DE ARTíCULOS } \\
\text { IRRELEVANTES, ¿Es posible definir al menos un GCA con } \\
\text { suficientes experimentos relacionados con el tema } \\
\text { /pregunta de revisión? } \\
\text { - Al finalizar la FASE DE BúSQUEDA, ¿se cuenta con una } \\
\text { pregunta de revisión bien definida? ¿se cuenta con } \\
\text { unos criterios de inclusión/exclusión de estudios } \\
\text { claros? }\end{array}$ \\
\hline $\begin{array}{l}\text { Extracción de } \\
\text { Datos }\end{array}$ & $\Delta$ & $\begin{array}{ll}\text { GPAs y datos } \\
\text { experimentales } \\
\text { disponibles }\end{array}$ & $\begin{array}{l}\text { - Al finalizar las actividades de LECTURA SUPERFICIAL y } \\
\text { LECTURA EN PROFUNDIDAD, ¿existen experimentos } \\
\text { disponibles que no han sido excluidos por problemas } \\
\text { de reporte de los datos y resultados experimentales? } \\
\text { - } \quad \text { Luego de la PREPARACIÓN DE CLUSTERS DE LECTURA, ¿existen } \\
\text { clusters de lectura con más de un experimento? } \\
\text { - Al finalizar la fase de EXTRACCIÓN DE DATOS, ¿se cuenta } \\
\text { con GPAs disponibles que sean de interés para los } \\
\text { revisores? }\end{array}$ \\
\hline
\end{tabular}




\begin{tabular}{|c|c|c|c|}
\hline Fase & & Hito & Criterios de continuidad/parada del proceso \\
\hline $\begin{array}{l}\text { Valoración de } \\
\text { la calidad }\end{array}$ & $\boldsymbol{\Delta}$ & $\begin{array}{l}\text { Experimentos de } \\
\text { calidad media-alta } \\
\text { disponibles }\end{array}$ & $\begin{array}{l}\text { - Luego de aplicar la escala de calidad, ¿existen } \\
\text { experimentos o cuasi-experimentos con un nivel de } \\
\text { calidad media-alta? }\end{array}$ \\
\hline $\begin{array}{l}\text { Síntesis de } \\
\text { Datos }\end{array}$ & $\boldsymbol{\Delta}$ & $\begin{array}{l}\text { Evidencias obtenidas } \\
\text { con un nivel de } \\
\text { confianza medio-alto }\end{array}$ & $\begin{array}{l}\text { - Durante la actividad AGREGAR EXPERIMENTOS USANDO EL } \\
\text { MÉTODO, ¿se dispone de grupos de experimentos } \\
\text { homogéneos? } \\
\text { - Al CONSOLIDAR Y CLASIFICAR LAS EVIDENCIAS OBTENIDAS, } \\
\text { ¿existe al menos una evidencia cuyo nivel de } \\
\text { confianza haya sido establecido como medio-alto? } \\
\text { - Al finalizar la SínTESIS DE DATOS, ¿se ha generado al } \\
\text { menos una evidencia? }\end{array}$ \\
\hline
\end{tabular}

\subsubsection{El equipo de revisión}

Las actividades involucradas en una RS no deberían ser acometidas por una sola persona (J. P. T. Higgins \& S. Green, 2006). Tales actividades deben ser realizadas por un grupo de investigadores con las habilidades y el conocimiento necesarios para producir una RS de calidad (IOM, 2011). En este proceso se requiere de la participación y la colaboración de varios tipos de expertos en diferentes áreas, tales como: el tópico bajo estudio, la metodología de RS, Estadística, Ciencias de la información, mediciones y evaluación de tecnología, investigación cualitativa, entre otras.

Por lo anterior, los miembros de un equipo de RS varían en cuanto a los roles profesionales y la profundidad del conocimiento que deben poseer (Murphy et al., 1998). Con base en las recomendaciones de (CRD, 2009; J. P. T. Higgins \& S. Green, 2006; IOM, 2011; McGowan \& Sampson, 2005), en esta investigación se ha propuesto el siguiente conjunto de roles: Líder, Experto en búsquedas, Experto en el tópico, Recolector de datos, Evaluador, y Experto en agregación. Como puede observarse, los roles propuestos están fuertemente relacionados con las fases propuestas para el proceso de RS; donde cada una de las fases es acometida por al menos un rol específico a esa fase. La Tabla 5.1 resume estos roles y las actividades asociadas a ellos.

Tabla 5.2. Roles propuestos para el equipo de RS y actividades asociadas

\begin{tabular}{|c|c|c|}
\hline Rol & Fase & Actividades \\
\hline Líder & Búsqueda & $\begin{array}{l}\text { - } \quad \text { Determinación del tema } \\
\text { - } \quad \text { Selección de GCA } \\
\text { - } \quad \begin{array}{l}\text { Establecer la pregunta de revisión y los criterios de } \\
\text { inclusión/exclusión }\end{array}\end{array}$ \\
\hline & Síntesis de datos & - $\quad$ Seleccionar GPA \\
\hline
\end{tabular}




\begin{tabular}{|c|c|c|}
\hline & Reportes & - $\quad$ Generar Informe de Revisión \\
\hline \multirow[t]{2}{*}{ Experto en búsquedas } & Búsqueda & $\begin{array}{ll}\text { - } & \text { Búsqueda preliminar de estudios por tema } \\
\text { - } & \text { Búsqueda refinada } \\
\text { - } & \text { Descarte de estudios irrelevantes } \\
\text { - } & \text { Búsqueda y lectura de antecedentes }\end{array}$ \\
\hline & Reportes & - $\quad$ Generar Informe de Revisión \\
\hline \multirow[t]{2}{*}{ Experto en el tópico } & Búsqueda & $\begin{array}{l}\text { - } \quad \text { Búsqueda preliminar de estudios por tema } \\
\text { - } \quad \text { Búsqueda refinada }\end{array}$ \\
\hline & Extracción & - $\quad$ Definición y agrupamiento de conceptos \\
\hline \multirow[t]{2}{*}{ Recolector de datos } & Extracción & $\begin{array}{ll}- & \text { Lectura superficial } \\
\text { - } & \text { Preparación de clusters } \\
\text { - } & \text { Lectura en profundidad } \\
\text { - } & \text { Descripción y Agrupamiento de conceptos } \\
\text { - } & \text { Organización de datos }\end{array}$ \\
\hline & Reportes & - $\quad$ Generar Informe de Revisión \\
\hline Evaluador & $\begin{array}{l}\text { Valoración de la } \\
\text { calidad }\end{array}$ & - $\quad$ Asignación del nivel de calidad \\
\hline \multirow[t]{2}{*}{$\begin{array}{l}\text { Especialista } \\
\text { agregación }\end{array}$} & Síntesis de datos & $\begin{array}{ll}- & \text { Seleccionar GPA } \\
\text { - } & \text { Seleccionar el método de agregación } \\
\text { - } & \text { Agregar } \\
\text { - } & \text { Consolidar y clasificar evidencias } \\
\text { - } & \text { Combinar evidencias }\end{array}$ \\
\hline & Reportes & - Generar Informe de Revisión \\
\hline
\end{tabular}

Idealmente, cada uno de estos roles debería ser desempeñado por un participante diferente dentro del proceso de revisión. No obstante, la separación de roles estará determinada por los recursos con los que se cuente en el equipo de revisión. En cualquier caso, los perfiles y criterios de éxito de cada uno de estos roles deben ser considerados en la conformación del equipo de RS y en la propuesta de medición del proceso de revisión. El perfil de cada uno de estos roles es descrito a continuación.

\section{Líder}

Es el encargado de promover y coordinar la RS. De acuerdo con (IOM, 2011), este rol debe poseer conocimientos y experiencia en los métodos relacionados con la RS y capacidad para la toma de decisiones.

Como se describe en la tabla 5.1, el líder será responsable de las actividades estrechamente relacionadas con la definición del objetivo de revisión, la pregunta de revisión y los criterios de 
inclusión/exclusión de estudios; lo que supone ejercer funciones de supervisión y coordinación, así como la ejecución de algunas actividades específicas. Sus criterios de éxito son:

- $\quad$ Proceso de revisión eficiente.

- $\quad$ Datos experimentales confiables generados para el posterior proceso de síntesis.

- $\quad$ Obtener evidencias adecuadamente.

\section{Experto en búsquedas}

Según (McGowan \& Sampson, 2005), los buscadores expertos son una parte importante del equipo y son cruciales durante el todo el proceso de RS (desde el desarrollo de la propuesta y la pregunta de investigación hasta la publicación). Necesita conocer las particularidades de la estructura de datos y las funciones de las bases de datos bibliográficas y especializadas, así como los aspectos técnicos y metodológicos de la búsqueda.

Es el encargado de la localización de los estudios empíricos en las bases de datos bibliográficas, así como en otras fuentes (p.e. bibliografías, Internet, etc.). Es responsable del desarrollo de estrategias de búsqueda óptimas, incluyendo: selección de repositorios, campos de búsqueda, cadena de búsqueda y el universo de búsqueda. También es responsable de documentar la estrategia, determinar las propiedades de las búsquedas utilizadas y mantener el control de las referencias utilizadas durante la RS (véase Tabla 5.1). Sus criterios de éxito son:

- Proceso de búsqueda óptima (alta recuperación y alta precisión).

\section{Experto en el tópico}

Los autores que abordan el problema de la definición del equipo de RS, tales como (CRD, 2009; J. P. T. Higgins \& S. Green, 2006; IOM, 2011; McGowan \& Sampson, 2005), coinciden en la conveniencia de contar con un experto en el tópico. En una RS se requieren conocimientos acerca del tópico de interés, así como de la terminología relacionada con el mismo y de las posibles fuentes de información para la búsqueda de estudios primarios. Lo anterior hace necesario contar con la asesoría de un especialista en estas áreas, el cual puede o no formar parte del equipo de revisores.

Es un experto que realiza funciones de soporte al Experto en búsquedas, específicamente en el desarrollo de la cadena de búsqueda adecuada al tema de revisión seleccionado. Para el caso del proceso de RS que se propone en esta investigación, debe poseer conocimientos avanzados en el área de IS o manejo de la literatura especializada (p.e. SWEBOK, terminología IEEE, etc.). Sus funciones están relacionadas tanto con búsquedas preliminares como con búsquedas refinadas, donde se requiera el 
análisis de artículos para la obtención de términos de búsqueda. Su experticia será también aplicada a la Definición y agrupamiento de conceptos (véase Tabla 5.1). Sus criterios de éxito son:

- $\quad$ Proceso de búsqueda óptima (alta recuperación y alta precisión)

\section{Recolector de datos}

Una vez seleccionados los estudios que participarán en la RS, los datos experimentales deben ser extraídos de los mismos y presentados de una manera estándar. Aunque los autores anteriormente mencionados no incluyen un rol para el encargado de la extracción de datos, los estándares propuestos por (IOM, 2011) establecen que deberían incluirse tantos expertos como sea necesario.

En esta investigación se ha considerado que para la Extracción de datos es requerido un no sólo un profundo conocimiento en IS y en los diversos términos relacionados con las tecnologías ensayadas, sino también en experimentación, específicamente los componentes del diseño experimental (factores, variables respuesta, etc.). Por lo que se ha definido un rol específico para esta tarea; el cual debe poseer experticia, imparcialidad y objetividad en la obtención de los datos relevantes de cada experimento seleccionado. Las actividades asociadas con este rol son mostradas en la Tabla 5.1. Sus criterios de éxito son:

- Completitud de los datos experimentales obtenidos.

- Uniformidad y estandarización de los datos experimentales para facilitar la síntesis

\section{Evaluador}

Es el rol encargado de aplicar la escala de calidad a cada uno de los estudios involucrados en el grupo a agregar. Se basa en los datos extraídos previamente. Debe conocer sobre los elementos de calidad que están siendo evaluados.

Sus criterios de éxito son:

- $\quad$ Asignación objetiva del nivel de calidad de cada estudio.

\section{Especialista en agregación}

Algunos autores como (IOM, 2011; McGowan \& Sampson, 2005) establecen que uno de los miembros que deben ser incluidos en el equipo de RS es el estadístico o experto en métodos cuantitativos. Como una generalización de estos roles se ha propuesto la participación de un Especialista en agregación, del cual se espera que posea conocimientos en diversas técnicas estadísticas de agregación (meta-análisis). 
Este rol es el encargado tanto de la Síntesis de datos aplicada a GPA, como de la combinación de estas evidencias obtenidas (véase Tabla 5.1). Los criterios de éxito para este rol son los siguientes:

- $\quad$ Evidencias válidas obtenidas de experimentos con alto nivel de fiabilidad.

- $\quad$ Evidencias soportadas por el mayor número posible de experimentos.

- Recomendaciones prácticas disponibles para los profesionales.

- $\quad$ Recomendaciones aplicables a una o más tareas del proceso de desarrollo.

Después de describir de manera general el proceso de RS propuesto en esta investigación, se requiere conocer las particularidades de cada fase así como las actividades específicas y la documentación asociada a cada fase. Estos detalles son descritos en los siguientes capítulos (6 a 10). 


\section{CAPITULO 6. FASE DE BÚSQUEDA}

En este capítulo se presenta la FASE DE BÚSQUEDA, la primera del proceso de RS propuesto en esta investigación. La búsqueda o localización de estudios primarios es una fase que ha sido común en todos los procesos de RS encontrados en la literatura consultada y que han sido analizados en el CAPíTULO 3 ESTADO DE LA CUESTIÓN.

Como ya se explicó, de manera muy general, en el Capítulo 5, existen algunos problemas para aplicar la FASE DE BúSQUEDA en IS, tal como es propuesta actualmente en los procesos de RS. En la sección 6.1 CARACTERÍSTICAS ESPECÍFICAS DE IS QUE PROVOCAN VARIACIONES EN LA FASE DE BúSQUEDA se describen con más detenimiento aquellos problemas que fueron identificados en la sección 5.1 y que atañen directamente a esta fase. Este análisis servirá de base para entender las mejoras que se incorporan a esta fase.

Una vez que se han identificado los problemas o limitaciones de los procesos de RS actuales en cuanto a la búsqueda de estudios primarios en IS, ha sido posible establecer los mecanismos pertinentes para solventar tales limitaciones. La sección 6.2 - APROXIMACIÓN A LA SOLUCIÓN plantea las respuestas a cada una de las limitaciones identificadas en las secciones anteriores.

Tales respuestas son posteriormente estructuradas en forma de actividades y tareas dentro de la fase, la cual es descrita en la sección 6.3 - ActIVIDADES PROPUESTAS PARA LA FASE DE BúSQUEDA. Esta sección describe los fundamentos de la fase así como las actividades propuestas en detalle (hasta el nivel de tareas y pasos) y los formularios sugeridos para documentar la información generada durante la ejecución de las actividades. La fase se encuentra dividida en diez actividades que a su vez se agrupan en dos escenarios.

En el primer escenario, el revisor comienza la revisión con un objetivo muy general (apenas tiene idea del tema o la tecnología de interés). A partir de esto se realiza una búsqueda y posteriormente la selección de aquellos experimentos que son relevantes al tema de revisión planteado. Los experimentos que han sido localizados son entonces agrupados según el tópico o sub-tema específico, de manera que el revisor pueda apreciar: 1) los tópicos sobre los cuales se ha experimentado, 2) la cantidad de experimentos disponibles por cada uno de ellos, con base en estos grupos el revisor puede establecer un objetivo de revisión más preciso (incluyendo la pregunta de revisión y los criterios de inclusión/exclusión).

En el segundo escenario, el revisor cuenta un objetivo específico de revisión, lo cual permite localizar tanto las RS previas como los experimentos de interés. Esto se realiza a través de una búsqueda con términos muy específicos, la cual puede ser completada con una búsqueda por referencias. Luego de realizar esta búsqueda de experimentos el revisor debe proceder a la selección de aquellos que sean relevantes y a la organización de los mismos en grupos que puedan ser candidatos para una agregación durante la fase de SínTESIS DE DATOS. 


\subsection{Características específicas de la IS que provocan variaciones en la Fase de Búsqueda}

Una de las actividades más importantes de una RS es la identificación de los estudios primarios. Su importancia radica en que a través de esta actividad se obtendrán los datos que, luego de un proceso de agregación o combinación, producirán nuevas evidencias acerca de la tecnología de interés.

Como se describe en esta sección, la búsqueda de experimentos en IS no es comparable a la realizada en otras disciplinas, tales como Medicina, Psiquiatría, Enfermería, Educación, entre otras; por lo que las actividades utilizadas en tales disciplinas no son directamente aplicables a la búsqueda de experimentos

en IS. Estas actividades deben ser analizadas a la luz de las características particulares de la ISE para proponer un conjunto de actividades y tareas adecuadas.

Por otra parte, puede observarse también en el ESTADO DE LA CUESTIÓN que las metodologías específicas para IS (J. Biolchini et al., 2005; B. Kitchenham, 2004) no analizan exhaustivamente tales características ni presentan una propuesta al respecto.

Es por esto que en esta investigación el primer paso para definir la fase de BúSQUEDA ha sido identificar las características de la ISE, que la hacen diferente a otras disciplinas basadas en evidencias y que afectan la búsqueda de experimentos. Como se adelantó en el Capítulo 5, estas características son:

1. Escasez de experimentos controlados que hayan sido adecuadamente reportados.

2. Dificultad para localizar experimentos a través de las bases de datos o bases bibliográficas existentes.

3. Terminología poco estandarizada en la publicación de experimentos, tanto para referirse a la tecnología ensayada como a los elementos del estudio, por ejemplo, el tipo de estudio.

4. Dificultad para establecer el objetivo o la pregunta de la RS tempranamente, lo cual dificulta el desarrollo de un protocolo de revisión.

Estas características son descritas en detalle a continuación.

\subsubsection{ESCASEZ DE EXPERIMENTOS REPORTADOS ADECUADAMENTE}

Como se describió en el ESTADO DE LA CUESTIÓN, la conducción de experimentos y RS en algunas disciplinas como Medicina, Psiquiatría o Educación, dan muestra de una amplia experiencia y madurez. Una ejemplo de ello es la Cochrane Library, base de datos on-line que cuenta para la fecha con más 7000 revisiones y más de 420 mil experimentos controlados sobre diferentes temas de la Salud (The Cochrane Collaboration, 2017). Por lo tanto, en estas disciplinas es muy fácil obtener experimentos y, por consiguiente, una muestra lo suficientemente grande de sujetos como para obtener conclusiones válidas. De hecho, y debido a esta misma abundancia, existe el problema de que, si la selección de estudios no se 
lleva a cabo de forma cuidadosa, las piezas de conocimiento obtenidas tras la síntesis puedan estar afectados por el sesgo de selección, al observarse diferencias significativas entre los grupos comparados. El riesgo de incurrir en este tipo de distorsiones lleva a los revisores de tales disciplinas a ser muy rigurosos en la inclusión de estudios

Por el contrario, en IS existe una reducida cantidad de experimentos publicados. Como ejemplo, obsérvese que el número de experimentos almacenados en la Cochrane Library para el período 1993-2002 es de poco más de 241.700 (The Cochrane Collaboration, 2010); mientras que, para el mismo período, en IS (Sjøberg et al., 2005) identificaron sólo un conjunto de 103 experimentos.

Por otra parte, muchos de los experimentos publicados en IS muestran falta de rigurosidad en la descripción de los métodos utilizados y los resultados obtenidos (T. Dybå, Dingsøyr, \& Hanssen, 2007), lo cual compromete la confiabilidad de los datos que éstos proporcionan y, por consiguiente, la SíNTESIS DE DATOS.

Debido precisamente a la escasez de experimentos en IS, muchas de las RS que se conducen en esta área incluyen tanto experimentos controlados como otros tipos de estudios primarios (p.e. casos de estudio, estudios observacionales, etc.) los cuales proporcionan información estadística limitada que restringe el uso del meta-análisis comprometiendo en muchos casos la validez de sus resultados (CRD, 2009; Cruzes \& Dyba, 2010).Tal problemática ha llevado a los investigadores a plantearse otros tipos de revisiones menos exigentes en cuanto a la calidad y los datos requeridos; como es el caso de las revisiones de alcance (Petticrew \& Roberts, 2007), también conocidos como estudios de mapeo (B. Kitchenham, 2004). Sin embargo, este tipo de revisiones están orientadas exclusivamente a establecer un catálogo de estudios en relación a un tema; por lo que no llegan a satisfacer el objetivo de generar nuevas evidencias.

La disponibilidad de experimentos controlados reportados adecuadamente constituye entonces una limitación importante para la generación de nuevas evidencias a través de RS en IS. Por lo tanto, las metodologías existentes en otras áreas no pueden ser directamente aplicables. Por otra parte, las metodologías para RS propias de la disciplina de IS (J. Biolchini et al., 2005; B. Kitchenham, 2004) tampoco llegan a proponer una solución que permita resolver estos problemas.

\subsubsection{BASES DE DATOS BIBLIOGRÁFICAS POCO ADECUADAS}

Una de las ventajas que encuentran los revisores del área de las Ciencias de la Salud al momento de localizar experimentos sobre algún tema de interés, es la disponibilidad de bases de datos especializadas no sólo en el área sino también en el tipo de estudio, tales como: MEDLINE, AIDSLINE, CANCERLIT, Dissertation Abstracts Online y TOXLINE, entre otras. Bases de datos como éstas centralizan y organizan multitud de estudios relacionados con esta área. Por otra parte, cuentan con un importante repositorio de experimentos que es proporcionado por The Cochrane Central Register of Controlled Trials (CENTRAL) (Pilkington, 2007; Sampson et al., 2011). 
Es por ello que tales bases de datos constituyen prácticamente un estándar de facto para la búsqueda de estudios empíricos en general y, en particular, de experimentos (p.e. MEDLINE, CENTRAL). Por lo tanto, los revisores en estas áreas no necesitan preocuparse de la selección de las bases de datos a utilizar; lo cual se ve reflejado en que las metodologías y procesos para RS existente no proporcionen orientación para tal selección.

No obstante, la situación en IS es muy diferente a la de aquellas áreas o disciplinas antes mencionadas. En este sentido, se han identificado dos inconvenientes: el primero de ellos en relación a la cobertura de las bases de datos usadas en RS en IS, y el segundo en relación al desempeño de las mismas.

\subsubsection{Cobertura de las bases de datos bibliográficas}

En IS no se cuenta con bases de datos especializadas en esta disciplina; debiendo hacerse uso de bases de datos bibliográficas del área de Ingeriría tales como ACM Digital Library o IEEE Xplore, así con otras aún más generalistas como ISI Web of Science o SCOPUS, que agrupan publicaciones de diferentes ciencias o áreas de conocimiento.

Esto impone la necesidad de delimitar muy bien el universo de búsqueda (las restricciones de: área, tipo de publicación y rango de años, con las cuales se realiza la búsqueda) a fin de no obtener una gran cantidad de resultados irrelevantes ni dejar por fuera algunas disciplinas relacionadas directa o indirectamente con la IS. Para delimitar el universo de búsqueda, se requiere filtrar la búsqueda; sin embargo, no todas las bases de datos usadas en IS poseen opciones avanzadas de filtrado de la búsqueda, por lo que frecuentemente es difícil delimitarla adecuadamente.

\subsubsection{Desempeño de las bases de datos bibliográficas}

Las bases de datos utilizadas en las RS en IS suelen presentar problemas con los resultados o ser poco fiables (T. Dybå et al., 2007). Éstas no siempre cuentan con el texto completo del artículo y en muchos casos tampoco cuentan con su resumen o con "palabras claves" asociadas al mismo.

Como éstas, otras limitaciones asociadas a la localización de publicaciones en IS han sido ya identificadas por algunos autores. Por ejemplo, (Brereton et al., 2007) comentan limitaciones respecto al modelo de organización y el uso de expresiones booleanas en los motores de búsqueda de las bases de datos bibliográficas. Su experiencia con algunas de ellas (IEEEXplore, ACM Digital Library y ScienceDirect) y otros servicios de indexación (Google Scholar, Citeseer library, Keele University's electronic library, Inspec y El Compendex) les lleva a concluir que los motores de búsqueda actuales en IS no están diseñados para dar soporte a las RS de la literatura.

Por otra parte, en (Bailey et al., 2007) se analizó el solapamiento entre los resultados de las bases de datos bibliográficas para estudios en IS, enfocándose en un grupo de bases de datos bibliográficas y 
servicios de indexación (IEEEXplore, ACM Digital Library, ScienceDirect, Google Scholar, Citeseer y Web of Science) y determinando el solapamiento entre ellas en diferentes áreas de la IS y el impacto de tal solapamiento al momento de completar una RS. Como resultado colateral, los autores identificaron ciertas limitaciones para las búsquedas, tales como interfaces de usuario inconsistentes, limitaciones del número de resultados presentados y el número de veces en que algunos motores de búsqueda estuvieron no disponibles, porque se encontraban ocupados o fuera de servicio.

En el análisis que se ha realizado como parte de este trabajo, también se han identificado diferencias significativas entre algunas bases de datos (IEEEXplore, ACM Digital Library, SpringerLink, Scopus, ISI WebOfScience y ScienceDirect) que podrían afectar los resultados de una búsqueda. Las dos limitaciones más importantes que se encontraron fueron (O. Dieste \& Grimán, 2007; O. Dieste, Grimán, \& Juristo, 2008):

- Recursos bibliográficos limitados. Algunas bases de datos se limitan sólo a publicaciones de una editorial o de un grupo limitado de editoriales. Por tanto, estas bases de datos no cubren un amplio espectro de publicaciones. Éste es el caso de las bases de datos IEEEXplore ${ }^{\circledR}$ y ACM Digital Library, las cuales indexan un grupo pequeño de revistas y actas de conferencias que han sido editadas por IEEE y $A C M$, respectivamente. Esta limitación es especialmente cierta para SpringerLink y ScienceDirect ${ }^{\circledR}$, las cuales indexan un grupo aún menor de revistas publicadas por Springer y Elsevier, respectivamente. Esto representa una limitación para las RS en IS en virtud de que los experimentos que eventualmente pueden llegar a ser potencialmente útiles para una RS suelen ser publicados en muchas fuentes distintas. Esta limitación es sin duda un impedimento para las búsquedas en una RS, ya que para lograr una cobertura aceptable del universo de búsqueda, que incluya todas las publicaciones potencialmente de interés para la RS, cada búsqueda tiene que ser ejecutada varias veces en diferentes bases de datos para luego combinar los resultados de todas ellas.

- Resúmenes o textos de los artículos incompletos. El resumen o texto completo de los artículos no se encuentra siempre disponible en las bases de datos bibliográficas. Esto representa una debilidad importante, ya que el texto completo del artículo es necesario para la RS. En (O. Dieste \& Grimán, 2007; O. Dieste, A. Grimán, \& N. Juristo, 2008) tanto IEEEXplore como ACM Digital Library presentaron este problema.

Otros problemas que pueden tener impacto en los resultados de las búsquedas son particulares a bases de datos concretas. Dichos problemas se presentan a continuación para cada una de las bases de datos analizadas (O. Dieste \& Grimán, 2007; O. Dieste, A. Grimán, \& N. Juristo, 2008):

- IEEEXplore presenta las siguientes limitaciones:

- $\quad$ En el modo de Búsqueda básica: 
- Para localizar artículos, realiza la búsqueda en todos sus campos. Como se verá más adelante, al realizar la búsqueda en todos los campos del artículo la precisión de los resultados disminuye.

- No realiza la búsqueda de los términos especificados, tanto en singular como en plural. Esto implica que la forma plural de cada uno de los términos en la cadena de búsqueda tiene que ser introducida por separado.

- $\quad$ En el modo de Búsqueda avanzada:

- El número máximo de resultados para una búsqueda está limitado a 500 documentos. Esto podría restringir el número de artículos relevantes que son obtenidos del universo de búsqueda.

- Los resultados pueden ser exportados únicamente de manera parcial; esto significa que se pueden seleccionar los resultados mostrados en una página pero no todos los resultados de la búsqueda. Esto produce que la operación de exportación a archivos de texto o Manejadores de Referencias (herramienta útil en una RS) sea muy ineficiente.

- ACM Digital Library, y especialmente su modalidad de Búsqueda avanzada, presenta las siguientes debilidades:

- El usuario no puede definir la búsqueda libremente. Sólo pueden realizarse búsquedas en campos pre-establecidos (título, resumen, revisión, toda la información). Esto constituye un serio inconveniente si se toma en cuenta que buscar exclusivamente en el título o exclusivamente en el resumen disminuirá la capacidad de recuperación de la búsqueda, mientras que buscar en todos los campos producirá un decremento de su precisión.

- El número de resultados está limitado a 200 documentos por búsqueda. Esto restringe la RS, ya que se trata de una cantidad muy pequeña en comparación con el universo de búsqueda, que puede llegar a incluir miles de artículos.

- El algoritmo de búsqueda falla cuando se trata de realizar una búsqueda con valores alternativos (valores enlazados a través de una cláusula O) en uno de los campos. En tales casos, los resultados de las búsquedas no son confiables e incluyen artículos que realmente no se corresponden con la condición de búsqueda especificada. Esto añade un esfuerzo adicional para el descarte de artículos irrelevantes.

- Los resultados de una búsqueda no pueden ser exportados a los formatos de texto o Manejadores de Referencias. Esto es un impedimento significativo para una RS.

- Busca todos los términos que tienen la misma raíz que el término especificado en la cadena; por ejemplo, si la cadena de búsqueda incluye el término experiment, localizará artículos que contengan los términos experimental, experimentation, experimentally, etc. Este modo de búsqueda tiene una 
alta recuperación; sin embargo, compromete la precisión. Por lo tanto, es preferible dejar a los investigadores la decisión de buscar por raíz o por palabras exactas.

- La base de datos de ISI Web of Knowledge es usada en un gran número de disciplinas. Además de la base de datos propia, proporciona acceso a otras bases de datos tales como Derwent Innovations Index ${ }^{\mathrm{SM}}$, BIOSIS Previews ${ }^{\circledR}$ y en especial a MEDLINE ${ }^{\circledR}$ con una poderosa máquina de búsqueda para identificar estudios clínicos. Sin embargo, presenta varias limitaciones para la búsqueda de experimentos en IS. Muchas de estas limitaciones podrían ser una consecuencia de los comienzos de ISI y su misión. ISI (acrónimo de Institute for Scientific Information) inicialmente vendía su índice de citas (y otros productos para estimar la productividad científica) antes de que existiera la Web. En este sentido, el soporte Web, aunque se ha extendido, continúa enfocándose en los autores, revistas, años y otros campos que no tienen relación con las búsquedas de contenido. Esto significa que:

- El término no puede ser buscado en el resumen o las palabras claves. Este es un factor limitante significativo para cualquier RS, como se verá más adelante.

- Aunque puede ser utilizada para buscar en más de una base de datos, no proporciona suficiente ayuda acerca de la cobertura de cada una de ellas o su solapamiento. Esto dificulta decidir cuál de ellas seleccionar.

- La semántica de comandos en la búsqueda avanzada es compleja, y el sistema no proporciona suficiente información acerca de tales comandos.

Las características y limitaciones anteriormente descritas, hacen necesario que se realice una cuidadosa selección de la(s) base(s) de datos bibliográfica(s) a ser utilizadas en cada RS particular; para lo cual se requerirá aplicar algunos criterios que permitan realizar esta selección adecuadamente. Sin embargo, tales criterios no son abordados en ninguna de las propuestas o metodologías analizadas en el ESTADO DE LA CUESTIÓN. De la misma manera no se toma en cuenta en tales propuestas la problemática asociada a la selección del universo de búsqueda en bases de datos generalistas como las utilizadas en las RS en IS.

\subsubsection{FALTA DE ESTANDARIZACIÓN DE LA TERMINOLOGÍA}

En el ESTADO DE LA CUESTIÓN puede observarse que algunas metodologías del área de Medicina (CC y CDR), así como otros trabajos relacionados (Dickersin, Scherer, \& Lefebvre, 1994; Haynes, Wilczynski, McKibbon, Walker, \& Sinclair, 1994), son capaces de proponer a los revisores estrategias y patrones para las cadenas de búsqueda.

Esto es posible gracias a la madurez que caracteriza tales disciplinas, producto de varias décadas de práctica, lo que ha derivado en una terminología bastante uniforme, que es compartida por la mayoría de los experimentadores. Un ejemplo de ello son los medical subject headings (MeSH), una iniciativa de la 
U.S. National Library of Medicine (NLM) que cuenta con más de 50 años y que ha establecido un vocabulario controlado para las publicaciones en medicina, siendo utilizado por un gran número de bases de datos para indexar los artículos existentes en un esquema jerárquico de temas especializados (US National Library of Medicine, 1999). NML también cuenta con otros proyectos como el Sistema de Lenguaje Médico Unificado (conocido como UMLS ${ }^{\circledR}$ ) que integra y distribuye terminología clave y estándares de clasificación y codificación que faciliten la creación de sistemas y servicios de información biomédica, incluyendo los registros electrónicos en el área de Ciencias de la salud (US National Library of Medicine, 2009).

Esto influye en que los revisores de estas disciplinas puedan localizar experimentos fácilmente, utilizando cadenas de búsqueda razonablemente estandarizadas en las bases de datos de las que disponen (p.e. CENTRAL, MEDLINE, entre otros). Tales cadenas suelen contener todos o algunos de los componentes de la pregunta de revisión (i.e. Participantes, Intervenciones, Resultados, y Diseño del estudio) (CRD, 2009; J. P. T. Higgins \& S. Green, 2006). Como ejemplo de ello se han mencionado en el ESTADO DE LA CUESTIÓN varios trabajos relacionados con la propuesta de cadenas de búsquedas de alta recuperación para diferentes temas médicos, que incluyen términos muy específicos relacionados tanto con el tratamiento ensayado como con el diseño del estudio (experimento controlado aleatorizado, estudio de cohorte, etc.) (Dickersin et al., 1994; Haynes et al., 1994), los cuales son, entre los componentes de la pregunta de revisión, los mínimos a considerar a la hora de realizar una búsqueda

Por el contrario, los artículos que publican experimentos en IS son generalmente poco rigurosos en el uso de la terminología, tanto la relacionada con los tratamientos estudiados como con el tipo de estudio, tipo de sujeto y otros aspectos del experimento; llegando incluso a no establecer adecuadamente el área en la que están encuadrados (por ejemplo, requisitos, diseño, etc.) (A. Jedlitschka \& D. Pfahl, 2005). Esto deriva en una dificultad para localizar experimentos relevantes.

Para lograr localizar un número suficiente de estos estudios, los revisores tienden a aplicar estrategias intuitivas. Una de ellas es el uso de cadenas de búsqueda muy generalistas que incluyen términos relacionados con el tema de interés (por ejemplo, pruebas de software) más que términos que hagan alusión a los tratamientos específicos sobre los cuales desean realizar la revisión (por ejemplo, técnicas de prueba de caja blanca) (A. Davis, Dieste, Hickey, Juristo, \& Moreno, 2006; Jørgensen \& Shepperd, 2007; Pedreira, Piattini, Luaces, \& Brisaboa, 2007). Si bien esta estrategia podría recuperar un número grande de estudios, una proporción considerable de ellos será seguramente irrelevante puesto que el uso de los términos será casuístico, por lo cual se requerirá de un gran esfuerzo de lectura para descartar tales artículos y seleccionar aquellos que son potencialmente útiles para la RS [REFs].

Por lo anterior, las propuestas existentes en otras disciplinas no llegan a ser útiles en la resolución de los problemas arriba descritos ya que no se ven obligados a abordar tal problemática. De la mima manera, puede observarse en el análisis presentado en el ESTADO DE LA CUESTIÓN que no existe ninguna propuesta de solución dentro de la IS. 


\subsubsection{DIFICULTAD PARA ESTABLECER UNA PREGUNTA DE REVISIÓN TEMPRANA}

Prácticamente todas las metodologías de RS descritas en el ESTADO DE LA CUESTIÓN, recomiendan definir la pregunta de revisión al comienzo del proceso. Para definir la pregunta de revisión suelen utilizarse cuatro componentes claves (Counsell, 1997; CRD, 2009; J. P. T. Higgins \& S. Green, 2006; Richardson et al., 1995): los tipos de participantes, los tipos de intervenciones, los tipos de variables respuesta o resultados de interés, y los tipos de diseño de los estudios (en adelante se hará referencia a estos componentes por su acrónimo inglés PIOS). Una vez que la pregunta de revisión es definida claramente en base a estos cuatro componentes (PIOS), es posible utilizar PIOS para definir las cadenas de búsqueda con términos asociados a cada uno de los componentes; establecer criterios de inclusión/exclusión de estudios; y definir los datos que deberán ser extraídos de los estudios primarios.

Por otra parte, (Pogue \& Yusuf, 1998.; Zanchetti \& Mancia, 1998) afirman que en la práctica los estudios primarios de los que se dispone para la revisión también influyen en la definición (o redefinición, en muchos casos) de la pregunta de revisión, de los objetivos específicos de la revisión, y de los criterios de inclusión/exclusión de estudios. Dependiendo del número y tipo de estudios identificados, el objetivo planteado a priori podrá o no satisfacerse. No obstante, los estudios que serán incluidos en una RS no llegan a conocerse por completo hasta muy avanzado el proceso de revisión.

De acuerdo con (J. P. T. Higgins \& S. Green, 2006), incluso en disciplinas muy maduras, como Medicina, se observa este problema, encontrándose que en pocas ocasiones puede realizarse una completa definición de tales aspectos (pregunta de revisión, objetivo, y criterios de inclusión/exclusión) de manera prospectiva siendo necesario localizar previamente los estudios primarios y utilizar el conocimiento de sus resultados en la definición de los aspectos antes mencionados.

En tales disciplinas el problema puede verse compensado por el hecho de que existen abundantes estudios empíricos, por lo que es bastante probable que una pregunta de revisión que ha sido planteada muy tempranamente sea respondida, ya que la probabilidad de que se localice un número suficiente de estudios de calidad aceptable y que se ajusten a los criterios establecidos en términos de PIOS tiende a ser alta.

No obstante, como ya se indicó anteriormente, éste no es el caso de la IS. En esta disciplina, a diferencia de otras disciplinas con amplia experiencia en la experimentación, no se cuenta aún con una cantidad de estudios empíricos considerable. Los estudios existentes presentan además una calidad de reporte cuestionable o su diseño no permite utilizar métodos de agregación confiables. En tales condiciones, proponer una pregunta de revisión tempranamente puede llegar a ser una labor ociosa y frustrante, ya que probablemente no se puedan recuperar estudios suficientes que sean posteriormente agregados con garantías, de modo que se satisfaga el objetivo planteado.

Como se afirma en (Brereton et al., 2007) es difícil establecer tempranamente el alcance de las RS en IS. En (Budgen, Turner, Brereton, \& Kitchenham, 2008) los autores proponen el uso de los estudios de 
mapeo, previamente reseñados por (Kitchenham. B.A. \& Charters, 2007; Petticrew \& Roberts, 2007), como una herramienta que puede apoyar al revisor en establecer la disponibilidad de estudios para los diversos temas de la IS. Sin embargo, en éstos y otros antecedentes analizados en el ESTADO DE LA CUESTIÓN no existen lineamientos claros sobre cómo realizar este tipo de análisis.

\subsection{Aproximación a la solución}

Una vez identificadas las características de la IS que limitan la búsqueda de experimentos siguiendo los procesos existentes, se resumen a continuación las soluciones propuestas en esta investigación para cada una de tales limitaciones. Estas propuestas son posteriormente estructuradas en forma de actividades o tareas en la sección 6.3.

1. Escasez de experimentos reportados adecuadamente: Tal como se estableció en la sección 6.1, mientras que en Medicina y otras áreas de las Ciencias de la Salud existe un gran número de experimentos, en IS este número es más bien escaso lo cual amenaza la fiabilidad de los resultados de la agregación estadística en virtud del bajo número de sujetos.

- Solución: para solucionar esta limitación se busca maximizar el número de experimentos que son localizados durante la FASE DE BÚSQUEDA, a fin de poder utilizar un número significativo de sujetos durante la SíNTESIS DE DATOS. De esta manera, al contar con un número considerable de experimentos, se aumenta la potencia estadística y por consiguiente, existirá mayor probabilidad de que los resultados que se obtengan sean significativos. En particular, se proponen recomendaciones para la búsqueda basadas en la exhaustividad, que persiguen recuperar la mayor cantidad posible de experimentos útiles para la RS. Todo ello debe hacerse sin perder de vista las amenazas a la validez de los resultados que puedan producirse como consecuencia del sesgo. Tales recomendaciones incluyen una definición/selección adecuada de los distintos elementos que componen una estrategia de búsqueda, i.e. las bases de datos bibliográficas, el universo de búsqueda, los campos de búsqueda, y los términos de la cadena de búsqueda.

2. Bases de datos bibliográficas poco adecuadas: como se explicó en detalle en la sección 6.1, los resultados de las búsquedas de experimentos en IS generalmente se ven afectados por las bases de datos que son utilizadas. Esto se resume en que las búsquedas arrojan una gran cantidad de artículos irrelevantes que deben ser leídos y descartados, por lo que el coste de recuperar cada artículo potencialmente útil es muy elevado.

- Solución: En la presente investigación se incorporan recomendaciones que persiguen reducir los efectos de este problema al incluir criterios para comparar las bases de datos bibliográficas existentes y seleccionar aquella que presente menos inconvenientes en su funcionamiento; al mismo tiempo que ofrezca una mayor cobertura en cuanto a las publicaciones que indexa. La 
selección de una base de datos adecuada, obliga a que se tome en cuenta no sólo su capacidad de localización (efectividad) sino también su eficiencia (precisión), en el sentido de minimizar la cantidad de artículos inútiles que aparecen con la búsqueda, mientras se intenta maximizar la cantidad de artículos potencialmente útiles que son localizados.

3. Falta de estandarización de la terminología: en una búsqueda sistemática de experimentos, frecuentemente las cadenas de búsqueda incluyen términos relativos a los cuatro componentes de la pregunta de revisión (PIOS) que se pretende localizar y los relacionados con la tecnología que ensaya el experimento. Cuando los experimentadores hacen un uso poco estándar de esta terminología, es prácticamente imposible recuperar todos los experimentos relevantes para una RS. Para lograr esto, en la mayoría de los casos se necesitaría un número inmanejable de términos equivalentes o sinónimos. Se requiere entonces optimizar el esfuerzo de localización de experimentos.

- Solución: Como una solución a este problema se proponen un conjunto de recomendaciones que buscan lograr una alta recuperación y precisión en las búsquedas, así como una baja especificidad. Tales recomendaciones están orientadas a la definición de cadenas óptimas de búsqueda, para lo cual se utiliza, entre otros recursos, la recursividad.

4. Dificultad para definir la pregunta de revisión tempranamente: En aquellos casos en los que el revisor no puede o no desea establecer a priori la pregunta de revisión y sólo se cuenta con un objetivo de revisión a alto nivel, se requiere un estudio exploratorio que le proporcione al revisor información acerca de los experimentos disponibles en IS, en particular sobre la cantidad de experimentos que ensayan cierta tecnología y los objetivos específicos de cada uno de ellos. De esta manera la formulación de la pregunta de revisión será establecida una vez que el revisor cuente con información suficiente para determinar que existe una base de evidencia suficiente para responder a la pregunta que se plantee.

- Solución: se propone incorporar el uso de estudios sistemáticos de mapeo a fin de organizar los experimentos existentes de acuerdo al tema tratado o la tecnología que ensayan. Con base en esta clasificación se seleccionará aquella área en la cual es viable definir un objetivo de revisión específico y realizar una RS, y se definirá la pregunta de revisión. En este punto, la viabilidad de la RS está determinada exclusivamente por la existencia de un número suficiente de experimentos acerca de la tecnología de interés.

Nótese que el estudio de mapeo aquí propuesto tiene como único propósito realizar una valoración preliminar de la evidencia disponible; por lo tanto, es un estudio que tiene un interés exploratorio y cuantitativo más que cualitativo. No se incluirán en este mapeo preliminar estudios de todo tipo sino que el tipo de estudio estará restringido a experimentos. El resultado de este estudio responderá básicamente a la pregunta "¿qué se ha ensayado en relación a X?", donde X se refiere a una cierta tecnología (método, técnica, etc.). 


\subsection{Actividades propuestas para la Fase de Búsqueda}

Como resultado de analizar las características de la ISE que pueden influir en la FASE DE BúsQUEDA, se ha propuesto un conjunto de actividades que buscan resolver las limitaciones anteriormente identificadas: escasez de experimentos, bases de datos bibliográficas inadecuadas, falta de estandarización de la terminología, y dificultad para definir la pregunta de revisión de manera temprana.

Como se observa en la figura 6.1 ( $\mathrm{a}$ y b) esto ha llevado a que la propuesta para esta fase sea más compleja que la observada en los procesos de RS analizados en el ESTADO DE LA CUESTIÓN ya que considera dos escenarios distintos (el de una RS que comienza con un objetivo específico claramente definido y el de una RS que comienza sólo con un objetivo general). El escenario más complejo es precisamente este último, el cual incluye diez actividades en total.

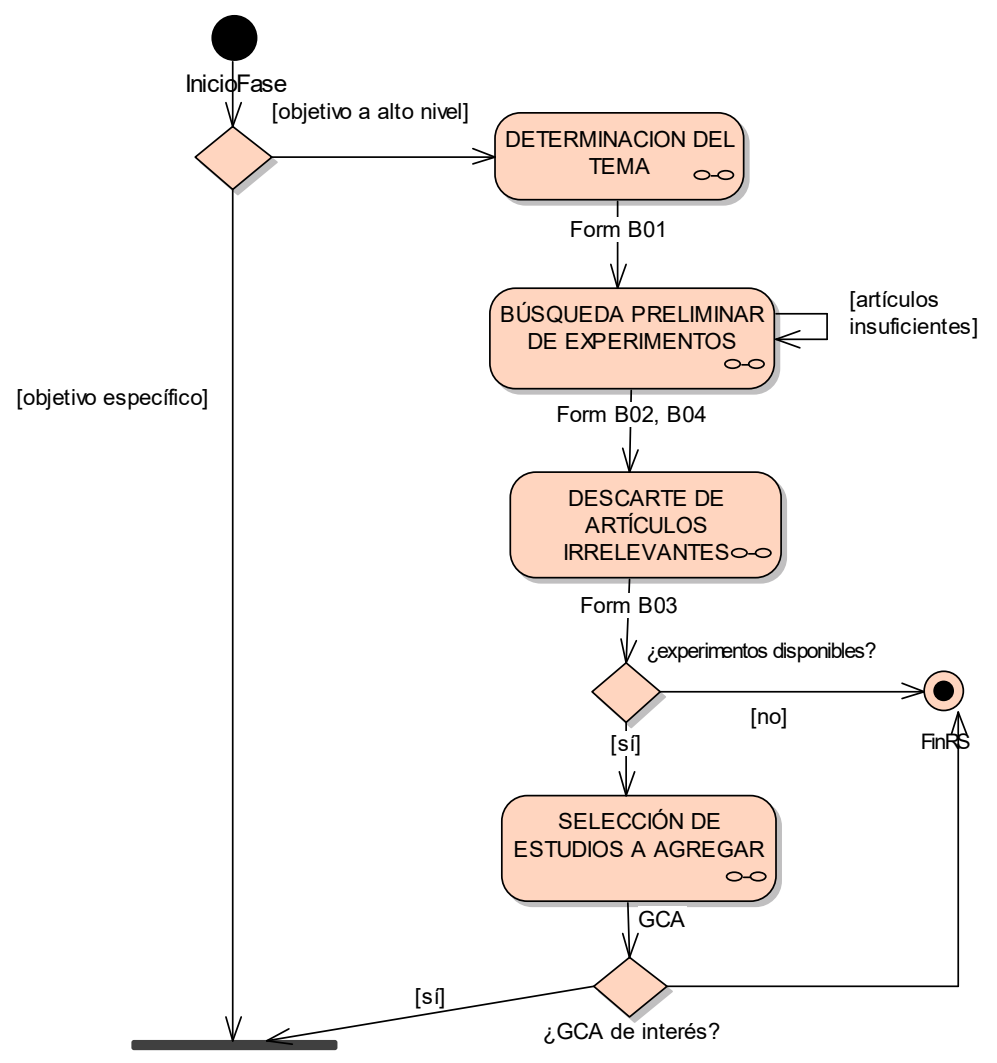

Figura 6.1.a. Actividades de la Fase de Búsqueda exclusivas al escenario "Objetivo a alto nivel"

Precisamente el segundo escenario, en el que los revisores sólo poseen una idea general del tema de interés sobre el que desean obtener evidencias, incorpora actividades que serán determinantes para el establecimiento del objetivo final de la RS (incluyendo la pregunta de revisión y los criterios de inclusión/exclusión). Ellas permitirán localizar los experimentos disponibles sobre un tema y realizar un 
agrupamiento de éstos con base en los factores y variables respuesta, para luego seleccionar el grupo de experimentos que resulte de mayor interés para la RS.

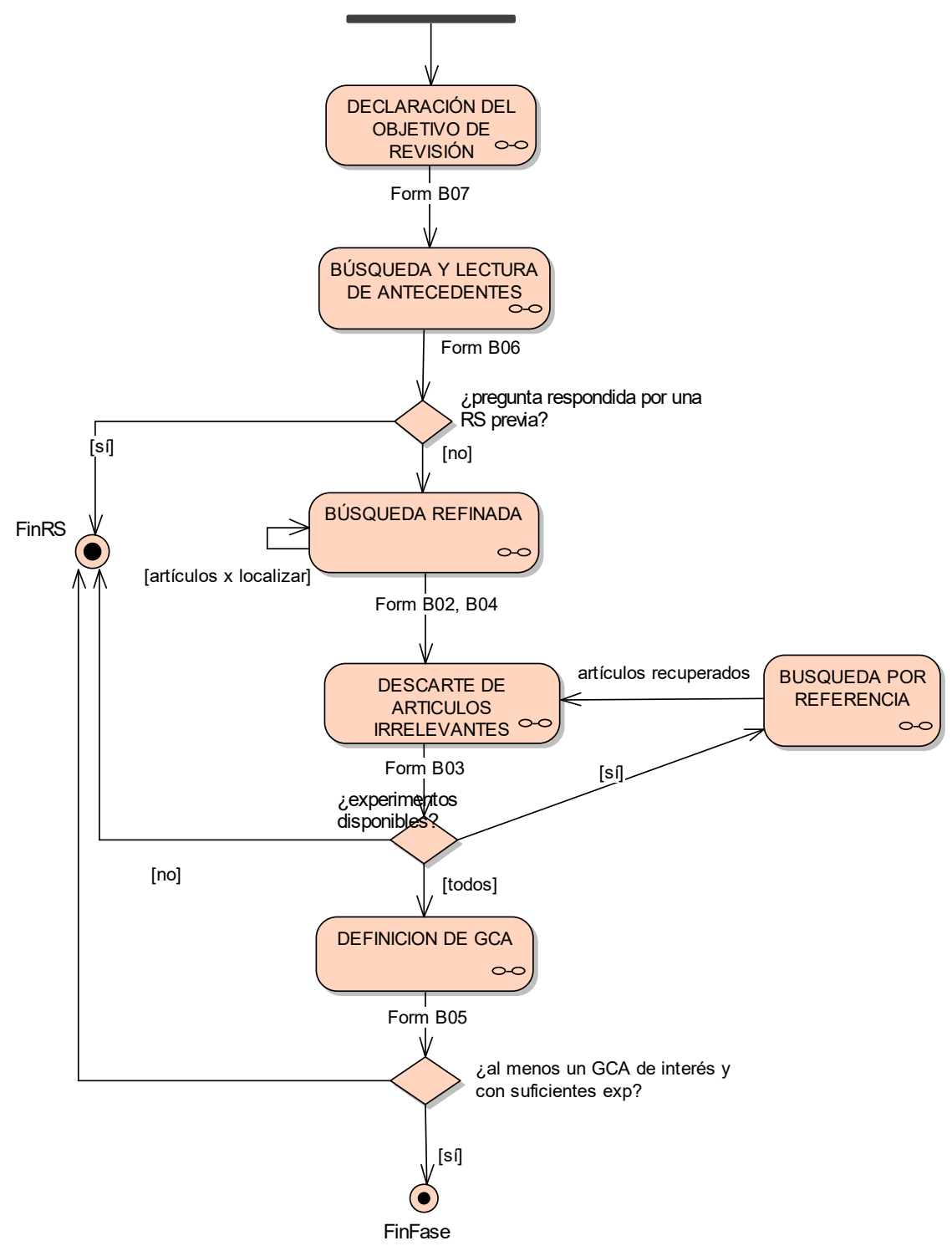

Figura 6.1.b. Actividades de la FASE DE BÚSQUEDA comunes a ambos escenarios

Las actividades propuestas para esta fase satisfacen los requerimientos surgidos del análisis de la sección anterior. En primer lugar, impera en esta fase el principio de la exhaustividad, lo que se traduce en que se busca maximizar el número de experimentos localizados a fin de aumentar la potencia estadística. Nótese que a mayor tamaño de la muestra (o mayor potencia estadística) mayor es la probabilidad de obtener evidencias válidas y significativas durante la fase de SíNTESIS DE DATOS. 
Otra característica de esta fase es la sistematicidad, lo cual se traduce en que la fase propuesta prescribe claramente las actividades, tareas y pasos a seguir por el revisor. Esta sistematicidad es fundamental para que los revisores novatos puedan acometer la RS (B. Kitchenham, Brereton, et al., 2010), al mismo tiempo que facilita que una RS sea replicada por otros investigadores (Kitchenham. B.A. \& Charters, 2007) (CRD, 2009) y que se pueda verificar la trazabilidad entre las distintas tareas.

Por último, la fase responde a un requerimiento de documentación, implícito en las características anteriores. Por ello incorpora el uso de un conjunto de formularios para el registro de los resultados y las decisiones de las distintas actividades. Esta característica no sólo apoya la repetibilidad del proceso, sino que contribuye a la reducción de sesgos y facilita las auditorías del proceso.

La figura 6.1 muestra los dos caminos posibles en el proceso de búsqueda, dependiendo del escenario que se presente.

- Escenario 1. El revisor cuenta desde el comienzo con un objetivo específico claramente definido que responde a una determinada pregunta. El establecimiento de un objetivo así de preciso requiere experiencia en revisiones anteriores, conocimiento acerca del tema, o conocimiento de los experimentos disponibles sobre la tecnología de interés y las variables estudiadas en tales experimentos. Este escenario consta de seis actividades: DECLARACIÓN DEL OBJETIVO DE REVISIÓN,

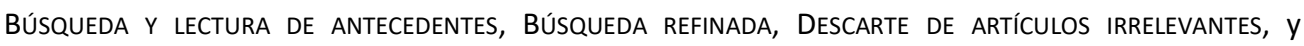
DEFINICIÓN DE GRUPOS A AgREgAR. La Búsqueda REFINAdA es, sin duda, la más importante en este escenario, y requiere que se proporcione al revisor con un conjunto de recomendaciones que garanticen la optimalidad de la búsqueda. Ésta se logra cuando tanto la capacidad de recuperación de artículos como la precisión de los resultados tienen un nivel aceptable o alto. Las recomendaciones propuestas en este escenario persiguen como objetivo resolver tanto el problema de escasez de experimentos como los problemas asociados al uso de las bases de datos en IS. Nótese en la figura 6.1 que en este escenario todas las actividades de la fase deberían ser acometidas.

- Escenario 2. El revisor no cuenta con un objetivo específico, sino que posee una idea general u objetivo a alto nivel acerca de una cierta tecnología de interés. Con esto el revisor busca responder a una pregunta del tipo ¿qué se sabe acerca de la tecnología $X$ ? Esto puede ocurrir por diferentes razones: el revisor realiza la RS como parte de un ejercicio académico (por ejemplo, una tesis de máster o doctorado), el revisor posee poca experiencia en revisiones similares (no queriendo decir con ello que posean pocos conocimientos acerca del campo de las RS), o el revisor desconoce las posibles variantes de una tecnología, posiblemente por la falta de estandarización de la terminología. En todos estos casos el revisor requiere que la búsqueda le proporcione información acerca de los experimentos disponibles antes de definir de manera precisa su objetivo y pregunta de revisión. 
Este escenario consta de diez actividades. Las cuatro primeras son exclusivas de este escenario: Determinación del tema, Búsqueda PRELIMINAR DE EXPERIMENTOS, DESCARTE DE ARTículos IRRELEVANTES, y SELECCIÓN DE ESTUDIOS A AGREGAR. Con estas actividades la fase de BúsQUEDA garantiza que se establezca un objetivo de revisión no sólo preciso sino también viable, que puede ser alcanzado a partir de los experimentos disponibles. De esta manera se busca enfrentar la dificultad para definir la pregunta de revisión tempranamente. Luego de acometer el primer conjunto de actividades de este escenario, deben ejecutarse también las seis actividades que corresponden al primer escenario (objetivo específico).

Las secciones 6.3.5 a 6.3.10 corresponden al primer escenario. Por lo tanto, si se cuenta con un objetivo específico desde el comienzo del proceso (por ejemplo, "comparar las técnicas basadas en escenarios y las basadas en perspectivas para la lectura de código"), las actividades descritas en las secciones 6.3.1 a 6.3.4 podrán ser omitidas, pasando directamente a la actividad 6.3.5 - DECLARACIÓN DEL OBJETIVO DE REVISIÓN.

Esta fase tiene como salidas uno o más grupos de experimentos que corresponden con el objetivo de revisión y que son potencialmente agregables, así como la estrategia de búsqueda utilizada junto con sus estadísticas. De este conjunto de salidas, los GCA serán, junto con el objetivo de la revisión, los elementos clave a ser analizados durante la siguiente fase (EXTRACCIÓN DE DATOS), como preparación para realizar, finalmente, la SínTESIS DE DATOS.

Se tiene entonces que la fase de BúSQUEDA será fundamental en el proceso de RS propuesto en esta investigación. Esta fase es la principalmente responsable de la eficacia del proceso de RS, ya que persigue la identificación de los estudios primarios necesarios para acometer el resto de las fases de la RS. En las siguientes secciones, se describe cada una de las actividades que componen esta fase, detallando sus tareas y entregables.

\subsubsection{DETERMINACIÓN DEL TEMA}

El objetivo de esta actividad es establecer el área o tecnología sobre la cual se desea realizar la RS. Las tareas aquí propuestas están orientadas a definir de forma no ambigua el tema que da origen a la RS (llamado en adelante tema de revisión). En el contexto de este trabajo, el tema de revisión se define entonces como el área de interés sobre la que el revisor desea obtener información o generar nuevas evidencias.

Esto es importante para que el proceso acometido y todos sus productos puedan ser interpretados correctamente por todos los revisores involucrados y por cualquier profesional o investigador que desee utilizar o replicar la RS en el futuro.

Por tratarse del escenario objetivo a alto nivel anteriormente explicado, es previsible que el tema de revisión sea planteado de una manera muy general en este escenario y sea refinado posteriormente, hasta llegar a establecer un objetivo específico. Así, la búsqueda puede comenzar con una información muy básica sobre el tema, ya que progresivamente se irá obteniendo información que permitirá definir de manera precisa el alcance de la RS. 
Las tareas de esta actividad incluyen, como se muestran en la figura 6.2, seleccionar el tema y describirlo. A continuación, se detalla cada una de estas tareas.

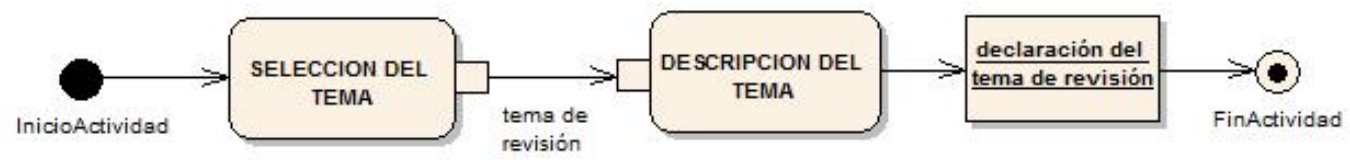

Figura 6.2. Tareas relacionadas con la Determinación del tema de revisión

\subsubsection{Selección del tema de revisión}

Es lógico suponer que los revisores tienen una intención clara acerca del área que es de su interés; por ejemplo, realizar una tesis o conocer el estado de la cuestión para proponer un proyecto de investigación. Por lo tanto, el objetivo de esta primera tarea es establecer el área o tema sobre el que se desea obtener información y generar evidencias a través de la RS. Pruebas de software, educción de requisitos, y aseguramiento de la calidad, son ejemplos de áreas o temas de la IS que pueden ser de interés en una RS.

Nótese que en estos ejemplos se proporciona información muy básica sobre el tema; sin embargo, esto no representa un problema para la búsqueda.

Esto presenta una ventaja clara frente al uso de una pregunta de revisión específica. Dada la escasez de experimentos en IS, es más que probable que no sea posible identificar un número significativo de estudios primarios. Sin embargo, un tema genérico permitirá obtener un mapa amplio que relacione los experimentos disponibles y los distintos aspectos del tema sobre los que se ha generado alguna evidencia empírica. Más adelante en esta fase, se describirá en detalle cómo llegar a un objetivo específico a partir del mapa de estudios mencionado.

Recomendación:

Cuanto más general sea el tema planteado, mayor será la cantidad de experimentos que serán localizados en las actividades subsiguientes de este escenario, lo cual permitirá a su vez explorar distintas vertientes o aspectos. Puede entonces afirmarse que a mayor generalidad del tema de revisión, mayor cantidad y diversidad de experimentos localizados.

Para facilitar la comprensión del proceso propuesto en esta investigación, el tema inspección de software será utilizado en adelante para ilustrar los ejemplos relacionados con todas las actividades.

\subsubsection{Descripción del tema de revisión}

Para que una RS sea útil a la mayor cantidad posible de profesionales y académicos, parece lógico evitar la ambigüedad; proporcionando para ello toda la información pertinente para que sus resultados puedan ser 
interpretados adecuadamente y aplicados de manera efectiva en la mejora de la práctica de la IS o en la toma de decisiones.

Esta actividad consiste en definir los aspectos fundamentales relacionados con la tecnología que se desea estudiar en la RS. Esta información servirá como entrada a la actividad de BÚSQUEDA PRELIMINAR DE EXPERIMENTOS.

La importancia de la descripción del tema radica entonces la necesidad de dominar los conocimientos mínimos relacionados con éste que permitan no sólo entender los factores y variables respuesta que componen cada uno de los experimentos localizados y determinar su relevancia dentro de la RS, sino también proponer términos para las cadenas de búsqueda que puedan recuperar experimentos estrechamente relacionados con el tema de interés, aumentando de esta manera la recuperación y la precisión de las estrategias de búsqueda utilizadas.

Para ello, se propone utilizar el formulario B01 - Declaración del tema de revisión (véase el Apéndice B), el cual contiene como campos principales:

- Nombre del tema: un título que enuncia el área con la cual se relacionará la revisión (por ejemplo, inspección de software).

- Descripción: una explicación suficientemente clara de la definición y el alcance de los conceptos involucrados en el tema de revisión seleccionado.

Recomendación:

Incluir en la descripción del tema aquellos aspectos más resaltantes del mismo, o aquellos que mejor lo definan y caractericen, ya que una clara definición de estos aspectos facilitará que el revisor se oriente en futuras actividades de esta fase (por ejemplo, durante el agrupamiento de experimentos) y en otras fases de la RS (por ejemplo, la extracción y la síntesis de datos).

A manera de ejemplo, se presenta en la tabla 6.1 una breve descripción del tema inspección de software. En esta definición pueden observarse las fases que componen el proceso de inspección, lo cual permite entender que muchos experimentos que se dedican a estudiar esta tecnología se enfoquen principalmente en aquellas fases que pueden estar más directamente relacionadas con la efectividad de la técnica (i.e. la Preparación, la Reunión de inspección y el Re-trabajo) y/o en la relación entre ellas.

Esta definición podría además incluir una categorización de las técnicas de lectura generalmente asociadas a la inspección de software (p.e. basada en lista de chequeo, basada en perspectiva, basada en caso de uso, etc.). Esto proporcionaría además información útil en el momento de analizar los experimentos disponibles, los cuales generalmente suelen comparar dos o más de estas técnicas de lectura en términos de su efectividad y eficiencia. 
Tabla 6.1. Ejemplo de Declaración del tema de revisión

\section{Nombre del tema: Inspección de software}

Descripción

La inspección de software, como un proceso estructurado, ha sido descrita originalmente por Fagan en 1976. Consiste de seis etapas:

1. Planificación. El organizador asegura: que los materiales a ser inspeccionados satisfagan los criterios de inspección, la disponibilidad de los participantes involucrados, la hora y lugar de la reunión.

2. Introducción. El autor presenta un resumen del alcance y propósito del producto del trabajo.

3. Lectura individual (frecuentemente llamada Preparación). Los inspectores analizan el producto del trabajo de manera individual con el objetivo de entenderlo a fondo.

4. Reunión de inspección. El equipo de inspección se organiza para discutir el producto de la inspección y detectar tantos defectos como sea posible.

5. Re-trabajo. El autor revisa el producto del trabajo.

6. Seguimiento. El moderador verifica la calidad del re-trabajo y decide si se requiere re-inspección.

\subsubsection{BÚSQUEDA PRELIMINAR DE EXPERIMENTOS}

Cuando un revisor inicia la RS sin un objetivo específico persigue obtener un mapa de los estudios que se encuentran disponibles acerca del tema de revisión que ha seleccionado. De esta manera, el revisor podrá escoger un aspecto particular dentro del tema y, finalmente, definir un objetivo de revisión preciso y viable; todo ello con base en los experimentos localizados.

En consecuencia, la actividad de BÚSQUEDA PRELIMINAR DE EXPERIMENTOS tiene como propósito recopilar un conjunto base de artículos que reporten experimentos que puedan ser relevantes al tema de revisión, y que ayuden a definir un objetivo y pregunta de revisión específicos.

Las tareas concretas a realizar durante esta actividad se muestran en la figura 6.3. Se comienza por seleccionar las fuentes de información (bases de datos bibliográficas, revistas científicas, actas de congresos, entre otras), así como los campos de búsqueda (título, resumen, todo el documento, palabras clave, etc.) y los términos que se usarán en la cadena de búsqueda. Todas estas decisiones deben documentarse de manera que puedan ser revisadas o replicadas en el futuro, tanto en la misma RS como en otras RS. Finalmente se realiza la búsqueda con las características establecidas y se obtiene un conjunto de artículos o publicaciones que deben ser posteriormente analizados. 


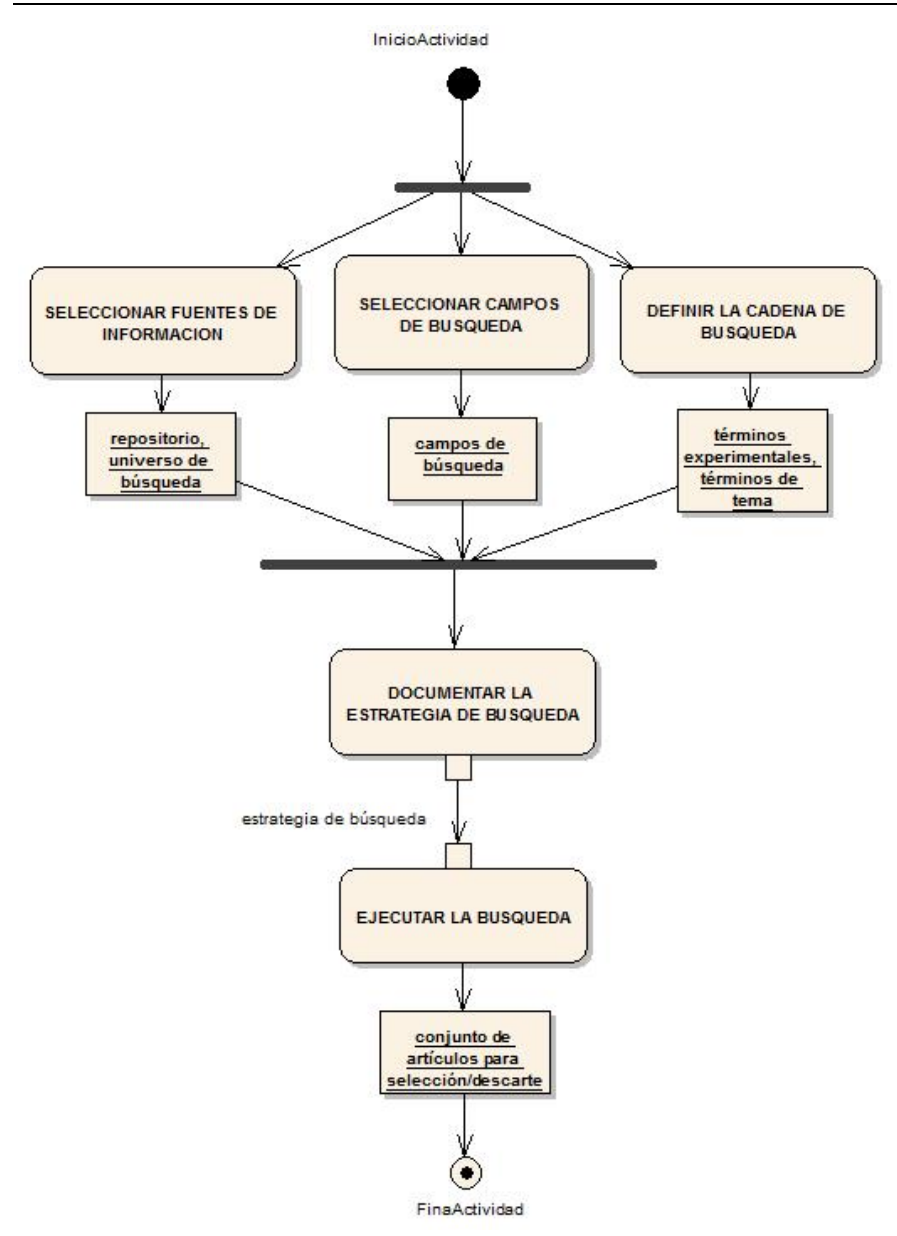

Figura 6.3. Tareas relacionadas con la Búsqueda preliminar de experimentos

Como puede observarse, las tareas de esta actividad contribuyen a la RS con la localización de un conjunto de estudios acerca de un tema, implicando la toma de decisiones relativas a dónde y cómo realizar la búsqueda. Tales decisiones serán fundamentales para lograr una alta recuperación y precisión de la estrategia de búsqueda; lo que se traducirá en localizar el mayor número posible de experimentos potencialmente útiles para la RS con el menor esfuerzo posible. De esta manera, el objetivo de la RS podrá establecerse con mucha precisión (aunque esto corresponde a una actividad posterior, 6.3.5 - DECLARACIÓN DEL OBJETIVO DE REVISIÓN). A continuación se describe cada una de las tareas involucradas en esta actividad.

\subsubsection{Seleccionar fuentes de información}

El objetivo de esta tarea es decidir dónde buscar los experimentos. Esta decisión puede tener un gran impacto en el número de artículos relevantes identificados, lo que constituye un factor muy importante para el éxito de la RS. 
La búsqueda en fuentes de información pueden realizarse tanto de manera electrónica (en las bases de datos bibliográficas, buscadores como Google Scholar, etc.) como de manera manual (por ejemplo, en aquellos casos en que se incluir artículos de congresos muy recientes o congresos muy específicos que no se encuentren indexados en una base de datos) (Hannay, Dybå, Arisholm, \& Sjøberg, 2009).

Mientras las búsquedas en bases de datos electrónicas suelen ser muy productivas en virtud de que el esfuerzo de búsqueda es relativamente reducido y la mayoría de las publicaciones importantes en el dominio de la IS se encuentran actualmente indexadas en algún motor de búsqueda o base de datos bibliográfica; las búsquedas manuales pueden requerir un gran esfuerzo y localizar un número poco significativo de experimentos relevantes (O. Dieste, Grimán, Juristo, \& López, 2008).

Recomendación:

Si se decide acometer una búsqueda manual ésta debería estar bien acotada de manera que no consuma un esfuerzo y tiempo considerables dentro de esta fase.

En cuanto a la búsqueda en base de datos electrónicas, no se cuenta en IS con bases de datos especializadas en experimentos, por lo que los revisores suelen recurrir a bases de datos del área de Ingeniería (IEEE Xplore, ACM DL) o incluso a otras más generalistas (SpringerLink, ISIWOK, Google Scholar). No todas estas bases de datos presentan la mismas condiciones para un RS y, puesto que no existe mucho solapamiento entre ellas (Bailey et al., 2007), deberían aplicarse criterios para seleccionar las bases de datos apropiadas.

Con el fin de orientar la decisión del revisor se ha propuesto un conjunto de criterios para la selección de una base de datos bibliográfica:

- Cobertura. Actualmente se cuenta con un número considerable de publicaciones indexadas en las bases de datos bibliográficas que suelen ser utilizadas por los revisores en IS. No obstante, parece existir poco solapamiento entre ellas (Bailey et al., 2007), lo que hace que deban utilizarse varias bases de datos para recuperar la mayor cantidad posible de estudios primarios (Bailey et al., 2007; Brereton et al., 2007). Utilizar meta-buscadores como ISI Web o SCOPUS puede, sin embargo, permitir ahorrar esfuerzo al realizar las búsquedas de manera simultánea en diferentes bases de datos. El problema que se presenta con este tipo de motores de búsqueda es que son muy generalistas, ya que no sólo incluyen bases de datos relacionadas con la Ingeniería (ninguna de ellas específica a la IS) sino también bases de datos relacionadas con otras disciplinas o áreas de conocimiento. Por lo tanto, debe evaluarse cada base de datos en relación a su cobertura en cuanto a publicaciones y a áreas de conocimiento; buscando utilizar el menor número de bases de datos e incluir en la búsqueda sólo aquellas áreas relacionadas a la IS (p.e. Sistemas de Información, Inteligencia Artificial, etc.).

- Actualización del contenido. Las publicaciones indexadas en la base de datos deben ser actualizadas regularmente. Esto resultará en que la base de datos contendrá las publicaciones más recientes. 
- Completitud del texto. El texto completo debería estar disponible y no únicamente el resumen. Esto será muy conveniente cuando la lectura del resumen no sea suficiente para entender el propósito del experimento que se describe en el artículo.

- Facilidad de la búsqueda. Debe resultar fácil especificar las cadenas de búsqueda. Para ello es importante que el motor de búsqueda permita establecer consultas utilizando diferentes campos del artículo así como operadores booleanos.

- Calidad de los resultados. La precisión de los resultados es un aspecto crítico. Desafortunadamente, no todas las librerías digitales ejecutan las búsquedas apropiadamente. Algunas de ellas presentan errores de precisión producto de del uso de mayúsculas o plurales; otras fallan cuando se utiliza el operador OR en un campo con diferentes valores alternativos, etc. Esto resulta en una absoluta anarquía, ya que los revisores asumen que los resultados son confiables, y en una revisión común (no un estudio como éste) es poco probable que los revisores perciban los errores existentes.

- Versatilidad de la exportación de resultados. Los resultados de la búsqueda en la base de datos deben poder ser exportados a un archivo de texto, manejador de referencias u otro formato de intercambio. De esta manera, el revisor puede añadir cualquier información de interés, agregar resultados de otras bases de datos o procesar información cuando se requiera. Si la base de datos no proporciona esta funcionalidad, el revisor tiene que generar este archivo manualmente.

- Usabilidad. El motor de búsqueda debería ser fácil de entender y operar, incluyendo una interfaz amigable y consistente, así como ayudas para el usuario e interacción con otras aplicaciones (por ejemplo, manejadores de referencias como EndNote, ProCite, entre otros).

\section{Recomendaciones:}

Durante el desarrollo de esta investigación, las siguientes fueron las bases de datos que obtuvieron mejores resultados en cuanto a los criterios anteriormente mencionados:

- SCOPUS puede considerarse la Base de datos con las mejores características de las mencionadas aquí.

- $\quad$ Pueden considerarse otras DB con cobertura media aunque con algunos inconvenientes de funcionamiento: IEEEXplore, e ISI Web of Knowledge.

- $\quad$ ACM DL, presenta una cobertura media pero un desempeño bastante pobre.

- Por último, Sciencedirect presenta un buen desempeño pero una cobertura bastante reducida (únicamente las publicaciones de Elsevier).

\subsubsection{Seleccionar el universo de búsqueda}


Además de la base de datos, un segundo aspecto importante a considerar es el Universo de búsqueda. Esta tarea se refiere a decidir el área de conocimiento, el conjunto de publicaciones de un cierto tipo (principalmente, revistas y actas de conferencias) entre las que se desea localizar experimentos, y el rango de años que se desea incluir en la búsqueda.

Una búsqueda puede ser completamente abierta, sin restricción alguna para las publicaciones, o estar confinada por alguno de los siguientes criterios: tipo de publicación, área de conocimiento, año de publicación. Por ejemplo, una búsqueda avanzada en IEEE Xplore permite seleccionar entre diferentes tipos de contenidos (conferencias, revistas, libros, entre otros) así como definir un rango para el año de publicación. Sería entonces posible restringir el universo de la búsqueda en IEEE Xplore para que sólo recupere artículos de revistas en un período dado (por ejemplo, para el período 2002 - 2010).

En algunas RS, tales como (Jørgensen \& Shepperd, 2007) y (Kampenes, Dyba, Hannay, \& Sjøberg, 2007) los autores han restringido aún más el universo de búsqueda, limitándolo a publicaciones reconocidas solamente. Afortunadamente, ésta no es una tendencia entre los revisores, tal como se observa en (A. Davis, Dieste, Juristo, \& Moreno, 2006; T. Dybå \& T. Dingsøyr, 2008; Hannay et al., 2009; Juristo, Moreno, \& Vegas, 2004; B. A. Kitchenham, Mendes, \& Travassos, 2007; Pedreira et al., 2007).

El no limitar la búsqueda de experimentos a un conjunto de publicaciones específicas (generalmente, por su reconocimiento en el área) ha demostrado tener impacto en la cantidad de experimentos recuperados y, por lo tanto, en el sesgo de publicación. Tal impacto se comprobó en (O. Dieste et al., 2009), donde se analizaron dos de las RS mencionadas, (A. Davis et al., 2006) y (Juristo et al., 2004), y se determinó que un número considerable de artículos relevantes podrían no haber sido localizados de haber limitado el universo de búsqueda a publicaciones reconocidas únicamente.

Recomendaciones:

No es recomendable confinar las búsquedas a fuentes reconocidas o con altos factores de impacto ya que esta restricción puede causar perjuicios (sesgos o distorsiones) en los resultados.

Además, la búsqueda debería explorar publicaciones en IS y áreas afines. En la mayoría de las RS pueden considerarse como áreas afines Sistemas de información e Inteligencia artificial. Excepcionalmente, algún tema de RS, como por ejemplo educción de requisitos, podría requerir que se consideren como áreas afines la psicología, economía, calidad, entre otros.

Por último, aunque se recomienda no limitar el número ni tipo de publicación (artículos, revisiones, editoriales) para no reducir los resultados, sí se considera útil limitar el área de conocimiento para la búsqueda (por ejemplo, en SCOPUS al delimitar las áreas a Ingeniería y Ciencias de la Computación pueden excluirse de la búsqueda aquellas publicaciones que pertenecen a las ciencias sociales, medicina, etc.; sin dejar fuera otras disciplinas bastante relacionadas con la IS, como las mencionadas en el punto anterior). El uso de términos comunes a diferentes áreas puede llevar a obtener un gran número de artículos irrelevantes, producto del uso casuístico de tales términos en artículos que no 
corresponden a la IS (o alguna otra disciplina afín).

\subsubsection{Seleccionar campos de búsqueda}

El objetivo de esta tarea es decidir cuáles son los campos de la base de datos que serán más adecuados para realizar la búsqueda; es decir, aquellos que arrojarán menos basura en los resultados. Se busca que la recuperación de artículos sea alta con un mínimo esfuerzo de revisión manual para el descarte de artículos irrelevantes.

No obstante, la selección de los campos de búsqueda no resultó en esta investigaron ser una tarea trivial. Es por esto que el estudio del impacto de los campos de búsqueda en la eficacia de la búsqueda se ha dividido en dos partes. La primera de ellas, analizó los resultados de buscar por distintos campos sólo con los términos relacionados con el tipo de estudio (experimento) pero no incluyó términos relacionados con el tema de la revisión (por ejemplo, inspección de software) (véase Apéndice D.1). Este tipo de búsqueda no es muy útil para una RS sino más bien para la elaboración de un estudio de mapeo muy amplio donde se busque identificar todos los experimentos disponibles en IS y clasificarlos bajo un tema. Sin embargo, la complejidad del análisis ameritó un estudio separado. En este primer análisis los campos ensayados fueron: título, resumen, título-resumen, título-resumen-palabras clave, y todos los campos. El resultado indicó que, incluso utilizando un universo de publicaciones limitado, la búsqueda se vuelve muy ineficiente (recupera una gran cantidad de artículos irrelevantes) cuando se realiza en todos los campos del artículo. Los mejores resultados obtenidos en este estudio corresponden a la búsqueda en títuloresumen, seguida por la búsqueda en título-resumen-palabras clave.

Posteriormente, se realizó un análisis similar pero esta vez incluyendo en la cadena de búsqueda no sólo los términos relacionados con el tipo de estudio (experimento controlado) sino también aquellos relacionados con el tema de revisión ${ }^{2}$. Este tipo de búsqueda es la que más se ajusta a la actividad que se quiere acometer, ya que permite localizar los experimentos disponibles en relación a un tema en IS. Se usó para este análisis el tema inspección de software, obteniendo como resultado que al incorporar esta nueva parte de la cadena los resultados de la búsqueda en título-resumen-palabras clave pasan a ser los más coste-efectivos; esto es, localizan la mayor proporción de artículos relevantes del total de artículos recuperados.

\section{Recomendaciones:}

- Una búsqueda óptima es aquella que incluya el título-resumen y palabras clave como campos de la búsqueda.

\footnotetext{
2 Para mayor detalle sobre este estudio referirse al Apéndice B
} 
- $\quad$ La búsqueda por título-resumen es una alternativa aceptable.

- La búsqueda por todos los campos no es recomendable, aunque ésta tiene una tasa de recuperación alta, detectará más artículos irrelevantes.

\subsubsection{Definir la cadena de búsqueda}

Esta tarea tiene como propósito la definición de una cadena de términos adecuada para localizar los experimentos de interés.

En las RS de algunas disciplinas, como Medicina, suelen utilizarse durante la búsqueda de estudios primarios, los cuatro componentes clave de la pregunta de revisión (participantes, tratamientos, resultados y el diseño del estudio) (J. P. T. Higgins \& S. Green, 2006). No obstante, debido a que en este escenario no se ha definido la pregunta de revisión, sólo se cuenta con información para definir dos grupos de términos para componer la cadena de búsqueda: 1) los términos relacionados con el tema de interés (p.e. inspecciones de software, pruebas, etc.) y 2) los términos relacionados con el tipo de estudio (experimentos).

En ciertas disciplinas, como Medicina, se tiene además que la estandarización de la terminología permite realizar búsquedas de experimentos muy precisas en bases de datos especialmente estructuradas para tal fin. Un ejemplo de ello son los términos MeSH de los que se habló en la sección 6.1.3. MeSH es la lista de términos que componen un vocabulario controlado usado para el análisis de temas de la literatura biomédica en la Biblioteca Nacional de Medicina (NLH, por sus siglas en inglés) de los Estados Unidos de América. MeSH impone uniformidad y consistencia para la indexación de la literatura ya que los términos son organizados de forma jerárquica (conocido como Estructuras de árbol) y actualizados anualmente. Los indexadores de la NLH examinan los artículos y asignan los encabezados más específicos que permitan describir lo que se discute en cada uno de ellos (US National Library of Medicine, 2001).Para ello pueden utilizar entre 5 y 15 encabezados. Además de asignar los términos que describen el tópico del artículo, los indexadores proporcionan términos que reflejan el material representado o tipo de publicación (ensayo clínico, editorial o revisión). De esta manera, el uso de MeSH estandariza la información relacionada con el tema o tópico sobre el cual trata el estudio así como la información relacionada con el tipo de estudio; siendo ambos tipos de información necesarios al momento de realizar una búsqueda; al ser dos de los componentes de la pregunta de revisión: los términos relacionados con el tema de interés y los términos relacionados con el tipo de estudio.

Volviendo a la problemática ya planteada en las secciones 5.1 y 6.1 de este trabajo, a diferencia de Medicina, en IS se presentan problemas de falta de estandarización no sólo en cuanto a los términos relacionados con el tema del experimento sino también con los términos utilizados para definir el tipo de estudio. 
En cuanto a los temas en IS, a pesar de que existen algunas iniciativas de estandarización de la terminología que representa los principales conceptos, por ejemplo (IEEE, 2004a), (ACM, 1998) (IEEE, 1990), aún actualmente se utiliza una gran diversidad de términos para referirse a una misma tecnología. De la misma manera, se observa que los autores en IS utilizan una terminología no estandarizada al referirse al tipo de estudio del que trata la publicación (O. Dieste et al., 2009).

Por lo anterior, una búsqueda de experimentos en IS puede arrojar un gran número de artículos no relevantes, requiriendo de un esfuerzo de descarte significativo. Por otra parte, es posible que no se recuperen los experimentos-objetivo, disminuyendo de esta manera la calidad o el éxito de la RS.

Por ello, se consideró fundamental proponer algunas recomendaciones acerca del uso de los términos de búsqueda más efectivos. Para realizar esta propuesta, se analizaron por separado las dos partes de la cadena de búsqueda mencionadas al principio: aquella que corresponde a los términos que hacen referencia al tipo de estudio (experimento controlado) y la que hace referencia al tema de la revisión (por ejemplo, pruebas de software, educción de requisitos, inspección de software).

\section{Recomendaciones (1ra parte):}

Las recomendaciones obtenidas (véase Apéndice A) para la primera parte de la cadena (los términos correspondientes al tipo de estudio) son las siguientes ${ }^{3}$ :

- Usar el término experiment para la búsqueda de experimentos ha demostrado no ser una mala estrategia; sin embargo, el utilizar este término en solitario deja fuera un gran número de artículos donde se utiliza una terminología variada para referirse a los experimentos. No obstante, el número de artículos irrelevantes que se recuperan con el término experiment es uno de los mejores ya que, siendo un término específico ( $y$ no de uso generalista), tiende a localizar artículos que reportan estudios como los que se quieren recuperar. En consecuencia, esta cadena puede ser utilizada si se desea que la búsqueda sea lo más rápida posible.

- Al combinar experiment con sus sinónimos cercanos (los términos que los autores utilizan en lugar del término experiment; por ejemplo, experimental study, experimental comparison, experimental analysis, experimental evidence, y experimental setting, entre otros) se obtienen búsquedas óptimas. En cambio, si se suman otros términos más generales como experimentation, empirical study o empirical evaluation a los sinónimos anteriores, se pueden detectar muchos más experimentos pero se incrementa mucho el número de artículos irrelevantes. En consecuencia, para reducir el número de artículos que no son detectados utilizando el término experiment, se recomienda, en primer lugar,

\footnotetext{
${ }^{3}$ Esta parte de la investigación ha sido publicada en (O. Dieste \& Grimán, 2007; O. Dieste, A. Grimán, \& N. Juristo,
} 2008) 
utilizar una estrategia óptima (i.e. la representada por la cadena de búsqueda experiment $O R$ experimental study OR experimental analysis OR experimental evidence OR experimental setting) o una cadena de alta recuperación (como la representada por la cadena de búsqueda experiment $O R$ empirical study $O R$ experimental study OR empirical evaluation OR experimentation OR experimental comparison $O R$ experimental analysis $O R$ experimental evidence $O R$ experimental setting). No se recomienda utilizar estos sinónimos, ni siquiera empirical study, en solitario ya que ellos dejan por fuera la mayoría de los experimentos.

Respecto a la segunda parte de la cadena de búsqueda, aquella que incluye los términos relacionados con el tema de revisión, la manera de proceder será diferente dependiendo de si se trata de una búsqueda preliminar (como en este caso) o una búsqueda exhaustiva (el cual será tratado más adelante en este capítulo, en la actividad 6.2.6).

\section{Recomendaciones (2da parte):}

Sobre la base anterior, en el estudio realizado se han obtenido las siguientes recomendaciones para optimizar la segunda parte de la búsqueda:

- Para el caso de la búsqueda preliminar, La heurística más intuitiva es utilizar un único término con el que se haga referencia a la tecnología; no obstante, el revisor podría querer incorporar más de un término, para obtener mayor precisión en los resultados.

- En cualquier caso, utilizar uno o más términos simples representativos del tema o tecnología, de ser posible utilizando la literatura especializada o un estándar, como SWEBOK (IEEE, 2004a).

- También pueden utilizarse como términos los artefactos que son generados o los productos sobre los cuales se aplica la tecnología (por ejemplo, en el caso anterior, inspección de diseño, revisión de código, o revisión de software).

A continuación, se muestra un ejemplo en el que se ha utilizado (IEEE, 2004a) para definir el tema inspecciones de software:

(...) un tipo particular de revisión o auditoria, cuyo propósito es detectar e identificar anomalías del producto software. Es liderizado por un facilitador imparcial entrenado en técnicas de inspección. Los miembros de un equipo de inspección poseen diferentes tipos de experiencia. Cada miembro del equipo debe examinar el producto software y otros artefactos antes de la reunión de inspección aplicando, quizás, técnicas analíticas (un tipo de técnica estática) a todo el producto o a una parte de él. Comúnmente se utiliza una lista de chequeo como herramienta de inspección. Las técnicas de revisión o auditoria, dentro de las que se ubican las inspecciones, son, al mismo tiempo, un tipo de técnica estática.

De esta manera, los términos resaltados en la definición pueden ser utilizados para formar la cadena de búsqueda; tomando en cuenta que algunos de ellos son más generales y pueden recuperar artículos menos precisos (por ejemplo, revisión, auditoria, técnica analítica, técnica estática y lista de chequeo), 
mientras que otros son más específicos a las inspecciones de software (por ejemplo, detección de anomalías de software, técnica de inspección, equipo de inspección y reunión de inspección).

\subsubsection{Documentar la estrategia de búsqueda}

El propósito de esta tarea es registrar la estrategia utilizada para asegurar que la búsqueda sea repetible y que pueda ser aplicada por cualquier revisor. Una estrategia de búsqueda debería incluir al menos los siguientes elementos:

- Repositorio: la base de datos bibliográfica donde se realizó la búsqueda; por ejemplo, IEEE Xplore, Scopus, ACM DL, entre otros.

- Campos de búsqueda: los segmentos del documento donde se realiza la búsqueda (por ejemplo, título, resumen, título y resumen, o todos los campos).

- Cadena de búsqueda: los términos que componen la consulta realizada a la base de datos bibliográfica; por ejemplo, experiment, software inspection, etc. Tales términos serán utilizados por el motor de búsqueda de la base de datos bibliográfica para buscar en los campos indicados. Cuando se utiliza más de un término para la búsqueda, suelen utilizarse cláusulas como AND y OR, entre otras, propias del motor de búsqueda que está siendo utilizado.

La Tabla 6.2 muestra un ejemplo de cómo puede ser documentada la estrategia de búsqueda utilizada en el proceso de revisión. Como puede observarse, se trata de una búsqueda en el título y el resumen del artículo, utilizando un conjunto de términos alternativos (el campo de búsqueda puede contener cualquiera de ellos y no necesariamente todos). En este ejemplo, las cláusulas TITLE y ABS son las utilizadas por el motor de búsqueda de SCOPUS para realizar la búsqueda en los campos Título y Resumen, respectivamente.

Tabla 6.2. Ejemplo de documentación de una estrategia de búsqueda

\begin{tabular}{|l|l|}
\hline Repositorio & Campos/Cadena de búsqueda \\
\hline Scopus & $\begin{array}{l}\text { ABS("software inspection" AND (experiment OR "experimental study" OR "experimental } \\
\text { comparison" OR "experimental analysis" OR "experimental evidence" OR "experimental } \\
\text { setting")) OR TITLE("software inspection" AND (experiment OR "experimental study" OR } \\
\text { "experimental comparison" OR "experimental analysis" OR "experimental evidence" OR } \\
\text { "experimental setting")) }\end{array}$ \\
\hline
\end{tabular}

\section{Recomendaciones:}

- $\quad$ Registrar esta información para cada repositorio utilizado. 
- Utilizar un manejador para referencias bibliográficas como los que se han mencionado anteriormente.

\subsubsection{Ejecutar la búsqueda}

Con esta tarea se busca obtener un conjunto de artículos utilizando la estrategia de búsqueda diseñada para la RS.

De los artículos obtenidos, algunos, o incluso muchos, pueden no ser de interés para la RS. Por ello, los resultados obtenidos deberían ser presentados en un formato que permita su análisis y el filtrado de artículos irrelevantes. En el Apéndice B se presenta el formulario B02-Análisis de artículos recuperados, propuesto para registrar los artículos recuperados en las búsquedas. La información que recoge este formulario es la siguiente:

- Identificador (ID): código con el que se conocerá el artículo durante todo el proceso de RS. Para asignar un identificador puede utilizarse un valor numérico que corresponda con la posición del artículo dentro del formulario de registro; también puede asignarse un código alfanumérico que represente alguna característica del artículo o del proyecto (por ejemplo, INS\#\# o REQ\#\# podrían ser formatos de codificación en una revisión sobre inspección de software o requisitos, respectivamente). El ID asignado acompañará al artículo a lo largo de las diferentes actividades donde se necesite hacer mención a éste.

- Autores: se sugiere indicar el listado completo de autores del artículo, evitando el uso de abreviaciones (por ejemplo, “et al."). Esto permitirá identificar más rápidamente artículos duplicados o que estén relacionados.

- Referencia: indica la fuente original del artículo. Aunque éste haya sido localizado en un repositorio bibliográfico debe conocerse la referencia a la revista o conferencia en la cual se encuentra publicado. Esto permitirá: 1) recuperar el artículo directamente en caso necesario, y 2) si fuese necesario, establecer estadísticas sobre la distribución de artículos en el universo de búsqueda.

- Fichero: ubicación física del artículo en el directorio del proyecto de RS. Es recomendable organizar el repositorio de acuerdo a los buscadores utilizados para facilitar cualquier comprobación de los artículos que sea necesaria posteriormente.

- Resumen: puede incluirse en esta sección aquellos extractos del resumen del artículo en los que se resalten los aspectos de interés del estudio, i.e. objetivo, número y naturaleza de los participantes (sujetos experimentales), tratamientos o intervenciones ensayadas, conclusiones de los experimentadores.

- Relevancia: indica si el artículo es o no útil para la RS. Este atributo no será valorado en esta actividad.

En la Tabla 6.2 se muestra un ejemplo de artículos recuperados en una búsqueda de estudios sobre inspección de software. 
Tabla 6.3. Ejemplo de registro de artículos recuperados

\begin{tabular}{|c|c|c|c|c|c|}
\hline ID & Autores & Referencia & Fichero & Resumen & ¿Relevante? \\
\hline 1 & $\begin{array}{l}\text { L. } \\
\text { Harjumaa }\end{array}$ & $\begin{array}{l}\text { A pattern approach } \\
\text { to software } \\
\text { inspection process } \\
\text { improvement. } \\
\text { Software Process } \\
\text { Improvement and } \\
\text { Practice, vol. 10, pp. } \\
455-465,2005 \text {. }\end{array}$ & $\begin{array}{l}\text { /Scopus/sco } \\
\text { _28.pdf }\end{array}$ & $\begin{array}{l}\text { - Introduce un conjunto } \\
\text { de patrones para } \\
\text { orientar en la mejora } \\
\text { del proceso de } \\
\text { inspección }\end{array}$ & Sí $\square$ No $\square$ \\
\hline 2 & $\begin{array}{l}\text { A. Bianchi, } \\
\text { F. } \\
\text { Lanubile, } \\
\text { G. } \\
\text { Visaggio, }\end{array}$ & $\begin{array}{l}\text { A controlled } \\
\text { experiment to } \\
\text { assess the } \\
\text { effectiveness of } \\
\text { inspection } \\
\text { meetings. } \\
\text { International } \\
\text { Software Metrics } \\
\text { Symposium, } \\
\text { Proceedings, pp. 42- } \\
\text { 50, 2001. }\end{array}$ & $\begin{array}{l}\text { /scopus/Sco } \\
\text { _34.pdf }\end{array}$ & 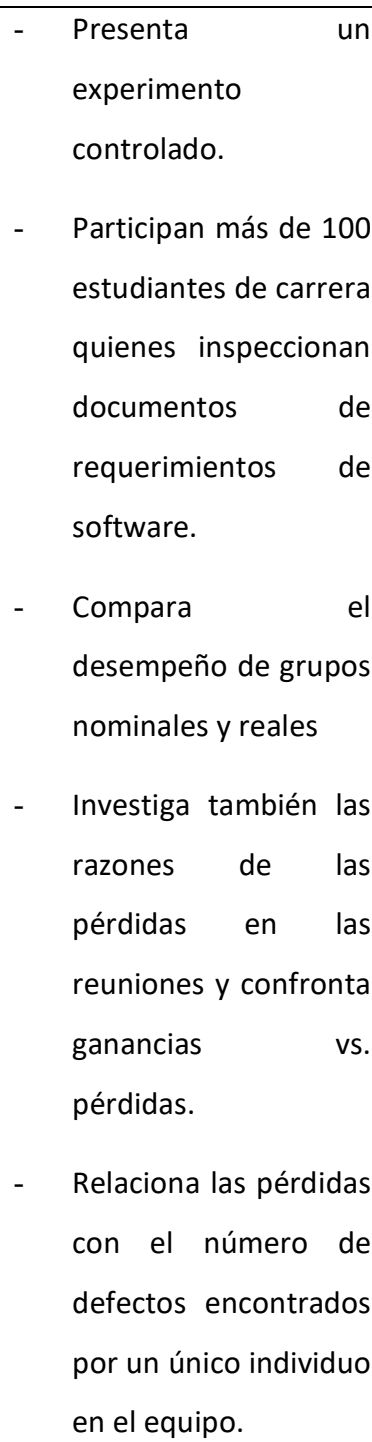 & Sí $\square$ No $\square$ \\
\hline
\end{tabular}




\section{Recomendación:}

Independientemente del formato utilizado para registrar el resultado de la BúSQUEDA PRELIMINAR, cada una de las referencias a los artículos identificados como relevantes debería registrarse utilizando algún programa manejador de referencias (ProCite ${ }^{\circledR}$, EndNote $^{\circledR}$, etc.). Esto permitirá mantener actualizada la lista de referencias de los estudios relevantes, documentar comentarios, enlazar directamente con la fuente de la publicación, etc.

Las actividades anteriores pueden ejecutarse de manera iterativa hasta reunir un número suficiente de artículos recuperados. Para ello se proponen las siguientes estrategias:

1. Ensayar nuevas cadenas de búsqueda utilizando nuevos términos específicos. Estos pueden ser sinónimos aplicados a la tecnología; por ejemplo, de acuerdo a (IEEE, 2004a), detección de defectos podría ser un sinónimo para buscar estudios sobre inspección de software.

2. Ensayar nuevas cadenas de búsqueda utilizando nuevos términos más generales. Estos pueden ser, por ejemplo, la categoría a la que pertenece la tecnología de interés. En el caso de la inspección de software, podría utilizarse revisión de software. Debe tomarse en cuenta que si bien esto puede aumentar la recuperación de la búsqueda, también tiene una alta probabilidad de obtener basura.

3. Modificar las fuentes de información. Incluir otras publicaciones del área que no hayan sido consideradas, o incluso incluir otras áreas afines al área de interés.

4. Modificar los campos de búsqueda. En último lugar, si el equipo está dispuesto a asumir los costes involucrados, podrían modificarse los campos de búsqueda para tratar de maximizar la recuperación de artículos. Sin embargo, debe tenerse en cuenta el esfuerzo de descarte de artículos irrelevantes que esta estrategia puede provocar.

\subsubsection{DESCARTE DE ARTÍCULOS IRRELEVANTES}

Esta actividad es realizada una vez que se concluye la BúsQUEDA PRELIMINAR. Tiene como propósito analizar los artículos recuperados para eliminar aquellos que no sean relevantes para el objetivo de la RS y los cuales han sido recuperados debido a la imprecisión de la cadena de búsqueda. Para ello, se proponen las tareas mostradas en la figura 6.4. 


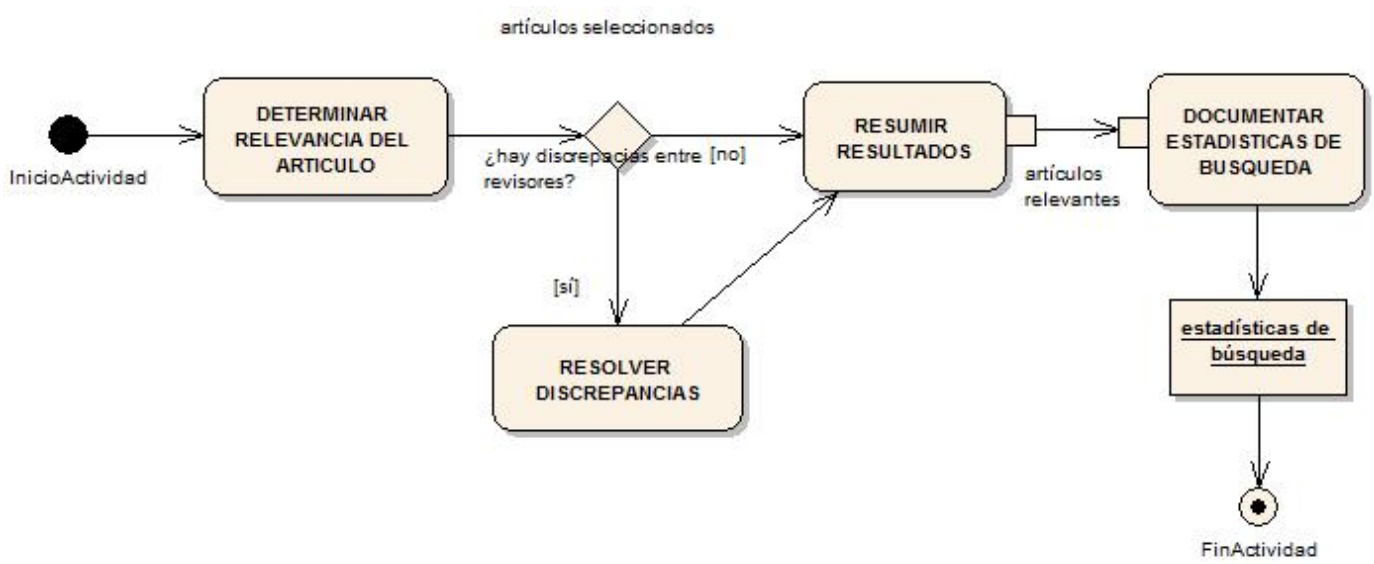

Figura 6.4. Tareas relacionadas con el DESCARTE DE ARTÍCULOS IRRELEVANTES

Esta actividad pertenece al escenario objetivo a alto nivel por lo que busca complementar las actividades previas para permitir así definir el objetivo de la RS.

\subsubsection{Determinar la relevancia del artículo}

Esta tarea tiene como propósito decidir si un artículo es de interés o no para la RS. Esta decisión será tomada con base en el objetivo del experimento. Un artículo se considerará relevante (o potencialmente elegible) cuando reporte un experimento y éste sea de interés para la el tema de la RS.

\section{Recomendaciones:}

El análisis para determinar si un artículo es potencialmente elegible puede hacerse de tres maneras:

- Leer sólo títulos: esta estrategia es recomendable sólo en aquellos casos donde el volumen de artículos recuperados sea muy grande. En tales casos el proceso se hará más eficiente al limitar el análisis, en una primera iteración, sólo al título del artículo. No obstante, es posible que para algunos artículos con títulos poco significativos sea necesario contar con más información, como se indica a continuación.

- Leer título y resumen: cuando el volumen de artículos recuperados no sea muy grande, es recomendable realizar este tipo de análisis ya que, además de descartar artículos con mayor precisión, permite identificar artículos duplicados y replicaciones de estudios.

- Leer el documento completo: por razones de eficiencia, esta estrategia no debería aplicarse en esta fase. Cuando el número de artículos sea grande, o muy grande, la lectura de cada documento completo implicará un enorme coste en tiempo y esfuerzo. Teniendo, además, en mente que el objetivo de esta tarea es simplemente filtrar los artículos irrelevantes, es poco probable que la lectura 
del documento completo sea mucho más efectiva que la estrategia anterior (analizar, solamente, título y resumen).

Luego de la lectura de cada uno de los artículos es necesario documentar los resultados de esta tarea. Puesto que se ha recomendado la lectura del título y resumen solamente, la información recogida en el formulario B02-Análisis de artículos recuperados (Apéndice C.2) es suficiente para llevar a cabo esta tarea. Durante el descarte de artículos irrelevantes se completará el campo referente a la relevancia del artículo para la RS.

\section{Recomendación:}

Cuando se cuente con recursos suficientes, es recomendable realizar un doble chequeo de los estudios para determinar su relevancia. Este doble chequeo consiste en que dos revisores, de manera paralela e independiente, realicen la revisión de los artículos y tomen una decisión acerca de su selección/descarte. Una vez que se obtienen los resultados de los revisores involucrados, es posible calcular el índice de coincidencia (inter-rater agreement o kappa statistics). Para presentar los resultados de los revisores que participan en esta actividad, puede utilizarse el formulario B02b_Análisis de artículos recuperados - Doble chequeo presentado en el Apéndice B.

\subsubsection{Resolver discrepancias}

Cuando más de un revisor participa en el descarte de artículos irrelevantes, puede requerirse un esfuerzo adicional para resolver las diferencias entre ellos. Tales diferencias pueden deberse a descuidos por parte de alguno(s) de los revisores o a interpretaciones diferentes de los aspectos involucrados en el experimento. El objetivo de esta tarea es apoyar la toma de decisión cuando existan discrepancias de opinión o juicio entre los revisores.

Algunas técnicas que pueden ser efectivas para resolver los desacuerdos entre los revisores son las siguientes (J. P. T. Higgins \& S. Green, 2006; K. Khan et al., 2001):

- Rectificación: en muchas ocasiones las diferencias en cuanto a la selección de un estudio obedecen a errores de omisión por parte de uno de los revisores sobre aspectos clave del estudio en cuestión. En tales casos, la discusión de los resultados pondrá en evidencia los aspectos que hayan sido omitidos, con la consecuente rectificación de una de las partes.

- Consenso: cuando las discrepancias entre los revisores se deban a diferencias en cuanto a la interpretación de los diversos aspectos del estudio, la discusión de tales aspectos debe llevar no sólo a lograr el acuerdo de la mayoría sino también a reducir las objeciones de la minoría para llegar a la decisión más satisfactoria. En caso de que no se alcance el consenso, es recomendable 
realizar una votación para evitar una situación de bloqueo. En aquellos casos en que se produzca una situación de bloqueo será necesario recurrir a algún otro método de resolución de conflictos.

- Juicio de expertos: cuando se alcance una situación de bloqueo al momento de decidir sobre seleccionar o no un estudio, puede requerirse la intervención de uno o más árbitros expertos que emitan su opinión acerca del estudio. La experticia de los árbitros consultados debe establecerse en relación con los criterios de inclusión/exclusión utilizados. Por ejemplo, solicitar la opinión de expertos en experimentación, en análisis estadístico, o en RS en el tema de interés.

- Información adicional: cuando no sea posible resolver las discrepancias por alguna de las técnicas mencionadas anteriormente, se pude recurrir a los autores del estudio para solicitar información adicional que permita aclarar las dudas o mal interpretaciones que puedan existir acerca de los aspectos involucrados con el estudio. Esto ameritará colocar el estudio en un estado de "pendiente por decidir" mientras se logra concretar la información necesaria para la toma de decisión.

\section{Recomendación:}

Durante la discusión es recomendable realizar una lectura completa del contenido del artículo.

\subsubsection{Resumir resultados}

El propósito de esta tarea es resumir la información de los artículos que han sido seleccionados. Los artículos relevantes pueden ser resumidos en el formulario B03-Resumen de artículos relevantes presentado en el Apéndice B. Este formulario está compuesto por los siguientes campos:

- ID del artículo: puede asignarse un número consecutivo o un código alfanumérico.

- $\quad$ Autores: es conveniente describir la lista completa de autores del artículo.

- Referencia: colocar en este campo el título del artículo junto con los datos de la publicación (volumen, número, números de páginas y año).

- Fichero: es conveniente indicar la ubicación física del repositorio que contiene artículo a fin de agilizar su posterior recuperación.

- Resumen: con base en el resumen del artículo, describir los aspectos más importantes del estudio; por ejemplo, objetivo, factor y variables respuesta, conclusiones, entre otros.

- Observación: este campo es útil para dejar registro de cualquier información que pueda ser relevante para las etapas posteriores.

En la Tabla 6.4 se muestra un ejemplo de resumen de artículos relevantes sobre inspección de software. 
Tabla 6.4. Ejemplo de resumen de artículos relevantes

\begin{tabular}{|c|c|c|c|c|}
\hline Autores & Referencia & Fichero & Resumen & Observación \\
\hline $\begin{array}{l}\text { R.Pe } \\
\text { aes W.Cl }\end{array}$ & $\begin{array}{l}1 . \quad \text { An } \\
\text { Experimental Evaluation } \\
\text { of an Experience-Based } \\
\text { Capture-Recapture } \\
\text { Method in Software Code } \\
\text { Inspections, Empirical } \\
\text { Software Engineering, } \\
\text { vol. V3, pp. 381-406, } \\
\text { 1998. }\end{array}$ & $\begin{array}{l}\text { /Sprin } \\
\text { ger/ } \\
\text { Spring } \\
\text { er4.pdf }\end{array}$ & $\begin{array}{l}\text { - Propone un método de } \\
\text { captura-recaptura basado en la } \\
\text { experiencia } \\
\text { - Un experimento de inspección } \\
\text { de código-C es conducido para } \\
\text { evaluar las mejoras del método } \\
\text { y su aplicabilidad a } \\
\text { inspecciones de código } \\
\text { - Concluye acerca de: } \\
\text { estimaciones del método vs } \\
\text { estimaciones del método de } \\
\text { máxima probabilidad, } \\
\text { sensibilidad de las inspecciones } \\
\text { ante cambios en los datos de } \\
\text { inspección }\end{array}$ & $\begin{array}{l}\text { Es dudoso } \\
\text { si se trata de } \\
\text { un } \\
\text { experimento } \\
\text { o un caso de } \\
\text { estudio }\end{array}$ \\
\hline $\begin{array}{l}\text { M. } \\
\text { Babar, } \\
\quad \text { B.Kit } \\
\text { chenha } \\
\text { m, } \\
\quad \text { L } \\
\text { Zhu, } \\
\quad \text { I.Gor } \\
\text { ton, } \\
\text { R.Jeffery } \\
\text {, }\end{array}$ & $\begin{array}{l}2 . \quad \text { An empirical } \\
\text { study of groupware } \\
\text { support for distributed } \\
\text { software architecture } \\
\text { evaluation process, } \\
\text { Journal of Systems and } \\
\text { Software, vol. 79, pp. } \\
\text { 912-925, 2006. }\end{array}$ & $\begin{array}{l}\quad \text { /scedir } \\
\text { ect/ } \\
\text { sdirect1.p } \\
\text { df }\end{array}$ & $\begin{array}{l}\text { - Presenta un estudio piloto } \\
\text { (experimento) usado para } \\
\text { evaluar la viabilidad de un } \\
\text { experimento + grande que } \\
\text { investigue la factibilidad del } \\
\text { soporte groupware para la } \\
\text { evaluación distribuida de } \\
\text { arquitecturas de software } \\
\text { - El estudio piloto arrojó algunos } \\
\text { hallazgos acerca de la viabilidad } \\
\text { de un proceso de EA soportado } \\
\text { por groupware. }\end{array}$ & $\begin{array}{l}\quad \text { El mismo } \\
\text { estudio } \\
\text { aparece en } \\
\text { ID_5 }\end{array}$ \\
\hline $\begin{array}{l}\text { T.Th } \\
\text { elin, } \\
\text { P.Runes } \\
\text { on } \\
\quad \text { C.W } \\
\text { ohlin }\end{array}$ & $\begin{array}{l}3 . \quad \text { An } \\
\text { Experimental Comparison } \\
\text { of Usage-Based and } \\
\text { Checklist-Based Reading, } \\
\text { IEEE Transactions on } \\
\text { Software Engineering, } \\
\text { 29(8):687-704, 2003. }\end{array}$ & $\begin{array}{l}\quad \text { /Xplor } \\
\text { e/Xplore3 } \\
\text { 0.pdf }\end{array}$ & $\begin{array}{l}\text { - Presenta un experimento en el } \\
\text { cual se compara UBR con CBR } \\
\text { - Miden: efectividad y eficiencia } \\
\text { en detectar fallos críticos desde } \\
\text { el punto de vista del usuario. }\end{array}$ & $\begin{array}{l}\text { Es } \\
\text { dudoso si es } \\
\text { experimento } \\
\text { o caso de } \\
\text { estudio }\end{array}$ \\
\hline $\begin{array}{l}\text { T. } \\
\text { Thelin } \\
\quad \text { C.An } \\
\text { dersson } \\
\qquad \text { P.Ru } \\
\text { neson, } \\
\quad \text { N.Dz } \\
\text { amashvil } \\
\text { i- } \\
\text { Fogelstr } \\
\text { om, }\end{array}$ & $\begin{array}{l}\text { 4. A replicated } \\
\text { experiment of usage- } \\
\text { based and checklist- } \\
\text { based reading, } 2004 . \\
\text { Proceedings of the 10th } \\
\text { International Symposium } \\
\text { on Software Metrics } \\
\text { (METRICS'04), pp. 246- } \\
256\end{array}$ & $\begin{array}{l}\text { /Xplor } \\
\text { e/ Xplore } \\
\text { 5.pdf }\end{array}$ & $\begin{array}{l}\text { - Presenta la replicación de un } \\
\text { experimento que comparó } \\
\text { técnicas de lectura basada en } \\
\text { uso vs basada en checklist } \\
\text { - Presenta tanto la replicación } \\
\text { como el experimento original y } \\
\text { compara ambos resultados } \\
\text { (Xplore_30.pdf) } \\
\text { - La replicación confirmó los } \\
\text { resultados del exp. original }\end{array}$ & $\begin{array}{l}\quad \text { Muestra } \\
\text { una } \\
\text { replicación de } \\
\text { ID_3 }\end{array}$ \\
\hline
\end{tabular}




\begin{tabular}{|c|c|c|c|c|}
\hline $\begin{array}{l}\quad \text { M.B } \\
\text { abar, } \\
\text { B.Kitche } \\
\text { nham, } \\
\text { L.Zh } \\
\text { u, } \\
\text { R.Jef } \\
\text { fery }\end{array}$ & 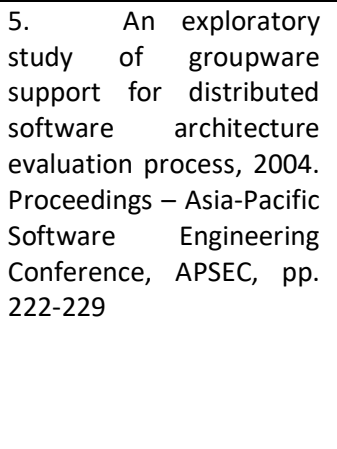 & $\begin{array}{l}\text { /Xplor } \\
\text { e/ } \\
\text { Xplore } \\
\text { 8.pdf }\end{array}$ & 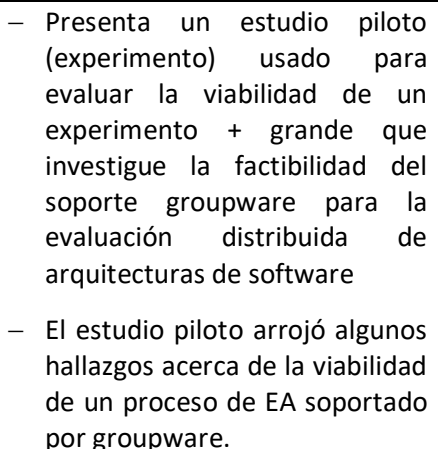 & $\begin{array}{l}\quad \text { El mismo } \\
\text { estudio } \\
\text { aparece en } \\
\text { ID_2 }\end{array}$ \\
\hline
\end{tabular}

\section{Recomendaciones:}

- Puede utilizarse el campo Observación del formulario para indicar información importante sobre el artículo; por ejemplo, algún elemento que debería ser chequeado posteriormente antes de incluir el artículo, alguna condición importante del estudio que se desea destacar, etc. Si el artículo consiste en una replicación de un estudio previo, podría indicarse en este campo el artículo donde aparece el experimento original que está siendo replicado. También puede utilizarse este campo para indicar que varios artículos reportan el mismo estudio empírico.

- Cuando las búsquedas sean realizadas en diferentes repositorios, pueden encontrarse múltiples apariciones del mismo artículo; en estos casos deberán eliminarse dichas duplicaciones.

- Cuando un mismo estudio aparezca publicado con diferente alcance en fuentes distintas que han sido consideradas relevantes (por ejemplo, una versión corta se encuentra publicada en un artículo de conferencia mientras que una versión más extensa se encuentra publicada en una revista), ambos artículos deben ser utilizados en conjunto; esto es, de manera complementaria.

\subsubsection{Documentar estadísticas de las búsquedas}

El objetivo de esta tarea es resumir los resultados de las búsquedas, así como el número de experimentos y replicaciones que han sido identificadas. Para ello puede utilizarse el formulario B04Estadísticas de búsqueda propuesto en el Apéndice C.4. En este formulario, se describe la siguiente información:

- Repositorio: se refiere al nombre de cada una de las bases de datos bibliográficas consultadas.

- Artículos recuperados: se refiere al número de artículos que son obtenidos una vez que se ejecuta la búsqueda en un repositorio.

- Artículos relevantes: se refiere al número de artículos obtenidos en un repositorio luego del descarte de artículos irrelevantes. 
- Total de artículos relevantes (distintos): se refiere al número total de artículos obtenidos al ejecutar la búsqueda en todos los repositorios, no incluyendo artículos que se encuentren duplicados.

- Total de estudios (distintos): se refiere al número total de experimentos recuperados luego de ejecutar la búsqueda en todos los repositorios. Este número no necesariamente coincidirá con el total de artículos recuperados, ya que un artículo puede reportar más de un experimento.

- Total de replicaciones: se refiere al número total de replicaciones que se encuentran en el conjunto de estudios seleccionados.

En la Tabla 6.5 se presenta un ejemplo donde se documentan las estadísticas de búsqueda en cinco bases de datos bibliográficas. En total, 81 artículos resultaron relevantes luego de las tareas anteriores. Nótese que, debido a las duplicaciones, sólo 58 de los 81 artículos relevantes son distintos. Además, en estos 58 artículos, 54 estudios relevantes aparecen reportados, de los cuales 51 son distintos (los otros tres estudios se encuentran reportados en alguno de los artículos anteriores con un alcance diferente). Por otra parte, 4 de los 58 estudios, son replicaciones.

Tabla 6.5. Ejemplo de estadísticas de búsqueda

\begin{tabular}{|c|c|c|}
\hline Repositorio & Artículos recuperados & Artículos relevantes \\
\hline Xplore & 30 & 22 \\
\hline SpringerLink & 11 & 11 \\
\hline ScienceDirect & 10 & 9 \\
\hline ACM DL & 19 & 16 \\
\hline Scopus & 34 & 23 \\
\hline \multicolumn{2}{|c|}{ Total artículos relevantes (distintos) } & 58 \\
\hline \multicolumn{2}{|c|}{ Total estudios (distintos) } & 51 \\
\hline \multicolumn{2}{|c|}{ Total replicaciones } & 4 \\
\hline
\end{tabular}

\section{Evaluación de la continuidad del proceso}

Una vez que se han descartado los artículos irrelevantes, puede presentarse alguno de los siguientes escenarios:

- Se cuenta con estudios suficientes para continuar con el proceso.

- No se ha logrado obtener estudios suficientes para continuar con el proceso debido a que no existen estudios relacionados con el tema de revisión.

En este punto, debe tomarse una decisión sobre continuar con el proceso o detenerlo (véase Tabla 5.2

- Hitos del proceso de RS); en cuyo caso, el proceso podría comenzar nuevamente con una motivación o 
necesidad diferente. Deberá generarse igualmente el Informe de Revisión a fin de documentar la experiencia aunque no sea exitosa.

\subsubsection{SELECCIÓN DE ESTUDIOS CANDIDATOS}

El propósito de esta actividad es contribuir al establecimiento de un objetivo de revisión específico, con base en los artículos seleccionados como relevantes en la actividad anterior. Las tareas indicadas en la figura 6.5, y que se describen en las secciones siguientes, deben ser ejecutadas para completar esta actividad.

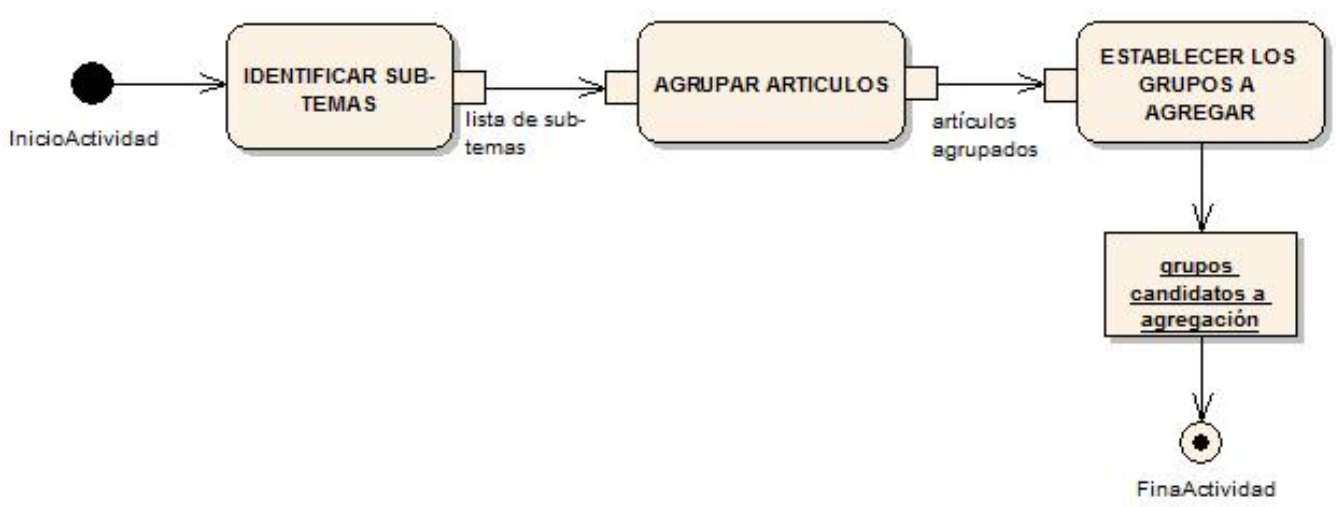

Figura 6.5. Tareas relacionadas con la Selección de estudios a agregar

\subsubsection{Identificar sub-temas}

El propósito de esta tarea es identificar los temas (o sub-temas) relacionados con cada experimento a fin de permitir a los revisores decidir cuál de ellos ofrece mayor potencial para generar conocimiento útil a través de la RS.

Esta tarea es de vital importancia dentro del proceso de revisión, ya que permitirá establecer un objetivo preciso de revisión al seleccionar un GCA que podrá ser utilizado posteriormente durante la agregación.

Dado que hasta el momento solamente se cuenta con un tema de revisión establecido, el cual puede ser muy general, cada artículo relevante recuperado puede tratar un sub-tema diferente; esto es, una especialización del tema de revisión (un tema de estudio mucho más específico que el anterior). De esta manera, una gran variedad de su-temas pueden identificarse en el conjunto de artículos relevantes.

Por ello, la identificación del tema requiere de un análisis riguroso de cada artículo relevante, así como de cierto nivel de conocimiento en el área de la IS.

A continuación, se describen los pasos involucrados en esta tarea. Para facilitar su comprensión se utilizará como ejemplo el artículo identificado como ID_1 en la Tabla 6.4. 
i. Leer título, resumen y palabras claves de cada uno de los estudios relevantes identificados en el DesCARTE DE ARTículos IRRELEVANTES, resaltando los términos relacionados con el tema de estudio. En el artículo mencionado anteriormente, la información de título, resumen y palabras claves es la siguiente:

An Experimental Evaluation of an Experience-Based Capture-Recapture Method in Software Code Inspections. (Runeson \& Wholin, 1998)

Abstract. In order to improve the efficiency of inspections, quantitative data on defect content have to be the basis for decisions in the inspection process. An experience-based capture-recapture method is proposed, which overcomes some problems with the basic pre-requisites of the original method. A C-code inspection experiment is conducted to evaluate the enhanced method and its applicability to software code inspections. It is concluded that the experience-based estimation procedure gives significantly better estimates than the maximum-likelihood method and the estimates are not very sensitive to changes in the inspection data.

Keywords: software inspection, capture-recapture, defect content estimation, experience-based estimation, experiment

ii. Analizar la información anterior y establecer el objetivo general del estudio resaltando las menciones al tema específico de estudio. Extraído del artículo anterior, se tiene el siguiente objetivo:

Proponer un método de estimación de defectos por captura-recaptura (basado en la experiencia) y su aplicabilidad a las inspecciones de software, para mejorar los problemas presentados por el método original (de máxima probabilidad).

iii. Establecer uno o más sub-temas con base en el análisis anterior. En el ejemplo anterior puede considerarse como sub-tema general comparación de métodos de estimación de defectos; en particular, la comparación de métodos basados en experiencia versus métodos basados en probabilidad.

iv. Una vez identificado el sub-tema de cada estudio, es conveniente asignar un código para facilitar su posterior referencia.

Recomendaciones:

- Un caso especial al determinar el tema, son los estudios que tratan la validación de una nueva propuesta (por ejemplo, un nuevo método, técnica, etc.). Estos estudios deberían ser clasificados bajo un sub-tema particular, que permita distinguirlos en el momento de la selección de los grupos agregables, en vista de que tales estudios presentan características especiales: no ensayan tratamientos comúnmente conocidos sino novedosos (por ejemplo, el resultado de un proyecto de tesis, etc.) y no son comparados con otro método. De esta manera, el experimento investiga los resultados obtenidos antes y después de la aplicación de la técnica o método propuesto. 
- Debido a que este tipo de estudios puede no ser demasiado interesante para los revisores, será útil identificarlos claramente, para su posterior inclusión/exclusión.

- En el caso en que la información analizada no sea suficiente para determinar el sub-tema (o tema específico de estudio) debería leerse el texto completo del artículo.

En la Tabla 6.6 se presentan algunos ejemplos de sub-temas relacionados con la inspección de software.

Tabla 6.6. Ejemplos de sub-temas de inspección de software

\begin{tabular}{|l|c|}
\hline \multicolumn{1}{|c|}{ ID Sub-tema (ST) } & Descripción \\
\hline ST-1 & Comparación de técnicas de lectura y métodos de inspección \\
\hline ST-2 & Evaluación de la Costo-efectividad (de reuniones u otros factores) \\
\hline ST-3 & $\begin{array}{c}\text { Comparación inspección tradicional vs. soportada por herramientas (por } \\
\text { ejemplo, groupware) }\end{array}$ \\
\hline ST-4 & Mejora de una o más técnicas \\
\hline ST-5 & Validación de nuevas propuestas \\
\hline
\end{tabular}

\subsubsection{Agrupar artículos}

El objetivo de esta tarea es organizar los experimentos relevantes basados en los sub-temas anteriormente identificados. Para hacer esto, se propone utilizar el formulario B05-Agrupamiento por sub-tema y tipo de estudio (véase Apéndice B) en el cual se describen:

- Sub-tema: se refiere a cada uno de los tópicos específicos obtenidos en la tarea anterior. Para cada uno de los sub-temas se indican los estudios correspondientes.

- Tipo de estudio: los estudios divididos por cada sub-tema son al mismo tiempo categorizados según su tipo. Como el interés de esta investigación se concentra en los experimentos, podría considerarse separar los experimentos controlados y aleatorizados (que se llamarán simplemente experimentos) y de aquellos no aleatorizados (cuasi-experimentos).

\section{Recomendaciones:}

Debe tomarse en cuenta que en los resúmenes de los artículos seleccionados previamente, puede no ser claro el tipo de estudio; por ejemplo, en algunos casos puede hacerse referencia al término experimento sin que se reporte efectivamente un experimento controlado aleatorizado (RCT). En esos casos, es conveniente separar aquellos estudios que indican explícitamente que se ha aplicado un experimento controlado de los que indican solamente que se ha conducido un experimento; tomando en cuenta que algunos de estos últimos podrían ser reclasificados como casos de estudios o cuasi-experimentos cuando se realice una lectura completa, posteriormente. 
En la Tabla 6.7, se muestra un ejemplo de la distribución de estudios en los sub-temas mencionados en la Tabla 6.6.

Tabla 6.7. Artículos agrupados por sub-tema

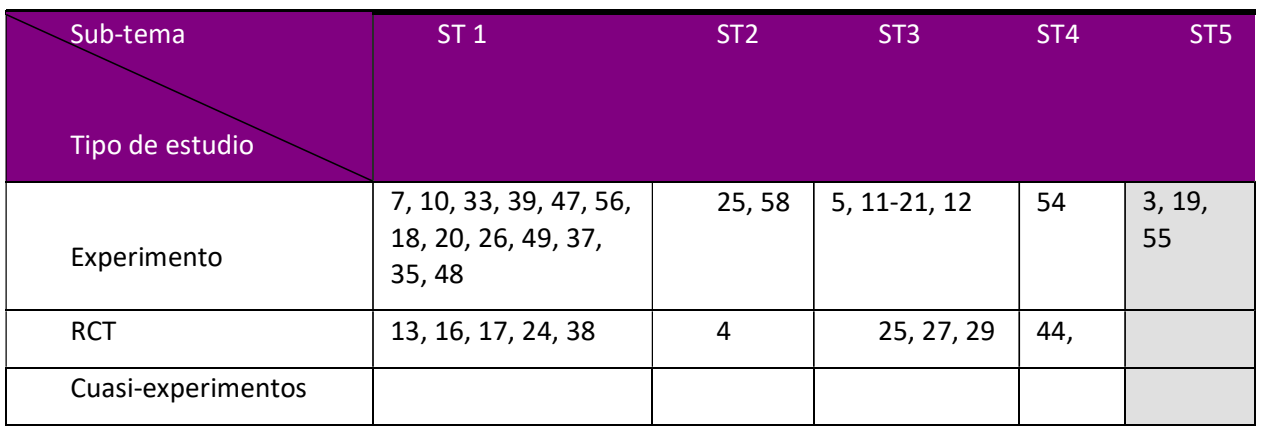

Las áreas sombreadas representan los estudios que se presumen de menor calidad con base, en su tipo de estudio, exclusivamente. Nótese que los artículos que reportan la validación de una nueva propuesta, a pesar de ser un experimento, tenderán a ser considerados estudios de poco interés para la mayoría de las RS.

\subsubsection{Establecer los grupos candidatos a agregación}

Esta tarea tiene como propósito seleccionar uno o más grupos de estudios que potencialmente puedan ser combinados para obtener evidencias. Tales grupos pueden ser seleccionados con base en el formulario B05 (por ejemplo, experimentos sobre comparación de técnicas de lectura de código).

\section{Recomendaciones:}

- Pueden seleccionarse más de un grupo de estudios, siempre que éstos parezcan coherentes y agregables entre sí, y cuenten con un número suficiente de estudios.

- Debe tomarse en cuenta que estudios sobre la validación de una nueva propuesta, pueden resultar de utilidad en aquellos casos en que son referenciados por otro estudio de interés para la revisión o cuando sus conclusiones proporcionen información sobre otras técnicas y métodos ampliamente reconocidos de interés para la revisión.

Los grupos deben ser seleccionados con base en el interés del revisor, buscando maximizar el número de estudios/sujetos de manera de aumentar la probabilidad de obtener resultados válidos.

Como ejemplo, en la Tabla 6.8 se muestran los posibles GCAs en una RS sobre inspección de software, relacionados con el sub-tema comparación de técnicas de lectura y métodos de inspección.

Tabla 6.8. Grupos candidatos a agregación 


\section{Grupo candidatos a agregación $\quad$ Artículo} ST1- RCTs

ART_7, ART_10, ART_33, ART_39, ART_47, ART_56, ART_18, ART_20, ART_26, ART_49, ART_37, ART_35, ART_48, ART_13, ART_16, ART_17, ART_24, ART_38

Nótese que ésta es la última actividad que pertenece exclusivamente al escenario objetivo a alto nivel, por lo que a partir de aquí se presentarán actividades que son comunes para ambos escenarios. Esto significa que las actividades que se describen a continuación podrán ser acometidas por el revisor, independientemente de que éste haya comenzado el proceso teniendo sólo un objetivo a alto nivel, ya que para este momento se cuenta con información suficiente para establecer un objetivo específico.

\section{Evaluación de la continuidad del proceso}

Una vez que se han obtenido los GCA, puede presentarse alguno de los siguientes escenarios:

- Se cuenta con al menos un GCA de interés y con experimentos suficientes.

- No se ha logrado obtener al menos un GCA con experimentos suficientes o los GCA identificados no son de interés para los revisores.

En este punto, debe tomarse una decisión sobre continuar con el proceso o detenerlo (véase Tabla 5.2 - Hitos del proceso de RS); en cuyo caso, el proceso podría comenzar nuevamente con una motivación o necesidad diferente.

\subsubsection{DECLARACIÓN DEL OBJETIVO DE REVISIÓN}

El propósito de esta actividad es definir con precisión el objetivo de revisión, la pregunta de revisión y los criterios de inclusión/exclusión de estudios. Las tareas a realizar son las mostradas en la figura 6.6 y descritas en las siguiente secciones.

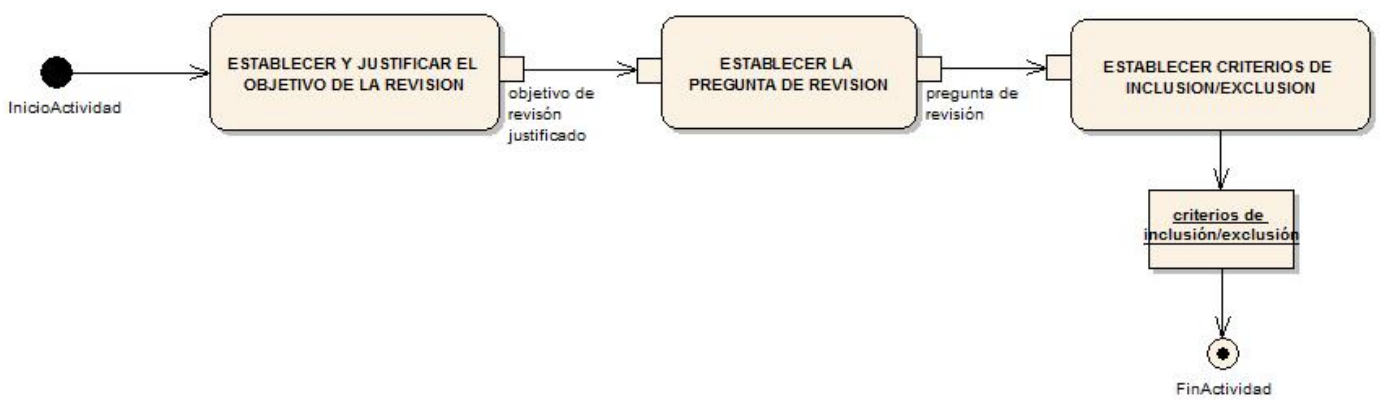

Figura 6.6. Tareas relacionadas con la DECLARACIÓN DEL OBJETIVO DE REVISIÓN 
El resultado de esta actividad deberá ser documentada para facilitar su verificación posterior durante la RS o en consultas futuras. Para ello, se propone el formulario B07_Declaración del objetivo de revisión (véase el Apéndice B).

\subsubsection{Establecer y justificar el objetivo de la revisión}

Esta tarea busca describir, de manera clara y precisa, la meta que se persigue alcanzar con la RS. EI objetivo de la revisión debe representar la meta que se desea alcanzar de una manera bastante refinada y, por lo tanto, establecer la información concreta que se desea obtener con la RS. Por ello, se dice que el objetivo de revisión orientará las posteriores actividades dentro del proceso. Adicionalmente, los beneficios de proseguir con este objetivo de investigación deberían ser establecidos desde el punto de vista académico y/o profesional. Para documentar este objetivo, se sugiere utilizar las siguientes secciones del formulario B07_Declaración del objetivo de revisión:

- Enunciado: describir el objetivo de manera específica incluyendo la tecnología de interés y, de ser posible, los tratamientos a ser comparados.

- Justificación: describir los beneficios que se espera obtener de realizar la RS para el objetivo anteriormente planteado.

La tabla 6.9 muestra el enunciado y justificación del objetivo de revisión en el caso de estudio que se ha venido tratando como ejemplo.

Tabla 6.9. Ejemplo de enunciado y justificación de un objetivo de revisión en el formulario B07

\begin{tabular}{|l|l|l|}
\hline Enunciado & $\begin{array}{l}\text { Comparar técnicas de lectura de código y métodos de inspección de } \\
\text { software. }\end{array}$ \\
\cline { 2 - 4 } & \multirow{3}{*}{ OBJETIVO } & $\begin{array}{l}\text { Desde el punto de vista académico, la comparación de técnicas de lectura } \\
\text { de código y métodos de inspección puede permitir establecer los } \\
\text { problemas abiertos (variables no ensayadas, técnicas de mayor interés } \\
\text { para la comunidad, etc.); en cambio, desde el punto de vista profesional, } \\
\text { esta revisión permitirá mejorar el cuerpo de conocimiento relacionado con } \\
\text { esta tecnología, lo cual permitiría, al mismo tiempo, orientar a los } \\
\text { desarrolladores en sus organizaciones acerca de las mejores prácticas para } \\
\text { asegurar la calidad del producto software. }\end{array}$ \\
\hline
\end{tabular}

\subsubsection{Establecer la pregunta de revisión}

Esta tarea tiene como propósito delimitar el alcance de la RS, al establecer un conjunto de restricciones que buscan describir con precisión aquello que se quiere investigar. Estas restricciones permiten realizar la búsqueda de estudios primarios de una manera más específica, establecer los criterios de inclusión/exclusión y planificar la extracción de datos.

Según (J. P. T. Higgins \& S. Green, 2006) para considerar que una pregunta ha sido claramente definida, ésta debe especificar: el tipo de sujetos involucrados en la RS, los tipos de tratamientos o comparaciones, 
los tipos de resultados y los tipos de diseño de los estudios de interés. Esto es lo que se conoce en la literatura especializada como PIOS (acrónimo de: Participants/Population, Interventions, Outcomes, Study Design). En esta investigación se ha tomado la propuesta de (J. P. T. Higgins \& S. Green, 2006) y se ha complementado con algunos elementos adicionales; proponiéndose para esta tarea describir los siguientes aspectos en el formulario B07:

- Situación y ambiente experimental: en primer lugar se trata de establecer el interés de la RS en cuanto a la aplicación de una tecnología a un tipo de problema particular. Por ejemplo, para el caso de las técnicas de lectura de código y métodos de inspección de software, se podría establecer la siguiente situación: "Ias técnicas a estudiar buscan detectar defectos en el código y otros artefactos; para ello, se cuenta con la participación de analistas, arquitectos, programadores, y otros roles involucrados en el proceso de desarrollo". En segundo lugar se debe también establecer si la RS está interesada en un tipo de sujetos particular con base en su perfil (estudiante, profesional), su edad, su experticia, su grado de entrenamiento, nivel educativo, etc.

- Tratamientos: este aspecto se refiere a los factores, y niveles de los mismos, que son de interés para la RS. Por lo tanto, establece las comparaciones que serán consideradas dentro de la revisión. En el ejemplo anterior, puede ser de interés estudiar las técnicas de lectura de código basadas en listas de chequeo, casos de uso, perspectivas, escenarios y métodos ad-hoc; así como las distintas comparaciones entre ellos.

- Variables respuesta: en este punto se busca delimitar el interés de la RS a unos resultados específicos medidos dentro de cada experimento, por ejemplo, respecto a las técnicas antes mencionadas, puede ser de interés para los revisores solamente el estudio de la efectividad y la eficiencia de la técnica en la detección de defectos.

- Tipo de diseño: se refiere al interés de la RS en un tipo de estudio particular o a un conjunto de tipos de estudios (p.e. experimentos, casos de estudio, estudios observacionales, etc.). En el contexto de esta investigación, se ha establecido de antemano que la RS sólo incluirá experimentos.

En la tabla 6.10 se muestra el uso del formulario B07 para la RS en inspección de software.

Tabla 6.10. Ejemplo de los componentes de la pregunta de revisión en el formulario B07

\begin{tabular}{|c|c|c|}
\hline \multirow{4}{*}{$\begin{array}{l}\text { PREGUNTA } \\
\text { DE REVISIÓN }\end{array}$} & $\begin{array}{l}\text { Situación } \\
\text { ambiente } \\
\text { experimental }\end{array}$ & $\begin{array}{l}\text { La presente RS está interesada en estudios que ensayen las } \\
\text { técnicas de interés utilizando como sujetos a estudiantes en el nivel } \\
\text { de pre-grado, independientemente de su nivel de entrenamiento o } \\
\text { experticia. }\end{array}$ \\
\hline & Tratamientos & $\begin{array}{l}\text { Técnicas de lectura de código basadas en listas de chequeo, casos } \\
\text { de uso, perspectivas, escenarios y métodos ad-hoc; así como las } \\
\text { distintas comparaciones entre ellos. }\end{array}$ \\
\hline & $\begin{array}{l}\text { Variables } \\
\text { respuesta }\end{array}$ & $\begin{array}{l}\text { Efectividad y la eficiencia de la técnica en la detección de } \\
\text { defectos }\end{array}$ \\
\hline & Tipo de diseño & Experimentos \\
\hline
\end{tabular}




\subsubsection{Establecer los criterios de inclusión/exclusión de estudios}

Esta última tarea persigue establecer los criterios que regirán la selección de artículos dentro de la RS. Aunque diversos criterios pueden ser definidos por el revisor, una parte de ellos pueden derivarse directamente de la pregunta de revisión descrita en la tarea anterior. Con base en los componentes de la pregunta de revisión, los criterios que han sido considerados en el marco de esta investigación son los siguientes:

- Inclusión/exclusión por diseño del estudio. Además de establecer el tipo de estudio (experimento, caso de estudio, estudio observacional, etc.), puede limitarse aún más el interés de la RS utilizando otros aspectos del diseño experimental, tales como la aleatorización, o el ensayo de factores adicionales, etc.

- Inclusión/exclusión de estudios según el tipo de sujeto. Al establecer este criterio se puede limitar la RS a estudios que incluyan sólo estudiantes o profesionales como parte de los sujetos experimentales.

- Inclusión/exclusión de estudios que validan una tecnología. Este criterio permite establecer si la RS está interesada en aquellos estudios donde se propone una nueva tecnología y se evalúa la misma; por ejemplo, estudios donde se evalúan los resultados de una tesis o proyecto de investigación. En tales casos, no se trata de un estudio comparativo sino de la medición de los resultados de aplicar la nueva propuesta (por ejemplo, un caso de estudio). Aunque este tipo de estudios puede resultar en problemas durante la agregación, no se descarta su valor para otros fines ya que pudieran proporcionar información adicional acerca de alguna tecnología conocida o incluir referencias a algún estudio de interés para la revisión.

- Inclusión/exclusión de estudios según la relevancia de la tecnología ensayada. Este criterio permite restringir la RS a tecnologías más o menos conocidas; por ejemplo, una RS podría sólo considerar aquellos estudios que evalúen o comparen dos o más técnicas de lectura o métodos de detección de defectos ampliamente reconocidas en la literatura del área.

- Inclusión/exclusión de estudios de acuerdo a las mediciones. Este criterio permite restringir los estudios incluidos en la RS según la variable respuesta que es medida. Por ejemplo, la efectividad de la técnica.

- Inclusión/exclusión de estudios por contexto experimental. Se refiere a limitar la RS a estudios que apliquen la tecnología de interés en etapas particulares del proceso de desarrollo (tarea experimental), a determinados objetos o en un ambiente específico (laboratorio o industria).

Tabla 6.11. Ejemplo de los criterios de I/O en el formulario B07

\begin{tabular}{|l|l|l|l|}
\hline & & - & $\begin{array}{l}\text { Experimentos y cuasi-experimentos conducidos en } \\
\text { laboratorio } \\
\text { CRITERIOS DE I/E }\end{array}$ \\
& Incluir & $\begin{array}{l}\text { con estudiantes universitarios (pre-grado), } \\
\text { que evalúen o comparen la efectividad de dos o más }\end{array}$ \\
\hline
\end{tabular}




\begin{tabular}{|l|l|l|}
\hline & & $\begin{array}{l}\text { técnicas de lectura o métodos de detección de defectos } \\
\text { ampliamente reconocidas en la literatura del área, } \\
\text { para la detección de errores en el diseño de modelos UML. }\end{array}$ \\
\cline { 2 - 4 } & $-\quad \begin{array}{l}\text { Casos de estudio y Cuasi-experimentos } \\
\text { Excluir }\end{array}$ & $\begin{array}{l}\text { Estudios en los que los autores propongan la técnica y la } \\
\text { validen en comparación con una técnica conocida. }\end{array}$ \\
& $-\quad \begin{array}{l}\text { Estudios sin grupo control } \\
\text { Estudios conducidos sin supervisión, por ejemplo, aquellos } \\
\text { donde los sujetos aplicaron la técnica fuera del laboratorio }\end{array}$ \\
& $-\quad$ Estudios observacionales \\
\hline
\end{tabular}

\subsubsection{BÚSQUEDA Y LECTURA DE ANTECEDENTES}

Un escenario posible cuando se comienza una RS es que ya exista alguna revisión previa sobre el mismo objetivo. El propósito de esta actividad es realizar una exploración rápida para descartar que ya exista una RS que satisfaga el objetivo establecido para la actual RS.

Para ello, se propone acometer las tareas mostradas en la figura 6.7.

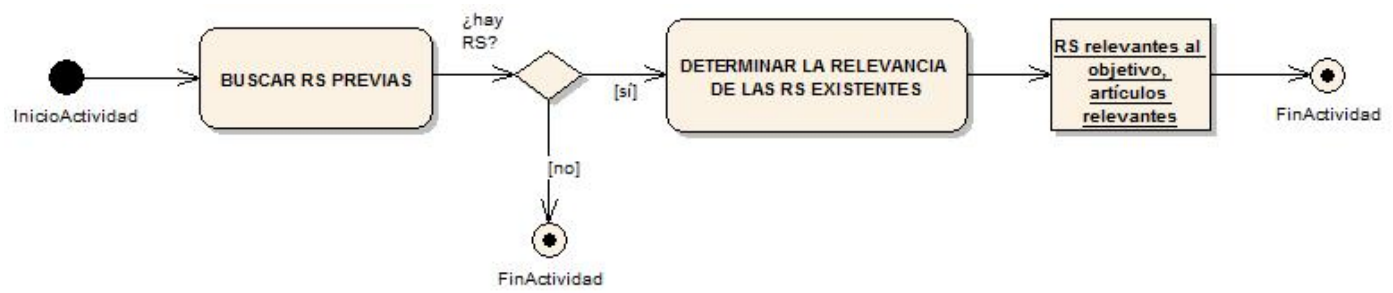

Figura 6.7. Tareas relacionadas con la actividad BÚSQUEDA Y LECTURA DE ANTECEDENTES

\subsubsection{Buscar RS previas}

El objetivo de esta tarea es localizar las revisiones anteriores que hayan afrontado un objetivo de revisión similar.

Debido a que actualmente no existen muchas RS realizadas en IS, es imposible realizar recomendaciones de búsquedas empíricamente. No obstante, es razonable suponer que para ello puedan utilizarse heurísticas similares a las descritas en la actividad BÚSQUEDA PRELIMINAR DE ESTUDIOS POR TEMA, en la sección 6.3.2. Para ello, en el paso correspondiente a la definición de la cadena de búsqueda, deberán sustituirse los términos relacionados con el tipo de estudio (por ejemplo, experiment, experimental analysis, etc.) por systematic review, secundary study, meta-análisis, etc. El resto de las recomendaciones pueden ser aplicadas en esta búsqueda.

Las RS recuperadas durante esta búsqueda deben ser documentadas en el formulario B06_Análisis de las RS recuperadas (véase Apéndice C.6) para facilitar su posterior análisis, el cual incluye:

- Identificador (ID) del antecedente: un código que permite identificar de manera única cada entrada en la lista de RS localizadas.

- Autores de la RS: una lista con los nombres de los revisores que figuran en la RS. 
- Referencia de la fuente original: datos bibliográficos que aunque la RS haya sido localizado en un repositorio bibliográfico debe conocerse la referencia a la revista o conferencia en la cual se encuentra publicado.

- Fichero en el directorio del proyecto: ubicación física del artículo en el directorio del proyecto de RS.

- Elementos del resumen: un extracto del resumen de la RS en el cual se resaltan los aspectos de interés, i.e. objetivo de revisión, criterios de inclusión/exclusión, conclusiones de los experimentadores, etc.

- Satisfacción del objetivo: indica si la RS responde o no al objetivo de la actual RS. Este atributo no será valorado en esta actividad.

Recomendaciones:

- Para asignar el ID, podría asignarse un valor numérico consecutivo que corresponda con su entrada en el formulario de registro. También puede asignarse un código alfanumérico que permita representar alguna característica del antecedente (por ejemplo, INS\# o REQ\# podrían utilizarse como formato de codificación de RS sobre inspecciones de código o requisitos, respectivamente).

- En cuanto a los autores, debe indicarse el listado completo de autores, evitando el uso de abreviaciones del tipo et al. Esto permitirá identificar más rápidamente revisiones duplicadas o que están relacionadas.

En la Tabla 6.12 se muestra un ejemplo de una búsqueda de RS sobre inspección de software.

Tabla 6.12. Ejemplo de documentación de una RS previa

\begin{tabular}{|c|c|c|c|c|c|}
\hline D & Autore & Referencia & Fichero & Resumen & $\begin{array}{l}\text { ¿Satisface } \\
\text { objetivo? }\end{array}$ \\
\hline 1 & $\begin{array}{l}\text { S.Kollanus } \\
\text { J. Koskinen }\end{array}$ & $\begin{array}{l}\text { Survey of Software } \\
\text { Inspection } \\
\text { Research: 1991-2005. } \\
\text { Computer Science and } \\
\text { Information Systems } \\
\text { Reports. Working Papers } \\
\text { WP-40. University of } \\
\text { Jyväskylä, 2007. }\end{array}$ & /RS/RS_3.pdf & $\begin{array}{l}\text { - El artículo presenta una } \\
\text { encuesta sistemática de } \\
\text { la investigación } \\
\text { conducida en el área de } \\
\text { inspecciones de software } \\
\text { entre 1991-2005 y revela } \\
\text { las tendencias que han } \\
\text { emergido. } \\
\text { - Cubre también artículos } \\
\text { relacionados con peer- } \\
\text { reviews. } \\
\text { - Utilizó } 15 \text { revistas de } \\
\text { reputación en Ingeniería } \\
\text { de Software e ICSE. } \\
\text { - Concluyen que las } \\
\text { inspecciones } \\
\text { generalmente producen }\end{array}$ & Sí $\square$ No $\square$ \\
\hline
\end{tabular}




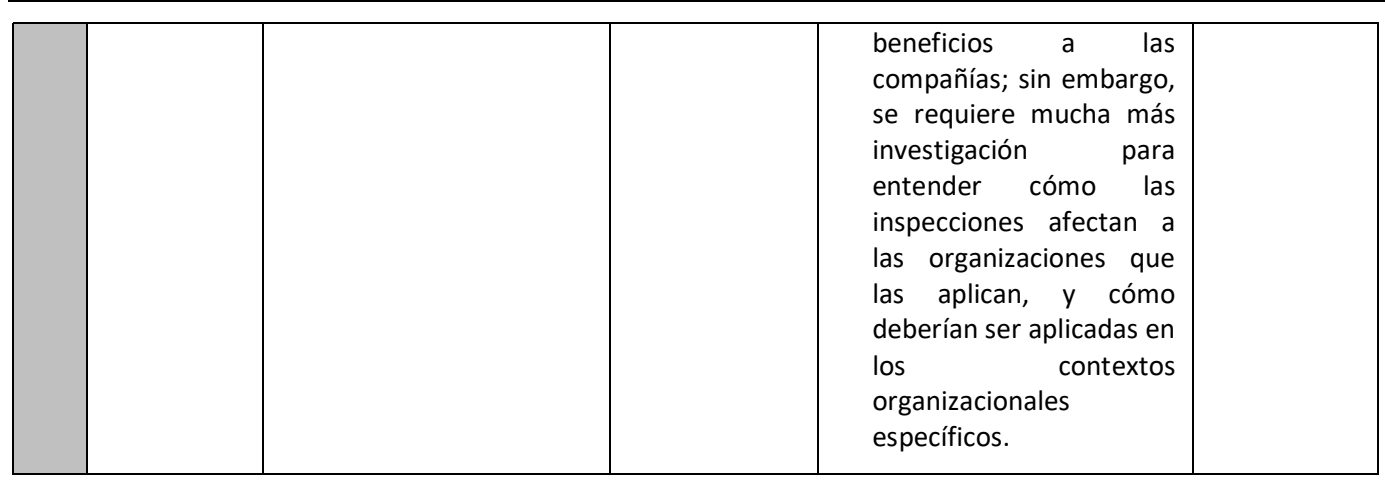

\subsubsection{Determinar la relevancia de las RS existentes}

El propósito de esta tarea es determinar la relevancia y la adecuación de la(s) RS que sean localizadas en relación al objetivo propuesto para la RS actual en la DECLARACIÓN DEL OBJETIVO DE REVISIÓN. Esto implicar determinar si las RS localizadas se corresponden completamente con dicho objetivo.

\section{Recomendación:}

En el caso de que se localice alguna RS previa que no sea de calidad o que no satisfaga completamente el objetivo, los estudios utilizados en dicha RS deberían ser extraídos.

En este análisis se utilizará el formulario generado en la tarea anterior, cumplimentando el campo relacionado con la respuesta al objetivo. En esta tarea pueden participar dos revisores, utilizando los mecanismos anteriormente mencionados en la sección 6.3.3.2. RESOLVER DISCREPANCIAS (votación, consenso, etc.) para manejar las discrepancias que surjan entre ambos.

\section{Evaluación de la continuidad del proceso}

En el caso de que las revisiones encontradas respondan completamente al objetivo, la RS debería darse por terminada. En cambio, si ninguna revisión es encontrada o las existentes no responden al objetivo planteado, lo cual podría considerarse como el escenario más probable, el proceso continúa con la actividad siguiente (véase Tabla 5.2 - Hitos del proceso de RS).

\subsubsection{BÚSQUEDA REFINADA}

Una vez que se cuenta con un objetivo específico definido (el cual incluye la pregunta y los criterios de inclusión/exclusión) es necesario realizar una búsqueda refinada que localice, a través de una estrategia muy exhaustiva, la mayor cantidad de artículos potencialmente relevantes. 
El objetivo de esta actividad es entonces detectar el mayor número posible de artículos relevantes (o potencialmente elegibles) de una manera óptima con respecto al esfuerzo de selección/descarte de artículos.

Como puede verse en la figura 6.8, las tareas a realizar dentro de esta actividad son básicamente las mismas que se describieron en la sección 6.3.2 para la BúSQUEDA PRELIMINAR DE ESTUDIOS POR TEMA. Esto es así debido a que la única diferencia entre ambas actividades radica en el nivel de detalle que se utiliza para definir la cadena de búsqueda. Por lo tanto, las actividades SeleCCIONAR FUENTES DE INFORMACIÓN, SELECCIONAR

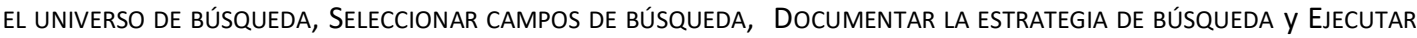
LA BÚSQUEDA no serán descritas nuevamente en esta sección (véanse las secciones 6.3.2.1, 6.3.2.2, 6.3.2.3, 6.3.2.5 y 6.3.2.6, dentro de la BÚSQUEDA PRELIMINAR DE ESTUDIOS POR TEMA). Debe tomarse en cuenta que las tareas, recomendaciones y formularios descritos en las mencionadas secciones deben ser aplicadas en esta actividad. No obstante, si se inició la RS a través del escenario objetivo a alto nivel, no será necesario realizar nuevamente la selección de las fuentes de información ni de los campos de búsqueda, ya que se contará para este momento con las decisiones acerca de la base de datos bibliográfica y los campos de búsqueda a utilizar. 


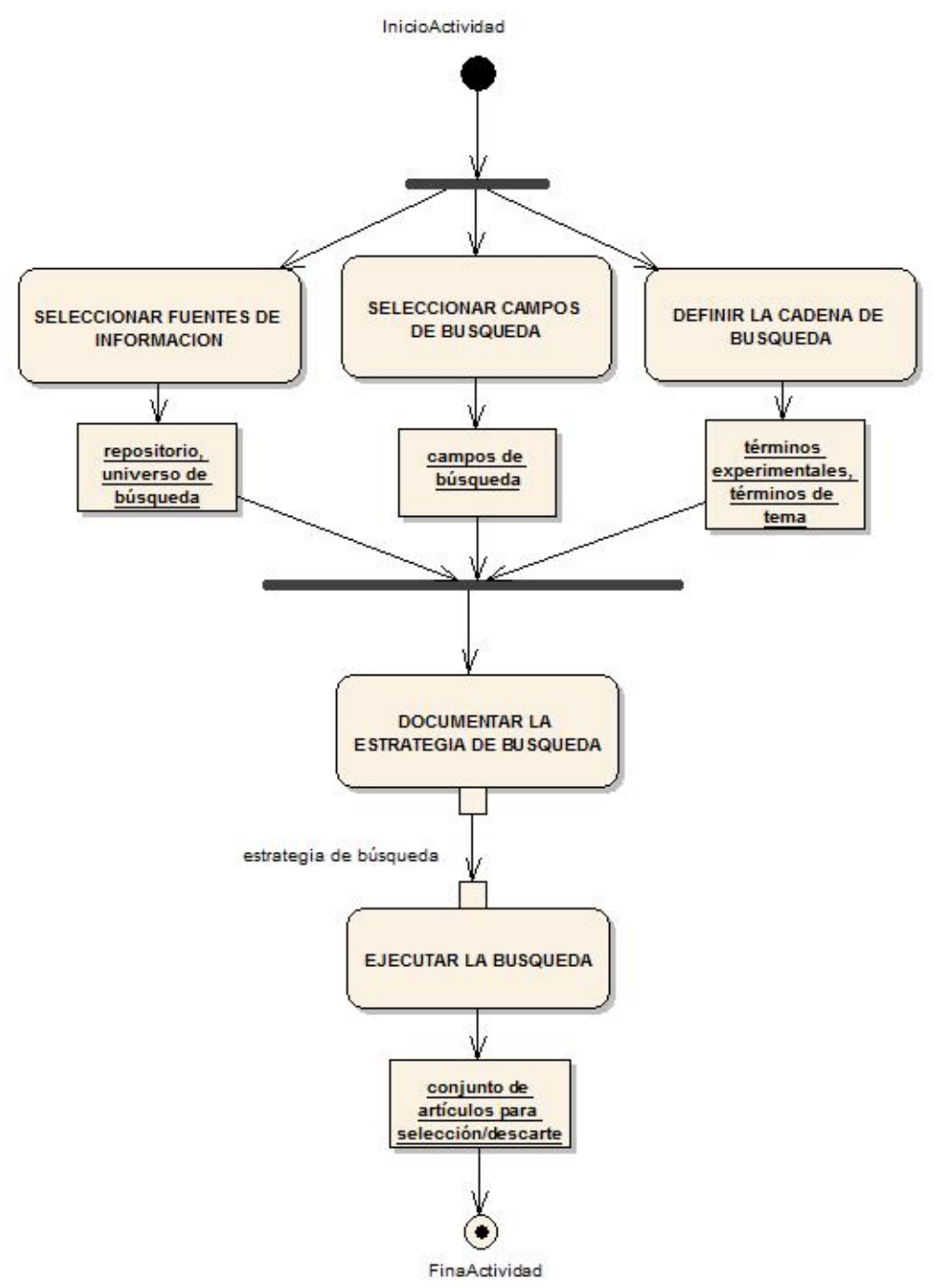

Figura 6.8. Tareas relacionadas con la actividad BúSQUEDA REFINADA

Esta sección se centrará entonces es describir la tarea Definir la cadena de búsqueda.

\subsubsection{Definir la cadena de búsqueda}

Una de los propósitos de definir la pregunta de revisión es que los componentes de la misma pueden ser convenientemente utilizados al momento de definir la cadena de búsqueda. Como se explicó en la sección 6.3.5.2, tales componentes incluyen la Población (Participants), los Tratamientos (Interventions), las Variables Respuesta (Outcomes), y el Tipo de Diseño (Study Design).

No obstante, en esta investigación se han estudiado solamente dos de estos componentes y su utilidad en la definición de la cadena de búsqueda (véase Apéndice D.2): el tipo de estudio (que en el caso de la presente investigación está limitado a experimentos), y los tratamientos; es decir, la tecnología que 
interesa estudiar a los revisores. El uso de los otros componentes de la pregunta en la definición de la cadena de búsqueda no ha sido estudiado por las siguientes razones:

- En cuanto al tipo de sujeto, se presume que tendrá un bajo impacto como restricción de la búsqueda ya que típicamente los experimentos utilizan estudiantes como sujetos experimentales y sólo unos pocos de ellos ensayan tecnologías con sujetos profesionales.

- En cuanto a las variables respuesta, se ha considerado que debido a que las bases de datos bibliográficas de uso en IS no están preparadas para realizar búsquedas por campos específicos al diseño experimental, incluir términos relacionados con las mediciones o variables respuesta puede hacer la búsqueda demasiado compleja. En caso de que se desee utilizar esta restricción, se sugiere utilizar la misma estrategia que se describe en esta sección para los términos relacionados con los tratamientos.

Con respecto a la primera parte se mantienen para esta actividad todas las recomendaciones que han sido ya descritas en la sección 6.3.2.3 (dentro la BÚSQUEDA PRELIMINAR DE ESTUDIOS POR TEMA).

En cuanto a la segunda parte, se ha realizado un estudio de cómo optimizar la búsqueda incorporando términos muy específicos relacionados con el objetivo de la revisión. Para ello, se han analizado diferentes estrategias de búsqueda que podrían permitir maximizar la cantidad de estudios recuperados:

a. Estrategia generalista: esta estrategia corresponde a un revisor con conocimientos muy generales acerca de la tecnología. Consiste en realizar la búsqueda con un único término que sea muy representativo de la tecnología de interés.

Recomendaciones:

- Puede ser una estrategia aceptable en aquellos casos en los que no sea prioritario maximizar la cantidad de material relevante a incorporar en la RS o cuando se cuente con recursos limitados. Sin embargo, este término arrojará mejores resultados cuando se cuente con conocimientos amplios sobre el tema.

- Al tratar de maximizar la recuperación, incorporando términos, se corre el riesgo de que la precisión desmejore significativamente por efecto del uso de términos poco específicos. La consulta a expertos puede contribuir a prevenir resultados de este tipo; no obstante, una estrategia de búsqueda de este tipo es altamente dependiente del perfil y conocimiento del experto.

b. Estrategia generalista apoyada en estándares: este tipo de búsqueda corresponde a un revisor con conocimientos generales del tema que utiliza algún estándar de la IS, por ejemplo, el Software Engineering Body of Knowledge -SWEBOK (IEEE, 2004b), el Standard Glossary of Software Engineering Terminology (IEEE, 1990) y el Computing Classification System (Machine, 1998), como apoyo para realizar la búsqueda. 


\section{Recomendaciones:}

El uso de documentación estándar es también una estrategia que puede contribuir a mejorar las propiedades de una búsqueda; no obstante, los resultados serán dependientes del tópico y el estándar utilizado. La completitud y organización de los contenidos pueden ser determinantes para la identificación de términos útiles para la búsqueda. Por otra parte, no existe garantía de que los autores de los experimentos sigan tales estándares al momento de escribir sus títulos y resúmenes. En cuanto al tema, la madurez de éste puede ser determinante para contar con un vocabulario más o menos estandarizado que esté siendo usado por los autores de los experimentos; esto hace que difícilmente pueda obtenerse el $100 \%$ de los artículos relevantes en un tema de IS. Por ejemplo, en el caso de inspección de software resultó especialmente útil el Standard Glossary de IEEE.

c. Estrategia especialista: esta estrategia parte de los términos sugeridos por un experto en la tecnología.

d. Estrategia iterativa: en esta estrategia se utiliza uno o más términos "semilla" para ejecutar una primera búsqueda; posteriormente se extraen nuevos términos de cada estudio relevante recuperado para incorporar estos términos en sucesivas cadenas de búsqueda. Esta estrategia incluye los siguientes pasos (véase Figura 6.9):

1. Identificar un término "semilla" que será aquel con el que se ejecute la primera iteración de búsqueda. La identificación de este primer término dependerá, como se dijo anteriormente, de los conocimientos y experiencia del revisor, pudiéndose incluso utilizar alguno de los estándares que se han mencionado anteriormente en esta sección. En este punto la estrategia iterativa se alimenta de las estrategias anteriores. Por otra parte, debe tenerse en cuenta que los resultados de las iteraciones serán sensibles al hecho de utilizar un término semilla muy general o, por el contrario, muy específico.

2. Una vez ejecutada la primera búsqueda (iteración 1), los artículos recuperados son sometidos entonces a la actividad de selección/descarte para eliminar aquellos que sean irrelevantes para la SR. Para esta actividad se utilizará el título y resumen de cada artículo. En aquellos casos en los que exista duda acerca de la relevancia del artículo, deberá leerse el texto completo.

3. Al mismo tiempo que se determina que un artículo es relevante se extraen del título, resumen y palabras claves aquellos términos que sean representativos de la tecnología de interés (por ejemplo, sinónimos, términos representando categorías para la tecnología, tipos específicos de la tecnología, técnicas relacionadas con ella, etc.) que permitirán construir una nueva cadena de búsqueda para la próxima iteración.

4. El ciclo se repite hasta que no se localicen nuevos artículos relevantes o hasta que se alcance otro criterio de satisfacción establecido por los revisores. 


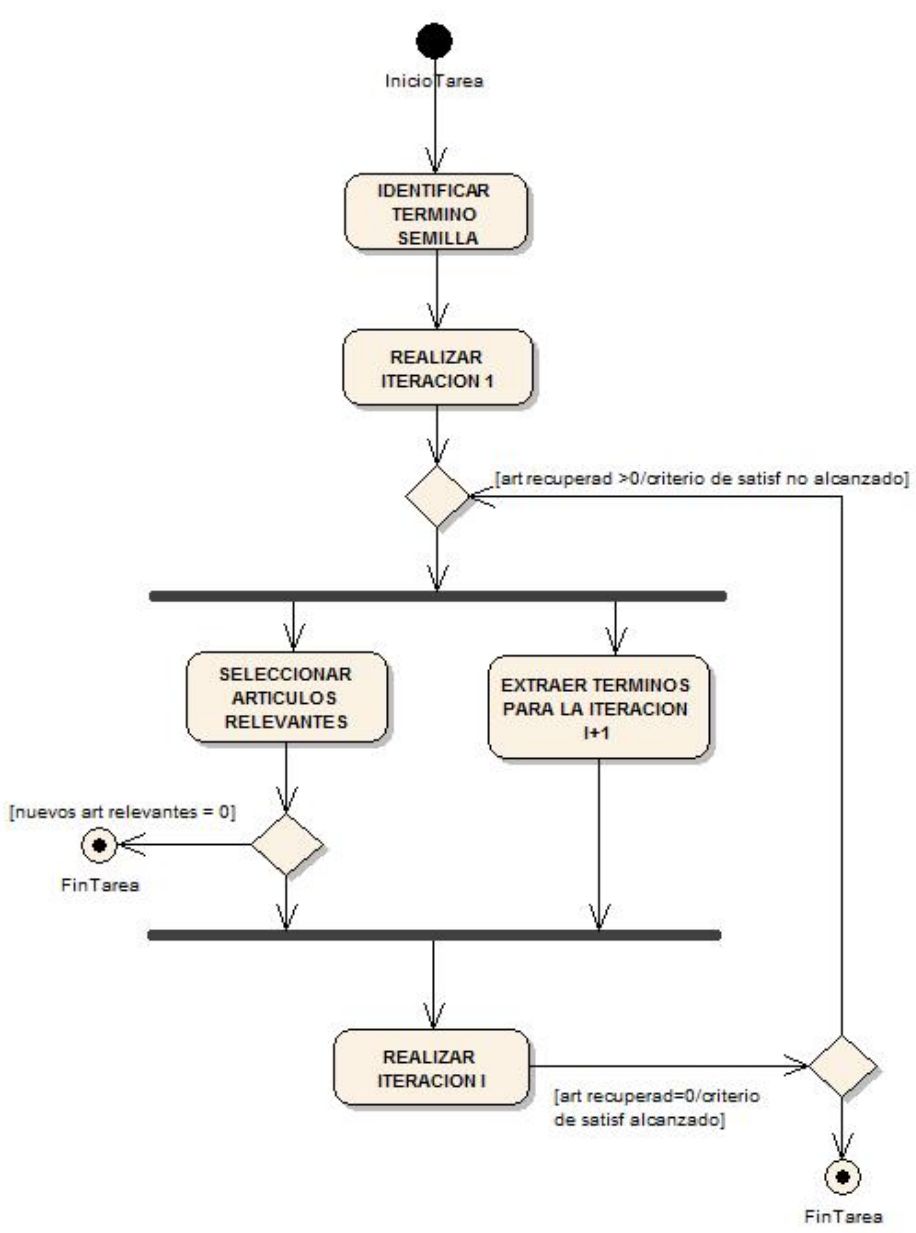

Figura 6.9. Tareas relacionadas con la BúSQUEDA ITERATIVA

\section{Recomendaciones:}

- En aquellos casos en los que se cuente con recursos ilimitados o donde maximizar la cantidad de artículos relevantes para la RS sea de alta prioridad, la estrategia iterativa puede proporcionar resultados muy satisfactorios. Sin embargo, esta estrategia no es excluyente con las anteriores y requiere decisiones acerca del término con el que se debe comenzar a iterar.

- Utilizar un término semilla que sea más o menos específico puede garantizar un valor de recuperación aceptable en la primera iteración, lo cual permitirá al mismo tiempo la extracción de la mayor cantidad de términos útiles para la próxima iteración. Por otra parte, los términos extraídos deberían ser convenientemente seleccionados ya que el efecto de usar términos muy generales puede ser muy perjudicial para la precisión de la búsqueda.

- Seleccionar uno o más términos no-generales a ser utilizados como semilla en la primera iteración. En este paso puede ser recomendable utilizar alguna de las estrategias previas, con especial énfasis en el uso de documentación estándar (IEEE Glossary Standard) o la consulta a expertos. No obstante, se previene sobre el uso de términos semilla demasiado específicos ya 
que éstos podrían presentar una muy baja recuperación, lo que sólo permitiría extraer un número extremadamente pequeño de términos para la siguiente iteración.

- A partir de la primera iteración de búsqueda extraer aquellos términos presentes en título, resumen y palabras clave que sean pertinentes al tema. En este paso debe tomarse en cuenta nuevamente el grado de especificidad de los términos, considerando que aquellos que sean más generales producirán una pérdida de precisión en la búsqueda.

- Ensayar en cada iteración los términos extraídos en la iteración anterior (no de manera acumulativa), de manera que se evite el re-trabajo generado al revisar los mismos artículos recurrentemente.

- Tomar en cuenta que las iteraciones que utilizan términos más específicos determinan también ciclos más cortos que permiten ver resultados más rápidamente, lo que en algunos casos puede ser un hito importante dentro de la RS.

- En aquellos casos en los que se cuente con recursos ilimitados, el criterio de parada podrá ser simplemente el que no se localicen nuevos artículos relevantes. En otros casos, para establecer un criterio de parada debe considerarse que a mayor número de iteraciones, donde cada iteración arroje cada vez menos artículos relevantes, el esfuerzo de descarte de artículos irrelevantes tenderá a ser mayor; esto puede ser determinante en el consumo de recursos cuando éstos son escasos.

Adicionalmente, tomar en cuenta que si se ha comenzado la RS a través del escenario objetivo a alto nivel, se cuenta previamente con un grupo de estudios que fueron obtenidos en la BúSQUEDA PRELIMINAR DE ESTUDIOS POR TEMA, esto representa una ventaja al llegar a esta actividad ya que podrán ser utilizados como base para obtener términos que se utilicen en la cadena de búsqueda refinada.

A continuación se muestra un ejemplo de la estrategia iterativa utilizando inspección de software como término semilla. La primera iteración estaría basada en la siguiente cadena de búsqueda:

"software inspection" AND (experiment OR "experimental study" OR "experimental comparison" OR "experimental analysis" OR "experimental evidence" OR "experimental setting")

Para cada uno de los artículos relevantes recuperados en esta iteración deben analizarse los títulos y resúmenes para identificar términos que permitan ejecutar una nueva búsqueda (segunda iteración). En el siguiente ejemplo se han resaltado los términos relacionados con inspección de software, que podrían hacer parte de la cadena de búsqueda. Los términos identificados serán, entonces, aquellos que signifiquen un sinónimo o refinamiento del término inspección de software (por ejemplo, defect detección method, scenario-detection method, defect detection rate, ad hoc method, y checklist method):

An Experiment To Assess Different Defect Detection Methods For Software Requirements Inspections 
(Porter \& Votta, 1994)

Software requirements specifications (SRS) are usually validated by inspections, in which several reviewers read all or part of the specification and search for defects. We hypothesize that different methods for conducting these searches may have significantly different rates of success.

Using a controlled experiment, we show that a Scenario-based detection method, in which each reviewer executes a specific procedure to discover a particular class of defects has a higher $\underline{\text { defect }}$

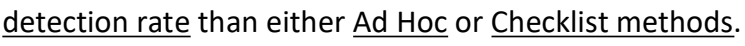

We describe the design, execution, and analysis of the experiment so others may reproduce it and test our results for different kinds of software developments and different populations of software engineers.

En la segunda iteración, se combinan los términos relacionados con el tema de revisión, con aquellos términos relacionados con el tipo de estudio:

("software inspection" OR "design inspection" OR "defect detection" OR "requirement inspection" OR "model inspection" OR "inspection method" OR "detection method") AND ("reading technique" OR "perspective-based" OR "checklist-based" OR "meeting-based" OR "usage-based" OR "scenario-based" OR "code defect" OR "ad hoc method" OR "n-fold inspection" OR "code assessment" OR "code comprehension") AND (experiment OR "experimental study" OR "experimental comparison" OR "experimental analysis" OR "experimental evidence" OR "experimental setting")

El proceso se repite entonces hasta que se agoten los artículos relevantes o el número de nuevos artículos recuperados no sea significativo.

\subsubsection{DESCARTE DE ARTÍCULOS IRRELEVANTES}

Para contar con un conjunto de artículos potencialmente elegibles, es necesario realizar un análisis de los artículos recuperados por la búsqueda ejecutada y eliminar aquellos que no son relevantes para el objetivo de la RS y que han sido recuperados por la falta de precisión en la cadena de búsqueda. Para realizar este análisis deben seguirse las tareas mostradas en la figura 6.10. 


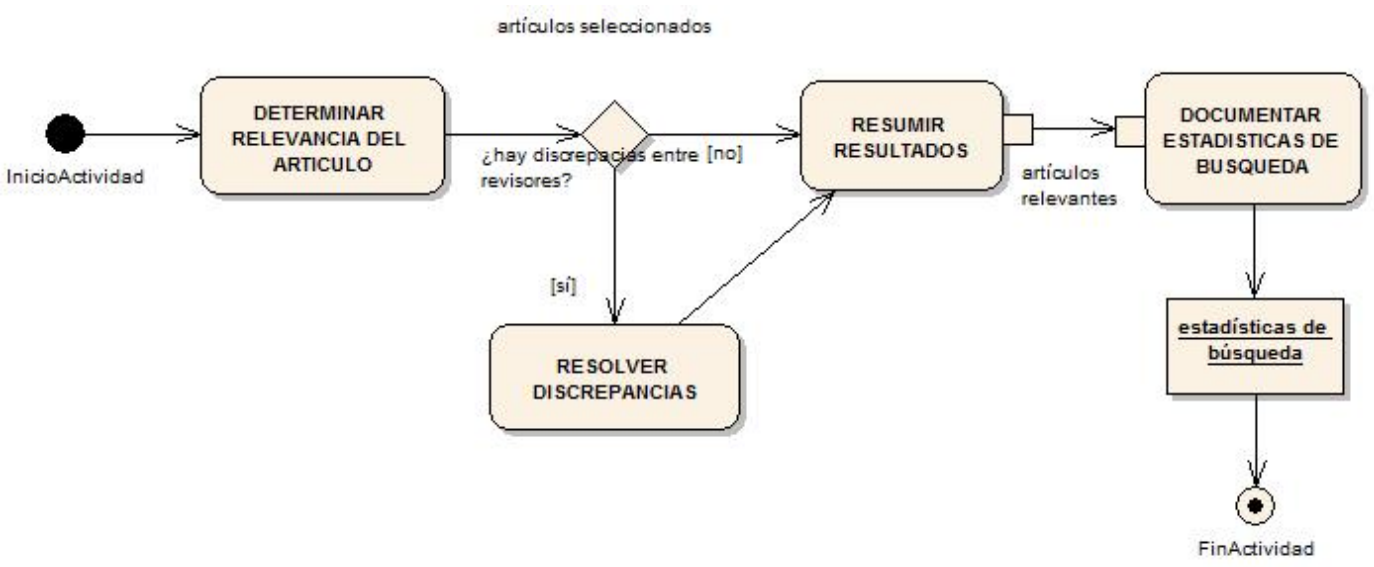

Figura 6.10. Tareas relacionadas con el DESCARTE DE ARTíCULOS IRRELEVANTES

Nótese que estas tareas son exactamente las mismas que fueron descritas anteriormente en sección 6.2.3; por lo que no serán nuevamente descritas en esta sección.

De tal manera, se mantienen para este escenario todas las recomendaciones ya presentadas en el escenario madurez del conocimiento. Igualmente se recomienda utilizar los formularios allí indicados: B02b_Formulario de Análisis de artículos recuperados - Doble chequeo, B03_Formulario para Resumen de artículos relevantes, y B04_Formulario para Estadísticas de búsqueda (véase Apéndice C).

Con respecto a la tarea 6.3.3.1. DESCARTE DE ARTíCULOS IRRELEVANTES, debe tomarse en cuenta que para su ejecución en este nuevo escenario, pueden incorporarse nuevos criterios para la selección/descarte de los artículos; estos criterios vienen determinados por los criterios de inclusión/exclusión establecidos junto con la pregunta de revisión.

\subsubsection{BÚSQUEDA POR REFERENCIAS}

Siempre que se cuente con un conjunto de artículos considerados relevantes, las referencias bibliográficas de éstos pueden ser utilizadas para identificar artículos potencialmente relevantes no recuperados por las búsquedas previas. Esta actividad tiene como propósito analizar cada artículo recuperado para determinar si en las referencias bibliográficas que utiliza puede identificarse algún experimento que no haya sido localizado a través de las búsquedas realizadas durante esta fase.

No se recomienda realizar esta tarea con artículos que no hayan sido seleccionados como relevantes (o potencialmente elegibles) para la RS, debido a que puede resultar en un enorme esfuerzo poco efectivo, al recuperar un porcentaje muy bajo de artículos no detectados previamente. Por otra parte, puede potenciarse el riesgo de sesgar la revisión, bien por el juicio del revisor o por la disponibilidad de las publicaciones de interés que se localicen en las referencias analizadas.

\subsubsection{DEFINICIÓN/ACTUALIZACIÓN DE GRUPOS CANDIDATOS A AGREGACIÓN}


Esta actividad tiene como propósito agrupar los experimentos localizados durante esta fase en un esquema de artículos/sub-temas que permitirá posteriormente seleccionar aquel o aquellos grupos que son de interés para la SíNTESIS DE DATOS. Como puede observarse en la figura 6.11 las tareas involucradas en esta actividad son básicamente las mismas que se describieron anteriormente en la sección 6.2.4 SELECCIÓN DE ESTUDIOS CANDIDATOS. Esto obedece que el propósito que se persigue en ambos casos es similar.

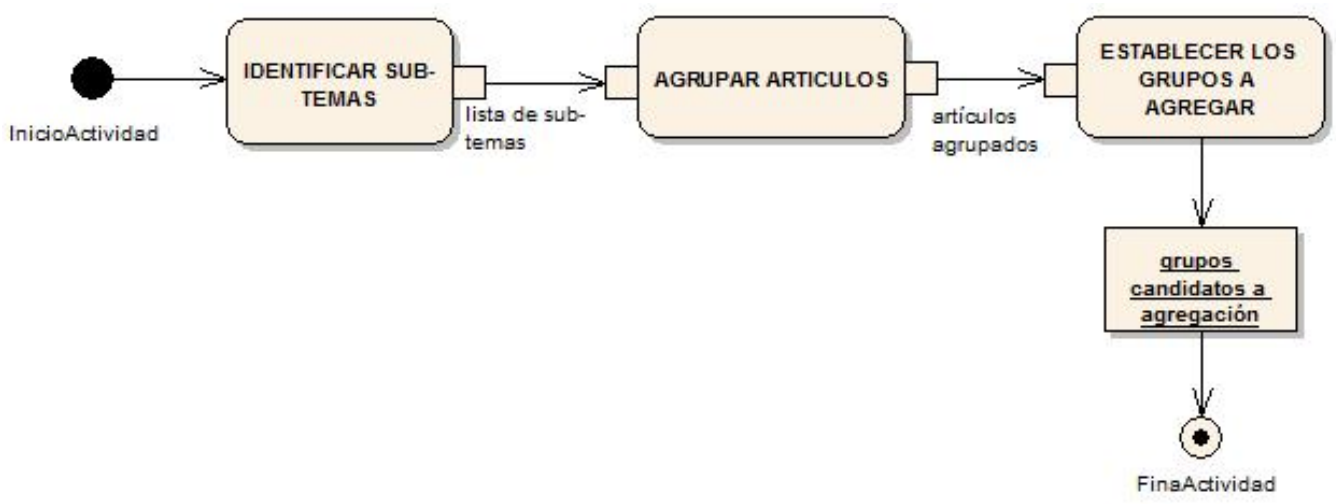

Figura 6.11. Tareas relacionadas con la Definición de grupos candidatos a agregar

En la actividad 6.2.4. SELECCIÓN DE ESTUDIOS A AGREGAR se busca organizar los experimentos localizados en la BúSQUEDA PRELIMINAR DE ESTUDIOS POR TEMA, de acuerdo al sub-tema que trata cada uno de ellos para permitir al revisor definir más concretamente el objetivo de la revisión. En la presente actividad se busca organizar los experimentos localizados a través de la BúSQUEDA REFINADA de acuerdo al sub-tema que trata cada uno de ellos para permitir al revisor escoger aquellos grupos de experimentos que más le interesa agregar.

Por lo tanto, las tareas mostradas en la figura 6.11 no se describirán nuevamente en esta sección, sino que se mantienen las recomendaciones y formularios (en particular, el B05_Agrupamiento por sub-tema y tipo de estudio) presentados en la sección 6.2.4.

Debe tomarse en cuenta que cuando se haya comenzado la RS en un escenario de objetivo a alto nivel y, por tanto, ya se haya obtenido un primer conjunto de GCAs, como producto de la actividad 6.2.4. SELECCIÓN DE ESTUdIOS CANDIDATOS, los resultados de ambas actividades (SELECCIÓN DE ESTUDIOS CANDIDATOS y DEFINICIÓN DE GRUPOS CANDIDATOS) deben ser combinados.

Una vez que se ha culminado con esta actividad, se cuenta con un conjunto de experimentos organizados en GCAs, los cuales contienen información potencialmente relevante para satisfacer el objetivo específico planteado para la actual RS.

\section{Evaluación de la continuidad del proceso}

Al final de esta fase deben satisfacerse los siguientes hitos (véase Tabla 5.2 - Hitos del proceso de RS): 
- Pregunta de revisión bien definida y criterios de inclusión/exclusión claros

- Además debe contarse con al menos un GCA de interés para el equipo de RS y con suficientes experimentos

En este punto, debe tomarse una decisión sobre continuar con el proceso o detenerlo; en cuyo caso, el proceso podría comenzar nuevamente con una motivación o necesidad diferente. 


\section{CAPÍTULO 7. FASE DE EXTRACCIÓN DE DATOS}

En este capítulo se describen las actividades, tareas y formularios relacionados con la fase de EXTRACCIÓN DE DATOS. Dentro del proceso de RS esta fase tiene como propósito obtener, de cada estudio primario, los datos relevantes tanto para su agregación durante la SínTESIS DE DATOS como para la VALORACIÓN DE LA CALIDAD.

Puede observarse en el Capítulo 3- ESTADO DE LA CUESTIÓN que la EXTRACCIÓN DE DATOS ha sido recurrente en los procesos de RS que se siguen en las distintas disciplinas. Sin embargo, aunque los elementos que componen un experimento en IS (tales como factores, niveles, variables respuesta, parámetros, sujetos, entre otros) son prácticamente los mismos que en cualquier otra disciplina, hay características particulares de la IS que hace que la recolección de tales datos se realice con más dificultad que en otras disciplinas experimentales (como Medicina, Educación, etc.). Al igual que en la fase anterior, es necesario comenzar a abordar esta fase describiendo con mayor detalle las características que son particulares a la IS y que afectan la manera como se realiza la extracción de los datos de un experimento. Esto será descrito en la sección 7.1 - CARACTERÍsticAS ESPECífICAS DE LA IS QUE PROVOCAN VARIACIONES EN LA FASE DE EXTRACCIÓN DE DATOS.

Para resolver los problemas identificados en la sección 7.1, esta investigación propone un conjunto de respuestas que son presentadas en la sección 7.2 - APROXIMACIÓN A LA SOLUCIón, la cual establece los principios y prácticas generales que serán implementados en esta fase. Tal implementación se realiza a través de actividades, tareas y recomendaciones concretas que son propuestas para obtener los datos de los experimentos con la mayor efectividad posible y con economía de recursos. Esta economía de recursos se refiere a la optimización del tiempo dedicado a la lectura de los experimentos, necesaria para recolectar los datos más relevantes del mismo.

Los detalles de las actividades, tareas y recomendaciones propuestas para esta fase son descritas en la sección 7.3 - ACTIVIDADES PROPUESTAS PARA LA FASE DE EXTRACCIÓN DE DATOS. La fase consta de siete actividades, de las cuales únicamente dos concentran la lectura de los experimentos (una lectura parcial y una lectura más exhaustiva). Las otras actividades de la fase sirven de apoyo a las actividades de lectura antes mencionadas ya que buscan: lograr la estandarización de la nomenclatura utilizada, facilitar la comprensión de los experimentos, resumir los resultados producto de la lectura, y establecer grupos muy similares que sean potencialmente agregables (en virtud de que ensayen las mismas técnicas y métricas en un mismo contexto). De esta manera, las actividades de lectura deberán realizarse necesariamente de manera secuencial, mientras que las actividades de apoyo a la comprensión de los experimentos, así como las de organización de los mismos, podrán darse en paralelo con las actividades de lectura. 


\subsection{Características específicas de la IS que provocan variaciones en la Fase de Extracción de Datos}

La EXTRACCIÓN DE DATOS es una labor fundamental dentro de un proceso de RS. Como actividad dentro de la RS tiene una doble utilidad, ya que a través de ésta será posible recopilar los datos necesarios tanto para valorar la calidad de los experimentos como para, posteriormente, obtener evidencias a través de la agregación y responder a la pregunta de revisión. La manera en que se extraigan los datos será determinante en la generación de evidencias confiables; por ejemplo, si se extraen métricas que son conceptualmente diferentes pero que se registran con el mismo nombre, se podría llegar a combinar resultados que no son compatibles. Por otra parte, si varios experimentos miden una misma métrica y ésta es registrada con un nombre diferente para cada uno de los experimentos, se puede llegar a excluir experimentos (y sujetos) que son pertinentes a la agregación, perdiendo innecesariamente poder estadístico.

Aunque los datos requeridos por una RS en cualquier disciplina o área es básicamente la misma, en IS se aprecian una serie de circunstancias muy particulares que impiden que la extracción se realice de la misma manera que se realiza en Medicina, Psiquiatría, Educación, Ciencias sociales, etc. Como puede observarse en el CAPÍtUlo 2 - ESTADO DE LA CUESTIÓN, la EXTRACCIÓN DE DATOS es considerada como una actividad relativamente sencilla que requiere poco esfuerzo; esto ocurre especialmente en aquellas disciplinas (por ejemplo, Medicina) que cuentan con un vocabulario controlado y lineamientos para el reporte de los elementos y los resultados del experimento. En estos casos el esfuerzo de extracción está principalmente determinado por el volumen de datos a extraer y el volumen de estudios. En general, las metodologías revisadas dedican algunas pocas recomendaciones para decidir qué características del experimento recolectar, como (J. P. T. Higgins \& S. Green, 2006) (CRD, 2009).

Sin embargo, en ISE los aspectos de estandarización de vocabulario no están aún solucionados (J. C. Biolchini et al., 2007); y lo mismo ocurre con la calidad del reporte de experimentos (Jedlitschka \& Pfahl, 2005)(A. Jedlitschka \& Ciolkowski, 2004), a pesar de que existen trabajos que buscan promover la estandarización de la terminología relacionada con la disciplina (IEEE, 1990) (IEEE, 2004a) (ACM, 1998) (R. L. Glass et al., 2002) o, más específicamente, con la experimentación en IS (J. C. Biolchini et al., 2007), o la calidad del reporte de experimentos en IS (Jedlitschka \& Pfahl, 2005)(Jørgensen \& Shepperd, 2007$)$ (B. Kitchenham et al., 2006).

A pesar de esto, esta problemática no ha sido aún abordada por los procesos que son específicos para la IS, como (B. Kitchenham, Brereton, Budgen, Turner, et al., 2009) (J. Biolchini et al., 2005); aunque sus trabajos incluyen la EXTRACCIÓN DE DATOS como una etapa de la RS, no entran en detalles sobre los problemas que deben ser resueltos para que esta actividad sea aplicada a la IS con resultados satisfactorios. 
Por lo anterior, como punto de partida para esta fase deben analizarse aquellas características que provocan cambios en la manera de realizar la EXTRACCIÓN DE DATOS en IS:

1. Diversidad de variables respuesta y métricas.

2. Existencia de múltiples términos sinónimos que hacen referencia a una misma tecnología, e incluso la existencia de un mismo término que hace referencia a tecnologías diferentes. Falta de estandarización de la terminología relacionada con la tecnología bajo estudio.

3. Reporte incompleto de los experimentos.

\subsubsection{DIVERSIDAD DE VARIABLES RESPUESTA Y MÉTRICAS}

En los experimentos de Medicina los tratamientos generalmente son comparados a través de variables universalmente aceptadas en el domino respectivo (por ejemplo: $\mathrm{mmHg}$ para la presión arterial, grados centígrados para la fiebre, etc.). Además, en muchos dominios esto es fácil, al basarse en consideraciones físicas. En IS, aunque los experimentos ensayen tratamientos en el mismo dominio, frecuentemente tienden a utilizar métricas muy diversas debido a la inexistencia de una forma de medir universal o comúnmente aceptados (A. Jedlitschka \& Ciolkowski, 2004). Por ejemplo, al analizar los experimentos que comparan técnicas de inspección de software, los cuales han sido utilizados como "runnig example", pudo observarse que:

a. Algunos estudios, como (Porter, Votta, \& Basili, 1995), evalúan la efectividad del método desde el punto de vista del revisor individual, mientras que otros estudios la evalúan desde el punto de vista del equipo (Sandahl et al., 1998).

b. Mientras que algunos estudios definen la eficiencia con base en los recursos usados (Porter et al., 1995), otros con base en el tiempo utilizado (Cantone, Colasanti, Abdulnabi, Lomartire, \& Calavaro, 2003).

c. Mientras algunos estudios miden el tiempo gastado por el individuo durante la inspección (Fusaro, Lanubile, \& Visaggio, 1997), otros estudios miden el tiempo gastado durante la preparación de la inspección (Thelin, Runeson, \& Wohlin, 2003).

Esto refleja que la IS es una disciplina inmadura, en la que todavía prima el desarrollo de tecnologías (independientemente de su efectividad) frente a una evaluación rigurosa de las mismas. Desde el punto de vista de una RS, esta situación hace que sea difícil organizar los experimentos y decidir cuándo agregarlos, ya que la agregación que se realice durante la SínTESIS DE DATOS debería incluir tantos experimentos como sea posible, los cuales deben ser de naturaleza muy semejante a fin de: aumentar el poder estadístico, evitar heterogeneidad y promover la validez de los resultados. 
Como ejemplo, puede observarse como en la RS realizada en (O. Dieste \& Juristo, 2011) la diversidad de técnicas y variables respuesta que se obtuvieron durante la extracción de datos produjo conjuntos muy pequeños de evidencia similar para la agregación. Como resultado, en esta RS también se dedicó mucho esfuerzo a estudios que no se usaron posteriormente durante la agregación. El 60\% de los artículos revisados no contribuyeron a ninguna agregación; esto quiere decir que si los revisores hubieran concentrado sus esfuerzos en el subconjunto de los $40 \%$ restantes, se habrían obtenido los mismos resultados con tan sólo la mitad del coste en términos de tiempo y esfuerzo.

Aunque este problema afecta principalmente a la SÍNTESIS, es durante la EXTRACCIÓN DE DATOS donde se identificará esta falta de coincidencia entre las variables respuesta, pudiendo proporcionársele una solución temprana.

\subsubsection{FALTA DE ESTANDARIZACIÓN DE LA TERMINOLOGÍA}

Como se mencionó en la FASE DE BúSQUEDA, en Medicina se han desarrollado proyectos a los largo de los años que han permitido contar con un vocabulario controlado para el uso en la indexación de las publicaciones del área, tal es el caso de los medical subject headings -MeSH- (US National Library of Medicine, 1999) y el Sistema de Lenguaje Médico Unificado -UMLS $®$ - (US National Library of Medicine, 2009). Como ejemplo, el proyecto UMLS ha sido desarrollado desde 1986, si bien se trata de una iniciativa dirigida a la recuperación de la información biomédica por medios informáticos, es ejemplo de un esfuerzo de colaboración internacional que seguramente tiene impacto en todos los ámbitos de las Ciencias de la Salud en los que el reporte de información es requerido. Este proyecto ha llevado al desarrollo de tres fuentes experimentales de conocimiento: el Meta-thesaurus, la Red Semántica y el Mapa de Fuentes de Información (Lindberg, Humphreys, \& McCray, 1993). Sin duda, estas iniciativas dan muestra de la madurez de esta disciplina.

La experiencia recogida en esta investigación (J. C. Biolchini et al., 2007) ha revelado que la terminología utilizada en los experimentos de IS es poco estandarizada o uniforme. En general, se observa que los artículos que reportan experimentos en IS no son rigurosos en el uso de conceptos y en la definición que de ellos se hace; lo cual puede llevar a que dos estudios ensayen el mismo tratamiento o estudien la misma variable respuesta pero dándole nombres diferentes. Esto, sin duda, conllevará a una errónea extracción de tratamientos y variables respuesta, lo que será un problema durante la futura agregación al no haber claridad en cuanto a la compatibilidad entre ambos estudios.

\subsubsection{REPORTE INCOMPLETO DE LOS EXPERIMENTOS}

En ISE los estándares de reporte son muy recientes (Kitchenham et al., 2006) (Jedlitschka \& Pfahl, 2005) (Jørgensen, 2004) y no son promovidos por ninguna revista o conferencia. Por ello, es frecuente encontrar experimentos que no reportan información sobre el diseño y sus resultados (A. Jedlitschka \& D. Pfahl, 2005). A modo de ejemplo, puede observarse en la tabla 7.24 cómo para el caso de estudio sobre 
inspección de software el experimento identificado como E01 no presenta ninguna información cuantitativa para la métrica M01. Experiencias similares son descritas por (Ciolkowski, 2009) (T. Dybå \& T. Dingsøyr, 2008) (Mendes, 2005) y (Kampenes et al., 2007).

Esto típicamente constituye un problema no trivial para la RS, ya que esta información es utilizada para evaluar la calidad de los experimentos, y decidir de esta manera qué estudios incluir y cuáles excluir durante la SíNTESIS DE DATOS. Los datos ausentes pueden limitar además la efectividad de la SínTESIS DE DATOS (Cruzes \& Dyba, 2010).

\subsection{Aproximación a la solución}

Una vez que se han identificado aquellas características que suponen un problema durante la EXTRACCIÓN DE DATOS de experimentos en IS, es posible proponer soluciones que permitan dar respuesta a esta problemática. Las soluciones que son presentadas en esta sección serán posteriormente implementadas a manera de actividades, tareas, artefactos o recomendaciones específicas de esta fase.

1. Diversidad de variables respuesta y métricas: como se mencionó en la sección anterior, a diferencia de otras disciplinas, en IS no se cuenta con medidas estándar o universalmente aceptadas para evaluar la tecnología; por ello los experimentos presentan una gran variedad de variables respuesta y métricas lo cual dificulta tanto la comprensión de los experimentos como su agregación. Desde el punto de la extracción se busca: 1) maximizar el aprendizaje de los revisores al realizar la lectura y extracción de datos; 2) Minimizar el esfuerzo de lectura. Desde el punto de vista de la agregación, se espera maximizar la cantidad de evidencias agregables. En otras palabras, se quiere lograr la mayor cantidad de resultados (agregaciones) posibles. En respuesta a los objetivos anteriores, en esta investigación se propone una solución que incluye:

- Realizar la lectura en al menos dos iteraciones: una lectura superficial que permita agrupar los experimentos que presentan los mismos niveles y variables respuesta, y al menos una lectura en profundidad, donde se extraen la mayor parte de los datos.

- En la lectura en profundidad se propone concentrarse sólo en aquellos experimentos que tienen más probabilidad de participar de alguna agregación durante la SíNTESIS DE DATOS. Para ello, durante la lectura superficial se generarán clusters de lectura que orienten la lectura en profundidad.

- Generar grupos potencialmente agregables que sean prometedores para la síntesis al contar con el número mínimo de experimentos compatibles requeridos por los métodos de agregación. Este agrupamiento se realizará con base en niveles y variables respuesta semejantes, lo cual proporcionará mayor confianza en las evidencias resultantes de la agregación de los mismos. Con el agrupamiento se busca una manera rápida y temprana de identificar aquellos grupos más prometedores dentro de los Grupos candidatos a agregación 
que han sido seleccionados en la fase anterior. Por grupos prometedores se entenderá aquellos grupos que pueden aportar más evidencias a la Síntesis de datos.

- Utilizar la variable respuesta como un nivel más abstracto que el de métrica; permitiendo agrupar en una misma variable respuesta aquellas métricas relacionadas en cuanto al objetivo de medición.

2. Falta de estandarización de la terminología: como se indicó en la sección la falta de estandarización de la terminología es también un problema con el que tiene que lidiar la extracción si se quiere que la Síntesis de datos no se vea comprometida. Por lo tanto se busca establecer una semántica común que afronte el problema de la falta de uniformidad conceptual.

- Solución: para satisfacer el objetivo anterior, se propone realizar una actividad en paralelo con la lectura donde se definan y agrupen los conceptos de manera que se estandarice el uso de los términos. Esto incluye factores, niveles, variables respuesta, métricas, y cualquier otra variable; especialmente aquellas necesarias para el agrupamiento de los experimentos en cualquier actividad.

3. Reporte incompleto de los experimentos: en la sección 7.1 se describieron experiencias en las que es evidente que la falta de información en el reporte del experimento puede impactar la agregación. En la aproximación que se presenta en esta sección se busca extraer de un experimento tantos datos y resultados como sea posible para incorporarlo eventualmente dentro de una agregación, o excluirlo siempre que no presente un mínimo de la información requerida.

- Solución: como respuesta al requerimiento anterior, se propone extraer y resumir no sólo los resultados cuantitativos sino también los resultados cualitativos reportados por el experimento. Además, siempre que sea posible, identificar la significancia de los resultados que están siendo extraídos. En este enfoque, no la extracción no se limita a los resultados experimentales sino también observacionales y de contexto. De esta manera, los revisores podrán encontrar alguna utilidad para el experimento, bien como participante en una agregación, como evidencia indirecta o complementaria para la obtenida a través de la agregación, o para plantearse nuevas hipótesis o preguntas de investigación. Independientemente de esto, se recomendará la exclusión de los experimentos que no cumplan con un reporte de los datos mínimos necesarios.

A continuación, se describe la manera en que estas soluciones son implementadas dentro de la fase.

\subsection{Actividades propuestas para la Fase de Extracción de Datos}

El propósito de esta fase es recolectar los datos más relevantes de los experimentos incluidos en el GCA seleccionado al final de la FASE DE BÚSQUEDA. Al mismo tiempo, incluye actividades que buscan resolver los 
problemas de falta de estandarización de la terminología, diversidad de métricas y variables respuesta, y la baja calidad de reporte de los experimentos. Como fin último, al resolver el problema de la diversidad, se espera conseguir aumentar el número de experimentos potencialmente agregables.

El método propuesto para la EXTRACCIÓN DE DATOS utiliza iteraciones y agrupamiento para propiciar la eficiencia, al tiempo que concentra el esfuerzo del proceso de revisión en aquellos estudios con mayor potencial para la agregación. En la Figura 7.1 se muestran las actividades propuestas para esta fase:

1. La lectura de los experimentos se realizará en al menos dos iteraciones: una LECTURA SUPERFICIAL, que permitirá establecer los niveles y variables respuesta de cada experimento, y una LECTURA EN PROFUNDIDAD que recolectará todos los datos asociados a aquellos experimentos que se consideren de interés. Para soportar la selección de los experimentos que deben ser leídos la PREPARACIÓN DE CLUSTERS DE LECTURA permite agrupar los experimentos según su compatibilidad en cuanto a niveles y variables respuesta.

2. Durante las iteraciones de lectura de los experimentos no sólo se extraen los datos de interés sino que también se normalizan la denominación de los factores, niveles, variables respuesta y métricas a través de la DESCRIPCIÓN Y AGRUPAMIENTO DE CONCEPTOS. Esto se traduce que aquellos conceptos (factores, niveles, variables respuesta y métricas) que sean equivalentes pasarán a ser tratados como iguales aunque hayan sido nombrados de manera diferente en los experimentos analizados. Asimismo, se separarán aquellos conceptos que siendo diferentes reciben la misma denominación. Debido a que la EXTRACCIÓN DE DATOS puede producir un gran volumen de información, es conveniente presentar la misma de manera resumida para facilitar su procesamiento durante la SíNTESIS DE DATOS, esto se realizará a través de la actividad ORGANIZACIÓN DE LOS DATOS, parte de la cual se desarrollará en paralelo con todas las actividades de esta fase.

3. Como resultado final de la fase se establecerán grupos potencialmente agregables (GPA) con base a la información detallada recogida durante la LECTURA EN PROFUNDIDAD. Tales grupos serán la entrada para la SínTESIS DE DATOS; por lo tanto, si no se obtiene al menos un GPA de interés para los revisores y que contenga suficientes experimentos, el proceso debería ser detenido. 


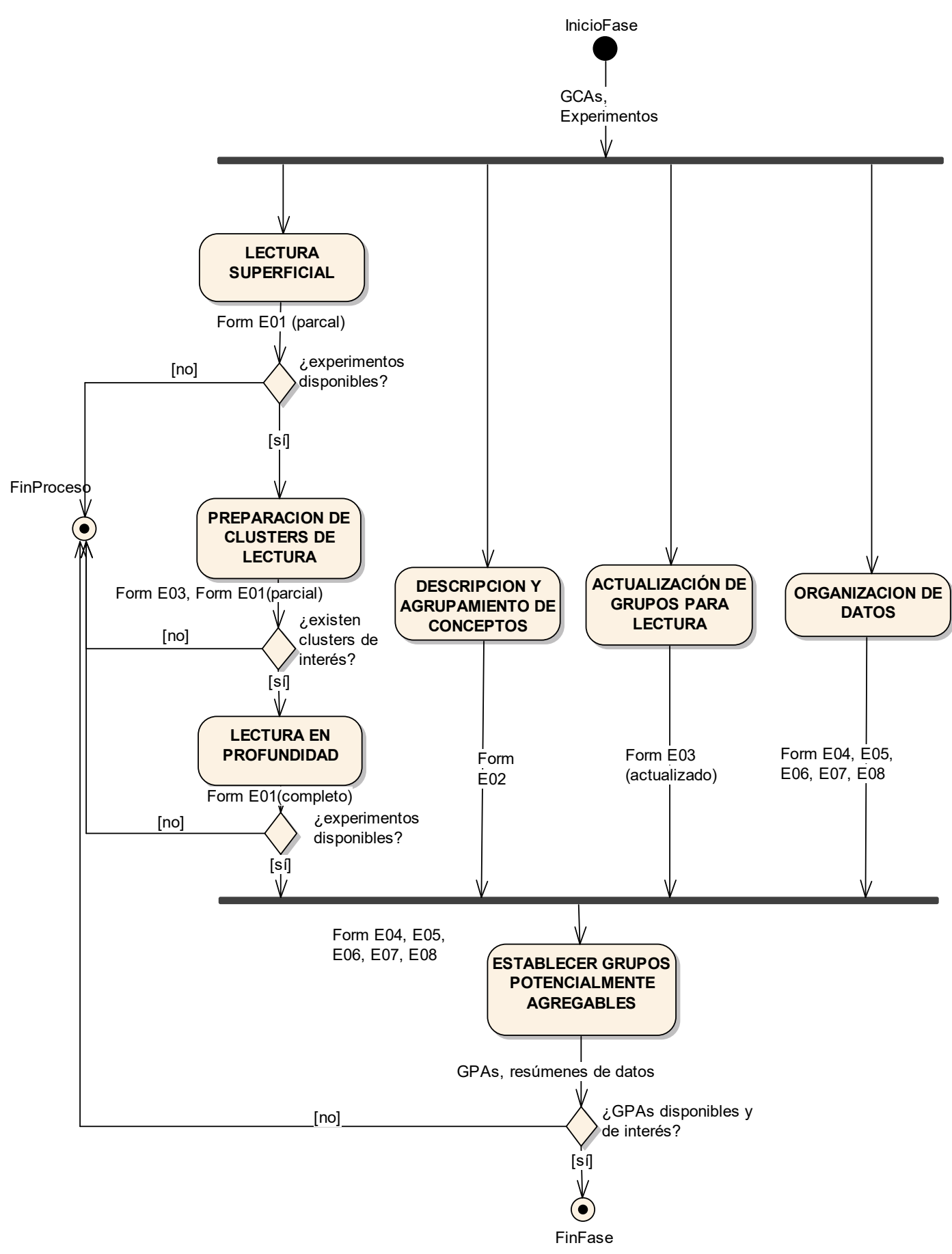

Figura 7.1. Actividades de la Fase de Extracción de datos

Nótese que en esta fase existen varios puntos donde el proceso pudiera ser cancelado debido a que se excluyan todos los experimentos del GCA seleccionados, por criterios de calidad de reporte. En las 
siguientes secciones, se describe cada una de las actividades que componen esta fase, detallando sus tareas y entregables.

\subsubsection{Lectura Superficial}

Esta actividad tiene como objetivo extraer un conjunto mínimo de datos de los experimentos de un GCA; así como estandarizar la terminología utilizada en éstos para referirse a los factores, niveles y variables respuesta. De esta manera se busca facilitar la organización de los datos de acuerdo a su similitud y promover la comprensión de los experimentos cuando se realice su LECTURA EN PROFUNDIDAD. Para ello, una vez que se cuenta con un GCA que ha sido seleccionado en la fase de BúsQuedA, se comenzará la EXTRACCIÓN DE DATOS con la lectura del título y resumen.

Esta lectura se enfoca en conocer qué tecnologías (tratamientos) son comparadas en cada experimento seleccionado en la fase de BúSQUEDA y sobre qué base han sido evaluadas (métricas). Además busca identificar el tipo de participantes (sujetos) y la etapa del proceso de desarrollo a la que ha sido aplicada la tecnología durante en el experimento (tarea), así como estar al tanto de si se trata de un experimento original.

Durante la identificación de estos datos es conveniente aplicar la DESCRIPCIÓN Y AGRUPAMIENTO DE CONCEPTOS (véase la actividad 7.3.4) utilizando para ello el formulario E02-Conceptos del Experimento (Apéndice F.2), ya que la diversidad de la nomenclatura utilizada por los autores para referirse a los datos del experimento es alta.

Debe considerarse que, aún teniendo denominaciones distintas, tales variables podrían estar midiendo más o menos lo mismo con ciertas diferencias en cuanto a la manera en que la medida se realiza. Dado que la cantidad de experimentos disponibles en IS suele ser escaso, si se busca maximizar el número de experimentos a ser combinados en una agregación particular, debe obviarse las diferencias de nomenclatura de las variables definidas en los experimentos de un grupo y enfocarse en los conceptos que ellas representan.

Para el registro de esta actividad se propone el formulario E01-Datos del Experimento (véase el Apéndice C), el cual funcionará como repositorio de toda la información relacionada con el estudio durante el proceso completo de RS. Sin embargo, durante la presente actividad sólo se cumplimentarán las siguientes secciones de dicho formulario (Identificación y Características del experimento, únicamente los campos: tratamientos, variables respuesta, métricas, sujetos experimentales, replicación, y tarea experimental.

- Identificación: se refiere a los datos relacionados con el artículo en el cual se encuentra publicado el experimento, tales como sus autores, título de la publicación y fuente. 
- Objetivo: describir el objetivo del experimento tal y como es indicado por los autores en el resumen del artículo.

- Tópico: se refiere al área de conocimiento o tipo de tecnología involucrada en el estudio, por ejemplo, educción de requerimientos, inspecciones de software, etc. Puede utilizarse para llenar este campo los términos del sistema de clasificación (keywords) de la IEEE.

- Factores: se refiere a cualquier característica del desarrollo de software que es estudiada en el experimento y que afecta una variable respuesta (Juristo \& Moreno, 2001). Muchas veces el factor es referido por los autores como variable independiente. Por ejemplo, el en caso de estudio sobre Inspección de software el factor corresponde a Método de inspección o Técnica de lectura.

- Niveles: se refiere a los posibles valores de un factor dentro de un experimento primario. Cada nivel corresponde a una alternativa para el factor (Juristo \& Moreno, 2001). En el caso de estudio mencionado anteriormente, Checklist-based reading (CBR), Scenario-based reading (SBR), entre otros, son niveles posibles del factor Técnica de lectura. En medicina los niveles son conocidos también como tratamientos o intervenciones.

- Variables respuesta: según (Juristo \& Moreno, 2001) estas variables representan el efecto de las diferentes alternativas del factor sobre el objeto con el cual se está experimentando. Se refiere a variables que únicamente pueden ser medidas después de que el experimento ha sido ejecutado. Las variables respuesta son también llamadas variables dependientes y suelen ser de tipo cuantitativo. Por ejemplo, la precisión de la técnica podría ser un ejemplo de variable respuesta para el caso de estudio sobre inspección de software. Las variables respuesta en un experimento son frecuentemente asociadas con el concepto de métrica. Las variables respuesta son medidas a través de las métricas que son aplicadas a los productos o entregables que se generan durante el proceso de desarrollo, o a cualquiera de sus actividades o recursos involucrados.

Para ayudar a la estandarización es necesario establecer dos niveles conceptuales: 1) se utilizará variable respuesta como un nivel conceptual más alto, que representa el objetivo que quiere ser medido en el estudio (por ejemplo: eficiencia, coste, etc.); 2) la métrica se considerará en un segundo nivel conceptual más operacional, que representa las variables que son evaluadas en los experimentos (por ejemplo, número de defectos encontrados por sujeto, tasa de detección de defectos por etapa, etc.). De esta manera, diferentes métricas pueden ser relacionadas a través de una misma variable respuesta, lo que permite que experimentos que miden métricas distintas puedan ser combinados para analizar la variable respuesta que es común para todas ellas. Un ejemplo del agrupamiento por variable respuesta sería el siguiente: Los estudios A y B comparan técnicas de inspección de software y miden el tiempo de detección de defectos durante la fase de reunión y el coste por defecto durante la fase inspección, respectivamente. Se puede observar que ambos estudios tiene como objetivo de medición (variable respuesta) la eficiencia; por lo tanto, tanto el estudio A como el B pueden ser asignados al mismo grupo. 
La diversidad terminológica identificada en este trabajo no sólo es producto de un uso inadecuado de los términos, sino que también se produce porque los experimentadores suelen analizar muchas métricas (con un alto nivel de especificidad), que corresponden a una misma variable respuesta. Por ambas razones (la inmadurez en el uso de términos así como la proliferación de métricas muy específicas) la propuesta de introducir el nivel conceptual de variable respuesta permitirá mantener un número manejable de grupos que contienen a su vez un número significativo de estudios, en lugar de una gran cantidad de grupos que incluyan muy pocos estudios.

- Tipo de estudio: se refiere el tipo de diseño que han utilizado los experimentadores. Típicamente en IS pueden encontrarse experimentos del tipo RCT, cuasi-experimentos, casos de estudio y estudios observacionales.

- Tarea experimental: se refiere a la actividad específica que llevan a cabo los sujetos durante el experimento. Según (Sjøeberg et al., 2005) tales tareas son una característica importante de un experimento en ingeniería de software. Pueden incluir desde desarrollar una aplicación de software hasta ejecutar varias operaciones sobre una aplicación existente. La tarea experimental se encuentra siempre vinculada con alguna etapa del proceso de desarrollo de software; por ejemplo: la educción de requisitos, el diseño de la arquitectura, la inspección de software, etc. Aunque la tecnología concreta bajo estudio puede estar más o menos relacionada con la informática; por ejemplo, características de personalidad de los desarrolladores, como en (Gómez, Acuña, \& Rico, 2007).

Algunos tipos de tareas experimentales que representan tareas relevantes aplicadas a los artefactos de software son: Planificar (planificación de un proyecto, análisis de requisitos, estimación), Crear (diseñar, codificar), Modificar (realizar mantenimiento de diseño o de código) y Analizar (inspeccionar, probar, revisar documentos) (Sjøeberg et al., 2005).

- Sujetos experimentales: se refiere a la(s) persona(s) que aplica(n) los métodos o técnicas dentro del experimento; por ejemplo, un desarrollador o un equipo de desarrolladores (Juristo \& Moreno, 2001). Los sujetos dentro de un experimento suelen tener el perfil de estudiante o profesional, según si proviene del ambiente académico y participa del experimento en un ambiente de laboratorio, o proviene de un ambiente de industria.

- Replicación: se refiere a experimentos donde otros investigadores, en otro contexto y con muestras diferentes, intentan reproducir un estudio tan fielmente como sea posible. De tal manera, si los resultados entre ambos experimentos son consistentes, se añadiría confianza a la hipótesis del experimento original (Judd, Smith, \& Kidder, 1991).

\section{Recomendación:}

Para extraer estos datos, se sugiere que el revisor lea únicamente el título y resumen del artículo, ya que, por lo general, la información requerida acerca del estudio acostumbra a estar disponible en tales campos. 
Ello es especialmente cierto cuando el estudio utiliza un abstract estructurado (A. Jedlitschka \& D. Pfahl, 2005). Sin embargo, es posible que en algunos casos la sola lectura de título y resumen sea insuficiente para extraer la información requerida. En tales casos se requerirá una lectura con mayor detalle del artículo procurando siempre economizar esfuerzo de lectura ya que una lectura profunda puede ser muy costosa en términos de tiempo. Si aún realizando esta lectura en profundidad no se logra identificar toda la información requerida, el experimento debería ser excluido, ya que esto limitará su participación en la SÍNTESIS DE DATOS.

La extracción realizada permitirá en la siguiente actividad la organización de los estudios con base en el grado de similitud entre ellos; entendiendo por similitud la concordancia entre las características del experimento.

\section{Evaluación de la continuidad del proceso}

Una vez que se ha realizado la lectura superficial de todos los experimentos de un GCA puede ocurrir que:

- Se cuenta con experimentos suficientes para continuar con el proceso.

- Se han excluido todos los experimentos del GCA en virtud de su baja calidad de reporte, lo cual hace imposible extraer al menos los datos más básicos y, en consecuencia, impedirá que un experimento pueda participar en la agregación.

En este punto, debe tomarse una decisión sobre continuar con el proceso o detenerlo (véase Tabla 5.2 - Hitos del proceso de RS).

\subsubsection{PREPARACIÓN DE CLUSTERS DE LECTURA}

Al momento de entender los experimentos de un GCA y tratar de extraer sus datos; cuanto más diferentes sean, más difícil puede llegar a ser comprender las particularidades de las tecnologías y las tareas que se ensayan en ellos, las medidas que están siendo recolectadas y los resultados que fueron obtenidos.

Al mismo tiempo, un criterio importante a considerar durante la agregación de experimentos que se realizará en la FASE DE SÍNTESIS es que tales experimentos aborden ensayos similares en cuanto a los tratamientos que son comparados y la manera en que son evaluados. Por esto, se puede afirmar que cuanto más parecidos sean los experimentos en un grupo, más fácil será su lectura y la extracción de sus datos y, posteriormente, su agregación.

Aunque en la FASE DE BÚSQUEDA se realizó un agrupamiento de los experimentos que fueron localizados según el tema o tópico que estudiaban, dentro de cada GCA puede haber más o menos heterogeneidad en cuanto a las características particulares de los experimentos (por ejemplo: los tratamientos específicos que son comparados, las medidas que son recolectadas para cada una de tales comparaciones, entre otros). 
El objetivo de esta actividad es resumir los datos básicos extraídos anteriormente y organizar los estudios según su similitud, para propiciar que aquellos que sean más compatibles sean leídos en conjunto. Por compatibilidad debe entenderse: la comparación de los mismos tratamientos y evaluación las mismas variables respuesta para un contexto similar. Agrupar experimentos compatibles facilitará su comprensión, la selección de aquellos de mayor interés para la RS y, finalmente, su agregación.

Para lograr el objetivo anterior se proponen criterios de agrupamiento que están principalmente orientados por la compatibilidad de los estudios:

\section{Estudios con igual tarea experimental}

El agrupamiento de experimentos de acuerdo a la tarea experimental busca no sólo que durante la lectura se analicen aquellos estudios que abordan una etapa del proceso de desarrollo similar sino también preparar el camino para que durante la SíNTESIS DE DATOS se obtenga la mayor cantidad de conclusiones y recomendaciones válidas para una tarea específica. Ello no excluye que, con posterioridad a la SínTESIS, sea posible derivar conclusiones sobre distintas etapas o productos del proceso de desarrollo mediante la comparación de la misma tecnología en distintas etapas; por ejemplo, conclusiones sobre la ventaja de aplicar una técnica de inspección en diferentes etapas del proceso de desarrollo (requisitos o diseño, por ejemplo).

En aquellos casos en que la tarea experimental sea irrelevante como criterio de discriminación, se omitirá este nivel y se pasará al siguiente. Por ejemplo, la tarea experimental puede ser un aspecto importante en una RS sobre técnicas de inspección de software ya que tales técnicas pueden ser aplicadas en diferentes etapas del proceso de desarrollo; sin embargo, será menos relevante en una RS sobre técnicas de educción de requisitos, ya que en este caso la tarea es realizada con mayor intensidad en la etapa inicial del proceso de desarrollo y con una intensidad mucho menor en las etapas subsiguientes, en las cuales las acciones a seguir son básicamente las mismas. Por lo tanto, para este ejemplo se puede suponer inicialmente que la efectividad de la técnica no será sensible a la etapa del proceso de desarrollo en la cual se aplique.

\section{Estudios con el mismo tipo de sujeto experimental}

El tipo de sujeto experimental (estudiante o profesional) es una de las variables del contexto experimental que puede influir en los resultados que se obtienen de la experimentación (Cronbach, 1982) (C. Wohlin et al., 2000). En algunos casos la experiencia y el entrenamiento que proviene de la práctica profesional, así como la madurez y el nivel de compromiso con que los sujetos asumen la tarea experimental, conllevarán a que ésta sea aplicada de manera más completa y rigurosa por profesionales que por estudiantes, influyendo en los resultados obtenidos. Por lo anterior, la similitud entre las poblaciones de sujetos será un factor determinante para prevenir la heterogeneidad durante la SíNTESIS DE DATOS.

4. Estudios que ensayan los mismos niveles y variables respuestas

Como ya se ha mencionado anteriormente, puede encontrarse una gran diversidad de métricas que están siendo medidas en los distintos experimentos dentro de un GCA. En cuanto a los niveles del factor, se 
presenta una situación más o menos similar. Dentro de un mismo grupo pueden encontrarse experimentos con niveles compartidos total o parcialmente; lo cual implica que cada uno de estos niveles no está necesariamente presente en todos los experimentos del grupo. Leer los estudios que han comparado los mismos niveles y variables respuesta es importante para facilitar su comprensión y la extracción de sus datos.

5. Replicaciones

Se espera que aquellos estudios que sean replicaciones de un experimento guarden una gran similitud con él y con otras replicaciones de éste. Por lo tanto, es deseable que tales experimentos sean leídos en conjunto para posteriormente ser agregados también conjuntamente.

Los criterios anteriormente descritos pueden presentar variantes debido a casos que ameritan un tratamiento especial. El más importante, a efectos de esta investigación, es el de los estudios en los que la tarea o sujeto experimental sean el factor de interés, como en (Dyer, Kagel, \& Levin, 1989) y (Potters \& Van Winden, 1996), donde se comparan estudiantes sin experiencia versus profesionales. Para este caso se recomienda:

1. Excluir el estudio.

2. Utilizar otras variables del contexto experimental (A. Jedlitschka, Ciolkowski, \& Pfahl, 2008) en lugar de la tarea experimental o el tipo de sujeto experimental; por ejemplo, el tipo de aplicación, el dominio de aplicación, el tipo de organización, la experiencia de los participantes, las restricciones de tiempo, el proceso, las herramientas, o el tamaño del proyecto.

La actividad involucra un conjunto pequeño de tareas que son mostradas en la figura 7.2, las cuales producen como salida el formulario E03-Clusters de lectura (véase el Apéndice C).

Este algoritmo debe aplicarse a todos los estudios incluidos en un GCA seleccionado en la fase de BúSQUEDA. Para ello se toman como entrada los datos obtenidos en la LECTURA SUPERFICIAL (registrados en los diferentes Formularios de Extracción) y se generan clusters de lectura que contienen estudios muy parecidos en cuanto a sus datos básicos. El proceso representado en la figura 7.2 asume que se ha seleccionado, de entre los factores ensayados en el estudio, aquel que es de interés para la RS. Una vez se ha seleccionado el factor de interés, el algoritmo para el agrupamiento está compuesto por los siguientes pasos:

\subsubsection{Describir el factor principal y el grupo candidato a agregación}

En esta tarea se recomienda utilizar el encabezado del formulario E03-Clusters de Lectura, el cual incluye los siguientes campos: 
- Grupo candidato a agregación.

- Factor.

Generar un documento E03 por cada GCA. La tabla 7.1 muestra un ejemplo de factor principal y grupo candidato a agregación correspondiente al caso de estudio que se viene manejando.

Tabla 7.1. Ejemplo de grupo candidato y factor principal. Caso de estudio: inspección de software

\begin{tabular}{|c|c|}
\hline GRUPO CANDIDATO A AGREGACIÓN & $\begin{array}{l}\text { Experimentos que comparan métodos o técnicas de inspección de } \\
\text { software }\end{array}$ \\
\hline FACTOR & Técnica (método) de inspección de software \\
\hline
\end{tabular}

\subsubsection{Agrupar estudios por tarea experimental}

Con base en el Formulario de Extracción, identificar la tarea que corresponde al experimento. Para esta tarea debe utilizarse la sección I del formulario E03-Clusters de lectura (véase Apéndice F.3), que incluye como campos:

- Tarea.

- Estudios.

En caso de que en el formulario no exista un grupo que corresponda a la tarea aplicada en el experimento que se está agrupando, generar una entrada para ésta y asignar el experimento a este nuevo grupo. Por ejemplo, si se toma del caso de estudio el formulario Datos del Experimento de ART_27 con los datos básicos extraídos en la actividad anterior, se observa que en cuanto a la tarea experimental se indica que "cada equipo inspeccionó dos SRS usando una combinación de Ad hoc, CBR y SBR"; por lo tanto, la tarea correspondiente es la de Requisitos. Tal y como se observa en la Tabla 7.2, se creó un grupo con esta tarea y se repitió este paso para todos los experimentos seleccionados en la FASE DE BúsQUEDA para el caso de estudio de Inspección de Software.

Tabla 7.2. Ejemplo Agrupamiento por tarea. Caso de estudio: inspección de software

\begin{tabular}{|l|l|}
\hline TAREA & ESTUDIOS \\
\hline Requisitos & $\begin{array}{l}\text { ART_27, ART_78, ART_45, ART_80, ART_81, ART_14, ART_44, ART_11, ART_89, } \\
\text { ART_75, ART_54 }\end{array}$ \\
\hline Diseño & ART_19, ART_08, ART_17, ART_46, ART_25 \\
\hline Diseño con UML & ART_82, ART_18, ART_28 \\
\hline Código & ART_85, ART_23a, ART_23b, ART_23c \\
\hline
\end{tabular}


Debido a que usualmente los experimentos ensayan una única tarea, la tendencia será a que los grupos que han sido organizados según este criterio sean disjuntos. En caso de que exista algún estudio cuyo objetivo sea la comparación de dos o más tareas, éste debe ser excluido.

\subsubsection{Agrupar estudios por tipo de sujeto experimental}

Para esta tarea se debe utilizar la Sección II del Formulario E03-Clusters de lectura, que incluye los campos:

- Tarea.

- $\quad$ Tipo de sujeto.

- Estudios.

Debe clasificarse el experimento según se trate de estudiantes que participan en un ambiente académico o profesionales que pueden participar tanto en ambientes académicos (por ejemplo, cursos de especialización en una universidad o programas de postgrado) como en un ambiente industrial. El criterio que prevalecerá para la clasificación será el perfil del sujeto y no el ambiente en el que aplica la tarea. Igual que en el paso anterior, si un estudio ensaya ambos tipos de sujetos, éste deberá excluirse. En el ejemplo del experimento identificado como ART_27 se indica que los sujetos que participan en el experimento son estudiantes de post-grado, por lo tanto se considerará que el tipo de sujeto es "Estudiante", creando un grupo para este tipo dentro del grupo creado en el paso anterior (como se muestra en la tabla 7.3).

Tabla 7.3. Ejemplo Agrupamiento por tipo de sujeto. Caso de estudio: inspección de software

\begin{tabular}{|c|c|c|}
\hline \multicolumn{1}{|c|}{ TAREA } & TIPO DE SUJETO & ESTUDIOS \\
\hline \multirow{2}{*}{ Requisitos } & ESTUDIANTES & $\begin{array}{c}\text { ART_27, ART_78, ART_45, ART_80, ART_14, ART_44, } \\
\text { ART_11,ART_89, ART_75, ART_54 }\end{array}$ \\
\cline { 2 - 3 } & PROFESIONALES & ART_81 \\
\hline \multirow{2}{*}{ Diseño } & ESTUDIANTES & ART_19, ART_08, ART_17, ART_46, ART_25 \\
\cline { 2 - 3 } & PROFESIONALES & \\
\hline \multirow{2}{*}{$\begin{array}{l}\text { UMLeño con } \\
\text { UML }\end{array}$} & ESTUDIANTES & ART_82, ART_18, ART_28 \\
\cline { 2 - 3 } & PROFESIONALES & \\
\hline \multirow{2}{*}{ Código } & ESTUDIANTES & ART_85, ART_23a, ART_23b, ART_23c \\
\cline { 2 - 3 } & PROFESIONALES & \\
\hline
\end{tabular}




\subsubsection{Agrupar estudios independientes y replicaciones}

En esta tarea se utilizarán las secciones III y IV del formulario de Clusters de lectura, que contienen los siguientes campos:

- Grupo: un identificador para el grupo de experimentos que se está formando.

- $\quad$ Niveles: los tratamientos que son ensayados en el grupo de experimentos.

- Variables respuesta: las variables que son medidas en el grupo de experimentos.

- Métricas: las mediciones específicas que son evaluadas en los tratamientos.

- Artículos: los experimentos que reportan los niveles y variables anteriores, en el caso de las replicaciones, los artículos son separados en Estudio original y Replicaciones.

Para cada uno de los estudios dentro de los grupos formados en el paso anterior, deben realizarse los siguientes pasos a fin de especificar sus niveles y variables respuesta:

1. Formar un grupo para cada grupo tarea/tipo de sujeto. Por ejemplo, Requisitos - Estudiantes.

2. Seleccionar cada uno de los estudios incluidos en un grupo tarea/tipo de sujeto. A partir del formulario E01-Datos del experimento, identificar los niveles que son ensayados dentro del estudio. En el ejemplo del experimento ART_27 se ensayan tres niveles (Ad Hoc, CBR y SBR) y se evalúan dos variables respuesta (Efectividad método y Efectividad reunión). Leer el campo REPLICACIóN del formulario donde se indica si el experimento es una replicación parcial o total de otro experimento, así como los datos del experimento original. Este paso está destinado a agrupar replicaciones que ensayen los mismos niveles del factor principal, así como las mismas variables respuesta; en caso contrario se sugiere tratar el experimento como un estudio independiente y no como una replicación.

3. Agrupar como estudio independiente. Si no se trata de una replicación vaciar los datos relacionados con los niveles, las variables respuesta y las métricas en la sección III (Estudios independientes) del formulario E03-Clusters de lectura. En la tabla 7.4 se puede observar como ejemplo el resumen de datos del experimento ART_27.

Tabla 7.4. Ejemplo de resumen de datos del experimento ART_27. Caso de estudio: inspección de software

\begin{tabular}{|l|l|l|l|}
\hline \multicolumn{2}{|c|}{ TAREA EXPERIMENTAL } & \multicolumn{2}{c|}{ Requisitos } \\
\hline \multicolumn{2}{|c|}{ TIPO DE SUJETO } & Estudiantes \\
\hline ARTÍCULOS & NIVELES & VARIABLE RESPUESTA & MÉTRICA \\
\hline ART_27 & AH, CBR, SBR & Efectividad método & Tasa individual de detección de \\
\hline
\end{tabular}




\begin{tabular}{|l|l|l|}
\hline \multirow{2}{*}{} & \multirow{2}{*}{} & fallos \\
\cline { 3 - 3 } & & $\begin{array}{l}\text { Tasa grupal de detección de } \\
\text { fallos }\end{array}$ \\
\cline { 3 - 3 } & Efectividad reunión & Tasa de ganancia de reuniones \\
\cline { 3 - 4 } & & Tasa de pérdida de reuniones \\
\hline
\end{tabular}

4. Agrupar replicaciones. En caso de que el estudio se trate de una replicación, agruparlo con el estudio original utilizando para ello la Sección IV (Replicaciones) del formulario E03-Clusters de lectura. Si el estudio original ha sido previamente incorporado a un grupo como si fuese un estudio independiente, deberá ser desincorporado del mismo. Esto implica que lo estudios originales y sus replicaciones participarán de un solo grupo el cual será identificado con un código. En la tabla 7.5 se pueden observar cómo se ha movido el experimento ART_27 a la sección de Replicaciones, donde aparece con otros experimentos por los que es replicado.

Tabla 7.5. Ejemplo de Agrupamiento de Replicaciones. Caso de estudio: inspección de software

\begin{tabular}{|c|c|c|c|c|c|}
\hline \multicolumn{3}{|c|}{ TAREA EXPERIMENTAL } & \multicolumn{3}{|l|}{ Requisitos } \\
\hline \multicolumn{3}{|c|}{ TIPO DE SUJETO } & \multicolumn{3}{|l|}{ Estudiantes } \\
\hline GRUPO & $\begin{array}{l}\text { ESTUDIO } \\
\text { ORIGINAL }\end{array}$ & REPLICACIONES & NIVELES & $\begin{array}{l}\text { VARIABLE } \\
\text { RESPUESTA }\end{array}$ & MÉTRICA \\
\hline \multirow[t]{4}{*}{ R1 } & \multirow[t]{4}{*}{ ART_27 } & \multirow[t]{4}{*}{$\begin{array}{l}\text { ART_78, ART_45, } \\
\text { ART_80, ART_81 }\end{array}$} & \multirow[t]{4}{*}{$\begin{array}{l}\text { CBR, } A H, \\
\text { SBR }\end{array}$} & \multirow[t]{2}{*}{$\begin{array}{l}\text { Efectividad } \\
\text { método }\end{array}$} & $\begin{array}{l}\text { Tasa individual de } \\
\text { detección de fallos }\end{array}$ \\
\hline & & & & & $\begin{array}{l}\text { Tasa grupal de } \\
\text { detección de fallos }\end{array}$ \\
\hline & & & & \multirow[t]{2}{*}{$\begin{array}{l}\text { Efectividad } \\
\text { reunión }\end{array}$} & $\begin{array}{l}\text { Tasa de ganancia } \\
\text { de reuniones }\end{array}$ \\
\hline & & & & & $\begin{array}{l}\text { Tasa de pérdida de } \\
\text { reuniones }\end{array}$ \\
\hline R2 & ART_89 & ART_75 & CBR, SBR & Precisión & \\
\hline \multirow[t]{2}{*}{ R3 } & \multirow[t]{2}{*}{ ART_19 } & \multirow[t]{2}{*}{ ART_08 } & \multirow[t]{2}{*}{ CBR, UBR } & $\begin{array}{l}\text { Efectividad } \\
\text { método }\end{array}$ & \\
\hline & & & & $\begin{array}{l}\text { Eficiencia } \\
\text { método }\end{array}$ & \\
\hline
\end{tabular}


En la tabla 7.6 se puede observar que el experimento ART_27 ya no aparece en los grupos de estudios independientes.

Tabla 7.6. Ejemplo de Agrupamiento de Replicaciones. Caso de estudio: inspección de software

\begin{tabular}{|c|c|c|c|}
\hline \multicolumn{2}{|c|}{ TAREA EXPERIMENTAL } & \multicolumn{2}{|l|}{ Requisitos } \\
\hline \multicolumn{2}{|c|}{ TIPO DE SUJETO } & \multicolumn{2}{|c|}{ Estudiantes } \\
\hline ARTÍCULOS & NIVELES & $\begin{array}{l}\text { VARIABLE } \\
\text { RESPUESTA }\end{array}$ & MÉTRICA \\
\hline $\begin{array}{l}\text { ART_14, } \\
\text { ART_84 }\end{array}$ & CBR, SBR, AH & Efectividad método & $\begin{array}{l}\text { Tasa grupal de detección de fallos } \\
\text { por tipo de fallo }\end{array}$ \\
\hline ART_54 & CBR, SBR & Precisión & Precisión de técnicas de estimación \\
\hline ART_83 & SBR & Usabilidad & Usabilidad de un framework \\
\hline \multirow{3}{*}{ ART_11 } & \multirow{3}{*}{$\mathrm{AH}, \mathrm{CBR}$} & Efectividad roles & \\
\hline & & \multirow{2}{*}{ Efectividad método } & Tasa de detección de defectos \\
\hline & & & Capacidad de detección \\
\hline \multirow{3}{*}{ ART_01 } & \multirow{3}{*}{ CBR, PBR } & \multirow{2}{*}{ Efectividad método } & Núm de fallos detectados \\
\hline & & & Núm de requisitos \\
\hline & & Eficiencia método & Recursos usados \\
\hline \multirow{2}{*}{ ART_44 } & \multirow{2}{*}{ CBR, UBR } & \multirow{2}{*}{ Efectividad método } & Efectividad individual \\
\hline & & & Efectividad grupal \\
\hline
\end{tabular}

\subsubsection{Conformar clusters de lectura}

El objetivo de este paso es permitir una fácil visualización de los niveles y variables respuesta analizados en cada grupo para facilitar tanto la decisión de qué estudios leer como la comprensión de los estudios leídos. Una vez finalizado el agrupamiento, se sugiere realizar un resumen de los datos de los estudios que han sido descritos en los pasos anteriores. Para ello se utilizarán las secciones I-IV del formulario E03Clusters de lectura y se actualizará la Sección V (Clusters de lectura) de dicho documento. En esta sección se tendrá una tabla para cada uno de los grupos formados por una tarea/tipo de sujeto que han sido identificados en el paso anterior. Cada tabla está compuesta por los Estudios, Niveles y las Variables respuesta. 
La tabla 7.7 muestra la estructura sugerida para la representación de los datos de los experimentos de un grupo. Nótese que los experimentos se disponen en forma vertical bajo la columna denominada "Estudios", mientras que los niveles y las variables respuesta son dispuestos de manera horizontal.

Tabla 7.7. Ejemplo de representación tabular

\begin{tabular}{|l|l|l|l|l|l|l|l|l|l|l|l|}
\hline \multirow{2}{*}{ ESTUDIOS } & \multicolumn{6}{l|}{ NIVELES ENSAYADOS } & \multicolumn{6}{l|}{ VARIABLES RESPUESTA } \\
\cline { 2 - 11 } & & & & & & & & & & & \\
& & & & & & & & & & & \\
\hline & & & & & & & & & & & \\
\hline & & & & & & & & & & & \\
\hline
\end{tabular}

Para realizar esta representación se recomienda seguir los siguientes pasos:

1. Seleccionar un grupo tarea/tipo de sujeto; por ejemplo, Requisitos - Estudiantes.

2. Representar cada estudio. Incluir una entrada para identificar el estudio y agregar los niveles y variables respuesta en caso de que no aparezcan ya representados. Utilizar una $\mathrm{X}$ para marcar los niveles y variables respuesta que corresponden al experimento. Incluir tanto estudios independientes como grupos de replicaciones. La tabla 7.8 muestra un ejemplo de esta representación para el caso de estudio sobre inspección de software.

Tabla 7.8. Ejemplo de representación de los estudios del grupo Requisitos - Estudiantes

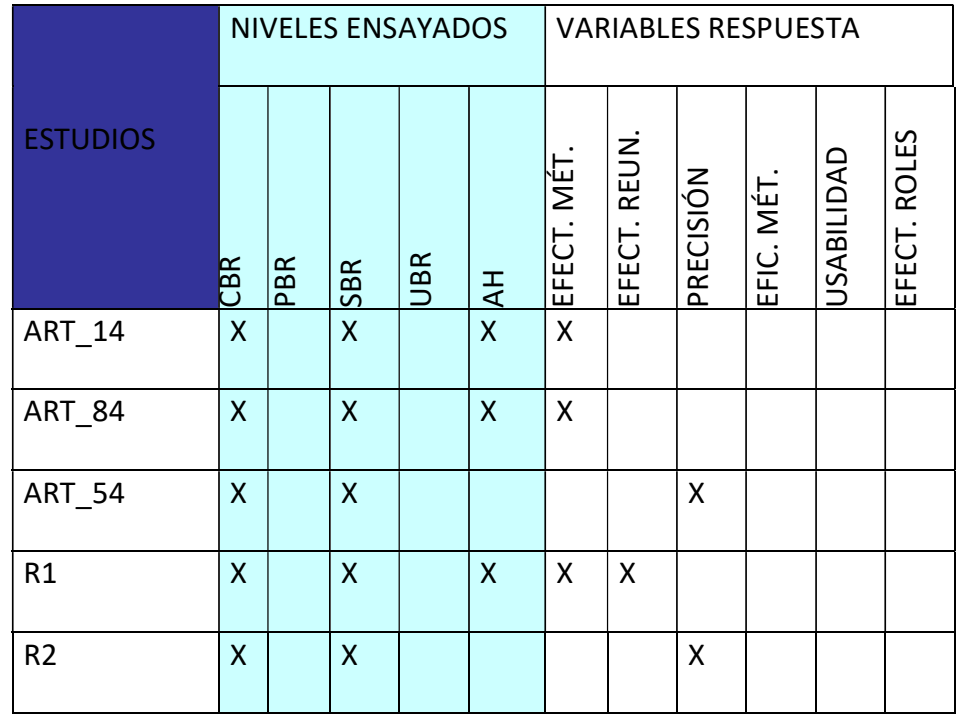

3. Una vez finalizada la representación de todos los estudios de un grupo Tarea/Tipo de sujeto, reorganizarlos de manera que los estudios que comparten los mismos niveles se ubiquen juntos, 
comenzando por aquellos que comparten exactamente los mismos niveles y siguiendo con aquellos que comparten niveles parcialmente. Por ejemplo, en la tabla 7.9 se observa como la replicación R1 (que contiene al experimento ART_27) ensaya exactamente los mismos niveles que ART_14 y ART_84, y sólo coincide en dos niveles con R2 y ART_54 (los que, a su vez, ensayan exactamente los mismos dos niveles).

Tabla 7.9. Ejemplo de re-organización de los estudios del grupo Requisitos - Estudiantes

\begin{tabular}{|c|c|c|c|c|c|c|c|c|c|c|c|}
\hline \multirow[b]{2}{*}{ ESTUDIOS } & \multicolumn{5}{|c|}{ NIVELES ENSAYADOS } & \multicolumn{6}{|c|}{ VARIABLES RESPUESTA } \\
\hline & $\stackrel{r}{e}$ & $\frac{\mathscr{c}}{\underline{M}}$ & $\begin{array}{l}\stackrel{\mathscr{N}}{\sim} \\
\text { ñ }\end{array}$ & 舀 & $\frac{I}{4}$ & 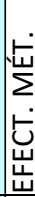 & 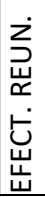 & 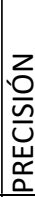 & 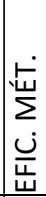 & 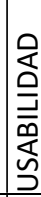 & 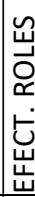 \\
\hline R1 & $x$ & & $x$ & & $x$ & $x$ & $x$ & & & & \\
\hline ART_14 & $x$ & & $\mathrm{x}$ & & $x$ & $X$ & & & & & \\
\hline ART_84 & $x$ & & $\mathrm{x}$ & & $x$ & $\mathrm{x}$ & & & & & \\
\hline $\mathrm{R} 2$ & $x$ & & $x$ & & & & & $x$ & & & \\
\hline ART_54 & $x$ & & $x$ & & & & & $x$ & & & \\
\hline
\end{tabular}

4. Agrupar los estudios que ensayan exactamente los mismos niveles en un nuevo nivel de la tabla que se llamará Cluster y que representa un grupo de estudios que debería ser leído en conjunto. La tabla 7.10 muestra este agrupamiento usando la columna identificada como cluster. Nótese que el cluster C1.1 agrupa a la replicación R1 junto con dos estudios independientes ART_14 y ART_84.

Tabla 7.10. Ejemplo de representación tabular agrupando en clusters

\begin{tabular}{|c|c|c|c|c|c|c|c|c|c|c|c|c|}
\hline \multicolumn{2}{|c|}{ CLUSTER } & \multicolumn{5}{|c|}{ NIVELES ENSAYADOS } & \multicolumn{6}{|c|}{ VARIABLES RESPUESTA } \\
\hline 으 & 号 & $\stackrel{\mathscr{c}}{\mathscr{0}}$ & $\begin{array}{l}\stackrel{\alpha}{0} \\
\underline{a}\end{array}$ & $\begin{array}{l}\stackrel{0}{\tilde{v}} \\
\tilde{n}\end{array}$ & $\begin{array}{l}\stackrel{r}{9} \\
\stackrel{و}{\supset}\end{array}$ & $\frac{I}{4}$ & 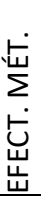 & 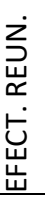 & $\begin{array}{l}z \\
\text { 음 } \\
\underline{\underline{u}} \\
\text { 品 } \\
\underline{a}\end{array}$ & $\begin{array}{l}\stackrel{5}{\dot{w}} \\
\frac{\dot{u}}{\dot{w}}\end{array}$ & 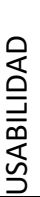 & 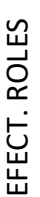 \\
\hline \multirow[t]{3}{*}{$\overline{C 1.1}$} & $\mathrm{R} 1$ & $x$ & & $x$ & & $x$ & $x$ & $x$ & & & & \\
\hline & ART_14 & $\mathrm{x}$ & & $x$ & & $x$ & $x$ & & & & & \\
\hline & ART_84 & $x$ & & $x$ & & $x$ & $x$ & & & & & \\
\hline
\end{tabular}




\begin{tabular}{|l|l|l|l|l|l|l|l|l|l|l|l|l|}
\hline C1.2 & R2 & $X$ & & $X$ & & & & & $X$ & & & \\
& ART_54 & $X$ & & $X$ & & & & & $X$ & & & \\
\hline
\end{tabular}

Las tablas 7.11 a 7.14 muestran ejemplos de la representación tabular de los clusters de lectura correspondientes a las siguientes tareas del caso de estudio: Requisitos- Estudiantes, Código - Estudiantes, Diseño - Estudiantes, y Diseño con UML - Estudiantes.

Tabla 7.11. Ejemplo de representación tabular: Requisitos - Estudiantes

\begin{tabular}{|c|c|c|c|c|c|c|c|c|c|c|c|c|}
\hline \multicolumn{2}{|c|}{ CLUSTER } & \multicolumn{5}{|c|}{ NIVELES ENSAYADOS } & \multicolumn{6}{|c|}{ VARIABLES RESPUESTA } \\
\hline 으 & 음 & 怘 & $\begin{array}{l}\stackrel{0}{0} \\
\alpha\end{array}$ & $\begin{array}{l}\stackrel{0}{\tilde{m}} \\
\tilde{\sim}\end{array}$ & 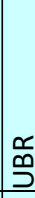 & $\frac{I}{4}$ & 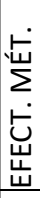 & 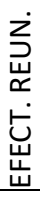 & 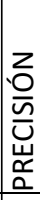 & 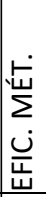 & 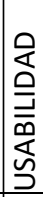 & 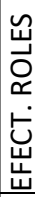 \\
\hline \multirow[t]{3}{*}{ C1.1 } & R1 & $x$ & & $x$ & & $\mathrm{x}$ & $x$ & $x$ & & & & \\
\hline & ART_14 & $x$ & & $x$ & & $x$ & $\mathrm{x}$ & & & & & \\
\hline & ART_84 & $x$ & & $\mathrm{X}$ & & $x$ & $x$ & & & & & \\
\hline \multirow[t]{2}{*}{ C1.2 } & $\mathrm{R} 2$ & $\mathrm{X}$ & & $x$ & & & & & $x$ & & & \\
\hline & ART_54 & $x$ & & $x$ & & & & & $x$ & & & \\
\hline \multirow[t]{2}{*}{ C1.3 } & R3 & $\mathrm{X}$ & & & $x$ & & $\mathrm{X}$ & & & $x$ & & \\
\hline & ART_44 & $x$ & & & $x$ & & $\mathrm{X}$ & & & & & \\
\hline C1.4 & ART_01 & $\mathrm{X}$ & $\mathrm{x}$ & & & & $\mathrm{X}$ & & & $x$ & & \\
\hline C1.5 & ART_11 & $\mathrm{X}$ & & & & $x$ & & $\mathrm{X}$ & & & & $\mathrm{x}$ \\
\hline C1.6 & ART_83 & & & $x$ & & & & & & & $x$ & \\
\hline
\end{tabular}

Tabla 7.12. Ejemplo de representación tabular: Código - Estudiantes

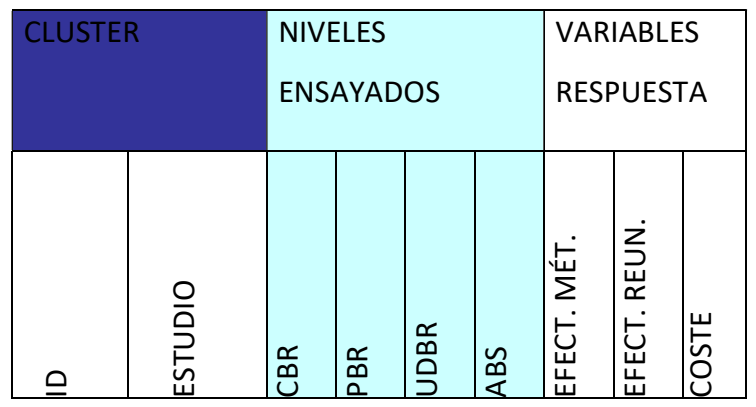




\begin{tabular}{|l|l|l|l|l|l|l|l|l|}
\hline C2.1 & ART_85 & $X$ & $X$ & & & $X$ & $X$ & $X$ \\
\hline C2.2 & ART_23 & $X$ & & $X$ & $X$ & $X$ & & \\
\hline C2.3 & ART_86 & & $X$ & & & $X$ & & \\
\hline
\end{tabular}

Tabla 7.13. Ejemplo de agrupamiento: Diseño - - Estudiantes

\begin{tabular}{|c|c|c|c|c|c|c|c|c|c|c|}
\hline \multicolumn{2}{|c|}{ CLUSTER } & \multicolumn{4}{|c|}{$\begin{array}{l}\text { NIVELES } \\
\text { ENSAYADOS }\end{array}$} & \multicolumn{5}{|c|}{ VARIABLES RESPUESTA } \\
\hline 으 & $\begin{array}{l}\text { 음 } \\
\stackrel{ }{n} \\
\text { แ }\end{array}$ & $\stackrel{r}{0}$ & $\begin{array}{l}\stackrel{0}{\infty} \\
\underline{\alpha}\end{array}$ & 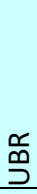 & 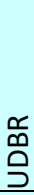 & 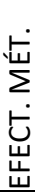 & 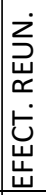 & 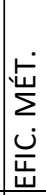 & 岕 & 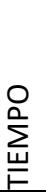 \\
\hline C3.1 & ART_82 & $x$ & & & $x$ & $x$ & & & & \\
\hline \multirow[t]{3}{*}{ C3.2 } & ART_18 & $\mathrm{X}$ & $\mathrm{X}$ & & & $X$ & $\mathrm{X}$ & & $x$ & \\
\hline & ART_28 & $x$ & $\mathrm{X}$ & & & $x$ & $\mathrm{X}$ & & & \\
\hline & ART_42 & $\mathrm{X}$ & $X$ & & & $\mathrm{X}$ & & & & \\
\hline C3.3 & ART_73 & & & $X$ & & $x$ & & $X$ & & $x$ \\
\hline
\end{tabular}

Tabla 7.14. Ejemplo de agrupamiento: Diseño con UML - Estudiantes

\begin{tabular}{|c|c|c|c|c|c|c|c|c|c|}
\hline \multicolumn{2}{|c|}{ CLUSTER } & \multicolumn{3}{|c|}{$\begin{array}{l}\text { NIVELES } \\
\text { ENSAYADOS }\end{array}$} & \multicolumn{5}{|c|}{ VARIABLES RESPUESTA } \\
\hline 으 & $\begin{array}{l}\stackrel{ }{0} \\
\stackrel{ }{\mathfrak{n}} \\
\end{array}$ & $\stackrel{\mathscr{c}}{\stackrel{0}{u}}$ & $\begin{array}{l}\stackrel{\alpha}{0} \\
\underline{a}\end{array}$ & 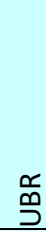 & 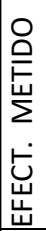 & 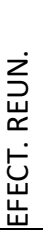 & $\begin{array}{l}\stackrel{\dot{w}}{\dot{\Sigma}} \\
\frac{\dot{u}}{\dot{w}}\end{array}$ & 峁 & 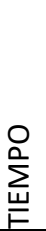 \\
\hline \multirow[t]{3}{*}{ C4.1 } & ART_17 & $\mathrm{x}$ & $x$ & & $\mathrm{X}$ & & & $x$ & $x$ \\
\hline & ART_46 & $\mathrm{x}$ & $x$ & & $\mathrm{x}$ & & & $x$ & $x$ \\
\hline & ART_25 & $\mathrm{x}$ & $x$ & & $\mathrm{x}$ & $x$ & & & \\
\hline \multirow[t]{2}{*}{$\mathrm{C} 4.2$} & ART_40 & $\mathrm{x}$ & & $x$ & $x$ & $x$ & $\mathrm{x}$ & & $x$ \\
\hline & ART_44 & $X$ & & $x$ & $x$ & & & & \\
\hline
\end{tabular}


Este agrupamiento permite observar rápidamente que algunos clusters contienen un grupo considerable de experimentos mientras que otros incluyen únicamente un número muy pequeño de experimentos, lo cual hace que se pierda interés en tales experimentos al no ser probable que participen en la agregación que se llevará a cabo en la fase de SínTESIS DE DATOS. Por ejemplo, se tiene que para el grupo Requisitos/Estudiantes del caso de estudio, el cluster C1.1 parece ser prometedor al contar con un número considerable de experimentos muy parecidos en cuanto a los niveles y variables respuesta. Dentro de este grupo le siguen los clusters C1.2 y C1.3. Por ello, parece justificado dedicar tiempo a la lectura en profundidad de estos experimentos. Por otra parte, los clusters C1.4, C1.5 y C1.6 muestran un único experimento, lo cual genera poco interés en ellos en virtud de que seguramente no formarán parte de la agregación durante la fase de SínTESIS DE DATOS.

\section{Evaluación de la continuidad del proceso}

Una vez que se han establecido los clusters de lectura, es posible que los revisores no mantengan el interés o no encuentren prometedores los grupos de experimentos identificados en esta actividad. Lo que lleva a tomar una decisión sobre continuar con el proceso o detenerlo (véase Tabla 5.2 - Hitos del proceso de RS).

\subsubsection{Lectura en Profundidad}

El propósito de esta actividad es extraer el resto de las características relevantes de los experimentos seleccionados (tales como: Parámetros, Variables de bloque, Hipótesis, Ambiente, Tipo de estudio, Proceso experimental, Aleatorización, Ocultamiento, Enmascaramiento, Métodos de medición y análisis de resultados, Amenazas a la validez, Resultados experimentales y Hallazgos) necesarios tanto para valorar la calidad del estudio como para agregar sus resultados experimentales con los resultados de otros experimentos similares. Para ello, se utilizarán los clusters de lectura obtenidos en la actividad anterior; seleccionando aquellos que sean de mayor interés para la RS por su compatibilidad (similitud en cuanto a los niveles y variables respuesta) o por la cantidad de estudios que éstos incluyen; como podría ser, por ejemplo, los experimentos incluidos en los clusters $\mathrm{C} 1.1, \mathrm{C} 1.2$ y $\mathrm{C} 1.3$, ya que reúnen un número interesante de experimentos y ensayan niveles en común (C1.1 y C1.2 tienen en común 2 niveles, y ambos comparten 1 nivel con C1.3). Las tareas a seguir en esta actividad son mostradas en la figura 7.3. 


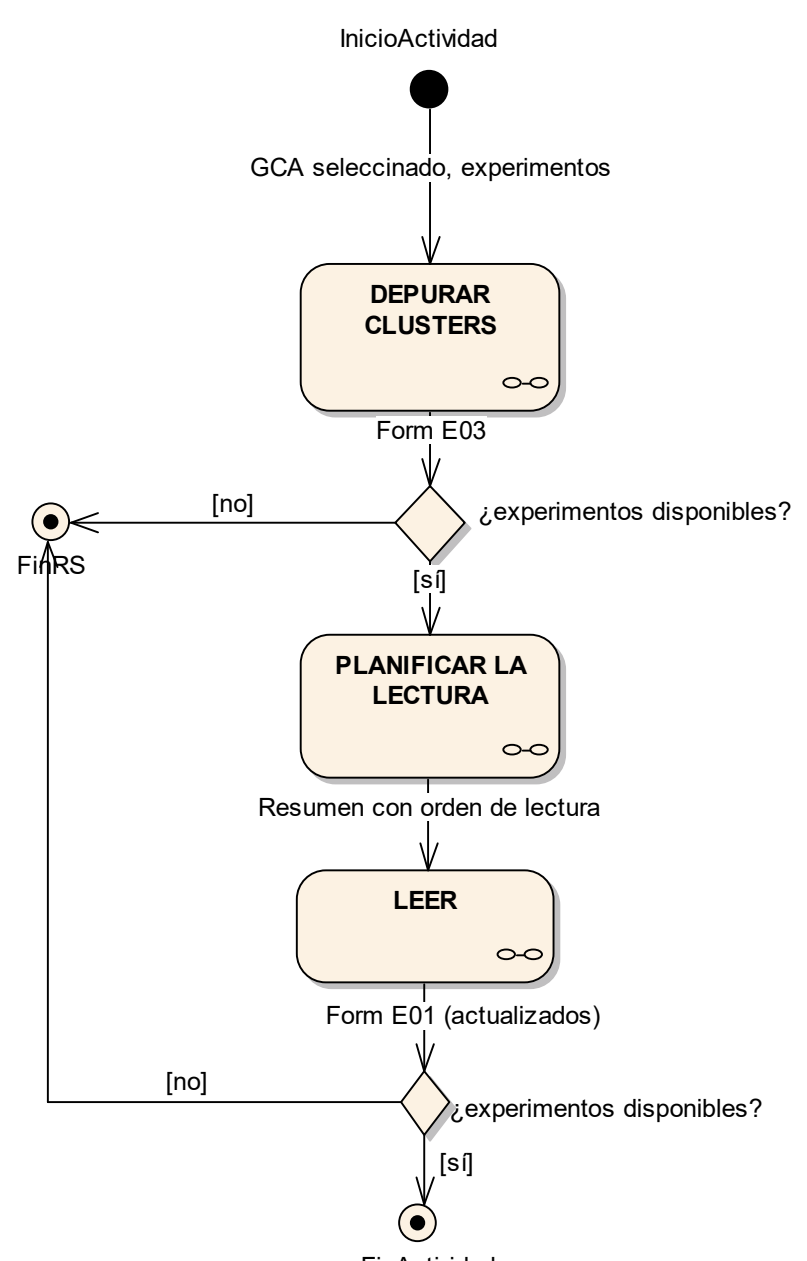

FinActividad

Figura 7.2. Tareas de la actividad LECTURA EN PROFUNDIDAD

En la figura 7.3 se muestra cómo los clusters de lectura que son de interés son seleccionados y depurados de manera iterativa en esta actividad; posteriormente, se establece el orden de lectura con base en los grupos re-estructurados, para finalmente leer los estudios en detalle siguiendo el orden propuesto. Como salida de esta actividad se obtienen los formularios E01-Datos del experimento (uno por cada experimento) actualizados con la información necesaria para la evaluación de la calidad del estudio y su agregación.

\subsubsection{Depurar los clusters de lectura}

Esta tarea toma como entrada los clusters de lectura resultantes de la actividad anterior, organizados por tarea/tipo de sujeto; así como los clusters de lectura que cada uno de tales grupos contiene para eliminar experimentos que no serán útiles durante la agregación, bien porque ensayan sólo un nivel o porque son 
los únicos en evaluar una variable respuesta. Para cada uno de los grupos tarea/tipo de sujeto, se depurarán los clusters como se indica a continuación:

1. Identificar las filas que representan artículos que ensayan un único nivel; éste es el caso de los experimentos que validan el uso de una tecnología versus no utilizar nada. Para ello, identificar aquellas filas que en la sección Niveles ensayados de la tabla posean una única marca (X). La fila correspondiente al estudio deberá ser removida de la tabla y el estudio deberá ser excluido. Como resultado de esta re-estructuración, los clusters sólo incluirán estudios que comparen dos o más niveles.

2. Identificar aquellas variables respuesta que han sido estudiadas por un único experimento. Esto es equivalente a recorrer las columnas que representan las variables respuesta e identificar aquéllas donde aparezca una única marca (X). La variable respuesta identificada deberá ser removido de la tabla y el estudio deberá ser excluido. Como consecuencia de esta depuración, los clusters sólo incluirán variables respuesta que han sido analizados por dos o más estudios potencialmente agregables.

Las tablas 7.15 a 7.18 muestran ejemplos la re-estructuración anteriormente descrita, aplicada a los grupos que se obtuvieron en la actividad anterior.

Tabla 7.15. Ejemplo de re-estructuración: Requisitos-Estudiantes

\begin{tabular}{|c|c|c|c|c|c|c|c|c|c|c|c|c|}
\hline \multicolumn{2}{|c|}{ CLUSTERS } & \multicolumn{5}{|c|}{ NIVELES ENSAYADOS } & \multicolumn{6}{|c|}{ VARIABLES RESPUESTA } \\
\hline$\underline{\underline{\theta}}$ & $\begin{array}{l}\stackrel{\circ}{0} \\
\stackrel{?}{\mathrm{n}}\end{array}$ & $\begin{array}{l}\stackrel{r}{0} \\
\underline{U}\end{array}$ & $\begin{array}{l}\stackrel{r}{\infty} \\
\underline{a}\end{array}$ & 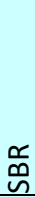 & $\begin{array}{l}\text { 品 } \\
\text { 号 }\end{array}$ & $\frac{I}{\alpha}$ & 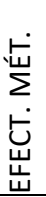 & 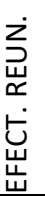 & 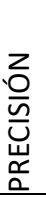 & 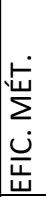 & 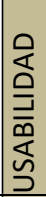 & 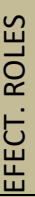 \\
\hline \multirow[t]{3}{*}{ C1.1 } & R1 & $x$ & & $x$ & & $x$ & $x$ & $x$ & & & & \\
\hline & ART_14 & $x$ & & $x$ & & $x$ & $x$ & & & & & \\
\hline & ART_84 & $x$ & & $x$ & & $x$ & $x$ & & & & & \\
\hline \multirow[t]{2}{*}{$\mathrm{C} 1.2$} & $\mathrm{R} 2$ & $x$ & & $x$ & & & & & $x$ & & & \\
\hline & ART_54 & $x$ & & $x$ & & & & & $x$ & & & \\
\hline \multirow[t]{2}{*}{1.3} & R3 & $x$ & & & $x$ & & $\mathrm{x}$ & & & $x$ & & \\
\hline & ART_44 & $x$ & & & $x$ & & $x$ & & & & & \\
\hline 1.4 & ART_01 & $x$ & $x$ & & & & $x$ & & & $x$ & & \\
\hline 1.5 & ART_11 & $x$ & & & & $x$ & & $\mathrm{X}$ & & & & $x$ \\
\hline 1.6 & ART_83 & & & $x$ & & & & & & & $x$ & \\
\hline
\end{tabular}


Tabla 7.16. Ejemplo de re-estructuración: Código - Estudiantes

\begin{tabular}{|c|c|c|c|c|c|c|c|c|}
\hline \multicolumn{2}{|c|}{ CLUSTERS } & \multicolumn{4}{|c|}{$\begin{array}{l}\text { NIVELES } \\
\text { ENSAYADOS }\end{array}$} & \multicolumn{3}{|c|}{$\begin{array}{l}\text { VARIABLES } \\
\text { RESPUESTA }\end{array}$} \\
\hline 으 & 음 & $\stackrel{\mathscr{0}}{\mathscr{Q}}$ & $\begin{array}{l}\stackrel{a}{0} \\
\stackrel{0}{a}\end{array}$ & $\begin{array}{l}\frac{1}{0} \\
\stackrel{9}{2}\end{array}$ & 吕 & 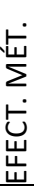 & 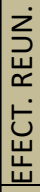 & 峁 \\
\hline C2.1 & ART_85 & $x$ & $x$ & & & $x$ & $x$ & $x$ \\
\hline C2.2 & ART_23 & $x$ & & $X$ & $x$ & $X$ & & \\
\hline C2.3 & ART_86 & & $x$ & & & $x$ & & \\
\hline
\end{tabular}

Tabla 7.17. Ejemplo de re-estructuración: Diseño - - Estudiantes

\begin{tabular}{|c|c|c|c|c|c|c|c|c|c|c|}
\hline \multicolumn{2}{|c|}{ CLUSTERS } & \multicolumn{4}{|c|}{$\begin{array}{l}\text { NIVELES } \\
\text { ENSAYADOS }\end{array}$} & \multicolumn{5}{|c|}{ VARIABLES RESPUESTA } \\
\hline 으 & 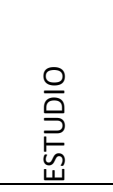 & 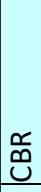 & $\frac{\mathscr{c}}{\underline{m}}$ & $\begin{array}{l}\stackrel{\circ}{9} \\
\stackrel{9}{\supset}\end{array}$ & $\begin{array}{l}\stackrel{r}{0} \\
\stackrel{0}{\rho}\end{array}$ & 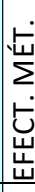 & 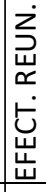 & 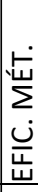 & 岕 & 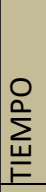 \\
\hline C3.1 & ART_82 & $x$ & & & $\mathrm{x}$ & $x$ & & & & \\
\hline \multirow[t]{3}{*}{ C3.2 } & ART_18 & $\mathrm{X}$ & $X$ & & & $x$ & $x$ & & $x$ & \\
\hline & ART_28 & $\mathrm{X}$ & $X$ & & & $x$ & $\mathrm{X}$ & & & \\
\hline & ART_42 & $\mathrm{X}$ & $x$ & & & $x$ & & & & \\
\hline C3.3 & ART_73 & & & $x$ & & $\mathrm{X}$ & & $\mathrm{X}$ & & $x$ \\
\hline
\end{tabular}

Tabla 7.18. Ejemplo de re-estructuración: Diseño con UML - Estudiantes

\begin{tabular}{|l|l|l|}
\hline CLUSTER & $\begin{array}{l}\text { NIVELES } \\
\text { ENSAYADOS }\end{array}$ & VARIABLES RESPUESTA \\
\hline
\end{tabular}




\begin{tabular}{|c|c|c|c|c|c|c|c|c|c|}
\hline 으 & 음 & $\begin{array}{l}\stackrel{x}{0} \\
0\end{array}$ & $\begin{array}{l}\stackrel{x}{\underline{\alpha}} \\
\underline{a}\end{array}$ & 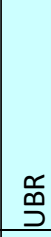 & 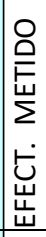 & 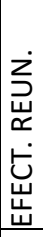 & 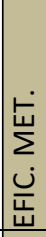 & $\begin{array}{l}\text { 岕 } \\
\text { О } \\
\end{array}$ & 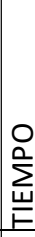 \\
\hline \multirow[t]{3}{*}{$\overline{C 4} .1$} & ART_17 & $x$ & $x$ & & $x$ & & & $x$ & $x$ \\
\hline & ART_46 & $x$ & $x$ & & $x$ & & & $x$ & $x$ \\
\hline & ART_25 & $x$ & $x$ & & $x$ & $x$ & & & \\
\hline \multirow[t]{2}{*}{ C4.2 } & ART_40 & $x$ & & $x$ & $x$ & $x$ & $x$ & & $x$ \\
\hline & ART_44 & $x$ & & $x$ & $x$ & & & & \\
\hline
\end{tabular}

Respecto a los estudios que son excluidos por ser únicos en tratar una determinada variable respuesta, debe tomarse en cuenta que éstos podrían medir otras variables respuesta que sí sean compartidos por otros estudios. Por lo tanto, un experimento puede aparecer en uno o más clusters con una variable respuesta que es común a otros estudios, al mismo tiempo que evalúa otra variable respuesta para la cual es único. Por ejemplo, en la tabla 7.15 se observa que el ART_11 ensaya dos niveles ( $\mathrm{CBR}, \mathrm{AH})$ del factor técnica de inspección para la tarea requisitos, midiendo también dos variables respuesta (efectividad reunión y efectividad roles). Mientras la variable respuesta efectividad reunión es también analizado por la replicación R1, la variable respuesta efectividad roles no es común a ningún otro estudio. Por lo tanto, ART_11 podría ser agregable durante la síntesis para la combinación CBR, AH/efectividad reunión mientras que las piezas de conocimiento que puede aportar acerca de la combinación $C B R$, AH/efectividad roles no pueden ser combinadas directamente con ningún otro estudio, por lo que tal variable respuesta deber ser excluida.

\section{Evaluación de la continuidad del proceso}

Una vez que se han depurado los clusters de lectura, es posible que todos los experimentos llegaran a ser excluidos por ensayar un único nivel o ser únicos en evaluar una determinada métrica. En este caso el proceso deberá ser cancelado ya que no se cuenta con estudios primarios para la agregación (véase Tabla 5.2 - Hitos del proceso de RS).

\subsubsection{Planificar la lectura}


Luego de haber realizado la depuración de los clusters, lo que sigue es establecer el orden de lectura de los estudios. El orden de lectura más adecuado es aquél que obtiene la mayor comprensión posible de los experimentos que son leídos. Para ello es necesario seleccionar los clusters más parecidos de manera que tanto la lectura y la extracción de los datos como la síntesis que se realizará posteriormente se beneficien al máximo de la compatibilidad entre los experimentos en cuanto a los niveles y variables respuesta que analizan. Para ello se propone el algoritmo mostrado en la figura 7.3.

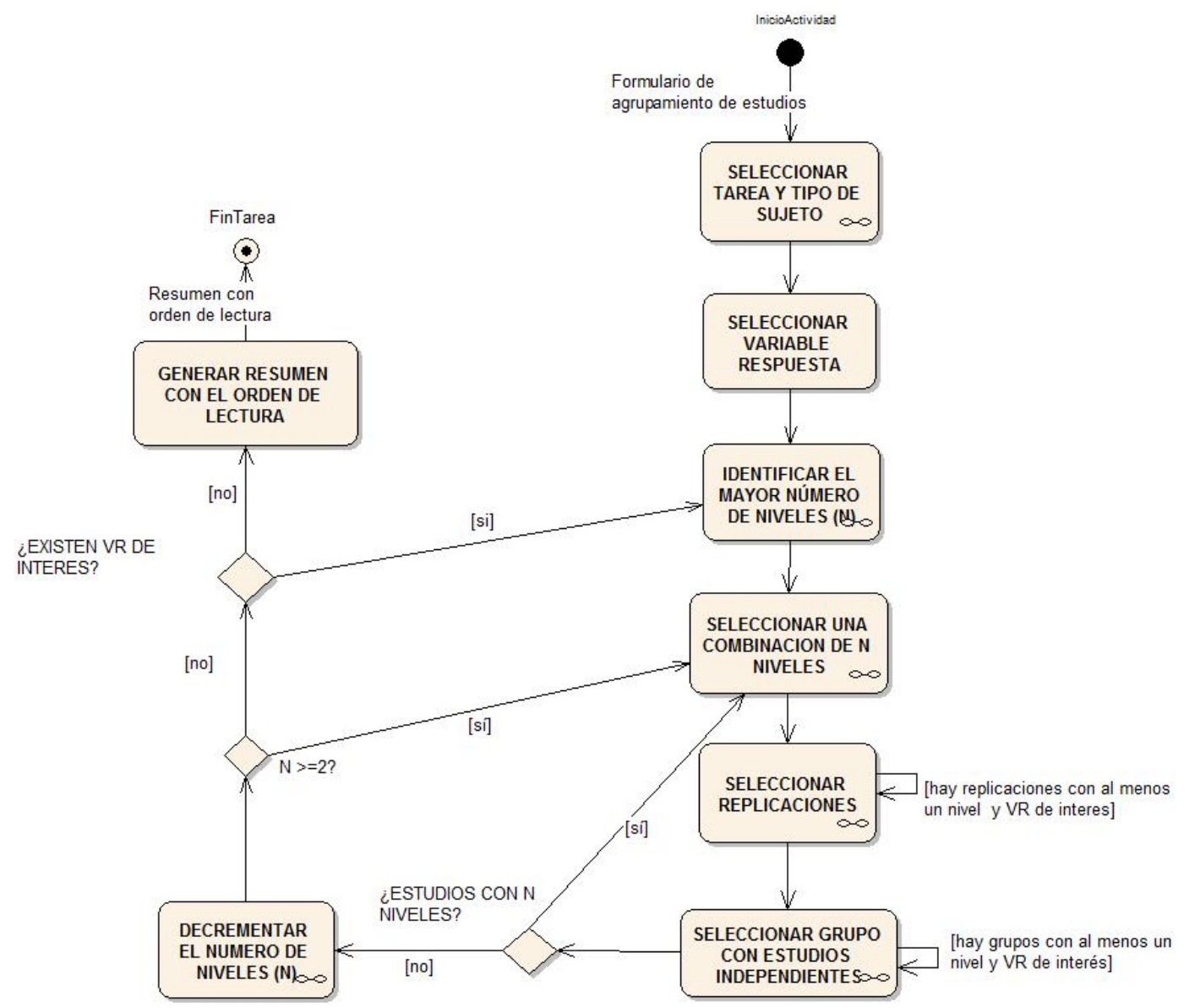

Figura 7.3. Pasos de la tarea PLANIFICAR LA LECTURA

Con el algoritmo mostrado en la figura 7.3 se promueve que para cada combinación de niveles del factor se lean primero aquellos experimentos que ensayan exactamente los mismos niveles y posteriormente se lean aquellos experimentos que difieren en alguno de los niveles (siguiendo un orden decreciente). Por ejemplo, se debería comenzar leyendo los experimentos que ensayan los niveles CBR, SBR y Ad Hoc, para posteriormente leer los experimentos que ensayan SBR-CBR, SBR-Ad Hoc, y CBR-Ad Hoc. El algoritmo propuesto consta de los siguientes pasos, que deberán repetirse para cada grupo tarea/tipo de sujeto: 
1. Seleccionar tarea y tipo de sujeto. Deberá seleccionarse un grupo de interés con base en la tarea experimental y el tipo de sujeto; por ejemplo, el grupo Requisitos - Estudiantes del caso de estudio de inspección de software.

2. Seleccionar variable respuesta. Para cada grupo seleccionado en el paso anterior se deberán seleccionar las variables respuesta de interés para la RS; por ejemplo, Efectividad del método. Para cada variable respuesta realizar los siguientes pasos:

2.1. Identificar el mayor número de niveles. Identificar, entre los estudios que analicen la variable respuesta, aquél que ensaye el mayor número de niveles (llamado en adelante $\mathrm{N}$ ).

2.2. Repetir los siguientes pasos mientras $\mathrm{N}$ sea mayor o igual a 2:

2.2.1. Seleccionar una combinación de $\mathrm{N}$ niveles. Se busca seleccionar una combinación de niveles de interés que no haya sido leída previamente.

2.2.2. Seleccionar replicaciones. Escoger dentro de los estudios aquellos que representen replicaciones que han ensayado exactamente la misma combinación de niveles y variable respuesta seleccionados. Repetir este paso para todas aquellas replicaciones que ensayen al menos uno de los niveles incluidos en la combinación de $\mathrm{N}$ niveles inicial, y la variable respuesta de interés.

2.2.3. Seleccionar estudios independientes. Escoger los estudios independientes que han ensayado exactamente la misma combinación de niveles y variables respuesta establecidos. Repetir este paso para todos aquellos estudios que ensayen al menos uno de los niveles incluidos en la combinación de $\mathrm{N}$ niveles inicial, y la variable respuesta de interés.

2.2.4. Repetir los pasos 2.2 .1 a 2.2.4 mientras existan grupos con $\mathrm{N}$ niveles que no hayan sido aún seleccionados.

2.2.5. Decrementar el valor de $\mathrm{N}$. Con esto se busca repetir el procedimiento para una nueva combinación de niveles, donde el número $\mathrm{N}$ de niveles sea cada vez menor.

3. Generar resumen con el orden de lectura. Consiste en recomendar la secuencia en que debería ser leídos los clusters para cada grupo tarea/tipo de sujeto. Este paso debe realizarse para cada grupo tarea - tipo de sujeto que sea de interés.

3.1 Presentar el orden por cada variable respuesta seleccionada.

3.2 Utilizar los siguientes símbolos: (/) para indicar correspondencia, $(\rightarrow)$ para indicar orden o secuencia, y ([ ]) para indicar opcionalidad.

3.3 Dentro de un cluster se recomienda dar prioridad a la lectura de las replicaciones, seguidas por los estudios independientes. Esto se debe a que las replicaciones pueden considerarse como los estudios 
más similares; por lo que se puede aprovechar al máximo el aprendizaje obtenido de la lectura de uno de ellos para comprender mejor sus replicaciones.

Un ejemplo de la salida de esta tarea para el caso de inspecciones de software se muestra en la tabla 7.19. Por ejemplo, el orden de lectura propuesto para los estudios cuya tarea experimental es Requisitos comienza con el cluster C1.1 (comenzando por la replicación R1 y continuando con los estudios ART_14 y ART 84), continúa con el cluster C1.3 (comenzando con la replicación R3 y continuando con el estudio ART 44) y, por último, el cluster C1.4. Si se ha seguido este orden, los siguientes clusters a leer son C1.5, y C1.2, que corresponden a las variables respuesta Efectividad de método y Precisión, respectivamente.

Tabla 7.19. Ejemplo de Orden de lectura para los grupos relacionados con inspección de software

\begin{tabular}{|c|c|}
\hline Tarea & VR / Orden de lectura \\
\hline Requisitos & 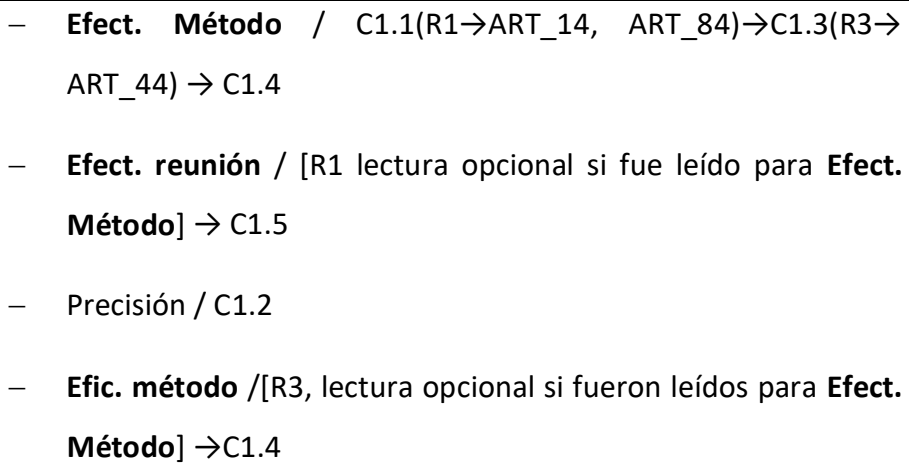 \\
\hline Código & Efect. Método / C2.1 $\rightarrow$ C2.2 \\
\hline Diseño & 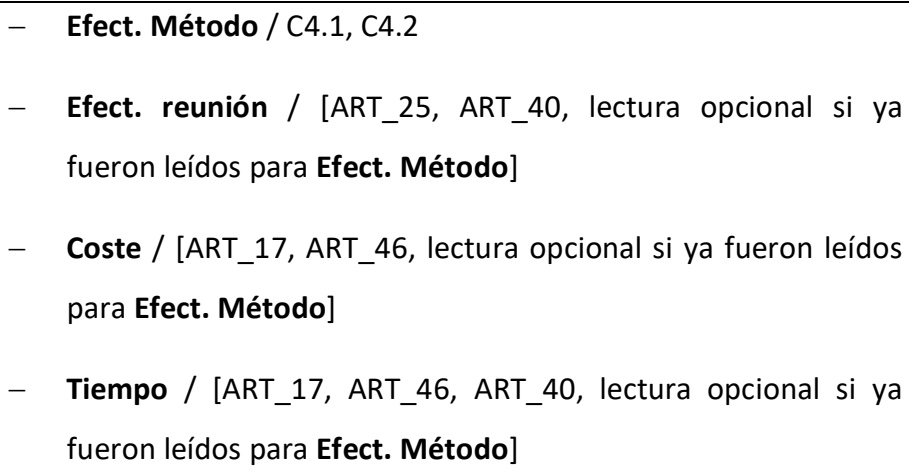 \\
\hline Diseño con UML & $\begin{array}{ll}- & \text { Efect. Método / C3.1 } \rightarrow \text { C3.2 } \\
\text { - } & \text { Efect. reunión / }[\text { ART_18, ART_48 lectura opcional si fueron } \\
& \text { leídos para Efect. Método] }\end{array}$ \\
\hline
\end{tabular}


En la tabla 7.19 es evidente que el orden de la lectura resultante está orientado, en primer lugar, por la tarea y, en segundo lugar, por variables respuesta.

\subsubsection{Leer}

Esta tarea consiste en la extracción de los siguientes datos necesarios para completar el formulario E01Datos del experimento (véase el Apéndice C):

- Parámetros: cualquier característica (cualitativa o cuantitativa) del proyecto de software, que permanecerá invariable o constante durante la experimentación.

- Variables de bloque: cualquier característica (cualitativa o cuantitativa) del proyecto de software, que haya sido asignada por los experimentadores.

- Hipótesis: las explicaciones sugeridas respecto al fenómeno que se estudia y que son probadas durante la experimentación.

- Sujetos experimentales: aunque ya en la lectura superficial se identificó el perfil (tipo) del sujeto, en este nuevo ciclo de lectura deberá completarse esta información con: número de sujetos, entrenamiento, experiencia previa, y población de la cual se extrajo la muestra.

- Ambiente: el entorno en el que se realiza el estudio. Éste puede ser: academia, en caso de que el estudio se haya realizado en una universidad $u$ otro tipo de entorno en el que participen estudiantes; laboratorio, en el caso en que el estudio se haya realizado en un entorno controlado pero no académico; e industria, en aquellos casos en los que el estudio se haya realizado en un entorno real (por ejemplo, una empresa).

- Proceso experimental: aunque ya en la lectura superficial se identificó la tarea experimental, en esta actividad deberá completarse la información con: la duración de la tarea, los objetos o materiales utilizados, y otras variables o constantes (por ejemplo, limitaciones o restricciones asumidas durante el experimento).

- Aleatorización: registra si los participantes en el experimento fueron asignados a los diferentes grupos utilizando un procedimiento aleatorio.

- Ocultamiento (concealment): usada para registrar si se utilizó algún procedimiento para prevenir el conocimiento a priori de la asignación a grupos en el experimento.

- Enmascaramiento (blinding): indicar si se utilizó algún proceso para mantener a los participantes, investigadores, asesores y demás involucrados, en desconocimiento de las intervenciones a las cuales han sido asignados los participantes en un estudio.

- Métodos de medición y análisis de los resultados: describe los métodos usados para medir las variables respuesta (por ejemplo, instrumentos, herramientas automatizadas, etc.) así como los métodos estadísticos utilizados para su análisis. 
- Amenazas a la validez: describe los aspectos relacionados con el estudio que podrían llevar a los experimentadores a alcanzar conclusiones incorrectas acerca de la relación entre dos o más factores, observaciones, etc. En este campo debe indicarse la fuente de cada amenaza y si la misma ha sido tratada o no durante el experimento.

- Resultados experimentales: se refiere a los valores proporcionados por el análisis de los autores acerca de las salidas del experimento; por ejemplo, medias, varianzas, correlaciones, intervalos de confianza, etc.

- Hallazgos: los razonamientos o interpretaciones proporcionados por los experimentadores acerca de los resultados experimentales obtenidos.

Al mismo tiempo, esta lectura permitirá recolectar opiniones del revisor acerca de aspectos inherentes a la calidad del estudio y la dificultad de extracción de los datos, los cuales serán valorados posteriormente para asignar un nivel de calidad y confiabilidad a cada estudio.

Para realizar la extracción de cada artículo, en el formulario de E01-Datos del Experimento deberán acometerse los siguientes pasos:

1. Realizar la lectura completa del artículo y rellenar los campos del formulario correspondientes a las secciones CARACTERísticAS DEL EXPERIMENTO y SALIDAS.

2. Una vez terminada la lectura del artículo, intentar rellenar cualquier campo que haya quedado vacío. Si es necesario, debería realizarse una nueva lectura del documento.

3. Durante la lectura, realizar el llenado de los campos Comentarios sobre la dificultad de extracción y Comentarios sobre la calidad del artículo, ya que éstos permitirán más adelante asignar una valoración sobre la calidad del estudio en cuanto a su contenido y al reporte de los resultados experimentales.

4. Usar el campo de Comentarios Adicionales del revisor, que se encuentra al final del formulario, para exponer cualquier apreciación del revisor acerca del contenido y valor de las piezas de conocimiento extraídas.

\section{Recomendaciones:}

- Si se utiliza el formulario por primera vez, se debe hacer una primera lectura de éste para obtener una idea general de aquellos elementos del estudio que son de interés para la extracción.

- Debe tomarse en cuenta que un mismo artículo puede reportar más de un experimento; en tal caso, se debe llenar un formulario E01-Datos del Experimento para cada uno de ellos.

- Durante todo el proceso puede utilizarse el formulario E02-Conceptos del experimento para aclarar el uso de aquellos conceptos (por ejemplo, factores, niveles, variables respuesta y métricas) que serán de interés durante la síntesis. 
- Es recomendable extraer los datos a medida que éstos vayan apareciendo en el artículo.

- Cuando sea imposible identificar los datos requeridos por el formulario, el experimento debería ser excluido, ya que esto limitará la valoración de su calidad y su participación en la SínTESIS DE DATOS.

\section{Evaluación de la continuidad del proceso}

Una vez que se ha realizado la lectura de todos los experimentos de un GCA puede ocurrir que:

- Se cuenta con experimentos suficientes para continuar con el proceso.

- Se han excluido todos los experimentos del GCA en virtud de su baja calidad de reporte, lo cual hace imposible extraer al menos los datos más básicos y, en consecuencia, impedirá que un experimento pueda participar en la agregación.

En este punto, debe tomarse una decisión sobre continuar con el proceso o detenerlo (véase Tabla 5.2 - Hitos del proceso de RS).

\subsubsection{Descripción y agrupamiento de conceptos}

Esta actividad debe realizarse durante toda la fase de EXTRACCIÓN DE DATOS y su objetivo es establecer una semántica común para aquellos datos (particularmente los factores, niveles, variables respuesta y métricas) que, siendo equivalentes, sean llamados de una manera diferente por los experimentadores; o que, siendo conceptos diferentes, sean llamados de la misma forma. De esta manera, los conceptos que sean sinónimos son agrupados bajo una terminología estándar en una suerte de glosario al que puede recurrir el revisor para decidir si dos o más estudios son compatibles en cuanto a que analizan niveles y variables respuesta similares.

La actividad más temprana donde debería hacerse uso de la descripción y agrupamiento de conceptos es la LECTURA SUPERFICIAL, ya que ésta extrae los datos que permitirán posteriormente agrupar los estudios con base en su compatibilidad y homogeneidad. No obstante, la LECTURA EN PROFUNDIDAD, permitirá extraer con más precisión los datos ya extraídos en la LECTURA SUPERFICIAL y además identificar y definir las variables respuesta y métricas que frecuentemente no aparecen descritas en el resumen del artículo.

Para documentar las definiciones de los diferentes conceptos, se ha propuesto el formulario E02Conceptos del Experimento (véase el Apéndice F.2), el cual está compuesto de las siguientes secciones que corresponde a tipos de conceptos: Factores, Niveles, Variables respuesta, Métricas, Otros. Para cada uno de los tipos de conceptos, el formulario incluye los siguientes datos:

- Nombre del concepto (Factor/Nivel/Variable respuesta/Métrica).

- Definición. 
- $\quad$ Estudios que lo utilizan.

- $\quad$ Nombre utilizado en el estudio.

En este formulario se registrará una entrada para cada concepto relevante para la extracción y síntesis de los datos.

\subsubsection{Actualización de clusters}

El agrupamiento de estudios que se realiza en la actividad PREPARACIÓn DE CLUSTERS DE LECTURA con base en la LECTURA SUPERFICIAL no es necesariamente un agrupamiento definitivo, debido a que la información obtenida de los resúmenes de los artículos suele ser poco precisa. Esta actividad busca revisar y modificar los clusters que han sido establecidos al comienzo de la FASE DE EXTRACCIÓN. Esto es posible gracias a que se cuenta con una información más completa acerca de las características del estudio: la tarea experimental, factores, niveles y variables respuesta. Por lo tanto, la actualización de grupos y clusters es una actividad que se puede realizar de manera paralela al resto de las actividades de la fase.

La salida de esta actividad no será más que el formulario E03-Clusters de lectura actualizado con aquellos grupos que hayan sido reconsiderados.

\subsubsection{Organización de datos}

Esta actividad tiene como objetivo preparar los datos experimentales extraídos en los formularios para que sean más fácilmente manipulados y agregados a través del método seleccionado durante la fase de SíNTESIS DE DATOS. La ORGANIZACIÓN DE LOS DATOS consiste en una serie de resúmenes que puede iniciarse en paralelo con la LECTURA SUPERFICIAL, cuando se resumen los factores, niveles, y variables respuesta; culminando en LECTURA EN PROFUNDIDAD donde se recolectan las métricas y los resultados de las mismas.

Las tareas que deben acometerse en esta actividad son mostradas en la figura 7.4. 


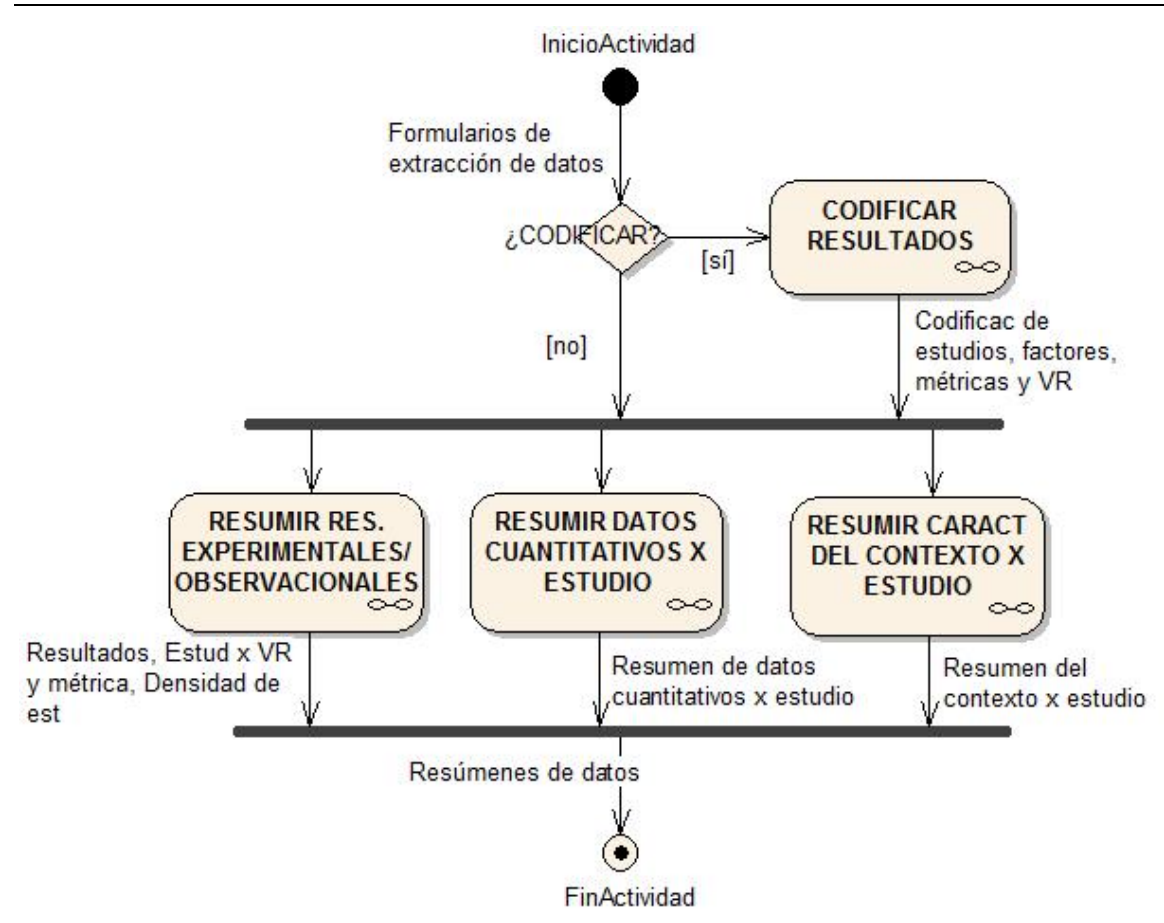

Figura 7.4. Tareas de la actividad ORGANIZACIÓN DE LOS DATOS

La figura 7.5 muestra cómo la presente actividad se concentra en resumir los datos más importantes del estudio, en particular los resultados experimentales y observacionales recogidos durante su conducción, la información relativa a las características del contexto experimental y los resultados cuantitativos necesarios para aplicar meta-análisis.

Debe tomarse en cuenta que si esta actividad es comenzada al inicio de la Extracción de datos, pueden aparecer los resúmenes experimentos que han sido excluidos durante la Lectura superficial, la Preparación de los clusters de lectura o la Lectura en profundidad, en virtud de su calidad de reporte o de que no son prometedores para la agregación.

Como una tarea opcional, los datos relacionados con la identificación del estudio, sus tratamientos, variables respuesta y métricas podrían ser enmascarados (a través de una codificación) para evitar que se introduzcan sesgos durante la SínTESIS DE DATOS.

\subsubsection{Codificar datos}

Esta tarea busca ocultar los detalles de la identidad de los estudios incluidos en la extracción, así como la de sus niveles, variables respuesta y métricas, a fin de evitar que se introduzca algún sesgo debido a las preferencias o prejuicios de los revisores. Tal ocultamiento será útil especialmente en aquellos casos en 
los que se considere que existe conflicto de intereses, por ejemplo, cuando alguno de los revisores tenga la autoría de alguna de las técnicas o algún otro motivo para su preferencia/descalificación.

No obstante, debe tomarse en cuenta que la codificación de datos es una tarea que demandará tiempo adicional durante la extracción, lo que elevará el coste global del proceso. Al mismo tiempo, la compresión de los resultados será también más compleja para los responsables de realizar la SíNTESIS DE DATOS. Por lo tanto, deberán tomarse en cuenta tanto las ventajas como los inconvenientes antes de tomar la decisión de acometer esta tarea. La codificación puede iniciarse junto con la LECTURA SUPERFICIAL y se completarse durante la LECTURA EN PROFUNDIDAD. Esta tarea utilizará el formulario E10- Codificación de dato (véase Apéndice $\mathrm{C}$ ).

Para la codificación de los datos se propone entonces asignar un código a cada estudio, nivel de un factor, VR y métrica. Ejemplos del resultado de esta tarea, aplicados al caso de estudio sobre Inspección de Software son mostrados en las tablas 7.20 a 7.23 para los estudios, los niveles de los factores, las variables respuesta y las métricas, respectivamente.

Tabla 7.20. Ejemplo de Codificación de estudios

\begin{tabular}{|l|l|}
\hline CÓDIGO & ARTICULO \\
\hline E01 & ART_27 (Xplore_16) \\
\hline E02 & ART_78 (springer_12) \\
\hline E03 & ART_45 (sco_16) \\
\hline E04 & ART_80 (springer_13) \\
\hline E05 & ART_81 (springer_15) \\
\hline E06 & ART_14 (ACM_2) \\
\hline E07 & ART_44 (springer_14) \\
\hline E08 & ART_11 (Xplore_7) \\
\hline E09 & ART_89 (sdirect_4.pdf) \\
\hline E10 & ART_75 (Xplore_27) \\
\hline
\end{tabular}

Tabla 7.21. Ejemplo de Codificación de factores

\begin{tabular}{|c|c|l|}
\hline FACTORES & CÓDIGO & \multicolumn{1}{|c|}{ NIVEL } \\
\hline $\begin{array}{c}\text { TÉCNICA } \\
\text { (PRINCIPAL) }\end{array}$ & T01 & Ad Hoc (AH) \\
\cline { 2 - 3 } & T02 & $\begin{array}{l}\text { Checklist-based reading } \\
\text { (CBR) }\end{array}$ \\
\cline { 2 - 3 } & T03 & $\begin{array}{l}\text { Scenario-based reading } \\
\text { (SBR) }\end{array}$ \\
\hline
\end{tabular}




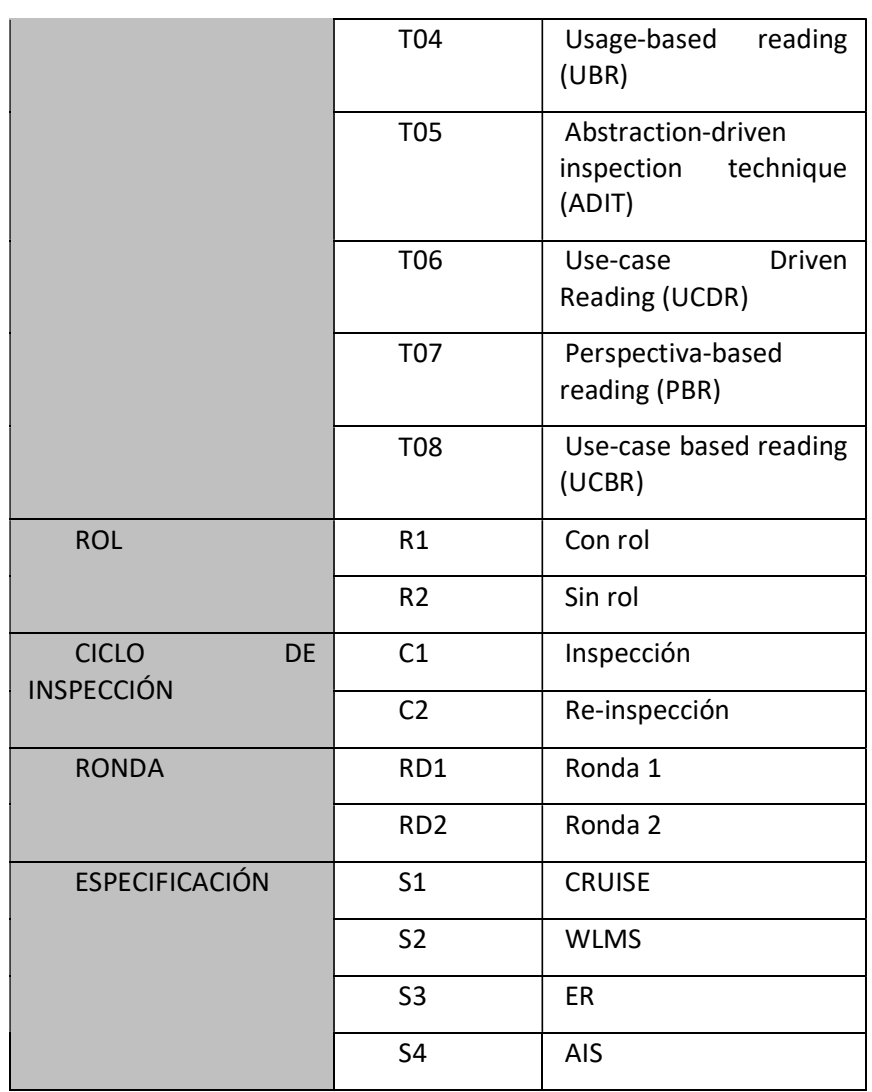

Tabla 7.22. Ejemplo de Codificación de Variables Respuesta

\begin{tabular}{|l|l|}
\hline CÓDIGO & \multicolumn{1}{|l|}{ VARIABLE RESPUESTA } \\
\hline V01 & Efectividad individual \\
\hline V02 & Efectividad del equipo \\
\hline V03 & Eficiencia individual - Global \\
\hline V04 & Eficiencia individual - Inspección \\
\hline V05 & Eficiencia individual - Preparación \\
\hline V06 & Eficiencia equipo \\
\hline V07 & Coste de detección \\
\hline V08 & Habilidad del inspector \\
\hline V09 & Efectividad del método \\
\hline V10 & Eficiencia individual \\
\hline V11 & Eficiencia del método \\
\hline
\end{tabular}

Tabla 7.23. Ejemplo de Codificación de métricas 


\begin{tabular}{|c|c|c|c|}
\hline CÓDIGO & MÉTRICAS & FORMULACIÓN & $\begin{array}{l}\text { VR } \\
\text { ASOCIADA }\end{array}$ \\
\hline M01 & $\begin{array}{l}\text { Tasa de detección de fallos } \\
\text { individual }\end{array}$ & $\begin{array}{l}\text { Número de defectos detectado por un } \\
\text { individuo / número total de fallos } \\
\text { conocidos en la especificación }\end{array}$ & \multirow{4}{*}{ V01 } \\
\hline M02 & $\begin{array}{l}\text { Número de defectos encontrados } \\
\text { por individuo }\end{array}$ & & \\
\hline M03 & $\begin{array}{l}\text { Número de falsos positivos por } \\
\text { individuo }\end{array}$ & & \\
\hline M13 & $\begin{array}{l}\text { Tasa de detección de fallos } \\
\text { individual (por tipo de fallo } \mathrm{A}, \mathrm{B}, \mathrm{C} \text { ) } \\
\text { (OBSERVACIONAL) }\end{array}$ & $\begin{array}{l}\text { Número de fallos del tipo T detectados } \\
\text { por un individuo/número de fallos del } \\
\text { tipo T conocidos }\end{array}$ & \\
\hline M04 & $\begin{array}{l}\text { Tasa de detección de fallos por } \\
\text { equipo }\end{array}$ & $\begin{array}{l}\text { Número de defectos detectado por un } \\
\text { equipo / número total de fallos } \\
\text { conocidos en la especificación }\end{array}$ & \multirow[t]{4}{*}{ V02 } \\
\hline M05 & $\begin{array}{l}\text { Número de defectos encontrados } \\
\text { por equipo }\end{array}$ & & \\
\hline M22 & $\begin{array}{l}\text { Tasa de detección de fallos (por } \\
\text { tamaño de equipo por tipo de fallo } \\
\text { A, B, C) (OBSERVACIONAL) }\end{array}$ & & \\
\hline M23 & $\begin{array}{l}\text { Tasa de detección de fallos por } \\
\text { tamaño de } \\
\text { (OBSERVACIONAL) }\end{array}$ & & \\
\hline M06 & $\begin{array}{l}\text { Número de defectos encontrados } \\
\text { por un individuo por unidad de } \\
\text { tiempo }\end{array}$ & $\begin{array}{l}\text { Número de defectos positivos } \\
\text { encontrados/tiempo disponible para el } \\
\text { experimento }\end{array}$ & V03 \\
\hline M07 & Tiempo gastado por individuo & $\begin{array}{l}\text { Tiempo gastado por cada participante } \\
\text { para las inspecciones individuales }\end{array}$ & \\
\hline M28 & $\begin{array}{lrrr}\text { Tiempo } & \text { gastado } & \text { por } & \text { individuo } \\
\text { durante } & \text { la } & & \text { inspección } \\
\text { (OBSERVACIONAL) } & & \end{array}$ & & V04 \\
\hline M29 & $\begin{array}{l}\text { Tiempo gastado por individuo } \\
\text { durante la preparación }\end{array}$ & & V05 \\
\hline M10 & $\begin{array}{l}\text { Número de defectos encontrados } \\
\text { por un equipo por unidad de tiempo }\end{array}$ & $\begin{array}{l}\text { Número de defectos positivos } \\
\text { encontrados/ tiempo disponible para el } \\
\text { experimento }\end{array}$ & V06 \\
\hline M09 & $\begin{array}{l}\text { Tiempo máximo gastado por un } \\
\text { equipo durante la inspección }\end{array}$ & & \\
\hline
\end{tabular}

\subsubsection{Resumir datos cuantitativos por estudio}

Esta tarea tiene como objetivo presentar de manera resumida los datos cuantitativos de los estudios (media, varianza y número de sujetos experimentales) por cada tratamiento y métrica, ya que éstos datos suelen ser requeridos por algunos de los métodos de agregación estadística (específicamente aquellos de tipo paramétrico) que se utilizarán en la SíNTESIS DE DATOS. Para ello se propone utilizar el formulario EO4Resumen de datos cuantitativos (véase Apéndice F.4), el cual está compuesto por: 
- Estudio.

- Métrica.

- $\quad$ Factores adicionales.

- $\quad$ Nivel.

- Datos cuantitativos.

- Significancia.

- Observaciones.

En este formulario se incluyen tanto los resultados expresados de manera narrativa, como de manera numérica. Aunque estos valores deben ser presentados para cada métrica y cada nivel del factor principal (por ejemplo, la Técnica), cuando en algún estudio se haya ensayado un factor adicional (por ejemplo, el Rol, la Especificación, etc.) los resultados se proporcionarán de dos maneras: 1) el valor promedio por cada tratamiento, y 2) el valor correspondiente al tratamiento separado en los diferentes niveles del factor adicional.

Por ejemplo, en la tabla 7.24 se muestra un resumen de datos donde se observa que el estudio E01 ha ensayado el factor adicional Especificación con dos niveles (WLMS y CRUISE). Por lo tanto, los resultados de E01 han sido presentados tanto con un valor promedio como con los valores correspondientes a cada nivel del factor Especificación. Otros casos de factores adicionales que han sido ensayados, se encuentran en E04 y E08, los cuales han estudiados los factores Ronda y Rol, respectivamente. En tales casos se ha procedido de la misma manera.

Para efectos de la agregación que se realizará en la fase de SínTESIS DE DATOS, es recomendable que los datos extraídos se encuentren en un formato bastante uniforme. Por lo tanto, al finalizar este resumen se deberá tratar de asignar los valores correspondientes a los factores adicionales para todos los estudios seleccionados. Para ello, debe tomarse en cuenta que el factor adicional puede o no haber sido descrito como tal por los experimentadores. En el caso en que haya sido indicado, será fácil extraer sus niveles y resultados; en caso contrario, deberá hacerse una interpretación del diseño y la ejecución del experimento para determinar los niveles del factor que subyacen en el diseño. Por ejemplo, en el estudio E01 no se describe ni el Rol ni la Ronda como factores adicionales; sin embargo, al analizar el diseño y ejecución del experimento se observa que no se utilizaron roles y el la inspección se realizó en una sola ronda. Con base en esta información, se asignan los valores R2 (Sin rol) y RD1 (Ronda 1) a los factores Rol y Ronda, respectivamente.

Por el nivel de detalle requerido en esta tarea, debería iniciarse en paralelo con la LECTURA EN PROFUNDIDAD. 
Tabla 7.24. Ejemplo de Resumen de datos cuantitativos

\begin{tabular}{|c|c|c|c|c|c|c|c|c|c|c|}
\hline \multirow[t]{2}{*}{ EST. } & \multirow[t]{2}{*}{ MET. } & \multicolumn{3}{|c|}{ FACTORES ADICIONALES } & \multirow[t]{2}{*}{ NIVEL } & \multicolumn{3}{|c|}{ DATOS CUANTITATIVOS } & \multirow[t]{2}{*}{ SIGNIFICACIÓN } & \multirow[t]{2}{*}{ OBSERVACIONES } \\
\hline & & ESPECIF & $\mathrm{ROL}$ & RONDA & & MEDIA & VARIANZA & NÚM. SUJ. & & \\
\hline \multirow{15}{*}{$01^{E}$} & \multirow[t]{9}{*}{ M04 } & \multirow[t]{3}{*}{ Promedio } & \multirow[t]{3}{*}{ R2 } & \multirow[t]{3}{*}{ RD1 } & T01 & 0.37 & 0.10 & 13 equipos & \multirow{15}{*}{$\begin{array}{l}\text { M04/T03>T01>T02 } \\
\text { M01/T03>T01 }>\text { T02 } \\
\text { (CRUISE) } \\
\text { M01/T01>T03>T02 } \\
\text { (WLMS) }\end{array}$} & \multirow{3}{*}{$\begin{array}{l}\text { Calculadas a partir de los } \\
\text { datos originales sin considerar la } \\
\text { especificación (no es significativa) }\end{array}$} \\
\hline & & & & & T02 & 0.325 & 0.123 & 8 equipos & & \\
\hline & & & & & T03 & 0.51 & 0.112 & 12 equipos & & \\
\hline & & \multirow[t]{3}{*}{ S1 } & \multirow[t]{3}{*}{ R2 } & \multirow[t]{3}{*}{ RD1 } & T01 & 0.43 & 0.08 & 6 equipos & & \\
\hline & & & & & T02 & 0.42 & 0.12 & 4 equipos & & \\
\hline & & & & & T03 & 0.57 & 0.11 & 6 equipos & & \\
\hline & & \multirow[t]{3}{*}{ S2 } & \multirow[t]{3}{*}{ R2 } & \multirow[t]{3}{*}{ RD1 } & T01 & 0.31 & 0.09 & 7 equipos & & \\
\hline & & & & & T02 & 0.24 & 0.05 & 4 equipos & & \\
\hline & & & & & T03 & 0.45 & 0.07 & 5 equipos & & \\
\hline & \multirow[t]{6}{*}{ M01 } & \multirow[t]{3}{*}{ S1 } & \multirow[t]{3}{*}{ R2 } & \multirow[t]{3}{*}{ RD1 } & T01 & $\begin{array}{r}\text { Sin } \\
\text { inform. }\end{array}$ & Sin inform. & 18 sujetos & & \multirow[t]{6}{*}{$\begin{array}{l}\text { No proporcionan } \mathrm{M} \text { sino la } \\
\text { mediana }\end{array}$} \\
\hline & & & & & T02 & $\begin{array}{r}\text { Sin } \\
\text { inform. }\end{array}$ & Sin inform. & 12 sujetos & & \\
\hline & & & & & T03 & $\begin{array}{r}\text { Sin } \\
\text { inform. }\end{array}$ & Sin inform. & 18 sujetos & & \\
\hline & & \multirow[t]{3}{*}{ S2 } & \multirow[t]{3}{*}{ R2 } & \multirow[t]{3}{*}{ RD1 } & T01 & $\begin{array}{r}\text { Sin } \\
\text { inform. }\end{array}$ & Sin inform. & 21 sujetos & & \\
\hline & & & & & T02 & $\begin{array}{r}\text { Sin } \\
\text { inform. }\end{array}$ & Sin inform. & 12 sujetos & & \\
\hline & & & & & T03 & $\begin{array}{r}\text { Sin } \\
\text { inform. }\end{array}$ & Sin inform. & 15 sujetos & & \\
\hline \multirow{2}{*}{ E04 } & \multirow[t]{2}{*}{ M04 } & \multirow[t]{2}{*}{ Promedio } & \multirow[t]{2}{*}{ R2 } & \multirow[t]{2}{*}{ RD1 } & T03 & 0.27 & 0.05 & 4 equipos & \multirow{2}{*}{$\begin{array}{l}\text { M04/T03>T02 } \\
\text { (RONDA1) }\end{array}$} & Promediando \\
\hline & & & & & T02 & 0.23 & 0.03 & 4 equipos & & \\
\hline
\end{tabular}




\begin{tabular}{|c|c|c|c|c|c|c|c|c|c|c|}
\hline \multirow[t]{2}{*}{ EST. } & \multirow[t]{2}{*}{ MET. } & \multicolumn{3}{|c|}{ FACTORES ADICIONALES } & \multirow[t]{2}{*}{ NIVEL } & \multicolumn{3}{|c|}{ DATOS CUANTITATIVOS } & \multirow[t]{2}{*}{ SIGNIFICACIÓN } & \multirow[t]{2}{*}{ OBSERVACIONES } \\
\hline & & \multirow[t]{3}{*}{ ESPECIF } & \multirow[t]{3}{*}{ ROL } & RONDA & & MEDIA & VARIANZA & NÚM. SUJ. & & \\
\hline & & & & RD2 & T03 & 0.22 & 0.09 & 4 equipos & $\mathrm{M04/T02>T03}$ & \\
\hline & & & & & T02 & 0.32 & 0.05 & 4 equipos & (RONDA2 & \\
\hline & & \multirow[t]{4}{*}{ S1 } & \multirow[t]{4}{*}{ R2 } & \multirow[t]{2}{*}{ RD1 } & T03 & 0.23 & 0.04 & & & \\
\hline & & & & & T02 & 0.19 & 0.06 & & & \\
\hline & & & & \multirow[t]{2}{*}{ RD2 } & T03 & 0.17 & 0.05 & & & \\
\hline & & & & & T02 & 0.27 & 0.01 & & & \\
\hline & & \multirow[t]{4}{*}{ S2 } & \multirow[t]{4}{*}{ R2 } & \multirow[t]{2}{*}{ RD1 } & T03 & 0.3 & 0.09 & & & \\
\hline & & & & & T02 & 0.26 & 0.18 & & & \\
\hline & & & & \multirow[t]{2}{*}{ RD2 } & T03 & 0.27 & 0.01 & & & \\
\hline & & & & & T02 & 0.36 & 0.1 & & & \\
\hline \multirow[t]{6}{*}{ E08 } & \multirow[t]{6}{*}{ M04 } & \multirow[t]{6}{*}{ S3 } & \multirow{2}{*}{$\begin{array}{l}\mathrm{Pr} \\
\text { omedi } \\
0\end{array}$} & \multirow[t]{2}{*}{ RD1 } & T01 & 0.64 & 0.17 & 25 equipos & \multirow{6}{*}{$\begin{aligned} & \text { M04/T02>T01 } \\
& \text { M04/T02>T01 } \text { (si } \\
& \text { ROLES }=\text { No) } \\
& \text { M04/T01>T02 } \text { (si } \\
& \text { ROLES }=\text { Yes) }\end{aligned}$} & \\
\hline & & & & & T02 & 0.71 & 0.24 & 26 equipos & & \\
\hline & & & \multirow[t]{2}{*}{ R2 } & \multirow[t]{2}{*}{ RD1 } & T01 & 0.57 & 0.16 & 25 & & \\
\hline & & & & & T02 & 0.8 & 0.16 & 25 & & \\
\hline & & & \multirow[t]{2}{*}{ R1 } & \multirow[t]{2}{*}{ RD1 } & T01 & 0.70 & 0.15 & 25 & & \\
\hline & & & & & T02 & 0.58 & 0.27 & 25 & & \\
\hline
\end{tabular}




\subsubsection{Resumir características del contexto}

Según (A. Jedlitschka \& D. Pfahl, 2005) el contexto de un estudio incluye factores particulares que podrían afectar la generalidad y utilidad de las conclusiones; por ejemplo, el dominio de aplicación, el tipo de compañía, la experiencia de los participantes, las restricciones de tiempo, el proceso, las herramientas, y el tamaño del proyecto. El propósito de esta tarea es presentar de manera resumida un conjunto de datos relacionados con el contexto del experimento que se consideran relevantes en esta investigación a efectos de la interpretación y generalización de las evidencias que se pudieran obtener como producto de la agregación durante la SíNTESIS DE DATOS.

Aunque en el contexto de un experimento se pueden incluir diferentes características, esta tarea se limita a presentar aquellas que puedan afectar la validez externa de los estudios y por lo tanto la generalización de sus resultados; y que, por consiguiente, pueden afectar también la generalidad de las evidencias resultantes de la RS.

En relación a la generalización, (Cronbach, 1982) propone un modelo llamado UTOS (acrónimo para units, treatments, observations and setting) que establece que la generalización al dominio de la aplicación al cual se refiere el experimento incluye características como los sujetos, los tratamientos (niveles), las variables respuesta y el ambiente. Mientras que los tratamientos y las variables respuesta no son considerados como características del contexto, los sujetos y el ambiente sí forman parte de éste. Por otra parte, específicamente para IS (C. Wohlin et al., 2000) (Conradi \& Wang, 2003) y (Sjøberg et al., 2005) han agregado otras características del contexto que pueden afectar la validez externa de un estudio, como son la Tarea que es aplicada (incluyendo su Duración) y los Objetos a los cuales se le aplican los tratamientos. Lo anterior lleva a proponer que el resumen de características del contexto más relevantes para esta investigación incluya:

- Sujetos: referida al tipo de sujeto (estudiante, profesional) y su experiencia,

- Ambiente: se refiere al entorno en el cual ha sido conducido el experimento, laboratorio o industria.

- Proceso experimental: se refiere a la Tarea realizada durante el experimento, junto con su Duración y los Objetos utilizados.

Estos datos del experimento fueron recogidos durante la LECTURA SUPERFICIAL y la LECTURA EN PROFUNDIDAD en el formulario E01-Datos del experimento. Se recomienda utilizar el formulario E05_Resumen de características del contexto (véase Apéndice F.5) para presentar este resumen. Este formulario incluye los siguientes datos:

- Estudio.

- Sujetos.

- Ambiente. 


\section{- Proceso experimental.}

Nótese que un análisis similar ha sido realizado ya durante la PREPARACIÓn DE CLUSTERS PARA LECTURA. Por lo tanto, ambas tareas podrían realizarse de manera simultánea. Un ejemplo de resumen del contexto utilizando estas características es presentado en la tabla 7.25.

Tabla 7.25. Ejemplo de Resumen de contexto experimental

\begin{tabular}{|c|c|c|c|c|c|}
\hline \multirow[t]{2}{*}{ EST. } & \multirow[t]{2}{*}{ SUJETOS } & \multirow[t]{2}{*}{ AMBIENTE } & \multicolumn{2}{|c|}{ PROCESO EXPERIMENTAL } & \multirow[b]{2}{*}{ OBJETOS } \\
\hline & & & TAREA & DURACIÓN & \\
\hline E01 & Estudiantes & Laboratorio & Requisitos & & \\
\hline E02 & Estudiantes & Laboratorio & Requisitos & & \\
\hline E03 & Estudiantes & Laboratorio & Requisitos & & \\
\hline E04 & Estudiantes & Laboratorio & Requisitos & & \\
\hline E05 & Profesionales & Industria & Requisitos & & \\
\hline E09 & Estudiantes & Laboratorio & Requisitos & & \\
\hline E10 & Estudiantes & Laboratorio & Requisitos & & \\
\hline E06 & Estudiantes & Laboratorio & Requisitos & & \\
\hline E07 & Estudiantes & Laboratorio & Requisitos & & \\
\hline E08 & Estudiantes & Laboratorio & Requisitos & & \\
\hline E11 & Estudiantes & Laboratorio & Requisitos & & \\
\hline E12 & Estudiantes & Laboratorio & Código & & \\
\hline E13 & Estudiantes & Laboratorio & Código & & \\
\hline E14 & Estudiantes & Laboratorio & Código & & \\
\hline E15 & Estudiantes & Laboratorio & Código & & \\
\hline E16 & Estudiantes & Laboratorio & UML & & \\
\hline E17 & Estudiantes & Laboratorio & UML & & \\
\hline E18 & Estudiantes & Laboratorio & UML & & \\
\hline E19 & Estudiantes & Laboratorio & Diseño & & \\
\hline E20 & Estudiantes & Laboratorio & Diseño & & \\
\hline E21 & Estudiantes & Laboratorio & Diseño & & \\
\hline
\end{tabular}




\begin{tabular}{|l|l|l|l|l|l|}
\hline EST. & SUJETOS & AMBIENTE & \multicolumn{2}{|c|}{ PROCESO EXPERIMENTAL } \\
\cline { 4 - 6 } & & & TAREA & DURACIÓN & OBJETOS \\
\hline E22 & Estudiantes & Laboratorio & Diseño & & \\
\hline E23 & Estudiantes & Laboratorio & Diseño & & \\
\hline
\end{tabular}

\subsubsection{Resumir resultados experimentales y observacionales}

Algunos experimentos pueden incluir comparaciones indirectas; esto es, comparaciones no aleatorizadas y que no corresponden a los niveles de algún factor sino a variables que resultan ser interesantes al final del estudio y que se realizan frecuentemente utilizando métodos análisis de sub-grupos o meta-regresión sobre los resultados experimentales (J. P. T. Higgins \& S. Green, 2006). Por ejemplo, en el experimento E01 (ART_27) del caso de estudio, en el que se compara la efectividad de los métodos de inspección Ad Hoc, SBR y CBR, una vez que los investigadores obtuvieron los resultados, consideraron de interés evaluar la Efectividad del método en relación al tipo de fallo, aún cuando el tipo de fallo no fue establecido como un factor dentro del diseño del experimento. Estas comparaciones pueden ser consideradas como resultados observacionales aún cuando se reportan en el marco de un experimento aleatorizado, proporcionando evidencia indirecta (J. P. T. Higgins \& S. Green, 2006). El propósito de esta tarea es presentar de manera resumida los resultados obtenidos en cada uno de los experimentos, tanto los resultados experimentales como los observacionales, en caso de que existan. Para ello se sugiere utilizar el formulario E06-Resumen de resultados experimentales y observacionales (véase el Apéndice F.6), el cual recoge la siguiente información:

- Estudio.

- Niveles.

- Métricas.

- Resultados experimentales.

- Resultados observacionales.

La razón de que en esta investigación se mantenga un registro de los resultados observacionales de los experimentos obedece a que algunos estudios, tales como (Beal \& Finch, 1991) (Horwitz \& Feinstein, 1979) (Feinstein \& Horwitz, 1982) (Levine et al., 1994), sostienen la hipótesis de que resultados obtenidos de forma no-aleatorizada pueden considerarse válidos. Sin embargo, existe gran controversia en cuanto a la validez de los resultados observacionales frente a los resultados experimentales ya que otros investigadores (Britton et al., 1998; Petitti, 1998; Reeves et al., 1998) (Kunz \& Oxman, 1998) (Benson \& Hartz, 2000; Concato, Shah, \& Horwitz, 2000; J. P. T. Higgins \& S. Green, 2006) afirman que los resultados obtenidos de manera no-aleatorizada pueden estar sesgados; por lo que no deberían prevalecer por 
encima de los resultados experimentales. Los resultados experimentales, al ser obtenidos utilizando la aleatorización, son los únicos con los cuales se puede afirmar de manera confiable una relación de causalidad. Esto no es posible a partir de resultados observacionales. Por lo tanto, serán los resultados experimentales los que sean agregados en la fase de SÍNTESIS DE DATOS. Los resultados observacionales podrán ser utilizados con el fin de facilitar la comprensión del experimento o de plantearse futuras preguntas de revisión.

En el ejemplo de la Tabla 7.26, los datos representados en la tabla muestran los niveles tratados y las métricas analizadas en cada estudio, junto con los resultados experimentales y observacionales obtenidos del mismo. 
Tabla 7.26. Ejemplo de Resumen de resultados experimentales y observaciones por estudio

\begin{tabular}{|c|c|c|c|c|}
\hline EST. & NIVELES & MÉTRICAS & RESULTADOS EXPERIMENTALES & RESULTADOS OBSERVACIONALES \\
\hline E01 & $\begin{array}{l}\text { T01, T02, } \\
\text { T03 }\end{array}$ & M01, M04, & $\begin{array}{l}\text { M04/T01>T02 } \\
\text { M04/T03>T01>T02 } \\
\text { M01/T03>T01>T02 (CRUISE) } \\
\text { M01/T01>T03>T02 (WLMS) }\end{array}$ & $\begin{array}{l}\text { M32/T03> T01, T02 (para defectos del tipo DT para los cuales fueron creados } \\
\text { los escenarios, CRUISE) } \\
\text { M32/T03> T01> T02 (para defectos del tipo MF para los cuales fueron creados } \\
\text { los escenarios, CRUISE) } \\
\text { M32/ T01, T02> T03 (para defectos del tipo IF para los cuales fueron creados los } \\
\text { escenarios, CRUISE) } \\
\text { M32/T03> T01> T02 (para defectos del tipo DT para los cuales fueron creados } \\
\text { los escenarios, WLMS) } \\
\text { M32/T03=T01=T02 (para defectos del tipo MF, IF para los cuales fueron creados } \\
\text { los escenarios, WLMS) }\end{array}$ \\
\hline E02 & $\begin{array}{l}\text { T01, T02, } \\
\text { T03 }\end{array}$ & $\begin{array}{l}\text { M04, M07, } \\
\text { M32 }\end{array}$ & $\begin{array}{l}\text { M04/T02>T01>T03 n.S. } \\
\text { M04/ T01>T02 >T03 para CRUISE } \\
\text { M04/ T02=T03>T01 para WLMS } \\
\text { M07/no se dice nada de las técnicas, sólo el \% de } \\
\text { estudiantes que terminaron en un lapso dado. }\end{array}$ & $\begin{array}{l}\text { M32/(T03,DT })>(T 03, \text { otras fallas })>(T 03, M F)=(T 03, I F) \text { para CRUISE } \\
\text { M32/(T03,DT })>(T 03, \text { otras fallas })>(T 03, I F)>(T 03, M F) \text { para WLMS } \\
\text { M32/(T03,otras fallas })>(T 03, D T)=(T 03, I F)>(T 03, M F)\end{array}$ \\
\hline E04 & T02, T03 & M04 & $\begin{array}{l}\text { M04/T03>T02 (RONDA1) } \\
\text { M04/T02>T03 (RONDA2) }\end{array}$ & \\
\hline E05 & T01, T02, & M04 & M04/T03>T01>T02 & \\
\hline
\end{tabular}




\begin{tabular}{|c|c|c|c|c|}
\hline & T03 & & & \\
\hline E07 & T02, T04 & $\begin{array}{l}\text { M01, M06, } \\
\text { M13, M27 }\end{array}$ & $\begin{array}{l}\text { M01/T02>T04 n.s. } \\
\text { M06/ T02>T04 }\end{array}$ & $\begin{array}{l}\text { M13/T04>T02 (fallos del tipo A+B) n.s. } \\
\text { M13/T02>T04 (fallos del tipo A) n.s. } \\
\text { M13/T04>T02 (fallos del tipo B) } \\
\text { M13/ T02>T04 (fallos del tipo C) } \\
\text { M27/T02>T04 (fallos del tipo A, C) } \\
\text { M27/ T02>T04 n.s. (fallos del tipo A+B) } \\
\text { M27/T04>T02 (fallos del tipo B) }\end{array}$ \\
\hline E21 & T02, T07 & $\begin{aligned} & \text { M01, } \text { M04, } \\
& \text { M07, M34 }\end{aligned}$ & $\begin{array}{l}\text { M01/T07<T02 n.s. } \\
\text { M04/T02>T07 } \\
\text { M07/T02>T07 } \\
\text { M34/T07>T02 }\end{array}$ & \\
\hline
\end{tabular}




\subsubsection{ESTABLECER GRUPOS POTENCIALMENTE AGREGABLES}

El propósito de esta actividad es organizar los experimentos de un GCA de manera que se pueda establecer fácilmente cuáles de ellos deberían ser agregados en la futura fase de SíNTESIS DE DATOS; tomando en cuenta para ello que existan dos o más experimentos que midan la misma métrica para un mismo par de niveles. A esta similitud en cuanto a las mediciones realizadas (métricas o variables respuesta) y los niveles ensayados se ha hecho referencia en esta fase como compatibilidad de los experimentos.

Nótese que las actividades de PREPARACIÓN DE CLUSTERS PATA LECTURA y LECTURA EN PROFUNDIDAD han estado orientadas por la compatibilidad entre tratamientos y variables respuesta; sin embargo, en esta actividad se considera necesario refinar este criterio de compatibilidad el nivel de métrica. Esto obedece a que una misma variable respuesta podría englobar métricas que, aún teniendo el mismo objetivo de medición, lo miden de manera diferente; por ejemplo, en el caso de estudio sobre inspección de software, la variable respuesta Coste del método podría englobar una métrica que en un experimento mida la Inversión de dinero necesaria para aplicar el método, al mismo tiempo que engloba otra métrica para otro experimento que mide el Tiempo invertido en aplicarlo. En ambos experimentos se estaría midiendo la misma variable respuesta pero con métricas muy diferentes. Mientras lo anterior puede representar una ventaja al momento de la lectura en profundidad, para la agregación utilizando métodos estadísticos como los que se describen en la siguiente fase (SÍNTESIS DE DATOS) representaría un problema (O. Dieste, Fernández, \& García, 2008).

En la figura 7.5 se muestran las tareas propuestas para esta actividad, las cuales analizan la cantidad de estudios existentes por métrica y por contexto e identifican grupos potencialmente agregables (GPAs) de acuerdo a los niveles ensayados y la métrica analizada. 


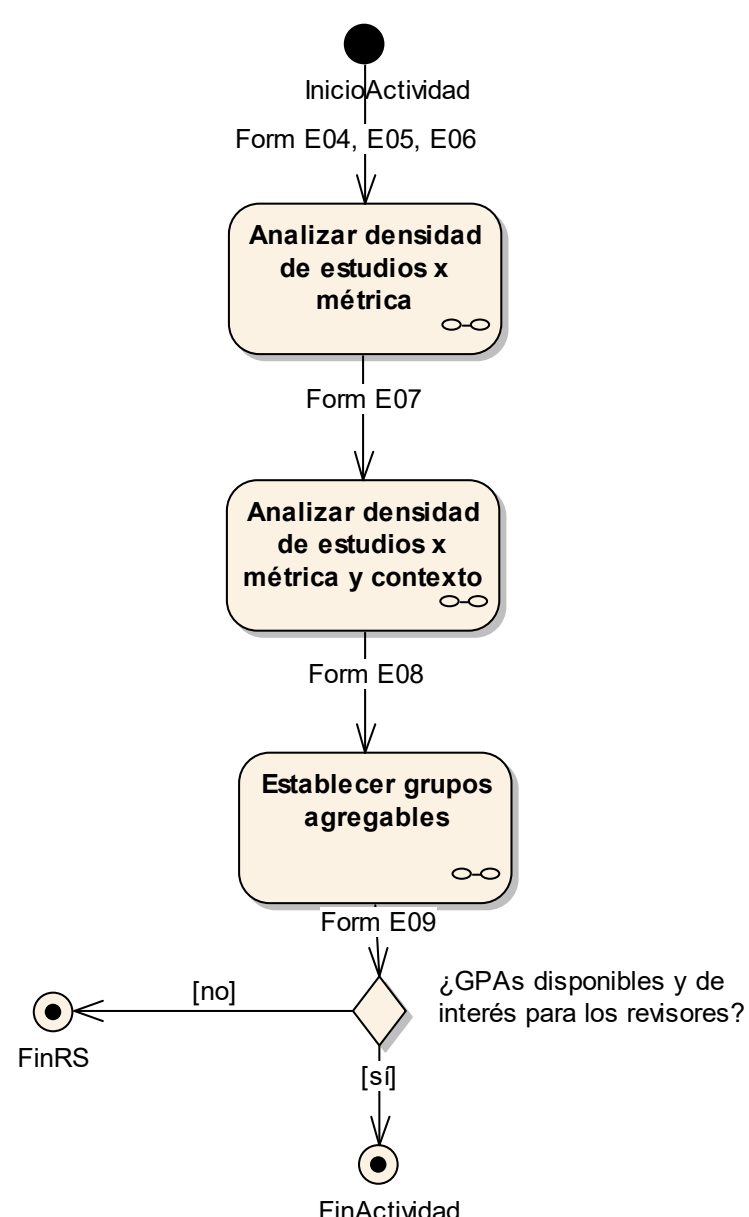

Figura 7.5. Tareas de la actividad Identificar GPAs

\subsubsection{Analizar densidad de estudios por métrica}

Esta primera tarea tiene como propósito mapear cada una de las variables respuesta (y sus métricas) presentes en grupo candidato a agregación con los experimentos contenidos en él. Esto dará al revisor una aproximación a aquellas variables respuesta/métricas que han sido más recurrentemente estudiadas en los distintos experimentos; lo cual se traduce en que reúnen un mayor número de sujetos experimentales. Lo anterior representa una ventaja si se busca generar evidencias significativas durante la SíNTESIS DE DATOS, ya que el número de sujetos determinará el poder estadístico de la agregación. Por lo tanto, parece lógico enfocarse en aquellas métricas que concentren el mayor número de experimentos.

Esta tarea puede realizarse en paralelo con la LECTURA SUPERFICIAL o la PREPARACIÓN DE LOS CLUSTERS DE LECTURA; utilizando el formulario E07-Densidad de estudios por métrica (presentado en el Apéndice F.7), el cual se componen de:

- Variable respuesta. 
- Métrica.

- Estudios.

- Observaciones.

Para ello se recomienda seguir los siguientes pasos:

1. Por cada experimento del grupo candidato a agregación verificar si existe una entrada en el formulario E07-Densidad de estudios por métrica para sus variables respuesta y métricas. Para esto, utilizar la terminología estandarizada que se encuentra en el formulario E02-Conceptos de los experimentos.

2. En caso de que exista la entrada correspondiente asignar el experimento a cada grupo variable respuesta/métrica. Si el experimento reporta varias métricas o variables respuesta deberá a aparecer en cada una de las entradas asociadas.

3. En caso de que no exista una entrada para las variables respuesta/métricas correspondientes, deberán crearse.

4. Utilizar la columna Observaciones para anotar cualquier comentario o duda en relación a los datos que se están representando o el experimento al que pertenecen.

En la tabla 7.27, se presenta un ejemplo de este análisis para el caso de estudio sobre inspecciones de software. En ella se pueden apreciar resumidos los estudios correspondientes a cada métrica.

\section{Recomendación:}

Este análisis puede hacerse tanto para las métricas experimentales como para las observacionales, aunque no necesariamente estas últimas serán incluidas en la agregación.

Tabla 7.27. Ejemplo de Resumen de densidad de estudios por métrica

\begin{tabular}{|c|c|c|c|}
\hline $\begin{array}{l}\text { VARIABLE } \\
\text { RESPUESTA }\end{array}$ & MÉTRICA & ESTUDIOS & OBSERVACIONES \\
\hline \multirow{6}{*}{ V01 } & M01 & $\begin{array}{l}\text { E01, E03, E07, E12, E19, E20, E21, } \\
\text { E22 }\end{array}$ & \\
\hline & M02 & E12, E16, E19, E22 & \\
\hline & M03 & E12, E16 & \\
\hline & M13 & E07, E19, E20 & \\
\hline & M14 & E08, E22 & \\
\hline & M16 & E12 & \\
\hline
\end{tabular}




\begin{tabular}{|c|c|c|c|}
\hline $\begin{array}{l}\text { VARIABLE } \\
\text { RESPUESTA }\end{array}$ & MÉTRICA & ESTUDIOS & OBSERVACIONES \\
\hline & M17 & E19, E22 & \\
\hline & M18 & E19, E20 & \\
\hline & M19 & E12 & \\
\hline & M20 & E22 & \\
\hline & M21 & E22 & \\
\hline & M32 & E01, E02, E06 & \\
\hline \multirow{5}{*}{ V03 } & M06 & E07, E19, E20 & \\
\hline & M07 & E02, E12, E19, E20, E21, E22 & \\
\hline & M08 & E19, E20 & \\
\hline & $\mathrm{M} 27$ & E07, E19, E20 & \\
\hline & M33 & E22 & \\
\hline V04 & M28 & E19, E20 & \\
\hline V05 & M29 & E19, E20 & \\
\hline \multirow{2}{*}{ V07 } & M11 & E13, E14, E15, E17 & \\
\hline & M34 & E21 & \\
\hline
\end{tabular}

\subsubsection{Analizar densidad de estudios por métrica y contexto}

El resumen obtenido de la tarea anterior puede ser orientador para los revisores a efectos de determinar cuántos experimentos han evaluado una determinada métrica. Sin embargo, si se desea agregar experimentos muy compatibles es necesario organizarlos siguiendo el criterio de similitud de niveles y métricas explicado anteriormente; incluyendo además algunas características del contexto (específicamente, la tarea y el tipo de sujetos). El objetivo de esta tarea es presentar los experimentos de un grupo candidato a agregación agrupados por tarea, tipo de sujeto, niveles y métrica.

Para el registro de los resultados de esta tarea se propone el formulario E08-Densidad de estudios por métrica y contexto; el cual registra la siguiente información:

- Tarea.

- $\quad$ Sujetos.

- Variable respuesta. 
- Métrica.

- Nivel A y B.

Para cada grupo candidato a agregación y factor principal se deben seguir los siguientes pasos:

1. Para cada una de las métricas descritas en el resumen E07-Densidad de estudios por métrica aplicar los siguientes pasos:

1.1. Para cada uno de los experimentos indicados en el resumen representar de manera tabular los niveles ensayados en el experimento como se muestra en la tabla 7.28.

Tabla 7.28. Formato para el análisis de densidad de estudios por métrica y tarea-tipo de sujeto

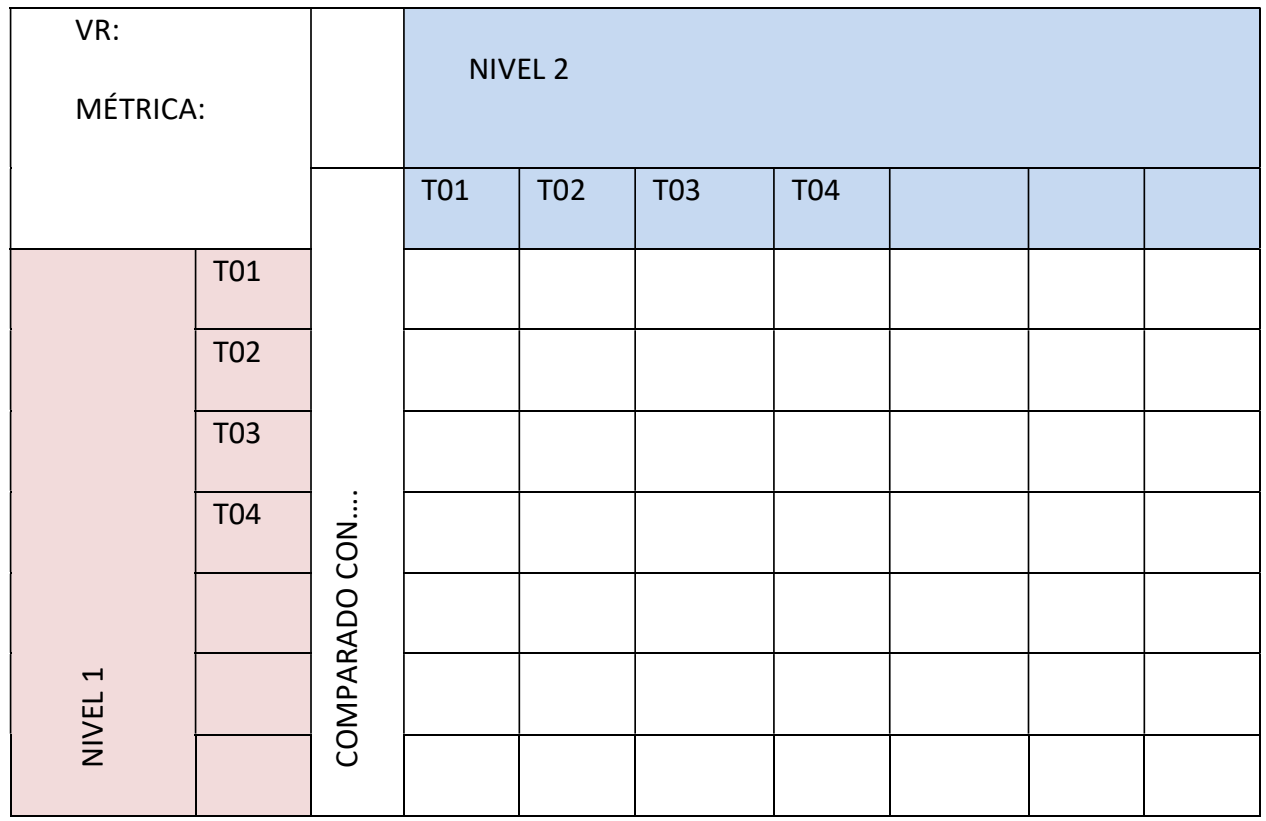

1.2. Si es necesario crear las entradas en los niveles ensayados por experimento no existen crear las entradas que sean necesarias.

1.3. Asignar el experimento a la celda que corresponde según los dos niveles ensayados. Cuando el experimento ensaye más de dos niveles se asignará a tantas celdas como combinaciones posibles de niveles. Por ejemplo, para la métrica M01 den caso de estudio, el experimento identificado como E01 (ART_27) ensaya tres niveles: CBR, SBR y Ad Hoc, por lo que debería aparecer en tres celdas indicando que se comparan: CBR-SBR, CBR-Ad Hoc y SBR-Ad Hoc. Esto es ilustrado por la tabla 7.29. 
Tabla 7.29. Formato para el análisis de densidad de estudios por métrica M01 y tarea-tipo de sujeto

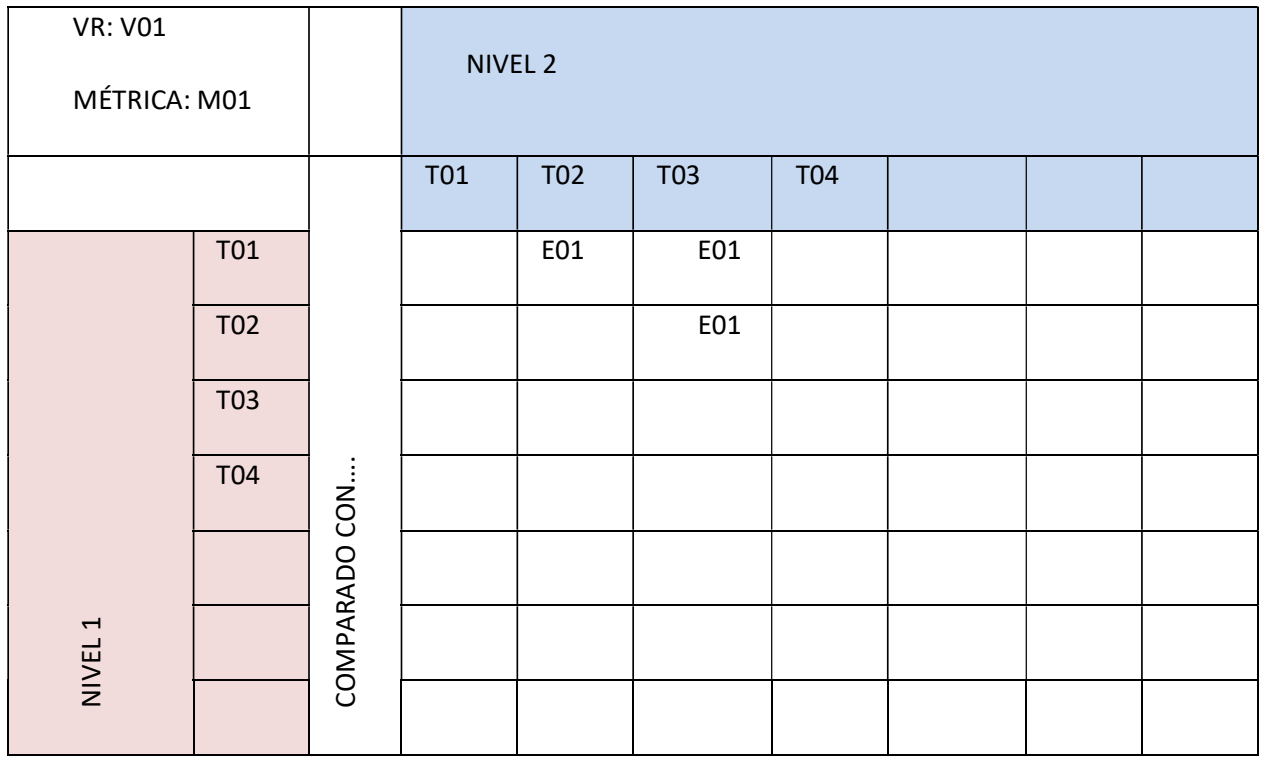

2. Una vez que se han representado en las tablas todos los experimentos por cada métrica, deberán ser separadas por tarea-tipo de sujeto, generando una tabla por cada una grupo tarea-tipo de sujeto.

3. Resaltar las celdas donde aparezcan dos o más experimentos.

De esta manera, es fácil identificar visualmente aquellas combinaciones de niveles/métrica que han sido ensayadas en al menos dos estudios. En las Tablas 7.30 a 7.32 se presentan ejemplos de esta representación para el caso de estudio. Por ejemplo, en la tabla 7.30 se observa que E01 y E03 comparan M01 para las técnicas T01 y T03; al mismo tiempo que E01 es el único estudio en comparar T01, T02 y T03, y E07 es el único estudio en medir M01 para T02 y T04. Por lo tanto, el grupo formado por E01 y E03 para M01 y las técnicas T01/T03 es resaltado en la tabla.

Tabla 7.30. Ejemplo de densidad de estudios para la métrica M01 y la tarea Requisitos

\begin{tabular}{l} 
TAREA: REQUISITOS \\
TIPO DE SUJETO: ESTUDIANTES \\
\hline
\end{tabular}

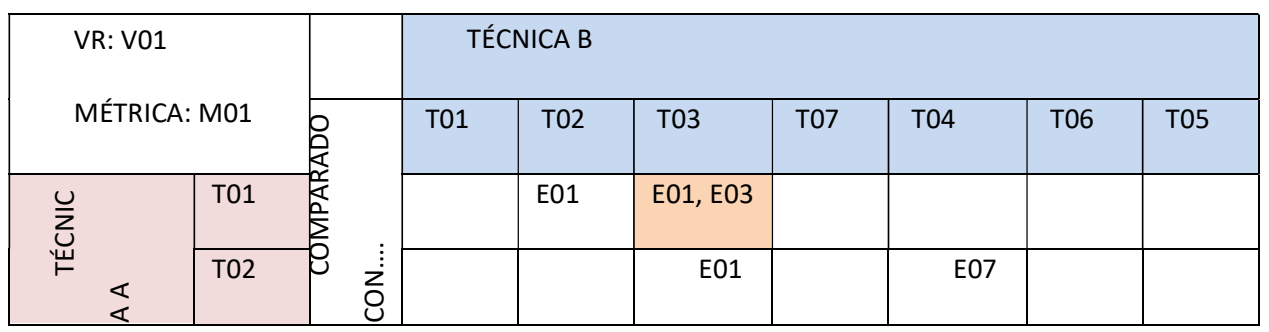




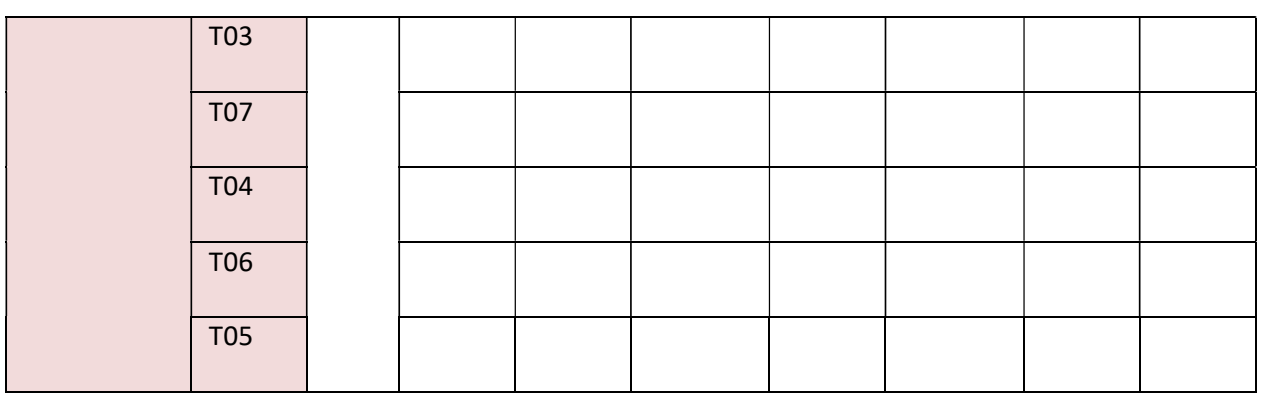

Tabla 7.31. Ejemplo de densidad de estudios para la métrica M03 y la tarea Código

TAREA: CÓDIGO

TIPO DE SUJETO: ESTUDIANTES

\begin{tabular}{|c|c|c|c|c|c|c|c|c|c|}
\hline \multirow{2}{*}{\multicolumn{2}{|c|}{$\begin{array}{l}\text { VR: V01 } \\
\text { MÉTRICA: M03 }\end{array}$}} & & \multicolumn{7}{|c|}{ TÉCNICA B } \\
\hline & & \multirow{8}{*}{ 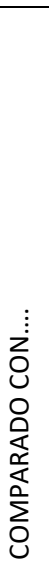 } & T01 & T02 & T03 & T07 & T04 & T06 & T05 \\
\hline \multirow{7}{*}{ 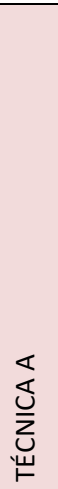 } & T01 & & & & & & & & \\
\hline & T02 & & & & & & & & E12 \\
\hline & T03 & & & & & & & & \\
\hline & T07 & & & & & & & & \\
\hline & T04 & & & & & & & & \\
\hline & T06 & & & & & & & & \\
\hline & T05 & & & & & & E12 & & \\
\hline
\end{tabular}

Tabla 7.32. Ejemplo de densidad de estudios para la métrica M01 y la tarea Diseño

TAREA: DISEÑO

TIPO DE SUJETO: ESTUDIANTES

\begin{tabular}{|c|c|c|c|c|c|c|c|c|c|c|}
\hline \multirow{2}{*}{\multicolumn{2}{|c|}{$\begin{array}{l}\text { VR: V01 } \\
\text { MÉTRICA: M01 }\end{array}$}} & & & \multicolumn{7}{|c|}{ TÉCNICA B } \\
\hline & & \multirow{3}{*}{\multicolumn{2}{|c|}{ 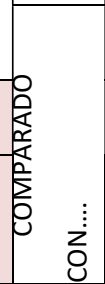 }} & T01 & T02 & T03 & T07 & T04 & T06 & T05 \\
\hline \multirow{2}{*}{ 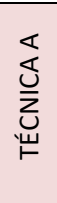 } & T01 & & & & & & & & & \\
\hline & T02 & & & & & & $\begin{array}{l}\text { E21, } \\
\text { E22 }\end{array}$ & & & \\
\hline
\end{tabular}




\begin{tabular}{|c|c|}
\hline T03 & \\
\hline T07 & \\
\hline T04 & $\begin{array}{l}\text { E19, } \\
\text { E20 }\end{array}$ \\
\hline T06 & \\
\hline T05 & \\
\hline
\end{tabular}

Una vez obtenido este análisis, es posible establecer grupos potencialmente agregables con un alto grado de compatibilidad. Tales grupos serán establecidos en el siguiente paso.

\subsubsection{Establecer grupos agregables}

A partir del análisis realizado en el paso anterior, es entonces posible establecer grupos compatibles; esto es, experimentos que comparten la misma tarea, métrica, y comparan los mismos tratamientos. Tales grupos corresponderán a aquellas celdas dentro de las tablas realizadas en la tarea anterior, donde se localicen dos o más experimentos.

Cada uno de los grupos potencialmente agregables es establecido para una combinación de dos niveles y una métrica, en relación con una tarea específica. Adicionalmente, los experimentos se presentan separados por tipo de sujeto. Para el registro de estos resultados se propone el formulario EO9Resumen de grupos potencialmente agregables; el cual registra la siguiente información:

- $\quad$ ID del grupo.

- Métrica/Técnicas.

- Estudios.

- Tarea.

- Observaciones.

En la tabla 7.23 se presenta, a manera de ejemplo, los grupos agregables del caso de estudio sobre inspecciones de software. Nótese que estos grupos sólo incluyen las métricas de tipo experimental (aquellas que se corresponden con las variables respuesta establecidas en las hipótesis experimentales).

Tabla 7.33. Grupos potencialmente agregables para el caso de estudio según el factor Técnica 


\begin{tabular}{|c|c|c|c|c|c|}
\hline grupo & & Estudiantes & Profesionales & & \\
\hline A01 & M01/T01+T03 & E01, E03 & & Requisitos & \\
\hline $\mathrm{A} 02$ & M04 / T01+T02 & $\begin{aligned} &(E 01, E 02, \\
&E 06), \text { E08 }\end{aligned}$ & E05 & Requisitos & -- \\
\hline $\mathrm{A} 03$ & M04 / T01+T03 & $\begin{array}{l}(\text { E01, E02, } \\
\text { E06) }\end{array}$ & E05 & Requisitos & -- \\
\hline A04 & M04/ T02+T03 & $\begin{array}{l}\text { (E01, E02, } \\
\text { E03, E04, E06) }\end{array}$ & E05 & Requisitos & \\
\hline A05 & M04/ T02+T07 & E13, E14, E15 & & Código & \\
\hline A06 & M11/ T02+T07 & E13, E14, E15 & & Código & \\
\hline A07 & M07/T02+T04 & $\begin{array}{l}\text { E12,(E19, } \\
\text { E20) }\end{array}$ & & Diseño & \\
\hline A08 & M01/ T02+T04 & E19, E20 & & Diseño & \\
\hline A09 & M06/ T02+T04 & $\begin{array}{l}\text { E07, (E19, } \\
\text { E20) }\end{array}$ & & Diseño & \\
\hline A10 & M28/ T02+T04 & E19, E20 & & Diseño & \\
\hline A11 & M29/ T02+T04 & E19, E20 & & Diseño & \\
\hline
\end{tabular}

\section{Evaluación de la continuidad del proceso}

Finalmente, tal y como se describió en el capítulo 5, al final de esta fase deben satisfacerse el siguiente hito (véase Tabla 5.2 - Hitos del proceso de RS) : GPAs disponibles y de interés para los revisores.

En caso contrario, el proceso debería ser cancelado ya que o no se cuenta con el mínimo número de experimentos para la agregación o no se justifica el esfuerzo de agregación de experimentos que no son de interés para el equipo de RS. Deberá generarse igualmente el Informe de Revisión a fin de documentar la experiencia aunque no sea exitosa. 


\section{CAPÍTULO 8. FASE DE VALORACIÓN DE LA CALIDAD}

Como se ha señalado en capítulos previos, la Fase de Búsqueda propuesta en esta investigación tiene como propósito detectar la mayor cantidad de estudios relevantes para la RS. No obstante, debemos tomar en cuenta que no todos los estudios empíricos son diseñados y ejecutados adecuadamente. Por el contrario, una gran cantidad de estudios poseen serias deficiencias metodológicas que provocan que sus resultados sean poco fiables o estén distorsionados; dichos estudios se dice que poseen una baja calidad. Incluir estudios de baja calidad en una RS puede conducir a resultados erróneos.

Por esta razón, cuando se conduce una RS no es suficiente con garantizar que los estudios primarios estén relacionados con la pregunta de investigación; lo cual es, de hecho, una práctica regular. Se hace necesaria la evaluación de su calidad a fin de reducir el sesgo y comprender muy bien las comparaciones que se realizan entre los tratamientos, así como la interpretación de los resultados (J. P. T. Higgins \& S. Green, 2006).

Las actividades propuestas en esta fase tienen como propósito asegurar que los estudios incluidos en la RS, y en cuyos resultados se fundamentarán las conclusiones y recomendaciones que finalmente se generen, posean un nivel de calidad adecuado. Adicionalmente, la utilización de estudios de alta calidad facilitará la toma de decisiones durante la fase de SínTESIS DE DATOS.

Frecuentemente, para la Evaluación de la Calidad se utilizan generalmente listas de chequeo y escalas de calidad que permiten asignar una puntuación o nivel de calidad a cada experimento. Tal puntuación será utilizada para incluir o eliminar al experimento del proceso de revisión, y/o ponderar su contribución durante la SíNTESIS DE DATOS.

Por lo tanto, la EVALUACIÓN DE LA CALIDAD persigue identificar estudios con baja calidad, esto es, validez limitada, que pueden afectar negativamente tanto los resultados de la Síntesis como la interpretación de los mismos. Para (K. Khan et al., 2001), los componentes involucrados en la Evaluación de la Calidad, y a los que nos dedicaremos en las próximas secciones, son los siguientes:

- Calidad del estudio, el grado en el cual un estudio emplea medidas para minimizar los sesgos, enfocándose en la validez interna;

- El sesgo, la tendencia a producir resultados que se alejan sistemáticamente de los resultados "reales";

- La validez interna, el grado en el cual los resultados de un estudio tienden a aproximarse a la "verdad"; y 
- La validez externa, el grado en el cual los efectos que son observados en un estudio son aplicables fuera del mismo (en la práctica rutinaria).

En las próximas secciones se describen las características de la IS que deben considerarse para la Evaluación de la Calidad, así como la manera en que proponemos que tales características sean abordadas. Finalmente, se presentan las tareas a realizar en esta fase.

\subsection{Características específicas de la IS que provocan variaciones en la Fase de Valoración de la Calidad}

Al igual que en las etapas anteriores de la RS, existen algunos aspectos de orden metodológico, relacionados con la calidad, que pueden considerarse diferentes en la IS respecto a otras disciplinas. Dichos aspectos son descritos a continuación.

\subsubsection{Definición de Calidad poco clara}

La definición de Calidad de un experimento no es aún suficientemente clara para muchos experimentadores y revisores, no sólo en el área de la IS sino también en disciplinas experimentales maduras.

Algunos autores, tales como (Emerson, Burdick, Hoaglin, Mosteller, \& Chalmers, 1990), (Balk et al., 2002) (Britton et al., 1998) (Deeks et al., 2003; T. Dybå \& T. Dingsøyr, 2008), consideran incluso que la calidad no es un constructo cuya existencia se pueda demostrar empíricamente.

Aunque tales posturas son probablemente extremas, sí parece existir un acuerdo acerca de que la Evaluación de la Calidad es usualmente difícil, y frecuentemente imposible de realizar (K. Khan et al., 2001).

Esto ha generado escepticismo entre los revisores quienes tienen que analizar los beneficios y costes de aplicar Evaluación de la Calidad. Tales costes son medidos por algunos investigadores no sólo en términos del tiempo y esfuerzo utilizados sino también en términos de los estudios excluidos y, por consiguiente, una menor potencia estadística del resultado de la RS.

Como se verá más adelante, este último aspecto es especialmente crítico en IS, siendo que se trata de una disciplina con un universo de experimentos muy limitado.

A pesar de esta falta de consenso en relación a la calidad de experimentos y su evaluación, no se encuentran en la literatura estudios (revisiones o mapeos sistemáticos, así como ontologías) que permitan identificar con claridad los aspectos asociados a tales constructos. 


\subsubsection{Sujetos y objetos experimentales}

A diferencia de otras disciplinas experimentales (por ejemplo, Medicina), en IS los sujetos experimentales no suelen entenderse como aquellos quienes son sometidos a los efectos de uno o varios tratamientos. En lugar de esto, los sujetos que participan en estudios empíricos en IS suelen ser los responsables de aplicar a uno o más objetos (por ejemplo, un documento de diseño, código fuente u otro artefacto) los tratamientos que se quieren ensayar. Esto es así debido a la naturaleza de los experimentos que son conducidos en IS, donde generalmente los tratamientos de interés son técnicas; así como métodos, procesos y herramientas, los cuales son aplicados por alguien (los sujetos) durante la ejecución de una tarea, para generar un producto o resultado.

Para aplicar los tratamientos, los sujetos deben utilizar sus conocimientos acerca del mismo, así como su experiencia y su habilidad. Lo anterior suele conllevar una alta variabilidad en los resultados; asumiéndose, además, que tales resultados son dependientes no sólo de la efectividad del tratamiento en sí mismo sino también de la habilidad del sujeto para aplicarlo.

En virtud de lo anterior, los procesos de reclutamiento y selección de los sujetos en los experimentos realizados en IS no son necesariamente los mismos que en otras disciplinas. Los experimentos en IS suelen prestar especial atención al entrenamiento, la experiencia y el tipo de sujeto. Adicionalmente, suele utilizarse un diseño de medidas repetidas tanto para sobrellevar el problema del escaso número de sujetos como minimizar su variabilidad.

En contrapartida, los instrumentos de evaluación propuestos en otras disciplinas, y que han sido analizados en el Estado de la Cuestión, tienden a incluir preguntas relacionadas con los sujetos pero exclusivamente enfocadas en la población de la cual han sido seleccionados o en el método de muestreo. Lo mismo ocurre con aquellos instrumentos propuestos para la IS, como es el caso de (T. Dybå \& T. Dings $\varnothing y r, 2008)$ (B. Kitchenham, Brereton, Budgen, Turner, et al., 2009) (B. Kitchenham et al., 2008) y (B. Kitchenham, Pfleeger, Pickard, Jones, Hoaglin, Emam, et al., 2002). Más aún, ninguno de ellos hace mención a los objetos experimentales.

\subsubsection{Validación de los instrumentos}

Según (Churcill, 1979) una medida es válida cuando las diferencias en los valores observados reflejan diferencias reales en la característica que se intenta medir, exclusivamente. Si una medida es válida, será también confiable.

La validez de un instrumento de medición (evaluación) de la Calidad es un aspecto de la máxima importancia ya que esto asegura que el instrumento cumpla con su propósito. Sin embargo, y a pesar del uso extendido de las escalas de calidad, algunos autores han sembrado la duda acerca de los riesgos de aplicar tales instrumentos para la evaluación de la calidad (Jüni, Witschi, Bloch, \& Egger, 1999). Por ello, se considera necesario conocer la validez de un instrumento de evaluación antes de utilizarlo (Yates, 
Morley, Eccleston, \& de Williams, 2005). Esto es, la propiedad del instrumento de medir aquello que se espera que mida (Web Center for Social Research Methods, 2006).

Por ejemplo, los instrumentos de EC generalmente tienden a valorar muy positivamente los aspectos metodológicos del estudio que, teóricamente, promueve su validez interna. Sin embargo, no existe evidencia empírica de que tales instrumentos sean capaces de identificar efectivamente los posibles errores sistemáticos (sesgos) que han sido cometidos durante la planificación y conducción del experimento en IS. En honor a la verdad, la evidencia empírica en otras ciencias es también muy limitada.

Aunque en otras áreas es más común la validación de los instrumentos de evaluación de la calidad, p.e. (Hardestya \& Beardenb, 2004), en el área de IS no se tiene conocimiento de trabajos en este sentido. Las pocas escalas existentes, i.e. (T. Dybå \& T. Dingsøyr, 2008) (B. Kitchenham, Brereton, Budgen, Turner, et al., 2009) (B. Kitchenham et al., 2008; B. Kitchenham, Pfleeger, Pickard, Jones, Hoaglin, El Emam, et al., 2002), no han reportado estudios acerca de la validez de las mismas. Si bien es cierto que en el trabajo de (B. Kitchenham et al., 2012), se presenta un estudio sobre la validez de las evaluaciones de calidad, éste se enfoca en el estudio del número de revisores recomendados y el beneficio del uso de escalas de calidad versus una evaluación general por parte de los revisores.

Esta situación de falta de iniciativas de validación de las escaladas existentes, nos lleva a tener reservas al momento de seleccionar y aplicar alguna de éstas.

\subsubsection{Enmascaramiento (blinding)}

A diferencia de aspectos como los mencionados en el punto anterior (sujetos y objetos experimentales), pareciera haber una aceptación generalizada de que el enmascaramiento (blinding) es un indicador importante de calidad. Es por ello que todas las metodologías presentadas en el Estado de la Cuestión incluyen preguntas relacionadas con esta variable. Sin embargo, la situación de la IS es también diferente a otras disciplinas en lo que se relaciona con este aspecto.

Debido al rol que juegan los sujetos dentro de los experimentos en IS, es imposible aplicar el enmascaramiento en tales estudios. Tal y como fue descrito en el punto anterior, los tratamientos requieren de una alta participación de los sujetos, quienes deben estar conscientes de las técnicas y métodos que están siendo aplicados (J. Biolchini et al., 2005). En consecuencia, el enmascaramiento no puede ser utilizado, en IS, como un indicador de la calidad de un experimento.

\subsubsection{Calidad de reporte}

La IS es una disciplina bastante inmadura en su vertiente experimental. Esto se traduce, entre otras características, en que el reporte de los experimentos adolece de estandarización y falta de completitud. Lo anterior puede llevar a los revisores a suponer que algunos aspectos metodológicos no han sido 
satisfechos sin que esto sea necesariamente cierto y, por lo tanto, a valorar negativamente la calidad del estudio. Algunas recomendaciones de reporte, tales como (A. Jedlitschka \& D. Pfahl, 2005) han sido propuestas; sin embargo, incluso en publicaciones muy posteriores al mencionado trabajo, puede observarse la omisión de detalles del estudio que son relevantes para la determinación de su calidad.

\subsubsection{Escaso número de instrumentos de evaluación de la calidad}

Mientras que en Medicina puede encontrarse un número considerable de instrumentos para la evaluación de la calidad de los experimentos, en IS se cuenta con muy pocos, los cuales además no han sido adecuadas a las características particulares de la disciplina.

En el caso de la lista de preguntas presentada en (B. Kitchenham, Brereton, Budgen, Turner, et al., 2009) las preguntas fueron tomadas de diferentes fuentes y disciplinas y fueron organizadas de acuerdo a la etapa del estudio que evalúan. Se observa que, en términos prácticos, 50 elementos es un número enorme de preguntas que deben ser respondidas por cada estudio de la RS. En su trabajo, Kitchenham sugiere analizar la lista de preguntas a la luz de cada RS para seleccionar aquellas que mejor se relacionan con la pregunta de investigación. Sin embargo, esta estrategia no es fácilmente aplicable y puede llegar hacer muy ineficiente la tarea de seleccionar las preguntas más adecuadas a cada una de ellas. Además, no están claros los criterios de selección de las preguntas a utilizar. Por último, las preguntas tienen que ser asignadas a una escala de medición ya que no todas tienen una respuesta simple sí/no; lo que implica una mezcla de ambos tipos de preguntas, tanto preguntas del tipo lista de chequeo como preguntas del tipo escala de calidad. Además de tratarse de una recopilación de preguntas que deben aún ser procesadas para constituir una escala de calidad concreta, los aspectos considerados han sido propuestos sin ser sometidos a ninguna validación.

En (B. Kitchenham, Pfleeger, Pickard, Jones, Hoaglin, Emam, et al., 2002), en cambio, se presenta una lista manejable de preguntas; sin embargo, no se presenta ningún indicio de validación de los ítems incluidos en esta lista. La lista de chequeo propuesta en (B. Kitchenham et al., 2008) presenta evidencias de validación. Lamentablemente, tal validación se limita a la usabilidad y consistencia de los ítems evaluados de una manera subjetiva. En consecuencia, resulta cuando menos cuestionable que esta lista de chequeo pueda ser utilizada, sin más, para la evaluación de la calidad de experimentos en IS.

Por otra parte, aún cuando (T. Dybå \& T. Dingsøyr, 2008) incluyen un conjunto significativo de aspectos relacionados con la validez interna de un estudio, algunos otros aspectos metodológicos sugeridos en la literatura (A. R. Jadad et al., 1996) como determinantes en la validez interna de un experimento (por ejemplo, aleatorización, enmascaramiento (blinding), ocultamiento (concealment), análisis de intención del tratamiento, entre otros) no han sido incorporados. Seguramente esto se deba a que la lista de chequeo propuesta por Dybå et al. (T. Dybå \& T. Dingsøyr, 2008) no ha sido desarrollada específicamente para estudios del tipo experimento sino para estudios empíricos en general. Por lo tanto, si se decidiera 
utilizar este trabajo como escala de calidad, y la aleatorización o el enmascaramiento estuvieran relacionados con el sesgo, tal relación no podría ser detectada.

El reducido número de instrumentos, y lo que es peor, la carencia de una validación empírica de los mismos, establece serias limitaciones al momento de decidir cómo llevar a cabo la EC de una determinada RS. Como consecuencia de esto, los evaluadores incurren en el riesgo de cometer más sesgos con origen metodológico durante la Evaluación de la Calidad que los propiamente derivados de los estudios primarios.

\subsubsection{Escaso número de experimentos}

Esta característica ha llegado a ser determinante en la adecuación de todas las etapas del proceso de RS llevado a cabo en esta tesis. Debido a que los resultados de la agregación tienden a ser más confiables a medida que se incorporan más estudios ( $y$, por lo tanto, más sujetos), todo el proceso de RS sigue como premisa la maximización de la cantidad de estudios primarios a ser incluidos.

En la Medicina basada en Evidencia los revisores pueden permitirse ser muy selectivos en cuanto a los estudios a incluir, debido a la relativa abundancia de ensayos clínicos o experimentos. En IS, la situación en bien distinta. El número de experimentos disponible tiende a ser escaso, y durante la etapa de Evaluación de la calidad, el número de experimentos (y sujetos) se puede ver aún más mermado debido a exclusiones innecesarias de experimentos, producto del uso de instrumentos de calidad inadecuados o mal construidos.

Como conclusión del análisis anterior se puede concluir que ninguno de los instrumentos analizados en el Estado de la Cuestión podría ser utilizado directamente en la evaluación de experimentos en IS, sin que se incurra en el riesgo de penalizar innecesariamente el número de experimentos a incluir en la Síntesis, como efecto del uso de los instrumentos inadecuados, que no guardan relación con la validez real del experimento.

\subsection{Aproximación a la solución}

Una vez identificadas las características de la IS que limitan la EC de experimentos siguiendo las propuestas disponibles tanto en IS como en otras disciplinas, se resumen a continuación las soluciones propuestas en esta investigación para cada una de tales limitaciones. Estas propuestas son posteriormente estructuradas en forma de actividades o tareas en la sección 8.3.

1. Definición de Calidad poco clara: Tal como se describió en la sección 8.1, en la IS aún no existe un consenso en relación a la definición de Calidad de un experimento, así como tampoco en relación a su operacionalización (los aspectos específicos del diseño y la conducción del experimento que pueden ser efectivamente utilizados para predecir la calidad del mismo). Esto nos lleva a afirmar que existe 
controversia no sólo en cuanto al concepto de calidad sino también en cuanto a la viabilidad de su valoración.

$\checkmark$ Solución: para sobrellevar esta limitación, se requiere realizar un análisis del concepto de Calidad de un experimento. Esto incluye determinar aquellos aspectos que se encuentran directamente relacionados con el mismo. Partiremos de la premisa de que la calidad posee un fundamento real, objetivo y como tal puede ser, sino medido, al menos estimado. Se asume la idea generalmente aceptada de que la calidad está relacionada con la manera como se ejecuta y se reporta el experimento (B. Kitchenham, Pfleeger, Pickard, Jones, Hoaglin, Emam, et al., 2002) (B. A. Kitchenham, 2004). La calidad de un experimento es generalmente interpretado como el grado en que un estudio emplea métodos para minimizar los sesgos, es decir, intenta maximizar su validez interna (K. Khan et al., 2001). Un experimento de buena calidad está libre de sesgo. Los resultados no sesgados, por consiguiente, son internamente válidos.

El sesgo es un error sistemático que se observa en los resultados experimentales como una desviación de los resultados experimentales de su valor real. Kitchenham (B. A. Kitchenham, 2004) define el sesgo como una tendencia a producir resultados que se separan sistemáticamente de los resultados "verdaderos". Por ejemplo, si se encuentra que la técnica A es $50 \%$ mejor que la técnica B en un experimento específico, pero se conoce que la diferencia real es de $30 \%$, el $20 \%$ restante sería considerado como sesgo. El sesgo no es cancelado entre sujetos, lo cual lo hace diferente al error aleatorio. En el caso del sesgo de ejecución inducido por el experimentador, por ejemplo, todos los sujetos que recibieron ayuda (incluso si esta ayuda se proporcionó inadvertidamente) tienden a obtener mejores resultados que los sujetos que no recibieron ayuda. En principio, el sesgo se puede cuantificar si hay suficientes experimentos, siempre que tales experimentos no se vean afectados por el mismo error sistemático (que es una suposición razonable para experimentos independientes). Como el sesgo de un experimento singular no se puede calcular, los instrumentos estándar de EC están generalmente dirigidos a la evaluación de la validez interna de los experimentos y a deducir la calidad de la experiencia de esta evaluación (CRD, 2009). Esto puede ser utilizado para ponderar la contribución de cada uno de los estudios incluidos dentro del proceso de RS.

Según el criterio de validez interna, un experimento de alta calidad sería aquel que utilice la aleatorización para crear grupos experimentales homogéneos, utilice el ocultamiento para asignar a los sujetos e investigadores, logre un seguimiento completo de los resultados, etc. Por el contrario, un experimento de calidad pobre sería aquel que utilice pocos o ninguno de los métodos anteriores para prevenir errores sistemáticos durante la conducción del estudio (K. Khan 
et al., 2001). La prevención del sesgo es entonces el resultado de una planificación, operación y control cuidadosos, lo cual maximiza la validez interna del experimento (CRD, 2009). Desafortunadamente, la relación entre validez interna y sesgo no es todavía suficientemente clara para muchos revisores. Hay estudios tanto a favor (T. Dybå \& T. Dingsøyr, 2008) (B. Kitchenham, Pfleeger, Pickard, Jones, Hoaglin, El Emam, et al., 2002) (B. Kitchenham, 2004) como en contra (Jüni et al., 1999) (Balk et al., 2002) (Britton et al., 1998) (Deeks et al., 2003) (Emerson et al., 1990) de esta relación.

Por supuesto, la validez interna es sólo una de las muchas facetas que determinan la bondad de un experimento. La validez externa también juega un papel clave. Sin embargo, la validez externa está subordinada a la validez interna. Esta última es, de hecho, a la que más atención se le ha prestado. La Figura 8.1 claramente explica por qué: la validez interna refleja el grado en que los resultados experimentales son exactos, y la exactitud se determina por la minimización del riesgo de sesgo (K. Khan et al., 2001).

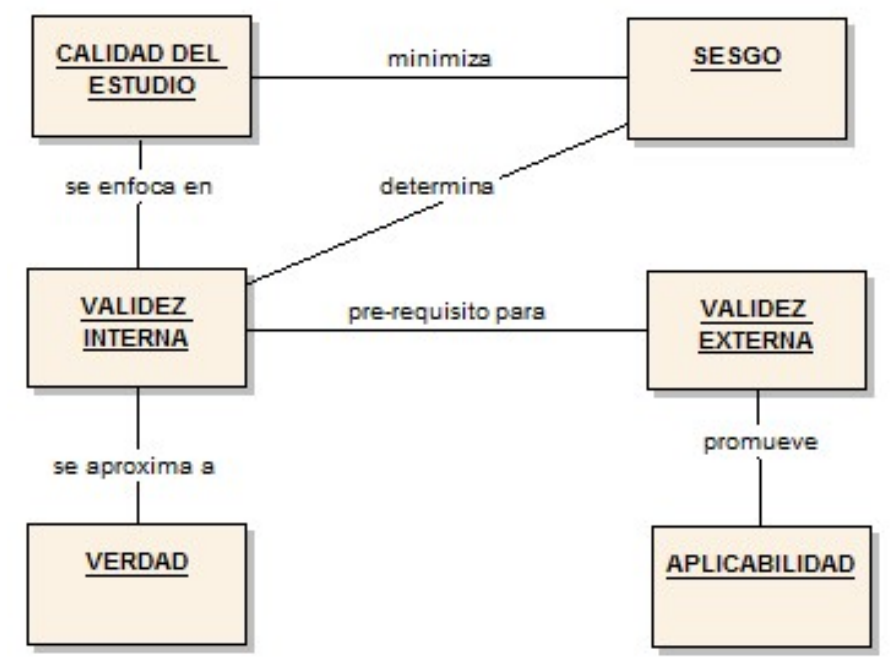

Figura 8.1. Componentes de la calidad de un experimento

Con base en la figura 8.1, se podría afirmar que, si se consiguen resultados precisos, entonces el experimento posee una buena calidad y es posible extrapolar con éxito los resultados a otras poblaciones o contextos. Si los resultados no son precisos (debido al sesgo), la extrapolación será inútil. Dado que el sesgo no es calculable, la calidad se determina por un conjunto de parámetros de diseño experimental y de ejecución que garantiza la validez de los resultados (J. P. Higgins \& S. Green, 2006; A. R. Jadad et al., 1996; K. Khan et al., 2001; Kitchenham. B.A. \& Charters, 2007; Petticrew \& Roberts, 2007). Visto de esta manera, la validez interna es un requisito previo para la validez externa (K. Khan et al., 2001). 
2. Sujetos y objetos experimentales: como se describió en la sección anterior, las escalas existentes son muy limitados al considerar a los sujetos y los objetos involucrados en el experimento, los cuales parecieran tener un impacto considerable en los resultados.

$\checkmark$ Solución: como solución a esta limitación se plantea la inclusión de los aspectos antes señalados dentro los elementos a evaluar en un experimento. Sin embargo, sabemos de antemano que esto conllevará a que ninguna de las listas de chequeo existentes pueda ser aplicada en su versión actual. Por lo tanto, la consideración de los aspectos relacionados con los sujetos y los objetos, obliga cuando menos a la mejora de alguna de las listas de cheque existentes.

3. Validez del instrumento: como se explicó anteriormente, para el interés de esta investigación no es suficiente con desarrollar o seleccionar un instrumento que permita evaluar los experimentos. Por el contrario, se hace necesario comprobar su validez a fin de garantizar que se ha propuesto el instrumento idóneo.

$\checkmark$ Solución: En particular, estamos interesados en asegurar en alguna medida, la validez de contenido (o face validity) y la validez de constructo, específicamente la convergente). Para ello, utilizaremos modelos lineales y medidas como el coeficiente alfa para eliminar los items que no sean consistentes dentro del conjunto de ítems propuestos. Se seguirá una estrategia para la validación del mismo, la cual incluirá:

i. Aplicar el instrumento: seleccionar uno o más conjuntos de experimentos para ser sometidos a la EC utilizando el instrumento propuesto. Este paso debe generar un resultado que pueda ser comparado con otros indicadores. Los conjuntos de experimentos deberán ser homogéneos y haber sido combinados utilizando metaanálisis. Para facilitar la aplicación de la escala, la respuesta a cada pregunta será dicotómica; esto es, sólo podrá ser respondida con "sí" o "no". El índice de calidad del experimento se calculará como el porcentaje de respuestas afirmativas. Un experimento con puntuaciones cercanas a 1 (esto es, 100\%) será considerado como experimento de buena calidad, y aquellos que obtengan puntuaciones cercanas a 0 serán catalogados como experimentos con una pobre calidad:

ii. Utilizar el juicio de expertos: someter los experimentos del paso anterior a la valoración subjetiva por parte de un grupo de expertos. Tal valoración busca aprovechar la experiencia de los evaluadores en relación al diseño y conducción de experimentos. Con base en la experiencia, un experto podría distinguir entre experimentos de buena y mala calidad en una RS.

iii. Calcular el sesgo: el conjunto de experimentos seleccionados en los pasos anteriores (o un sub-conjunto del mismo) se someterá a algún tipo de medición 
objetiva con la cual se pueda comparar los resultados obtenidos tanto por el instrumento de evaluación como por el juicio de expertos.

Para operacionalizar la estimación del sesgo, se necesita conocer las diferencias reales entre los tratamientos experimentales. En los estudios de sesgo se estima el valor verdadero combinando todos los resultados experimentales disponibles mediante meta-análisis de los estudios (estratificados de acuerdo a su calidad o a alguna característica de calidad) (Juni, Altman, \& Egger, 2001). Para ello, la mejor opción es calcular la desviación del resultado de cada experimento frente al "resultado verdadero" reportado por la RS correspondiente (Proximidad al valor medio). No obstante, esta estrategia requiere contar con un número grande de estudios que contribuyan a una agregación. Para efectos de la presente investigación esto no es posible ya que el número de experimentos disponibles en IS es sumamente reducido. Confeccionar RS específicas para esta investigación no parece razonable, ya que no podríamos superar ni en número ni en calidad las evidencias obtenidas por las RS disponibles en la literatura. Como estrategia alternativa, se utilizarán RS ya existentes. Éstas agregan resultados experimentales, obteniendo estimaciones (más o menos precisas) de las diferencias entre las técnicas ensayadas. Dichas diferencias, a efectos operativos, pueden considerarse como los 'valores verdaderos'.

iv. Triangular los resultados anteriores: esta actividad permitirá finalmente comprobar la validez del instrumento propuesto. Tal triangulación se realizará de la siguiente manera:

- Correlacionar el resultado de la aplicación del instrumento propuesto con la valoración obtenida a través del juicio de expertos.

- Correlacionar los resultados de calidad obtenidos con el instrumento con los resultados calculados de sesgo. Para ello se comparará el análisis de resultado de la puntuación obtenido con el instrumento de evaluación tanto globalmente como a nivel de los ítems individuales.

- Comparar el instrumento propuesto con otros instrumentos de calidad reconocidos en diferentes áreas.

4. Enmascaramiento: como se describió en la sección anterior, es poco probable, quizás imposible, que los sujetos lleguen a aplicar las técnicas o métodos ensayados sin tener un conocimiento de los mismos. Esto hace suponer que el utilizar el enmascaramiento como un elemento de evaluación de la calidad, llevará a los revisores a penalizar injustamente a la mayoría, sino todos, los estudios evaluados en IS.

$\checkmark$ Solución: al igual que en caso de otras variables, se debe comprobar la relación entre esta variable y la calidad. De esta manera, buscamos no penalizar aquellos experimentos que 
pudieran estar contribuyendo con la agregación y que, sin embargo, no incluyen dentro de su diseño esta práctica.

5. Calidad de reporte: esta característica es tan importante que es posible descartar estudios con resultados significativos, con base en la poca información que reporta; llevando esto a descartar evidencias que podrían contribuir de manera importante con la Síntesis de Datos. Es necesario entonces asegurar la inclusión de la mayor cantidad posible de estudios a fin de aumentar la potencia estadística.

$\checkmark$ Solución: la manera de lidiar con esta limitación no es muy diferente de la solución propuesta para otras características. La propuesta base de contar con un instrumento que incluya un conjunto mínimo de ítems fuertemente relacionados con la calidad, trae como beneficio añadido que se requiera de un conjunto mínimos de datos en el reporte del experimento. Con suerte, este conjunto mínimo de ítems coincida con los más comúnmente reportados. De esta manera, tratamos de que el revisor se centre en los ítems que se están evaluando, en lugar de emitir opiniones subjetivas motivadas en aspectos del reporte y no de la calidad interna. Se busca con esto asegurar que independientemente de la habilidad del revisor para extraer información, se puedan obtener los datos mínimos requeridos. Por otra parte, se propondrán preguntas abiertas que puedan ser respondidas fácilmente independientemente de que la información sea reportada de forma más o menos explícita.

6. Escaso número de instrumentos de evaluación de la calidad: precisamente la escasez de propuestas en relación a este tema conlleva a que muchas de las características mencionadas en esta sección sigan siendo problemas abiertos en el área de ISE. Por otra parte, las propuestas existentes no consideran los aspectos señalados como problemáticos, sino que se han orientado al uso de escalas muy parecidas a las propuestas en otras áreas. Por ello, se trata de una limitación que es transversal al resto de las restricciones mencionadas en la sección 8.1.

$\checkmark$ Solución: derivado del análisis de las características de la IS que limitan la Evaluación de la Calidad, se hace necesario la propuesta de un nuevo instrumento que recoja todas las consideraciones presentadas en esta sección. Por lo tanto, esta solución es transversal a todas estas características. Para ello, se realizará un estudio que permita contar con un instrumento que recoja de manera sencilla los elementos más estrechamente relacionados con la calidad; sin dejar de considerar aquellos que son particulares para la IS.

7. Escaso número de experimentos: esta característica tiene su impacto en cada una de las fases de la RS que se proponen en esta investigación. Aunque se espera que con el tiempo, la base experimental en la IS sea cada vez mayor y presente mayor calidad, en estos momentos es necesario lidiar con una cantidad limitada de experimentos controlados que nos permitan obtener evidencias y conclusiones bien fundamentadas. Es por lo tanto una limitación que debe ser abordada sistémicamente a lo largo de todo el proceso. 
$\checkmark$ Solución: durante esta fase se busca promover que sean excluidos la menor cantidad posible de experimentos. Esto se logrará, al igual que en las características anteriores, al contar con un conjunto de ítems de evaluación que predigan de manera confiable la calidad; en lugar de un conjunto grande de ítems cuya relación con la calidad no ha sido validada, que puedan penalizar innecesariamente los pocos experimentos de los que se dispone. Lo anterior requerirá del uso de una escala que no sea excesivamente conservadora.

Como puede observarse, la escasa adherencia de los instrumentos de evaluación disponibles en las distintas disciplinas (incluida la IS) a las características señaladas en esta sección, implica la necesidad de un análisis riguroso del concepto de calidad de un experimento. Un análisis de tal naturaleza debe conducir a la propuesta de un instrumento de evaluación que afronte las restricciones aquí mencionadas. Con el propósito de llegar a proponer un instrumento de EC que sea válido para el área de la IS, se utilizará una metodología similar a la utilizada en otros estudios en el campo de la Medicina (Balk et al., 2002; Jüni et al., 1999; Schultz et al., 1995). La misma es aplicada y discutida ampliamente en el Apéndice XX.

Como resultado del estudio realizado en (O. Dieste, Grimán, Juristo, \& Saxena, 2011), se deriva la recomendación de un conjunto de variables por estar relacionadas con el sesgo, éstas son: aleatorización, población, método de muestreo, e hipótesis.

Estos hallazgos parecen estar en la línea de las escalas y listas de chequeo comúnmente utilizadas en Medicina y otras disciplinas. Sin embargo, esta afirmación amerita un análisis profundo y más detallado de los antecedentes de los que disponemos. Es por ello que hemos comparado las preguntas que han resultado predictivas en nuestra escala con 15 escalas comúnmente utilizadas en diferentes disciplinas como Medicina, Ciencias Sociales, e Ingeniería del Software. El propósito de tal comparación es identificar cuáles de estas preguntas se encuentran presentes en las diferentes escalas analizadas y cuáles de ellas no están siendo utilizadas.

En primer lugar, comparamos las preguntas relacionadas con HIPÓTESIS, ALEATORIZACIÓN, AMENAZAS A LA VALIDEZ y SIGNIFICANCIA ESTADÍSTICA con la propuesta de (Jadad, 1998) encontrando apenas dos coincidencias; en particular, la aleatorización y su método de secuencia son las únicas preguntas de la lista de Jadad que coinciden con el grupo de preguntas predictivas. La escala de Jadad incluye otros componentes como el enmascaramiento (blinding), el ocultamiento (concealment) y las pérdidas (drop-outs) que, aunque son estándar en esta materia, no han sido consideradas en nuestro estudio o no han resultado predictivas en el mismo.

Otra escala importante por el uso frecuente que tiene en distintas disciplinas, no sólo en Medicina, es la escala CONSORT (Moher, Schulz, \& Altman, 2001). Al comparar el conjunto de preguntas predictivas, encontramos que todas ellas están siendo consideradas por la escala CONSORT. No obstante, esta escala contiene alrededor de 15 componentes adicionales (por ejemplo, Contexto, Tratamientos, Medidas de resultados, Tamaño de la muestra, Métodos estadísticos, Efectos secundarios, entre otros) que no han sido validados en este estudio o que han resultado no predictivos. 
Otra propuesta que cuenta con un gran número de aspectos a ser evaluados en relación a la calidad es la escala de (Down \& Black, 1998), la cual incluye casi 20 componentes de calidad. En esta propuesta se puede ver claramente que los aspectos HIPÓTESIS, ALEATORIZACIÓN y SIGNIFICANCIA ESTADÍSTICA están siendo consideradas; mientras que la inclusión de AMENAZAS A LA VALIDEZ no es evidente. Por otra parte, esta escala incluye muchos otros componentes, tales como Medidas de resultados, Confusores, Pérdidas de pacientes, Validez externa, Enmascaramiento, Análisis de datos, Pérdidas y retiros, entre otros, que no han sido estudiados en nuestra escala o que no han resultado variables predictivas de la calidad.

Una escala mucho más simple es la de (Buffett, Ciliska, \& Thomas, 2007), conocida como QATool, la cual incluye AMENAZAS A LA VALIDEZ y Sesgo de selección (ALEATORIZACIÓN), junto con otras variables que no han resultado relacionadas en nuestro estudio con la calidad, como es el caso de Diseño del estudio, Enmascaramiento, Confusores, Métodos estadísticos, entre otros. Otra escala muy similar es la propuesta por (Reisch, Tyson, \& Mize, 1989), la cual no ha sido propuesta exclusivamente para estudios del tipo RCT sino para cualquier tipo de estudio. Entre los componentes que incluye esta escala, solamente Propósito y Aleatorización son coincidentes con algunas de las variables que resultaron correlacionadas con la calidad en nuestro estudio, HIPÓTESIS y ALEATORIZACIÓN, respectivamente.

Otra escala general de Medicina que podemos utilizar como referencia es la propuesta por (Zaza et al., 2000); no obstante, nuestro análisis revela que del grupo de variables predictivas, sólo HIPÓTESIS ha sido considerada dentro de esta escala. La escala incluye otras variables, que o bien no han sido estudiadas en nuestra investigación o no han resultado correlacionadas con la calidad del estudio.

Por otra parte, incluimos dos escalas específicas para RCTs muy populares en Medicina y que resultan muy simples, la escala Consenso Delphi, propuesta por (Khan, Daya, \& Jadad, 1996), y la escala de (ARCHE, 2007) que está basada en la escala de Jadad. En ambos casos, la coincidencia con nuestras variables (HIPÓTESIS, ALEATORIZACIÓN, AMENAZAS A LA VALIDEZ y SIGNIFICANCIA ESTADÍSTICA) es mínima. Solamente, la ALEATORIZACIÓN ha sido considerada, mientras que otras variables como el Enmascaramiento, que no ha resultado correlacionado con la calidad, sí es considerado en ambas escalas. Las últimas dos escalas de Medicina que utilizamos como referencia son la escala de (NIHCE, 2007) y GRADE (Guyatt, Oxman, \& Vist, 2008). Siendo la primera de ellas bastante compleja, con cerca de 20 variables siendo medidas para determinar la calidad del estudio. No obstante, solamente dos de ellas han resultado en este estudio correlacionadas con la calidad: Datos de la muestra (HIPÓTESIS) y ALEATORIZACIÓN. En el caso de GRADE nos encontramos con una escala mucho más simple para calificar la fortaleza de un cuerpo de evidencia. Esta escala incluye efectivamente la Aleatorización, junto con otras variables recurrentes entre las distintas escalas (como Ocultamiento, Enmascaramiento, Retiros y Pérdidas) que no han sido correlacionadas en este estudio con la calidad.

En otras disciplinas aparte de Medicina, encontramos escalas que incluyen las variables estándar, como es el caso de la escala de (Williams et al., 2001) utilizada en el área de Medio Ambiente y Salud Pública. Esta escala que sólo contiene 8 preguntas, considera, sin embargo, muchas de las variables antes mencionadas 
para Medicina. Siendo la Aleatorización la única que coincide con nuestras variables predictivas, específicamente con ALEATORIZACIÓN.

Intentamos también comparar nuestros resultados con una escala propuesta por (Campbell \& Stanley, 1963) para el área de Ciencias Sociales, específicamente para estudios de tipo cuasi-experimento; sin embargo, no encontramos ninguna coincidencia con las variables que en nuestro estudio han resultado relacionadas con la calidad.

Por último, hemos utilizado dos escalas de calidad propuestas para Ingeniería del software. La primera de ellas es la propuesta por (B. Kitchenham, Brereton, Budgen, \& Li, 2009), la cual es una escala bastante simple donde se incluyen 8 preguntas relacionadas con Poder estadístico, Análisis estadístico, Asignación de participantes, Enmascaramiento y Mediciones. Como se ha visto a través de este análisis, sólo una de estas variables coincide con nuestras variables predictoras, Asignación de participantes, la cual se corresponde con ALEATORIZACIÓN. El resto de las variables no han sido incluidas en nuestro estudio o no han podido ser correlacionadas con la calidad del experimento. La segunda escala que hemos utilizado en esta disciplina es la propuesta por (T. Dybå \& T. Dingsøyr, 2008), la cual es también simple aunque no está dirigida exclusivamente a estudios del tipo RCT. Al analizar las 11 preguntas incluidas en esta escala encontramos muchas de las variables que hemos observado a lo largo de esta comparación; aunque no incluye aquellas variables especialmente recurrentes en las escalas tradicionales de calidad (por ejemplo, Aleatorización, Enmascaramiento, Ocultamiento, etc.). De tal manera, sólo es posible asociar una de nuestras variables, AMENAZAS A LA VALIDEZ, con algunas de las preguntas de (T. Dybå \& T. Dingsøyr, 2008), en particular aquellas relacionadas con Reclutamiento.

El análisis anterior permite concluir:

- Que las variables incluidas en esta investigación son recurrentes en las escalas de calidad y listas de chequeo ampliamente usadas en diferentes disciplinas.

- Que tales escalas y listas de chequeo evalúan variables que han sido incluidas en esta investigación no pareciendo estar correlacionadas con la calidad.

- Que existe un conjunto de variables que están siendo evaluadas por los instrumentos de calidad actuales pero que no han sido validados ni en esta investigación ni por sus autores. Tales variables deben formar parte de un estudio más extenso que no está incluido en el alcance de esta investigación.

En consecuencia, tales variables deben prevalecer en cualquier instrumento de evaluación de la calidad, al mismo tiempo que debería evitarse incluir arbitrariamente muchos otros elementos o variables. 
De ser así, el resultado de la evaluación que hagamos de la calidad no será mejor sino que arrojará peores resultados (resultados más sesgados) para la posterior agregación.

Tomando como base esta recomendación se proponen a continuación las tareas a realizar para la EC de experimentos.

\subsection{Actividades propuestas para la Fase de Valoración de la}

\section{Calidad}

El propósito de esta fase es asignar un valor de calidad a cada uno de los estudios obtenidos durante la búsqueda, con el fin de tomar decisiones acerca de su participación y su contribución en la Síntesis de Datos. La asignación del nivel de calidad de un estudio se basa en las siguientes premisas generales:

- Los experimentos controlados que no presenten los datos requeridos para la agregación, serán eliminados durante la Fase Búsqueda o Extracción de datos. Por lo tanto, el nivel de calidad Baja será reservado para los cuasi-experimentos.

- La valoración del nivel de calidad se realizará sobre la base de las variables que resultaron fuertemente correlacionados con la calidad en el estudio realizado en esta investigación (Apéndice ZZZ).

- $\quad$ Para que un cuasi-experimento sea considerado de calidad alta deberá posee grupo de control.

- La aleatorización no será un elemento a evaluar en los cuasi-experimentos. Se asume como un elemento presente en los experimentos.

La entrada a esta fase la constituyen los estudios agrupados tanto para la lectura (GCA) como para la agregación (GPA). Como resultado final, se obtendrá un formulario con los ítems de calidad evaluados y el nivel de calidad asignado. Las actividades que se proponen para esta fase son mostradas en la Figura 8.2 y son descritas a continuación. 


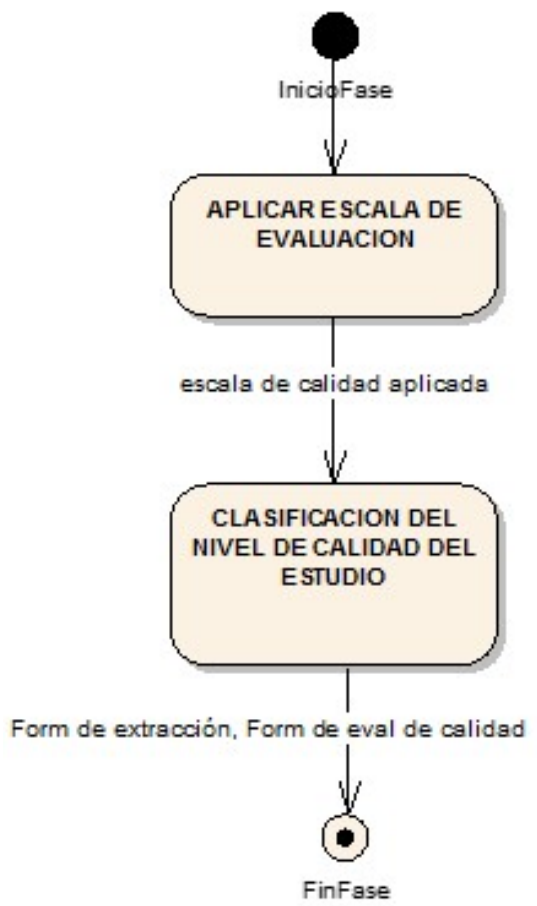

Figura 8.2. Actividades de la Fase de Evaluación de la calidad

\subsubsection{Aplicar escala de evaluación}

El objetivo de esta actividad es determinar la calidad de cada estudio primario (experimentos y cuasiexperimentos) y permitir, de esta manera, ponderar su contribución a la agregación posteriormente. Para ello se utilizará la escala de calidad que resultó del estudio descrito en el Apéndice ZZ, y que se describe en la figura 8.3.

Para dar respuesta a este instrumento, se sugieren las siguientes heurísticas:

- De ser necesario, realizar varias iteraciones de lectura del artículo e interpretación de la información, para dar respuesta a cada criterio contenido en la escala de calidad.

- En caso de que se cuente con más de un revisor para la aplicación de la lista de chequeo, las discrepancias que surjan entre ambos resultados deberán ser manejadas a través de técnicas de toma de decisiones (por ejemplo, votaciones, consenso, etc.).

\begin{tabular}{|l|l|}
\hline $\begin{array}{l}\text { Nombre de la Revisión: } \\
\text { Id del Estudio: }\end{array}$ & $\begin{array}{l}\text { Evaluador: } \\
\text { Fecha: }\end{array}$ \\
\hline Items del cuestionario & Valor asignado \\
\hline
\end{tabular}




\begin{tabular}{|l|c|}
\hline $\begin{array}{l}\text { ¿Se establecen las hipótesis y se discute su relación con el objetivo en } \\
\text { un sección de Introducción? }\end{array}$ & Sí $\square$ No $\square$ \\
\hline $\begin{array}{l}\text { ¿El investigador define el proceso por el que se aplica el tratamiento a } \\
\text { los objetos y sujetos (por ejemplo, la aleatorizaición)? }\end{array}$ & Sí $\square$ No $\square$ \\
\hline ¿Se menciona la significancia estadística junto con los resultados? & Sí $\square$ No $\square$ \\
\hline $\begin{array}{l}\text { ¿Se mencionan las amenazas a la validez y cómo éstas afectan los } \\
\text { resultados y los hallazgos? }\end{array}$ & Sí $\square$ No $\square$ \\
\hline & Baja $\square$ Media $\square$ Alta $\square$ \\
\hline Nivel de calidad asignado & \\
\hline
\end{tabular}

Figura 8.3. Formato de Evaluación de Calidad

El nivel de calidad del estudio se asigna de acuerdo a los lineamientos indicados en la actividad Clasificación del nivel de calidad del es, sección 8.3.2.

La salida de esta actividad es:

- Escala de calidad aplicada, incluye las respuestas a un conjunto mínimo de preguntas que son aquellas que resultaron efectivamente relacionadas con la calidad (ver Figura 8.4).

\subsubsection{Clasificación del nivel de calidad del estudio}

Cada uno de los estudios debería contribuir al proceso de Síntesis de Datos, en función del nivel de calidad determinado en esta fase. El objetivo de esta actividad es precisamente establecer el nivel de calidad de acuerdo a las respuestas a la escala de calidad obtenidas en la tarea anterior.

Hemos definido dos procedimientos distintos dependiendo del tipo de diseño (experimental o cuasiexperimental) de los estudios primarios. Éstos se describen en las secciones 8.3.2.2 y 8.3.2.3, respectivamente. Antes de describir dichos procedimientos haremos explícitas algunas premisas que se asumen al momento de aplicar esta Fase en la siguiente sección.

Para asignar niveles de calidad a estudios primarios incluidos en un grupo agregable, se tendrán en cuenta las siguientes consideraciones.

\subsubsection{Criterios generales para la asignación de niveles de calidad}


- Sólo participan en la RS experimentos controlados (i.e. que cuentan con un grupo de comparación) y cuasi-experimentos (estudios que no cuentan con un grupo de control o cuyas unidades experimentales no hayan sido asignadas a los tratamientos de manera aleatoria). Aquellos estudios que no cumplan con estas condiciones deberán ser considerados de calidad Baja y, en consecuencia, excluidos de la agregación durante la fase de Síntesis. En el caso de los cuasi-experimentos se busca distinguir entre cuasi-experimentos de calidad baja-media-alta.

- Aquellos estudios que no presentan los datos necesarios para su agregación han sido calificados como de calidad Baja y han sido descartados durante la fase de Síntesis (incluso durante la Búsqueda). En consecuencia, las actividades relacionadas con esta fase buscan discriminar entre los restantes experimentos; asignando niveles de calidad media y alta.

- La Aleatorización resultó fuertemente correlacionada con la calidad durante la construcción de la escala de calidad propuesta (véase Apéndice ZZZ). Sin embargo, dado que el tipo de estudio incluido en este proceso comprende tanto experimentos controlados como cuasi-experimentos, esta característica servirá sólo como diferenciador entre ambos tipos de estudios mas no como criterio de asignación de un nivel de calidad. Lo anterior se traduce en que el valor de Aleatorización para un experimento será siempre 1; mientras que para un cuasi-experimento será siempre 0.

\subsubsection{Análisis de niveles de calidad para experimentos}

La distinción entre niveles de calidad para el caso de los experimentos no es un tema trivial. La alternativa más rentable es seguir las recomendaciones de las jerarquías de evidencias; sin embargo, no confinamos nuestro procedimiento de discusión únicamente a dichas recomendaciones.

Por una parte, las jerarquías de evidencias sitúan a los experimentos controlados en el mayor nivel de confianza, lo que para nuestros propósitos equivale al nivel de calidad alto (nótese que confianza = ausencia de sesgo).

Por otra parte, asignar un nivel de calidad alto a los experimentos controlados, por el mero hecho de serlo, parece excesivo.

Aplicando un enfoque conservador, creemos razonable que aquellos experimentos que posean los datos necesarios para la SíNTESIS DE DATOS sean considerados como mínimo de calidad Media.

Finalmente, para calificar la calidad de un experimento como Alta, debemos incorporar requisitos adicionales, lo que lleva a determinar aquellas preguntas de la escala de calidad (o sus aspectos subyacentes) que son diferenciadoras:

- Hipótesis (P3): tal como se explicó durante la creación de la escala de calidad (véase Apéndice E), esta pregunta se perfiló como un buen predictor de la calidad con un coeficiente de correlación bastante 
alto. Sin embargo, se trata de un aspecto bastante recurrente en los experimentos por lo que no consideramos este criterio como un discriminante entre los niveles de calidad medio y alto.

- $\quad$ Amenazas a la validez (P8): esta pregunta mostró una tendencia fuerte a predecir la calidad, siendo además una característica que aglutina diferentes aspectos que pueden afectar los resultados del estudio. Por lo tanto, parece lógico considerarla como un elemento discriminante.

- Significancia estadística (P9): en el caso de esta pregunta, aunque se presentó como un buen predictor de la calidad, no creemos razonable utilizarla como criterio diferenciador, ya que ello conllevaría a que sólo los estudios con resultados significativos sean considerados de Alta calidad.

Con base en el análisis anterior, las condiciones que determinarán los niveles de calidad Media - Alta para un experimento se presentan en la Tabla 8.1.

Tabla 8.1. Condiciones de los niveles de calidad de un experimento

\begin{tabular}{|l|l|l|}
\hline \multirow{2}{*}{ Pregunta } & \multicolumn{2}{|c|}{ Nivel de calidad } \\
\cline { 2 - 3 } & Alta & Media \\
\hline P3 (hipótesis) & Indiferente & Indiferente \\
\hline P6 (aleatorización)* & 1 & 1 \\
\hline P8 (amenazas a la validez)** & 0 & Indiferente \\
\hline P9 (significancia estadística) & Indiferente & \\
\hline $\begin{array}{l}* \\
\text { aste valor aparece a 1 porque se asume que en los experimentos controlados se realiza una } \\
* * \text { Un valoatoria } \\
\text { de esta característica es negativa para la calidad. }\end{array}$
\end{tabular}

\subsubsection{Análisis de niveles de calidad para cuasi-experimentos}

Una situación similar se presenta para los cuasi-experimentos. En este caso se busca distinguir entre 3 niveles de calidad. Utilizaremos los 3 niveles de calidad (bajo, medio, alto) ya que, de lo contrario, (por ejemplo, usando sólo los niveles medio y alto) no existirán diferencias en la práctica entre experimentos controlados y cuasi-experimentos, lo cual no sólo va en contra de lo estipulado en las jerarquías de evidencia, sino también contra las creencias generalmente aceptadas en IS.

Siguiendo esta premisa, consideraremos que para que un cuasi-experimento sea de calidad Alta, debe cumplir con la condición de ser controlado; no presentar amenazas a la validez y contar además con la presencia de Hipótesis. De esta manera, utilizaremos un criterio adicional que permite asignar este nivel de calidad de manera más estricta que en el caso de los experimentos de calidad Alta. 
En aquellos casos en los que el cuasi-experimento presente amenazas a la validez y no cuente con hipótesis, independientemente de que sea o no controlado, será considerado de calidad Baja. En todos los otros casos, será asignado un nivel de calidad Media.

En resumen, los elementos de la escala de calidad serán considerados de la siguiente manera:

- Hipótesis (P3): la presencia de este elemento será considerada como discriminante para asignar el nivel de calidad. Nos permitirá de esta manera establecer un criterio adicional para que un cuasiexperimento sea considerado equivalente a un experimento de calidad Alta.

- Amenazas a la validez (P8): la falta de control en un diseño cuasi-experimental es una fuente de amenazas para el estudio. En la medida en la que un diseño cuasi-experimental pueda eliminar posibles amenazas a la validez determina su utilidad. Por esta razón, este criterio es considerado un elemento discriminante en relación a la calidad. De tal manera que sólo aquellos estudios que no presenten amenazas a la validez podrán ser considerados de calidad alta.

- Significancia estadística (P9): en el caso de esta pregunta, se seguirá el mismo razonamiento utilizado para los experimentos; según el cual no se considerará como un criterio discriminante en relación con la calidad.

- Control: según (O. Dieste, Grimán, et al., 2011), el control de las posibles fuentes de variación es una de las maneras de eliminar el error en el análisis estadístico realizado en los estudios empíricos. El control busca hacer el ambiente del estudio tan uniforme y homogéneo como sea posible. La ausencia de control o el uso de un control parcial genera una baja validez interna, una menor manipulación y un incremento en las variables confusoras. En un diseño cuasi-experimental, el investigador carece de control sobre la asignación a las condiciones y/o no manipula la variable causal de interés. La falta de control sobre la asignación de participantes a la variable independiente hace que la validez interna de un cuasi-experimento sea cuestionable. Por lo anterior, usaremos el uso de un grupo control o grupo de comparación en el cuasi-experimento como un criterio discriminante para asignar el nivel de calidad. Esto se traducirá en que ciertos diseños cuasi-experimentales (aquellos que incluyen un grupo de control no-equivalente) obtendrán un mejor nivel de calidad que aquellos que utilizan un diseño de pre-test/post-test de un solo grupo.

Con base en el análisis anterior, las condiciones que determinarán los niveles de calidad Baja- Media Alta para un cuasi-experimento se presentan en la Tabla 8.2.

Tabla 8.2. Relación de preguntas y niveles de calidad de un cuasi-experimento

\begin{tabular}{|l|l|l|l|}
\hline \multirow{2}{*}{ Pregunta } & \multicolumn{3}{|l|}{ Nivel de calidad } \\
\cline { 2 - 4 } & Alta & Media & Baja \\
\hline
\end{tabular}




\begin{tabular}{|c|c|c|c|}
\hline P3 (hipótesis) & 1 & \multirow{5}{*}{ Casos restantes } & 0 \\
\hline P6 (aleatorización)* & 0 & & 0 \\
\hline P8 (amenazas a la validez)** & 0 & & 1 \\
\hline P9 (significancia estadística) & Ind & & 0 \\
\hline Control & 1 & & Ind \\
\hline \multicolumn{4}{|c|}{ * Este valor aparece a 0 porque en los cuasi-experimentos no se realiza una asignación aleatoria } \\
\hline
\end{tabular}

La salida de esta actividad es:

- Formulario de Extracción (actualizado): el nivel de calidad asignado es reflejado en el Formulario de Extracción correspondiente.

- Formato de Evaluación de calidad (actualizado): el nivel de calidad asignado es reflejado en el Formulario de Extracción correspondiente.

\section{Evaluación de la continuidad del proceso}

El proceso se detiene si no se cuenta con al menos dos estudios de calidad media-alta dentro del grupo agregable. 


\section{CAPITULO 9. FASE DE SÍNTESIS DE DATOS}

Según (Churchill, 1979), el análisis de estudios puede ser narrativo, como un resumen estructurado y una discusión de las características y hallazgos de los estudios, o cuantitativos e incluir análisis estadísticos.

En cualquier caso, la fase de Síntesis debería proponer una manera de responder a las siguientes preguntas (Churchill, 1979): (1) ¿cuál es la dirección del efecto?, (2) ¿cuál es el tamaño del efecto?, (3) ¿el efecto es consistente entre los estudios?, y (4) ¿cuál es la fortaleza de la evidencia obtenida acerca del efecto?.

Cada tipo de análisis da soporte a estas interrogantes en mayor o menor medida. Por una parte, la síntesis narrativa utiliza métodos subjetivos en lugar de estadísticos para dar respuesta a las 4 preguntas planteadas, en revisiones donde el meta-análisis no es factible o lo suficientemente sensible. Aún así, en una síntesis narrativa se debe pre-especificar, justificar y seguir sistemáticamente el método utilizado para cada estadio, ya que es posible introducir sesgo si se hace un énfasis inapropiado en los resultados de un estudio en detrimento de los de otro (Churchill, 1979). Para ello, algunas tareas iniciales son clave en el análisis narrativo: resumir los resultados de los estudios, resumir el alcance y tamaño de las asociaciones que estos estudios reportan, y describir las características más importantes de los estudios incluidos (tales como la población dentro de la cual el estudio fue conducido, los métodos de estudio, los detalles de las intervenciones que fueron evaluadas, y sus resultados, si son relevantes).

Por otra parte, el meta-análisis puede responder las 3 primeras de estas preguntas. Para ello, utiliza la combinación estadística de resultados provenientes de dos o más estudios primarios. Es la técnica estadística más comúnmente utilizada, a pesar de tener desventajas. Por ejemplo, el uso del meta-análisis para describir el tamaño del efecto puede no ser significativo si los experimentos son tan diversos que el efecto estimado no puede ser interpretado en algún contexto específico.

Lógicamente, el mero uso de métodos estadísticos no garantiza que los resultados de una revisión sistemática sean válidos en mayor medida de lo que son para un estudio primario, ya que tales métodos, como cualquier herramienta, deben ser utilizados adecuadamente para poder obtener resultados confiables.

El presente capítulo, busca dar soporte a la comprensión, selección y aplicación de las diversas técnicas o métodos de análisis de estudios primarios; a fin de dar respuesta a las preguntas que típicamente se plantea una RS, ajustándose además a las características propias de la IS. Para ello, se promueve en primer lugar, pero no de manera excluyente, el uso de técnicas estadísticas; en la búsqueda de maximizar el aprovechamiento de la base de estudios disponibles, incluso a pesar de los problemas de calidad que puedan presentar. 
De acuerdo a (Churchill, 1979) la aplicación de métodos estadísticos, como el meta-análisis, permite lograr los siguientes objetivos:

- $\quad$ Incrementar el poder estadístico: muchos de los estudios individuales son demasiado pequeños para detectar efectos pequeños o incluso medios, pero cuando varios de ellos son combinados existe una oportunidad mayor de detectar un efecto medio o bajo.

- Mejorar la precisión: la estimación del efecto de un tratamiento puede ser mejorada cuando se basa en más información.

- Responder a preguntas no planteadas por los estudios individuales: los estudios primarios frecuentemente incluyen tipos de sujetos distintos y tratamientos en distintas operacionalizaciones. Estudiar sub-conjuntos de estudios en los cuales las características difieran de los estudios restantes puede permitir la investigación de la consistencia del efecto y, si es relevante, permitir que sean investigadas aquellas razones que producen diferencias en los efectos estimados.

- Promover discusiones: las cuales surgen de estudios aparentemente conflictivos o generar nuevas hipótesis. El análisis estadístico de los resultados permite que los grados de conflicto sean formalmente evaluados y se exploren y cuantifiquen las razones que motivan resultados diferentes.

\subsection{Características específicas de la IS que provocan variaciones en la Fase de Síntesis de Datos}

Como se mencionó en la introducción, existen varias limitaciones descritas en la literatura en relación al uso del meta-análisis (Churchill, 1979; Hardestya \& Beardenb, 2004; Lau, 1998; Palma \& DelgadoRodriguez, 2005).

Una crítica metodológica frecuente al meta-análisis es que "combinan "manzanas con peras"; para referirse a que el meta-análisis intenta la combinación estadística de resultados que provienen de estudios que presentar una gran variabilidad (heterogeneidad) entre ellos. La interpretación del meta-análisis en caso de heterogeneidad o variabilidad entre los estudios es difícil y controvertida.

Por otra parte, meta-análisis de estudios con riesgo de sesgo pueden llevar a conclusiones muy erróneas. Si existe sesgo en todos (o algunos) de los estudios individuales, el meta-análisis simplemente combinará los errores y producirá un resultado "erróneo", el cual se puede interpretar como de mayor credibilidad.

Finalmente, es probable que los meta-análisis en presencia de sesgos graves de publicación

o informe generen un resumen inapropiado. 
A continuación, se analizan estas limitaciones a la luz de las características presentes en la IS, a fin de identificar requerimientos específicos de esta fase:

1. Escasos experimentos y replicaciones.

2. Grupos de experimentos muy heterogéneos.

3. Baja calidad de reporte.

4. Amplio rango de calidad en los experimentos.

5. Diversidad de variables respuesta y métricas.

\subsubsection{ESCASOS EXPERIMENTOS Y REPLICACIONES}

Aunque en algunas áreas de la IS puede localizarse una importante cantidad de experimentos, como se observa en la revisión reportada en (da Silva et al., 2011), ésta no es una situación recurrente. La escasez de estudios primarios en IS es una realidad que ha sido reportada en varias ocasiones (Pickard, Kitchenham, \& Jones, 1998; Shepperd, 2011). Encontrándose además que el tipo de estudio predominante son los estudios observacionales (Shepperd, 2011). Esto es notorio cuando se analizan los resultados de estudios terciarios como el presentado en (Cruzes \& Dyba, 2010), donde se observa que de 31 RS localizadas, sólo 2 de ellas incluyeron únicamente experimentos controlados. El resto de las RS incluyeron tanto estudios empíricos como no empíricos desde una variedad de perspectivas.

Aunque esta característica supone retos para todo el proceso de RS, es la FASE DE SínTESIS la que se ve finalmente impactada, ya que es en ésta donde se deben combinar los resultados de los estudios primarios para obtener nuevas evidencias confiables.

De tal manera, la cantidad de evidencias obtenidas, así como su validez, se ve directamente afectada por la cantidad de experimentos disponibles para soportar la misma (Miller, 2000). Esto es así, debido a que los métodos de meta-análisis son más potentes y exactos cuando mayor es el número de sujetos disponible (Dieste, Fernandez, García-Martinez, \& Juristo, 2012) (Sterne, Gavaghan, \& Egger, 2000).

Esta situación se presenta también en otras disciplinas. En el caso específico de la IS, se observó en el Estado de la Cuestión que no ha sido efectivamente abordada ni mucho menos resuelta aún (Shepperd, 2011).

\subsubsection{GRUPOS DE EXPERIMENTOS MUY HETEROGÉNEOS}


Otra de las características que ha sido referida por los investigadores en esta área es la diversidad entre estudios primarios en IS (Shepperd, 2011).

Si las comparaciones que se realizan en los estudios primarios son diversos, entonces el meta-análisis puede carecer de sentido y enmascarar las diferencias reales en los efectos. Es importante no combinar resultados que sean demasiado diversos. Cuando existen resultados diversos, algunos de los cuales podrían presentar diferentes direcciones (contradictorios), se requiere un análisis adicional de aspectos tales como: el diseño del estudio, su configuración, los tipos de desarrollador, las características del cliente y dominio, los detalles de la aplicación, así como la naturaleza de la cultura organizacional para determinar la consistencia subyacente (Cruzes \& Dyba, 2010).

Al revisar el Estado de la Cuestión en el área de la IS, encontramos sólo un trabajo seminal que aborda el tema de la heterogeneidad de los estudios primarios (Ciolkowski, 2009).

\subsubsection{BAJA CALIDAD DE REPORTE}

Con base en estudios terciarios recientes, se puede afirmar que los métodos y estilos de reporte de muchos de los estudios primarios en IS son tan diversos que hacen difícil la síntesis de los datos (Cruzes \& Dyba, 2010; Imtiaz, Bano, Ikram, \& Niazi, 2013); coincidiendo con los trabajos de (Hayes, 1999; Miller, 2000; Pickard et al., 1998) donde anteriormente identificaron la dificultad para acceder a los datos originales de los estudios primarios u otros detalles experimentales.

Tal situación ha sido referida como una de las causas de que en la mayoría de las RS en IS se observe la ausencia de síntesis (Cruzes \& Dyba, 2010); limitándose a catalogaciones, mapas de estudios o análisis narrativo. Por otra parte, esto lleva a que las preguntas de investigación sean muy generales y no sean construidas realmente con base en los efectos y las intervenciones (Shepperd, 2011). Aunque existen propuestas como la de (Jedlitschka \& Pfahl, 2005), parecen requerirse mejores protocolos de reporte, lo que facilitará el proceso de extracción de la información al mismo tiempo que hace que realizar un metaanálisis sea factible.

\subsubsection{AMPLIO RANGO DE CALIDAD EN LOS EXPERIMENTOS}

El resultado provisto por un meta-análisis puede considerarse tan confiable como los métodos usados para estimar el efecto en cada uno de los estudios primarios. En otras palabras, conducir un meta-análisis no resuelve los problemas inherentes al diseño y ejecución de los estudios primarios que éste incluye. Tampoco corrige los sesgos producto de una publicación selectiva, donde los estudios que reportan efectos dramáticos serán probablemente más identificados, resumidos, y consecuentemente combinados en el meta-análisis, que los estudios que reportan tamaños de efecto más pequeños. 
Algunos estudios, tales como (Palma \& Delgado-Rodriguez, 2005), han concluido que más del $75 \%$ de los meta-análisis no reportan ninguna evaluación empírica del sesgo de publicación; por lo tanto, la frecuencia real de esta forma de sesgo es desconocida.

El proceso de revisión inevitablemente localiza estudios que son diversos en su diseño, calidad metodológica, intervenciones específicas usadas, y tipos de pacientes estudiados. Sin embargo, combinar estudios de calidad pobre con aquellos que fueron conducidos más rigurosamente podría no ser útil y conllevar a malas estimaciones o a un falso sentido de la precisión en cuanto a la misma (Lau, 1998).

Existen en IS realmente pocos trabajos que busquen abordar esta situación. Trabajos como el de (Kitchenham et al., 2012) presentan un paliativo para la extracción de datos. Mientras que otros trabajos, tales como (T. Dybå \& T. Dingsøyr, 2008) (Kitchenham, Brereton, Budgen, Turner, et al., 2009) (Kitchenham et al., 2008; Kitchenham, Pfleeger, Pickard, Jones, Hoaglin, El Emam, et al., 2002), sí se enfocan en la evaluación de la calidad del estudio pero sin mayor especificidad en relación a las características propias de la IS. Esto es abordado más ampliamente en nuestra investigación a través del capítulo de Evaluación de la Calidad.

\subsubsection{DIVERSIDAD DE VARIABLES RESPUESTA Y MÉTRICAS}

Otro de los retos de la Síntesis en la IS se refiere al hecho de que en IS no existe la comprensión de los conceptos más fundamentales; un ejemplo de ello lo encontramos en debates sobre la productividad del software y los factores que influyen en ella (Shepperd, 2011).

Esto ha traído como consecuencia la falta de una terminología estándar en los estudios primarios, misma que ha sido identificada a través de diversas investigaciones (Cruzes \& Dyba, 2010; Imtiaz et al., 2013; Pickard et al., 1998). Como se afirmó anteriormente, ésta es una problemática que afecta todas las fases del proceso.

Por otra parte, debe recordarse que una de las críticas más frecuentes al meta-análisis es precisamente su permisividad para mezclar datos que no son semejantes. Esto ha llevado a afirmar que no es confiable agregar variables respuesta y métricas diferentes.

Esta diversidad es abordada en trabajos como el presentado por (Ciolkowski, 2009) desde el punto de vista de la agregación.

\subsection{Aproximación a la solución}

Luego de revisar las características que suponen una limitación durante la SíNTESIS DE DATOS de experimentos en IS, es necesario dar respuestas que permitan sobrellevar esta problemática en nuestra 
propuesta. A continuación, se describen de manera teórica las soluciones propuestas para posteriormente llevarlas a actividades y heurísticas concretas en la sección 9.3.

1. Escasos experimentos y replicaciones: aunque la experimentación en IS ha cobrado cada vez más interés, existe aún una base experimental que es escasa y diversa, limitando considerablemente el potencial de la agregación. Cualquier solución que busque maximizar la cantidad de estudios que se incluyan en el meta-análisis, debe además lidiar con los problemas de reporte y calidad metodológica; así como la diversidad de variables y métricas. Por ello, la solución propuesta debe considerar estas limitaciones de manera sistémica.

- Una manera de sobrellevar esta problemática, consiste flexibilizar los requerimientos para la agregación, sin perjuicio de su calidad. Por ejemplo, no exigir un número mínimo de experimentos por agregación. Esto se traduce en que, a efectos de generar conclusiones, incluso se permitirá que experimentos singulares contribuyan a una agregación. Por otra parte, se deben usar los métodos de meta-análisis más precisos y poderosos, a fin de aprovechar el mayor número posible de experimentos.

2. Grupos de experimentos muy heterogéneos: como se mencionó anteriormente, se debe lidiar con esta problemática considerando también la situación de escases de experimentos en IS. Esto nos debe llevar a proponer una solución que permita una cierta flexibilidad en cuanto a la participación de un estudio dentro de la agregación, pero que al mismo tiempo permita generar evidencias y conclusiones a partir de grupos de estudios homogéneos. A menudo no tiene sentido combinar todos los estudios incluidos en un único meta-análisis, algunas veces existe una mezcla de comparaciones de tratamientos diferentes con comparadores diferentes, y es posible que cada combinación de ellos se deba considerar por separado. Otra manera de compensar esta característica consiste en la utilización de técnicas estadísticas y no estadísticas (visuales) de estimación de la heterogeneidad.

- Se utilizarán técnicas estadísticas que permitan determinar el grado de homogeneidad de los estudios. Al mismo tiempo, se permitirá que el juicio del revisor sea utilizado a través de la inspección visual de los efectos. De esta manera, se buscará agrupar los estudios más similares y consistentes en sub-grupos donde se puedan establecer evidencias más confiables y se pueda analizar las condiciones de tales evidencias, es decir, se pueda identificar el contexto en el que se generan las mismas. Estas técnicas permitirán también generar conclusiones acerca de los resultados contradictorios dentro de un mismo grupo de interés (GPA), en función de los elementos del contexto.

3. Baja calidad de reporte: esta problemática es transversal a varias de las fases de la RS, teniendo un impacto particular en cada una de ella. Sin embargo, la afectación más importante podemos verla a 
nivel de la síntesis, donde los datos del experimento son requeridos para generar las evidencias. Aunque en otras fases del proceso de RS se han propuesto soluciones que conlleven a poder cumplir el objetivo de la misma, se requiere contar en la agregación con una estrategia que permita incorporar aquellos estudios con un reporte deficientes de los datos referidos a la media, varianza, y número de sujetos

- Una manera de atacar el problema de la ausencia de datos reportados, es la incorporación de técnicas de meta-análisis poco exigentes (p.e. el conteo de votos). Aunque algunos autores sugieren solicitar a los autores aquellos datos requeridos para la agregación, en nuestra propuesta no será incorporado inicialmente, ya que se considera como una solución que puede ser costosa en términos de tiempo. Se evaluará, sin embargo, el impacto de no aplicar esta estrategia. De la misma manera, no se incluirá inicialmente como parte de la propuesta, el cálculo de los parámetros requeridos a partir de otra información descrita en el estudio, ya que se considera que cuando no existe reporte de los parámetros básicos es poco probable que los autores incluyan otros parámetros que puedan servir de referencia. Sin embargo, esta estrategia también se evaluará durante la aplicación del proceso al caso de estudio.

4. Amplio rango de calidad en los experimentos: existen en IS una gran diversidad de temas que han sido ensayados en diferentes estudios. Algunos de esos ensayos fueron conducidos mucho tiempo atrás, cuando la experimentación en esta área era aún muy inmadura. Más recientemente se siguen realizando ensayos sobre tales tópicos y, aunque no podemos afirmar que se conduzcan con total madurez, sí se observan mejoras desde el punto de vista metodológico y de reporte. No obstante, no se cuenta con un volumen de experimentos lo suficientemente grande como para prescindir de aquellos experimentos de menor calidad. Tampoco es posible excluir tales estudios sin incurrir en el sesgo. Es necesario analizar sistemáticamente y con objetividad cada uno de los estudios disponibles antes de decidir sobre su contribución dentro de la RS, más específicamente, en la Síntesis de Datos.

- Debido a que no parece posible establecer criterios rigurosos de I/E de estudios primarios basados en su nivel de calidad, sin afectar otras características de las mencionadas en la sección 9.1 (por ejemplo, la escasez de experimentos), la alternativa que parece ser más adecuada es la de establecer un nivel de calidad mínimo aceptable para cada tipo de estudio a incluir (experimentos y cuasi-experimentos). Adicionalmente, parece posible matizar las evidencias obtenidas asignando un nivel de confianza que considere la calidad promedio del grupo de estudios involucrados en la agregación. 
5. Diversidad de variables respuesta y métricas: tal como se ha mencionado anteriormente, una de las limitaciones que presenta el meta-análisis está referido a la combinación de resultados poco relacionados. Esto ha dado origen a que las evidencias generadas por esta vía no sean consideradas válidas o a que su uso sea realmente cuestionable o limitado. Sin embargo, no podemos olvidar que existen otras características, como la escasez de experimentos y replicaciones, que hacen dudar sobre la conveniencia de descartar experimentos por motivo de su diversidad. Por lo tanto, cualquier solución que se proponga para sobrellevar esta diversidad, debe ir de la

- Una manera de lidiar con esta problemática es incluir métodos no-estadísticos que permitan, una vez obtenidas las evidencias, relacionarlas a un cierto nivel, con base en las definiciones establecidas inicialmente. Por otra parte, se hace necesario mantener una suerte de diccionario que permita definir y uniformizar los conceptos asociados al estudio.

\subsection{Actividades propuestas para la Fase de Síntesis de Datos}

El propósito de esta fase es obtener nuevas evidencias a partir de los grupos de experimentos potencialmente agregables (GPA) obtenidos como resultado de la fase de EXTRACCIÓN DE DATOS. Se han incorporado a esta fase las propuestas realizadas en la sección 9.2 para resolver los retos que plantea la IS. Por lo tanto, la fase que se propone en este trabajo se basa en los siguientes principios:

- La Síntesis se concentra en aquellos GPAs de interés para el revisor que han sido identificados en la fase de EXTRACCIÓN DE DATOS. Estos GPAs fueron identificados al separar los estudios primarios según las variables del contexto, agrupándolos además por métrica.

- Uso de una variedad de métodos de síntesis cuantitativos (específicamente a través de las técnicas de meta-análisis).

- Selección de la técnica de meta-análisis más adecuada para el GPA que se está agregando, con base en los datos disponibles, los parámetros del experimento, y el efecto.

- Combinación de grupos homogéneos de experimentos. Esta homogeneidad se basa en: la tarea experimental, el tipo de sujeto, la métrica, los tratamientos, y el estimador $Q$.

- Agrupamiento de evidencias por diferentes criterios (niveles, métrica y variable respuesta. 
La entrada a esta fase la constituyen los GPAs obtenidos en la fase de EXTRACCIÓN DE DATOS, junto con los resúmenes de datos cuantitativos, experimentales y observacionales que fueron también recolectados en esa fase. Como resultado final, se obtendrá un resumen de las evidencias obtenidas durante esta fase, agrupadas de acuerdo a diversos criterios (tratamiento, métrica, variable respuesta, tarea, y tipo de sujeto), así como un Listado de potenciales hipótesis de investigación para futuros experimentos. En la figura 9.1, se muestran las actividades propuestas para la fase de SíNTESIS DE DATOS:

- En primer lugar, se seleccionan los GPA relevantes entre aquellos identificados en la fase de EXTRACCIÓN DE DATOS.

- Para cada uno de los GPAs seleccionados, se realiza la agregación aplicando técnicas de meta-análisis. Para ello deberá seleccionarse el o los métodos más adecuado(s) según los datos disponibles y los parámetros estadísticos del grupo de experimentos seleccionado (por ejemplo, el número de sujetos, el tamaño del efecto, entre otros).

- Los resultados de la aplicación de un método son registrados en el formulario S01-Plantilla de Agregación. Éstos son tomados como aceptables siempre que el grupo de experimentos sea homogéneo. Cuando un grupo no es homogéneo, es dividido iterativamente en subgrupos de experimentos cada vez más parecidos, con la intención de lograr homogeneidad. Una vez que se cuenta con un grupo homogéneo, se establece la evidencia y las condiciones para las cuales ésta es considerada válida.

- Una vez obtenidas las agregaciones es necesario consolidar las mismas y asignarles un nivel de confianza que dependerá de ciertos criterios objetivos asociados al método utilizado; así como de la calidad de los estudios. Al mismo tiempo, se recogen nuevas Hipótesis de investigación que pudieran surgir al analizar las evidencias; por ejemplo, pueden plantearse interrogantes (hipótesis) de investigación al tratar de explicar los factores que hacen que un grupo de experimentos sea heterogéneo, o al establecer las condiciones para las cuales se puede afirmar una evidencia. Para ello se utilizan los formularios SO2-Listado de evidencias y S03-Listado de Hipótesis.

- En caso de que no se obtengan grupos homogéneos de experimentos, la fase se dará por concluida. De la misma manera, se detiene la Síntesis cuando los grupos homogéneos obtenidos contengan un único experimento o estudio empírico.

- Finalmente, las evidencias de todos los GPA seleccionados son resumidas de acuerdo a un conjunto de heurísticas, buscando reunir todas las posibles conclusiones respecto a la tecnología de interés. Para esta actividad se utiliza el formulario S04- Resumen de evidencias. Esto puede dar pie a una labor de generalización que, aunque fuera del alcance 
de esta propuesta, es una actividad recomendable para generar nuevo conocimiento útil a la IS.

- Este proceso puede repetirse para todos aquellos GPA que sean de interés para el equipo de revisores.

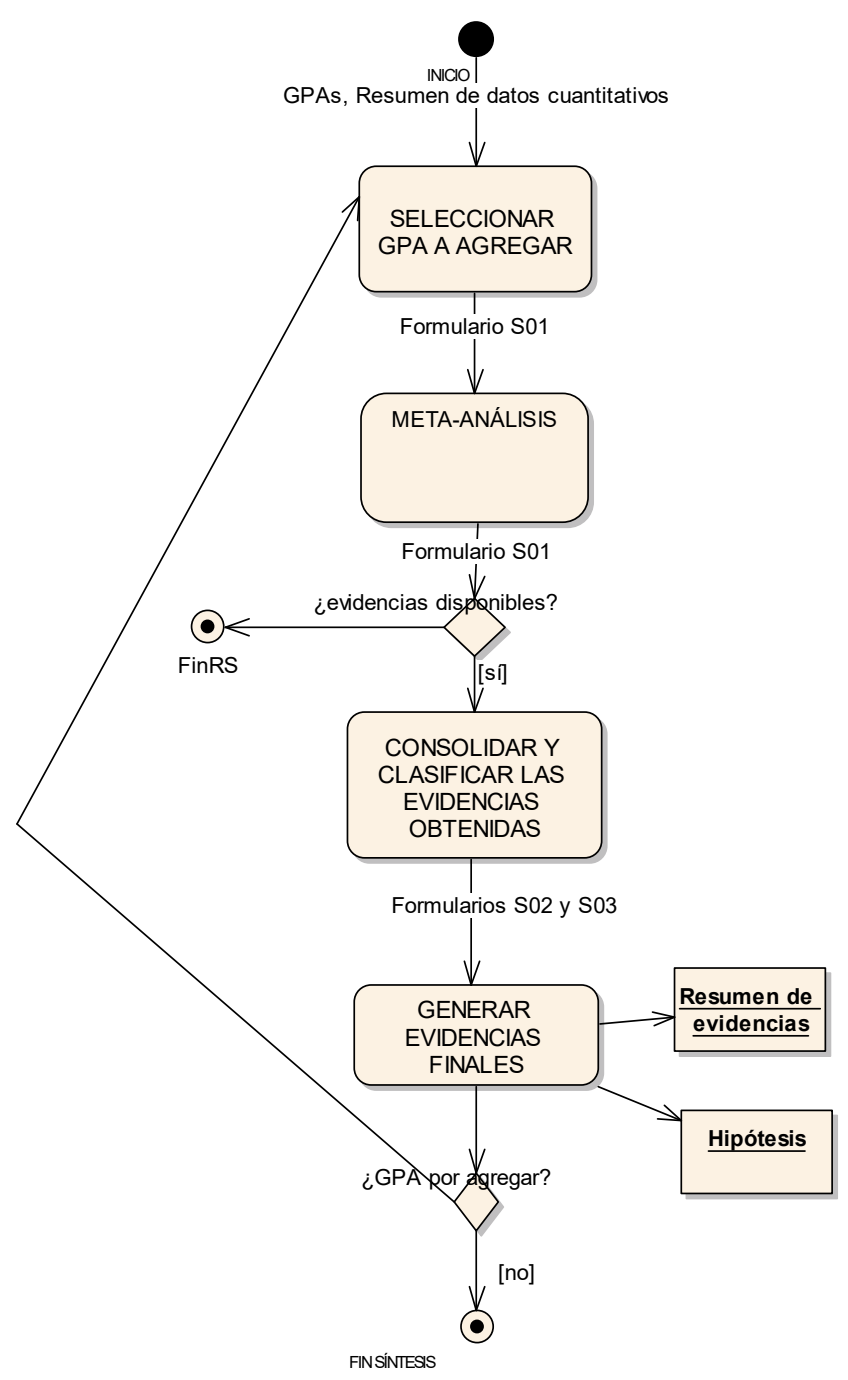

Figura 9.1. Actividades de la Fase de Síntesis de datos

Nótese que durante el desarrollo de las actividades relacionadas directamente con la agregación del GPA (actividad 9.3.1. Meta-análisis), se utiliza el formulario S01 - Plantilla de agregación que, como se muestra en la Figura 9.2, recoge la siguiente información:

- SECCIÓN DE IDENTIFICACIÓN: incluye información básica sobre el grupo y los tratamientos/métricas ensayados en el mismo. 
- SECCIÓN 1 - DATOS DEL ESTUDIO: está sección recoge los datos cuantitativos de los experimentos del GPA (o sub-grupo, en caso de que se haya realizado una descomposición) y está conformada de la siguiente manera:

- Factores secundarios: se refiere a factores adicionales ensayados en los estudios. Se indican con el símbolo $\mathrm{X}$ aquellos estudios que incluyen tales factores, los mismos fueron identificados en la fase de EXTRACCIÓN DE DATOS.

- Resultados experimentales: se refiere a las medias, varianzas y número de sujetos por cada tratamiento del factor principal.

- SeCCIÓn 2 - Forest Plot: esta sección presenta el resultado de la agregación de manera gráfica. Se propone el uso del forest plot por ser el utilizado por las técnicas más frecuentes de meta-análisis; pudiendo utilizarse en general para todas ellas.

- Sección 3 - Homogeneidad: en esta sección se indica el cálculo de los parámetros de homgeneidad Q e $I^{2}$.

- Sección 4 - Efecto global: se utiliza para indicar el efecto encontrado en la agregación; en términos de la comparación entre ambos tratamientos ( $A$ mejor que $B, B$ mejor que $A, A$ igual a B).

- SECCIÓN 5 - INTERPRETACIÓN DEL EFECTO:

- SECCIÓN 6 - FACTORES ENSAYAdOS PARA LOS QUE EXISTE EVIDENCIA:

- SECCIÓN 7 - TEXTO DE LA EVIDENCIA: en esta sección se expresa de manera narrativa el resultado obtenido de la agregación; a fin de que la evidencia pueda ser luego consolidada con otras evidencias dentro de la RS. 


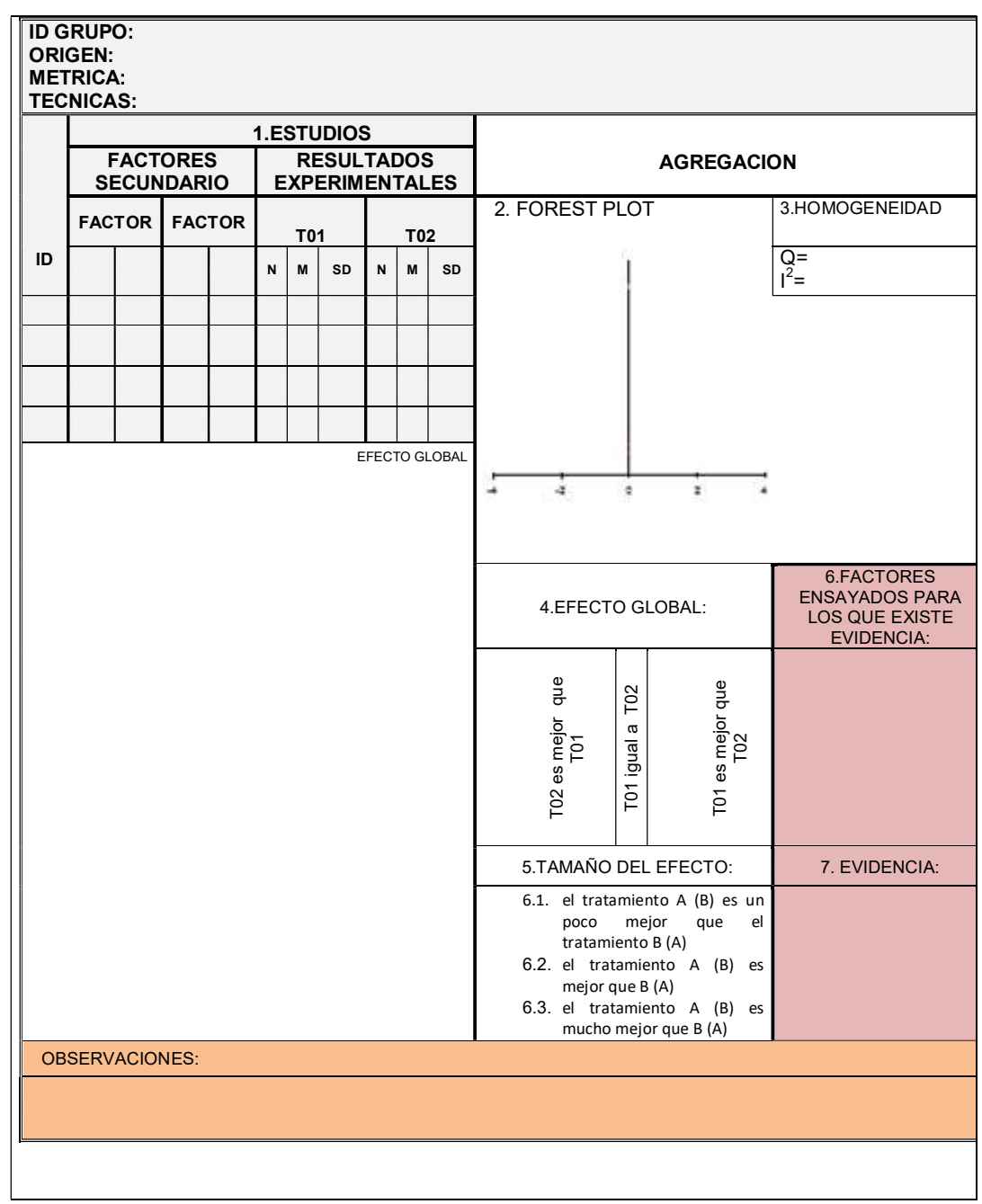

Figura 9.2. Plantilla para la agregación del grupo de estudios

\subsubsection{SELECCIONAR GRUPO DE ESTUDIOS A AGREGAR}

El propósito de esta actividad es escoger un GPA entre los identificados en la fase de EXTRACCIÓN DE DATOS, incluyendo los resultados obtenidos para cada nivel del factor principal ( $y$, opcionalmente, otros factores) ensayados en los experimentos del grupo, a fin de facilitar su agregación a través del meta-análisis.

La selección del grupo a agregar estará sujeta al propósito del revisor. Las tareas asociadas a esta actividad son descritas a continuación. 


\subsubsection{Seleccionar GPA}

sta tarea es la responsable de escoger un GPA que se corresponda con el propósito del revisor. Para realizar esta selección, se sugiere usar como criterios la métrica y los tratamientos ensayados por los experimentos del grupo.

Nótese que en la actividad ESTABLECER GRUPOS POTENCIALMENTE AGREGABLES de la fase de EXTRACCIÓN DE DATOS, se han configurado los GPAs de manera que se aprecien tanto los experimentos que han sido ensayados en ambientes industriales (con sujetos profesionales) como los experimentos conducidos con estudiantes.

Una vez seleccionado un GPA a agregar, iniciar el vaciado de los datos de identificación del grupo en el formulario S01-PLANTILLA DE AGREGACIÓN:

- $\quad$ Id. grupo el grupo al que se refiere la agregación.

- $\quad$ Origen del grupo o grupo del cual proviene.

- $\quad$ Métrica para la cual se realiza la agregación

- $\quad$ Técnicas o tratamientos que se comparan en el estudio.

\section{Recomendaciones:}

- Agregar por separado los experimentos conducidos con profesionales y estudiantes. La razón para ello es que, para obtener resultados válidos, el meta-análisis debería ser aplicado a un grupo de experimentos con características (diseño del estudio y contexto) lo más similares posible. De esta manera se busca garantizar que las diferencias entre los resultados individuales de los experimentos que participan en el meta-análisis obedezcan exclusivamente al azar y no a la presencia de Heterogeneidad.

- Los resultados obtenidos de la agregación de experimentos en la industria y en la academia pueden ser contrastados durante la actividad 9.3.4.3_RESUMEN DE EVIDENCIAS.

El ejemplo 9.1 ilustra la aplicación de esta tarea al caso de estudio.

Ejemplo 9.1 - Caso de estudio: Inspección de Software

Analizando los GPAs identificados en la fase de EXTRACCIÓN DE DATOS del caso de estudio, se observa que existen 2 GPAs (A04 y A10) que comparan las técnicas T02, T03 y T04, para las métricas M04 y M28. El primero de ellos (A04) está enfocado en la tarea de Requisitos, mientras que A10 está enfocado en la tarea de Diseño. 
En este caso resulta prometedor el agregar ambos GPAs a fin de obtener evidencias sobre los tratamientos y métricas ensayados, en dos tareas diferentes del proceso de desarrollo.

\subsubsection{Identificar datos cuantitativos del GPA}

Una vez seleccionado un GPA, es necesario contar con los datos cuantitativos de los experimentos incluidos en el mismo. El objetivo de esta tarea es registrar en la Plantilla de agregación la media, la desviación típica, y el número de sujetos para cada uno de los estudios incluidos en el grupo. Esto se realiza a partir del formulario EO4 - Resumen de datos cuantitativos.

Los resultados en el formulario indicado se encuentran separados según la combinación de niveles del factor principal estudiado en el experimento. Sin embargo, como se explicó en la fase de EXTRACCIÓN DE DATOS, los resultados de un experimento podrían estar siendo afectados por un factor distinto al principal (que Ilamaremos Adicional o Secundario). Por ejemplo, en el caso de Inspección de software un factor adicional podría ser el Artefacto que es inspeccionado. Esto debe ser tomado en cuenta en esta tarea ya que cuando se genere una evidencia, producto de la agregación de un grupo de estudios, deberán documentarse las condiciones (factores adicionales) que parezcan influir en ella. Esto permitirá hacer interpretaciones y conclusiones posteriormente.

Los pasos a seguir en esta tarea son los siguientes:

1. Vaciar los datos en la Sección 1 de la Plantilla de Agregación, incluyendo no sólo los datos cuantitativos (media, desviación típica y número de sujetos), sino también los factores secundarios o adicionales que han sido ensayados en el estudio (p.e. Programa, Especificación, Rol, etc.). Indicar la presencia de éstos con una ' $X$ '.

2. Descomponer cada experimento de acuerdo a los factores adicionales ensayados. Si un experimento ha ensayado factores adicionales que resultaron tener una interacción con el factor principal (y por lo tanto los resultados obtenidos han sido diferentes cuando se han ensayado los distintos niveles del factor adicional y el factor principal), el estudio original debe ser descompuesto en tantos sub-estudios diferentes como niveles del factor adicional hayan sido ensayados. De tal manera, cada uno de los sub-estudios resultantes representa una combinación particular de niveles del factor principal y de los factores adicionales. Así, cada uno de los subestudios será tratado de manera independiente.

3. Resaltar con subrayado $(\underline{X})$ los experimentos que han probado experimentalmente la interacción del factor principal y los factores adicionales. Nótese que durante la EXTRACCIÓN DE DATOS se identificaron los factores adicionales del GPA, de manera general, pero no todos los experimentos ensayaron todos los factores adicionales. Por lo tanto, se ha intentado deducir el 
valor para aquellos experimentos en los que, no habiendo ensayado explícitamente el factor adicional, la variable estaba presente. Esto es posible ya que los factores adicionales típicamente se relacionan con la tarea experimental. Por lo tanto, durante la presente fase es conveniente destacar aquellos experimentos en los que se probó estadísticamente la interacción del factor adicional con el factor principal.

En el ejemplo 9.2 se ilustra la realización de esta tarea.

EJEMPLO 9.2 - Caso de estudio: Inspección de software

De los resultados de la fase de EXTRACCIÓN DE DATOS, se elige el GPA identificado como A01, el cual reúne cinco estudios (E01, E02, E05, E06 y E08), observando la siguiente información:

- Los estudios han ensayado las técnicas T01 y T02 para evaluar la métrica M04.

- Se identificaron 3 factores adicionales: Especificación, Rol y Ronda.

- Los estudios E01, E02, E05 y E06 han ensayado las técnicas T01 y T02, junto con el factor adicional Especificación con dos niveles (CRUISE y WLMS).

- E08 ha comparado las mismas técnicas, pero utilizando la especificación ER, aunque sin analizarlo como un factor adicional.

- Así mismo, E08 se ha llevado a cabo utilizando roles y sin el uso de roles.

Al separar aquellos experimentos que presentan factores adicionales, en el resumen de este grupo se obtienen ocho experimentos independientes que presentan los datos y características experimentales descritas en la Tabla 9.1. Por lo tanto, hay tres factores adicionales, pero no todos los experimentos han ensayado tales factores. Para E01, E02 y E06, se ha deducido el valor para el factor adicional Rol; mientras que para E08 se ha hecho lo propio para asignar el valor del factor adicional Especificación. También se ha derivado el valor de Ronda. 
Tabla 9.1. Resumen de Datos cuantitativos del grupo A01

\begin{tabular}{|c|c|c|c|c|c|c|c|c|c|}
\hline \multirow[b]{3}{*}{ Est. } & \multirow{2}{*}{\multicolumn{3}{|c|}{ OTROS FACTORES }} & \multicolumn{6}{|c|}{ FACTOR PRINCIPAL } \\
\hline & & & & \multicolumn{3}{|c|}{ T01 } & \multicolumn{3}{|c|}{$\mathrm{TO2}$} \\
\hline & $\begin{array}{l}\text { Espe } \\
\text { c. }\end{array}$ & ol & $\begin{array}{l}\text { Ron } \\
\text { da }\end{array}$ & $\mathbf{N}$ & M & SD & $\mathbf{N}$ & M & SD \\
\hline EO & CRUI & $\mathrm{N}$ & & & 0,4 & 0,0 & & 0,4 & \\
\hline $1 a$ & SE & $\mathrm{R}$ & 1 & 6 & 3 & 8 & 4 & 2 & 0,12 \\
\hline & $W L$ & $\mathrm{~N}$ & & & 0,3 & 0,0 & & 0,2 & \\
\hline $1 b$ & MS & $\mathrm{R}$ & 1 & 7 & 1 & 9 & 4 & 4 & 0,05 \\
\hline & CRUI & $\mathrm{N}$ & & & 0,2 & & & 0,2 & \\
\hline $2 a$ & SE & $\mathrm{R}$ & 1 & 3 & 3 & NP & 3 & 1 & NP \\
\hline EO & WL & $N$ & & & 0,2 & & & 0,3 & \\
\hline $2 b$ & MS & $\mathrm{R}$ & 1 & 3 & 7 & NP & 3 & 3 & NP \\
\hline E0 & CRUI & $\mathrm{N}$ & & & 0,3 & & & 0,2 & \\
\hline $6 a$ & SE & $\mathrm{R}$ & 1 & 5 & 2 & 0,1 & 1 & 5 & 0,08 \\
\hline EO & WL & $\mathrm{N}$ & & & 0,4 & 0,0 & & 0,2 & \\
\hline
\end{tabular}

En la tabla 9.1 cada estudio presenta un conjunto de condiciones determinadas por los niveles del factor principal y de los factores adicionales (identificados en la tabla 9.1 como 'Otros factores'). Nótese que de este grupo de estudios, seis reportan tanto las medias como las varianzas y el número de sujetos; mientras que dos de ellos (E02a y E02b) sólo reportan las medias y el número de sujetos, no reportando la varianza. Estos datos serán determinantes para la próxima actividad.

En la figura 9.3 se presenta el vaciado de los datos y condiciones de los experimentos del grupo A01 en la sección 1 de la Plantilla de agregación. Se observa, por ejemplo, que el estudio E01a ha utilizado la Especificación CRUISE, sin incorporar Roles y en una sola Ronda; mientras que el estudio E01b ha utilizado la Especificación WLMS. Nótese también que se ha utilizado una $\underline{X}$ como indicativo de que los autores reportaron que la interacción del factor principal con el factor adicional Especificación fue estadísticamente significativa.

\begin{tabular}{|c|c|c|c|c|c|c|c|c|c|c|c|c|c|}
\hline \multirow{4}{*}{$D^{\text {I }}$} & \multicolumn{13}{|c|}{ 1.ESTUDIOS } \\
\hline & \multicolumn{7}{|c|}{ CONDICIONES } & \multicolumn{6}{|c|}{ RESULTADOS EXPERIMENTALES } \\
\hline & \multicolumn{3}{|c|}{ ESPECIFICACION } & \multicolumn{2}{|c|}{ ROL } & \multicolumn{2}{|c|}{ RONDA } & \multicolumn{3}{|c|}{ T01 } & \multicolumn{3}{|c|}{ T02 } \\
\hline & CRUISE & WLMS & ER & $C R$ & NR & R1 & R2 & $\mathbf{N}$ & M & SD & $\mathbf{N}$ & M & SD \\
\hline E01a & $\underline{x}$ & & & & x & $x$ & & 6 & 0,43 & 0,08 & 4 & 0,42 & 0,12 \\
\hline E01b & & $\underline{x}$ & & & $x$ & $x$ & & 7 & 0,31 & 0,09 & 4 & 0,24 & 0,05 \\
\hline E06a & $\underline{x}$ & & & & $x$ & $x$ & & 5 & 0,32 & 0,1 & 1 & 0,25 & 0,08 \\
\hline E06b & & $\underline{x}$ & & & x & $x$ & & 5 & 0,43 & 0,09 & 2 & 0,29 & 0 \\
\hline E08a & & & $x$ & & $x$ & $x$ & & 24 & 0,7 & 0,15 & 25 & 0,58 & 0,27 \\
\hline 08b & & & $x$ & $x$ & & $x$ & & $5^{2}$ & 0,57 & 0,16 & 25 & 0,8 & 0,16 \\
\hline
\end{tabular}

Figura 9.3. Datos y condiciones de los estudios de A01 en la Plantilla de agregación 


\subsubsection{META- ANÁLISIS}

El objetivo de esta actividad es aplicar la(s) técnica(s) de meta-análisis más adecuada(s) para los experimentos del GPA seleccionado en la actividad anterior para obtener nuevas evidencias. Incluye las siguientes tareas:

1. Seleccionar técnica de meta-análisis

2. Realizar meta-análisis

3. Analizar la consistencia de los efectos

4. Descomponer en sub-grupos

5. Definir las condiciones de la evidencia

En general, estas tareas responden a varias de las premisas descritas en la sección 9.2. En primer lugar, buscan aprovechar la mayor cantidad posible de experimentos; evitando que los revisores se vean obligados a excluir experimentos, por ejemplo, por reportar parcialmente los datos cuantitativos (o no reportarlos).

Ésta ha sido una solución propuesta en otras áreas en trabajos como (Gurevitch \& Hedges, 1999). Es por ello que la solución propuesta en esta investigación incluye el uso de métodos más flexibles que puedan ser aplicados con los datos disponibles en los estudios a agregar.

Los métodos a seleccionar incluyen:

- $\quad$ Diferencia de medias ponderadas (DMP) de efectos fijos y aleatorios,

- $\quad$ Radio de respuesta paramétrico (RR-P) y no paramétrico (RR-NP) logarítmicos, y

- $\quad$ Conteo de Votos Estadístico (CVE).

Para la selección del método más adecuado será necesario aplicar criterios asociados con:

- Datos disponibles en los estudios: se refiere específicamente a la (media, desviación típica y número de sujetos, ya que tales datos son requeridos para la aplicación de un conjunto de métodos de metaanálisis.

- Desempeño del método: esto incluye características tales como la tasa de rechazo, el poder empírico y la exactitud de los métodos de meta-análisis, ya que éstas han demostrado no proporcionar 
resultados muy precisos cuando son aplicadas en ciertas situaciones; por ejemplo, en casos de muestras pequeñas (pocos experimentos y sujetos) (L. V. Hedges, Gurevitch, \& Curtis, 1999).

Otra premisa de esta actividad es que los experimentos que se agreguen deben ser homogéneos a fin de evitar un sesgo de análisis e interpretación en la RS (Cooper, 1982). Para lograr la homogeneidad necesaria se propone el análisis de la consistencia de los efectos junto con un proceso iterativo de descomposición de grupos que deberá repetirse hasta que se logren alcanzar las condiciones de homogeneidad o consistencia de estudios necesarias para generar una evidencia válida. Una vez que el conjunto de estudios es homogéneo, se detiene la descomposición, se establece la evidencia derivada de los efectos combinados y las condiciones para las cuales tal evidencia puede ser afirmada.

A continuación, se describen en detalle las tareas listadas.

\subsubsection{Seleccionar el método de meta-análisis}

En esta tarea se busca seleccionar el método de meta-análisis más adecuado para agregar un GPA. Para ello, parece lógico considerar las características de los estudios que lo componen y el desempeño de los métodos bajo tales características.

Como se describió anteriormente, es frecuente que los experimentos en IS no reporten algunos datos cuantitativos (especialmente las medias y las desviaciones típicas). Esto es una limitante para aplicar algunos métodos de meta-análisis que requieren tales datos para el cálculo del estimador. Por otra parte, solicitar los datos originales a los experimentadores puede ser una solución lenta y con pocas garantías de éxito, especialmente en aquellos casos en los que tratamos con estudios muy antiguos. Es por ello que la solución propuesta en esta investigación debe incluir el uso de métodos más flexibles que puedan ser aplicados con los datos que suelen estar disponibles en los estudios a agregar.

Por otra parte, no todas las técnicas de meta-análisis presentan la misma capacidad para estimar el efecto en condiciones de pocos experimentos y pocos sujetos; haciéndose necesario elegir aquella que proporcione los mejores resultados en tales condiciones. Por ello, se propone utilizar un criterio adicional al de la disponibilidad de datos, referente al desempeño de la técnica.

Existen diferentes formas de hacer tal análisis y selección; sin embargo, existen pocos referentes en el área de IS (Dieste et al., 2012) (Lajeunesse \& Forbes, 2003) (Friedrich, Adhikari, \& Beyene, 2008) (Dieste, Fernández, Garcíla, \& Juristo, 2011) (L. Hedges, 1982). En esta tesis se ha decidido utilizar los criterios de 
comparación de métodos de meta-análisis propuestos por (Dieste et al., 2012), basados en el poder estadístico (PE) y la exactitud (EX).

El trabajo de (Dieste et al., 2012) es parte de una investigación complementaria a la presente investigación, como se indica en (Grimán, 2007). Aunque tal investigación plantea un análisis exhaustivo de los métodos de meta-análisis, la tarea descrita en esta sección se limitará al procedimiento propuesto por los autores para la selección del método más adecuado a ciertas características muestrales. Para cada GPA, el procedimiento a seguir es el siguiente:

a. Clasificar los estudios

Como se describió anteriormente, es frecuente que los experimentos en IS no reporten algunos datos cuantitativos (especialmente las medias y las desviaciones típicas). Esto es una limitante para aplicar algunas técnicas de meta-análisis que requieren tales datos para el cálculo del estimador.

Por otra parte, solicitar los datos originales a los experimentadores puede ser una solución lenta y con pocas garantías de éxito, especialmente en aquellos casos en los que tratamos con estudios muy antiguos.

Por ello, en esta tarea se analizará el criterio relacionado con la disponibilidad de datos de los estudios y se clasificarán los mismos con base en esto. Partiremos de conocer los datos requeridos por cada técnica de meta-análisis para el cálculo del efecto, tal como se muestra en la tabla 9.2.

Tabla 9.2. Resumen de datos requeridos por cada técnica de meta-análisis

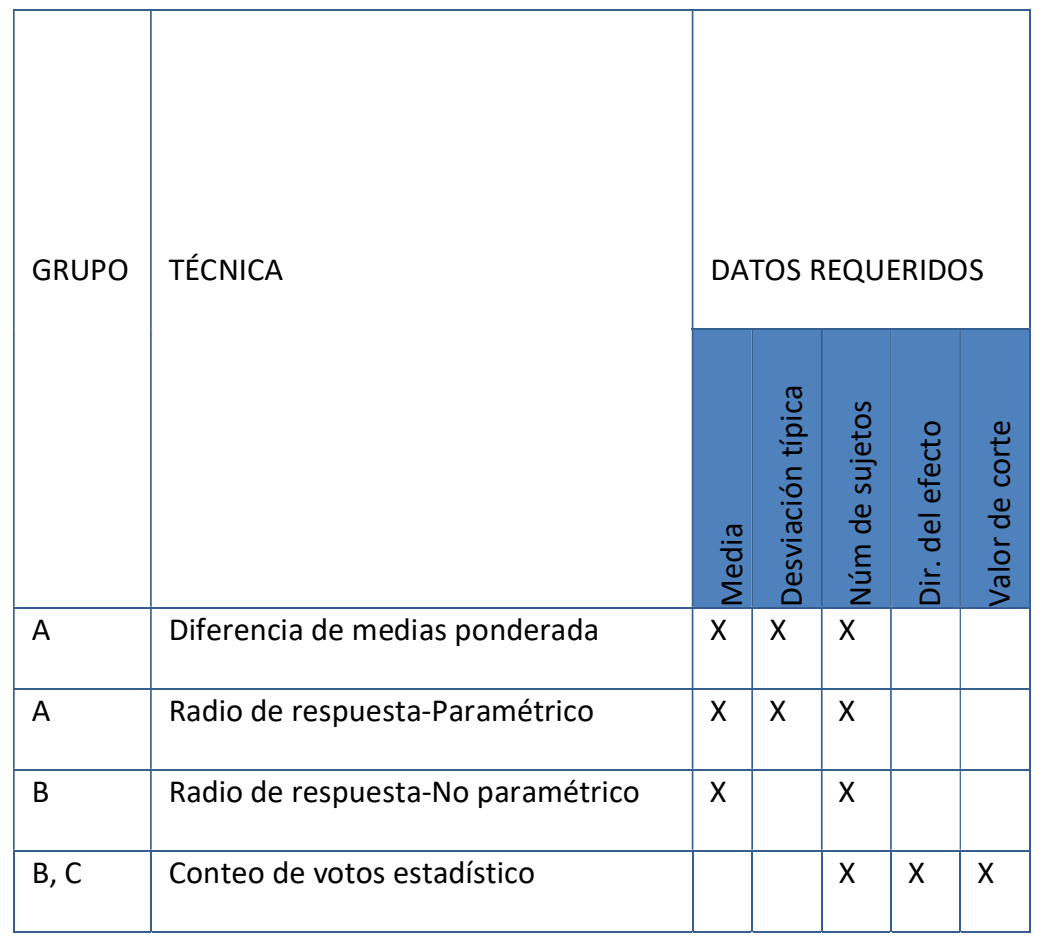


Con base en la tabla 9.2, se deduce que, cuando se cuente con todos los datos cuantitativos, todas las técnicas de meta-análisis podrán ser aplicadas; sin embargo, la aplicabilidad de las mismas se ve reducida a medida que se disponen de datos parciales de la siguiente manera:

- Cuando se disponga de Medias, Desviaciones típicas y Número de sujetos: se podrán aplicar todos los métodos. Los estudios que reporten estos parámetros serán clasificados como Grupo A.

- Cuando se disponga únicamente de Medias y Número de sujetos: sólo podrán aplicarse las técnicas RR-NP y CVE. Los estudios que sólo reporten estos parámetros serán clasificados como Grupo B.

- Cuando se disponga únicamente de la Dirección del efecto y el Número de sujetos: sólo podrá aplicarse la técnica de CVE. Los estudios con esta característica harán parte del Grupo C.

a. Estimar el tamaño del efecto

Calcular el tamaño del efecto es necesario para conocer el desempeño de un método con base en la investigación descrita en (Dieste et al., 2012), ya que se trata de uno de los parámetros de entrada de la simulación Monte Carlo utilizada en dicha investigación. El cálculo del tamaño el efecto puede realizarse de 4 maneras alternativas:

1. Calcular el efecto global usando DMP y los experimentos del Grupo A: esta estrategia puede ser utilizada de manera óptima cuando el grupo A contenga dos o más experimentos con tamaños de muestra de 8 o más sujetos por grupo.

2. Escoger el experimento con el mayor tamaño de muestra como el tamaño de efecto de la población: Si éste corresponde al Grupo B, utilizar el experimento con el tamaño de muestra siguiente.

3. Calcular el tamaño del efecto utilizando RR-np con el Grupo B y una estimación de la varianza poblacional:

b. Determinar la Varianza global del grupo de estudios:

Será calculada tomando los experimentos del grupo A y calculando el promedio de los cocientes de la desviación típica (SD) entre la media (M) para todos los experimentos de ese tratamiento (N), como se muestra en la fórmula (1). 


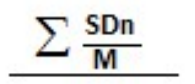

N
(1)

La varianza será categorizada de la siguiente manera (Dieste et al., 2012):

- $\quad$ Baja: menor a $25 \%$ de la media.

- $\quad$ Media: 25 - 55\% de la media.

- $\quad$ Alta: mayor al 55\% de la media.

Cuando la varianza de la muestra no pueda ser calculada, se sugiere utilizar la varianza media del dominio (Cohen, 1977) que, según se afirma en (Dybå, Kampenes, \& Sjoberg, 2006) en el caso de la IS puede considerarse media.

Resumir los parámetros para las agregaciones a través de las diferentes técnicas; considerando aquellos estudios que pueden ser agregados por cada técnica según los datos disponibles, tal como se describió anteriormente. Presentar como resultado un resumen con el formato de la Tabla 9.3:

Tabla 9.3. Resumen de parámetros para las agregaciones

\begin{tabular}{|c|c|c|}
\hline Técnica & No. de experimentos & No. de Sujetos \\
\hline DMP & & \\
\hline RR-P & & \\
\hline RR-NP & & \\
\hline CVE & & \\
\hline
\end{tabular}

\section{c. Estimar el nivel de heterogeneidad}

\section{d. Chequear el desempeño del método}

Con los parámetros anteriores (Varianza, Tamaño del efecto, Número de experimentos y Número de sujetos por experimento) identificar el resultado de exactitud (EX) y poder estadístico (PE) en las tablas obtenidas de (Dieste et al., 2012).

e. Seleccionar el método más adecuado con base en los resultados del análisis anterior); en el cual se pueden obtener varios tipos de resultados:

- Un único método es recomendado por ambos criterios (EX y PE): En este caso se selecciona el método como el más adecuado. 
- Más de un método es recomendado por ambos criterios (EX y PE): se sugiere basar la selección en las comparaciones detalladas presentadas en (Dieste, Fernandez, GarcíaMartinez, \& Juristo, 2011) y seleccionar el método con el mayor valor de EX/PE.

- Si los métodos tienen EX y PE similares, aplicar cualquiera de ellos.

- Si uno tiene mayor EX y el(los) otro(s) presenta mayor PE: escoger aquel que tenga el mayor $\mathrm{PE}$, debido a que esta característica es más relevante en presencia de pocos experimentos y sujetos.

- Ningún método es recomendado por ambas características (EX y PE): proceder como en el caso anterior.

En el ejemplo 9.3 se ilustra la aplicación de esta tarea.

EJEMPLO 9.3 - Caso de estudio: Inspección de software

El GPA identificado como A01, contiene 8 experimentos; sin embargo, sólo 6 de ellos reportan la desviación típica, mientras que los otros 2 sólo reportan la media y el número de sujetos por tratamiento. Por lo tanto, a un sub-conjunto de estudios de este grupo (conteniendo 6 estudios) podría aplicárseles todos los métodos de agregación, mientras que al conjunto completo que contiene 8 estudios, sólo pueden aplicarse los métodos RR-NP y CVE:

- Conjunto A01: Agregar E01a, E01b, E06a, E06b, E08a y E08b, utilizando todas las técnicas (incluyendo DMP y RR_p).

- Conjunto A01': Agregar E01a, E01b, E02a, E02b, E06a, E06b, E08a y E08b, utilzando RR_np y CVE.

\subsubsection{Realizar meta-análisis}

Una vez seleccionado el método de meta-análisis más prometedor, esta tarea tiene como propósito aplicar el método al conjunto de estudios incluidos en el GPA, y registrar los resultados. Para lograr este objetivo se propone:

1. Aplicar la(s) fórmula(s) descrita(s) en el CAṔ́tulo 3 - ESTADO DE LA CUESTIÓN para el método seleccionado.

2. Se sugiere utilizar un gráfico del tipo Forest Plot, incluso en el caso del CVE, no siendo realmente necesario. 
3. Para la interpretación del resultado, utilizar la información descrita en el Apéndice D.

4. El registro de la agregación realizada en esta tarea se hace utilizando la sección $\mathbf{2}$ de la Plantilla de Agregación, incluyendo tanto el cálculo de los efectos individuales como el valor del efecto global.

5. A fin de re-comprobar que la información proporcionada por el método de agregación se corresponde con la reportada en el estudio, en aquellos casos en los cuales el efecto haya sido reportado como significativo por los experimentadores se incluirá una marca (utilizando el símbolo *) junto al valor del efecto en la gráfica. Esta marca se utilizará también más adelante con otros propósitos.

El ejemplo 9.4 muestra la aplicación del método seleccionado en el paso anterior para el grupo A01.

EJEMPLO 9.4 - Caso de estudio: Inspección de software

En el paso 3.3.2.1 - Seleccionar técnica de meta-análisis, se seleccionó el método DMP para la agregación del grupo A01; con la cual se obtiene un efecto global $(d)$ igual a -0.13 .

Este resultado es obtenido al calcular los siguientes estimadores:

$d=J(N-2) \frac{Y^{E}-Y^{C}}{S_{P}}$

donde:

$d$ es el tamaño del efecto

$J(N-2)=$ es el factor de corrección, calculado como:

$J=1-\frac{3}{4 N-9}$

Y es la media de los grupos experimental (E) y control (C)

$S p$ es la desviación típica combinada de ambos grupos, calculada de la siguiente manera:

$S_{P}=\sqrt{\frac{\left(n^{E}-1\right)\left(s^{E}\right)^{2}+\left(n^{C}-1\right)\left(s^{C}\right)^{2}}{n^{E}+n^{C}-2}}$

$s$ es la desviación típica de los grupos experimental (E) y control (C)

$n$ es el número de sujetos experimentales en los grupos experimental (E) y control (C)

$N$ es el número de sujetos experimentales en ambos grupos $(\mathrm{nE}+\mathrm{nC})$ 
En el gráfico, también se observa la marca $(*)$ que indica que el efecto correspondiente a un estudio ha sido reportado como estadísticamente significativo. En la figura 9.4 muestra la Plantilla de Agregación para el grupo A01. 


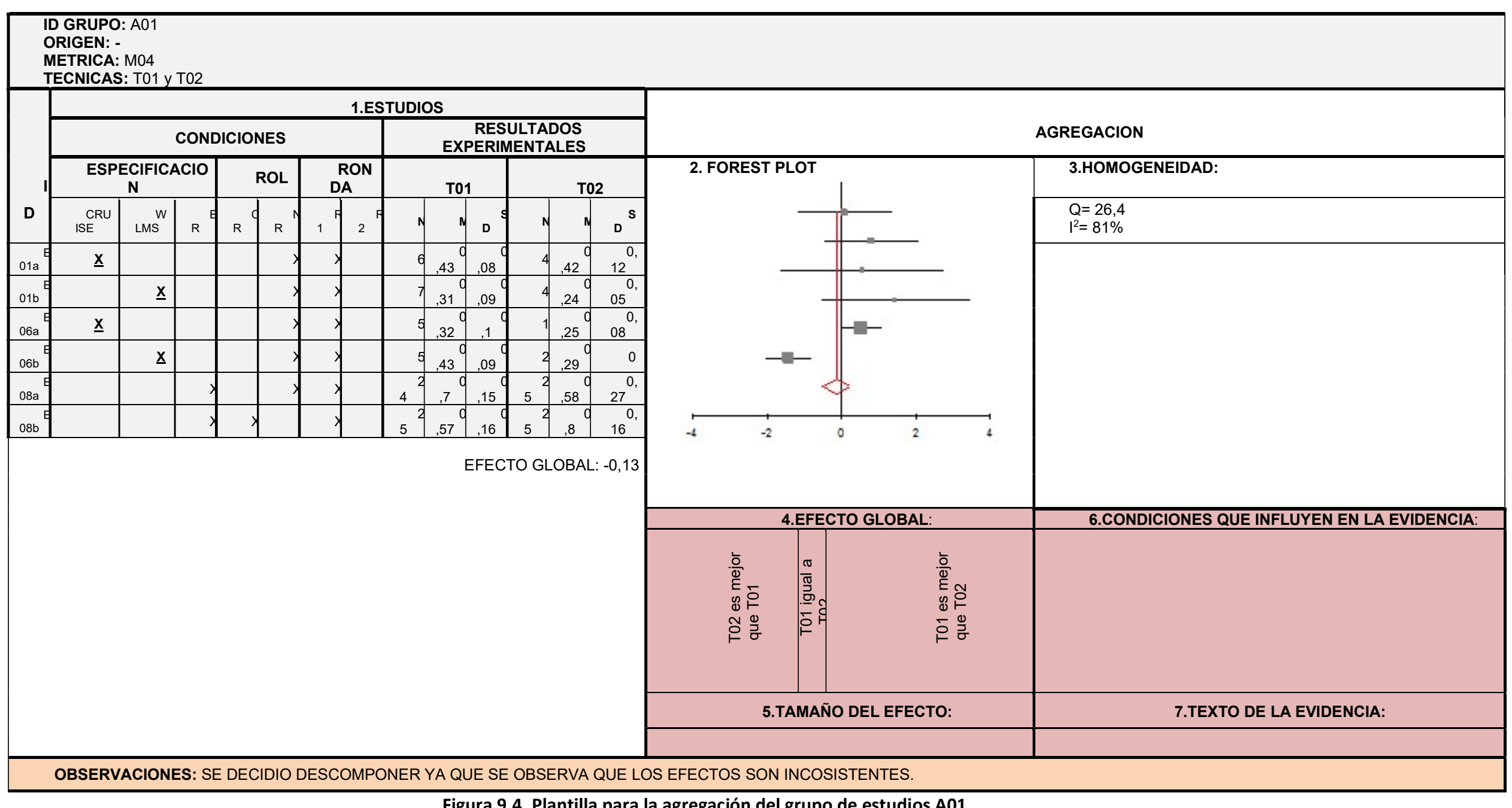

Figura 9.4. Plantilla para la agregación del grupo de estudios A01 


\subsubsection{Analizar la consistencia de los efectos}

Debido a que una RS incluye no sólo replicaciones de estudios sino una variedad de estudios independientes, es muy frecuente encontrar diferencias entre dichos estudios. Según (Higgins \& Green, 2006) cualquier tipo de variabilidad que se pueda encontrar entre los estudios en una RS se denomina Heterogeneidad.

El objetivo de esta tarea es determinar si el efecto global que se obtiene de la agregación de un grupo es producto de la combinación de estudios primarios homogéneos y es, por consiguiente, un resultado confiable para el revisor. La salida de esta tarea incluye dos estimadores de homogeneidad (Q e $I^{2}$ ), los cuales apoyan la decisión de descomponer o no el grupo de estudios. La Plantilla de Agregación (sección 3) es actualizada en esta tarea.

Para analizar la consistencia de los efectos se proponen entonces los siguientes pasos:

1. Calcular los estimadores de heterogeneidad. Tales estimadores están asociados al método de agregación utilizado. Se sugiere que sean calculados a través del método más exacto y con mayor poder empírico, y de acuerdo a las condiciones del grupo de estudios (según el paso 9.3.2.1).

Sin embargo, estos estimadores pueden presentar problemas bajo ciertas condiciones del meta-análisis. Por ejemplo, es bien conocido que el estimador $Q\left(y\right.$, en consecuencia, el estimador derivado $\mathrm{I}^{2}$ ) posee poca potencia para detectar heterogeneidad cuando se cuenta con pocos estudios o estudios muy pequeños; o, por el contrario, mucha potencia para detectar cantidades mínimas de heterogeneidad que son irrelevantes en la práctica, cuando se cuenta con muchos estudios (Dieste, Fernandez, Garcia, \& Juristo, 2011). Es necesario no sólo establecer la consistencia de los efectos (homogeneidad) sino también identificar aquellos estudios cuyas características pueden estar incidiendo en la homogeneidad del grupo.

2. Realizar un análisis visual del gráfico obtenido a partir de la agregación (tarea 9.3.2.2). Como se menciona en el punto anterior, conocer el valor de los estimadores $Q$ e $I^{2}$ no es siempre suficiente para averiguar si un grupo de estudios es homogéneo. Es por ello que se propone el uso de una técnica más intuitiva.

La inspección visual se basa en el forest plot. Su objetivo es identificar qué estudios no solapan sus intervalos de confianza con el efecto global. Esto permite identificar estudios concretos que se apartan de los restantes.

Al realizar esta inspección, debe tomarse en cuenta no sólo que los efectos se encuentren alineados verticalmente sino también el solapamiento de sus intervalos de confianza. De esta manera, si los intervalos de confianza no se solapan (o se solapan muy poco) se puede suponer la presencia de heterogeneidad estadística (Higgins \& Green, 2006). 
Una estrategia alternativa, basada en los mismos principios, sería localizar conjuntos de estudios cuyos intervalos de confianza se solapen y difieran de otros conjuntos de estudios. Dichos conjuntos deberían lograr tamaños de efecto globales distintos que no solaparían con los intervalos de confianza del otro conjunto de estudios.

Si el análisis visual comprueba que el conjunto de estudios es heterogéneo se procederá en el siguiente paso a descomponer el grupo en sub-grupos de estudios similares y se repetirán los pasos 9.3.2.1 a 9.3.2.3. Si, por el contrario, se comprueba que el grupo es homogéneo, es decir, que los efectos son consistentes entre sí, se continuará con el paso siguiente (9.3.2.4).

Un caso excepcional se presenta cuando el método de agregación seleccionado, en virtud de su exactitud y potencia empírica, sea el CVE, ya que el forest plot asociado a este método no permitirá realizar un análisis visual como el descrito anteriormente. En este caso, se limitará a generar la evidencia correspondiente, sin poder concluir nada acerca de la homogeneidad de los estudios a partir de los cuales ha sido obtenida.

En el siguiente ejemplo se presenta la aplicación de esta tarea.

Ejemplo 9.5. Caso de estudio: Inspección de Software

En el ejemplo 9.4, para el grupo A01 el estimador Q fue calculado en 26,4. A partir de este valor puede calcularse el parámetro $\mathrm{I}^{2}$ que para el grupo A01 fue de $81 \%$. Las fórmulas para el cálculo de estos

$$
I^{2}=[(Q-d f) / Q] \times 100 \%
$$

Donde:

$d f$ representa los grados de libertad

$\mathrm{df}=$ Num de estudios -1

Nótese en la figura 9.5 que $I^{2}$ puede considerarse alto $\left(I^{2}>50 \%\right)$, lo cual se confirma al verificar gráficamente el alineamiento de los efectos individuales respecto al efecto global. Es evidente que el estudio E08b no se encuentra alineado (solapado) con el resto de los estudios ni con el efecto global. Por lo tanto, se considera que el grupo A01 presenta heterogeneidad. 


\subsubsection{Descomponer en sub-grupos}

El objetivo de esta tarea es obtener grupos de estudios homogéneos para la agregación, partiendo de un grupo de estudios que ha demostrado poseer heterogeneidad. Como resultado de aplicar esta actividad se obtendrán dos o más subgrupos de estudios para ser agregados a través del método que corresponda.

De las estrategias para manejar la heterogeneidad (L. V. Hedges \& Olkin, 1985), en esta investigación se ha considerado la descomposición y análisis de sub-grupos como la estrategia más adecuada, ya que permite obtener grupos homogéneos a partir de los cuales generar una evidencia, así como identificar los posibles factores que introducen inconsistencia en los efectos; permitiendo, además, conservar el mayor número de estudios posible. Para ello se han propuesto los siguientes pasos:

1. Descomponer el grupo inicial en sub-grupos de estudios homogéneos. Tal descomposición seguirá el criterio de "consistencia de efectos" analizando las medias e intervalos de confianza del forest plot, tal y como se describió en la actividad anterior. Para ello, se identificarán aquellos estudios cuyos efectos sean similares, verificando que éstos se encuentren alineados y que los intervalos de confianza se solapen. Los estudios que presenten tales características de consistencia serán metaanalizados juntos de nuevo a fin de obtener una homogeneidad creciente (un valor de $\mathrm{I}^{2}$ bajo).

Para que una descomposición sea válida, además de disminuir la heterogeneidad, tiene que implicar una diferencia clara entre los grupos que se generan, esto es, que pueda ser explicada por la presencia o ausencia de algún nivel de alguno de los factores conocidos. En caso contrario, los sub-grupos que se formen, aún teniendo resultados consistentes no llevarán a una evidencia clara.

2. Aplicar nuevamente los pasos 9.3.1 a 9.3.3 a cada sub-grupo, generando nuevas Plantillas de Agregación para cada uno de ellos, las cuales serán tratadas de manera independiente, hasta el momento de generar las evidencias.

3. La descomposición se detiene cuando se haya alcanzado el grado de homogeneidad deseado o cuando no sea posible separar los estudios del grupo en conjuntos homogéneos.

\section{EJEMPLO 9.6: CASO DE ESTUDIO - INSPECCIÓN DE SOFTWARE}

En la gráfica de la figura 9.5, puede observarse que existen estudios aislados (E08b). Se procede a descomponer el grupo en sub-grupos con efectos más similares. Esta descomposición lleva a dividir los estudios en dos sub-grupos:

- $\quad$ El sub-grupo A01_1 contiene entonces el conjunto de estudios que en la gráfica de A01 (Figura 9.5) presentaron los efectos más consistentes, lo cual se refleja en que sus 
resultados se encuentran bastante alineados respecto al efecto global, además de que sus intervalos se solapan entre sí. Estos estudios son: E01a, E01b, E06a, E06b y E08a.

- $\quad$ Por lo tanto, el estudio E08b, es el único estudio cuyo efecto no fue consistente con los anteriores; siendo asignado al sub-grupo A01_2.

El sub-grupo A01_1 puede ser agregado nuevamente. Para ello se llevará a cabo la Actividad 9.3.10, a fin de seleccionar el método que resulte mejor a las condiciones de este conjunto de estudios. En esta segunda iteración deberá nuevamente evaluarse si agregar sólo los 5 estudios que forman el sub-grupo o incluir además los dos estudios que fueron dejados por fuera durante la primera iteración (E02a y E02b). Para tomar tal decisión, deberán compararse los valores de precisión y poder de las técnicas de metaanálisis para ambas alternativas. Esta recomendación deberá aplicarse también en las descomposiciones posteriores.

La agregación de este sub-grupo utilizando el método DMP es mostrado en la Figura 9.6. Nótese que en este caso, al analizar las medidas de homogeneidad y la consistencia de los efectos en la gráfica (Actividad 9.3.2.3), se observa que el conjunto de efectos es bastante consistente $\left(Q=1,44, I^{2}=0 \%\right)$, por lo tanto, se puede considerar que el grupo de estudios es homogéneo.

Por otra parte, el sub-grupo A01_2 contiene un único estudio, por lo que no se puede hablar de agregación. De todas maneras, los datos y la gráfica mostrando sólo el efecto individual del estudio son también presentados en una Plantilla de Agregación (véase la Figura 9.7). 
JPO: A01_1

$\mathrm{N}: \mathrm{A} 01$

CA: $\mathrm{M} 04$

CAS: T01 y T02

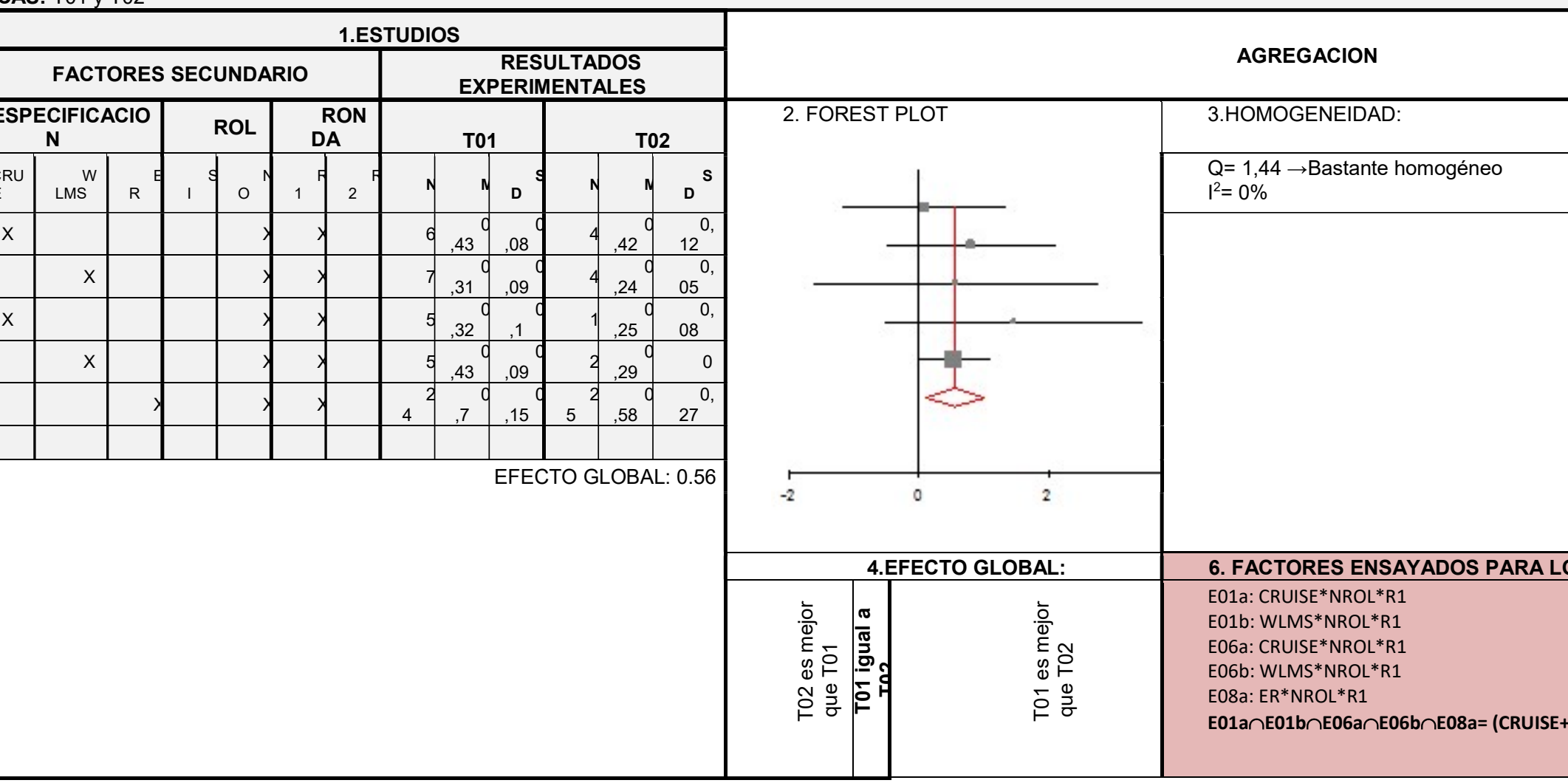




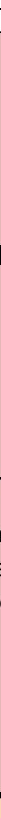

Figura 9.6. Plantilla para la agregación del grupo de estudios A01_1 
JPO: A01_2

N: A01

CA: $\mathrm{M} 04$

CAS: T01 y T02

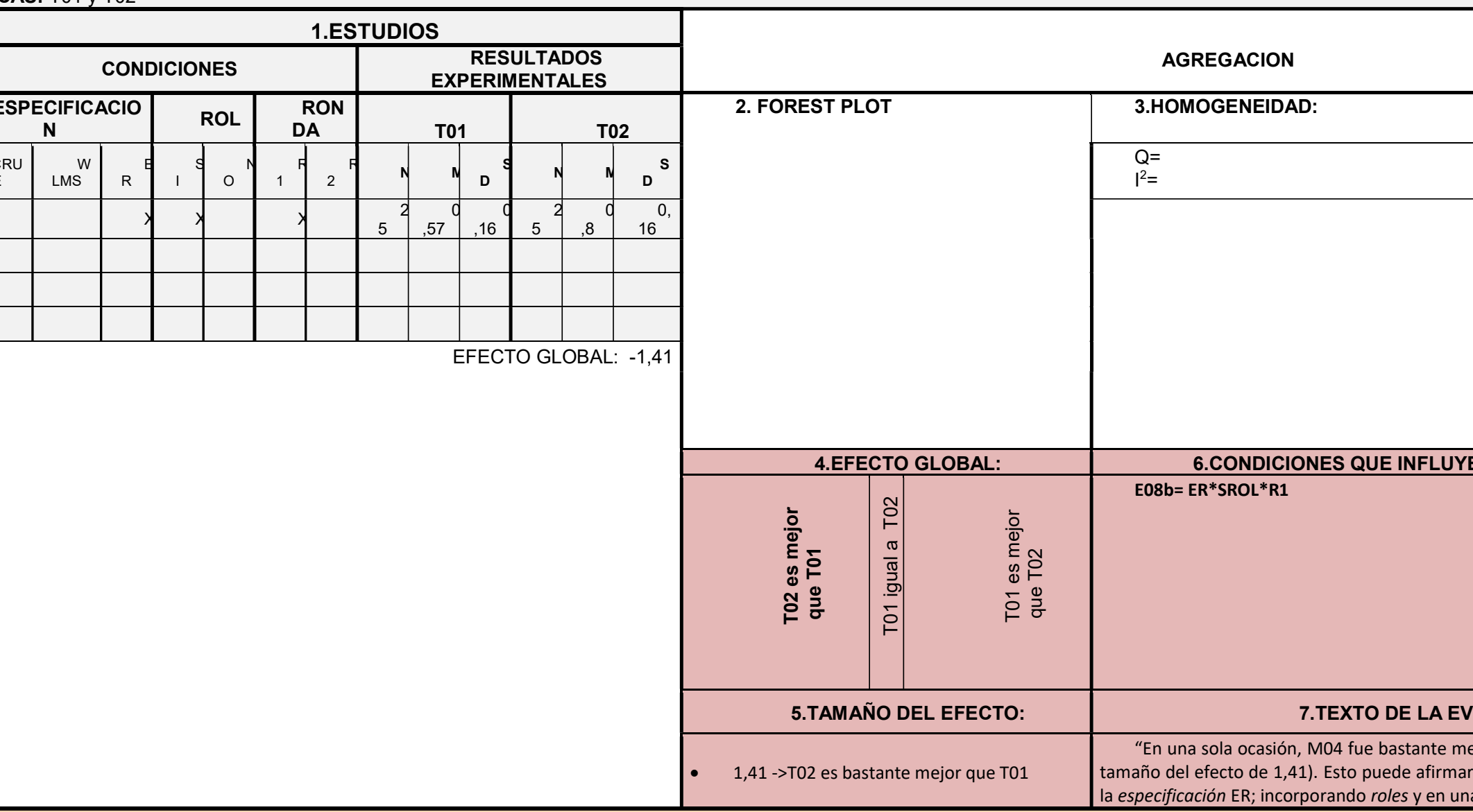

Figura 9.7. Plantilla para la agregación del grupo de estudios $A 01 \_2$ 


\subsubsection{Definir las condiciones de la evidencia}

El objetivo de esta tarea es establecer las características de los estudios que forman parte de una determinada agregación, contribuyendo a la generación de una evidencia. De esta manera, es posible establecer el contexto en el cual la evidencia ha sido probada. Esta actividad se acometerá una vez que la descomposición descrita en la actividad anterior se haya detenido y, por lo tanto, se cuente con grupos homogéneos de estudios.

El resultado de esta tarea es una expresión que representa las condiciones bajo las cuales se ha obtenido un efecto global, documentando las mismas en la Plantilla de Agregación - Sección 6. La expresión a utilizar será una manera semi-formal de hacer explícitos los factores (y sus niveles) que se encuentran subyacentes en un grupo de estudios. El procedimiento propuesto para definir esta expresión es la siguiente:

- Tomar las condiciones de los estudios que aparecen indicadas con el símbolo X en la Sección 1 de la plantilla.

- Para cada estudio, formar una expresión que resuma los factores y sus niveles.

- La combinación de factores es denotada a través del símbolo *; con un significado similar al operador AND de un álgebra boolena.

- La combinación de varios niveles de un mismo factor es denotada a través del símbolo +; con un significado similar al operador OR de un álgebra boolena.

- Una vez que se tenga una expresión para cada estudio, simplificarlas para generar una expresión que represente las condiciones de todo el grupo. De esta manera, la expresión resultante contiene las condiciones para las cuales se puede generar la evidencia del grupo de estudios en cuestión.

\section{Ejemplo 9.7:}

En la Figura 9.6 se observa que el estudio E01a ha sido ensayado la especificación CRUISE, sin incluir roles, y en una sola ronda. Estas condiciones pueden ser representadas por la siguiente expresión: CRUISE*NR*R1.

Tomando como ejemplo el grupo A01_1, se definen las siguientes expresiones para los estudios, usando como entrada las Xs que se encuentran en la Sección 1 de la Plantilla de Agregación. Para cada una de estos estudios se genera entonces una expresión, como se muestra a continuación: 
E01a: CRUISE*NR*R1
E01b: WLMS*NR*R1
E06a: CRUISE*NR*R1
E06b: WLMS*NR*R1
E08a: ER*NR*R1

Al simplificar las expresiones obtenidas para A01_1, se obtiene una única expresión que representa los distintos niveles (de cada factor adicional) que subyacen en los estudios involucrados en la agregación:

\section{$E 01 a \cap E 01 b \cap E 06 a \cap E 06 b \cap E 08 a=$ \\ (CRUISE+WLMS+ER)*NR*R1.}

La expresión (CRUISE+WLMS+ER)*NR*R1, es la expresión que representa al grupo de estudios A01_1 donde se han ensayado 3 Especificaciones (CRUISE, WLMS y ER), sin incluir el uso de Roles (NR) y utilizando una sola Ronda (R1).

\subsubsection{Definir las evidencias}

El objetivo de esta tarea es definir cada evidencia de acuerdo a un conjunto mínimo de elementos que permiten que ésta sea generalizada apropiadamente y posteriormente aplicada por los profesionales de IS. Como resultado de esta tarea se obtiene una o más evidencias asociadas a un grupo. Para definir cada evidencia deberá procederse de la siguiente manera:

1. Indicar la interpretación del efecto global en la Plantilla de Agregación - Sección 4. Los efectos calculados por el método -tanto los efectos individuales como el efecto global- pueden tomar valores positivos o negativos, por lo que visualmente son representados a la derecha o izquierda del gráfico. De tal manera, la interpretación de estos valores en la gráfica será la siguiente:

- $\quad$ Si el efecto global estimado es positivo (el valor se localiza a la derecha del origen) se interpretará que el tratamiento $\mathrm{A}$ ha resultado ser mejor que el tratamiento $\mathrm{B}$.

- $\quad$ Si, por el contrario, el efecto global es negativo (el valor se localiza a la izquierda del origen), se interpretará como que el tratamiento B es mejor que el tratamiento A.

- Por último, si el efecto global se localiza sobre el origen de la gráfica, se podrá suponer que los tratamientos $A$ y $B$ son iguales.

Ejemplo 9.8: 
Este valor se interpreta como que la técnica T02 es en promedio mejor que la técnica T01, con un tamaño de efecto de 0.13 ; no obstante, este valor no es significativo estadísticamente, ya que su intervalo de confianza (representado por el ancho del diamante en el gráfico) incluye el valor 0.

2. Interpretar el tamaño del efecto global dependiendo del método utilizado. Esta información será indicada en la Plantilla de Agregación - Sección 5. De la siguiente manera:

- $\quad$ Si se ha aplicado el método RR hablar de \% de mejora en términos medios.

- $\quad$ Si se ha aplicado el método DMP o CVE hablar de la probabilidad de que se de el efecto

- $\quad$ Nótese que no se recomienda matizar la interpretación que se ha dado previamente al efecto global, p.e. el tratamiento $A$ es un poco mejor que el tratamiento $B$, el tratamiento $A$ es mejor que $B$, o el tratamiento $A$ es mucho mejor que $B$.

3. Expresar el resultado de manera textual: el resultado de la agregación puede tomarse directamente del gráfico y/o del efecto global registrado en la Sección 4 de la Plantilla de Agregación. Una de las siguientes alternativas debe afirmarse en la evidencia: "el tratamiento A es mejor que el tratamiento B", "el tratamiento B es mejor que el tratamiento A", o "los tratamientos A y B son iguales".

4. Indicar el tamaño del efecto: la magnitud de la diferencia $(d \circ r$ ) entre ambos tratamientos debe aparecer en la evidencia, expresado tanto en su valor original como en su interpretación según la Sección 5 de la Plantilla de Agregación.

5. Establecer las condiciones de la evidencia: se tomarán directamente de la Sección 6 de la Plantilla de agregación. Estas condiciones limitan la validez de la evidencia que es obtenida a los factores (y niveles) que han sido ensayados en cada grupo.

6. Justificar la potencia: se refiere a la cantidad de estudios involucrados en la agregación, los cuales son tomados de la Sección 1 o directamente del gráfico.

7. Cuando el efecto se haya obtenido con base en un solo experimento, debería hacerse explícito en la evidencia; por ejemplo, "en determinadas condiciones experimentales, muy específicas, y en una sola ocasión, se ha dado que...". Este tipo de evidencia puede considerarse como válida aunque se encuentra en un nivel muy bajo, ya que es soportada al menos por sólo un experimento. Estas evidencias serán documentadas en la Plantilla de Agregación - Sección 7.

\section{Ejemplo:}

Se observa que en la gráfica de la agregación del grupo A01_1 (véase figura 9), el efecto global (representado por el diamante) se encuentra a la derecha del gráfico, por lo que se interpreta que el resultado favorece a T01. Además, puede observarse que el intervalo de confianza (representado por los vértices laterales del diamante) no incluyen el valor cero, por lo 
que el efecto global $(0,56)$ es estadísticamente significativo. Este resultado, junto con las condiciones para las cuales ha sido determinado y el número de estudios en la agregación (potencia), conformarán la evidencia (Sección 7 de la Plantilla de Agregación), de la siguiente manera:

- Evidencia: M04 parece ser mejor cuando se usa T01 que cuando se usa T02 (con un tamaño del efecto de 0,56), esto se puede afirmar con base en 5 estudios. Esto ha sido probado para 5 estudios utilizando las especificaciones CRUISE, WLMS y ER; sin utilizar roles y relaizando la inspección en una ronda.

- $\quad$ Tamaño del efecto: 0,56.

- $\quad$ Condiciones de la evidencia: Ha sido probado utilizando tres especificaciones (CRUISE, WLMS y ER); cuando no se utilizó roles y la inspección se realizó en una ronda.

- $\quad$ Potencia: Ha sido probado para tres estudios.

Una vez que se ha agregado el grupo A01_1, debe repetirse el proceso para A01_2, el otro subgrupo en el que se descompuso A01. Puede observarse en la figura 10, que al contar con un solo estudio en el grupo no se puede hablar de una agregación propiamente, ya que por definición una agregación debe contener al menos dos estudios; sin embargo, para efectos de comparación con el sub-grupo anterior, es útil representar gráficamente el efecto individual de E08b y generar una evidencia a partir de éste. Nótese en la gráfica de la Plantilla de Agregación (figura 10) que el efecto obtenido se ubica a la izquierda del origen, por lo que se interpreta que la técnica T02 resulta mejor que la técnica T01. El valor absoluto del tamaño del efecto es de 1,41 por lo que puede considerarse grande. Por lo tanto, se puede afirmar como evidencia obtenida de A01_2, que T02 fue bastante mejor que T01, para este único estudio.

Con base en los resultados y condiciones del estudio E08b (ER*CR*R1) puede afirmarse la evidencia: "en una sola ocasión, M04 fue bastante mejor con T02 que con T01 (con un tamaño del efecto de 1,41). Esto puede afirmarse para la especificación ER; incorporando roles y en una inspección de una sola ronda".

Puede observarse que esta evidencia parece contradictoria respecto a la obtenida en la agregación de A01_1; sin embargo, se retomará esta discrepancia en la próxima actividad.

\subsubsection{CONSOLIDAR Y CLASIFICAR EVIDENCIAS}

Esta actividad tiene como propósito resumir todas las evidencias encontradas en las distintas agregaciones realizadas durante la Síntesis de datos y asignarle un Nivel de confianza dependiendo de la 
manera como fueron obtenidas. Como se observa en la Figura 1, esta actividad se realiza una vez que todas las agregaciones han sido completadas, lo cual permitirá tener una visión global de las evidencias obtenidas en cada grupo. El resumen a realizar en esta actividad implica las siguientes tareas:

1. Obtener las evidencias obtenidas en cada grupo/sub-grupo a partir de las Plantillas de Agregación (Sección 7) previamente generadas y listarlas de manera conjunta. En la Tabla 9.4se propone una estructura básica para reportar las evidencias obtenidas durante esta fase.

Tabla 9.4. Listado de Evidencias

\begin{tabular}{|l|l|l|l|}
\hline $\begin{array}{c}\text { ID_- } \\
\text { EV }\end{array}$ & Evidencia & $\begin{array}{c}\text { Grupo del } \\
\text { que se obtiene }\end{array}$ & $\begin{array}{c}\text { Nivel de } \\
\text { confianza }\end{array}$ \\
\hline & & & \\
\hline & & & \\
\hline
\end{tabular}

Tabla 9.4. Ejemplo de Listado de evidencias

\begin{tabular}{|c|c|c|c|}
\hline ID & Evidencia & $\begin{array}{l}\text { Gru } \\
\text { po }\end{array}$ & $\begin{array}{l}\text { Nivel } \\
\text { de } \\
\text { confianza }\end{array}$ \\
\hline EV & $\begin{array}{l}\text { "M04 parece ser mejor cuando se usa T01 que cuando se } \\
\text { usa T02 (con un tamaño del efecto de 0,56). Esto fue } \\
\text { estadísticamente significativo, siendo probado con cinco } \\
\text { estudios, para tres especificaciones (CRUISE, WLMS y ER). Este } \\
\text { resultado se obtuvo sin utilizar roles y realizando la inspección } \\
\text { en una ronda". }\end{array}$ & $-1^{\mathrm{A} 01}$ & \\
\hline EV & $\begin{array}{l}\text { "En una sola ocasión, M04 fue bastante mejor (con un } \\
\text { tamaño del efecto de 1,41) cuando se utilizó T02 que cuando } \\
\text { se utilizó T01. Esto fue estadísticamente significativo, siendo } \\
\text { probado para la especificación ER; incorporando roles y en } \\
\text { una inspección de una sola ronda". }\end{array}$ & $-^{\mathrm{A} 01}$ & \\
\hline EV & $\begin{array}{l}\text { "En algunos casos ( } 4 \text { estudios) M04 fue bastante mejor } \\
\text { cuando se utilizó T03 que cuando se aplicó T01 (con un } \\
\text { tamaño del efecto de } 1,5 \text { ). Este resultado fue } \\
\text { estadísticamente significativo para las especificaciones CRUISE } \\
\text { y WLMS; cuando no se utilizó roles y la inspección se realizó } \\
\text { en una ronda" }\end{array}$ & A12 & \\
\hline $11^{E V}$ & $\begin{array}{l}\text { "Para diez estudios, M04 resultó un poco mejor al utilizar } \\
\text { T03 que al utilizar T02 (con un valor absoluto del tamaño del } \\
\text { efecto igual a 0,21). Sin embargo, esto no fue } \\
\text { estadísticamente significativo. Esto fue así para dos }\end{array}$ & $\mathrm{A} 02$ & \\
\hline
\end{tabular}




\begin{tabular}{|c|c|c|}
\hline & $\begin{array}{l}\text { especificaciones (WLMS y CRUISE), sin utilizar roles y, parece } \\
\text { ser que, con independencia de que la inspección se realice en } \\
\text { una ronda o en dos rondas". }\end{array}$ & \\
\hline $13^{E V}$ & $\begin{array}{l}\text { EV11 se confirmó cuando se agregaron dos estudios } \\
\text { adicionales utilizando un método menos riguroso: } \\
\text { "Para un grupo grande de estudios (doce en total), M04 } \\
\text { resultó } 10 \% \text { mejor cuando se usó T03 que cuando se usó T02. } \\
\text { Esto fue así con las especificaciones WLMS y CRUISE, sin } \\
\text { utilizar roles y, parece ser que, con independencia de que la } \\
\text { inspección se realizara en una ronda o en dos rondas". } \\
\text { Sin embargo, esto no fue estadísticamente significativo. }\end{array}$ & $\mathrm{A} 02$ \\
\hline $14^{E V}$ & $\begin{array}{l}\text { "Para tres estudios se comprobó que M04 fue mucho } \\
\text { mejor cuando se utilizó T07 que cuando se utilizó T02 (con un } \\
\text { tamaño de efecto de } 0,96 \text { ). Tal resultado fue estadísticamente } \\
\text { significativo. Siendo así cuando se inspeccionó el código de } \\
\text { TELE SYS, sin utilizar roles y en una sola ronda". }\end{array}$ & A03 \\
\hline $24^{E V}$ & $\begin{array}{l}\text { "Al combinar dos de los estudios, M04 fue bastante mejor } \\
\text { (un tamaño de efecto del } 0,98 \text { ) cuando se utilizó T01 que } \\
\text { cuando se utilizó T02; sin embargo, esto no fue } \\
\text { estadísticamente significativo. Esto fue así para dos } \\
\text { especificaciones (CRUISE y WLMS), sin utilizar roles y } \\
\text { realizando la inspección en una ronda". } \\
\text { Esto fue probado en un ambiente industrial. }\end{array}$ & A13 \\
\hline $28^{E V}$ & $\begin{array}{l}\text { "Para dos estudios, M04 fue bastante mejor (un tamaño } \\
\text { de efecto de 1,35) al utilizar T03 que al aplicar T02; sin } \\
\text { embargo, esto no fue estadísticamente significativo. Esto fue } \\
\text { así para dos especificaciones (CRUISE y WLMS), sin utilizar } \\
\text { roles y realizando la inspección en una ronda". Esto fue } \\
\text { probado en un ambiente industrial. }\end{array}$ & A14 \\
\hline
\end{tabular}

2. Luego de listar las evidencias obtenidas, sería recomendable proponer hipótesis que traten de explicar evidencias aparentemente inconsistentes. Por ejemplo, si al descomponer un grupo que inicialmente era heterogéneo en dos sub-grupos, y en cada agregación se detectaron efectos opuestos, sería recomendable generar una hipótesis sobre cuál ha sido el factor o nivel (o combinaciones de ellos) que han producido dicha contradicción. Para aquellos casos donde las condiciones que explican la diferencia entre ambos sub-grupos es muy compleja, recomendamos generar una evidencia aunque ésta no sea muy precisa: p.e. "en determinadas condiciones experimentales, muy específicas, se ha dado que...". En la tabla 9.5 se propone un formato para documentar las hipótesis propuestas.

Tabla 9.5. Listado de Hipótesis 


\begin{tabular}{|l|l|l|}
\hline $\begin{array}{r}\text { ID_- } \\
\text { Hip }\end{array}$ & Hipótesis & Grupos involucrados \\
\hline & & \\
\hline & & \\
\hline & & \\
\hline & & \\
\hline & & \\
\hline
\end{tabular}

Tabla 9.6. Resumen de hipótesis

\begin{tabular}{|l|l|c|}
\hline ID & \multicolumn{1}{|c|}{ Hipótesis } & \multicolumn{1}{c|}{$\begin{array}{c}\text { Grupos } \\
\text { involucrados }\end{array}$} \\
\hline H01 & $\begin{array}{l}\text { El rol parece influir en M04; de manera que cuando se aplica } \\
\text { la técnica sin rol T01 es mejor que T02 y cuando se aplica con rol } \\
\text { T02 es mejor que T01, esto se ha dado sólo para la especificación } \\
\text { ER. }\end{array}$ & A01_1,A01_2 \\
\hline
\end{tabular}

3. Resumir aquellas condiciones no ensayadas en los estudios de un grupo. Debido a que cada sub-grupo puede probar una combinación de niveles del factor principal y de los factores secundarios que determinan la presencia o no de efecto entre los tratamientos, puede ser útil para los revisores contar con un listado de aquellas condiciones que no han sido ensayadas en ninguno de los estudios incluidos en la revisión a fin de plantearse nuevas hipótesis de trabajo.

A manera de ejemplo, en las tabla 9.4 y 9.6 se presenta un resumen de las evidencias y las hipótesis obtenidas de la Síntesis de datos de los experimentos de Inspección de Software.

A manera de ejemplo, a continuación se lista algunas condiciones que no fueron ensayadas en los estudios incluidos en esta RS:

- No se ha estudiado M04 con las técnicas T01 y T02, incluyendo dos rondas, en ninguno de los estudios incluidos en esta revisión. A01

- No se ha probado M04 con las técnicas T01 y T02, con una sola ronda, cuando los equipos utilizan rol y las especificaciones CRUISE y WLMS. A01

- No se ha probado M04 utilizando las técnicas T01 y T03 e incorporando dos rondas. A12

- $\quad$ No se ha probado M04 utilizando las técnicas T01 y T03 y utilizando roles. A12

- $\quad$ No ha sido evaluada M04 utilizando T02 y T03 e incorporando roles. A02 
- No ha sido probada M04 utilizando las técnicas T07 y T02 incorporando roles o una segunda ronda. A03

- M04 no ha sido probada en un ambiente industrial comparando T01 y T02 utilizando roles ni con dos rondas. A13

- M04 no ha sido probada para T02 y T03 utilizando roles ni incluyendo dos rondas. A13

4. Asignar un nivel de confianza a cada una de las evidencias listadas. En la tabla 9.4 cada evidencia es relacionada con el grupo de agregación al cual pertenece (esto permitirá establecer el o los estudios que la soportan) y será calificada con un Nivel de confianza, el cual dependerá de la calidad de los estudios del grupo así como de la Exactitud (Ex) y el poder estadístico (PE) del método de agregación. Otras dimensiones, tales como la homogeneidad del grupo de estudios y el diseño de los mismos, no han sido consideradas ya que se asume que cada evidencia ha sido obtenida de un grupo con efectos consistentes (homogéneo) y los estudios involucrados son experimentos controlados (RCTs).

La calidad de los estudios será determinada a través de los criterios establecidos en la fase de Evaluación de la Calidad. Como resultado, cada estudio puede ser considerado de una calidad media o alta. Para determinar el nivel de confianza que debe ser asignado, se propone la escala descrita en la Tabla 9.7.

- Calidad de los estudios: sólo se considerarán dos niveles de calidad, media y alta, ya que los estudios de calidad baja (aquellos que no reporten los datos mínimos para ser agregados a través del meta-análisis) son automáticamente descartados. Los dos niveles considerados se definen de la siguiente manera (véase Capítulo 8 - Evaluación de la Calidad):

- Calidad Media: se refiere a estudios que reportan los datos mínimos para el meta-análisis y cumplen con algunos, pero no todos, los criterios de calidad establecidos.

- Calidad Alta: se refiere a estudios que reportan los datos mínimos para el metaanálisis y cumplen con todos los criterios de calidad establecidos.

- Exactitud: se proponen dos niveles de fiabilidad, media y alta. Una fiabilidad baja no parece admisible en el meta-análisis; es decir, para ser confiable un método de agregación no debería incurrir en una probabilidad mayor al 10\% de error tipo I. Los dos niveles considerados se definen de la siguiente manera:

- Exactitud Media: cuando el método posea una fiabilidad entre el 90 y $94 \%$ (corresponde a un $\alpha=0,1$ ).

- Fiabil Exactitud idad Alta: cuando el método posea una fiabilidad mayor o igual al 95\% (corresponde a un $\alpha=0,05$ ). 
- Poder estadístico: de la misma manera que para la fiabilidad, sólo se han definido dos niveles para el poder estadístico medio y alto.

- Poder Medio: un poder estadístico que se encuentre entre el 50 y $79 \%$ (corresponde a un $\beta=50 \%$ ).

- Poder Alto: un poder estadístico mayor o igual al $80 \%$ (corresponde a un $\beta=20 \%$ ).

Lógicamente, la Fiabilidad y el Poder estadístico no pueden ser usados como criterios de clasificación de manera conjunta, ya que un determinado fenómeno (p.e la comparación de dos técnicas) puede estar sometido a cualquiera de los dos tipos de error asociados al contraste de hipótesis, pero no a ambos. Por lo tanto, se designará el Nivel de confianza considerando lo siguiente:

- Cuando la evidencia apunte a la existencia de un efecto, utilizar como criterios de clasificación la Fiabilidad y la Calidad de los estudios.

- En caso contrario, esto es, cuando la evidencia apunte a la no existencia de un efecto, utilizar como criterios de clasificación el Poder estadístico y la Calidad de los estudios.

Tabla 9.7. Niveles de confianza

\begin{tabular}{|c|c|c|c|c|}
\hline $\begin{array}{l}\text { Efec } \\
\text { to }\end{array}$ & Ex & $\mathbf{P}$ & $\begin{array}{l}\text { Calidad de los } \\
\text { estudios }\end{array}$ & $\begin{array}{c}\text { Nivel de } \\
\text { confianza }\end{array}$ \\
\hline \multirow{4}{*}{ Sí } & Media & & Media & 3 \\
\hline & Alta & & Media & \multirow{2}{*}{2} \\
\hline & Media & & Alta & \\
\hline & Alta & & Alta & 1 \\
\hline \multirow{4}{*}{ No } & & Media & Media & 3 \\
\hline & & Alta & Media & \multirow{2}{*}{2} \\
\hline & & Media & Alta & \\
\hline & & Alta & Alta & 1 \\
\hline
\end{tabular}

El nivel de confianza que ha sido asignado a cada evidencia será útil no sólo para efectos de filtrar aquellas evidencias que son de mayor interés para los revisores o profesionales, sino que también sirve como base para matizar la evidencia final.

Tabla 9.8. Interpretación de los niveles de confianza 


\begin{tabular}{|c|c|c|}
\hline confianz & & \\
\hline 1 & $\begin{array}{l}\text { Razonamiento fuerte para el cambio } \\
\text { práctico }\end{array}$ & $\begin{array}{l}\text { Efectividad establecida a un } \\
\text { grado que amerita aplicación }\end{array}$ \\
\hline 2 & $\begin{array}{l}\text { Razonamiento moderado para el } \\
\text { cambio práctico }\end{array}$ & $\begin{array}{l}\text { Efectividad establecida a un } \\
\text { grado que justifica la consideración } \\
\text { de aplicar los resultados }\end{array}$ \\
\hline 3 & $\begin{array}{l}\text { Poca justificación para el cambio } \\
\text { práctico }\end{array}$ & $\begin{array}{l}\quad \text { Efectividad no establecida. La } \\
\text { consideración de aplicar los } \\
\text { resultados queda sujeta al juicio del } \\
\text { profesional }\end{array}$ \\
\hline 4 & $\begin{array}{l}\text { No hay razonamiento para soportar } \\
\text { el cambio en la práctica }\end{array}$ & Efectividad no establecida \\
\hline
\end{tabular}

\subsubsection{COMBINAR EVIDENCIAS}

El propósito de esta actividad es resumir todas las evidencias obtenidas para cada una de las tecnologías estudiadas en la RS.

\subsubsection{Establecer jerarquías}

La primera tarea de esta actividad tiene como objetivo establecer una estructura que permita organizar las evidencias obtenidas.

Para ello se realiza como primer paso un árbol que estructura los niveles ensayados en la RS (las tecnologías) a modo de jerarquía. Por ejemplo, en la figura 9.12 se muestra una jerarquía para las técnicas ensayadas en la RS de inspección de software. Nótese que los niveles medios y superiores del árbol han sido propuestos con base en las defunciones de las técnicas dadas por los autores. De esta manera, pueden derivarse evidencias tanto para una tecnología en particular como para una categoría de tecnologías.

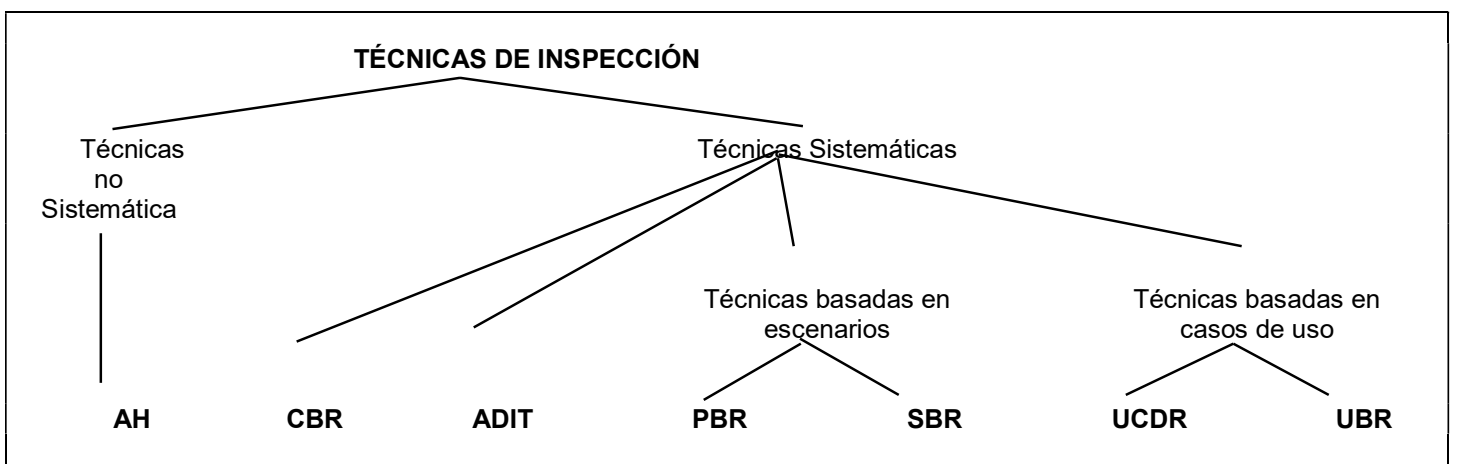

Figura 9.12. Jerarquía de técnicas para la RS sobre inspección de software 
Por otra parte, se establece una jerarquía para las distintas métricas y VRs evaluadas en la RS. Como se observa en la figura 9.13, se ha estructurado una jerarquía de VRs para agrupar las distintas métricas de la RS sobre inspección de software.

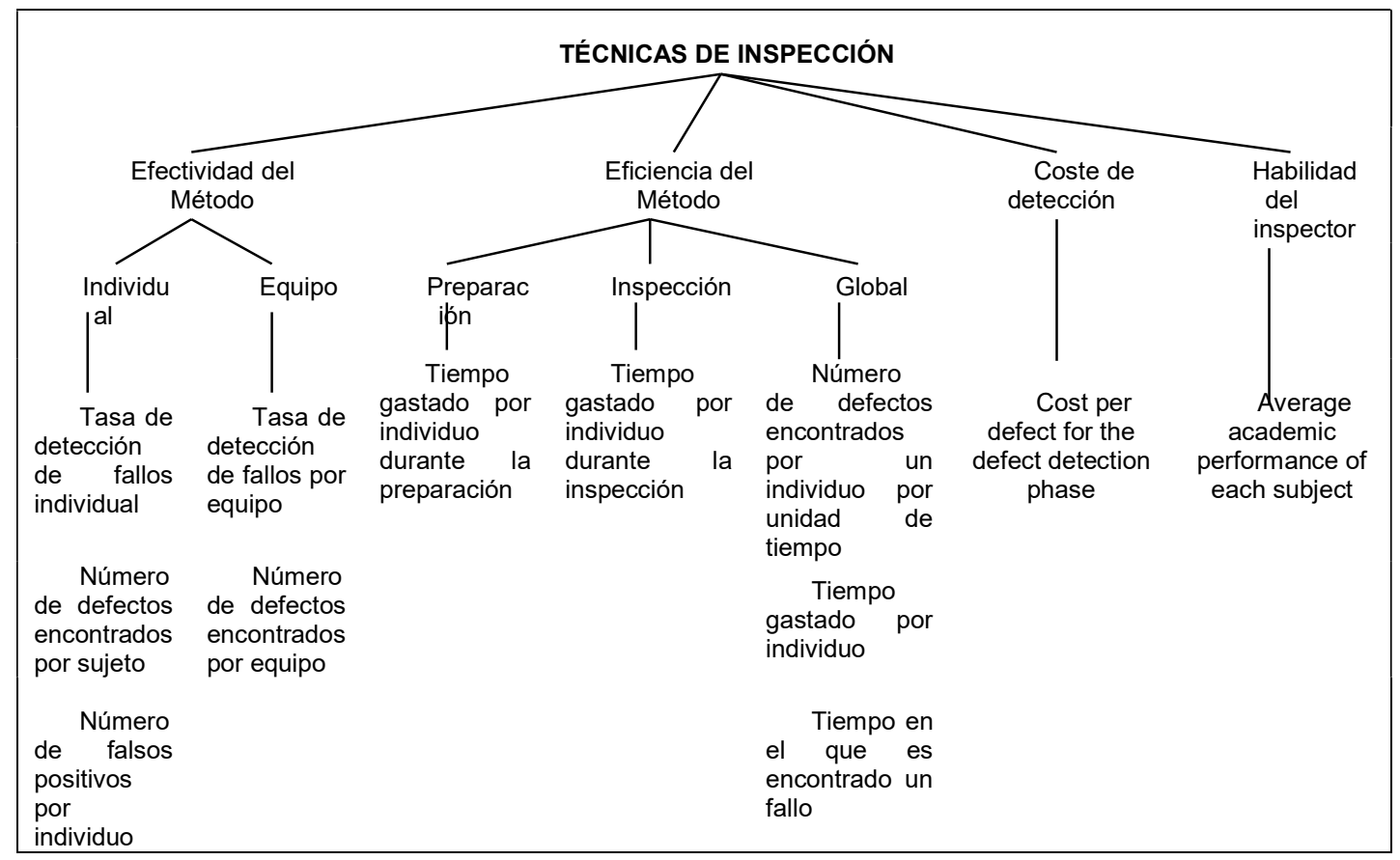

Figura 9.13. Jerarquía de VR y métricas para la RS sobre inspección de software

\subsubsection{Relacionar evidencias con la jerarquía de métricas y niveles}

Esta tarea buscar hacer explícita la relación de cada evidencia con la métricas y las técnicas involucradas en la misma.

De tal manera, una vez que se han establecido las jerarquías para las técnicas y las métricas/VR, se relaciona cada evidencia obtenida en la actividad anterior con cada par métrica-técnica. Por ejemplo, en la tabla 5, se observa que la EV18 ("cuando se utilizó la especificación TAXI, sin roles y en una sola ronda, la Tasa de detección de fallos individual fue mejor para UBR que para CBR -en un 28\%-, aunque este resultado no fue estadísticamente significativo. Esto sólo fue así en dos estudios") involucra la métrica Tasa de detección de fallos individual y a las técnicas CBR y UBR. Por lo tanto, en la tabla 6 se han colocado dos entradas identificadas como EV18 en la casillas donde se interceptan la métrica en cuestión con la técnica CBR y con la técnica UBR, respectivamente.

Este procedimiento se repite para cada una de las evidencias obtenidas o para aquellas evidencias de interés dando origen a la tabla Relación de evidencias con cada nivel/métrica (ver tabla 6). Nótese que en 
esta tabla se han vaciado todas las evidencias obtenidas en la actividad anterior, no obstante éstas podrían haber sido filtradas según el grado de certidumbre y el pérfil del usuario. De la siguiente manera:

- Perfil Gerente: presentar solamente las evidencias con grado de certidumbre X.

- Perfil Profesional: presentar las evidencias con grado de certidumbre Y.

- $\quad$ Perfil Investigador: presentar las evidencias con grado de certidumbre Z. 
Propuesta de un proceso RS de experimentos en IS

Reportes

Tabla 6. Ejemplo de Relación de evidencias con cada nivel/métrica para el caso de inspección de software

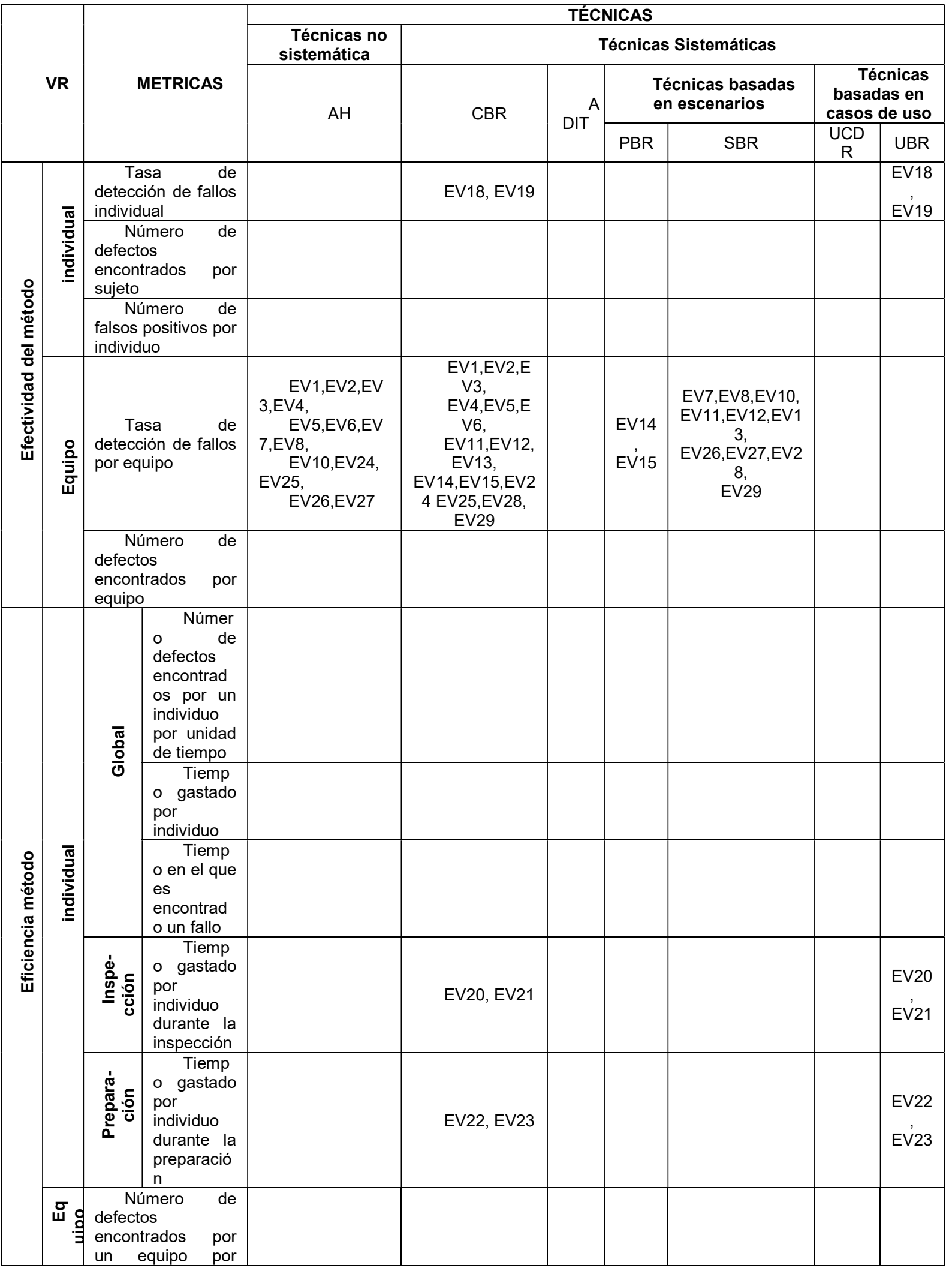




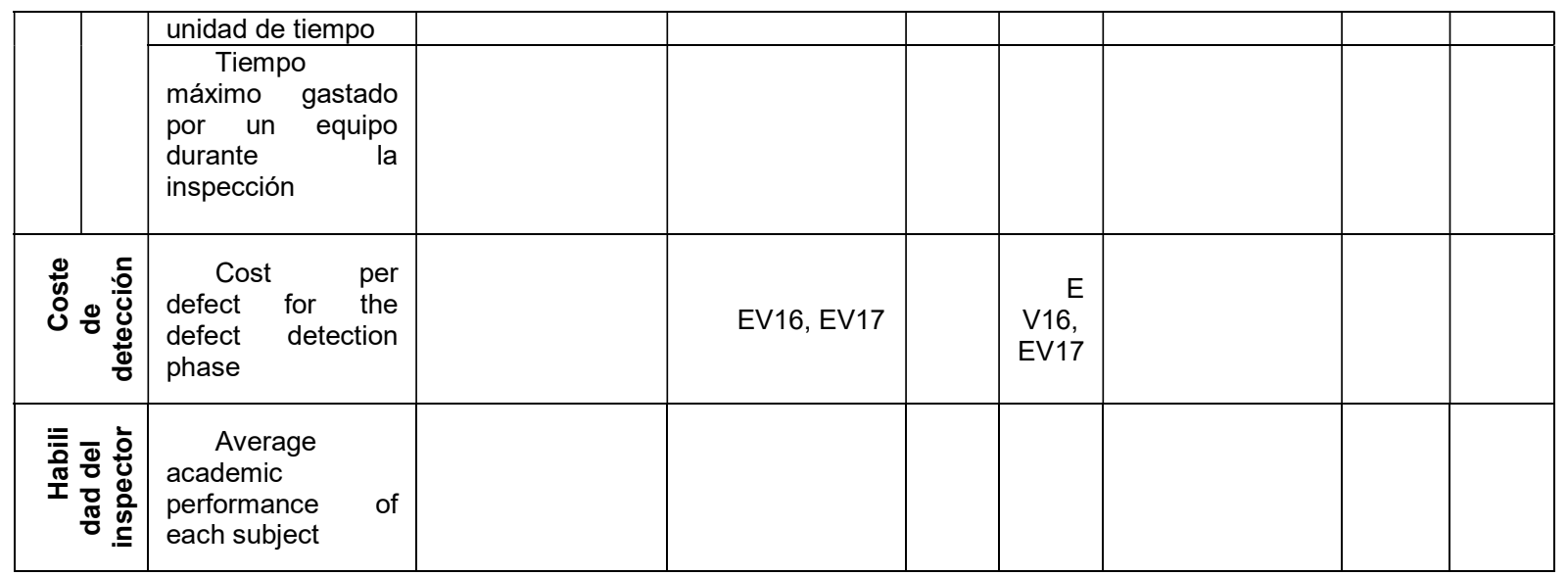

\subsubsection{Resumir evidencias}

La última tarea de esta actividad es combinar todas las evidencias obtenidas de acuerdo a un criterio. Esto persigue resumir de manera sencilla las evidencias que han podido ser recogidos durante la RS de manera que los profesionales e investigadores puedan dar soporte a aquellas decisiones que involucren alguna de las tecnologías estudiadas en la RS. Los criterios que pueden utilizarse para combinar las evidencias son:

- $\quad$ Nivel y/o Categoría de niveles

- Métrica y/o Variable respuesta

La combinación de evidencias según este criterio busca proporcionar todo el conocimiento posible acerca de cada técnica y puede ser utilizada por los profesionales de la ingeniería del software que para comparar y seleccionar tecnologías. Para el primer caso, el procedimiento a seguir es combinar todas las evidencias obtenidas para un nivel (p.e. técnica, método) y las diferentes métricas evaluadas. Para ello se recorre cada una de las columnas de la tabla 'Relación de evidencias con cada nivel/métrica'. Los resultados de esta combinación pueden ser documentados en el formulario 'Resumen de evidencias por tecnología' (ver Apéndce D).

Un ejemplo de este resumen para la RS de inspección de software es presentado en la tabla 9.9.

Tabla 7. Ejemplo de resumen de evidencias por nivel

\begin{tabular}{|c|c|c|}
\hline $\begin{array}{c}\text { Nivel o } \\
\text { tecnología }\end{array}$ & Evidencias obtenidas \\
\hline CBR & $\begin{array}{l}\text { En relación a la efectividad de la técnica, existe una tendencia a que cuando la } \\
\text { inspección se realice en una sola ronda y sin incorporar roles, CBR sea menos } \\
\text { efectiva que } \mathrm{AH} \text { en términos de la Tasa de detección de fallos por equipo. En }\end{array}$ \\
\hline
\end{tabular}




\begin{tabular}{|c|c|}
\hline & $\begin{array}{l}\text { tales condiciones CBR fue también mucho menos efectiva que PBR. } \\
\text { - Aunque no se puede afirmar con certeza, parece también haber una tendencia } \\
\text { a que CBR se comporte con menos efectividad que SBR, independientemente } \\
\text { de que la inspección se realice en una o dos rondas. } \\
\text { - En algún caso, al incorporar roles, CBR ha demostrado ser más efectiva que AH. } \\
\text { Sin embargo, en la mayoría de los casos encontrados parece haber una } \\
\text { tendencia a que se mantenga la superioridad de AH frente a CBR. } \\
\text { En algunas ocasiones, cuando la efectividad de CBR ha sido medida en términos } \\
\text { de la Tasa de detección de fallos individual, CBR parece haber tenido un peor } \\
\text { comportamiento que UBR. } \\
\text { No se sabe nada de la efectividad de CBR frente a SBR/PBR/UBR utilizando roles } \\
\text { durante la inspección, ni de la efectividad de CBR frente a AH/PBR/UBR } \\
\text { utilizando dos rondas. } \\
\text { En cuanto a la eficiencia, es posible que en algunos casos el Tiempo gastado por } \\
\text { un individuo durante la inspección sea un poco mayor al utilizar CBR que al } \\
\text { utilizar una técnica basada en casos de uso (UBR). Esto ha sido así cuando la } \\
\text { inspección no incorpora roles y se realiza en una sola ronda. De manera similar, al coste, se ha podido comprobar que en algunas } \\
\text { el Tiempo gastado por un individuo durante la preparación fue mayor al utilizar } \\
\text { cBR que al utilizar UBR. } \\
\text { incorporado roles ni una segunda ronda. }\end{array}$ \\
\hline
\end{tabular}

Para el segundo criterio el procedimiento es similar, aunque la combinación de evidencias se realizará recorriendo cada fila de la tabla 'Relación de evidencias con cada nivel/métrica'. La combinación de evidencias según este criterio busca proporcionar todo el conocimiento posible acerca de un aspecto en particular de la tecnología evaluada (p.e. eficiencia, efectividad, etc.). Los resultados de esta combinación pueden ser documentados en el formulario ‘Resumen de evidencias por variable respuesta (ver Apéndice D). Un ejemplo de este resumen para la RS de inspección de software es presentado en la tabla 9.10.

Tabla 9.10. Ejemplo de resumen de evidencias por métrica

\begin{tabular}{|l|l|}
\hline $\begin{array}{l}\text { Métrica/ } \\
\text { VR }\end{array}$ & Evidencias obtenidas \\
\hline & \\
\hline
\end{tabular}




\section{CAPÍTULO 10. FASE DE REPORTE}

Una vez concluidas las fases anteriores, es posible generar un reporte de la agregación, bien sea para cada uno de los grupos por separado o de manera compilada.

En ambos casos, es recomendable utilizar un reporte completo que permita comprender el contexto en el cual se han generado las evidencias y recomendaciones mencionadas.

Para ello, se propone utilizar el Informe de la Revisión Sistemática como documento en el que se recopile toda la información relacionada con RS y las evidencias obtenidas, bien sea para un sólo grupo de estudios o para varios grupos relacionados. En resumen, este informe contendrá la siguiente información.

Para la elaboración del informe se sugieren las siguientes actividades:

\subsection{Presentar una Introducción a la RS.}

Esto incluye describir la organización delos estudios incluidos en la misma, presentando para ello:

- $\quad$ Identificación de estudios.

- Grupos de agregación.

\subsection{Presentar un resumen de los datos procesados durante la RS.}

Esta información consta de los siguientes aspectos:

- Estudios incluidos.

- $\quad$ Factor principal/Niveles.

- Métricas.

- $\quad$ Otros factores ensayados.

- Resultados experimentales.

- Dependiendo del perfil del usuario, la información indicada puede ser presentada de manera codificada o de manera natual.

\subsection{Presentar las evidencias obtenidas.}


Para ello puede decidirse un criterio de filtrado en virtud del perfil del usuario de la RS. En particular, para aquellos usuarios con un perfil de Gerente o Profesional se deberían presentar las evidencias sin ningún tipo de codificación, esto es, en un lenguaje totalmente natural. Esto incluye:

- $\quad$ Traducir las métricas y niveles codificadas a los valores originales.

- $\quad$ Interpretar el tamaño del efecto.

- $\quad$ Interpretar el grado de de confianza.

Por otra parte, cuando el usuario de la revisión posea un perfil Investigador las evidencias pueden ser presentadas de dos maneras:

- $\quad$ Tal y como se ha descrito para los perfiles Gerente y Profesional, o

- Evidencias con las métricas y niveles codificados, el valor correspondiente al tamaño efecto expresado en los términos originales de $d$ o $r$ arrojados por el método utilizado, grado de confianza sin interpretación.

\subsection{Presentar las hipótesis establecidas y las restricciones de la RS en función de las condiciones no ensayadas por los estudios.}

A continuación se presenta el contenido del Informe de Revisción resultado de esta fase. 


\section{INFORME DE LA REVISIÓN SISTEMÁTICA}

\section{Introducción a la Revisión Sistemática}

[En esta sección se describirá el propósito que originalmente motivó la revisión sistemática. En aquellos casos en los cuales no se contó con una pregunta de revisión precisa desde el comienzo, se describirá en esta sección:

Estrategia de búsqueda superficial utilizada, incluyendo las cadenas y bases de datos utilizados

Resumen de resultados

Grupos potencialmente agregables identificados

Finalmente, esta sección describirá el grupo agregable que ha sido escogido para ejecutar la revisión sistemática y la pregunta de revisión.

Si la pregunta de revisión fue establecida inicialmente, esta sección la aborda directamente]

\section{Identificación de estudios}

[Esta sección describe los resultados de la búsqueda refinada, así como los resultados de la evaluación de los estudios. Finalmente, presenta un resumen de los estudios seleccionados y de los estudios excluidos junto con el criterio de exclusión utilizado. Debería contener un resumen con la siguiente información:

Estrategia de búsqueda refinada

Resumen de resultados

Evaluación de la calidad

Estudios seleccionados

Estudios excluidos

]

\section{Síntesis de datos}

Factor principal/Niveles

[Describir el factor principal de acuerdo con la pregunta de revisión establecida. Por ejemplo, "en los estudios identificados se han ensayado las siguientes técnicas: T1, T2...Tn.] 


\section{Métricas}

[Describir las métricas para las cuales se han ensayado los niveles anteriores. Por ejemplo, "las técnicas T1 y $\mathrm{T} 2$ han sido ensayadas para las siguientes métricas: M1, M2, ...Mn.]

\section{Otros factores ensayados}

[Describir aquellos otras variables moderadoras que han sido ensayadas como factores en los estudios seleccionados. Describir los niveles para cada uno de los factores adicionalmente estudiados.

Por ejemplo, las técnicas T1 y T2 han sido ensayadas utilizando otros factores, tales como: F1, F2...Fn. A continuación se presentan los niveles para cada uno de estos factores:

\begin{tabular}{|c|c|c|c|}
\hline FACTOR & Nivel 1 & Nivel 2 & ...Nivel $n$ \\
\hline F1 & N1 & N2 & \\
\hline F2 & N3 & N4 & \\
\hline Fn & N5 & N6 & N7 \\
\hline
\end{tabular}

]

\section{Resultados experimentales}

[Esta sección describe los resultados cuantitativos y cualitativos reportados por los estudios seleccionados. En lo posible deberá representarse a través de una tabla que muestre de manera resumida los valores obtenidos para las diferentes métricas y niveles ensayados, por cada uno de los factores analizados.]

\section{Grupos de agregación}

[Esta sección presenta el resumen de los grupos que pudieron ser agregados, esto es, aquellos grupos que contienen al menos dos estudios que ensayaron los mismos niveles y métricas.] 


\section{Evidencias}

[Esta sección presenta las piezas de conocimiento que han sido obtenidas de la agregación. La presentación de estas evidencias puede hacerse en diferentes formatos, dependiendo del perfil del lector:

Estadístico

Investigadores en Ingeniería del Software

Profesionales en Ingeniería del Software

Gerentes]

\section{Recomendaciones}

[Esta sección presenta las recomendaciones que se derivan de las evidencias anteriores. Tales recomendaciones deben contener alguna indicación de la generabilidad de la misma con base en la fiabilidad de la(s) evidencia(s) correspondiente(s).]

\section{Generalización}




\section{PARTE III - VALIDACIÓN}




\section{CAPÍTULO 11. EVALUACIÓN DE LA PROPUESTA}

Típicamente, la propuesta de un nuevo método o proceso implica la evaluación o validación del mismo a fin de comprobar que satisface los requerimientos mínimos para ser considerado como una contribución real a su área de conocimiento. Tal evaluación implica necesariamente la identificación de aquellas mejoras requeridas para que la solución propuesta alcance los objetivos de investigación.

Aunque existen diversos métodos para evaluar la propuesta de un nuevo proceso, éstos se encuentran limitados por aspectos relacionados con el tiempo, la naturaleza del conocimiento a evaluar, los riesgos de realizar la evaluación, entre otros. Es por ello que cuando se estableció el camino metodológico a seguir en esta investigación (descrito en el Capítulo 4 - Metodología) se seleccionó el método de evaluación utilizando para ello el enfoque sistemático provisto por DESMET (B. Kitchenham, 1996), lo cual garantizaría que la evaluación fuera factible y al mismo tiempo útil. Es así como se seleccionó un método basado en características que permitirá medir la calidad de la propuesta de manera objetiva; estando al mismo basado en la aplicación de la propuesta a un caso de estudio.

Hasta el momento, se ha descrito una propuesta de proceso de RS adecuado a la IS junto con algunos ejemplos de su aplicación a fin de garantizar una mejor comprensión. Este capítulo en cambio tiene como objetivo utilizar la aplicación de esta propuesta como una forma de evaluación y presentar de una manera comprensiva los resultados obtenidos; así como recolectar las críticas o recomendaciones realizadas por los evaluadores.

\subsection{ANÁLISIS DE CARACTERÍSTICAS POR CASO DE ESTUDIO}

Tal como se describió en el Capítulo 4, una vez aplicado un conjunto de criterios técnicos y prácticos propuestos por DESMET (B. Kitchenham, 1996), fue posible concluir que el método más adecuado para la evaluación de esta propuesta es el Análisis de características por Caso de estudio. Siendo esto, además, consistente con la premisa del modelo de I-A seguido en esta investigación, el cual promueve el uso de los casos de estudio participativos. Traduciéndose esto en que durante la I-A los investigadores no sólo observan los fenómenos, sino que participan e intervienen en el tema que está bajo estudio (Baskerville \& Wood-Harper, 1996).

La estrategia para conducir la evaluación según el método de Análisis de características por Caso de estudio incluye las siguientes actividades (B. Kitchenham, 1996): 
1. Decidir las propiedades o características requeridas.

2. Priorizar estas características con respecto a los usuarios del método.

3. Decidir el nivel de confianza que es requerido en los resultados y seleccionar el nivel de rigurosidad requerido para el análisis de características.

4. Establecer una escala que pueda ser aplicada a todas las características.

5. Asignar responsabilidades para conducir el análisis de características.

6. Llevar a cabo la evaluación.

7. Analizar e interpretar los resultados.

Para facilitar la comprensión de los resultados obtenidos de la evaluación, el capítulo ha sido estructurado de la siguiente manera: en primer lugar, se establecen las características a ser evaluadas para el proceso de RS con base en las hipótesis de investigación; posteriormente, se presenta la selección y planificación de los proyectos piloto; seguidamente, cada uno de los casos de estudio es presentado. En cada caso, se presenta el análisis de los resultados obtenidos a la luz de las características de interés.

\subsection{DEFINICIÓN Y PRIORIZACIÓN DE LAS CARACTERÍSTICAS REQUERIDAS}

La propuesta de proceso de RS para la IS desarrollada en esta investigación puede considerarse como un objeto de evaluación de carácter metodológico. Prescribe lineamientos y recomendaciones específicas a lo largo de fases, actividades, tareas y artefactos. Asimismo incluye técnicas y métodos que apoyan en la obtención de resultados y el cumplimiento de su objetivo.

Tiene entonces sentido que, al definir un conjunto de características para su evaluación, se incluyan propiedades que especifiquen lo que se espera de un proceso de esta naturaleza. Tales características serán la base sobre la que se establecerá la contribución del proceso y su idoneidad en relación al problema que se espera resolver con él. Estas características serán la base de la evaluación a realizar en este capítulo.

Durante la investigación, no se localizó en la literatura un conjunto de características propuestas previamente, por lo que se realizó una propuesta con base en la experiencia. Para proponer este conjunto de características deben considerarse aquellas propiedades que son generalmente valoradas en todo proceso o metodología, p.e. su Efectividad y Eficiencia. La primera de ellas está asociada con sus resultados y el logro de sus objetivos; mientras que la segunda está planteada en función de sus costos. A parte de éstas 
características, es necesario también valorar la facilidad con la que se puede implementar el proceso, esto es, su Factibilidad, así como el apoyo que proporciona a aquel quien lo utiliza, el Grado de soporte que provee.

Es así como para esta evaluación se han propuesto 4 características generales que representan las propiedades o atributos que el proceso debe cumplir. Tales características son el Grado de soporte, la Efectividad, la Eficiencia, y la Factibilidad. Tal como se describe en la tabla 11.1. En un sentido general, las características señaladas anteriormente buscan medir la contribución y utilidad del proceso propuesto.

En el contexto específico de un proceso de RS para la IS, tales características pueden ser priorizadas ya que difícilmente se puede lograr alcanzar altos niveles de todas ellas, pues éstas entran en competencia entre sí (p.e. Eficiencia y Efectividad). Se busca entonces alcanzar un cierto equilibrio entre estos atributos o características. De tal manera, se tiene que el Grado de soporte y la Efectividad tienen una prioridad alta, mientras que la Eficiencia es considerada menos importante. Con ello, se busca dar a entender que el soporte que brinde el proceso, así como sus resultados son requerimientos que deben ser ampliamente satisfechos por el proceso. Por otra parte, al estar generalmente en conflicto, la Eficiencia puede ser sacrificada en alguna medida y en virtud del logro de mejores resultados. La Factibilidad fue la característica considerada más importante, pues sólo si el proceso puede ser implementado completamente podrá ofrecer los beneficios esperados para sus usuarios.

Por último, al tratar de evaluar un proceso metodológico complejo, es lógico pensar que para valorar de manera objetiva algunas de sus características se haga uso de la comparación del proceso evaluado contra un baseline, preferiblemente externo.

Una vez establecidas las características o propiedades de interés, es necesario establecer las subcaracterísticas asociadas, así como la definición operacional para cada una de ellas (véase Tabla 11.2). Es así como el Grado de soporte es definido a través de 2 sub-características: el Modelo de proceso y la Documentación. Nótese que estas sub-características establecen cuán adecuado y completos son los componentes del proceso y el material de apoyo (p.e. manual).

Por otra parte, la Efectividad es definida con base en los resultados obtenidos por el proceso y su utilidad. Mientras que la Eficiencia, en cambio, es definida con base en el tiempo y esfuerzo requeridos por el proceso. Finalmente, la Factibilidad es representada por una única sub-característica referida a la implementación del proceso.

La definición operacional de todas las sub-características es expresada a través de preguntas específicas que son valoradas a través de una escala de likert de 2 ó 3 valores. 
Nótese que las características y sub-características propuestas para esta evaluación son de carácter generalista. No se considera necesario incluir los requerimientos específicos de una RS en IS, debido a que tales aspectos fueron analizados a priori en cada fase, asegurando su incorporación en el diseño de la propuesta.

Tabla 11.1. Características a ser evaluadas

\begin{tabular}{|c|c|c|}
\hline Nivel & Descripción & Prioridad \\
\hline Grado de soporte & $\begin{array}{l}\text { Se refiere a la estructura y documentación del proceso, y si éstos } \\
\text { orientan a los usuarios inexpertos en su implementación. }\end{array}$ & Alta \\
\hline Efectividad & $\begin{array}{l}\text { Esta característica evalúa si el proceso alcanza el objetivo de una RS. } \\
\text { Evalúa los resultados obtenidos con el proceso de RS, y los compara } \\
\text { con enfoques alternativos. } \\
\text { La evaluación de esta característica requiere la participación de } \\
\text { usuarios expertos en el proceso. }\end{array}$ & Alta \\
\hline Eficiencia & $\begin{array}{l}\text { Se refiere al uso de recursos para acometer el proceso de RS } \\
\text { evaluado. Se enfoca principalmente en evaluar el tiempo } \\
\text { consumido por las tareas así como la curva de aprendizaje (esfuerzo) } \\
\text { de los revisores. }\end{array}$ & Media \\
\hline Factibilidad & $\begin{array}{l}\text { Se refiere a que el proceso pueda ser acometido completamente. Es } \\
\text { especialmente interesante en el caso de usuarios con poca o } \\
\text { ninguna experiencia }\end{array}$ & Muy alta \\
\hline
\end{tabular}

Tabla 11.2. Sub-características a evaluar

\begin{tabular}{|c|c|c|c|}
\hline Característica & Sub-Característica & Preguntas & Escala \\
\hline Grado de soporte & $\begin{array}{l}\text { Modelo de } \\
\text { proceso }\end{array}$ & $\begin{array}{l}\text { ¿Es adecuado al objetivo? } \\
\text { Se considera que un proceso de RS es adecuado } \\
\text { al objetivo cuando la mayoría de las actividades } \\
\text { propuestas contribuyen a alcanzar evidencias, } \\
\text { conclusiones o recomendaciones que son } \\
\text { considerada, coherentes, válidas y significativas }\end{array}$ & 1=No, 3=Sí \\
\hline
\end{tabular}




\begin{tabular}{|c|c|c|c|}
\hline & $\begin{array}{l}\text { ¿El proceso posee consistencia entre sus } \\
\text { componentes? } \\
\text { Un proceso de RS es consistente cuando todos } \\
\text { sus componentes son definidos de una manera } \\
\text { clara, estandarizada y fácil de comprender. }\end{array}$ & 1=No, 3=Sí \\
\hline & & $\begin{array}{l}\text { ¿El proceso se encuentra bien organizado? } \\
\text { Un proceso se considera bien organizado cuando } \\
\text { posea una estructura coherente que permita } \\
\text { identificar las entradas, salidas y el flujo de cada } \\
\text { una de las actividades. }\end{array}$ & 1=No, 3=Sí \\
\hline & & $\begin{array}{l}\text { ¿El proceso es completo (auto-contenido)? } \\
\text { Se entiende por auto-contenido a aquel proceso } \\
\text { que describe toda la información necesaria para } \\
\text { ser comprendido e implementado; incluyendo } \\
\text { aquella que corresponda con referencias } \\
\text { externas }\end{array}$ & 1=No, 3=Sí \\
\hline & & $\begin{array}{l}\text { ¿Se comporta según lo esperado? } \\
\text { Se espera que el proceso oriente paso a paso a } \\
\text { los revisores y que cada actividad genere un } \\
\text { resultado que agregue valor a la revisión: } \\
\text { - Debe localizar evidencias relevantes } \\
\text { suficientes } \\
\text { - Debe permitir extraer los datos necesarios } \\
\text { para la evaluación crítica de los estudios y su } \\
\text { agregación } \\
\text { Debe permitir jerarquizar los estudios } \\
\text { primarios según su calidad } \\
\text { Debe llegar a conclusiones o } \\
\text { recomendaciones sobre las comparaciones } \\
\text { de interés }\end{array}$ & 1=Sí, 3=No \\
\hline
\end{tabular}




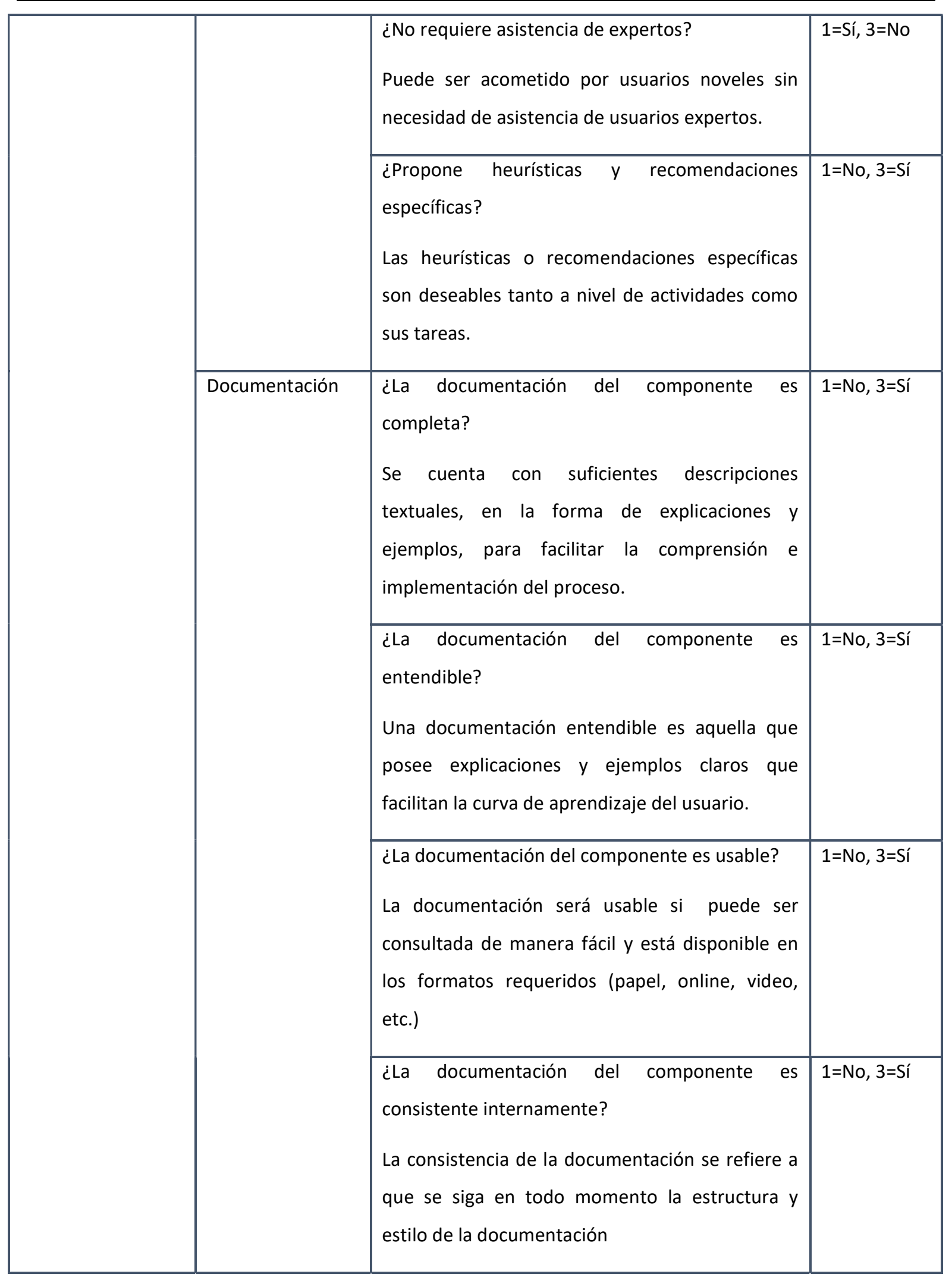




\begin{tabular}{|c|c|c|c|}
\hline & & $\begin{array}{l}\text { ¿La documentación del componente es adecuada } \\
\text { para la audiencia? } \\
\text { El documento será adecuada a la audiencia si el } \\
\text { contenido (y su nivel) es apropiado a los usuarios } \\
\text { a los que está dirigido el documento }\end{array}$ & 1=No, 3=Sí \\
\hline \multirow[t]{4}{*}{ Efectividad } & \multirow[t]{4}{*}{ Resultados } & $\begin{array}{l}\text { ¿Alcanza su objetivo? } \\
\text { El proceso de RS debe obtener conclusiones } \\
\text { válidas y útiles sobre la comparación de } 2 \\
\text { tecnologías }\end{array}$ & 1=No, 3=Sí \\
\hline & & $\begin{array}{l}\text { Capacidad para producir los resultados } \\
\text { esperados } \\
\text { De acuerdo con los siguientes niveles: } \\
\text { - Baja: si el proceso genera menos de la } \\
\text { mitad de los resultados esperados } \\
\text { - Media: el proceso obtiene entre el 50- } \\
\text { 70\% de los resultados esperados } \\
\text { - Alta: el proceso alcanza entre } 90-100 \% \\
\text { de los resultados esperados }\end{array}$ & $\begin{array}{l}\text { 1=baja, } \\
\text { 2=media, } \\
\text { 3=alta }\end{array}$ \\
\hline & & $\begin{array}{l}\text { Capacidad para producir resultados relevantes } \\
\text { Los resultados se considerarán relevantes de } \\
\text { acuerdo a los siguientes niveles: } \\
\text { - Baja: los resultados obtenidos no } \\
\text { presentan significancia } \\
\text { - Media: los resultados obtenidos tienen } \\
\text { una relevancia limitada en un contexto } \\
\text { específico } \\
\text { - Alta: los resultados obtenidos son } \\
\text { relevantes para cualquier contexto }\end{array}$ & $\begin{array}{l}\text { 1=baja, } \\
2=\text { media, } \\
3=a l t a\end{array}$ \\
\hline & & Capacidad para producir resultados útiles & 1=baja, \\
\hline
\end{tabular}




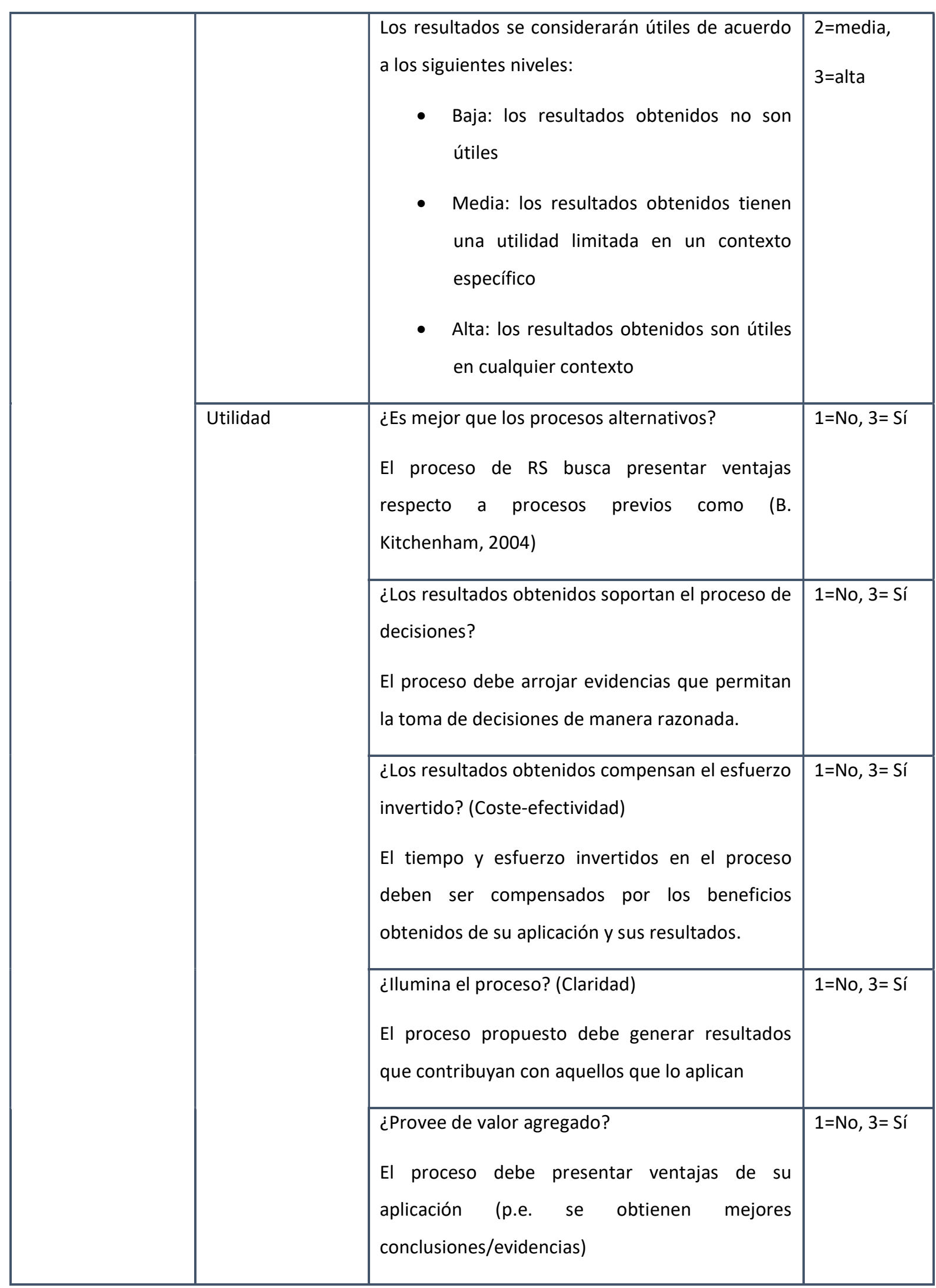




\begin{tabular}{|c|c|c|c|}
\hline & & $\begin{array}{l}\text { ¿Soporta una hipótesis? } \\
\text { El proceso debe poder generar evidencias que } \\
\text { respondan a una hipótesis referida a la } \\
\text { comparación de } 2 \text { o más técnicas. }\end{array}$ & 1=No, 3= Sí \\
\hline & & $\begin{array}{l}\text { ¿Satisface criterios de ganancia específicos? } \\
\text { Se espera que el proceso responda a los intereses } \\
\text { de los revisores }\end{array}$ & 1=No, 3= Sí \\
\hline \multirow[t]{2}{*}{ Eficiencia } & Esfuerzo & $\begin{array}{l}\text { Facilidad de aprendizaje } \\
\text { El sistema es fácilmente comprensible y facilita la } \\
\text { curva de aprendizaje }\end{array}$ & $\begin{array}{l}\text { 1=baja, } \\
2=\text { media, } \\
3=\text { alta }\end{array}$ \\
\hline & Tiempo & $\begin{array}{l}\text { No. de horas }(n) \\
\text { Número de horas que toma el proceso de RS }\end{array}$ & $\begin{array}{l}1=n \geq 480 \\
3=n<480\end{array}$ \\
\hline \multirow[t]{2}{*}{ Factibilidad } & Implementación & $\begin{array}{l}\text { ¿El proceso es entendible? } \\
\text { Es posible entender el proceso para acometer sus } \\
\text { actividades y tareas }\end{array}$ & 1=No, 3= Sí \\
\hline & & $\begin{array}{l}\text { Facilidad de implementación } \\
\text { El proceso incluye actividades y técnicas que } \\
\text { pueden ser fácilmente acometidas }\end{array}$ & $\begin{array}{l}\text { 1=baja, } \\
2=\text { media, } \\
3=\text { alta }\end{array}$ \\
\hline
\end{tabular}

\subsection{SELECCIÓN DE EVALUADORES Y PROYECTOS}

Otra de las actividades necesarias para la evaluación es la asignación de responsabilidades. Esto implica que se debe seleccionar el caso de estudio y el o los evaluadores que llevarán a cabo el mismo.

En este contexto, un caso de estudio se refiere a la conducción de una revisión sistemática en la que se aplique el proceso propuesto. La selección del caso de estudio implica a su vez la consideración de los siguientes aspectos:

- Área o tópico en la que se hará la revisión, lo cual estará determinado en buena medida por la existencia de estudios primarios relacionados con el tema, y la disponibilidad de aún antecedente que sirva con referente (baseline) para comparar los resultados. 
- $\quad$ El Perfil del evaluador es otro aspecto determinante, pues si bien es deseable que el perfil que posea el evaluador influirá tanto en la comprensión del proceso como en los resultados obtenidos, es requerido que tal perfil se corresponda con el de la mayoría de usuarios del proceso.

- Referente para la comparación de resultados (baseline): precisamente porque no es sencillo determinar si la aplicación del proceso realizada por los evaluadores es adecuada, contar con un estudio de referencia es útil a fin de establecer posibles defectos en el proceso, así como identificar mejoras requeridas. En este contexto, el referente será un estudio en el que se haya realizado la RS a través de otro proceso.

- Finalmente, el caso de estudio debe permitir evaluar las características propuestas en la sección anterior. En el caso en que se considere que el caso de estudio no permite valorar una característica requerida del proceso, se deberá seleccionar un segundo caso de estudio. Lo anterior determina que no todas las características tienen que ser evaluadas a través de un mismo caso de estudio; pudiéndose seleccionar más de un caso de estudio hasta lograr valorar las 4 características propuestas.

Se decidió ejecutar más de un caso de estudio que permitiera una evaluación por distintos perfiles, en diferentes tópicos y con el fin de valorar todas las características. En cada caso de estudio se tomó como baseline el trabajo más relevante dentro del tópico y que fuera contemporáneo con la conducción de la evaluación.

\section{Caso de estudio 1}

La evaluación del proceso propuesto requiere de la participación de revisores noveles para poder hacer una valoración objetiva de algunas de las características definidas en la sección 11.1. Esto implica contar con profesionales sin experiencia en revisiones sistemáticas, lo cual permitirá establecer, con la mayor objetividad y precisión posible el Grado de soporte, la Eficiencia y Factibilidad del proceso.

Para ello, en el caso de estudio 1 , se consideró adecuado involucrar a estudiantes de post-grado (específicamente, estudiantes que realizan su tesis de Máster), quienes poseen conocimientos avanzados sobre la IS y las tecnologías más actuales, aún cuando no poseen experiencia en RS.

Se puede considerar que el perfil de estos revisores se corresponde con el de la mayoría de los profesionales que eventualmente pudieran ser usuarios del proceso propuesto; quienes se encuentran 
involucrados en diversas decisiones en las que tienen que seleccionar la tecnología más adecuada a las restricciones de sus proyectos, dentro de una gran variedad de tecnologías disponibles.

Al igual que los revisores seleccionados para este caso de estudio, los profesionales de la IS poseen conocimientos generales, y en algunos casos especializados, sobre la disciplina (p.e. análisis, implementación, pruebas, etc.) mas no suelen poseer conocimientos ni experiencia en el uso de evidencias empíricas.

Por otra parte, se decidió aplicar el proceso de RS en el área de Programación en pareja, ya que se contaba con una revisión bastante rigurosa contemporánea con el caso de estudio, reportada por (Hannay et al., 2009), la cual pudo servir como gold standard.

Por último, en este caso de estudio sólo se evaluaron las fases de Búsqueda y Extracción de datos, debido a las restricciones de tiempo impuestas por el programa de Máster al que pertenecían los evaluadores.

\section{Caso de estudio 2}

Si bien los revisores que se seleccionaron en el caso de estudio 1 son representativos de una población de interés para esta investigación, se requiere también comprobar las características del proceso con un revisor experimentado.

Un revisor con experiencia en RS debe ser capaz de aplicar las actividades propuestas por el proceso obteniendo el mayor provecho de las mismas en términos de evidencias.

Al mismo tiempo, se quiso incorporar un revisor que no tuviera que superar la curva de aprendizaje para que la complejidad del proceso no fuese un factor determinante. Es por esto que el Grado de soporte no es evaluado en este caso.

El caso de estudio 2 fue realizado en el área de Inspección de software ya que se contaba en este caso con un referente, la revisión realizada por (Ciolkowski, 2009). Tal como se indicó arriba, se utiliza un evaluador con experiencia en el proceso; por lo que se espera contar con la base necesaria para determinar de manera precisa la Efectividad, la Eficiencia y la Factibilidad del mismo. Esta característica no podría ser evaluada por investigadores con poca experiencia.

En este caso de estudio se aplicaron y evaluaron todas las fases del proceso propuesto.

Las tablas 13.3 - 13.4 resumen las condiciones de ambos casos de estudio. 
Tabla 11.3. Ejercicios de evaluación realizados sobre el proceso de RS

\begin{tabular}{|l|l|l|l|l|}
\hline $\begin{array}{l}\text { Caso de } \\
\text { estudio }\end{array}$ & Evaluador & Perfil & Tópico & Baseline \\
\hline 1 & $\begin{array}{l}\text { Nilupa Bandara, } \\
\text { Sanka } \\
\text { Samaranayake }\end{array}$ & Novel & $\begin{array}{l}\text { Programación en } \\
\text { pareja }\end{array}$ & $\begin{array}{l}\text { (Kitchenham. } \\
\text { B.A. \& Charters, } \\
\text { 2007) }\end{array}$ \\
\hline 2 & Anna Grimán & Experto & $\begin{array}{l}\text { Inspección } \\
\text { software }\end{array}$ & $\begin{array}{l}\text { (Ciolkowski, } \\
\text { 2009) }\end{array}$ \\
\hline
\end{tabular}

Tabla 11.4. Ejercicios de evaluación realizados sobre el proceso de RS

\begin{tabular}{|c|c|c|c|c|c|c|c|c|c|c|}
\hline \multirow{2}{*}{$\begin{array}{l}\text { Caso de } \\
\text { estudio }\end{array}$} & \multirow[b]{2}{*}{ Tópico } & \multicolumn{4}{|c|}{ Características a evaluar } & \multicolumn{5}{|c|}{ Fases a evaluar } \\
\hline & & $\begin{array}{l}\stackrel{8}{ \pm} \\
\stackrel{0}{0} \\
\stackrel{0}{0}\end{array}$ & 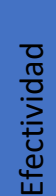 & 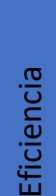 & 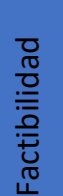 & $\begin{array}{l}\frac{\pi}{0} \\
\frac{d}{\partial} \\
\frac{0}{0} \\
y \\
0\end{array}$ & 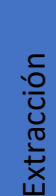 & $\begin{array}{l}\frac{0}{\pi} \\
\frac{\pi}{\pi} \\
\frac{0}{\pi}\end{array}$ & 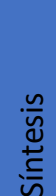 & 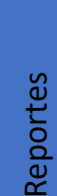 \\
\hline 1 & $\begin{array}{l}\text { Programación en } \\
\text { pareja }\end{array}$ & $x$ & & $x$ & $x$ & $x$ & $x$ & & & \\
\hline 2 & $\begin{array}{l}\text { Inspección de } \\
\text { software }\end{array}$ & & $x$ & $x$ & $x$ & $x$ & $x$ & $x$ & $x$ & $x$ \\
\hline
\end{tabular}

En las próximas secciones ambos casos de estudio son descritos y analizados.

\subsection{CASO DE ESTUDIO 1 (PROGRAMACIÓN EN PAREJA)}

En este caso de estudio se llevaron a cabo dos RS sobre el mismo tópico. En una de ellos, (Bandara, 2010) aplicó el proceso propuesto en esta investigación. En la segunda revisión, (Samaranayake, 2010) aplicó el proceso propuesto por (Kitchenham. B.A. \& Charters, 2007) que es, además, uno de los antecedentes 
analizados en esta investigación. De tal manera, la RS realizada siguiendo el proceso de (Kitchenham. B.A. \& Charters, 2007) serviría como baseline contra el cual comparar los resultados obtenidos por el proceso propuesto.

En ambos casos, los evaluadores fueron tesistas del Máster en Ingeniería de Software Empírico (EMSE) de la UPM. Ambos revisores registraron cuidadosamente los tiempos, los resultados intermedios, los problemas encontrados y las soluciones adoptadas. Al final de cada fase (Búsqueda y Extracción de Datos) los resultados, los tiempos invertidos, y los problemas encontrados fueron rigurosamente comparados en términos cuantitativos y cualitativos.

\subsubsection{Preparación del caso de estudio}

Los revisores fueron provistos con manuales estilo cookbook con los lineamientos para cada una de las fases del proceso propuesto. Así mismo, se les proporcionó el procedimiento propuesto por (B. Kitchenham, 2004) , así como el estudio de referencia.

Por otra parte, para realizar la comparación de los procesos Grimán versus Kitchenham, (Bandara, 2010) y (Samaranayake, 2010) establecieron las siguientes tareas genéricas o procesos a alto nivel (ver Tabla 11.5):

Tabla 11.5. Tareas genéricas relacionadas con las fases de Búsqueda y Extracción

\begin{tabular}{|c|c|}
\hline Fase & Tareas Genéricas \\
\hline Búsqueda & $\begin{array}{ll}\text { - } & \text { Planificación de la revisión } \\
\text { - } & \text { Estrategia de búsqueda } \\
\text { - } & \text { Descarte de artículos irrelevantes } \\
\text { - } & \text { Selección de artículos relevantes }\end{array}$ \\
\hline $\begin{array}{l}\text { Extracción de } \\
\text { Datos }\end{array}$ & $\begin{array}{ll}\text { - } & \text { Estrategia de extracción } \\
\text { - } & \text { Extracción de datos } \\
\text { - } & \text { Formulación de grupos de agregación }\end{array}$ \\
\hline
\end{tabular}

Por último, los revisores establecieron junto con sus supervisores la siguiente caracterización para los problemas encontrados durante la ejecución de las distintas tareas:

- Documentación insuficiente (PB1): problemas asociados a descripciones de texto o instrucciones insuficientes provistas en la documentación de los lineamientos.

- Problemas relacionados con eficiencia (PB2): se refiere a problemas asociados con tareas ineficientes, las cuales son extremadamente consumidoras de tiempo. Tales tareas producen poco 
valor ante el esfuerzo invertido. Incluyen también aquellos casos en los que las restricciones impuestas por las instrucciones dadas, limiten la cobertura de la revisión.

- Errores en la documentación de lineamientos de la RS (PB3): problemas asociadas con instrucciones o referencias incorrectas y errores en la lógica de procedimientos.

- Ambigüedad o imprecisión en la documentación de lineamientos de la RS (PB4): problemas asociados a ambigüedades e imprecisiones de las instrucciones especificadas.

\subsubsection{Resultados del caso de estudio}

Recuérdese que los revisores sólo compararon dos de las fases del proceso, debido a las restricciones de tiempo sobrevenidas del programa de estudio. No obstante, (Samaranayake, 2010) acometió la fase de Síntesis de datos siguiendo los lineamientos de (Kitchenham. B.A. \& Charters, 2007), aunque con resultados pocos satisfactorios, como se discutirá más adelante.

Las tablas 11.6 y 11.7 resumen los resultados obtenidos y los problemas encontrados al ejecutar las fases de Búsqueda y Extracción de acuerdo a ambos procesos.

Como se mencionó anteriormente, era previsible que el bajo perfil de los revisores tuviera un impacto en los resultados obtenidos; sin embargo, esto representaba un requerimiento a efectos de evaluar características como el Grado de soporte, la Eficiencia y la Factibilidad, ya que permite tener una medición más objetiva de las mismas.

La validez y precisión de los resultados obtenidos por los revisores en este caso de estudio, puede ser determinada al comparar los mismos con una revisión de referencia o gold standard: (Hannay et al., 2009). La tabla 11.8 presenta la comparación de los resultados de aplicar ambos procesos Grimán y Kitchenham, versus los resultados obtenidos en el gold standard.

Tabla 11.6. Resultados más relevantes obtenidos de ambos procesos

\begin{tabular}{|l|l|l} 
Fase & Proceso propuesto por Grimán & Proceso propuesto por Kitchenham
\end{tabular}




\begin{tabular}{|c|c|c|c|}
\hline Búsqueda & $\begin{array}{l}\text { - Fuentes de información: IEEEXplore, } \\
\text { ACM DL, Google Scholar } \\
\text { - } \quad \text { Total artículos recuperados: } 168 \\
\text { - } \quad \text { Total artículos relevantes: } 63 \\
\text { - } \quad \text { Total artículos seleccionados: } 10 \\
\text { - } \quad \text { Tiempo total: } 219 \text { horas }\end{array}$ & - & $\begin{array}{l}\text { Fuentes de información: IEEEXplore, } \\
\text { ACM DL, Google Scholar } \\
\text { Total artículos recuperados: } 530 \\
\text { Total artículos relevantes: } 58 \\
\text { Total de artículos seleccionados: } 17 \\
\text { Tiempo total: } 132 \text { horas }\end{array}$ \\
\hline $\begin{array}{l}\text { Extracción de } \\
\text { Datos }\end{array}$ & 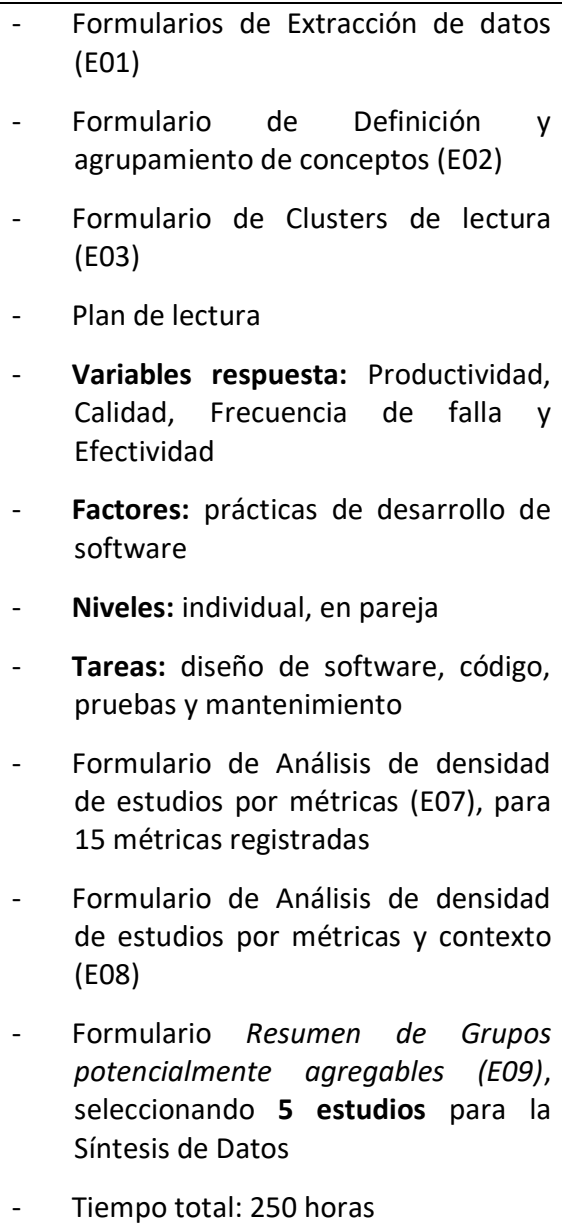 & - & $\begin{array}{l}\text { Formularios de extracción de datos } \\
\text { cumplimentados } \\
\text { Variables respuesta: Esfuerzo, } \\
\text { Calidad, y Duración } \\
\text { Tiempo total: } 207 \text { horas } \\
\text { Cantidad de artículos seleccionados } \\
\text { para la Síntesis: } 4\end{array}$ \\
\hline
\end{tabular}


Tabla 11.7. Problemas identificados en ambos procesos

\begin{tabular}{|c|c|c|}
\hline Fase & Proceso propuesto por Grimán & Proceso propuesto por Kitchenham \\
\hline Búsqueda & 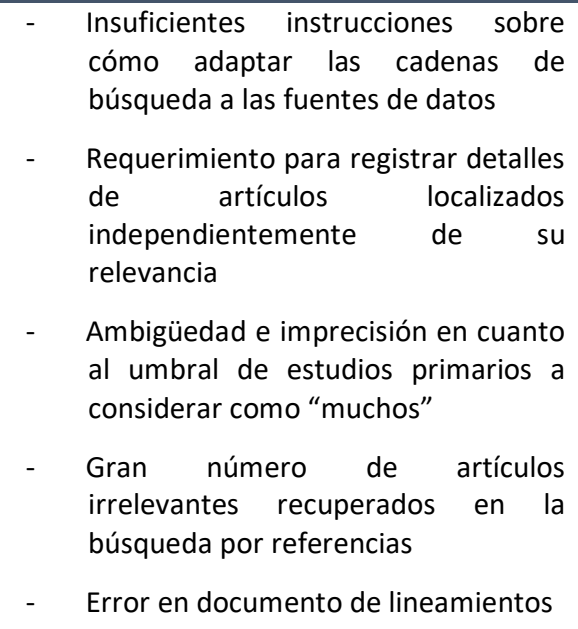 & $\begin{array}{l}\text { - Insuficientes instrucciones sobre } \\
\text { cómo seleccionar las fuentes de } \\
\text { datos } \\
\text { - Insuficiente número de artículos } \\
\text { relevantes obtenidos a través de las } \\
\text { cadenas de búsqueda formuladas } \\
\text { - Insuficientes instrucciones sobre } \\
\text { cómo adaptar las cadenas de } \\
\text { búsqueda a las fuentes de datos } \\
\text { - Falta de instrucciones sobre cómo } \\
\text { formular los criterios de } \\
\text { inclusión/exclusión }\end{array}$ \\
\hline $\begin{array}{l}\text { Extracción de } \\
\text { Datos }\end{array}$ & 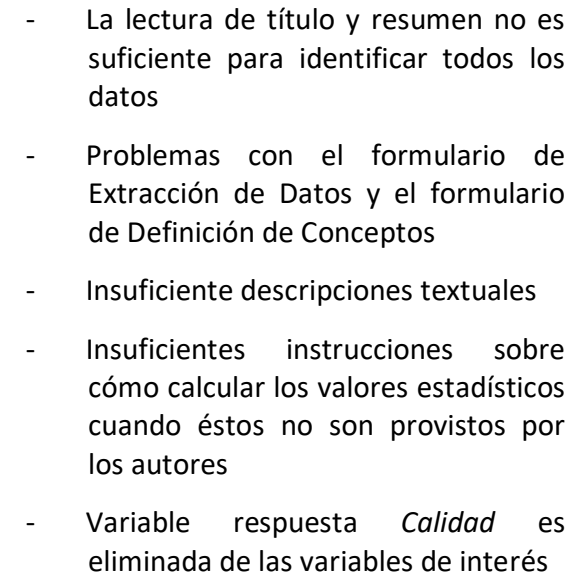 & $\begin{array}{l}\text { - Insuficientes instrucciones sobre } \\
\text { cómo seleccionar los campos de } \\
\text { datos } \\
\text { - Insuficientes instrucciones sobre } \\
\text { cómo llevar a cabo la tarea de } \\
\text { extracción de datos piloto } \\
\text { - Insuficientes instrucciones sobre } \\
\text { cómo llevar a cabo el proceso de } \\
\text { extracción de datos }\end{array}$ \\
\hline
\end{tabular}


Tabla 11.8. Comparación de los procesos Grimán y Kitchenham versus (Hannay et al., 2009)

\begin{tabular}{|c|c|c|c|}
\hline $\begin{array}{l}\text { Actividad } \\
\text { relevante }\end{array}$ & $\begin{array}{l}\text { Resultados obtenidos al aplicar el proceso de } \\
\text { Grimán }\end{array}$ & $\begin{array}{l}\text { Resultados obtenidos al aplicar el proceso de } \\
\text { Kitchenham }\end{array}$ & Resultados obtenidos en la revisión original \\
\hline $\begin{array}{c}\text { Bases de } \\
\text { datos incluidas }\end{array}$ & - $\quad 3$ Bases de datos bibliográficas & $\begin{array}{l}\text { - } 5 \text { Bases de datos bibliográficas } \\
\text { - Búsqueda manual: actas de congresos } \\
\text { del área }\end{array}$ & - 3 Bases de datos bibliográficas \\
\hline $\begin{array}{l}\text { Campos de } \\
\text { búsqueda }\end{array}$ & - $\quad$ Título, resumen y palabras claves & Título, resumen y palabras claves & - $\quad$ No especificados \\
\hline $\begin{array}{l}\text { No. } \\
\text { Artículos } \\
\text { recuperados }\end{array}$ & -168 & $-\quad 236$ & -539 \\
\hline $\begin{array}{l}\quad \text { No. } \quad \text { de } \\
\text { artículos } \\
\text { relevantes }\end{array}$ & $-63(37.5 \%)$ & $-\quad 57(24.1 \%)$ & -57 \\
\hline $\begin{array}{l}\quad \text { No. de } \\
\text { artículos } \\
\text { seleccionados }\end{array}$ & -10 & $-\quad 18(7.6 \%)$ & $-\quad 18(31.6 \%)$ \\
\hline $\begin{array}{l}\quad \text { No } \quad \text { de } \\
\text { artículos } \\
\text { agregables }\end{array}$ & -4 & $-\quad 18$ & -4 \\
\hline $\begin{array}{l}\quad \text { Variables } \\
\text { respuesta } \\
\text { consideradas en la } \\
\text { 'Síntesis }\end{array}$ & $\begin{array}{ll}- & \text { Efectividad } \\
\text { - } & \text { Productividad }\end{array}$ & $\begin{array}{ll}\text { - } & \text { Calidad } \\
\text { - } & \text { Esfuerzo } \\
\text { - } & \text { Duración }\end{array}$ & $\begin{array}{ll}\text { - } & \text { Calidad } \\
\text { - } & \text { Esfuerzo } \\
\text { - } & \text { Duración }\end{array}$ \\
\hline
\end{tabular}


Respecto a los resultados obtenidos aplicando el proceso propuesto en esta investigación, es necesario realizar un análisis para identificar los posibles factores que afectaron los resultados, lo cual llevó a concluir lo siguiente:

- El número de artículos recuperados se vio afectado debido a que el revisor no aplicó la búsqueda refinada prescrita en el proceso, la cual debía incluir una búsqueda iterativa de términos relacionados con "Pair Programming".

- El número de artículos seleccionados como relevantes se vio afectado por la aplicación incorrecta de los criterios de I/E por parte del revisor, ya que se excluyeron artículos que evaluaban dos o más técnicas de programación en pareja. Adicionalmente, la búsqueda por referencias fue realizada extemporáneamente, al momento de contar con los grupos potencialmente agregables ya seleccionados.

- El número de artículos seleccionados para la Extracción de datos también se vio afectado ya que sólo los estudios explícitamente identificados como experimentos controlados fueron seleccionados, mientras que no se incluyeron aquellos identificados solamente como "experimentos" ni los cuasi-experimentos.

Es de hacer notar que los resultados obtenidos utilizando ambos procesos son también producto de la experiencia de los revisores. Éste es sin duda un factor adicional que influyó en la interpretación y la aplicación de las instrucciones dadas. Sin embargo, este factor era interesante de analizar ya que, como se mencionó anteriormente, era requerido en esta evaluación que el perfil de los revisores fuera lo más parecido posible al perfil de un revisor promedio en el ámbito profesional. Es por ello, que los resultados de ambas aplicaciones será comparado posteriormente con la revisión realizada por (Hannay et al., 2009), el cual servirá como referencia para determinar qué tan cercanos estuvieron los resultados del caso de estudio de los resultados obtenidos por revisores expertos.

Cabe recordar las consideraciones realizadas previamente sobre los resultados obtenidos aplicando el proceso de Grimán. Adicionalmente, es necesario resaltar lo siguiente:

- Aunque el número de artículos recuperados es inferior al obtenido en la revisión de (Hannay et al., 2009), la precisión de la búsqueda es mayor (el número de artículos relevantes es superior).

- El número de artículos seleccionados, una vez corregidos los defectos de implementación en los que incurrió el revisor, tenderá a ser igual o superior al número de artículos seleccionados en el gold standard. 
Proceso de RS de experimentos en Ingeniería del Software Evaluación de la propuesta

- La omisión de las variables respuestas consideradas por (Hannay et al., 2009) responden a la falta de estudios que evalúen la misma y que puedan ser agregados en la fase de Síntesis. Por lo tanto, este descarte no debería afectar los resultados de la revisión de manera considerable. Por contrario, los revisores advierten que aunque en (Hannay et al., 2009) todos los artículos relevantes son incluidos en la Síntesis de datos, existe inconsistencia entre las tareas y las variables respuesta que son evaluadas en varios de ellos, lo que consideran como cálculos propensos a errores.

El análisis anterior, lleva a concluir que los resultados obtenidos en el caso de estudio son producto no sólo de la efectividad de las actividades/tareas sino también de la experiencia y conocimiento de los revisores. Esto, sin embargo, no afecta la evaluación de las características establecidas para este caso de estudio, el cual es presentado más adelante.

Cabe destacar que, luego de aplicar ambos proceso al caso de estudio, los evaluadores concluyen que el proceso propuesto en este trabajo es más adecuado a las RSL en ISE, debido a las siguientes razones (Bandara, 2010) (Samaranayake, 2010):

- Presenta un flujo de actividades bien definido, comprensible y secuenciado.

- Presenta un modelo no-iterativo que evita la sobrecarga impuesta por múltiples correcciones.

- Contiene plantillas bien definidas para reportes.

- Adecuado para usar estudios empíricos y técnicas meta-analíticas.

En resumen, el proceso propuesto presentó las siguientes ventajas respecto al proceso de Kitchenham:

Búsqueda:

- Instrucciones claras y completas para la definición de los criterios de inclusión/exclusión.

- Plantillas para 4 formularios asociados al proceso de Búsqueda.

- Recomendaciones sobre fuentes de datos preferentes.

- Las cadenas de búsqueda obtienen un número mayor de artículos relevantes.

Extracción de datos:

Anna Grimán Padua 
- Lineamientos específicos sobre los datos del estudio a ser extraídos. Se extrae un número más completo de datos. Las variables dependientes e independientes son claramente registradas.

- Plantillas para un conjunto de 9 formularios de Extracción de datos.

- Propone una manera de agrupar los estudios para su lectura, evitando re-trabajo y pérdida de esfuerzo al momento de la lectura en profundidad.

- Finalmente, se registraron tiempos de Extracción de datos menores.

Sin embargo, los evaluadores afirman que el proceso requiere mejoras a las tareas ineficientes y la documentación de los lineamientos, para que los investigadores en el área de IS puedan aprovechar su potencial completamente.

\subsubsection{Evaluación de características}

Con base en el análisis anterior se puede afirmar que a pesar de la poca experiencia de los revisores, la aplicación del proceso propuesto a un caso de estudio real por parte de revisores externos ha permitido identificar diferentes necesidades, en tres líneas de acción: mejoras al proceso, mejoras al material de adiestramiento, y mayor entrenamiento formal de los revisores.

Al mismo tiempo, el análisis de los resultados y la comparación con (Hannay et al., 2009), ha permitido confirmar la no pertinencia de la evaluación de la característica Efectividad en este caso. Por el contrario, se pueden establecer conclusiones en relación al resto de las características propuestas para su análisis a través del caso de estudio.

En la tabla 11.9 se da respuesta a las preguntas establecidas para cada una de ellas, junto con una justificación para las mismas. 
Tabla 11.9. Evaluación de características con base en el caso de estudio 1

\begin{tabular}{|c|c|c|c|c|}
\hline Característica & Sub-Característica & Preguntas & Valor & Observación \\
\hline \multirow[t]{5}{*}{ Grado de soporte } & \multirow[t]{5}{*}{ Modelo de proceso } & $\begin{array}{l}\text { ¿Es adecuado al objetivo? (1=No, } \\
3=S i ́)\end{array}$ & 3 & $\begin{array}{l}\text { A pesar de que el proceso no es completado por los revisores, puede } \\
\text { afirmarse que el objetivo de cada componente (Búsqueda y } \\
\text { Extracción de datos) es alcanzado. }\end{array}$ \\
\hline & & $\begin{array}{l}\text { ¿El proceso posee consistencia } \\
\text { entre sus componentes? }(1=\mathrm{No} \text {, } \\
3=\mathrm{Si})\end{array}$ & 3 & $\begin{array}{l}\text { Los evaluadores no reportan problemas encontrados en relación a la } \\
\text { consistencia de los componentes. Por el contrario, afirman que el } \\
\text { proceso presenta un flujo de actividades "bien definido". }\end{array}$ \\
\hline & & $\begin{array}{l}\text { ¿El proceso se encuentra bien } \\
\text { organizado? }(1=N o, 3=S i ́)\end{array}$ & 3 & $\begin{array}{l}\text { Los evaluadores no reportan problemas de organización del } \\
\text { proceso. Por el contrario, afirman que el proceso presenta un flujo } \\
\text { "bien secuenciado". }\end{array}$ \\
\hline & & $\begin{array}{l}\text { ¿El proceso es completo? }(1=\mathrm{No} \text {, } \\
3=\mathrm{Si})\end{array}$ & 1 & $\begin{array}{l}\text { Los evaluadores reportaron aspectos relacionados con la falta de } \\
\text { heurísticas que han sido considerados como pertinentes en la } \\
\text { discusión de resultados. }\end{array}$ \\
\hline & & $\begin{array}{l}\text { ¿Se comporta según lo esperado? } \\
(1=\text { No, 3=Sí) }\end{array}$ & 3 & $\begin{array}{l}\text { Cada una de las fases genera los resultados esperados según lo } \\
\text { previsto. } \\
\text { Por otra parte, según los evaluadores, el proceso es "adecuado para } \\
\text { usar estudios empíricos y técnicas meta-analíticas". }\end{array}$ \\
\hline
\end{tabular}




\begin{tabular}{|c|c|c|c|}
\hline & $\begin{array}{l}\text { ¿No requiere asistencia de } \\
\text { expertos? }(1=S i ́, 3=\text { No) }\end{array}$ & 1 & $\begin{array}{l}\text { En el análisis de resultados se evidenció la necesidad de } \\
\text { adiestramiento y las debilidades del proceso al ser aplicado por } \\
\text { revisores inexpertos }\end{array}$ \\
\hline & $\begin{array}{l}\text { ¿Propone heurísticas y } \\
\text { recomendaciones específicas? } \\
(1=\text { No, 3=Sí) }\end{array}$ & 3 & $\begin{array}{l}\text { Existen heurísticas propuestas a nivel de actividades y tareas. Los } \\
\text { evaluadores afirman que el proceso "contiene plantillas bien } \\
\text { definidas para reportes". }\end{array}$ \\
\hline \multirow[t]{5}{*}{ Documentación } & $\begin{array}{l}\text { ¿La documentación del } \\
\text { componente es completa? (1=No, } \\
\text { 3=Sí) }\end{array}$ & 1 & $\begin{array}{l}\text { Los evaluadores reportaron problemas de falta de descripciones } \\
\text { textuales adicionales, en forma de explicaciones y ejemplos. }\end{array}$ \\
\hline & $\begin{array}{l}\text { ¿La documentación del } \\
\text { componente es entendible? (1=No, } \\
\text { 3=Sí) }\end{array}$ & 1 & \multirow{3}{*}{$\begin{array}{l}\text { Los evaluadores no reportaron problemas en cuanto al formato y } \\
\text { estilo del Cookbook, ni respecto a su comprensión. Por el contrario, } \\
\text { afirman que el proceso es "comprensible". } \\
\text { Sin embargo, se identificaron defectos en la aplicación que llevan a } \\
\text { concluir que algunas descripciones deben ser mejoradas } \\
\text { Los evaluadores no reportaron problemas. }\end{array}$} \\
\hline & $\begin{array}{l}\text { ¿La documentación del } \\
\text { componente es usable? }(1=\text { No, } \\
\text { 3=Sí) }\end{array}$ & 3 & \\
\hline & $\begin{array}{l}\text { ¿La documentación del } \\
\text { componente es consistente } \\
\text { internamente? (1=No, 3=Sí) }\end{array}$ & 3 & \\
\hline & $\begin{array}{l}\text { ¿La documentación del } \\
\text { componente es adecuada para la } \\
\text { audiencia? (1=No, 3=Sí) }\end{array}$ & 1 & $\begin{array}{l}\text { Los evaluadores reportaron la necesidad de mejores descripciones, } \\
\text { por lo que se entiende que no es adecuado para revisores sin } \\
\text { experiencia. }\end{array}$ \\
\hline
\end{tabular}




\begin{tabular}{|c|c|c|c|c|}
\hline \multirow[t]{2}{*}{ Eficiencia } & Esfuerzo & $\begin{array}{l}\text { Facilidad de aprendizaje (1=baja, } \\
\text { 2=media, } 3=a l t a)\end{array}$ & 2 & $\begin{array}{l}\text { Los revisores pudieron aprender la mayoría de las actividades en un } \\
\text { tiempo razonable. Además, afirman que el proceso "presenta un } \\
\text { modelo no-iterativo que evita la sobrecarga impuesta por múltiples } \\
\text { correcciones". }\end{array}$ \\
\hline & Tiempo & No. de horas ( $n$ ) & $\begin{array}{l}469 \\
\text { horas }\end{array}$ & \\
\hline \multirow[t]{2}{*}{ Factibilidad } & \multirow[t]{2}{*}{ Implementación } & $\begin{array}{l}\text { ¿El proceso es entendible? }(1=\mathrm{No}, \\
3=\mathrm{Si})\end{array}$ & 3 & $\begin{array}{l}\text { Los evaluadores afirman que el proceso "presenta un flujo de } \\
\text { actividades bien definido, comprensible y secuenciado". }\end{array}$ \\
\hline & & $\begin{array}{l}\text { Facilidad de implementación } \\
(1=\text { baja, 2=media, 3=alta) }\end{array}$ & 2 & $\begin{array}{l}\text { Los revisores pudieron acometer las actividades en un tiempo } \\
\text { razonable. No obstante, se identificó la necesidad de adiestramiento } \\
\text { en determinadas tareas. }\end{array}$ \\
\hline
\end{tabular}


En el Gráfico 1, se presentan los porcentajes alcanzados por cada una de las características evaluadas. Para ello, se ha analizado el número de preguntas que alcanzaron un valor igual o mayor al $67 \%$ ( 2 o 3 en la escala). Nótese que estos resultados se encuentran alineados con las conclusiones obtenidas en el análisis realizado en la sección anterior y los problemas presentados en la tabla 11.7.

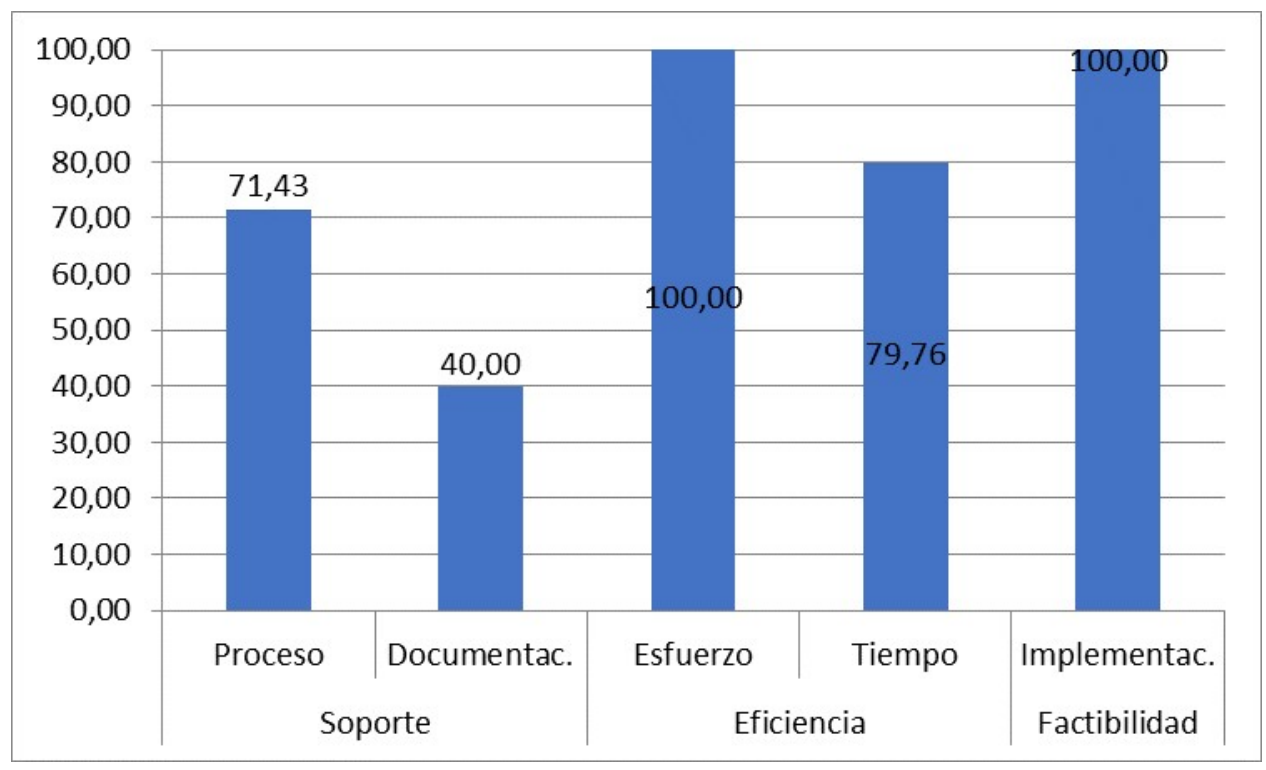

Gráfico 1. Porcentajes de las características evaluadas en el caso de estudio 1

- En cuanto al Soporte, se observa la necesidad de mejorar la documentación y reforzar el entrenamiento de los revisores. Así mismo, el modelo de proceso debe sufrir algunas modificaciones para mejorar su completitud y auto-definición.

- En cuanto a la Eficiencia, el valor obtenido para el Esfuerzo ha sido alto. Por otra parte, debe recordarse que el Tiempo fue una de las características más criticadas durante la evaluación. En una comparación con el tiempo reportado en el estudio de referencia, se observa que fue ligeramente menor (339 horas), obteniendo que las fases ejecutadas durante la evaluación (Búsqueda y Extracción) tomaron un 38\% más de tiempo para el proceso propuesto, donde la mayor diferencia de tiempo se observó en la Búsqueda. Sin embargo, se cuenta con una referencia reconocida en el área (Samaranayake, 2010) donde se afirma que etapas equivalentes a éstas, en promedio pueden tomar 588 horas (este valor puede ser mayor de acuerdo a otros autores). Esto implica que para el proceso propuesto, el tiempo invertido en ambas fases fue al menos de un $30 \%$ más eficiente en términos de tiempo que el promedio en la literatura. 
- Por último, la Factibilidad fue la característica mejor valorada, lo cual es consistente con la realidad ya que se pudieron aplicar y obtener resultados en todas las actividades. Aunque algunas de ellas fueron conducidas de manera deficiente, los resultados obtenidos contribuyeron con el propósito del proceso.

Se puede afirmar que el proceso propuesto proporciona un alto Grado de Soporte, es además factible y eficiente (al menos parcialmente). Lamentablemente, en este caso de estudio sólo se llegaron a aplicar dos de las fases del proceso de RS, por lo cual no puede valorarse la eficiencia global del proceso sino sólo lo correspondiente a las fases de Búsqueda y Extracción que son, por su naturaleza, las más demandantes de tiempo. Por otra parte, los tiempos obtenidos en la aplicación del proceso se vieron afectados no sólo por la naturaleza de las actividades realizadas sino también por la experiencia y grado de comprensión de los revisores respecto al proceso.

A pesar de los resultados obtenidos, el capítulo siguiente se dedicará a analizar en detalle las críticas y recomendaciones planteadas por los evaluadores a fin de establecer las mejoras a que hubiera lugar.

\subsection{CASO DE ESTUDIO 2 (INSPECCIÓN DE SOFTWARE)}

Tal como se indicó al inicio de este capítulo, el caso de estudio 2 fue conducido siguiendo las heurísticas y actividades recomendadas en esta investigación. Éste fue conducido por la tesista y aplicado a Inspección de Software ya que se contaba con un referente importante en esta área y se quería comprobar el comportamiento del proceso en otro contexto diferente al del caso de estudio 1.

Como se dijo anteriormente, en este caso se deseaba contar con un revisor experto, que además contara con amplios conocimientos sobre el proceso a fin de valorar lo más objetivamente posible características como la Efectividad y la Eficiencia. Adicionalmente, en este caso de estudio se esperaba no encontrar limitaciones en la comprensión y ejecución de las actividades y tareas, con lo que se esperaba valorar también la Factibilidad.

En esta sección se presenta un resumen de los resultados obtenidos y su comparación con el referente del área (Ciolkowski, 2009). El proceso seguido por (Ciolkowski, 2009) está basado en los enfoques clásicos de meta-análisis; no obstante, es posible encontrar actividades trazables con la propuesta de (Kitchenham. B.A. 
\& Charters, 2007), por lo que pueden ser fácilmente establecidas fases y actividades genéricas para la comparación.

\subsubsection{Preparación del caso de estudio}

Previo a la ejecución del caso de estudio se contó con la definición de las actividades y tareas prescritas por el proceso y se obtuvo acceso a las BD bibliográficas. En algunos casos fue requerido solicitar los artículos seleccionados a la biblioteca por no encontrarse accesibles a través de la BD en su formato de texto completo.

Para la comparación con el estudio de referencia, fue necesario proponer tareas genéricas que permitiesen establecer una correspondencia entre ambos procesos, Grimán y Ciolkowski. La Tabla 11.10 muestra la correspondencia de las actividades entre ambos procesos comparados. Las fases genéricas fueron tomadas de (Kitchenham. B.A. \& Charters, 2007).

Tabla 11.10. Fases y actividades genéricas para la comparación

\begin{tabular}{|c|c|c|c|}
\hline Fase & $\begin{array}{l}\text { Actividad } \\
\text { genérica }\end{array}$ & Grimán & (Ciolkowski, 2009) \\
\hline \multirow[t]{2}{*}{ Búsqueda } & Definición & $\begin{array}{l}\text { 1. Determinación del tema } \\
\text { 2. Búsqueda preliminar de } \\
\text { experimentos } \\
\text { 3. Descarte de artículos irrelevantes } \\
\text { 4. Selección de estudios candidatos } \\
\text { 5. Declaración del objetivo de } \\
\text { revisión }\end{array}$ & $\begin{array}{l}\text { 1. Definir metas } \\
\text { 2. Definir variables dependientes e } \\
\text { independientes } \\
\text { 3. Definir criterios de inclusión de } \\
\text { estudios }\end{array}$ \\
\hline & $\begin{array}{l}\text { Selección de } \\
\text { estudios }\end{array}$ & $\begin{array}{l}\text { 1. Búsqueda y lectura de } \\
\text { antecedentes } \\
\text { 2. Búsqueda refinada } \\
\text { 3. Búsqueda por referencias } \\
\text { 4. Descarte de artículos irrelevantes } \\
\text { 5. Definición/Actualización de } \\
\text { grupos candidatos a agregación }\end{array}$ & $\begin{array}{l}\text { 1. Recolectar estudios primarios de } \\
\text { acuerdo al objetivo } \\
\text { 2. Evaluar su adecuación de } \\
\text { acuerdo a los criterios de } \\
\text { inclusión } \\
\text { 3. Extraer datos }\end{array}$ \\
\hline $\begin{array}{l}\text { Extracció } \\
\mathrm{n} \text { de datos }\end{array}$ & \begin{tabular}{l}
\multicolumn{1}{c}{ Extraer } \\
registrar \\
información
\end{tabular} & $\begin{array}{l}\text { 1. Lectura superficial } \\
\text { 2. Preparación de clusters de } \\
\text { lectura } \\
\text { 3. Lectura en profundidad } \\
\text { 4. Descripción y agrupación de } \\
\text { conceptos } \\
\text { 5. Actualización de grupos de } \\
\text { lectura }\end{array}$ & $\begin{array}{l}\text { 1. Extraer datos de contexto } \\
\text { 2. Extraer efectos }\end{array}$ \\
\hline
\end{tabular}


Proceso de RS de experimentos en Ingeniería del Software

Validación

\begin{tabular}{|c|c|c|c|c|}
\hline & & & $\begin{array}{l}\text { Organización de datos } \\
\text { Establecer grupos } \\
\text { potencialmente agregables }\end{array}$ & \\
\hline $\begin{array}{l}\text { Evaluació } \\
\mathrm{n} \text { de la } \\
\text { calidad }\end{array}$ & $\begin{array}{l}\text { Establecer la } \\
\text { calidad del } \\
\text { estudio a partir } \\
\text { de determinados } \\
\text { aspectos }\end{array}$ & 1 & $\begin{array}{l}\text { Aplicar escala de evaluación } \\
\text { Calificar el nivel de calidad del } \\
\text { estudio }\end{array}$ & $\begin{array}{l}\text { No definen/describen tareas que } \\
\text { lleven a determinar la calidad del } \\
\text { estudio }\end{array}$ \\
\hline \multirow[t]{3}{*}{$\begin{array}{l}\text { Síntesis } \\
\text { de datos }\end{array}$} & \begin{tabular}{l}
\multicolumn{2}{c}{ Seleccionar } \\
estudios a \\
agregar
\end{tabular} & & $\begin{array}{l}\text { Seleccionar grupo de estudios a } \\
\text { agregar }\end{array}$ & \\
\hline & Meta-análisis & & Meta-análisis & $\begin{array}{l}\text { 1. Calcular tamaño del efecto } \\
\text { individual } \\
\text { 2. Agregar o combinar tamaños de } \\
\text { efectos } \\
\text { 3. Evaluar heterogeneidad } \\
\text { 4. Manejar la heterogeneidad }\end{array}$ \\
\hline & $\begin{array}{l}\text { Consolidar } \\
\text { información }\end{array}$ & & $\begin{array}{l}\text { Consolidad y clasificar evidencias } \\
\text { Combinar evidencias }\end{array}$ & $\begin{array}{l}\text { 5. Visualizar y evaluar la } \\
\text { información }\end{array}$ \\
\hline
\end{tabular}

\subsubsection{Resultados del caso de estudio}

En esta sección sólo se hará mención a los resultados obtenidos de manera resumida, para observar en detalle todos los resultados obtenidos en este caso de estudio, véase el Apéndice G-Caso de estudio.

En esta ejecución se cubrieron todas las fases del proceso propuesto. Sin embargo, la comparación de las mismas con el estudio de referencia sólo incluirá las fases de Búsqueda, Extracción de datos, y Síntesis de datos. Con respecto a la Evaluación de la calidad, (Ciolkowski, 2009) no presenta resultados concretos. Por el contrario, en la actividad correspondiente a la selección de los estudios, se limita a hacer comentarios generales acerca de cada uno de ellos. En cambio, en el caso de estudio realizado por la tesista se utilizó la escala de calidad propuesta que incluye cuatro ítems de calidad; obteniendo como resultado que todos los estudios incluidos en la agregación fueran clasificados como de calidad Alta. Las tablas 11.11 a 11.13 muestran un resumen de los resultados obtenidos con ambos procesos.

Nótese que mientras que en (Ciolkowski, 2009) el objetivo de la revisión es establecido de manera bastante precisa, en el caso de estudio realizado en este proyecto se optó por un punto de partida más general. Esto último tuvo como propósito evaluar el soporte de la propuesta en cuanto a establecer un objetivo concreto 
a partir de la evidencia disponible; procurando de esta manera optimizar el esfuerzo invertido en la revisión y dirigirlo hacia aquellos temas más prometedores. Lo anterior determinó el acometimiento de un conjunto de tareas en el caso de estudio, que conllevaron a la definición de un objetivo, partiendo de un tema del interés (Inspección de Software). Otras de las diferencias se comentan a continuación:

Fase de Búsqueda

Una de las características que distingue la fase de Búsqueda propuesta de la acometida por (Ciolkowski, 2009) es que la primera incluye actividades orientadas a definir el objetivo de la revisión; posteriormente, se selecciona un grupo candidato a agregación que será aquél que reúna la mayor cantidad de estudios relevantes.

Fase de Extracción

Al comparar la fase de Extracción acometida en nuestro caso de estudio con el seguido por (Ciolkowski, 2009) también se observan algunas diferencias. Una de ellas estriba en el hecho de que (Ciolkowski, 2009) solicita a los autores aquellos datos que son necesarios para calcular la información que no aparece reportada en el artículo y que es requerida para el meta-análisis.

Por otra parte, en nuestra propuesta la lectura es organizada de manera que se invierta esfuerzo solamente en aquellos grupos que son prometedores y muy similares, lo cual permite además comprender mejor la información extraída.

Fase de Síntesis

Desde el punto de vista metodológico los procesos de (Ciolkowski, 2009) y Grimán son similares en cuanto a la esencia, ya que ambos reconocen la necesidad de realizar la agregación en condiciones de noheterogeneidad. Sin embargo, este principio en Grimán es tratado desde el mismo momento de la extracción, cuando se conforman grupos de lectura basados en la similitud de los estudios en cuanto a tarea, tipos de sujeto, variables respuesta y técnicas.

En (Ciolkowski, 2009), por el contrario, el punto de partida es una agregación global de los estudios, independientemente de su contexto. Posteriormente, se analiza la heterogeneidad y se realiza un análisis de sub-grupos. 
Tabla 11.11. Resultados obtenidos para las actividades genéricas de la fase de Búsqueda en los procesos comparados.

\begin{tabular}{|c|c|c|}
\hline Actividad & Resultados Grimán & Resultados Ciolkowski \\
\hline Definición & $\begin{array}{l}\text { 1. Determinación del tema: } \\
\text { Se establece como tema de interés la Inspección de Software, sin } \\
\text { restricciones asociadas a las etapas de la misma (individual, grupal) } \\
\text { 2. Búsqueda preliminar de experimentos: } \\
\text { Se utilizaron } 5 \text { Bases Bibliográficas: Scopus, IEEEXplore, } \\
\text { ScienceDirect, SpringerLink, ACM Digital Library (ACM DL) } \\
\text { El período de búsqueda no estuvo limitado. } \\
\text { La búsqueda se realizó en los campos Título-Resumen. } \\
\text { Se utilizó una cadena de búsqueda óptima incorporando términos } \\
\text { experimentales + el término asociado a la tecnología (software } \\
\text { inspection). } \\
\text { 3. Descarte de artículos irrelevantes: } \\
\text { solapamientos entre las diferentes bases de datos. Luego de eliminar } \\
\text { estos solapamientos, se obtuvieron } 90 \text { de interés potencial. } \\
\text { En total se obtuvieron } 127 \text { artículos, sin considerar los }\end{array}$ & 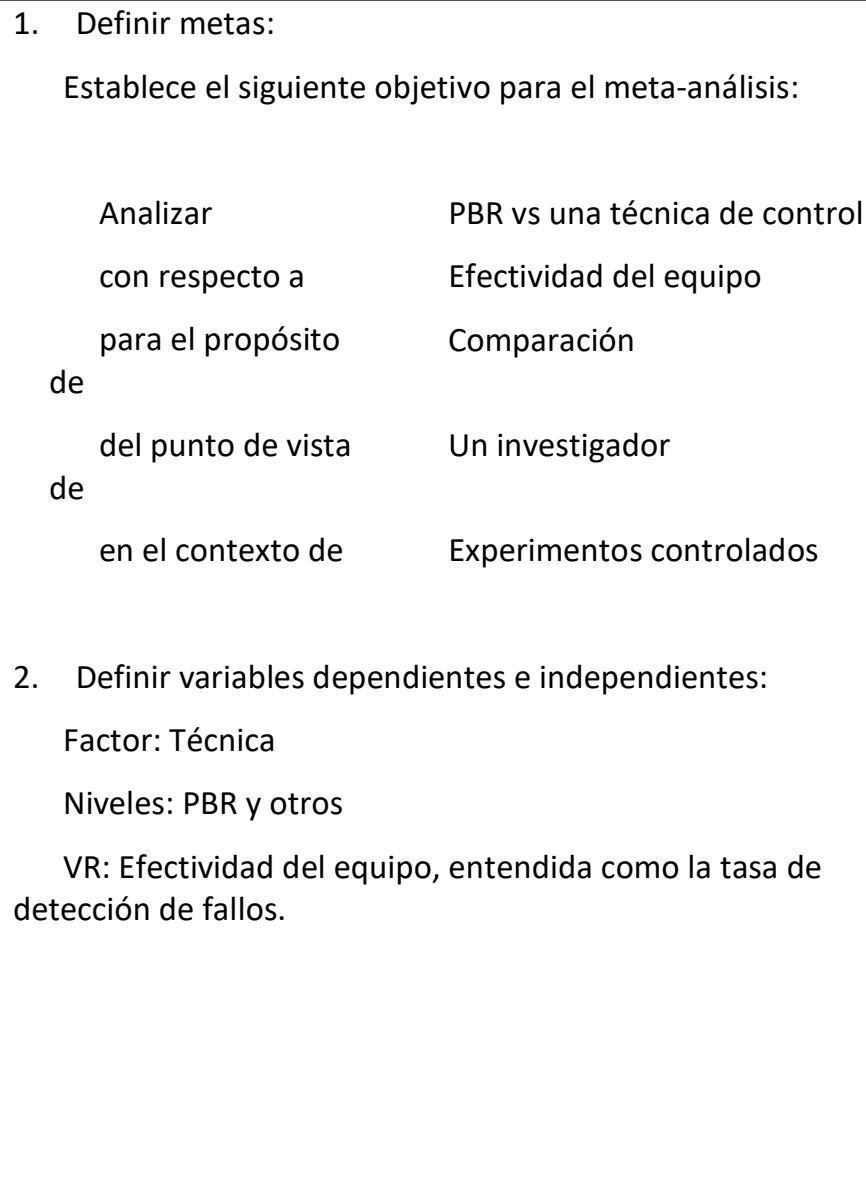 \\
\hline
\end{tabular}




\begin{tabular}{|c|c|c|}
\hline & $\begin{array}{l}\text { Se obtuvieron } 77 \text { artículos relevantes con base en una lectura } \\
\text { superficial (Título-Resumen). } \\
\text { 4. Selección de estudios candidatos: } \\
\text { Se identificaron } 16 \text { sub-temas a partir de los artículos previamente } \\
\text { seleccionados como relevantes. } \\
\text { Se seleccionó el sub-tema con mayor número de artículos ( } 25 \\
\text { artículos): Comparación de técnicas de lectura/Métodos de inspección. } \\
\text { Declaración del objetivo de revisión: } \\
\text { Objetivo: Comparar técnicas de lectura de código y métodos de } \\
\text { inspección de software. } \\
\text { Factor: Técnicas de lectura de código basadas en listas de chequeo, } \\
\text { casos de uso, perspectivas, escenarios y métodos ad-hoc; así como las } \\
\text { distintas comparaciones entre ellos. } \\
\text { Variables respuesta: Efectividad y la eficiencia de la técnica en la } \\
\text { detección de defectos } \\
\text { Tipo de diseño: experimentos } \\
\text { comariterios de Inclusión: incluir experimentos y cuasi-experimentos } \\
\text { conducidos en laboratorio con estudiantes universitarios, que evalúen o } \\
\text { detectividad de dos o más técnicas de lectura o métodos de } \\
\text { arearrores en el diseño de modelos UML. }\end{array}$ & \\
\hline $\begin{array}{l}\text { Selección de } \\
\text { estudios }\end{array}$ & $\begin{array}{l}\text { 6. Búsqueda y lectura de antecedentes: } \\
\text { No se identificaron. } \\
\text { 7. Búsqueda refinada: } \\
\text { Se realizaron } 2 \text { iteraciones adicionales utilizando solamente la BD }\end{array}$ & $\begin{array}{l}\text { 3. Recolectar estudios: } \\
\text { - Se utilizaron varias Bases de datos bibliográficas y literatura } \\
\text { gris, principalmente referida a reportes técnicos en los que } \\
\text { participaron previamente los autores. } \\
\text { - } \quad \text { Se utilizó la cadena de búsqueda (“PBR") OR (“perspective }\end{array}$ \\
\hline
\end{tabular}




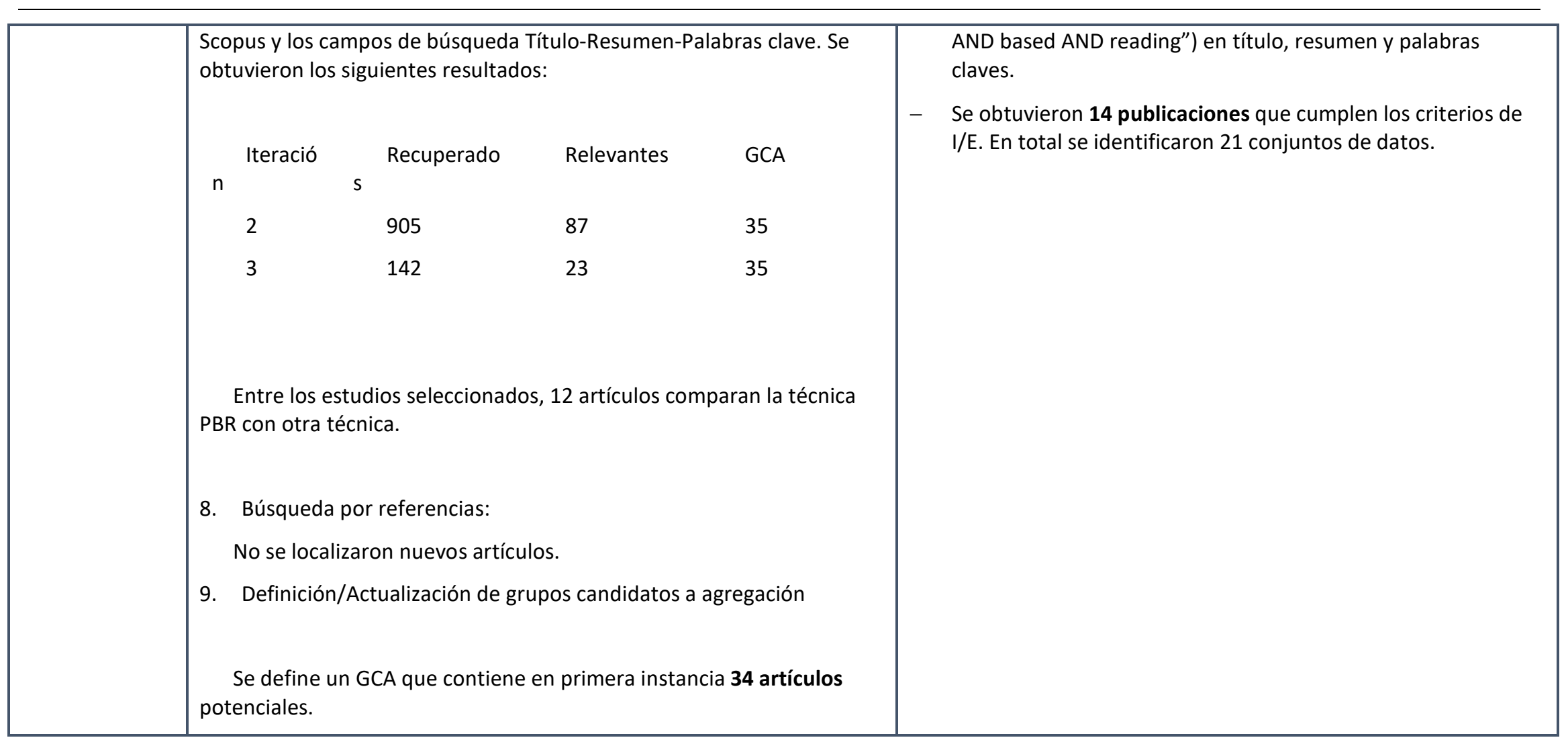


Tabla 11.12. Resultados obtenidos para las actividades genéricas de la fase de Extracción en los procesos comparados.

\begin{tabular}{|c|c|c|}
\hline Actividad & Resultados Grimán & Resultados Ciolkowski \\
\hline $\begin{array}{cc}\text { Extraer } & y \\
\text { registrar datos } & \end{array}$ & $\begin{array}{l}\text { Lectura superficial } \\
\text { Se extrajeron únicamente los datos asociados a: Identificación, Objetivo, } \\
\text { Tópico, Factores, Niveles, Variables respuesta, Tipo de estudio, Tarea } \\
\text { experimental, Sujetos experimentales, Replicación } \\
\text { 2. Preparación de clusters de lectura } \\
\text { Se conformaron } 15 \text { clusters de lectura de los cuales } 5 \text { contienen a PBR. } \\
\text { 3. Lectura en profundidad } \\
\text { Se realizó la extracción del resto de los datos siguiendo un orden que } \\
\text { incluyó: } \\
\quad 4 \text { tareas: Requisitos, Diseño, Diseño UML y Código } \\
\quad 6 \text { variables respuesta: Efectividad método, Efectividad reunión, Coste, } \\
\quad \text { y Tiempo } \\
\text { 5. Actualización de grupos de lectura } \\
\text { respuesta y factores. } \\
\text { Descripción y agrupación de conceptos } \\
\text { contienen a PBR. } \\
\text { - }\end{array}$ & $\begin{array}{l}\text { 1. Extraer datos de contexto } \\
\text { Se extrajeron los siguientes datos: Control, Sujetos, Fase, Equipos, } \\
\text { Material. } \\
\text { 2. Extraer efectos } \\
\text { - Se extrajo el número de sujetos por cada experimento } \\
\text { conducido } \\
\text { - Se estableció la disponibilidad de los siguientes datos: media, } \\
\text { desviación estándar, prueba estadística y p-value. } \\
\text { - Adicionalmente, se extrajo el tamaño del efecto (d), el intervalo } \\
\text { de confianza m ( } 95 \% \text { Cl), la significancia estadística ( } p \text { ) y el peso } \\
\text { conjunto o relativo ( } w_{i} \text { ). } \\
\text { En aquellos casos en los que la información de la agregación no } \\
\text { estuvo disponible, fueron solicitados los datos originales a los } \\
\text { autores y calculados los efectos. }\end{array}$ \\
\hline
\end{tabular}




\begin{tabular}{|c|}
\hline $\begin{array}{l}\text { Se mantienen } 4 \text { grupos asociados a tareas del proceso de desarrollo: } \\
\text { Requisitos, Diseño, Diseño UML y Código } \\
\text { - El orden de lectura está determinado por } 3 \text { variables respuesta: } \\
\text { Efectividad del método, Efectividad de la reunión, y Coste } \\
\text { 6. Organización de datos } \\
\text { Se resumieron los datos de } 23 \text { estudios: } \\
\text { - } \quad 08 \text { técnicas distintas } \\
\text { - } 11 \text { factor principal y } 4 \text { factores adicionales respuesta y } 34 \text { métricas } \\
\text { 7. Establecer grupos potencialmente agregables } \\
\text { Se establecieron } 11 \text { Grupos candidatos a agregación, de los cuales } \mathbf{2} \\
\text { contienen PBR. }\end{array}$ \\
\hline
\end{tabular}


Tabla 11.13. Resultados obtenidos para las actividades genéricas de la fase de Síntesis en los procesos comparados.

\begin{tabular}{|c|c|c|}
\hline Actividad & Resultados Grimán & Resultados Ciolkowski \\
\hline \begin{tabular}{l}
\multicolumn{2}{c}{ Seleccionar } \\
estudios a \\
agregar
\end{tabular} & $\begin{array}{l}\text { - Se seleccionaron } 11 \text { grupos agregables, los cuales contienen a un total de } \\
14 \text { estudios, para las tareas: Requisitos, Diseño y Código. } \\
\text { - } \quad \text { Los grupos sujetos profesionales y estudiantes. } \\
\text { - Sólo } 2 \text { de los grupos seleccionados incluyen PBR, con un total de } \mathbf{3} \\
\text { estudios. }\end{array}$ & No hay una actividad equivalente \\
\hline Meta-análisis & $\begin{array}{l}\text { - Se realizaron } 9 \text { agregaciones utilizando WMD, } 2 \text { de las cuales incluyeron a } \\
\text { PBR. Todas estas agregaciones fueron realizadas para un contexto } \\
\text { académico. } \\
\text { - Se realizaron } 5 \text { agregaciones utilizando el método de RR no para métrico, } \\
\text { para un contexto académico. } \\
\text { - Se realizaron } 3 \text { agregaciones utilizando el método WMD para estudios en } \\
\text { un contexto industrial. }\end{array}$ & $\begin{array}{l}\text { - Se analizaron los siguientes sub-grupos: } \\
\circ \text { Por factores de contexto } \\
\circ \text { Por independencia de estudios } \\
\text { - } \quad \text { Se aplicó WMD a los estudios incluidos, tanto de manera global } \\
\text { como por sub-grupos: } \\
\circ \text { Requerimientos: AR vs PBR } \\
\circ \text { Requerimientos: PBR vs CBR } \\
\circ \text { Diseño/Código: PBR vs CBR }\end{array}$ \\
\hline $\begin{array}{l}\text { Consolidar } \\
\text { información }\end{array}$ & $\begin{array}{l}\text { - Se obtuvieron } 15 \text { evidencias de las agregaciones realizadas, respecto a las } \\
\text { técnicas AH, CBR, PBR, SBR y UBR. Para las variables respuesta: Efectividad, } \\
\text { Eficiencia y Coste del método. } \\
\text { - } \quad \text { De las evidencias encontradas, } 4 \text { tienen relación con PBR: } \\
\text { - En lo que respecta a la efectividad, la técnica PBR ha demostrado en } \\
\text { algunas ocasiones tener mejor Tasa de detección de fallos por equipo } \\
\text { que la técnica basada en checklist (CBR). } \\
\text { - Estos resultados se han obtenido sin utilizar roles y en inspecciones de } \\
\text { una sola ronda. No se sabe nada del comportamiento de la técnica } \\
\text { PBR frente a CBR cuando se utilizan roles o la inspección incluye una } \\
\text { segunda ronda. } \\
\text { En cuanto al Coste por defecto para la fase de detección, es posible } \\
\text { que la técnica PBR resulte bastante más económica que la técnica } \\
\text { CBR. }\end{array}$ & $\begin{array}{l}\text { - } \quad \text { Efecto global: no se determinó } \\
\text { - Influencia de la técnica de control: } \\
\quad \text { o Requerimientos: } \mathrm{PBR}<\mathrm{CBR} \\
\quad \text { Diseño/código: } \mathrm{PBR}>\mathrm{CBR} \\
\text { - Influencia de la experiencia: PBR > CBR, AR (para profesionales) } \\
\text { - Influencia del tipo de equipo: los equipos nominales presentaron } \\
\text { - } \quad \text { Independencia de estudios: los estudios dependientes fueron } \\
\text { significativamente mejores que los independientes. } \\
\text { - Robustez de los resultados: ninguno de los sub-grupos es } \\
\text { realmente robusto. }\end{array}$ \\
\hline
\end{tabular}




\begin{tabular}{|l|l|l|}
\hline & - & Estos resultados se han obtenido sin utilizar roles y en inspecciones de \\
& $\begin{array}{l}\text { una sola ronda. No se sabe nada del comportamiento de la técnica } \\
\text { PBR frente a CBR cuando se utilizan roles o la inspección incluye una } \\
\text { segunda ronda. }\end{array}$ & \\
\hline
\end{tabular}


Entre los procesos seguidos en ambos casos de estudio pueden observarse algunas similitudes y diferencias. La principal semejanza la encontramos en la estructura del proceso. Si bien ambas revisiones involucran actividades o tareas diferentes, a alto nivel ambos procesos presentan fases bastantes parecidas que corresponden con el estándar de la comunidad en cuanto a RS. Ambos procesos al final de la Fase de Búsqueda, y luego de aplicar los criterios de inclusión/exclusión, logran recuperar un conjunto similar de estudios (12 en el caso de Grimán y 14 en el caso de Ciolkowski).

Los procesos seguidos, sin embargo, presentan también diferencias determinantes para los resultados. Algunos de ellos se describen a continuación:

- Objetivo: Aunque ambos parten de un objetivo para la revisión y la agregación, en ambos casos este objetivo tuvo un nivel de granularidad diferente. El proceso seguido en el caso de estudio de Grimán parte de un objetivo muy general, mientras Ciolkowski parte de un objetivo muy específico. Esto no descalifica la comparación para efectos de validación, sin embargo, lleva que en el primer caso se obtenga un conjunto amplio de estudios, los cuales ensayan diferentes técnicas de Inspección de Software; mientras que en el segundo caso lleva a localizar solamente experimentos que ensayan la técnica PBR (aunque incluye también artículos relacionados con la técnica SBR).

- Conjunto base vs agregaciones: En el caso de Grimán, se parte de un conjunto inicial de 12 estudios; sin embargo, el número de agregaciones realizadas en relación a PBR es bajo (sólo 2), con lo cual el número de evidencias es también limitado y éstas se encuentran basadas en un número pequeño de estudios (3 estudios). Lo anterior hace suponer que en el caso de Grimán, el número de estudios que son recuperados inicialmente se ve reducido a lo largo del proceso, debido a la aplicación de algunas heurísticas. Mientras que en el caso de Ciolcowski tales heurísticas no son consideradas. Por lo anterior, aunque el número de artículos recuperados por Grimán es similar a los recuperados por Ciolcowski, en el primer caso sólo un sub-conjunto muy pequeño de éstos participan de la Síntesis.

A continuación se realiza un análisis de los artículos recuperados en el caso de estudio de Grimán y su tratamiento a lo largo del proceso. Así mismo, se comparan los estudios recuperados en ambos procesos. Esto permitirá determinar si existen heurísticas en nuestro proceso que deberían ser revisadas.

En la tabla 11.14 se presentan los artículos recuperados en nuestro caso de estudio durante la Fase de Búsqueda, que incluyen a PBR. Se indica si el mismo fue incluido en la Síntesis y si está presente en el conjunto de (Ciolkowski, 2009). 
Proceso de RS de experimentos en Ingeniería del Software

Validación

Tabla 11.14. Comparación de estudios recuperados y agregados en ambos procesos

\begin{tabular}{|c|c|c|c|}
\hline Estudio & $\begin{array}{l}\text { ¿lncluido en la } \\
\text { Síntesis? }\end{array}$ & $\begin{array}{l}\text { ¿lncluido en } \\
\text { Ciolkowski? }\end{array}$ & Observación \\
\hline $\begin{array}{l}6 . \quad \text { T. Berling and T. Thelin. A case study of } \\
\text { reading techniques in a software company, } 2004 . \\
\text { Proceedings } 2004 \text { International Symposium on } \\
\text { Empirical Software Engineering, ISESE 2004, pp. } \\
229238\end{array}$ & No & No & Es un caso de estudio \\
\hline $\begin{array}{l}\text { 7. G. Sabaliauskaite, F. Matsukawa, S. } \\
\text { Kusumoto, and K. Inoue. An experimental } \\
\text { comparison of checklist based reading and } \\
\text { perspective based reading for UML design } \\
\text { document inspection, International Symposium on } \\
\text { Empirical Software Engineering (ISESE'02) }\end{array}$ & No & No & $\begin{array}{l}\text { ART_17 / E21 } \\
\text { Es incluido en un cluster } \\
\text { pero no posee los datos para } \\
\text { la agregación de M04 }\end{array}$ \\
\hline $\begin{array}{l}\text { G. Sabaliauskaite, S. Kusumoto, and K. Inoue. } \\
\text { Assessing defect detection performance of } \\
\text { interacting teams in object oriented design } \\
\text { inspection, Information and Software Technology, } \\
\text { vol. 46, pp. } 875886,2004 \text {. }\end{array}$ & No & No & $\begin{array}{l}\text { ART_25 / E23 } \\
\text { No llega a estar en un } \\
\text { cluster } \\
\text { No presenta datos }\end{array}$ \\
\hline $\begin{array}{l}\text { G. Sabaliauskaite, S. Kusumoto, and K. Inoue. } \\
\text { Comparing reading techniques for object oriented } \\
\text { design inspection, IEICE Transactions on } \\
\text { Information and Systems E87 D (4), pp. } 976 \text { 984, } \\
2004\end{array}$ & No & No & $\begin{array}{l}\text { ART_28 / E18 } \\
\text { No llega a estar en un } \\
\text { cluster } \\
\text { No presenta datos }\end{array}$ \\
\hline $\begin{array}{l}\text { G. Sabaliauskaite, F. Matsukawa, S. Kusumoto, } \\
\text { and K. Inoue. Further investigations of reading } \\
\text { techniques for object oriented design inspection, } \\
\text { Information and Software Technology, vol. 45, pp. } \\
571585,2003 \text {. }\end{array}$ & No & No & $\begin{array}{l}\text { ART_46/E22 } \\
\text { No llega a estar en un } \\
\text { cluster } \\
\text { No presenta datos }\end{array}$ \\
\hline $\begin{array}{l}\text { 8. O. Laitenberger, K. El Emam, and T. G. } \\
\text { Harbich. An internally replicated quasi } \\
\text { experimental comparison of checklist and } \\
\text { perspective based reading of code documents, IEEE } \\
\text { Transactions on Software Engineering, vol. 27, pp. } \\
387421,2001 .\end{array}$ & Sí & No & $\begin{array}{l}\text { ART_23 / E13, E14, E15 } \\
\text { Agregados }\end{array}$ \\
\hline $\begin{array}{l}\text { 9. Lulu He, Jeffrey Carver. PBR vs. checklist: } \\
\text { a replication in the } \mathrm{n} \text { fold inspection context, } \\
\text { Proceedings of the } 2006 \text { ACM/IEEE International } \\
\text { symposium on empirical software engineering } \\
\text { ISESE '06 }\end{array}$ & No & No & $\begin{array}{l}\text { ART_58 } \\
\text { No reporta datos }\end{array}$ \\
\hline $\begin{array}{l}\text { 10. Zhang, Z., Basili, V., Shneiderman, B. } \\
\text { Perspective based usability inspection: An } \\
\text { empirical validation of efficacy. 1999) Empirical }\end{array}$ & No & No & $\begin{array}{l}\text { ART_87, } \\
\text { Eliminado al actualizar } \\
\text { los clusters porque es el }\end{array}$ \\
\hline
\end{tabular}




\begin{tabular}{|c|c|c|c|}
\hline Software Engineering, 4 (1), pp. 4369. & & & $\begin{array}{l}\frac{\text { único estudio para el cluster }}{\text { USABILIDAD }} \\
\text { Compara una técnica } \\
\text { desarrollada por los autores }\end{array}$ \\
\hline $\begin{array}{l}\text { Basili, V. R., Green, S., Laitenberger, O., } \\
\text { Lanubile, F., Shull, F., Sørumgård, S., and Zelkowitz, } \\
\text { M. V. The Empirical Investigation of Perspective- } \\
\text { Based Reading. Journal of Empirical Software } \\
\text { Engineering, 1, } 2 \text { (1996),133-164 }\end{array}$ & No & Sí & $\begin{array}{l}\text { ART_88 } \\
\text { Se elimina en la } \\
\text { Búsqueda por no estar } \\
\text { disponible el fulltext en } \\
\text { Scopus }\end{array}$ \\
\hline $\begin{array}{l}\text { O. Laitenberger, C. Atkinson, M. Schlich, and K. } \\
\text { El Emam. An experimental comparison of reading } \\
\text { techniques for defect detection in UML design } \\
\text { documents, Journal of Systems and Software, vol. } \\
\text { 53, pp. } 183 \text { 204, } 2000 \text {. }\end{array}$ & No & Sí & $\begin{array}{l}\text { ART_18, } \\
\text { Está en los clusters } \\
\text { Se elimina en Extracción } \\
\text { porque está sólo en el } \\
\text { agrupamiento, no pasa a } \\
\text { GPA }\end{array}$ \\
\hline $\begin{array}{l}\text { O. Laitenberger, J.M. DeBaud. Perspective } \\
\text { based reading of code documents at Robert Bosch } \\
\text { GmbH. (1997) Information and Software } \\
\text { Technology, } 39 \text { (11), pp. } 781791 .\end{array}$ & No & Sí & $\begin{array}{l}\text { ART_86 } \\
\text { Está en los clusters y } \\
\text { posteriormente se elimina } \\
\text { porque no compara PBR con } \\
\text { otra técnica } \\
\end{array}$ \\
\hline $\begin{array}{l}\text { J. Maldonado, J. Carver, F. Shull, S. Fabbri, E. } \\
\text { Dória, L. Martimiano,M. Mendonça, and V. Basili. } \\
\text { “Perspective based reading: A replicated } \\
\text { experiment focused on individual reviewer } \\
\text { effectiveness. (2006) Empirical Software } \\
\begin{array}{lll}\text { Engineering, } 11 \text { (1), pp. } 119142 . & \end{array}\end{array}$ & No & No & $\begin{array}{l}\text { ART_59 } \\
\text { Se eliminó por no } \\
\text { presentar los datos M y SD }\end{array}$ \\
\hline
\end{tabular}

Del análisis anterior se identifican 3 criterios de descarte de los artículos recuperados inicialmente:

- Falta de datos: el experimento no reporta los datos mínimos necesarios para la agregación. En el caso de Ciolkowski estos datos fueron solicitados a los autores (en algunos casos Ciolkowski se encontraba entre los autores).

- Comparación de tratamientos: el experimento no compara dos técnicas sino que compara el uso de una técnica versus no usar ninguna; o evalúa la efectividad de una técnica.

- Disponibilidad del documento: el fulltext del documento no se encuentra disponible en Scopus.

- Único estudio en el grupo: el estudio fue el único en comparar las técnicas para una métrica dada. 
La tabla 11.115 muestra los estudios incluidos por Ciolkowski y una comparación con nuestro caso de estudio.

Tabla 11.15. Análisis de artículos no incluidos en el caso de estudio

\begin{tabular}{|c|c|c|}
\hline Resultados Ciolkowski & $\begin{array}{l}\text { ¿Incluido en } \\
\text { Grimán? }\end{array}$ & Observación \\
\hline $\begin{array}{l}\text { V. R. Basili, S. Green, O. Laitenberger, F. Lanubile, F. Shull, } \\
\text { S. Sorumgard, and M. V. Zelkowitz, "The empirical } \\
\text { investigation of perspective-based reading," Journal of } \\
\text { Empirical Software Engineering, vol. 1, no. 2, pp. 133-164, } \\
\text { 1996. }\end{array}$ & Sí & \\
\hline $\begin{array}{l}\text { S. Biff, "Analysis of the impact of reading technique } \\
\text { and inspector capability on individual inspection } \\
\text { performance," in Proceedings of Seventh Asia-Pacific } \\
\text { Software Engineering Conference, APSEC 2000., 2000, pp. } \\
\text { 136-145. }\end{array}$ & No & $\begin{array}{l}\text { No está localizable en Scopus } \\
\text { (sería posible localizarlo si se } \\
\text { utilizara la BD Xplore) } \\
\quad \text { Por otra parte, compara las } \\
\text { técnica CBR vs SBR. }\end{array}$ \\
\hline $\begin{array}{l}\text { S. Biffl, M. Halling, and, S. Koszegi, "Investigating the } \\
\text { accuracy of defect estimation models for individuals and } \\
\text { teams based on inspection data," in Journal of Empirical } \\
\text { Software Engineering, Rome, Italy, 2003, pp. 232-243. }\end{array}$ & No & $\begin{array}{l}\text { No recuperable en Scopus. } \\
\text { Puede ser localizado en la BD } \\
\text { Xplore (no aparece incluido en } \\
\text { JEMSE sino en ISESE 03) } \\
\text { Compara la técnica CBR vs } \\
\text { PBR }\end{array}$ \\
\hline $\begin{array}{l}\text { M. Ciolkowski, "Evaluating the effectiveness of } \\
\text { different inspection techniques on informal requirements } \\
\text { documents," Diploma Thesis, University of Kaiserslautern, } \\
\text { 1999. }\end{array}$ & No & Se trata de literatura gris. \\
\hline $\begin{array}{l}\text { M. Ciolkowski, C. Differding, O. Laitenberger, and J. } \\
\text { Münch, "Empirical investigation of perspective-based } \\
\text { reading: A replicated experiment," ISERN, Tech. Rep. ISERN- } \\
\text { 97-13, 1997. }\end{array}$ & No & Se trata de literatura gris. \\
\hline $\begin{array}{l}\text { C. Denger, M. Ciolkowski, and F. Lanubile, "Investigating } \\
\text { the active guidance factor in reading techniques for defect } \\
\text { detection," in International Symposium on Empirical } \\
\text { Software Engineering, ISESE '04, 2004, pp. 219-228. }\end{array}$ & No & $\begin{array}{l}\text { No llega a ser recuperado en } \\
\text { Scopus debido a que esta BD no } \\
\text { indexó esta conferencia sino } \\
\text { posteriormente. Sólo es posible } \\
\text { localizar el resumen. } \\
\text { Puede ser localizado en la BD } \\
\text { Xplore, ya que debería salir en la } \\
\text { iteración } 3 \text {, al tener los términos } \\
\text { active guidance y experiment }\end{array}$ \\
\hline $\begin{array}{l}\text { O. Laitenberger, C. Atkinson, M. Schlich, and K. E. } \\
\text { Emam, "An experimental comparison of reading techniques } \\
\text { for defect detection in UML design documents," Journal of } \\
\text { Systems and Software, vol. 53, pp. 183-204, } 2000 \text {. }\end{array}$ & Sí & \\
\hline $\begin{array}{l}\text { O. Laitenberger and J.-M. DeBaud, "Perspective-based } \\
\text { reading of code documents at robert bosch gmbh," Tech. }\end{array}$ & No & Se trata de literatura gris \\
\hline
\end{tabular}




\begin{tabular}{|c|c|c|}
\hline Rep. ISERN-97-14, 1997. & & $\begin{array}{l}\text { En el caso de Grimán se } \\
\text { incorporó una versión publicada } \\
\text { de este reporte como artículo. }\end{array}$ \\
\hline $\begin{array}{l}\text { F. Lanubile, T. Mallardo, F. Calefato, C. Denger, and M. } \\
\text { Ciolkowski, "Assessing the impact of active guidance for } \\
\text { defect detection: a replicated experiment," in 10th } \\
\text { International Symposium on Software Metrics, 2004., 2004, } \\
\text { pp. 269-278. }\end{array}$ & No & $\begin{array}{l}\text { REPLICA a Denger } 2004 \\
\text { En Scopus sólo puede } \\
\text { recuperarse el resumen. La BD } \\
\text { incorporó ISESE posteriormente } \\
\text { Puede ser localizado en } \\
\text { Xplore, como resultado de la } \\
\text { iteración 3, ya que tiene los } \\
\text { términos active guidance y } \\
\text { experiment } \\
\text { Ciolkowski es uno de los } \\
\text { autores. }\end{array}$ \\
\hline $\begin{array}{l}\text { F. Lanubile and G. Visaggio, "Evaluating defect detection } \\
\text { techniques for software requirements inspections," ISERN, } \\
\text { Tech. Rep. ISERN-00-08, } 2000 \text {. }\end{array}$ & No & Se trata de literatura gris \\
\hline $\begin{array}{l}\text { J. Maldonado, J. Carver, F. Shull, S. Fabbri, E. Dória, L. } \\
\text { Martimiano, M. Mendonça, and V. Basili, "Perspective-based } \\
\text { reading: A replicated experiment focused on individual } \\
\text { reviewer effectiveness," Journal of Empirical Software } \\
\text { Engineering, vol. 11, no. 1, pp. 119-142, } 2006 \text {. }\end{array}$ & Sí & \\
\hline
\end{tabular}

Del análisis anterior, se pueden observar que los experimentos no recuperados en el proceso de Grimán se deben a:

- Uso de la BD: el artículo no se encontraba indexado en Scopus para el momento de la búsqueda. Debe recordarse que en el caso de estudio Grimán, las búsquedas fueron confinadas a esta BD.

- Tipo de literatura: el experimento se encuentra reportado en un documento no publicado. En el caso de Grimán, este tipo de literatura no fue considerado debido a que su calidad es dudosa, ya que ésta no ha sido sometida a la evaluación crítica que caracteriza a una conferencia o revista científica.

Con base en los análisis anteriores, se resumen a continuación las razones por las cuales los estudios fueron omitidos o descartados en el caso de estudio conducido por Grimán limitando fuertemente los resultados de la misma:

- $\quad$ Falta de datos

- Comparación de tratamientos

- Uso de la BD/Disponibilidad del documento 
- Único estudio en el grupo

- Tipo de literatura (literatura gris)

Nótese que algunas de estas limitaciones (p.e. la falta de orientaciones para obtener los datos cuando no son reportados en el experimento, o las limitaciones de la BD Scopus) fueron también reportadas en el caso de estudio 1, por lo que se requiere un análisis más profundo de los mismos, lo cual será conducido en el siguiente capítulo.

\subsubsection{Evaluación de características}

A diferencia del caso de estudio 1 , en este caso de estudio fue notorio que los factores que influyeron en los resultados obtenidos son de carácter metodológico, en el sentido de la aplicación de prácticas o heurísticas que redujeron la recuperación de estudios o evidencias finales. Fue posible identificar estos factores gracias a la comparación de los resultados del caso de estudio con el caso de referencia.

También se pudo notar que al revisor poseer amplios conocimientos sobre el proceso, los problemas de comprensión y filtrado presentes en el caso de estudio 1 no se identificaron en este caso de estudio. Por ello, se reafirma que no tiene sentido evaluar la característica Grado de soporte con base en la experiencia de este caso. Al mismo tiempo, se considera que sí será de gran utilidad la valoración de la Efectividad y la Eficiencia del proceso desde la perspectiva de esta revisión.

Para realizar una valoración objetiva del proceso y dejar evidencia de aquellos elementos que deben ser detenidamente analizados, se procedió a responder a las características definidas para esta evaluación, tal como se presenta en la tabla 11.16 .

En el Gráfico 2, se presentan los porcentajes alcanzados por cada una de las características evaluadas. Para ello, se ha analizado el número de preguntas que alcanzaron un valor igual o mayor al $67 \%$ ( 2 o 3 en la escala). 


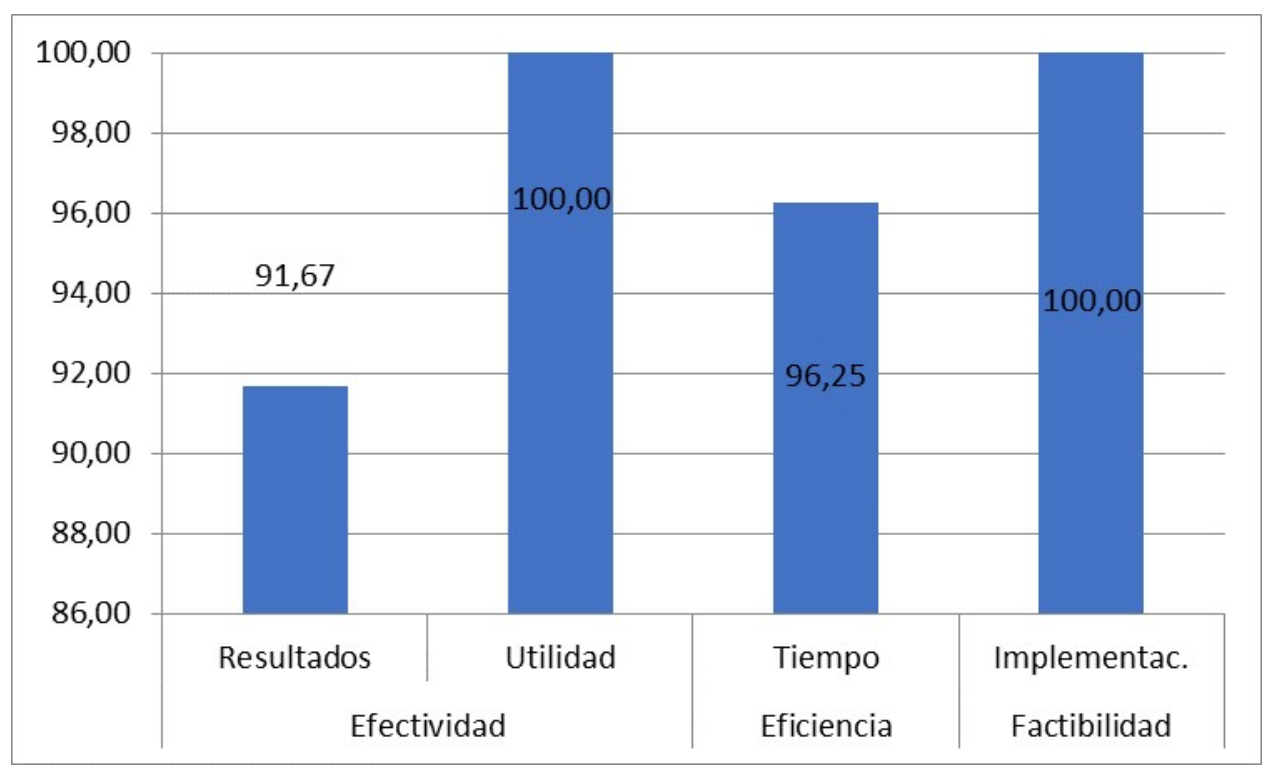

Gráfico 2. Porcentajes de las características evaluadas en el caso de estudio 2 
Proceso de RS de experimentos en Ingeniería del Software

Validación

\section{Tabla 11.16. Evaluación de características con base en el caso de estudio 2}

\begin{tabular}{|c|c|c|c|c|}
\hline Característica & Sub-Característica & Preguntas & Valor & Observación \\
\hline \multirow[t]{5}{*}{ Efectividad } & \multirow[t]{4}{*}{ Resultados } & ¿Alcanza su objetivo? (1=No, 3= Sí) & 3 & $\begin{array}{l}\text { Se considera que la respuesta es afirmativa pues se } \\
\text { obtuvieron evidencias como parte de los } \\
\text { resultados, lo cual constituye el objetivo } \\
\text { fundamental del proceso }\end{array}$ \\
\hline & & $\begin{array}{l}\text { Capacidad para producir los resultados } \\
\text { esperados (1=baja, 2=media, } 3=a l t a)\end{array}$ & 2 & $\begin{array}{l}\text { Se da una valoración media debido a que } \\
\text { comparativamente no se obtienen todos los } \\
\text { resultados esperados }\end{array}$ \\
\hline & & $\begin{array}{l}\text { Capacidad para producir resultados } \\
\text { relevantes (1=baja, 2=media, 3=alta) }\end{array}$ & 3 & $\begin{array}{l}\text { Se considera que la respuesta es afirmativa pues se } \\
\text { obtuvieron evidencias sobre la comparación de } \\
\text { técnicas }\end{array}$ \\
\hline & & $\begin{array}{l}\text { Capacidad para producir resultados útiles } \\
(1=\text { baja, } 2=\text { media }, 3=a l t a)\end{array}$ & 3 & $\begin{array}{l}\text { Se considera que la respuesta es afirmativa pues se } \\
\text { obtuvieron evidencias junto con el contexto de } \\
\text { aplicación }\end{array}$ \\
\hline & Utilidad & $\begin{array}{l}\text { ¿Es mejor que los procesos alternativos? } \\
\left(1=\text { No, } 3=S^{\prime}\right)\end{array}$ & 3 & $\begin{array}{l}\text { Se considera que la respuesta es afirmativa debido } \\
\text { a que el proceso proporcionó elementos para } \\
\text { asegurar que el esfuerzo fuese coste-efectivo y que } \\
\text { los resultados obtenidos fueran coherentes, a }\end{array}$ \\
\hline
\end{tabular}




\begin{tabular}{|c|c|c|c|c|}
\hline & & & & $\begin{array}{l}\text { través de prácticas orientadas a manejar la } \\
\text { heterogeneidad. De esta manera, las evidencias } \\
\text { obtenidas son consistentes y confiables. }\end{array}$ \\
\hline & & $\begin{array}{l}\text { ¿Los resultados obtenidos soportan el } \\
\text { proceso de decisiones? }(1=\mathrm{No}, 3=\mathrm{Si})\end{array}$ & 3 & $\begin{array}{l}\text { Las evidencias obtenidas permiten establecer las } \\
\text { ventajas de un tratamiento sobre otro e identificar } \\
\text { los factores que explican tal comportamiento. }\end{array}$ \\
\hline & & $\begin{array}{l}\text { ¿Los resultados obtenidos compensan el } \\
\text { esfuerzo invertido? (Coste-efectividad) }\end{array}$ & 3 & $\begin{array}{l}\text { La confiabilidad de las evidencias obtenidas } \\
\text { compensa la inversión en tiempo. Se considera que } \\
\text { cuando el proceso sea automatizado o se cuente } \\
\text { con el apoyo de herramientas automáticas, los } \\
\text { tiempos de ejecución serán considerablemente } \\
\text { menores }\end{array}$ \\
\hline & & ¿llumina el proceso? (1=No, 3= Sí) & 3 & El proceso es altamente prescriptivo \\
\hline & & ¿Provee de valor agregado? (1=No, 3= Sí) & 3 & $\begin{array}{l}\text { Incluye un conjunto de recomendaciones que van } \\
\text { desde la recuperación óptima de estudios hasta la } \\
\text { generación de evidencias con un nivel de calidad y } \\
\text { confianza. }\end{array}$ \\
\hline & & ¿Soporta una hipótesis? $(1=$ No, 3= Sí) & 3 & $\begin{array}{l}\text { El proceso permite responder a hipótesis } \\
\text { establecidas sobre la base de comparar } \\
\text { tratamientos }\end{array}$ \\
\hline & & ¿Satisface criterios de ganancia específicos? & 3 & Genera ganancias en términos de confianza en los \\
\hline
\end{tabular}




\begin{tabular}{|c|c|c|c|c|}
\hline & & $(1=N o, 3=S i)$ & & $\begin{array}{l}\text { resultados, eventualmente también en términos } \\
\text { de ahorro de esfuerzo en tareas como la lectura y } \\
\text { descarte de artículos irrelevantes }\end{array}$ \\
\hline Eficiencia & Esfuerzo & $\begin{array}{l}\text { Facilidad de aprendizaje (1=baja, 2=media, } \\
3=a l t a)\end{array}$ & $\mathrm{N} / \mathrm{A}$ & $\begin{array}{l}\text { No es objetiva la evaluación de esta métrica } \\
\text { considerando el perfil del evaluador y su } \\
\text { participación en la definición del proceso }\end{array}$ \\
\hline \multirow[t]{2}{*}{ Factibilidad } & Implementación & ¿El proceso es entendible? $(1=$ No, $3=S i ́)$ & $\mathrm{N} / \mathrm{A}$ & $\begin{array}{l}\text { No es objetiva la evaluación de esta métrica } \\
\text { considerando el perfil del evaluador y su } \\
\text { participación en la definición del proceso }\end{array}$ \\
\hline & & $\begin{array}{l}\text { Facilidad de implementación (1=baja, } \\
\text { 2=media, 3=alta) }\end{array}$ & 3 & $\begin{array}{l}\text { Las actividades pudieron ser acometidas en su } \\
\text { totalidad sin más limitaciones que las establecidas } \\
\text { por las herramientas utilizadas (p.e. las BD } \\
\text { bibliográficas), las cuales son comunes para } \\
\text { cualquier proceso de esta naturaleza. }\end{array}$ \\
\hline
\end{tabular}


De la gráfica se desprende el siguiente análisis:

- La Efectividad es altamente valorada ya que el evaluador considera que los resultados obtenidos son confiables y coherentes. Sin embargo, se observa un porcentaje de no satisfacción en cuanto a la cobertura de los resultados obtenidos, lo cual se vio castigado en el caso de estudio debido al uso de la BD Scopus, así como otras heurísticas que conllevan al descarte de artículos relevantes durante el proceso. En relación a la utilidad el valor alcanzado es alto (100\%).

- En relación a la Implementación, el resultado la valoración es alta al igual que en el caso de estudio 1, ya que las tareas y herramientas prescritas son técnicamente accesibles para cualquier revisor.

- Finalmente, en relación a la Eficiencia, sólo se valoró el Tiempo invertido en esta evaluación. No se contaba con una medición de tiempos tomada durante la ejecución del estudio de referencia; sin embargo, sí se encontró un referente en el área que hiso posible establecer que en el proceso propuesto se invirtió al menos casi un 4\% menos de tiempo ya que, según (Samaranayake, 2010), una RS o meta-análisis puede tomar entre 1310 a 2518 horas. La percepción, sin embargo, es que estos tiempos están fuertemente influenciados por la calidad de las BD de datos bibliográficas y de los estudios primarios, entre otros factores, algunos de los cuales fueron discutidos en el caso de estudio 1.

Luego del análisis realizado en esta sección se puede afirmar que el proceso propuesto es factible, efectivo y eficiente.

En el siguiente capítulo, se presenta un análisis más detallado de los resultados y problemas identificados durante ambos casos de estudio a fin de determinar los posibles cambios o mejoras requeridos. 


\section{CAPÍTULO 12. IMPACTO DE LA EVALUACIÓN}

En este capítulo se analizan las desventajas y aquellos factores identificados por los revisores en el capítulo anterior que parecieron influir en los resultados obtenidos. Algunos de éstos fueron recurrentes en ambos casos de estudio.

Todos estos elementos identificados a través de las evaluaciones serán generalizados bajo el concepto de limitación y serán analizados a fin de determinar su relevancia y las implicaciones que tienen para el proceso propuesto en esta investigación.

Aquellas posibles mejoras que resulten relevantes y pertinentes a fin de aumentar la calidad del proceso, serán implementadas en la propuesta; sin embargo, para efecto de este capítulo sólo se indicará el contenido de la propuesta a ser modificado de la manera más precisa posible, es decir, no se presentará la descripción de fases, actividades o tareas completas, sino aquellas partes que se ven impactadas por el cambio o modificación

\subsection{ANÁLISIS DE LAS LIMITACIONES DEL PROCESO}

Debe recordarse que en la validación del proceso, descrita en el capítulo anterior, las limitaciones reportadas o identificadas por los revisores estuvieron enfocadas en las fases de Búsqueda y Extracción. La tabla 12.1 presenta el análisis de cada una de ellas; indicando el caso de estudio del que proviene, así como su análisis y la solución a implementar en caso de que éste concluya que la recomendación es pertinente.

Tabla 12.1. Limitaciones encontradas durante la validación del proceso

\begin{tabular}{|l|c|c|}
\hline Limitación & $\begin{array}{c}\text { Caso de } \\
\text { estudio donde } \\
\text { se identificó }\end{array}$ & \begin{tabular}{c} 
Análisis/Solución \\
\hline $\begin{array}{l}\text { Pocas descripciones } \\
\text { lineamientos en los }\end{array}$
\end{tabular}$\quad 1 \quad \begin{array}{l}\text { La crítica realizada por los evaluadores no se considera precisa ya } \\
\text { que la cantidad de contenido proporcionada por los documentos de } \\
\text { lineamientos de cada proceso no indica necesariamente la calidad de } \\
\text { la información. En el caso particular del proceso propuesto por } \\
\text { Kitchenham, la documentación incluye una cantidad importante de } \\
\text { teoría que escapa del alcance y propósito de un manual. Mientras } \\
\text { tanto, la documentación provista para la aplicación del proceso } \\
\text { propuesto en esta investigación, se limita a proporcionar } \\
\text { lineamientos y heurísticas a manera de cookbook o manual de cocina, } \\
\text { omitiendo teorías y conceptos que corresponden a otro tipo de } \\
\text { documentación (p.e. un reporte técnico). } \\
\text { No se ha identificado la necesidad de modificaciones al proceso } \\
\text { propuesto con base en esta observación. }\end{array}$ \\
\hline
\end{tabular}




\begin{tabular}{|c|c|c|}
\hline $\begin{array}{l}\text { Poca orientación } \\
\text { para definir la pregunta } \\
\text { de investigación }\end{array}$ & 1 & 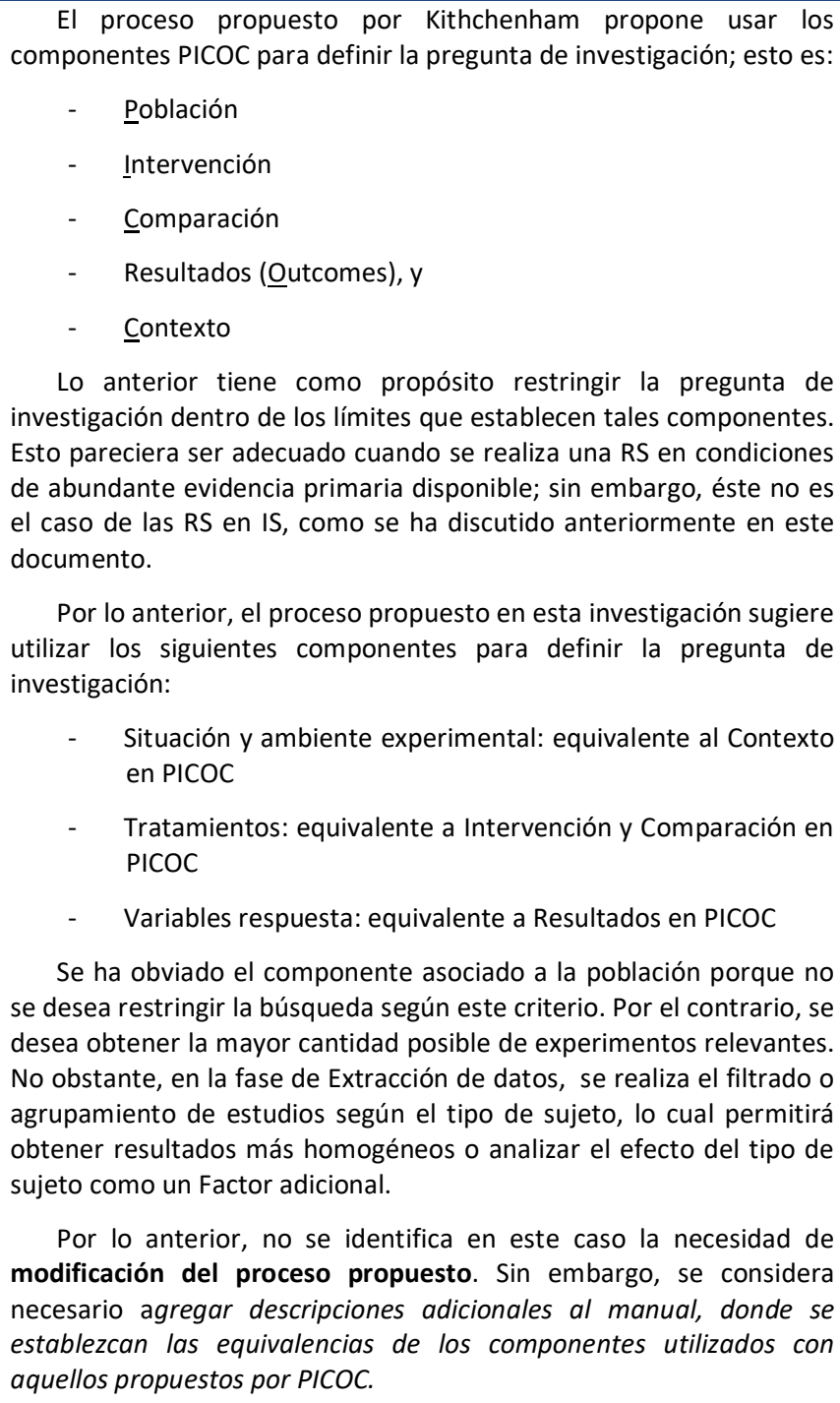 \\
\hline $\begin{array}{l}\text { Falta de orientación } \\
\text { para generar la cadena } \\
\text { de búsqueda con el } \\
\text { tema }\end{array}$ & 1 & $\begin{array}{l}\text { Para el momento de la ejecución del caso de estudio el revisor no } \\
\text { contaba con la versión completa de la fase de Búsqueda, lo cual se } \\
\text { traduce en que no contaba con las heurísticas asociadas a la } \\
\text { búsqueda refinada. Esto incluye una búsqueda iterativa para obtener } \\
\text { los términos a utilizar en relación a la tecnología de interés. } \\
\text { Por lo anterior, no se considera necesario acometer ninguna } \\
\text { modificación al proceso propuesto. } \\
\text { Cabe destacar que aunque los revisores reportan que el proceso } \\
\text { de Kitchenham sí describe claramente la manera de proponer la } \\
\text { cadena de búsqueda, en DK6 se describe cómo las cadenas } \\
\text { propuestas obtuvieron resultados muy pobres y requirieron de un } \\
\text { esfuerzo importante para ser mejoradas. }\end{array}$ \\
\hline \begin{tabular}{lr}
\multicolumn{2}{c}{ Seleccionar } \\
artículos & relevante \\
propone & tareas \\
adicionales &
\end{tabular} & 1 & $\begin{array}{l}\text { Las tareas adicionales propuestas por en el proceso de Grimán } \\
\text { tienen como propósito la conformación de los Grupos potencialmente } \\
\text { agregables, los cuales permitirán posteriormente realizar la Síntesis } \\
\text { de datos de una manera más eficaz. La utilidad de estas tareas es }\end{array}$ \\
\hline
\end{tabular}




\begin{tabular}{|c|c|c|}
\hline & & $\begin{array}{l}\text { posteriormente resaltada por los revisores (ver DK18). } \\
\text { Aunque la existencia de tales actividades impacta la longitud del } \\
\text { proceso, no se considera necesario realizar ninguna modificación de } \\
\text { éste. }\end{array}$ \\
\hline $\begin{array}{l}\text { Falta de orientación } \\
\text { para adaptar las } \\
\text { cadenas de búsqueda a } \\
\text { las BD }\end{array}$ & 1 & $\begin{array}{l}\text { El requerimiento mencionado no se consideró durante el } \\
\text { desarrollo de la propuesta como parte del alcance de la misma. } \\
\text { Se considera que establecer las heurísticas particulares para } \\
\text { adaptar las cadenas de búsqueda a la sintaxis y estructura de cada } \\
\text { base de datos bibliográfica es una tarea innecesaria debido a: } \\
\text { 1. Perfil de los revisores en IS: frecuentemente los revisores en } \\
\text { esta área cuentan con conocimientos de búsqueda y } \\
\text { recuperación de información, manejos de bases de datos } \\
\text { complejas, operadores lógicos, etc. } \\
\text { 2. Independientemente del perfil del usuario, la adaptación de } \\
\text { las cadenas de búsqueda a las especificaciones de cada } \\
\text { buscador es una tarea de baja complejidad; las bases de } \\
\text { datos bibliográficas suelen contar con ayudas en línea } \\
\text { suficientes para el usuario promedio. } \\
\text { 3. Heurísticas como las requeridas por los evaluadores, } \\
\text { tendrían que ser constantemente actualizadas, en la medida } \\
\text { en que aparezcan nuevas fuentes de datos. } \\
\text { Por lo anterior no se considera necesario incorporar ninguna } \\
\text { mejora al proceso en virtud de esta crítica. } \\
\text { la falta de experiencia de los mismos en el uso de BD bibliográficas, lo } \\
\text { cual es comprensible debido a que este tipo de BD no suele ser } \\
\text { utilizada extensivamente por los estudiantes hasta que éstos } \\
\text { incursionan en actividades de investigación. }\end{array}$ \\
\hline $\begin{array}{l}\text { Tiempo invertido en } \\
\text { documentar detalles de } \\
\text { artículos irrelevantes }\end{array}$ & 1 & $\begin{array}{l}\text { Los detalles solicitados para esta actividad son básicamente la } \\
\text { identificación del artículo y el resumen del mismo. Esta información, } \\
\text { aunque básica, permitirá realizar el descarte/selección del artículo. Al } \\
\text { mismo tiempo, mantener registro de esta información será lo que } \\
\text { permitirá en el futuro que el proceso sea repetible y auditable. } \\
\text { En este caso se presentan dos variables en conflicto: eficiencia } \\
\text { versus repetibilidad, lo que implica que uno de las dos variables } \\
\text { resulta castigada en beneficio de la otra (trade-off). Según el interés } \\
\text { de esta investigación, la repetibilidad del proceso debe ser un } \\
\text { elemento a privilegiar dentro de la propuesta. Adicionalmente, se } \\
\text { considera que una inversión mayor de tiempo en las etapas } \\
\text { tempranas del proceso, se verá compensada por una mayor calidad } \\
\text { de los resultados y del proceso mismo. } \\
\text { Por otra parte, el hecho de que el proceso propuesto por } \\
\text { Kitchenham no requiera el registro de los resultados, dejando tal } \\
\text { decisión al revisor, no puede ser considerado una ventaja respecto al } \\
\text { proceso propuesto en esta investigación. Por el trade-off mencionado } \\
\text { anteriormente, es lógico suponer que en la medida en que el proceso } \\
\text { sea menos documentado, éste será más ágil (al menos en las etapas } \\
\text { tempranas) mientras que su calidad (y la de sus resultados) será } \\
\text { cuestionable. } \\
\text { Por otra parte, existen herramientas software que permitirín } \\
\text { registrar de manera automática la información requerida; no siendo } \\
\text { necesaria su transcripción. Aunque no se ha recomendado esta } \\
\text { práctica explícitamente en el proceso propuesto, es perfectamente }\end{array}$ \\
\hline
\end{tabular}




\begin{tabular}{|c|c|c|}
\hline & & $\begin{array}{l}\text { conveniente y aceptable en línea con el propósito de la tarea. } \\
\text { Se interpreta que los revisores, en virtud de su poca experiencia, } \\
\text { han tomado las instrucciones de manera literal obviando las ventajas } \\
\text { de incorporar una herramienta software para agilizar el proceso de } \\
\text { documentación de los resultados. Por lo anterior, se realizará la } \\
\text { siguiente modificación al proceso incorporar como recomendación el } \\
\text { uso de apoyo automatizado para documentar los resultados de las } \\
\text { búsquedas ejecutadas. }\end{array}$ \\
\hline $\begin{array}{l}\text { Búsqueda por } \\
\text { referencia a partir de } \\
\text { artículos relevantes }\end{array}$ & 1 & $\begin{array}{l}\text { Los revisores proponen que la búsqueda por referencia no se } \\
\text { realice con el conjunto base de artículos relevantes sino que se realice } \\
\text { al final de la fase de Búsqueda, cuando se cuenta con los grupos } \\
\text { potencialmente agregables para la Extracción de datos. Sin embargo, } \\
\text { el espíritu de la fase de Búsqueda es localizar la mayor cantidad } \\
\text { posible de artículos relevantes y conformar grupos que sean } \\
\text { prometedores para la extracción y la síntesis de datos. Por lo tanto, el } \\
\text { realizar la búsqueda por referencias al final de la fase aumenta la } \\
\text { probabilidad de que se descarten grupos agregables por su bajo } \\
\text { contenido de estudios, mientras que eventualmente se localizarían } \\
\text { nuevos estudios sólo dentro de aquellos grupos que ya son } \\
\text { considerados potencialmente agregables. Esta práctica introduciría un } \\
\text { cierto nivel de sesgo en la búsqueda y al mismo tiempo no } \\
\text { garantizaría una reducción del tiempo de revisión desde un punto de } \\
\text { vista global. } \\
\text { Por todo esto, no se ha considerado necesario realizar ninguna } \\
\text { modificación en el proceso a partir de la crítica realizada. }\end{array}$ \\
\hline $\begin{array}{l}\text { No deja claro si se } \\
\text { incluirán sólo estudios } \\
\text { que } \\
\text { "experimento } \\
\text { controlado" }\end{array}$ & 1 & $\begin{array}{l}\text { Efectivamente el lineamiento no es claro en la documentación, } \\
\text { producto de que no se estableció oportunamente la } \\
\text { diferencia/equivalencia entre los tipos de estudio } \\
\text { "experimento"/"experimento controlado" ni la pertinencia de } \\
\text { incorporar estudios de tipo cuasi-experimento. } \\
\text { Cabe destacar que este defecto produjo en el caso de estudio una } \\
\text { pérdida de (al menos) } 27 \text { estudios relevantes que debieron parte de } \\
\text { los grupos potencialmente agregables. } \\
\text { Como consecuencia de esto, en la fase de Búsqueda debe } \\
\text { establecerse de manera clara los tipos de estudio a seleccionar. }\end{array}$ \\
\hline $\begin{array}{l}\text { Ambigüedad al } \\
\text { recomendar la lectura } \\
\text { de tít-res en presencia } \\
\text { de muchos artículos }\end{array}$ & 1 & $\begin{array}{l}\text { En la recomendación dada no se establece un límite preciso para } \\
\text { aplicar la heurística de lectura sobre título y resumen. Esto es debido } \\
\text { a que este valor se considera subjetivo. } \\
\text { Por lo tanto, se propone eliminar la recomendación dada, debido } \\
\text { a su carácter subjetivo. }\end{array}$ \\
\hline \begin{tabular}{lr}
\multicolumn{1}{c}{ Descarte } & $y$ \\
documentación & de \\
información & sobre \\
todos los & artículos \\
recuperados & es \\
ineficiente &
\end{tabular} & 1 & $\begin{array}{l}\text { Las críticas relacionadas con el tiempo requieren un análisis } \\
\text { basado en la efectividad esperada en el proceso. } \\
\text { Actividades como el Descarte de artículos irrelevantes y la } \\
\text { Selección de artículos relevantes tienen como propósito alcanzar un } \\
\text { conjunto óptimo de estudios primarios, suficientes para realizar la } \\
\text { Síntesis de datos de manera satisfactoria; logrando además que el } \\
\text { proceso sea repetible (esto es, reproducible y auditable). } \\
\text { Como se ha discutido anteriormente, lograr tal efectividad } \\
\text { requiere una inversión de tiempo. Es por ello que difícilmente se } \\
\text { pueda contar con un proceso ágil que incorpore al mismo tiempo } \\
\text { prácticas de calidad. }\end{array}$ \\
\hline
\end{tabular}




\begin{tabular}{|c|c|c|}
\hline & & $\begin{array}{l}\text { Por otra parte, actividades con Establecer los grupos } \\
\text { potencialmente agregables buscan promover la eficiencia a largo } \\
\text { plazo en el proceso, al concentrar el esfuerzo de extracción y síntesis } \\
\text { de datos en aquellos grupos de estudios que son prometedores. De } \\
\text { esta manera, se obtendrán resultados significativos, soportados por } \\
\text { un mayor número de evidencias primarias. } \\
\text { Por todo ello, se considera que las tareas indicadas no deben ser } \\
\text { modificadas. } \\
\text { Luego de su aplicación a este caso de estudio, se entiende que } \\
\text { dependiendo del perfil de los revisores y su experiencia, el proceso } \\
\text { puede llegar a ser relativamente ineficiente. Se requiere entonces de } \\
\text { un entrenamiento completo en las prácticas asociadas al proceso para } \\
\text { compensar el coste en tiempo que implica la curva de aprendizaje de } \\
\text { algunas actividades. }\end{array}$ \\
\hline $\begin{array}{l}\quad \text { Mayor número de } \\
\text { tareas para la } \\
\text { extracción de datos }\end{array}$ & 1 & $\begin{array}{l}\text { Las actividades adicionales propuestas en el proceso tienen como } \\
\text { propósito obtener resultados de mayor calidad y optimizar el proceso } \\
\text { de RS. Por ello, no se considera necesaria la modificación de las } \\
\text { tareas indicadas. }\end{array}$ \\
\hline $\begin{array}{l}\text { Explicaciones y } \\
\text { ejemplos requeridos } \\
\text { para la extracción de } \\
\text { datos }\end{array}$ & 1 & $\begin{array}{l}\text { Considerando que el proceso está dirigido a revisores con poca } \\
\text { experiencia, se considera que es pertinente incorporar descripciones } \\
\text { adicionales y ejemplos relacionados con los formularios asociados a } \\
\text { la extracción de datos: grupos agregables, codificación de estudios, } \\
\text { factores adicionales, campo "observación". } \\
\text { Por otra parte, esta crítica refuerza la necesidad de proporcionar } \\
\text { entrenamiento a los revisores novatos, respecto a las prácticas a } \\
\text { utilizar en el proceso. }\end{array}$ \\
\hline $\begin{array}{lr}\text { Variables } & \text { respuesta } \\
\text { importantes } & \text { son } \\
\text { descartadas }\end{array}$ & 1 y 2 & $\begin{array}{l}\text { Las variables respuesta que fueron omitidas luego del proceso de } \\
\text { extracción son aquellas que en los grupos potencialmente agregables } \\
\text { no contaban con más de un estudio que analizara tal variable. Por lo } \\
\text { tanto, el grupo en cuestión no podría ser agregado en la fase de } \\
\text { Síntesis, por lo que su eliminación evita que se invierta tiempo en la } \\
\text { extracción de dados de estudios que no son prometedores para la } \\
\text { síntesis de datos. } \\
\text { Por lo anterior, no se identifica ningún cambio necesario del } \\
\text { proceso en virtud de esta crítica. }\end{array}$ \\
\hline \begin{tabular}{l}
\multicolumn{1}{c}{ La lectura } \\
superficial no resultó \\
suficiente para el \\
llenado del formulario \\
de extracción
\end{tabular} & 1 & $\begin{array}{l}\text { En este caso, los revisores parecen haber confundido el objetivo e } \\
\text { implementación de la tarea Lectura superficial. En ésta, se solicita } \\
\text { solamente el llenado de los aspectos básicos del estudio, lo cual debe } \\
\text { permitir tomar decisiones respecto al mismo. } \\
\text { Nuevamente, se observa la necesidad de que los revisores que } \\
\text { utilicen por primera vez el proceso reciban entrenamiento en las } \\
\text { prácticas asociadas a las diferentes fases. } \\
\text { Se reitera la heurística planteada ya que realizar la lectura de } \\
\text { todo el documento en la actividad de Lectura superficial es } \\
\text { incompatible con el propósito de la misma. } \\
\text { Se interpreta que lo anterior puede haber afectado } \\
\text { considerablemente los tiempos invertidos en esta actividad. }\end{array}$ \\
\hline $\begin{array}{l}\quad \text { Error } \\
\text { identificación } \\
\text { formulario } \\
\text { Definición } \\
\text { agrupamiento } \\
\text { conceptos }\end{array}$ & 1 & $\begin{array}{l}\text { La crítica realizada se limita al nombre del formulario utilizado por } \\
\text { que es procedente realizar el cambio en el Manual. }\end{array}$ \\
\hline Mejora requerida & 1 & La incorporación de un formato diferente para describir los \\
\hline
\end{tabular}




\begin{tabular}{|c|c|c|}
\hline $\begin{array}{ll}\text { por la sección de } \\
\text { resultados } & \text { del } \\
\text { formulario } & \text { de } \\
\text { Extracción de datos } & \end{array}$ & & $\begin{array}{l}\text { resultados en el formulario de extracción es discutible. En éste se } \\
\text { pretende dar libertad a los revisores para describir todo aquello que } \\
\text { consideren como un resultado del estudio analizado. } \\
\text { Por otra parte, el llenado de la el formulario de Extracción de } \\
\text { datos es realizado en paralelo al Resumen de datos cuantitativos } \\
\text { donde pueden ser registrados datos relacionados con medias, } \\
\text { varianzas y números de sujetos. } \\
\text { En virtud de lo anterior, no se toma en consideración el cambio } \\
\text { propuesto por los evaluadores. }\end{array}$ \\
\hline $\begin{array}{l}\text { Insuficientes } \\
\text { instrucciones sobre } \\
\text { cómo calcular los } \\
\text { valores estadísticos } \\
\text { cuando éstos no son } \\
\text { provistos por los } \\
\text { autores }\end{array}$ & 1 у 2 & $\begin{array}{l}\text { Es de notar que en el Caso de Estudio } 1 \text { los revisores resaltaron } \\
\text { como una de las debilidades del proceso propuesto el hecho de que } \\
\text { lo estudios fueran descartados en virtud de la falta de datos. Entre sus } \\
\text { recomendaciones incluyen la necesidad de contar con un mecanismo } \\
\text { que permita obtener los mismos y maximizar el número de } \\
\text { experimentos que participan en la Síntesis. } \\
\text { Flexibilizar este criterio implica o bien solicitar los datos } \\
\text { requeridos a los autores o realizar los cálculos necesarios para } \\
\text { obtener los mismos. La primera solución puede llegar a ser inviable. } \\
\text { En primer lugar, por razones de confidencialidad por parte de los } \\
\text { experimentadores; en segundo lugar, porque implica un tiempo de } \\
\text { espera difícil de estimar. } \\
\text { En el caso de Ciolcowski se indica que se utilizó esta práctica; sin } \\
\text { embargo, hay que considerar que el autor era parte de los } \\
\text { experimentadores, por lo que no queda demostrada la efectividad de } \\
\text { la consulta en un contexto general. } \\
\text { En cuanto al cálculo de los datos, pudiera ser una solución para } \\
\text { contar con la información requerida en un tiempo razonable, a fin de } \\
\text { aumentar la cantidad de estudios incluidos en la síntesis. } \\
\text { Idealmente, esto puede realizarse a partir de los datos crudos. Sin } \\
\text { embargo, cuando no se cuente con tales datos, pueden utilizarse } \\
\text { otros estimadores (p.e. el tamaño del efecto). } \\
\text { Como solución a esta crítica, se propone incluir recomendaciones } \\
\text { o heurísticas para el cálculo de medias, varianzas y número de sujetos } \\
\text { a partir de la información disponible. }\end{array}$ \\
\hline $\begin{array}{l}\text { Proceso de } \\
\text { extracción ineficiente }\end{array}$ & 1 & $\begin{array}{l}\text { Para el momento de aplicar el caso de estudio no se contaba con } \\
\text { el análisis de aquellos elementos del estudio que serían relevantes } \\
\text { para el proceso de Síntesis de Datos y Valoración de la calidad. } \\
\text { Una vez abordada esta fase, es posible hacer una revisión de los } \\
\text { elementos del formulario que pueden ser omitidos durante el } \\
\text { proceso de extracción. }\end{array}$ \\
\hline $\begin{array}{l}\text { Tiempo adicional } \\
\text { requerido para el } \\
\text { establecimiento de los } \\
\text { grupos potencialmente } \\
\text { agregables }\end{array}$ & 1 & $\begin{array}{l}\text { Aunque se requirió un tiempo adicional, el mismo fue } \\
\text { considerado irrelevante por los mismos revisores; por lo tanto, la } \\
\text { crítica realizada no será considerada en el sentido de mejoras a } \\
\text { alguna tarea o fase. }\end{array}$ \\
\hline $\begin{array}{l}\text { Pérdida de estudios } \\
\text { por: uso de Scopus } \\
\text { limitando la cantidad de } \\
\text { artículos relevantes }\end{array}$ & 2 & $\begin{array}{l}\text { Aunque el proceso no prescribe que se utilice exclusivamente la } \\
\text { BD Scopus, sí recomienda su uso. } \\
\text { En el caso de estudio 2, se optó por su uso exclusivo debido al } \\
\text { porcentaje de solapamiento observado en búsquedas previas y el } \\
\text { esfuerzo adicional que ello implica en términos de análisis y descarte. }\end{array}$ \\
\hline
\end{tabular}




\begin{tabular}{|c|c|c|}
\hline & & $\begin{array}{l}\text { Se consideró al inicio de la RS que la BD Scopus era la más } \\
\text { completa a pesar de las restricciones de licenciamiento. No obstante, } \\
\text { fueron diversas las ocasiones en el caso de estudio } 2 \text { en los que no se } \\
\text { logró localizar un experimento o éste no se encontraba en el formato } \\
\text { de texto completo requerido. } \\
\text { Nuevamente, es de hacer notar que en el Caso de Estudio } 1 \text { los } \\
\text { revisores también identificaron como una debilidad el uso de la BD } \\
\text { Scopus, debido a sus restricciones. } \\
\text { Una vez analizados los resultados de los casos de estudio fue } \\
\text { evidente que, a pesar de los solapamientos que puedan existir entre } \\
\text { BD, la búsqueda no puede estar limitada a una única BD ya que limita } \\
\text { severamente los resultados. En el caso de la BD Scopus podría ser } \\
\text { incluso difícil de acceder para muchos revisores. } \\
\text { Lo anterior sugiere eliminar la recomendación del uso de la BS } \\
\text { Scopus. }\end{array}$ \\
\hline $\begin{array}{l}\text { No incorpora } \\
\text { literatura gris limitando } \\
\text { la cantidad de artículos } \\
\text { relevantes }\end{array}$ & 2 & $\begin{array}{l}\text { Debido a que en el proceso propuesto se espera maximizar la } \\
\text { cantidad de estudios de alta calidad. Y debido a que la literatura gris } \\
\text { no garantiza que los resultados publicados sean confiables y libres de } \\
\text { sesgo, no se considera pertinente incorporar este tipo de literatura. } \\
\text { Se presume que muchos de los estudios que correspondan a este tipo } \\
\text { de literatura, eventualmente serán eliminados en el proceso a través } \\
\text { de las tareas de evaluación de la calidad. }\end{array}$ \\
\hline $\begin{array}{l}\text { Pérdida de estudios } \\
\text { por encontrarse en } \\
\text { aislados en un grupo } \\
\text { agregable }\end{array}$ & 2 & $\begin{array}{l}\text { El proceso propuesto pretende invertir el esfuerzo en aquellos } \\
\text { estudios que sean prometedores para la agregación. Puesto que una } \\
\text { agregación no sería posible al contar con un único estudio que ensaye } \\
\text { una variable respuesta, no se considera coste-efectivo invertir } \\
\text { esfuerzo en la lectura y extracción de datos de estudios que se } \\
\text { encuentren solos en los grupos conformados tempranamente. }\end{array}$ \\
\hline $\begin{array}{l}\text { Pérdida de estudios } \\
\text { por incluir sólo aquellos } \\
\text { que comparan } 2 \text { o más } \\
\text { técnicas }\end{array}$ & 2 & $\begin{array}{l}\text { La propuesta realizada en esta investigación no necesariamente } \\
\text { está limitada a estudios que comparen } 2 \text { o más técnicas, aunque un } \\
\text { estudio en tales condiciones sería potencialmente descartable por las } \\
\text { tareas de extracción ya que seguramente se encontraría en una } \\
\text { situación de aislamiento. } \\
\text { Por lo anterior, no se considera adecuado modificar el proceso } \\
\text { con base en este factor. }\end{array}$ \\
\hline
\end{tabular}

\subsection{IMPLEMENTACIÓN DE MEJORAS}

Entre las debilidades o limitaciones descritas arriba, se decidió abordar sólo algunas de ellas ya que se encontró que están justificadas y son muy relevantes para el proceso, en otros casos su implementación no implica cambios muy dramáticos.

En general, las mejoras que se decidió implementar incluyen un conjunto de prácticas que no requieren una investigación adicional. En cambio, otras decisiones parecen requerir profundizar en la investigación a un nivel que escapa del alcance de esta tesis. Es el caso, por ejemplo, de la efectividad del uso de literatura gris en el contexto de una RS; las implicaciones de agregar estudios que comparen 2 técnicas con estudios que comparen una técnica versus ad hoc, entre otras. Tales decisiones podrán ser evaluadas en futuros trabajos y en ciclos de investigación posteriores. 
A continuación se presentan las mejoras consideradas pertinentes para el proceso propuesto con base en las evaluaciones realizadas en ambos casos de estudio.

\subsubsection{Pregunta de Revisión}

Esta mejora está asociada con la actividad Declaración del objetivo de revisión - Tarea: Establecer la pregunta de revisión.

Como resultado del análisis final de la validación se decide agregar descripciones adicionales, donde se establezcan las equivalencias de los componentes utilizados en el proceso para la definición de la pregunta de investigación, con aquellos propuestos por PICOC. De tal manera, los revisores con experiencia en el proceso de revisión propuesto por Kitchenham encontrarán más fácil de entender esta tarea.

Esto es implementado de la siguiente manera en el manual:

Se propone describir los siguientes aspectos en el formulario B07:

- Situación y ambiente experimental: en primer lugar se trata de establecer el interés de la RS en cuanto a la aplicación de una tecnología a un tipo de problema particular. Por ejemplo, para el caso de las técnicas de lectura de código y métodos de inspección de software, se podría establecer la siguiente situación: "las técnicas a estudiar buscan detectar defectos en el código y otros artefactos; para ello, se cuenta con la participación de analistas, arquitectos, programadores, y otros roles involucrados en el proceso de desarrollo". En segundo lugar se debe también establecer si la RS está interesada en un tipo de sujetos particular con base en su perfil (estudiante, profesional), su edad, su experticia, su grado de entrenamiento, nivel educativo, etc. Este elemento es equivalente al Contexto en PICOC.

- Tratamientos: este aspecto se refiere a los factores, y niveles de los mismos, que son de interés para la RS. Por lo tanto, establece las comparaciones que serán consideradas dentro de la revisión. En el ejemplo anterior, puede ser de interés estudiar las técnicas de lectura de código basadas en listas de chequeo, casos de uso, perspectivas, escenarios y métodos ad-hoc; así como las distintas comparaciones entre ellos. Este elemento es equivalente a los componentes Intervención y Comparación en PICOC.

- Variables respuesta: en este punto se busca delimitar el interés de la RS a unos resultados específicos medidos dentro de cada experimento, por ejemplo, respecto a las técnicas antes mencionadas, puede ser de interés para los revisores solamente el estudio de la efectividad y la eficiencia de la técnica en la detección de defectos. Este componente es equivalente a los Resultados en PICOC.

- Tipo de diseño: se refiere al interés de la RS en un tipo de estudio particular o a un conjunto de tipos de estudios (p.e. experimentos, casos de estudio, estudios observacionales, etc.). En el contexto de esta investigación, se ha establecido de antemano que la RS sólo incluirá experimentos. 


\subsubsection{Resultados de búsquedas}

Esta mejora está asociada con la actividad Búsqueda preliminar/refinada - Tarea: Documentar la estrategia de búsqueda.

Una vez evaluada la propuesta se decide recomendar el uso de herramientas software para documentar los resultados de las búsquedas ejecutadas. Esto es incorporado en el manual como parte de las recomendaciones de la siguiente manera:

RECOMENDACIONES:

- Registrar esta información para cada repositorio utilizado.

- Utilizar un manejador para referencias bibliográficas como los que se han mencionado anteriormente.

- Incorporar el uso de herramientas de software para extraer y documentar los resultados de las búsquedas.

\subsubsection{Tipo de estudio a incluir}

Esta mejora está asociada con la actividad Establecer la meta de revisión - Tarea: Establecer pregunta de revisión.

Como producto del análisis realizado luego de la evaluación de la propuesta se considera necesario aclarar en la definición del tipo de estudio que podrán ser incluidos tanto los estudios que indiquen ser experimentos controlados, así como aquellos que indiquen sólo ser experimentos y los cuasiexperimentos. Esto es acometido modificando el texto de la siguiente manera:

- Tipo de diseño: se refiere al interés de la RS en un tipo de estudio particular o a un conjunto de tipos de estudios (p.e. experimentos, casos de estudio, estudios observacionales, etc.). En el contexto de esta investigación, se ha establecido de antemano que la RS sólo incluirá experimentos/experimentos controlados y cuasi-experimentos.

Adicionalmente, se consideró pertinente establecer claramente que los tipos de estudios a seleccionar son los experimentos controlados (o simplemente "experimentos") y los cuasi-experimentos en la actividad Selección de estudios candidatos - Tarea: Agrupar artículos. A través de la siguiente modificación:

\section{RECOMENDACIONES:}

Debe tomarse en cuenta que en los resúmenes de los artículos seleccionados previamente, puede no ser claro el tipo de estudio; por ejemplo, en algunos casos puede hacerse referencia al término experimento sin que se reporte efectivamente un experimento controlado aleatorizado (RCT). En esos casos, es conveniente separar aquellos estudios que indican explícitamente que se ha aplicado un experimento controlado de los que indican solamente que se ha conducido un experimento; tomando en cuenta que 
algunos de estos últimos podrían ser reclasificados como casos de estudios o cuasi-experimentos cuando se realice una lectura completa, posteriormente. Cuando el estudio que indique solamente "experimento" se trate de un RCT deberá ser incluido en la selección junto con aquellos otros RCT explícitamente identificados y los cuasi-experimentos.

\subsubsection{Lectura de artículo completo}

Otra de las necesidades de mejora identificadas tiene que ver con la ambigüedad en las heurísticas asociadas a la actividad Descarte de artículos irrelevantes- Tarea: Determinar la relevancia del artículo. Por lo que se decidió eliminar la recomendación dada donde se hace referencia a "muchos artículos recomendados", debido a su carácter subjetivo; quedando de la siguiente manera:

- Leer el documento completo: por razones de eficiencia, esta estrategia no debería aplicarse en esta fase. Teniendo, además, en mente que el objetivo de esta tarea es simplemente filtrar los artículos irrelevantes, es poco probable que la lectura del documento completo sea mucho más efectiva que la estrategia anterior (analizar, solamente, título y resumen).

\subsubsection{Formularios}

Esta mejora está asociada a la actividad Lectura en profundidad y consistirá en incorporar descripciones adicionales y ejemplos relacionados con el contenido/elemento a llenar en los siguientes formularios: Extracción, Resumen de grupos potencialmente agregables (ver Apéndice $\mathrm{X} y \mathrm{Z})$.

Por otra parte, también en relación con esta actividad, es requerido cambiar la identificación del formulario Conceptos del experimento.

\subsubsection{Resumen de datos cuantitativos}

Los datos cuantitativos son resumidos como parte de las tareas de la actividad Lectura en profundidad; específicamente, la tarea Resumir datos cuantitativos. En relación a esta tarea, luego del análisis realizado, se decidió incluir recomendaciones o heurísticas para el cálculo de efectos en aquellos estudios que no incluyan las medias, varianzas y el número de sujetos. La heurística orientará en el cálculo del estimador a partir de la información disponible. De la siguiente manera:

RECOMENDACIÓN: 
En aquellos casos en los que no se cuente con los datos requeridos para la agregación (i.e. media desviación típica y número de sujetos), se sugiere realizar el cálculo del efecto utilizando otros estimadores, de acuerdo a la propuesta de (Bandara, 2010); por ejemplo, a partir de t-test con base en medias y desviaciones estándar y/o errores estándar, o del F-test cuando se cuenta o no con MSEs ${ }^{\S}$.

\subsubsection{Contenido del Formulario de Extracción}

El cambio propuesto en esta sección atañe también a la actividad de Lectura en profundidad. En virtud de que en ambos casos de estudio los revisores percibieron que el proceso de extracción de datos llega a consumir mucho tiempo atentando contra la eficiencia del proceso, es necesario realizar un análisis de los datos extraídos durante esta actividad a fin de eliminar aquellos que puedan ser redundantes o innecesarios.

Para ello, es preciso basarse en los requerimientos de las fases de Calidad y Síntesis. De tal manera, los datos mínimos a ser extraídos en el formulario durante la lectura deben contener aquellos requeridos para el agrupamiento y la agregación, así como aquellos necesarios para responder a las preguntas de calidad. Satisfecho estos requerimientos, es posible eliminar aquel contenido que no contribuya ni con estas fases.

Este análisis lleva a modificar el formulario de la siguiente manera:

- $\quad$ En la sección Sujetos experimentales sólo describir el número y su perfil.

- Se elimina la sección de Hallazgos.

- En la sección de Proceso experimental sólo se describirá la tarea.

- Se elimina la sección de Método de medición y análisis de los resultados.

El resto de los datos recolectados en el formulario, son utilizados para la conformación de clusters de lectura o grupos candidatos a agregación, la valoración de la calidad o la agregación misma; razón por la cual no puede reducirse más el contenido del formulario.

Se sugiere adicionalmente, incorporar en la actividad de Lectura en profundidad el uso de herramientas de software para el análisis y laminería de texto, las cuales pueden facilitar la extracción automática de algunos datos. Sin embargo, debe tenerse en cuenta que muchos estudios antiguos han sido digitalizados y a pesar de estar disponibles en formato PDF, los mismos no permiten la edición del texto.

${ }^{\S}$ Mean Squared Error, el promedio de los cuadrados de los errores. 


\subsubsection{Fuentes de información}

La actividad asociada en este caso es la Búsqueda preliminar de experimentos Tarea: Seleccionar fuentes de información.

Si bien el proceso propuesto en esta investigación busca minimizar el esfuerzo de descarte de artículos derivado de los solapamientos de las BD bibliográficas, fue evidente durante la validación (lo mismo que en el estudio realizado sobre el universo de búsqueda en el capítulo 6) que confinar la búsqueda puede tener un costo considerable en términos de estudios recuperados y evidencias obtenidas. Es por ello que, en atención a los resultados obtenidos y la comparación de los mismos con los referentes en cada caso, se decidió modificar la recomendación que sugiere el uso de Scopus por encima de otras bases de datos. No obstante, se decide también incorporar una nota en la que se desaconseja el uso de literatura gris, lo cual sí fue una práctica observada en el caso de estudio 2. Esto se debe a que este tipo de literatura puede comprometer la calidad de los estudios incluidos. Por otra parte, se observó en el caso de estudio 2 que esta literatura estuvo principalmente referida a documentos no publicados (p.e. tesis), siendo éste un tipo de información cuyo acceso suele ser restringido. La recomendación es modificada de la siguiente manera:

\section{RECOMENDACIONES:}

国 Durante el desarrollo de esta investigación, las siguientes fueron las bases de datos que obtuvieron mejores resultados en cuanto a los criterios anteriormente mencionados: SCOPUS, IEEEXplore, e ISI Web of Knowledge.

줄 En este proceso no se aconseja la inclusión de literatura gris.

Finalmente, se tiene que en total se acometieron 8 mejoras al proceso de RS propuesto. Puede observarse que las mismas están principalmente orientadas a mejorar las siguientes características: Grado de soporte, Eficiencia y Efectividad, como se muestra a continuación en la tabla 12.2.

Tabla 12.2. Mejoras incorporadas al proceso y su relación con las características evaluadas

\begin{tabular}{|l|c|}
\hline Característica & Mejora incorporada \\
\hline Grado de soporte & $\begin{array}{c}\text { Pregunta de revisión, Tipo de estudio a incluir, } \\
\text { Formularios y Resumen de datos cuantitativos }\end{array}$ \\
\hline Eficiencia & $\begin{array}{c}\text { Resultados de la búsqueda, Lectura de artículo } \\
\text { completo y Contenido del formulario de extracción }\end{array}$ \\
\hline Efectividad & Tipo de estudio a incluir y Fuentes de información \\
\hline
\end{tabular}


Precisamente las características referidas fueron las que resultaron más afectadas en la validación del proceso presentada en el capítulo anterior. Por lo tanto, con estas mejoras se asegura una mayor calidad para el proceso de RS propuesto. 


\section{CAPÍTULO 13. CONCLUSIONES Y TRABAJOS FUTUROS}

\subsection{Conclusiones}

El proceso de RS es un proceso costoso que requiere de experiencia y soporte amplio para revisiores poco experimentados. Este trabajo revela la enorme complejidad del proceso de RS. A fin de lidiar con esta complejidad la propuesta presentada en esta investigación aporta las siguientes contribuciones:

- $\quad$ La FASE DE BÚSQUEDA incluyó recomendaciones sobre la estrategia de búsqueda que se debe seguir para la localización de experimentos, con el fin de maximizar la recuperación de experimentos reduciendo el esfuerzo de descarte de artículos irrelevantes. Esta estrategia incluye no sólo los campos en los cuales se debe realizar la búsqueda sino también recomendaciones para la definición de cadenas de búsquedas óptimas relacionadas con los tratamientos, las métricas y el tipo de estudio que se quiere localizar.

- Para sobrellevar la escasez de estudios se incorporó no sólo experimentos controlados aleatorizados (RCT) sino también cuasi-experimentos.

- Para evitar la lectura de material irrelevante, la lectura durante la EXTRACCIÓN DE DATOS se realiza en dos ciclos: una lectura superficial que extraiga sólo los datos necesarios para formar grupos de experimentos similares en cuanto a niveles y mediciones, y otra lectura en profundidad que debería concentrarse en aquellos grupos de experimentos que sean más parecidos y, por lo tanto, con posibilidades de ser agregados más adelante.

- Desde el punto de vista de la SínTESIS DE DATOS, se busca es agregar la mayor cantidad de experimentos que sea posible, siempre siguiendo el criterio de máxima similitud entre ellos. Durante la EXTRACCIÓN DE DATOS se identifican aquellos experimentos que son más compatibles en cuanto a los niveles que ensayan y las variables que son medidas.

- Al identificar durante la extracción grupos de experimentos compatibles que pueden considerarse como grupos potencialmente agregables, es posible que la agregación se concentre en aquellos grupos que cumplan con las condiciones mínimas de número de experimentos y similitud de niveles y variables respuesta.

- Durante la FASE DE BÚSQUEDA se incluyó un conjunto de actividades y recomendaciones para la conducción de una búsqueda preliminar (búsqueda de alcance o estudio de mapeo) que permita conocer la base de experimentos disponibles antes de acometer las actividades propias de la RS. 
Esta búsqueda preliminar permite generar una categorización de los experimentos localizados en grupos candidatos a agregación entre los cuales se seleccionará aquél que resulte de interés para los revisores. Con base en el grupo seleccionado se podrá definir la pregunta de revisión.

- Se propone que el protocolo de revisión sea documentado al final del proceso, en lugar de establecerlo al inicio sin haber explorado lo que existe acerca de la tecnología. De esta manera, el protocolo de revisión pasa a ser el artefacto que documenta las decisiones tomadas durante la RS, y que puede ser usado para determinar si el proceso ha sido conducido adecuadamente.

- Se incluyen recomendaciones para la selección de la base de datos bibliográfica más adecuada. Por otra parte, se han analizado estrategias en los distintos campos de búsqueda que proporcionan estas bases de datos, y se ha comparado el desempeño de los resultados para varios de las bases de datos disponibles en IS. Con base en lo anterior, es posible proporcionar un conjunto de recomendaciones que, si bien no resuelven el problema de no contar con bases de datos especialmente destinadas al registro de experimentos, permitirán reducir el esfuerzo de localización de los experimentos en IS tratando al mismo tiempo de maximizar la recuperación de los mismos.

- Se proponen recomendaciones para construir cadenas de búsqueda óptimas, que permitan recuperar la mayor cantidad posible de experimentos, con el menor esfuerzo necesario para el descarte de artículos irrelevantes. Estas recomendaciones se han obtenido luego de analizar diferentes estrategias de búsqueda en las bases de datos bibliográficas disponibles en IS.

- Se propone el agrupamiento de aquellos conceptos que sean similares pero que aparezcan reportados con una terminología distinta. Se recomienda que esta uniformización de la terminología se inicie durante la lectura de los experimentos y sea mantenida durante todo el proceso.

- Se proponen agrupar los experimentos con base en los niveles que ensayan y las variables respuesta que miden, y organizar la lectura según la similitud de los experimentos en cuanto a estas características.

- $\quad$ Se propone que las evidencias que son obtenidas a este nivel (métrica) sean resumidas junto con otras métricas relacionadas con la misma variable respuesta.

- Se propone recolectar no sólo los datos de tipo cuantitativo (medias y varianzas) sino también aquella información de tipo cualitativa $(a>b)$ que permita realizar la agregación utilizando técnicas no paramétricas.

- Se propone la incorporación de técnicas de agregación que permitan la combinación de experimentos que no presenten todos (o ninguno) de los datos cuantitativos, pero para los cuales se cuente con información cualitativa relacionada con el efecto y su dirección. 
- Se propone descartar aquellos experimentos y cuasi-experimentos que posean una calidad pobre. Esto discriminar entre los estudios de calidad media y alta.

- Se ha propuesto el agrupamiento por distintos criterios que se relacionan con el contexto: 1 ) agrupamiento de experimentos por tipo de sujeto, 2) agrupamiento de experimentos por tarea, y 3) agrupamiento de experimentos por niveles y variables respuesta. Como resultado, se presentan los experimentos resumidos por contexto, incluyendo otras características como el ambiente y el objeto.

- Se propone realizar la agregación de los experimentos por niveles y métrica bajo condiciones de igual sujeto y tarea. Adicionalmente se realiza un análisis de la heterogeneidad, no sólo desde el punto de vista de los parámetros estadísticos, sino también gráfico, procurando mantener los grupos de experimentos más homogéneos posibles. Finalmente, cuando se genera una evidencia para un grupo homogéneo de experimentos, se registran las condiciones para las cuales ha sido obtenida.

- Se propone una escala minimalista, donde los elementos que han sido incluidos son aquellos que han aparecido en nuestro estudio fuertemente relacionados con la calidad; pareciendo ser buenos predictores del mismo.

\subsection{Futuras líneas}

- Este trabajo debe ser sometido a iteraciones adicionales de I-A; así como evaluaciones adicionales por parte de revisores independientes.

- Se espera optimizar aún más el instrumento de recolección de datos para evitar esfuerzos innecesarios de documentación.

- Dada la abundancia de casos de estudio en el área de la Ingeniería de Software, es necesario ampliar el alcance del proceso propuesto a fin de incorporar los mismos considerando que aquellos casos de estudios conducidos adecuadamente pueden contribuir de manera importante con la generación de evidencias.

- Dado el esfuerzo y experiencia requeridos para acometer una RS, arecce difícil que este tipo de prácticas lleguen a ser en el corto plazo, una actividad recurrente en el ámbito industrial. Sin embargo, se considera de una gran contribución al proceso de toma de decisiones; se considera necesario trabajar en la automatización del proceso; incorporando técnicas automáticas de recuperación de la información, extracción de datos y síntesis. 
- Una manera de aumentar la eficiencia de este proceso, al mismo tiempo que se garantiza la validez de sus resultados, es a través de actividades y heurísticas muy específicas que orienten al revisor y que incluyan instrumentos que permitan documentarlo en profundidad. Por ejemplo, nuestra investigación persigue identificar estrategias de búsqueda de experimentos, formularios de adquisición de datos, etc. Sin embargo, el uso de prácticas muy efectivas y con amplio impacto en la gestión del conocimiento, como es la documentación del proceso, puede resultar en costos elevados en tiempo. Por lo anterior, deben dedicarse esfuerzos a promover aún más la costeefectividad del proceso que garantice calidad de manera óptima. 


\section{REFERENCIAS BIBLIOGRÁFICAS}

Dieste, O., \& Grimán, A. (2007). Developing Search Strategies for Detecting Relevant Experiments for Systematic Reviews. Paper presented at the 1st International Symposium on Empirical Software Engineering and Measurement (ESEM'07), Madrid, Spain.

Higgins, J. P., \& Green, S. (2006). Cochrane Handbook for Systematic Reviews of Interventions 4.2.6 [updated September 2006]. In The Cochrane Library (Vol. 4). Chichester, UK: John Wiley \& Sons, Ltd.

Khan, K., Khalid, S., ter Riet, G., Glanville, J., Sowden, A. J., \& Kleijnen, J. (2001). Undertaking Systematic Review of Research on Effectiveness (No. 4). York: NHS Centre for Reviews and Dissemination. (University_of_York o. Document Number)

NHMRC. (2000). How to review the evidence: systematic identification and review of the scientific literature: Australian National Health and Medical Research Council.

NIHCE. (2007). The guidelines manual [Electronic Version]. Retrieved 02-july-2007, from $\underline{\text { www.nice.org.uk }}$

Wikipedia. (2007). Retrieved Julio, 11, 2007, from http://en.wikipedia.org/wiki/Cohen's kappa

Andrew, S. P., \& Teri, M. K. (2003). Support for decision making in conservation practice: an evidencebased approach. Journal for Nature Conservation, 11(2), 83-90.

ARCHE. (2007). Conducting a review. http://www.ualberta.ca/ARCHE/sysreviewsproc.html\#question.

Biolchini, J., Mian, P., Natali, A., \& Travassos, G. H. (2005). Systematic Review in Software Engineering (ES 679/05). Retrieved from Rio de Janeiro, Brasil:

Bowman, K., \& Hayman, S. (2004). Sound evidence for what works in vocational education and training: How we undertook a systematic review of research about skill development for mature age workers. Paper presented at the Association for Active Educational Researchers Conference - AARE 2004, Melbourne.

CEBC. (2006). Guidelines for Systematic Review in Conservation and Environmental Management. v.2.0. Retrieved from Birmingham:

EPPI-Centre. (2002). Core Keywording Strategy: Data collection for a register of educational research. Version 0.9.7. . London: Evidence for Policy and Practice Information and Co-ordinating Centre.

Higgins, J. P. T., \& Green, S. (2006). Cochrane Handbook for Systematic Reviews of Interventions 4.2.6 [updated September 2006] The Cochrane Library (Vol. 4). Chichester, UK: John Wiley \& Sons, Ltd.

Jadad, A. R., Moore, R. A., Carrol, D., Jenkinson, C., Reynolds, J. M., Gavaghan, D. J., \& McQuay, H. J. (1996). Assessing the quality of reports of randomized clinical trials: Is blinding necessary? . Controlled Clinical Trials, 17, 1-12. 
JBI. (s/f). The JBI Approach to the Systematic Review of Evidence. Retrieved from http://www.joannabriggs.edu.au/about/system review.php

Khan, K., Khalid, S., ter Riet, G., Glanville, J., Sowden, A. J., \& Kleijnen, J. (2001). Undertaking Systematic Review of Research on Effectiveness (4). Retrieved from York:

Kitchenham, B. (2004). Procedures for Performing Systematic Reviews (TR/SE-0401/ NICTA Technical Report 0400011T.1). Retrieved from

Kitchenham. B.A., \& Charters, S. (2007). Guidelines for performing Systematic Literature Reviews in Software Engineering (EBSE Technical Report EBSE-2007-01). Retrieved from

Little, J., \& Higgins, J. P. T. (2006). The HuGENet ${ }^{\text {TM }}$ HuGE Review Handbook, version 1.0.

NHMRC. (2000a). How to review the evidence: systematic identification and review of the scientific literature: Australian National Health and Medical Research Council.

NHMRC. (2000b). How to use the evidence: assessment and application of scientific evidence: Australian National Health and Medical Research Council.

NHMRC. (2001). How to compare the costs and benefits: evaluation of the economic evidence: Australian National Health and Medical Research Council (NHMRC).

NIHCE. (2007). The guidelines manual. Retrieved from www.nice.org.uk

Pai, M., McCulloch, M., Gorman, J. D., Pai, N., Enanoria, W., G.Kennedy, . . Colford, J. M. (2004). Systematic reviews and meta-analyses: An illustrated, step-by-step guide. THE NATIONAL MEDICAL JOURNAL OF INDIA, 17(2), 86-95.

Petersen, K., Feldt, R., Mujtaba, S., \& Mattsson, M. (2008). Systematic Mapping Studies in Software Engineering. Paper presented at the 12th International Conference on Evaluation and Assessment in Software Engineering, Bari, Italy.

Petersen, K., Vakkalanka, S., \& Kuzniarz, L. (2015). Guidelines for conducting systematic mapping studies in software engineering: An update. Information and Software Technology(64), 1-18.

Schultz, K. F., Chalmers, I., Hayes, R. J., \& Altman, D. G. (1995). Empirical evidence of bias. Dimensions of methodological quality associated with estimates of treatment effects in controlled trials. Journal of the American Medical Association, 273(5), 408-412.

SIGN. (2004). SIGN50: A guideline developers' handbook.

TheCampbellCollaboration (s/f, Julio, 2007). [Systematic Reviews I: The Basics].

Williams, J., Weightman, A. L., Weaver, N., Temple, M., Palmer, S., Kitcher, H., . . Sander, L. (2001). Built Environment and health of the public systematic review methodology.

Baskerville, R., \& Wood-Harper, A. (1996). A Critical Perspective on Action Research as a Method for Information Systems Research. Journal of Information Technology, 11(3), 235-246.

Creswell, J. W. (2002). Research Design: Qualitative, Quantitative, and Mixed Methods Approaches (2nd ed.). California: SAGE Publications, Inc.

Jonker, J., \& Pennink, B. (2010). The Essence of Research Methodology. Berlin: Springer.

Kitchenham, B. (1996). Evaluating Software Engineering Methods and Tools. Part 3: Selecting an appropriate evaluation method - practical issues. ACM SIGSOFT - Software Engineering Notes, 21(4), 9-12.

Pérez, M., Grimán, A., Mendoza, L., \& Rojas, T. (2004). A Systemic Methodological Framework for IS Research. Paper presented at the Tenth Americas Conference on Information Systems (AMCIS'04), New York.

ACM. (1998). Computing Classification System [Electronic Version], 
Agha, R., Cooper, D., \& Muir, G. (2007). The reporting quality of randomised controlled trials in surgery: a systematic review. International Journal of Surgery, 5(6), 413-422.

Areia, M., Soares, M., \& Dinis-Ribeiro, M. (2010). Quality reporting of endoscopic diagnostic studies in gastrointestinal journals: where do we stand on the use of the STARD and CONSORT statements? Endoscopy, 42(2), 138-147.

Bailey, J., Zhang, C., \& Budgen, D. (2007). Search Engine Overlaps : Do they agree or disagree? Paper presented at the Second International Workshop on Realising Evidence-Based Software Engineering (REBSE'07).

Begg, C. B., Cho, M., Eastwood, S., Horton, R., Moher, D., Olkin, I., et al. (1996). Improving the quality of reporting of randomized controlled trials. CONSORT statement. . JAMA(276), 637-639.

Biolchini, J., Mian, P., Natali, A., \& Travassos, G. H. (2005). Systematic Review in Software Engineering (No. ES 679/05). Rio de Janeiro, Brasil: COPPE/UFRJo. Document Number)

Biolchini, J. C., Mian, P. G., Natali, A. C., Conte, T. U., \& Travassos, G. H. (2007). Scientific research ontology to support systematic review in software engineering. Advanced Engineering Informatics, 21(2), 133--151.

Brereton, O. P., Kitchenham, B., Budgen, D., Turner, M., \& Khalil, M. (2007). Lessons from applying the systematic literature review process within the software engineering domain. Journal of Systems and Software, 80, 571-583.

CDR. (2009). Systematic reviews: CRD's guidance for undertaking reviews in health care. York: University of York. (Centre_for_Reviews_and_Dissemination o. Document Number)

Ciolkowski, M. (2009). What do we know about perspective-based reading? An approach for quantitative aggregation in software engineering. Paper presented at the 3rd International Symposium on Empirical Software Engineering and Measurement (ESEM'09).

Cohen, J. (1977). Statistical Power Analysis for the Behavioral Sciences (Revised ed.). New York: Academic Press.

Conradi, R., \& Wang, A. I. (2003). Empirical methods and studies in software engineering: Experiences from ESERNET: Springer.

Counsell, C. (1997). Formulating questions and locating primary studies for inclusion in systematic reviews. Annals of Internal Medicine, 127, 380-387.

CRD. (2009). Systematic reviews: CRD's guidance for undertaking reviews in health care. York: University of York. (NHS Centre for Reviews and Dissemination o. Document Number) 
Cronbach, L. J. (1982). Designing evaluations of educational and social programs. San Francisco.

Dieste, O., Grimán, A., \& Juristo, N. (2009). Developing search strategies for detecting relevant experiments. Empirical Software Engineering, 14(5), 513-539.

Dieste, O., \& Juristo, N. (2011). Systematic Review and Aggregation of Empirical Studies on Elicitation Techniques. IEEE Transactions on Software Engineering, 37(2), 283-304.

Dybå, T., Arisholm, E., Sjoberg, D. I. K., Hannay, J. E., \& Shull, F. (2007). Are two heads better than one? On the effectiveness of pair programming. IEEE Software, 24(6), 10-13.

Dybå, T., Kampenes, V. B., \& Sjoberg, D. I. K. (2006). A systematic review of statistical power in software engineering experiments. Information and Software Technology, 48(8), 745-755.

Higgins, J. P. T., \& Green, S. (2006). Cochrane Handbook for Systematic Reviews of Interventions 4.2.6 [updated September 2006]. In The Cochrane Library (Vol. 4). Chichester, UK: John Wiley \& Sons, Ltd.

IEEE. (1990). Standard Glossary of Software Engineering Terminology o. Document Number)

IEEE. (2004). Guide to the Software Engineering Body of Knowledge. Los Alamitos, California.

IOM. (2011). Finding What Works in Health Care. Standards for Systematic Reviews. Washington: The National Academies Press.

Jedlitschka, A., \& Ciolkowski, M. (2004). Towards Evidence in Software Engineering. Paper presented at the ACM/IEEE Intern. Symposium on Software Engineering 2004 (ISESE2004),

Jedlitschka, A., \& Pfahl, D. (2005). Reporting guidelines for controlled experiments in software engineering. Paper presented at the International Symposium on Empirical Software Engineering. ISESE 2005 Noosa heads, Australia.

Kitchenham, B., Al-Khilidar, H., Babar, M. A., Berry, M., Cox, K., Keung, J., et al. (2008). Evaluating guidelines for reporting empirical software engineering studies. Empirical Software Engineering, 13, 97121.

Kitchenham, B., Brereton, P., Budgen, D., Turner, M., Bailey, J., \& Linkman, S. (2009). Systematic literature reviews in software engineering - A systematic literature review Inf. Softw. Technol., 51(1), 7-15.

Kitchenham, B. A., Budgen, D., \& Brereton, O. P. (2011). Using mapping studies as the basis for further research - A participant-observer case study. Information \& Software Technology (INFSOF), 53(6), 638-651.

Kitchenham. B.A., \& Charters, S. (2007). Guidelines for performing Systematic Literature Reviews in Software Engineering (No. EBSE Technical Report EBSE-2007-01)o. Document Number) 
Lisboa, L. B., Garcia, V. C., Lucrédio, D., de Almeida, E. S., Meira, S. R., \& Fortes, R. P. (2010). A systematic review of domain analysis tools. Information and Software Technology, 52(1), 1-13.

Lucas, F., Molina, F., \& A., T. (2009). A systematic review of UML model consistency management. Information and Software Technology, 5(12), 1631-1645.

McGowan, J., \& Sampson, M. (2005). Systematic reviews need systematic searchers. J Med Libr Assoc., 93(1), 74-80.

Mignini, L. E., \& Khan, K. S. (2006). Methodological quality of systematic reviews of animal studies: a survey of reviews of basic research. BMC Medical Research Methodology, 6(10), 1--6.

Morais, Y., Burity, T., \& Elias, G. (2009). A Systematic Review of Software Product Lines Applied to Mobile Middleware. Paper presented at the 6th International Conference on Information Technology.

Murphy, M. K., Black, N. A., Lamping, D. L., McKee, C. M., Sanderson, C., Askham, J., et al. (1998). Consensus development methods, and their use in clinical guidelines development. Health Technology Assessment, 2(3), 1-88.

NHMRC. (2000). Handbook series on preparing clinical practice guidelines. Retrieved 11-03-2010, from http://www.health.gov.au/hfs/nhmrc/publicat/synopses/cp65syn.htm

NIHCE. (2007). The guidelines manual [Electronic Version]. Retrieved 02-july-2007, from www.nice.org.uk

Pilkington, K. (2007). Searching for CAM evidence: an evaluation of therapy-specific search strategies. Journal of Alternative and Complementary Medicine, 13(4), 451-459.

Richardson, W. S., Wilson, M. S., Nishikawa, J., \& Hayward, R. S. A. (1995). The Well-built Clinical Question: A Key to Evidence Based Decisions. ACP Journal Club, 123(3), A12-A13.

Sampson, M., Cogo, E., Ajiferuke, I., Manheimer, E., Campbell, K., Daniel, R., et al. (2011). Searching for controlled trials of complementary and alternative medicine: A comparison of 15 databases. Evidencebased Complementary and Alternative Medicine, 1-9.

Shadish, W. R., Cook, T. D., \& Campbell, D. T. (2002). Experimental and Quasi-experimental Designs for Generalized Causal Inference: Houghton Mifflin Company.

Sjøberg, D. I. K., Hannay, J., Hansen, O., Kampenes, V., Karahasanovi, A., Liborg, N., et al. (2005). A Survey of Controlled Experiments in Software Engineering. IEEE Transactions on Software Engineering, 31(9), 733-753.

Wohlin, C., Runenson, P., Höst, M., Ohlsson, M. C., Regnell, B., \& Wesslén, A. (2000). Experimentation in software engineering: an introduction Klwer Academic Publishers. 
Zhang, H., Kitchenham, B., \& Pfahl, D. (2008). Reflections on 10 Years of Software Process Simulation Modeling: A Systematic Review. Lecture Notes in Computer Science, 5007/2008, 345--356.

Ziogas, D. C., \& Zintzaras, E. (2009). Analysis of the quality of reporting of randomized controlled trials in acute and chronic myeloid leukemia, and myelodysplastic syndromes as governed by the CONSORT statement. Ann Epidemiol 19(7), 494-500.

ACM. (1998). Computing Classification System [Electronic Version],

Bailey, J., Zhang, C., \& Budgen, D. (2007). Search Engine Overlaps : Do they agree or disagree? Paper presented at the Second International Workshop on Realising Evidence-Based Software Engineering (REBSE'07).

Biolchini, J., Mian, P., Natali, A., \& Travassos, G. H. (2005). Systematic Review in Software Engineering (No. ES 679/05). Rio de Janeiro, Brasil: COPPE/UFRJo. Document Number)

Brereton, O. P., Kitchenham, B., Budgen, D., Turner, M., \& Khalil, M. (2007). Lessons from applying the systematic literature review process within the software engineering domain. Journal of Systems and Software, 80, 571-583.

Budgen, D., Turner, M., Brereton, P., \& Kitchenham, B. (2008). Using mapping studies in software engineering. Paper presented at the The 20th Annual Psychology of Programming Interest Group Conference.

CDR. (2009). Systematic reviews: CRD's guidance for undertaking reviews in health care. York: University of York. (C. f. R. a. Dissemination o. Document Number)

Counsell, C. (1997). Formulating questions and locating primary studies for inclusion in systematic reviews. Annals of Internal Medicine, 127, 380-387.

Cruzes, D., \& Dyba, T. (2010). Synthesizing Evidence in Software Engineering Research. Paper presented at the 4th International Symposium on Empirical Software Engineering and Measurements.

Davis, A., Dieste, O., Hickey, A., Juristo, N., \& Moreno, A. M. (2006). Effectiveness of requirements elicitation techniques: Empirical results derived from a systematic review. Paper presented at the Re'06: 14th leee International Requirements Engineering Conference, Proceedings. from <Go to ISI>://ISIP:000242104000018

Davis, A., Dieste, O., Juristo, N., \& Moreno, A. M. (2006). Effectiveness of Requirements Elicitation Techniques: Empirical Results derived from a Systematic Review. Paper presented at the 14th IEEE International Requirements Engineering Conference RE'06, Minneapolis, USA.

Dickersin, K., Scherer, R., \& Lefebvre, C. (1994). Systematic Reviews: Identifying relevant studies for 
systematic reviews. British Medical Journal(309), 1286-1291.

Dieste, O., \& Grimán, A. (2007). Developing Search Strategies for Detecting Relevant Experiments for Systematic Reviews. Paper presented at the 1st International Symposium on Empirical Software Engineering and Measurement (ESEM'07), Madrid, Spain.

Dieste, O., Grimán, A., \& Juristo, N. (2008). Developing search strategies for detecting relevant experiments. Empirical Software Engineering, 1 - 27.

Dieste, O., Grimán, A., \& Juristo, N. (2009). Developing search strategies for detecting relevant experiments. Empirical Software Engineering, 14(5), 513-539.

Dieste, O., Grimán, A., Juristo, N., \& López, M. (2008, October). Revisiones Sistemáticas: Recomendaciones para un Proceso Adecuado a la Ingeniería del Software. Paper presented at the XIII Jornadas Internacionales de Ingeniería del Software y Base de Datos, Gijón.

Dybå, T., \& Dingsøyr, T. (2008). Empirical studies of agile software development: A systematic review. . Information and Software Technology, 50(9-10), 833-859.

Dybå, T., Dingsøyr, T., \& Hanssen, G. K. (2007). Applying Systematic Reviews to Diverse Study Types: An Experience Report. Paper presented at the First International Symposium on Empirical Software Engineering and Measurement, Madrid, Spain.

Hannay, J. E., Dybå, T., Arisholm, E., \& Sjøberg, D. I. K. (2009). The effectiveness of pair programming: A meta-analysis. Information and Software Technology, 51(7), 1110-1122.

Haynes, R. B., Wilczynski, N., McKibbon, K. A., Walker, C. J., \& Sinclair, J. C. (1994). Developing optimal search strategies for detecting clinically sound studies in MEDLINE. Journal of the American Medical Informatics Association, 1(6), 447-458.

Higgins, J. P. T., \& Green, S. (2006). Cochrane Handbook for Systematic Reviews of Interventions 4.2.6 [updated September 2006]. In The Cochrane Library (Vol. 4). Chichester, UK: John Wiley \& Sons, Ltd.

IEEE. (1990). Standard Glossary of Software Engineering Terminology o. Document Number)

IEEE. (2004a). Guide to the Software Engineering Body of Knowledge. Los Alamitos, California.

IEEE. (2004b). Software Engineering Body of Knowledge.

Jedlitschka, A., \& Pfahl, D. (2005, 17-18 Nov.). Reporting experiments in Software Engineering. Paper presented at the International Symposium on Empirical Software Engineering (ISESE'05), Noosa Heads, Australia. 
Jørgensen, M., \& Shepperd, M. (2007). A systematic review of software development cost estimation studies. IEEE Transactions on Software Engineering, 33(1), 33-53.

Juristo, N., Moreno, A. M., \& Vegas, S. (2004). Reviewing 25 years of testing technique experiments. Empirical Software Engineering, 9(1-2), 7-44.

Kampenes, V. B., Dyba, T., Hannay, J. E., \& Sjøberg, D. I. K. (2007). A systematic review of effect size in software engineering experiments. Information and Software Technology, 49(11-12), 1073-1086.

Khan, K., Khalid, S., ter Riet, G., Glanville, J., Sowden, A. J., \& Kleijnen, J. (2001). Undertaking Systematic Review of Research on Effectiveness (No. 4). York: NHS Centre for Reviews and Dissemination. (University_of_York o. Document Number)

Kitchenham, B. (2004). Procedures for Performing Systematic Reviews (No. TR/SE-0401/ NICTA Technical Report 0400011T.1): Keele University o. Document Number)

Kitchenham, B., Brereton, P., Turner, M., Niazi, M., Linkman, S. G., Pretorius, R., et al. (2010). Refining the systematic literature review process - two participant-observer case studies. Journal of Empirical Software Engineering, 15(6), 618--653.

Kitchenham, B. A., Mendes, E., \& Travassos, G. H. (2007). Cross versus within-company cost estimation studies: A systematic review. IEEE Transactions on Software Engineering, 33(5), 316329.

Kitchenham. B.A., \& Charters, S. (2007). Guidelines for performing Systematic Literature Reviews in Software Engineering (No. EBSE Technical Report EBSE-2007-01)o. Document Number)

Machine, A. o. C. (1998). Computing Classification System [Electronic Version],

Pedreira, O., Piattini, M., Luaces, M. R., \& Brisaboa, N. R. (2007). A systematic review of software process tailoring. ACM SIGSOFT Software Engineering Notes, 32, 1-6.

Petticrew, M., \& Roberts, H. (2007). Systematic Reviews in the Social Sciences. A practical Guide.: Blackwell Publishing.

Pilkington, K. (2007). Searching for CAM evidence: an evaluation of therapy-specific search strategies. Journal of Alternative and Complementary Medicine, 13(4), 451-459.

Pogue, J., \& Yusuf, S. (1998.). Overcoming the limitations of current meta-anlysis of randomised controlled trials. Lancet(351), 47-52.

Richardson, W. S., Wilson, M. S., Nishikawa, J., \& Hayward, R. S. A. (1995). The Well-built Clinical Question: A Key to Evidence Based Decisions. ACP Journal Club, 123(3), A12-A13. 
Sampson, M., Cogo, E., Ajiferuke, I., Manheimer, E., Campbell, K., Daniel, R., et al. (2011). Searching for controlled trials of complementary and alternative medicine: A comparison of 15 databases. Evidence-based Complementary and Alternative Medicine, 1-9.

Sjøberg, D. I. K., Hannay, J., Hansen, O., Kampenes, V., Karahasanovi, A., Liborg, N., et al. (2005). A Survey of Controlled Experiments in Software Engineering. IEEE Transactions on Software Engineering, 31(9), 733-753.

The Cochrane Collaboration. (2010). The Cochrane Library (Publication. Retrieved 05-22-2011, from John Wiley \& Sons, Ltd. : http://www.thecochranelibrary.com/view/0/index.html

US National Library of Medicine. (1999, 09-21-2010). Medical Subject Headings. Retrieved 05-23-2011, 2011, from http://www.nlm.nih.gov/mesh/meshhome.html

US National Library of Medicine. (2001, 10-10-2008). PubMed Tutorial. Retrieved 06-032011, 2011, from http://www.nlm.nih.gov/bsd/disted/pubmedtutorial/015 010.html

US National Library of Medicine. (2009, 05-19-2011). Unified Medical Language System. Retrieved 05-23-2011, 2011, from http://www.nlm.nih.gov/research/umls/index.html

Zanchetti, A., \& Mancia, G. (1998). Searching for information from unreported trials--amnesty for the past and prospective meta-analyses for the future. Journal of Hypertension(16), 125.

ACM. (1998). Computing Classification System [Electronic Version],

Beal, S. M., \& Finch, C. F. (1991). An overview of retrospective case-control studies investigating the relationship between prone sleeping position and SIDS. Journal of Paediatric Child Health(27), 334-339.

Benson, K., \& Hartz, A. J. (2000). A comparison of observational studies and randomized, controlled trials. The New England Journal of Medicine(342), 1878--1886.

Biolchini, J., Mian, P., Natali, A., \& Travassos, G. H. (2005). Systematic Review in Software Engineering (No. ES 679/05). Rio de Janeiro, Brasil: COPPE/UFRJo. Document Number)

Biolchini, J. C., Mian, P. G., Natali, A. C., Conte, T. U., \& Travassos, G. H. (2007). Scientific research ontology to support systematic review in software engineering. Advanced Engineering Informatics, 21(2), 133--151.

Britton, A., McKee, M., Black, N., Mc Pherson, K., Sanderson, C., \& Bain, C. (1998). Choosing between randomised and non-randomised studies: a systematic review. Health Technology Assessment, 2(13), 3-4. 
Cantone, G., Colasanti, L., Abdulnabi, Z. A., Lomartire, A., \& Calavaro, G. (2003). Evaluating checklist based and use case driven reading techniques as applied to software analysis and design UML artifacts. Lecture Notes in Computer Science (2765), 142-165.

CDR. (2009). Systematic reviews: CRD's guidance for undertaking reviews in health care. York: University of York. (C. f. R. a. Dissemination o. Document Number)

Ciolkowski, M. (2009). What do we know about perspective-based reading? An approach for quantitative aggregation in software engineering. Paper presented at the 3rd International Symposium on Empirical Software Engineering and Measurement (ESEM'09).

Concato, J., Shah, N., \& Horwitz, R. I. (2000). Randomized, controlled trials, observational studies, and the hierarchy of research designs. The New England Journal of Medicine(342), 1887-1892.

Conradi, R., \& Wang, A. I. (2003). Empirical methods and studies in software engineering: Experiences from ESERNET: Springer.

Cronbach, L. J. (1982). Designing evaluations of educational and social programs. San Francisco.

Cruzes, D., \& Dyba, T. (2010). Synthesizing Evidence in Software Engineering Research. Paper presented at the 4th International Symposium on Empirical Software Engineering and Measurements.

Dieste, O., Fernández, E., \& García, R. (2008). Statistical techniques for aggregating experiments results: Facultad de Informática, Universidad Politécnica de Madrid.

Dieste, O., \& Juristo, N. (2011). Systematic Review and Aggregation of Empirical Studies on Elicitation Techniques. IEEE Transactions on Software Engineering, 37(2), 283-304.

Dybå, T., \& Dingsøyr, T. (2008). Empirical studies of agile software development: A systematic review. . Information and Software Technology, 50(9-10), 833-859.

Dyer, D., Kagel, J. H., \& Levin, D. (1989). A comparison of naive and experienced bidders in common value offer auctions: A laboratory analysis. The Economic Journal, 99(394), 108-115.

Feinstein, A. R., \& Horwitz, R. I. (1982). Double standards, scientific methods, and epidemiological research. The New England Journal of Medicine(307), 1611--1617.

Fusaro, P., Lanubile, F., \& Visaggio, G. (1997). A Replicated Experiment to Assess Requirements Inspection Techniques. Empirical Software Engineering(2), 39-57.

Glass, R. L., Vessey, I., \& Ramesh, V. (2002). Research in Software Engineering: an Analysis of literature. Information and Software Technology, 44, 491-506. 
Higgins, J. P. T., \& Green, S. (2006). Cochrane Handbook for Systematic Reviews of Interventions 4.2.6 [updated September 2006]. In The Cochrane Library (Vol. 4). Chichester, UK: John Wiley \& Sons, Ltd.

Horwitz, R. I., \& Feinstein, A. R. (1979). Methodological standards and contradictory results in case-control research. American Journal of Medicine(66), 556--564.

IEEE. (1990). Standard Glossary of Software Engineering Terminology o. Document Number)

IEEE. (2004a). Guide to the Software Engineering Body of Knowledge. Los Alamitos, California.

IEEE. (2004b). Software Engineering Body of Knowledge.

Jedlitschka, A., \& Ciolkowski, M. (2004). Towards Evidence in Software Engineering. Paper presented at the ACM/IEEE Intern. Symposium on Software Engineering 2004 (ISESE2004),

Jedlitschka, A., Ciolkowski, M., \& Pfahl, D. (2008). Reporting Controlled Experiments in Software Engineering. In F. Shull, J. Singer \& D. I. Sjoberg (Eds.), Guide to Advanced Empirical Software Engineering. London: Springer

Jedlitschka, A., \& Pfahl, D. (2005). Reporting guidelines for controlled experiments in software engineering. Paper presented at the International Symposium on Empirical Software Engineering. ISESE 2005 Noosa heads, Australia.

Jørgensen, M., \& Shepperd, M. (2007). A systematic review of software development cost estimation studies. IEEE Transactions on Software Engineering, 33(1), 33-53.

Judd, C. M., Smith, E. R., \& Kidder, L. H. (1991). Research Method in Social Relations. Orlando: Harcourt Brace Jovanovich College Publishers.

Juristo, N., \& Moreno, A. M. (2001). Basics of Software Engineering Experimentation. Boston: Kluwer Academic Publishers.

Kampenes, V. B., Dyba, T., Hannay, J. E., \& Sjøberg, D. I. K. (2007). A systematic review of effect size in software engineering experiments. Information and Software Technology, 49(11-12), 1073-1086.

Kitchenham, B., Al-Kilidar, H., Ali Babar, M., Berry, M., Cox, K., Keung, J., et al. (2006). Evaluating guidelines for empirical software engineering studies. Paper presented at the International Symposium on Empirical Software Engineering - ISESE 2006, Río de Janeiro, Brasil.

Kitchenham, B., Brereton, P., Budgen, D., Turner, M., Bailey, J., \& Linkman, S. (2009). Systematic literature reviews in software engineering - A systematic literature review Inf. Softw. Technol., 51(1), 7--15. 
Kunz, R., \& Oxman, A. (1998). The unpredictability paradox: review of empirical comparisons of randomised and non-randomised clinical trials. British Medical Journal(317), 1185--1190.

Levine, M., Walter, S., Lee, H., Haines, T., Holbrook, A., \& Moyer, V. (1994). Users' guides to the medical literature, IV: how to use an article about harm. Journal of the American Medical Association(271), 1615--1619.

Lindberg, D. A., Humphreys, B. L., \& McCray, A. T. (1993). The Unified Medical Language System. Methods of information in medicine, 32(4), 281-291.

Machine, A. o. C. (1998). Computing Classification System [Electronic Version],

Marta Gómez, Silvia Acuña, \& Rico, R. (2007). Estudio Experimental en Equipos de Desarrollo de Software sobre las Relaciones entre Personalidad, Satisfacción y Calidad del Producto. Paper presented at the JIISIC 2007.

Mendes, E. (2005). A Systematic Review of Web Engineering Research. Paper presented at the ACM/IEEE International Symposium on Empirical Software Engineering, Noosa heads, Australia.

Petitti, D. B. (1998). Hormone replacement therapy and heart disease prevention: experimentation trumps observation. Journal of the American Medical Association(280), 650-652.

Porter, A. A., Votta, L. G., \& Basili, V. R. (1995). Comparing Detection Methods for Software Requirements Inspections: A Replicated Experiment. IEEE Transactions on Software Engineering, 21(6), 563-575.

Potters, J., \& Van Winden, F. (1996). The Performance of Professionals and Students in an Experimental Study of Lobbying Social Science Research Network.

Reeves, B. C., MacLehose, R. R., Harvey, I. M., Sheldon, T. A., Russel, I. T., \& Black, A. M. S. (1998). Comparisons of effect size estimates derived from randomised and non-randomised studies. In N. Black (Ed.), Health Services Research Methods: a guide to best practice (pp. 73--85). London: BMJ Publishing Group.

Sandahl, K., Blomkvist, O., Karlsson, J., Krysander, C., Lindvall, M., \& Ohlsson, N. (1998). An extended replication of an experiment for assessing methods for software requirements inspections. Empirical Software Engineering(3), 327-354

Sjøberg, D. I. K., Hannay, J., Hansen, O., Kampenes, V., Karahasanovi, A., Liborg, N., et al. (2005). A Survey of Controlled Experiments in Software Engineering. IEEE Transactions on Software Engineering, 31(9), 733-753. 
Sjøeberg, D., Hannay, J., Hansen, O., Kampenes, V., Karahasanovic, A., Liborg, N., et al. (2005).

A survey of controlled experiments in software engineering. IEEE Transactions on Software Engineering, 31(9), 733-753.

Thelin, T., Runeson, P., \& Wohlin, C. (2003). An Experimental Comparison of Usage Based and Checklist Based Reading. IEEE Transactions on Software Engineering, 29(8), 687-704.

US National Library of Medicine. (1999, 09-21-2010). Medical Subject Headings. Retrieved 05-23-2011, 2011, from http://www.nlm.nih.gov/mesh/meshhome.html

US National Library of Medicine. (2009, 05-19-2011). Unified Medical Language System. Retrieved 05-23-2011, 2011, from http://www.nlm.nih.gov/research/umls/index.html

Wohlin, C., Runenson, P., Höst, M., Ohlsson, M. C., Regnell, B., \& Wesslén, A. (2000). Experimentation in software engineering: an introduction Klwer Academic Publishers.

Churchill, G. (1979). A paradigm for developing better measures of marketing constructs. Journal of Marketing Research, 16(1), 64-73.

Ciolkowski, M. (2009). What do we know about perspective-based reading? An approach for quantitative aggregation in software engineering. Paper presented at the 3rd International Symposium on Empirical Software Engineering and Measurement (ESEM'09), Orlando, USA.

Cohen, J. (1977). Statistical Power Analysis for the Behavioral Sciences (Revised ed.). New York: Academic Press.

Cooper, H. (1982). Scientific Guidelines for Conducting Integrative Research Reviews. Review of Educational Research, 52(2), 291-302.

Cruzes, D., \& Dyba, T. (2010). Synthesizing Evidence in Software Engineering Research. Paper presented at the 4th International Symposium on Empirical Software Engineering and Measurements, Bolzano, Italia.

da Silva, F., Santos, A., Soares, S., Franaa, A., Monteiro, C., \& Maciel, F. (2011). Six years of systematic literature reviews in software engineering: An updated tertiary study. Information and Software Technology, 53(9), 899-913.

Dieste, O., Fernandez, E., García-Martinez, R., \& Juristo, N. (2011). Comparative analysis of metaanalysis methods: when to use which? Paper presented at the 15th Annual Conference on Evaluation \& Assessment in Software Engineering (EASE 2011).

Dieste, O., Fernandez, E., García-Martinez, R., \& Juristo, N. (2012). Comparison of meta-analysis: understanding the influence of experiments' statistical parameters. Empirical Softw. Engineering, (submited).

Dieste, O., Fernandez, E., Garcia, R., \& Juristo, N. (2011). The risk of using the $Q$ heterogeneity estimator for software engineering experiments Paper presented at the International Symposium on Empirical Software Engineering and Measurement (ESEM), Banff, AB.

Dieste, O., Fernández, E., Garcí1a, R., \& Juristo, N. (2011). “Compara-

tive analysis of meta-anaysis methods: when to use which? Paper presented at the 15th International Conference on Evaluation and Assessment in Software Engineering (EASE'2011), Durham, UK.

Dybå, T., Kampenes, V. B., \& Sjoberg, D. I. K. (2006). A systematic review of statistical power in software engineering experiments. Information and Software Technology, 48(8), 745-755. 
Friedrich, J., Adhikari, N., \& Beyene, J. (2008). The ratio of means method as an alternative to mean differences for analyzing continuous outcome variables in meta-analysis: A simulation study. BMC Medical Research Methodology, 8(1), 32.

Grimán, A. (2007). Proposal of a Review Process of Empirical Studies in Software Engineering. Paper presented at the 2nd International Doctoral Symposium on Empirical Software Engineering, Madrid, Spain.

Gurevitch, J., \& Hedges, L. (1999). Statistical Issues in Ecological Meta-Analyses. Ecology, 80(4), $1142-1149$.

Hardestya, D., \& Beardenb, W. (2004). The use of expert judges in scale development. Implications for improving face validity of measures of unobservable constructs. Journal of Business Research (57), 98107.

Hayes, W. (1999). Research Synthesis in Software Engineering: A Case for Meta-Analysis. Paper presented at the Sixth IEEE Int'1 Software Metrics Symposium.

Hedges, L. (1982). Estimation of effect size from a series of independent experiments. Psychological Bulletin, 92(2), 490-499.

Hedges, L. V., Gurevitch, J., \& Curtis, P. S. (1999). The Meta-Analysis of Response Ratios in Experimental Ecology. Ecology, 80(4), 1150-1156.

Hedges, L. V., \& Olkin, I. (1985). Statistical methods for meta-analysis. San Diego:: Academic Press.

Higgins, J. P., \& Green, S. (2006). Cochrane Handbook for Systematic Reviews of Interventions 4.2.6 [updated September 2006] The Cochrane Library (Vol. 4). Chichester, UK: John Wiley \& Sons, Ltd.

Imtiaz, S., Bano, M., Ikram, N., \& Niazi, M. (2013). A tertiary study: experiences of conducting systematic literature reviews in software engineering. Paper presented at the 17 th International Conference on Evaluation and Assessment in Software Engineering - EASE '13 Porto de Galinhas, Brazil. http://dl.acm.org/citation.cfm?id=2461025

Jedlitschka, A., \& Pfahl, D. (2005). Reporting guidelines for controlled experiments in software engineering. Paper presented at the International Symposium on Empirical Software Engineering. ISESE 2005 Noosa heads, Australia.

Kitchenham, B., Sjoberg, D. I. K., Dybå, T., Pfahl, D., Brereton, O. P., Budgen, D., . . Runenson, P. (2012). Three empirical studies on the agreement of reviewers about the quality of software engineering experiments Information and Software Technology, 54, 804-819.

Lajeunesse, M., \& Forbes, M. (2003). Variable reporting and quantitative reviews: a comparison of three meta-analytical techniques. Ecology Letters, 6, 448-454.

Lau, J. (1998). Summing up evidence: One answer is not always enough. Lancet(351), 123-127,

Miller, J. (2000). Applying Meta-analytical Procedures to Software Engineering Experiments. Journal of Information Technology, 54(1), 29-39.

Palma, S., \& Delgado-Rodriguez, M. (2005). Assessment of publication bias in meta-analyses of cardiovascular diseases. Journal of Epidemiol Community Health(59), 864-869.

Pickard, L. M., Kitchenham, B. A., \& Jones, P. W. (1998). Combining empirical results in Software Engineering. Information and Software Technology, 40(4), 811-821.

Shepperd, M. (2011). Combining Evidence and Meta-analysis in Software Engineering. In A. De Lucia \& F. Ferrucci (Eds.), Software Engineering (pp. 46-70). Salerno, Italia: Springer.

Sterne, J. A. C., Gavaghan, D. J., \& Egger, M. (2000). Publication and related bias in meta-analysis: Power of statistical tests and prevalence in the literature. Journal of Clinical Epidemiology(53), 1119-1129.

Bandara, N. (2010). Comparison of two Systematic Review Processes: Grimán's Process. Universidad Politécnica de Madrid, Madrid. 
Baskerville, R., \& Wood-Harper, A. (1996). A Critical Perspective on Action Research as a Method for Information Systems Research. Journal of Information Technology, 11(3), 235-246.

Booth, A., Papaioannou, D., \& Sutton, A. (2012). Systematic Approaches to a Successful Literature Review: SAGE Publications.

Ciolkowski, M. (2009). What do we know about perspective-based reading? An approach for quantitative aggregation in software engineering. Paper presented at the 3rd International Symposium on Empirical Software Engineering and Measurement (ESEM'09).

Hannay, J. E., Dybå, T., Arisholm, E., \& Sjøberg, D. I. K. (2009). The effectiveness of pair programming: A meta-analysis. Information and Software Technology, 51(7), 1110-1122.

Kitchenham, B. (1996). Evaluating Software Engineering Methods and Tools. Part 3: Selecting an appropriate evaluation method - practical issues. ACM SIGSOFT - Software Engineering Notes, 21(4), 9-12.

Kitchenham, B. (2004). Procedures for Performing Systematic Reviews (No. TR/SE-0401/ NICTA Technical Report 0400011T.1): Keele University o. Document Number)

Kitchenham. B.A., \& Charters, S. (2007). Guidelines for performing Systematic Literature Reviews in Software Engineering (No. EBSE Technical Report EBSE-2007-01)o. Document Number)

Samaranayake, S. (2010). Comparison of two Systematic Review Processes: Kitchenham's Process. Universidad Politécnica de Madrid, Madrid.

Thalheimer, W., \& Cook, S. (2002). How to calculate effect sizes from published research: A simplified methodology [Electronic Version]. Work-Learning Research Retrieved November 31, 2002, from http://work-learning.com/effect sizes.htm.

. (2004). Journal of Business Research(57).

ACM. (1998). Computing Classification System

Agha, R., Cooper, D., \& Muir, G. (2007). The reporting quality of randomised controlled trials in surgery: a systematic review. International Journal of Surgery, 5(6), 413-422.

Andrew, S. P., \& Teri, M. K. (2003). Support for decision making in conservation practice: an evidencebased approach. Journal for Nature Conservation, 11(2), 83-90.

$\begin{array}{lllll}\text { ARCHE. (2007). Conducting a r a } & \text { a }\end{array}$ http://www.ualberta.ca/ARCHE/sysreviewsproc.html\#question.

Areia, M., Soares, M., \& Dinis-Ribeiro, M. (2010). Quality reporting of endoscopic diagnostic studies in gastrointestinal journals: where do we stand on the use of the STARD and CONSORT statements? Endoscopy, 42(2), 138-147.

Bailey, J., Zhang, C., \& Budgen, D. (2007). Search Engine Overlaps : Do they agree or disagree? Paper presented at the Second International Workshop on Realising Evidence-Based Software Engineering (REBSE'07), Minneapolis, Minnesota, USA.

Balk, E. M., Bonis, P. A. L., Moskowitz, H., Schmid, C. H., Ioannidis, J. P. A., Wang, C., \& Lau, J. (2002). Correlation of Quality Measures With Estimates of Treatment Effect in Meta-analyses of Randomized Controlled Trials. JAMA, 287(22), 2973-2982. 
Bandara, N. (2010). Comparison of two Systematic Review Processes: Grimán's Process. (MSc), Universidad Politécnica de Madrid, Madrid.

Baskerville, R., \& Wood-Harper, A. (1996). A Critical Perspective on Action Research as a Method for Information Systems Research. Journal of Information Technology, 11(3), 235-246.

Beal, S. M., \& Finch, C. F. (1991). An overview of retrospective case-control studies investigating the relationship between prone sleeping position and SIDS. Journal of Paediatric Child Health(27), 334-339.

Begg, C. B., Cho, M., Eastwood, S., Horton, R., Moher, D., Olkin, I., . . Stroup, D. F. (1996). Improving the quality of reporting of randomized controlled trials. CONSORT statement. . JAMA(276), 637639.

Benson, K., \& Hartz, A. J. (2000). A comparison of observational studies and randomized, controlled trials. The New England Journal of Medicine(342), 1878--1886.

Biolchini, J., Mian, P., Natali, A., \& Travassos, G. H. (2005). Systematic Review in Software Engineering. Rio de Janeiro, Brasil: COPPE/UFRJ.

Biolchini, J. C., Mian, P. G., Natali, A. C., Conte, T. U., \& Travassos, G. H. (2007). Scientific research ontology to support systematic review in software engineering. Advanced Engineering Informatics, 21(2), 133--151. doi: 10.1016/j.aei.2006.11.006

Bowman, K., \& Hayman, S. (2004). Sound evidence for what works in vocational education and training: How we undertook a systematic review of research about skill development for mature age workers. Paper presented at the Association for Active Educational Researchers Conference AARE 2004, Melbourne.

Brereton, O. P., Kitchenham, B., Budgen, D., Turner, M., \& Khalil, M. (2007). Lessons from applying the systematic literature review process within the software engineering domain. Journal of Systems and Software, 80, 571-583.

Britton, A., McKee, M., Black, N., Mc Pherson, K., Sanderson, C., \& Bain, C. (1998). Choosing between randomised and non-randomised studies: a systematic review. Health Technology Assessment, 2(13), 3-4.

Brooks, A. (1997). Meta analysis - a silver bullet - for meta-analysts. Empirical Software Engineering, 2(4), 333-338.

Budgen, D., Turner, M., Brereton, P., \& Kitchenham, B. (2008). Using mapping studies in software engineering. Paper presented at the The 20th Annual Psychology of Programming Interest Group Conference, Lancaster University, UK. .

Buffett, C., Ciliska, D., \& Thomas, H. (2007). Quality Assesment Tool for Quantitative Studies. McMaster University

Campbell, D., \& Stanley, J. C. (1963). Experimental and quasi-experimental designs for research Experimental and quasi-experimental designs for research

Boston: Houghton Mifflin Company

Cantone, G., Colasanti, L., Abdulnabi, Z. A., Lomartire, A., \& Calavaro, G. (2003). Evaluating checklist based and use case driven reading techniques as applied to software analysis and design UML artifacts. Lecture Notes in Computer Science(2765), 142-165.

CEBC. (2006). Guidelines for Systematic Review in Conservation and Environmental Management. v.2.0 (pp. 1-23). Birmingham: Centre for Evidence-based Conservation.

Churcill, G. (1979). A paradign for developing better meassures of marketing constructs. Journal of Marketing Research, 16(1), 64-73.

Ciolkowski, M. (2009). What do we know about perspective-based reading? An approach for quantitative aggregation in software engineering. Paper presented at the 3rd International Symposium on Empirical Software Engineering and Measurement (ESEM'09), Orlando, USA.

Cohen, J. (1977). Statistical Power Analysis for the Behavioral Sciences (Revised ed.). New York: Academic Press.

Concato, J., Shah, N., \& Horwitz, R. I. (2000). Randomized, controlled trials, observational studies, and the hierarchy of research designs. The New England Journal of Medicine(342), 1887--1892.

Conradi, R., \& Wang, A. I. (2003). Empirical methods and studies in software engineering: Experiences from ESERNET: Springer.

Cooper, H. (1982). Scientific Guidelines for Conducting Integrative Research Reviews. Review of Educational Research, 52(2), 291-302.

Counsell, C. (1997). Formulating questions and locating primary studies for inclusion in systematic reviews. Annals of Internal Medicine, 127, 380-387.

CRD. (2009). Systematic reviews: CRD's guidance for undertaking reviews in health care. York: University of York. 
Creswell, J. W. (2002). Research Design: Qualitative, Quantitative, and Mixed Methods Approaches (2nd ed.). California: SAGE Publications, Inc.

Cronbach, L. J. (1982). Designing evaluations of educational and social programs. San Francisco.

Cruzes, D., \& Dyba, T. (2010). Synthesizing Evidence in Software Engineering Research. Paper presented at the 4th International Symposium on Empirical Software Engineering and Measurements, Bolzano, Italia.

Davis, A., Dieste, O., Hickey, A., Juristo, N., \& Moreno, A. M. (2006). Effectiveness of requirements elicitation techniques: Empirical results derived from a systematic review. Paper presented at the Re'06: 14th Ieee International Requirements Engineering Conference, Proceedings, Minneapolis, MO. $<$ Go to ISI $>$ ://ISIP:000242104000018

Davis, A., Dieste, O., Juristo, N., \& Moreno, A. M. (2006). Effectiveness of Requirements Elicitation Techniques: Empirical Results derived from a Systematic Review. Paper presented at the 14th IEEE International Requirements Engineering Conference RE'06, Minneapolis, USA.

Deeks, J. J., Dinnes, J., D'Amico, R., Sowden, A. J., Sakarovitch, C., Song, F., . . Altman, D. G. (2003). Evaluating non-randomised intervention studies. Health Technology Assessment, 7(27), 3-4.

Dickersin, K., Scherer, R., \& Lefebvre, C. (1994). Systematic Reviews: Identifying relevant studies for

systematic reviews. British Medical Journal(309), 1286-1291.

Dieste, O., Fernandez, E., García-Martinez, R., \& Juristo, N. (2011). Comparative analysis of meta-analysis methods: when to use which? Paper presented at the 15th Annual Conference on Evaluation \& Assessment in Software Engineering (EASE 2011).

Dieste, O., Fernandez, E., García-Martinez, R., \& Juristo, N. (2012). Comparison of meta-analysis: understanding the influence of experiments' statistical parameters. Empirical Softw. Engineering, (submited).

Dieste, O., Fernández, E., \& García, R. (Producer). (2008). Statistical techniques for aggregating experiments results. Retrieved from http://oa.upm.es/cgi/users/home?screen=EPrint::View\&eprintid=4501

Dieste, O., Fernandez, E., Garcia, R., \& Juristo, N. (2011). The risk of using the $Q$ heterogeneity estimator for software engineering experiments Paper presented at the International Symposium on Empirical Software Engineering and Measurement (ESEM), Banff, AB.

Dieste, O., \& Grimán, A. (2007). Developing Search Strategies for Detecting Relevant Experiments for Systematic Reviews. Paper presented at the 1st International Symposium on Empirical Software Engineering and Measurement (ESEM'07), Madrid, Spain.

Dieste, O., Grimán, A., \& Juristo, N. (2008). Developing search strategies for detecting relevant experiments. Empirical Software Engineering, 1 - 27.

Dieste, O., Grimán, A., \& Juristo, N. (2009). Developing search strategies for detecting relevant experiments. Empirical Software Engineering, 14(5), 513-539.

Dieste, O., Grimán, A., Juristo, N., \& López, M. (2008, October). Revisiones Sistemáticas: Recomendaciones para un Proceso Adecuado a la Ingeniería del Software. Paper presented at the XIII Jornadas Internacionales de Ingeniería del Software y Base de Datos, Gijón.

Dieste, O., Grimán, A., Juristo, N., \& Saxena, H. (2011). Quantitative determination of the relationship of between internal validity and bias in software engineering experiments: Consequences for systematic literature reviews. Paper presented at the Empirical Software Engineering and Measurement (ESEM), Alberta, Canada.

Dieste, O., \& Juristo, N. (2011). Systematic Review and Aggregation of Empirical Studies on Elicitation Techniques. IEEE Transactions on Software Engineering, 37(2), 283-304.

Döring, N. A. (2002). Personal home pages on the Web: A review of research. Journal of ComputerMediated Communication, 7(3), 21.

Down, S. H., \& Black, N. (1998). The feasibility of creating a checklist for assessment of the methodological quality both of the randomised and non-randomised studies of health care interventions. J Epidemiol Community Health, 52, 377-384.

Dybå, T., Arisholm, E., Sjoberg, D. I. K., Hannay, J. E., \& Shull, F. (2007). Are two heads better than one? On the effectiveness of pair programming. IEEE Software, 24(6), 10-13.

Dybå, T., \& Dingsøyr, T. (2008). Empirical studies of agile software development: A systematic review. . Information and Software Technology, 50(9-10), 833-859. 
Dybå, T., \& Dingsøyr, T. (2008). Strength of Evidence in Systematic Reviews in Software Engineering. Paper presented at the ESEM'2008.

Dybå, T., Dingsøyr, T., \& Hanssen, G. K. (2007). Applying Systematic Reviews to Diverse Study Types: An Experience Report. Paper presented at the First International Symposium on Empirical Software Engineering and Measurement, Madrid, Spain.

Dybå, T., Kampenes, V. B., \& Sjoberg, D. I. K. (2006). A systematic review of statistical power in software engineering experiments. Information and Software Technology, 48(8), 745-755.

Dybå, T., Kitchenham, B. A., \& Jørgensen, M. (2005). Evidence-Based Software Engineering for Practitioners. IEEE Software(January/February).

Dyer, D., Kagel, J. H., \& Levin, D. (1989). A comparison of naive and experienced bidders in common value offer auctions: A laboratory analysis. The Economic Journal, 99(394), 108-115.

Emerson, J. D., Burdick, E., Hoaglin, D. C., Mosteller, F., \& Chalmers, T. C. (1990). An empirical study of the possible relation of treatment differences to quality scores in controlled randomized clinical trials. Controlled Clinical Trials, 11, 339-352.

EPPI-Centre. (2002). Core Keywording Strategy: Data collection for a register of educational research. Version 0.9.7. . London: Evidence for Policy and Practice Information and Co-ordinating Centre.

Feinstein, A. R., \& Horwitz, R. I. (1982). Double standards, scientific methods, and epidemiological research. The New England Journal of Medicine(307), 1611--1617.

Fusaro, P., Lanubile, F., \& Visaggio, G. (1997). A Replicated Experiment to Assess Requirements Inspection Techniques. Empirical Software Engineering(2), 39-57.

Glass, G. (1976, April, 21). Primary, secondary, and meta-analysis of research. Paper presented at the Presidential address to the Annual Meeting of the American Educational Research Association, San Francisco.

Glass, R. L., Vessey, I., \& Ramesh, V. (2002). Research in Software Engineering: an Analysis of literature. Information and Software Technology, 44, 491-506.

Gómez, M., Acuña, S., \& Rico, R. (2007). Estudio Experimental en Equipos de Desarrollo de Software sobre las Relaciones entre Personalidad, Satisfacción y Calidad del Producto. Paper presented at the JIISIC 2007.

Grimán, A. (2007). Proposal of a Review Process of Empirical Studies in Software Engineering. Paper presented at the 2nd International Doctoral Symposium on Empirical Software Engineering, Madrid, Spain.

Gurevitch, J., \& Hedges, L. (1999). Statistical Issues in Ecological Meta-Analyses. Ecology, 80(4), 11421149.

Guyatt, G. H., Oxman, A., \& Vist, G. E. (2008). GRADE: an emerging consensus on rating quality of evidence and strength of recommendations. $B M J(336), 924-926$.

Hannay, J. E., Dybå, T., Arisholm, E., \& Sjøberg, D. I. K. (2009). The effectiveness of pair programming: A meta-analysis. Information and Software Technology, 51(7), 1110-1122.

Hardestya, D., \& Beardenb, W. (2004). The use of expert judges in scale development . Implications for improving face validity of measures of unobservable constructs. Journal of Business Research, 57, 98-107.

Hayes, W. (1999). Research synthesis in software engineering: A case for meta-analysis. Paper presented at the International Software Metrics Symposium.

Haynes, R. B., Wilczynski, N., McKibbon, K. A., Walker, C. J., \& Sinclair, J. C. (1994). Developing optimal search strategies for detecting clinically sound studies in MEDLINE. Journal of the American Medical Informatics Association, 1(6), 447-458.

Hedges, L. V., Gurevitch, J., \& Curtis, P. S. (1999). The Meta-Analysis of Response Ratios in Experimental Ecology. Ecology, 80(4), 1150-1156.

Hedges, L. V., \& Olkin, I. (1985). Statistical methods for meta-analysis. San Diego:: Academic Press.

Higgins, J. P., \& Green, S. (2006). Cochrane Handbook for Systematic Reviews of Interventions 4.2.6 [updated September 2006] The Cochrane Library (Vol. 4). Chichester, UK: John Wiley \& Sons, Ltd.

Higgins, J. P. T., \& Green, S. (2006). Cochrane Handbook for Systematic Reviews of Interventions 4.2.6 [updated September 2006] The Cochrane Library (Vol. 4). Chichester, UK: John Wiley \& Sons, Ltd.

Horwitz, R. I., \& Feinstein, A. R. (1979). Methodological standards and contradictory results in casecontrol research. American Journal of Medicine(66), 556--564.

IEEE. (1990). Standard Glossary of Software Engineering Terminology.

IEEE. (2004a). Guide to the Software Engineering Body of Knowledge. Los Alamitos, California.

IEEE. (2004b). Software Engineering Body of Knowledge. 
IOM. (2011). Finding What Works in Health Care. Standards for Systematic Reviews. Washington: The National Academies Press.

Jadad, A. (1998). Randomised controlled trials: A users guide. London: BMJ Books.

Jadad, A. R., Moore, R. A., Carrol, D., Jenkinson, C., Reynolds, J. M., \& Gavaghan, D. J. (1996). Assessing the quality of reports of randomized clinical trials: Is blinding necessary? . Controlled Clinical Trials, 17, 1-12.

Jadad, A. R., Moore, R. A., Carrol, D., Jenkinson, C., Reynolds, J. M., Gavaghan, D. J., \& McQuay, H. J. (1996). Assessing the quality of reports of randomized clinical trials: Is blinding necessary? . Controlled Clinical Trials, 17, 1-12.

JBI. (s/f). The JBI Approach to the Systematic Review of Evidence. http://www.joannabriggs.edu.au/about/system_review.php

Jedlitschka, A., \& Ciolkowski, M. (2004). Towards Evidence in Software Engineering. Paper presented at the ACM/IEEE Intern. Symposium on Software Engineering 2004 (ISESE2004),, Redondo Beach, California.

Jedlitschka, A., Ciolkowski, M., \& Pfahl, D. (2008). Reporting Controlled Experiments in Software Engineering. In F. Shull, J. Singer \& D. I. Sjoberg (Eds.), Guide to Advanced Empirical Software Engineering. London: Springer

Jedlitschka, A., \& Pfahl, D. (2005, 17-18 Nov.). Reporting experiments in Software Engineering. Paper presented at the International Symposium on Empirical Software Engineering (ISESE'05), Noosa Heads, Australia.

Jedlitschka, A., \& Pfahl, D. (2005). Reporting guidelines for controlled experiments in software engineering. Paper presented at the International Symposium on Empirical Software Engineering. ISESE 2005 Noosa heads, Australia.

Jonker, J., \& Pennink, B. (2010). The Essence of Research Methodology. Berlin: Springer.

Jørgensen, M., \& Shepperd, M. (2007). A systematic review of software development cost estimation studies. IEEE Transactions on Software Engineering, 33(1), 33-53.

Judd, C. M., Smith, E. R., \& Kidder, L. H. (1991). Research Method in Social Relations. Orlando: Harcourt Brace Jovanovich College Publishers.

Juni, P., Altman, D., \& Egger, M. (2001). Systematic reviews in Healthcare. Assessing the quality of controlled clinical trials. BMJ, 323, 42-46.

Jüni, P., Witschi, A., Bloch, R., \& Egger, M. (1999). The hazards of scoring the quality of clinical trials for meta-analysis. The Journal of the American Medical Association, 282, 1054-1060.

Juristo, N., \& Moreno, A. M. (2001). Basics of Software Engineering Experimentation. Boston: Kluwer Academic Publishers.

Juristo, N., Moreno, A. M., \& Vegas, S. (2004). Reviewing 25 years of testing technique experiments. Empirical Software Engineering, 9(1-2), 7-44.

Kampenes, V. B., Dyba, T., Hannay, J. E., \& Sjøberg, D. I. K. (2007). A systematic review of effect size in software engineering experiments. Information and Software Technology, 49(11-12), 1073-1086.

Khan, K., Daya, S., \& Jadad, A. R. (1996). The importance of quality of primary studies in producing unbiased systematic reviews. Arch. Intern. Med., 156(6), 661-666.

Khan, K., Khalid, S., Riet, G. t., Glanville, J., Sowden, A. J., \& (eds.), J. K. (2001). Undertaking Systematic Review of Research on Effectiveness. CRD's Guidance for those Carrying Out or Commissioning Reviews: NHS Centre for Reviews and Dissemination, University of York.

Khan, K., Khalid, S., ter Riet, G., Glanville, J., Sowden, A. J., \& Kleijnen, J. (2001). Undertaking Systematic Review of Research on Effectiveness (2 nd ed.). York: NHS Centre for Reviews and Dissemination.

Kitchenham, B. (1996). Evaluating Software Engineering Methods and Tools. Part 3: Selecting an appropriate evaluation method - practical issues. ACM SIGSOFT - Software Engineering Notes, 21(4), 9-12.

Kitchenham, B. (2004). Procedures for Performing Systematic Reviews: Keele University

Kitchenham, B., Al-Khilidar, H., Babar, M. A., Berry, M., Cox, K., Keung, J., . . Zhu, L. M. (2008). Evaluating guidelines for reporting empirical software engineering studies. Empirical Software Engineering, 13, 97-121.

Kitchenham, B., Al-Kilidar, H., Ali Babar, M., Berry, M., Cox, K., Keung, J., . . . Zhu, L. (2006). Evaluating guidelines for empirical software engineering studies. Paper presented at the International Symposium on Empirical Software Engineering - ISESE 2006, Río de Janeiro, Brasil. 
Kitchenham, B., Brereton, O. P., Budgen, D., \& Li, Z. (2009). An Evaluation of Quality Checklist Proposals - A participant-observer case study Paper presented at the 13th International Conference on Evaluation and Assessment in Software Engineering (EASE), Durham University, UK.

Kitchenham, B., Brereton, P., Budgen, D., Turner, M., Bailey, J., \& Linkman, S. (2009). Systematic literature reviews in software engineering - A systematic literature review Inf. Softw. Technol., 51(1), 7--15. doi: http://dx.doi.org/10.1016/j.infsof.2008.09.009

Kitchenham, B., Brereton, P., Turner, M., Niazi, M., Linkman, S. G., Pretorius, R., \& Budgen, D. (2010). Refining the systematic literature review process - two participant-observer case studies. Journal of Empirical Software Engineering, 15(6), 618--653.

Kitchenham, B., Budgen, D., \& Brerenton, P. (2015). Evidence-based Software Engineering and Systematic Research: Chapman and Hall/CRC

Kitchenham, B., Budgen, D., Brereton, P., \& Linkman, S. (2005). Realising Evidence-Based Software Engineering. Paper presented at the REBSE'05, St. Louis, Missouri, USA.

Kitchenham, B., Dybå, T., \& Jørgensen, M. (2004). Evidence-based Software Engineering. Paper presented at the International Conference on Software Engineering (ICSE'04).

Kitchenham, B., Pfleeger, S. L., Pickard, L. M., Jones, P. W., Hoaglin, D., Emam, K. E., \& Rosenberg, J. (2002). Preliminary Guidelines for Empirical Research in Software Engineering. IEEE Transactions on Software Engineering, 28(8), 721-734.

Kitchenham, B., Pfleeger, S. L., Pickard, L. M., Jones, P. W., Hoaglin, D. C., El Emam, K., \& Rosenberg, J. (2002). Preliminary guidelines for empirical research in software engineering. IEEE Transactions on Software Engineering, 28(8), 721 -734.

Kitchenham, B., Pretorius, R., Budgen, D., Brereton, O. P., Turner, M., Niazi, M., \& S., L. (2010). Systematic Literature Reviews in Software Engineering - A Tertiary Study. Information and Software Technology, 52(8), 792-805. doi: http://dx.doi.org/10.1016/j.infsof.2010.03.006

Kitchenham, B., Sjøberg, D. I. K., Dybå, T., Pfahl, D., Brereton, P., Budgen, D., . . Runeson, P. (2012). Three empirical studies on the agreement of reviewers about the quality of software engineering experiments Information and Software Technology, 54, 804-819.

Kitchenham, B. A. (2004). Procedures for performing systematic reviews: Department of Computer Science, Keele University.

Kitchenham, B. A., Budgen, D., \& Brereton, O. P. (2011). Using mapping studies as the basis for further research - A participant-observer case study. Information \& Software Technology (INFSOF), 53(6), 638--651.

Kitchenham, B. A., Mendes, E., \& Travassos, G. H. (2007). Cross versus within-company cost estimation studies: A systematic review. IEEE Transactions on Software Engineering, 33(5), 316-329.

Kitchenham. B.A., \& Charters, S. (2007). Guidelines for performing Systematic Literature Reviews in Software Engineering.

Kunz, R., \& Oxman, A. (1998). The unpredictability paradox: review of empirical comparisons of randomised and non-randomised clinical trials. British Medical Journal(317), 1185--1190.

Lajeunesse, M., \& Forbes, M. (2003). Variable reporting and quantitative reviews: a comparison of three meta-analytical techniques. Ecology Letters, 6, 448-454.

Levine, M., Walter, S., Lee, H., Haines, T., Holbrook, A., \& Moyer, V. (1994). Users' guides to the medical literature, IV: how to use an article about harm. Journal of the American Medical Association(271), 1615--1619.

Lindberg, D. A., Humphreys, B. L., \& McCray, A. T. (1993). The Unified Medical Language System. Methods of information in medicine, 32(4), 281-291.

Lisboa, L. B., Garcia, V. C., Lucrédio, D., de Almeida, E. S., Meira, S. R., \& Fortes, R. P. (2010). A systematic review of domain analysis tools. Information and Software Technology, 52(1), 1-13.

Little, J., \& Higgins, J. P. T. (2006). The HuGENet ${ }^{\mathrm{TM}}$ HuGE Review Handbook, version 1.0.

Lucas, F., Molina, F., \& A., T. (2009). A systematic review of UML model consistency management. Information and Software Technology, 5(12), 1631-1645.

Machine, A. o. C. (1998). Computing Classification System

McGowan, J., \& Sampson, M. (2005). Systematic reviews need systematic searchers. J Med Libr Assoc., 93(1), 74-80.

Mendes, E. (2005). A Systematic Review of Web Engineering Research. Paper presented at the ACM/IEEE International Symposium on Empirical Software Engineering, Noosa heads, Australia.

Mignini, L. E., \& Khan, K. S. (2006). Methodological quality of systematic reviews of animal studies: a survey of reviews of basic research. BMC Medical Research Methodology, 6(10), 1--6. 
Miller, J. (1999). Can results from software engineering experiments be safely combined? Paper presented at the International Software Metrics Symposium.

Miller, J. (2000). Applying meta-analytical procedures to software engineering experiments. Journal of Systems and Software, 54(1), 29-39.

Miller, J. (2000). Applying Meta-analytical Procedures to Software Engineering Experiments. Journal of Information Technology, 54(1), 29-39.

Moher, D., Schulz, K. F., \& Altman, D. G. (2001). The CONSORT statement: revised recommendations for improving the quality of reports of parallel-group randomised trials. Lancet, 357, 1191-1194.

Morais, Y., Burity, T., \& Elias, G. (2009). A Systematic Review of Software Product Lines Applied to Mobile Middleware. Paper presented at the 6th International Conference on Information Technology.

Murphy, M. K., Black, N. A., Lamping, D. L., McKee, C. M., Sanderson, C., Askham, J., \& Marteur, T. (1998). Consensus development methods, and their use in clinical guidelines development. Health Technology Assessment, 2(3), 1-88.

NHMRC. (2000a). Handbook series on preparing clinical practice guidelines Retrieved from http://www.health.gov.au/hfs/nhmrc/publicat/synopses/cp65syn.htm

NHMRC. (2000b). How to review the evidence: systematic identification and review of the scientific literature: Australian National Health and Medical Research Council.

NHMRC. (2000c). How to use the evidence: assessment and application of scientific evidence: Australian National Health and Medical Research Council.

NHMRC. (2001). How to compare the costs and benefits: evaluation of the economic evidence: Australian National Health and Medical Research Council (NHMRC).

NIHCE. (2007). The guidelines manual. www.nice.org.uk

Pai, M., McCulloch, M., Gorman, J. D., Pai, N., Enanoria, W., G.Kennedy, . . . Colford, J. M. (2004). Systematic reviews and meta-analyses: An illustrated, step-by-step guide. THE NATIONAL MEDICAL JOURNAL OF INDIA, 17(2), 86-95.

Pearson, K. (1904). Report on certain enteric fever inoculation statistics. British Medical Journal, 3, 12431246.

Pedreira, O., Piattini, M., Luaces, M. R., \& Brisaboa, N. R. (2007). A systematic review of software process tailoring. ACM SIGSOFT Software Engineering Notes, 32, 1-6.

Pérez, M., Grimán, A., Mendoza, L., \& Rojas, T. (2004). A Systemic Methodological Framework for IS Research. Paper presented at the Tenth Americas Conference on Information Systems (AMCIS'04), New York.

Petersen, K., Feldt, R., Mujtaba, S., \& Mattsson, M. (2008). Systematic Mapping Studies in Software Engineering. Paper presented at the 12th International Conference on Evaluation and Assessment in Software Engineering, Bari, Italy.

Petersen, K., Vakkalanka, S., \& Kuzniarz, L. (2015). Guidelines for conducting systematic mapping studies in software engineering: An update. Information and Software Technology(64), 1-18.

Petitti, D. B. (1998). Hormone replacement therapy and heart disease prevention: experimentation trumps observation. Journal of the American Medical Association(280), 650--652.

Petticrew, M., \& Roberts, H. (2007). Systematic Reviews in the Social Sciences. A practical Guide.: Blackwell Publishing.

Pickard, L. M., Kitchenham, B. A., \& Jones, P. W. (1998). Combining empirical results in Software Engineering. Information and Software Technology, 40(4), 811-821.

Pilkington, K. (2007). Searching for CAM evidence: an evaluation of therapy-specific search strategies. Journal of Alternative and Complementary Medicine, 13(4), 451-459.

Pogue, J., \& Yusuf, S. (1998.). Overcoming the limitations of current meta-anlysis of randomised controlled trials. Lancet(351), 47-52.

Porter, A. A., Votta, L. G., \& Basili, V. R. (1995). Comparing Detection Methods for Software Requirements Inspections: A Replicated Experiment. IEEE Transactions on Software Engineering, 21(6), 563-575.

Potters, J., \& Van Winden, F. (1996). The Performance of Professionals and Students in an Experimental Study of Lobbying Social Science Research Network.

Premkumar, G. (2003). A meta-analysis of research on information technology implementation in small business. Journal of Organizational Computing and Electronic Commerce, 13(2), 91-121. 
Rainer, A., Jagielska, D., \& Hall, T. (2005, May 17). Software engineering practice versus evidencebased software engineering research. Paper presented at the REBSE'05, St. Louis, Missouri, USA.

Reeves, B. C., MacLehose, R. R., Harvey, I. M., Sheldon, T. A., Russel, I. T., \& Black, A. M. S. (1998). Comparisons of effect size estimates derived from randomised and non-randomised studies. In N. Black (Ed.), Health Services Research Methods: a guide to best practice (pp. 73--85). London: BMJ Publishing Group.

Reisch, J., Tyson, J., \& Mize, S. (1989). Aid to Evaluation of Therapeutic Studies. Pediatrics, 84(5), 815824.

Richardson, W. S., Wilson, M. S., Nishikawa, J., \& Hayward, R. S. A. (1995). The Well-built Clinical Question: A Key to Evidence Based Decisions. ACP Journal Club, 123(3), A12-A13.

Samaranayake, S. (2010). Comparison of two Systematic Review Processes: Kitchenham's Process. (MSc), Universidad Politécnica de Madrid, Madrid.

Sampson, M., Cogo, E., Ajiferuke, I., Manheimer, E., Campbell, K., Daniel, R., \& Moher, D. (2011). Searching for controlled trials of complementary and alternative medicine: A comparison of 15 databases. Evidence-based Complementary and Alternative Medicine, 1-9.

Sandahl, K., Blomkvist, O., Karlsson, J., Krysander, C., Lindvall, M., \& Ohlsson, N. (1998). An extended replication of an experiment for assessing methods for software requirements inspections. Empirical Software Engineering(3), 327-354

Schultz, K. F., Chalmers, I., Hayes, R. J., \& Altman, D. G. (1995). Empirical evidence of bias. Dimensions of methodological quality associated with estimates of treatment effects in controlled trials. Journal of the American Medical Association, 273(5), 408-412.

Shadish, W. R., Cook, T. D., \& Campbell, D. T. (2002). Experimental and Quasi-experimental Designs for Generalized Causal Inference: Houghton Mifflin Company.

SIGN. (2004). SIGN50: A guideline developers' handbook.

Sjøberg, D. I. K., Hannay, J., Hansen, O., Kampenes, V., Karahasanovi, A., Liborg, N., \& Rekdal, A. (2005). A Survey of Controlled Experiments in Software Engineering. IEEE Transactions on Software Engineering, 31(9), 733-753.

Sjøeberg, D., Hannay, J., Hansen, O., Kampenes, V., Karahasanovic, A., Liborg, N., \& Rekdal, A. (2005). A survey of controlled experiments in software engineering. IEEE Transactions on Software Engineering, 31(9), 733-753.

Sterne, J. A. C., Gavaghan, D. J., \& Egger, M. (2000). Publication and related bias in meta-analysis: Power of statistical tests and prevalence in the literature. Journal of Clinical Epidemiology(53), 11191129.

The Cochrane Collaboration. (2010). The Cochrane Library. The Cochrane Collaboration Retrieved 05-222011, from John Wiley \& Sons, Ltd. http://www.thecochranelibrary.com/view/0/index.html

TheCampbellCollaboration (s/f, Julio, 2007). [Systematic Reviews I: The Basics].

Thelin, T., Runeson, P., \& Wohlin, C. (2003). An Experimental Comparison of Usage Based and Checklist Based Reading. IEEE Transactions on Software Engineering, 29(8), 687-704.

US National Library of Medicine. (1999, 09-21-2010). Medical Subject Headings. Retrieved 05-23-2011, 2011, from http://www.nlm.nih.gov/mesh/meshhome.html

US National Library of Medicine. (2001, 10-10-2008). PubMed Tutorial. Retrieved 06-03-2011, 2011, from http://www.nlm.nih.gov/bsd/disted/pubmedtutorial/015 010.html

US National Library of Medicine. (2009, 05-19-2011). Unified Medical Language System. Retrieved 0523-2011, 2011, from http://www.nlm.nih.gov/research/umls/index.html

Web Center for Social Research Methods. (2006). Research Methods Knowledge Base. Measurement Validity Types. Retrieved 12-10-2010, 2010

Whitten, D., \& Stephens, C. (2002). A meta-analysis of emerging infomediary knowledge management systems: An expert systems application in the e-tailing environment. Journal of Computer Information Systems, 43(1), 48-54.

Wikipedia. (2007). Retrieved Julio, 11, 2007, from http://en.wikipedia.org/wiki/Cohen's kappa

Williams, J., Weightman, A. L., Weaver, N., Temple, M., Palmer, S., Kitcher, H., . . . Sander, L. (2001). Built Environment and health of the public systematic review methodology.

Wohlin, C., Peterson, H., \& Aurum, A. (2003). Combining data from reading experiments in Software Inspections. A feasibility study. In N. Juristo \& A. Moreno (Eds.), Lecture Notes on Empirical Software Engineering: World Scientific Publishing.

Wohlin, C., Runenson, P., Höst, M., Ohlsson, M. C., Regnell, B., \& Wesslén, A. (2000). Experimentation in software engineering: an introduction Klwer Academic Publishers.

Yates, S., Morley, S., Eccleston, C., \& de Williams, A. (2005). A scale for rating de quality of psychological trials for pain. Pain, 117, 314-325. 
Zanchetti, A., \& Mancia, G. (1998). Searching for information from unreported trials--amnesty for the past and prospective meta-analyses for the future. Journal of Hypertension(16), 125.

Zaza, S., Wright-De Agüero, L. K., Briss, P. A., Truman, B. I., Hopkins, D. P., Hennessy, M. H., . . . Pappaioanou, M. (2000). Data Collection Instrument and Procedure for Systematic Reviews in the Guide to Community Preventive Services. Am J Prev Med, 18(1S), 44-74.

Zhang, H., Kitchenham, B., \& Pfahl, D. (2008). Reflections on 10 Years of Software Process Simulation Modeling: A Systematic Review. Lecture Notes in Computer Science, 5007/2008, 345--356.

Ziogas, D. C., \& Zintzaras, E. (2009). Analysis of the quality of reporting of randomized controlled trials in acute and chronic myeloid leukemia, and myelodysplastic syndromes as governed by the CONSORT statement. Ann Epidemiol, 19(7), 494-500. 


\section{APENDICE A. GLOSARIO DE TÉRMINOS}

\section{A}

Agregación:

Aleatorización:

Análisis de sensibilidad:

Aplicabilidad:

Artículo relevante:

Asignación:

B

Base de datos bibliográfica:

Base de evidencia:

Búsqueda de alcance:
Ver Síntesis

Asignación de los participantes en un estudio de investigación, a dos o más grupos alternativos, utilizando un procedimiento casual, tal como la generación de números aleatorios generados por un computador (NIHCE, 2007).

Permite explorar la generalidad de los resultados a otros entornos; para ello, el análisis es repetido utilizando diferentes asunciones para examinar el efecto de los resultados [REF].

Véase Validez externa

Artículos que reportan estudios de interés para la revisión sistemática (O. Dieste \& Grimán, 2007).

La manera en que los sujetos son asignados a los diferentes grupos dentro del estudio, puede utilizarse un método aleatorio o no-aleatorio (NHMRC, 2000b).

Repositorio especializado en el almacenamiento de artículos de una o más áreas, o de una o más publicaciones. [REF].

Conjunto de conocimientos relacionados con un área. [REF].

Se realiza en un grupo pequeño de bases de datos para 

existentes y estudios primarios. [REF].

Cadena de búsqueda:

Caso-control (estudio):

Coeficiente Kappa :

Cohorte (estudio de):

Comparativo (estudio):

Consenso:

Criterios de inclusión/exclusión

Cuasi-experimental (estudio):
Conjunto de términos utilizados en una búsqueda para detectar material. [REF].

Comparación de exposiciones para intervenciones entre participantes que presentan un resultado (casos) y aquellos que no lo presentan (controles). [REF].

El coeficiente Kappa de Cohen (llamado también "estadística Kappa" o "análisis Kappa") es una medida de la confiabilidad entre dos individuos que miden las mismas variables binarias, o que clasifican $\mathrm{N}$ objetos dentro de $\mathrm{C}$ categorías mutuamente excluyentes (Wikipedia, 2007). [REF].

Comparación de los resultados entre participantes que han recibido una intervención y un grupo que no lo ha recibido (i.e. no asignado por el investigador) en un estudio de seguimiento (NIHCE, 2007).

Estudio que incluye un grupo de comparación o control (NHMRC, 2000b).

Técnica para alcanzar acuerdos respecto a un tópico particular (NIHCE, 2007).

Estándares explícitos para decidir la elegibilidad de un estudio para la revisión sistemática (NIHCE, 2007). Pueden estar referidos, por ejemplo, a la población, el diseño del estudio, las intervenciones o los resultados (J. P. Higgins \& S. Green, 2006).

Un estudio en el cual la asignación de participantes a diferentes grupos de intervención es controlada por el investigador pero no se realiza una genuina aleatorización y 
ocultamiento de asignación. [REF].

D

No hay elementos en la lista.

$\mathrm{E}$

Efecto (medición de, efecto de La relación observada entre las intervenciones y los un tratamiento, estimación de, resultados, o una estadística para resumir la fortaleza de la tamaño de un efecto): asociación observada (NIHCE, 2007).

Efecto adverso:

Efecto no deseado producido por una medicación u otra intervención. [REF].

Elemento de distorsión Factor que puede influenciar el resultado, (confoundig): independientemente de la intervención estudiada (NIHCE, 2007).

Enmascaramiento (blinding):

Mantener a los participantes, investigadores, asesores y demás involucrados, en desconocimiento de las intervenciones a las cuales han sido asignados los participantes en un estudio (NIHCE, 2007).

Ensayo clínico:

Definir

Epidemiologico (estudio):

Estudio de una enfermedad dentro de una población, definiendo su incidencia y preponderancia, y examinando los roles de las influencias externas y las intervenciones (NIHCE, 2007).

Error estándar:

Definir

Error Tipo I:

Definir

Error Tipo II:

Definir

Estrategia de búsqueda:

Selección de una cadena de términos de búsqueda, los campos de búsqueda, las bases de datos bibliográficas y las publicaciones, en las cuales se realizará la búsqueda de artículos para la revisión sistemática. [REF]. 
Estudio cross-seccional:

Estudio primario:

Estudio secundario investigación secundaria):

Estudio terciario:

Evidencia primaria:

Evidencia:

Experimental (estudio):

Experimento controlado:

$\mathrm{F}$

Factor:
Un estudio que examina la relación entre enfermedades y otras variables de interés que existan en una población definida en un momento particular (NHMRC, 2000b).

Definir

Estudio que genera datos originales, más que analizar datos de estudios existentes (los cuales son llamados estudios secundarios) (NIHCE, 2007).

(o Estudio que analiza los datos de estudios existentes (los cuales son llamados estudios primarios) (NIHCE, 2007).

Definir

Definir

Información en la cual se basa una decisión o un lineamiento; obtenida de un rango de fuentes, incluyendo randomized controlled trials, estudios observacionales, opiniones de expertos (de profesionales clínicos y/o pacientes) (NIHCE, 2007).

Datos acerca de la efectividad de un nuevo tratamiento o intervención, derivados de los estudios que comparan ésta con alternativas apropiadas (NHMRC, 2000b).

Un estudio en el cual algunas condiciones, particularmente las decisiones relacionadas con la asignación de los participantes a los diferentes grupos de intervención, están bajo el control del investigador. [REF].

Definir

\footnotetext{
Variable independiente controlada; cuyos valores son establecidos por el experimentador (http://www.stat.yale.edu/Courses/1997-98/101/expdes.htm).
} 
Falso negativo:

Falso positivo:

G

Grupo control:

Grupos candidatos a agregación:

$\mathrm{H}$

Heterogeneidad:

Inferencia:

Inter-rater agreement (índice):

Intervención:

Investigación cualitativa:
Concluir erróneamente que no es efectiva (NIHCE, 2007).

Concluir erróneamente que una intervención es efectiva (NIHCE, 2007).

Grupo contra cuyos resultados se realizan comparaciones. [REF].

Un conjunto de artículos agrupados por sub-tema y tipo de estudio. [REF].

Diferencias en el efecto del tratamiento entre estudios que contribuyen al meta-análisis (NHMRC, 2000b).

Proceso de derivar una conclusión basándose únicamente en lo que se conoce. [REF].

Evalúa el alcance de las coincidencias entre los diferentes recolectores de datos. [REF].

Un procedimiento terapéutico, tales como tratamiento con un agente farmacéutico, cirugía, un suplemento dietético, un cambio dietético o psicoterapia. Su característica clave es que una persona, o su ambiente, es manipulada para obtener algún beneficio para la persona (NHMRC, 2000b).

Investigación relacionada con resultados subjetivos acerca de fenómenos emocionales, sociales y de experiencia, en salud y 
bienestar social (NIHCE, 2007).

Inferencia estadística:

Definir

J

No hay elementos en la lista.

K

No hay elementos en la lista.

$\mathrm{L}$

Lista de chequeo:

Lista compuesta por preguntas que orientan la evaluación. [REF].

M

Mapa sistemático:

Estructura jerárquica de temas relacionados con un área. [REF].

Meta-análisis:

El uso de técnicas estadísticas para combinar, dentro de una medida única, los resultados de estudios que se relacionan con una misma pregunta de investigación (K. Khan et al., 2001).

Meta-regresión:

El uso de un modelo de regresión lineal, con una estimación 
del efecto del tratamiento, tanto para la variable dependiente y los descriptores del nivel del estudio como para las variables independientes (NHMRC, 2000b).

Modelo de efecto aleatorio:

Modelo de efecto fijo:

Modelo multi-variado:

Método de Varianza Inversa:

$\mathrm{O}$

Objetivo de revisión (o de la revisión sistemática):

Observational (estudio):

Ocultamiento de asignación:
Es un tipo de modelo lineal jerárquico, que asume que los datos describen una jerarquía de diferentes poblaciones cuyas diferencias están restringidas por la jerarquía. [REF].

Usado frecuentemente para estimar los datos de un panel, donde la población de los individuos ha sido observada en el tiempo, es utilizada para contrarrestar la heterogeneidad no observada. [REF].

Un modelo estadístico para el análisis de la relación entre variables pronóstico (independientes) y las variables de salida (dependientes) (K. Khan et al., 2001).

Método utilizado en el meta-análisis, en el cual el peso dado a cada estudio es igual al inverso de la varianza del efecto estimado (i.e. 1 dividido por el cuadrado del error estándar). De esta manera, a los estudios más grandes, los cuales tienen errores estándar más pequeños, se les asigna un peso mayor que a los estudios más pequeños, los cuales tienen un error estándar mayor (J. P. Higgins \& S. Green, 2006).

Una declaración de la meta que se persigue alcanzar con la revisión sistemática. [REF].

Estudio retrospectivo o prospectivo, en el cual el investigador observa el curso natural de los eventos con o sin grupos de control; por ejemplo, estudios de cohorte, estudios de casocontrol (NIHCE, 2007).

El proceso utilizado para prevenir el conocimiento a priori de la asignación a grupos en un randomized controlled trial (NIHCE, 2007). 
Optimalidad de una búsqueda:

Balance entre una alta recuperación y una alta precisión. [REF].

$P$

Peso:

p-valor:

Pieza de conocimiento:

Pre/post test (estudio):

Precisión (o especificidad de una búsqueda):

Pregunta de revisión (o de investigación):

Prognosis:

Protocolo de revisión:

Q

No hay elementos en la lista.
En Meta-análisis.

La probabilidad de que una diferencia observada pudiera haber ocurrido por casualidad, asumiendo que no existen, de hecho, diferencias subyacentes entre los medios de las observaciones (NIHCE, 2007).

Datos experimentales reportados en los estudios empíricos. [REF].

Los resultados del estudio son medidos en los participantes antes y después de recibir la intervención (NHMRC, 2000b).

La habilidad de excluir artículos irrelevantes. [REF].

Una declaración de lo que se desea investigar en la revisión sistemática; estructura con base en los participantes, las intervenciones, los tipos de estudios y los resultados de interés. [REF].

Un curso o resultado probable de una enfermedad (NIHCE, 2007).

Documento escrito que contiene los antecedentes, la especificación del problema y la metodología de la revisión sistemática (K. Khan et al., 2001). 
Randomised controlled trial -RCT (estudio):

Recuperación (o sensibilidad de
na búsqueda):

Reporte de cometido:

Resultados experimentales:

Revisión:

Revisión sistemática:

$S$

Series de casos:
Un estudio comparativo en el cual los participantes son asignados de manera aleatoria a la intervención y grupos de control y monitoreados para examinar las diferencias de los resultados entre los grupos (NIHCE, 2007).

La proporción de estudios relevantes identificados por una estrategia de búsqueda, expresada como el porcentaje de todos los estudios relevantes sobre un tópico dado (NIHCE, 2007).

Proporciona la información general de los objetivos de la revisión propuesta, el razonamiento para llevar a cabo la revisión y los antecedentes del problema clínico que se quiere tratar (la tecnología relacionada, sus alternativas, etc.). [REF].

Medida de los posibles resultados que pueden provenir de las exposiciones a una intervención preventiva o terapéutica (NIHCE, 2007).

Un artículo que resume una variedad de estudios primarios diferentes y puede presentar conclusiones acerca de la efectividad de una intervención particular. Puede o no ser sistemática (K. Khan et al., 2001).

Una revision de la evidencia sobre una pregunta claramente formulada, que utiliza métodos sistemáticos y explícitos para identificar, seleccionar y evaluar críticamente la investigación primaria relevante, y extraer y analizar datos de los estudios que son incluidos en la revisión. Los métodos estadísticos (metaanálisis) pueden o no ser utilizados (K. Khan et al., 2001).

Reporte de un número de casos de una enfermedad dada; cubriendo, usualmente, el curso de la enfermedad y la respuesta 


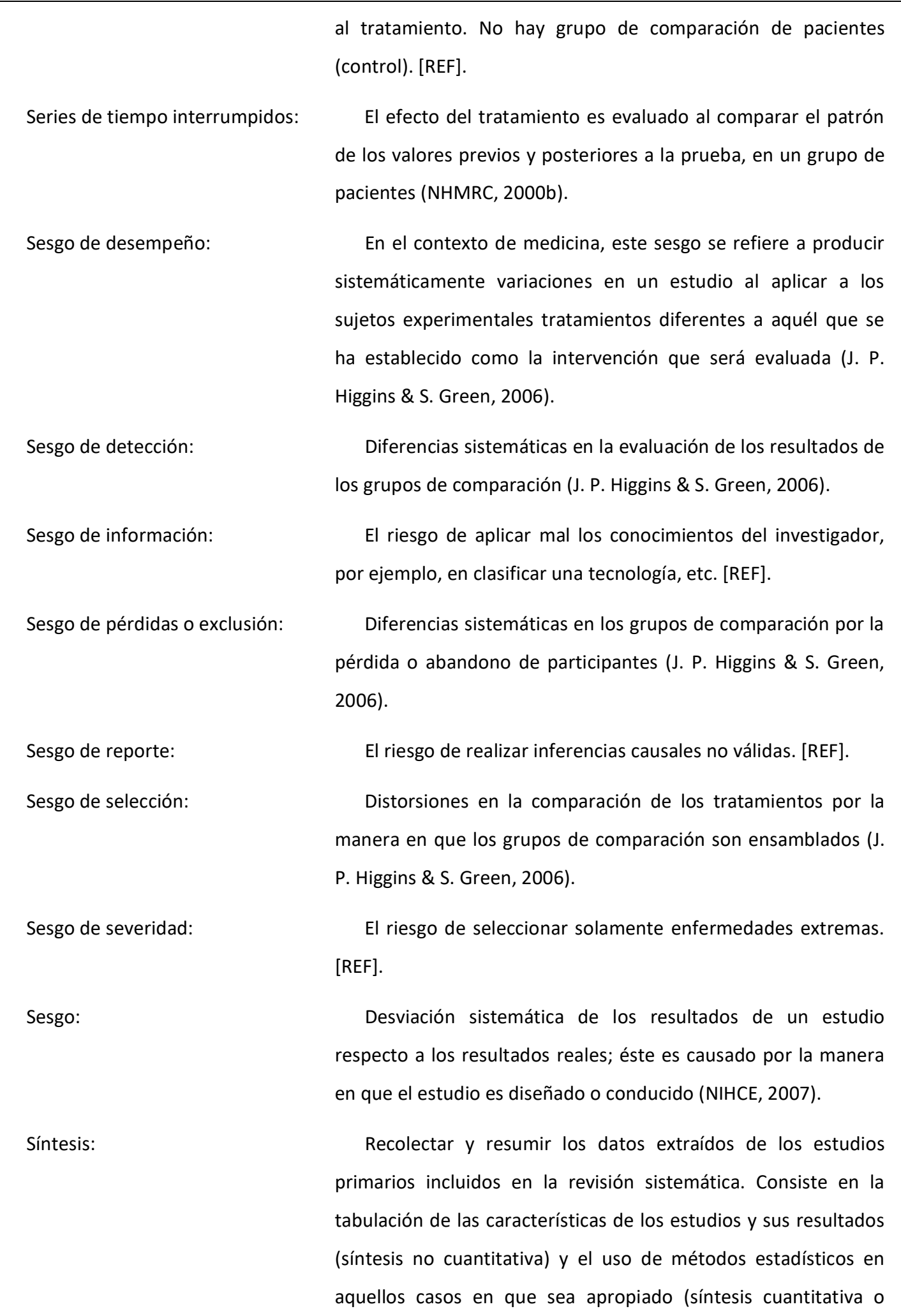




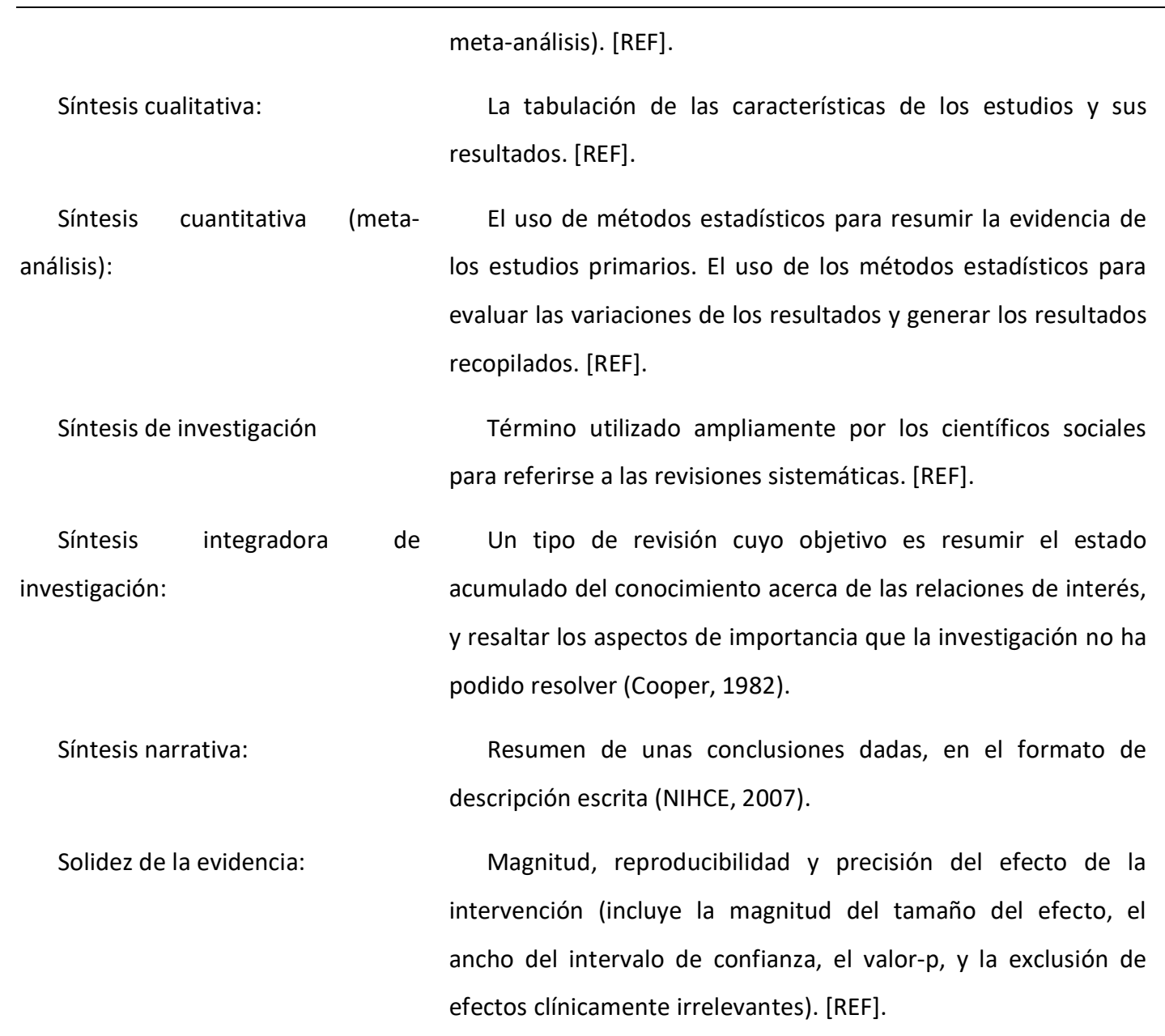

$\mathrm{T}$

Tema de revisión:

Tratamiento:
Enunciado y justificación del área o tópico sobre la cual se desea obtener información o generar conclusiones a través de la revisión sistemática. [REF].

Algo que los investigadores administran a las unidades experimentales (http://www.stat.yale.edu/Courses/199798/101/expdes.htm) [REF].

$U$ 
V

Validez externa:

Validez interna:

Variable respuesta

W

No hay elementos en la lista.

$\mathrm{X}$

No hay elementos en la lista.

Y

No hay elementos en la lista.

W
Generalidad o aplicabilidad de los resultados. El grado en el cual los resultados de una observación, estudio o revisión, tienen probabilidad de mantenerse en un entorno clínico real (NIHCE, 2007).

DEFINIR

El grado en el cual los resultados de un estudio tienen probabilidad de aproximarse a "la verdad" para los participantes reclutados en el estudio (esto es, cestán los resultados libres de sesgo?)(NIHCE, 2007).

Variable dependiente que está siendo medida. [REF]. 
No hay elementos en la lista. 


\section{APÉNDICE B. DOCUMENTOS DE LA FASE DE BÚSQUEDA}


Formulario B01 - Declaración del tema de revisión 
B01 - Declaración del tema de revisión

Propósito:

Documentar el tema seleccionado por los revisores agregando una breve descripción del mismo que permita interpretar la información reportada por los experimentos durante el proceso de RS.

Instrucciones:

1. Al realizar la declaración del tema de revisión, llene el campo Nombre del tema con un descriptor de la tecnología a la cual se refiere el tema. Puede proporcionarse un tema general o específico dependiendo del conocimiento e interés del revisor acerca del mismo.

2. Describa brevemente el tema, proporcionando información que pueda definir o caracterizar la tecnología relacionada con el tema, y que permita en actividades y fases futuras interpretar la información que aparece en los experimentos localizados (por ejemplo, los niveles de los factores que ensayan, las variables respuesta evaluadas, o los resultados obtenidos).

Formulario DE Declaración del tema de revisión Realizado por:

Fecha:

Nombre del tema:

Descripción: 


(n)


B02 - Análisis de artículos recuperados

Propósito:

Recoger un listado de títulos y resúmenes de los estudios que han sido localizados durante la búsqueda y determinar su relevancia (o elegibilidad) para la RS

Instrucciones:

1. Al efectuar la búsqueda, rellene los valores para el identificador (ID) del artículo dentro del conjunto, los autores del artículo, la referencia completa del artículo en su fuente original, su ubicación física en el directorio del proyecto, y los elementos más importantes del resumen del artículo.

2. Para el descarte/selección del artículo, responda Sí o No a la pregunta ¿Relevante?

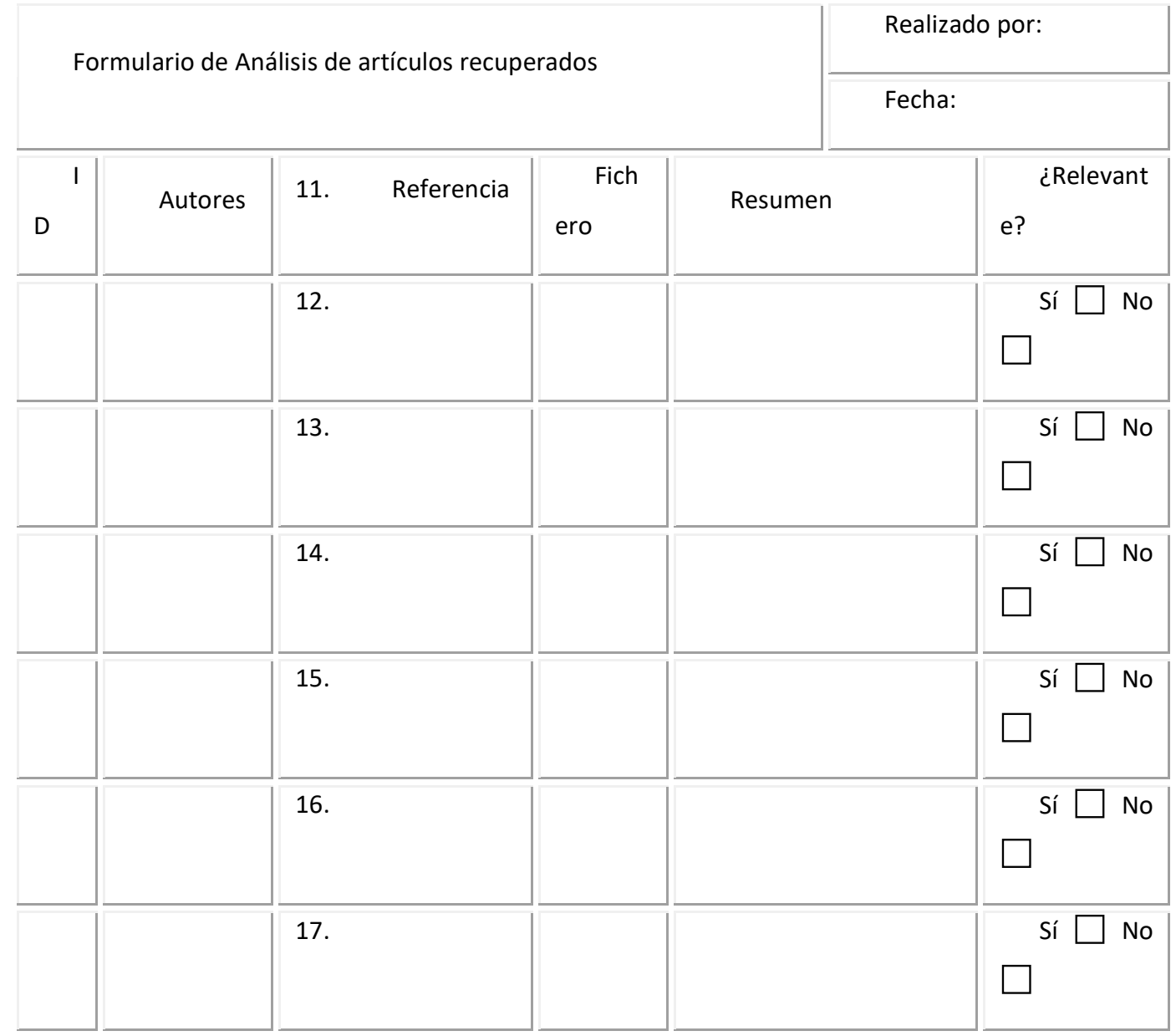


Proceso de RS de experimentos en Ingeniería del Software

Impacto de la Evaluación

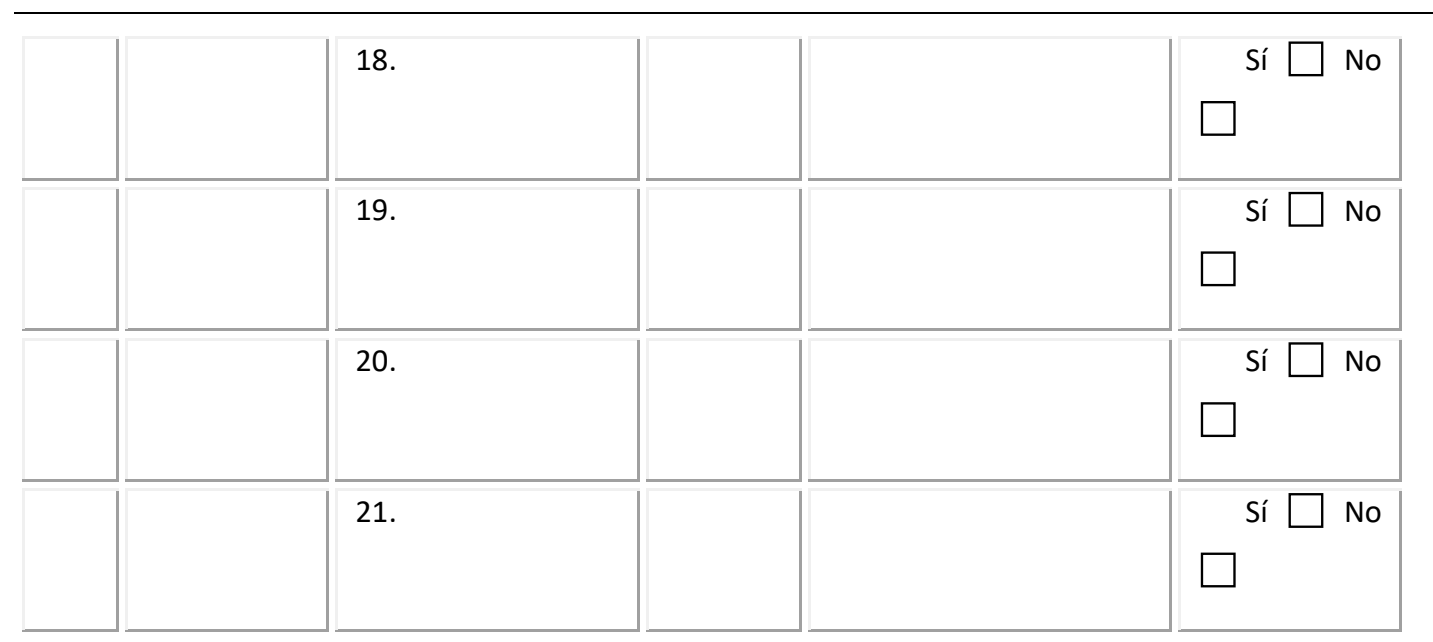


B02_b - Análisis de artículos recuperados - Doble chequeo

Propósito:

Recoger un listado de títulos y resúmenes de los estudios que han sido localizados durante la búsqueda y determinar su relevancia (o potencialidad) para la RS desde la perspectiva de dos revisores distintos.

Instrucciones:

3. Al efectuar la búsqueda, rellene los valores para el identificador (ID) del artículo dentro del conjunto, los autores del artículo, la referencia completa del artículo en su fuente original, su ubicación física en el directorio del proyecto, y los elementos más importantes del resumen del artículo.

4. Para el descarte/selección del artículo, responda Sí o No a la pregunta ¿Relevante?

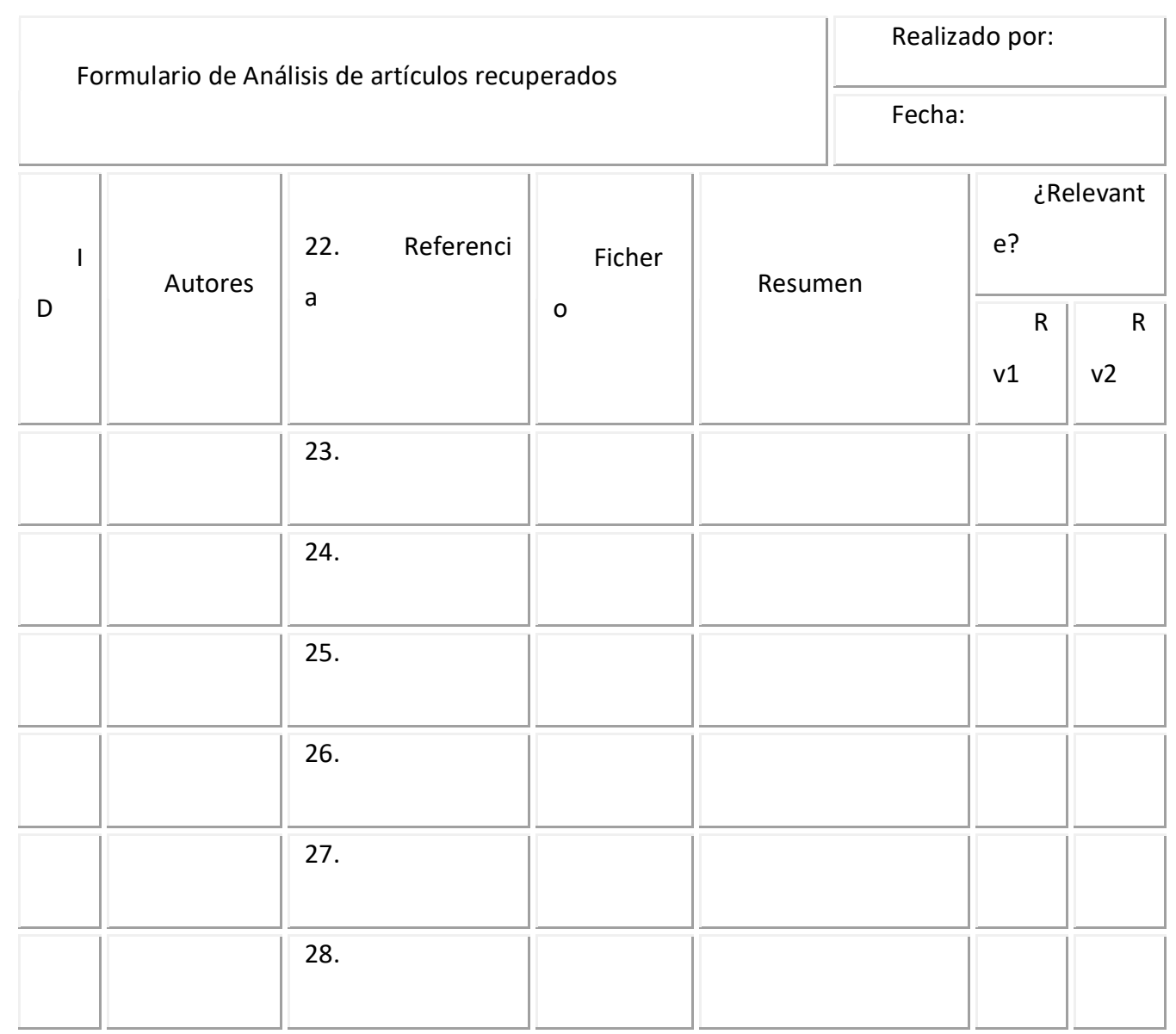


Proceso de RS de experimentos en Ingeniería del Software

Impacto de la Evaluación

\begin{tabular}{|l|l|l|l|l|l|}
\hline & 29. & & & & \\
\hline & 30. & & & & \\
\hline & 31. & & & & \\
\hline
\end{tabular}




$\begin{array}{llllll}\text { Formulario } & \text { B03 } & - & \text { Resumen } & \text { de } & \text { artículos }\end{array}$


B03 - Resumen de artículos relevantes

Propósito:

Recoger un listado de títulos y resúmenes de los estudios que han sido seleccionados por su relevancia para la RS.

Instrucciones:

1. Rellene los valores: identificador (ID) del artículo dentro del conjunto, los autores del artículo, la referencia completa del artículo en su fuente original, su ubicación física en el directorio del proyecto, y los elementos más importantes del resumen del artículo; para cada artículo seleccionado como relevante.

2. En el campo observaciones coloque cualquier información resaltante sobre el artículo, por ejemplo, condiciones del estudio, limitaciones del estudio, si se trata de una replicación, etc. Si el estudio aparece en otro artículo dentro del conjunto, indique en este campo el ID del estudio relacionado.

Formulario para Resumen de artículos relevantes

Realizado por:

\begin{tabular}{|c|c|c|c|c|c|c|}
\hline & & & & & \multicolumn{2}{|c|}{ Fecha: } \\
\hline \multirow[t]{6}{*}{ D } & Autores & 33. & Referencia & $\begin{array}{ll} & \text { Ficher } \\
\text { o } & \end{array}$ & Resumen & Obs. \\
\hline & & 34. & & & & \\
\hline & & 35. & & & & \\
\hline & & 36. & & & & \\
\hline & & 37. & & & & \\
\hline & & 38. & & & & \\
\hline & & & & & & \\
\hline
\end{tabular}




\begin{tabular}{|l|l|l|l|l|l|l|}
\hline & 39. & & & & & \\
\hline
\end{tabular}


B04 - Estadísticas de búsqueda

Propósito:

Resumir los resultados de las búsquedas realizadas con respecto a los artículos relevantes que han sido determinados, así como el número de experimentos y replicaciones que han sido identificadas.

Instrucciones:

1. Para cada repositorio (base de datos bibliográfica) utilizada indique el número de artículos obtenidos o recuperados.

2. Luego del descarte de artículos irrelevantes, indique el número de artículos relevantes por cada repositorio.

3. Con base en el formulario FBUS_002 (véase Apéndice C), totalice el número de artículos relevantes distintos que se obtuvieron de la búsqueda, los estudios identificados que sean distintos y el número de replicaciones.

Formulario para Estadísticas de búsqueda

Realizado por:

Fecha:

\begin{tabular}{|l|l|l|l|}
\hline & $\begin{array}{l}4 . \quad \text { Artículos } \\
\text { Repositorio }\end{array}$ & Artículos relevantes \\
\hline & 45. & & \\
\hline & 46. & \\
\hline & 47. & \\
\hline & 48. & \\
\hline & 49. & \\
\hline
\end{tabular}


Proceso de RS de experimentos en Ingeniería del Software

Impacto de la Evaluación

\begin{tabular}{|l|l|l|}
\hline & & \\
\hline $51 . \quad$ & Total artículos relevantes (distintos) & \\
\hline $52 . \quad$ Total estudios (distintos) & \\
\hline $53 . \quad$ Total replicaciones & \\
\hline
\end{tabular}


Formulario B05 - Agrupamiento por sub-tema y tipo de estudio 
B05 - Agrupamiento por sub-tema y tipo de estudio

Propósito:

Presentar un resumen de los artículos considerados como relevantes (o potencialmente elegibles), organizados según: 1) el sub-tema o tópico específico que tratan, y 2) el tipo de diseño experimental utilizado en el estudio que reportan.

Instrucciones:

1. Identificar los sub-temas correspondientes a cada artículo, con base en la información proporcionada en título y resumen.

2. Identificar el tipo de estudio correspondiente a cada artículo, con base en la información proporcionada en título y resumen.

3. Identificar estudios del tipo tesis o validación de una propuesta.

4. Distribuir los artículos según el sub-tema y tipo de estudio.

Formulario de Agrupamiento por sub-tema y tipo de estudio

Realizado por:

Fecha:

\begin{tabular}{|c|c|c|c|c|c|}
\hline Sub-tema & $\begin{array}{r}\text { Sub- } \\
\text { tema } 1\end{array}$ & $\begin{array}{r}\text { Sub- } \\
\text { tema } 2\end{array}$ & $\ldots$ & $\begin{array}{l}\text { Sub- } \\
\text { tema } n\end{array}$ & $\begin{array}{l}\text { Validación de una } \\
\text { nueva propuesta }\end{array}$ \\
\hline Experiment & & & & & \\
\hline $\mathrm{RCT}$ & & & & & \\
\hline
\end{tabular}


B06 - Análisis de RS recuperadas

Propósito:

Recoger un listado de títulos y resúmenes de los antecedentes que han sido localizados durante la búsqueda para determinar la adecuación al objetivo de la actual RS

Instrucciones:

5. Al efectuar la búsqueda de antecedentes, rellene los valores para identificador (ID) del artículo dentro del conjunto, los autores del artículo, la referencia completa del artículo en su fuente original, su ubicación en el directorio del proyecto, y los elementos más importantes del resumen del artículo.

6. Para determinar la adecuación de la RS al objetivo de la actual revisión, responda Sí o No a la pregunta ¿Satisface el objetivo?

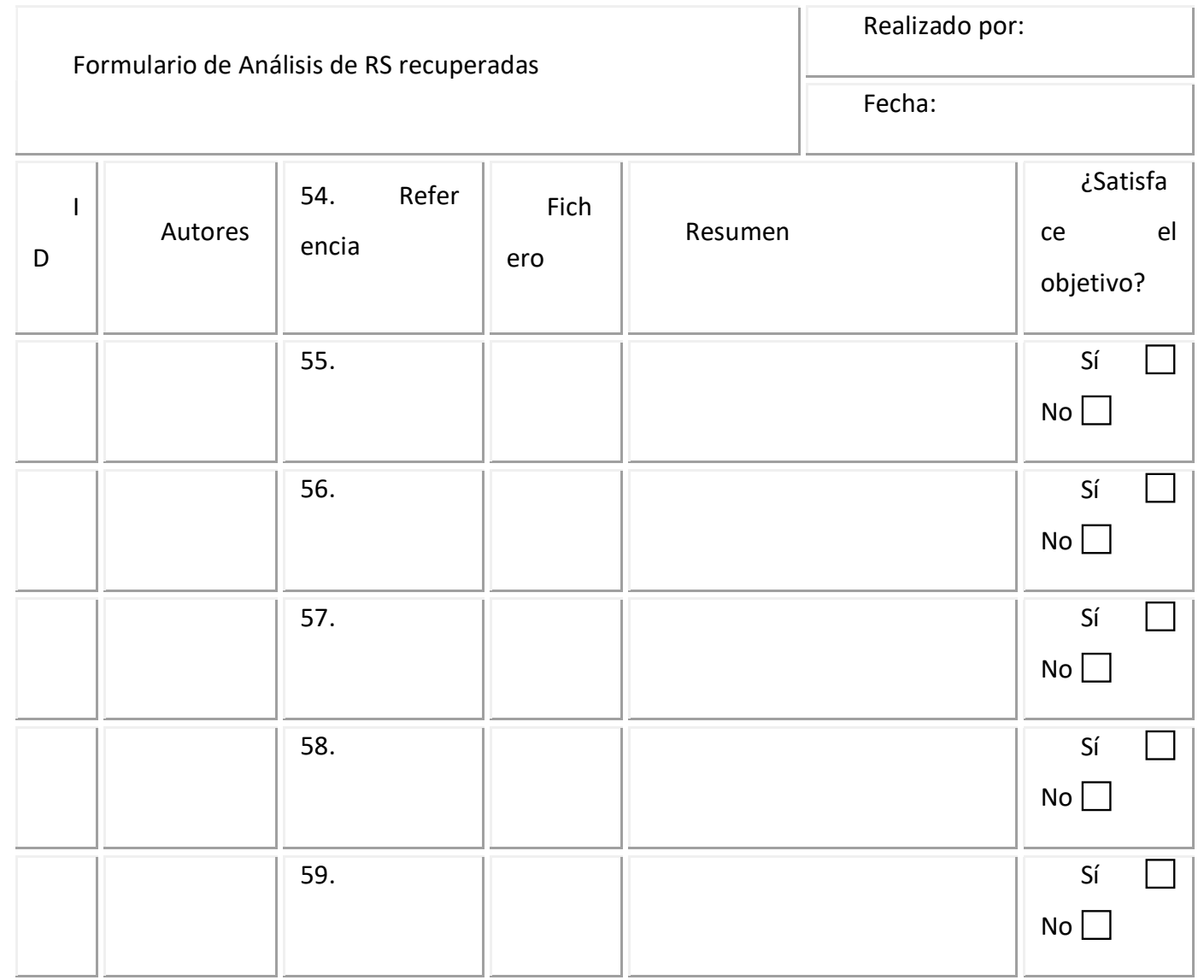




\begin{tabular}{|c|c|}
\hline 60. & $\begin{array}{l}\text { Sí } \square \\
\text { No } \square\end{array}$ \\
\hline 61. & $\begin{array}{c}\text { Sí } \square \\
\text { No } \square\end{array}$ \\
\hline 62. & $\begin{array}{c}\text { Sí } \square \\
\text { No } \square\end{array}$ \\
\hline 63. & $\begin{array}{c}\text { Sí } \square \\
\text { No } \square\end{array}$ \\
\hline 64. & $\begin{array}{c}\text { Sí }_{\text {No }} \square \\
\text { N }\end{array}$ \\
\hline
\end{tabular}




Formulario $\quad$ B07 $\quad-\quad$ Declaración $\quad$ del $\quad$ objetivo $\quad$ de $\quad$ revisión


B07 - Declaración del objetivo de revisión

Propósito:

Documentar los aspectos más relevantes del objetivo de revisión, la pregunta de revisión y los criterios de inclusión/exclusión de estudios.

Instrucciones:

1. Definir el enunciado y justificación del objetivo de revisión establecido.

2. Detallar los aspectos del ambiente experimental (tipo y perfil de los sujetos, ambiente, etc.), tratamientos (los factores y sus niveles) y las variables respuesta.

3. Establecer criterios para la inclusión o exclusión de estudios en la RS.

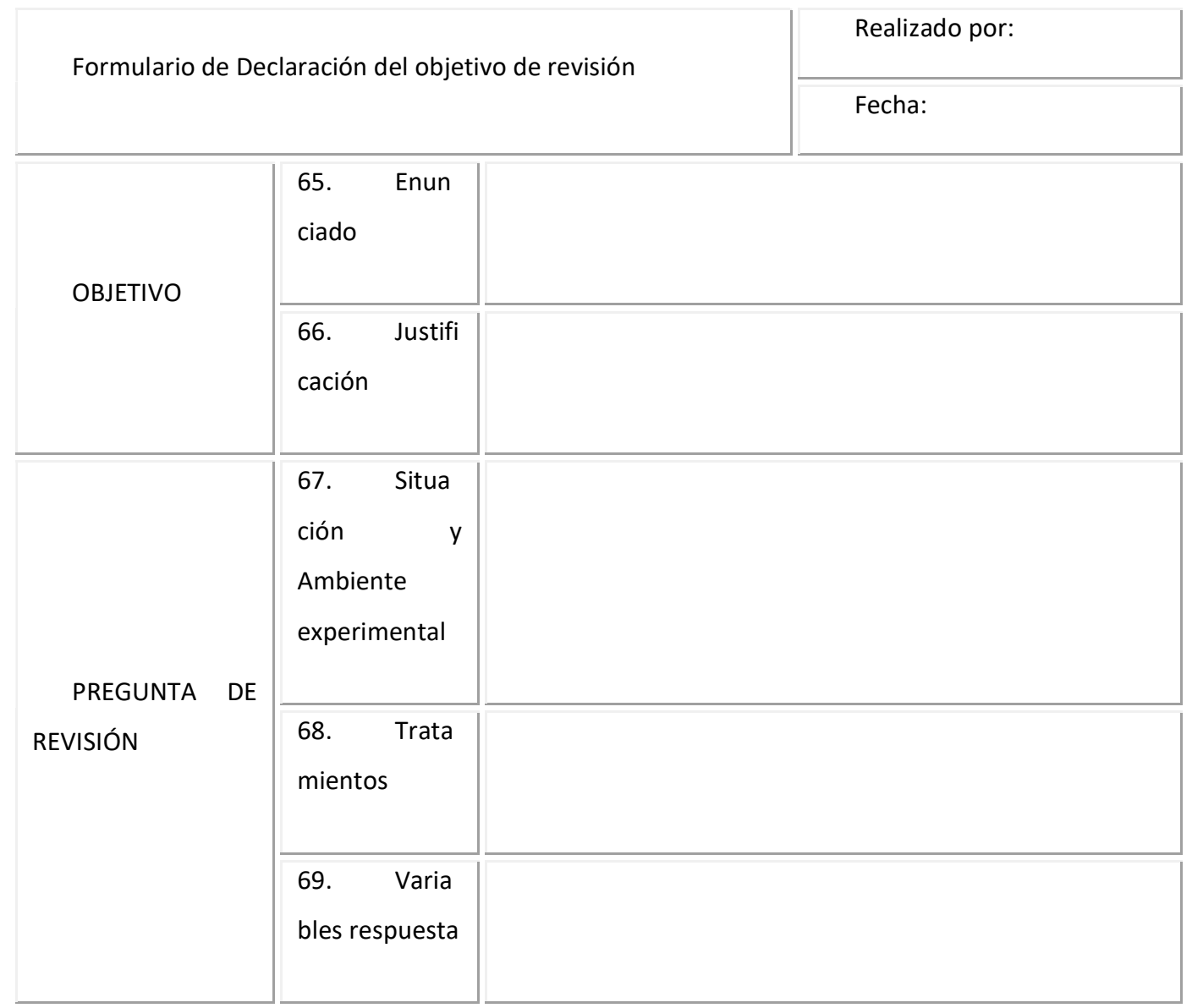


Proceso de RS de experimentos en Ingeniería del Software

Impacto de la Evaluación

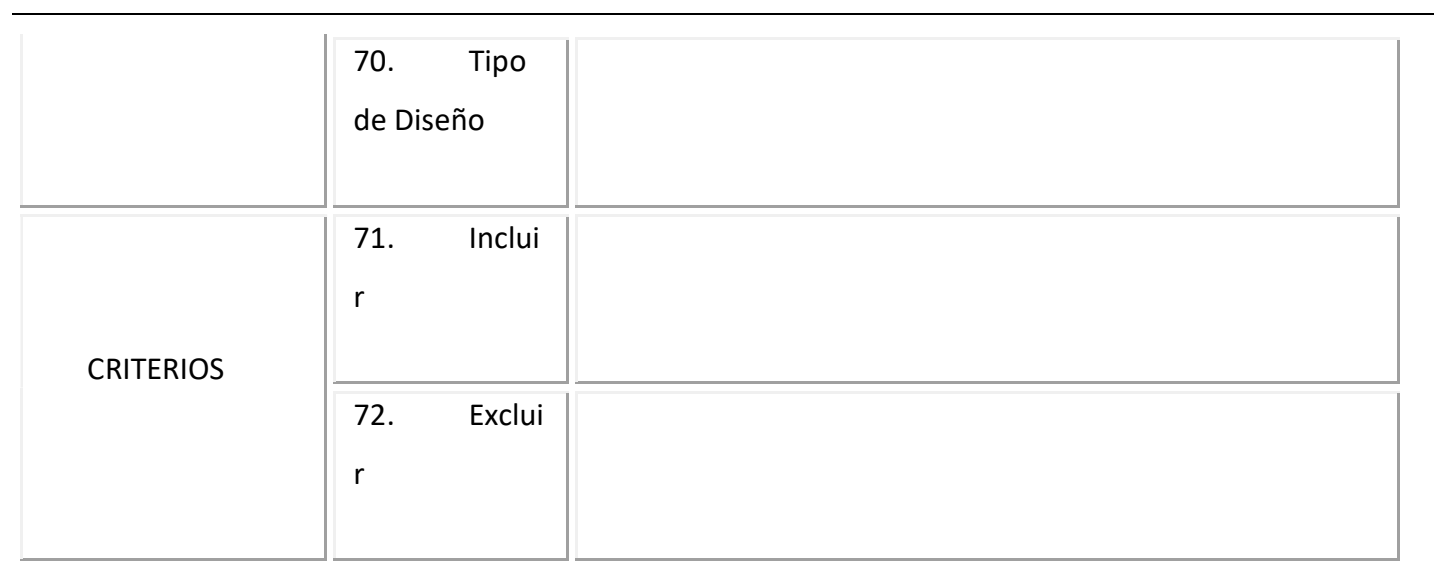




\section{Estudio}

sobre

la

selección

de

campos

de

búsqueda 
Estudio sobre la selección de cadenas de búsqueda 
APÉNDICE C. DOCUMENTOS DE LA FASE EXTRACCIÓN DE DATOS 


\section{Formulario E01-Datos del Experimentos}




\section{E01 - DATOS DEL EXPERIMENTO}

Propósito:

Recopilar los datos de un experimento relevante a la Síntesis de Datos y a la Valoración de la Calidad.

Instrucciones:

1. Lea cuidadosamente la información proporcionada en forma de ayuda en cada campo.

2. Llene cada campo del formulario con la información extraída del artículo. De ser necesario, realice más de una iteración en la lectura del experimento hasta extraer la información solicitada.

3. En caso de que no cuente con la información para llenar algún campo o éste no aplique al tipo de estudio que está analizando indique no sabe o no aplica en el campo correspondiente. Para cada pieza de información vaciada en el formulario debe indicar:

- Fuente: corresponde a la localización en el artículo de la información en la cual fundamenta su respuesta. Si ha extraído la información textualmente y de una sección específica del mismo, indique el número de página. Si, por el contrario, la información se encontraba descrita en varias partes del artículo seleccione la opción general. En caso de que su respuesta sea resultado de su interpretación y no haya sido tomada literalmente del artículo, indíquelo seleccionando la casilla Interpretado.

- Confianza: se refiere a la seguridad que tiene el revisor acerca de la información que está vaciando en cada campo del formulario. Seleccione textual en caso de que la respuesta pueda ser tomada directamente de alguna frase o párrafo del artículo; interpretado, si la información no aparece de manera explícita en el artículo pero puede inferirse de su lectura; por último, seleccione la opción poco seguro en caso de que su nivel de confianza respecto a la información que está vaciando en el campo sea baja.

4. Utilice el campo Observaciones sobre la dificultad de extracción para indicar su opinión relevante acerca de cuán difícil le ha resultado la extracción de cada conjunto de datos del formulario. Esta opinión puede ser utilizada posteriormente para valorar la calidad del reporte de los resultados experimentales.

5. En caso de que tenga comentarios acerca de la calidad del estudio o de la información proporcionada por éste, utilice el campo Observaciones sobre la Calidad que se encuentra en cada sección del formulario. 
E01-DATOS DEL EXPERIMENTO

Identificación

Autores/Título/

Publicación

Ubicación (opcional)

[Indique la referencia bibliográfica que corresponde al artículo; especificando los autores, el título completo del mismo y el nombre de la revista o congreso en la que se encuentra publicada, la fecha de publicación (año) y número de páginas]

[Este campo del formulario es opcional y corresponde a la localización del documento en una base de datos bibliográfica o en un repositorio de proyecto. Indicar el nombre de la base de datos, DOI o nombre del directorio donde se puede localizar el artículo.]

[Haga referencia al objetivo del estudio. Describa de manera breve el objetivo que indican los autores; normalmente esta información es fácilmente localizable en el resumen del artículo.]

Objetivo 


\begin{tabular}{|c|c|c|}
\hline Tópico & $\begin{array}{l}\text { [Indique el área de conocimiento o tipo de tecnología involucrada en el estudio, por ejemplo, educción de } \\
\text { requerimientos, inspecciones de software, etc. Puede utilizar para llenar este campo los términos del sistema de } \\
\text { clasificación (keywords) de la IEEE.] } \\
\text { ¿El tópico es provisto por los autores? } \square \text { Sí } \square \text { No }\end{array}$ & $\begin{array}{l}\text { Fuente: } \\
\text { Textual: } \square \text { General } \\
\text { Pág. } \square \\
\square \text { Interpretado } \square \text { Poco } \\
\text { seguro }\end{array}$ \\
\hline \multicolumn{3}{|c|}{ Observaciones sobre la calidad: } \\
\hline \multicolumn{3}{|c|}{ [Utilice este campo para indicar sus observaciones acerca del objetivo y tópico del estudio] } \\
\hline \multicolumn{3}{|c|}{ Observaciones sobre la dificultad de extracción: } \\
\hline \multicolumn{3}{|c|}{ [Utilice este campo para indicar sus observaciones acerca de la dificultad de extraer estos campos del estudio] } \\
\hline
\end{tabular}




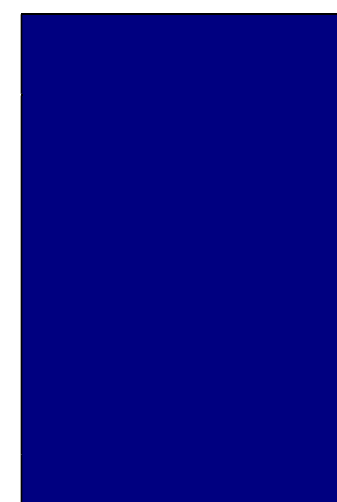

TRATAMIENTOS

\begin{tabular}{|c|c|c|}
\hline Factor 1: & Niveles: & \\
\hline \multirow{4}{*}{$\begin{array}{l}\text { Indique cada factor o variable } \\
\text { independiente establecida en } \\
\text { el estudio. Una variable } \\
\text { independiente puede ser } \\
\text { cualquier característica del } \\
\text { desarrollo de software de la } \\
\text { cual se estudia su efecto. } \\
\text { Indique la descripción que dan } \\
\text { los autores de cada factor en }\end{array}$} & \multirow[t]{2}{*}{$\begin{array}{l}\text { - Indique los valores de los factores durante cada experimento elemental. } \\
\text { - Indique la descripción que dan los autores de cada factor en el } \\
\text { Formulario FEXT_002. }\end{array}$} & $\begin{array}{l}\text { Fuente: } \\
\text { Textual: } \square \text { General } \\
\text { Pág. } \square \\
\square \text { Interpretado } \square \text { Poco } \\
\text { seguro }\end{array}$ \\
\hline & & $\begin{array}{ccc}\text { ¿Usado } & \text { en } & \text { la } \\
\text { agregación? } \square \text { sí } \square \text { No }\end{array}$ \\
\hline & & $\begin{array}{l}\text { Fuente: } \\
\text { Textual: } \square \text { General } \\
\text { Pág. } \square \\
\square \text { Interpretado } \square \text { Poco } \\
\text { seguro }\end{array}$ \\
\hline & & $\begin{array}{c}\text { ¿Usado en la } \\
\text { agregación? } \square \text { Sí } \square \text { No }\end{array}$ \\
\hline
\end{tabular}




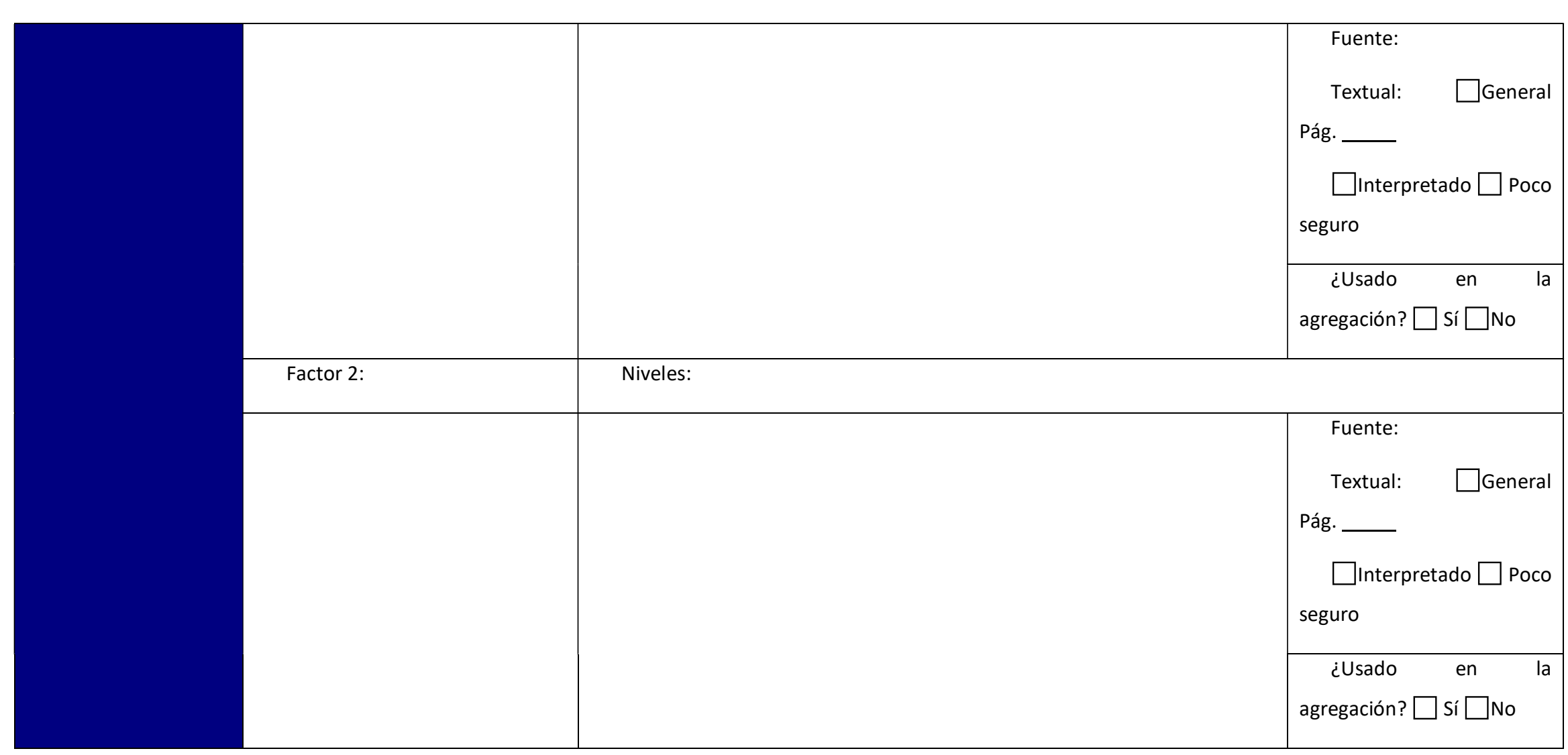




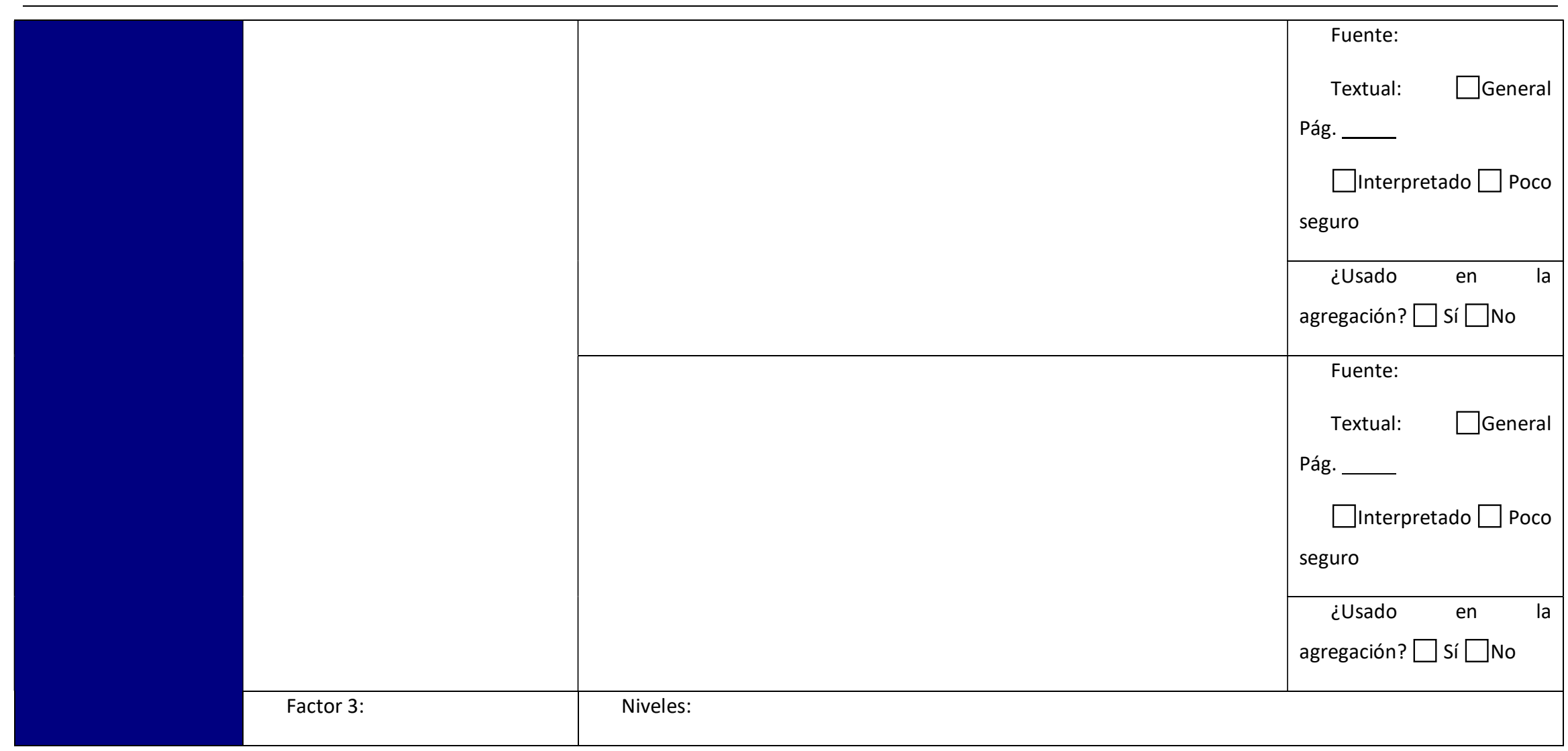




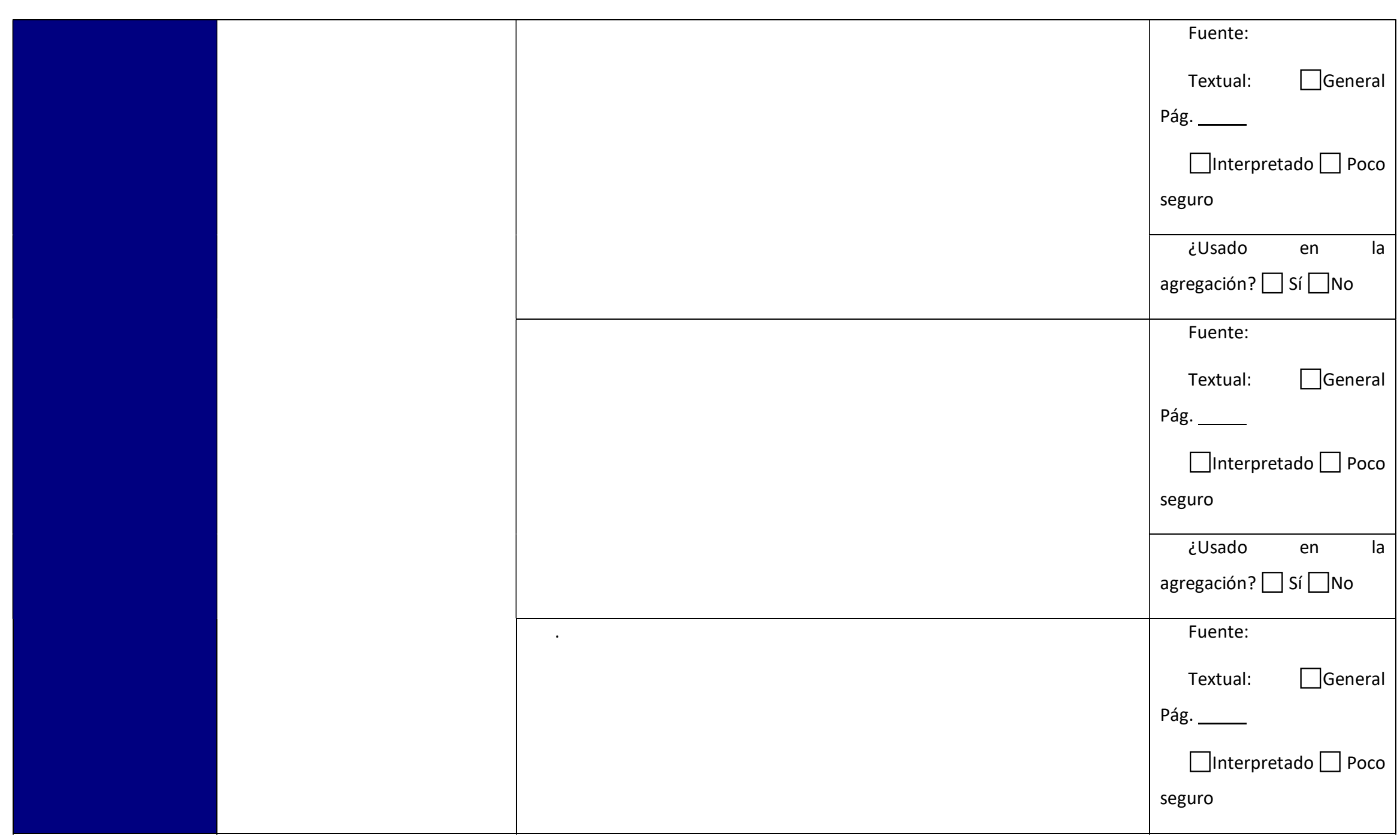




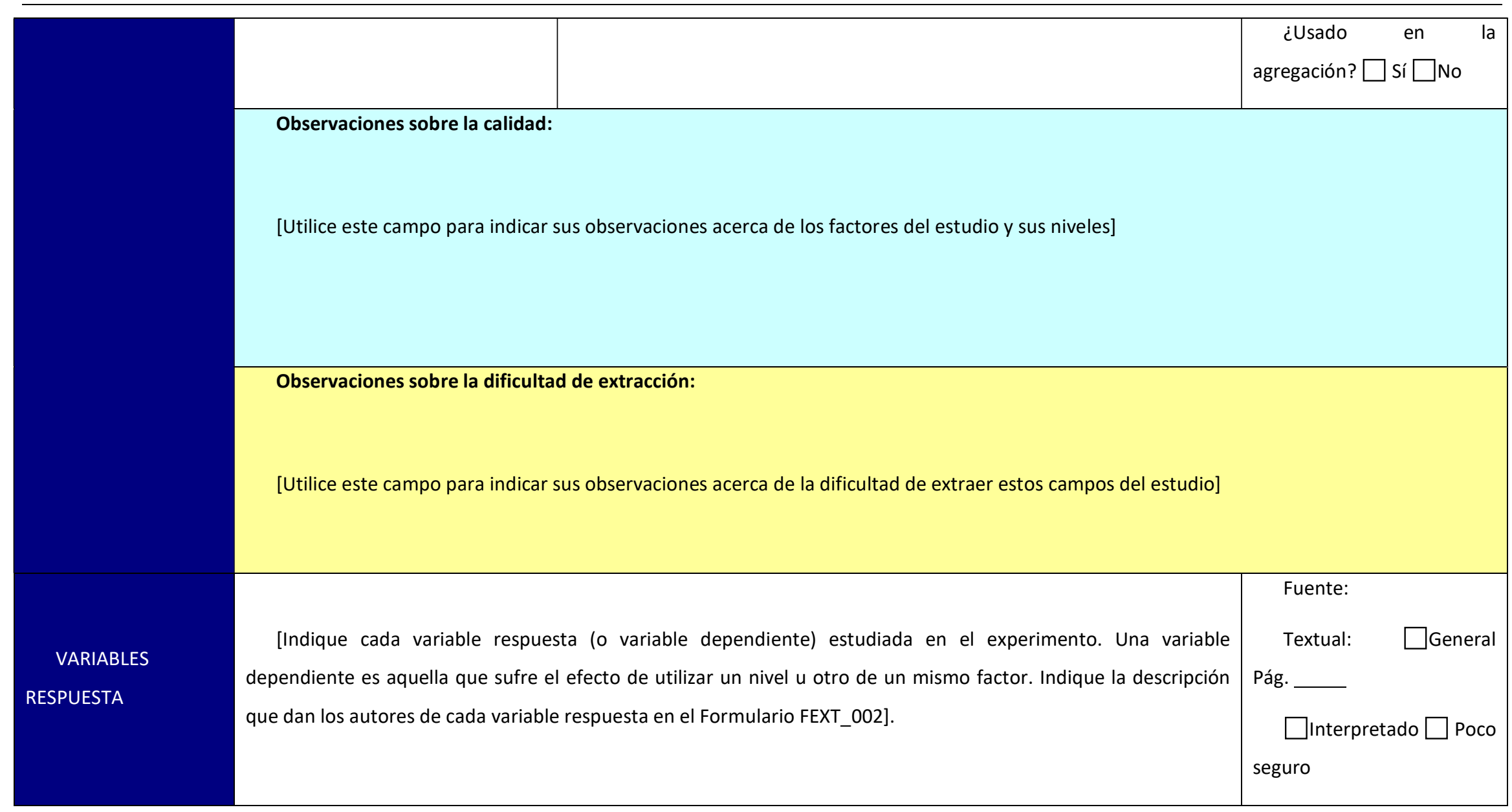




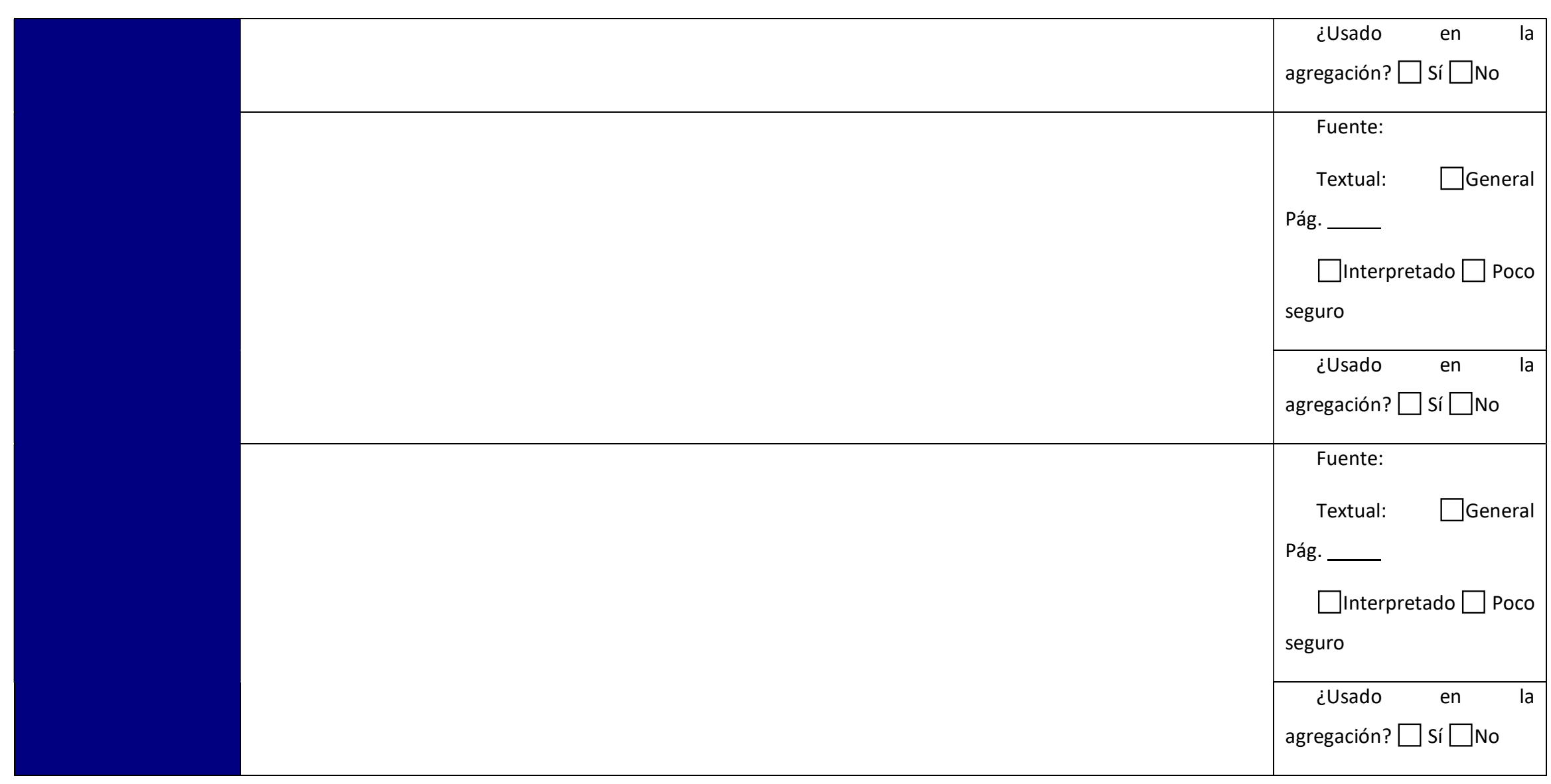




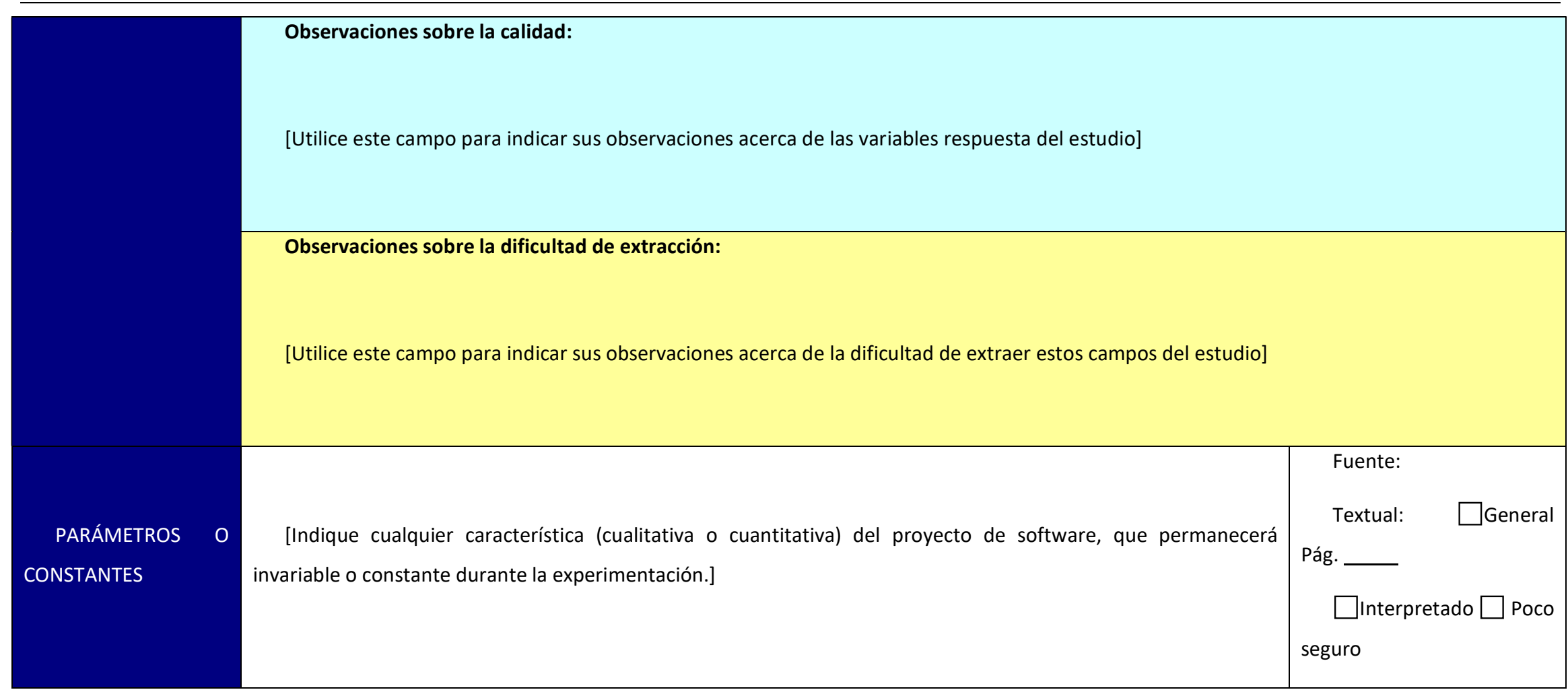




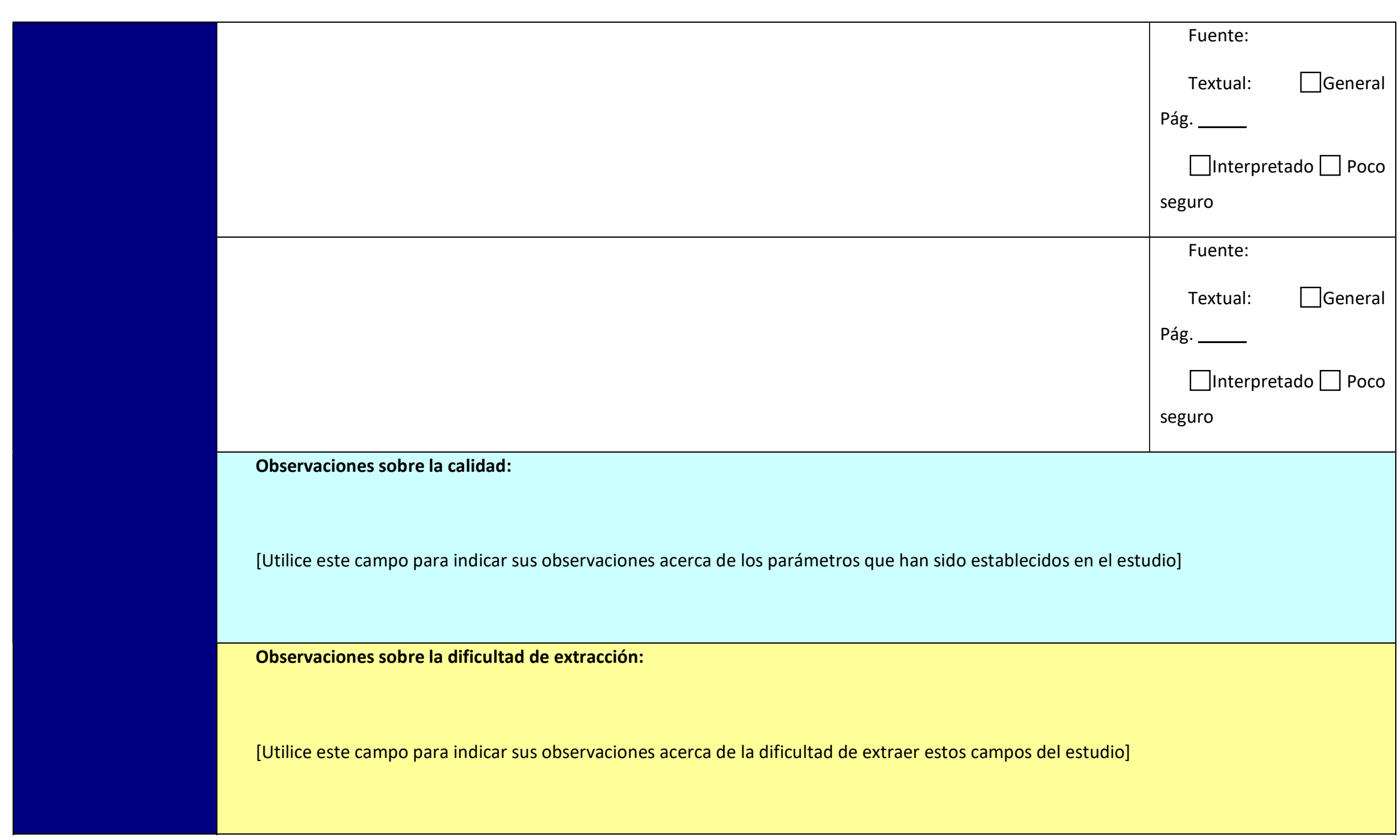




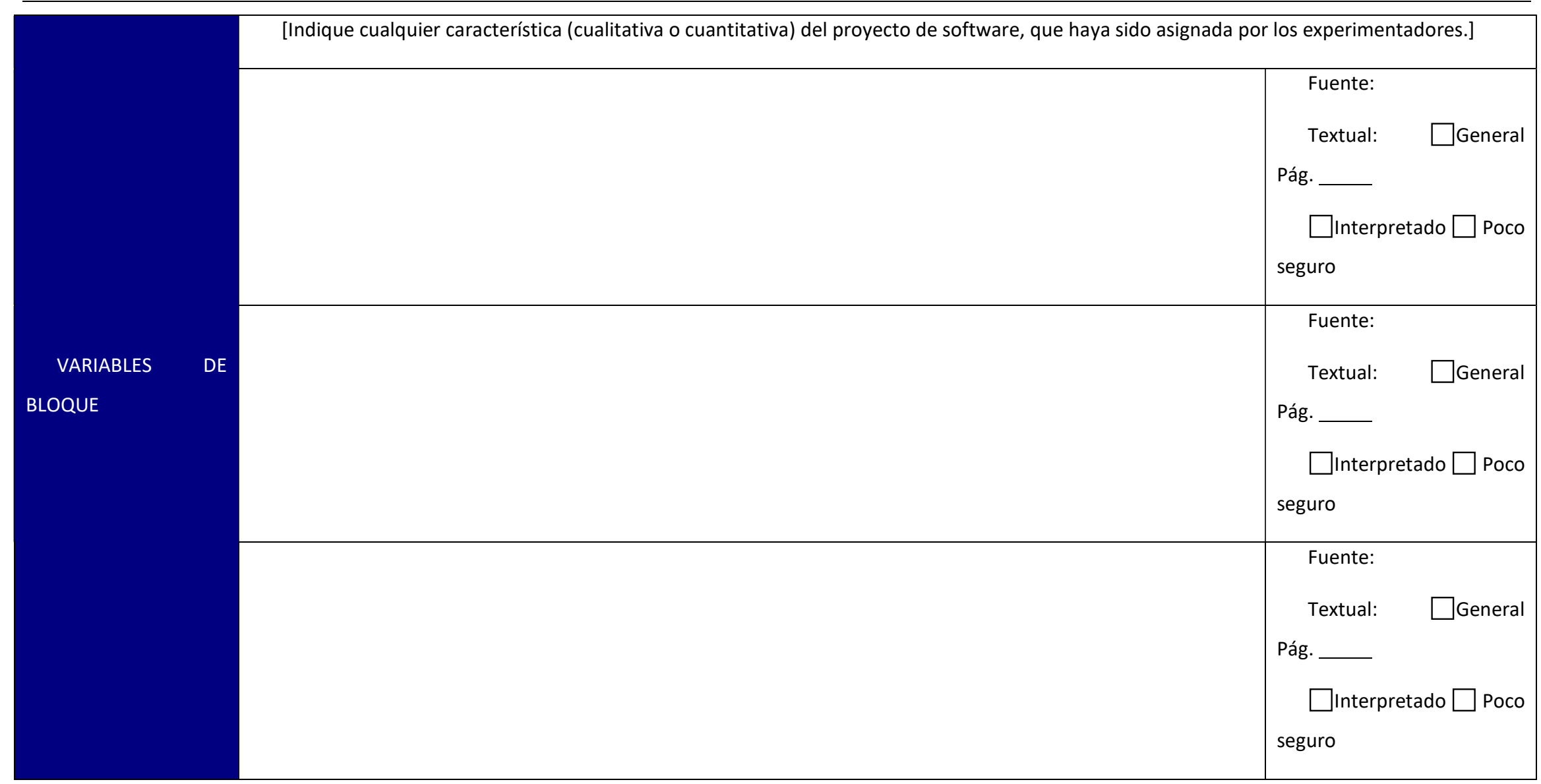




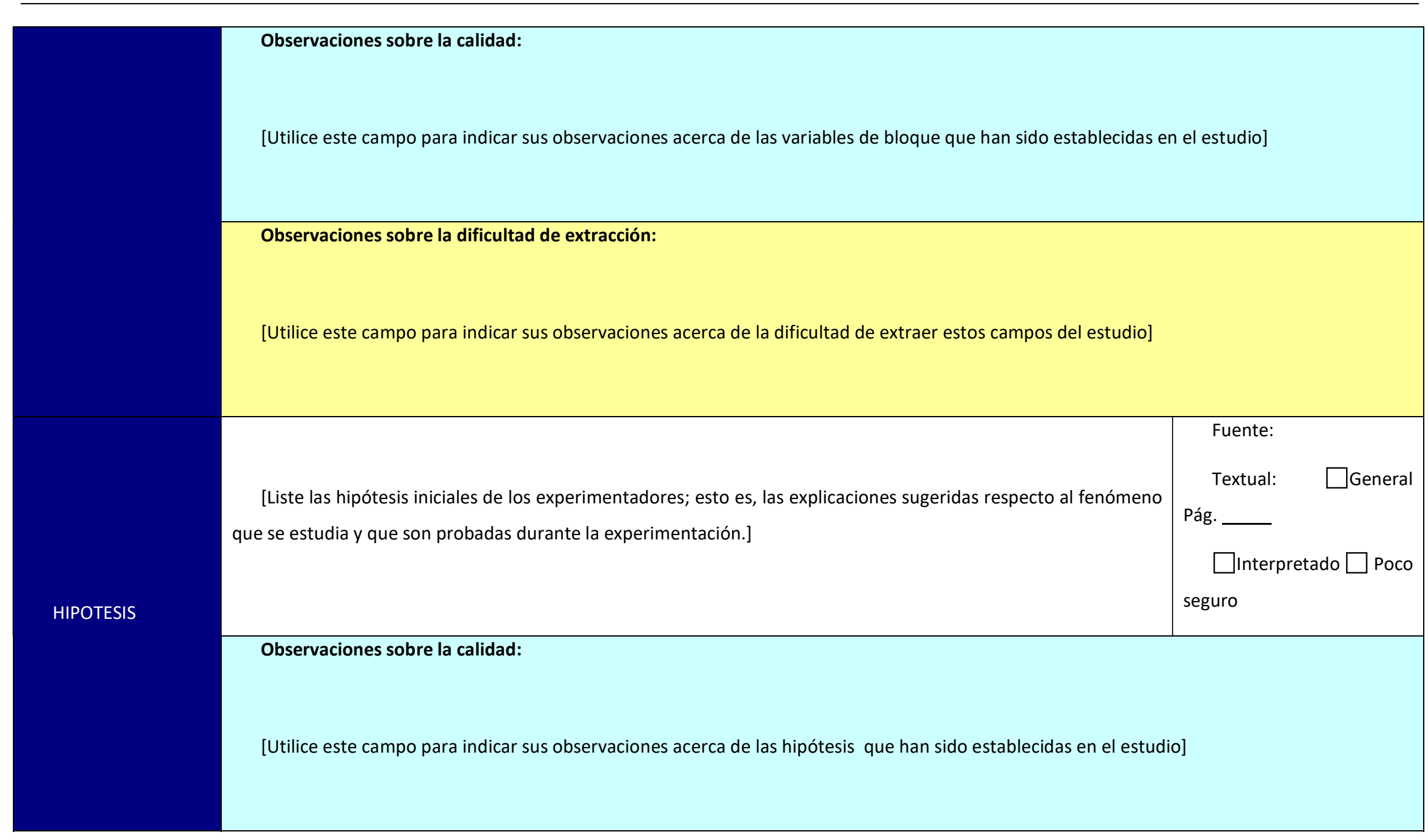




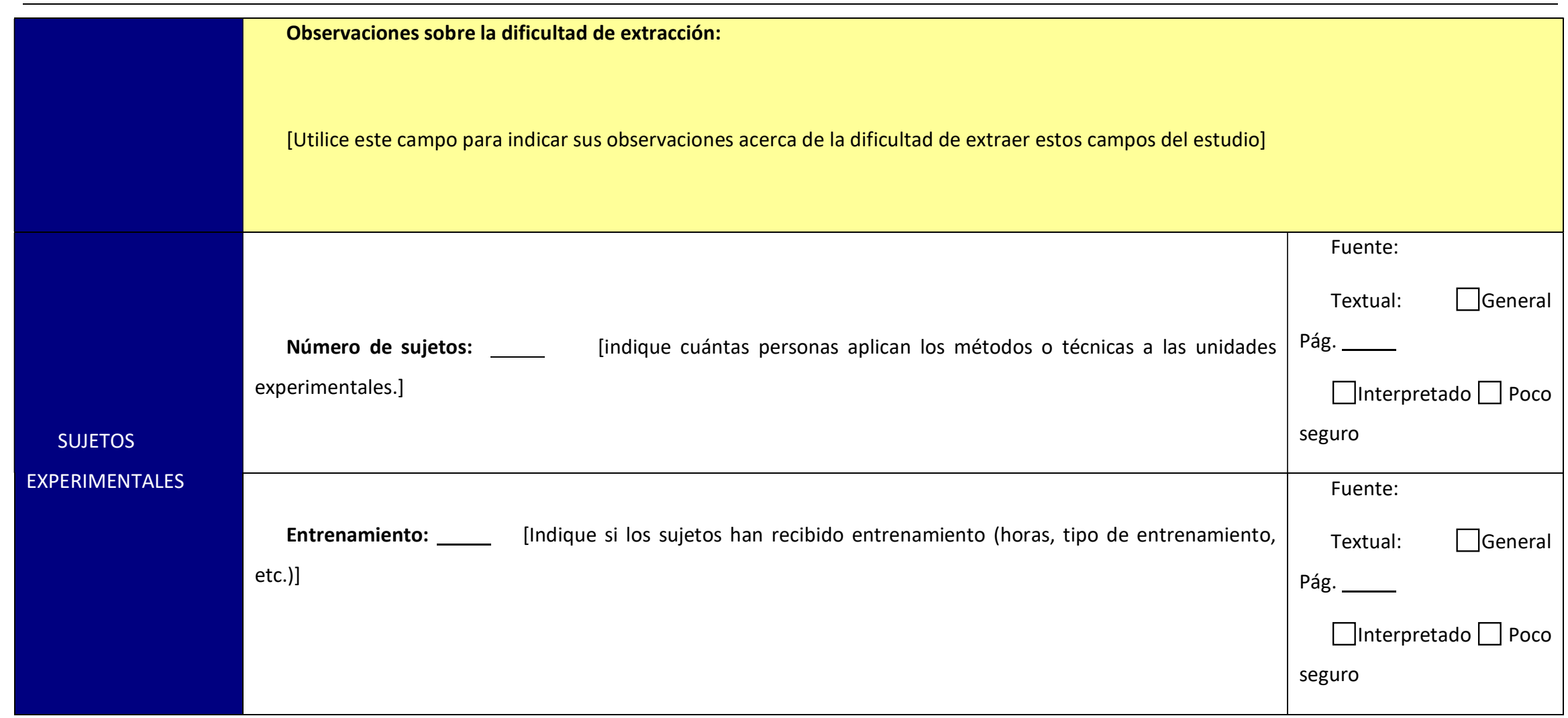




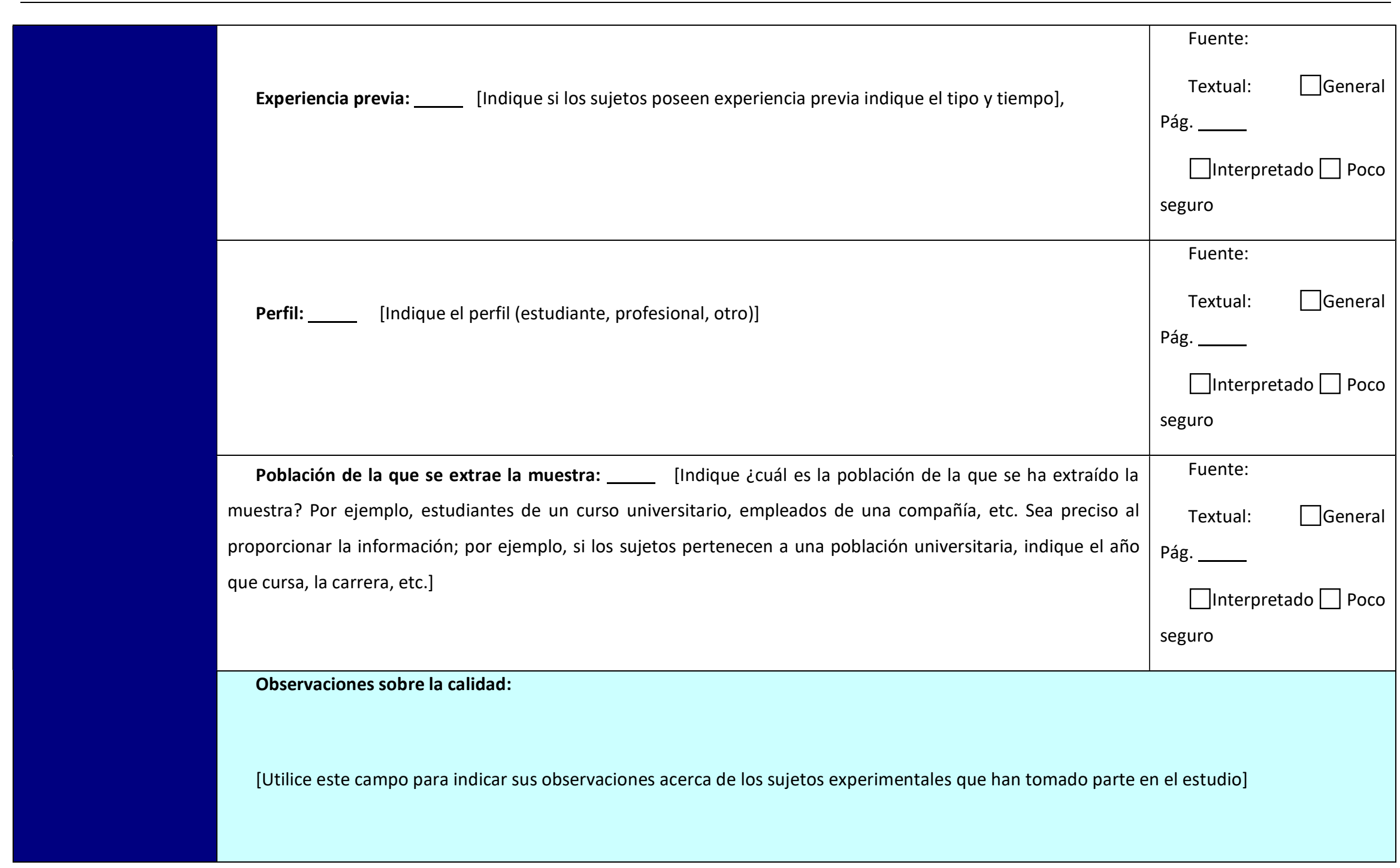




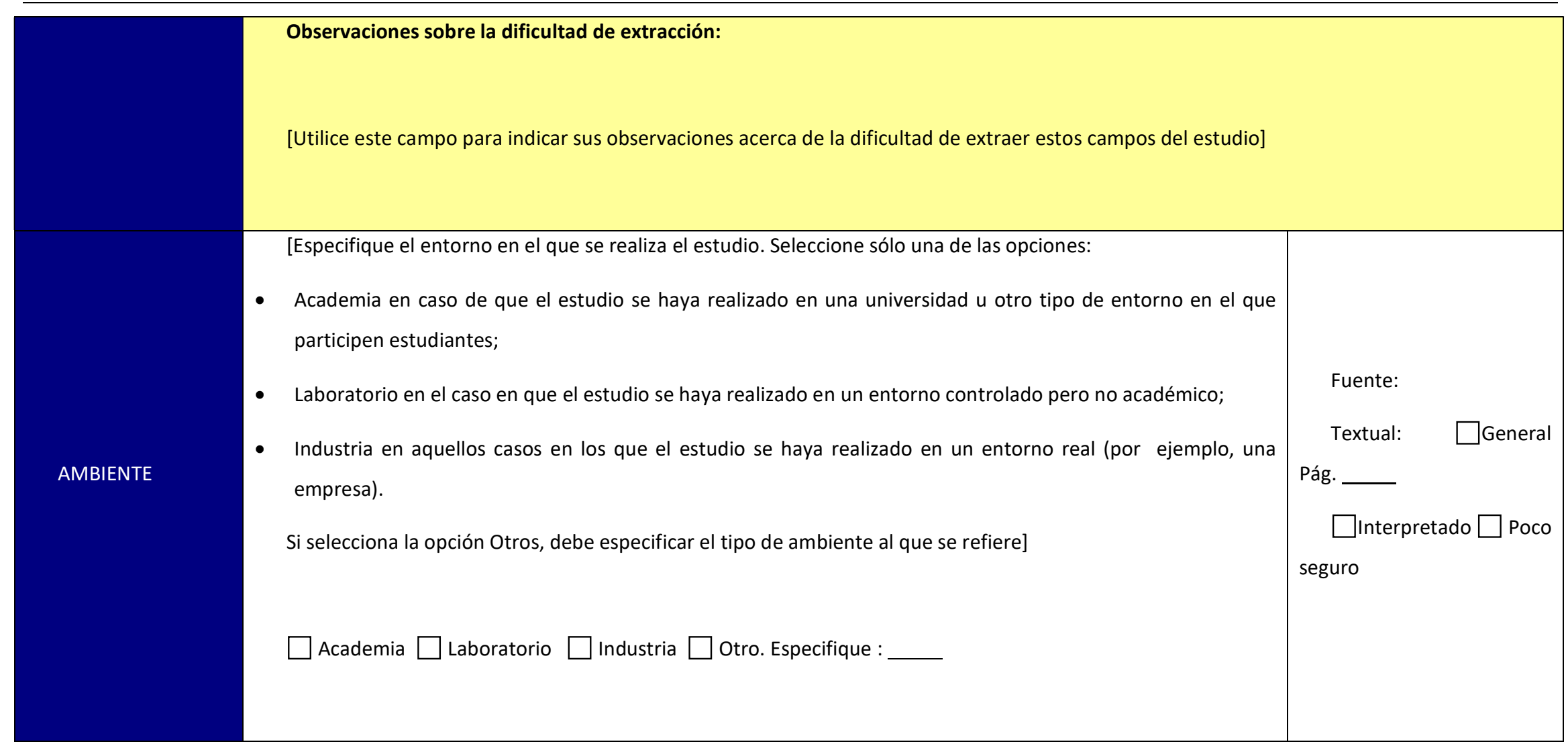




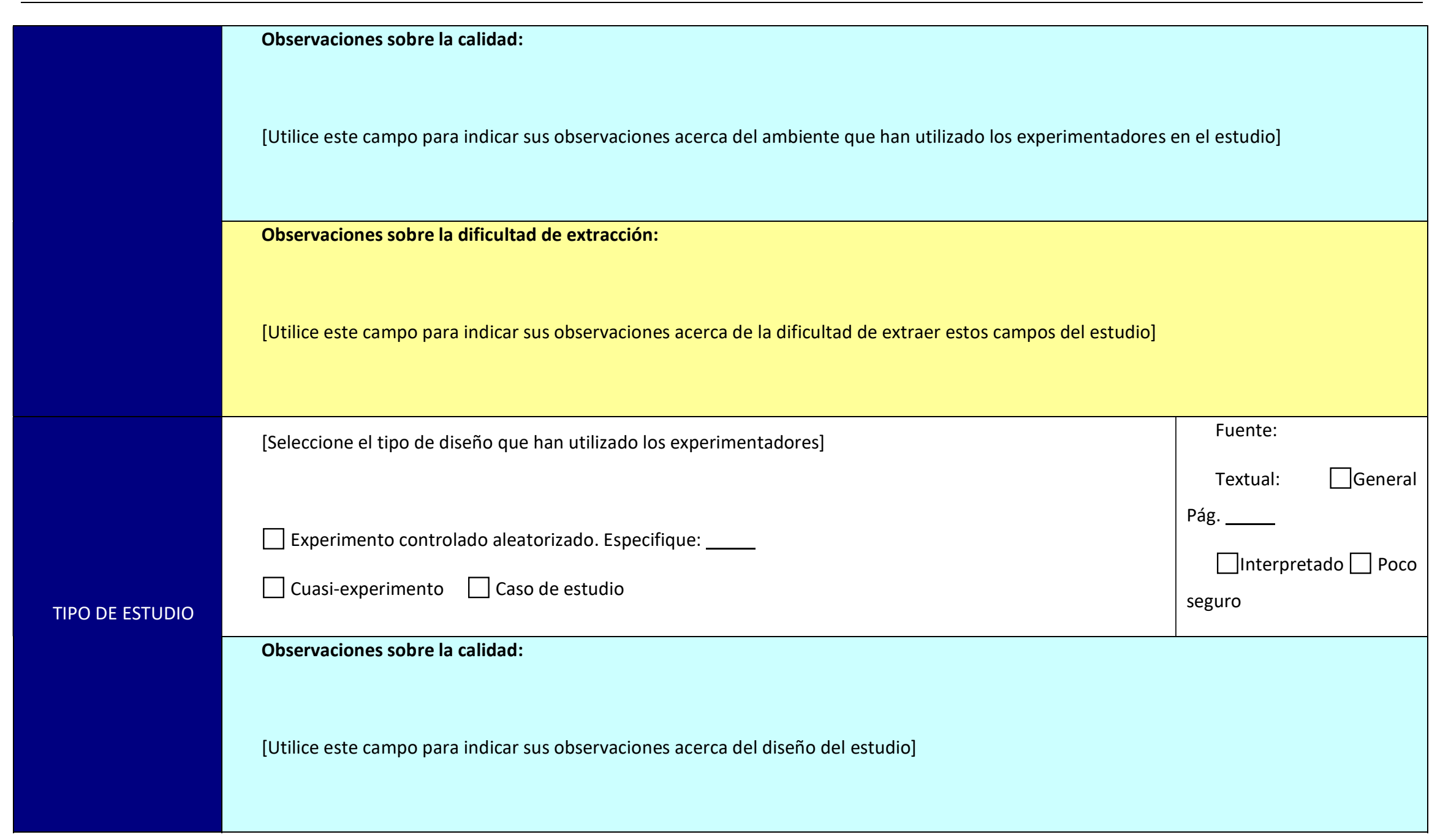




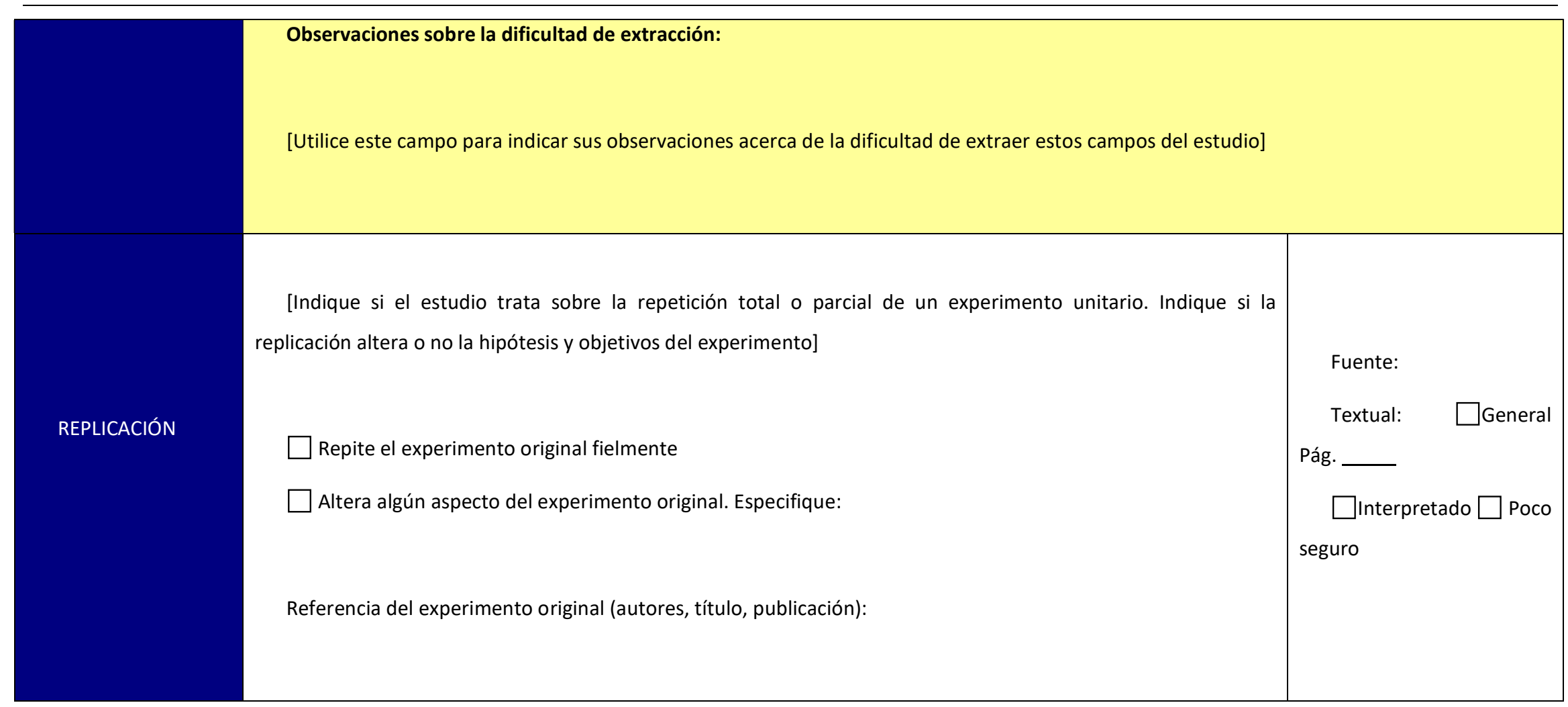




\begin{tabular}{|c|c|c|}
\hline & \multicolumn{2}{|l|}{$\begin{array}{l}\text { Observaciones sobre la calidad: } \\
\text { [Utilice este campo para indicar sus observaciones acerca del diseño de la replicación] }\end{array}$} \\
\hline PROCESO & $\begin{array}{l}\text { Observaciones sobre la dificultad de extracción: } \\
\text { [Utilice este campo para indicar sus observaciones acerca de la dificultad de extraer estos campos del estudio] }\end{array}$ & $\begin{array}{l}\text { Fuente: } \\
\text { Textual: } \square \text { General } \\
\text { Pág. } \square \\
\square \text { Interpretado } \square \text { Poco } \\
\text { seguro }\end{array}$ \\
\hline EXPERIMENTAL & $\begin{array}{l}\text { Duración de la tarea: ___ [Describa la duración de la actividad junto con su unidad de medida (minutos, } \\
\text { horas, días, etc.); en caso de que el tiempo haya sido ilimitado indíquelo igualmente en este campo]] }\end{array}$ & $\begin{array}{l}\text { Fuente: } \\
\text { Textual: } \square \text { General } \\
\text { Pág. } \square \\
\square \text { Interpretado } \square \text { Poco } \\
\text { seguro }\end{array}$ \\
\hline
\end{tabular}




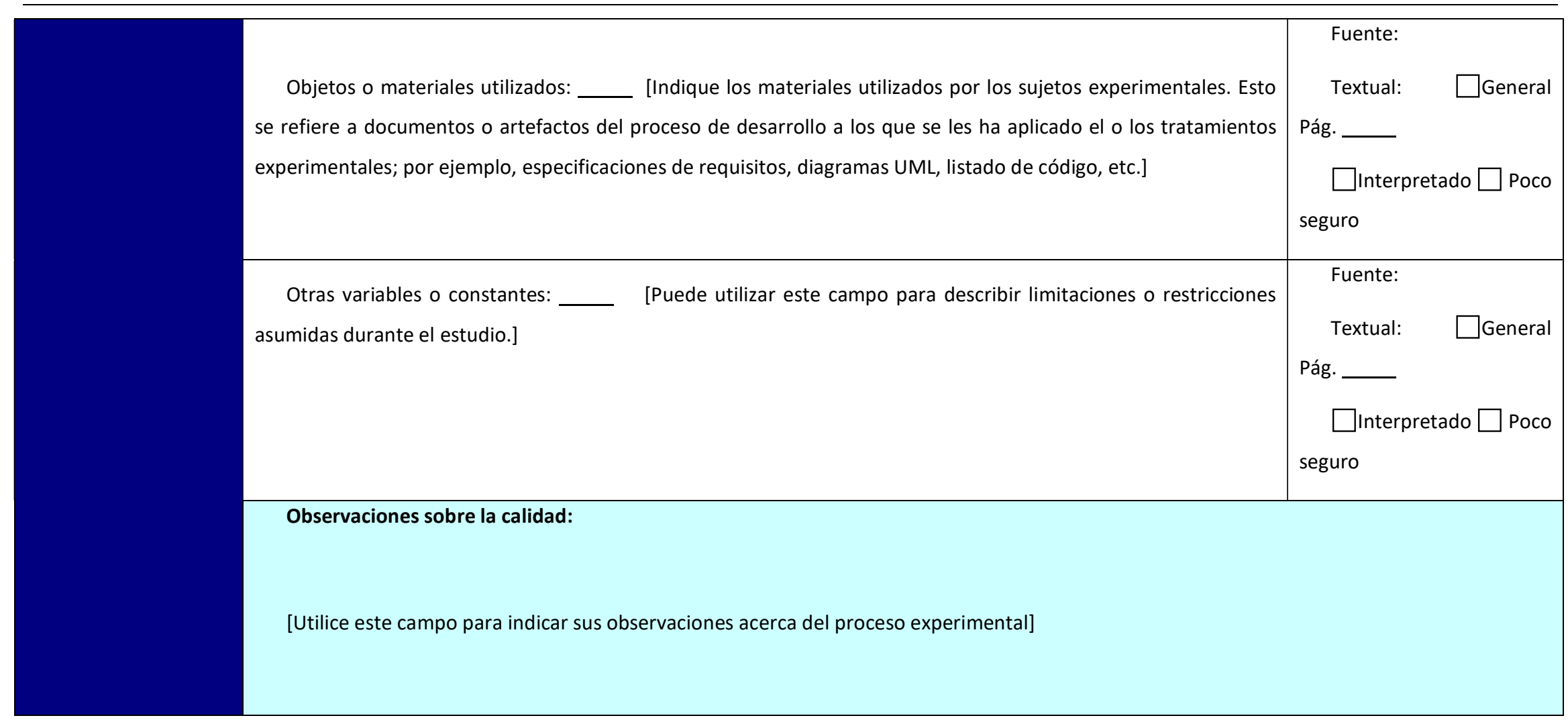




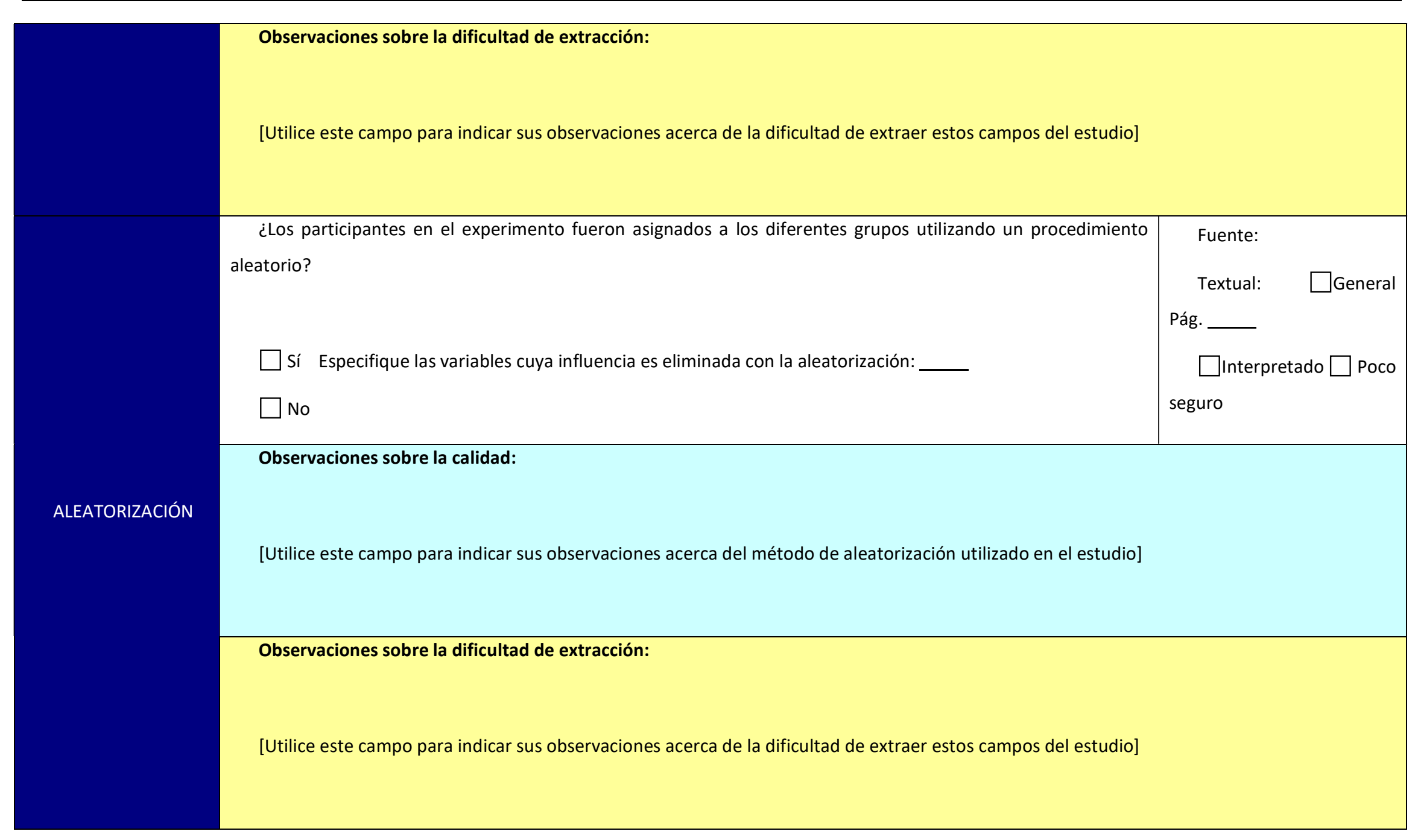




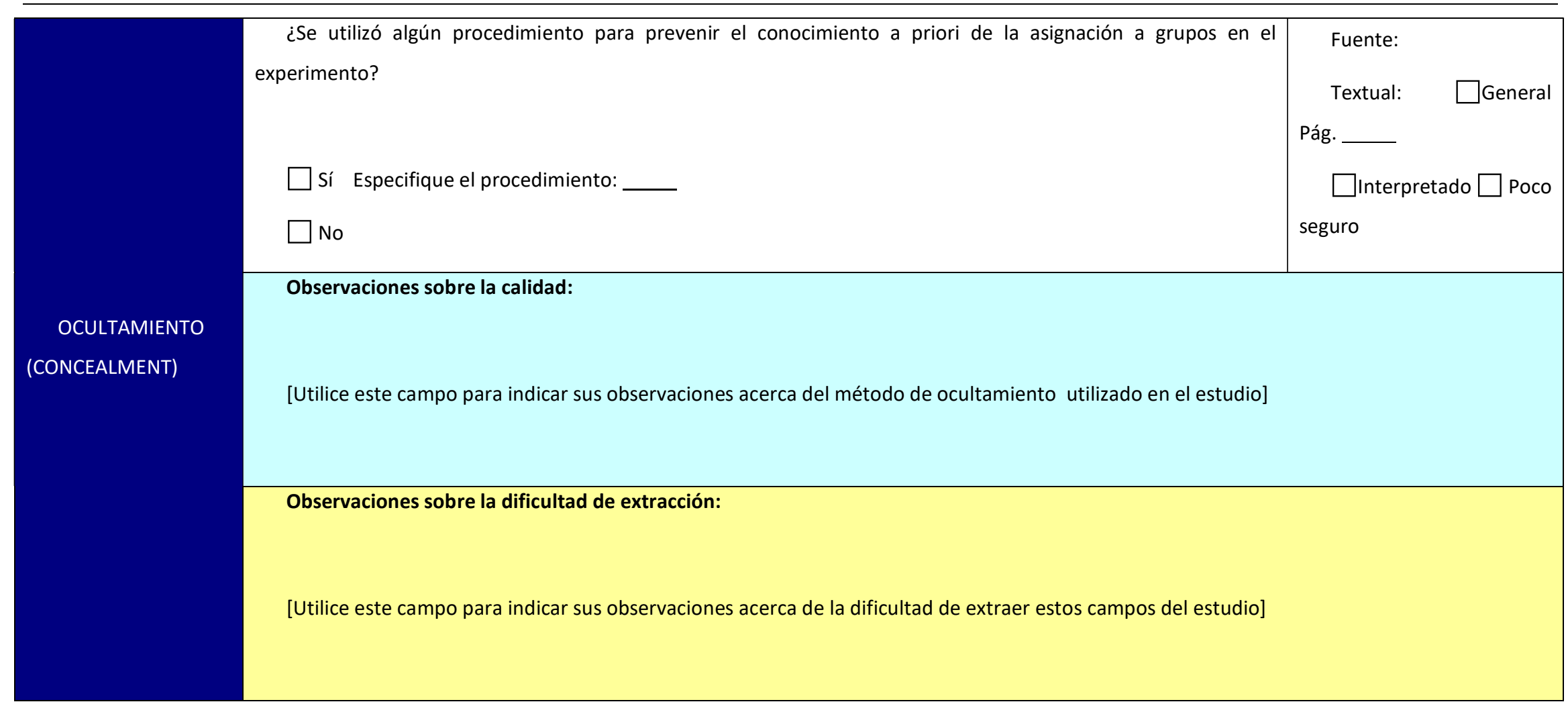




\begin{tabular}{|c|c|c|}
\hline & $\begin{array}{l}\text { [Indique a continuación si se utilizó algún proceso para mantener a los participantes, investigadores, asesores y } \\
\text { demás involucrados, en desconocimiento de las intervenciones a las cuales han sido asignados los participantes en } \\
\text { un estudio.] } \\
\square \text { Sujeto respecto a la tarea } \square \text { Experimentador respecto al sujeto } \square \text { Juez respecto a la unidad experimental } \\
\square \text { Ninguno }\end{array}$ & $\begin{array}{l}\text { Fuente: } \\
\text { Textual: } \square \text { General } \\
\text { Pág. } \square \\
\square \text { Interpretado } \square \text { Poco } \\
\text { seguro }\end{array}$ \\
\hline
\end{tabular}




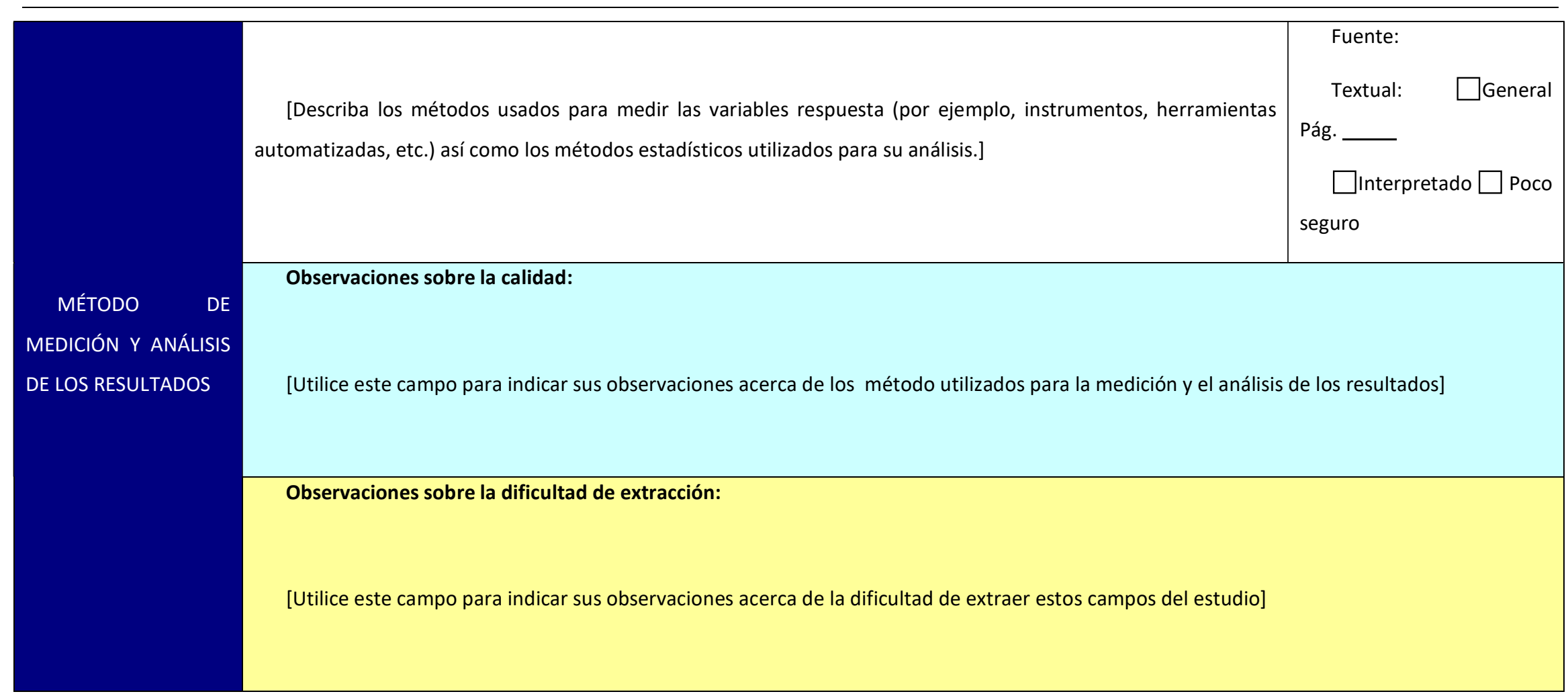




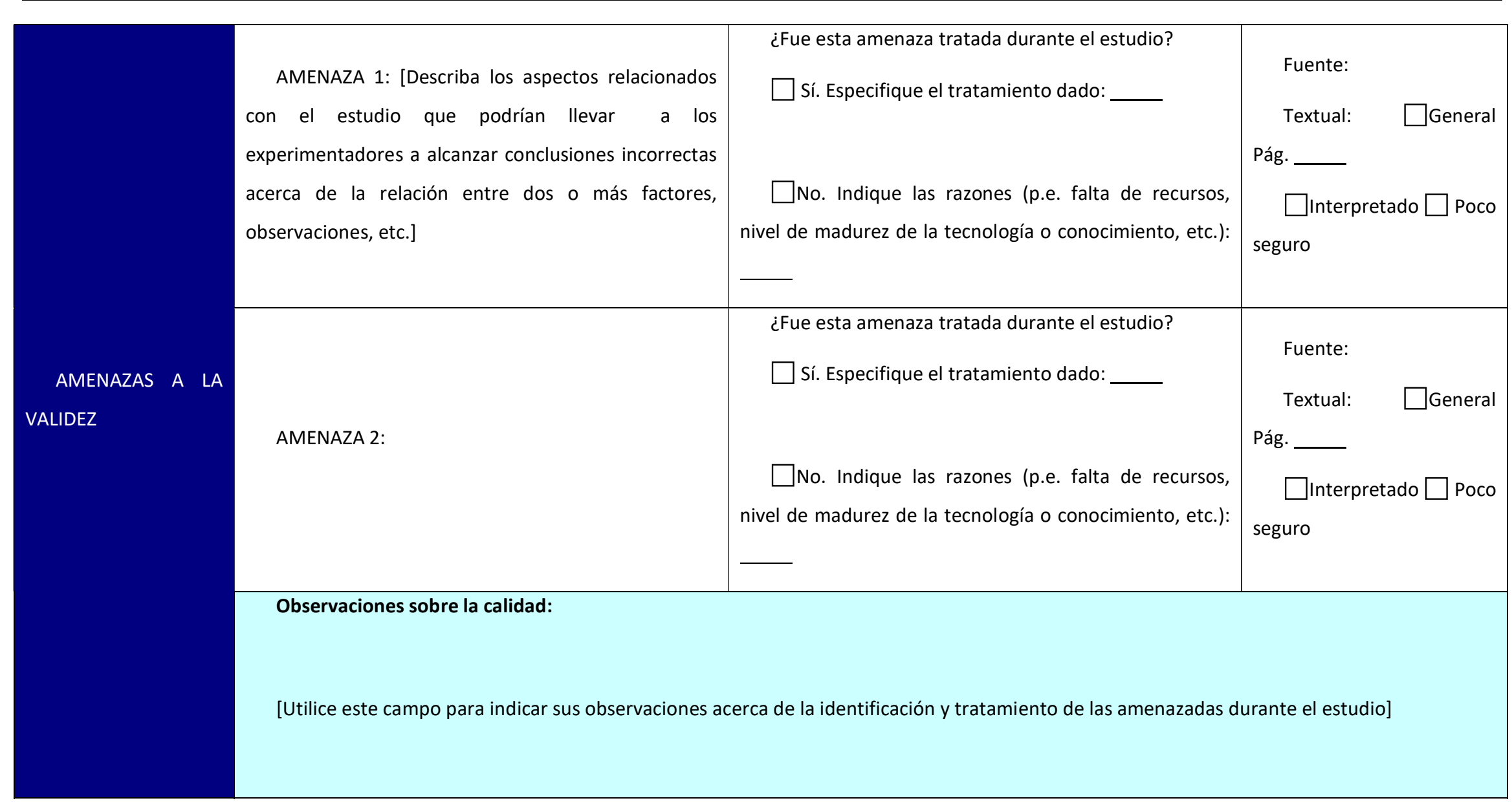




Observaciones sobre la dificultad de extracción:
[Utilice este campo para indicar sus observaciones acerca de la dificultad de extraer estos campos del estudio]

Salidas

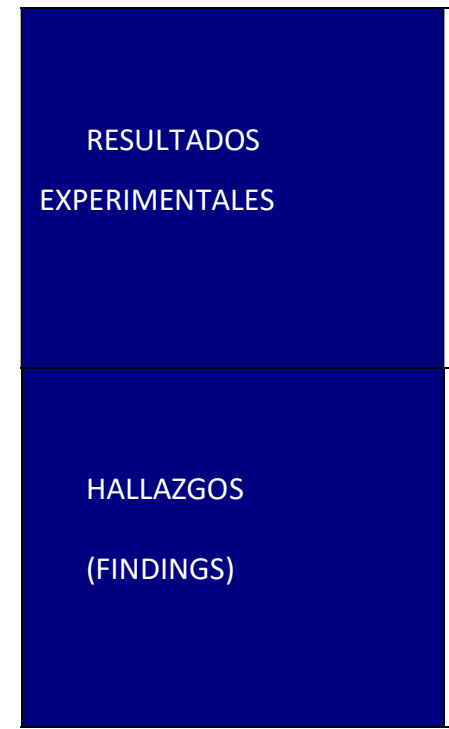

\begin{tabular}{|c|c|}
\hline $\begin{array}{l}\text { [Indique los valores proporcionados por el análisis de los autores acerca de las salidas del experimento; } \\
\text { por ejemplo, medias, varianzas, correlaciones, intervalos de confianza, etc.] }\end{array}$ & $\begin{array}{l}\text { Fuente: } \\
\text { Textual: } \square \text { General } \\
\text { Pág. } \square \\
\square \text { Interpretado } \\
\text { Poco seguro }\end{array}$ \\
\hline
\end{tabular}




\begin{tabular}{|l|l|}
\hline Observaciones sobre la calidad: \\
\hline [Utilice este campo para indicar sus observaciones acerca de los resultados y hallazgos del estudio] \\
\hline Observaciones sobre la dificultad de extracción: \\
\hline [Utilice este campo para indicar sus observaciones acerca de la dificultad de extraer estos campos del estudio] \\
\hline
\end{tabular}

Agregación

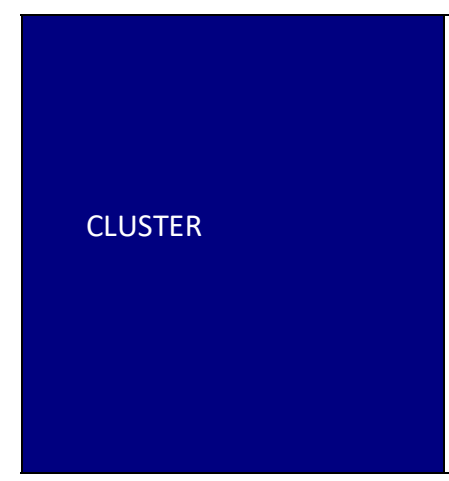

Cluster: / Revisión: [Indique el grupo (cluster) en el que fue utilizado el estudio durante la extracción/ agregación. Indique la revisión en la cual es utilizado]

¿Fue posible asignar fácilmente el estudio con base en la información proporcionada por los autores? $\square$ Sí $\square$ No 


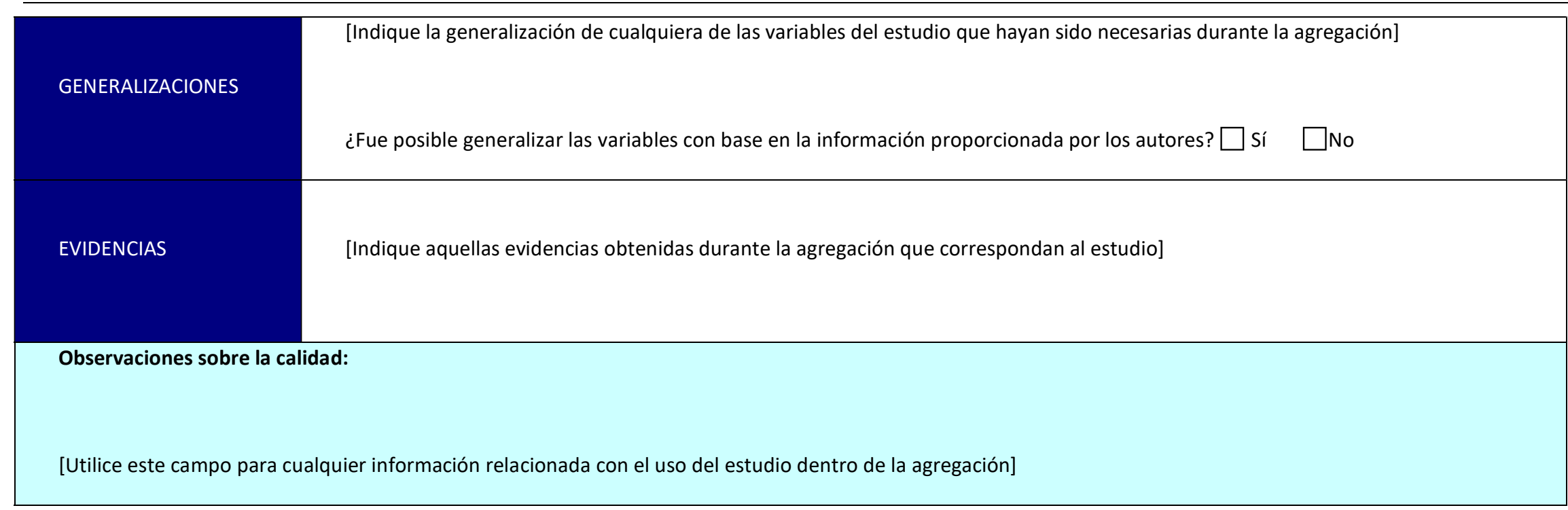

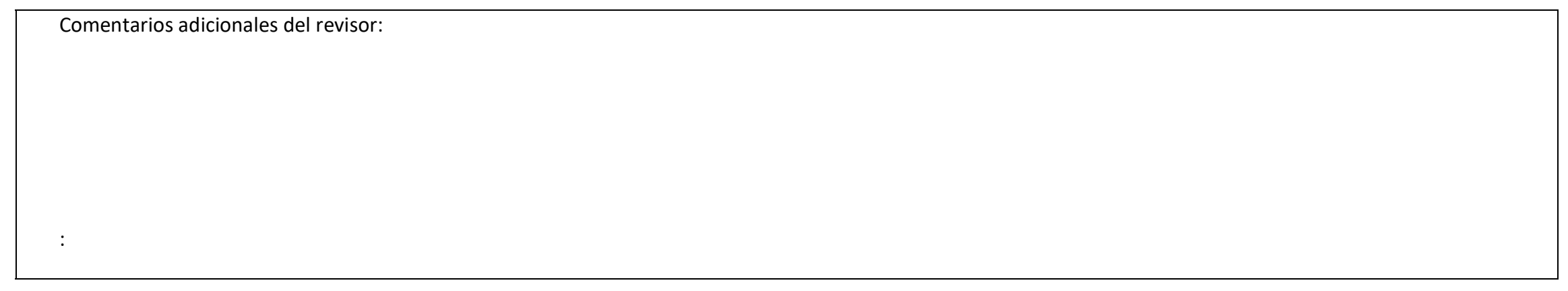




\section{Formulario E02-Conceptos del Experimentos}


E02 -Conceptos del experimento

Propósito:

Estandarizar la terminología utilizada en los estudios, proporcionando un término ampliamente aceptado así como una definición a los conceptos más importantes descritos en el experimento (factor, nivel, variable respuesta y métrica) y las diferentes maneras en que ha sido llamada por los experimentadores.

Instrucciones:

1. Llene cada campo del formulario con la información solicitada. De ser necesario, utilice literatura especializada; por ejemplo, el Standard Glossary of Software Engineering Terminology (IEEE, 1990), el SWEBOK (IEEE, 2004b), el Computing Classification System (Machine, 1998), entre otros.

2. Seleccione el tipo de concepto que está definiendo de acuerdo al rol que éste tiene en el estudio, en la extracción de datos, en la síntesis de datos y utilice la sección correspondiente del formulario: factor, nivel, variable respuesta, métrica.

3. Utilice la sección Otros para describir otros conceptos que a su juicio sean tratados de manera confusa o poco uniforme en los distintos estudios. 
CONCEPTOS del experimento

Realizado por:

Fecha:

I. Factores:

\begin{tabular}{|c|c|c|c|}
\hline FACTOR & DEFINICIÓN & ESTUDIO QUE LO UTILIZAN & NOMBRE UTILIZADO EN EL ESTUDIO \\
\hline & & & \\
\hline & & & \\
\hline
\end{tabular}

II. Niveles:

\begin{tabular}{|c|c|c|c|}
\hline NIVEL & DEFINICIÓN & ESTUDIO QUE LO UTILIZAN & NOMBRE UTILIZADO EN EL ESTUDIO \\
\hline & & & \\
\hline & & & \\
\hline
\end{tabular}

III. Variables respuesta:

\begin{tabular}{|l|l|l|l|}
\hline VARIABLE RESPUESTA & DEFINICIÓN & ESTUDIO QUE LA UTILIZAN & NOMBRE UTILIZADO EN EL ESTUDIO \\
\hline & & \\
\hline
\end{tabular}




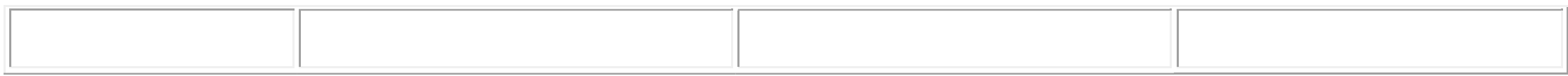

IV. Métricas:

\begin{tabular}{|c|c|c|c|}
\hline MÉTRICA & DEFINICIÓN/FORMULACIÓN & ESTUDIO QUE LA UTILIZAN & NOMBRE UTILIZADO EN EL ESTUDIO \\
\hline & & & \\
\hline & & & \\
\hline & & & \\
\hline
\end{tabular}

IV. Otros:

\begin{tabular}{|l|l|l|l|}
\hline CONCEPTO & DEFINICIÓN/FORMULACIÓN & ESTUDIO QUE LA UTILIZAN & NOMBRE UTILIZADO EN EL ESTUDIO \\
\hline & & & \\
\hline & & & \\
\hline
\end{tabular}




\section{Formulario E03-Cluster de lectura}


E03 - Clusters de lectura

Propósito:

Agrupar estudios compatibles en lo que respecta a la tarea experimental, tipo de sujeto, niveles y variables respuesta.

Instrucciones:

1. Utilice las secciones I a IV de este documento para agrupar los estudios según los siguientes tres criterios: estudios con igual tarea experimental, estudios con igual tipo de sujeto experimental, y estudios que ensayan los mismos niveles y analizan las mismas variables respuesta.

2. Describir por separado aquellos grupos que correspondan a replicaciones de estudios y aquellos que agrupan estudios independientes. En cualquier caso, cada grupo representa una combinación de ciertos niveles del factor de interés y la variable respuesta que es medida en el estudio. Esta variable respuesta representa el concepto u objetivo que se busca medir y se encuentra expresado en el estudio a través de un conjunto de métricas (VR).

3. Utilice la sección $\mathrm{V}$ para representar de manera tabular los clusters de estudios junto con sus tratamientos y variables respuesta. 
Proceso de RS de experimentos en Ingeniería del Software

\begin{tabular}{|l|l|}
\hline CLUSTERS DE LECTURA & Realizado por: \\
\hline & Fecha: \\
\hline
\end{tabular}

I. AGRUPAMIENTO POR TAREA EXPERIMENTAL

\begin{tabular}{|c|c|c|}
\hline $\begin{array}{c}\text { GRUPO } \\
\text { AGREGACIÓN: }\end{array}$ & CANDIDATO \\
\hline FACTOR: & & \\
\hline TAREA & $73 . \quad$ ESTUDIOS & \\
\hline
\end{tabular}

II. AGRUPAMIENTO POR SUJETO EXPERIMENTAL

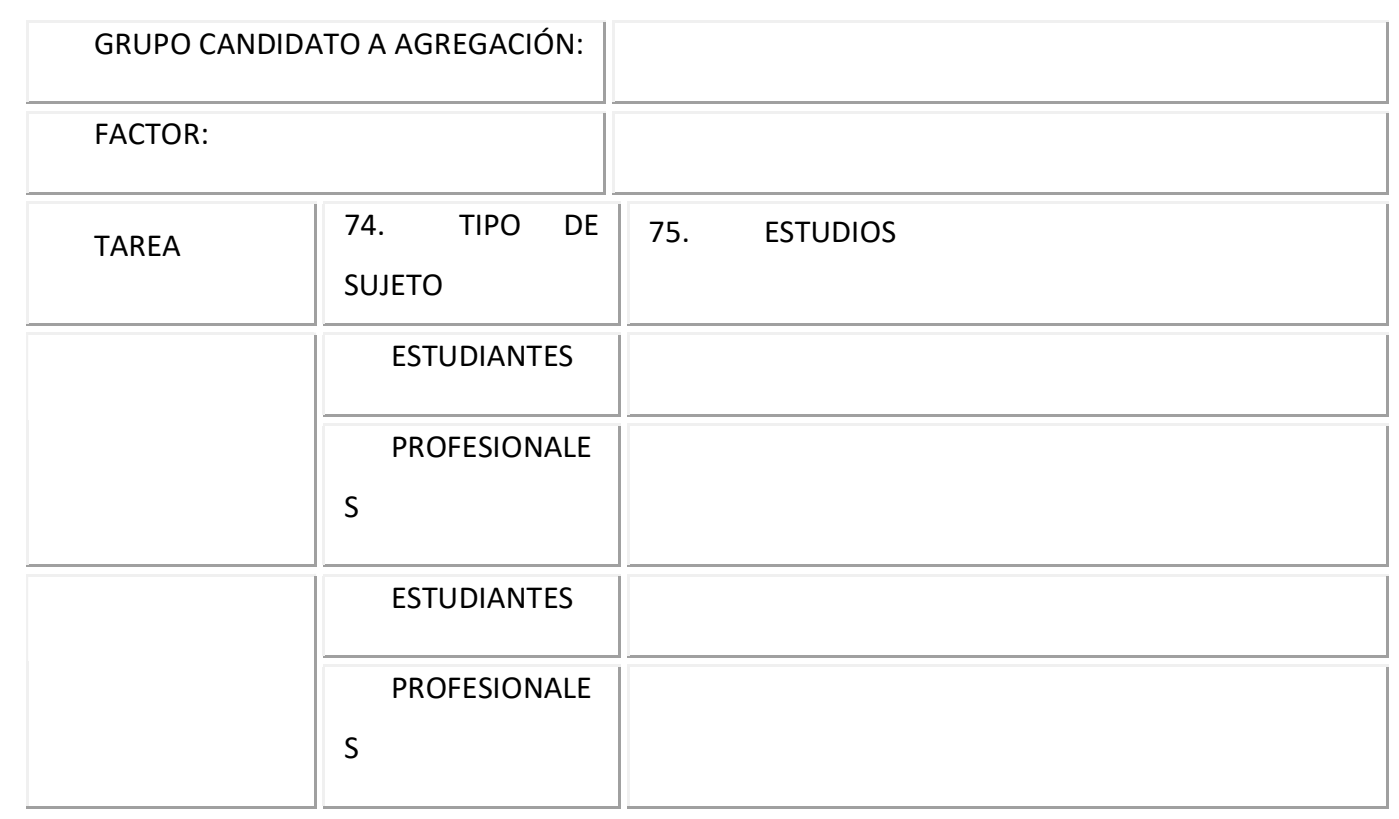

III. AGRUPAMIENTO POR NIVELES Y VARIABLE RESPUESTA - REPLICACIONES 


\begin{tabular}{|r|l|l|l|l|l|}
$\begin{array}{l}\text { GRUPO CANDIDATO } \\
\text { AGREGACIÓN: }\end{array}$ & \\
\hline FACTOR: & REPLICACIONES & NIVELES & VARIABLE & MÉTRICA \\
\hline TIPO DE SUJETO EXPERIMENTAL & & & RESPUESTA & \\
\hline TAREA EXPERIMENTAL & & & & \\
\hline GRUPO & ESTUDIO & & & \\
\hline
\end{tabular}

IV. AGRUPAMIENTO POR NIVELES Y VR - ESTUDIOS INDEPENDIENTES

\begin{tabular}{|c|c|c|c|c|}
\hline \multicolumn{5}{|c|}{ AGREGACIÓN: } \\
\hline \multicolumn{5}{|c|}{ FACTOR: } \\
\hline \multicolumn{5}{|c|}{ TIPO DE SUJETO EXPERIMENTAL } \\
\hline \multicolumn{5}{|c|}{ TAREA EXPERIMENTAL } \\
\hline GRUPO & NIVELES & $\begin{array}{l}\text { VARIABLE } \\
\text { RESPUESTA }\end{array}$ & MÉTRICA & ARTÍCULOS \\
\hline
\end{tabular}

V. REPRESENTACIÓN TABULAR DE LOS CLUSTERS

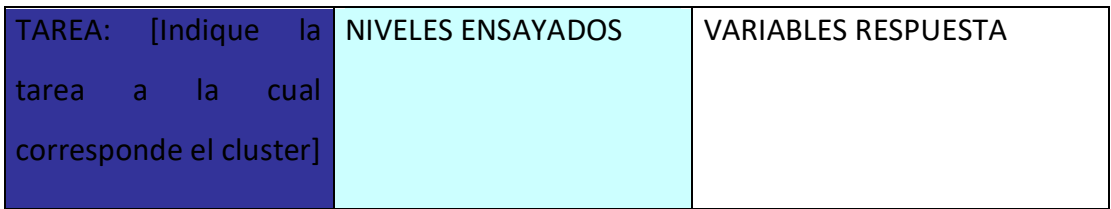


Proceso de RS de experimentos en Ingeniería del Software

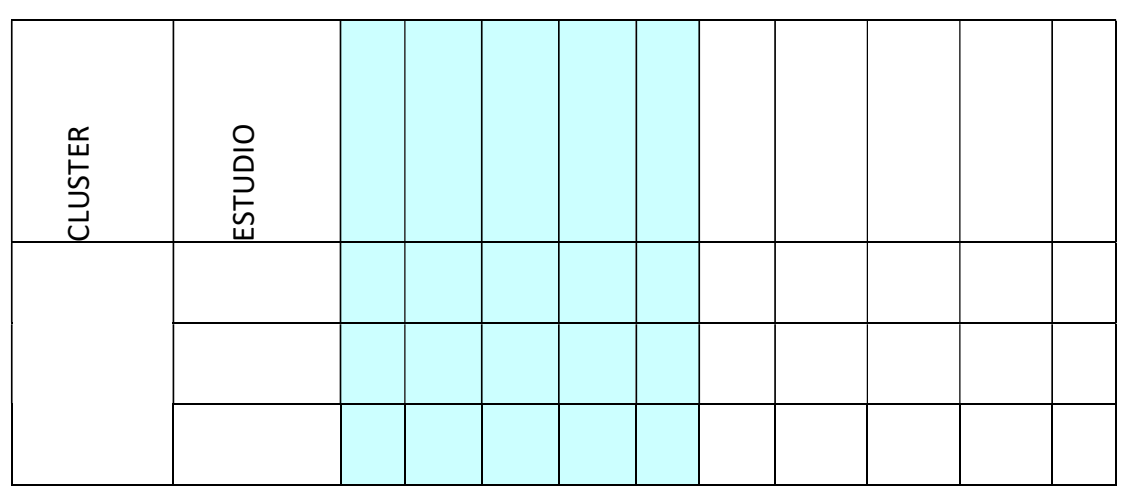


Formulario E04-Resumen de Datos Cuantitativos 
E04 - Resumen de datos cuantitativos

Propósito:

Presentar de manera breve la información necesaria para agregar cada estudio durante la fase de SínTESIS DE DATOS, a través de un método paramétrico de meta-análisis.

Instrucciones:

1. Por cada estudio indique la siguiente información:

a. La media, varianza y número de sujetos experimentales, por cada métrica y tratamiento ensayado.

b. Cuando en algún estudio se haya ensayado un factor adicional (por ejemplo, el Rol, la Especificación, etc.) los resultados se proporcionarán de dos maneras:

- El valor promedio por cada tratamiento, $y$

- El valor correspondiente al tratamiento separado en los diferentes niveles del factor adicional.

Por ejemplo, en la tabla 16 se muestra un resumen de datos donde se observa que el estudio E01 ha ensayado el factor adicional Especificación con dos niveles (WLMS y CRUISE). Por lo tanto, los resultados de E01 han sido presentados tanto con un valor promedio como con los valores correspondientes a cada nivel del factor Especificación. Otros casos de factores adicionales que han sido ensayados, se encuentran en E04 y E08, los cuales han estudiados los factores Ronda y Rol, respectivamente. En tales casos se ha procedido de la misma manera.

2. Los resultados expresados de manera textual. Para ello utilizar, por ejemplo, la siguiente nomenclatura:

a. A>B, indica que el tratamiento $A$ es mejor que el tratamiento $B$, independientemente de la métrica (esto significa que si la métrica es Coste, $A>B$ quiere decir que $A$ es más costo-efectiva que B).

b. $A<B$, indica que el tratamiento $B$ es mejor para una métrica determinada que el tratamiento $\mathrm{A}$.

c. $A=B$, indica que para una métrica específica los tratamientos $A$ y $B$ se comportaron de la misma manera.

Caso de estudio 
d. n.s. (no significativo), indica que los resultados presentados para una determinada métrica no alcanzaron significancia estadística en las pruebas realizadas en el estudio. Por lo tanto, M1/A>B n.s., indicará que el tratamiento A obtuvo un mejor resultado que el tratamiento $B$ para la métrica 1 pero esto no puede ser afirmado con un $90 / 95 \%$ de confianza.

3. Cualquier observación que pueda ser relevante para la agregación. 
Proceso de RS de experimentos en Ingeniería del Software

RESUMEN DE DATOS CUANTITATIVOS

Realizado por:

Fecha:

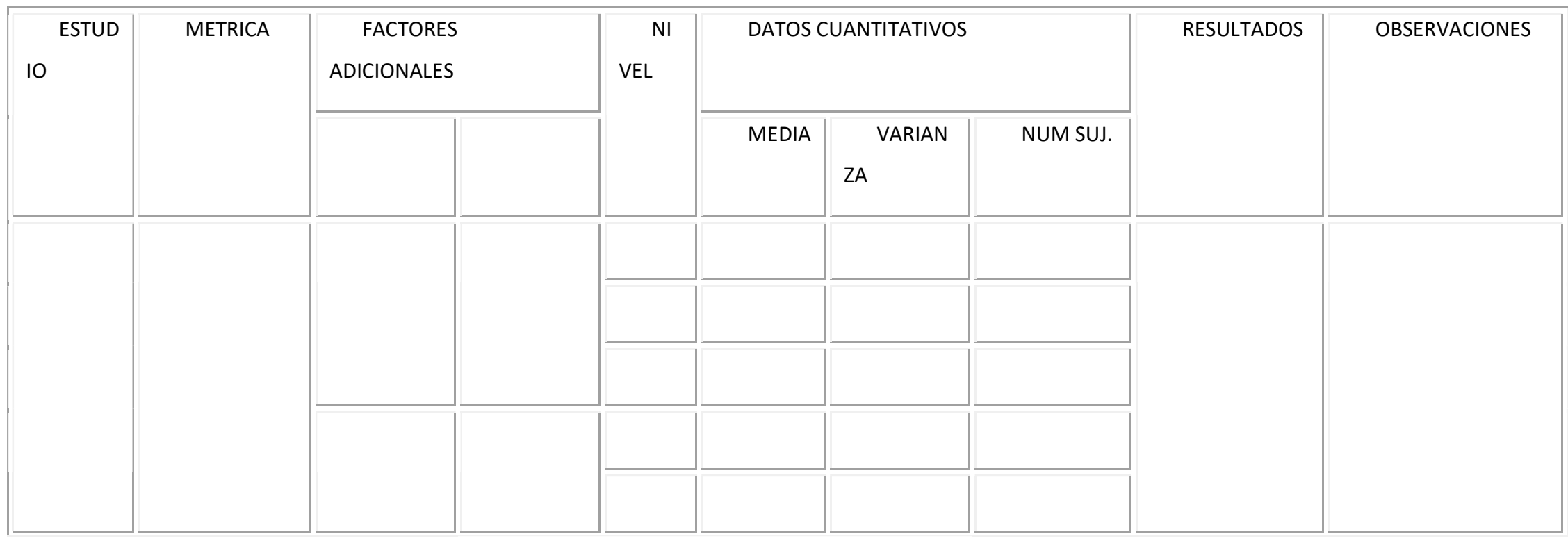

Caso de estudio 


\begin{tabular}{|l|l|l|l|l|l|l|}
\hline & & & & & & \\
\hline
\end{tabular}


Formulario E05-Resumen de contexto experimental 
E05 - Resumen de contexto experimental

Propósito:

Recoger un conjunto mínimo de datos relacionados con el entorno en el cual ha sido conducido el experimento, a fin de proporcionar información básica acerca de la diversidad de los estudios incluidos en un cluster.

Instrucciones:

1. Para cada estudio indicar:

a. Ambiente: se refiere al entorno en el cual ha sido conducido el experimento, laboratorio o industria. Esta característica generalmente está asociada al tipo de sujeto (estudiante, profesional) y su experiencia, por lo que puede suponerse que esta característica tenga una incidencia directa sobre las evidencias obtenidas.

b. Proceso experimental: se refiere a la tarea realizada durante el experimento y los objetos utilizados. Agrupar los estudios según esta característica permitirá obtener evidencias relacionadas con una etapa particular del proceso de desarrollo. Tales evidencias pueden luego ser generalizadas para un conjunto de etapas.

2. En algunos casos podría ser de interés conocer los objetos que han sido utilizados por los sujetos durante la aplicación de la tarea experimental.

3. Utilice la columna Observaciones para indicar que un estudio pertenece a algún grupo de replicaciones. 
Proceso de RS de experimentos en Ingeniería del Software

\begin{tabular}{|l|l|}
\hline RESUMEN DE CONTEXTO EXPERIMENTAL & Realizado por: \\
\hline & Fecha: \\
\hline
\end{tabular}

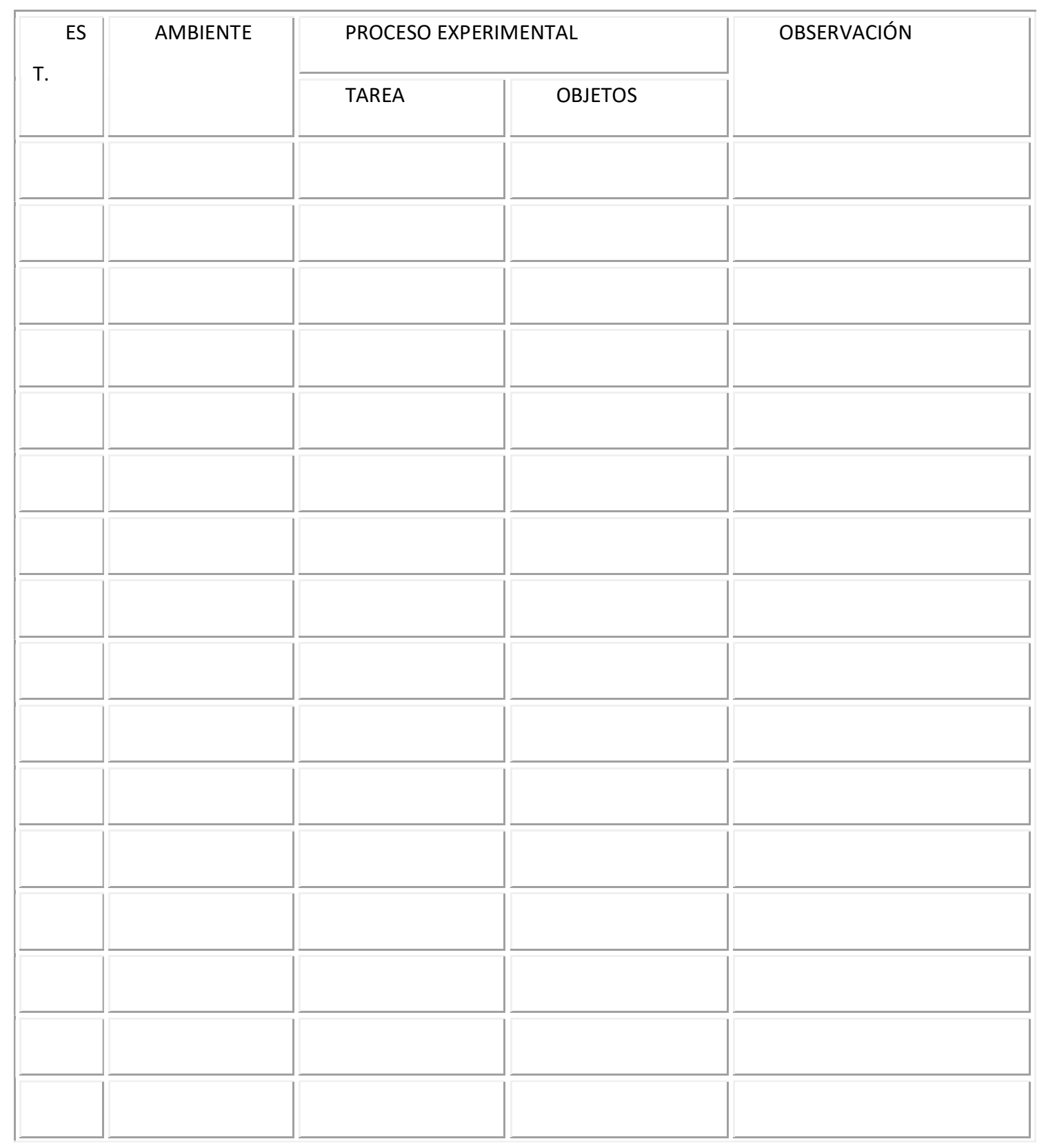

Caso de estudio 
Software

\begin{tabular}{|l|l|l|l|l|l|}
\hline & & & & \\
\hline & & & & \\
\hline & & & & \\
\hline & & & & & \\
\hline & & & & & \\
\hline & & & & & \\
\hline & & & & & \\
\hline
\end{tabular}




\section{Formulario E06-Resumen de Resultados Experimentales y Observacionales}




\section{E06 - Resumen de resultados experimentales y observacionales}

Propósito:

Recoger la información relativa a los resultados obtenidos durante la conducción del experimento, tanto para las métricas que han sido definidas en las hipótesis experimentales (experimentales) como para aquellas que sean producto del análisis o procesamiento de las mismas (observacionales).

Instrucciones:

1. Para cada estudio indicar los niveles ensayados y las métricas analizadas, junto con los resultados obtenidos expresándolos de manera textual. Para ello utilizar, por ejemplo, la siguiente nomenclatura:

a. $A>B$, indica que el tratamiento $A$ es mejor que el tratamiento $B$, independientemente de la métrica (esto significa que si la métrica es Coste, A>B quiere decir que A es más costoefectiva que B).

b. $A<B$, indica que el tratamiento $B$ es mejor para una métrica determinada que el tratamiento $\mathrm{A}$.

c. $A=B$, indica que para una métrica específica los tratamientos $A$ y $B$ se comportaron de la misma manera.

d. n.s. (no significativo), indica que los resultados presentados para una determinada métrica no alcanzaron significancia estadística en las pruebas realizadas en el estudio. Por lo tanto, M1/A>B n.s., indicará que el tratamiento $A$ obtuvo un mejor resultado que el tratamiento B para la métrica 1 pero esto no puede ser afirmado con un $90 / 95 \%$ de confianza. 
Proceso de RS de experimentos en Ingeniería del Software

\section{RESUMEN DE RESULTADOS EXPERIMENTALES Y OBSERVACIONALES}

Realizado por:

Fecha:

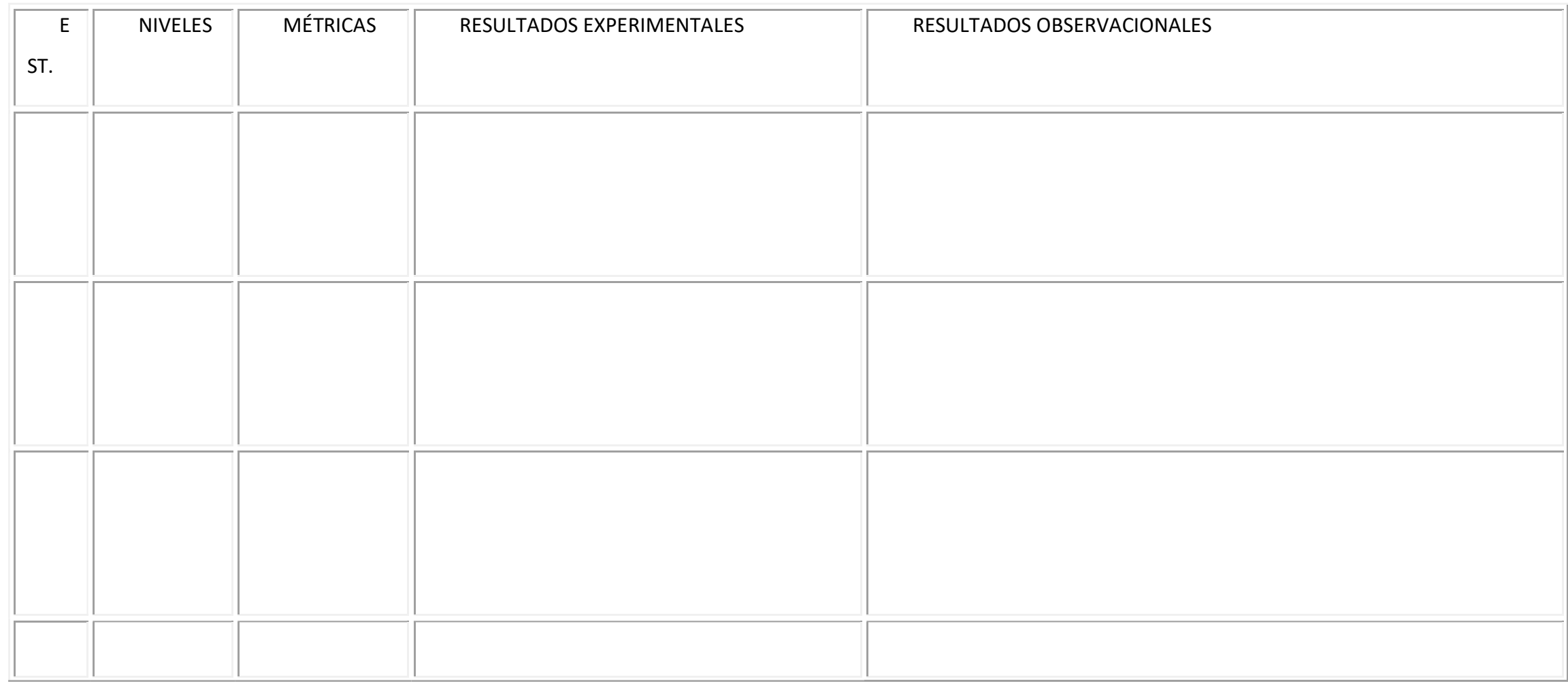

Caso de estudio 


\begin{tabular}{|l|l|l|l|l|l|}
\hline \hline & & & & \\
\hline & & & & & \\
\hline & & & & & \\
\hline & & & & & \\
\hline
\end{tabular}


Formulario E07- Estudios por métrica 


\section{E07 -Estudios por métrica}

Propósito:

Presentar de manera resumida la distribución de estudios por métrica y variable respuesta, a fin de identificar: aquellas métricas más frecuentemente analizadas en los distintos estudios, las métricas que cuentan con más estudios potencialmente agregables.

Instrucciones:

1. Para cada variable respuesta identificada en los clusters, indicar las métricas relacionadas y los estudios que han ensayado tales métricas.

2. En caso de existir confusión sobre alguna métrica, utilizar el formulario E02_Descripción y Agrupamiento de conceptos.

3. Este análisis puede hacerse tanto para las métricas experimentales como para las observacionales, aunque no necesariamente estas últimas serán incluidas en la agregación.

4. Utilizar la columna de Observaciones para indicar cualquier información que pueda ser útil en el momento de la agregación. 
ANÁLISIS DE DENSIDAD DE ESTUDIOS POR MÉTRICA

Realizado por:

Fecha:

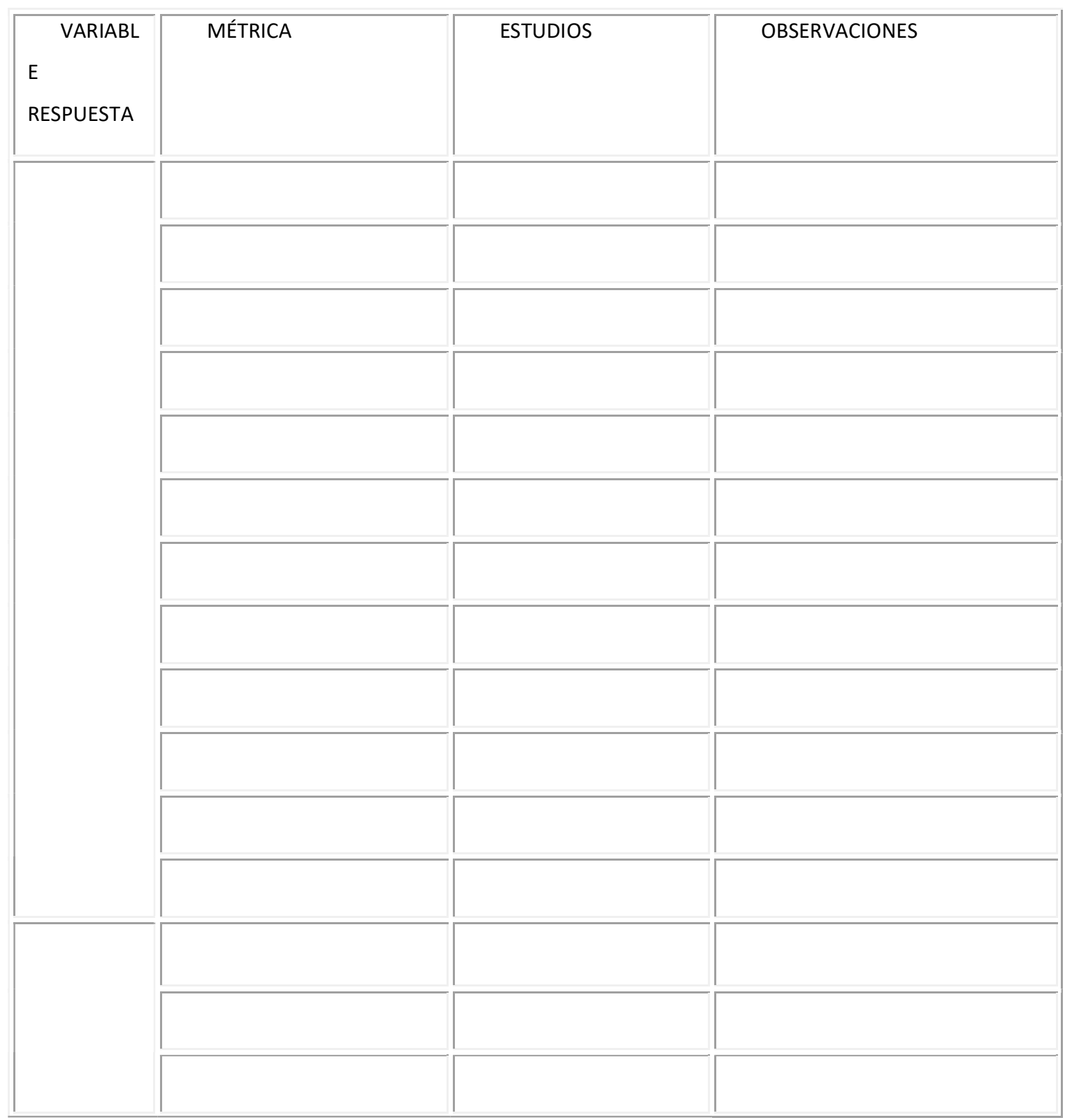

Caso de estudio 


\begin{tabular}{|l|l|l|l|l|}
\hline & & & & \\
\hline & & & & \\
\hline & & & & \\
\hline
\end{tabular}




\section{Formulario E08-Estudios por métrica y Contexto}




\section{E08 -Estudios por métrica y contexto}

Propósito:

Presentar de manera resumida y tabular los estudios que han ensayado cada combinación de niveles y métricas, a fin de identificar grupos potencialmente agregables según un criterio de máxima compatibilidad.

Instrucciones:

1. Puede utilizar como base para este análisis los grupos identificados en el formulario E07_Análisis de densidad de estudios por métrica, así como los clusters identificados en la actividad Lectura en profundidad.

2. Utilice una tabla para cada métrica identificada previamente

3. Señale en la tabla la tarea experimental a la que corresponden los estudios incluidos, la variable repuesta asociada a la métrica analizada, y la métrica.

4. Localice la celda que corresponde a intersección de los dos niveles ensayados en el estudio; por ejemplo, si el estudio ensaya las técnicas T01 y T03 deberá localizar la intersección de la fila T01 y la columna T03.

5. En la celda de intersección de los dos niveles indique el estudio en cuestión.

6. Si un estudio compara más de dos niveles deberá indicarlo en cada combinación de dos niveles posible. Por ejemplo, si un estudio ensaya las técnicas T01, T02 y T03, deberá indicar el estudio en las celdas T01/T02, T01/T03 y T02/T03.

7. Para facilitar la visualización, puede resaltar aquellas celdas donde se localice el número mínimo de estudios considerado como potencial para la agregación; por ejemplo, las celdas donde se localicen dos o más estudios. 
Proceso de RS de experimentos en Ingeniería del Software

\begin{tabular}{ll|l|}
\hline $\begin{array}{l}\text { ANÁLISIS DE DENSIDAD DE ESTUDIOS POR MÉTRICA Y } \\
\text { CONTEXTO }\end{array}$ & Realizado por: \\
\cline { 2 - 2 } & Fecha: \\
\hline
\end{tabular}

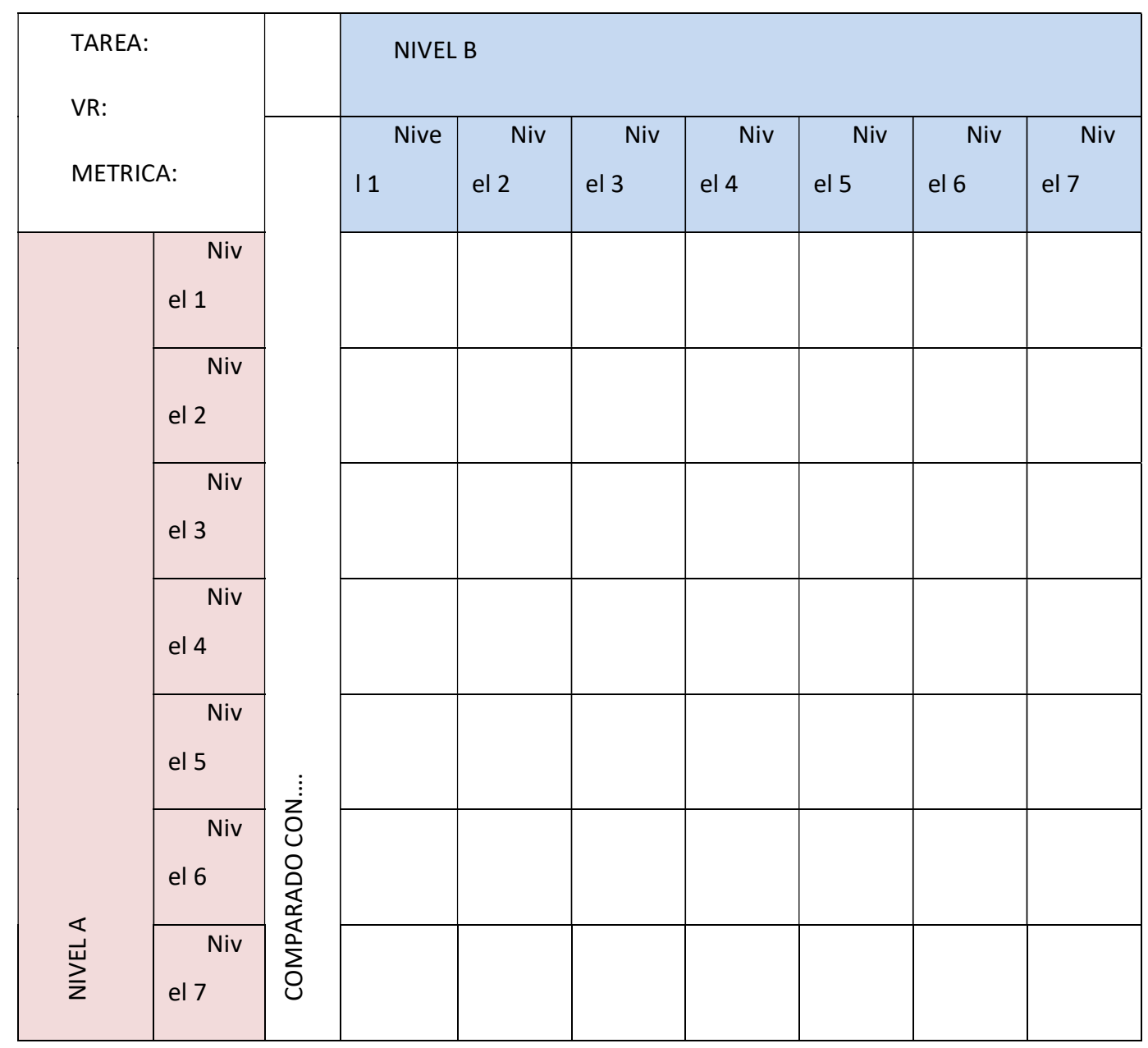

\begin{tabular}{|c|c|c|c|c|c|c|c|c|}
\hline TAREA: & & \multicolumn{7}{|c|}{ NIVEL B } \\
\hline METRICA: & 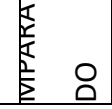 & Nive & Niv & Niv & Niv & Niv & Niv & Niv \\
\hline
\end{tabular}

Caso de estudio 


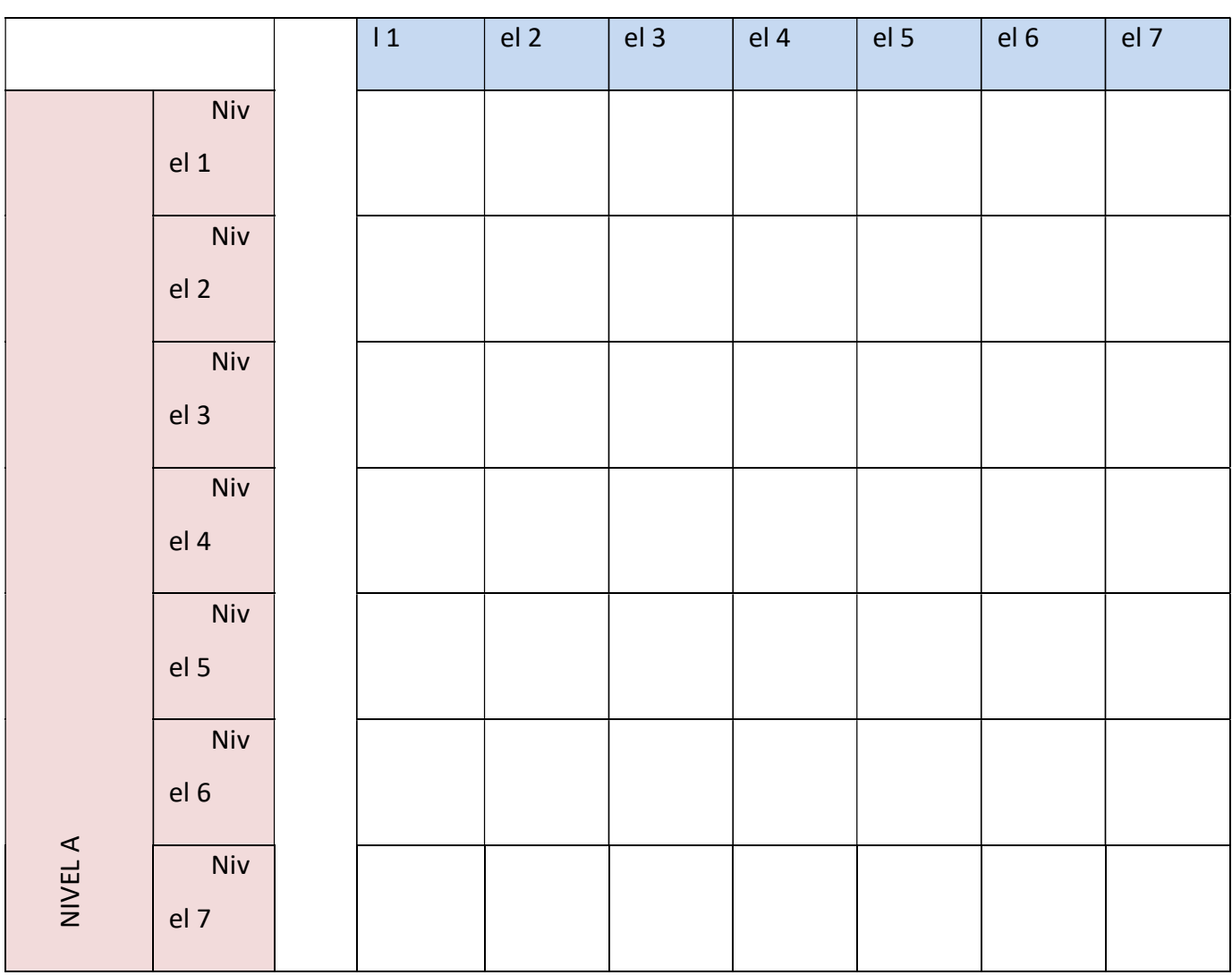

\begin{tabular}{|c|c|c|c|c|c|c|c|c|c|}
\hline \multirow{2}{*}{\multicolumn{2}{|c|}{$\begin{array}{l}\text { TAREA: } \\
\text { VR: } \\
\text { METRICA: }\end{array}$}} & & \multicolumn{7}{|c|}{ NIVEL B } \\
\hline & & \multirow{6}{*}{ 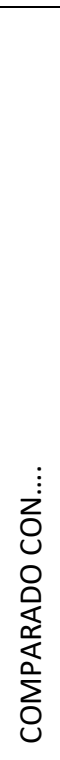 } & | $1^{\text {Nive }}$ & $\begin{array}{l}\text { Niv } \\
\text { el } 2\end{array}$ & $\begin{array}{l}\text { Niv } \\
\text { el } 3\end{array}$ & $\begin{array}{l}\text { Niv } \\
\text { el } 4\end{array}$ & el 5 Niv & $\begin{array}{l}\text { Niv } \\
\text { el } 6\end{array}$ & $\begin{array}{l}\text { Niv } \\
\text { el } 7\end{array}$ \\
\hline \multirow{5}{*}{$\sum_{\bar{z}}^{\overleftarrow{L}}$} & $\begin{array}{l}\text { Niv } \\
\text { el } 1\end{array}$ & & & & & & & & \\
\hline & $\begin{array}{l}\text { Niv } \\
\text { el } 2\end{array}$ & & & & & & & & \\
\hline & $\begin{array}{l}\text { Niv } \\
\text { el } 3\end{array}$ & & & & & & & & \\
\hline & $\begin{array}{l}\text { Niv } \\
\text { el } 4\end{array}$ & & & & & & & & \\
\hline & Niv & & & & & & & & \\
\hline
\end{tabular}


Proceso de RS de experimentos en Ingeniería del Software

\begin{tabular}{|c|}
\hline el 5 \\
\hline $\begin{array}{l}\text { Niv } \\
\text { el } 6\end{array}$ \\
\hline $\begin{array}{l}\text { Niv } \\
\text { el } 7\end{array}$ \\
\hline
\end{tabular}




\section{Formulario E09-Resumen de Grupos PotencialmenTe Agregables}




\section{E09 - Resumen de grupos potencialmente agregables}

Propósito:

Registrar los grupos de estudios muy compatibles según el criterio de agregación utilizado en esta propuesta. Tales grupos incluirán estudios que que comparten la misma tarea, métrica, y comparan los mismos tratamientos.

Instrucciones:

1. En el análisis de densidad de estudios por métrica y contexto, localizar aquellas celdas donde aparezca un número determinado de estudios. Este número de estudios deberá ser definido previamente por los revisores y corresponde al número mínimo de estudios que se consideran necesarios para obtener una evidencia válida durante la agregación.

2. A menos que los revisores decidan lo contrario, incluir solamente las métricas de tipo experimental (aquellas que han sido definidas en el diseño del estudio y establecidas en las hipótesis experimentales).

3. Descartar métricas donde, aún contándose con el número mínimo de estudios requeridos, la mayoría de los estudios no proporcione información cuantitativa o narrativa acerca de los resultados obtenidos para la métrica en cuestión. Utilizar el Resumen de datos cuantitativos y el Resumen de datos experimentales y observacionales, para validar esta condición.

Caso de estudio 


\begin{tabular}{ll|l|l|}
\hline $\begin{array}{l}\text { ANÁLISIS DE DENSIDAD DE ESTUDIOS POR MÉTRICA Y } \\
\text { CONTEXTO }\end{array}$ & Realizado por: \\
\hline
\end{tabular}

\begin{tabular}{|c|c|c|c|c|c|}
\hline \multirow{2}{*}{$D^{\prime}$} & \multirow{2}{*}{ Métrica / NIVELES } & \multicolumn{2}{|l|}{ Estudios } & \multirow{2}{*}{ Tarea } & \multirow{2}{*}{ Observación } \\
\hline & & Laboratorio & Industria & & \\
\hline & & & & & \\
\hline & & & & & \\
\hline & & & & & \\
\hline & & & & & \\
\hline & & & & & \\
\hline & & & & & \\
\hline & & & & & \\
\hline & & & & & \\
\hline & & & & & \\
\hline & & & & & \\
\hline
\end{tabular}




\section{APÉNDICE D - FORMULARIOS DE LA FASE DE SÍNTESIS DE DATOS}




\section{Formulario S01 - Plantilla de agregación}




\section{S01 - PLANTILLA DE AGREGACIÓN}

Propósito:

Registrar los datos cuantitativos relacionados con el factor principal y los factores adicionales que son ensayados en un GPA o en un sub-grupo de éste. Así mismo, registra los resultados de la agregación, la interpretación de la evidencia y las condiciones para las cuales ésta ha sido obtenida.

Instrucciones:

1. Llene la sección 1 de la plantilla utilizando para ello el formulario E04-Resumen de datos cuantitativos. Indique claramente la presencia de factores adicionales al factor principal.

En la sección 2, represente de manera gráfica el resultado de la agregación tal como se indica en el Apéndice G.2.

Llene la sección 3 indicando el valor de los parámetros Q e $\mathrm{I}^{2}$, utilizando para ello las siguiente ecuaciones:

\begin{tabular}{|l|l|}
\hline $\mathrm{Q}=\sum_{\mathrm{i}=1}^{\mathrm{k}} \mathrm{W}_{\mathrm{i}}(\mathrm{ES}-\overline{\mathrm{ES}})^{2}$ & $\begin{array}{l}\mathrm{I}^{2}=[(\mathrm{Q}-d f) / \mathrm{Q}] \times 100 \% \\
\text { donde } d f \text { representa los grados de } \\
\text { libertad } \mathrm{y} d \mathrm{ff}=\text { Num de estudios }-1\end{array}$ \\
\hline
\end{tabular}

Indique en la sección 4 la interpretación del efecto obtenido en la agregación.

Llene la sección 5 indicando el tamaño del efecto según el valor arrojado por la técnica de meta-análisis.

Describa en la sección 6 las condiciones para las cuales se está generando la evidencia.

Describa la evidencia de manera textual en la sección 7. 
ORIGEN: -

METRICA:

TECNICAS:

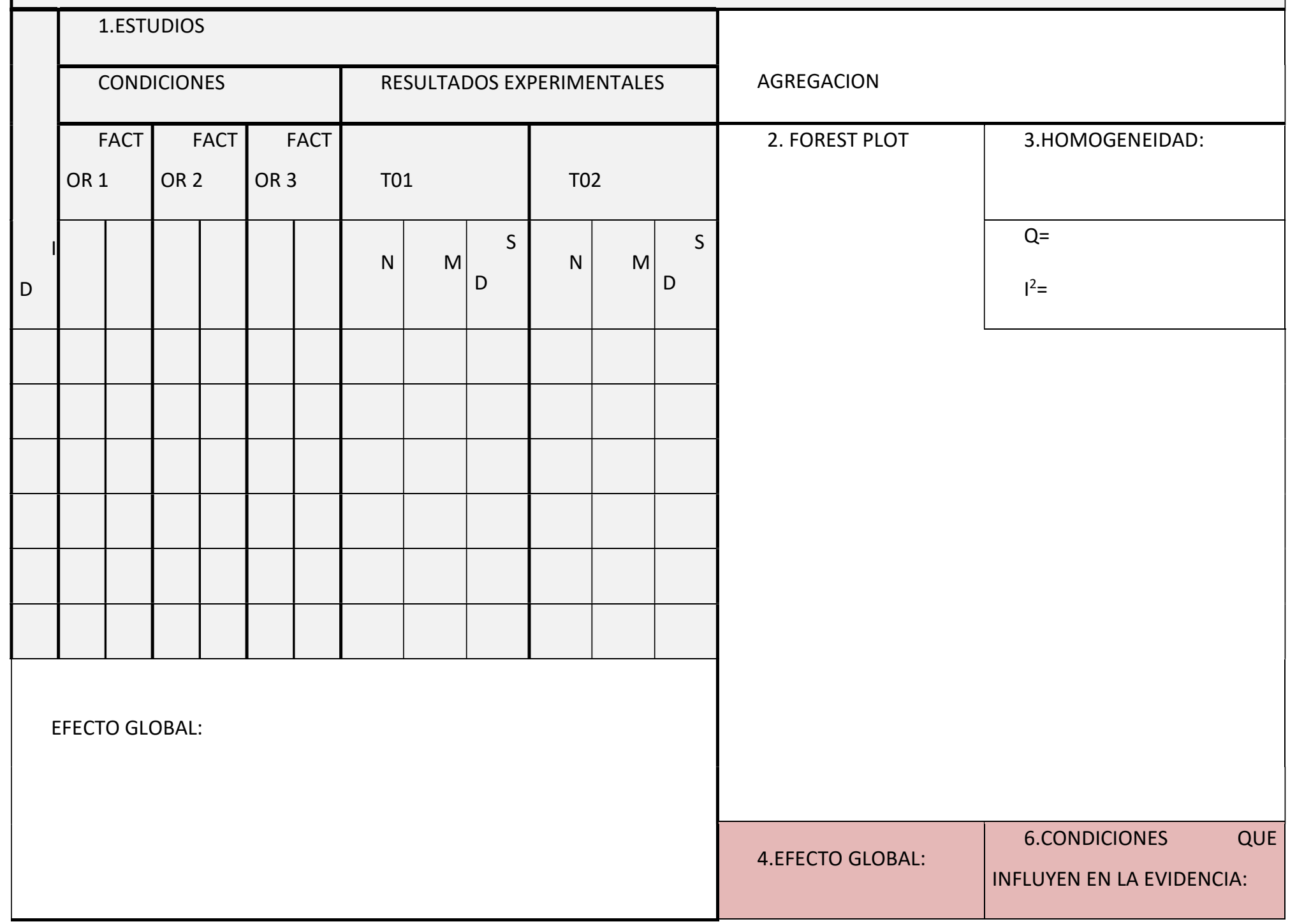




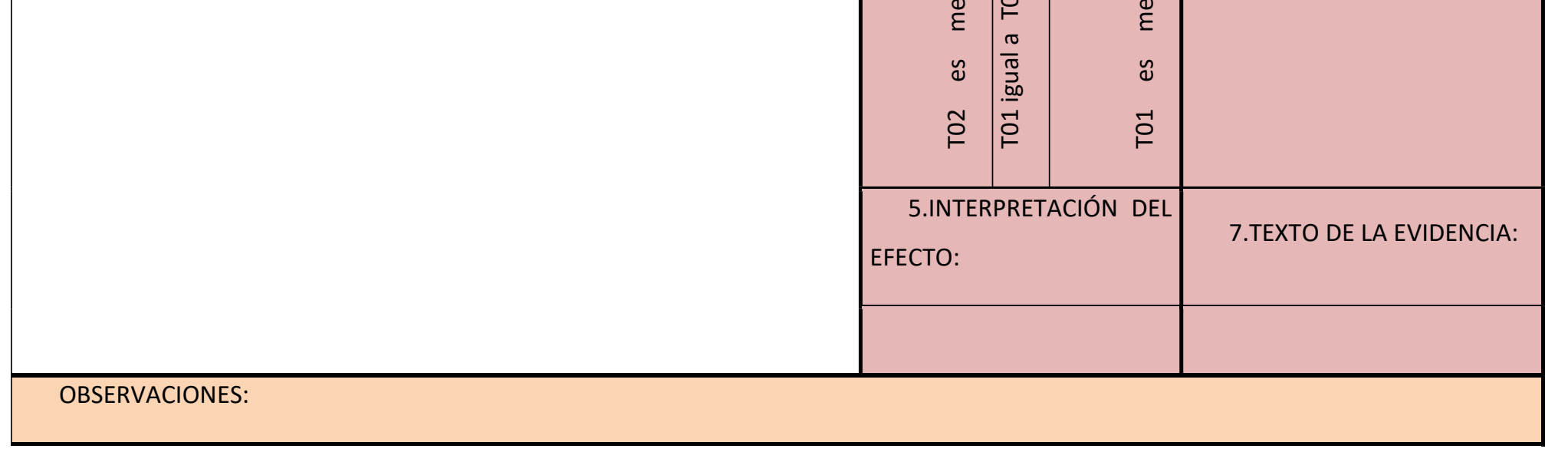




\section{Representación gráfica de cada técnica}




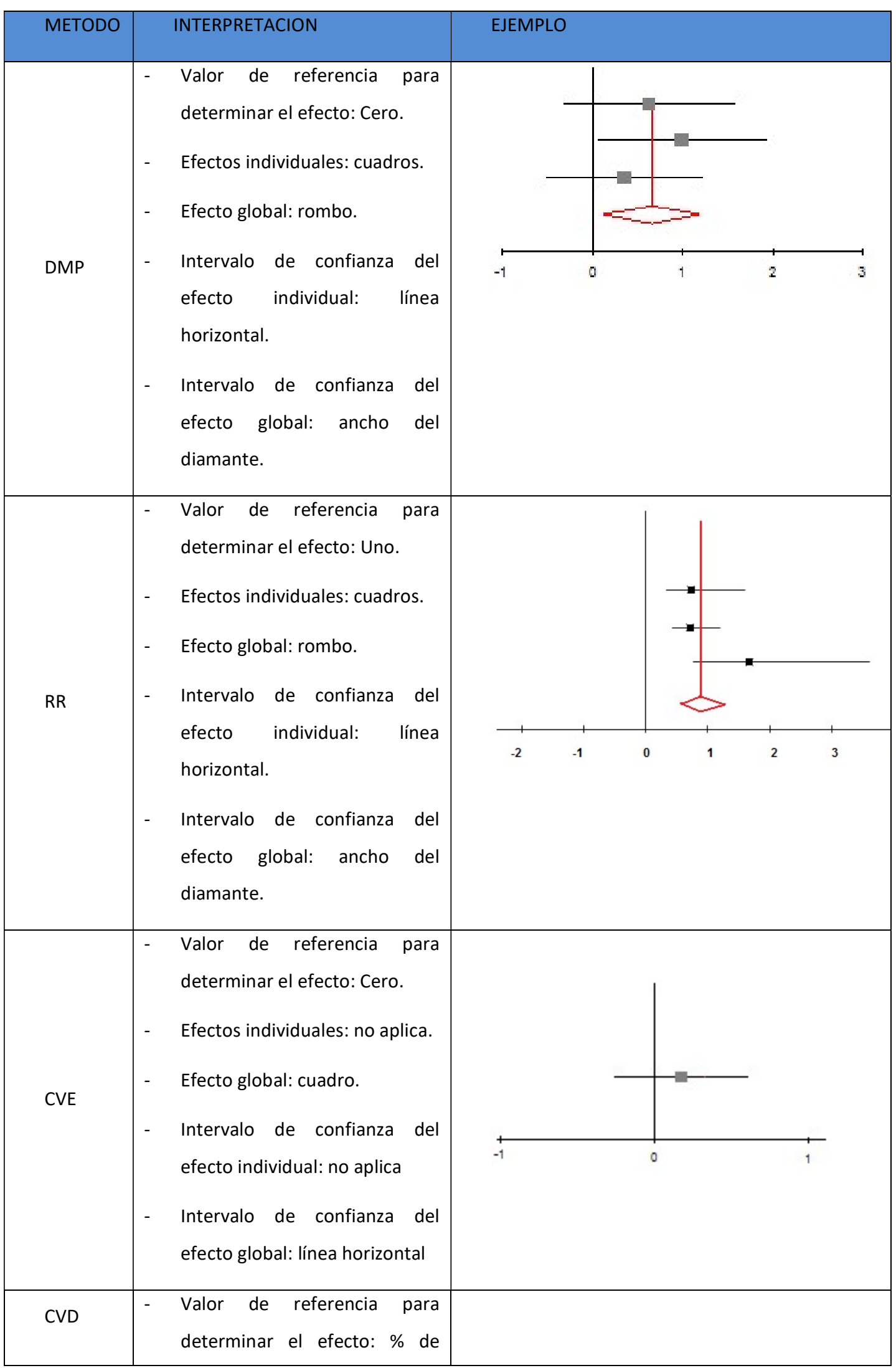


Proceso de RS de experimentos en Ingeniería del Software

\begin{tabular}{|l|l|l|}
\hline & votos a favor establecido. \\
& Efectos individuales: voto \\
positivo c/evidencia (++), voto & \\
positivo s/evidencia (+), voto & \\
nulo (0), voto negativo \\
c/evidencia (--), voto negativo \\
s/efecto (-). \\
Efecto global: \% de votos a \\
favor. \\
Intervalo de confianza del \\
efecto individual: no aplica \\
Intervalo de confianza del \\
efecto global: no aplica
\end{tabular}


Formulario S02 - Listado de evidencias 
Proceso de RS de experimentos en Ingeniería del Software

SO2 - LISTADO DE EVIDENCIAS

Propósito:

Instrucciones:

Caso de estudio 
Extracción de Datos

Proceso de RS de experimentos en Ingeniería del

Software

\begin{tabular}{|c|c|c|c|}
\hline \multicolumn{2}{|c|}{ LISTADO DE EVIDENCIAS } & \multicolumn{2}{|c|}{ Realizado por: } \\
\hline & \multirow[b]{2}{*}{ Evidencia } & \multicolumn{2}{|c|}{ Fecha: } \\
\hline $\begin{array}{l}\text { ID } \\
{ }^{E v}\end{array}$ & & \begin{tabular}{l}
\multicolumn{2}{c}{ Gru } \\
po del \\
que se \\
obtiene
\end{tabular} & $\begin{array}{l}\text { Nivel } \\
\text { de } \\
\text { confianza }\end{array}$ \\
\hline & & & \\
\hline & & & \\
\hline & & & \\
\hline & & & \\
\hline & & & \\
\hline & & & \\
\hline & & & \\
\hline & & & \\
\hline & & & \\
\hline
\end{tabular}


Formulario S03 - Listado de hipótesis

Caso de estudio 
SO3 - LISTADO DE HIPÓTESIS

Propósito:

Instrucciones: 


\begin{tabular}{|l|l|l|}
\hline LISTADO DE HIPÓTESIS & Realizado por: \\
\hline & Fecha: \\
\hline
\end{tabular}

\begin{tabular}{|c|c|c|c|}
\hline $\begin{array}{r}\text { ID } \\
-H i p\end{array}$ & Evidencia & $\begin{array}{l}\text { Gru } \\
\text { po del } \\
\text { que se } \\
\text { obtiene }\end{array}$ & $\begin{array}{l}\text { Nivel } \\
\text { de } \\
\text { confianza }\end{array}$ \\
\hline & & & \\
\hline & & & \\
\hline & & & \\
\hline & & & \\
\hline & & & \\
\hline & & & \\
\hline & & & \\
\hline & & & \\
\hline & & & \\
\hline
\end{tabular}


Potencia empírica y Exactitud de los métodos de meta-análisis 


\section{APÉNDICE G - CASO DE ESTUDIO}

En este apéndice se presenta la implementación de cada una de las fases propuestas para el proceso de RS, a el tópico de Inspección de Software. Se presentan los resultados detallados de cada tarea y actividad.

Caso de estudio 


\section{BÚSQUEDA}

\section{Objetivo}

Localizar los experimentos disponibles en IS acerca de un tópico de interés, con el fin de que el revisor pueda establecer una pregunta de revisión.

Una vez que el revisor cuenta con una pregunta de revisión establecida, esta fase se ocupa de localizar la mayor cantidad de experimentos relacionados con los tratamientos, variables respuesta y tipos de estudios de interés para la revisión.

ACTIVIDADES

1. Determinación del tema

2. Búsqueda preliminar de experimentos

3. Descarte de artículos irrelevantes

4. Selección de estudios candidatos

5. Declaración del objetivo de revisión

6. Búsqueda y lectura de antecedentes

7. Búsqueda refinada

8. Descarte de artículos irrelevantes (iterativo)

9. Búsqueda por referencias

10. Definición/Actualización de grupos candidatos a agregación (GCA)

\begin{tabular}{|l|l|}
\hline Entrada & Salida \\
\hline$-\quad$ Tecnología de interés & - B01_Declaración del tema de revisión \\
- B07_Declaración del objetivo de Revisión & - B02_Análisis de artículos recuperados \\
& $-\begin{array}{l}\text { B03_Resumen de artículos relevantes } \\
\text { (Conjunto base) }\end{array}$ \\
\hline
\end{tabular}




\begin{tabular}{|l|ll|}
\hline & $-\quad$ B04_Estadísticas de Búsqueda \\
- & B05_Agrupamiento por sub-tema y tipo de \\
estudio & \\
- & Grupo candidato a agregación \\
- & B06_Análisis de las RS recuperadas \\
- & B07_Declaración del objetivo de Revisión \\
\hline
\end{tabular}

A continuación se resumen las tareas y artefactos asociadas con cada una de las actividades anteriormente indicadas y se presentan los resultados más relevantes obtenidos para el caso de estudio.

Caso de estudio 


\section{- 1.1. DETERMINACIÓN DEL TEMA}

\begin{tabular}{|l|c|c|}
\hline \multicolumn{2}{|l|}{ Objetivo } & \multicolumn{2}{|c|}{ Salida } \\
\hline \multicolumn{2}{|c|}{ Establecer el área o tecnología sobre la cual se desea realizar la RS. } \\
\hline Entrada & B01_Declaración del Tema de revisión \\
\hline Tecnología de interés & Entradas & Salidas \\
\hline Tareas & \multicolumn{2}{|c|}{ Tema de revisión } \\
\hline 1.1.1. Selección del tema & Tema de revisión & B01 Declaración \\
\hline 1.1.2. Descripción del tema & & dema de revisión \\
\hline
\end{tabular}

\subsubsection{Selección del tema de revisión}

El tema en el cual se enmarca la presente revisión es la de Inspecciones de software. Esta área de conocimiento ha venido teniendo un fuerte crecimiento dentro del ámbito profesional desde que la Control y el Aseguramiento de la calidad han tomado un rol protagónico dentro de la estructura de las empresas de software y han llegado a constituirse en prácticas clave para la obtención de altos niveles de calidad y certificaciones; logrando de esta manera una ventaja competitiva dentro de un mercado caracterizado por altos índices de fracaso en los proyectos.

\subsubsection{Descripción del tema de revisión}

A continuación se presenta el formulario B01_Declaración del tema de revisión, describiendo el tema seleccionado para el presente caso de estudio. 


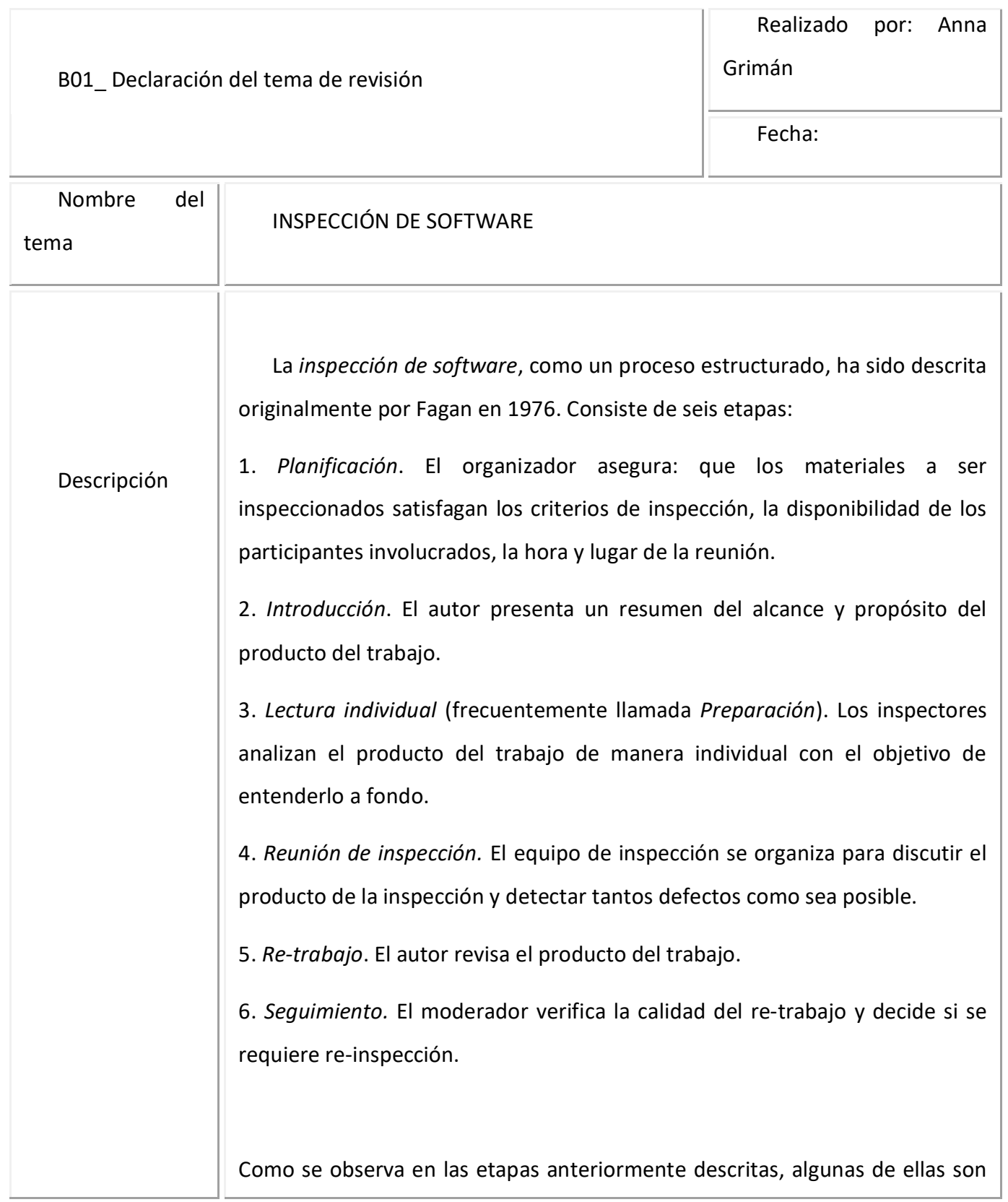

Caso de estudio 
de carácter individual (lectura), mientras que otras son de carácter grupal (reunión). El sentido de ambas etapas es identificar el mayor número de errores posible a través de la sinergia entre todos los revisores. 


\section{- 1.2. BÚSQUEDA PRELIMINAR DE EXPERIMENTOS}

\begin{tabular}{|c|c|c|}
\hline \multicolumn{3}{|l|}{ Objetivo } \\
\hline \multicolumn{3}{|c|}{$\begin{array}{l}\text { Recopilar un conjunto base de artículos que reporten experimentos que puedan ser relevantes a } \\
\text { tema de revisión, y que ayuden a definir un objetivo y pregunta de revisión específicos. }\end{array}$} \\
\hline Entrada & \multicolumn{2}{|l|}{ Salida } \\
\hline B01_Declaración del Tema de revisión & \multicolumn{2}{|c|}{ B02_Análisis de artículos recuperados } \\
\hline \multicolumn{3}{|l|}{ Tareas } \\
\hline & Entradas & Salidas \\
\hline $\begin{array}{l}\text { 1.2.1. Seleccionar fuentes de } \\
\text { información y universo de búsqueda }\end{array}$ & $\begin{array}{l}\text { - B01_Declaración del } \\
\text { Tema de revisión }\end{array}$ & $\begin{array}{ll}- & \text { Repositorios } \\
\text { - } \quad \text { Universo de búsqueda }\end{array}$ \\
\hline 1.2.2. Seleccionar campos de Búsqueda & - $\quad$ Repositorios & - $\quad$ Campos de búsqueda \\
\hline 1.2.3. Definir la cadena de Búsqueda & $\begin{array}{l}\text { - } \quad \text { Términos } \\
\text { experimentales } \\
\text { - Términos del tema }\end{array}$ & - $\quad$ Cadena de búsqueda \\
\hline $\begin{array}{l}\text { 1.2.4. Documentar la estrategia de } \\
\text { búsqueda }\end{array}$ & $\begin{array}{l}\text { - } \quad \text { Repositorio } \\
\text { - } \quad \text { Universo de búsqueda } \\
\text { - } \quad \text { Campos de búsqueda } \\
\text { - } \quad \text { Cadena de búsqueda }\end{array}$ & $\begin{array}{l}\text { Estrategia } \\
\text { Búsqueda }\end{array}$ \\
\hline 1.2.5. Ejecutar la Búsqueda & $\begin{array}{l}\text { Estrategia de } \\
\text { Búsqueda }\end{array}$ & $\begin{array}{ll}\text { - } & \text { B02_Análisis de } \\
& \text { artículos recuperados }\end{array}$ \\
\hline
\end{tabular}

Caso de estudio 


\subsubsection{Seleccionar fuentes de información}

Para este caso de estudio se seleccionaron 5 repositorios o bases de datos bibliográficas con el objetivo de maximizar la cantidad de artículos recuperados:

- Scopus

- $\quad$ IEEEXplore

- ScienceDirect

- $\quad$ SpringerLink

- $\quad$ ACM Dgital Library (ACM DL)

\subsubsection{Seleccionar campos de búsqueda}

Para el presente caso de estudio se seleccionaron los siguientes campos de Búsqueda:

- Título

- Resumen.

\subsubsection{Definir la cadena de búsqueda}

Por tratarse de una búsqueda preliminar, se utilizó un término general "software inspection". También hemos agregado la cadena de búsqueda recomendada en (Dieste et al., 2008) como cadena óptima para la recuperación de experimentos controlados: experiment $O R$ "experimental study" $O R$ "experimental comparison" OR "experimental analysis" OR "experimental evidence" OR "experimental setting". 


\subsubsection{Documentar la estrategia de búsqueda}

A continuación se presenta la cadena de búsqueda utilizada en cada uno de las 5 bases de datos bibliográficas (ver tabla A.1).

\section{Tabla A.1. Estrategias de búsqueda}

\begin{tabular}{|c|c|}
\hline Repositorio & Cadena de búsqueda \\
\hline Xplore & $\begin{array}{l}\text { (<or>(experiment, 'experimental study', 'experimental comparison', 'experimental } \\
\text { analysis', 'experimental evidence', 'experimental setting') }<i n>(a b, t i)) \quad<a n d> \\
\text { ('software inspection'<in>(ab,ti)) }\end{array}$ \\
\hline Springerlink & $\begin{array}{l}\text { "software inspection" (experiment OR "experimental study" OR "experimental } \\
\text { comparison" OR "experimental analysis" OR "experimental evidence" OR } \\
\text { "experimental setting") }\end{array}$ \\
\hline ScienceDirect & $\begin{array}{l}\text { TITLE-ABSTR-KEY("software inspection") and TITLE-ABSTR-KEY(experiment OR } \\
\text { "experimental study" OR "experimental comparison" OR "experimental analysis" OR } \\
\text { "experimental evidence" OR "experimental setting") }\end{array}$ \\
\hline ACM DL & $\begin{array}{l}\text { +"software inspection" experiment "experimental study" "experimental } \\
\text { comparison" "experimental analysis" "experimental evidence" "'experimental } \\
\text { setting" }\end{array}$ \\
\hline Scopus & $\begin{array}{l}\text { ABS("software inspection" AND (experiment OR "experimental study" OR } \\
\text { "experimental comparison" OR "experimental analysis" OR "experimental evidence" } \\
\text { OR "experimental setting")) OR TITLE("software inspection" AND (experiment OR } \\
\text { "experimental study" OR "experimental comparison" OR "experimental analysis" OR } \\
\text { "experimental evidence" OR "experimental setting")) }\end{array}$ \\
\hline
\end{tabular}

Caso de estudio 


\subsubsection{Ejecutar la búsqueda}

A continuación se presenta el resultado de ejecutar las estrategias de búsquedas definidas anteriormente. En la tabla A.2 se indica el número de artículos recuperados en cada repositorio.

Tabla A.2. Resultados obtenidos por repositorio

\begin{tabular}{|l|c|}
\hline Repositorio & No. de artículos recuperados \\
\hline Xplore & 30 \\
\hline Springerlink & 11 \\
\hline ScienceDirect & 10 \\
\hline ACM DL & 19 \\
\hline SCOPUS & 57 \\
\hline TOTAL & 127 \\
\hline
\end{tabular}

A continuación se presenta el formulario B02_Análisis de Artículos Recuperados, con la descripción de los artículos obtenidos en la primera iteración de búsqueda. Nótese que aunque se recuperaron 127 artículos en total, existen solapamientos entre los resultados obtenidos de los diferentes repositorios por lo que en total el número de artículos distintos queda reducido a 90 . En esta actividad aún no se ha de evaluar la relevancia del artículo para la RS. 


\begin{tabular}{|c|c|c|c|c|c|}
\hline 1 & Fichero & Autores & Referencia & Resumen & $\begin{array}{l}\text { ¿Releva } \\
\text { nte? }\end{array}$ \\
\hline 1 & $\begin{array}{l}\text { /Xplore/ } \\
\text { Xplore_ } \\
\text { 1.pdf }\end{array}$ & $\begin{array}{l}\text { T.Berlig and } \\
\text { T. Thelin, }\end{array}$ & $\begin{array}{l}2 . \quad \text { A case study of reading } \\
\text { techniques in a software company, } 2004 . \\
\text { Proceedings - } 2004 \text { International } \\
\text { Symposium on Empirical Software } \\
\text { Engineering, ISESE 2004, pp. 229-238 }\end{array}$ & $\begin{array}{l}\text { - Aplica un estudio empírico en una } \\
\text { organización de desarrollo } \\
\text { _ Un documento de requisitos es } \\
\text { usado para comparar dos técnicas } \\
\text { de lectura (basada en checklist y } \\
\text { basada en perspectiva) } \\
\text { - Discuten efectividad y eficiencia de } \\
\text { una técnica frente a la otra }\end{array}$ & \\
\hline 2 & $\begin{array}{l}\text { /Springe } \\
\text { r/ } \\
\text { Springer }\end{array}$ & $\begin{array}{l}\text { F. } \\
\text { MacDonald and } \\
\text { J. Miller, }\end{array}$ & $\begin{array}{l}\text { 3. A Comparison of Tool-Based and } \\
\text { Paper-Based Software Inspection, } \\
\text { Empirical Software Engineering, vol. V3, }\end{array}$ & $\begin{aligned} & \text { - } \text { uncribe } \\
& \text { controlado comparando la } \\
& \text { efectividad la inspección de }\end{aligned}$ & \\
\hline
\end{tabular}

Caso de estudio 


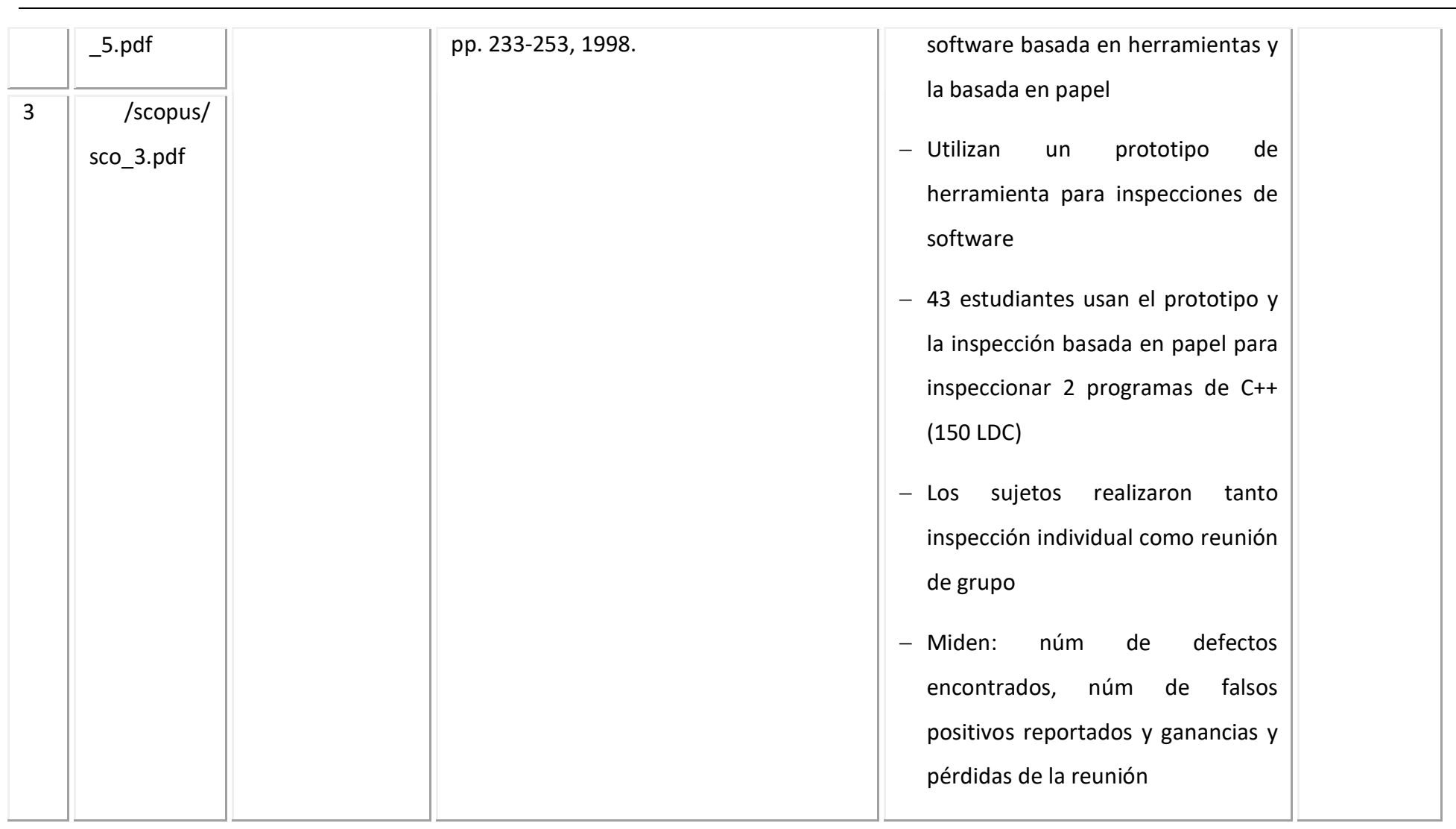


Proceso de RS de experimentos en Ingeniería del Software

\begin{tabular}{|c|c|c|c|c|}
\hline 4 & $\begin{array}{l}\text { /Xplore/ } \\
\text { Xplore_ } \\
\text { 2.pdf }\end{array}$ & $\begin{array}{l}\text { M. } \\
\text { Kalinowski and } \\
\text { G. H. Travassos, }\end{array}$ & $\begin{array}{l}\text { 4. A computational framework for } \\
\text { supporting software inspections, } 2004 . \\
\text { Proceedings }-19^{\text {th }} \text { International } \\
\text { Conference on Automated Software } \\
\text { Engineering, ASE 2004, pp. } 46-55\end{array}$ & $\begin{array}{l}\text { - Describe un framework } \\
\text { computacional cuyos requisitos se } \\
\text { basan en estudios empíricos sobre } \\
\text { inspección de software } \\
\text { - Evalúa la factibilidad del } \\
\text { framework a través de: } \\
\text { On caso de estudio } \\
\text { On estudio } \\
\text { experimental que } \\
\text { evaluó la actividad } \\
\text { de planificación de } \\
\text { la inspección de } \\
\text { software } \\
\text { - El estudio experimental arrojó } \\
\text { resultados sobre la experiencia de } \\
\text { los sujetos y su relación con la } \\
\text { planificación y la efectividad en la } \\
\text { detección de defectos, al utilizar el } \\
\text { framework comput.Sl }\end{array}$ \\
\hline
\end{tabular}

Caso de estudio 


\begin{tabular}{|c|c|c|c|c|}
\hline 5 & $\begin{array}{l}\text { /Xplore/ } \\
\text { Xplore_ } \\
\text { 3.pdf }\end{array}$ & \multirow[t]{2}{*}{$\begin{array}{l}\text { A. Bianchi, F. } \\
\text { Lanubile, and G. } \\
\text { Visaggio, }\end{array}$} & \multirow{2}{*}{$\begin{array}{l}\text { 5. A controlled experiment to } \\
\text { assess the effectiveness of inspection } \\
\text { meetings, 2001. International Software } \\
\text { Metrics Symposium, Proceedings, pp. } 42- \\
50\end{array}$} & $\begin{array}{l}\text { - Presenta un experimento } \\
\text { controlado } \\
\text { - Participan + de } 100 \text { estudiantes de }\end{array}$ \\
\hline 6 & $\begin{array}{l}\text { /scopus/ } \\
\text { Sco_34.pdf }\end{array}$ & & & $\begin{array}{l}\text { carrera quienes inspeccionan } \\
\text { documentos de requerimientos de } \\
\text { software } \\
\text { - Compara el desempeño de grupos } \\
\text { nominales y reales } \\
\text { - Investiga también las razones de } \\
\text { las pérdidas en las reuniones y } \\
\text { confronta ganancias vs pérdidas } \\
\text { - Relaciona las pérdidas con el núm } \\
\text { de defectos encontrados por un } \\
\text { único individuo en el equipo }\end{array}$ \\
\hline 7 & $\begin{array}{l}\text { /Springe } \\
\mathrm{r} / \\
\text { Springer } \\
\text { 8.pdf }\end{array}$ & $\begin{array}{l}\text { B. Stefan, G. } \\
\text { Paul, and H. } \\
\text { Michael, }\end{array}$ & \multirow[t]{2}{*}{$\begin{array}{l}\text { 6. A family of experiments to } \\
\text { investigate the effects of groupware for } \\
\text { software inspection, Automated } \\
\text { Software Engineering, vol. V13, pp. 373- } \\
394,2006 \text {. }\end{array}$} & \multirow[t]{2}{*}{$\begin{array}{l}\text { - Conduce una familia de } \\
\text { experimentos en un ambiente } \\
\text { académico para investigar el efecto } \\
\text { del soporte de herramientas a la } \\
\text { detección de defectos y a las } \\
\text { reuniones de inspección }\end{array}$} \\
\hline 8 & /Scopus & & & \\
\hline
\end{tabular}


Proceso de RS de experimentos en Ingeniería del Software

\begin{tabular}{|c|c|c|c|c|}
\hline & /sco_17.pdf & & & $\begin{array}{l}\text { - Discute: la efectividad de los } \\
\text { inspectores y equipos con y sin } \\
\text { herramientas, el esfuerzo de } \\
\text { inspección y el solapamiento de } \\
\text { defectos, eficiencia de los equipos } \\
\text { de inspección, el núm de falsos } \\
\text { positivos identificados y no } \\
\text { identificados, núm de defectos } \\
\text { verdaderos perdidos durante la } \\
\text { reunión }\end{array}$ \\
\hline 9 & $\begin{array}{l}\text { /Scopus } \\
\text { /Fulltext ND }\end{array}$ & Harjumaa, L. & $\begin{array}{l}\text { A pattern approach to software } \\
\text { inspection process improvement. } \\
\text { Software Process Improvement and } \\
\text { Practice. Volume } 10 \text {, Issue } 4 \text {, October } \\
\text { 2005, Pages } 455-465\end{array}$ & $\begin{array}{l}\text { Concrete guidelines are often } \\
\text { helpful when planning software } \\
\text { process improvement. Small } \\
\text { companies, in particular, need } \\
\text { detailed and unambiguous } \\
\text { instructions detailing what process } \\
\text { areas to improve, and how to achieve } \\
\text { the improvement. This article } \\
\text { introduces a set of patterns to direct } \\
\text { the improvement of the software } \\
\text { inspection process. The pattern }\end{array}$ \\
\hline
\end{tabular}

Caso de estudio 


\begin{tabular}{|c|c|c|c|c|}
\hline & & & & $\begin{array}{l}\text { approach has been applied, since it } \\
\text { has been used very successfully for } \\
\text { knowledge-sharing purposes and } \\
\text { other areas of software engineering. } \\
\text { The approach involves an evaluation } \\
\text { of the inspection process capability, } \\
\text { setting an overall goal for the } \\
\text { improvement and updating the } \\
\text { process according to pre-defined } \\
\text { actions. Experiments with initial } \\
\text { patterns show that the method } \\
\text { provides a feasible and quick way of } \\
\text { making inspections more effective. } \\
\text { Using patterns may also be beneficial } \\
\text { when launching more wide-ranging } \\
\text { SPI activities, as companies can run } \\
\text { preliminary trials of the improvement } \\
\text { process on a smaller scale first. }\end{array}$ \\
\hline 10 & $\begin{array}{l}\text { /xplore/ } \\
\text { Xplore_- } \\
\text { 4.pdf }\end{array}$ & $\begin{array}{l}\text { P. Murphy } \\
\text { and J. Miller, }\end{array}$ & $\begin{array}{l}\text { 7. A process for asynchronous } \\
\text { software inspection, Proceedings, Eighth } \\
\text { IEEE International Workshop on Software } \\
\text { Technology and Engineering Practice, }\end{array}$ & $\begin{array}{l}\text { - Propone un modelo de inspección } \\
\text { soportado por una herramienta de } \\
\text { comunicación asíncrona basado en } \\
\text { correo-e }\end{array}$ \\
\hline
\end{tabular}


Proceso de RS de experimentos en Ingeniería del Software

\begin{tabular}{|c|c|c|c|c|}
\hline & & & $\begin{array}{l}\text { 1997. [Incorporating Computer Aided } \\
\text { Software Engineering]. 14-18 July } 1997 \\
\text { Page(s):96-104 }\end{array}$ & 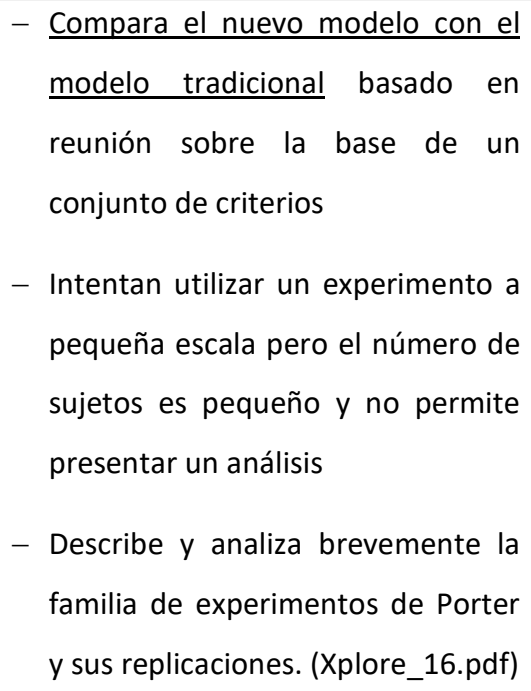 \\
\hline 11 & $\begin{array}{l}\text { /Xplore/ } \\
\text { Xplore_ } \\
\text { 5.pdf }\end{array}$ & $\begin{array}{l}\text { T. Thelin, C. } \\
\text { Andersson, } \mathrm{P} \text {. } \\
\text { Runeson, and N. } \\
\text { Dzamashvili- } \\
\text { Fogelstrom, }\end{array}$ & $\begin{array}{l}8 . \quad \text { A replicated experiment of } \\
\text { usage-based and checklist-based reading, } \\
\text { 2004. Proceedings - Software Metrics } \\
\text { Symposium, pp. 246-256 }\end{array}$ & $\begin{array}{l}\text { - Presenta la replicación de un } \\
\text { experimento que comparó técnicas } \\
\text { de lectura basada en uso vs basada } \\
\text { en checklist } \\
\text { - Presenta tanto la replicación como } \\
\text { el experimento original y compara } \\
\text { ambos resultados (Xplore_30.pdf) } \\
\text { - La replicación confirmó los }\end{array}$ \\
\hline
\end{tabular}

Caso de estudio 


\begin{tabular}{|c|c|c|c|c|}
\hline & & & & resultados del exp. original \\
\hline 12 & $\begin{array}{l}\text { /Xplore/ } \\
\text { Xplore_ } \\
\text { 6.pdf }\end{array}$ & $\begin{array}{l}\text { I. Tervonen, } \\
\text { J. lisakka, and L. } \\
\text { Harjumaa, }\end{array}$ & $\begin{array}{l}\text { 9. A tailored capability model for } \\
\text { inspection process improvement, } \\
\text { Proceedings. Second Asia-Pacific } \\
\text { Conference on Quality Software, } 2001 . \\
\text { 10-11 Dec. } 2001 \text { Page(s):275-282 }\end{array}$ & $\begin{array}{l}\text { - Presenta un modelo para evaluar la } \\
\text { capacidad del proceso de } \\
\text { inspección y soportar la } \\
\text { identificación de puntos débiles en } \\
\text { el proceso } \\
\text { - Presenta la aplicación del modelo } \\
\text { en la evaluación de una compañía }\end{array}$ \\
\hline 13 & $\begin{array}{l}\text { /ACM/A } \\
\text { CM_1.pdf }\end{array}$ & $\begin{array}{l}\text { Monvorath } \\
\text { Phongpaibul, } \\
\text { Barry Boehm }\end{array}$ & $\begin{array}{l}\text { 10. An empirical comparison } \\
\text { between pair development and software } \\
\text { inspection in Thailand, Proceedings of }\end{array}$ & $\begin{array}{r}\text { - Compara las similitudes y } \\
\text { diferencias entre el desarrollo por } \\
\text { pares y la inspección de software }\end{array}$ \\
\hline 14 & $\begin{array}{l}\text { /Scopus } \\
\text { /fulltext ND }\end{array}$ & & $\begin{array}{l}\text { the } 2006 \mathrm{ACM} / \mathrm{IEEE} \text { international } \\
\text { symposium on International symposium } \\
\text { on empirical software engineering ISESE } \\
\text { ' } 06\end{array}$ & $\begin{array}{l}\text { como técnicas de verificación en } \\
\text { Thailand. } \\
\text { - Aplican un experimento de clase y } \\
\text { uno de industria } \\
\text { - Se investigó el esfuerzo de } \\
\text { desarrollo, el efecto en la calidad y }\end{array}$ \\
\hline
\end{tabular}


Proceso de RS de experimentos en Ingeniería del Software

\begin{tabular}{|c|c|c|c|c|}
\hline & & & & el tiempo calendario \\
\hline 15 & $\begin{array}{l}\text { /Springe } \\
\text { r/ } \\
\text { Springer } \\
\text { _7.pdf }\end{array}$ & $\begin{array}{l}\text { C. Atiq and L. } \\
\text { Lesley Pek Wee, }\end{array}$ & $\begin{array}{l}\text { 11. An Empirical Investigation on the } \\
\text { Impact of Training-by-Examples on } \\
\text { Inspection Performance. PROFES 2004, } \\
\text { LNCS 3009, pp. 203-219, } 2004 \text {. }\end{array}$ & $\begin{array}{l}\text { - Conducen un experimento para } \\
\text { probar el efecto del entrenamiento } \\
\text { basado en ejemplos en la } \\
\text { inspección de requisitos }\end{array}$ \\
\hline 16 & $\begin{array}{r}\text { /Scopus } \\
\text { /fulltext ND }\end{array}$ & & & $\begin{array}{l}\text { - Compara el desempeño de un } \\
\text { grupo entrenado vs uno que no ha } \\
\text { recibido entrenamiento }\end{array}$ \\
\hline 17 & $\begin{array}{l}\text { /Xplore/ } \\
\text { Xplore_ } \\
\text { 7.pdf }\end{array}$ & $\begin{array}{l}\text { C. D. } \\
\text { Rombach, } \mathrm{O} . \\
\text { Kude, A. Aurum, } \\
\text { R. Jeffery, and C. } \\
\text { Wohlin, }\end{array}$ & $\begin{array}{l}\text { 12. An empirical study of an ER- } \\
\text { model inspection meeting, Conference } \\
\text { Proceedings of the EUROMICRO, pp. 308- } \\
\text { 315. 2003. }\end{array}$ & $\begin{array}{l}\text { - Documenta un experimento a gran } \\
\text { escala conducido durante una } \\
\text { reunión de inspección de Modelo } \\
\text { ER } \\
\text { - Investiga cuál técnica de lectura } \\
\text { tiene una tasa más eficiente de } \\
\text { detección de defectos cuando se } \\
\text { buscan defectos en un modelo ER } \\
\text { - También explora el efecto del uso } \\
\text { de Roles en una reunión de equipo }\end{array}$ \\
\hline
\end{tabular}

Caso de estudio 


\begin{tabular}{|c|c|c|c|c|}
\hline & & & & $\begin{array}{l}\text { - Por último, investiga la habilidad } \\
\text { de los revisores para encontrar } \\
\text { ciertas categorías de defectos }\end{array}$ \\
\hline 19 & $\begin{array}{l}\text { /scedire } \\
\text { ct/ } \\
\text { sdirect_1.p } \\
\text { df } \\
\text { (/Xplore } \\
\text { /Xplore_8.p } \\
\text { df) } \\
\text { /scopus/ } \\
\text { sco_5.pdf }\end{array}$ & $\begin{array}{l}\text { M. A. Babar, } \\
\text { B. Kitchenham, } \\
\text { L. Zhu, I. Gorton, } \\
\text { and R. Jeffery, }\end{array}$ & $\begin{array}{l}\text { 13. An empirical study of groupware } \\
\text { support for distributed software } \\
\text { architecture evaluation process, Journal } \\
\text { of Systems and Software, vol. } 79 \text {, pp. } \\
912-925,2006 \text {. }\end{array}$ & $\begin{array}{l}\text { - Presenta un estudio piloto } \\
\text { (experimento) usado para evaluar } \\
\text { la viabilidad de un experimento + } \\
\text { grande que investigue la } \\
\text { factibilidad del soporte groupware } \\
\text { para la evaluación distribuida de } \\
\text { arquitecturas de software } \\
\text { - El estudio piloto arrojó algunos } \\
\text { hallazgos acerca de la viabilidad de } \\
\text { un proceso de EA soportado por } \\
\text { groupware. }\end{array}$ \\
\hline 20 & $\begin{array}{l}\text { /Xplore/ } \\
\text { Xplore_ } \\
\text { 9.pdf }\end{array}$ & $\begin{array}{l}\text { P. } \\
\text { Grunbacher, M. } \\
\text { Halling, and } \mathrm{S} \text {. } \\
\text { Biffl, }\end{array}$ & $\begin{array}{l}\text { 14. An empirical study on } \\
\text { groupware support for software } \\
\text { inspection meetings, Proceedings of the } \\
18^{\text {th }} \text { IEEE International Conference on } \\
\text { Automated Software Engineering } \\
\text { (ASE'03). }\end{array}$ & $\begin{array}{l}\text { - Presentan un experimento en un } \\
\text { ambiente académico con } 37 \\
\text { sujetos para investigar el efecto del } \\
\text { soporte de una herramienta } \\
\text { groupware a las reuniones de } \\
\text { inspección } \\
\text { - Concluyen sobre: el esfuerzo }\end{array}$ \\
\hline
\end{tabular}


Proceso de RS de experimentos en Ingeniería del Software

\begin{tabular}{|c|c|c|c|c|}
\hline & & & & $\begin{array}{l}\text { utilizado en la reunión, } \\
\text { identificación de falsos positivos, } \\
\text { reducción del núm de defectos } \\
\text { reales perdidos }\end{array}$ \\
\hline 21 & $\begin{array}{l}\text { /ACM/ } \\
\text { Acm_2.p } \\
\text { df }\end{array}$ & $\begin{array}{l}\text { Porter, L. G. } \\
\text { Votta }\end{array}$ & $\begin{array}{l}\text { 15. An experiment to assess } \\
\text { different defect detection methods for } \\
\text { software requirements inspections, } \\
\text { Proceedings of the } 16^{\text {th }} \text { international } \\
\text { conference on Software engineering } \\
\text { ICSE '94 }\end{array}$ & $\begin{array}{l}\text { - Usa experimento controlado } \\
\text { - Dirigido a probar la efectividad de } \\
\text { los Métodos de detección basados } \\
\text { en escenarios Vs. Métodos ad hoc } \\
\text { o checklist } \\
\text { - Cada revisor utiliza un } \\
\text { procedimiento específico para } \\
\text { descubrir un tipo particular de } \\
\text { defecto } \\
\text { - Describe el diseño, ejecución y } \\
\text { análisis del experimento }\end{array}$ \\
\hline 22 & $\begin{array}{l}\text { /Xplore/ } \\
\text { Xplore_10.p } \\
\text { df }\end{array}$ & $\begin{array}{l}\text { A. Porter, H. } \\
\text { P. Siy, C. A. } \\
\text { Toman, and L. G. } \\
\text { Votta, }\end{array}$ & $\begin{array}{l}\text { 16. An experiment to assess the } \\
\text { cost-benefits of code inspections in large } \\
\text { scale software development, IEEE } \\
\text { Transactions on Software Engineering, }\end{array}$ & $\begin{array}{l}\text { - Conduce un proyecto a largo plazo } \\
\text { - Evalúa la costo-efectividad de } \\
\text { diversos métodos de inspección de }\end{array}$ \\
\hline
\end{tabular}

Caso de estudio 


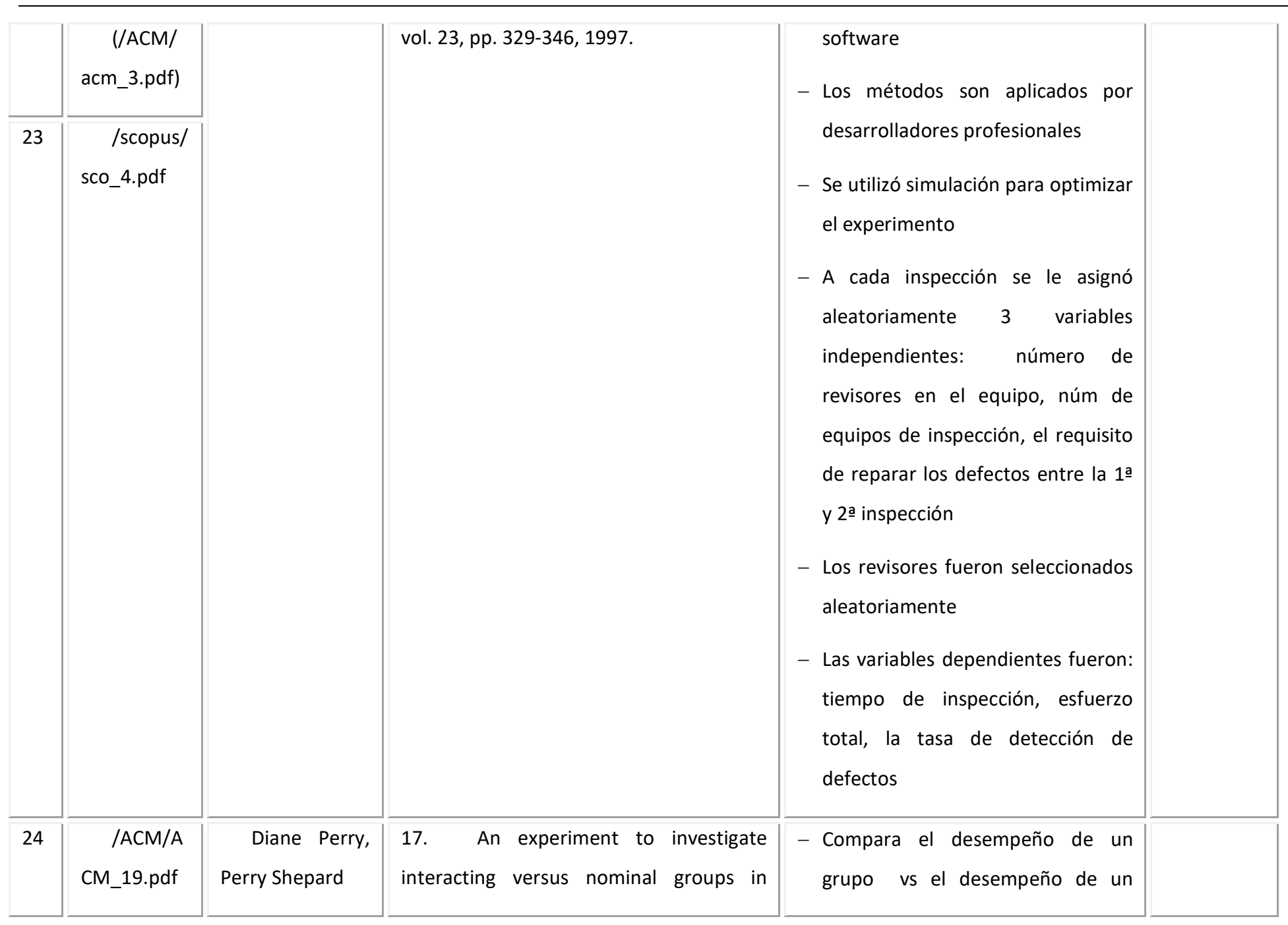


Proceso de RS de experimentos en Ingeniería del Software

\begin{tabular}{|c|c|c|c|c|}
\hline & & & $\begin{array}{l}\text { software inspection, Proceedings of the } \\
2003 \text { conference of the Centre for } \\
\text { Advanced Studies on Collaborative } \\
\text { research CASCON '03 }\end{array}$ & $\begin{array}{l}\text { individuo en el uso de técnicas } \\
\text { estructuradas }\end{array}$ \\
\hline 25 & $\begin{array}{l}\text { /Xplore/ } \\
\text { Xplore_29.p } \\
\text { df }\end{array}$ & $\begin{array}{l}\quad \text { G. } \\
\text { Sabaliauskaite, } \\
\text { F. Matsukawa, S. } \\
\text { Kusumoto, and } \\
\text { K. Inoue, }\end{array}$ & $\begin{array}{l}\text { 18. An experimental comparison of } \\
\text { checklist-based reading and perspective- } \\
\text { based reading for UML design document } \\
\text { inspection, International Symposium on } \\
\text { Empirical Software Engineering (ISESE'02) }\end{array}$ & $\begin{array}{l}\text { - Describe un experimento } \\
\text { controlado en el que participaron } \\
59 \text { estudiantes } \\
\text { - Compara } 2 \text { técnicas de lectura: } \\
\text { basada en checklist y basada en } \\
\text { perspectiva, en la inspección de } \\
\text { diseño } 00 \\
\text { - Comparan: efectividad, tiempo, } \\
\text { costo x defecto }\end{array}$ \\
\hline 26 & $\begin{array}{l}\text { /scedire } \\
\text { ct/ } \\
\text { Sdirect_ } \\
\text { 9.pdf }\end{array}$ & $\begin{array}{l}\quad \text { O. } \\
\text { Laitenberger, C. } \\
\text { Atkinson, M. } \\
\text { Schlich, and K. El } \\
\text { Emam, }\end{array}$ & $\begin{array}{l}\text { 19. An experimental comparison of } \\
\text { reading techniques for defect detection } \\
\text { in UML design documents, Journal of } \\
\text { Systems and Software, vol. } 53 \text {, pp. 183- } \\
204,2000 \text {. }\end{array}$ & $\begin{array}{l}\text { - Compara una técnica basada en } \\
\text { escenario (PBR) para detección de } \\
\text { defectos en documentos de diseño } \\
\text { OO que utilizan UML, con la técnica } \\
\text { basada en checklist (CBR) más } \\
\text { tradicional. }\end{array}$ \\
\hline
\end{tabular}

Caso de estudio 


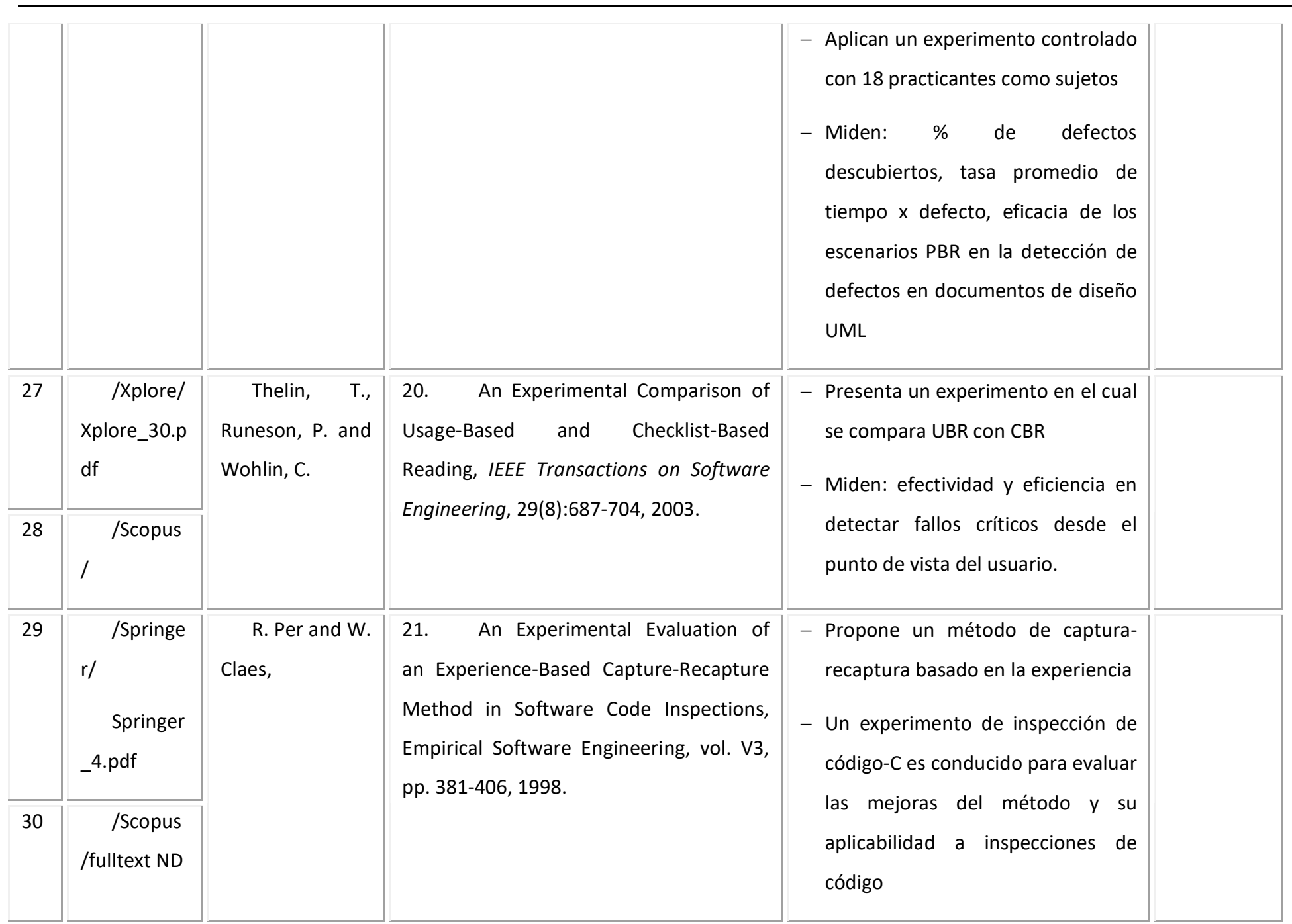


Proceso de RS de experimentos en Ingeniería del Software

\begin{tabular}{|c|c|c|c|c|}
\hline & & & & $\begin{array}{l}\text { - Concluye acerca de: estimaciones } \\
\text { del método vs estimaciones del } \\
\text { método de máxima probabilidad, } \\
\text { sensibilidad de las inspecciones } \\
\text { ante cambios en los datos de } \\
\text { inspección }\end{array}$ \\
\hline 31 & $\begin{array}{l}\text { /ACM/ } \\
\text { Acm_6.p } \\
d f\end{array}$ & $\begin{array}{l}\quad \text { G. Michael } \\
\text { Schneider, } \\
\text { Johnny Martin, } \\
\text { W. T. Tsai }\end{array}$ & $\begin{array}{l}\text { 22. An experimental study of fault } \\
\text { detection in user requirements } \\
\text { documents, ACM Transactions on } \\
\text { Software Engineering and Methodology } \\
\text { (TOSEM), Volume } 1 \text { Issue } 2 \text { April } 1992\end{array}$ & $\begin{array}{l}\text { - Describe un experimento } \\
\text { diseñado para confirmar los } \\
\text { resultados de un proyecto anterior } \\
\text { - } \text { Mide la rata de detección de } \\
\text { fallos en docs de requerimientos } \\
\text { de usuario } \\
-\quad 9 \text { equipos de inspección } \\
\text { independientes } \\
\text { - Aplica la técnica de inspección } \\
\text { de requerimentos N-fold y la } \\
\text { compara con el uso de técnicas } \\
\text { formales } \\
\text { - También mide la variabilidad en } \\
\text { el desempeño del equipo de }\end{array}$ \\
\hline
\end{tabular}

Caso de estudio 


\begin{tabular}{|c|c|c|c|c|}
\hline & & & & $\begin{array}{l}\text { inspección y la dificultad de } \\
\text { localizar diferentes tipos de fallas } \\
\text { en DRU }\end{array}$ \\
\hline 32 & $\begin{array}{l}\text { /Xplore/ } \\
\text { Xplore_ } \\
\text { 8.pdf } \\
\text { (/scedire } \\
\text { ct/ } \\
\text { sdirect_1.p } \\
\text { df) }\end{array}$ & $\begin{array}{l}\text { M. A. Babar, } \\
\text { B. Kitchenham, } \\
\text { L. Zhu, and R. } \\
\text { Jeffery, }\end{array}$ & $\begin{array}{l}23 . \text { An exploratory study of } \\
\text { groupware support for distributed } \\
\text { software architecture evaluation process, } \\
\text { 2004. Proceedings - Asia-Pacific Software } \\
\text { Engineering Conference, APSEC, pp. 222- } \\
229\end{array}$ & $\begin{array}{l}\text { - Presenta un estudio piloto } \\
\text { (experimento) usado para evaluar } \\
\text { la viabilidad de un experimento }+ \\
\text { grande que investigue la } \\
\text { factibilidad del soporte groupware } \\
\text { para la evaluación distribuida de } \\
\text { arquitecturas de software } \\
\text { - El estudio piloto arrojó algunos } \\
\text { hallazgos acerca de la viabilidad de } \\
\text { un proceso de EA soportado por } \\
\text { groupware. }\end{array}$ \\
\hline 33 & $\begin{array}{l}\text { /Xplore/ } \\
\text { Xplore_ } \\
\text { 15.pdf }\end{array}$ & $\begin{array}{l}\text { O. } \\
\text { Laitenberger, K. } \\
\text { El Emam, and T. } \\
\text { G. Harbich, }\end{array}$ & $\begin{array}{l}\text { 24. An internally replicated quasi- } \\
\text { experimental comparison of checklist and } \\
\text { perspective based reading of code } \\
\text { documents, IEEE Transactions on }\end{array}$ & $\begin{array}{l}\text { - Compara una técnica de lectura } \\
\text { basada en scenario (PBR) para } \\
\text { detección de defectos en código, } \\
\text { con el enfoque CBR más tradicional }\end{array}$ \\
\hline 34 & $\begin{array}{r}\text { /Scopus } \\
\text { /fulltext ND }\end{array}$ & & $\begin{array}{l}\text { Software Engineering, vol. 27, pp. 387- } \\
421,2001 .\end{array}$ & $\begin{array}{l}\text { - Hace la comparación en una serie } \\
\text { de } 3 \text { estudios, un quasi- } \\
\text { experimento y } 2 \text { replicaciones }\end{array}$ \\
\hline
\end{tabular}


Proceso de RS de experimentos en Ingeniería del Software

\begin{tabular}{|c|c|c|c|c|}
\hline & & & & $\begin{array}{l}\text { internas } \\
\text { - Utiliza } 60 \text { desarrolladores de } \\
\text { software profesionales } \\
\text { - Presenta un análisis meta-analítico } \\
\text { - Compara efectividad y costo }\end{array}$ \\
\hline 35 & $\begin{array}{l}\text { /ACM/ } \\
\text { Acm_7.p }\end{array}$ & $\begin{array}{l}\text { Hidetake } \\
\text { Uwano, } \\
\text { Masahide } \\
\text { Nakamura, Akito } \\
\text { Monden, Ken- } \\
\text { ichi Matsumoto }\end{array}$ & $\begin{array}{l}25 . \quad \text { Analyzing individual } \\
\text { performance of source code review using } \\
\text { reviewers' eye movement, Proceedings } \\
\text { of the } 2006 \text { symposium on Eye tracking } \\
\text { research \& applications ETRA ' } 06\end{array}$ & $\begin{array}{l}\text { - Analiza } 30 \text { procesos de revisión } \\
\text { - } 6 \text { programas y } 5 \text { sujetos que } \\
\text { utilizan un ambiente integrado que } \\
\text { mide y registra el movimiento } \\
\text { ocular de los revisores de código } \\
\text { - Identifica un patrón } \\
\text { - Realiza un análisis cuantitativo } \\
\text { sobre el tiempo usado en el patrón } \\
\text { y el tiempo en detectar fallas }\end{array}$ \\
\hline 36 & $\begin{array}{l}\text { /Scedire } \\
\text { ct/ } \\
\text { sdirect_2.p } \\
\text { df }\end{array}$ & $\begin{array}{l}\text { G. } \\
\text { Sabaliauskaite, } \\
\text { S. Kusumoto, } \\
\text { and K. Inoue, }\end{array}$ & $\begin{array}{l}\text { 26. Assessing defect detection } \\
\text { performance of interacting teams in } \\
\text { object-oriented design inspection, } \\
\text { Information and Software Technology, }\end{array}$ & $\begin{array}{l}\text { - Reporta un experimento } \\
\text { controlado con } 54 \text { estudiantes de } \\
\text { carrera que inspeccionan }\end{array}$ \\
\hline
\end{tabular}

Caso de estudio 


\begin{tabular}{|c|c|c|c|c|}
\hline 37 & $\begin{array}{l}\text { /scopus/ } \\
\text { sco_8.pdf }\end{array}$ & & vol. 46, pp. 875-886, 2004 & $\begin{array}{l}\text { documentos de diseño OO. } \\
\text { - Compara el desempeño de los } \\
\text { equipos de inspección utilizando } \\
\text { dos técnicas de lectura: CBR y PBR } \\
\text { - Compara el desempeño de equipos } \\
\text { nominales e interactivos } \\
\text { - Falsos positivos identificados }\end{array}$ \\
\hline 38 & $\begin{array}{l}\text { /ACM/ } \\
\text { Acm_8.p } \\
\text { df }\end{array}$ & $\begin{array}{rr}\text { Philip } & \text { M. } \\
\text { Johnson, } & \text { Danu } \\
\text { Tjahjono } & \end{array}$ & $\begin{array}{l}\text { 27. Assessing software review } \\
\text { meetings: a controlled experimental } \\
\text { study using CSRS, Proceedings of the } \mathbf{1 9}^{\text {th }} \\
\text { international conference on Software } \\
\text { engineering ICSE ' } 97\end{array}$ & $\begin{array}{l}\text { - Conducen un experimento } \\
\text { controlado que evalúa varias } \\
\text { medidas de costo y efectividad } \\
\text { para un método de revisión basado } \\
\text { en reunió y otro no basado en ella } \\
\text { - Utilizan un ambiente de revisión de } \\
\text { software colaborativo } \\
\text { - Utilizan } 24 \times 3 \text { grupos de personas } \\
\text { - Miden: núm de defectos } \\
\text { descubiertos, esfuerzo requerido, } \\
\text { presencia de sinergia en los grupos } \\
\text { basados en reunión, falsos } \\
\text { positivos en los grupos no-basados, }\end{array}$ \\
\hline
\end{tabular}


Proceso de RS de experimentos en Ingeniería del Software

\begin{tabular}{|c|c|c|c|c|}
\hline & & & & $\begin{array}{l}\text { respuestas a cuestionarios } \\
\text { cualitativos }\end{array}$ \\
\hline 39 & $\begin{array}{l}\text { /Xplore/ } \\
\text { Xplore_16.p } \\
\text { df }\end{array}$ & $\begin{array}{l}\text { A. Porter, L. } \\
\text { Votta, and V. } \\
\text { Basili. }\end{array}$ & $\begin{array}{l}\text { 28. Comparing detection methods } \\
\text { for software requirements inspections: A } \\
\text { replicated experiment. IEEE Transactions } \\
\text { on Software Engineering, 21(6):563- } \\
575,1995\end{array}$ & $\begin{array}{l}\text { - Conduce un experimento } \\
\text { aleatorizado con } 48 \text { estudiantes } \\
\text { - Cada equipo inspeccionó } 2 \text { SRS } \\
\text { usando alguna combinación de } \\
\text { métodos Ad hoc, checklist y } \\
\text { escenarios } \\
\text { - Miden: tasa de detección de fallos } \\
\text { individual y grupal, tasas de } \\
\text { ganancia y pérdida de la reunión }\end{array}$ \\
\hline 40 & $\begin{array}{r}\text { /Scopus } \\
\text { /fulltext ND }\end{array}$ & $\begin{array}{l}\text { Sabaliauskait } \\
\text { e, G., Kusumoto, } \\
\text { S., Inoue, K. }\end{array}$ & $\begin{array}{l}\text { 29. Comparing reading techniques for } \\
\text { object-oriented design inspection, IEICE } \\
\text { Transactions on Information and Systems E87- } \\
\text { D (4), pp. 976-984, } 2004\end{array}$ & $\begin{array}{l}\text { - For more than twenty-five years } \\
\text { software inspections have been } \\
\text { considered an effective method for } \\
\text { defect detection. Inspections have } \\
\text { been investigated through } \\
\text { controlled experiments in } \\
\text { university environment and } \\
\text { industry case studies. However, in } \\
\text { most cases software inspections }\end{array}$ \\
\hline
\end{tabular}

Caso de estudio 


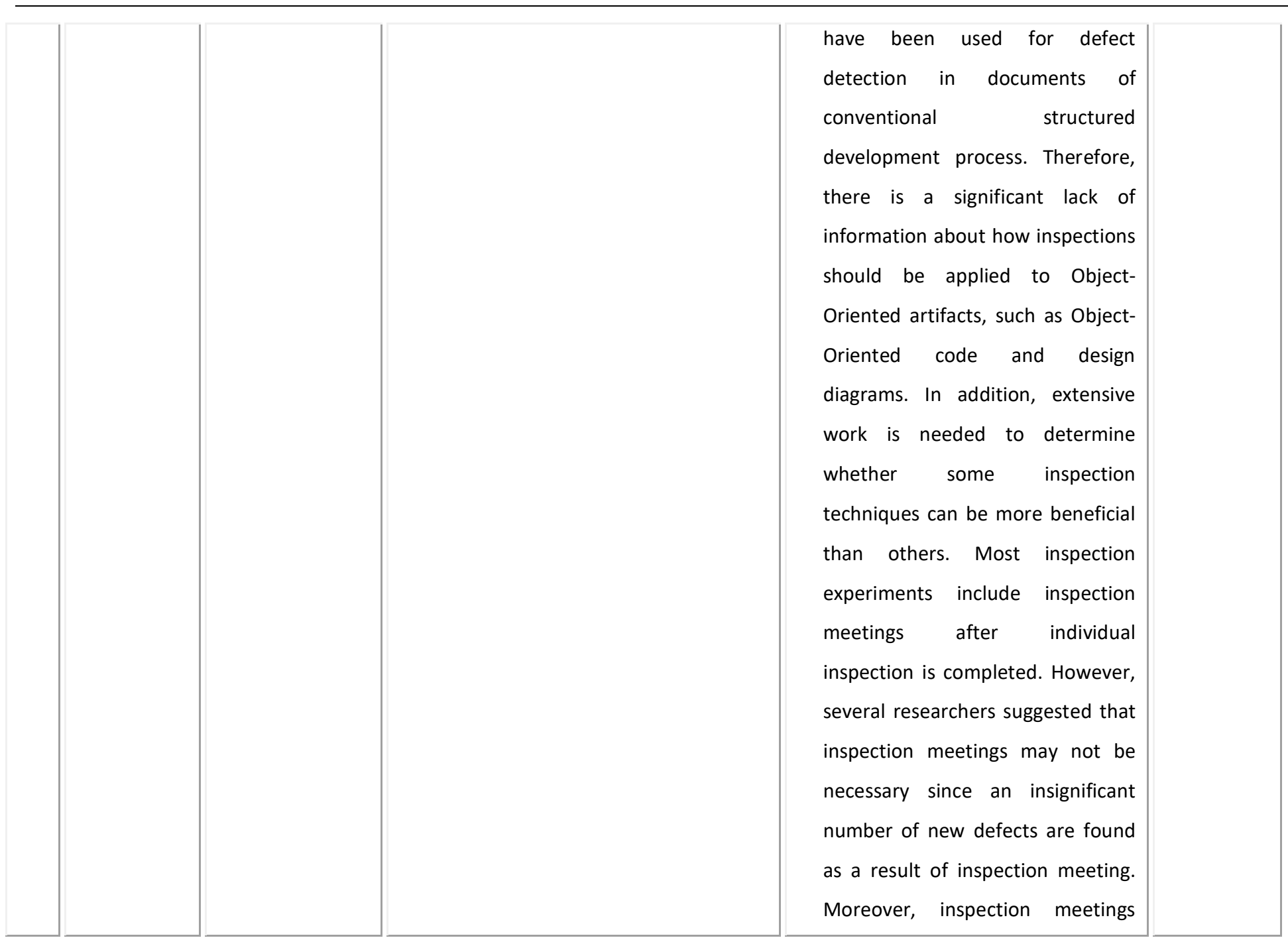


Proceso de RS de experimentos en Ingeniería del Software

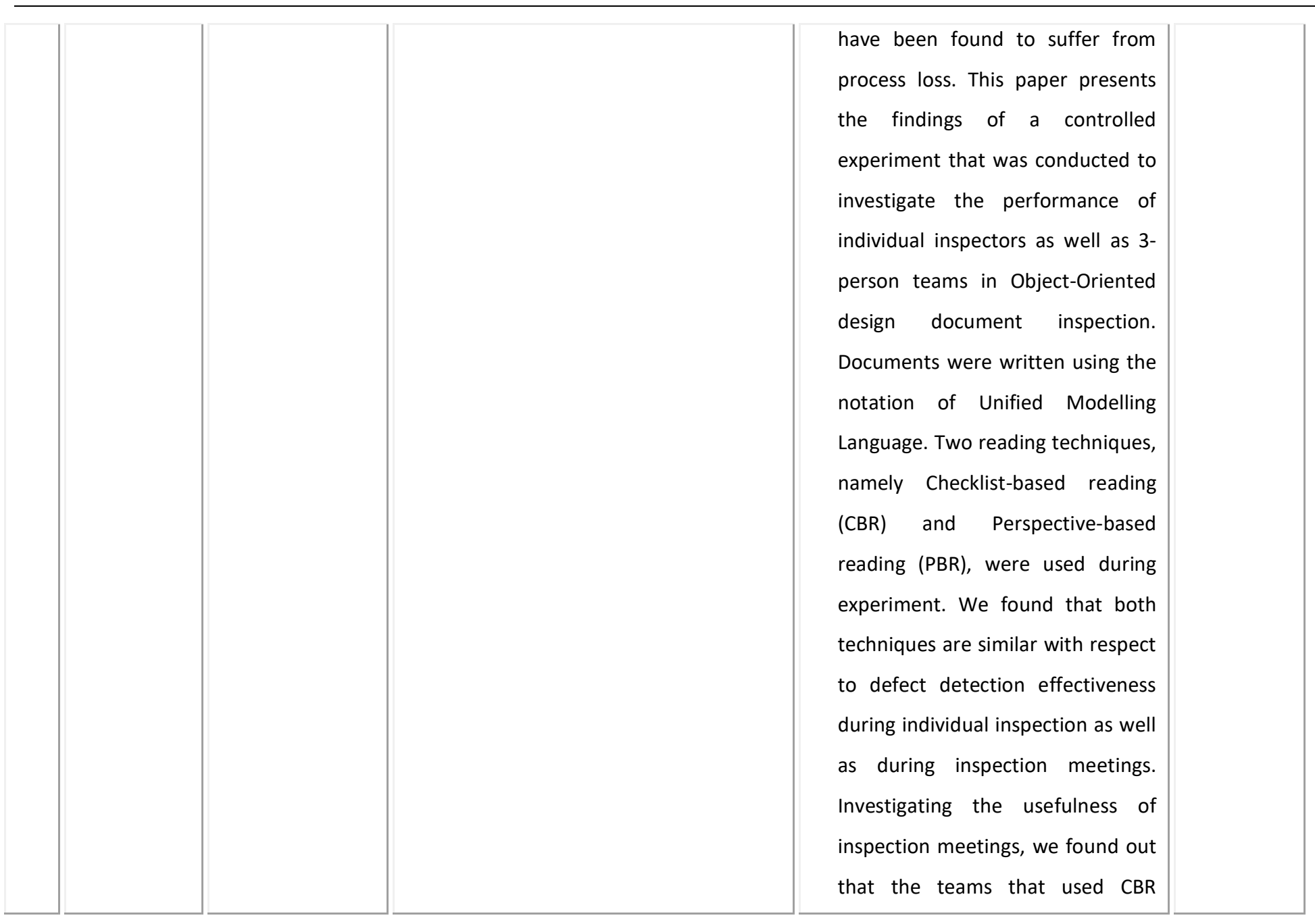

Caso de estudio 


\begin{tabular}{|c|c|c|c|c|}
\hline & & & & $\begin{array}{l}\text { technique exhibited significantly } \\
\text { smaller meeting gains (number of } \\
\text { new defect first found during team } \\
\text { meeting) than meeting losses } \\
\text { (number of defects first identified } \\
\text { by an individual but never included } \\
\text { into defect list by a team); } \\
\text { meanwhile the meeting gains were } \\
\text { similar to meeting losses of the } \\
\text { teams that used PBR technique. } \\
\text { Consequently, CBR 3-person team } \\
\text { meetings turned out to be less } \\
\text { beneficial than PBR 3-person team } \\
\text { meetings. }\end{array}$ \\
\hline 41 & $\begin{array}{l}\text { /Scopus } \\
\text { Sco_2.p }\end{array}$ & $\begin{array}{l}\text { P. Vitharana } \\
\text { and K. } \\
\text { Ramamurthy, }\end{array}$ & $\begin{array}{l}\text { 30. Computer-mediated group } \\
\text { support, anonymity, and the software } \\
\text { inspection process: An empirical } \\
\text { investigation, IEEE Transactions on } \\
\text { Software Engineering, vol. 29, pp. 167- } \\
\text { 180, } 2003 \text {. }\end{array}$ & $\begin{array}{l}\text { - Propone las posibles influencias del } \\
\text { anonimato de los miembros de un } \\
\text { grupo en las salidas de un proceso } \\
\text { de inspección mediado por el } \\
\text { computador } \\
\text { - Valida estas relaciones a través de } \\
\text { un conjunto de experimentos }\end{array}$ \\
\hline
\end{tabular}


Proceso de RS de experimentos en Ingeniería del Software

\begin{tabular}{|c|c|c|c|c|}
\hline & & & & $\begin{array}{l}\text { controlados } \\
\text { - Se emplean dos tareas diferentes } \\
\text { de inspección con niveles } \\
\text { cambiantes de complejidad de } \\
\text { código } \\
\text { - Miden: tiempo en ejecutar las } \\
\text { tareas, efectividad en encontrar los } \\
\text { errores "sembrados", actitud }\end{array}$ \\
\hline 42 & $\begin{array}{l}\text { /Scedire } \\
\text { ct/ } \\
\text { Sdirect_ } \\
\text { 5.pdf } \\
\text { /scopus/ } \\
\text { sco_7.pdf }\end{array}$ & $\begin{array}{l}\text { T. Thelin and } \\
\text { P. Runeson }\end{array}$ & $\begin{array}{l}\text { 31. Confidence intervals for capture- } \\
\text { recapture estimations in software } \\
\text { inspections, Information and Software } \\
\text { Technology, vol. 44, pp. 683-702, } 2002 \text {. }\end{array}$ & $\begin{array}{l}\text { - Replica un estudio captura- } \\
\text { recaptura } \\
\text { - Insvestiga los intervalos de } \\
\text { confianza para estimadores de } \\
\text { captura-recaptura utilizando } \\
\text { conjuntos de datos de dos } \\
\text { experimentos de inspección }\end{array}$ \\
\hline 44 & $\begin{array}{r}\text { /Scopus } \\
\text { /fulltext ND }\end{array}$ & Harjumaa, L. & $\begin{array}{l}\text { 32. Distributed software inspections - } \\
\text { An experiment with Adobe Acrobat, } \\
\text { International Conference on Computer } \\
\text { Science and Technology, pp. 26-31, } 2003\end{array}$ & $\begin{array}{l}\text { - Several computer tools for } \\
\text { supporting software inspections } \\
\text { exist. Most of them are prototypes } \\
\text { that demonstrate particular }\end{array}$ \\
\hline
\end{tabular}

Caso de estudio 


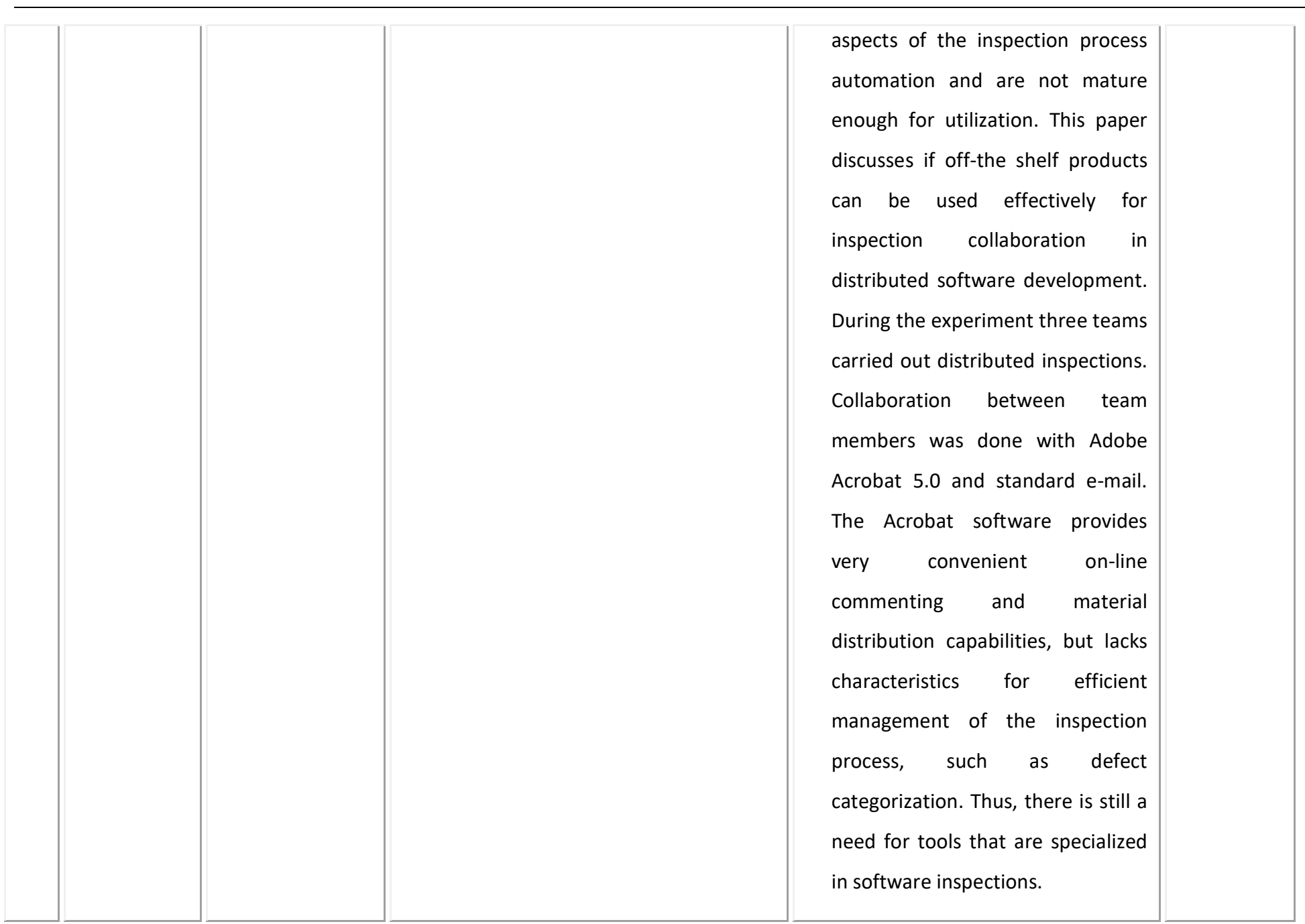


Proceso de RS de experimentos en Ingeniería del Software

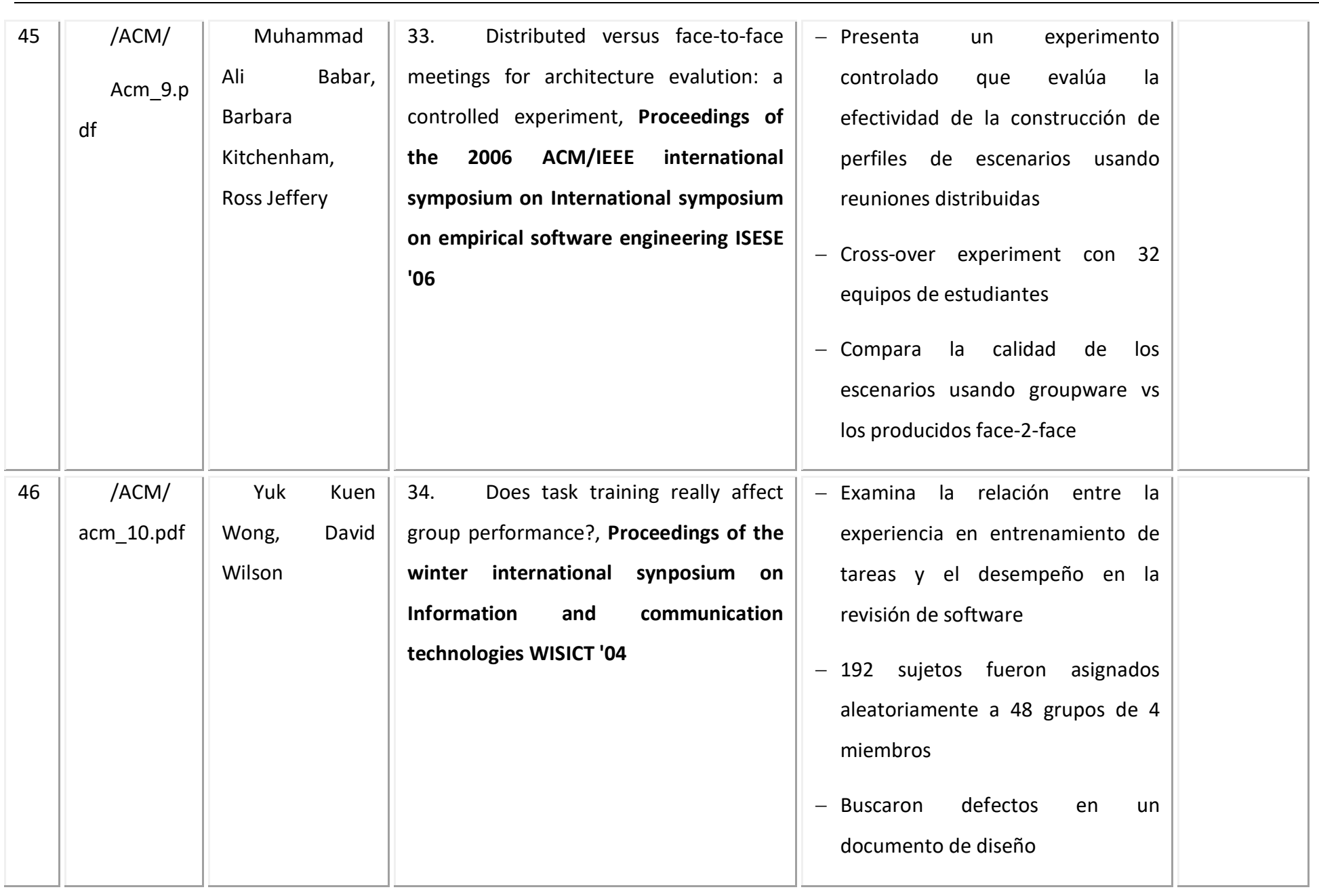

Caso de estudio 


\begin{tabular}{|c|c|c|c|c|}
\hline 47 & $\begin{array}{l}\text { /ACM/a } \\
\mathrm{cm} \_11 . p d f\end{array}$ & $\begin{array}{l}\text { Christian F. J. } \\
\text { Lange, Michel R. } \\
\text { V. Chaudron }\end{array}$ & $\begin{array}{l}\text { 35. Effects of defects in UML } \\
\text { models: an experimental investigation, } \\
\text { May } 2006 \text { Proceeding of the 28th } \\
\text { international conference on Software } \\
\text { engineering ICSE '06 }\end{array}$ & $\begin{array}{l}\text { - Presenta } 2 \text { experimentos } \\
\text { controlados } \\
\text { - Investiga cuántos investigadores } \\
\text { detectan defectos y cuántos } \\
\text { defectos causan diferentes } \\
\text { interpretaciones para diferentes } \\
\text { lectores } \\
\text { - Utilizan } 111 \text { estudiantes y } 48 \\
\text { practicantes industriales }\end{array}$ \\
\hline 48 & $\begin{array}{r}\text { /Scopus } \\
\text { /fulltext ND }\end{array}$ & $\begin{array}{c}\text { Kelly, D., } \\
\text { Shepard, T. }\end{array}$ & $\begin{array}{l}\text { Eight maxims for software inspectors. } \\
\text { Software Testing Verification and } \\
\text { Reliability } \\
\text { Volume } 14 \text {, Issue 4, December 2004, } \\
\text { Pages } 243-256\end{array}$ & $\begin{array}{l}\text { Software inspections are an } \\
\text { intensely people-centric activity. Even } \\
\text { though this is routinely recognized in } \\
\text { industry, much of the research } \\
\text { focuses on inspection mechanics. } \\
\text { During three years of inspection } \\
\text { experiments, even though the main } \\
\text { purpose of the experiments was to } \\
\text { investigate the effectiveness of a } \\
\text { particular technique, the inspectors } \\
\text { involved provided broad comments } \\
\text { on many other aspects of inspections. }\end{array}$ \\
\hline
\end{tabular}


Proceso de RS de experimentos en Ingeniería del Software

\begin{tabular}{|c|c|c|c|c|}
\hline & & & & $\begin{array}{l}\text { Their comments were collected and } \\
\text { organized into themes. } \\
\text { These themes are presented here } \\
\text { as a set of maxims that cover all the } \\
\text { topics that the inspectors felt were } \\
\text { important as they endeavoured to do } \\
\text { good inspections. }\end{array}$ \\
\hline 49 & $\begin{array}{l}\text { /Scedire } \\
\text { ct/ } \\
\text { sdirect_6.p } \\
\text { df }\end{array}$ & $\begin{array}{l}\text { S. S. So, S. D. } \\
\text { Cha, and Y. R. } \\
\text { Kwon, }\end{array}$ & $\begin{array}{l}\text { 36. Empirical evaluation of a fuzzy } \\
\text { logic-based software quality prediction } \\
\text { model, Fuzzy Sets and Systems, vol. 127, } \\
\text { pp. 199-208, } 2002 \text {. }\end{array}$ & $\begin{array}{l}\text { - Propone un enfoque automatizado } \\
\text { y basado en lógica difusa } \\
\text { - Analizan los datos de inspección y } \\
\text { aquellos obtenidos en }\end{array}$ \\
\hline 50 & $\begin{array}{l}\text { /scopus/ } \\
\text { sco_6.pdf }\end{array}$ & & & $\begin{array}{l}\text { experimentos de inspección } \\
\text { separados } \\
\text { - Valida el modelo de predicción de } \\
\text { la calidad propuesto }\end{array}$ \\
\hline 51 & $\begin{array}{l}\text { /Springe } \\
\text { r/ } \\
\text { Springer_11 } \\
\text {.pdf }\end{array}$ & T. Thomas, & $\begin{array}{l}\text { 37. Empirical Evaluations of Usage- } \\
\text { Based Reading and Fault Content } \\
\text { Estimation for Software Inspections, } \\
\text { Empirical Software Engineering, vol. V8, }\end{array}$ & $\begin{array}{c}\text { - Describe } 6 \text { investigaciones } \\
\text { empíricas de } 2 \text { técnicas de } \\
\text { inspección de software: técnica de } \\
\text { lectura (UBR) y de estimación de }\end{array}$ \\
\hline
\end{tabular}

Caso de estudio 


\begin{tabular}{|c|c|c|c|c|}
\hline 52 & $\begin{array}{l}\text { Scopus/ } \\
\text { sco_14.pdf }\end{array}$ & & pp. 309-313, 2003. & $\begin{array}{l}\text { contenido de fallas (captura- } \\
\text { recaptura) }\end{array}$ \\
\hline 53 & $\begin{array}{r}\text { /Scopus } \\
\text { /fulltext ND }\end{array}$ & Miller, J. & $\begin{array}{l}\text { Estimating the number of remaining } \\
\text { defects after inspection. Software Testing } \\
\text { Verification and Reliability, } 9 \text { (3), pp. 167- } \\
\text { 189. } 1999 .\end{array}$ & $\begin{array}{l}\text { An essential component of all } \\
\text { software inspection processes is a } \\
\text { well-founded decision about } \\
\text { continuing or stopping the current } \\
\text { process. This decision should be } \\
\text { based upon directly relevant } \\
\text { quantitative information - the number } \\
\text { of defects remaining in the artefact. } \\
\text { This quantity can be estimated by the } \\
\text { use of capture-recapture methods. } \\
\text { Several software engineering papers } \\
\text { have explored this topic, but the } \\
\text { question of which capture-recapture } \\
\text { technique is best still remains } \\
\text { unresolved. This paper attempts to } \\
\text { shed further light upon this question. } \\
\text { After reviewing the relevant capture- } \\
\text { recapture models and previous } \\
\text { evaluations within a software } \\
\text { engineering context the paper }\end{array}$ \\
\hline
\end{tabular}


Proceso de RS de experimentos en Ingeniería del Software

\begin{tabular}{|c|c|c|c|c|}
\hline & & & & $\begin{array}{l}\text { proceeds to evaluate the models by } \\
\text { using data collected from subject- } \\
\text { based experiments on software } \\
\text { inspection. The experiments used } \\
\text { artefacts where the number of } \\
\text { defects was known and hence a direct } \\
\text { measure of the accuracy of the } \\
\text { various capture-recapture techniques } \\
\text { was available. The paper reports that } \\
\text { most heterogeneity models show, in } \\
\text { general, superior performance - } \\
\text { especially the Jackknife estimator. } \\
\text { However, the paper concludes that } \\
\text { further work is required to correct the } \\
\text { limitations of the current models if } \\
\text { reliable estimates are to be achieved. }\end{array}$ \\
\hline 54 & $\begin{array}{l}\text { /Scedire } \\
\text { ct/ } \\
\text { sdirect_4.p } \\
\text { df }\end{array}$ & S. Biffl, & $\begin{array}{l}\text { 38. Evaluating defect estimation } \\
\text { models with major defects, Journal of } \\
\text { Systems and Software, vol. 65, pp. 13-29, }\end{array}$ & $\begin{array}{l}\text { - Se basa en la estimación de } \\
\text { defectos en documentos de } \\
\text { requisitos de software }\end{array}$ \\
\hline
\end{tabular}

Caso de estudio 


\begin{tabular}{|c|c|c|c|c|}
\hline 55 & $\begin{array}{r}\text { /Scopus } \\
\text { /fulltext ND }\end{array}$ & & 2003. & $\begin{array}{l}\text { - Compara el desempeño de técnicas } \\
\text { objetivas y subjetivas de } \\
\text { estimación del contenido de } \\
\text { defectos } \\
\text { - Conduce un experimento } \\
\text { controlado con } 31 \text { equipos de } \\
\text { inspección de 4-6 personas } \\
\text { - Miden: precisión }\end{array}$ \\
\hline 56 & $\begin{array}{c}\text { /ACM/ } \\
\text { acm_12.pdf }\end{array}$ & $\begin{array}{l}\text { Stefan Biffl, } \\
\text { Wilfried } \\
\text { Grossmann }\end{array}$ & $\begin{array}{l}\text { 39. Evaluating the accuracy of defect } \\
\text { estimation models based on inspection } \\
\text { data from two inspection cycles, } \\
\text { Proceedings of the 23rd International } \\
\text { Conference on Software Engineering } \\
\text { ICSE '01 }\end{array}$ & $\begin{array}{l}\text { - Considera } 3 \text { escenarios para } \\
\text { combinar conjuntos de datos de } \\
\text { los procesos de inspección- } \\
\text { reinspección } \\
\text { - Evalúa la precisión de la estimación } \\
\text { de defectos } \\
\text { - Utiliza los datos de un experimento } \\
\text { donde } 31 \text { equipos inpeccionaron- } \\
\text { reinspeccionaron docs de } \\
\text { requisitos de usuario. }\end{array}$ \\
\hline
\end{tabular}


Proceso de RS de experimentos en Ingeniería del Software

\begin{tabular}{|c|c|c|c|c|}
\hline 57 & $\begin{array}{l}\text { /Springe } \\
\text { r/ } \\
\text { Springer_1. } \\
\text { pdf }\end{array}$ & $\begin{array}{l}\text { T. Thomas, R. } \\
\text { Per, W. Claes, O. } \\
\text { Thomas, and A. } \\
\text { Carina, }\end{array}$ & $\begin{array}{l}\text { 40. Evaluation of Usage-Based } \\
\text { Reading-Conclusions after Three } \\
\text { Experiments, Empirical Software } \\
\text { Engineering, vol. V9, pp. 77-110, } 2004 .\end{array}$ & $\begin{array}{l}\text { - Presenta una serie de } \\
\text { experimentos para evaluar UBR } \\
\text { aplicado a un documento de } \\
\text { diseño de alto nivel }\end{array}$ \\
\hline 58 & $\begin{array}{l}\text { /Scopus } \\
\text { /fulltext ND }\end{array}$ & & & $\begin{array}{l}\text { - El foco es el 3er experimento: } \\
\text { investigar la información } \\
\text { necesitada por UBR para la } \\
\text { preparación y las reuniones de } \\
\text { inspección de software } \\
\text { - Discute la eficiencia y efectividad }\end{array}$ \\
\hline 59 & $\begin{array}{c}\text { /ACM/ } \\
\text { acm_3.pdf } \\
\text { (Xplore_ } \\
\text { 10.pdf) }\end{array}$ & $\begin{array}{l}\text { Porter, H. } \\
\text { Siy, C. A. Toman, } \\
\text { and L. G. Votta }\end{array}$ & $\begin{array}{l}41 . \quad \text { Experiment to assess the cost- } \\
\text { benefits of code inspections in large scale } \\
\text { software development, Proceedings of } \\
\text { the ACM SIGSOFT Symposium on the } \\
\text { Foundations of Software Engineering, }\end{array}$ & $\begin{array}{l}\text { - Conduce un proyecto a largo plazo } \\
\text { - Evalúa la costo-efectividad de } \\
\text { diversos métodos de inspección de } \\
\text { software }\end{array}$ \\
\hline 60 & $\begin{array}{l}\text { (Scopus/ } \\
\text { no_docume } \\
\text { nt) }\end{array}$ & & 1995. & $\begin{array}{l}\text { - Los métodos son aplicados por } \\
\text { desarrolladores profesionales } \\
\text { - Se utilizó simulación para optimizar } \\
\text { el experimento } \\
\text { - A cada inspección se le asignó }\end{array}$ \\
\hline
\end{tabular}

Caso de estudio 


\begin{tabular}{|c|c|c|c|c|}
\hline & & & & $\begin{array}{l}\text { aleatoriamente } 3 \text { variables } \\
\text { independientes: número de } \\
\text { revisores en el equipo, núm de } \\
\text { equipos de inspección, el requisito } \\
\text { de reparar los defectos entre la 1ạ } \\
\text { y 2ạ inspección } \\
\text { - Los revisores fueron seleccionados } \\
\text { aleatoriamente } \\
\text { - Las variables dependientes fueron: } \\
\text { tiempo de inspección, esfuerzo } \\
\text { total, la tasa de detección de } \\
\text { defectos }\end{array}$ \\
\hline 61 & $\begin{array}{r}\text { /Scopus } \\
\text { /fulltext ND }\end{array}$ & $\begin{array}{l}\text { Laitenberger, } \\
\text { O., Atkinson, C., } \\
\text { Schlich, M., El } \\
\text { Emam, K. }\end{array}$ & $\begin{array}{l}\text { Experimental comparison of reading } \\
\text { techniques for defect detection in UML } \\
\text { design documents, Journal of Systems } \\
\text { and Software } 53 \text { (2), pp. 183-204, } 2000\end{array}$ & $\begin{array}{l}\text { - The basic motivation for software } \\
\text { inspections is to detect and } \\
\text { remove defects before they } \\
\text { propagate to subsequent } \\
\text { development phases where their } \\
\text { detection and removal become } \\
\text { more expensive. To maximize this } \\
\text { potential, the examination of the } \\
\text { artefact under inspection must be }\end{array}$ \\
\hline
\end{tabular}


Proceso de RS de experimentos en Ingeniería del Software

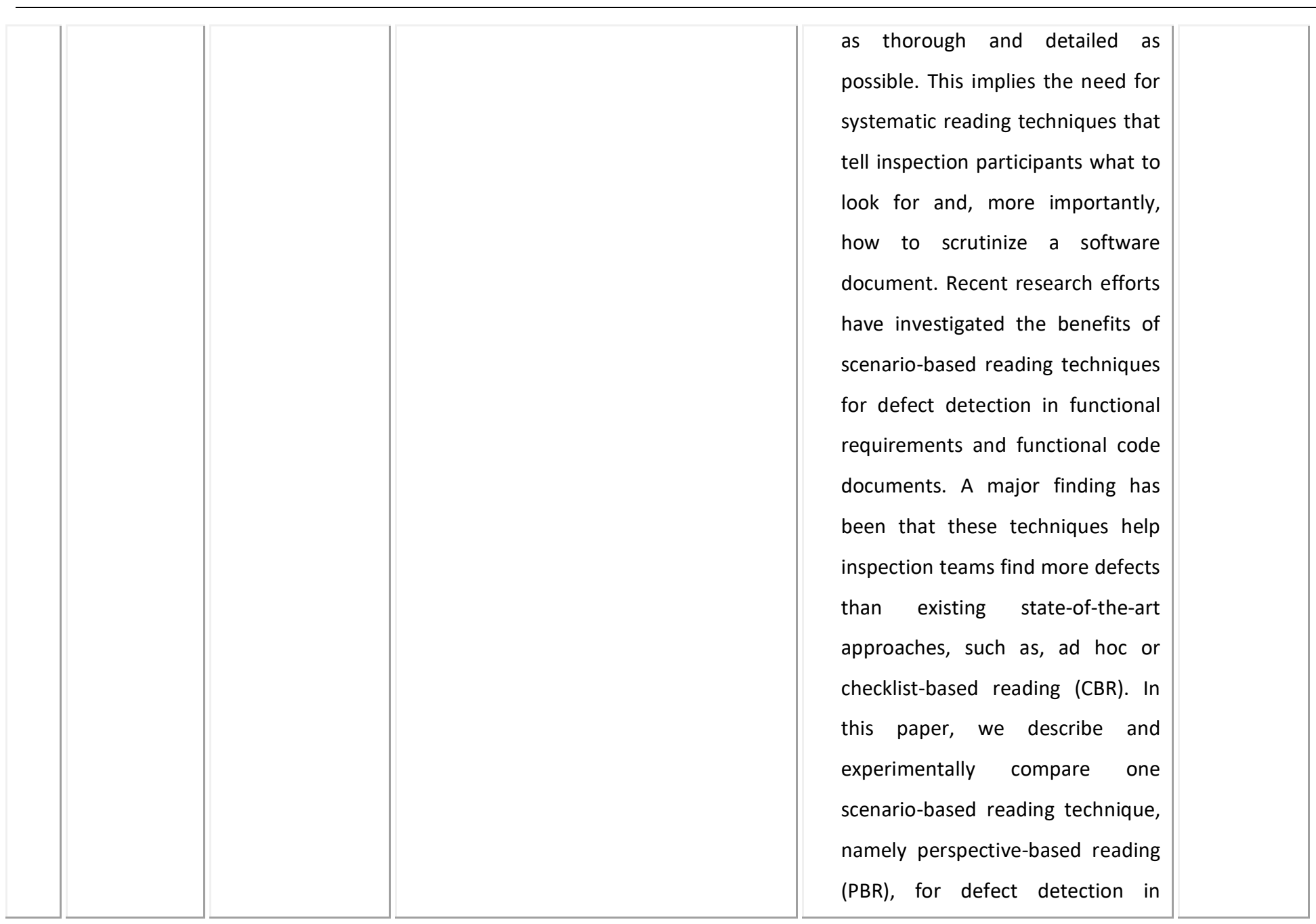

Caso de estudio 


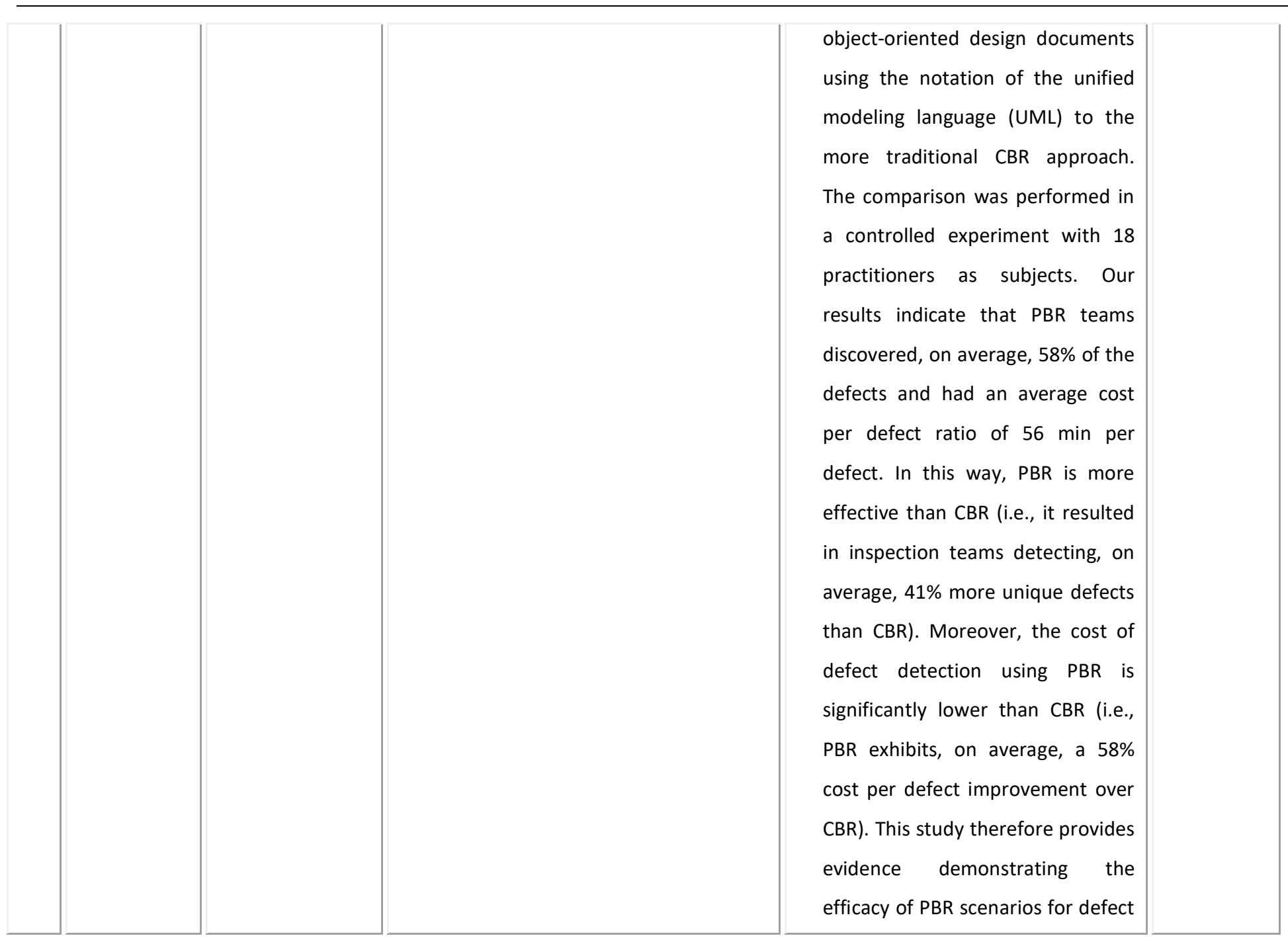


Proceso de RS de experimentos en Ingeniería del Software

\begin{tabular}{|c|c|c|c|c|}
\hline & & & & $\begin{array}{l}\text { detection in UML design } \\
\text { documents. In addition, it } \\
\text { demonstrates that a PBR } \\
\text { inspection is a promising approach } \\
\text { for improving the quality of models } \\
\text { developed using the UML notation. }\end{array}$ \\
\hline 62 & $\begin{array}{r}\text { /Scopus } \\
\text { /fulltext ND }\end{array}$ & $\begin{array}{l}\text { Wohlin, } \\
\text { Claes, Runeson, } \\
\text { Per, Brantestam, } \\
\text { Johan }\end{array}$ & $\begin{array}{l}\text { Experimental evaluation of capture- } \\
\text { recapture in software inspections, } \\
\text { Software Testing Verification and } \\
\text { Reliability } 5 \text { (4), pp. 213-232, } 1995\end{array}$ & $\begin{array}{l}\text { The use of capture-recapture to } \\
\text { estimate the residual faults in a } \\
\text { software artifact has evolved as a } \\
\text { promising method. However, the } \\
\text { assumptions needed to make the } \\
\text { estimates are not completely } \\
\text { fulfilled in software development, } \\
\text { leading to an underestimation of } \\
\text { the residual fault content. } \\
\text { Therefore, a method employing a } \\
\text { filtering technique with an } \\
\text { experience factor to improve the } \\
\text { estimates of the residual faults is } \\
\text { proposed in this paper. An } \\
\text { experimental study of the capture- }\end{array}$ \\
\hline
\end{tabular}

Caso de estudio 


\begin{tabular}{|c|c|c|c|c|}
\hline & & & & $\begin{array}{l}\text { recapture method with this } \\
\text { correction method has been } \\
\text { conducted. It is concluded that the } \\
\text { correction method improves the } \\
\text { capture-recapture estimate of the } \\
\text { number of residual defects in the } \\
\text { inspected document. }\end{array}$ \\
\hline 63 & $\begin{array}{r}\text { /Scopus } \\
\text { /fulltext ND }\end{array}$ & \begin{tabular}{ll}
\multicolumn{1}{c}{ Thelin, } & T., \\
Erlansson, & M., \\
Höst, & M., \\
Wohlin, C. &
\end{tabular} & $\begin{array}{l}\text { Experimentation with usage-based } \\
\text { reading, Lecture Notes in Computer } \\
\text { Science (including subseries Lecture } \\
\text { Notes in Artificial Intelligence and Lecture } \\
\text { Notes in Bioinformatics) 2765, pp. 193- } \\
207,2003\end{array}$ & $\begin{array}{l}\text { - Software inspections are regarded } \\
\text { as an important technique to } \\
\text { detect faults throughout the } \\
\text { software development process. } \\
\text { The individual preparation phase of } \\
\text { software inspections has enlarged } \\
\text { its focus from only comprehension } \\
\text { to also include fault searching. } \\
\text { Hence, reading techniques to } \\
\text { support the reviewers on fault } \\
\text { detection are needed. Usage-based } \\
\text { reading (UBR) is a reading } \\
\text { technique, which focuses on the } \\
\text { important parts from a user's point } \\
\text { of view in a software document by }\end{array}$ \\
\hline
\end{tabular}


Proceso de RS de experimentos en Ingeniería del Software

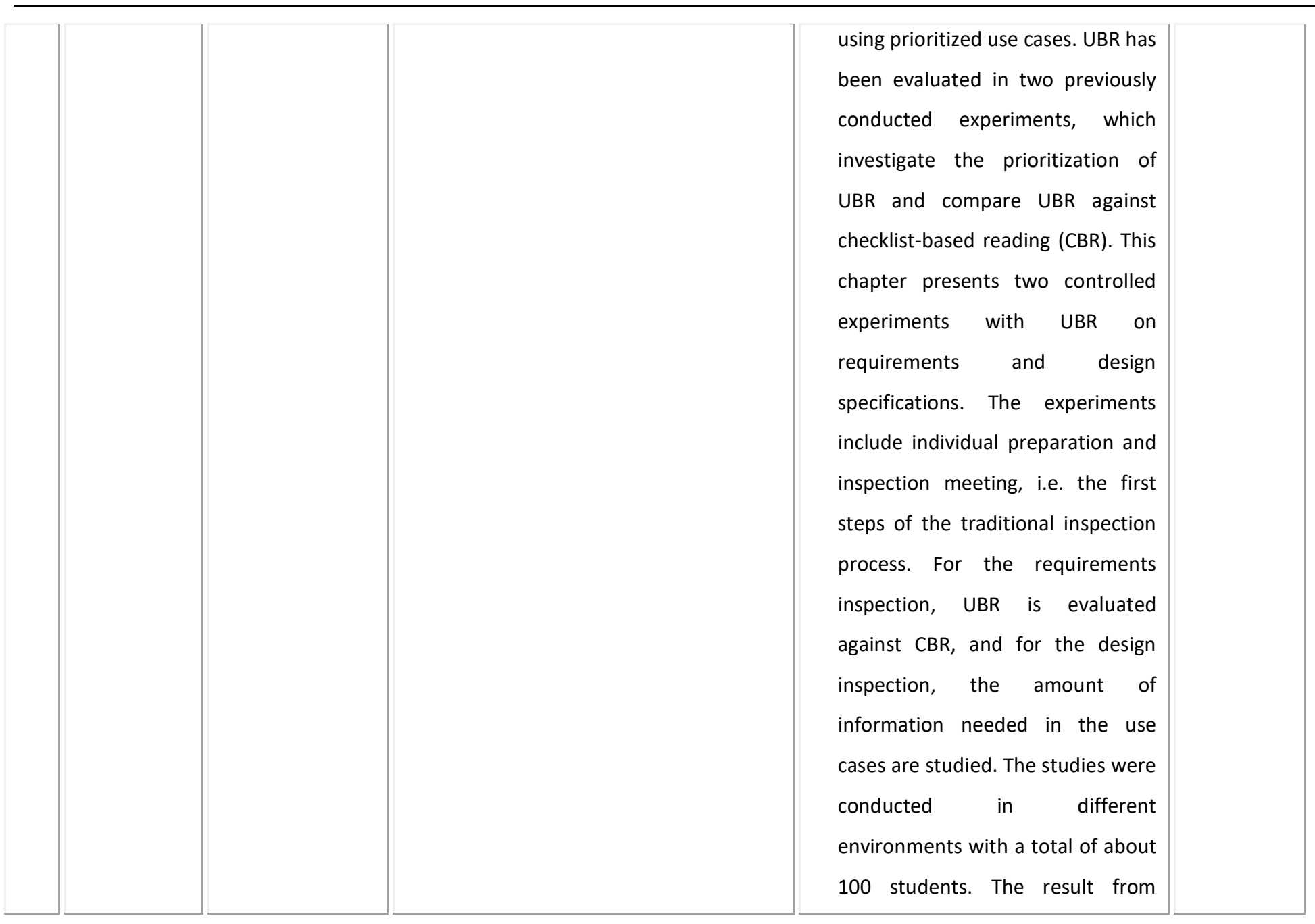

Caso de estudio 


\begin{tabular}{|c|c|c|c|c|}
\hline & & & & $\begin{array}{l}\text { these experiments shows that UBR } \\
\text { is not better than CBR for } \\
\text { requirements inspections. Results } \\
\text { from the experiment on design } \\
\text { inspection indicate that use cases } \\
\text { developed in advance are } \\
\text { preferable compared to developing } \\
\text { them as part of the preparation } \\
\text { phase of the inspection. }\end{array}$ \\
\hline 64 & $\begin{array}{l}\text { /Springe } \\
\text { r/ } \\
\text { Springer_6. } \\
\text { pdf }\end{array}$ & $\begin{array}{l}\text { J. Miller, M. } \\
\text { Wood, and M. } \\
\text { Roper, }\end{array}$ & $\begin{array}{l}\text { 42. Further Experiences with } \\
\text { Scenarios and Checklists, Empirical } \\
\text { Software Engineering, vol. V3, pp. 37-64, } \\
\text { 1998. }\end{array}$ & $\begin{array}{l}\text { - Es una replicación del experimento } \\
\text { de Porter et al. (1995) } \\
\text { (Xplore_16.pdf) } \\
\text { - Evalúa la ayuda a la detección }\end{array}$ \\
\hline 65 & $\begin{array}{l}\text { Scopus/ } \\
\text { sco_16.pdf }\end{array}$ & & & $\begin{array}{l}\text { utilizando enfoques basados en } \\
\text { escenarios y en checklist } \\
\text { - Compara los resultados del } \\
\text { experimento con otros } \\
\text { - Miden: desempeño, pérdidas de la } \\
\text { reunión }\end{array}$ \\
\hline 66 & /Scedire & G. & Further investigations of reading & - Describe la evaluación de CBR y \\
\hline
\end{tabular}


Proceso de RS de experimentos en Ingeniería del Software

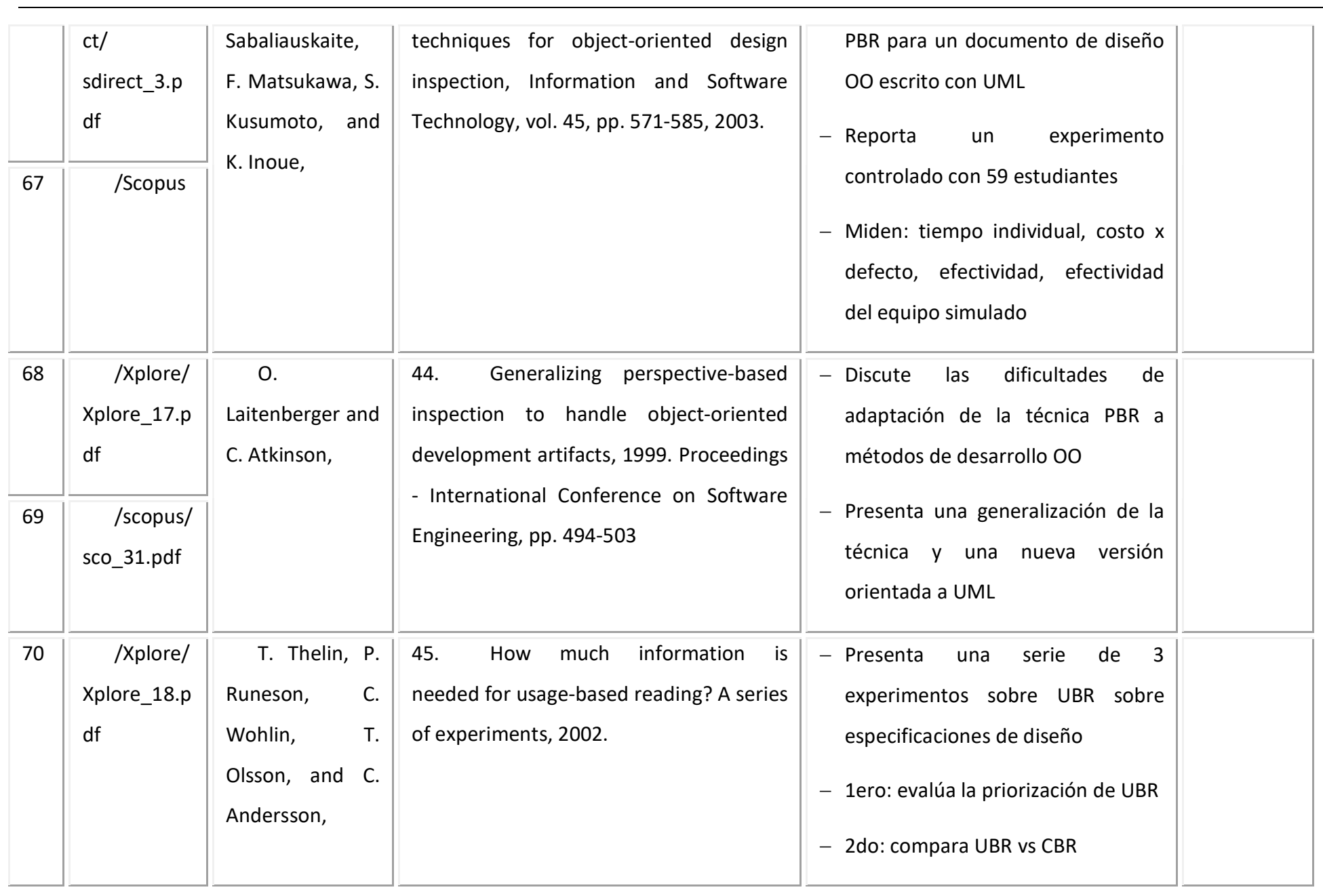

Caso de estudio 


\begin{tabular}{|c|c|c|c|c|}
\hline & & & & $\begin{array}{l}\text { - 3ero: investiga la cantidad de } \\
\text { información necesitada en los } \\
\text { casos de uso y si un enfoque más } \\
\text { activo ayuda a los revisores a } \\
\text { detectar más fallas } \\
\text { - El 3er experimento fue conducido } \\
\text { en dos sitios distintos con } 82 \\
\text { sujetos } \\
\text { - Miden: efectividad y eficiencia }\end{array}$ \\
\hline 71 & $\begin{array}{r}\text { /Scopus } \\
\text { /fulltext ND }\end{array}$ & $\mathrm{N} / \mathrm{D}$ & $\begin{array}{l}\text { Increasing the understanding of } \\
\text { effectiveness in software inspections } \\
\text { using published data sets }\end{array}$ & N/D \\
\hline 72 & $\begin{array}{l}\text { /Xplore/ } \\
\text { Xplore_19.p } \\
\text { df }\end{array}$ & $\begin{array}{l}\text { L. Harjumaa, } \\
\text { I. Tervonen, and } \\
\text { P. Vuorio, }\end{array}$ & $\begin{array}{l}\text { 46. Improving software inspection } \\
\text { process with patterns, 2004. Proceedings } \\
\text { - Fourth International Conference on } \\
\text { Quality Software, QSIC 2004, pp. 118-125 }\end{array}$ & $\begin{array}{l}\text { - Describe patrones para mejorar el } \\
\text { proceso de inspección de software } \\
\text { - Los patrones son experimentados } \\
\text { en una compañía de software } \\
\text { - Evalúan la capacidad inicial del } \\
\text { proceso } \\
\text { - Actualizan el proceso de acuerdo a }\end{array}$ \\
\hline
\end{tabular}


Proceso de RS de experimentos en Ingeniería del Software

\begin{tabular}{|c|c|c|c|c|}
\hline & & & & $\begin{array}{l}\text { determinadas metas } \\
\text { - Miden la ejecución posterior del } \\
\text { proceso }\end{array}$ \\
\hline 73 & $\begin{array}{l}\text { /Springe } \\
\text { r/ } \\
\text { Springer_10 } \\
\text {.pdf }\end{array}$ & $\begin{array}{l}\text { S. Tor and A. } \\
\text { Tanveer Husain, }\end{array}$ & $\begin{array}{l}\text { 47. Improving the Software } \\
\text { Inspection Process, } 2005 .\end{array}$ & $\begin{array}{l}\text { - Muestra los resultados de } 3 \\
\text { experimentos } \\
\text { - Presentan y combinan resultados } \\
\text { para dar recomendaciones en }\end{array}$ \\
\hline 74 & $\begin{array}{r}\text { /Scopus } \\
\text { /fulltext ND }\end{array}$ & & & $\begin{array}{l}\text { inspección de código } \\
\text { - Discuten: beneficios de utilzar } \\
\text { grupos de inspección grandes, } \\
\text { mecanismos de decisión en las } \\
\text { reuniones }\end{array}$ \\
\hline 75 & $\begin{array}{l}\text { /Xplore/ } \\
\text { Xplore_20.p } \\
\text { df }\end{array}$ & H. Petersson, & $\begin{array}{l}\text { 48. Individual reviewer contribution } \\
\text { to the effectiveness of software } \\
\text { inspection teams, } 2001 .\end{array}$ & $\begin{array}{l}\text { - Se enfoca en la contribución del } \\
\text { individuo en la efectividad del } \\
\text { grupo } \\
\text { - Analiza los datos de experimentos } \\
\text { realizados }\end{array}$ \\
\hline
\end{tabular}

Caso de estudio 


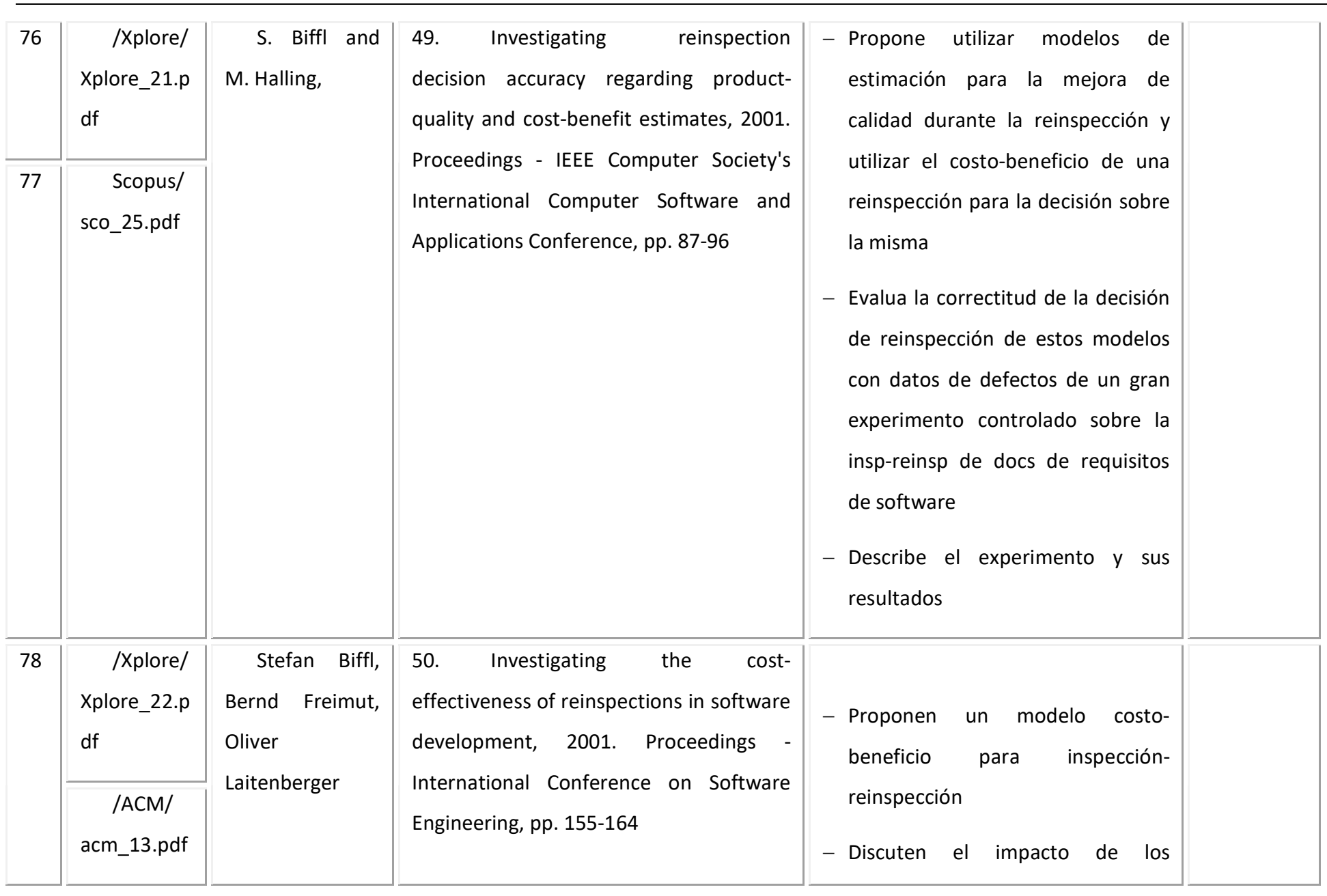


Proceso de RS de experimentos en Ingeniería del Software

\begin{tabular}{|c|c|c|c|c|}
\hline 79 & $\begin{array}{l}\text { /scopus/ } \\
\text { sco_9.pdf }\end{array}$ & & & $\begin{array}{l}\text { parámetros costo y beneficio sobre } \\
\text { la ganancia neta de una } \\
\text { reinspección }\end{array}$ \\
\hline 80 & & & & $\begin{array}{l}\text { - Utilizan datos empíricos de un } \\
\text { experimento en el cual } 31 \text { equipos } \\
\text { de estudiantes inspeccionaron- } \\
\text { reinspeccionaron un documento } \\
\text { de requisitos } \\
\text { - Comparan los beneficios y } \\
\text { ganancia de neta de la } \\
\text { reinspección respecto a la } \\
\text { inspección inicial }\end{array}$ \\
\hline 81 & $\begin{array}{r}\text { /Scopus } \\
\text { /fulltext ND }\end{array}$ & $\begin{array}{c}\text { Biffl, } \\
\text { Halling, } M .\end{array}$ & $\begin{array}{l}\text { Investigating the defect detection } \\
\text { effectiveness and cost benefit of nominal } \\
\text { inspection teams, IEEE Transactions on } \\
\text { Software Engineering } 29(5), \text { pp. 385-397 }\end{array}$ & $\begin{array}{l}\text { - Inspection is an effective but also } \\
\text { expensive quality assurance } \\
\text { activity to find defects early during } \\
\text { software development. The defect } \\
\text { detection process, team size, and } \\
\text { staff hours invested can have a } \\
\text { considerable impact on the defect } \\
\text { detection effectiveness and cost- }\end{array}$ \\
\hline
\end{tabular}

Caso de estudio 


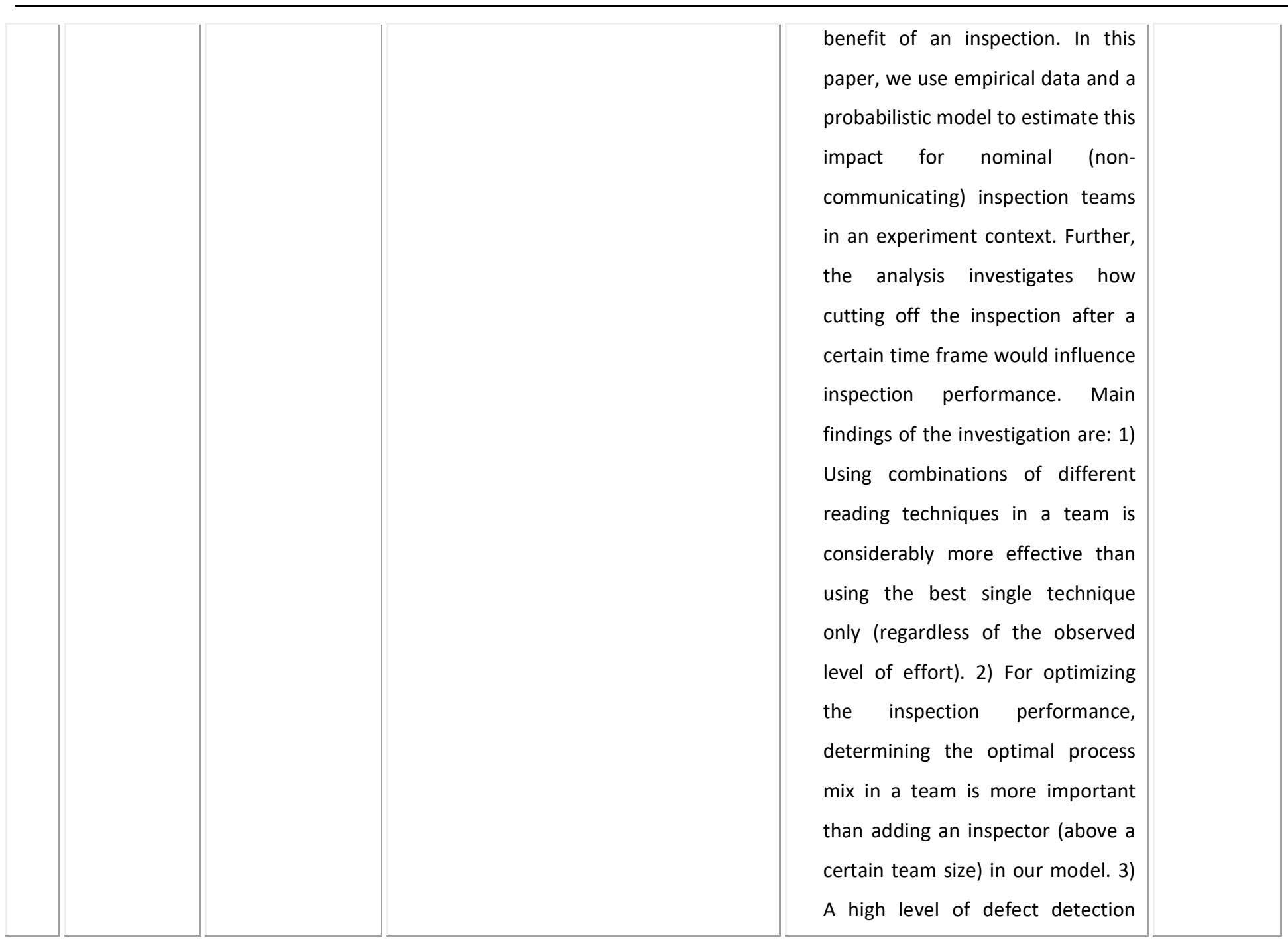


Proceso de RS de experimentos en Ingeniería del Software

\begin{tabular}{|c|c|c|c|c|}
\hline & & & & $\begin{array}{l}\text { effectiveness is much more costly } \\
\text { to achieve than a moderate level } \\
\text { since the average cost for the } \\
\text { defects found by the inspector last } \\
\text { added to a team increases more } \\
\text { than linearly with growing effort } \\
\text { investment. The work provides an } \\
\text { Initial baseline of inspection } \\
\text { performance with regard to } \\
\text { process diversity and effort in } \\
\text { inspection teams. We encourage } \\
\text { further studies on the topic of time } \\
\text { usage with defect detection } \\
\text { techniques and its effect on } \\
\text { inspection effectiveness in a } \\
\text { variety of inspection contexts to } \\
\text { support inspection planning with } \\
\text { limited resources. }\end{array}$ \\
\hline 82 & $\begin{array}{l}\text { /Xplore/ } \\
\text { Xplore_23.p } \\
\text { df }\end{array}$ & $\begin{array}{l}\text { S. Biffl, M. } \\
\text { Halling, and M. } \\
\text { Kohle, }\end{array}$ & $\begin{array}{l}\text { 51. Investigating the effect of a } \\
\text { second software inspection cycle. Cost- } \\
\text { benefit data from a large-scale }\end{array}$ & $\begin{array}{l}\text { - Reporta un experimento } \\
\text { controlado que compara el efecto } \\
\text { de dos ciclos de inspección }\end{array}$ \\
\hline
\end{tabular}

Caso de estudio 


\begin{tabular}{|c|c|c|c|c|}
\hline & & & $\begin{array}{l}\text { experiment on reinspection of a software } \\
\text { requirements document, } 2000 .\end{array}$ & $\begin{array}{l}\text { - Un documento de requisitos es re- } \\
\text { inspeccionado por } 31 \text { equipos } \\
\text { - Presenta: efectividad, eficiencia, } \\
\text { ganancia neta, ROI de un segundo } \\
\text { ciclo de inspección } \\
\text { - Evalúan los supuestos y la } \\
\text { correctitud de los criterios de } \\
\text { decisión }\end{array}$ \\
\hline 83 & $\begin{array}{r}\text { /Scopus } \\
\text { /fulltext ND }\end{array}$ & $\begin{array}{l}\quad \text { Winkler, D., } \\
\text { Hailing, M., Biffl, } \\
\text { S. }\end{array}$ & $\begin{array}{l}\text { Investigating the effect of expert } \\
\text { ranking of use cases for design } \\
\text { inspection, Conference Proceedings of } \\
\text { the EUROMICRO 30, pp. 362-371 }\end{array}$ & $\begin{array}{l}\text { - Inspection is an important } \\
\text { approach to reduce defects in } \\
\text { software engineering artifacts. } \\
\text { Reading techniques such as Usage- } \\
\text { Based Reading (UBR) can focus } \\
\text { inspector attention on specific } \\
\text { types of defects (missing and } \\
\text { wrong information) and specific } \\
\text { defect severity classes (critical, } \\
\text { important and not important } \\
\text { defects). For empirical } \\
\text { investigation the replication of } \\
\text { experiments can help increase the }\end{array}$ \\
\hline
\end{tabular}


Proceso de RS de experimentos en Ingeniería del Software

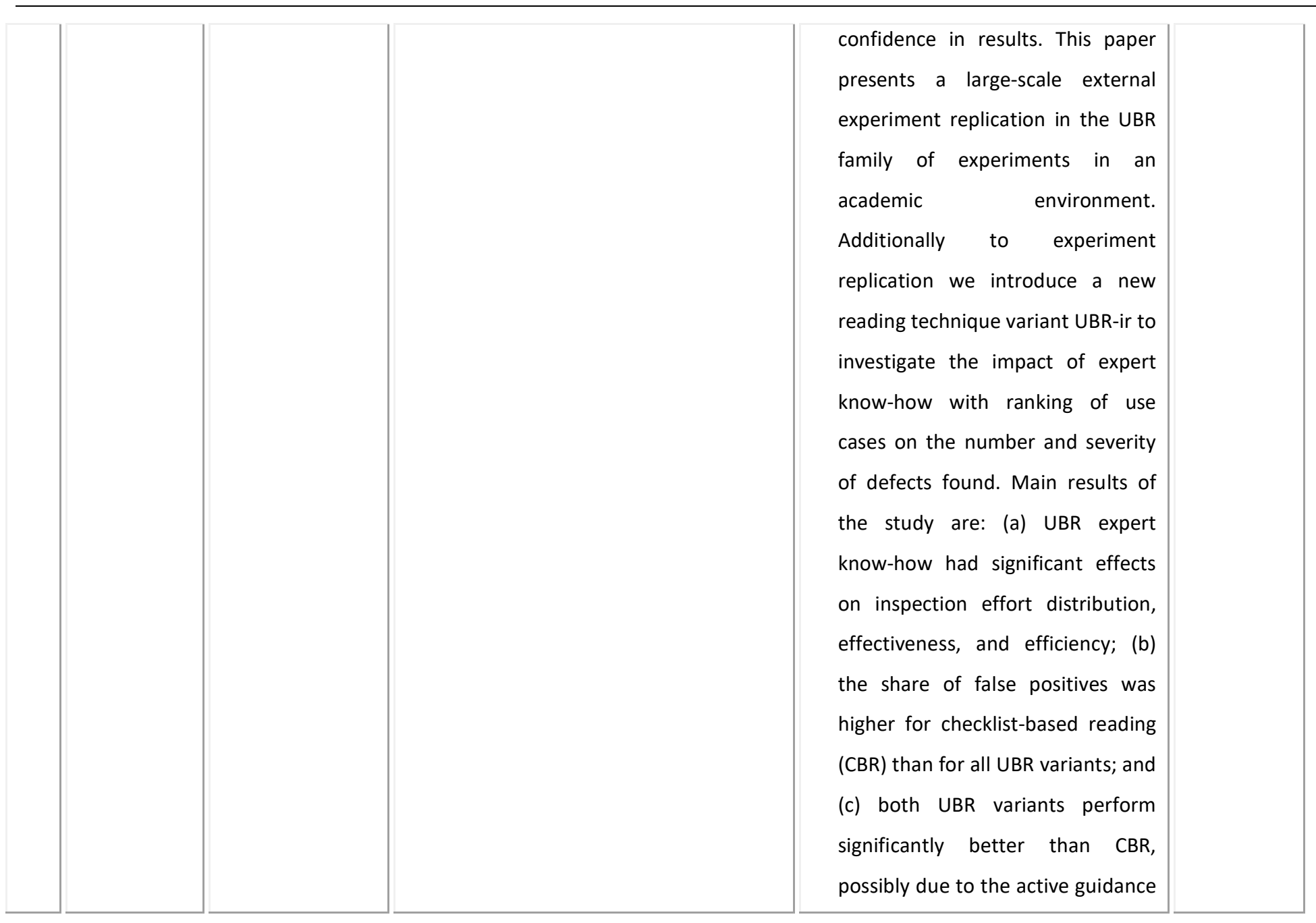

Caso de estudio 


\begin{tabular}{|c|c|c|c|c|}
\hline & & & & of use cases. \\
\hline 84 & $\begin{array}{l}\text { /Springe } \\
\text { r/ } \\
\text { Springer_2. } \\
\text { pdf }\end{array}$ & $\begin{array}{l}\text { W. Dietmar, } \\
\text { B. Stefan, and T. } \\
\text { Bettina, }\end{array}$ & $\begin{array}{l}\text { 52. Investigating the Impact of } \\
\text { Active Guidance on Design Inspection, } \\
\text { 2005. Lecture Notes in Computer Science } \\
\text { 3547, pp. } 458-473\end{array}$ & $\begin{array}{l}\text { - Comparan el desempeño de este } \\
\text { enfoque en un experimento } \\
\text { controlado en un ambiente } \\
\text { académico }\end{array}$ \\
\hline 85 & $\begin{array}{r}\text { /Scopus } \\
\text { /fulltext ND }\end{array}$ & & & $\begin{array}{c}\text { - Miden efectividad y eficiencia de } \\
\text { CBR y UBR usando active guidance }\end{array}$ \\
\hline 86 & $\begin{array}{l}\text { /Xplore/ } \\
\text { Xplore_24.p } \\
\text { df }\end{array}$ & $\begin{array}{l}\text { B. Freimut, } \\
\text { O. Laitenberger, } \\
\text { and S. Biffl, }\end{array}$ & $\begin{array}{l}53 . \quad \text { Investigating the impact of } \\
\text { reading techniques on the accuracy of } \\
\text { different defect content estimation } \\
\text { techniques, } 2001 \text {. }\end{array}$ & $\begin{array}{l}\text { - Examina el impacto de } 2 \text { técnicas } \\
\text { de lectura: SBR y CBR en la } \\
\text { precisión de diferentes técnicas de } \\
\text { estimación }\end{array}$ \\
\hline 87 & $\begin{array}{r}\text { /Scopus } \\
\text { /fulltext ND }\end{array}$ & & & $\begin{array}{l}\text { - Se basa en datos recogidos en un } \\
\text { gran experimento con estudiantes }\end{array}$ \\
\hline 88 & $\begin{array}{l}\text { /Xplore/ } \\
\text { Xplore_25.p } \\
\text { df }\end{array}$ & D. O'Neill, & $\begin{array}{l}54 . \quad \text { Issues in software inspection, } \\
\text { Software, IEEE, vol. } 14 \text {, pp. } 18-19,1997 .\end{array}$ & $\begin{array}{l}\text { - Propone sugerencias para } \\
\text { implementar inspecciones en } \\
\text { todos los niveles del proceso de } \\
\text { desarrollo }\end{array}$ \\
\hline 89 & $\begin{array}{l}\text { /Xplore/ } \\
\text { Xplore_26.p }\end{array}$ & $\begin{array}{l}\text { A. } \\
\text { Dunsmore, }\end{array}$ & $\begin{array}{l}\text { 55. Object-oriented inspection in } \\
\text { the face of delocalisation, } 2000 .\end{array}$ & - Investiga la aplicación de la \\
\hline
\end{tabular}


Proceso de RS de experimentos en Ingeniería del Software

\begin{tabular}{|c|c|c|c|c|}
\hline & $d f$ & \multirow{3}{*}{$\begin{array}{l}\text { Roper, and M. } \\
\text { Wood, }\end{array}$} & \multirow{3}{*}{$\begin{array}{l}\text { Proceedings - International Conference } \\
\text { on Software Engineering, pp. 467-476 }\end{array}$} & \multirow{3}{*}{$\begin{array}{l}\text { inspección a código oo. } \\
\text { - Realiza un análisis de los defectos } \\
\text { difíciles de encontrar durante un } \\
\text { experimento de inspección }\end{array}$} \\
\hline 90 & $\begin{array}{c}\text { /ACM/ } \\
\text { acm_14.pdf }\end{array}$ & & & \\
\hline 91 & $\begin{array}{r}\text { Scopus/ } \\
\text { sco_30.pdf }\end{array}$ & & & \\
\hline 92 & $\begin{array}{r}\text { /Scopus } \\
\text { /fulltext ND }\end{array}$ & $\begin{array}{l}\quad \text { Conradi, R., } \\
\text { Mohagheghi, P., } \\
\text { Arif, T., Hegde, } \\
\text { L.C., Bunde, } \\
\text { G.A., Pedersen, } \\
\text { A. }\end{array}$ & $\begin{array}{l}\text { Object-oriented reading techniques } \\
\text { for inspection of UML models - An } \\
\text { industrial experiment. Lecture Notes in } \\
\text { Computer Science (including subseries } \\
\text { Lecture Notes in Artificial Intelligence and } \\
\text { Lecture Notes in Bioinformatics), } 2743 \text {, } \\
\text { pp. } 483-500 .\end{array}$ & $\begin{array}{l}\text { Object-oriented design and } \\
\text { modeling with UML has become a } \\
\text { central part of software development } \\
\text { in industry. Software inspections are } \\
\text { used to cost-efficiently increase the } \\
\text { quality of the developed software by } \\
\text { early defect detection and correction. } \\
\text { Several models presenting the total } \\
\text { system need to be inspected for } \\
\text { consistency with each other and with } \\
\text { external documents such as } \\
\text { requirement specifications. Special } \\
\text { Object Oriented Reading Techniques } \\
\text { (OORTs) have been developed to help } \\
\text { inspectors in the individual reading }\end{array}$ \\
\hline
\end{tabular}

Caso de estudio 


\begin{tabular}{|c|c|c|c|c|}
\hline & & & & $\begin{array}{l}\text { step of inspection of UML models. } \\
\text { The paper describes an experiment } \\
\text { performed at Ericsson in Norway to } \\
\text { evaluate the cost-efficiency of } \\
\text { tailored OORTs in a large-scale } \\
\text { software project. The results showed } \\
\text { that the OORTs fit well into an } \\
\text { incremental development process, } \\
\text { and managed to detect defects not } \\
\text { found by the existing reading } \\
\text { techniques. The study demonstrated } \\
\text { the need for further development and } \\
\text { empirical assessment of these } \\
\text { techniques, and for better integration } \\
\text { with industrial work practice. }\end{array}$ \\
\hline 93 & $\begin{array}{l}\text { /Scedire } \\
\text { ct/ } \\
\text { sdirect_7.p } \\
\text { df }\end{array}$ & J. Miller, & $\begin{array}{l}\text { 56. On the independence of } \\
\text { software inspectors, Journal of Systems } \\
\text { and Software, vol. 60, pp. 5-10, } 2002 \text {. }\end{array}$ & $\begin{array}{l}\text { - Investiga si los resultados de un } \\
\text { inspector individual durante la fase } \\
\text { de preparación son dependientes o } \\
\text { independientes }\end{array}$ \\
\hline 94 & $\begin{array}{l}\text { Scopus/ } \\
\text { sco_23.pdf }\end{array}$ & & & $\begin{array}{l}\text { - Usa datos de un experimento } \\
\text { previo y una simulación a partir de }\end{array}$ \\
\hline
\end{tabular}


Proceso de RS de experimentos en Ingeniería del Software

\begin{tabular}{|c|c|c|c|c|}
\hline & & & & ellos \\
\hline 95 & $\begin{array}{c}\text { /ACM/ } \\
\text { acm 15.pdf }\end{array}$ & \multirow{2}{*}{$\begin{array}{l}\text { Pankaj } \\
\text { Jalote, } \\
\text { Haragopal }\end{array}$} & \multirow{2}{*}{$\begin{array}{l}\text { 57. Overcoming the NAH syndrome } \\
\text { for inspection deployment, Proceedings } \\
\text { of the 20th international conference on } \\
\text { Software engineering ICSE ' } 98\end{array}$} & - Ejecutan un experimento para \\
\hline 96 & $\begin{array}{r}\text { /Scopus } \\
\text { /fulltext ND }\end{array}$ & & & $\begin{array}{l}\text { here" en una organización que } \\
\text { realiza una inspección de software } \\
\text { - Adicionalmente, comparar las } \\
\text { inspecciones de código con las } \\
\text { pruebas de unidad } \\
\text { - Miden: capacidad de detección de } \\
\text { defectos, efectos de la inspección } \\
\text { en los costos globales del } \\
\text { desarrollo. }\end{array}$ \\
\hline 97 & $\begin{array}{c}\text { /ACM/ } \\
\text { acm_17.pdf }\end{array}$ & \multirow[t]{2}{*}{$\begin{array}{l}\text { Lulu He, } \\
\text { Jeffrey Carver }\end{array}$} & \multirow{2}{*}{$\begin{array}{l}\text { 58. PBR vs. checklist: a replication in } \\
\text { the } n \text {-fold inspection context, } \\
\text { Proceedings of the } 2006 \text { ACM/IEEE } \\
\text { International symposium on empirical } \\
\text { software engineering ISESE ' } 06\end{array}$} & $\begin{array}{c}\text { - Describe un experimento para } \\
\text { validar la efectividad de } \\
\text { Perspectiva-based reading en una }\end{array}$ \\
\hline 98 & $\begin{array}{r}\text { /Scopus } \\
\text { /fulltext ND }\end{array}$ & & & $\begin{array}{l}\text { inspección N-fold basada en } \\
\text { reunión } \\
\text { - Busca validar la hipótesis original } \\
\text { de que PBR ayuda a incrementar la }\end{array}$ \\
\hline
\end{tabular}

Caso de estudio 


\begin{tabular}{|c|c|c|c|c|}
\hline & & & & $\begin{array}{l}\text { efectividad (individual y grupal) de } \\
\text { detección de fallos, comparado con } \\
\text { un enfoque Checklist } \\
\text { _ Investiga los diferentes impactos } \\
\text { de PBR y checklist en la efectividad } \\
\text { de una reunión de equipo } \mathrm{N} \text {-fold } \\
\text { - Investiga algunas características de } \\
\text { PBR }\end{array}$ \\
\hline 99 & $\begin{array}{l}\text { /Scopus } \\
\text { /fulltext ND }\end{array}$ & \begin{tabular}{l}
\multicolumn{2}{l}{ Maldonado, } \\
J.C., Carver, J., \\
Shull, F., Fabbri, \\
S., Dória, E., \\
Martimiano, L., \\
Mendonça, M., \\
Basili, V.
\end{tabular} & \begin{tabular}{l}
\multicolumn{1}{c}{ Perspective-based reading: } \\
replicated experiment focused \\
individual reviewer effectiveness
\end{tabular} & $\begin{array}{l}\text { This paper describes a replication } \\
\text { conducted to compare the } \\
\text { effectiveness of inspectors using } \\
\text { Perspective Based Reading (PBR) to } \\
\text { the effectiveness of inspectors using a } \\
\text { checklist. The goal of this replication } \\
\text { was to better understand the } \\
\text { complementary aspects of the PBR } \\
\text { perspectives. To this end, a brief } \\
\text { discussion of the original study is } \\
\text { provided as well as a more detailed } \\
\text { description of the replication. A } \\
\text { detailed statistical analysis is then }\end{array}$ \\
\hline
\end{tabular}


Proceso de RS de experimentos en Ingeniería del Software

\begin{tabular}{|c|c|c|c|c|}
\hline & & & & $\begin{array}{l}\text { provided along with analysis of the } \\
\text { PBR perspectives. For the individual } \\
\text { PBR perspectives, we saw an } \\
\text { interesting dichotomy: In the original } \\
\text { study there was little overlap among } \\
\text { the sets of defects found by each of } \\
\text { the three perspectives, while in the } \\
\text { replication two of the three } \\
\text { perspectives found similar sets of } \\
\text { defects on one of the two documents } \\
\text { used in the study. Interestingly this } \\
\text { document was the only case where } \\
\text { the users of PBR were not more } \\
\text { effective than the users of a checklist. } \\
\text { This result leads to a new hypothesis } \\
\text { that the complementary aspect of the } \\
\text { PBR perspectives is the characteristic } \\
\text { that provides the benefit over other } \\
\text { defect detection techniques. }\end{array}$ \\
\hline 100 & $\begin{array}{l}\text { /Scopus } \\
/ \text { ND }\end{array}$ & $\begin{array}{l}\text { Dunsmore, } \\
\text { A., Roper, M., }\end{array}$ & $\begin{array}{l}\text { Practical code inspection techniques } \\
\text { for object-oriented systems: An }\end{array}$ & $\begin{array}{l}\text { The aim of empirical software } \\
\text { engineering research is to help }\end{array}$ \\
\hline
\end{tabular}

Caso de estudio 


\begin{tabular}{|c|c|c|c|c|}
\hline & & Wood, M. & $\begin{array}{l}\text { experimental comparison. IEEE Software, } \\
20 \text { (4), pp. } 21-29 .\end{array}$ & $\begin{array}{l}\text { determine the effectiveness of } \\
\text { development processes and } \\
\text { techniques. This paper highlights } \\
\text { problems that could arise when } \\
\text { inspecting oo code. It also discusses } \\
\text { the results of a long-term empirical } \\
\text { study invesgitating reading strategies } \\
\text { specifically developed to address } \\
\text { these difficulties. }\end{array}$ \\
\hline 101 & $\begin{array}{l}\text { /Scopus } \\
\text { /ND }\end{array}$ & $\begin{array}{l}\text { Murphy, } \\
\text { Paul, Miller, } \\
\text { James }\end{array}$ & $\begin{array}{l}\text { Process for asynchronous software } \\
\text { inspection. (1997) Proceedings of the } \\
\text { International Workshop on Software } \\
\text { Technology and Engineering Practice, } \\
\text { STEP, pp. 96-104. }\end{array}$ & $\begin{array}{l}\text { Although there exists a multitude } \\
\text { of different inspection processes, the } \\
\text { basic process has remained } \\
\text { unchanged since it was first defined } \\
\text { by Fagan in 1976. The process has as } \\
\text { its central component an inspection } \\
\text { meeting which all participants attend. } \\
\text { But is this meeting cost effective? } \\
\text { Recent work suggests this is not the } \\
\text { case. An inspection model that } \\
\text { dispenses totally with the need for } \\
\text { the inspectors to be in the same place } \\
\text { at the same time is presented. It }\end{array}$ \\
\hline
\end{tabular}


Proceso de RS de experimentos en Ingeniería del Software

\begin{tabular}{|l|l|l|}
\hline $\mid$ & $\begin{array}{l}\text { replaces the meeting with further } \\
\text { individual inspections combined with } \\
\text { asynchronous communication } \\
\text { between inspectors. A prototype tool } \\
\text { has been developed that supports the } \\
\text { asynchronous model. In contrast to a } \\
\text { previously developed asynchronous } \\
\text { inspection tool, it uses electronic mail } \\
\text { as the basis for communication and } \\
\text { the reasons for this approach are } \\
\text { discussed. The inspection model is } \\
\text { evaluated in comparison with the } \\
\text { traditional, meting-oriented } \\
\text { approach on a number of criteria. An } \\
\text { initial attempt was made to gain } \\
\text { quantitative data by carrying out a } \\
\text { small-scale experiment, but whilst } \\
\text { encouraging results being obtained, } \\
\text { the number of subjects was too low } \\
\text { for any significant conclusions to be } \\
\text { drawn. Larger scale experiments are } \\
\text { planned for the future to obtain more }\end{array}$ \\
\hline
\end{tabular}

Caso de estudio 


\begin{tabular}{|c|c|c|c|c|}
\hline & & & & data. \\
\hline 102 & $\begin{array}{c}\text { /ACM/ } \\
\text { acm_18.pdf }\end{array}$ & $\begin{array}{l}\text { Diane Kwlly, } \\
\text { Terry Shepard }\end{array}$ & $\begin{array}{l}\text { 59. Qualitative observations from } \\
\text { software code inspection experiments, } \\
\text { Proceedings of the } 2002 \text { conference of } \\
\text { the Centre for Advanced Studies on } \\
\text { Collaborative research CASCON ' } 02\end{array}$ & $\begin{array}{l}\text { - Recoge y organiza observaciones } \\
\text { que fueron hechas durante una } \\
\text { serie de experimentos previos } \\
\text { - Presenta comentarios y análisis de } \\
\text { los resultados de tales } \\
\text { experimentos } \\
\text { - Describe brevemente } 3 \text { de los } \\
\text { experimentos }\end{array}$ \\
\hline 103 & $\begin{array}{l}\text { /Scopus } \\
\text { /ND }\end{array}$ & $\begin{array}{ll}\quad \begin{array}{l}\text { Perry, } \\
\text { Porter, }\end{array} & \text { A., } \\
\text { Wade, } & \text { M.W., } \\
\text { Votta, } & \text { L.G., } \\
\text { Perpich, J. }\end{array}$ & $\begin{array}{l}\text { Reducing inspection interval in large- } \\
\text { scale software development. (2002) IEEE } \\
\text { Transactions on Software Engineering, } 28 \\
\text { (7), pp. 695-705. }\end{array}$ & $\begin{array}{l}\text { We have found that, when } \\
\text { software is developed by multiple, } \\
\text { geographically separated teams, the } \\
\text { cost-benefit trade-offs of software } \\
\text { inspection change. In particular, this } \\
\text { situation can significantly lengthen } \\
\text { the inspection interval (calendar time } \\
\text { needed to complete an inspection). } \\
\text { Our research goal was to find a way } \\
\text { to reduce the inspection interval } \\
\text { without reducing inspection } \\
\text { effectiveness. We believed that }\end{array}$ \\
\hline
\end{tabular}


Proceso de RS de experimentos en Ingeniería del Software

\begin{tabular}{|l|l|l|}
\hline $\mid$ & $\mid \begin{array}{l}\text { Internet technology offered some } \\
\text { potential solutions, but we were not } \\
\text { sure which technology to use nor } \\
\text { what effects it would have on } \\
\text { effectiveness. To conduct this } \\
\text { research, we drew on the results of } \\
\text { several empirical studies we had } \\
\text { previously performed. These results } \\
\text { clarified the role that meetings and } \\
\text { individuals play in inspection } \\
\text { effectiveness and interval. We } \\
\text { conducted further studies showing } \\
\text { that manual inspections without } \\
\text { meetings were just as effective as } \\
\text { manual inspections with them. On the } \\
\text { basis of these and other findings and } \\
\text { understanding of Internet }\end{array}$ \\
\hline $\begin{array}{l}\text { our } \\
\text { technology, we built an economical } \\
\text { and effective tool that reduced the } \\
\text { interval without reducing } \\
\text { effectiveness. This tool, Hypercode, } \\
\text { supports meetingless software }\end{array}$
\end{tabular}

Caso de estudio 


\begin{tabular}{|l|l|l|}
\hline $\mid$ & $\begin{array}{l}\text { inspections with geographically } \\
\text { distributed reviewers. HyperCode is a } \\
\text { platform independent tool, } \\
\text { developed on top of Internet } \\
\text { browser, that integrates seamlessly } \\
\text { into the current development } \\
\text { process. By seamless, we mean the } \\
\text { tool produces a paper flow that is } \\
\text { almost identical to the current } \\
\text { inspection process. HyperCode's } \\
\text { acceptance by its user community has } \\
\text { been excellent. Moreover, we } \\
\text { estimate that using HyperCode has } \\
\text { reduced the inspection interval by 20 } \\
\text { to 25 percent. We believe that, had } \\
\text { we focused solely on technology } \\
\text { (without considering the information } \\
\text { our studies had uncovered), we would } \\
\text { have created a more complex, but not } \\
\text { necessarily more effective tool. We } \\
\text { probably would have supported } \\
\text { group meetings, restricted each } \\
\text { participant's access to review }\end{array}$ \\
\hline
\end{tabular}


Proceso de RS de experimentos en Ingeniería del Software

\begin{tabular}{|c|c|c|c|c|}
\hline & & & & $\begin{array}{l}\text { comments, and supported a wider } \\
\text { variety of inspection methods. In } \\
\text { other words, the principles derived } \\
\text { from our empirical studies } \\
\text { dramatically and successfully directed } \\
\text { our search for a technological } \\
\text { solution. }\end{array}$ \\
\hline 104 & $\begin{array}{l}\text { /Scopus } \\
\text { /ND }\end{array}$ & $\begin{array}{c}\text { Thelin, } \\
\text { Runeson, } \mathrm{P} .\end{array}$ & $\begin{array}{l}\text { Robust estimations of fault content } \\
\text { with capture-recapture and detection } \\
\text { profile estimators. (2000) Journal of } \\
\text { Systems and Software, } 52 \text { (2), pp. 139- } \\
148 .\end{array}$ & $\begin{array}{l}\text { Inspections are widely used in the } \\
\text { software engineering community as } \\
\text { efficient contributors to reduced fault } \\
\text { content and improved product } \\
\text { understanding. In order to measure } \\
\text { and control the effect and use of } \\
\text { inspections, the fault content after an } \\
\text { inspection must be estimated. The } \\
\text { capture-recapture method, with its } \\
\text { origin in biological sciences, is a } \\
\text { promising approach for estimation of } \\
\text { the remaining fault content in } \\
\text { software artefacts. However, a } \\
\text { number of empirical studies show }\end{array}$ \\
\hline
\end{tabular}

Caso de estudio 


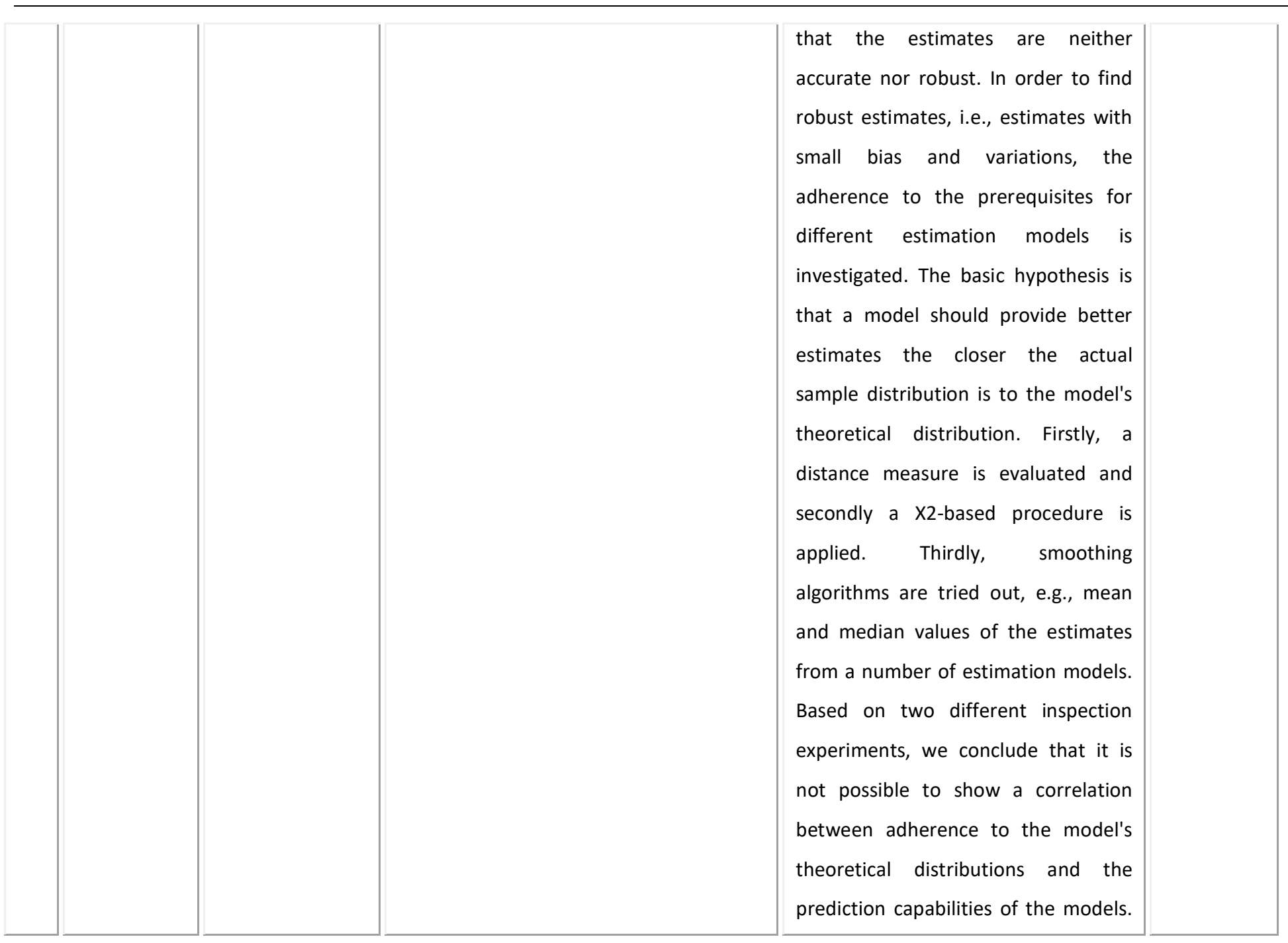


Proceso de RS de experimentos en Ingeniería del Software

\begin{tabular}{|c|c|c|c|c|}
\hline & & & & $\begin{array}{l}\text { This indicates that there are other } \\
\text { factors that affect the estimation } \\
\text { capabilities more than the } \\
\text { prerequisites. Neither does the } \\
\text { investigation point out any specific } \\
\text { model to be superior. On the } \\
\text { contrary, the Mh-JK model, which has } \\
\text { been shown as the best alternative in } \\
\text { a prior study, is inferior in this study. } \\
\text { The most robust estimations are } \\
\text { achieved by the smoothing } \\
\text { algorithms. }\end{array}$ \\
\hline 105 & $\begin{array}{l}\text { /Scopus } \\
\text { /ND }\end{array}$ & $\begin{array}{l}\text { Dunsmore, } \\
\text { A., Roper, M., } \\
\text { Wood, M. }\end{array}$ & $\begin{array}{l}\text { Role of comprehension in software } \\
\text { inspection. (2000) Journal of Systems and } \\
\text { Software, } 52 \text { (2), pp. 121-129. }\end{array}$ & $\begin{array}{l}\text { In spite of code inspections having } \\
\text { been demonstrated as an effective } \\
\text { defect detection process, little work } \\
\text { has been done to determine how this } \\
\text { process best supports the object- } \\
\text { oriented paradigm. In contrast, this } \\
\text { paradigm (or at least its questionable } \\
\text { manifestation in C++) is well } \\
\text { supported by tools that purport to aid }\end{array}$ \\
\hline
\end{tabular}

Caso de estudio 


\begin{tabular}{|l||l|l|}
\hline $\mid$ & $\begin{array}{l}\text { comprehension. These tools typically } \\
\text { take the form of visualisation tools } \\
\text { designed to assist in the maintenance } \\
\text { process, and it is natural to consider } \\
\text { that these tools (or adaptations } \\
\text { thereof) might also support } \\
\text { inspection. However, since these } \\
\text { tools claim to aid comprehension, it is } \\
\text { important to consider the role of } \\
\text { comprehension in inspection. Or put } \\
\text { simply, does comprehension matter, } \\
\text { or there simple techniques in } \\
\text { existence which are similarly effective } \\
\text { in detecting defects? This paper } \\
\text { presents the issues associated with } \\
\text { inspections (and the complications } \\
\text { presented by the object-oriented } \\
\text { paradigm) and comprehension, and } \\
\text { presents the results of two } \\
\text { experiments which considered the } \\
\text { relationship between comprehension } \\
\text { and inspection. The results indicate a } \\
\text { relationship, but further work is }\end{array}$ \\
\hline
\end{tabular}


Proceso de RS de experimentos en Ingeniería del Software

\begin{tabular}{|c|c|c|c|c|}
\hline & & & & $\begin{array}{l}\text { needed to determine the precise } \\
\text { nature of this relationship and how } \\
\text { inspections might best be supported } \\
\text { in the future. }\end{array}$ \\
\hline 106 & $\begin{array}{l}\text { /Scopus } \\
\text { /ND }\end{array}$ & Land, L.P.W. & $\begin{array}{l}\text { Software group reviews and the } \\
\text { impact of procedural roles on defect } \\
\text { detection performance. (2002) Empirical } \\
\text { Software Engineering, } 7 \text { (1), pp. 77-79. }\end{array}$ & $\begin{array}{l}\text { Software group reviews and the } \\
\text { impact of procedural roles on defect } \\
\text { detection performance was } \\
\text { discussed. The experiments were } \\
\text { conducted to operationalize the } \\
\text { review performance in terms of true } \\
\text { defects and false positives. The } \\
\text { findings of this thesis showed } \\
\text { implications on the development of } \\
\text { the software support for the software } \\
\text { review task. }\end{array}$ \\
\hline 107 & $\begin{array}{l}\text { /Xplore/ } \\
\text { Xplore_11.p } \\
\text { df }\end{array}$ & E. F. Berman & $\begin{array}{l}60 . \quad \text { Software inspections at } \\
\text { Fermilab-use and experience, Nuclear } \\
\text { Science, IEEE Transactions on, vol. } 45 \text {, pp. } \\
\text { 1937-1941, 1998. }\end{array}$ & $\begin{array}{l}\text { - Describe el proceso de inspección } \\
\text { del Fermi Nacional Accelerator Lab }\end{array}$ \\
\hline
\end{tabular}

Caso de estudio 


\begin{tabular}{|c|c|c|c|c|}
\hline 108 & $\begin{array}{l}\text { /Xplore/ } \\
\text { Xplore_12.p } \\
\text { df }\end{array}$ & $\begin{array}{l}\text { G. Chroust } \\
\text { and H. Lexen, }\end{array}$ & $\begin{array}{l}\text { 61. Software inspections-theory, } \\
\text { new approaches and an experiment, } \\
\text { 1999. }\end{array}$ & $\begin{array}{l}\text { - Discute aspectos de costo- } \\
\text { efectividad, ROI de las inspecciones } \\
\text { en general y de las reuniones en } \\
\text { particular. } \\
\text { - Refiere un experimento en } \\
\text { software improvement pero no lo } \\
\text { muestra }\end{array}$ \\
\hline 109 & $\begin{array}{c}\text { /ACM/ } \\
\text { acm_4.pdf }\end{array}$ & $\begin{array}{l}\text { Diane Kelly, } \\
\text { Terry Shepard }\end{array}$ & $\begin{array}{l}\text { 62. Task-directed software } \\
\text { inspection technique: an experiment and } \\
\text { case study, Proceedings of the } 2000 \\
\text { conference of the Centre for Advanced } \\
\text { Studies on Collaborative research } \\
\text { CASCON '00 }\end{array}$ & $\begin{array}{l}\text { - Estudiantes en un experimento } \\
\text { aplican dos técnicas dirigidas a } \\
\text { tareas y una técnica de inspección } \\
\text { no-estructurada estándar en la } \\
\text { industria a un código de ing civil en } \\
\text { uso en aplicaciones militares } \\
\text { - Presetan tanto un caso de estudio } \\
\text { como el experimento } \\
\text { - Analizan los resultados con una } \\
\text { clasificación ortogonal de defectos } \\
\text { para código computacional } \\
\text { desarrollada para la investigación } \\
\text { - Discuten: la contribución de la } \\
\text { técnica dirigida a tareas en la }\end{array}$ \\
\hline
\end{tabular}


Proceso de RS de experimentos en Ingeniería del Software

\begin{tabular}{|c|c|c|c|c|}
\hline & & & & $\begin{array}{l}\text { evaluación y entendimiento del } \\
\text { código por parte de los } \\
\text { inspectores, diferencias entre } \\
\text { inspectores experimentados y no } \\
\text { experimentados. }\end{array}$ \\
\hline 110 & $\begin{array}{l}\text { /Xplore/ } \\
\text { Xplore_ } \\
\text { 13.pdf }\end{array}$ & T. Thelin, & $\begin{array}{l}\text { 63. Team-based fault content } \\
\text { estimation in the software inspection } \\
\text { process, } 2004 \text { Proceedings - } \\
\text { International Conference on Software }\end{array}$ & $\begin{array}{l}\text { - Presenta un experimento que } \\
\text { compara métodos objetivos y } \\
\text { subjetivos de estimación de } \\
\text { contenido de fallos en diferentes }\end{array}$ \\
\hline 111 & $\begin{array}{l}\text { Scopus/ } \\
\text { sco_1.pdf }\end{array}$ & & Engineering 26, pp. 263-272 & $\begin{array}{l}\text { puntos } \\
\text { - Fue conducido en } 2 \text { universidades } \\
\text { con } 82 \text { revisores }\end{array}$ \\
\hline 112 & $\begin{array}{c}\text { /ACM/ } \\
\text { acm_5.pdf }\end{array}$ & $\begin{array}{l}\text { Christian } \\
\text { Denger, Ronny } \\
\text { Kolb }\end{array}$ & $\begin{array}{l}64 . \text { Testing and inspecting reusable } \\
\text { product line components: first empirical } \\
\text { results, Proceedings of the } 2006 \\
\text { ACM/IEEE international symposium on } \\
\text { International symposium on empirical } \\
\text { software engineering ISESE '06 }\end{array}$ & $\begin{array}{l}\text { - Compara dos técnicas de detección } \\
\text { de defectos: inspecciones de } \\
\text { código y pruebas funcionales en el } \\
\text { contexto de desarrollo de líneas de } \\
\text { productos } \\
\text { - Investiga el potencial de detección } \\
\text { de defectos de las técnicas en } \\
\text { componentes reutilizables de }\end{array}$ \\
\hline
\end{tabular}

Caso de estudio 


\begin{tabular}{|c|c|c|c|c|}
\hline & & & & $\begin{array}{l}\text { software } \\
\text { - Discuten: efectividad y esfuerzo } \\
\text { para detectar un defecto }\end{array}$ \\
\hline 113 & $\begin{array}{l}\text { /Xplore/ } \\
\text { xplore_14.p } \\
\text { df } \\
\text { (Springe } \\
\text { r_7.pdf) }\end{array}$ & $\begin{array}{l}\text { C. Atiq and L. } \\
\text { P. W. Land, }\end{array}$ & $\begin{array}{l}\text { The impact of training-by- } \\
\text { examples on inspection performance } \\
\text { using two laboratory experiments, } 2004 . \\
\text { Proceedings of the Australian Software } \\
\text { Engineering Conference, ASWEC 2004, } \\
\text { pp. } 279-288\end{array}$ & $\begin{array}{l}\text { - Dos experimentos de lab son } \\
\text { conducidos para probar el efecto } \\
\text { del entrenamiento usando } \\
\text { ejemplos de defectos }\end{array}$ \\
\hline 114 & $\begin{array}{l}\text { Scopus/ } \\
\text { no_docume } \\
\text { nt }\end{array}$ & & & \\
\hline 115 & $\begin{array}{l}\text { /Scedire } \\
\text { ct/ } \\
\text { sdirect_10.p } \\
\text { df }\end{array}$ & $\begin{array}{l}\text { A. } \\
\text { Dunsmore, M. } \\
\text { Roper, and M. } \\
\text { Wood, }\end{array}$ & $\begin{array}{l}\text { 66. The role of comprehension in } \\
\text { software inspection, Journal of Systems } \\
\text { and Software, vol. } 52 \text {, pp. 121-129, } 2000 \text {. }\end{array}$ & $\begin{array}{l}\text { - Presenta los resultados de dos } \\
\text { experimentos que relacionan la } \\
\text { comprensión del programa y la } \\
\text { inspección }\end{array}$ \\
\hline 116 & $\begin{array}{l}\text { /Scopus } \\
\text { /ND }\end{array}$ & $\begin{array}{l}\text { Land, L.P.W., } \\
\text { Sauer, } \quad \text { C., } \\
\text { Jeffery, R. }\end{array}$ & $\begin{array}{l}\text { The use of procedural roles in code } \\
\text { inspections: An experimental study. } \\
\text { (2000) Empirical Software Engineering, } 5\end{array}$ & $\begin{array}{l}\text { Software inspections are } \\
\text { important for finding defects in } \\
\text { software products (Fagan, 1976; Gilb, }\end{array}$ \\
\hline
\end{tabular}


Proceso de RS de experimentos en Ingeniería del Software

\begin{tabular}{|l|||l|l|}
\hline (1), pp.11-34. & $\begin{array}{l}\text { 1993; Humphrey, 1995; Strauss and } \\
\text { Ebenau, 1994). A typical inspection } \\
\text { includes two stages: individual } \\
\text { preparation followed by a group } \\
\text { review with roles assigned to each } \\
\text { reviewer. Research has shown that } \\
\text { group tasks typically result in process } \\
\text { loss (Lorge et al., 1958; Steiner, 1972). } \\
\text { In software defect detection also, } \\
\text { considerable defects found during } \\
\text { individual preparation are } \\
\text { subsequently not reported by the } \\
\text { group (Porter and Votta, 1994; Porter } \\
\text { et al., 1995, 1997; Land et al., 1997a, } \\
\text { 1997b; Siy, 1996; Votta, 1993). Our } \\
\text { objective is to study whether } \\
\text { procedural roles (moderator, reader, } \\
\text { recorder) affect group performance, } \\
\text { particularly in terms of process loss. } \\
\text { At the same time, the use of roles in } \\
\text { software reviews has also not been } \\
\text { empirically validated, although there }\end{array}$ \\
\hline
\end{tabular}

Caso de estudio 


\begin{tabular}{|c|c|c|c|c|}
\hline & & & & $\begin{array}{l}\text { are wide claims for their benefits. } \\
\text { Procedural roles made a limited } \\
\text { difference to group performance. } \\
\text { Further analyses provide possible } \\
\text { explanations for the results and a } \\
\text { deeper understanding of how groups } \\
\text { make their decisions based on } \\
\text { individual reviewers' findings. } \\
\text { Limitations of the research are } \\
\text { discussed. We also suggest how } \\
\text { procedural roles may greater impact } \\
\text { group performance. }\end{array}$ \\
\hline 117 & $\begin{array}{l}\text { /Scopus } \\
/ \text { ND }\end{array}$ & $\begin{array}{l}\text { Porter, Adam } \\
\text { A., Siy, Harvey } \\
\text { P., Votta Jr., } \\
\text { Lawrence G. }\end{array}$ & $\begin{array}{l}\text { Understanding the effects of } \\
\text { developer activities on inspection } \\
\text { interval. (1997) Proceedings - } \\
\text { International Conference on Software } \\
\text { Engineering, pp. 128-138. }\end{array}$ & $\begin{array}{l}\text { We have conducted an industrial } \\
\text { experiment to assess the cost-benefit } \\
\text { tradeoffs of several software } \\
\text { inspection processes. Our results to } \\
\text { date explain the variation in observed } \\
\text { effectiveness very well, but are } \\
\text { unable to satisfactorily explain } \\
\text { variation in inspection interval. In this } \\
\text { article we examine the effect of a new } \\
\text { factor - process environment - on }\end{array}$ \\
\hline
\end{tabular}


Proceso de RS de experimentos en Ingeniería del Software

\begin{tabular}{|c|c|c|c|c|}
\hline & & & & $\begin{array}{l}\text { inspection interval (calendar time } \\
\text { needed to complete the inspection). } \\
\text { Our analysis suggests that process } \\
\text { environment does indeed influence } \\
\text { inspection interval. In particular, we } \\
\text { found that non-uniform work } \\
\text { priorities, time-varying workloads, } \\
\text { and deadlines have significant effects. } \\
\text { Moreover, these experiences suggest } \\
\text { that regression models are inherently } \\
\text { inadequate for interval modeling, and } \\
\text { that queueing models may be more } \\
\text { effective. }\end{array}$ \\
\hline 118 & $\begin{array}{c}\text { /ACM/ } \\
\text { acm_6.pdf }\end{array}$ & \multirow{2}{*}{$\begin{array}{l}\text { Adam Porter, } \\
\text { Harvey Siy, } \\
\text { Audris Mockus, } \\
\text { Lawrence Votta }\end{array}$} & \multirow{2}{*}{$\begin{array}{l}\text { 67. Understanding the sources of } \\
\text { variation in software inspections, January } \\
\text { 1998, ACM Transactions on Software } \\
\text { Engineering and Methodology (TOSEM), } \\
\text { Volume } 7 \text { Issue } 1\end{array}$} & \multirow{2}{*}{$\begin{array}{l}\text { - Describe el experimento } \\
\text { previamente reportado en p92- } \\
\text { porter.pdf (00601071.pdf) y } \\
\text { estudian las variaciones en la } \\
\text { efectividad y el intervalo }\end{array}$} \\
\hline 119 & $\begin{array}{l}\text { Scopus/ } \\
\text { sco_29.pdf }\end{array}$ & & & \\
\hline 120 & $\begin{array}{l}\text { /Scedire } \\
\text { ct/ }\end{array}$ & $\begin{array}{r}\text { T. Thelin, P. } \\
\text { Runeson, and B. }\end{array}$ & $\begin{array}{l}\text { 68. Usage-based reading--an } \\
\text { experiment to guide reviewers with use }\end{array}$ & - Presenta un experimento \\
\hline
\end{tabular}

Caso de estudio 


\begin{tabular}{|c|c|c|c|c|}
\hline & $\begin{array}{l}\text { sdirect_8.p } \\
\text { df }\end{array}$ & Regnell, & $\begin{array}{l}\text { cases, Information and Software } \\
\text { Technology, vol. 43, pp. 925-938, } 2001 .\end{array}$ & $\begin{array}{l}\text { conducido con } 27 \text { estudiantes de IS } \\
\text { - Un grupo utilizó casos de uso }\end{array}$ \\
\hline 121 & /Scopus & & & $\begin{array}{l}\text { priorizados y el grupo control casos } \\
\text { de uso aleatoriamente ordenados } \\
\text { - Miden: efectividad y eficiencia en } \\
\text { detectar fallas }\end{array}$ \\
\hline 122 & $\begin{array}{l}\text { /Springe } \\
\text { r/ } \\
\text { Springer_3. } \\
\text { pdf }\end{array}$ & $\begin{array}{l}\text { B. Stefan and } \\
\text { J. G. Walter, }\end{array}$ & $\begin{array}{l}\text { 69. Using a Reliability Growth Model } \\
\text { to Control Software Inspection, Empirical } \\
\text { Software Engineering, vol. V7, pp. 257- } \\
284,2002 \text {. }\end{array}$ & $\begin{array}{l}\text { - Propone un modelo de crecimiento } \\
\text { de la confiabilidad y dos modelos } \\
\text { heurísticos lineales para estimar el } \\
\text { núm probable de defectos a ser } \\
\text { encontrados en la reinspección }\end{array}$ \\
\hline 123 & $\begin{array}{r}\text { Scopus/ } \\
\text { sco_15.pdf }\end{array}$ & & & $\begin{array}{l}\text { - Los modelos son evaluados con } \\
\text { datos de un experimento } \\
\text { controlado en reinspección } \\
\text { - Describe el experimento } \\
\text { controlado }\end{array}$ \\
\hline 124 & $\begin{array}{l}\text { /Xplore/ } \\
\text { Xplore_27.p } \\
\text { df }\end{array}$ & $\begin{array}{l}\text { M. Halling, S. } \\
\text { Biffl, } \\
\text { Grechenig, and } \\
\text { M. Kohle, }\end{array}$ & $\begin{array}{l}\text { 70. Using reading techniques to } \\
\text { focus inspection performance, } 2001 \text {. }\end{array}$ & $\begin{array}{l}\text { - Reporta la replicación de un } \\
\text { experimento a gran escala en un } \\
\text { ambiente académico (Biffl, 2003) } \\
\text { (sdirect_4.pdf) }\end{array}$ \\
\hline
\end{tabular}


Proceso de RS de experimentos en Ingeniería del Software

\begin{tabular}{|c|c|c|c|c|}
\hline & & & & $\begin{array}{l}\text { - Evalúa la efectividad de la } \\
\text { detección de defectos para } \\
\text { inspectores que utilizan Checklist o } \\
\text { escenarios enfocados a nivel } \\
\text { individual y de equipo }\end{array}$ \\
\hline 125 & $\begin{array}{l}\text { /Springe } \\
\text { r/ } \\
\text { Springer_9. } \\
\text { pdf }\end{array}$ & $\begin{array}{l}\text { H. Lasse, T. } \\
\text { llkka, and V. } \\
\text { Pekka, }\end{array}$ & $\begin{array}{l}\text { 71. Using Software Inspection as a } \\
\text { Catalyst for SPI in a Small Company, } \\
\text { 2004. }\end{array}$ & $\begin{array}{l}\text { - Presenta un experimento en una } \\
\text { pequeña compañía de software } \\
\text { que evalúa el efecto de la } \\
\text { inspección de software en la } \\
\text { mejora de procesos }\end{array}$ \\
\hline 126 & /Scopus & & & \\
\hline 127 & $\begin{array}{l}\text { /Xplore/ } \\
\text { Xplore_28.p } \\
\text { df }\end{array}$ & $\begin{array}{l}\text { A. Porter and } \\
\text { L. Votta, }\end{array}$ & $\begin{array}{l}\text { 72. What makes inspections work?, } \\
\text { Software, IEEE, vol. 14, pp. 99-102, } 1997 .\end{array}$ & $\begin{array}{l}\text { - Resumen los resultados de haber } \\
\text { conducido una familia de } \\
\text { experimentos para entender cómo } \\
\text { varios factores afectan los costos y } \\
\text { beneficios de la inspección }\end{array}$ \\
\hline
\end{tabular}

Caso de estudio 
B02_Análisis de artículos recuperados

Realizado por: Anna

Grimán

Fecha: $29 / 05 / 2008$

\begin{tabular}{|c|c|c|c|c|c|}
\hline$D^{1}$ & Fichero & Autores & Referencia & Resumen & $\begin{array}{l}\text { ¿Releva } \\
\text { nte? }\end{array}$ \\
\hline 1 & $\begin{array}{l}\text { /Xplore/ } \\
\text { Xplore_ } \\
\text { 1.pdf }\end{array}$ & $\begin{array}{l}\text { T.Berlig and } \\
\text { T. Thelin, }\end{array}$ & $\begin{array}{l}74 . \quad \text { A case study of reading } \\
\text { techniques in a software company, } 2004 . \\
\text { Proceedings - } 2004 \text { International } \\
\text { Symposium on Empirical Software } \\
\text { Engineering, ISESE 2004, pp. 229-238 }\end{array}$ & $\begin{array}{l}\text { - Aplica un estudio empírico en una } \\
\text { organización de desarrollo } \\
\text { _ Un documento de requisitos es } \\
\text { usado para comparar dos técnicas } \\
\text { de lectura (basada en checklist y } \\
\text { basada en perspectiva) } \\
\text { - Discuten efectividad y eficiencia de } \\
\text { una técnica frente a la otra }\end{array}$ & \\
\hline
\end{tabular}


Proceso de RS de experimentos en Ingeniería del Software

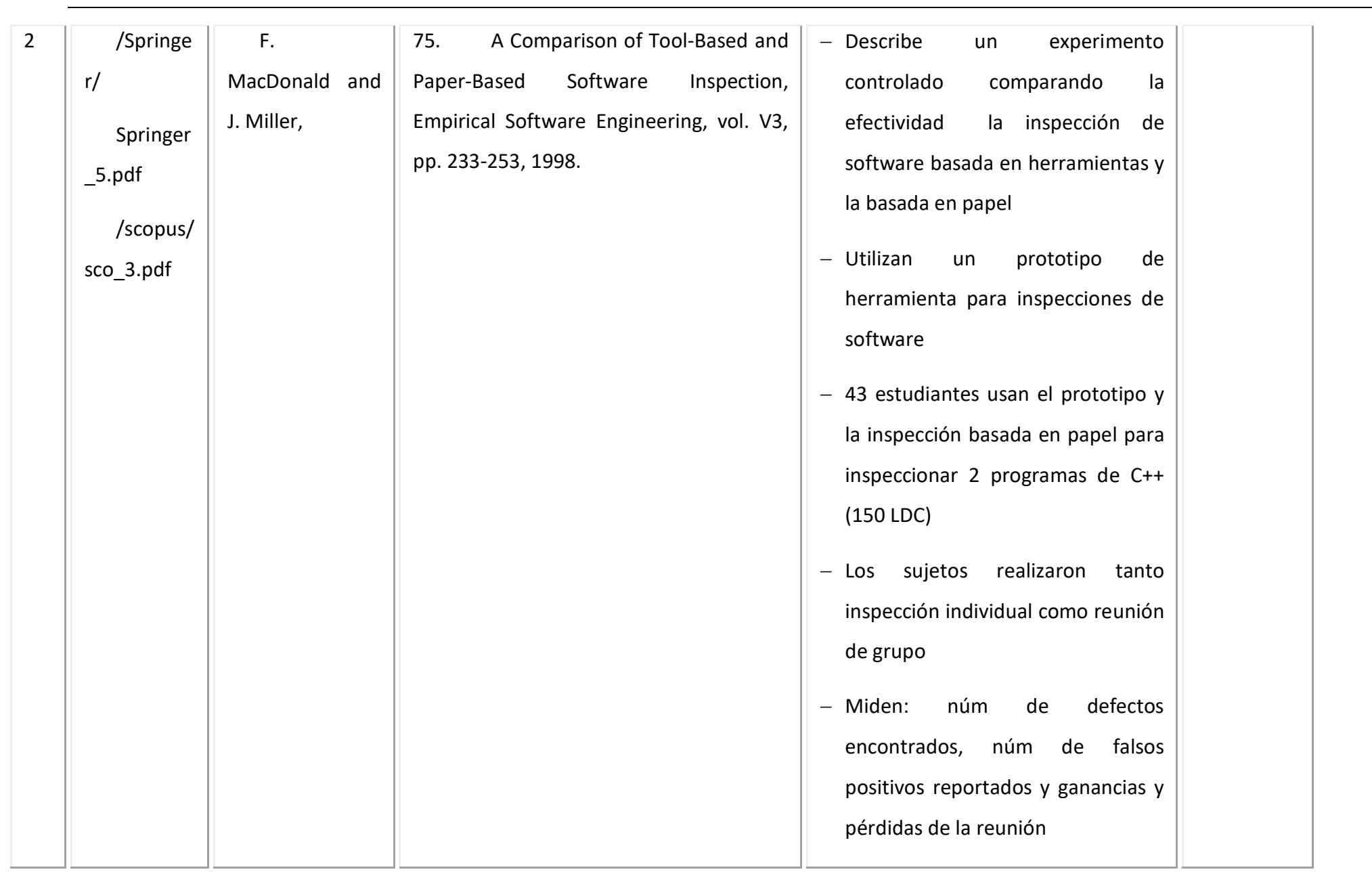

Caso de estudio 


\begin{tabular}{|c|c|c|c|c|}
\hline 3 & $\begin{array}{l}\text { /Xplore/ } \\
\text { Xplore_ } \\
\text { 2.pdf }\end{array}$ & $\begin{array}{l}\text { M. } \\
\text { Kalinowski and } \\
\text { G. H. Travassos, }\end{array}$ & $\begin{array}{l}\text { 76. A computational framework for } \\
\text { supporting software inspections, } 2004 . \\
\text { Proceedings }-19^{\text {th }} \text { International } \\
\text { Conference on Automated Software } \\
\text { Engineering, ASE 2004, pp. } 46-55\end{array}$ & $\begin{array}{l}\text { - Describe un framework } \\
\text { computacional cuyos requisitos se } \\
\text { basan en estudios empíricos sobre } \\
\text { inspección de software } \\
\text { - Evalúa la factibilidad del } \\
\text { framework a través de: } \\
\text { O Un caso de estudio } \\
\text { O Un estudio } \\
\text { experimental que } \\
\text { evaluó la actividad } \\
\text { de planificación de } \\
\text { la inspección de } \\
\text { software } \\
\text { - El estudio experimental arrojó } \\
\text { resultados sobre la experiencia de } \\
\text { los sujetos y su relación con la } \\
\text { planificación y la efectividad en la } \\
\text { detección de defectos, al utilizar el } \\
\text { framework comput.Sl } \\
\text { - }\end{array}$ \\
\hline
\end{tabular}


Proceso de RS de experimentos en Ingeniería del Software

\begin{tabular}{|c|c|c|c|c|}
\hline 4 & $\begin{array}{l}\text { /Xplore/ } \\
\text { Xplore_ } \\
\text { 3.pdf } \\
\text { /scopus/ } \\
\text { Sco_34.pdf }\end{array}$ & $\begin{array}{l}\text { A. Bianchi, F. } \\
\text { Lanubile, and G. } \\
\text { Visaggio, }\end{array}$ & $\begin{array}{l}77 . \quad \text { A controlled experiment to } \\
\text { assess the effectiveness of inspection } \\
\text { meetings, 2001. International Software } \\
\text { Metrics Symposium, Proceedings, pp. } 42- \\
50\end{array}$ & $\begin{array}{l}\text { - Presenta un experimento } \\
\text { controlado } \\
\text { - Participan + de } 100 \text { estudiantes de } \\
\text { carrera quienes inspeccionan } \\
\text { documentos de requerimientos de } \\
\text { software } \\
\text { - Compara el desempeño de grupos } \\
\text { nominales y reales } \\
\text { - Investiga también las razones de } \\
\text { las pérdidas en las reuniones y } \\
\text { confronta ganancias vs pérdidas } \\
\text { - Relaciona las pérdidas con el núm } \\
\text { de defectos encontrados por un } \\
\text { único individuo en el equipo }\end{array}$ \\
\hline 5 & $\begin{array}{l}\text { /Springe } \\
\text { r/ } \\
\text { Springer } \\
\text { 8.pdf }\end{array}$ & $\begin{array}{l}\text { B. Stefan, G. } \\
\text { Paul, and H. } \\
\text { Michael, }\end{array}$ & $\begin{array}{l}\text { 78. A family of experiments to } \\
\text { investigate the effects of groupware for } \\
\text { software inspection, Automated } \\
\text { Software Engineering, vol. V13, pp. 373- } \\
394,2006 \text {. }\end{array}$ & $\begin{array}{l}\text { - Conduce una familia de } \\
\text { experimentos en un ambiente } \\
\text { académico para investigar el efecto } \\
\text { del soporte de herramientas a la } \\
\text { detección de defectos y a las }\end{array}$ \\
\hline
\end{tabular}




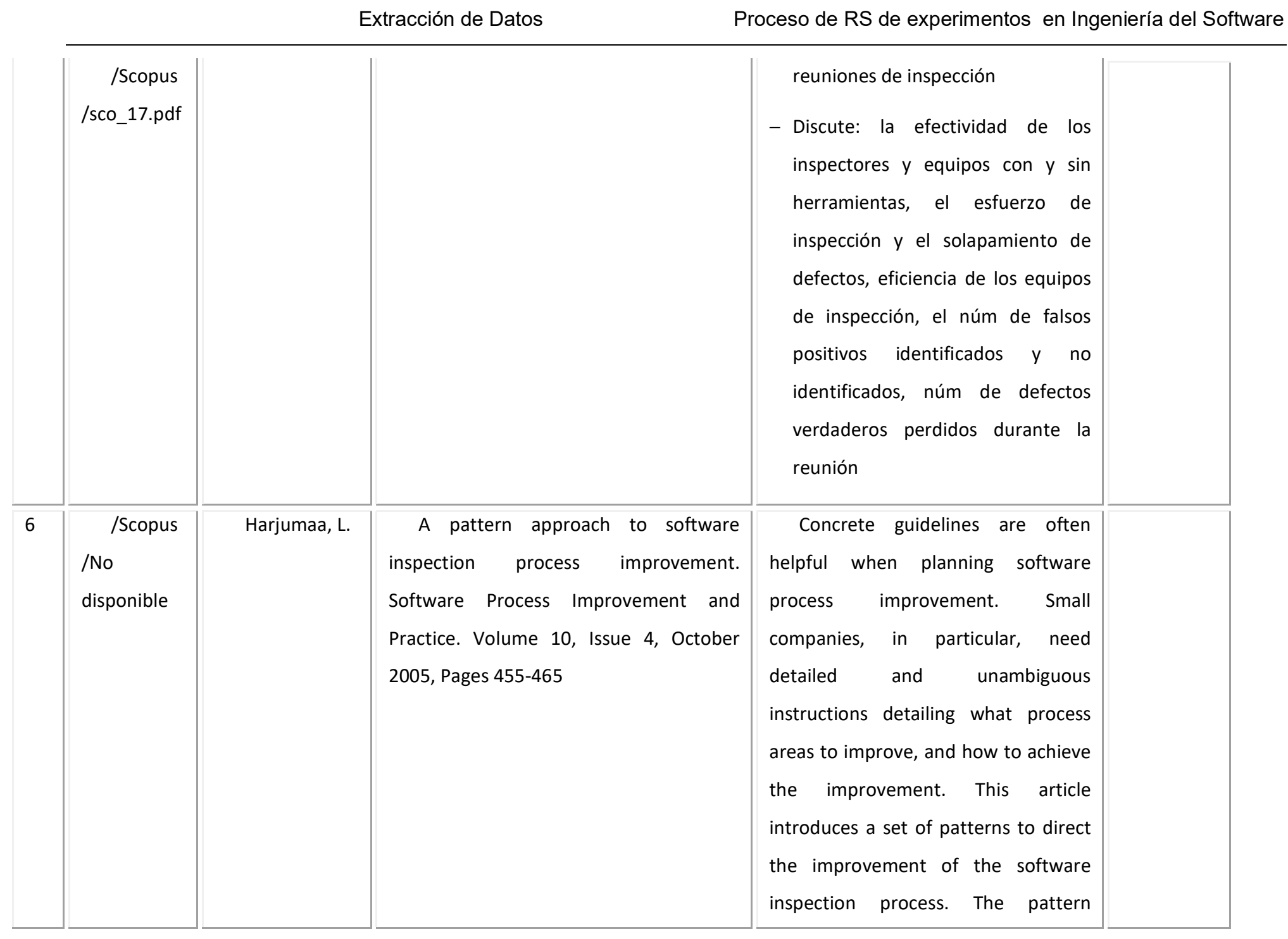


Proceso de RS de experimentos en Ingeniería del Software

\begin{tabular}{|c|c|c|c|c|}
\hline & & & & $\begin{array}{l}\text { approach has been applied, since it } \\
\text { has been used very successfully for } \\
\text { knowledge-sharing purposes and } \\
\text { other areas of software engineering. } \\
\text { The approach involves an evaluation } \\
\text { of the inspection process capability, } \\
\text { setting an overall goal for the } \\
\text { improvement and updating the } \\
\text { process according to pre-defined } \\
\text { actions. Experiments with initial } \\
\text { patterns show that the method } \\
\text { provides a feasible and quick way of } \\
\text { making inspections more effective. } \\
\text { Using patterns may also be beneficial } \\
\text { when launching more wide-ranging } \\
\text { SPI activities, as companies can run } \\
\text { preliminary trials of the improvement } \\
\text { process on a smaller scale first. }\end{array}$ \\
\hline 7 & $\begin{array}{l}\text { /xplore/ } \\
\text { Xplore_ }\end{array}$ & $\begin{array}{l}\text { P. Murphy } \\
\text { and J. Miller, }\end{array}$ & $\begin{array}{l}\text { 79. A process for asynchronous } \\
\text { software inspection, Proceedings, Eighth } \\
\text { IEEE International Workshop on Software }\end{array}$ & $\begin{array}{l}\text { - Propone un modelo de inspección } \\
\text { soportado por una herramienta de } \\
\text { comunicación asíncrona basado en }\end{array}$ \\
\hline
\end{tabular}

Caso de estudio 


\begin{tabular}{|c|c|c|c|c|}
\hline & 4.pdf & & $\begin{array}{l}\text { Technology and Engineering Practice, } \\
\text { 1997. [Incorporating Computer Aided } \\
\text { Software Engineering]. 14-18 July } 1997 \\
\text { Page(s):96-104 }\end{array}$ & $\begin{array}{l}\text { correo-e } \\
\text { - Compara el nuevo modelo con el } \\
\text { modelo tradicional basado en } \\
\text { reunión sobre la base de un } \\
\text { conjunto de criterios } \\
\text { - Intentan utilizar un experimento a } \\
\text { pequeña escala pero el número de } \\
\text { sujetos es pequeño y no permite } \\
\text { presentar un análisis } \\
\text { - Describe y analiza brevemente la } \\
\text { familia de experimentos de Porter } \\
\text { y sus replicaciones. (Xplore_16.pdf) }\end{array}$ \\
\hline 8 & $\begin{array}{l}\text { /Xplore/ } \\
\text { Xplore_ } \\
\text { 5.pdf }\end{array}$ & $\begin{array}{l}\text { T. Thelin, C. } \\
\text { Andersson, } \mathrm{P} . \\
\text { Runeson, and } \mathrm{N} \text {. } \\
\text { Dzamashvili- } \\
\text { Fogelstrom, }\end{array}$ & $\begin{array}{l}\text { 80. A replicated experiment of } \\
\text { usage-based and checklist-based reading, } \\
\text { 2004. Proceedings - Software Metrics } \\
\text { Symposium, pp. 246-256 }\end{array}$ & $\begin{array}{l}\text { - Presenta la replicación de un } \\
\text { experimento que comparó técnicas } \\
\text { de lectura basada en uso vs basada } \\
\text { en checklist } \\
\text { - Presenta tanto la replicación como } \\
\text { el experimento original y compara } \\
\text { ambos resultados (Xplore_30.pdf) } \\
\text { - La replicación confirmó los }\end{array}$ \\
\hline
\end{tabular}


Proceso de RS de experimentos en Ingeniería del Software

\begin{tabular}{|c|c|c|c|c|}
\hline & & & & resultados del exp. original \\
\hline 9 & $\begin{array}{l}\text { /Xplore/ } \\
\text { Xplore_ } \\
\text { 6.pdf }\end{array}$ & $\begin{array}{l}\text { I. Tervonen, } \\
\text { J. lisakka, and L. } \\
\text { Harjumaa, }\end{array}$ & $\begin{array}{l}\text { 81. A tailored capability model for } \\
\text { inspection process improvement, } \\
\text { Proceedings. Second Asia-Pacific } \\
\text { Conference on Quality Software, } 2001 . \\
\text { 10-11 Dec. } 2001 \text { Page(s):275-282 }\end{array}$ & $\begin{array}{l}\text { - Presenta un modelo para evaluar la } \\
\text { capacidad del proceso de } \\
\text { inspección y soportar la } \\
\text { identificación de puntos débiles en } \\
\text { el proceso } \\
\text { - Presenta la aplicación del modelo } \\
\text { en la evaluación de una compañía }\end{array}$ \\
\hline 10 & $\begin{array}{l}\text { /ACM/A } \\
\text { CM_1.pdf }\end{array}$ & $\begin{array}{l}\text { Monvorath } \\
\text { Phongpaibul, } \\
\text { Barry Boehm }\end{array}$ & $\begin{array}{l}82 . \text { An empirical comparison } \\
\text { between pair development and software } \\
\text { inspection in Thailand, Proceedings of } \\
\text { the } 2006 \text { ACM/IEEE international } \\
\text { symposium on International symposium } \\
\text { on empirical software engineering ISESE } \\
\text { ' } 06\end{array}$ & $\begin{array}{l}\text { - Compara las similitudes y } \\
\text { diferencias entre el desarrollo por } \\
\text { pares y la inspección de software } \\
\text { como técnicas de verificación en } \\
\text { Thailand. } \\
\text { - Aplican un experimento de clase y } \\
\text { uno de industria } \\
\text { - Se investigó el esfuerzo de }\end{array}$ \\
\hline
\end{tabular}

Caso de estudio 


\begin{tabular}{|c|c|c|c|c|}
\hline & & \multicolumn{2}{|c|}{ Extracción de Datos } & Proceso de RS de experimentos en Ingeniería del Soft \\
\hline & & & & $\begin{array}{l}\text { desarrollo, el efecto en la calidad y } \\
\text { el tiempo calendario }\end{array}$ \\
\hline 11 & $\begin{array}{l}\text { /Springe } \\
\text { r/ } \\
\text { Springer } \\
\text { _7.pdf } \\
\text { /Scopus } \\
\text { / }\end{array}$ & $\begin{array}{l}\text { C. Atiq and L. } \\
\text { Lesley Pek Wee, }\end{array}$ & $\begin{array}{l}\text { 83. An Empirical Investigation on the } \\
\text { Impact of Training-by-Examples on } \\
\text { Inspection Performance. PROFES 2004, } \\
\text { LNCS 3009, pp. 203-219, 2004. }\end{array}$ & $\begin{array}{l}\text { - Conducen un experimento para } \\
\text { probar el efecto del entrenamiento } \\
\text { basado en ejemplos en la } \\
\text { inspección de requisitos } \\
\text { - Compara el desempeño de un } \\
\text { grupo entrenado vs uno que no ha } \\
\text { recibido entrenamiento }\end{array}$ \\
\hline 12 & $\begin{array}{l}\text { /Xplore/ } \\
\text { Xplore_ } \\
\text { 7.pdf }\end{array}$ & $\begin{array}{l}\text { C. D. } \\
\text { Rombach, O. } \\
\text { Kude, A. Aurum, } \\
\text { R. Jeffery, and C. } \\
\text { Wohlin, }\end{array}$ & $\begin{array}{l}\text { 84. An empirical study of an ER- } \\
\text { model inspection meeting, } 2003 \text {. }\end{array}$ & $\begin{array}{l}\text { - Documenta un experimento a gran } \\
\text { escala conducido durante una } \\
\text { reunión de inspección de Modelo } \\
\text { ER } \\
\text { - Investiga cuál técnica de lectura } \\
\text { tiene una tasa más eficiente de } \\
\text { detección de defectos cuando se } \\
\text { buscan defectos en un modelo ER }\end{array}$ \\
\hline
\end{tabular}


Proceso de RS de experimentos en Ingeniería del Software

\begin{tabular}{|c|c|c|c|c|}
\hline & & & & $\begin{array}{l}\text { - También explora el efecto del uso } \\
\text { de Roles en una reunión de equipo } \\
\text { - Por último, investiga la habilidad } \\
\text { de los revisores para encontrar } \\
\text { ciertas categorías de defectos }\end{array}$ \\
\hline 13 & $\begin{array}{l}\text { /scedire } \\
\text { ct/ } \\
\text { sdirect_1.p } \\
\text { df } \\
\quad \text { //Xplore } \\
\text { /Xplore_8.p } \\
\text { df) } \\
\text { /scopus/ } \\
\text { sco_5.pdf }\end{array}$ & $\begin{array}{l}\text { M. A. Babar, } \\
\text { B. Kitchenham, } \\
\text { L. Zhu, I. Gorton, } \\
\text { and R. Jeffery, }\end{array}$ & $\begin{array}{l}\text { 85. An empirical study of groupware } \\
\text { support for distributed software } \\
\text { architecture evaluation process, Journal } \\
\text { of Systems and Software, vol. } 79 \text {, pp. } \\
912-925,2006 \text {. }\end{array}$ & $\begin{array}{l}\text { - Presenta un estudio piloto } \\
\text { (experimento) usado para evaluar } \\
\text { la viabilidad de un experimento + } \\
\text { grande que investigue la } \\
\text { factibilidad del soporte groupware } \\
\text { para la evaluación distribuida de } \\
\text { arquitecturas de software } \\
\text { - El estudio piloto arrojó algunos } \\
\text { hallazgos acerca de la viabilidad de } \\
\text { un proceso de EA soportado por } \\
\text { groupware. }\end{array}$ \\
\hline 14 & $\begin{array}{l}\text { /Xplore/ } \\
\text { Xplore_ }\end{array}$ & $\begin{array}{l}\text { P. } \\
\text { Grunbacher, M. } \\
\text { Halling, and } S .\end{array}$ & $\begin{array}{l}\text { 86. An empirical study on } \\
\text { groupware support for software } \\
\text { inspection meetings, Proceedings of the }\end{array}$ & $\begin{array}{l}\text { - Presentan un experimento en un } \\
\text { ambiente académico con } 37 \\
\text { sujetos para investigar el efecto del }\end{array}$ \\
\hline
\end{tabular}

Caso de estudio 


\begin{tabular}{|c|c|c|c|c|}
\hline & 9.pdf & Biffl, & $\begin{array}{l}18^{\text {th }} \text { IEEE International Conference on } \\
\text { Automated Software Engineering } \\
\text { (ASE'03). }\end{array}$ & $\begin{array}{l}\text { soporte de una herramienta } \\
\text { groupware a las reuniones de } \\
\text { inspección } \\
\text { - Concluyen sobre: el esfuerzo } \\
\text { utilizado en la reunión, } \\
\text { identificación de falsos positivos, } \\
\text { reducción del núm de defectos } \\
\text { reales perdidos }\end{array}$ \\
\hline 15 & $\begin{array}{l}\text { /ACM/ } \\
\text { Acm_2.p }\end{array}$ & $\begin{array}{l}\text { Porter, L. G. } \\
\text { Votta }\end{array}$ & $\begin{array}{l}87 . \text { An experiment to assess } \\
\text { different defect detection methods for } \\
\text { software requirements inspections, } \\
\text { Proceedings of the } 16^{\text {th }} \text { international } \\
\text { conference on Software engineering } \\
\text { ICSE '94 }\end{array}$ & $\begin{array}{l}\text { - Usa experimento controlado } \\
\text { - Dirigido a probar la efectividad de } \\
\text { los Métodos de detección basados } \\
\text { en escenarios Vs. Métodos ad hoc } \\
\text { o checklist } \\
\text { - Cada revisor utiliza un } \\
\text { procedimiento específico para } \\
\text { descubrir un tipo particular de } \\
\text { defecto } \\
\text { - Describe el diseño, ejecución y } \\
\text { análisis del experimento }\end{array}$ \\
\hline
\end{tabular}


Proceso de RS de experimentos en Ingeniería del Software

\begin{tabular}{|c|c|c|c|c|}
\hline 16 & $\begin{array}{l}\text { /Xplore/ } \\
\text { Xplore_10.p } \\
\text { df } \\
\text { (/ACM/ } \\
\text { acm_3.pdf) } \\
\text { /scopus/ } \\
\text { sco_4.pdf }\end{array}$ & $\begin{array}{l}\text { A. Porter, H. } \\
\text { P. Siy, C. A. } \\
\text { Toman, and L. G. } \\
\text { Votta, }\end{array}$ & $\begin{array}{l}\text { 88. An experiment to assess the } \\
\text { cost-benefits of code inspections in large } \\
\text { scale software development, IEEE } \\
\text { Transactions on Software Engineering, } \\
\text { vol. } 23 \text {, pp. 329-346, } 1997 \text {. }\end{array}$ & $\begin{array}{l}\text { - Conduce un proyecto a largo plazo } \\
\text { - Evalúa la costo-efectividad de } \\
\text { diversos métodos de inspección de } \\
\text { software } \\
\text { - Los métodos son aplicados por } \\
\text { desarrolladores profesionales } \\
\text { - Se utilizó simulación para optimizar } \\
\text { el experimento } \\
\text { - A cada inspección se le asignó } \\
\text { aleatoriamente } 3 \text { variables } \\
\text { independientes: } \\
\text { revisores en el equipo, núm de } \\
\text { equipos de inspección, el requisito } \\
\text { de reparar los defectos entre la 1á } \\
\text { y 2a inspección } \\
\text { - Los revisores fueron seleccionados } \\
\text { aleatoriamente } \\
\text { - Las variables dependientes fueron: } \\
\text { tiempo de inspección, esfuerzo }\end{array}$ \\
\hline
\end{tabular}

Caso de estudio 


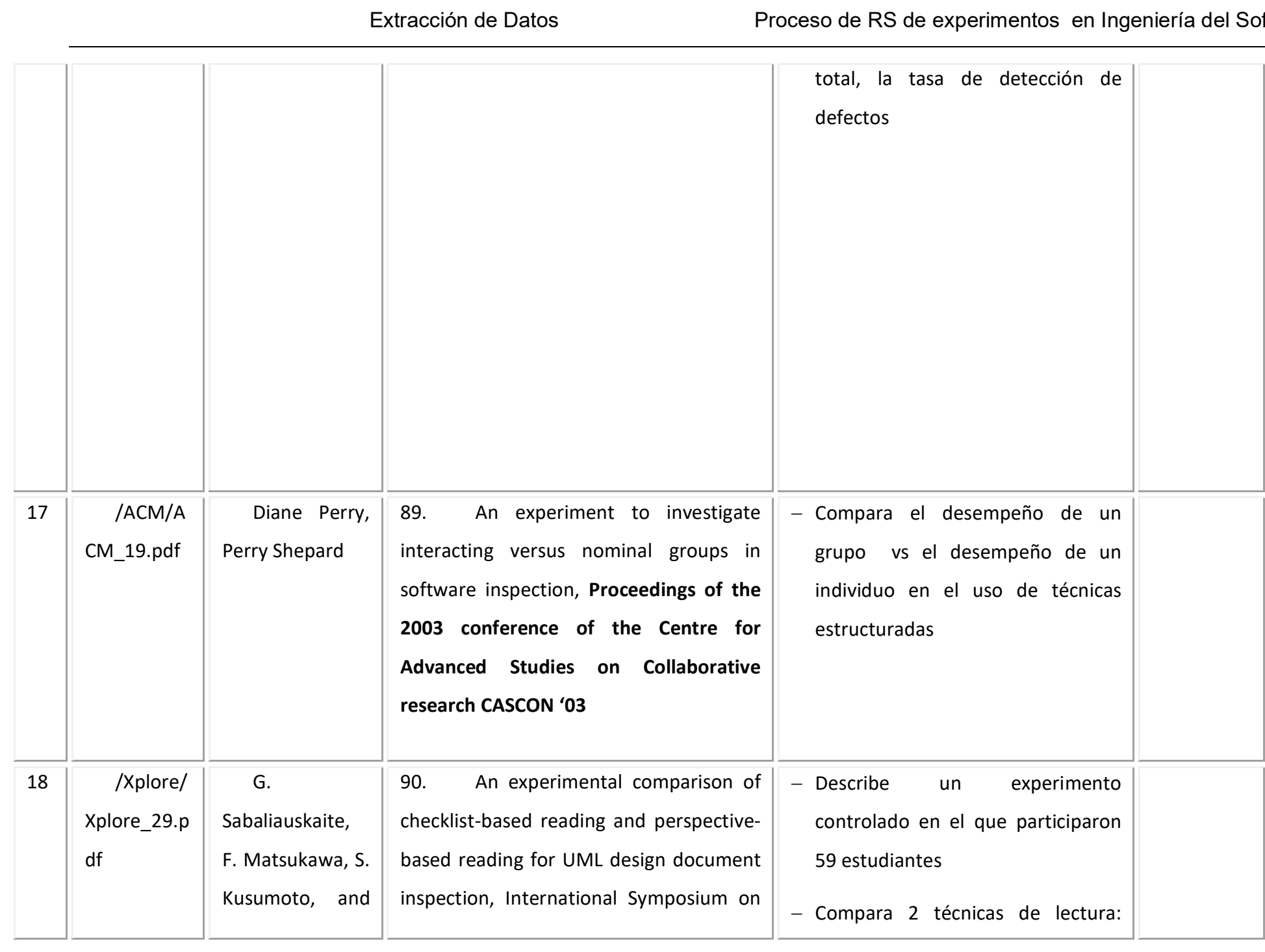


Proceso de RS de experimentos en Ingeniería del Software

\begin{tabular}{|c|c|c|c|c|}
\hline & & K. Inoue, & Empirical Software Engineering (ISESE'02) & $\begin{array}{l}\text { basada en checklist y basada en } \\
\text { perspectiva, en la inspección de } \\
\text { diseño } 00 \\
\text { - Comparan: efectividad, tiempo, } \\
\text { costo } x \text { defecto }\end{array}$ \\
\hline 19 & $\begin{array}{l}\text { /scedire } \\
\text { ct/ } \\
\text { Sdirect_ } \\
\text { 9.pdf }\end{array}$ & $\begin{array}{l}\text { O. } \\
\text { Laitenberger, C. } \\
\text { Atkinson, M. } \\
\text { Schlich, and K. El } \\
\text { Emam, }\end{array}$ & $\begin{array}{l}\text { 91. An experimental comparison of } \\
\text { reading techniques for defect detection } \\
\text { in UML design documents, Journal of } \\
\text { Systems and Software, vol. 53, pp. 183- } \\
204,2000 \text {. }\end{array}$ & $\begin{array}{l}\text { - Compara una técnica basada en } \\
\text { escenario (PBR) para detección de } \\
\text { defectos en documentos de diseño } \\
\text { OO que utilizan UML, con la técnica } \\
\text { basada en checklist (CBR) más } \\
\text { tradicional. } \\
\text { - Aplican un experimento controlado } \\
\text { con } 18 \text { practicantes como sujetos } \\
\text { - Miden: \% de defectos } \\
\text { descubiertos, tasa promedio de } \\
\text { tiempo x defecto, eficacia de los } \\
\text { escenarios PBR en la detección de } \\
\text { defectos en documentos de diseño } \\
\text { UML }\end{array}$ \\
\hline
\end{tabular}

Caso de estudio 


\begin{tabular}{|c|c|c|c|c|}
\hline 20 & $\begin{array}{l}\text { /Xplore/ } \\
\text { Xplore_30.p } \\
\text { df }\end{array}$ & $\begin{array}{l}\text { Thelin, T., } \\
\text { Runeson, P. and } \\
\text { Wohlin, C. }\end{array}$ & $\begin{array}{l}\text { 92. An Experimental Comparison of } \\
\text { Usage-Based and Checklist-Based } \\
\text { Reading, IEEE Transactions on Software } \\
\text { Engineering, 29(8):687-704, } 2003 \text {. }\end{array}$ & $\begin{array}{l}\text { - Presenta un experimento en el cual } \\
\text { se compara UBR con CBR } \\
\text { - Miden: efectividad y eficiencia en } \\
\text { detectar fallos críticos desde el } \\
\text { punto de vista del usuario. }\end{array}$ \\
\hline 21 & $\begin{array}{l}\text { /Springe } \\
\text { r/ } \\
\text { Springer } \\
\text { 4.pdf }\end{array}$ & $\begin{array}{l}\text { R. Per and W. } \\
\text { Claes, }\end{array}$ & $\begin{array}{l}\text { 93. An Experimental Evaluation of } \\
\text { an Experience-Based Capture-Recapture } \\
\text { Method in Software Code Inspections, } \\
\text { Empirical Software Engineering, vol. V3, } \\
\text { pp. 381-406, } 1998 \text {. }\end{array}$ & $\begin{array}{l}\text { - Propone un método de captura- } \\
\text { recaptura basado en la experiencia } \\
\text { - Un experimento de inspección de } \\
\text { código-C es conducido para evaluar } \\
\text { las mejoras del método y su } \\
\text { aplicabilidad a inspecciones de } \\
\text { código } \\
\text { - Concluye acerca de: estimaciones } \\
\text { del método vs estimaciones del } \\
\text { método de máxima probabilidad, } \\
\text { sensibilidad de las inspecciones } \\
\text { ante cambios en los datos de } \\
\text { inspección }\end{array}$ \\
\hline 22 & $\begin{array}{l}\text { /ACM/ } \\
\text { Acm_6.p }\end{array}$ & $\begin{array}{l}\text { G. Michael } \\
\text { Schneider, }\end{array}$ & $\begin{array}{l}\text { 94. An experimental study of fault } \\
\text { detection in user requirements }\end{array}$ & $\begin{array}{l}\text { - Describe un experimento } \\
\text { diseñado para confirmar los }\end{array}$ \\
\hline
\end{tabular}


Proceso de RS de experimentos en Ingeniería del Software

\begin{tabular}{|c|c|c|c|c|}
\hline & df & $\begin{array}{l}\text { Johnny Martin, } \\
\text { W. T. Tsai }\end{array}$ & $\begin{array}{l}\text { documents, ACM Transactions on } \\
\text { Software Engineering and Methodology } \\
\text { (TOSEM), Volume } 1 \text { Issue } 2 \text { April } 1992\end{array}$ & $\begin{array}{l}\text { resultados de un proyecto anterior } \\
\text { - } \text { Mide la rata de detección de } \\
\text { fallos en docs de requerimientos } \\
\text { de usuario } \\
-\quad 9 \text { equipos de inspección } \\
\text { independientes } \\
\text { - Aplica la técnica de inspección } \\
\text { de requerimentos N-fold y la } \\
\text { compara con el uso de técnicas } \\
\text { formales } \\
\text { - También mide la variabilidad en } \\
\text { el desempeño del equipo de } \\
\text { inspección y la dificultad de } \\
\text { localizar diferentes tipos de fallas } \\
\text { en DRU }\end{array}$ \\
\hline 23 & $\begin{array}{l}\text { /Xplore/ } \\
\text { Xplore_- } \\
\text { 8.pdf }\end{array}$ & $\begin{array}{l}\text { M. A. Babar, } \\
\text { B. Kitchenham, } \\
\text { L. Zhu, and R. } \\
\text { Jeffery, }\end{array}$ & $\begin{array}{l}\text { 95. An exploratory study of } \\
\text { groupware support for distributed } \\
\text { software architecture evaluation process, } \\
\text { 2004. Proceedings - Asia-Pacific Software } \\
\text { Engineering Conference, APSEC, pp. 222- }\end{array}$ & $\begin{array}{l}\text { - Presenta un estudio piloto } \\
\text { (experimento) usado para evaluar } \\
\text { la viabilidad de un experimento }+ \\
\text { grande que investigue la } \\
\text { factibilidad del soporte groupware }\end{array}$ \\
\hline
\end{tabular}

Caso de estudio 


\begin{tabular}{|c|c|c|c|c|}
\hline & $\begin{array}{l}\text { /scedire } \\
\text { ct/ } \\
\text { sdirect_1.p } \\
\text { df }\end{array}$ & & 229 & $\begin{array}{l}\text { para la evaluación distribuida de } \\
\text { arquitecturas de software } \\
\text { - El estudio piloto arrojó algunos } \\
\text { hallazgos acerca de la viabilidad de } \\
\text { un proceso de EA soportado por } \\
\text { groupware. }\end{array}$ \\
\hline 24 & $\begin{array}{l}\text { /Xplore/ } \\
\text { Xplore_ } \\
\text { 15.pdf }\end{array}$ & $\begin{array}{l}\text { O. } \\
\text { Laitenberger, K. } \\
\text { El Emam, and T. } \\
\text { G. Harbich, }\end{array}$ & $\begin{array}{l}\text { 96. An internally replicated quasi- } \\
\text { experimental comparison of checklist and } \\
\text { perspective based reading of code } \\
\text { documents, IEEE Transactions on } \\
\text { Software Engineering, vol. } 27, \text { pp. 387- } \\
421,2001 \text {. }\end{array}$ & $\begin{array}{l}\text { - Compara una técnica de lectura } \\
\text { basada en scenario (PBR) para } \\
\text { detección de defectos en código, } \\
\text { con el enfoque CBR más tradicional } \\
\text { - Hace la comparación en una serie } \\
\text { de } 3 \text { estudios, un quasi- } \\
\text { experimento y } 2 \text { replicaciones } \\
\text { internas } \\
\text { - Utiliza } 60 \text { desarrolladores de } \\
\text { software profesionales } \\
\text { - Presenta un análisis meta-analítico } \\
\text { - Compara efectividad y costo }\end{array}$ \\
\hline 25 & /ACM/ & $\begin{array}{l}\text { Hidetake } \\
\text { Uwano, }\end{array}$ & $\begin{array}{l}\text { 97. Analyzing individual } \\
\text { performance of source code review using }\end{array}$ & - Analiza 30 procesos de revisión \\
\hline
\end{tabular}


Proceso de RS de experimentos en Ingeniería del Software

\begin{tabular}{|c|c|c|c|c|}
\hline & df $\quad$ Acm_7.p & $\begin{array}{l}\text { Masahide } \\
\text { Nakamura, Akito } \\
\text { Monden, Ken- } \\
\text { ichi Matsumoto }\end{array}$ & $\begin{array}{l}\text { reviewers' eye movement, Proceedings } \\
\text { of the } 2006 \text { symposium on Eye tracking } \\
\text { research \& applications ETRA ' } 06\end{array}$ & $\begin{array}{l}\text { - } 6 \text { programas y } 5 \text { sujetos que } \\
\text { utilizan un ambiente integrado que } \\
\text { mide y registra el movimiento } \\
\text { ocular de los revisores de código } \\
\text { - Identifica un patrón } \\
\text { - Realiza un análisis cuantitativo } \\
\text { sobre el tiempo usado en el patrón } \\
\text { y el tiempo en detectar fallas }\end{array}$ \\
\hline 26 & $\begin{array}{l}\text { /Scedire } \\
\text { ct/ } \\
\text { sdirect_2.p } \\
\text { df } \\
\text { /scopus/ } \\
\text { sco_8.pdf }\end{array}$ & $\begin{array}{l}\text { G. } \\
\text { Sabaliauskaite, } \\
\text { S. Kusumoto, } \\
\text { and K. Inoue, }\end{array}$ & $\begin{array}{l}\text { 98. Assessing defect detection } \\
\text { performance of interacting teams in } \\
\text { object-oriented design inspection, } \\
\text { Information and Software Technology, } \\
\text { vol. } 46, \text { pp. } 875-886,2004 \text {. }\end{array}$ & $\begin{array}{l}\text { - Reporta un experimento } \\
\text { controlado con } 54 \text { estudiantes de } \\
\text { carrera que inspeccionan } \\
\text { documentos de diseño OO. } \\
\text { - Compara el desempeño de los } \\
\text { equipos de inspección utilizando } \\
\text { dos técnicas de lectura: CBR y PBR } \\
\text { - Compara el desempeño de equipos } \\
\text { nominales e interactivos } \\
\text { - Falsos positivos identificados }\end{array}$ \\
\hline
\end{tabular}

Caso de estudio 


\begin{tabular}{|c|c|c|c|c|c|}
\hline 27 & $\begin{array}{l}\text { /ACM/ } \\
\text { Acm_8.p }\end{array}$ & $\begin{array}{rr}\text { Philip } & \text { M. } \\
\text { Johnson, Danu } \\
\text { Tjahjono }\end{array}$ & $\begin{array}{l}\text { 99. Assessing software review } \\
\text { meetings: a controlled experimental } \\
\text { study using CSRS, Proceedings of the } 19^{\text {th }} \\
\text { international conference on Software } \\
\text { engineering ICSE ' } 97\end{array}$ & $\begin{array}{l}\text { - Conducen un experimento } \\
\text { controlado que evalúa varias } \\
\text { medidas de costo y efectividad } \\
\text { para un método de revisión basado } \\
\text { en reunió y otro no basado en ella } \\
\text { - Utilizan un ambiente de revisión de } \\
\text { software colaborativo } \\
\text { - Utilizan } 24 \times 3 \text { grupos de personas } \\
\text { - Miden: núm de defectos } \\
\text { descubiertos, esfuerzo requerido, } \\
\text { presencia de sinergia en los grupos } \\
\text { basados en reunión, falsos } \\
\text { positivos en los grupos no-basados, } \\
\text { respuestas a cuestionarios } \\
\text { cualitativos a }\end{array}$ & \\
\hline 28 & $\begin{array}{l}\text { /Xplore/ } \\
\text { Xplore_16.p } \\
\text { df }\end{array}$ & $\begin{array}{l}\text { A. Porter, L. } \\
\text { Votta, and V. } \\
\text { Basili. }\end{array}$ & $\begin{array}{l}\text { 100. Comparing detection methods } \\
\text { for software requirements inspections: A } \\
\text { replicated experiment. IEEE Transactions } \\
\text { on Software Engineering, 21(6):563- } \\
575,1995\end{array}$ & $\begin{array}{l}\text { - Conduce un experimento } \\
\text { aleatorizado con } 48 \text { estudiantes } \\
\text { - Cada equipo inspeccionó } 2 \text { SRS } \\
\text { usando alguna combinación de } \\
\text { métodos Ad hoc, checklist y }\end{array}$ & ART_81 \\
\hline
\end{tabular}


Proceso de RS de experimentos en Ingeniería del Software

\begin{tabular}{|c|c|c|c|c|}
\hline & & & & $\begin{array}{l}\text { escenarios } \\
\text { - Miden: tasa de detección de fallos } \\
\text { individual y grupal, tasas de } \\
\text { ganancia y pérdida de la reunión }\end{array}$ \\
\hline 29 & / /Scopus & $\begin{array}{l}\text { Sabaliauskait } \\
\text { e, G., Kusumoto, } \\
\text { S., Inoue, K. }\end{array}$ & $\begin{array}{l}\text { 101. Comparing reading techniques for } \\
\text { object-oriented design inspection, IEICE } \\
\text { Transactions on Information and Systems E87- } \\
\text { D (4), pp. 976-984, } 2004\end{array}$ & $\begin{array}{l}\text { - For more than twenty-five years } \\
\text { software inspections have been } \\
\text { considered an effective method for } \\
\text { defect detection. Inspections have } \\
\text { been investigated through } \\
\text { controlled experiments in } \\
\text { university environment and } \\
\text { industry case studies. However, in } \\
\text { most cases software inspections } \\
\text { have been used for defect } \\
\text { detection in documents of } \\
\text { conventional structured } \\
\text { development process. Therefore, } \\
\text { there is a significant lack of } \\
\text { information about how inspections } \\
\text { should be applied to Object- } \\
\text { Oriented artifacts, such as Object- }\end{array}$ \\
\hline
\end{tabular}

Caso de estudio 


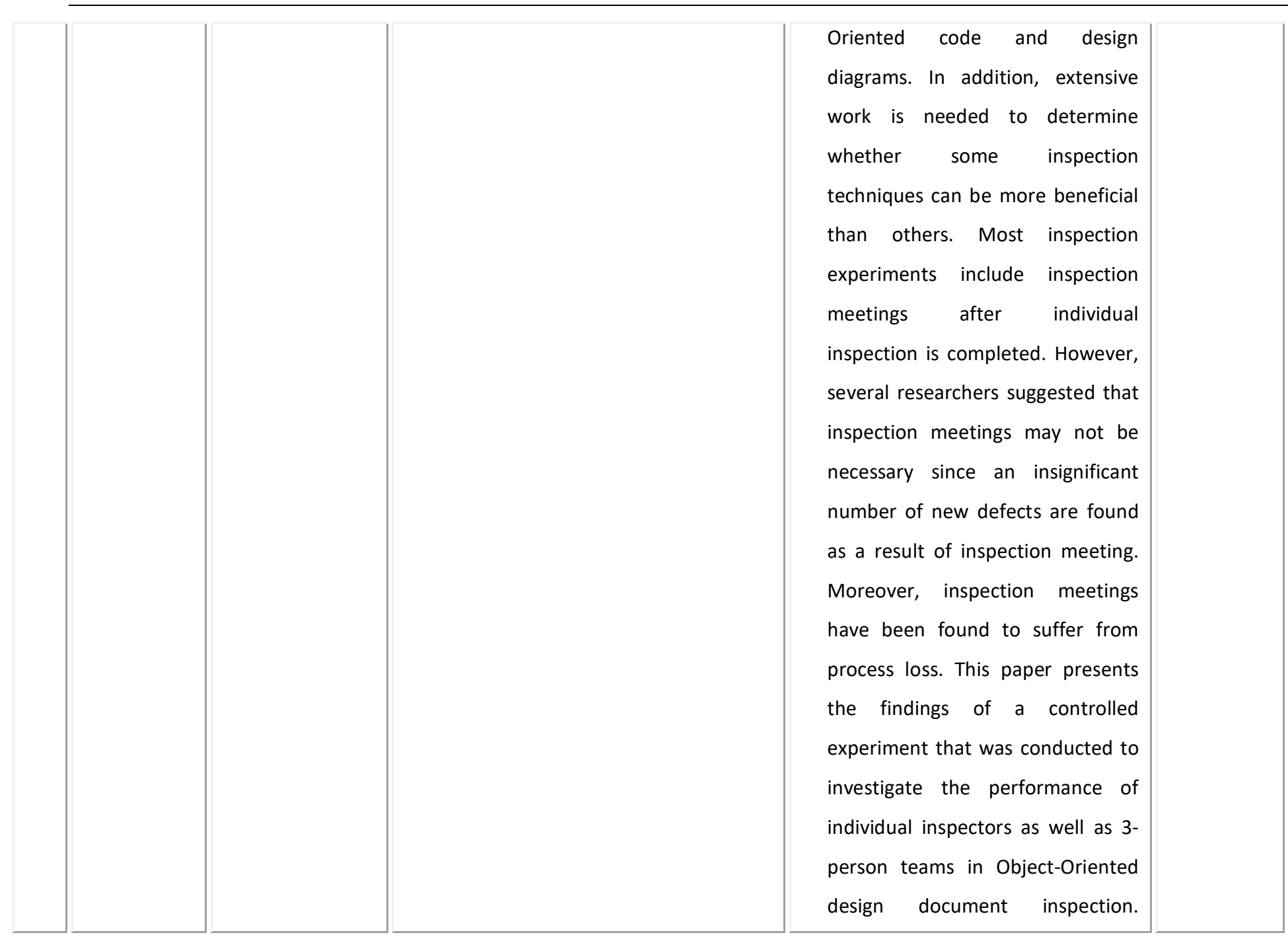


Proceso de RS de experimentos en Ingeniería del Software

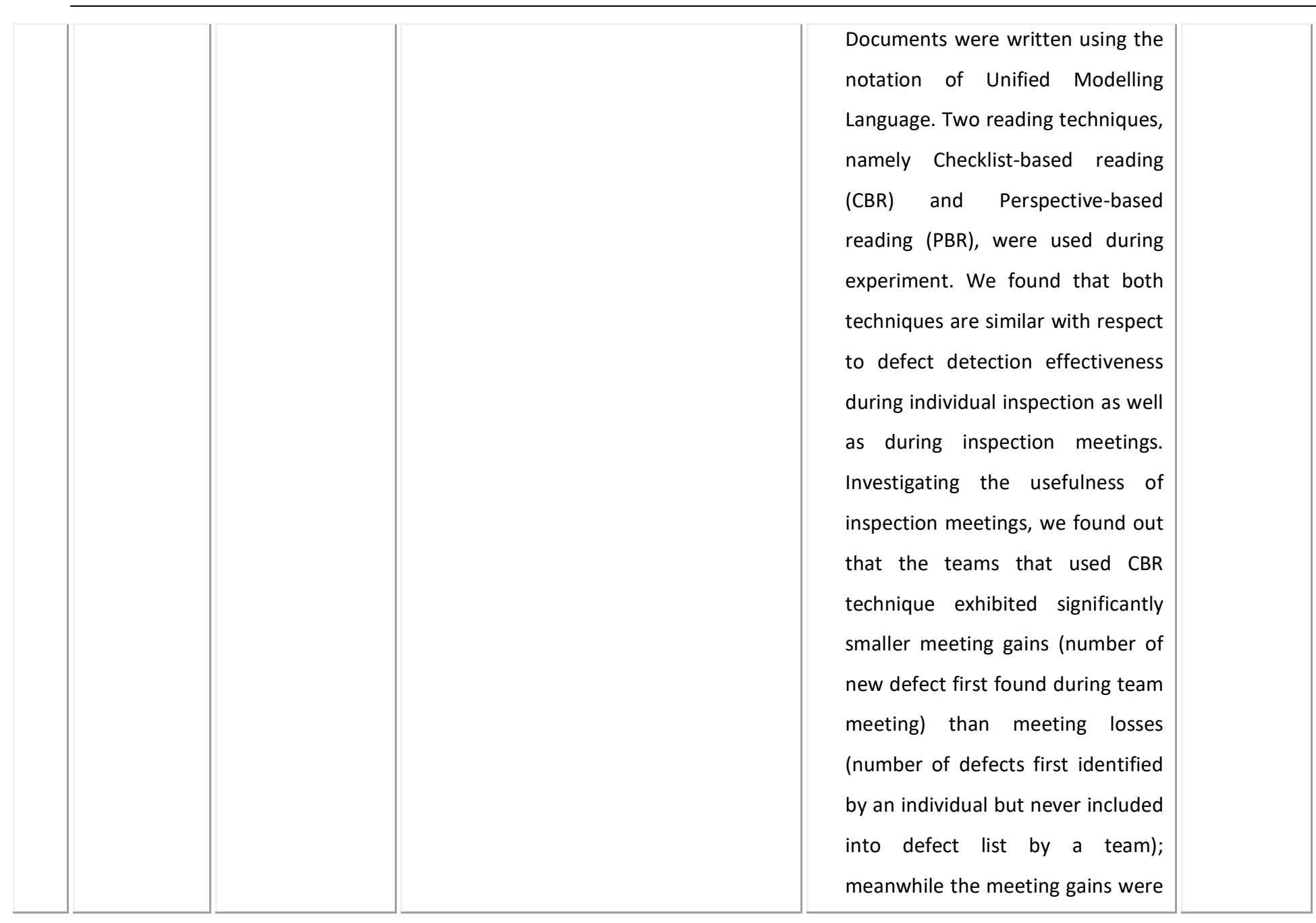

Caso de estudio 


\begin{tabular}{|c|c|c|c|c|}
\hline & & \multicolumn{2}{|c|}{ Extracción de Datos } & Proceso de RS de experimentos en Ingeniería del Soft \\
\hline & & & & $\begin{array}{l}\text { similar to meeting losses of the } \\
\text { teams that used PBR technique. } \\
\text { Consequently, CBR 3-person team } \\
\text { meetings turned out to be less } \\
\text { beneficial than PBR 3-person team } \\
\text { meetings. }\end{array}$ \\
\hline 30 & $\begin{array}{l}\text { /Scopus } \\
\text { Sco_2.p } \\
\text { df }\end{array}$ & $\begin{array}{l}\text { P. Vitharana } \\
\text { and K. } \\
\text { Ramamurthy, }\end{array}$ & $\begin{array}{l}\text { 102. Computer-mediated group } \\
\text { support, anonymity, and the software } \\
\text { inspection process: An empirical } \\
\text { investigation, IEEE Transactions on } \\
\text { Software Engineering, vol. 29, pp. 167- } \\
\text { 180, } 2003 \text {. }\end{array}$ & $\begin{array}{l}\text { - Propone las posibles influencias del } \\
\text { anonimato de los miembros de un } \\
\text { grupo en las salidas de un proceso } \\
\text { de inspección mediado por el } \\
\text { computador } \\
\text { - Valida estas relaciones a través de } \\
\text { un conjunto de experimentos } \\
\text { controlados } \\
\text { - Se emplean dos tareas diferentes } \\
\text { de inspección con niveles } \\
\text { cambiantes de complejidad de } \\
\text { código } \\
\text { - Miden: tiempo en ejecutar las } \\
\text { tareas, efectividad en encontrar los } \\
\text { errores "sembrados", actitud }\end{array}$ \\
\hline
\end{tabular}


Proceso de RS de experimentos en Ingeniería del Software

\begin{tabular}{|c|c|c|c|c|}
\hline 31 & $\begin{array}{l}\text { /Scedire } \\
\text { ct/ } \\
\text { Sdirect_ } \\
\text { 5.pdf } \\
\text { /scopus/ } \\
\text { sco_7.pdf }\end{array}$ & $\begin{array}{l}\text { T. Thelin and } \\
\text { P. Runeson, }\end{array}$ & $\begin{array}{l}\text { 103. Confidence intervals for capture- } \\
\text { recapture estimations in software } \\
\text { inspections, Information and Software } \\
\text { Technology, vol. 44, pp. 683-702, } 2002 \text {. }\end{array}$ & $\begin{array}{l}\text { - Replica un estudio captura- } \\
\text { recaptura } \\
\text { - Insvestiga los intervalos de } \\
\text { confianza para estimadores de } \\
\text { captura-recaptura utilizando } \\
\text { conjuntos de datos de dos } \\
\text { experimentos de inspección }\end{array}$ \\
\hline 32 & /Scopus & Harjumaa, L. & $\begin{array}{l}\text { 104. Distributed software inspections - } \\
\text { An experiment with Adobe Acrobat, } \\
\text { International Conference on Computer } \\
\text { Science and Technology, pp. 26-31, } 2003\end{array}$ & $\begin{array}{l}\text { - Several computer tools for } \\
\text { supporting software inspections } \\
\text { exist. Most of them are prototypes } \\
\text { that demonstrate particular } \\
\text { aspects of the inspection process } \\
\text { automation and are not mature } \\
\text { enough for utilization. This paper } \\
\text { discusses if off-the shelf products } \\
\text { can be used effectively for } \\
\text { inspection collaboration in } \\
\text { distributed software development. } \\
\text { During the experiment three teams } \\
\text { carried out distributed inspections. } \\
\text { Collaboration between team }\end{array}$ \\
\hline
\end{tabular}

Caso de estudio 


\begin{tabular}{|c|c|c|c|c|}
\hline & & \multicolumn{2}{|c|}{ Extracción de Datos } & ceso de RS de experimentos en Ing \\
\hline & & & & $\begin{array}{l}\text { members was done with Adobe } \\
\text { Acrobat } 5.0 \text { and standard e-mail. } \\
\text { The Acrobat software provides } \\
\text { very convenient on-line } \\
\text { commenting and material } \\
\text { distribution capabilities, but lacks } \\
\text { characteristics for efficient } \\
\text { management of the inspection } \\
\text { process, such as defect } \\
\text { categorization. Thus, there is still a } \\
\text { need for tools that are specialized } \\
\text { in software inspections. }\end{array}$ \\
\hline 33 & $\begin{array}{l}\text { /ACM/ } \\
\text { Acm_9.p } \\
\text { df }\end{array}$ & $\begin{array}{l}\text { Muhammad } \\
\text { Ali Babar, } \\
\text { Barbara } \\
\text { Kitchenham, } \\
\text { Ross Jeffery }\end{array}$ & $\begin{array}{l}\text { 105. Distributed versus face-to-face } \\
\text { meetings for architecture evalution: a } \\
\text { controlled experiment, Proceedings of } \\
\text { the } 2006 \text { ACM/IEEE international } \\
\text { symposium on International symposium } \\
\text { on empirical software engineering ISESE } \\
\text { '06 }\end{array}$ & $\begin{array}{l}\text { - Presenta un experimento } \\
\text { controlado que evalúa la } \\
\text { efectividad de la construcción de } \\
\text { perfiles de escenarios usando } \\
\text { reuniones distribuidas } \\
\text { - Cross-over experiment con } 32 \\
\text { equipos de estudiantes } \\
\text { - Compara la calidad de los } \\
\text { escenarios usando groupware vs }\end{array}$ \\
\hline
\end{tabular}


Proceso de RS de experimentos en Ingeniería del Software

\begin{tabular}{|c|c|c|c|c|}
\hline & & & & los producidos face-2-face \\
\hline 34 & $\begin{array}{c}\text { /ACM/ } \\
\text { acm_10.pdf }\end{array}$ & $\begin{array}{rr}\text { Yuk } & \text { Kuen } \\
\text { Wong, } & \text { David } \\
\text { Wilson } & \end{array}$ & $\begin{array}{l}\text { 106. Does task training really affect } \\
\text { group performance?, Proceedings of the } \\
\text { winter international synposium on } \\
\text { Information and communication } \\
\text { technologies WISICT '04 }\end{array}$ & $\begin{array}{l}\text { - Examina la relación entre la } \\
\text { experiencia en entrenamiento de } \\
\text { tareas y el desempeño en la } \\
\text { revisión de software } \\
\text { - } 192 \text { sujetos fueron asignados } \\
\text { aleatoriamente a } 48 \text { grupos de } 4 \\
\text { miembros } \\
\text { - Buscaron defectos en un } \\
\text { documento de diseño }\end{array}$ \\
\hline 35 & $\begin{array}{l}\text { /ACM/a } \\
\text { cm_11.pdf }\end{array}$ & $\begin{array}{l}\text { Christian F. J. } \\
\text { Lange, Michel R. } \\
\text { V. Chaudron }\end{array}$ & $\begin{array}{l}\text { 107. Effects of defects in UML } \\
\text { models: an experimental investigation, } \\
\text { May } 2006 \text { Proceeding of the 28th } \\
\text { international conference on Software } \\
\text { engineering ICSE '06 }\end{array}$ & $\begin{array}{l}\text { - Presenta } 2 \text { experimentos } \\
\text { controlados } \\
\text { - Investiga cuántos investigadores } \\
\text { detectan defectos y cuántos } \\
\text { defectos causan diferentes } \\
\text { interpretaciones para diferentes } \\
\text { lectores } \\
\text { - Utilizan } 111 \text { estudiantes y } 48 \\
\text { practicantes industriales }\end{array}$ \\
\hline
\end{tabular}

Caso de estudio 


\begin{tabular}{|c|c|c|c|c|}
\hline 36 & /Scopus & $\mathrm{N} / \mathrm{D}$ & Eight maxims for software inspectors & $\mathrm{N} / \mathrm{D}$ \\
\hline 37 & $\begin{array}{l}\text { /Scedire } \\
\text { ct/ } \\
\text { sdirect_6.p } \\
\text { df } \\
\text { /scopus/ } \\
\text { sco_6.pdf }\end{array}$ & $\begin{array}{l}\text { S. S. So, S. D. } \\
\text { Cha, and Y. R. } \\
\text { Kwon, }\end{array}$ & $\begin{array}{l}\text { 108. Empirical evaluation of a fuzzy } \\
\text { logic-based software quality prediction } \\
\text { model, Fuzzy Sets and Systems, vol. } 127 \text {, } \\
\text { pp. } 199-208,2002 \text {. }\end{array}$ & $\begin{array}{l}\text { - Popone un enfoque automatizado } \\
\text { y badado en lógica difusa } \\
\text { - Analizan los datos de inspección y } \\
\text { aquellos obtenidos en } \\
\text { experimentos de inspección } \\
\text { separados } \\
\text { - Valida el modelo de predicción de } \\
\text { la calidad propuesto }\end{array}$ \\
\hline 38 & $\begin{array}{l}\text { /Springe } \\
\text { r/ } \\
\text { Springer_11 } \\
\text {.pdf } \\
\text { Scopus/ } \\
\text { sco_14.pdf }\end{array}$ & T. Thomas, & $\begin{array}{l}\text { 109. Empirical Evaluations of Usage- } \\
\text { Based Reading and Fault Content } \\
\text { Estimation for Software Inspections, } \\
\text { Empirical Software Engineering, vol. V8, } \\
\text { pp. 309-313, } 2003 \text {. }\end{array}$ & $\begin{array}{l}\text { - Describe } 6 \text { investigaciones } \\
\text { empíricas de } 2 \text { técnicas de } \\
\text { inspección de software: técnica de } \\
\text { lectura (UBR) y de estimación de } \\
\text { contenido de fallas (captura- } \\
\text { recaptura) }\end{array}$ \\
\hline 39 & /Scopus & $\mathrm{N} / \mathrm{D}$ & $\begin{array}{l}\text { Estimating the number of remaining } \\
\text { defects after inspection }\end{array}$ & $\mathrm{N} / \mathrm{D}$ \\
\hline 40 & $\begin{array}{l}\text { /Scedire } \\
\text { ct/ }\end{array}$ & S. Biffl, & $\begin{array}{l}\text { 110. Evaluating defect estimation } \\
\text { models with major defects, Journal of }\end{array}$ & - Se basa en la estimación de \\
\hline
\end{tabular}


Proceso de RS de experimentos en Ingeniería del Software

\begin{tabular}{|c|c|c|c|c|}
\hline & $\begin{array}{l}\text { sdirect_4.p } \\
\text { df } \\
\text { /Scopus }\end{array}$ & & $\begin{array}{l}\text { Systems and Software, vol. 65, pp. 13-29, } \\
2003 .\end{array}$ & $\begin{array}{l}\text { defectos en documentos de } \\
\text { requisitos de software } \\
\text { - Compara el desempeño de técnicas } \\
\text { objetivas y subjetivas de } \\
\text { estimación del contenido de } \\
\text { defectos } \\
\text { - Conduce un experimento } \\
\text { controlado con } 31 \text { equipos de } \\
\text { inspección de 4-6 personas } \\
\text { - Miden: precisión }\end{array}$ \\
\hline 41 & $\begin{array}{c}\text { /ACM/ } \\
\text { acm_12.pdf }\end{array}$ & $\begin{array}{l}\quad \text { Stefan Biffl, } \\
\text { Wilfried } \\
\text { Grossmann }\end{array}$ & $\begin{array}{l}\text { 111. Evaluating the accuracy of defect } \\
\text { estimation models based on inspection } \\
\text { data from two inspection cycles, } \\
\text { Proceedings of the 23rd International } \\
\text { Conference on Software Engineering } \\
\text { ICSE '01 }\end{array}$ & $\begin{array}{l}\text { - Considera } 3 \text { escenarios para } \\
\text { combinar conjuntos de datos de } \\
\text { los procesos de inspección- } \\
\text { reinspección } \\
\text { - Evalúa la precisión de la estimación } \\
\text { de defectos } \\
\text { - Utiliza los datos de un experimento } \\
\text { donde } 31 \text { equipos inpeccionaron- } \\
\text { reinspeccionaron docs de }\end{array}$ \\
\hline
\end{tabular}

Caso de estudio 


\begin{tabular}{|c|c|c|c|c|}
\hline & & \multicolumn{2}{|c|}{ Extracción de Datos } & Proceso de RS de experimentos en Ingeniería del Soft \\
\hline & & & & requisitos de usuario. \\
\hline 42 & $\begin{array}{l}\text { /Springe } \\
\text { r/ } \\
\text { Springer_1. } \\
\text { pdf } \\
\text { /Scopus }\end{array}$ & $\begin{array}{l}\text { T. Thomas, R. } \\
\text { Per, W. Claes, O. } \\
\text { Thomas, and A. } \\
\text { Carina, }\end{array}$ & $\begin{array}{l}\text { 112. Evaluation of Usage-Based } \\
\text { Reading-Conclusions after Three } \\
\text { Experiments, Empirical Software } \\
\text { Engineering, vol. V9, pp. 77-110, } 2004 .\end{array}$ & $\begin{array}{l}\text { - Presenta una serie de } \\
\text { experimentos para evaluar UBR } \\
\text { aplicado a un documento de } \\
\text { diseño de alto nivel } \\
\text { - El foco es el 3er experimento: } \\
\text { investigar la información } \\
\text { necesitada por UBR para la } \\
\text { preparación y las reuniones de } \\
\text { inspección de software } \\
\text { - Discute la eficiencia y efectividad }\end{array}$ \\
\hline 43 & 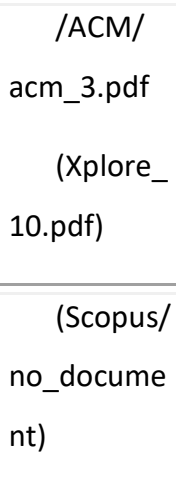 & $\begin{array}{l}\text { Porter, H. } \\
\text { Siy, C. A. Toman, } \\
\text { and L. G. Votta }\end{array}$ & $\begin{array}{l}\text { 113. Experiment to assess the cost- } \\
\text { benefits of code inspections in large scale } \\
\text { software development, Proceedings of } \\
\text { the ACM SIGSOFT Symposium on the } \\
\text { Foundations of Software Engineering, } \\
1995 .\end{array}$ & $\begin{array}{l}\text { - Conduce un proyecto a largo plazo } \\
\text { - Evalúa la costo-efectividad de } \\
\text { diversos métodos de inspección de } \\
\text { software } \\
\text { - Los métodos son aplicados por } \\
\text { desarrolladores profesionales } \\
\text { - Se utilizó simulación para optimizar }\end{array}$ \\
\hline
\end{tabular}


Proceso de RS de experimentos en Ingeniería del Software

\begin{tabular}{|c|c|c|c|c|}
\hline & & & & $\begin{array}{l}\text { el experimento } \\
\text { - A cada inspección se le asignó } \\
\text { aleatoriamente } 3 \text { variables } \\
\text { independientes: número de } \\
\text { revisores en el equipo, núm de } \\
\text { equipos de inspección, el requisito } \\
\text { de reparar los defectos entre la 1aa } \\
\text { y 2a inspección } \\
\text { - Los revisores fueron seleccionados } \\
\text { aleatoriamente } \\
\text { - Las variables dependientes fueron: } \\
\text { tiempo de inspección, esfuerzo } \\
\text { total, la tasa de detección de } \\
\text { defectos }\end{array}$ \\
\hline 44 & /Scopus & $\begin{array}{l}\text { Laitenberger, } \\
\text { O., Atkinson, C., } \\
\text { Schlich, M., El } \\
\text { Emam, K. }\end{array}$ & $\begin{array}{l}\text { Experimental comparison of reading } \\
\text { techniques for defect detection in UML } \\
\text { design documents, Journal of Systems } \\
\text { and Software } 53 \text { (2), pp. 183-204, } 2000\end{array}$ & $\begin{array}{l}\text { - The basic motivation for software } \\
\text { inspections is to detect and } \\
\text { remove defects before they } \\
\text { propagate to subsequent } \\
\text { development phases where their } \\
\text { detection and removal become }\end{array}$ \\
\hline
\end{tabular}

Caso de estudio 


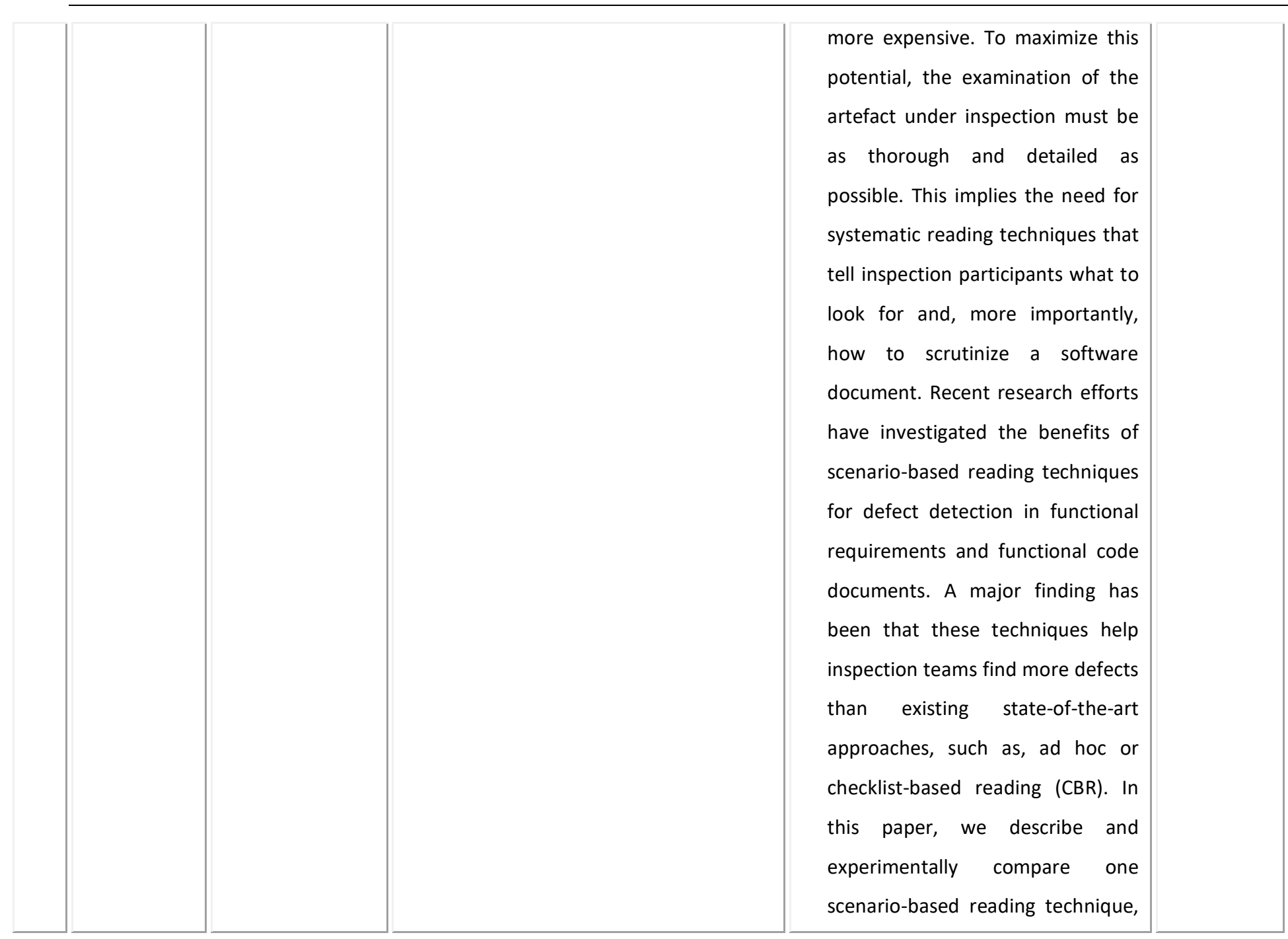


Proceso de RS de experimentos en Ingeniería del Software

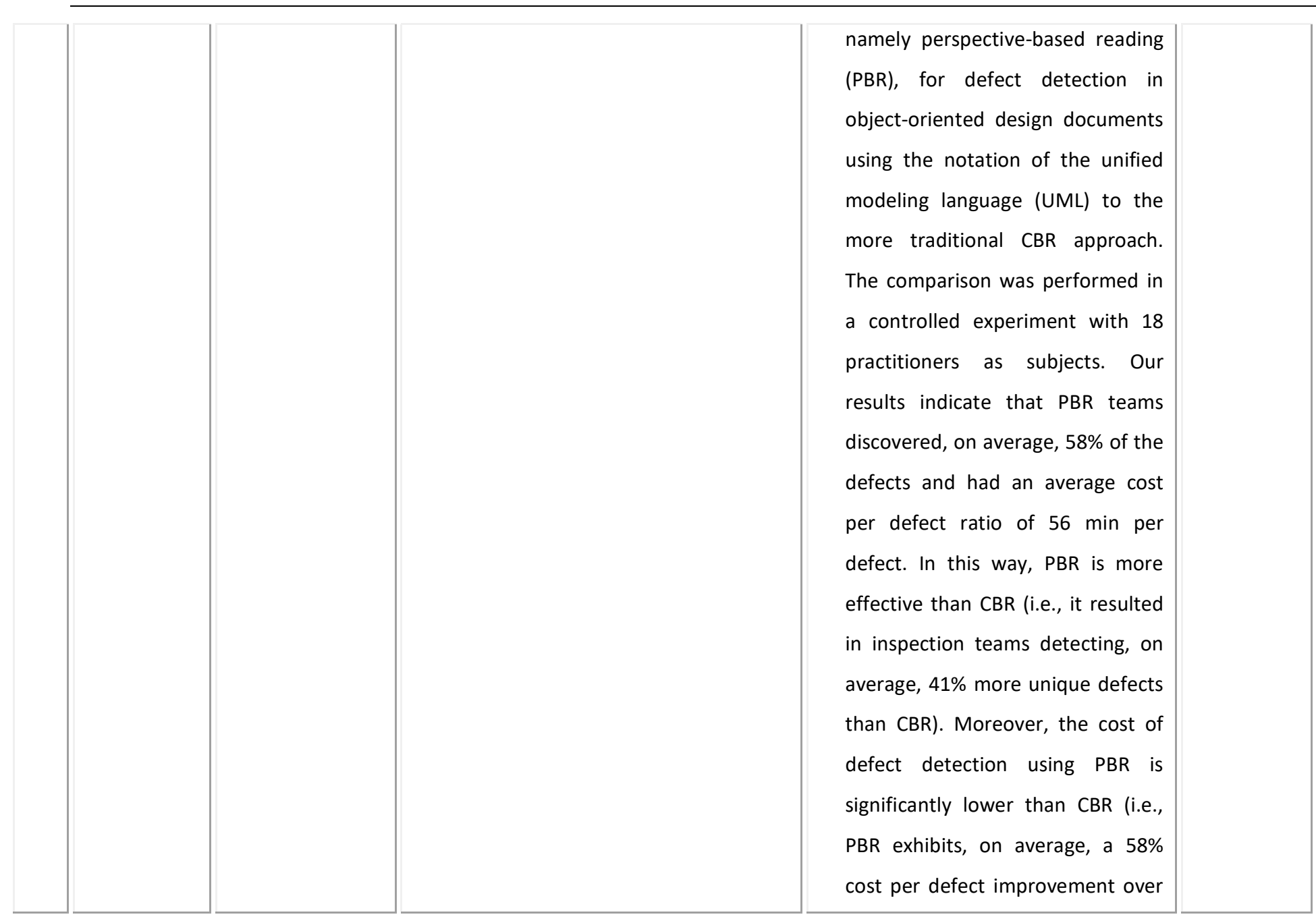

Caso de estudio 


\begin{tabular}{|c|c|c|c|c|}
\hline & & \multicolumn{2}{|c|}{ Extracción de Datos } & Proceso de RS de experimentos en Ingeniería del Soft \\
\hline & & & & $\begin{array}{l}\text { CBR). This study therefore provides } \\
\text { evidence demonstrating the } \\
\text { efficacy of PBR scenarios for defect } \\
\text { detection in UML design } \\
\text { documents. In addition, it } \\
\text { demonstrates that a PBR } \\
\text { inspection is a promising approach } \\
\text { for improving the quality of models } \\
\text { developed using the UML notation. }\end{array}$ \\
\hline 45 & /Scopus & $\begin{array}{l}\text { Wohlin, } \\
\text { Claes, Runeson, } \\
\text { Per, Brantestam, } \\
\text { Johan }\end{array}$ & $\begin{array}{l}\text { Experimental evaluation of capture- } \\
\text { recapture in software inspections, } \\
\text { Software Testing Verification and } \\
\text { Reliability } 5 \text { (4), pp. 213-232, } 1995\end{array}$ & $\begin{array}{l}\text { The use of capture-recapture to } \\
\text { estimate the residual faults in a } \\
\text { software artifact has evolved as a } \\
\text { promising method. However, the } \\
\text { assumptions needed to make the } \\
\text { estimates are not completely } \\
\text { fulfilled in software development, } \\
\text { leading to an underestimation of } \\
\text { the residual fault content. } \\
\text { Therefore, a method employing a } \\
\text { filtering technique with an } \\
\text { experience factor to improve the } \\
\text { estimates of the residual faults is }\end{array}$ \\
\hline
\end{tabular}


Proceso de RS de experimentos en Ingeniería del Software

\begin{tabular}{|c|c|c|c|c|}
\hline & & & & $\begin{array}{l}\text { proposed in this paper. An } \\
\text { experimental study of the capture- } \\
\text { recapture method with this } \\
\text { correction method has been } \\
\text { conducted. It is concluded that the } \\
\text { correction method improves the } \\
\text { capture-recapture estimate of the } \\
\text { number of residual defects in the } \\
\text { inspected document. }\end{array}$ \\
\hline 46 & /Scopus & 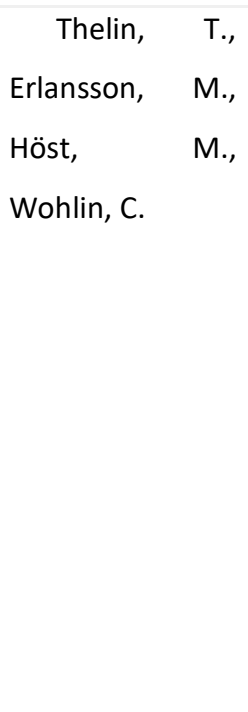 & $\begin{array}{l}\text { Experimentation with usage-based } \\
\text { reading, Lecture Notes in Computer } \\
\text { Science (including subseries Lecture } \\
\text { Notes in Artificial Intelligence and Lecture } \\
\text { Notes in Bioinformatics) 2765, pp. 193- } \\
207,2003\end{array}$ & $\begin{array}{l}\text { - Software inspections are regarded } \\
\text { as an important technique to } \\
\text { detect faults throughout the } \\
\text { software development process. } \\
\text { The individual preparation phase of } \\
\text { software inspections has enlarged } \\
\text { its focus from only comprehension } \\
\text { to also include fault searching. } \\
\text { Hence, reading techniques to } \\
\text { support the reviewers on fault } \\
\text { detection are needed. Usage-based } \\
\text { reading (UBR) is a reading }\end{array}$ \\
\hline
\end{tabular}

Caso de estudio 


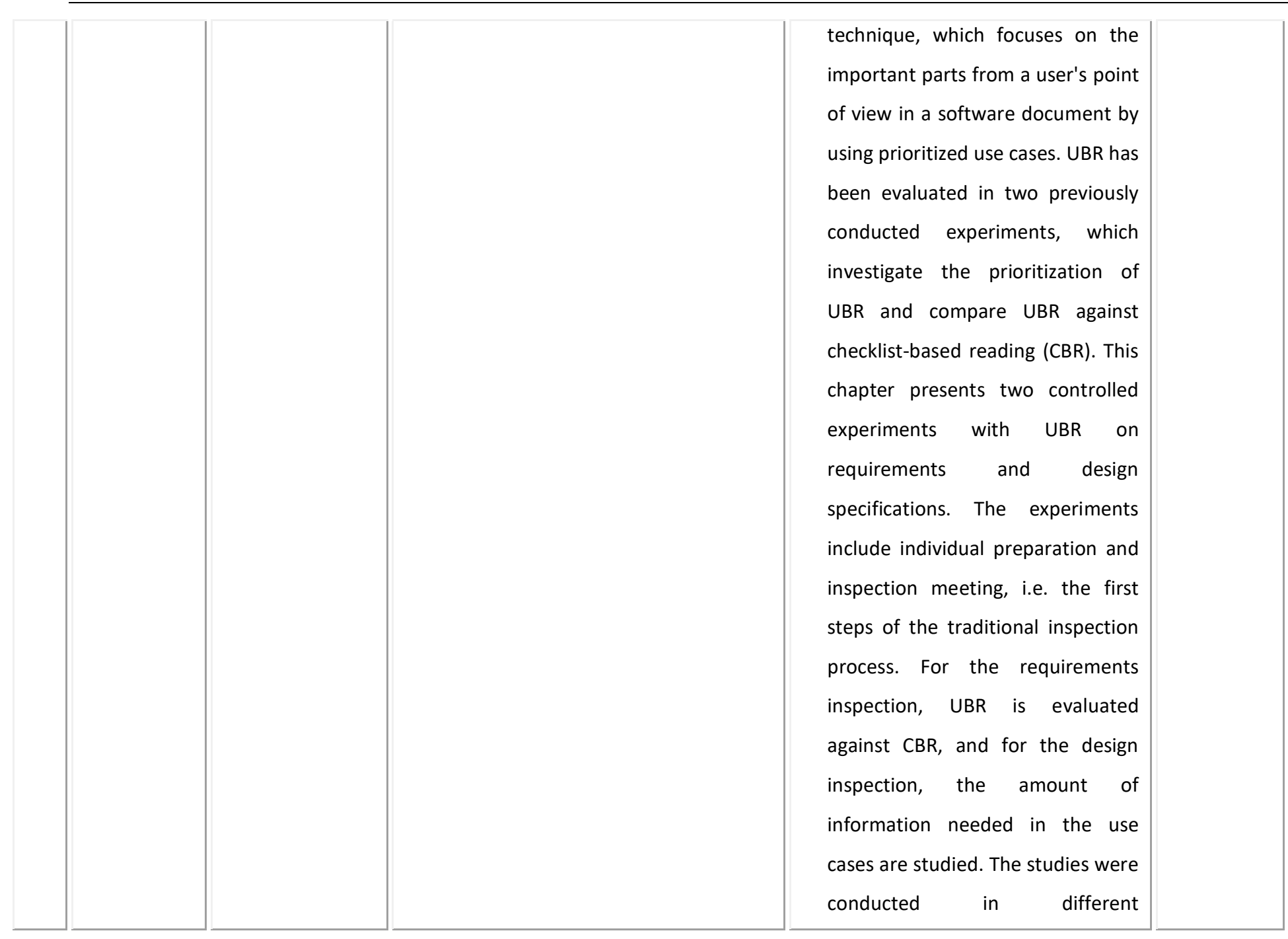


Proceso de RS de experimentos en Ingeniería del Software

\begin{tabular}{|c|c|c|c|c|}
\hline & & & & $\begin{array}{l}\text { environments with a total of about } \\
100 \text { students. The result from } \\
\text { these experiments shows that UBR } \\
\text { is not better than CBR for } \\
\text { requirements inspections. Results } \\
\text { from the experiment on design } \\
\text { inspection indicate that use cases } \\
\text { developed in advance are } \\
\text { preferable compared to developing } \\
\text { them as part of the preparation } \\
\text { phase of the inspection. }\end{array}$ \\
\hline 47 & $\begin{array}{l}\text { /Springe } \\
\text { r/ } \\
\text { Springer_6. } \\
\text { pdf } \\
\text { Scopus/ } \\
\text { sco_16.pdf }\end{array}$ & $\begin{array}{l}\text { J. Miller, M. } \\
\text { Wood, and M. } \\
\text { Roper, }\end{array}$ & $\begin{array}{l}\text { 114. Further Experiences with } \\
\text { Scenarios and Checklists, Empirical } \\
\text { Software Engineering, vol. V3, pp. 37-64, } \\
\text { 1998. }\end{array}$ & $\begin{array}{l}\text { - Es una replicación del experimento } \\
\text { de Porter et al. (1995) } \\
\text { (Xplore_16.pdf) } \\
\text { - Evalúa la ayuda a la detección } \\
\text { utilizando enfoques basados en } \\
\text { escenarios y en checklist } \\
\text { - Compara los resultados del } \\
\text { experimento con otros } \\
\text { - Miden: desempeño, pérdidas de la }\end{array}$ \\
\hline
\end{tabular}

Caso de estudio 


\begin{tabular}{|c|c|c|c|c|}
\hline & & \multicolumn{2}{|c|}{ Extracción de Datos } & Proceso de RS de experimentos en Ingeniería del Sof \\
\hline & & & & reunión \\
\hline 48 & $\begin{array}{l}\text { /Scedire } \\
\text { ct/ } \\
\text { sdirect_3.p } \\
\text { df } \\
\text { /Scopus }\end{array}$ & $\begin{array}{l}\text { G. } \\
\text { Sabaliauskaite, } \\
\text { F. Matsukawa, S. } \\
\text { Kusumoto, and } \\
\text { K. Inoue, }\end{array}$ & $\begin{array}{l}\text { 115. Further investigations of reading } \\
\text { techniques for object-oriented design } \\
\text { inspection, Information and Software } \\
\text { Technology, vol. } 45 \text {, pp. 571-585, } 2003 \text {. }\end{array}$ & $\begin{array}{l}\text { - Describe la evaluación de CBR y } \\
\text { PBR para un documento de diseño } \\
\text { OO escrito con UML } \\
\text { - Reporta un experimento } \\
\text { controlado con } 59 \text { estudiantes } \\
\text { - Miden: tiempo individual, costo x } \\
\text { defecto, efectividad, efectividad } \\
\text { del equipo simulado }\end{array}$ \\
\hline 49 & $\begin{array}{l}\text { /Xplore/ } \\
\text { Xplore_17.p } \\
\text { df } \\
\text { /scopus/ } \\
\text { sco_31.pdf }\end{array}$ & $\begin{array}{l}\quad \text { O. } \\
\text { Laitenberger and } \\
\text { C. Atkinson, }\end{array}$ & $\begin{array}{l}\text { 116. Generalizing perspective-based } \\
\text { inspection to handle object-oriented } \\
\text { development artifacts, 1999. Proceedings } \\
\text { - International Conference on Software } \\
\text { Engineering, pp. } 494-503\end{array}$ & $\begin{array}{l}\text { - Discute las dificultades de } \\
\text { adaptación de la técnica PBR a } \\
\text { métodos de desarrollo OO } \\
\text { - Presenta una generalización de la } \\
\text { técnica y una nueva versión } \\
\text { orientada a UML }\end{array}$ \\
\hline 50 & $\begin{array}{l}\text { /Xplore/ } \\
\text { Xplore_18.p } \\
\text { df }\end{array}$ & $\begin{array}{l}\text { T. Thelin, } \mathrm{P} . \\
\text { Runeson, } \mathrm{C} . \\
\text { Wohlin, } \mathrm{T} . \\
\text { Olsson, and } \mathrm{C} . \\
\text { Andersson, }\end{array}$ & $\begin{array}{l}\text { 117. How much information is } \\
\text { needed for usage-based reading? A series } \\
\text { of experiments, } 2002 \text {. }\end{array}$ & $\begin{array}{l}\text { - Presenta una serie de } 3 \\
\text { experimentos sobre UBR sobre } \\
\text { especificaciones de diseño } \\
\text { - 1ero: evalúa la priorización de UBR }\end{array}$ \\
\hline
\end{tabular}


Proceso de RS de experimentos en Ingeniería del Software

\begin{tabular}{|c|c|c|c|c|}
\hline & & & & $\begin{array}{l}\text { - 2do: compara UBR vs CBR } \\
\text { - 3ero: investiga la cantidad de } \\
\text { información necesitada en los } \\
\text { casos de uso y si un enfoque más } \\
\text { activo ayuda a los revisores a } \\
\text { detectar más fallas } \\
\text { - El 3er experimento fue conducido } \\
\text { en dos sitios distintos con } 82 \\
\text { sujetos } \\
\text { - Miden: efectividad y eficiencia }\end{array}$ \\
\hline 51 & /Scopus & N/D & $\begin{array}{l}\text { Increasing the understanding of } \\
\text { effectiveness in software inspections } \\
\text { using published data sets }\end{array}$ & $\mathrm{N} / \mathrm{D}$ \\
\hline 52 & $\begin{array}{l}\text { /Xplore/ } \\
\text { Xplore_19.p } \\
\text { df }\end{array}$ & $\begin{array}{l}\text { L. Harjumaa, } \\
\text { I. Tervonen, and } \\
\text { P. Vuorio, }\end{array}$ & $\begin{array}{l}\text { 118. Improving software inspection } \\
\text { process with patterns, 2004. Proceedings } \\
\text { - Fourth International Conference on } \\
\text { Quality Software, QSIC 2004, pp. 118-125 }\end{array}$ & $\begin{array}{l}\text { - Describe patrones para mejorar el } \\
\text { proceso de inspección de software } \\
\text { - Los patrones son experimentados } \\
\text { en una compañía de software } \\
\text { - Evalúan la capacidad inicial del }\end{array}$ \\
\hline
\end{tabular}

Caso de estudio 


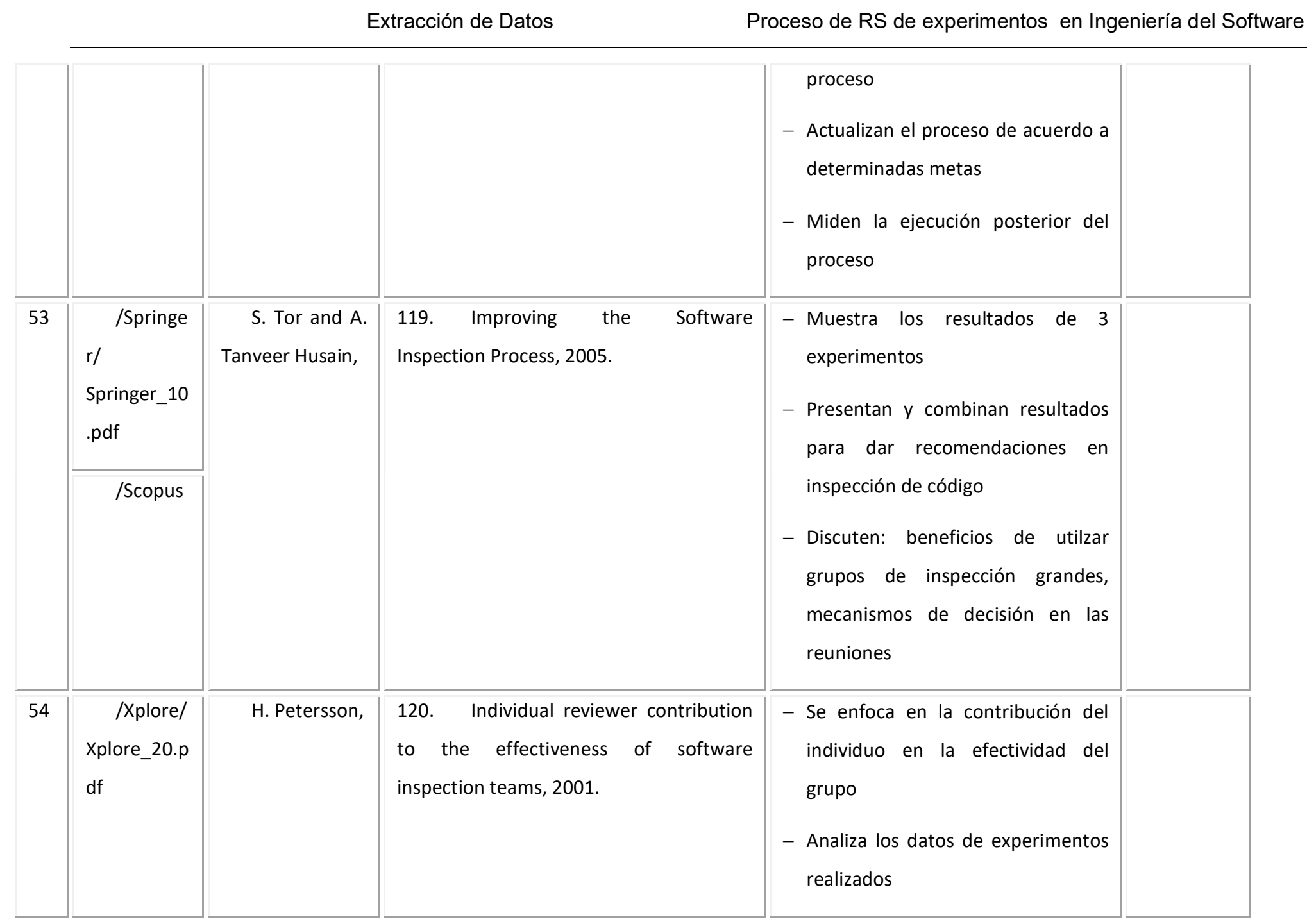


Proceso de RS de experimentos en Ingeniería del Software

\begin{tabular}{|c|c|c|c|c|}
\hline 55 & $\begin{array}{l}\text { /Xplore/ } \\
\text { Xplore_21.p } \\
\text { df } \\
\text { Scopus/ } \\
\text { sco_25.pdf }\end{array}$ & $\begin{array}{l}\text { S. Biffl and } \\
\text { M. Halling, }\end{array}$ & $\begin{array}{l}\text { 121. Investigating reinspection } \\
\text { decision accuracy regarding product- } \\
\text { quality and cost-benefit estimates, } 2001 . \\
\text { Proceedings - IEEE Computer Society's } \\
\text { International Computer Software and } \\
\text { Applications Conference, pp. } 87-96\end{array}$ & $\begin{array}{l}\text { - Propone utilizar modelos de } \\
\text { estimación para la mejora de } \\
\text { calidad durante la reinspección y } \\
\text { utilizar el costo-beneficio de una } \\
\text { reinspección para la decisión sobre } \\
\text { la misma } \\
\text { - Evalua la correctitud de la decisión } \\
\text { de reinspección de estos modelos } \\
\text { con datos de defectos de un gran } \\
\text { experimento controlado sobre la } \\
\text { insp-reinsp de docs de requisitos } \\
\text { de software } \\
\text { - Describe el experimento y sus } \\
\text { resultados }\end{array}$ \\
\hline 56 & $\begin{array}{l}\text { /Xplore/ } \\
\text { Xplore_22.p } \\
\text { df } \\
\text { /ACM/ } \\
\text { acm_13.pdf }\end{array}$ & $\begin{array}{l}\text { Stefan Biffl, } \\
\text { Bernd Freimut, } \\
\text { Oliver } \\
\text { Laitenberger }\end{array}$ & $\begin{array}{l}\text { 122. Investigating the cost- } \\
\text { effectiveness of reinspections in software } \\
\text { development, } 2001 \text {. Proceedings - } \\
\text { International Conference on Software } \\
\text { Engineering, pp. } 155-164\end{array}$ & $\begin{array}{l}\text { - Proponen un modelo costo- } \\
\text { beneficio para inspección- } \\
\text { reinspección } \\
\text { - Discuten el impacto de los }\end{array}$ \\
\hline
\end{tabular}

Caso de estudio 


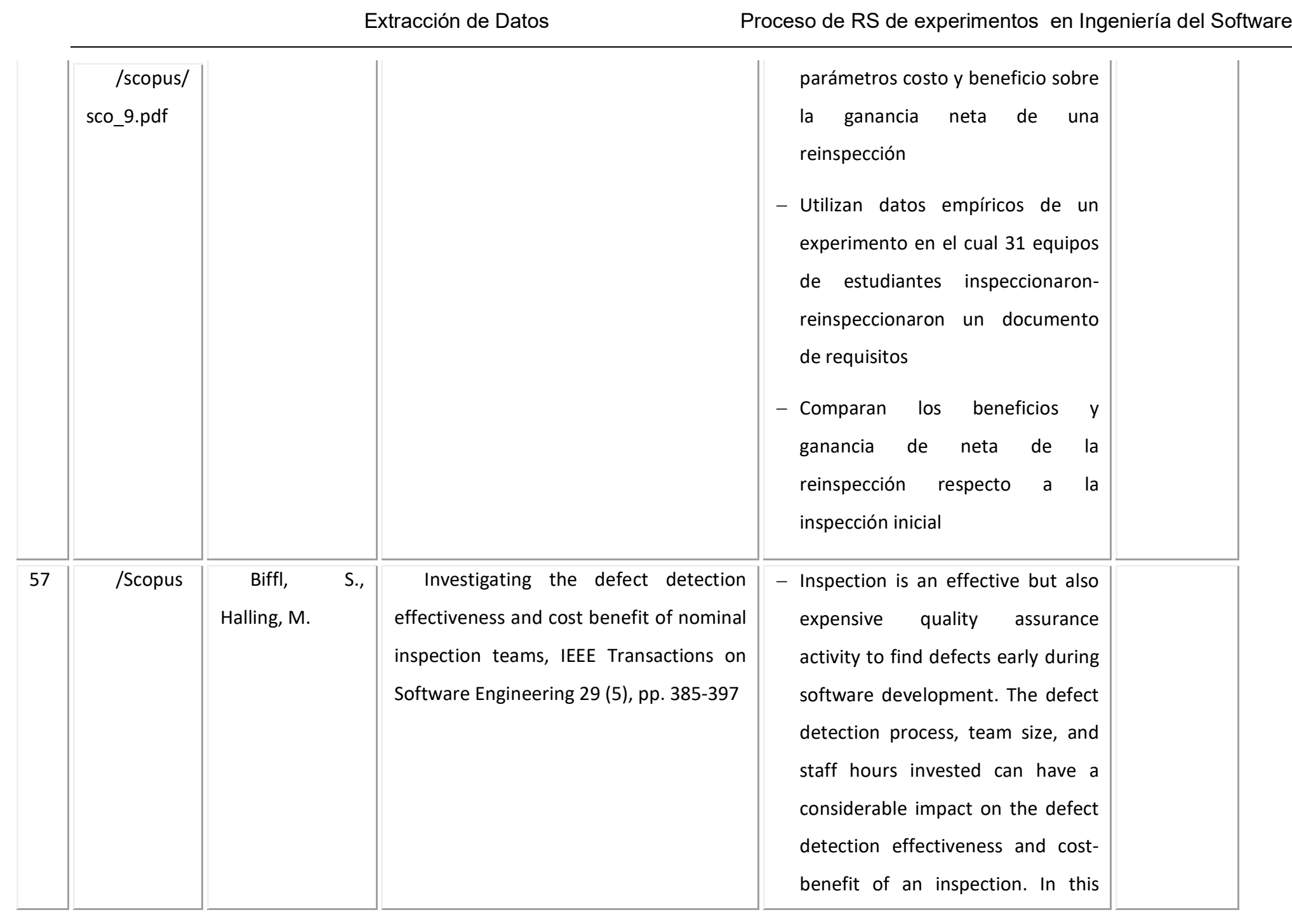


Proceso de RS de experimentos en Ingeniería del Software

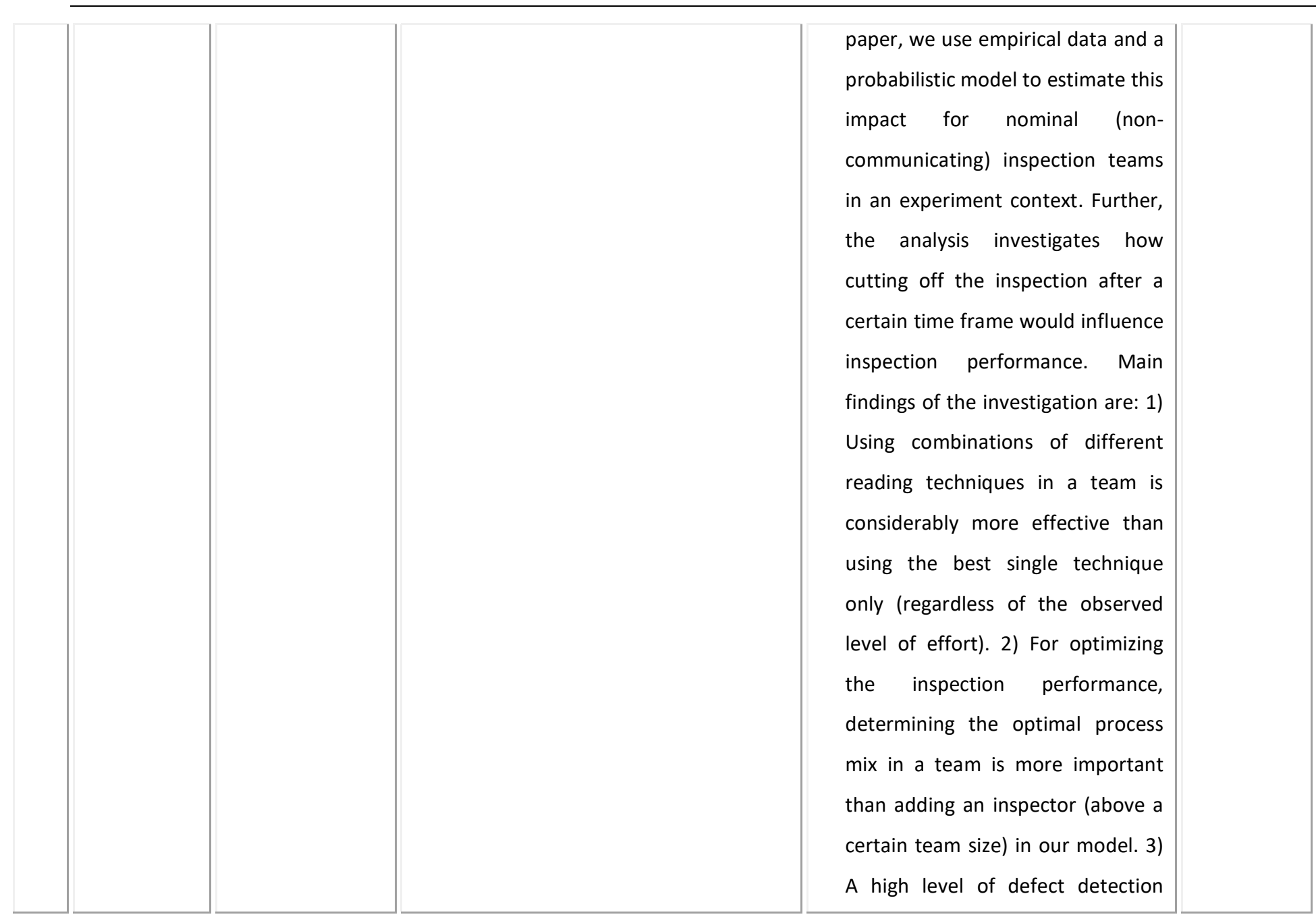

Caso de estudio 


\begin{tabular}{|c|c|c|c|c|}
\hline & & \multicolumn{2}{|c|}{ Extracción de Datos } & Proceso de RS de experimentos en Ingeniería del Soft \\
\hline & & & & $\begin{array}{l}\text { effectiveness is much more costly } \\
\text { to achieve than a moderate level } \\
\text { since the average cost for the } \\
\text { defects found by the inspector last } \\
\text { added to a team increases more } \\
\text { than linearly with growing effort } \\
\text { investment. The work provides an } \\
\text { Initial baseline of inspection } \\
\text { performance with regard to } \\
\text { process diversity and effort in } \\
\text { inspection teams. We encourage } \\
\text { further studies on the topic of time } \\
\text { usage with defect detection } \\
\text { techniques and its effect on } \\
\text { inspection effectiveness in a } \\
\text { variety of inspection contexts to } \\
\text { support inspection planning with } \\
\text { limited resources. }\end{array}$ \\
\hline 58 & $\begin{array}{l}\text { /Xplore/ } \\
\text { Xplore_23.p } \\
\text { df }\end{array}$ & $\begin{array}{l}\text { S. Biffl, M. } \\
\text { Halling, and M. } \\
\text { Kohle, }\end{array}$ & $\begin{array}{l}\text { 123. Investigating the effect of a } \\
\text { second software inspection cycle. Cost- } \\
\text { benefit data from a large-scale } \\
\text { experiment on reinspection of a software }\end{array}$ & $\begin{array}{l}\text { - Reporta un experimento } \\
\text { controlado que compara el efecto } \\
\text { de dos ciclos de inspección } \\
\text { - Un documento de requisitos es re- }\end{array}$ \\
\hline
\end{tabular}


Proceso de RS de experimentos en Ingeniería del Software

\begin{tabular}{|c|c|c|c|c|}
\hline & & & requirements document, 2000. & $\begin{array}{l}\text { inspeccionado por } 31 \text { equipos } \\
\text { - Presenta: efectividad, eficiencia, } \\
\text { ganancia neta, ROI de un segundo } \\
\text { ciclo de inspección } \\
\text { - Evalúan los supuestos y la } \\
\text { correctitud de los criterios de } \\
\text { decisión }\end{array}$ \\
\hline 59 & /Scopus & $\begin{array}{l}\quad \text { Winkler, D., } \\
\text { Hailing, M., Biffl, } \\
\text { S. }\end{array}$ & $\begin{array}{l}\text { Investigating the effect of expert } \\
\text { ranking of use cases for design } \\
\text { inspection, Conference Proceedings of } \\
\text { the EUROMICRO 30, pp. 362-371 }\end{array}$ & $\begin{array}{l}\text { - Inspection is an important } \\
\text { approach to reduce defects in } \\
\text { software engineering artifacts. } \\
\text { Reading techniques such as Usage- } \\
\text { Based Reading (UBR) can focus } \\
\text { inspector attention on specific } \\
\text { types of defects (missing and } \\
\text { wrong information) and specific } \\
\text { defect severity classes (critical, } \\
\text { important and not important } \\
\text { defects). For empirical } \\
\text { investigation the replication of } \\
\text { experiments can help increase the }\end{array}$ \\
\hline
\end{tabular}

Caso de estudio 


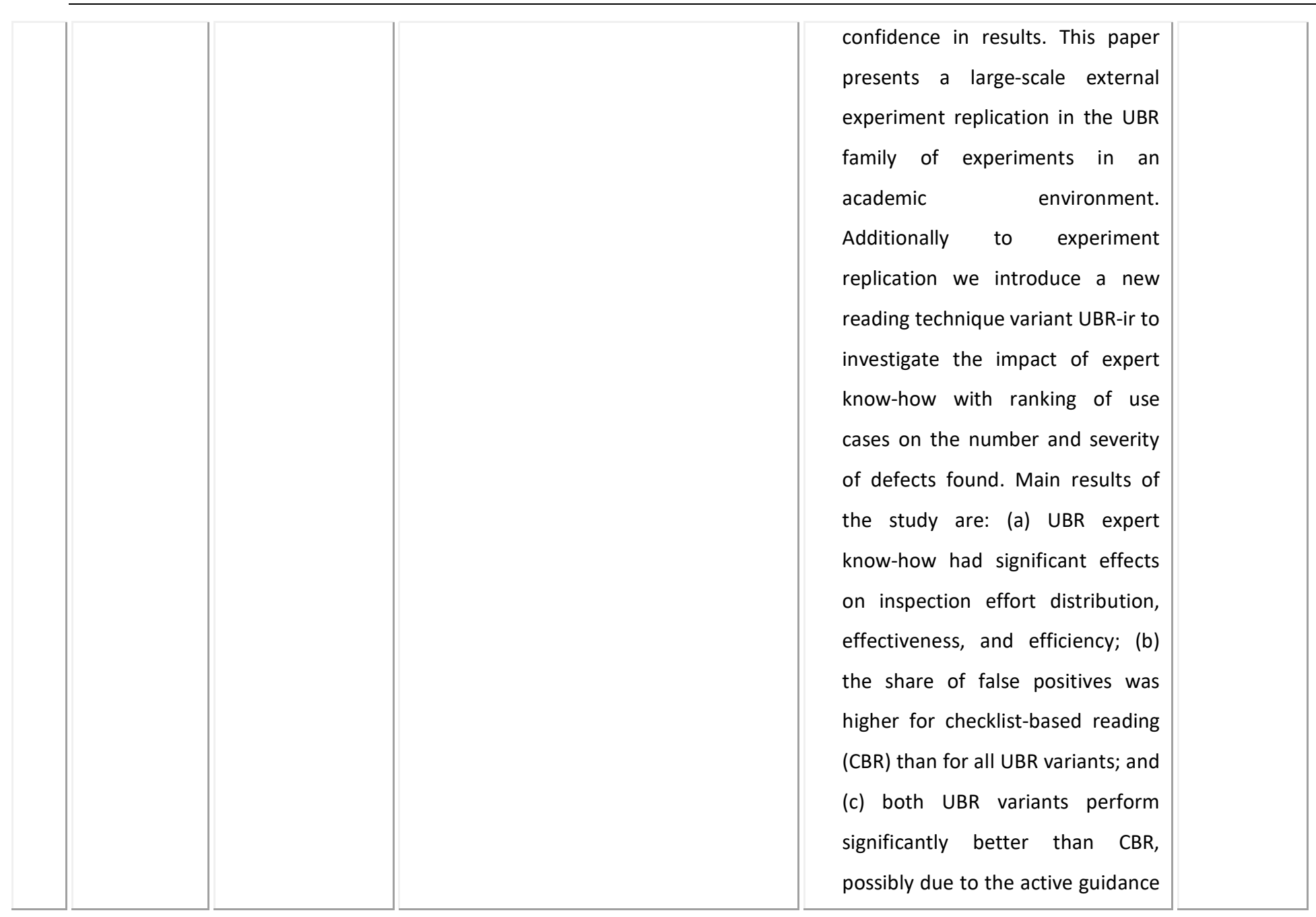


Proceso de RS de experimentos en Ingeniería del Software

\begin{tabular}{|c|c|c|c|c|}
\hline & & & & of use cases. \\
\hline 60 & $\begin{array}{l}\text { /Springe } \\
\text { r/ } \\
\text { Springer_2. } \\
\text { pdf } \\
\text { scopus/ } \\
\text { no_docume } \\
\text { nt }\end{array}$ & $\begin{array}{l}\text { W. Dietmar, } \\
\text { B. Stefan, and T. } \\
\text { Bettina, }\end{array}$ & $\begin{array}{l}\text { 124. Investigating the Impact of } \\
\text { Active Guidance on Design Inspection, } \\
\text { 2005. Lecture Notes in Computer Science } \\
\text { 3547, pp. } 458-473\end{array}$ & $\begin{array}{l}\text { - Comparan el desempeño de este } \\
\text { enfoque en un experimento } \\
\text { controlado en un ambiente } \\
\text { académico } \\
\text { - Miden efectividad y eficiencia de } \\
\text { CBR y UBR usando active guidance }\end{array}$ \\
\hline 61 & $\begin{array}{l}\text { /Xplore/ } \\
\text { Xplore_24.p } \\
\text { df } \\
\text { Scopus }\end{array}$ & $\begin{array}{l}\text { B. Freimut, } \\
\text { O. Laitenberger, } \\
\text { and S. Biffl, }\end{array}$ & $\begin{array}{l}\text { 125. Investigating the impact of } \\
\text { reading techniques on the accuracy of } \\
\text { different defect content estimation } \\
\text { techniques, } 2001 \text {. }\end{array}$ & $\begin{array}{l}\text { - Examina el impacto de } 2 \text { técnicas } \\
\text { de lectura: SBR y CBR en la } \\
\text { precisión de diferentes técnicas de } \\
\text { estimación } \\
\text { - Se basa en datos recogidos en un } \\
\text { gran experimento con estudiantes }\end{array}$ \\
\hline 62 & $\begin{array}{l}\text { /Xplore/ } \\
\text { Xplore_25.p } \\
\text { df }\end{array}$ & D. O'Neill, & $\begin{array}{l}\text { 126. Issues in software inspection, } \\
\text { Software, IEEE, vol. } 14, \text { pp. } 18-19,1997 .\end{array}$ & $\begin{array}{l}\text { - Propone sugerencias para } \\
\text { implementar inspecciones en } \\
\text { todos los niveles del proceso de } \\
\text { desarrollo }\end{array}$ \\
\hline 63 & /Xplore/ & A. & Object-oriented inspection in & - Investiga la aplicación de \\
\hline
\end{tabular}

Caso de estudio 


\begin{tabular}{|c|c|c|c|c|c|}
\hline & $\begin{array}{l}\text { Xplore_26.p } \\
\text { df } \\
\text { /ACM/ } \\
\text { acm_14.pdf }\end{array}$ & \multirow{2}{*}{\multicolumn{2}{|c|}{$\begin{array}{l}\text { Dunsmore, M. } \\
\text { Roper, and M. } \\
\text { Wood, }\end{array}$}} & \multirow[t]{2}{*}{$\begin{array}{l}\text { the face of delocalisation, } 2000 . \\
\text { Proceedings - International Conference } \\
\text { on Software Engineering, pp. 467-476 }\end{array}$} & \multirow[t]{2}{*}{$\begin{array}{l}\text { inspección a código oo. } \\
\text { - Realiza un análisis de los defectos } \\
\text { difíciles de encontrar durante un } \\
\text { experimento de inspección }\end{array}$} \\
\hline & $\begin{array}{l}\text { Scopus/ } \\
\text { sco_30.pdf }\end{array}$ & & & & \\
\hline 64 & /Scopus & N/D & & $\begin{array}{l}\text { Object-oriented reading techniques } \\
\text { for inspection of UML models - An } \\
\text { industrial experiment }\end{array}$ & $\mathrm{N} / \mathrm{D}$ \\
\hline \multirow[t]{2}{*}{65} & $\begin{array}{l}\text { /Scedire } \\
\text { ct/ } \\
\text { sdirect_7.p } \\
\text { df }\end{array}$ & \multirow{2}{*}{\multicolumn{2}{|c|}{ J. Miller, }} & \multirow[t]{2}{*}{$\begin{array}{l}\text { 128. On the independence of } \\
\text { software inspectors, Journal of Systems } \\
\text { and Software, vol. } 60 \text {, pp. 5-10, } 2002 \text {. }\end{array}$} & $\begin{array}{l}\text { - Investiga si los resultados de un } \\
\text { inspector individual durante la fase } \\
\text { de preparación son dependientes o } \\
\text { independientes }\end{array}$ \\
\hline & $\begin{array}{l}\text { Scopus/ } \\
\text { sco_23.pdf }\end{array}$ & & & & $\begin{array}{l}\text { - Usa datos de un experimento } \\
\text { previo y una simulación a partir de } \\
\text { ellos }\end{array}$ \\
\hline 66 & $\begin{array}{c}\text { /ACM/ } \\
\text { acm_15.pdf }\end{array}$ & $\begin{array}{l}\text { Pankaj } \\
\text { Jalote, }\end{array}$ & M. & $\begin{array}{l}\text { 129. Overcoming the NAH syndrome } \\
\text { for inspection deployment, Proceedings }\end{array}$ & $\begin{array}{l}\text { - Ejecutan un experimento para } \\
\text { reducir el síndrome "not applicable }\end{array}$ \\
\hline
\end{tabular}


Proceso de RS de experimentos en Ingeniería del Software

\begin{tabular}{|c|c|c|c|c|}
\hline & /Scopus & Haragopal & $\begin{array}{l}\text { of the 20th international conference on } \\
\text { Software engineering ICSE ' } 98\end{array}$ & $\begin{array}{l}\text { here" en una organización que } \\
\text { realiza una inspección de software } \\
\text { - Adicionalmente, comparar las } \\
\text { inspecciones de código con las } \\
\text { pruebas de unidad } \\
\text { - Miden: capacidad de detección de } \\
\text { defectos, efectos de la inspección } \\
\text { en los costos globales del } \\
\text { desarrollo. }\end{array}$ \\
\hline 67 & $\begin{array}{c}\text { /ACM/ } \\
\text { acm_17.pdf }\end{array}$ & $\begin{array}{l}\text { Lulu He, } \\
\text { Jeffrey Carver }\end{array}$ & $\begin{array}{l}\text { 130. PBR vs. checklist: a replication in } \\
\text { the } n \text {-fold inspection context, } \\
\text { Proceedings of the } 2006 \text { ACM/IEEE } \\
\text { International symposium on empirical } \\
\text { software engineering ISESE ' } 06\end{array}$ & $\begin{array}{l}\text { - Describe un experimento para } \\
\text { validar la efectividad de } \\
\text { Perspectiva-based reading en una } \\
\text { inspección N-fold basada en } \\
\text { reunión } \\
\text { - Busca validar la hipótesis original } \\
\text { de que PBR ayuda a incrementar la } \\
\text { efectividad (individual y grupal) de } \\
\text { detección de fallos, comparado con } \\
\text { un enfoque Checklist } \\
\text { - Investiga los diferentes impactos }\end{array}$ \\
\hline
\end{tabular}

Caso de estudio 


\begin{tabular}{|c|c|c|c|c|}
\hline & & \multicolumn{2}{|c|}{ Extracción de Datos } & Proceso de RS de experimentos en Ingeniería del Softwar \\
\hline & & & & $\begin{array}{l}\text { de PBR y checklist en la efectividad } \\
\text { de una reunión de equipo N-fold } \\
\text { - Investiga algunas características de } \\
\text { PBR }\end{array}$ \\
\hline 68 & /Scopus & $\mathrm{N} / \mathrm{D}$ & $\begin{array}{l}\text { Perspective-based reading: A } \\
\text { replicated experiment focused on } \\
\text { individual reviewer effectiveness }\end{array}$ & $\mathrm{N} / \mathrm{D}$ \\
\hline 69 & /Scopus & $\mathrm{N} / \mathrm{D}$ & $\begin{array}{l}\text { Practical code inspection techniques } \\
\text { for object-oriented systems: An } \\
\text { experimental comparison }\end{array}$ & $N / D$ \\
\hline 70 & /Scopus & $N / D$ & $\begin{array}{l}\text { Process for asynchronous software } \\
\text { inspection }\end{array}$ & $N / D$ \\
\hline 71 & $\begin{array}{c}\text { /ACM/ } \\
\text { acm_18.pdf }\end{array}$ & $\begin{array}{l}\text { Diane Kwlly, } \\
\text { Terry Shepard }\end{array}$ & $\begin{array}{l}\text { 131. Qualitative observations from } \\
\text { software code inspection experiments, } \\
\text { Proceedings of the } 2002 \text { conference of } \\
\text { the Centre for Advanced Studies on } \\
\text { Collaborative research CASCON ' } 02\end{array}$ & $\begin{array}{l}\text { - Recoge y organiza observaciones } \\
\text { que fueron hechas durante una } \\
\text { serie de experimentos previos } \\
\text { - Presenta comentarios y análisis de } \\
\text { los resultados de tales }\end{array}$ \\
\hline
\end{tabular}


Proceso de RS de experimentos en Ingeniería del Software

\begin{tabular}{|c|c|c|c|c|}
\hline & & & & $\begin{array}{l}\text { experimentos } \\
\text { - Describe brevemente } 3 \text { de los } \\
\text { experimentos }\end{array}$ \\
\hline 72 & /Scopus & $\mathrm{N} / \mathrm{D}$ & $\begin{array}{l}\text { Reducing inspection interval in large- } \\
\text { scale software development }\end{array}$ & $\mathrm{N} / \mathrm{D}$ \\
\hline 73 & /Scopus & $\mathrm{N} / \mathrm{D}$ & $\begin{array}{l}\text { Robust estimations of fault content } \\
\text { with capture-recapture and detection } \\
\text { profile estimators }\end{array}$ & $\mathrm{N} / \mathrm{D}$ \\
\hline 74 & /Scopus & $\mathrm{N} / \mathrm{D}$ & $\begin{array}{l}\text { Role of comprehension in software } \\
\text { inspection }\end{array}$ & N/D \\
\hline 75 & /Scopus & $\mathrm{N} / \mathrm{D}$ & $\begin{array}{l}\text { Software group reviews and the } \\
\text { impact of procedural roles on defect } \\
\text { detection performance }\end{array}$ & $\mathrm{N} / \mathrm{D}$ \\
\hline 76 & $\begin{array}{l}\text { /Xplore/ } \\
\text { Xplore_11.p } \\
\text { df }\end{array}$ & E. F. Berman & $\begin{array}{l}\text { 132. Software inspections at } \\
\text { Fermilab-use and experience, Nuclear } \\
\text { Science, IEEE Transactions on, vol. } 45 \text {, pp. } \\
\text { 1937-1941, } 1998 .\end{array}$ & $\begin{array}{l}\text { - Describe el proceso de inspección } \\
\text { del Fermi Nacional Accelerator Lab }\end{array}$ \\
\hline
\end{tabular}

Caso de estudio 


\begin{tabular}{|c|c|c|c|c|}
\hline 77 & $\begin{array}{l}\text { /Xplore/ } \\
\text { Xplore_12.p } \\
\text { df }\end{array}$ & $\begin{array}{l}\text { G. Chroust } \\
\text { and H. Lexen, }\end{array}$ & $\begin{array}{l}\text { 133. Software inspections-theory, } \\
\text { new approaches and an experiment, } \\
\text { 1999. }\end{array}$ & $\begin{array}{l}\text { - Discute aspectos de costo- } \\
\text { efectividad, ROI de las inspecciones } \\
\text { en general y de las reuniones en } \\
\text { particular. } \\
\text { - Refiere un experimento en } \\
\text { software improvement pero no lo } \\
\text { muestra }\end{array}$ \\
\hline 78 & $\begin{array}{c}\text { /ACM/ } \\
\text { acm_4.pdf }\end{array}$ & $\begin{array}{l}\text { Diane Kelly, } \\
\text { Terry Shepard }\end{array}$ & $\begin{array}{l}\text { 134. Task-directed software } \\
\text { inspection technique: an experiment and } \\
\text { case study, Proceedings of the } 2000 \\
\text { conference of the Centre for Advanced } \\
\text { Studies on Collaborative research } \\
\text { CASCON '00 }\end{array}$ & $\begin{array}{l}\text { - Estudiantes en un experimento } \\
\text { aplican dos técnicas dirigidas a } \\
\text { tareas y una técnica de inspección } \\
\text { no-estructurada estándar en la } \\
\text { industria a un código de ing civil en } \\
\text { uso en aplicaciones militares } \\
\text { - Presetan tanto un caso de estudio } \\
\text { como el experimento } \\
\text { - Analizan los resultados con una } \\
\text { clasificación ortogonal de defectos } \\
\text { para código computacional } \\
\text { desarrollada para la investigación } \\
\text { - Discuten: la contribución de la } \\
\text { técnica dirigida a tareas en la }\end{array}$ \\
\hline
\end{tabular}


Proceso de RS de experimentos en Ingeniería del Software

\begin{tabular}{|c|c|c|c|c|}
\hline & & & & $\begin{array}{l}\text { evaluación y entendimiento del } \\
\text { código por parte de los } \\
\text { inspectores, diferencias entre } \\
\text { inspectores experimentados y no } \\
\text { experimentados. }\end{array}$ \\
\hline 79 & $\begin{array}{l}\text { /Xplore/ } \\
\text { Xplore_ } \\
\text { 13.pdf } \\
\text { Scopus/ } \\
\text { sco_1.pdf }\end{array}$ & T. Thelin, & $\begin{array}{l}\text { 135. Team-based fault content } \\
\text { estimation in the software inspection } \\
\text { process, 2004. Proceedings - } \\
\text { International Conference on Software } \\
\text { Engineering 26, pp. 263-272 }\end{array}$ & $\begin{array}{l}\text { - Presenta un experimento que } \\
\text { compara métodos objetivos y } \\
\text { subjetivos de estimación de } \\
\text { contenido de fallos en diferentes } \\
\text { puntos } \\
\text { - Fue conducido en } 2 \text { universidades } \\
\text { con } 82 \text { revisores }\end{array}$ \\
\hline 80 & $\begin{array}{c}\text { /ACM/ } \\
\text { acm_5.pdf }\end{array}$ & \begin{tabular}{l}
\multicolumn{2}{c}{ Christian } \\
Denger, Ronny \\
Kolb
\end{tabular} & $\begin{array}{l}\text { 136. Testing and inspecting reusable } \\
\text { product line components: first empirical } \\
\text { results, Proceedings of the } 2006 \\
\text { ACM/IEEE international symposium on } \\
\text { International symposium on empirical } \\
\text { software engineering ISESE '06 }\end{array}$ & $\begin{array}{l}\text { - Compara dos técnicas de detección } \\
\text { de defectos: inspecciones de } \\
\text { código y pruebas funcionales en el } \\
\text { contexto de desarrollo de líneas de } \\
\text { productos } \\
\text { - Investiga el potencial de detección } \\
\text { de defectos de las técnicas en } \\
\text { componentes reutilizables de }\end{array}$ \\
\hline
\end{tabular}

Caso de estudio 


\begin{tabular}{|c|c|c|c|c|}
\hline & & \multicolumn{2}{|c|}{ Extracción de Datos } & Proceso de RS de experimentos en Ingeniería del Softwar \\
\hline & & & & $\begin{array}{l}\text { software } \\
\text { - Discuten: efectividad y esfuerzo } \\
\text { para detectar un defecto }\end{array}$ \\
\hline 81 & $\begin{array}{l}\text { /Xplore/ } \\
\text { xplore_14.p } \\
\text { df } \\
\text { (Springe } \\
\text { r_7.pdf) } \\
\text { Scopus/ } \\
\text { no_docume } \\
\text { nt }\end{array}$ & $\begin{array}{l}\text { C. Atiq and L. } \\
\text { P. W. Land, }\end{array}$ & $\begin{array}{l}\text { 137. The impact of training-by- } \\
\text { examples on inspection performance } \\
\text { using two laboratory experiments, } 2004 \text {. } \\
\text { Proceedings of the Australian Software } \\
\text { Engineering Conference, ASWEC 2004, } \\
\text { pp. } 279-288\end{array}$ & $\begin{array}{l}\text { - Dos experimentos de lab son } \\
\text { conducidos para probar el efecto } \\
\text { del entrenamiento usando } \\
\text { ejemplos de defectos }\end{array}$ \\
\hline 82 & $\begin{array}{l}\text { /Scedire } \\
\text { ct/ } \\
\text { sdirect_10.p } \\
\text { df }\end{array}$ & $\begin{array}{l}\text { A. } \\
\text { Dunsmore, M. } \\
\text { Roper, and M. } \\
\text { Wood, }\end{array}$ & $\begin{array}{l}\text { 138. The role of comprehension in } \\
\text { software inspection, Journal of Systems } \\
\text { and Software, vol. 52, pp. 121-129, } 2000 \text {. }\end{array}$ & $\begin{array}{l}\text { - Presenta los resultados de dos } \\
\text { experimentos que relacionan la } \\
\text { comprensión del programa y la } \\
\text { inspección }\end{array}$ \\
\hline 83 & /Scopus & N/D & $\begin{array}{l}\text { The use of procedural roles in code } \\
\text { inspections: An experimental study }\end{array}$ & N/D \\
\hline 84 & /Scopus & $\mathrm{N} / \mathrm{D}$ & Understanding the effects of & $\mathrm{N} / \mathrm{D}$ \\
\hline
\end{tabular}


Proceso de RS de experimentos en Ingeniería del Software

\begin{tabular}{|c|c|c|c|c|}
\hline & & & developer activities on inspection interval & \\
\hline 85 & $\begin{array}{r}\text { /ACM/ } \\
\text { acm_6.pdf } \\
\text { Scopus/ } \\
\text { sco_29.pdf }\end{array}$ & $\begin{array}{l}\text { Adam Porter, } \\
\text { Harvey Siy, } \\
\text { Audris Mockus, } \\
\text { Lawrence Votta }\end{array}$ & $\begin{array}{l}\text { 139. Understanding the sources of } \\
\text { variation in software inspections, January } \\
\text { 1998, ACM Transactions on Software } \\
\text { Engineering and Methodology (TOSEM), } \\
\text { Volume } 7 \text { Issue } 1\end{array}$ & $\begin{array}{l}\text { - Describe el experimento } \\
\text { previamente reportado en p92- } \\
\text { porter.pdf (00601071.pdf) y } \\
\text { estudian las variaciones en la } \\
\text { efectividad y el intervalo }\end{array}$ \\
\hline 86 & $\begin{array}{l}\text { /Scedire } \\
\text { ct/ } \\
\text { sdirect_8.p } \\
\text { df } \\
\text { /Scopus }\end{array}$ & $\begin{array}{l}\text { T. Thelin, P. } \\
\text { Runeson, and B. } \\
\text { Regnell, }\end{array}$ & $\begin{array}{l}\text { 140. Usage-based reading--an } \\
\text { experiment to guide reviewers with use } \\
\text { cases, Information and Software } \\
\text { Technology, vol. 43, pp. 925-938, } 2001 .\end{array}$ & $\begin{array}{l}\text { - Presenta un experimento } \\
\text { conducido con } 27 \text { estudiantes de IS } \\
\text { - Un grupo utilizó casos de uso } \\
\text { priorizados y el grupo control casos } \\
\text { de uso aleatoriamente ordenados } \\
\text { - Miden: efectividad y eficiencia en } \\
\text { detectar fallas }\end{array}$ \\
\hline 87 & $\begin{array}{l}\text { /Springe } \\
\text { r/ } \\
\text { Springer_3. } \\
\text { pdf }\end{array}$ & $\begin{array}{l}\text { B. Stefan and } \\
\text { J. G. Walter, }\end{array}$ & $\begin{array}{l}\text { 141. Using a Reliability Growth Model } \\
\text { to Control Software Inspection, Empirical } \\
\text { Software Engineering, vol. V7, pp. } 257- \\
284,2002 \text {. }\end{array}$ & $\begin{array}{l}\text { - Propone un modelo de crecimiento } \\
\text { de la confiabilidad y dos modelos } \\
\text { heurísticos lineales para estimar el } \\
\text { núm probable de defectos a ser } \\
\text { encontrados en la reinspección }\end{array}$ \\
\hline
\end{tabular}

Caso de estudio 


\begin{tabular}{|c|c|c|c|c|}
\hline & & \multicolumn{2}{|c|}{ Extracción de Datos } & Proceso de RS de experimentos en Ingeniería del Softwar \\
\hline & sco_15.pdf & & & $\begin{array}{l}\text { - Los modelos son evaluados con } \\
\text { datos de un experimento } \\
\text { controlado en reinspección } \\
\text { - Describe el experimento } \\
\text { controlado }\end{array}$ \\
\hline 88 & $\begin{array}{l}\text { /Xplore/ } \\
\text { Xplore_27.p } \\
\text { df }\end{array}$ & $\begin{array}{l}\text { M. Halling, S. } \\
\text { Biffl, T. } \\
\text { Grechenig, and } \\
\text { M. Kohle, }\end{array}$ & $\begin{array}{l}\text { 142. Using reading techniques to } \\
\text { focus inspection performance, } 2001 \text {. }\end{array}$ & $\begin{array}{l}\text { - Reporta la replicación de un } \\
\text { experimento a gran escala en un } \\
\text { ambiente académico (Biffl, 2003) } \\
\text { (sdirect_4.pdf) } \\
\text { - Evalúa la efectividad de la } \\
\text { detección de defectos para } \\
\text { inspectores que utilizan Checklist o } \\
\text { escenarios enfocados a nivel } \\
\text { individual y de equipo }\end{array}$ \\
\hline 89 & $\begin{array}{l}\text { /Springe } \\
\text { r/ } \\
\text { Springer_9. } \\
\text { pdf } \\
\text { /Scopus }\end{array}$ & $\begin{array}{l}\text { H. Lasse, T. } \\
\text { Ilkka, and V. } \\
\text { Pekka, }\end{array}$ & $\begin{array}{l}\text { 143. Using Software Inspection as a } \\
\text { Catalyst for SPI in a Small Company, } \\
2004 .\end{array}$ & $\begin{array}{l}\text { - Presenta un experimento en una } \\
\text { pequeña compañía de software } \\
\text { que evalúa el efecto de la } \\
\text { inspección de software en la } \\
\text { mejora de procesos }\end{array}$ \\
\hline
\end{tabular}


Proceso de RS de experimentos en Ingeniería del Software

\begin{tabular}{|c|c|c|c|c|}
\hline 90 & $\begin{array}{l}\text { /Xplore/ } \\
\text { Xplore_28.p } \\
\text { df }\end{array}$ & $\begin{array}{l}\text { A. Porter and } \\
\text { L. Votta, }\end{array}$ & $\begin{array}{l}\text { 144. What makes inspections work?, } \\
\text { Software, IEEE, vol. 14, pp. 99-102, } 1997 .\end{array}$ & $\begin{array}{l}\text { - Resumen los resultados de haber } \\
\text { conducido una familia de } \\
\text { experimentos para entender cómo } \\
\text { varios factores afectan los costos y } \\
\text { beneficios de la inspección }\end{array}$ \\
\hline
\end{tabular}




\section{- 1.3. DESCARTE DE ARTÍCULOS IRRELEVANTES}

\begin{tabular}{|c|c|c|}
\hline \multicolumn{3}{|l|}{ Objetivo } \\
\hline \multicolumn{3}{|c|}{$\begin{array}{l}\text { Analizar los artículos recuperados para eliminar aquellos que no sean relevantes para el objetivo de } \\
\text { la RS y los cuales han sido recuperados debido a la imprecisión de la cadena de búsqueda }\end{array}$} \\
\hline Entrada & \multicolumn{2}{|l|}{ Salida } \\
\hline B02_Análisis de artículos recuperados & \multicolumn{2}{|c|}{$\begin{array}{l}\text { B03_Resumen de artículos relevantes (Conjunto } \\
\text { base) }\end{array}$} \\
\hline \multicolumn{3}{|l|}{ Tareas } \\
\hline & Entradas & Salidas \\
\hline 1.3.1. Determinar relevancia del artículo & $\begin{array}{l}\text { B02_Análisis de } \\
\text { artículos recuperados }\end{array}$ & $\begin{array}{l}\text { B02_Análisis de } \\
\text { artículos recuperados } \\
\text { (actualizado) }\end{array}$ \\
\hline 1.3.2. Resolver discrepancias & $\begin{array}{l}\text { B02_Análisis de } \\
\text { artículos recuperados } \\
\text { (actualizado) }\end{array}$ & $\begin{array}{l}\text { B02_Análisis de } \\
\text { artículos recuperados } \\
\text { (actualizado) }\end{array}$ \\
\hline 1.3.3. Resumir resultados & $\begin{array}{l}\text { B02_Análisis de } \\
\text { artículos recuperados } \\
\text { (actualizado) }\end{array}$ & $\begin{array}{l}\text { B03_Resumen de } \\
\text { artículos relevantes } \\
\text { (Conjunto base) }\end{array}$ \\
\hline $\begin{array}{l}\text { 1.3.4. Documentar estadísticas de } \\
\text { búsqueda }\end{array}$ & & $\begin{array}{l}\text { B04_Estadísticas de } \\
\text { Búsqueda }\end{array}$ \\
\hline
\end{tabular}

\subsubsection{Determinar la relevancia del artículo}

La siguiente actividad es el análisis de los títulos y resúmenes de los resultados obtenidos de aplicar la búsqueda preliminar para descartar aquellos artículos que sean irrelevantes. Este análisis fue realizado 
por dos revisores con un porcentaje de coincidencia del 93.2\%. Se utilizó el formulario B02_b Análisis de artículos recuperados - Doble chequeo.

Caso de estudio 
B02b_Análisis de artículos recuperados

Realizado por: Anna Grimán

Fecha:

\begin{tabular}{|c|c|c|c|c|c|c|}
\hline \multirow[b]{2}{*}{ D } & \multirow{2}{*}{ Fichero } & \multirow{2}{*}{ Autores } & \multirow{2}{*}{ 145. Referencia } & \multirow{2}{*}{ Resumen } & \multicolumn{2}{|c|}{ ¿Relevante } \\
\hline & & & & & $\begin{array}{l}R \\
\text { ev1 }\end{array}$ & v2 \\
\hline 1 & $\begin{array}{l}\text { /Xplore/ } \\
\text { Xplore_ } \\
\text { 1.pdf }\end{array}$ & $\begin{array}{l}\text { T.Berlig and } \\
\text { T. Thelin, }\end{array}$ & $\begin{array}{l}\text { 146. A case study of reading } \\
\text { techniques in a software company, } \\
2004 \text { Proceedings - } 2004 \\
\text { International Symposium on Empirical } \\
\text { Software Engineering, ISESE 2004, pp. } \\
229-238\end{array}$ & $\begin{array}{l}\text { - Aplica un estudio empírico en una } \\
\text { organización de desarrollo } \\
\text { _ Un documento de requisitos es } \\
\text { usado para comparar dos técnicas } \\
\text { de lectura (basada en checklist y } \\
\text { basada en perspectiva) } \\
\text { - Discuten efectividad y eficiencia de } \\
\text { una técnica frente a la otra }\end{array}$ & 1 & $\mathrm{SI}$ \\
\hline 2 & $\begin{array}{l}\text { /Springe } \\
\mathrm{r} /\end{array}$ & $\begin{array}{l}\text { F. } \\
\text { MacDonald and }\end{array}$ & $\begin{array}{l}\text { 147. A Comparison of Tool-Based } \\
\text { and Paper-Based Software Inspection, }\end{array}$ & $\begin{array}{c}\text { - Describe un experimento } \\
\text { controlado comparando la }\end{array}$ & I & $\mathrm{SI}$ \\
\hline
\end{tabular}


Proceso de RS de experimentos en Ingeniería del Software

\begin{tabular}{|c|c|c|c|}
\hline $\begin{array}{c}\begin{array}{c}\text { Springer } \\
\text { 5.pdf }\end{array} \\
\text { /scopus/ } \\
\text { sco_3.pdf }\end{array}$ & J. Miller, & $\begin{array}{l}\text { Empirical Software Engineering, vol. } \\
\text { V3, pp. } 233-253,1998 .\end{array}$ & $\begin{array}{l}\text { efectividad la inspección de } \\
\text { software basada en herramientas y } \\
\text { la basada en papel } \\
\text { - Utilizan un prototipo de } \\
\text { herramienta para inspecciones de } \\
\text { software } \\
\text { - } 43 \text { estudiantes usan el prototipo y } \\
\text { la inspección basada en papel para } \\
\text { inspeccionar } 2 \text { programas de C++ } \\
\text { (150 LDC) } \\
\text { - Los sujetos realizaron tanto } \\
\text { inspección individual como reunión } \\
\text { de grupo } \\
\text { - Miden: núm de defectos } \\
\text { encontrados, núm de falsos } \\
\text { positivos reportados y ganancias y } \\
\text { pérdidas de la reunión }\end{array}$ \\
\hline
\end{tabular}

Caso de estudio 


\begin{tabular}{|c|c|c|c|c|c|c|}
\hline 3 & $\begin{array}{l}\text { /Xplore/ } \\
\text { Xplore_ } \\
\text { 2.pdf }\end{array}$ & $\begin{array}{l}\text { M. } \\
\text { Kalinowski and } \\
\text { G. H. Travassos, }\end{array}$ & $\begin{array}{l}\text { 148. A computational framework } \\
\text { for supporting software inspections, } \\
\text { 2004. Proceedings }-19^{\text {th }} \text { International } \\
\text { Conference on Automated Software } \\
\text { Engineering, ASE 2004, pp. } 46-55\end{array}$ & $\begin{array}{l}\text { - Describe un framework } \\
\text { computacional cuyos requisitos se } \\
\text { basan en estudios empíricos sobre } \\
\text { inspección de software } \\
\text { - Evalúa la factibilidad del } \\
\text { framework a través de: } \\
\text { O Un caso de estudio } \\
\text { On estudio } \\
\text { experimental que } \\
\text { evaluó la actividad } \\
\text { de planificación de } \\
\text { la inspección de } \\
\text { software } \\
\text { - El estudio experimental arrojó } \\
\text { resultados sobre la experiencia de } \\
\text { los sujetos y su relación con la } \\
\text { planificación y la efectividad en la } \\
\text { detección de defectos, al utilizar el } \\
\text { framework comput.Sl }\end{array}$ & I & SI \\
\hline 4 & /Xplore/ & A. Bianchi, F. & 149. A controlled experiment to & - Presenta & $\mathrm{s}$ & SI \\
\hline
\end{tabular}


Proceso de RS de experimentos en Ingeniería del Software

\begin{tabular}{|c|c|c|c|c|c|c|}
\hline & $\begin{array}{l}\text { Xplore_ } \\
\text { 3.pdf } \\
\text { /scopus/ } \\
\text { Sco_34.pdf }\end{array}$ & $\begin{array}{l}\text { Lanubile, and G. } \\
\text { Visaggio, }\end{array}$ & $\begin{array}{l}\text { assess the effectiveness of inspection } \\
\text { meetings, } 2001 . \quad \text { International } \\
\text { Software Metrics Symposium, } \\
\text { Proceedings, pp. } 42-50\end{array}$ & $\begin{array}{l}\text { controlado } \\
\text { - Participan + de } 100 \text { estudiantes de } \\
\text { carrera quienes inspeccionan } \\
\text { documentos de requerimientos de } \\
\text { software } \\
\text { - Compara el desempeño de grupos } \\
\text { nominales y reales } \\
\text { - Investiga también las razones de } \\
\text { las pérdidas en las reuniones y } \\
\text { confronta ganancias vs pérdidas } \\
\text { - Relaciona las pérdidas con el núm } \\
\text { de defectos encontrados por un } \\
\text { único individuo en el equipo }\end{array}$ & I & \\
\hline 5 & $\begin{array}{l}\text { /Springe } \\
\text { r/ } \\
\text { Springer } \\
\text { _8.pdf }\end{array}$ & $\begin{array}{l}\text { B. Stefan, G. } \\
\text { Paul, and H. } \\
\text { Michael, }\end{array}$ & \multirow[t]{2}{*}{$\begin{array}{l}\text { 150. A family of experiments to } \\
\text { investigate the effects of groupware } \\
\text { for software inspection, Automated } \\
\text { Software Engineering, vol. V13, pp. } \\
373-394,2006 \text {. }\end{array}$} & $\begin{array}{l}\text { - Conduce una familia de } \\
\text { experimentos en un ambiente } \\
\text { académico para investigar el efecto } \\
\text { del soporte de herramientas a la } \\
\text { detección de defectos y a las }\end{array}$ & $S$ & SI \\
\hline & /Scopus & & & reuniones de inspección & & \\
\hline
\end{tabular}

Caso de estudio 


\begin{tabular}{|c|c|c|c|c|c|c|}
\hline & & \multicolumn{2}{|c|}{ Extracción de Datos } & \multicolumn{3}{|c|}{ Proceso de RS de experimentos en Ingeniería del Soft } \\
\hline & /sco_17.pdf & & & $\begin{array}{l}\text { - Discute: la efectividad de los } \\
\text { inspectores y equipos con y sin } \\
\text { herramientas, el esfuerzo de } \\
\text { inspección y el solapamiento de } \\
\text { defectos, eficiencia de los equipos } \\
\text { de inspección, el núm de falsos } \\
\text { positivos identificados y no } \\
\text { identificados, núm de defectos } \\
\text { verdaderos perdidos durante la } \\
\text { reunión }\end{array}$ & & \\
\hline 6 & /Scopus & & $\begin{array}{l}\text { A pattern approach to software } \\
\text { inspection process improvement }\end{array}$ & - & S & \\
\hline 7 & $\begin{array}{l}\text { /xplore/ } \\
\text { Xplore_ } \\
\text { 4.pdf }\end{array}$ & $\begin{array}{l}\text { P. Murphy } \\
\text { and J. Miller, }\end{array}$ & $\begin{array}{l}\text { 151. A process for asynchronous } \\
\text { software inspection, Proceedings, } \\
\text { Eighth IEEE International Workshop } \\
\text { on Software Technology and } \\
\text { Engineering Practice, } 1997 . \\
\text { [Incorporating Computer Aided } \\
\text { Software Engineering]. 14-18 July } \\
\text { 1997 Page(s):96-104 }\end{array}$ & $\begin{array}{l}\text { - Propone un modelo de inspección } \\
\text { soportado por una herramienta de } \\
\text { comunicación asíncrona basado en } \\
\text { correo-e } \\
\text { - Compara el nuevo modelo con el } \\
\text { modelo tradicional basado en } \\
\text { reunión sobre la base de un } \\
\text { conjunto de criterios } \\
\text { - Intentan utilizar un experimento a }\end{array}$ & S & SI \\
\hline
\end{tabular}


Proceso de RS de experimentos en Ingeniería del Software

\begin{tabular}{|c|c|c|c|c|c|c|}
\hline & & & & $\begin{array}{l}\text { pequeña escala pero el número de } \\
\text { sujetos es pequeño y no permite } \\
\text { presentar un análisis } \\
\text { _- Describe y analiza brevemente la } \\
\text { familia de experimentos de Porter } \\
\text { y sus replicaciones. (Xplore_16.pdf) }\end{array}$ & & \\
\hline 8 & $\begin{array}{l}\text { /Xplore/ } \\
\text { Xplore_ } \\
\text { 5.pdf }\end{array}$ & $\begin{array}{l}\text { T. Thelin, } \mathrm{C} . \\
\text { Andersson, } \mathrm{P} . \\
\text { Runeson, and } \mathrm{N} \text {. } \\
\text { Dzamashvili- } \\
\text { Fogelstrom, }\end{array}$ & $\begin{array}{l}\text { 152. A replicated experiment of } \\
\text { usage-based and checklist-based } \\
\text { reading, 2004. Proceedings - } \\
\text { Software Metrics Symposium, pp. } \\
246-256\end{array}$ & $\begin{array}{l}\text { - Presenta la replicación de un } \\
\text { experimento que comparó técnicas } \\
\text { de lectura basada en uso vs basada } \\
\text { en checklist } \\
\text { - Presenta tanto la replicación como } \\
\text { el experimento original y compara } \\
\text { ambos resultados (Xplore_30.pdf) } \\
\text { - La replicación confirmó los } \\
\text { resultados del exp. original }\end{array}$ & I & SI \\
\hline 9 & $\begin{array}{l}\text { /Xplore/ } \\
\text { Xplore_ } \\
\text { 6.pdf }\end{array}$ & $\begin{array}{l}\text { I. Tervonen, } \\
\text { J. lisakka, and L. } \\
\text { Harjumaa, }\end{array}$ & $\begin{array}{l}\text { 153. A tailored capability model } \\
\text { for inspection process improvement, } \\
\text { Proceedings. Second Asia-Pacific } \\
\text { Conference on Quality Software, }\end{array}$ & $\begin{array}{l}\text { - Presenta un modelo para evaluar la } \\
\text { capacidad del proceso de } \\
\text { inspección y soportar la } \\
\text { identificación de puntos débiles en }\end{array}$ & $0^{N}$ & 0 \\
\hline
\end{tabular}

Caso de estudio 


\begin{tabular}{|c|c|c|c|c|c|c|}
\hline & & \multicolumn{2}{|c|}{ Extracción de Datos } & \multicolumn{3}{|c|}{ Proceso de RS de experimentos en Ingeniería del Software } \\
\hline & & & $\begin{array}{l}\text { 2001. 10-11 Dec. } 2001 \text { Page(s):275 - } \\
282\end{array}$ & $\begin{array}{l}\text { el proceso } \\
\text { _ Presenta la aplicación del modelo } \\
\text { en la evaluación de una compañía }\end{array}$ & & \\
\hline 10 & /Scopus & $\begin{array}{l}\text { Monvorath } \\
\text { Phongpaibul, } \\
\text { Barry Boehm }\end{array}$ & $\begin{array}{l}\text { 154. An empirical comparison } \\
\text { between pair development and } \\
\text { software inspection in Thailand, } \\
\text { Proceedings of the } 2006 \mathrm{ACM} / \mathrm{IEEE} \\
\text { international symposium on } \\
\text { International symposium on } \\
\text { empirical software engineering ISESE } \\
\text { '06 }\end{array}$ & $\begin{array}{l}\text { - Compara las similitudes y } \\
\text { diferencias entre el desarrollo por } \\
\text { pares y la inspección de software } \\
\text { como técnicas de verificación en } \\
\text { Thailand. } \\
\text { - Aplican un experimento de clase y } \\
\text { uno de industria } \\
\text { - Se investigó el esfuerzo de } \\
\text { desarrollo, el efecto en la calidad y } \\
\text { el tiempo calendario }\end{array}$ & 1 & $\mathrm{SI}$ \\
\hline 11 & $\begin{array}{l}\text { /Springe } \\
\text { r/ } \\
\text { Springer } \\
\text { _.pdf }\end{array}$ & $\begin{array}{l}\text { C. Atiq and L. } \\
\text { Lesley Pek Wee, }\end{array}$ & $\begin{array}{l}\text { 155. An Empirical Investigation on } \\
\text { the Impact of Training-by-Examples } \\
\text { on Inspection Performance. PROFES }\end{array}$ & $\begin{array}{l}\text { - Conducen un experimento para } \\
\text { probar el efecto del entrenamiento } \\
\text { basado en ejemplos en la } \\
\text { inspección de requisitos }\end{array}$ & I & $\mathrm{SI}$ \\
\hline
\end{tabular}


Proceso de RS de experimentos en Ingeniería del Software

\begin{tabular}{|c|c|c|c|c|c|c|}
\hline & /Scopus & & 2004, LNCS 3009, pp. 203-219, 2004. & $\begin{array}{l}\text { - Compara el desempeño de un } \\
\text { grupo entrenado vs uno que no ha } \\
\text { recibido entrenamiento }\end{array}$ & & \\
\hline 12 & $\begin{array}{l}\text { /Xplore/ } \\
\text { Xplore_ } \\
\text { 7.pdf }\end{array}$ & \begin{tabular}{l}
\multicolumn{1}{c}{ C. D. } \\
Rombach, O. \\
Kude, A. Aurum, \\
R. Jeffery, and C. \\
Wohlin,
\end{tabular} & $\begin{array}{l}\text { 156. An empirical study of an ER- } \\
\text { model inspection meeting, } 2003 \text {. }\end{array}$ & $\begin{array}{l}\text { - Documenta un experimento a gran } \\
\text { escala conducido durante una } \\
\text { reunión de inspección de Modelo } \\
\text { ER } \\
\text { - Investiga cuál técnica de lectura } \\
\text { tiene una tasa más eficiente de } \\
\text { detección de defectos cuando se } \\
\text { buscan defectos en un modelo ER } \\
\text { - También explora el efecto del uso } \\
\text { de Roles en una reunión de equipo } \\
\text { - Por último, investiga la habilidad } \\
\text { de los revisores para encontrar } \\
\text { ciertas categorías de defectos }\end{array}$ & I & SI \\
\hline 13 & $\begin{array}{l}\text { /scedire } \\
\text { ct/ } \\
\text { sdirect_1.p }\end{array}$ & $\begin{array}{l}\text { M. A. Babar, } \\
\text { B. Kitchenham, } \\
\text { L. Zhu, I. Gorton, }\end{array}$ & $\begin{array}{l}\text { 157. An empirical study of } \\
\text { groupware support for distributed } \\
\text { software architecture evaluation }\end{array}$ & $\begin{array}{c}\text { - Presenta un estudio piloto } \\
\text { (experimento) usado para evaluar }\end{array}$ & I & SI \\
\hline
\end{tabular}

Caso de estudio 


\begin{tabular}{|c|c|c|c|c|c|c|}
\hline & $\begin{array}{l}\text { df } \\
\text { (/Xplore } \\
\text { /Xplore_8.p } \\
\text { df) } \\
\text { /scopus/ } \\
\text { sco_5.pdf }\end{array}$ & and R. Jeffery, & $\begin{array}{l}\text { process, Journal of Systems and } \\
\text { Software, vol. } 79 \text {, pp. } 912-925,2006 .\end{array}$ & $\begin{array}{l}\text { la viabilidad de un experimento + } \\
\text { grande que investigue la } \\
\text { factibilidad del soporte groupware } \\
\text { para la evaluación distribuida de } \\
\text { arquitecturas de software } \\
\text { - El estudio piloto arrojó algunos } \\
\text { hallazgos acerca de la viabilidad de } \\
\text { un proceso de EA soportado por } \\
\text { groupware. }\end{array}$ & & \\
\hline 14 & $\begin{array}{l}\text { /Xplore/ } \\
\text { Xplore_ } \\
\text { 9.pdf }\end{array}$ & $\begin{array}{l}\quad \text { P. } \\
\text { Grunbacher, M. } \\
\text { Halling, and S. } \\
\text { Biffl, }\end{array}$ & $\begin{array}{l}\text { 158. An empirical study on } \\
\text { groupware support for software } \\
\text { inspection meetings, Proceedings of } \\
\text { the } 18^{\text {th }} \text { IEEE International Conference } \\
\text { on Automated Software Engineering } \\
\text { (ASE'03). }\end{array}$ & $\begin{array}{l}\text { - Presentan un experimento en un } \\
\text { ambiente académico con } 37 \\
\text { sujetos para investigar el efecto del } \\
\text { soporte de una herramienta } \\
\text { groupware a las reuniones de } \\
\text { inspección } \\
\text { - Concluyen sobre: el esfuerzo } \\
\text { utilizado en la reunión, } \\
\text { identificación de falsos positivos, } \\
\text { reducción del núm de defectos } \\
\text { reales perdidos }\end{array}$ & & SI \\
\hline
\end{tabular}


Proceso de RS de experimentos en Ingeniería del Software

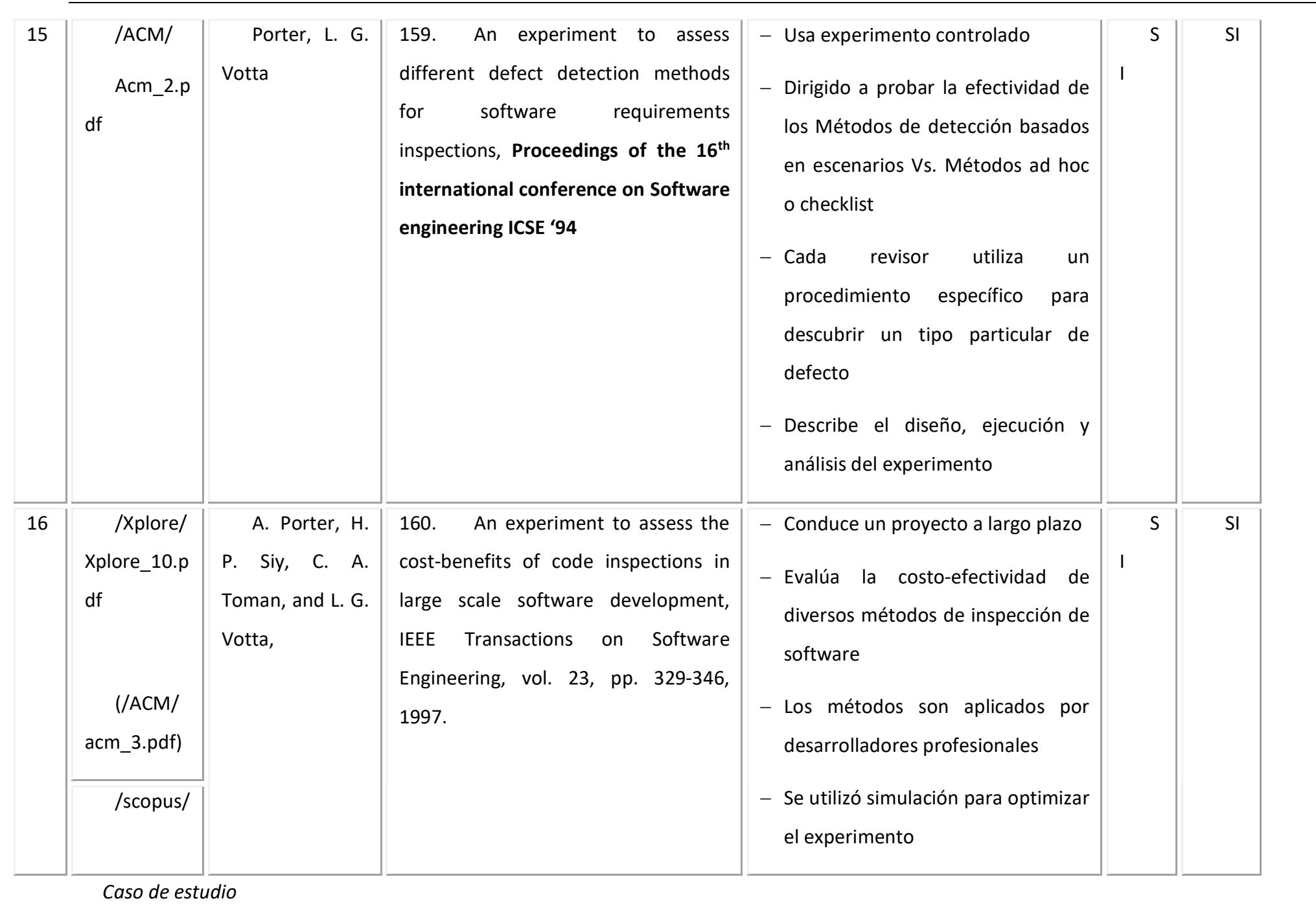




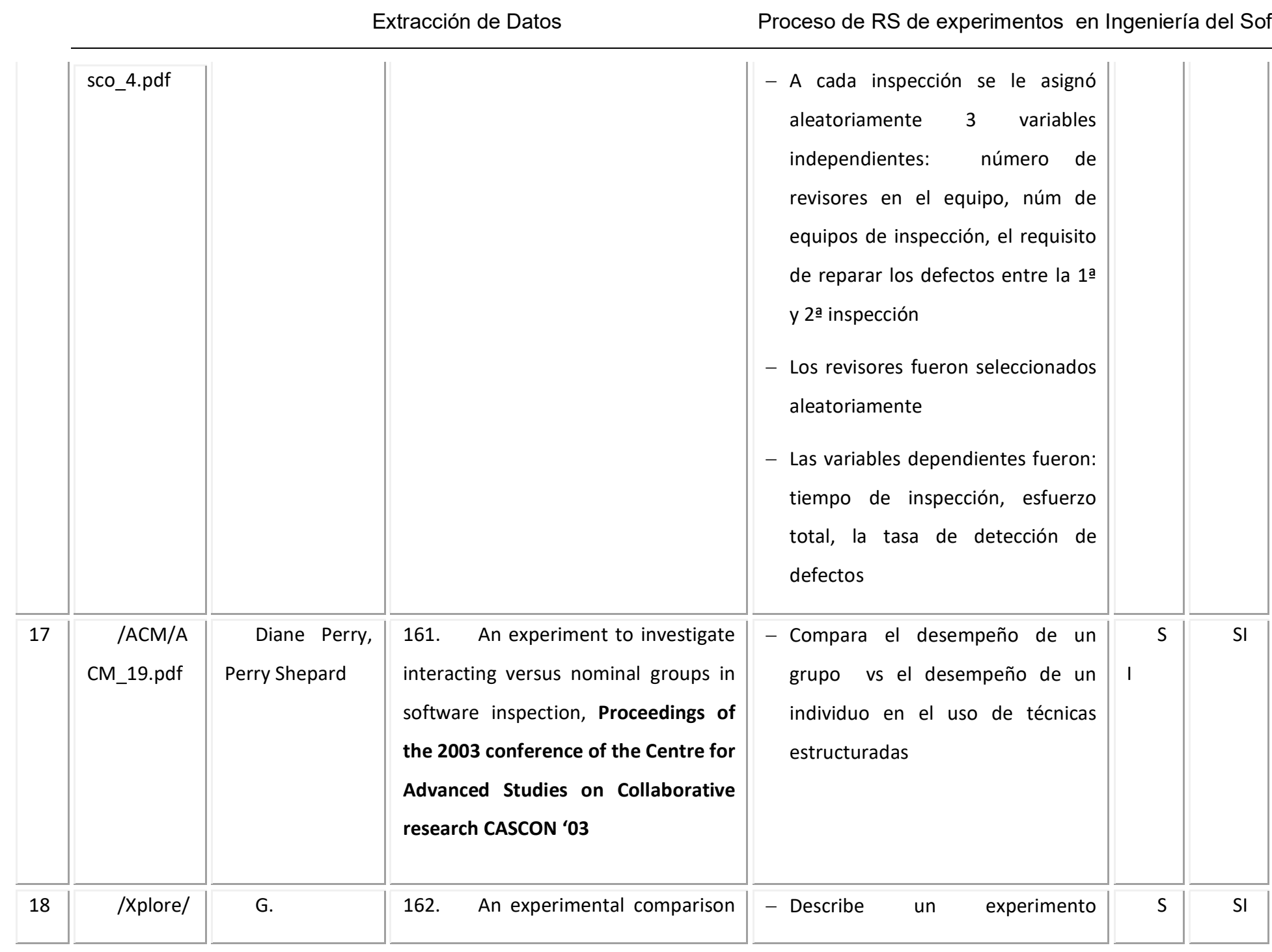


Proceso de RS de experimentos en Ingeniería del Software

\begin{tabular}{|c|c|c|c|c|c|c|}
\hline & $\begin{array}{l}\text { Xplore_29.p } \\
\text { df }\end{array}$ & $\begin{array}{l}\text { Sabaliauskaite, } \\
\text { F. Matsukawa, S. } \\
\text { Kusumoto, and } \\
\text { K. Inoue, }\end{array}$ & $\begin{array}{l}\text { of checklist-based reading and } \\
\text { perspective-based reading for UML } \\
\text { design document inspection, } \\
\text { International Symposium on Empirical } \\
\text { Software Engineering (ISESE'02) }\end{array}$ & $\begin{array}{l}\text { controlado en el que participaron } \\
59 \text { estudiantes } \\
\text { - Compara } 2 \text { técnicas de lectura: } \\
\text { basada en checklist y basada en } \\
\text { perspectiva, en la inspección de } \\
\text { diseño } 00 \\
\text { - Comparan: efectividad, tiempo, } \\
\text { costo } x \text { defecto }\end{array}$ & I & \\
\hline 19 & $\begin{array}{l}\text { /scedire } \\
\text { ct/ } \\
\text { Sdirect_ } \\
\text { 9.pdf }\end{array}$ & $\begin{array}{l}\quad \text { O. } \\
\text { Laitenberger, C. } \\
\text { Atkinson, M. } \\
\text { Schlich, and K. El } \\
\text { Emam, }\end{array}$ & $\begin{array}{l}\text { 163. An experimental comparison } \\
\text { of reading techniques for defect } \\
\text { detection in UML design documents, } \\
\text { Journal of Systems and Software, vol. } \\
53 \text {, pp. 183-204, } 2000 \text {. }\end{array}$ & $\begin{array}{l}\text { - Compara una técnica basada en } \\
\text { escenario (PBR) para detección de } \\
\text { defectos en documentos de diseño } \\
\text { OO que utilizan UML, con la técnica } \\
\text { basada en checklist (CBR) más } \\
\text { tradicional. } \\
\text { - Aplican un experimento controlado } \\
\text { con } 18 \text { practicantes como sujetos } \\
\text { - Miden: \% de defectos } \\
\text { descubiertos, tasa promedio de } \\
\text { tiempo x defecto, eficacia de los } \\
\text { escenarios PBR en la detección de }\end{array}$ & I & SI \\
\hline
\end{tabular}

Caso de estudio 


\begin{tabular}{|c|c|c|c|c|c|c|}
\hline & & \multicolumn{2}{|c|}{ Extracción de Datos } & \multicolumn{3}{|c|}{ Proceso de RS de experimentos en Ingeniería del Soft } \\
\hline & & & & $\begin{array}{l}\text { defectos en documentos de diseño } \\
\text { UML }\end{array}$ & & \\
\hline 20 & $\begin{array}{l}\text { /Xplore/ } \\
\text { Xplore_30.p } \\
\text { df } \\
\text { /Scopus }\end{array}$ & $\begin{array}{l}\text { Thelin, } \\
\text { Runeson, P. and } \\
\text { Wohlin, C. }\end{array}$ & $\begin{array}{l}\text { 164. An Experimental Comparison } \\
\text { of Usage-Based and Checklist-Based } \\
\text { Reading, IEEE Transactions on } \\
\text { Software Engineering, 29(8):687-704, } \\
2003 .\end{array}$ & $\begin{array}{l}\text { - Presenta un experimento en el cual } \\
\text { se compara UBR con CBR } \\
\text { - Miden: efectividad y eficiencia en } \\
\text { detectar fallos críticos desde el } \\
\text { punto de vista del usuario. }\end{array}$ & । & SI \\
\hline 21 & $\begin{array}{l}\text { /Springe } \\
\text { r/ } \\
\text { Springer } \\
\text { 4.pdf } \\
\text { /Scopus } \\
\text { / }\end{array}$ & $\begin{array}{l}\text { R. Per and W. } \\
\text { Claes, }\end{array}$ & $\begin{array}{l}\text { 165. An Experimental Evaluation } \\
\text { of an Experience-Based Capture- } \\
\text { Recapture Method in Software Code } \\
\text { Inspections, Empirical Software } \\
\text { Engineering, vol. V3, pp. 381-406, } \\
\text { 1998. }\end{array}$ & $\begin{array}{l}\text { - Propone un método de captura- } \\
\text { recaptura basado en la experiencia } \\
\text { - Un experimento de inspección de } \\
\text { código-C es conducido para evaluar } \\
\text { las mejoras del método y su } \\
\text { aplicabilidad a inspecciones de } \\
\text { código } \\
\text { - Concluye acerca de: estimaciones } \\
\text { del método vs estimaciones del } \\
\text { método de máxima probabilidad, } \\
\text { sensibilidad de las inspecciones } \\
\text { ante cambios en los datos de } \\
\text { inspección }\end{array}$ & I & SI \\
\hline
\end{tabular}


Proceso de RS de experimentos en Ingeniería del Software

\begin{tabular}{|c|c|c|c|c|c|c|}
\hline 22 & $\begin{array}{l}\text { /ACM/ } \\
\text { Acm_6.p } \\
\text { df }\end{array}$ & $\begin{array}{l}\text { G. Michael } \\
\text { Schneider, } \\
\text { Johnny Martin, } \\
\text { W. T. Tsai }\end{array}$ & $\begin{array}{l}\text { 166. An experimental study of } \\
\text { fault detection in user requirements } \\
\text { documents, ACM Transactions on } \\
\text { Software Engineering and } \\
\text { Methodology (TOSEM), Volume } 1 \\
\text { Issue } 2 \text { April } 1992\end{array}$ & $\begin{array}{l}\text { - Describe un experimento } \\
\text { diseñado para confirmar los } \\
\text { resultados de un proyecto anterior } \\
\text { - Mide la rata de detección de } \\
\text { fallos en docs de requerimientos } \\
\text { de usuario } \\
\text { - } 9 \text { equipos de inspección } \\
\text { independientes } \\
\text { - Aplica la técnica de inspección } \\
\text { de requerimentos N-fold y la } \\
\text { compara con el uso de técnicas } \\
\text { formales } \\
\text { - También mide la variabilidad en } \\
\text { el desempeño del equipo de } \\
\text { inspección y la dificultad de } \\
\text { localizar diferentes tipos de fallas } \\
\text { en DRU }\end{array}$ & । & SI \\
\hline
\end{tabular}

Caso de estudio 


\begin{tabular}{|c|c|c|c|c|c|c|}
\hline 23 & $\begin{array}{l}\text { /Xplore/ } \\
\text { Xplore_ } \\
\text { 8.pdf } \\
\text { (/scedire } \\
\text { ct/ } \\
\text { sdirect_1.p } \\
\text { df) }\end{array}$ & $\begin{array}{l}\text { M. A. Babar, } \\
\text { B. Kitchenham, } \\
\text { L. Zhu, and R. } \\
\text { Jeffery, }\end{array}$ & $\begin{array}{l}\text { 167. An exploratory study of } \\
\text { groupware support for distributed } \\
\text { software architecture evaluation } \\
\text { process, 2004. Proceedings - Asia- } \\
\text { Pacific Software Engineering } \\
\text { Conference, APSEC, pp. 222-229 }\end{array}$ & $\begin{array}{l}\text { - Presenta un estudio piloto } \\
\text { (experimento) usado para evaluar } \\
\text { la viabilidad de un experimento + } \\
\text { grande que investigue la } \\
\text { factibilidad del soporte groupware } \\
\text { para la evaluación distribuida de } \\
\text { arquitecturas de software } \\
\text { - El estudio piloto arrojó algunos } \\
\text { hallazgos acerca de la viabilidad de } \\
\text { un proceso de EA soportado por } \\
\text { groupware. }\end{array}$ & I & SI \\
\hline 24 & $\begin{array}{l}\text { /Xplore/ } \\
\text { Xplore } \\
\text { 15.pdf } \\
\text { /Scopus }\end{array}$ & $\begin{array}{l}\text { O. } \\
\text { Laitenberger, K. } \\
\text { El Emam, and T. } \\
\text { G. Harbich, }\end{array}$ & $\begin{array}{l}\text { 168. An internally replicated } \\
\text { quasi-experimental comparison of } \\
\text { checklist and perspective based } \\
\text { reading of code documents, IEEE } \\
\text { Transactions on Software Engineering, } \\
\text { vol. } 27 \text {, pp. } 387-421,2001 .\end{array}$ & $\begin{array}{l}\text { - Compara una técnica de lectura } \\
\text { basada en scenario (PBR) para } \\
\text { detección de defectos en código, } \\
\text { con el enfoque CBR más tradicional } \\
\text { - Hace la comparación en una serie } \\
\text { de } 3 \text { estudios, un quasi- } \\
\text { experimento y } 2 \text { replicaciones } \\
\text { internas } \\
\text { - Utiliza } 60 \text { desarrolladores de } \\
\text { software profesionales }\end{array}$ & $S$ & SI \\
\hline
\end{tabular}


Proceso de RS de experimentos en Ingeniería del Software

\begin{tabular}{|c|c|c|c|c|c|c|}
\hline & & & & $\begin{array}{l}\text { - Presenta un análisis meta-analítico } \\
\text { - Compara efectividad y costo }\end{array}$ & & \\
\hline 25 & $\begin{array}{l}\text { /ACM/ } \\
\text { Acm_7.p } \\
\text { df }\end{array}$ & $\begin{array}{l}\text { Hidetake } \\
\text { Uwano, } \\
\text { Masahide } \\
\text { Nakamura, Akito } \\
\text { Monden, Ken- } \\
\text { ichi Matsumoto }\end{array}$ & $\begin{array}{l}\text { 169. Analyzing individual } \\
\text { performance of source code review } \\
\text { using reviewers' eye movement, } \\
\text { Proceedings of the } 2006 \text { symposium } \\
\text { on Eye tracking research \& } \\
\text { applications ETRA '06 }\end{array}$ & $\begin{array}{l}\text { - Analiza } 30 \text { procesos de revisión } \\
\text { - } 6 \text { programas y } 5 \text { sujetos que } \\
\text { utilizan un ambiente integrado que } \\
\text { mide y registra el movimiento } \\
\text { ocular de los revisores de código } \\
\text { - Identifica un patrón } \\
\text { - Realiza un análisis cuantitativo } \\
\text { sobre el tiempo usado en el patrón } \\
\text { y el tiempo en detectar fallas }\end{array}$ & $\mathrm{O}^{\mathrm{N}}$ & $\begin{array}{r}\text { SI } \\
\text { (débil } \\
\text { ) }\end{array}$ \\
\hline 26 & $\begin{array}{l}\text { /Scedire } \\
\text { ct/ } \\
\text { sdirect_2.p } \\
\text { df } \\
\text { /scopus/ } \\
\text { sco_8.pdf }\end{array}$ & $\begin{array}{l}\text { G. } \\
\text { Sabaliauskaite, } \\
\text { S. Kusumoto, } \\
\text { and K. Inoue, }\end{array}$ & $\begin{array}{l}\text { 170. Assessing defect detection } \\
\text { performance of interacting teams in } \\
\text { object-oriented design inspection, } \\
\text { Information and Software } \\
\text { Technology, vol. 46, pp. } 875-886 \text {, } \\
2004 \text {. }\end{array}$ & $\begin{array}{l}\text { - Reporta un experimento } \\
\text { controlado con } 54 \text { estudiantes de } \\
\text { carrera que inspeccionan } \\
\text { documentos de diseño OO. } \\
\text { - Compara el desempeño de los } \\
\text { equipos de inspección utilizando } \\
\text { dos técnicas de lectura: CBR y PBR }\end{array}$ & I & SI \\
\hline
\end{tabular}

Caso de estudio 


\begin{tabular}{|c|c|c|c|c|c|c|}
\hline & & \multicolumn{2}{|c|}{ Extracción de Datos } & \multicolumn{3}{|c|}{ Proceso de RS de experimentos en Ingeniería del Soft } \\
\hline & & & & $\begin{array}{l}\text { - Compara el desempeño de equipos } \\
\text { nominales e interactivos } \\
\text { - Falsos positivos identificados }\end{array}$ & & \\
\hline 27 & $\begin{array}{l}\text { /ACM/ } \\
\text { Acm_8.p }\end{array}$ & $\begin{array}{rr}\text { Philip } & \text { M. } \\
\text { Johnson, Danu } \\
\text { Tjahjono }\end{array}$ & $\begin{array}{l}\text { 171. Assessing software review } \\
\text { meetings: a controlled experimental } \\
\text { study using CSRS, Proceedings of the } \\
\mathbf{1 9}^{\text {th }} \text { international conference on } \\
\text { Software engineering ICSE ' } 97\end{array}$ & $\begin{array}{l}\text { - Conducen un experimento } \\
\text { controlado que evalúa varias } \\
\text { medidas de costo y efectividad } \\
\text { para un método de revisión basado } \\
\text { en reunió y otro no basado en ella } \\
\text { - Utilizan un ambiente de revisión de } \\
\text { software colaborativo } \\
\text { - Utilizan 24x3 grupos de personas } \\
\text { - Miden: núm de defectos } \\
\text { descubiertos, esfuerzo requerido, } \\
\text { presencia de sinergia en los grupos } \\
\text { basados en reunión, falsos } \\
\text { positivos en los grupos no-basados, } \\
\text { respuestas a cuestionarios } \\
\text { cualitativos }\end{array}$ & 1 & $\mathrm{SI}$ \\
\hline 28 & $\begin{array}{l}\text { /Xplore/ } \\
\text { Xplore_16.p }\end{array}$ & $\begin{array}{l}\text { A. Porter, L. } \\
\text { Votta, and V. }\end{array}$ & $\begin{array}{l}\text { 172. Comparing detection } \\
\text { methods for software requirements }\end{array}$ & $\begin{array}{l}\text { - Conduce un experimento } \\
\text { aleatorizado con } 48 \text { estudiantes }\end{array}$ & $\mathrm{S}$ & $\mathrm{SI}$ \\
\hline
\end{tabular}


Proceso de RS de experimentos en Ingeniería del Software

\begin{tabular}{|c|c|c|c|c|c|}
\hline & $d f$ & Basili. & $\begin{array}{l}\text { inspections: A replicated experiment. } \\
\text { IEEE Transactions on Software } \\
\text { Engineering, 21(6):563-575,1995 }\end{array}$ & $\begin{array}{l}\text { - Cada equipo inspeccionó } 2 \text { SRS } \\
\text { usando alguna combinación de } \\
\text { métodos Ad hoc, checklist y } \\
\text { escenarios } \\
\text { - Miden: tasa de detección de fallos } \\
\text { individual y grupal, tasas de } \\
\text { ganancia y pérdida de la reunión }\end{array}$ & \\
\hline 29 & /Scopus & $\begin{array}{l}\text { Sabaliauskait } \\
\text { e, G., Kusumoto, } \\
\text { S., Inoue, K. }\end{array}$ & $\begin{array}{l}\text { 173. Comparing reading techniques } \\
\text { for object-oriented design inspection, } \\
\text { IEICE Transactions on Information and } \\
\text { Systems E87-D (4), pp. 976-984, } 2004\end{array}$ & $\begin{array}{l}\text { - For more than twenty-five years } \\
\text { software inspections have been } \\
\text { considered an effective method for } \\
\text { defect detection. Inspections have } \\
\text { been investigated through } \\
\text { controlled experiments in } \\
\text { university environment and } \\
\text { industry case studies. However, in } \\
\text { most cases software inspections } \\
\text { have been used for defect } \\
\text { detection in documents of } \\
\text { conventional structured } \\
\text { development process. Therefore, } \\
\text { there is a significant lack of }\end{array}$ & \\
\hline
\end{tabular}

Caso de estudio 


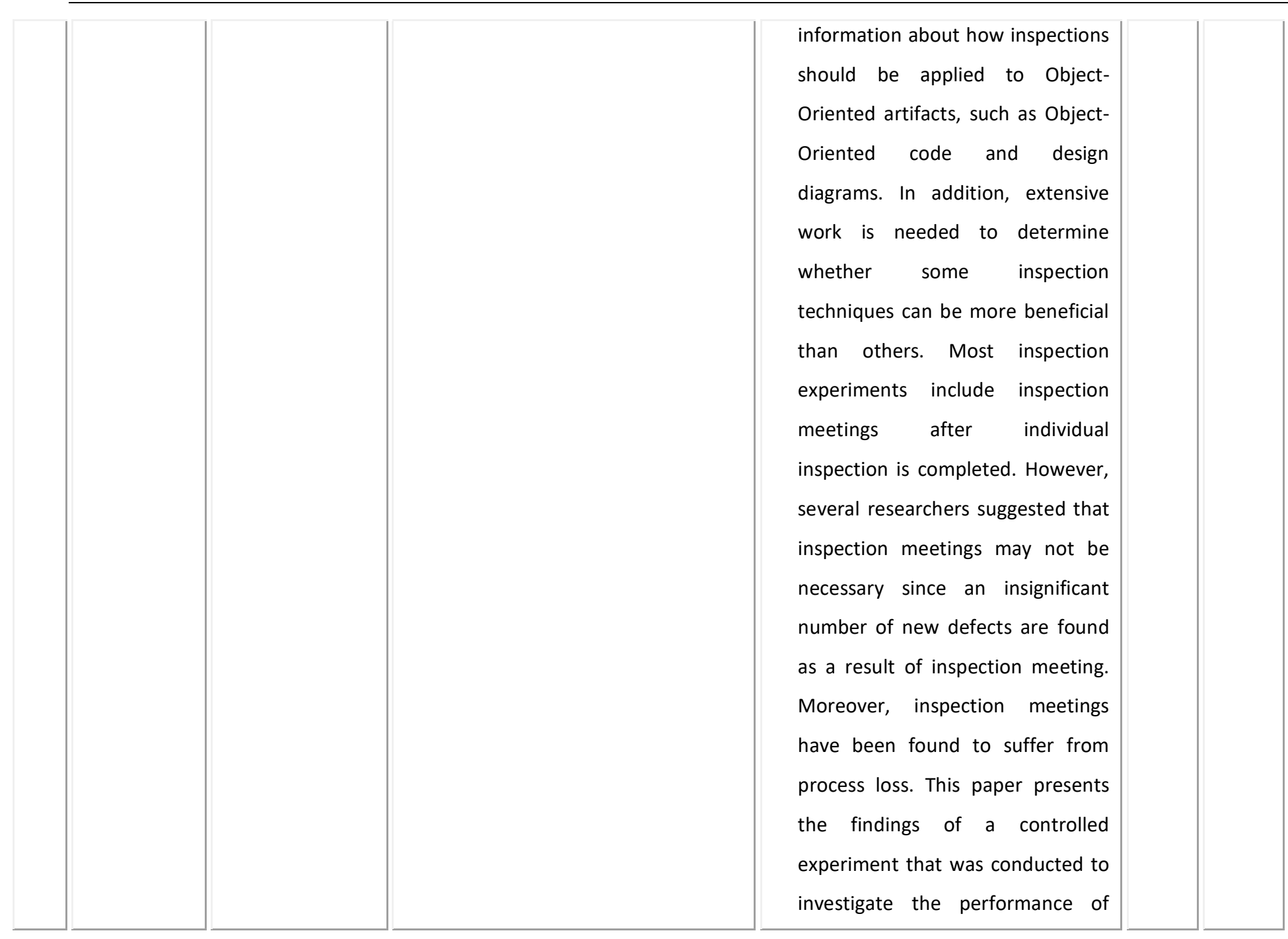


Proceso de RS de experimentos en Ingeniería del Software

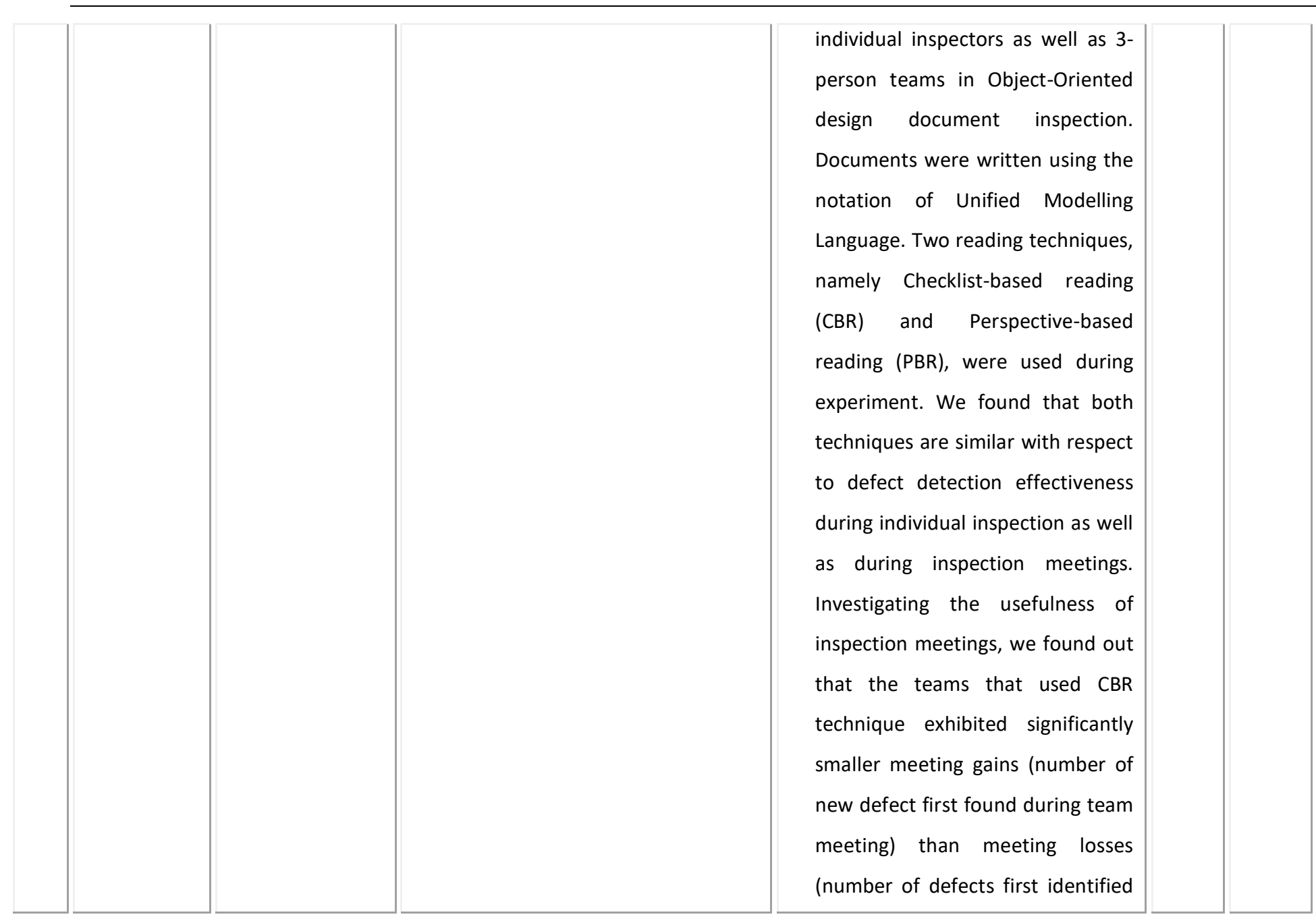

Caso de estudio 


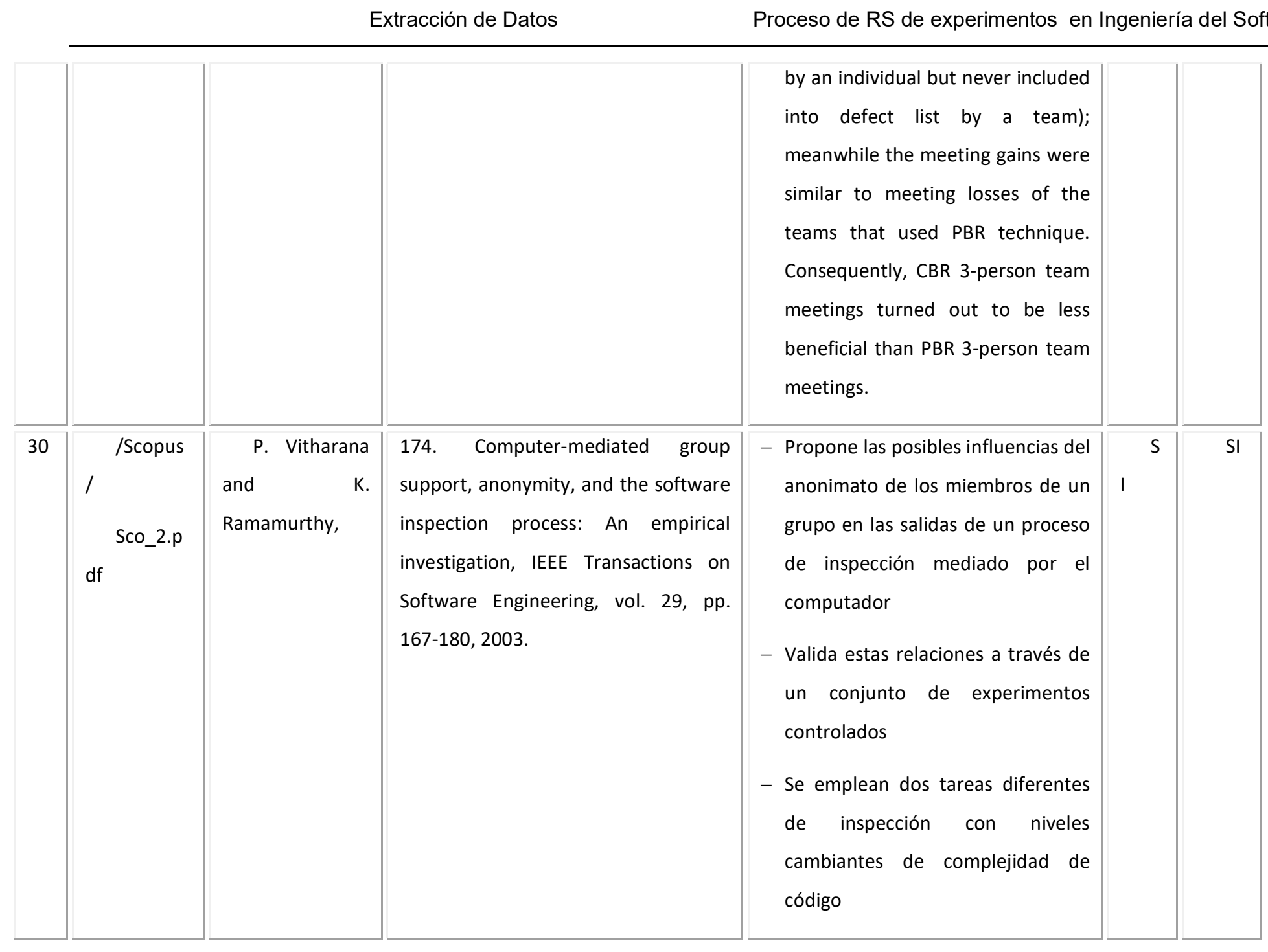


Proceso de RS de experimentos en Ingeniería del Software

\begin{tabular}{|c|c|c|c|c|c|c|}
\hline & & & & $\begin{array}{l}\text { - Miden: tiempo en ejecutar las } \\
\text { tareas, efectividad en encontrar los } \\
\text { errores "sembrados", actitud }\end{array}$ & & \\
\hline 31 & $\begin{array}{l}\text { /Scedire } \\
\text { ct/ } \\
\text { Sdirect_ } \\
\text { 5.pdf } \\
\text { /scopus/ } \\
\text { sco_7.pdf }\end{array}$ & $\begin{array}{l}\text { T. Thelin and } \\
\text { P. Runeson, }\end{array}$ & $\begin{array}{l}\text { 175. Confidence intervals for } \\
\text { capture-recapture estimations in } \\
\text { software inspections, Information and } \\
\text { Software Technology, vol. 44, pp. 683- } \\
702,2002 \text {. }\end{array}$ & $\begin{array}{l}\text { - Replica un estudio captura- } \\
\text { recaptura } \\
\text { - Insvestiga los intervalos de } \\
\text { confianza para estimadores de } \\
\text { captura-recaptura utilizando } \\
\text { conjuntos de datos de dos } \\
\text { experimentos de inspección }\end{array}$ & I & SI \\
\hline 32 & /Scopus & Harjumaa, L. & $\begin{array}{l}\text { 176. Distributed software inspections } \\
\text { - An experiment with Adobe Acrobat, } \\
\text { International Conference on Computer } \\
\text { Science and Technology, pp. } 26-31,2003\end{array}$ & $\begin{array}{l}\text { - Several computer tools for } \\
\text { supporting software inspections } \\
\text { exist. Most of them are prototypes } \\
\text { that demonstrate particular } \\
\text { aspects of the inspection process } \\
\text { automation and are not mature } \\
\text { enough for utilization. This paper } \\
\text { discusses if off-the shelf products }\end{array}$ & I & \\
\hline
\end{tabular}

Caso de estudio 


\begin{tabular}{|c|c|c|c|c|c|c|}
\hline & & \multicolumn{2}{|c|}{ Extracción de Datos } & \multicolumn{3}{|c|}{ Proceso de RS de experimentos en Ingeniería del Soft } \\
\hline & & & & $\begin{array}{l}\text { can be used effectively for } \\
\text { inspection collaboration in } \\
\text { distributed software development. } \\
\text { During the experiment three teams } \\
\text { carried out distributed inspections. } \\
\text { Collaboration between team } \\
\text { members was done with Adobe } \\
\text { Acrobat } 5.0 \text { and standard e-mail. } \\
\text { The Acrobat software provides } \\
\text { very convenient on-line } \\
\text { commenting and material } \\
\text { distribution capabilities, but lacks } \\
\text { characteristics for efficient } \\
\text { management of the inspection } \\
\text { process, such as defect } \\
\text { categorization. Thus, there is still a } \\
\text { need for tools that are specialized } \\
\text { in software inspections. }\end{array}$ & & \\
\hline 33 & $\begin{array}{l}\text { /ACM/ } \\
\text { Acm_9.p } \\
\text { df }\end{array}$ & $\begin{array}{l}\text { Muhammad } \\
\text { Ali Babar, } \\
\text { Barbara } \\
\text { Kitchenham, }\end{array}$ & $\begin{array}{l}\text { 177. Distributed versus face-to- } \\
\text { face meetings for architecture } \\
\text { evalution: a controlled experiment, } \\
\text { Proceedings of the } 2006 \mathrm{ACM} / \mathrm{IEEE}\end{array}$ & $\begin{array}{c}\text { - Presenta un experimento } \\
\text { controlado que evalúa la } \\
\text { efectividad de la construcción de } \\
\text { perfiles de escenarios usando }\end{array}$ & ${ }_{1} \mathrm{~S}$ & SI \\
\hline
\end{tabular}


Proceso de RS de experimentos en Ingeniería del Software

\begin{tabular}{|c|c|c|c|c|c|c|}
\hline & & Ross Jeffery & $\begin{array}{l}\text { international symposium on } \\
\text { International symposium on } \\
\text { empirical software engineering ISESE } \\
\text { '06 }\end{array}$ & $\begin{array}{l}\text { reuniones distribuidas } \\
\text { - Cross-over experiment con } 32 \\
\text { equipos de estudiantes } \\
\text { - Compara la calidad de los } \\
\text { escenarios usando groupware vs } \\
\text { los producidos face-2-face }\end{array}$ & & \\
\hline 34 & $\begin{array}{c}\text { /ACM/ } \\
\text { acm_10.pdf }\end{array}$ & $\begin{array}{rr}\text { Yuk } & \text { Kuen } \\
\text { Wong, } & \text { David } \\
\text { Wilson } & \end{array}$ & $\begin{array}{l}178 . \text { Does task training really } \\
\text { affect group performance?, } \\
\text { Proceedings of the winter } \\
\text { international synposium on } \\
\text { Information and communication } \\
\text { technologies WISICT '04 }\end{array}$ & $\begin{array}{l}\text { - Examina la relación entre la } \\
\text { experiencia en entrenamiento de } \\
\text { tareas y el desempeño en la } \\
\text { revisión de software } \\
\text { - } 192 \text { sujetos fueron asignados } \\
\text { aleatoriamente a } 48 \text { grupos de } 4 \\
\text { miembros } \\
\text { - Buscaron defectos en un } \\
\text { documento de diseño }\end{array}$ & I & SI \\
\hline 35 & $\begin{array}{l}\text { /ACM/a } \\
\mathrm{cm} \_11 . p d f\end{array}$ & $\begin{array}{l}\text { Christian F. J. } \\
\text { Lange, Michel R. } \\
\text { V. Chaudron }\end{array}$ & $\begin{array}{l}\text { 179. Effects of defects in UML } \\
\text { models: an experimental } \\
\text { investigation, May } 2006 \text { Proceeding } \\
\text { of the 28th international conference }\end{array}$ & $\begin{array}{l}\text { - Presenta } 2 \text { experimentos } \\
\text { controlados } \\
\text { - Investiga cuántos investigadores } \\
\text { detectan defectos y cuántos }\end{array}$ & I & SI \\
\hline
\end{tabular}

Caso de estudio 


\begin{tabular}{|c|c|c|c|c|c|c|}
\hline & & \multicolumn{2}{|c|}{ Extracción de Datos } & \multicolumn{3}{|c|}{ Proceso de RS de experimentos en Ingeniería del Softwa } \\
\hline & & & on Software engineering ICSE '06 & $\begin{array}{l}\text { defectos causan diferentes } \\
\text { interpretaciones para diferentes } \\
\text { lectores } \\
\text { - Utilizan } 111 \text { estudiantes y } 48 \\
\text { practicantes industriales }\end{array}$ & & \\
\hline 36 & /Scopus & & $\begin{array}{l}\text { Eight maxims for software } \\
\text { inspectors }\end{array}$ & - & S & \\
\hline & $\begin{array}{l}\text { /Scedire } \\
\text { ct/ } \\
\text { sdirect_6.p } \\
\text { df } \\
\text { /scopus/ } \\
\text { sco_6.pdf }\end{array}$ & $\begin{array}{l}\text { S. S. So, S. D. } \\
\text { Cha, and Y. R. } \\
\text { Kwon, }\end{array}$ & $\begin{array}{l}\text { 180. Empirical evaluation of a } \\
\text { fuzzy logic-based software quality } \\
\text { prediction model, Fuzzy Sets and } \\
\text { Systems, vol. 127, pp. 199-208, } 2002 \text {. }\end{array}$ & $\begin{array}{l}\text { - Popone un enfoque automatizado } \\
\text { y badado en lógica difusa } \\
\text { - Analizan los datos de inspección y } \\
\text { aquellos obtenidos en } \\
\text { experimentos de inspección } \\
\text { separados } \\
\text { - Valida el modelo de predicción de } \\
\text { la calidad propuesto }\end{array}$ & I & SI \\
\hline 37 & $\begin{array}{l}\text { /Springe } \\
\text { r/ } \\
\text { Springer_11 } \\
\text {.pdf }\end{array}$ & T. Thomas, & $\begin{array}{l}\text { 181. Empirical Evaluations of } \\
\text { Usage-Based Reading and Fault } \\
\text { Content Estimation for Software } \\
\text { Inspections, Empirical Software }\end{array}$ & $\begin{array}{l}\text { - Describe } 6 \text { investigaciones } \\
\text { empíricas de } 2 \text { técnicas de } \\
\text { inspección de software: técnica de } \\
\text { lectura (UBR) y de estimación de }\end{array}$ & I & SI \\
\hline
\end{tabular}


Proceso de RS de experimentos en Ingeniería del Software

\begin{tabular}{|c|c|c|c|c|c|c|}
\hline & $\begin{array}{r}\text { Scopus/ } \\
\text { sco_14.pdf }\end{array}$ & & $\begin{array}{l}\text { Engineering, vol. V8, pp. 309-313, } \\
2003 \text {. }\end{array}$ & $\begin{array}{l}\text { contenido de fallas (captura- } \\
\text { recaptura) }\end{array}$ & & \\
\hline 38 & /Scopus & & $\begin{array}{l}\text { Estimating the number of } \\
\text { remaining defects after inspection }\end{array}$ & - & 1 & \\
\hline 39 & $\begin{array}{l}\text { /Scedire } \\
\text { ct/ } \\
\text { sdirect_4.p } \\
\text { df }\end{array}$ & S. Biffl, & $\begin{array}{l}\text { 182. Evaluating defect estimation } \\
\text { models with major defects, Journal of } \\
\text { Systems and Software, vol. } 65, \mathrm{pp} .13- \\
29,2003 \text {. }\end{array}$ & $\begin{array}{l}\text { - Se basa en la estimación de } \\
\text { defectos en documentos de } \\
\text { requisitos de software } \\
\text { - Compara el desempeño de técnicas } \\
\text { objetivas y subjetivas de } \\
\text { estimación del contenido de } \\
\text { defectos } \\
\text { - Conduce un experimento } \\
\text { controlado con } 31 \text { equipos de } \\
\text { inspección de 4-6 personas } \\
\text { - Miden: precisión }\end{array}$ & 1 & SI \\
\hline 40 & $\begin{array}{c}\text { /ACM/ } \\
\text { acm_12.pdf }\end{array}$ & $\begin{array}{l}\text { Stefan Biffl, } \\
\text { Wilfried } \\
\text { Grossmann }\end{array}$ & $\begin{array}{l}\text { 183. Evaluating the accuracy of } \\
\text { defect estimation models based on } \\
\text { inspection data from two inspection }\end{array}$ & $\begin{array}{l}\text { - Considera } 3 \text { escenarios para } \\
\text { combinar conjuntos de datos de } \\
\text { los procesos de inspección- }\end{array}$ & 1 & $\mathrm{O}^{\mathrm{N}}$ \\
\hline
\end{tabular}

Caso de estudio 


\begin{tabular}{|c|c|c|c|c|c|c|}
\hline & & & $\begin{array}{l}\text { cycles, Proceedings of the } 23 \mathrm{rd} \\
\text { International Conference on } \\
\text { Software Engineering ICSE '01 }\end{array}$ & $\begin{array}{l}\text { reinspección } \\
\text { - Evalúa la precisión de la estimación } \\
\text { de defectos } \\
\text { - Utiliza los datos de un experimento } \\
\text { donde } 31 \text { equipos inpeccionaron- } \\
\text { reinspeccionaron docs de } \\
\text { requisitos de usuario. }\end{array}$ & & \\
\hline 41 & $\begin{array}{l}\text { /Springe } \\
\text { r/ } \\
\text { Springer_1. } \\
\text { pdf } \\
\text { /Scopus }\end{array}$ & $\begin{array}{l}\text { T. Thomas, R. } \\
\text { Per, W. Claes, O. } \\
\text { Thomas, and A. } \\
\text { Carina, }\end{array}$ & $\begin{array}{l}\text { 184. Evaluation of Usage-Based } \\
\text { Reading-Conclusions after Three } \\
\text { Experiments, Empirical Software } \\
\text { Engineering, vol. V9, pp. 77-110, } \\
2004 .\end{array}$ & $\begin{array}{l}\text { - Presenta una serie de } \\
\text { experimentos para evaluar UBR } \\
\text { aplicado a un documento de } \\
\text { diseño de alto nivel } \\
\text { - El foco es el 3er experimento: } \\
\text { investigar la información } \\
\text { necesitada por UBR para la } \\
\text { preparación y las reuniones de } \\
\text { inspección de software } \\
\text { - Discute la eficiencia y efectividad }\end{array}$ & I & SI \\
\hline 42 & /ACM/ & Porter, & Experiment to assess the & - Conduce un proyecto a largo plazo & $\mathrm{s}$ & SI \\
\hline
\end{tabular}


Proceso de RS de experimentos en Ingeniería del Software

\begin{tabular}{|c|c|c|c|c|}
\hline $\begin{array}{l}\text { acm_3.pdf } \\
\quad \text { (Xplore_ } \\
\text { 10.pdf) } \\
\text { (Scopus/ } \\
\text { no_docume } \\
\text { nt) }\end{array}$ & $\begin{array}{l}\text { Siy, C. A. Toman, } \\
\text { and L. G. Votta }\end{array}$ & $\begin{array}{l}\text { cost-benefits of code inspections in } \\
\text { large scale software development, } \\
\text { Proceedings of the ACM SIGSOFT } \\
\text { Symposium on the Foundations of } \\
\text { Software Engineering, } 1995 .\end{array}$ & $\begin{array}{l}\text { - Evalúa la costo-efectividad de } \\
\text { diversos métodos de inspección de } \\
\text { software } \\
\text { - Los métodos son aplicados por } \\
\text { desarrolladores profesionales } \\
\text { - Se utilizó simulación para optimizar } \\
\text { el experimento } \\
\text { - A cada inspección se le asignó } \\
\text { aleatoriamente } 3 \quad \text { variables } \\
\text { independientes: número de } \\
\text { revisores en el equipo, núm de } \\
\text { equipos de inspección, el requisito } \\
\text { de reparar los defectos entre la 1á } \\
\text { y 2a inspección } \\
\text { - Los revisores fueron seleccionados } \\
\text { aleatoriamente } \\
\text { - Las variables dependientes fueron: } \\
\text { tiempo de inspección, esfuerzo } \\
\text { total, la tasa de detección de }\end{array}$ & I \\
\hline
\end{tabular}

Caso de estudio 


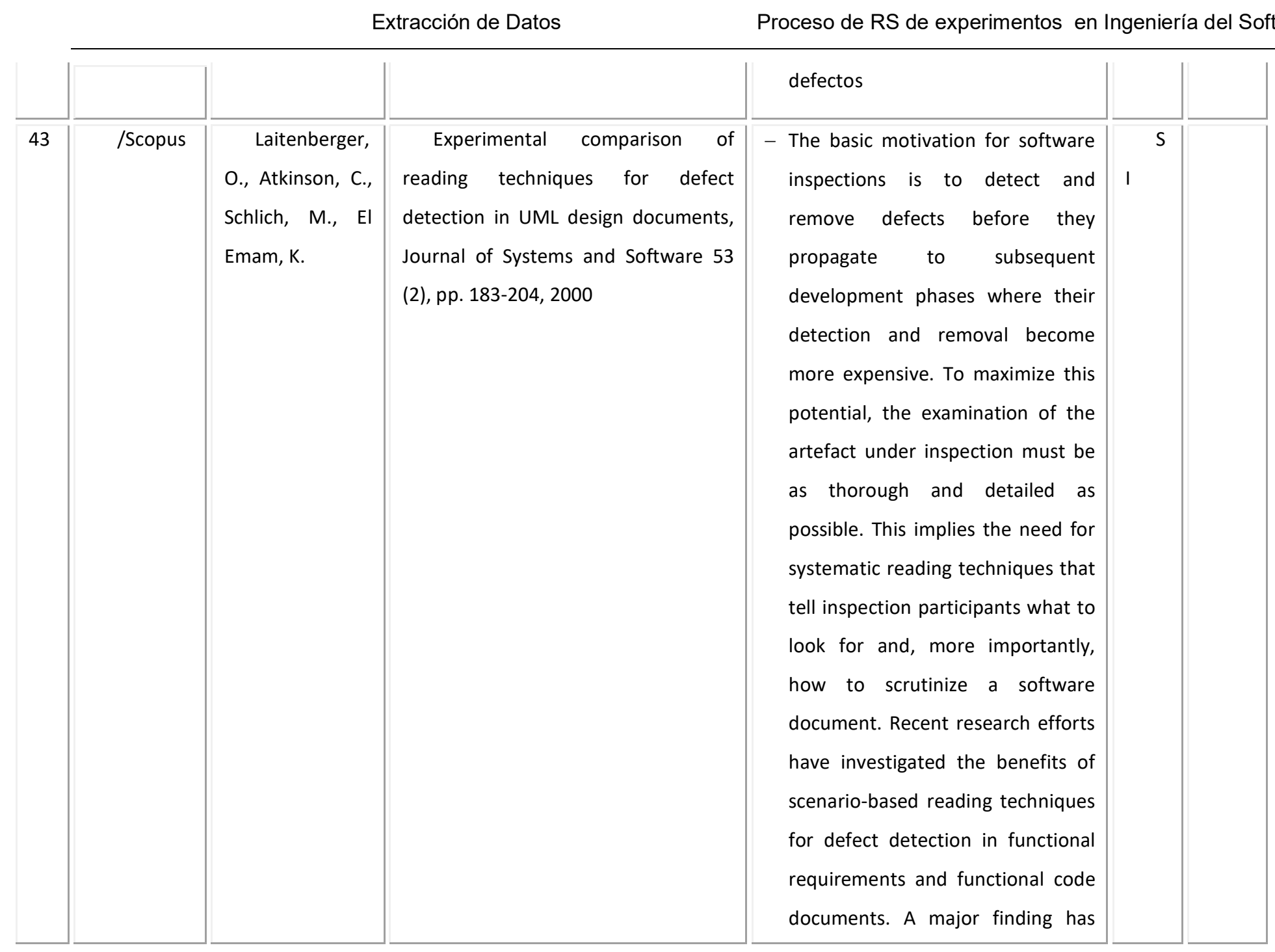


Proceso de RS de experimentos en Ingeniería del Software

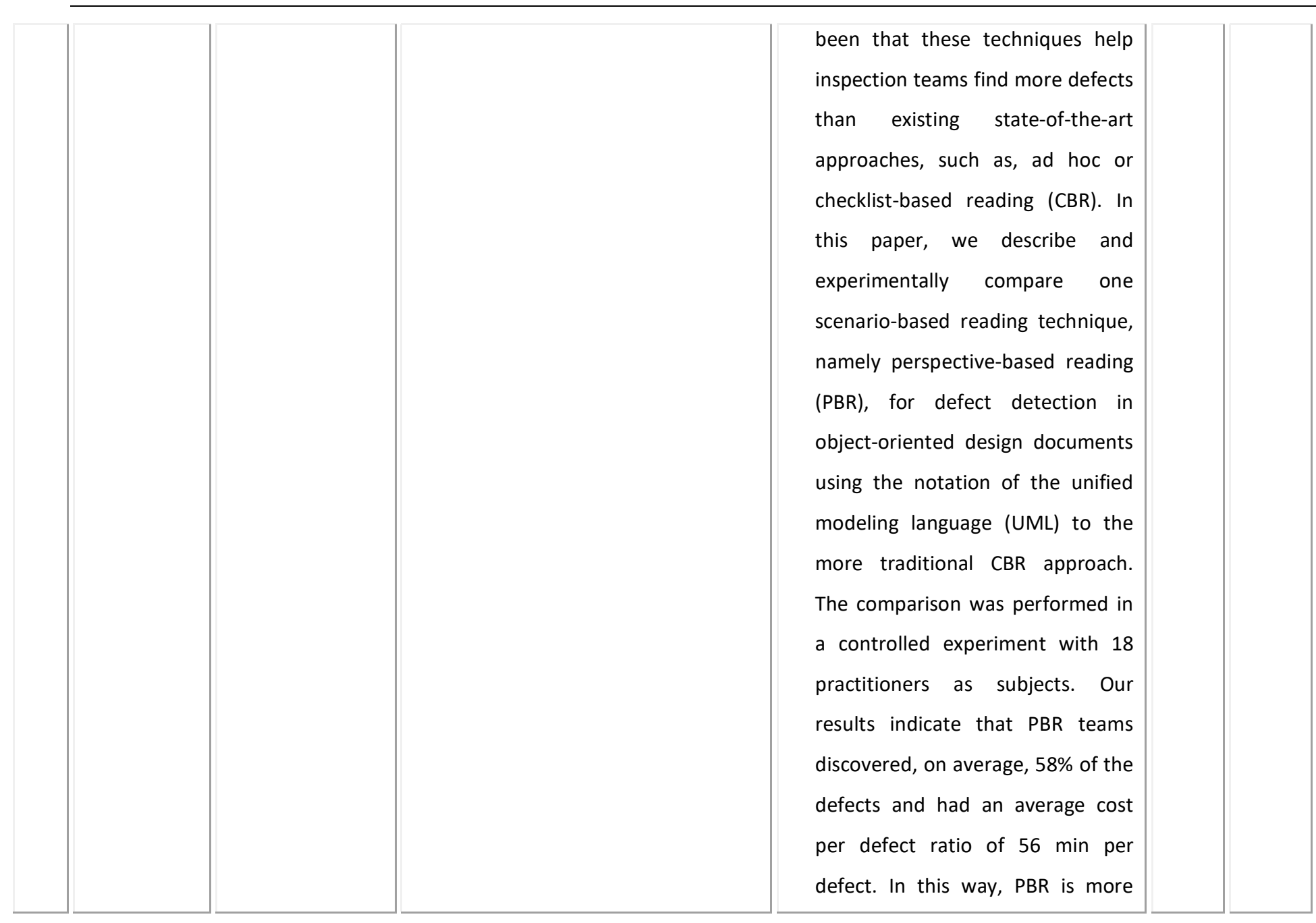

Caso de estudio 


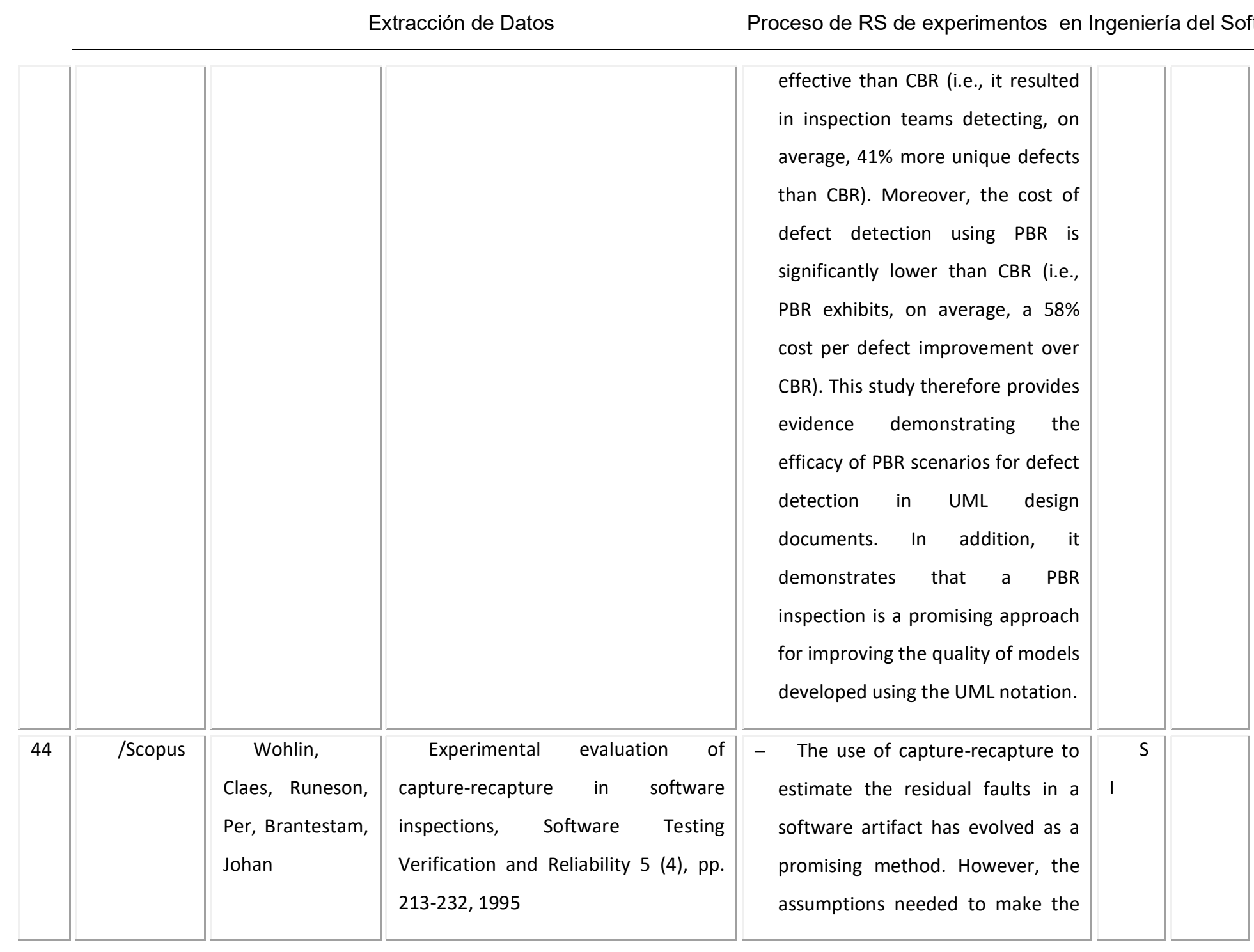


Proceso de RS de experimentos en Ingeniería del Software

\begin{tabular}{|c|c|c|c|c|c|}
\hline & & & & $\begin{array}{l}\text { estimates are not completely } \\
\text { fulfilled in software development, } \\
\text { leading to an underestimation of } \\
\text { the residual fault content. } \\
\text { Therefore, a method employing a } \\
\text { filtering technique with an } \\
\text { experience factor to improve the } \\
\text { estimates of the residual faults is } \\
\text { proposed in this paper. An } \\
\text { experimental study of the capture- } \\
\text { recapture method with this } \\
\text { correction method has been } \\
\text { conducted. It is concluded that the } \\
\text { correction method improves the } \\
\text { capture-recapture estimate of the } \\
\text { number of residual defects in the } \\
\text { inspected document. }\end{array}$ & \\
\hline 45 & /Scopus & $\begin{array}{l}\quad \text { Thelin, } \\
\text { Erlansson, } \\
\text { Höst, } \\
\text { Wohlin, }\end{array}$ & $\begin{array}{l}\text { Experimentation with usage-based } \\
\text { reading, Lecture Notes in Computer } \\
\text { Science (including subseries Lecture } \\
\text { Notes in Artificial Intelligence and }\end{array}$ & $\begin{array}{l}\text { - Software inspections are regarded } \\
\text { as an important technique to } \\
\text { detect faults throughout the } \\
\text { software development process. }\end{array}$ & $\begin{array}{l}\mathrm{S} \\
\mathrm{I}\end{array}$ \\
\hline
\end{tabular}

Caso de estudio 


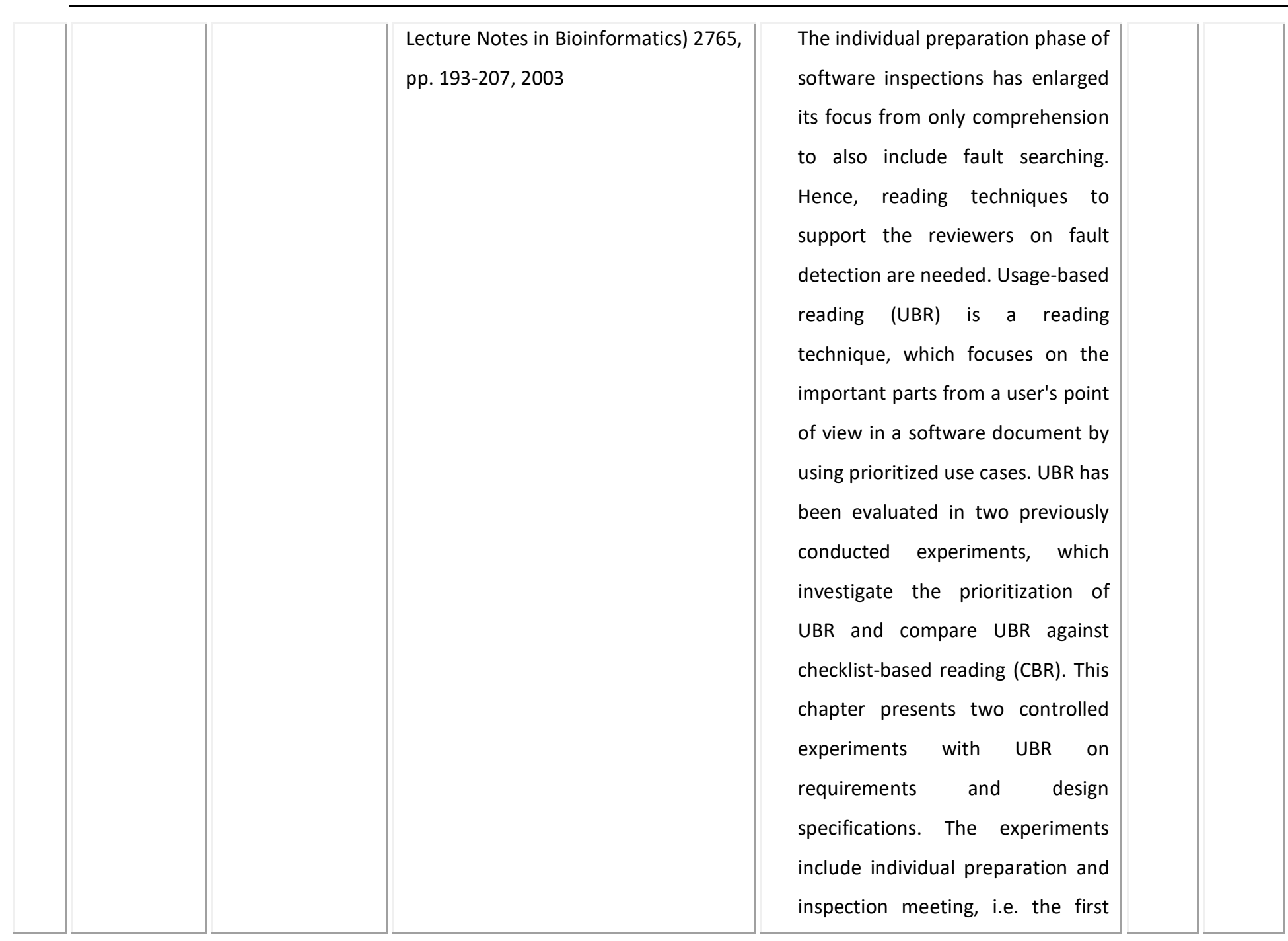


Proceso de RS de experimentos en Ingeniería del Software

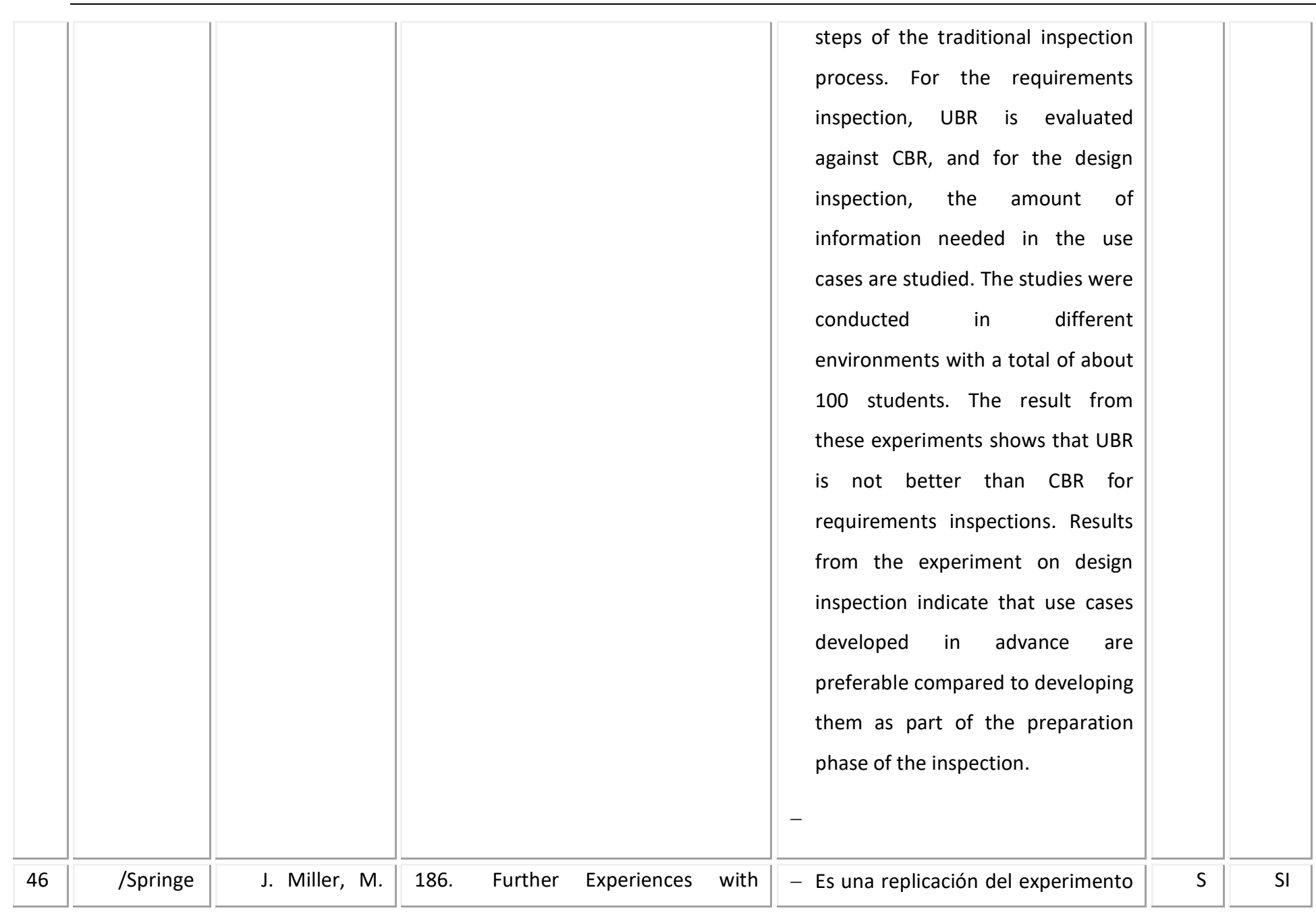

Caso de estudio 


\begin{tabular}{|c|c|c|c|c|c|c|}
\hline & $\begin{array}{r}\begin{array}{l}\text { r/ } \\
\text { Springer_6. } \\
\text { pdf }\end{array} \\
\text { Scopus/ } \\
\text { sco_16.pdf }\end{array}$ & $\begin{array}{l}\text { Wood, and M. } \\
\text { Roper, }\end{array}$ & $\begin{array}{l}\text { Scenarios and Checklists, Empirical } \\
\text { Software Engineering, vol. V3, pp. } 37- \\
64,1998 .\end{array}$ & $\begin{array}{l}\text { de Porter et al. (1995) } \\
\text { (Xplore_16.pdf) } \\
\text { - Evalúa la ayuda a la detección } \\
\text { utilizando enfoques basados en } \\
\text { escenarios y en checklist } \\
\text { - Compara los resultados del } \\
\text { experimento con otros } \\
\text { - Miden: desempeño, pérdidas de la } \\
\text { reunión }\end{array}$ & I & \\
\hline 47 & $\begin{array}{l}\text { /Scedire } \\
\text { ct/ } \\
\text { sdirect_3.p } \\
\text { df }\end{array}$ & $\begin{array}{l}\text { G. } \\
\text { Sabaliauskaite, } \\
\text { F. Matsukawa, S. } \\
\text { Kusumoto, and } \\
\text { K. Inoue, }\end{array}$ & $\begin{array}{l}\text { 187. Further investigations of } \\
\text { reading techniques for object- } \\
\text { oriented design inspection, } \\
\text { Information and Software } \\
\text { Technology, vol. 45, pp. 571-585, } \\
2003 \text {. }\end{array}$ & $\begin{array}{l}\text { - Describe la evaluación de CBR y } \\
\text { PBR para un documento de diseño } \\
\text { OO escrito con UML } \\
\text { - Reporta un experimento } \\
\text { controlado con } 59 \text { estudiantes } \\
\text { - Miden: tiempo individual, costo x } \\
\text { defecto, efectividad, efectividad } \\
\text { del equipo simulado }\end{array}$ & $S$ & SI \\
\hline 48 & $\begin{array}{l}\text { /Xplore/ } \\
\text { Xplore_17.p }\end{array}$ & $\begin{array}{l}\text { O. } \\
\text { Laitenberger and }\end{array}$ & $\begin{array}{l}\text { 188. Generalizing perspective- } \\
\text { based inspection to handle object- }\end{array}$ & $\begin{array}{c}\text { - Discute las dificultades de } \\
\text { adaptación de la técnica PBR a }\end{array}$ & $N$ & 0 \\
\hline
\end{tabular}


Proceso de RS de experimentos en Ingeniería del Software

\begin{tabular}{|c|c|c|c|c|c|c|}
\hline & /scopus/ & C. Atkinson, & $\begin{array}{l}\text { oriented development artifacts, } 1999 . \\
\text { Proceedings - International } \\
\text { Conference on Software Engineering, } \\
\text { pp. } 494-503\end{array}$ & $\begin{array}{l}\text { métodos de desarrollo } 00 \\
\text { - Presenta una generalización de la } \\
\text { técnica y una nueva versión } \\
\text { orientada a UML }\end{array}$ & & \\
\hline 49 & $\begin{array}{l}\text { /Xplore/ } \\
\text { Xplore_18.p } \\
\text { df }\end{array}$ & 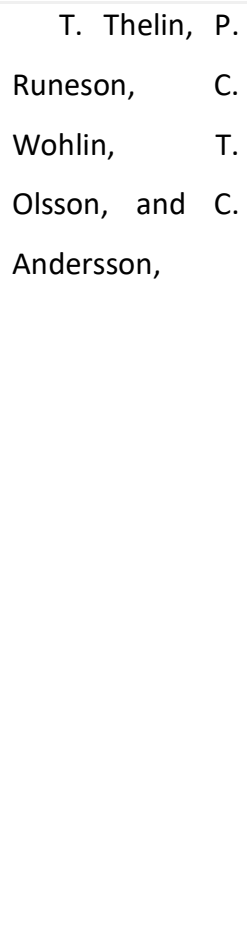 & $\begin{array}{l}\text { 189. How much information is } \\
\text { needed for usage-based reading? A } \\
\text { series of experiments, } 2002 \text {. }\end{array}$ & $\begin{array}{l}\text { - Presenta una serie de } 3 \\
\text { experimentos sobre UBR sobre } \\
\text { especificaciones de diseño } \\
\text { - 1ero: evalúa la priorización de UBR } \\
\text { - 2do: compara UBR vs CBR } \\
\text { - 3ero: investiga la cantidad de } \\
\text { información necesitada en los } \\
\text { casos de uso y si un enfoque más } \\
\text { activo ayuda a los revisores a } \\
\text { detectar más fallas } \\
\text { - El 3er experimento fue conducido } \\
\text { en dos sitios distintos con } 82 \\
\text { sujetos } \\
\text { - Miden: efectividad y eficiencia }\end{array}$ & ${ }^{S}$ & SI \\
\hline
\end{tabular}

Caso de estudio 


\begin{tabular}{|c|c|c|c|c|c|c|}
\hline & & \multicolumn{2}{|c|}{ Extracción de Datos } & \multicolumn{3}{|c|}{ Proceso de RS de experimentos en Ingeniería del Software } \\
\hline 50 & /Scopus & & $\begin{array}{l}\text { Increasing the understanding of } \\
\text { effectiveness in software inspections } \\
\text { using published data sets }\end{array}$ & - & $\mathrm{O}^{\mathrm{N}}$ & \\
\hline 51 & $\begin{array}{l}\text { /Xplore/ } \\
\text { Xplore_19.p } \\
\text { df }\end{array}$ & $\begin{array}{l}\text { L. Harjumaa, } \\
\text { I. Tervonen, and } \\
\text { P. Vuorio, }\end{array}$ & $\begin{array}{l}\text { 190. Improving software } \\
\text { inspection process with patterns, } \\
\text { 2004. Proceedings - Fourth } \\
\text { International Conference on Quality } \\
\text { Software, QSIC 2004, pp. 118-125 }\end{array}$ & $\begin{array}{l}\text { - Describe patrones para mejorar el } \\
\text { proceso de inspección de software } \\
\text { - Los patrones son experimentados } \\
\text { en una compañía de software } \\
\text { - Evalúan la capacidad inicial del } \\
\text { proceso } \\
\text { - Actualizan el proceso de acuerdo a } \\
\text { determinadas metas } \\
\text { - Miden la ejecución posterior del } \\
\text { proceso }\end{array}$ & $0^{N}$ & 0 \\
\hline 52 & $\begin{array}{l}\text { /Springe } \\
\text { r/ } \\
\text { Springer_10 } \\
\text {.pdf } \\
\text { /Scopus }\end{array}$ & $\begin{array}{l}\text { S. Tor and A. } \\
\text { Tanveer Husain, }\end{array}$ & $\begin{array}{l}\text { 191. Improving the Software } \\
\text { Inspection Process, } 2005 .\end{array}$ & $\begin{array}{l}\text { - Muestra los resultados de } 3 \\
\text { experimentos } \\
\text { - Presentan y combinan resultados } \\
\text { para dar recomendaciones en } \\
\text { inspección de código } \\
\text { - Discuten: beneficios de utilzar }\end{array}$ & $\mathrm{O}^{\mathrm{N}}$ & \\
\hline
\end{tabular}


Proceso de RS de experimentos en Ingeniería del Software

\begin{tabular}{|c|c|c|c|c|c|c|}
\hline & & & & $\begin{array}{l}\text { grupos de inspección grandes, } \\
\text { mecanismos de decisión en las } \\
\text { reuniones }\end{array}$ & & \\
\hline 53 & $\begin{array}{l}\text { /Xplore/ } \\
\text { Xplore_20.p } \\
\text { df }\end{array}$ & H. Petersson, & $\begin{array}{l}\text { 192. Individual reviewer } \\
\text { contribution to the effectiveness of } \\
\text { software inspection teams, } 2001 \text {. }\end{array}$ & $\begin{array}{l}\text { - Se enfoca en la contribución del } \\
\text { individuo en la efectividad del } \\
\text { grupo } \\
\text { - Analiza los datos de experimentos } \\
\text { realizados }\end{array}$ & $\mathrm{O}^{\mathrm{N}}$ & 0 \\
\hline 54 & $\begin{array}{l}\text { /Xplore/ } \\
\text { Xplore_21.p } \\
\text { df } \\
\text { Scopus/ } \\
\text { sco_25.pdf }\end{array}$ & $\begin{array}{l}\text { S. Biffl and } \\
\text { M. Halling, }\end{array}$ & $\begin{array}{l}\text { 193. Investigating reinspection } \\
\text { decision accuracy regarding product- } \\
\text { quality and cost-benefit estimates, } \\
\text { 2001. Proceedings - IEEE Computer } \\
\text { Society's International Computer } \\
\text { Software and Applications } \\
\text { Conference, pp.87-96 }\end{array}$ & $\begin{array}{l}\text { - Propone utilizar modelos de } \\
\text { estimación para la mejora de } \\
\text { calidad durante la reinspección y } \\
\text { utilizar el costo-beneficio de una } \\
\text { re-inspección para la decisión } \\
\text { sobre la misma } \\
\text { - Evalua la correctitud de la decisión } \\
\text { de reinspección de estos modelos } \\
\text { con datos de defectos de un gran } \\
\text { experimento controlado sobre la } \\
\text { insp-reinsp de docs de requisitos }\end{array}$ & I & SI \\
\hline
\end{tabular}

Caso de estudio 


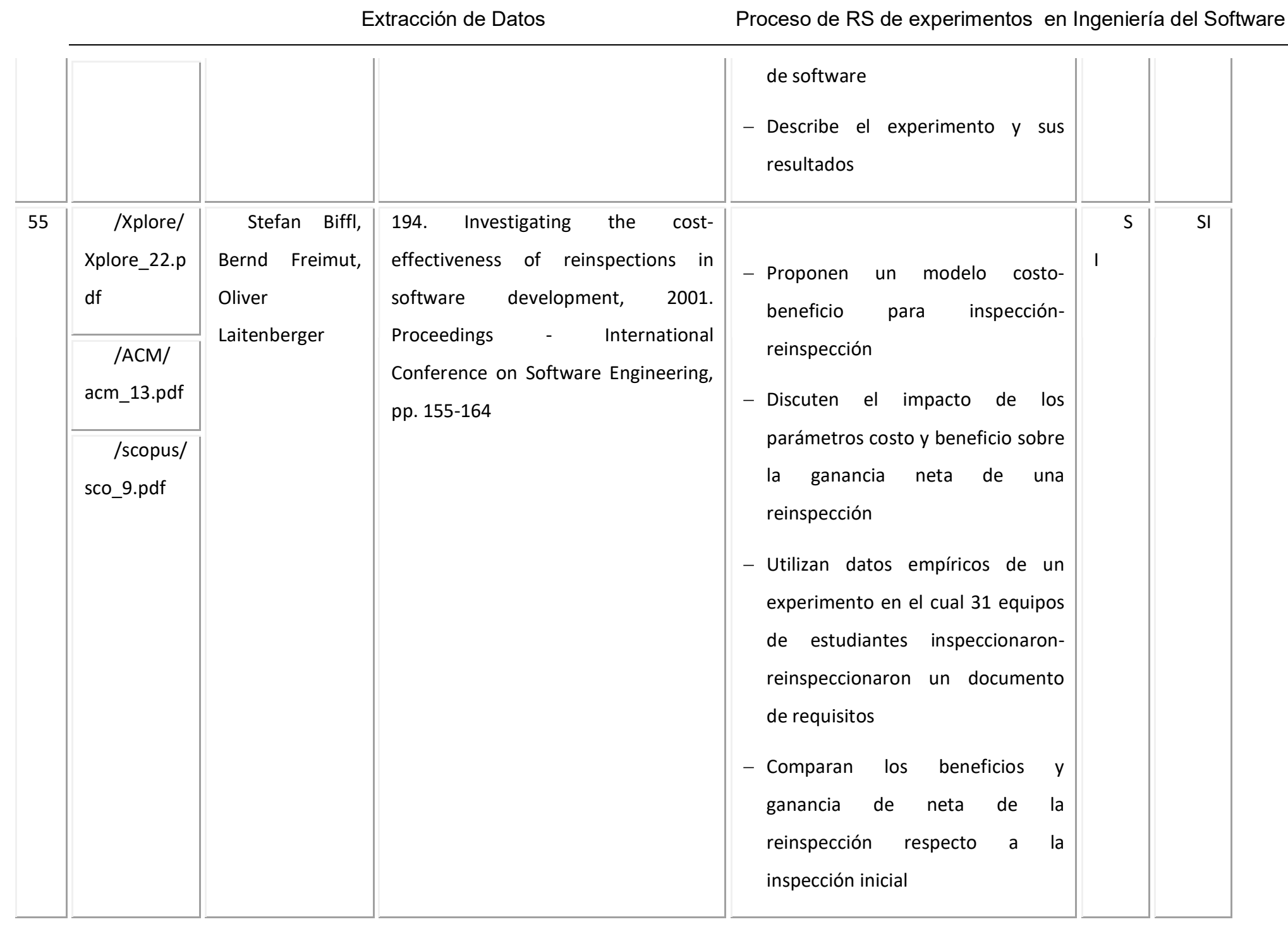


Proceso de RS de experimentos en Ingeniería del Software

\begin{tabular}{|c|c|c|c|c|c|}
\hline 56 & /Scopus & $\begin{array}{c}\text { Biffl, } \\
\text { Halling, } M .\end{array}$ & $\begin{array}{l}\text { Investigating the defect detection } \\
\text { effectiveness and cost benefit of } \\
\text { nominal inspection teams, IEEE } \\
\text { Transactions on Software Engineering } \\
29(5), \text { pp. } 385-397\end{array}$ & $\begin{array}{l}\text { - Inspection is an effective but also } \\
\text { expensive quality assurance } \\
\text { activity to find defects early during } \\
\text { software development. The defect } \\
\text { detection process, team size, and } \\
\text { staff hours invested can have a } \\
\text { considerable impact on the defect } \\
\text { detection effectiveness and cost- } \\
\text { benefit of an inspection. In this } \\
\text { paper, we use empirical data and a } \\
\text { probabilistic model to estimate this } \\
\text { impact for nominal (non- } \\
\text { communicating) inspection teams } \\
\text { in an experiment context. Further, } \\
\text { the analysis investigates how } \\
\text { cutting off the inspection after a } \\
\text { certain time frame would influence } \\
\text { inspection performance. Main } \\
\text { findings of the investigation are: } 1 \text { ) } \\
\text { Using combinations of different } \\
\text { reading techniques in a team is } \\
\text { considerably more effective than }\end{array}$ & $\mathrm{S}$ \\
\hline
\end{tabular}

Caso de estudio 


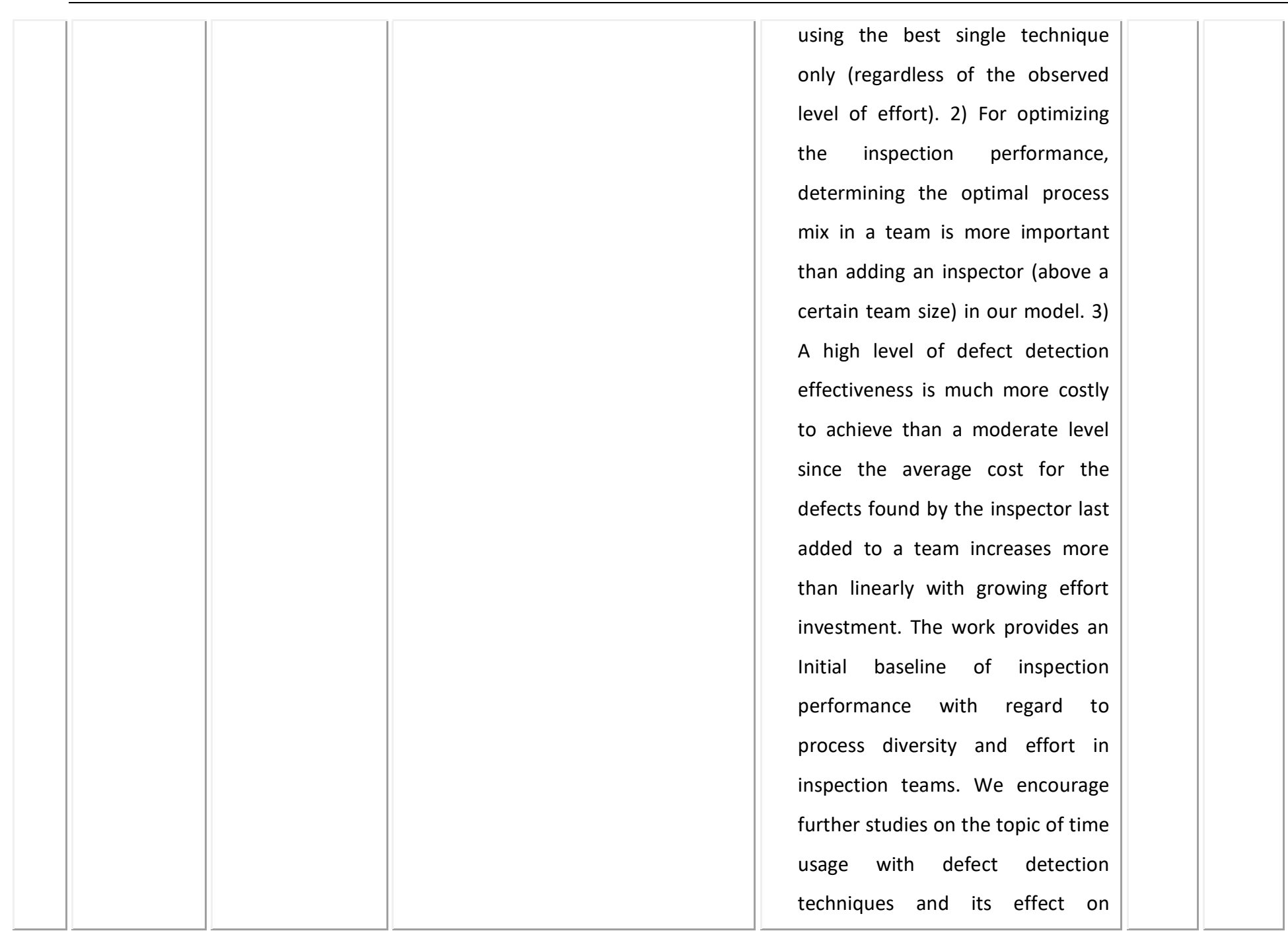


Proceso de RS de experimentos en Ingeniería del Software

\begin{tabular}{|c|c|c|c|c|c|c|}
\hline & & & & $\begin{array}{l}\text { inspection effectiveness in a } \\
\text { variety of inspection contexts to } \\
\text { support inspection planning with } \\
\text { limited resources. }\end{array}$ & & \\
\hline 57 & $\begin{array}{l}\text { /Xplore/ } \\
\text { Xplore_23.p } \\
\text { df }\end{array}$ & $\begin{array}{l}\text { S. Biffl, M. } \\
\text { Halling, and M. } \\
\text { Kohle, }\end{array}$ & $\begin{array}{l}\text { 195. Investigating the effect of a } \\
\text { second software inspection cycle. } \\
\text { Cost-benefit data from a large-scale } \\
\text { experiment on reinspection of a } \\
\text { software requirements document, } \\
2000 \text {. }\end{array}$ & $\begin{array}{l}\text { - Reporta un experimento } \\
\text { controlado que compara el efecto } \\
\text { de dos ciclos de inspección } \\
\text { - Un documento de requisitos es re- } \\
\text { inspeccionado por } 31 \text { equipos } \\
\text { - Presenta: efectividad, eficiencia, } \\
\text { ganancia neta, ROI de un segundo } \\
\text { ciclo de inspección } \\
\text { - Evalúan los supuestos y la } \\
\text { correctitud de los criterios de } \\
\text { decisión }\end{array}$ & 1 & SI \\
\hline 58 & /Scopus & $\begin{array}{l}\quad \text { Winkler, D., } \\
\text { Hailing, M., Biffl, } \\
\text { S. }\end{array}$ & $\begin{array}{l}\text { Investigating the effect of expert } \\
\text { ranking of use cases for design } \\
\text { inspection, Conference Proceedings of } \\
\text { the EUROMICRO 30, pp. 362-371 }\end{array}$ & $\begin{array}{l}\text { - Inspection is an important } \\
\text { approach to reduce defects in } \\
\text { software engineering artifacts. } \\
\text { Reading techniques such as Usage- }\end{array}$ & I & \\
\hline
\end{tabular}

Caso de estudio 


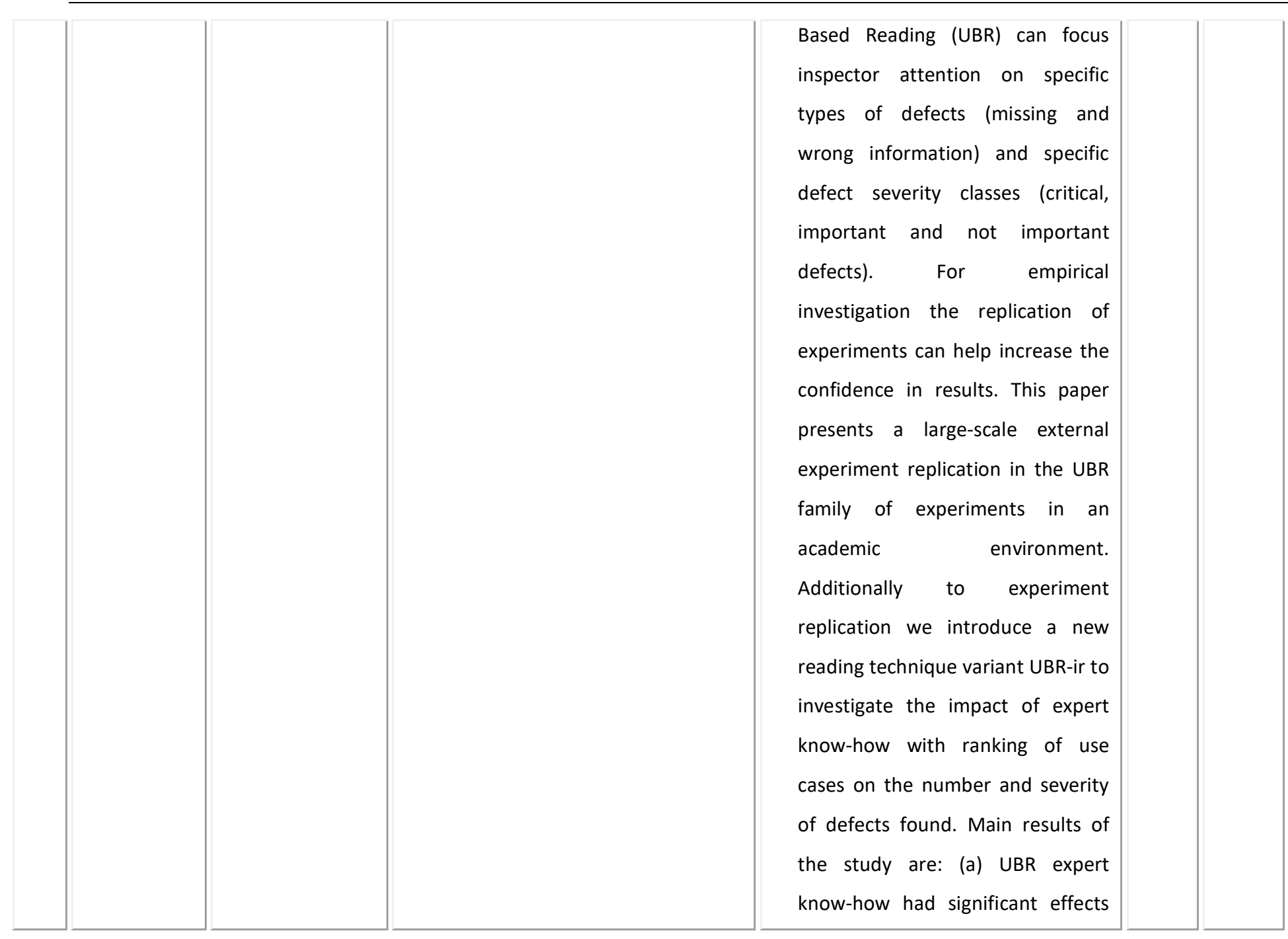


Proceso de RS de experimentos en Ingeniería del Software

\begin{tabular}{|c|c|c|c|c|c|c|}
\hline & & & & $\begin{array}{l}\text { on inspection effort distribution, } \\
\text { effectiveness, and efficiency; (b) } \\
\text { the share of false positives was } \\
\text { higher for checklist-based reading } \\
\text { (CBR) than for all UBR variants; and } \\
\text { (c) both UBR variants perform } \\
\text { significantly better than CBR, } \\
\text { possibly due to the active guidance } \\
\text { of use cases. }\end{array}$ & & \\
\hline 59 & $\begin{array}{l}\text { /Springe } \\
\text { r/ } \\
\text { Springer_2. } \\
\text { pdf } \\
\text { scopus/ } \\
\text { no_docume } \\
\text { nt }\end{array}$ & $\begin{array}{l}\text { W. Dietmar, } \\
\text { B. Stefan, and T. } \\
\text { Bettina, }\end{array}$ & $\begin{array}{l}\text { 196. Investigating the Impact of } \\
\text { Active Guidance on Design Inspection, } \\
\text { 2005. Lecture Notes in Computer } \\
\text { Science 3547, pp. } 458-473\end{array}$ & $\begin{array}{l}\text { - Comparan el desempeño de este } \\
\text { enfoque en un experimento } \\
\text { controlado en un ambiente } \\
\text { académico } \\
\text { - Miden efectividad y eficiencia de } \\
\text { CBR y UBR usando active guidance }\end{array}$ & I & SI \\
\hline 60 & $\begin{array}{l}\text { /Xplore/ } \\
\text { Xplore_24.p } \\
\text { df }\end{array}$ & $\begin{array}{l}\text { B. Freimut, } \\
\text { O. Laitenberger, } \\
\text { and S. Biffl, }\end{array}$ & $\begin{array}{l}\text { 197. Investigating the impact of } \\
\text { reading techniques on the accuracy of } \\
\text { different defect content estimation }\end{array}$ & $\begin{array}{l}\text { - Examina el impacto de } 2 \text { técnicas } \\
\text { de lectura: SBR y CBR en la } \\
\text { precisión de diferentes técnicas de }\end{array}$ & ${ }^{S}$ & SI \\
\hline
\end{tabular}

Caso de estudio 


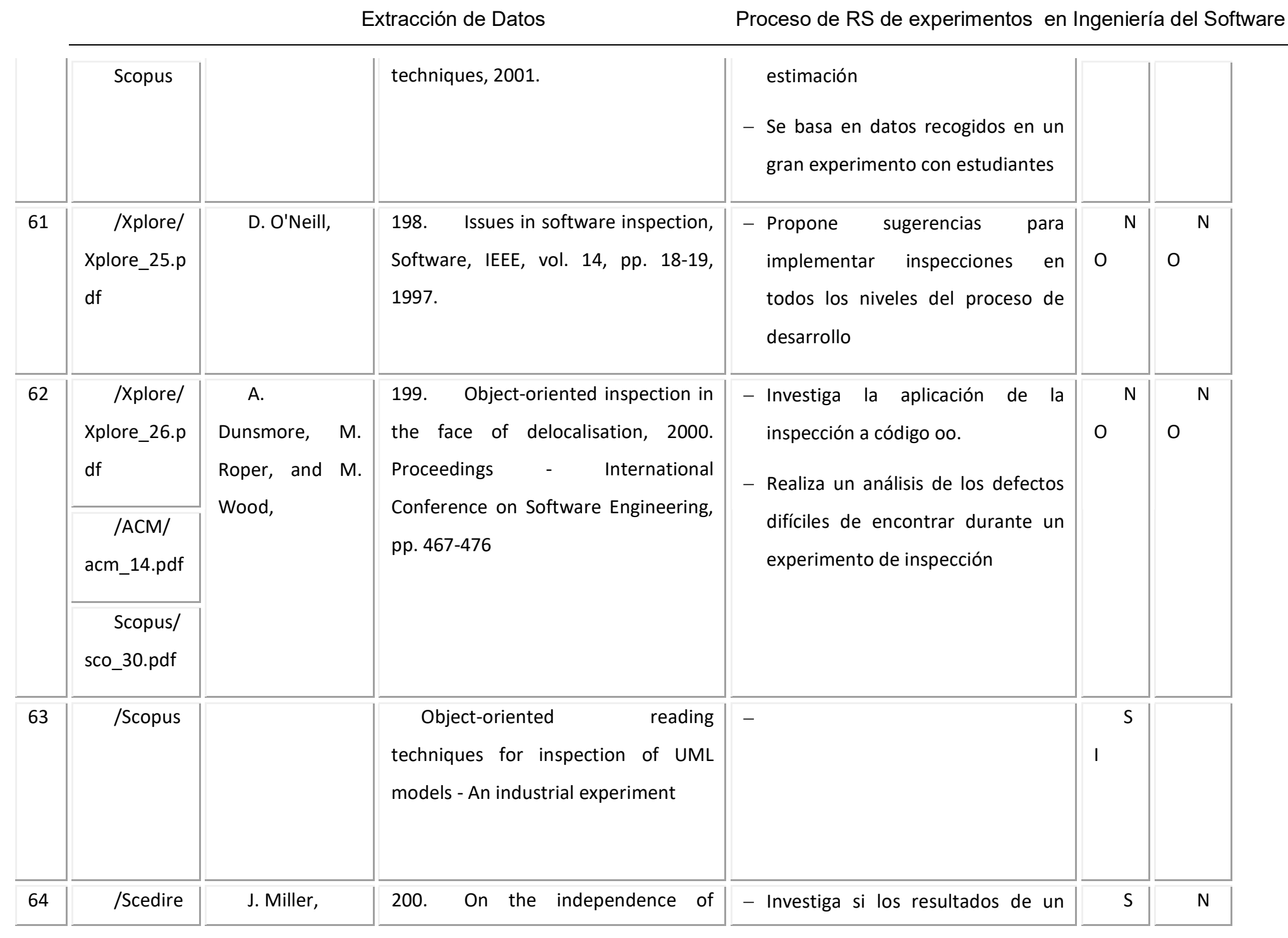


Proceso de RS de experimentos en Ingeniería del Software

\begin{tabular}{|c|c|c|c|c|c|c|}
\hline & $\begin{array}{r}\text { ct/ } \\
\text { sdirect_7.p } \\
\text { df } \\
\text { Scopus/ } \\
\text { sco_23.pdf }\end{array}$ & & $\begin{array}{l}\text { software inspectors, Journal of } \\
\text { Systems and Software, vol. } 60 \text {, pp. 5- } \\
10,2002 \text {. }\end{array}$ & $\begin{array}{l}\text { inspector individual durante la fase } \\
\text { de preparación son dependientes o } \\
\text { independientes } \\
\text { - Usa datos de un experimento } \\
\text { previo y una simulación a partir de } \\
\text { ellos }\end{array}$ & I & 0 \\
\hline 65 & $\begin{array}{c}\text { /ACM/ } \\
\text { acm_15.pdf } \\
\text { /Scopus }\end{array}$ & $\begin{array}{l}\text { Pankaj } \\
\text { Jalote, } \\
\text { Haragopal }\end{array}$ & $\begin{array}{l}201 . \quad \text { Overcoming the NAH } \\
\text { syndrome for inspection deployment, } \\
\text { Proceedings of the 20th international } \\
\text { conference on Software engineering } \\
\text { ICSE '98 }\end{array}$ & $\begin{array}{l}\text { - Ejecutan un experimento para } \\
\text { reducir el síndrome "not applicable } \\
\text { here" en una organización que } \\
\text { realiza una inspección de software } \\
\text { - Adicionalmente, comparar las } \\
\text { inspecciones de código con las } \\
\text { pruebas de unidad } \\
\text { - Miden: capacidad de detección de } \\
\text { defectos, efectos de la inspección } \\
\text { en los costos globales del } \\
\text { desarrollo. }\end{array}$ & 1 & SI \\
\hline 66 & $\begin{array}{c}\text { /ACM/ } \\
\text { acm_17.pdf }\end{array}$ & $\begin{array}{l}\text { Lulu He, } \\
\text { Jeffrey Carver }\end{array}$ & $\begin{array}{l}\text { 202. PBR vs. checklist: a } \\
\text { replication in the } n \text {-fold inspection }\end{array}$ & $\begin{array}{ccr}\text { - Describe } & \text { un experimento para } \\
\text { validar la efectividad de }\end{array}$ & I & SI \\
\hline
\end{tabular}

Caso de estudio 


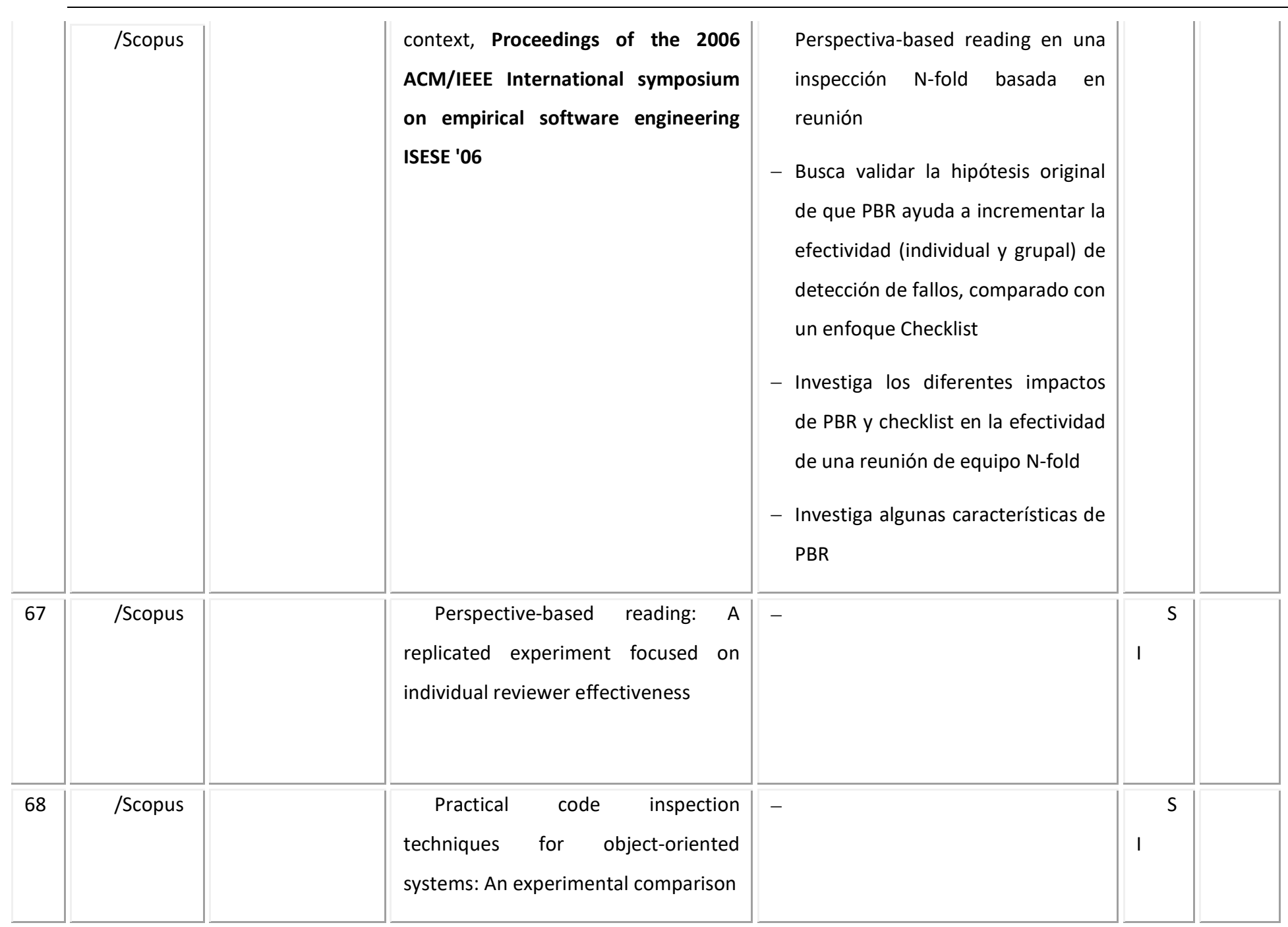


Proceso de RS de experimentos en Ingeniería del Software

\begin{tabular}{|c|c|c|c|c|c|c|}
\hline 69 & /Scopus & & $\begin{array}{l}\text { Process for asynchronous } \\
\text { software inspection }\end{array}$ & - & ${ }_{1}{ }^{S}$ & \\
\hline 70 & $\begin{array}{c}\text { /ACM/ } \\
\text { acm_18.pdf }\end{array}$ & $\begin{array}{l}\text { Diane Kwlly, } \\
\text { Terry Shepard }\end{array}$ & $\begin{array}{l}\text { 203. Qualitative observations } \\
\text { from software code inspection } \\
\text { experiments, Proceedings of the } 2002 \\
\text { conference of the Centre for } \\
\text { Advanced Studies on Collaborative } \\
\text { research CASCON '02 }\end{array}$ & $\begin{array}{l}\text { - Recoge y organiza observaciones } \\
\text { que fueron hechas durante una } \\
\text { serie de experimentos previos } \\
\text { - Presenta comentarios y análisis de } \\
\text { los resultados de tales } \\
\text { experimentos } \\
\text { - Describe brevemente } 3 \text { de los } \\
\text { experimentos }\end{array}$ & 1 & SI \\
\hline 71 & /Scopus & & $\begin{array}{l}\text { Reducing inspection interval in } \\
\text { large-scale software development }\end{array}$ & - & $\mathrm{O}^{\mathrm{N}}$ & \\
\hline 72 & /Scopus & & $\begin{array}{l}\text { Robust estimations of fault } \\
\text { content with capture-recapture and } \\
\text { detection profile estimators }\end{array}$ & - & । & \\
\hline
\end{tabular}

Caso de estudio 


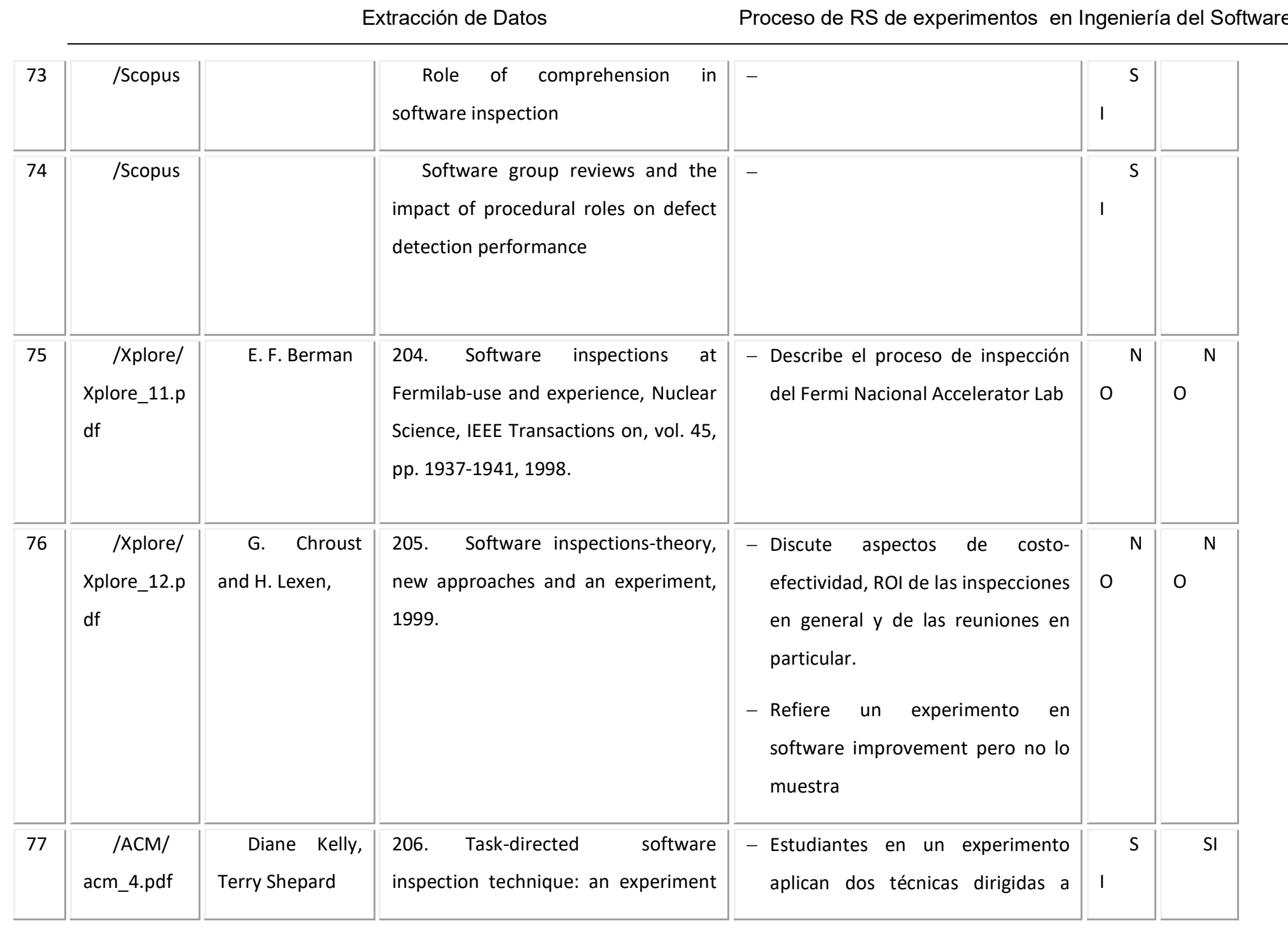


Proceso de RS de experimentos en Ingeniería del Software

\begin{tabular}{|c|c|c|c|c|c|c|}
\hline & & & $\begin{array}{l}\text { and case study, Proceedings of the } \\
2000 \text { conference of the Centre for } \\
\text { Advanced Studies on Collaborative } \\
\text { research CASCON '00 }\end{array}$ & $\begin{array}{l}\text { tareas y una técnica de inspección } \\
\text { no-estructurada estándar en la } \\
\text { industria a un código de ing civil en } \\
\text { uso en aplicaciones militares } \\
\text { - Presetan tanto un caso de estudio } \\
\text { como el experimento } \\
\text { - Analizan los resultados con una } \\
\text { clasificación ortogonal de defectos } \\
\text { para código computacional } \\
\text { desarrollada para la investigación } \\
\text { - Discuten: la contribución de la } \\
\text { técnica dirigida a tareas en la } \\
\text { evaluación y entendimiento del } \\
\text { código por parte de los } \\
\text { inspectores, diferencias entre } \\
\text { inspectores experimentados y no } \\
\text { experimentados. }\end{array}$ & & \\
\hline 78 & $\begin{array}{l}\text { /Xplore/ } \\
\text { Xplore_ }\end{array}$ & T. Thelin, & $\begin{array}{l}\text { 207. Team-based fault content } \\
\text { estimation in the software inspection }\end{array}$ & $\begin{aligned} \text { - Presenta un experimento que } \\
\text { compara métodos objetivos y }\end{aligned}$ & । & SI \\
\hline
\end{tabular}

Caso de estudio 


\begin{tabular}{|c|c|c|c|c|c|c|}
\hline & $\begin{array}{l}\text { Scopus/ } \\
\text { sco_1.pdf }\end{array}$ & & $\begin{array}{l}\text { process, } 2004 . \quad \text { Proceedings - } \\
\text { International Conference on Software } \\
\text { Engineering } 26, \text { pp. } 263-272\end{array}$ & $\begin{array}{l}\text { subjetivos de estimación de } \\
\text { contenido de fallos en diferentes } \\
\text { puntos } \\
\text { - Fue conducido en } 2 \text { universidades } \\
\text { con } 82 \text { revisores }\end{array}$ & & \\
\hline 79 & $\begin{array}{c}\text { /ACM/ } \\
\text { acm_5.pdf }\end{array}$ & $\begin{array}{l}\text { Christian } \\
\text { Denger, Ronny } \\
\text { Kolb }\end{array}$ & $\begin{array}{l}208 . \text { Testing and inspecting } \\
\text { reusable product line components: } \\
\text { first empirical results, Proceedings of } \\
\text { the } 2006 \text { ACM/IEEE international } \\
\text { symposium on International } \\
\text { symposium on empirical software } \\
\text { engineering ISESE ' } 06\end{array}$ & $\begin{array}{l}\text { - Compara dos técnicas de detección } \\
\text { de defectos: inspecciones de } \\
\text { código y pruebas funcionales en el } \\
\text { contexto de desarrollo de líneas de } \\
\text { productos } \\
\text { - Investiga el potencial de detección } \\
\text { de defectos de las técnicas en } \\
\text { componentes reutilizables de } \\
\text { software } \\
\text { - Discuten: efectividad y esfuerzo } \\
\text { para detectar un defecto }\end{array}$ & I & SI \\
\hline 80 & $\begin{array}{l}\text { /Xplore/ } \\
\text { xplore_14.p } \\
\text { df }\end{array}$ & $\begin{array}{l}\text { C. Atiq and L. } \\
\text { P. W. Land, }\end{array}$ & $\begin{array}{l}\text { 209. The impact of training-by- } \\
\text { examples on inspection performance } \\
\text { using two laboratory experiments, } \\
\text { 2004. Proceedings of the Australian }\end{array}$ & $\begin{array}{l}\text { - Dos experimentos de lab son } \\
\text { conducidos para probar el efecto } \\
\text { del entrenamiento usando } \\
\text { ejemplos de defectos }\end{array}$ & I & SI \\
\hline
\end{tabular}


Proceso de RS de experimentos en Ingeniería del Software

\begin{tabular}{|c|c|c|c|c|c|c|}
\hline & $\begin{array}{l}\text { (Springe } \\
\text { r_7.pdf) }\end{array}$ & & $\begin{array}{l}\text { Software Engineering Conference, } \\
\text { ASWEC 2004, pp. 279-288 }\end{array}$ & & & \\
\hline & $\begin{array}{l}\text { Scopus/ } \\
\text { no_docume } \\
\text { nt }\end{array}$ & & & & & \\
\hline 81 & $\begin{array}{l}\text { /Scedire } \\
\text { ct/ } \\
\text { sdirect_10.p } \\
\text { df }\end{array}$ & $\begin{array}{l}\text { A. } \\
\text { Dunsmore, M. } \\
\text { Roper, and M. } \\
\text { Wood, }\end{array}$ & $\begin{array}{l}210 . \quad \text { The role of comprehension in } \\
\text { software inspection, Journal of } \\
\text { Systems and Software, vol. 52, pp. } \\
121-129,2000 \text {. }\end{array}$ & $\begin{array}{l}\text { - Presenta los resultados de dos } \\
\text { experimentos que relacionan la } \\
\text { comprensión del programa y la } \\
\text { inspección }\end{array}$ & । & SI \\
\hline 82 & /Scopus & & $\begin{array}{l}\text { The use of procedural roles in } \\
\text { code inspections: An experimental } \\
\text { study }\end{array}$ & - & । & \\
\hline 83 & /Scopus & & $\begin{array}{l}\text { Understanding the effects of } \\
\text { developer activities on inspection } \\
\text { interval }\end{array}$ & - & $\mathrm{O}^{\mathrm{N}}$ & \\
\hline 84 & $\begin{array}{c}\text { /ACM/ } \\
\text { acm_6.pdf }\end{array}$ & $\begin{array}{l}\text { Adam Porter, } \\
\text { Harvey Siy, }\end{array}$ & $\begin{array}{l}\text { 211. Understanding the sources of } \\
\text { variation in software inspections, }\end{array}$ & $\begin{array}{cl}\text { - Describe el experimento } \\
\text { previamente }\end{array}$ & I & $0^{N}$ \\
\hline
\end{tabular}

Caso de estudio 
Extracción de Datos

Proceso de RS de experimentos en Ingeniería del Software

\begin{tabular}{|c|c|c|c|c|c|c|}
\hline 85 & $\begin{array}{r}\text { Scopus/ } \\
\text { sco_29.pdf }\end{array}$ & $\begin{array}{l}\text { Audris Mockus, } \\
\text { Lawrence Votta }\end{array}$ & $\begin{array}{l}\text { January 1998, ACM Transactions on } \\
\text { Software Engineering and } \\
\text { Methodology (TOSEM), Volume } 7 \\
\text { Issue } 1\end{array}$ & $\begin{array}{l}\text { porter.pdf (00601071.pdf) y } \\
\text { estudian las variaciones en la } \\
\text { efectividad y el intervalo }\end{array}$ & & \\
\hline 86 & $\begin{array}{l}\text { /Scedire } \\
\text { ct/ } \\
\text { sdirect_8.p } \\
\text { df } \\
\text { /Scopus }\end{array}$ & $\begin{array}{l}\text { T. Thelin, } \mathrm{P} \text {. } \\
\text { Runeson, and } \mathrm{B} \text {. } \\
\text { Regnell, }\end{array}$ & $\begin{array}{l}\text { 212. Usage-based reading--an } \\
\text { experiment to guide reviewers with } \\
\text { use cases, Information and Software } \\
\text { Technology, vol. 43, pp. 925-938, } \\
2001 \text {. }\end{array}$ & $\begin{array}{l}\text { - Presenta un experimento } \\
\text { conducido con } 27 \text { estudiantes de IS } \\
\text { - Un grupo utilizó casos de uso } \\
\text { priorizados y el grupo control casos } \\
\text { de uso aleatoriamente ordenados } \\
\text { - Miden: efectividad y eficiencia en } \\
\text { detectar fallas }\end{array}$ & 1 & $\mathrm{SI}$ \\
\hline 87 & $\begin{array}{l}\text { /Springe } \\
\text { r/ } \\
\text { Springer_3. } \\
\text { pdf } \\
\text { Scopus/ } \\
\text { sco_15.pdf }\end{array}$ & $\begin{array}{l}\text { B. Stefan and } \\
\text { J. G. Walter, }\end{array}$ & $\begin{array}{l}\text { 213. Using a Reliability Growth } \\
\text { Model to Control Software Inspection, } \\
\text { Empirical Software Engineering, vol. } \\
\text { V7, pp. 257-284, } 2002 \text {. }\end{array}$ & $\begin{array}{l}\text { - Propone un modelo de crecimiento } \\
\text { de la confiabilidad y dos modelos } \\
\text { heurísticos lineales para estimar el } \\
\text { núm probable de defectos a ser } \\
\text { encontrados en la reinspección } \\
\text { - Los modelos son evaluados con } \\
\text { datos de un experimento } \\
\text { controlado en reinspección } \\
\text { - Describe el experimento }\end{array}$ & I & SI \\
\hline
\end{tabular}


Proceso de RS de experimentos en Ingeniería del Software

\begin{tabular}{|c|c|c|c|c|c|c|}
\hline & & & & controlado & & \\
\hline 88 & $\begin{array}{l}\text { /Xplore/ } \\
\text { Xplore_27.p } \\
\text { df }\end{array}$ & $\begin{array}{l}\text { M. Halling, S. } \\
\text { Biffl, } \\
\text { Grechenig, and } \\
\text { M. Kohle, }\end{array}$ & $\begin{array}{l}\text { 214. Using reading techniques to } \\
\text { focus inspection performance, } 2001 .\end{array}$ & $\begin{array}{l}\text { - Reporta la replicación de un } \\
\text { experimento a gran escala en un } \\
\text { ambiente académico (Biffl, 2003) } \\
\text { (sdirect_4.pdf) } \\
\text { - Evalúa la efectividad de la } \\
\text { detección de defectos para } \\
\text { inspectores que utilizan Checklist o } \\
\text { escenarios enfocados a nivel } \\
\text { individual y de equipo }\end{array}$ & 1 & SI \\
\hline 89 & $\begin{array}{l}\text { /Springe } \\
\text { r/ } \\
\text { Springer_9. } \\
\text { pdf } \\
\text { /Scopus }\end{array}$ & $\begin{array}{l}\text { H. Lasse, T. } \\
\text { Ilkka, and V. } \\
\text { Pekka, }\end{array}$ & $\begin{array}{l}215 . \quad \text { Using Software Inspection as } \\
\text { a Catalyst for SPI in a Small Company, } \\
2004 .\end{array}$ & $\begin{array}{l}\text { - Presenta un experimento en una } \\
\text { pequeña compañía de software } \\
\text { que evalúa el efecto de la } \\
\text { inspección de software en la } \\
\text { mejora de procesos }\end{array}$ & I & SI \\
\hline 90 & $\begin{array}{l}\text { /Xplore/ } \\
\text { Xplore_28.p } \\
\text { df }\end{array}$ & $\begin{array}{l}\text { A. Porter and } \\
\text { L. Votta, }\end{array}$ & $\begin{array}{l}\text { 216. What makes inspections } \\
\text { work?, Software, IEEE, vol. 14, pp. 99- } \\
\text { 102, } 1997 .\end{array}$ & $\begin{array}{l}\text { - Resumen los resultados de haber } \\
\text { conducido una familia de } \\
\text { experimentos para entender cómo } \\
\text { varios factores afectan los costos y }\end{array}$ & 1 & SI \\
\hline
\end{tabular}

Caso de estudio 


\subsubsection{Resolver discrepancias}

Las discrepancias encontradas entre los revisores durante el análisis anterior fueron resueltas a través de la adquisición de información adicional por lectura completa del artículo, y la posterior rectificación.

\subsubsection{Resumir resultados}

A continuación se presenta el formulario B03_Resumen de artículos relevantes reportando el resultado obtenido del análisis realizado en la actividad anterior. Estos artículos constituyen el Conjunto base para esta Revisión.

Caso de estudio 
B03_Resumen de artículos relevantes

Realizado por: Anna Grimán

Fecha:

\begin{tabular}{|c|c|c|c|c|c|}
\hline D & Autores & 217. Referencia & Fichero & Resumen & $\begin{array}{l}\text { Observació } \\
\text { n }\end{array}$ \\
\hline 1 & $\begin{array}{l}\text { T. Berling } \\
\text { and T. Thelin, }\end{array}$ & $\begin{array}{l}218 . \quad \text { A case study of } \\
\text { reading techniques in a } \\
\text { software company, } 2004 . \\
\text { Proceedings - } 2004 \\
\text { International Symposium } \\
\text { on Empirical Software } \\
\text { Engineering, ISESE 2004, } \\
\text { pp. 229-238 }\end{array}$ & $\begin{array}{l}\text { /Xplore/ } \\
\text { Xplore_1. } \\
\text { pdf }\end{array}$ & $\begin{array}{l}\text { - Aplica un estudio empírico en una organización } \\
\text { de desarrollo } \\
\text { - Un documento de requisitos es usado para } \\
\text { comparar dos técnicas de lectura (basada en } \\
\text { checklist y basada en perspectiva) } \\
\text { - Discuten efectividad y eficiencia de una técnica } \\
\text { frente a la otra }\end{array}$ & $\begin{array}{l}\text { ART_01 } \\
\text { Es dudoso } \\
\text { si se trata de } \\
\text { un } \\
\text { experimento o } \\
\text { un caso de } \\
\text { estudio }\end{array}$ \\
\hline
\end{tabular}


Proceso de RS de experimentos en Ingeniería del Software

\begin{tabular}{|c|c|c|c|c|c|}
\hline 2 & $\begin{array}{c}\text { F. } \\
\text { MacDonald } \\
\text { and J. Miller, }\end{array}$ & $\begin{array}{l}\text { 219. A Comparison of } \\
\text { Tool-Based and Paper- } \\
\text { Based Software Inspection, } \\
\text { Empirical Software } \\
\text { Engineering, vol. V3, pp. } \\
\text { 233-253, 1998. }\end{array}$ & $\begin{array}{l}\text { /Springer/ } \\
\text { Springer_ } \\
\text { 5.pdf } \\
\text { /scopus/s } \\
\text { co_3.pdf } \\
\text { /scopus/s } \\
\text { co_18.pdf }\end{array}$ & $\begin{array}{l}\text { - Describe un experimento controlado } \\
\text { comparando la efectividad la inspección de } \\
\text { software basada en herramientas y la basada en } \\
\text { papel } \\
\text { - Utilizan un prototipo de herramienta para } \\
\text { inspecciones de software } \\
\text { - } 43 \text { estudiantes usan el prototipo y la inspección } \\
\text { basada en papel para inspeccionar } 2 \text { programas } \\
\text { de C++ (150 LDC) } \\
\text { - Los sujetos realizaron tanto inspección individual } \\
\text { como reunión de grupo } \\
\text { - Miden: núm de defectos encontrados, núm de } \\
\text { falsos positivos reportados y ganancias y pérdidas } \\
\text { de la reunión }\end{array}$ & ART_02 \\
\hline 3 & $\begin{array}{l}\text { M. } \\
\text { Kalinowski } \\
\text { and G. H. } \\
\text { Travassos, }\end{array}$ & $\begin{array}{l}\text { 220. A computational } \\
\text { framework for supporting } \\
\text { software inspections, } \\
\text { 2004. Proceedings }-19^{\text {th }} \\
\text { International Conference } \\
\text { on Automated Software }\end{array}$ & $\begin{array}{l}\text { /Xplore/ } \\
\text { Xplore_2. } \\
\text { pdf }\end{array}$ & $\begin{array}{l}\text { - Describe un framework computacional cuyos } \\
\text { requisitos se basan en estudios empíricos sobre } \\
\text { inspección de software } \\
\text { - Evalúa la factibilidad del framework a través de: } \\
\text { ○ Un caso de estudio }\end{array}$ & $\begin{array}{l}\text { ART_03 } \\
\text { Es dudoso } \\
\text { si se trata de } \\
\text { un } \\
\text { experimento o }\end{array}$ \\
\hline
\end{tabular}

Caso de estudio 


\begin{tabular}{|c|c|c|c|c|c|}
\hline & & $\begin{array}{l}\text { Engineering, ASE 2004, pp. } \\
46-55\end{array}$ & & $\begin{array}{l}\begin{array}{c}0 \text { Un estudio experimental que } \\
\text { evaluó la actividad de planificación }\end{array} \\
\text { de la inspección de software } \\
\text { - El estudio experimental arrojó resultados sobre la } \\
\text { experiencia de los sujetos y su relación con la } \\
\text { planificación y la efectividad en la detección de } \\
\text { defectos, al utilizar el framework comput.SI }\end{array}$ & $\begin{array}{l}\text { un caso de } \\
\text { estudio }\end{array}$ \\
\hline 4 & $\begin{array}{l}\text { A. Bianchi, } \\
\text { F. Lanubile, } \\
\text { and G. } \\
\text { Visaggio, }\end{array}$ & $\begin{array}{l}221 . \quad \text { A controlled } \\
\text { experiment to assess the } \\
\text { effectiveness of inspection } \\
\text { meetings, } 2001 . \\
\text { International Software } \\
\text { Metrics Symposium, } \\
\text { Proceedings, pp. } 42-50\end{array}$ & $\begin{array}{l}\text { /Xplore/ } \\
\text { Xplore_3. } \\
\text { pdf } \\
\text { /scopus/S } \\
\text { co_34.pdf }\end{array}$ & $\begin{array}{l}\text { - Presenta un experimento controlado } \\
\text { - Participant + de } 100 \text { estudiantes de carrera } \\
\text { quienes inspeccionan documentos de } \\
\text { requerimientos de software } \\
\text { - Compara el desempeño de grupos nominales y } \\
\text { reales } \\
\text { - Investiga también las razones de las pérdidas en } \\
\text { las reuniones y confronta ganancias vs pérdidas } \\
\text { - Relaciona las pérdidas con el núm de defectos } \\
\text { encontrados por un único individuo en el equipo }\end{array}$ & ART_04 \\
\hline
\end{tabular}


Proceso de RS de experimentos en Ingeniería del Software

\begin{tabular}{|c|c|c|c|c|c|}
\hline 5 & $\begin{array}{l}\text { B. Stefan, } \\
\text { G. Paul, and } \\
\text { H. Michael, }\end{array}$ & $\begin{array}{l}\text { 222. A family of } \\
\text { experiments to investigate } \\
\text { the effects of groupware } \\
\text { for software inspection, } \\
\text { Automated Software } \\
\text { Engineering, vol. V13, pp. } \\
\text { 373-394, 2006. }\end{array}$ & $\begin{array}{l}\text { /Springer/ } \\
\text { Springer_ } \\
\text { 8.pdf } \\
\text { /Scopus/s } \\
\text { co_17.pdf }\end{array}$ & $\begin{array}{l}\text { - Conduce una familia de experimentos en un } \\
\text { ambiente académico para investigar el efecto del } \\
\text { soporte de herramientas a la detección de } \\
\text { defectos y a las reuniones de inspección } \\
\text { - Discute: la efectividad de los inspectores y } \\
\text { equipos con y sin herramientas, el esfuerzo de } \\
\text { inspección y el solapamiento de defectos, } \\
\text { eficiencia de los equipos de inspección, el núm de } \\
\text { falsos positivos identificados y no identificados, } \\
\text { núm de defectos verdaderos perdidos durante la } \\
\text { reunión }\end{array}$ & ART_05 \\
\hline 6 & & $\begin{array}{l}\text { A pattern approach to } \\
\text { software inspection } \\
\text { process improvement }\end{array}$ & $D^{/ \text {Scopus } / N}$ & - & ART_06 \\
\hline 7 & $\begin{array}{l}\text { P. Murphy } \\
\text { and J. Miller, }\end{array}$ & $\begin{array}{l}\text { 223. A process for } \\
\text { asynchronous software } \\
\text { inspection, Proceedings, } \\
\text { Eighth IEEE International } \\
\text { Workshop on Software } \\
\text { Technology r and }\end{array}$ & $\begin{array}{l}\text { /xplore/ } \\
\text { Xplore_4. } \\
\text { pdf }\end{array}$ & $\begin{array}{l}\text { - Propone un modelo de inspección soportado por } \\
\text { una herramienta de comunicación asíncrona } \\
\text { basado en correo-e } \\
\text { - Compara el nuevo modelo con el modelo } \\
\text { tradicional basado en reunión sobre la base de un }\end{array}$ & $\begin{array}{l}\text { ART_07 } \\
\text { Se trata de } \\
\text { un caso de } \\
\text { estudio }\end{array}$ \\
\hline
\end{tabular}

Caso de estudio 


\begin{tabular}{|c|c|c|c|c|c|}
\hline & & $\begin{array}{l}\text { Engineering Practice, } 1997 . \\
\text { [incorporating } \text { Computer } \\
\text { Aided } \\
\text { Engineering]. } 14-18 \text { July } \\
1997 \text { Page(s):96- } 104\end{array}$ & & $\begin{array}{l}\text { conjunto de criterios } \\
\text { - Intentan utilizar un experimento a pequeña } \\
\text { escala pero el número de sujetos es pequeño y } \\
\text { no permite presentar un análisis } \\
\text { Describe y analiza brevemente la familia de } \\
\text { experimentos de Porter y sus replicaciones. } \\
\text { (Xplore_16.pdf) }\end{array}$ & \\
\hline 8 & $\begin{array}{l}\text { T. Thelin, } \\
\text { C. Andersson, } \\
\text { P. Runeson, } \\
\text { and N. } \\
\text { Dzamashvili- } \\
\text { Fogelstrom, }\end{array}$ & $\begin{array}{l}224 \text { A replicated } \\
\text { experiment of usage-based } \\
\text { and checklist-based } \\
\text { reading, 2004. Proceedings } \\
-\quad \text { errydianal Software } \\
\text { Metrics Symposium, pp. } \\
246-256\end{array}$ & $\begin{array}{l}\text { /Xplore/ } \\
\text { Xplore_5. } \\
\text { pdf }\end{array}$ & $\begin{array}{l}\text { - Presenta la replicación de un experimento que } \\
\text { comparó técnicas de lectura basada en uso vs } \\
\text { basada en checklist } \\
\text { - Presenta tanto la replicación como el } \\
\text { experimento original y compara ambos } \\
\text { resultados (Xplore_30.pdf) } \\
\text { - La replicación confirmó los resultados del exp } \\
\text { original }\end{array}$ & ART_08 \\
\hline
\end{tabular}


Proceso de RS de experimentos en Ingeniería del Software

\begin{tabular}{|c|c|c|c|c|c|}
\hline 9 & $\begin{array}{l}\text { Monvorat } \\
\text { h } \\
\text { Phongpaibul, } \\
\text { Barry Boehm }\end{array}$ & $\begin{array}{l}225 . \text { An empirical } \\
\text { comparison between pair } \\
\text { development and software } \\
\text { inspection in Thailand, } \\
\text { Proceedings of the } 2006 \\
\text { ACM/IEEE international } \\
\text { symposium on International } \\
\text { symposium on empirical } \\
\text { software engineering ISESE } \\
\text { '06 }\end{array}$ & $\begin{array}{l}\text { /ACM/AC } \\
\text { M_1.pdf }\end{array}$ & $\begin{array}{l}\text { - Compara las similitudes y diferencias entre el } \\
\text { desarrollo por pares y la inspección de software } \\
\text { como técnicas de verificación en Thailand. } \\
\text { - Aplican un experimento de clase y uno de } \\
\text { industria } \\
\text { - Se investigó el esfuerzo de desarrollo, el efecto } \\
\text { en la calidad y el tiempo calendario }\end{array}$ & ART_09 \\
\hline 10 & $\begin{array}{l}\text { C. Atiq } \\
\text { and L. Lesley } \\
\text { Pek Wee, }\end{array}$ & $\begin{array}{l}\text { 226. An Empirical } \\
\text { Investigation on the } \\
\text { Impact of Training-by- } \\
\text { Examples on Inspection } \\
\text { Performanc. PROFES 2004, } \\
\text { LNCS 3009, pp. 203-219, } \\
2004 \text {. }\end{array}$ & $\begin{array}{l}\text { /Springer/ } \\
\text { Springer_ } \\
\text { 7.pdf } \\
\text { /Scopus/N } \\
\text { D }\end{array}$ & $\begin{array}{l}\text { - Conducen un experimento para probar el efecto } \\
\text { del entrenamiento basado en ejemplos en la } \\
\text { inspección de requisitos } \\
\text { - Compara el desempeño de un grupo entrenado } \\
\text { vs uno que no ha recibido entrenamiento }\end{array}$ & ART_10 \\
\hline 11 & $\begin{array}{cc}\text { C. } & \text { D. } \\
\text { Rombach, } & \text { O. } \\
\text { Kude, } & \text { A. }\end{array}$ & $\begin{array}{l}\text { 227. An empirical study } \\
\text { of an ER-model inspection }\end{array}$ & $\begin{array}{l}\text { /Xplore/ } \\
\text { Xplore_7. }\end{array}$ & $\begin{array}{l}\text { - Documenta un experimento a gran escala } \\
\text { conducido durante una reunión de inspección de } \\
\text { Modelo ER }\end{array}$ & ART_11 \\
\hline
\end{tabular}

Caso de estudio 


\begin{tabular}{|c|c|c|c|c|c|}
\hline & $\begin{array}{l}\text { Aurum, R. } \\
\text { Jeffery, and } \\
\text { C. Wohlin, }\end{array}$ & meeting, 2003. & pdf & $\begin{array}{l}\text { - Investiga cuál técnica de lectura tiene una tasa } \\
\text { más eficiente de detección de defectos cuando se } \\
\text { buscan defectos en un modelo ER } \\
\text { - También explora el efecto del uso de Roles en } \\
\text { una reunión de equipo } \\
\text { - Por último, investiga la habilidad de los revisores } \\
\text { para encontrar ciertas categorías de defectos } \\
\text { - }\end{array}$ & \\
\hline 12 & $\begin{array}{l}\text { M. A. } \\
\text { Babar, B. } \\
\text { Kitchenham, } \\
\text { L. Zhu, I. } \\
\text { Gorton, and } \\
\text { R. Jeffery, }\end{array}$ & $\begin{array}{l}\text { 228. An empirical study } \\
\text { of groupware support for } \\
\text { distributed software } \\
\text { architecture evaluation } \\
\text { process, Journal of } \\
\text { Systems and Software, vol. } \\
79, \text { pp. } 912-925,2006 .\end{array}$ & $\begin{array}{l}\text { /scedirect } \\
\text { / } \\
\text { sdirect_1.pdf } \\
\text { /Xplore/X } \\
\text { plore_8.pdf } \\
\text { /scopus/s } \\
\text { co_5.pdf }\end{array}$ & $\begin{array}{l}\text { - Presenta un estudio piloto (experimento) usado } \\
\text { para evaluar la viabilidad de un experimento + } \\
\text { grande que investigue la factibilidad del soporte } \\
\text { groupware para la evaluación distribuida de } \\
\text { arquitecturas de software } \\
\text { - El estudio piloto arrojó algunos hallazgos acerca } \\
\text { de la viabilidad de un proceso de EA soportado } \\
\text { por groupware. }\end{array}$ & ART_12 \\
\hline 13 & $\begin{array}{l}\text { P. } \\
\text { Grunbacher, }\end{array}$ & $\begin{array}{l}\text { 229. An empirical study } \\
\text { on groupware support for }\end{array}$ & $\begin{array}{l}\text { /Xplore/ } \\
\text { Xplore_9. }\end{array}$ & $\begin{array}{l}\text { - Presentan un experimento en un ambiente } \\
\text { académico con } 37 \text { sujetos para investigar el }\end{array}$ & ART_13 \\
\hline
\end{tabular}


Proceso de RS de experimentos en Ingeniería del Software

\begin{tabular}{|c|c|c|c|c|c|}
\hline & $\begin{array}{l}\text { M. Halling, } \\
\text { and S. Biffl, }\end{array}$ & $\begin{array}{l}\text { software inspection } \\
\text { meetings, Proceedings of } \\
\text { the } 18^{\text {th }} \text { IEEE International } \\
\text { Conference on Automated } \\
\text { Software Engineering } \\
\text { (ASE'03). }\end{array}$ & pdf & $\begin{array}{l}\text { efecto del soporte de una herramienta } \\
\text { groupware a las reuniones de inspección } \\
\text { - Concluyen sobre: el esfuerzo utilizado en la } \\
\text { reunión, identificación de falsos positivos, } \\
\text { reducción del núm de defectos reales perdidos }\end{array}$ & \\
\hline 14 & $\begin{array}{l}\text { Porter, L. } \\
\text { G. Votta }\end{array}$ & $\begin{array}{l}230 . \text { An experiment to } \\
\text { assess different defect } \\
\text { detection methods for } \\
\text { software requirements } \\
\text { inspections, Proceedings of } \\
\text { the } 16^{\text {th }} \text { international } \\
\text { conference on Software } \\
\text { engineering ICSE '94 }\end{array}$ & $\begin{array}{l}\text { /ACM/ } \\
\text { Acm_2.pd }\end{array}$ & $\begin{array}{l}\text { - Usa experimento controlado } \\
\text { - Dirigido a probar la efectividad de los Métodos de } \\
\text { detección basados en escenarios Vs. Métodos ad } \\
\text { hoc o checklist } \\
\text { - Cada revisor utiliza un procedimiento específico } \\
\text { para descubrir un tipo particular de defecto } \\
\text { - Describe el diseño, ejecución y análisis del } \\
\text { experimento }\end{array}$ & ART_14 \\
\hline
\end{tabular}

Caso de estudio 


\begin{tabular}{|c|c|c|c|c|c|}
\hline 15 & $\begin{array}{l}\text { A. Porter, } \\
\text { H. P. Siy, C. A. } \\
\text { Toman, and } \\
\text { L. G. Votta, }\end{array}$ & $\begin{array}{l}231 . \text { An experiment to } \\
\text { assess the cost-benefits of } \\
\text { code inspections in large } \\
\text { scale software } \\
\text { development, IEEE } \\
\text { Transactions on Software } \\
\text { Engineering, vol. 23, pp. } \\
\text { 329-346, 1997. }\end{array}$ & $\begin{array}{l}\text { /Xplore/ } \\
\text { Xplore_10.pd } \\
\text { f } \\
\text { /ACM/ } \\
\text { acm_3.pdf } \\
\text { /scopus/s } \\
\text { co_4.pdf }\end{array}$ & $\begin{array}{l}\text { - Conduce un proyecto a largo plazo } \\
\text { - Evalúa la costo-efectividad de diversos métodos } \\
\text { de inspección de software } \\
\text { - Los métodos son aplicados por desarrolladores } \\
\text { profesionales } \\
\text { - Se utilizó simulación para optimizar el } \\
\text { experimento } \\
\text { - A cada inspección se le asignó aleatoriamente } 3 \\
\text { variables independientes: número de revisores } \\
\text { en el equipo, núm de equipos de inspección, el } \\
\text { requisito de reparar los defectos entre la } 1 \text { a y } 2^{a} \\
\text { inspección } \\
\text { - Los revisores fueron seleccionados } \\
\text { aleatoriamente } \\
\text { inspección, esfuerzo total, la tasa de detección de } \\
\text { defectos }\end{array}$ & $\begin{array}{l}\text { Se trata de } \\
\text { un caso de } \\
\text { estudio }\end{array}$ \\
\hline 16 & $\begin{array}{l}\text { Diane } \\
\text { Perry, Perry } \\
\text { Shepard }\end{array}$ & $\begin{array}{l}\text { 232. An experiment to } \\
\text { investigate interacting } \\
\text { versus nominal groups in }\end{array}$ & $\begin{array}{l}\text { /ACM/AC } \\
\text { M_19.pdf }\end{array}$ & $\begin{array}{l}\text { - Compara el desempeño de un grupo vs el } \\
\text { desempeño de un individuo en el uso de técnicas }\end{array}$ & ART_16 \\
\hline
\end{tabular}


Proceso de RS de experimentos en Ingeniería del Software

\begin{tabular}{|c|c|c|c|c|c|}
\hline & & $\begin{array}{l}\text { software inspection, } \\
\text { Proceedings of the } 2003 \\
\text { conference of the Centre for } \\
\text { Advanced Studies on } \\
\text { Collaborative research } \\
\text { CASCON '03 }\end{array}$ & & estructuradas & \\
\hline 17 & $\begin{array}{l}\text { G. } \\
\text { Sabaliauskait } \\
\text { e, F. } \\
\text { Matsukawa, } \\
\text { S. Kusumoto, } \\
\text { and K. Inoue, }\end{array}$ & $\begin{array}{l}233 . \text { An experimental } \\
\text { comparison of checklist- } \\
\text { based reading and } \\
\text { perspective-based reading } \\
\text { for UML design document } \\
\text { inspection, International } \\
\text { Symposium on Empirical } \\
\text { Software Engineering } \\
\text { (ISESE'02) }\end{array}$ & $\begin{array}{l}\text { /Xplore/ } \\
\text { Xplore_29.pd } \\
f\end{array}$ & $\begin{array}{l}\text { - Describe un experimento controlado en el que } \\
\text { participaron } 59 \text { estudiantes } \\
\text { - Compara } 2 \text { técnicas de lectura: basada en } \\
\text { checklist y basada en perspectiva, en la } \\
\text { inspección de diseño } 00 \\
\text { - Comparan: efectividad, tiempo, costo } x \text { defecto }\end{array}$ & ART_17 \\
\hline 18 & $\begin{array}{l}\text { O. } \\
\text { Laitenberger, } \\
\text { C. Atkinson, } \\
\text { M. Schlich, } \\
\text { and K. EI }\end{array}$ & $\begin{array}{l}\text { 234. An experimental } \\
\text { comparison of reading } \\
\text { techniques for defect } \\
\text { detection in UML design } \\
\text { documents, Journal of }\end{array}$ & $\begin{array}{l}\text { /scedirect } \\
/ \\
\text { sdirect_9. }\end{array}$ & $\begin{array}{l}\text { - Compara una técnica basada en escenario (PBR) } \\
\text { para detección de defectos en documentos de } \\
\text { diseño OO que utilizan UML, con la técnica } \\
\text { basada en checklist (CBR) más tradicional. } \\
\text { - Aplican un experimento controlado con } 18\end{array}$ & ART_18 \\
\hline
\end{tabular}

Caso de estudio 


\begin{tabular}{|c|c|c|c|c|c|}
\hline & Emam, & $\begin{array}{l}\text { Systems and Software, vol. } \\
53, \text { pp. } 183-204,2000 .\end{array}$ & & $\begin{array}{l}\text { practicantes como sujetos } \\
\text { - Miden: \% de defectos descubiertos, tasa } \\
\text { promedio de tiempo } x \text { defecto, eficacia de los } \\
\text { escenarios PBR en la detección de defectos en } \\
\text { documentos de diseño UML }\end{array}$ & \\
\hline 19 & $\begin{array}{l}\text { Thelin, T., } \\
\text { Runeson, P. } \\
\text { and Wohlin, } \\
\text { C. }\end{array}$ & $\begin{array}{l}235 . \text { An Experimental } \\
\text { Comparison of Usage- } \\
\text { Based and Checklist-Based } \\
\text { Reading, IEEE Transactions } \\
\text { on Software Engineering, } \\
\text { 29(8):687-704, 2003. }\end{array}$ & $\begin{array}{r}\text { /Xplore/X } \\
\text { plore_30.pdf }\end{array}$ & $\begin{array}{l}\text { - Presenta un experimento en el cual se compara } \\
\text { UBR con CBR } \\
\text { - Miden: efectividad y eficiencia en detectar fallos } \\
\text { críticos desde el punto de vista del usuario. }\end{array}$ & $\begin{array}{l}\text { ART_19 } \\
\quad \text { Es dudoso } \\
\text { si se trata de } \\
\text { un } \\
\text { experimento o } \\
\text { un caso de } \\
\text { estudio }\end{array}$ \\
\hline 20 & $\begin{array}{l}\text { R. Per and } \\
\text { W. Claes, }\end{array}$ & $\begin{array}{l}\text { 236. An Experimental } \\
\text { Evaluation of an } \\
\text { Experience-Based Capture- } \\
\text { Recapture Method in } \\
\text { Software Code Inspections, } \\
\text { Empirical Software } \\
\text { Engineering, vol. V3, pp. } \\
\text { 381-406, 1998. }\end{array}$ & $\begin{array}{l}\text { /Springer/ } \\
\text { Springer_ } \\
\text { 4.pdf }\end{array}$ & $\begin{array}{l}\text { 1. Propone un método de captura- } \\
\text { recaptura basado en la experiencia } \\
\text { 2. Un experimento de inspección de } \\
\text { código-C es conducido para evaluar las } \\
\text { mejoras del método y su aplicabilidad } \\
\text { a inspecciones de código } \\
\text { 3. Concluye acerca de: estimaciones del } \\
\text { método vs estimaciones del método de }\end{array}$ & $\begin{array}{l}\text { ART_20 } \\
\text { Es dudoso } \\
\text { si se trata de } \\
\text { un } \\
\text { experimento o } \\
\text { un caso de } \\
\text { estudio }\end{array}$ \\
\hline
\end{tabular}


Proceso de RS de experimentos en Ingeniería del Software

\begin{tabular}{|c|c|c|c|c|c|}
\hline & & & & $\begin{array}{l}\text { máxima probabilidad, sensibilidad de } \\
\text { las inspecciones ante cambios en los } \\
\text { datos de inspección }\end{array}$ & \\
\hline 21 & \begin{tabular}{l}
\multicolumn{1}{c}{ G. } \\
Michael \\
Schneider, \\
Johnny \\
Martin, W. T. \\
Tsai
\end{tabular} & 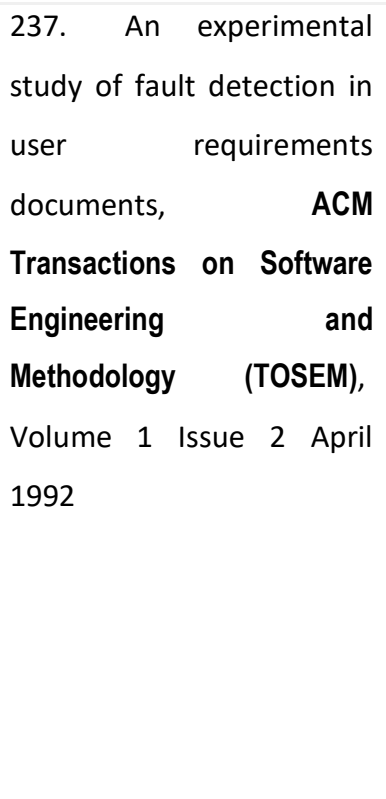 & $\begin{array}{l}\text { /ACM/ } \\
\text { Acm_6.pd }\end{array}$ & $\begin{array}{l}\text { - Describe un experimento diseñado para } \\
\text { confirmar los resultados de un proyecto anterior } \\
\text { - Mide la rata de detección de fallos en docs de } \\
\text { requerimientos de usuario } \\
\text { - } 9 \text { equipos de inspección independientes } \\
\text { - Aplica la técnica de inspección de } \\
\text { requerimentos } \mathrm{N} \text {-fold y la compara con el uso de } \\
\text { técnicas formales } \\
\text { - También mide la variabilidad en el } \\
\text { desempeño del equipo de inspección y la } \\
\text { dificultad de localizar diferentes tipos de fallas en } \\
\text { DRU }\end{array}$ & ART_21 \\
\hline
\end{tabular}

Caso de estudio 


\begin{tabular}{|c|c|c|c|c|c|}
\hline 22 & $\begin{array}{l}\quad \text { M. A. } \\
\text { Babar, } \\
\text { Kitchenham, } \\
\text { L. Zhu, and R. } \\
\text { Jeffery, }\end{array}$ & 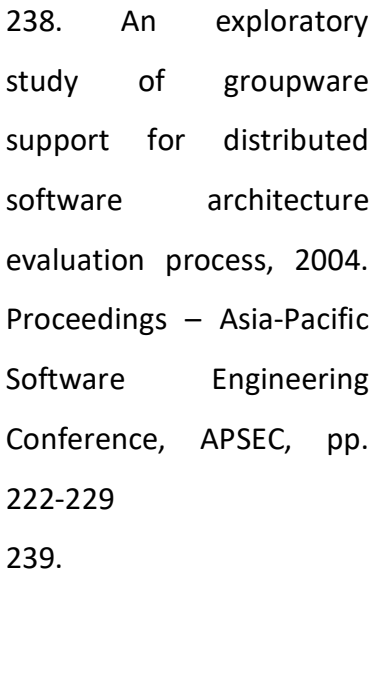 & $\begin{array}{l}\text { /Xplore/ } \\
\text { Xplore_8. } \\
\text { pdf } \\
\text { /scedirect } \\
\text { / sdirect_1.pdf } \\
\text { /Scopus/s } \\
\text { co_13.pdf }\end{array}$ & $\begin{array}{l}\text { - Presenta un estudio piloto (experimento) usado } \\
\text { para evaluar la viabilidad de un experimento + } \\
\text { grande que investigue la factibilidad del soporte } \\
\text { groupware para la evaluación distribuida de } \\
\text { arquitecturas de software } \\
\text { - El estudio piloto arrojó algunos hallazgos acerca } \\
\text { de la viabilidad de un proceso de EA soportado } \\
\text { por groupware. }\end{array}$ & $\begin{array}{l}\text { Es dudoso } \\
\text { si se trata de } \\
\text { un } \\
\text { experimento o } \\
\text { un caso de } \\
\text { estudio }\end{array}$ \\
\hline 23 & $\begin{array}{l}\text { O. } \\
\text { Laitenberger, } \\
\text { K. El Emam, } \\
\text { and T. G. } \\
\text { Harbich, }\end{array}$ & $\begin{array}{l}240 . \text { An internally } \\
\text { replicated quasi- } \\
\text { experimental comparison } \\
\text { of checklist and } \\
\text { perspective based reading } \\
\text { of code documents, IEEE } \\
\text { Transactions on Software } \\
\text { Engineering, vol. 27, pp. } \\
387-421,2001 .\end{array}$ & $\begin{array}{l}\text { /Xplore/ } \\
\text { Xplore_15 } \\
\text {.pdf } \\
\text { /Scopus/N } \\
\text { D }\end{array}$ & $\begin{array}{l}\text { - Compara una técnica de lectura basada en } \\
\text { scenario (PBR) para detección de defectos en } \\
\text { código, con el enfoque CBR más tradicional } \\
\text { - Hace la comparación en una serie de } 3 \text { estudios, } \\
\text { un quasi-experimento y } 2 \text { replicaciones internas } \\
\text { - Utiliza } 60 \text { desarrolladores de software } \\
\text { profesionales } \\
\text { - Presenta un análisis meta-analítico } \\
\text { - Compara efectividad y costo }\end{array}$ & $\begin{array}{l}\text { Es dudoso } \\
\text { si se trata de } \\
\text { un } \\
\text { experimento o } \\
\text { una revisión }\end{array}$ \\
\hline
\end{tabular}


Proceso de RS de experimentos en Ingeniería del Software

\begin{tabular}{|c|c|c|c|c|c|}
\hline 24 & $\begin{array}{l}\text { Hidetake } \\
\text { Uwano, } \\
\text { Masahide } \\
\text { Nakamura, } \\
\text { Akito } \\
\text { Monden, } \\
\text { Ken-ichi } \\
\text { Matsumoto }\end{array}$ & $\begin{array}{l}241 . \quad \text { Analyzing } \\
\text { individual performance of } \\
\text { source code review using } \\
\text { reviewers' eye movement, } \\
\text { Proceedings of the } 2006 \\
\text { symposium on Eye tracking } \\
\text { research \& applications } \\
\text { ETRA '06 }\end{array}$ & $\begin{array}{l}\text { /ACM/ } \\
\text { Acm_7.pd }\end{array}$ & $\begin{array}{l}\text { - Analiza } 30 \text { procesos de revisión } \\
\text { - } 6 \text { programas y } 5 \text { sujetos que utilizan un ambiente } \\
\text { integrado que mide y registra el movimiento } \\
\text { ocular de los revisores de código } \\
\text { - Identifica un patrón } \\
\text { - Realiza un análisis cuantitativo sobre el tiempo } \\
\text { usado en el patrón y el tiempo en detectar fallas }\end{array}$ & $\begin{array}{l}\text { Dudosa } \\
\text { relevancia }\end{array}$ \\
\hline 25 & \begin{tabular}{l}
\multicolumn{1}{c}{ G. } \\
Sabaliauskait \\
e, S. \\
Kusumoto, \\
and K. Inoue,
\end{tabular} & $\begin{array}{l}\text { 242. Assessing defect } \\
\text { detection performance of } \\
\text { interacting teams in } \\
\text { object-oriented design } \\
\text { inspection, Information } \\
\text { and Software Technology, } \\
\text { vol. } 46, \text { pp. 875-886, 2004. }\end{array}$ & $\begin{array}{l}\text { /Scedirect } \\
/ \\
\text { sdirect_2.pdf } \\
\text { /scopus/s } \\
\text { co_8.pdf }\end{array}$ & $\begin{array}{l}\text { - Reporta un experimento controlado con } 54 \\
\text { estudiantes de carrera que inspeccionan } \\
\text { documentos de diseño OO. } \\
\text { - Compara el desempeño de los equipos de } \\
\text { inspección utilizando dos técnicas de lectura: CBR } \\
\text { y PBR } \\
\text { - Compara el desempeño de equipos nominales e } \\
\text { interactivos } \\
\text { - Falsos positivos identificados }\end{array}$ & ART_25 \\
\hline 26 & $\begin{array}{l}\text { Philip M. } \\
\text { Johnson, }\end{array}$ & $\begin{array}{l}\text { 243. Assessing } \\
\text { software review meetings: }\end{array}$ & $\begin{array}{l}\text { /ACM/ } \\
\text { Acm_8.pd }\end{array}$ & $\begin{array}{l}\text { - Conducen un experimento controlado que evalúa } \\
\text { varias medidas de costo y efectividad para un }\end{array}$ & ART_26 \\
\hline
\end{tabular}

Caso de estudio 


\begin{tabular}{|c|c|c|c|c|c|}
\hline & $\begin{array}{l}\text { Danu } \\
\text { Tjahjono }\end{array}$ & $\begin{array}{l}\text { a controlled experimental } \\
\text { study using CSRS, } \\
\text { Proceedings of the 19th } \\
\text { international conference on } \\
\text { Software engineering ICSE } \\
\text { ' } 97\end{array}$ & $f$ & $\begin{array}{l}\text { método de revisión basado en reunió y otro no } \\
\text { basado en ella } \\
\text { - Utilizan un ambiente de revisión de software } \\
\text { colaborativo } \\
\text { - Utilizan } 24 \times 3 \text { grupos de personas } \\
\text { - Miden: núm de defectos descubiertos, esfuerzo } \\
\text { requerido, presencia de sinergia en los grupos } \\
\text { basados en reunión, falsos positivos en los grupos } \\
\text { no-basados, respuestas a cuestionarios } \\
\text { cualitativos }\end{array}$ & \\
\hline 27 & $\begin{array}{l}\text { A. Porter, } \\
\text { L. Votta, and } \\
\text { V. Basili. }\end{array}$ & $\begin{array}{l}244 . \quad \text { Comparing } \\
\text { detection methods for } \\
\text { software requirements } \\
\text { inspections: A replicated } \\
\text { experiment. } \quad \text { IEEE } \\
\text { Transactions on Software } \\
\text { Engineering, 21(6):563- } \\
575,1995\end{array}$ & $\begin{array}{l}\text { /Xplore/ } \\
\text { Xplore_16.pd } \\
f \\
\text { /Scopus/N } \\
\text { D }\end{array}$ & $\begin{array}{l}\text { - Conduce un experimento aleatorizado con } 48 \\
\text { estudiantes } \\
\text { - Cada equipo inspeccionó } 2 \text { SRS usando alguna } \\
\text { combinación de métodos Ad hoc, checklist y } \\
\text { escenarios } \\
\text { - Miden: tasa de detección de fallos individual y } \\
\text { grupal, tasas de ganancia y pérdida de la reunión }\end{array}$ & ART_27 \\
\hline 28 & $\begin{array}{l}\text { Sabaliausk } \\
\text { aite, G., }\end{array}$ & $\begin{array}{l}\text { 245. Comparing reading } \\
\text { techniques for object-oriented }\end{array}$ & D $/$ Scopus $/ \mathrm{N}$ & $\begin{array}{l}\text { - For more than twenty-five years software } \\
\text { inspections have been considered an effective }\end{array}$ & ART_28 \\
\hline
\end{tabular}


Proceso de RS de experimentos en Ingeniería del Software

\begin{tabular}{|c|c|c|}
\hline $\begin{array}{l}\text { Kusumoto, S., } \\
\text { Inoue, K. }\end{array}$ & $\begin{array}{l}\text { design inspection, IEICE } \\
\text { Transactions on Information and } \\
\text { Systems E87-D (4), pp. 976-984, } \\
2004\end{array}$ & $\begin{array}{l}\text { method for defect detection. Inspections have } \\
\text { been investigated through controlled } \\
\text { experiments in university environment and } \\
\text { industry case studies. However, in most cases } \\
\text { software inspections have been used for defect } \\
\text { detection in documents of conventional } \\
\text { structured development process. Therefore, } \\
\text { there is a significant lack of information about } \\
\text { how inspections should be applied to Object- } \\
\text { Oriented artifacts, such as Object-Oriented code } \\
\text { and design diagrams. In addition, extensive work } \\
\text { is needed to determine whether some inspection } \\
\text { techniques can be more beneficial than others. } \\
\text { Most inspection experiments include inspection } \\
\text { meetings after individual inspection is completed. } \\
\text { However, several researchers suggested that } \\
\text { inspection meetings may not be necessary since } \\
\text { an insignificant number of new defects are found } \\
\text { as a result of inspection meeting. Moreover, } \\
\text { inspection meetings have been found to suffer } \\
\text { from process loss. This paper presents the } \\
\text { findings of a controlled experiment that was }\end{array}$ \\
\hline
\end{tabular}

Caso de estudio 


\begin{tabular}{|l|l|l|}
\hline \multicolumn{1}{|l|}{} & $\begin{array}{l}\text { conducted to investigate the performance of } \\
\text { individual inspectors as well as 3-person teams in } \\
\text { Object-Oriented design document inspection. } \\
\text { Documents were written using the notation of } \\
\text { Unified Modelling Language. Two reading } \\
\text { techniques, namely Checklist-based reading (CBR) } \\
\text { and Perspective-based reading (PBR), were used } \\
\text { during experiment. We found that both } \\
\text { techniques are similar with respect to defect } \\
\text { detection effectiveness during individual } \\
\text { inspection as well as during inspection meetings. } \\
\text { Investigating the usefulness of inspection } \\
\text { meetings, we found out that the teams that used } \\
\text { CBR technique exhibited significantly smaller } \\
\text { meeting gains (number of new defect first found } \\
\text { during team meeting) than meeting losses } \\
\text { (number of defects first identified by an } \\
\text { individual but never included into defect list by a } \\
\text { team); meanwhile the meeting gains were similar } \\
\text { to meeting losses of the teams that used PBR } \\
\text { technique. Consequently, CBR 3-person team } \\
\text { meetings turned out to be less beneficial than }\end{array}$ \\
\hline
\end{tabular}


Proceso de RS de experimentos en Ingeniería del Software

\begin{tabular}{|c|c|c|c|c|c|}
\hline & & & & PBR 3-person team meetings. & \\
\hline 29 & $\begin{array}{l}\text { P. } \\
\text { Vitharana } \\
\text { and K. } \\
\text { Ramamurthy, }\end{array}$ & $\begin{array}{l}246 . \quad \text { Computer- } \\
\text { mediated group support, } \\
\text { anonymity, and the } \\
\text { software inspection } \\
\text { process: An empirical } \\
\text { investigation, } \\
\text { Transactions on Software } \\
\text { Engineering, vol. 29, pp. } \\
\text { 167-180, 2003. }\end{array}$ & $\begin{array}{l}\text { /Scopus/ } \\
\text { Sco_2.pdf }\end{array}$ & $\begin{array}{l}\text { - Propone las posibles influencias del anonimato } \\
\text { de los miembros de un grupo en las salidas de un } \\
\text { proceso de inspección mediado por el } \\
\text { computador } \\
\text { - Valida estas relaciones a través de un conjunto de } \\
\text { experimentos controlados } \\
\text { - Se emplean dos tareas diferentes de inspección } \\
\text { con niveles cambiantes de complejidad de código } \\
\text { - Miden: tiempo en ejecutar las tareas, efectividad } \\
\text { en encontrar los errores "sembrados", actitud }\end{array}$ & $\begin{array}{l}\text { Es dudoso } \\
\text { si se trata de } \\
\text { un } \\
\text { experimento o } \\
\text { un caso de } \\
\text { estudio }\end{array}$ \\
\hline 30 & $\begin{array}{l}\text { T. Thelin } \\
\text { and } \\
\text { Runeson, }\end{array}$ & $\begin{array}{l}247 . \text { Confidence } \\
\text { intervals for capture- } \\
\text { recapture estimations in } \\
\text { software inspections, } \\
\text { Information and Software } \\
\text { Technology, vol. 44, pp. } \\
683-702,2002 \text {. }\end{array}$ & $\begin{array}{l}\text { /Scedirect } \\
/ \\
\text { pdf } \\
\text { Sdirect_5. } \\
\text { /scopus/s } \\
\text { co_7.pdf }\end{array}$ & $\begin{array}{l}\text { - Replica un estudio captura-recaptura } \\
\text { - Insvestiga los intervalos de confianza para } \\
\text { estimadores de captura-recaptura utilizando } \\
\text { conjuntos de datos de dos experimentos de } \\
\text { inspección }\end{array}$ & $\begin{array}{l}\text { Es dudoso } \\
\text { si se trata de } \\
\text { un } \\
\text { experimento o } \\
\text { un caso de }\end{array}$ \\
\hline
\end{tabular}

Caso de estudio 


\begin{tabular}{|c|c|c|c|c|c|}
\hline & & & & & estudio \\
\hline 31 & $\begin{array}{l}\text { Harjumaa, } \\
\text { L. }\end{array}$ & $\begin{array}{l}248 . \quad \text { Distributed software } \\
\text { inspections - An experiment with } \\
\text { Adobe Acrobat, International } \\
\text { Conference on Computer Science } \\
\text { and Technology, pp. 26-31, } 2003\end{array}$ & D $/$ Scopus/N & $\begin{array}{l}\text { - Several computer tools for supporting software } \\
\text { inspections exist. Most of them are prototypes } \\
\text { that demonstrate particular aspects of the } \\
\text { inspection process automation and are not } \\
\text { mature enough for utilization. This paper } \\
\text { discusses if off-the shelf products can be used } \\
\text { effectively for inspection collaboration in } \\
\text { distributed software development. During the } \\
\text { experiment three teams carried out distributed } \\
\text { inspections. Collaboration between team } \\
\text { members was done with Adobe Acrobat } 5.0 \text { and } \\
\text { standard e-mail. The Acrobat software provides } \\
\text { very convenient on-line commenting and } \\
\text { material distribution capabilities, but lacks } \\
\text { characteristics for efficient management of the } \\
\text { inspection process, such as defect categorization. } \\
\text { Thus, there is still a need for tools that are } \\
\text { specialized in software inspections. }\end{array}$ & ART_31 \\
\hline
\end{tabular}


Proceso de RS de experimentos en Ingeniería del Software

\begin{tabular}{|c|c|c|c|c|c|}
\hline 32 & $\begin{array}{l}\quad \text { Muhamm } \\
\text { ad Ali Babar, } \\
\text { Barbara } \\
\text { Kitchenham, } \\
\text { Ross Jeffery }\end{array}$ & $\begin{array}{l}249 . \quad \text { Distributed versus } \\
\text { face-to-face meetings for } \\
\text { architecture evalution: a } \\
\text { controlled experiment, } \\
\text { Proceedings of the } 2006 \\
\text { ACM/IEEE international } \\
\text { symposium on International } \\
\text { symposium on empirical } \\
\text { software engineering ISESE } \\
06\end{array}$ & $\begin{array}{l}\text { /ACM/ } \\
\text { Acm_9.pd }\end{array}$ & $\begin{array}{l}\text { - Presenta un experimento controlado que evalúa } \\
\text { la efectividad de la construcción de perfiles de } \\
\text { escenarios usando reuniones distribuidas } \\
\text { - Cross-over experiment con } 32 \text { equipos de } \\
\text { estudiantes } \\
\text { - Compara la calidad de los escenarios usando } \\
\text { groupware vs los producidos face-2-face }\end{array}$ & ART_32 \\
\hline 33 & $\begin{array}{l}\text { Yuk Kuen } \\
\text { Wong, David } \\
\text { Wilson }\end{array}$ & $\begin{array}{l}250 . \text { Does task training } \\
\text { really affect group } \\
\text { performance?, } \\
\text { Proceedings of the winter } \\
\text { international synposium on } \\
\text { Information and } \\
\text { communication } \\
\text { technologies WISICT ' } 04\end{array}$ & $\begin{array}{c}\text { /ACM/ } \\
\text { acm_10.pdf }\end{array}$ & $\begin{array}{l}\text { - Examina la relación entre la experiencia en } \\
\text { entrenamiento de tareas y el desempeño en la } \\
\text { revisión de software } \\
\text { - } 192 \text { sujetos fueron asignados aleatoriamente a } 48 \\
\text { grupos de } 4 \text { miembros } \\
\text { - Buscaron defectos en un documento de diseño }\end{array}$ & ART_33 \\
\hline 34 & $\begin{array}{l}\text { Christian } \\
\text { F. J. Lange, }\end{array}$ & $\begin{array}{l}\text { 251. Effects of defects } \\
\text { in UML models: an }\end{array}$ & $\begin{array}{l}\text { /ACM/ac } \\
\text { m_11.pdf }\end{array}$ & $\begin{array}{l}\text { - Presenta } 2 \text { experimentos controlados } \\
\text { - Investiga cuántos investigadores }\end{array}$ & ART_34 \\
\hline
\end{tabular}

Caso de estudio 


\begin{tabular}{|c|c|c|c|c|c|}
\hline & $\begin{array}{l}\text { Michel R. V. } \\
\text { Chaudron }\end{array}$ & $\begin{array}{l}\text { experimental investigation, } \\
\text { May } 2006 \text { Proceeding of } \\
\text { the } 28 \text { th international } \\
\text { conference on Software } \\
\text { engineering ICSE '06 }\end{array}$ & & $\begin{array}{l}\text { defectos y cuántos defectos causan diferentes } \\
\text { interpretaciones para diferentes lectores } \\
\text { - Utilizan } 111 \text { estudiantes y } 48 \text { practicantes } \\
\text { industriales }\end{array}$ & \\
\hline 35 & & $\begin{array}{l}\text { Eight maxims for } \\
\text { software inspectors }\end{array}$ & D $/$ Scopus $/ \mathrm{N}$ & - & ART_35 \\
\hline 36 & $\begin{array}{l}\text { S. S. So, S. } \\
\text { D. Cha, and Y. } \\
\text { R. Kwon, }\end{array}$ & $\begin{array}{l}252 . \quad \text { Empirical } \\
\text { evaluation of a fuzzy logic- } \\
\text { based software quality } \\
\text { prediction model, Fuzzy } \\
\text { Sets and Systems, vol. 127, } \\
\text { pp. 199-208, } 2002 \text {. }\end{array}$ & $\begin{array}{l}\text { /Scedirect } \\
/ \\
\text { sdirect_6.pdf } \\
\text { /scopus/s } \\
\text { co_6.pdf }\end{array}$ & $\begin{array}{l}\text { - Popone un enfoque automatizado y badado en } \\
\text { lógica difusa } \\
\text { - Analizan los datos de inspección y aquellos } \\
\text { obtenidos en experimentos de inspección } \\
\text { separados } \\
\text { - Valida el modelo de predicción de la calidad } \\
\text { propuesto }\end{array}$ & $\begin{array}{l}\text { ART_36 } \\
\text { Es dudoso } \\
\text { si se trata de } \\
\text { un } \\
\text { experimento o } \\
\text { un caso de } \\
\text { estudio }\end{array}$ \\
\hline 37 & $\begin{array}{c}\text { T. } \\
\text { Thomas, }\end{array}$ & $\begin{array}{l}\text { 253. Empirical } \\
\text { Evaluations of Usage- } \\
\text { Based Reading and Fault } \\
\text { Content Estimation for } \\
\text { Software Inspections, }\end{array}$ & $\begin{array}{l}\text { /Springer/ } \\
\text { Springer_11.p } \\
\text { df }\end{array}$ & $\begin{array}{l}\text { - Describe } 6 \text { investigaciones empíricas de } 2 \\
\text { técnicas de inspección de software: técnica de } \\
\text { lectura (UBR) y de estimación de contenido de } \\
\text { fallas (captura-recaptura) }\end{array}$ & $\begin{array}{l}\text { ART_37 } \\
\text { Es dudoso } \\
\text { si } \quad \text { se trata de }\end{array}$ \\
\hline
\end{tabular}


Proceso de RS de experimentos en Ingeniería del Software

\begin{tabular}{|c|c|c|c|c|c|}
\hline & & $\begin{array}{l}\text { Empirical Software } \\
\text { Engineering, vol. V8, pp. } \\
\text { 309-313, 2003. }\end{array}$ & $\begin{array}{l}\text { /Scopus/s } \\
\text { co_14.pdf }\end{array}$ & & $\begin{array}{l}\text { un } \\
\text { experimento o } \\
\text { un caso de } \\
\text { estudio }\end{array}$ \\
\hline 38 & & $\begin{array}{l}\text { Estimating the number } \\
\text { of remaining defects after } \\
\text { inspection }\end{array}$ & $D^{/ \text {Scopus } / \mathrm{N}}$ & - & ART_38 \\
\hline 39 & S. Biffl, & $\begin{array}{l}254 . \quad \text { Evaluating defect } \\
\text { estimation models with } \\
\text { major defects, Journal of } \\
\text { Systems and Software, vol. } \\
65 \text {, pp. 13-29, } 2003 \text {. }\end{array}$ & $\begin{array}{l}\text { /Scedirect } \\
\text { sdirect_4.pdf } \\
\text { /Scopus }\end{array}$ & $\begin{array}{l}\text { - Se basa en la estimación de defectos en } \\
\text { documentos de requisitos de software } \\
\text { - Compara el desempeño de técnicas objetivas y } \\
\text { subjetivas de estimación del contenido de } \\
\text { defectos } \\
\text { - Conduce un experimento controlado con } 31 \\
\text { equipos de inspección de 4-6 personas } \\
\text { - Miden: precisión }\end{array}$ & ART_39 \\
\hline 40 & $\begin{array}{l}\text { T. } \\
\text { Thomas, R. } \\
\text { Per, W. Claes, } \\
\text { O. Thomas, }\end{array}$ & $\begin{array}{l}255 . \quad \text { Evaluation of } \\
\text { Usage-Based Reading- } \\
\text { Conclusions after Three } \\
\text { Experiments, Empirical }\end{array}$ & $\begin{array}{l}\text { /Springer/ } \\
\text { Springer_1.pd } \\
\text { f }\end{array}$ & $\begin{array}{l}\text { - Presenta una serie de experimentos para evaluar } \\
\text { UBR aplicado a un documento de diseño de alto } \\
\text { nivel } \\
\text { - El foco es el 3er experimento: investigar la }\end{array}$ & ART_40 \\
\hline
\end{tabular}

Caso de estudio 


\begin{tabular}{|c|c|c|c|c|c|}
\hline & and A. Carina, & $\begin{array}{l}\text { Software Engineering, vol. } \\
\text { v9, pp. } 77-110,2004 .\end{array}$ & /Scopus/N & $\begin{array}{l}\text { información necesitada por UBR para la } \\
\text { preparación y las reuniones de inspección de } \\
\text { software } \\
\text { - Discute la eficiencia y efectividad }\end{array}$ & \\
\hline 41 & $\begin{array}{l}\text { Porter, H. } \\
\text { Siy, C. A. } \\
\text { Toman, and } \\
\text { L. G. Votta }\end{array}$ & $\begin{array}{l}\text { 256. Experiment to } \\
\text { assess the cost-benefits of } \\
\text { code inspections in large } \\
\text { scale software } \\
\text { development, Proceedings } \\
\text { of the ACM SIGSOFT } \\
\text { Symposium on the } \\
\text { Foundations of Software } \\
\text { Engineering, } 1995 \text {. }\end{array}$ & $\begin{array}{l}\text { /ACM/ } \\
\text { acm_3.pdf } \\
\text { (Xplore_1 } \\
\text { 0.pdf) }\end{array}$ & $\begin{array}{l}\text { - Conduce un proyecto a largo plazo } \\
\text { - Evalúa la costo-efectividad de diversos métodos } \\
\text { de inspección de software } \\
\text { - Los métodos son aplicados por desarrolladores } \\
\text { profesionales } \\
\text { - Se utilizó simulación para optimizar el } \\
\text { experimento } \\
\text { - A cada inspección se le asignó aleatoriamente } 3 \\
\text { variables independientes: número de revisores } \\
\text { en el equipo, núm de equipos de inspección, el } \\
\text { requisito de reparar los defectos entre la 1ạ y 2a } \\
\text { inspección } \\
\text { - Los revisores fueron seleccionados } \\
\text { aleatoriamente } \\
\text { - Las variables dependientes fueron: tiempo de }\end{array}$ & $\begin{array}{l}\text { Se trata de } \\
\text { un caso de } \\
\text { estudio }\end{array}$ \\
\hline
\end{tabular}


Proceso de RS de experimentos en Ingeniería del Software

\begin{tabular}{|c|c|c|c|c|c|}
\hline & & & & $\begin{array}{l}\text { inspección, esfuerzo total, la tasa de detección de } \\
\text { defectos }\end{array}$ & \\
\hline 42 & \begin{tabular}{l}
\multicolumn{2}{c}{ Laitenber } \\
ger, O., \\
Atkinson, C., \\
Schlich, M., El \\
Emam, K.
\end{tabular} & $\begin{array}{l}\text { Experimental } \\
\text { comparison of reading } \\
\text { techniques for defect } \\
\text { detection in UML design } \\
\text { documents, Journal of } \\
\text { Systems and Software } 53 \\
\text { (2), pp. 183-204, } 2000\end{array}$ & $D^{/ \text {Scopus } / N}$ & $\begin{array}{l}\text { - The basic motivation for software inspections is } \\
\text { to detect and remove defects before they } \\
\text { propagate to subsequent development phases } \\
\text { where their detection and removal become more } \\
\text { expensive. To maximize this potential, the } \\
\text { examination of the artefact under inspection } \\
\text { must be as thorough and detailed as possible. } \\
\text { This implies the need for systematic reading } \\
\text { techniques that tell inspection participants what } \\
\text { to look for and, more importantly, how to } \\
\text { scrutinize a software document. Recent research } \\
\text { efforts have investigated the benefits of scenario- } \\
\text { based reading techniques for defect detection in } \\
\text { functional requirements and functional code }\end{array}$ & ART_42 \\
\hline
\end{tabular}

Caso de estudio 


\begin{tabular}{|l|l|}
\hline \multicolumn{1}{|l|}{$\mid$\begin{tabular}{|l|}
\hline documents. A major finding has been that these \\
techniques help inspection teams find more \\
defects than existing state-of-the-art approaches, \\
such as, ad hoc or checklist-based reading (CBR). \\
In this paper, we describe and experimentally \\
compare one scenario-based reading technique, \\
namely perspective-based reading (PBR), for \\
defect detection in object-oriented design \\
documents using the notation of the unified \\
modeling language (UML) to the more traditional \\
CBR approach. The comparison was performed in \\
a controlled experiment with 18 practitioners as \\
subjects. Our results indicate that PBR teams \\
discovered, on average, 58\% of the defects and \\
had an average cost per defect ratio of 56 min \\
per defect. In this way, PBR is more effective than \\
CBR (i.e., it resulted in inspection teams \\
detecting, on average, 41\% more unique defects \\
than CBR). Moreover, the cost of defect detection \\
using PBR is significantly lower than CBR (i.e., PBR \\
exhibits, on average, a 58\% cost per defect \\
improvement over CBR). This study therefore \\
provides evidence demonstrating the efficacy of
\end{tabular}} \\
\hline
\end{tabular}


Proceso de RS de experimentos en Ingeniería del Software

\begin{tabular}{|c|c|c|c|c|c|}
\hline & & & & $\begin{array}{l}\text { PBR scenarios for defect detection in UML design } \\
\text { documents. In addition, it demonstrates that a } \\
\text { PBR inspection is a promising approach for } \\
\text { improving the quality of models developed using } \\
\text { the UML notation. }\end{array}$ & \\
\hline 43 & $\begin{array}{l}\text { Wohlin, } \\
\text { Claes, } \\
\text { Runeson, Per, } \\
\text { Brantestam, } \\
\text { Johan }\end{array}$ & $\begin{array}{l}\text { Experimental } \\
\text { evaluation of capture- } \\
\text { recapture in software } \\
\text { inspections, } \\
\quad \text { Software Testing } \\
\text { Verification and Reliability } \\
5 \text { (4), pp. 213-232, } 1995\end{array}$ & $D^{/ \text {Scopus } / \mathrm{N}}$ & $\begin{array}{l}\text { The use of capture-recapture to estimate the } \\
\text { residual faults in a software artifact has evolved } \\
\text { as a promising method. However, the } \\
\text { assumptions needed to make the estimates are } \\
\text { not completely fulfilled in software development, } \\
\text { leading to an underestimation of the residual } \\
\text { fault content. Therefore, a method employing a } \\
\text { filtering technique with an experience factor to } \\
\text { improve the estimates of the residual faults is } \\
\text { proposed in this paper. An experimental study of } \\
\text { the capture-recapture method with this } \\
\text { correction method has been conducted. It is } \\
\text { concluded that the correction method improves } \\
\text { the capture-recapture estimate of the number of } \\
\text { residual defects in the inspected document. }\end{array}$ & ART_43 \\
\hline
\end{tabular}

Caso de estudio 


\begin{tabular}{|c|c|c|c|c|c|}
\hline 44 & $\begin{array}{l}\text { Thelin, T., } \\
\text { Erlansson, } \\
\text { M., Höst, M., } \\
\text { Wohlin, C. }\end{array}$ & $\begin{array}{l}\text { Experimentation with } \\
\text { usage-based reading, } \\
\text { Lecture Notes in Computer } \\
\text { Science (including } \\
\text { subseries Lecture Notes in } \\
\text { Artificial Intelligence and } \\
\text { Lecture Notes in } \\
\text { Bioinformatics) 2765, pp. } \\
\text { 193-207, 2003 }\end{array}$ & /Scopus/N & $\begin{array}{l}\text { - Software inspections are regarded as an } \\
\text { important technique to detect faults throughout } \\
\text { the software development process. The } \\
\text { individual preparation phase of software } \\
\text { inspections has enlarged its focus from only } \\
\text { comprehension to also include fault searching. } \\
\text { Hence, reading techniques to support the } \\
\text { reviewers on fault detection are needed. Usage- } \\
\text { based reading (UBR) is a reading technique, } \\
\text { which focuses on the important parts from a } \\
\text { user's point of view in a software document by } \\
\text { using prioritized use cases. UBR has been } \\
\text { evaluated in two previously conducted } \\
\text { experiments, which investigate the prioritization } \\
\text { of UBR and compare UBR against checklist-based } \\
\text { reading (CBR). This chapter presents two } \\
\text { controlled experiments with UBR on } \\
\text { requirements and design specifications. The } \\
\text { experiments include individual preparation and } \\
\text { inspection meeting, i.e. the first steps of the } \\
\text { traditional inspection process. For the } \\
\text { requirements inspection, UBR is evaluated } \\
\text { against CBR, and for the design inspection, the }\end{array}$ & ART_44 \\
\hline
\end{tabular}


Proceso de RS de experimentos en Ingeniería del Software

\begin{tabular}{|c|c|c|c|c|c|}
\hline & & & & $\begin{array}{l}\text { amount of information needed in the use cases } \\
\text { are studied. The studies were conducted in } \\
\text { different environments with a total of about } 100 \\
\text { students. The result from these experiments } \\
\text { shows that UBR is not better than CBR for } \\
\text { requirements inspections. Results from the } \\
\text { experiment on design inspection indicate that use } \\
\text { cases developed in advance are preferable } \\
\text { compared to developing them as part of the } \\
\text { preparation phase of the inspection. }\end{array}$ & \\
\hline 45 & $\begin{array}{l}\text { J. Miller, } \\
\text { M. Wood, } \\
\text { and } \quad \text { M. } \\
\text { Roper, }\end{array}$ & $\begin{array}{l}257 . \quad \text { Further } \\
\text { Experiences with Scenarios } \\
\text { and Checklists, Empirical } \\
\text { Software Engineering, vol. } \\
\text { V3, pp. 37-64, 1998. }\end{array}$ & $\begin{array}{l}\text { /Springer/ } \\
\text { Springer_6.pd } \\
\text { f } \\
\text { /Scopus/s } \\
\text { co_16.pdf }\end{array}$ & $\begin{array}{l}\text { - Es una replicación del experimento de Porter et } \\
\text { al. (1995) (Xplore_16.pdf) } \\
\text { - Evalúa la ayuda a la detección utilizando } \\
\text { enfoques basados en escenarios y en checklist } \\
\text { - Compara los resultados del experimento con } \\
\text { otros } \\
\text { - Miden: desempeño, pérdidas de la reunión }\end{array}$ & ART_45 \\
\hline
\end{tabular}

Caso de estudio 


\begin{tabular}{|c|c|c|c|c|c|}
\hline 46 & \begin{tabular}{l}
\multicolumn{1}{c}{ G. } \\
Sabaliauskait \\
e, F. \\
Matsukawa, \\
S. Kusumoto, \\
and K. Inoue,
\end{tabular} & $\begin{array}{l}258 . \quad \text { Further } \\
\text { investigations of reading } \\
\text { techniques for object- } \\
\text { oriented design inspection, } \\
\text { Information and Software } \\
\text { Technology, vol. } 45 \text {, pp. } \\
571-585,2003 \text {. }\end{array}$ & $\begin{array}{l}\text { /Scedirect } \\
\text { /sdirect_3.pd } \\
f \\
\text { /Scopus/N }\end{array}$ & $\begin{array}{l}\text { - Describe la evaluación de CBR y PBR para un } \\
\text { documento de diseño OO escrito con UML } \\
\text { - Reporta un experimento controlado con } 59 \\
\text { estudiantes } \\
\text { - Miden: tiempo individual, costo x defecto, } \\
\text { efectividad, efectividad del equipo simulado }\end{array}$ & ART_46 \\
\hline 47 & $\begin{array}{l}\text { T. Thelin, } \\
\text { P. Runeson, } \\
\text { C. Wohlin, T. } \\
\text { Olsson, and } \\
\text { C. Andersson, }\end{array}$ & $\begin{array}{l}259 . \text { How much } \\
\text { information is needed for } \\
\text { usage-based reading? A } \\
\text { series of experiments, } \\
2002 \text {. }\end{array}$ & $\begin{array}{r}\text { /Xplore/X } \\
\text { plore_18.pdf }\end{array}$ & $\begin{array}{l}\text { - Presenta una serie de } 3 \text { experimentos sobre UBR } \\
\text { sobre especificaciones de diseño } \\
\text { - 1ero: evalúa la priorización de UBR } \\
\text { - 2do: compara UBR vs CBR } \\
\text { - 3ero: investiga la cantidad de información } \\
\text { necesitada en los casos de uso y si un enfoque } \\
\text { más activo ayuda a los revisores a detectar más } \\
\text { fallas } \\
\text { - El 3er experimento fue conducido en dos sitios } \\
\text { distintos con } 82 \text { sujetos } \\
\text { - Miden: efectividad y eficiencia }\end{array}$ & ART_47 \\
\hline
\end{tabular}


Proceso de RS de experimentos en Ingeniería del Software

\begin{tabular}{|c|c|c|c|c|c|}
\hline 48 & $\begin{array}{cc}\begin{array}{c}\text { S. Biffl } \\
\text { and } \\
\text { Halling, }\end{array} & \end{array}$ & $\begin{array}{l}260 . \quad \text { Investigating } \\
\text { reinspection decision } \\
\text { accuracy regarding } \\
\text { product-quality and cost- } \\
\text { benefit estimates, } 2001 . \\
\text { Proceedings } \quad \text { IEEE } \\
\text { Computer Society's } \\
\text { International Computer } \\
\text { Software and Applications } \\
\text { Conference, pp. } 87-96\end{array}$ & $\begin{array}{l}\text { /Xplore/X } \\
\text { plore_21.pdf } \\
\text { /Scopus/s } \\
\text { co_25.pdf }\end{array}$ & $\begin{array}{l}\text { - Propone utilizar modelos de estimación para la } \\
\text { mejora de calidad durante la reinspección y } \\
\text { utilizar el costo-beneficio de una reinspección } \\
\text { para la decisión sobre la misma } \\
\text { - Evalua la correctitud de la decisión de } \\
\text { reinspección de estos modelos con datos de } \\
\text { defectos de un gran experimento controlado } \\
\text { sobre la insp-reinsp de docs de requisitos de } \\
\text { software } \\
\text { - Describe el experimento y sus resultados }\end{array}$ & ART_48 \\
\hline 49 & \begin{tabular}{l}
\multicolumn{2}{c}{ Stefan } \\
Biffl, Bernd \\
Freimut, \\
Oliver \\
Laitenberger
\end{tabular} & 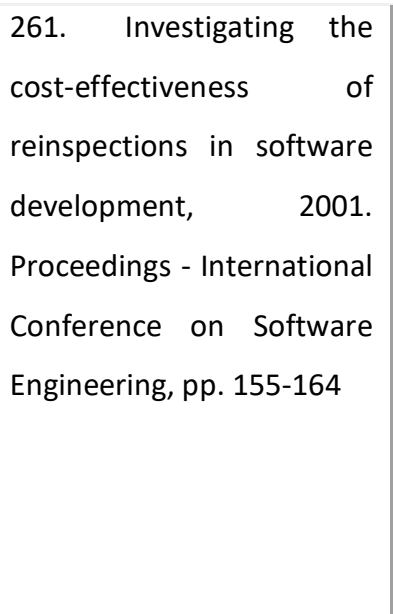 & $\begin{array}{l}\text { /Xplore/ } \\
\text { Xplore_22.pd } \\
\text { f } \\
\text { /ACM/ } \\
\text { acm_13.pdf }\end{array}$ & $\begin{array}{l}\text { - Proponen un modelo costo-beneficio para } \\
\text { inspección-reinspección } \\
\text { - Discuten el impacto de los parámetros costo y } \\
\text { beneficio sobre la ganancia neta de una } \\
\text { reinspección } \\
\text { - Utilizan datos empíricos de un experimento en el } \\
\text { cual } 31 \text { equipos de estudiantes inspeccionaron- } \\
\text { reinspeccionaron un documento de requisitos }\end{array}$ & ART_49 \\
\hline
\end{tabular}




\begin{tabular}{|c|c|c|c|c|c|}
\hline & & & & $\begin{array}{l}\text { - Comparan los beneficios y ganancia de neta de la } \\
\text { reinspección respecto a la inspección inicial }\end{array}$ & \\
\hline 50 & $\begin{array}{l}\text { Biffl, S., } \\
\text { Halling, M. }\end{array}$ & $\begin{array}{l}\text { Investigating the defect } \\
\text { detection effectiveness } \\
\text { and cost benefit of } \\
\text { nominal inspection teams, } \\
\text { IEEE Transactions on } \\
\text { Software Engineering } 29 \\
\text { (5), pp. } 385-397\end{array}$ & D & $\begin{array}{l}\text { - Inspection is an effective but also expensive } \\
\text { quality assurance activity to find defects early } \\
\text { during software development. The defect } \\
\text { detection process, team size, and staff hours } \\
\text { invested can have a considerable impact on the } \\
\text { defect detection effectiveness and cost-benefit of } \\
\text { an inspection. In this paper, we use empirical } \\
\text { data and a probabilistic model to estimate this } \\
\text { impact for nominal (noncommunicating) } \\
\text { inspection teams in an experiment context. } \\
\text { Further, the analysis investigates how cutting off } \\
\text { the inspection after a certain time frame would } \\
\text { influence inspection performance. Main findings } \\
\text { of the investigation are: 1) Using combinations of } \\
\text { different reading techniques in a team is } \\
\text { considerably more effective than using the best }\end{array}$ & ART_50 \\
\hline
\end{tabular}


Proceso de RS de experimentos en Ingeniería del Software

\begin{tabular}{|c|c|c|c|c|c|}
\hline & & & & $\begin{array}{l}\text { single technique only (regardless of the observed } \\
\text { level of effort). 2) For optimizing the inspection } \\
\text { performance, determining the optimal process } \\
\text { mix in a team is more important than adding an } \\
\text { inspector (above a certain team size) in our } \\
\text { model. 3) A high level of defect detection } \\
\text { effectiveness is much more costly to achieve than } \\
\text { a moderate level since the average cost for the } \\
\text { defects found by the inspector last added to a } \\
\text { team increases more than linearly with growing } \\
\text { effort investment. The work provides an Initial } \\
\text { baseline of inspection performance with regard } \\
\text { to process diversity and effort in inspection } \\
\text { teams. We encourage further studies on the topic } \\
\text { of time usage with defect detection techniques } \\
\text { and its effect on inspection effectiveness in a } \\
\text { variety of inspection contexts to support } \\
\text { inspection planning with limited resources. }\end{array}$ & \\
\hline 51 & $\begin{array}{l}\text { S. Biffl, M. } \\
\text { Halling, and } \\
\text { M. Kohle, }\end{array}$ & $\begin{array}{l}\text { 262. Investigating the } \\
\text { effect of a second software } \\
\text { inspection cycle. Cost- }\end{array}$ & $\begin{array}{l}\text { /Xplore/ } \\
\text { Xplore_23.pd } \\
f\end{array}$ & $\begin{array}{l}\text { - Reporta un experimento controlado que compara } \\
\text { el efecto de dos ciclos de inspección } \\
\text { - Un documento de requisitos es reinspeccionado }\end{array}$ & ART_51 \\
\hline
\end{tabular}

Caso de estudio 


\begin{tabular}{|c|c|c|c|c|c|}
\hline & & $\begin{array}{l}\text { benefit data from a large- } \\
\text { scale experiment on } \\
\text { reinspection of a software } \\
\text { requirements document, } \\
2000 .\end{array}$ & & $\begin{array}{l}\text { por } 31 \text { equipos } \\
\text { _ Presenta: efectividad, eficiencia, ganancia neta, } \\
\text { ROI de un segundo ciclo de inspección } \\
\text { _ Evalúan los supuestos y la correctitud de los } \\
\text { criterios de decisión }\end{array}$ & \\
\hline 52 & $\begin{array}{l}\text { Winkler, } \\
\text { D., Hailing, } \\
\text { M., Biffl, S. }\end{array}$ & $\begin{array}{l}\text { Investigating the effect } \\
\text { of expert ranking of use } \\
\text { cases for design } \\
\text { inspection, Conference } \\
\text { Proceedings of the } \\
\text { EUROMICRO 30, pp. } 362 \text { - } \\
371\end{array}$ & $\begin{array}{l}\text { /Scopus/N } \\
\text { D }\end{array}$ & $\begin{array}{l}\text { - Inspection is an important approach to reduce } \\
\text { defects in software engineering artifacts. Reading } \\
\text { techniques such as Usage-Based Reading (UBR) } \\
\text { can focus inspector attention on specific types of } \\
\text { defects (missing and wrong information) and } \\
\text { specific defect severity classes (critical, important } \\
\text { and not important defects). For empirical } \\
\text { investigation the replication of experiments can } \\
\text { help increase the confidence in results. This } \\
\text { paper presents a large-scale external experiment } \\
\text { replication in the UBR family of experiments in an } \\
\text { academic environment. Additionally to } \\
\text { experiment replication we introduce a new } \\
\text { reading technique variant UBR-ir to investigate } \\
\text { the impact of expert know-how with ranking of } \\
\text { use cases on the number and severity of defects }\end{array}$ & ART_52 \\
\hline
\end{tabular}


Proceso de RS de experimentos en Ingeniería del Software

\begin{tabular}{|c|c|c|c|c|c|}
\hline & & & & $\begin{array}{l}\text { found. Main results of the study are: (a) UBR } \\
\text { expert know-how had significant effects on } \\
\text { inspection effort distribution, effectiveness, and } \\
\text { efficiency; (b) the share of false positives was } \\
\text { higher for checklist-based reading (CBR) than for } \\
\text { all UBR variants; and } \\
\text { (c) both UBR variants } \\
\text { perform significantly better than CBR, possibly } \\
\text { due to the active guidance of use cases. }\end{array}$ & \\
\hline 53 & $\begin{array}{l}\text { W. } \\
\text { Dietmar, B. } \\
\text { Stefan, and T. } \\
\text { Bettina, }\end{array}$ & $\begin{array}{l}\text { 263. Investigating the } \\
\text { Impact of Active Guidance } \\
\text { on Design Inspection, } \\
\text { 2005. Lecture Notes in } \\
\text { Computer Science } 3547 \text {, } \\
\text { pp. } 458-473\end{array}$ & $\begin{array}{l}\text { /Springer/ } \\
\text { Springer_2.pd } \\
\text { f } \\
\text { /scopus/N } \\
\text { D }\end{array}$ & $\begin{array}{l}\text { - Comparan el desempeño de este enfoque en un } \\
\text { experimento controlado en un ambiente } \\
\text { académico } \\
\text { - Miden efectividad y eficiencia de CBR y UBR } \\
\text { usando active guidance }\end{array}$ & ART_53 \\
\hline 54 & $\begin{array}{l}\text { B. } \\
\text { Freimut, } \quad \text { o. } \\
\text { Laitenberger, } \\
\text { and S. Biffl, }\end{array}$ & $\begin{array}{l}\text { 264. Investigating the } \\
\text { impact of reading } \\
\text { techniques on the accuracy } \\
\text { of different defect content } \\
\text { estimation techniques, }\end{array}$ & $\begin{array}{l}\text { /Xplore/ } \\
\text { Xplore_24.pd } \\
\text { f } \\
\text { /Scopus/N }\end{array}$ & $\begin{array}{l}\text { - Examina el impacto de } 2 \text { técnicas de lectura: SBR } \\
\text { y CBR en la precisión de diferentes técnicas de } \\
\text { estimación } \\
\text { - Se basa en datos recogidos en un gran } \\
\text { experimento con estudiantes }\end{array}$ & ART_54 \\
\hline
\end{tabular}

Caso de estudio 


\begin{tabular}{|c|c|c|c|c|c|}
\hline & & \multicolumn{2}{|c|}{ Extracción de Datos } & \multicolumn{2}{|c|}{ Proceso de RS de experimentos en Ingeniería del Software } \\
\hline & & 2001. & D & & \\
\hline 55 & & $\begin{array}{l}\text { Object-oriented } \\
\text { reading techniques for } \\
\text { inspection of UML models } \\
\text { - An industrial experiment }\end{array}$ & $D^{/ \text {Scopus/N }}$ & - & ART_55 \\
\hline 56 & J. Miller, & $\begin{array}{l}265 . \text { On the } \\
\text { independence of software } \\
\text { inspectors, Journal of } \\
\text { Systems and Software, vol. } \\
60, \text { pp. 5-10, } 2002 .\end{array}$ & $\begin{array}{l}\text { /Scedirect } \\
/ \\
\text { sdirect_7.pdf } \\
\text { /Scopus/s } \\
\text { co_23.pdf }\end{array}$ & $\begin{array}{l}\text { - Investiga si los resultados de un inspector } \\
\text { individual durante la fase de preparación son } \\
\text { dependientes o independientes } \\
\text { - Usa datos de un experimento previo y una } \\
\text { simulación a partir de ellos }\end{array}$ & ART_56 \\
\hline 57 & \begin{tabular}{l}
\multicolumn{1}{c}{ Pankaj } \\
Jalote, M. \\
Haragopal
\end{tabular} & $\begin{array}{l}\text { 266. Overcoming the } \\
\mathrm{NAH} \text { syndrome for } \\
\text { inspection deployment, } \\
\text { Proceedings of the 20th } \\
\text { international conference on } \\
\text { Software engineering ICSE }\end{array}$ & $\begin{array}{l}\text { /ACM/ } \\
\text { acm_15.pdf } \\
\text { /Scopus/N }\end{array}$ & $\begin{array}{l}\text { - Ejecutan un experimento para reducir el } \\
\text { síndrome "not applicable here" en una } \\
\text { organización que realiza una inspección de } \\
\text { software } \\
\text { - Adicionalmente, comparar las inspecciones de }\end{array}$ & ART_57 \\
\hline
\end{tabular}


Proceso de RS de experimentos en Ingeniería del Software

\begin{tabular}{|c|c|c|c|c|c|}
\hline & & '98 & & $\begin{array}{l}\text { código con las pruebas de unidad } \\
\text { - Miden: capacidad de detección de defectos, } \\
\text { efectos de la inspección en los costos globales del } \\
\text { desarrollo. }\end{array}$ & \\
\hline 58 & $\begin{array}{l}\text { Lulu He, } \\
\text { Jeffrey Carver }\end{array}$ & $\begin{array}{l}267 . \quad \text { PBR vs. checklist: } \\
\text { a replication in the n-fold } \\
\text { inspection context, } \\
\text { Proceedings of the } 2006 \\
\text { ACM/IEEE International } \\
\text { symposium on empirical } \\
\text { software engineering ISESE } \\
\text { ' } 06\end{array}$ & $\begin{array}{c}\text { /ACM/ } \\
\text { acm_17.pdf }\end{array}$ & $\begin{array}{l}\text { - Describe un experimento para validar la } \\
\text { efectividad de Perspectiva-based reading en una } \\
\text { inspección } \mathrm{N} \text {-fold basada en reunión } \\
\text { - Busca validar la hipótesis original de que PBR } \\
\text { ayuda a incrementar la efectividad (individual y } \\
\text { grupal) de detección de fallos, comparado con un } \\
\text { enfoque Checklist } \\
\text { - Investiga los diferentes impactos de PBR y } \\
\text { checklist en la efectividad de una reunión de } \\
\text { equipo N-fold } \\
\text { - Investiga algunas características de PBR }\end{array}$ & ART_58 \\
\hline 59 & & \begin{tabular}{l}
\multicolumn{2}{c}{ Perspective-based } \\
reading: A replicated \\
experiment focused on \\
individual \\
reviewer
\end{tabular} & $D^{/ \text {Scopus } / \mathrm{N}}$ & - & ART_59 \\
\hline
\end{tabular}

Caso de estudio 


\begin{tabular}{|c|c|c|c|c|c|}
\hline & & \multicolumn{2}{|c|}{ Extracción de Datos } & \multicolumn{2}{|c|}{ Proceso de RS de experimentos en Ingeniería del Software } \\
\hline & & effectiveness & & & \\
\hline 60 & & $\begin{array}{l}\text { Practical code } \\
\text { inspection techniques for } \\
\text { object-oriented systems: } \\
\text { An experimental } \\
\text { comparison }\end{array}$ & D & - & ART_60 \\
\hline 61 & & \begin{tabular}{lr}
\multicolumn{1}{c}{ Process } & for \\
asynchronous software \\
inspection
\end{tabular} & $D^{/ S c o p u s / N}$ & - & ART_61 \\
\hline 62 & \begin{tabular}{l}
\multicolumn{2}{c}{ Diane } \\
Kwlly, Terry \\
Shepard
\end{tabular} & $\begin{array}{l}\text { 268. Qualitative } \\
\text { observations from } \\
\text { software code inspection } \\
\text { experiments, Proceedings } \\
\text { of the } 2002 \text { conference of } \\
\text { the Centre for Advanced } \\
\text { Studies on Collaborative }\end{array}$ & $\begin{array}{c}\text { /ACM/ } \\
\text { acm_18.pdf }\end{array}$ & $\begin{array}{l}\text { - Recoge y organiza observaciones que fueron } \\
\text { hechas durante una serie de experimentos } \\
\text { previos } \\
\text { - Presenta comentarios y análisis de los resultados } \\
\text { de tales experimentos } \\
\text { - Describe brevemente } 3 \text { de los experimentos }\end{array}$ & \begin{tabular}{l}
$\quad$ ART_62 \\
\multicolumn{1}{c}{ Puede } \\
existir una \\
publicación \\
previa \\
relacionada
\end{tabular} \\
\hline
\end{tabular}


Proceso de RS de experimentos en Ingeniería del Software

\begin{tabular}{|c|c|c|c|c|c|}
\hline & & research CASCON '02 & & & \\
\hline 63 & & $\begin{array}{l}\text { Robust estimations of } \\
\text { fault content with capture- } \\
\text { recapture and detection } \\
\text { profile estimators }\end{array}$ & D & - & ART_63 \\
\hline 64 & & $\begin{array}{l}\text { Role of comprehension } \\
\text { in software inspection }\end{array}$ & D & - & ART_64 \\
\hline 65 & & $\begin{array}{l}\text { Software group reviews } \\
\text { and the impact of } \\
\text { procedural roles on defect } \\
\text { detection performance }\end{array}$ & D & - & ART_65 \\
\hline 66 & \begin{tabular}{l}
\multicolumn{2}{c}{ Diane } \\
Kelly, Terry \\
Shepard
\end{tabular} & $\begin{array}{l}269 . \quad \text { Task-directed } \\
\text { software inspection } \\
\text { technique: an experiment } \\
\text { and case study, } \\
\text { Proceedings of the } 2000 \\
\text { conference of the Centre for } \\
\text { Advanced Studies on }\end{array}$ & $\begin{array}{c}\text { /ACM/ } \\
\text { acm_4.pdf }\end{array}$ & $\begin{array}{l}\text { - Estudiantes en un experimento aplican dos } \\
\text { técnicas dirigidas a tareas y una técnica de } \\
\text { inspección no-estructurada estándar en la } \\
\text { industria a un código de ing civil en uso en } \\
\text { aplicaciones militares } \\
\text { - Presetan tanto un caso de estudio como el }\end{array}$ & $\begin{array}{l}\text { ART_66 } \\
\text { Es dudoso } \\
\text { si se trata de } \\
\text { un } \\
\text { experimento o }\end{array}$ \\
\hline
\end{tabular}

Caso de estudio 


\begin{tabular}{|c|c|c|c|c|c|}
\hline & & $\begin{array}{l}\text { Collaborative research } \\
\text { CASCON '00 }\end{array}$ & & $\begin{array}{l}\text { experimento } \\
\text { - Analizan los resultados con una clasificación } \\
\text { ortogonal de defectos para código computacional } \\
\text { desarrollada para la investigación } \\
\text { - Discuten: la contribución de la técnica dirigida a } \\
\text { tareas en la evaluación y entendimiento del } \\
\text { código por parte de los inspectores, diferencias } \\
\text { entre inspectores experimentados y no } \\
\text { experimentados. }\end{array}$ & $\begin{array}{l}\text { un caso de } \\
\text { estudio }\end{array}$ \\
\hline 67 & T. Thelin, & $\begin{array}{l}270 . \quad \text { Team-based fault } \\
\text { content estimation in the } \\
\text { software inspection } \\
\text { process, 2004. Proceedings } \\
\text { - International Conference } \\
\text { on Software Engineering } \\
26, \text { pp. } 263-272\end{array}$ & $\begin{array}{l}\text { /Xplore/ } \\
\text { Xplore_13 } \\
\text {.pdf } \\
\text { /Scopus/s } \\
\text { co_1.pdf }\end{array}$ & $\begin{array}{l}\text { - Presenta un experimento que compara métodos } \\
\text { objetivos y subjetivos de estimación de contenido } \\
\text { de fallos en diferentes puntos } \\
\text { - Fue conducido en } 2 \text { universidades con } 82 \\
\text { revisores }\end{array}$ & ART_67 \\
\hline 68 & $\begin{array}{l}\text { Christian } \\
\text { Denger, } \\
\text { Ronny Kolb }\end{array}$ & $\begin{array}{l}\text { 271. Testing and } \\
\text { inspecting reusable } \\
\text { product line components: } \\
\text { first empirical results, }\end{array}$ & $\begin{array}{c}\text { /ACM/ } \\
\text { acm_5.pdf }\end{array}$ & $\begin{array}{l}\text { - Compara dos técnicas de detección de defectos: } \\
\text { inspecciones de código y pruebas funcionales en } \\
\text { el contexto de desarrollo de líneas de productos } \\
\text { - Investiga el potencial de detección de defectos de }\end{array}$ & $\begin{array}{r} \\
\text { Es dudoso } \\
\text { si se trata de }\end{array}$ \\
\hline
\end{tabular}


Proceso de RS de experimentos en Ingeniería del Software

\begin{tabular}{|c|c|c|c|c|c|}
\hline & & $\begin{array}{l}\text { Proceedings of the } 2006 \\
\text { ACM/IEEE international } \\
\text { symposium on International } \\
\text { symposium on empirical } \\
\text { software engineering ISESE } \\
\text { ' } 06\end{array}$ & & $\begin{array}{l}\text { las técnicas en componentes reutilizables de } \\
\text { software } \\
\text { - Discuten: efectividad y esfuerzo para detectar un } \\
\text { defecto }\end{array}$ & $\begin{array}{l}\text { un } \\
\text { experimento o } \\
\text { un caso de } \\
\text { estudio }\end{array}$ \\
\hline 69 & $\begin{array}{l}\text { C. Atiq } \\
\text { and L. P. W. } \\
\text { Land, }\end{array}$ & $\begin{array}{l}272 . \text { The impact of } \\
\text { training-by-examples on } \\
\text { inspection performance } \\
\text { using two laboratory } \\
\text { experiments, } 2004 . \\
\text { Proceedings of the } \\
\text { Australian Software }\end{array}$ & $\begin{array}{l}\text { /Xplore/ } \\
\text { xplore_14.pdf } \\
\text { /Springer_ } \\
\text { 7.pdf }\end{array}$ & $\begin{array}{l}\text { - Dos experimentos de lab son conducidos para } \\
\text { probar el efecto del entrenamiento usando } \\
\text { ejemplos de defectos }\end{array}$ & ART_69 \\
\hline
\end{tabular}

Caso de estudio 


\begin{tabular}{|c|c|c|c|c|c|}
\hline & & $\begin{array}{l}\text { Engineering Conference, } \\
\text { ASWEC 2004, pp. 279-288 }\end{array}$ & $\begin{array}{l}\text { /Scopus/N } \\
\text { D }\end{array}$ & & \\
\hline 70 & $\begin{array}{l}\text { A. } \\
\text { Dunsmore, } \\
\text { M. Roper, } \\
\text { and M. } \\
\text { Wood, }\end{array}$ & $\begin{array}{l}273 . \text { The role of } \\
\text { comprehension in } \\
\text { software inspection, } \\
\text { Journal of Systems and } \\
\text { Software, vol. 52, pp. } 121- \\
129,2000 \text {. }\end{array}$ & $\begin{array}{l}\text { /Scedirect } \\
\text { sdirect_10.pd } \\
f \\
\text { /Scopus/N }\end{array}$ & $\begin{array}{l}\text { - Presenta los resultados de dos experimentos que } \\
\text { relacionan la comprensión del programa y la } \\
\text { inspección }\end{array}$ & ART_70 \\
\hline 71 & & $\begin{array}{l}\text { The use of procedural } \\
\text { roles in code inspections: } \\
\text { An experimental study }\end{array}$ & D & - & ART_71 \\
\hline 72 & $\begin{array}{l}\quad \text { Adam } \\
\text { Porter, } \\
\text { Harvey Siy, } \\
\text { Audris } \\
\text { Mockus, } \\
\text { Lawrence } \\
\text { Votta }\end{array}$ & $\begin{array}{l}274 . \quad \text { Understanding } \\
\text { the sources of variation in } \\
\text { software inspections, } \\
\text { January 1998, ACM } \\
\text { Transactions on Software } \\
\text { Engineering and } \\
\text { Methodology (TOSEM), }\end{array}$ & $\begin{array}{c}\text { /ACM/ } \\
\text { acm_6.pdf } \\
\text { /Scopus/s } \\
\text { co_29.pdf }\end{array}$ & $\begin{array}{l}\text { - Describe el experimento previamente reportado } \\
\text { en p92-porter.pdf (00601071.pdf) y estudian las } \\
\text { variaciones en la efectividad y el intervalo }\end{array}$ & ART_72 \\
\hline
\end{tabular}


Proceso de RS de experimentos en Ingeniería del Software

\begin{tabular}{|c|c|c|c|c|c|}
\hline & & Volume 7 Issue 1 & & & \\
\hline 73 & $\begin{array}{l}\text { T. Thelin, } \\
\text { P. Runeson, } \\
\text { and B. } \\
\text { Regnell, }\end{array}$ & $\begin{array}{l}275 . \quad \text { Usage-based } \\
\text { reading--an experiment to } \\
\text { guide reviewers with use } \\
\text { cases, Information and } \\
\text { Software Technology, vol. } \\
\text { 43, pp. 925-938, } 2001 \text {. }\end{array}$ & $\begin{array}{l}\text { /Scedirect } \\
/ \\
\text { sdirect_8.pdf } \\
\text { /Scopus/N } \\
\text { D }\end{array}$ & $\begin{array}{l}\text { - Presenta un experimento conducido con } 27 \\
\text { estudiantes de IS } \\
\text { - Un grupo utilizó casos de uso priorizados y el } \\
\text { grupo control casos de uso aleatoriamente } \\
\text { ordenados } \\
\text { - Miden: efectividad y eficiencia en detectar fallas }\end{array}$ & ART_73 \\
\hline 74 & $\begin{array}{l}\text { B. Stefan } \\
\text { and J. G. } \\
\text { Walter, }\end{array}$ & $\begin{array}{l}276 . \quad \text { Using a Reliability } \\
\text { Growth Model to Control } \\
\text { Software Inspection, } \\
\text { Empirical Software } \\
\text { Engineering, vol. V7, pp. } \\
\text { 257-284, 2002. }\end{array}$ & $\begin{array}{l}\text { /Springer/ } \\
\text { Springer_3.pd } \\
\text { f } \\
\text { /Scopus/s } \\
\text { co_15.pdf }\end{array}$ & $\begin{array}{l}\text { - Propone un modelo de crecimiento de la } \\
\text { confiabilidad y dos modelos heurísticos lineales } \\
\text { para estimar el núm probable de defectos a ser } \\
\text { encontrados en la reinspección } \\
\text { - Los modelos son evaluados con datos de un } \\
\text { experimento controlado en reinspección } \\
\text { - Describe el experimento controlado }\end{array}$ & ART_74 \\
\hline 75 & $\begin{array}{l}\text { M. } \\
\text { Halling, }\end{array}$ & $\begin{array}{l}\text { 277. Using reading } \\
\text { techniques to focus }\end{array}$ & $\begin{array}{c}\text { /Xplore/ } \\
\text { Xplore_27.pd }\end{array}$ & $\begin{array}{l}\text { - Reporta la replicación de un experimento a gran } \\
\text { escala en un ambiente académico (Biffl, 2003) }\end{array}$ & ART_75 \\
\hline
\end{tabular}

Caso de estudio 


\begin{tabular}{|c|c|c|c|c|c|}
\hline & $\begin{array}{l}\text { Biffl, } \\
\text { Grechenig, } \\
\text { and M. Kohle, }\end{array}$ & $\begin{array}{l}\text { inspection performance, } \\
2001 .\end{array}$ & $f$ & $\begin{array}{l}\text { (sdirect_4.pdf) } \\
\text { _ Evalúa la efectividad de la detección de defectos } \\
\text { para inspectores que utilizan Checklist o } \\
\text { escenarios enfocados a nivel individual y de } \\
\text { equipo }\end{array}$ & \\
\hline 76 & $\begin{array}{l}\text { H. Lasse, } \\
\text { T. Ilkka, and } \\
\text { V. Pekka, }\end{array}$ & $\begin{array}{l}\text { 278. Using Software } \\
\text { Inspection as a Catalyst for } \\
\text { SPI in a Small Company, } \\
2004 .\end{array}$ & $\begin{array}{l}\text { /Springer/ } \\
\text { Springer_9.pd } \\
\text { f } \\
\text { /Scopus/N } \\
\text { D }\end{array}$ & $\begin{array}{c}\text { - Presenta un experimento en una pequeña } \\
\text { compañía de software que evalúa el efecto de la } \\
\text { inspección de software en la mejora de procesos }\end{array}$ & ART_76 \\
\hline 77 & $\begin{array}{l}\text { A. Porter } \\
\text { and L. Votta, }\end{array}$ & $\begin{array}{l}\text { What makes } \\
\text { inspections work?, } \\
\text { Software, IEEE, vol. 14, pp. } \\
\text { 99-102, } 1997 .\end{array}$ & $\begin{array}{l}\text { /Xplore/ } \\
\text { Xplore_28.pd } \\
f\end{array}$ & $\begin{array}{l}\text { - Resumen los resultados de haber conducido una } \\
\text { familia de experimentos para entender cómo } \\
\text { varios factores afectan los costos y beneficios de } \\
\text { la inspección }\end{array}$ & $\begin{array}{l}\text { ART_77 } \\
\text { Puede } \\
\text { existir una } \\
\text { publicación } \\
\text { previa } \\
\text { relacionada }\end{array}$ \\
\hline
\end{tabular}


Proceso de RS de experimentos en Ingeniería del Software

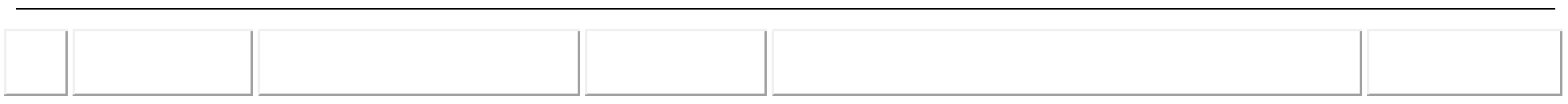

Caso de estudio 


\subsubsection{Documentar estadísticas de las búsquedas}

A continuación se presentan los resultados de las búsquedas realizadas.

B04 Formulario para Estadísticas de búsqueda

Realizado por: Anna Grimán

Fecha:

\begin{tabular}{|c|c|c|c|}
\hline \multicolumn{2}{|c|}{ Repositorio } & $\begin{array}{l}\text { 280. Artículos } \\
\text { recuperados }\end{array}$ & Artículos relevantes \\
\hline \multicolumn{2}{|c|}{ Xplore } & 30 & 22 \\
\hline \multicolumn{2}{|c|}{ SpringerLink } & 11 & 10 \\
\hline \multicolumn{2}{|c|}{ ScienceDirect } & 10 & 9 \\
\hline \multicolumn{2}{|c|}{ ACM DL } & 19 & 16 \\
\hline \multicolumn{2}{|c|}{ Scopus } & 57 & 51 \\
\hline & & 281. & \\
\hline 282. & \multicolumn{2}{|c|}{ Total artículos relevantes (distintos) } & 77 \\
\hline \multicolumn{3}{|c|}{ 283. Total estudios (distintos) } & (apróx.) 74 \\
\hline \multicolumn{3}{|c|}{ 284. Total replicaciones } & 5 \\
\hline
\end{tabular}

Cabe resaltar que existen artículos que aparecen en más de un repositorio, por lo cual se mantendrá sólo uno de ellos. También resaltamos que algunos experimentos se encuentran en diferentes publicaciones, p.e.: 


\section{Proceso de RS de experimentos en Ingeniería del Software}

-Springer_17 / Xplore_14: mismo experimento diferentes publicaciones $\rightarrow$ se incluyen ambos

-Xplore_8 / Sdirect_1: mismo experimento diferentes publicaciones $\rightarrow$ se incluyen ambos

- Xplore_10 / Acm_3: mismo experimento diferentes publicaciones $\rightarrow$ se incluyen ambos

En total, el conjunto base de artículos potenciales está formado por 77 artículos relevantes. De los artículos inicialmente identificados como relevantes, sin embargo, posteriormente algunos de ellos son descartados como producto de la Extracción.

Evaluación de la continuidad del proceso

Una vez que se han descartado los artículos irrelevantes, se cuenta con estudios suficientes para continuar con el proceso.

Caso de estudio 


\section{- 1.4. SELECCIÓN DE ESTUDIOS CANDIDATOS}

\begin{tabular}{|l|c|c|}
\hline \multicolumn{2}{|c|}{ Objetivo } \\
\multicolumn{2}{|c|}{ Contribuir al establecimiento de un objetivo de revisión específico, con base en los artículos } \\
seleccionados como relevantes en la actividad anterior \\
\hline Entrada & Salida \\
\hline B03_Resumen de artículos relevantes & - B05_Agrupamiento por sub-tema y tipo de estudio \\
\hline Tareas & - Grupo candidato a agregación \\
\hline 1.4.1. Identificar sub-temas & Entradas & Salidas \\
\hline 1.4.3. Establecer los grupos a agregar & B05_Agrupamiento por & Grupo candidato a \\
\hline 1.4.2. Agrupar artículos & artículos relevantes & Bub-tema y tipo de estudio \\
\end{tabular}

$-$

\subsubsection{Identificar sub-temas}

A continuación los sub-temas identificados a partir de los artículos relevantes encontrados en la actividad anterior.

Tabla XX. Sub-temas de "inspección de software" identificados en los artículos relevantes

\begin{tabular}{|l|l|}
\hline \multicolumn{1}{|c|}{ ID Sub- } & Descripción \\
tema & Comparación de técnicas de lectura/métodos de inspección \\
\hline ST-1 & Evaluación de la Costo-efectividad (de reuniones u otros factores) \\
\hline ST-2 & Comparación inspección tradicional vs soportada por herramientas (p.e. groupware) \\
\hline ST-3 & Mejora de una o más técnicas \\
\hline ST-4 & \\
\hline
\end{tabular}


Proceso de RS de experimentos en Ingeniería del Software

\begin{tabular}{|l|l|}
\hline ST-5 & Relación entre la inspección de software y SPI \\
\hline ST-6 & Comparación de inspección automática vs papel \\
\hline ST-7 & Comparación de la inspección con otro método de detección de errores \\
\hline ST-8 & Efectos de los cambios en los equipos \\
\hline ST-9 & Costo-efectividad de las técnicas en proyectos de gran escala \\
\hline ST-10 & Comparación entre tipos de grupos \\
\hline ST-11 & Capture-recapture \\
\hline ST-12 & Efectos de los defectos \\
\hline ST-13 & Comparación de modelos de estimación de defectos \\
\hline ST-14 & Reinspección \\
\hline ST-15 & \\
\hline ST-16 & \\
\hline
\end{tabular}

\subsubsection{Agrupar artículos}

A continuación se presenta el formulario B05_AGRUPAMIENTO POR SUB-TEMA Y TIPO DE ESTUDIO incluyendo los artículos agrupados según el sub-tema correspondiente y tipo de estudio.

Caso de estudio 
b05 Agrupamiento por sub-tema y tipo de estudio

Realizado por:

Fecha:

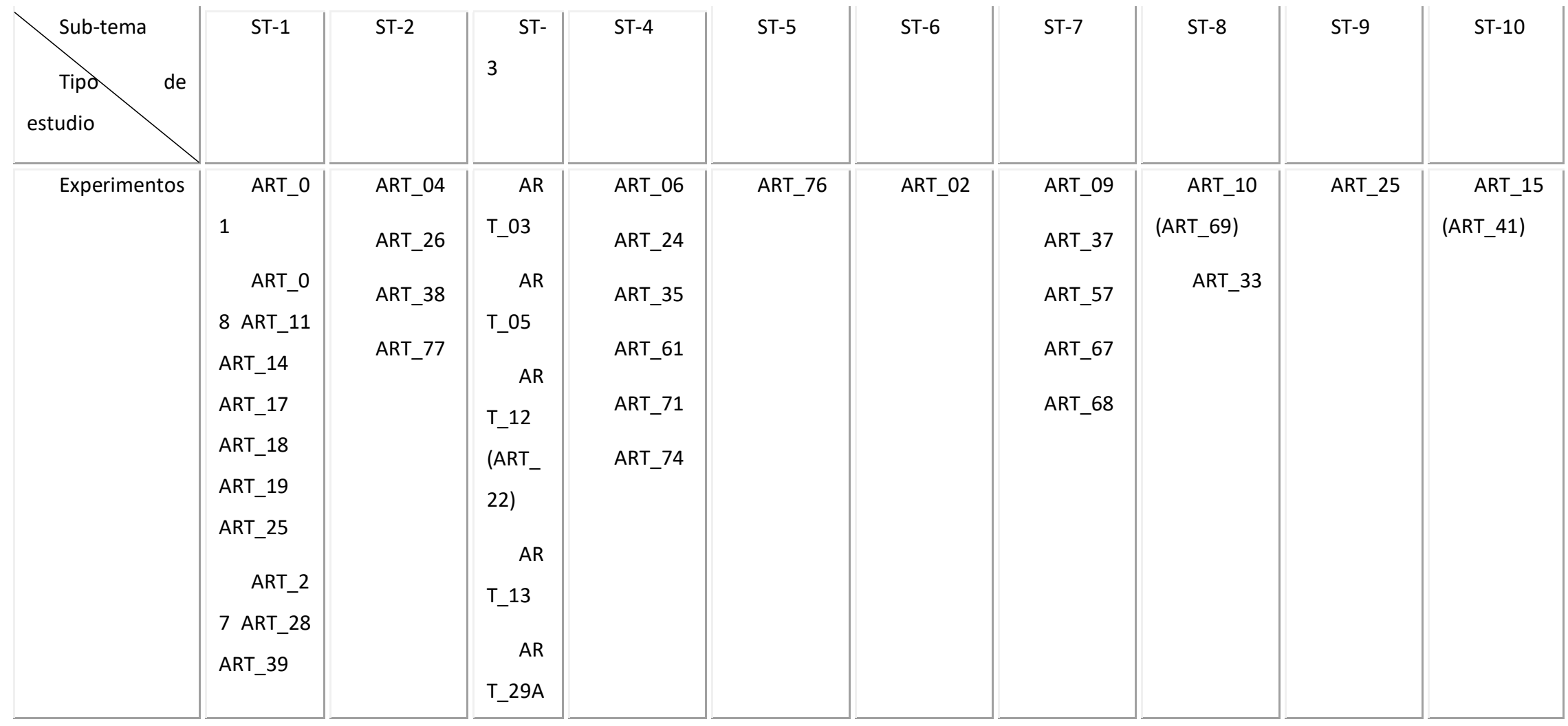


Proceso de RS de experimentos en Ingeniería del Software

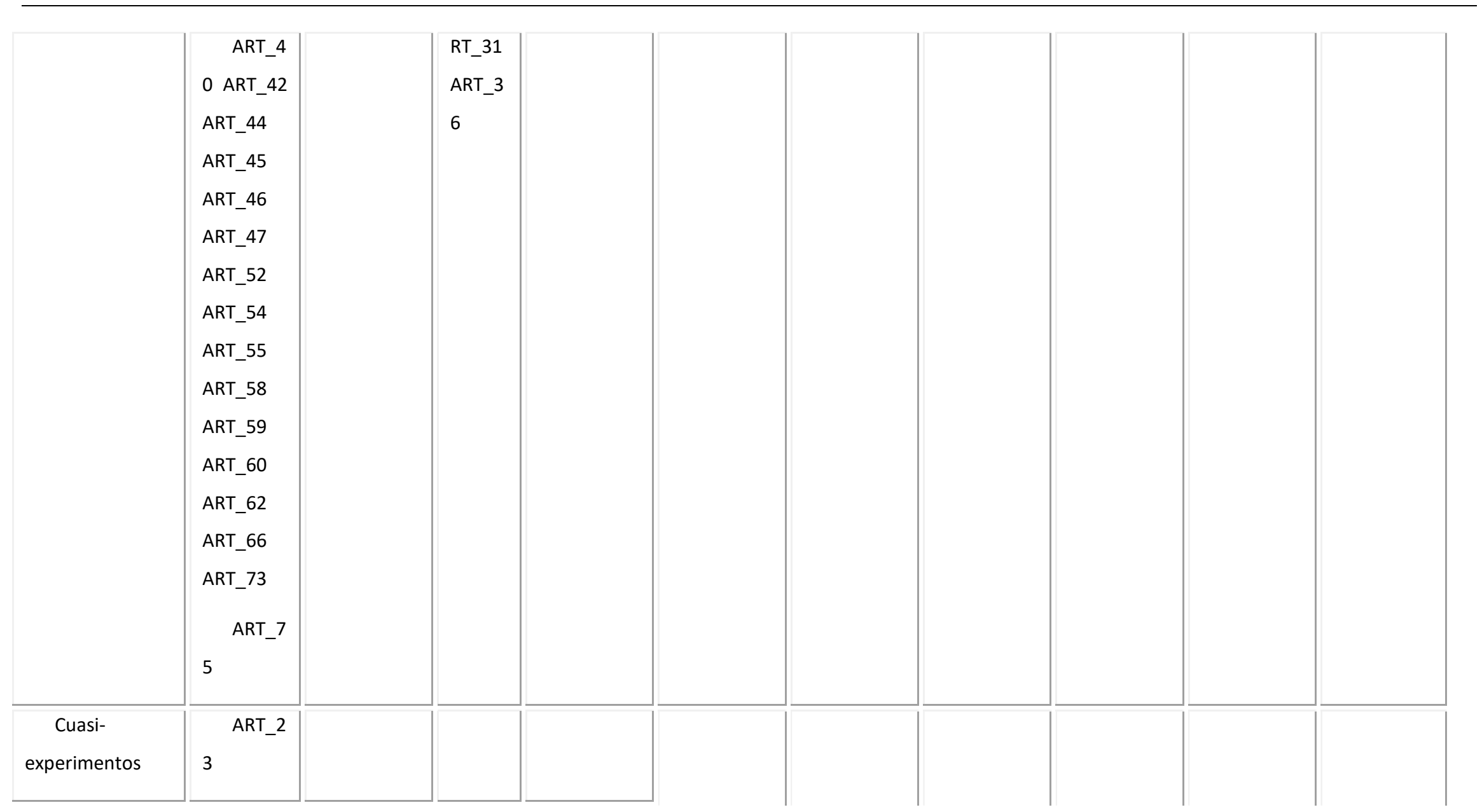


b05 Agrupamiento por sub-tema y tipo de estudio (CONTINUACIÓN...)

\begin{tabular}{|l|}
\hline Realizado por: \\
\hline Fecha: \\
\hline
\end{tabular}

\begin{tabular}{|c|c|c|c|c|c|c|c|}
\hline Sub-tema & $11^{\text {ST- }}$ & ST-12 & $13^{\text {ST- }}$ & ST-14 & ST-15 & ST-16 & Validación de una nueva propuesta \\
\hline Experimentos & $\begin{array}{c}\text { ART } \\
\text { _16 } \\
\text { ART } \\
-32 \\
\text { ART } \\
-50 \\
\text { ART } \\
\text { _56 } \\
\text { ART } \\
-65\end{array}$ & $\begin{array}{l}\text { ART_20 } \\
\text { ART_30 } \\
\text { ART_37 } \\
\text { ART_43 } \\
\text { ART_63 }\end{array}$ & $\begin{array}{r}\text { AR } \\
\text { T_34A } \\
\text { RT_72 }\end{array}$ & $\begin{array}{l}\text { ART_21 } \\
\text { ART_39 }\end{array}$ & $\begin{array}{l}\text { ART_53 } \\
\text { ART_64 } \\
\text { ART_70 }\end{array}$ & $\begin{array}{l}\text { ART_48 } \\
\text { ART_49 } \\
\text { ART_51 }\end{array}$ & \\
\hline Cuasi- & & & & & & & \\
\hline
\end{tabular}


experimentos 


\subsubsection{Establecer los grupos candidatos a agregación}

Para el presente caso de estudio se considerará como sub-tema de interés la Comparación de técnicas de lectura/Métodos de inspección. Las razones para seleccionar este sub-tema son las siguientes:

- Los grupos de experimentos son coherentes y agregables entre sí.

- El sub-tema es de especial interés para los revisores o la comunidad de Ingeniería del Software.

- Se cuenta con la mayor cantidad de experimentos y, por consiguiente, evidencias para la agregación.

La tabla A.3 resume los artículos incluidos en el sub-tema seleccionado. Nótese que algunos artículos considerados como relevantes, no son incluidos en esta lista debido a que se determina que se trata de un caso de estudio (ART_66), se encuentra duplicado (ART_62) o no se cuenta con el texto completo (ART_55).

Tabla A.3. Grupo de interés para la agregación

\begin{tabular}{|c|c|}
\hline Grupo agregable & Artículo \\
\hline $\begin{array}{l}\text { ST1- Experimentos } \\
\text { controlados }\end{array}$ & $\begin{array}{l}\text { ART_01, ART_08, ART_11, ART_14, ART_17, ART_18, ART_19, ART_25, } \\
\text { ART_27, ART_28, ART_39, ART_40, ART_42, ART_44, ART_45, ART_46, } \\
\text { ART_47, ART_52, ART_54, ART_58, ART_59, ART_60, ART_73, ART_75 }\end{array}$ \\
\hline $\begin{array}{l}\text { ST1-Quasi- } \\
\text { experimentos }\end{array}$ & ART_23 \\
\hline
\end{tabular}

El conjunto a agregar está entonces formado por $\mathbf{2 5}$ artículos.

Evaluación de la continuidad del proceso 
Proceso de RS de experimentos en Ingeniería del Software

Una vez que se han obtenido los GCA, se cuenta con al menos un GCA de interés y con experimentos suficientes.

Caso de estudio 


\section{- 1.5. DECLARACIÓN DEL OBJETIVO DE REVISIÓN}

\begin{tabular}{|c|c|c|}
\hline \multicolumn{3}{|l|}{ Objetivo } \\
\hline $\begin{array}{l}\text { Definir con precisión el objetivo de } \\
\text { inclusión/exclusión de estudios. }\end{array}$ & revisión, la pregunta de & evisión y los criterios de \\
\hline Entrada & \multicolumn{2}{|l|}{ Salida } \\
\hline Grupo Candidato a Agregar & \multicolumn{2}{|c|}{ B07_Declaración del objetivo de Revisión } \\
\hline \multicolumn{3}{|l|}{ Tareas } \\
\hline & Entradas & Salidas \\
\hline $\begin{array}{l}\text { Establecer y justificar el objetivo de la } \\
\text { revisión }\end{array}$ & $\begin{array}{l}\text { Grupo candidato a } \\
\text { agregar }\end{array}$ & $\begin{array}{l}\text { B07_Declaración del } \\
\text { objetivo de Revisión } \\
\text { (enunciado, justificación) }\end{array}$ \\
\hline Establecer la pregunta de revisión & Objetivo de la revisión & $\begin{array}{l}\text { B07_Declaración del } \\
\text { objetivo de Revisión } \\
\text { (Pregunta de revisión) }\end{array}$ \\
\hline $\begin{array}{ccc}\text { Establecer } & \text { criterios } & \text { de } \\
\text { inclusión/exclusión } & & \end{array}$ & Pregunta de revisión & $\begin{array}{l}\text { B07_Declaración del } \\
\text { objetivo de Revisión } \\
\text { (Criterios de I/E) }\end{array}$ \\
\hline
\end{tabular}

Cada una de las tareas ejecutadas a continuación, contribuyen a cumplimentar el formulario B07 con la información necesaria para establecer de manera precisa el objetivo de la revisión.

\subsubsection{Establecer y justificar el objetivo de la revisión}

A continuación se presenta el enunciado y justificación del objetivo de revisión en el caso de estudio.

B07 Declaración del objetivo de revisión

Realizado por:

Fecha: 


\begin{tabular}{|c|c|c|}
\hline & $\begin{array}{l}\text { 285. Enun } \\
\text { ciado }\end{array}$ & $\begin{array}{l}\text { Comparar técnicas de lectura de código y métodos de } \\
\text { inspección de software. }\end{array}$ \\
\hline OBJETIVO & $\begin{array}{l}286 . \quad J u s t i f i \\
\text { cación }\end{array}$ & $\begin{array}{l}\text { Desde el punto de vista académico, la comparación de } \\
\text { técnicas de lectura de código y métodos de inspección } \\
\text { puede permitir establecer los problemas abiertos } \\
\text { (variables no ensayadas, técnicas de mayor interés para la } \\
\text { comunidad, etc.); en cambio, desde el punto de vista } \\
\text { profesional, esta revisión permitirá mejorar el cuerpo de } \\
\text { conocimiento relacionado con esta tecnología, lo cual } \\
\text { permitiría, al mismo tiempo, orientar a los desarrolladores } \\
\text { en sus organizaciones acerca de las mejores prácticas para } \\
\text { asegurar la calidad del producto software. }\end{array}$ \\
\hline & $\begin{array}{l}287 . \quad \text { Situa } \\
\text { ción y } \\
\text { Ambiente } \\
\text { experimental }\end{array}$ & \\
\hline PREGUNTA DE & $\begin{array}{l}\text { 288. Trata } \\
\text { mientos }\end{array}$ & \\
\hline & $\begin{array}{l}\text { 289. Varia } \\
\text { bles respuesta }\end{array}$ & \\
\hline & $\begin{array}{l}\text { 290. Tipo } \\
\text { de Diseño }\end{array}$ & \\
\hline CRITERIOS & $\begin{array}{l}\text { 291. Inclui } \\
\text { r }\end{array}$ & \\
\hline
\end{tabular}

Caso de estudio 
292. Exclui

$r$

ran

\subsubsection{Establecer la pregunta de revisión}

A continuación se muestra el uso del formulario B07 para documentar la pregunta de revisión en este caso de estudio.

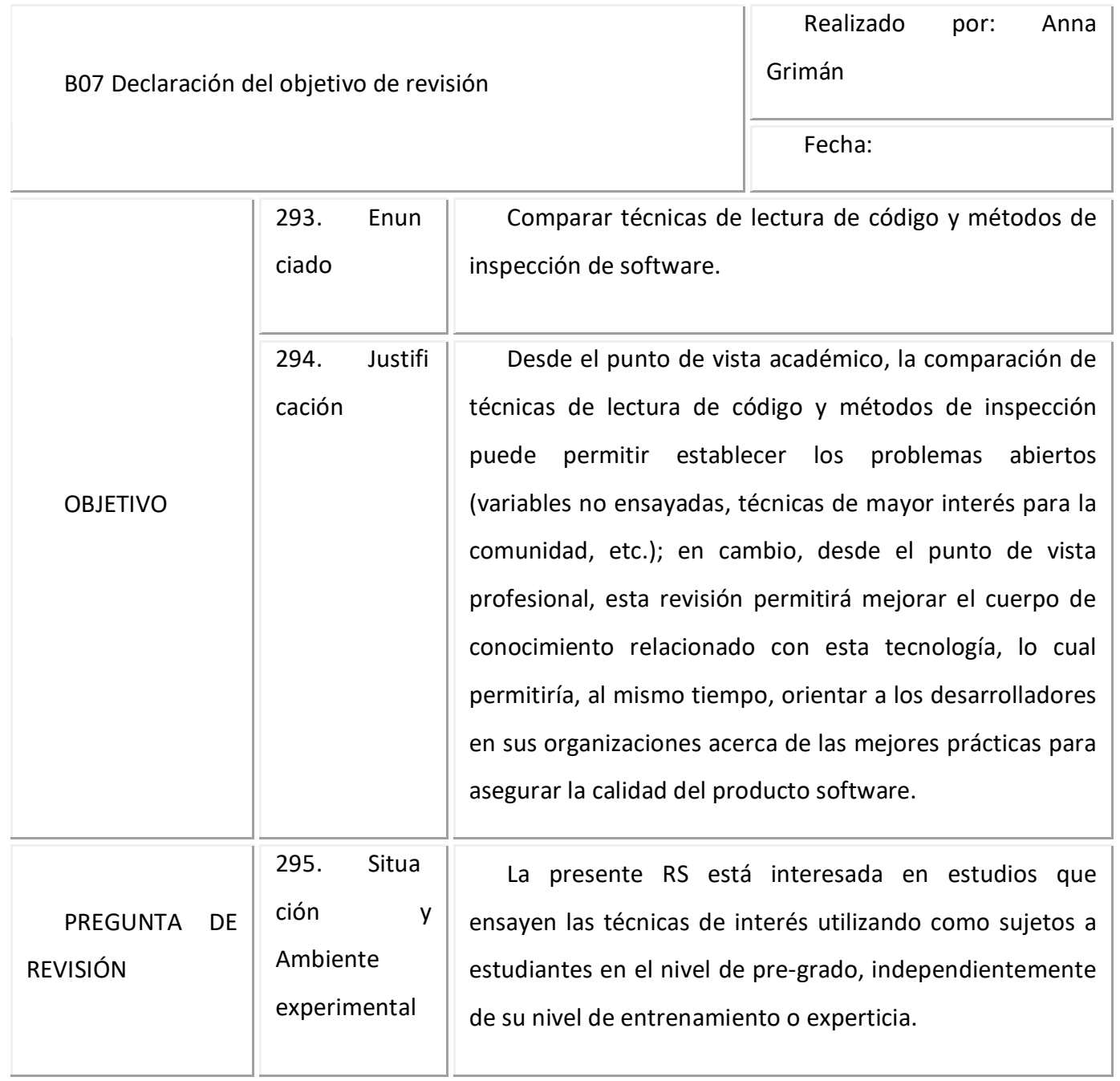




\begin{tabular}{|c|c|c|}
\hline & $\begin{array}{l}\text { 296. Trata } \\
\text { mientos }\end{array}$ & $\begin{array}{l}\text { Técnicas de lectura de código basadas en listas de } \\
\text { chequeo, casos de uso, perspectivas, escenarios y } \\
\text { métodos ad-hoc; así como las distintas comparaciones } \\
\text { entre ellos. }\end{array}$ \\
\hline & $\begin{array}{l}\text { 297. Varia } \\
\text { bles respuesta }\end{array}$ & $\begin{array}{l}\text { Efectividad y la eficiencia de la técnica en la detección } \\
\text { de defectos }\end{array}$ \\
\hline & $\begin{array}{l}\text { 298. Tipo } \\
\text { de Diseño }\end{array}$ & Experimentos \\
\hline \multirow{2}{*}{ CRITERIOS } & $\begin{array}{l}\text { 299. Inclui } \\
r\end{array}$ & \\
\hline & $\begin{array}{l}\text { 300. Exclui } \\
r\end{array}$ & \\
\hline
\end{tabular}

\subsubsection{Establecer los criterios de inclusión/exclusión de estudios}

A continuación se completa el formulario para la Declaración del objetivo de revisión, con la información referente a los criterios de inclusión/exclusión.

\begin{tabular}{|l||l|l|}
\hline B07 Declaración del objetivo de revisión & \multicolumn{2}{l|}{ Realizado por: } \\
\hline OBJETIVO & $\begin{array}{l}301 . \\
\text { ciado }\end{array}$ & $\begin{array}{l}\text { Compan } \\
\text { Comparar técnicas de lectura de código y métodos de } \\
\text { inspección de software. }\end{array}$ \\
\hline
\end{tabular}

Caso de estudio 


\begin{tabular}{|c|c|c|}
\hline & $\begin{array}{l}302 . \quad J u s t i f i \\
\text { cación }\end{array}$ & $\begin{array}{l}\text { Desde el punto de vista académico, la comparación de } \\
\text { técnicas de lectura de código y métodos de inspección } \\
\text { puede permitir establecer los problemas abiertos } \\
\text { (variables no ensayadas, técnicas de mayor interés para la } \\
\text { comunidad, etc.); en cambio, desde el punto de vista } \\
\text { profesional, esta revisión permitirá mejorar el cuerpo de } \\
\text { conocimiento relacionado con esta tecnología, lo cual } \\
\text { permitiría, al mismo tiempo, orientar a los desarrolladores } \\
\text { en sus organizaciones acerca de las mejores prácticas para } \\
\text { asegurar la calidad del producto software. }\end{array}$ \\
\hline \multirow{4}{*}{$\begin{array}{l}\text { PREGUNTA DE } \\
\text { REVISIÓN }\end{array}$} & $\begin{array}{l}\text { 303. Situa } \\
\text { ción y } \\
\text { Ambiente } \\
\text { experimental }\end{array}$ & $\begin{array}{l}\text { La presente RS está interesada en estudios que } \\
\text { ensayen las técnicas de interés utilizando como sujetos a } \\
\text { estudiantes en el nivel de pre-grado, independientemente } \\
\text { de su nivel de entrenamiento o experticia. }\end{array}$ \\
\hline & $\begin{array}{l}\text { 304. Trata } \\
\text { mientos }\end{array}$ & $\begin{array}{l}\text { Técnicas de lectura de código basadas en listas de } \\
\text { chequeo, casos de uso, perspectivas, escenarios y } \\
\text { métodos ad-hoc; así como las distintas comparaciones } \\
\text { entre ellos. }\end{array}$ \\
\hline & $\begin{array}{l}\text { 305. Varia } \\
\text { bles respuesta }\end{array}$ & $\begin{array}{l}\text { Efectividad y la eficiencia de la técnica en la detección } \\
\text { de defectos }\end{array}$ \\
\hline & $\begin{array}{l}\text { 306. Tipo } \\
\text { de Diseño }\end{array}$ & Experimentos \\
\hline CRITERIOS & $\begin{array}{l}307 . \\
r\end{array}$ & $\begin{array}{l}\text { - Experimentos y cuasi-experimentos conducidos } \\
\text { en laboratorio } \\
\text { - con estudiantes universitarios (pre-grado), } \\
\text { - que evalúen o comparen la efectividad de dos o } \\
\text { más técnicas de lectura o métodos de detección }\end{array}$ \\
\hline
\end{tabular}




\begin{tabular}{|c|c|c|c|}
\hline & & - & $\begin{array}{l}\text { de defectos ampliamente reconocidas en la } \\
\text { literatura del área, } \\
\text { para la detección de errores en el diseño de } \\
\text { modelos UML. }\end{array}$ \\
\hline $\begin{array}{l}308 . \\
r\end{array}$ & Exclui & - & $\begin{array}{l}\text { Casos de estudio } \\
\text { Estudios en los que los autores propongan la } \\
\text { técnica y la validen en comparación con una } \\
\text { técnica conocida. } \\
\text { Estudios sin grupo control } \\
\text { Estudios conducidos sin supervisión, por ejemplo, } \\
\text { aquellos donde los sujetos aplicaron la técnica } \\
\text { fuera del laboratorio } \\
\text { Estudios observacionales }\end{array}$ \\
\hline
\end{tabular}




\section{- 1.6. BÚSQUEDA Y LECTURA DE ANTECEDENTES}

\begin{tabular}{|l|c|c|c|}
\hline \multicolumn{2}{|c|}{ Objetivo } \\
Realizar una exploración rápida para descartar que ya exista una RS que satisfaga el objetivo \\
establecido para la actual RS & Salida \\
\hline Entrada & B06_Análisis de las RS recuperadas \\
\hline B07 Declaración del objetivo de revisión & Entradas & Salidas \\
\hline Tareas & B07_Declaración del & B06_Análisis de las RS \\
\hline Buscar RS previas & objetivo de revisión recuperadas \\
\hline Determinar la relevancia de las RS & B06_Análisis de las RS & B06_Análisis de las RS \\
\hline existentes
\end{tabular}

\subsubsection{Buscar RS previas}

Para el momento de acometer la Fase de Búsqueda en este caso de estudio, no se identificaron RS sobre el mismo tema.

\subsubsection{Determinar la relevancia de las $\mathrm{RS}$ existentes}

No aplica debido a que no hubo resultados en la actividad anterior. 


\section{- 1.7. BÚSQUEDA REFINADA}

\begin{tabular}{|c|c|c|}
\hline \multicolumn{3}{|l|}{ Objetivo } \\
\hline \multicolumn{3}{|c|}{$\begin{array}{l}\text { Detectar el mayor número posible de artículos relevantes (o potencialmente elegibles) de una } \\
\text { manera óptima con respecto al esfuerzo de selección/descarte de artículos. }\end{array}$} \\
\hline Entrada & Salida & \\
\hline \multicolumn{3}{|l|}{ Tareas } \\
\hline & Entradas & Salidas \\
\hline $\begin{array}{l}\text { 1.7.1. Seleccionar fuentes de } \\
\text { información }\end{array}$ & & $\begin{array}{l}\text { Repositorio, Universo } \\
\text { de búsqueda }\end{array}$ \\
\hline 1.7.2. Seleccionar campos de Búsqueda & & Campos de búsqueda \\
\hline 1.7.3. Definir la cadena de Búsqueda & & $\begin{array}{l}\text { Términos } \\
\text { experimentales, Términos } \\
\text { del tema }\end{array}$ \\
\hline $\begin{array}{l}\text { 1.7.4. Documentar la estrategia de } \\
\text { búsqueda }\end{array}$ & $\begin{array}{l}\text { - Repositorio, Universo } \\
\text { de búsqueda, Campos de } \\
\text { búsqueda, Términos }\end{array}$ & Estrategia de Búsqueda \\
\hline 1.7.5. Ejecutar la Búsqueda & $\begin{array}{l}\text { Estrategia de } \\
\text { Búsqueda }\end{array}$ & $\begin{array}{l}\text { B02_Análisis de } \\
\text { artículos recuperados }\end{array}$ \\
\hline
\end{tabular}

Debido a los solapamientos identificados en la Búsqueda preliminar, se decidió limitar la búsqueda refinada a la base de datos Scopus. Sin embargo, se decidió ampliar la búsqueda en lo relativo a los campos, incluyendo en esta actividad el campo "palabras clave".

Por otra parte, se decidió aplicar una estrategia iterativa, en la cual se realizaron 2 iteraciones adicionales a la realizada en la Búsqueda Preliminar (iteración 1). Por lo tanto, a la primera iteración

Caso de estudio 
corresponde la cadena de búsqueda que incluye sólo el término "software inspection". En la Tabla A.4 se resumen los artículos relevantes recuperados en la iteración 1 correspondientes al buscador Scopus.

\section{Tabla A.4. Cadena de Búsqueda}

\begin{tabular}{|c|c|c|c|}
\hline $\begin{array}{l}\text { Iteraci } \\
\text { ón }\end{array}$ & Cadena de búsqueda & $\begin{array}{l}\text { No. art. } \\
\text { recuperados }\end{array}$ & $\begin{array}{l}\text { No. de } \\
\text { art. } \\
\text { potenciales }\end{array}$ \\
\hline 1 & $\begin{array}{l}\text { ABS("software inspection" AND (experiment OR } \\
\text { "experimental study" OR "experimental comparison" OR } \\
\text { "experimental analysis" OR "experimental evidence" OR } \\
\text { "experimental setting")) OR TITLE("software inspection" } \\
\text { AND (experiment OR "experimental study" OR } \\
\text { "experimental comparison" OR "experimental analysis" } \\
\text { OR "experimental evidence" OR "experimental setting")) }\end{array}$ & 57 & 51 \\
\hline
\end{tabular}

La iteración siguiente se realizó con los términos extraídos de los artículos pertenecientes al grupo agregable. Tales términos corresponden a sinónimos de las técnicas de lectura de código y a los métodos de inspección.

A continuación se presentan las búsquedas realizadas en cada una de las iteraciones, así como sus resultados.

\subsubsection{Definir la cadena de búsqueda (segunda iteración)}

Para esta iteración se extrajeron los siguientes términos de los artículos de grupo agregable:

active guidance

capture-recapture

checklist-based reading inspection effectiveness

inspection maturity model

inspection meeting 


\begin{tabular}{|c|c|}
\hline code inspection & inspection method \\
\hline computer supported inspection & inspection model \\
\hline computer-based inspection & inspection pattern \\
\hline curve fitting & inspection performance \\
\hline defect content estimation technique & inspection planning \\
\hline defect data & inspection process \\
\hline defect density & inspection team \\
\hline defect detection & inspection technique \\
\hline defect estimation model & $\mathrm{n}$-fold inspection \\
\hline design inspection & paper-based inspection \\
\hline detection rate & perspective-based reading \\
\hline error detection & reading method \\
\hline estimation model & reading technique \\
\hline fagan & reinspection \\
\hline fault content estimation & scenario-based reading \\
\hline fault detection & software inspector \\
\hline individual inspection & software review \\
\hline inspection context & team-based inspection \\
\hline inspection data & tool-supported inspection \\
\hline
\end{tabular}

De la lista anterior se seleccionaron aquellos términos más recurrentes en los resúmenes revisados, agrupados en: sinónimos de "software inspection" y términos específicos del sub-tema de interés (véase Tabla A.5).

Caso de estudio 
Tabla A.5. Términos encontrados en los resúmenes de los grupos a agregar

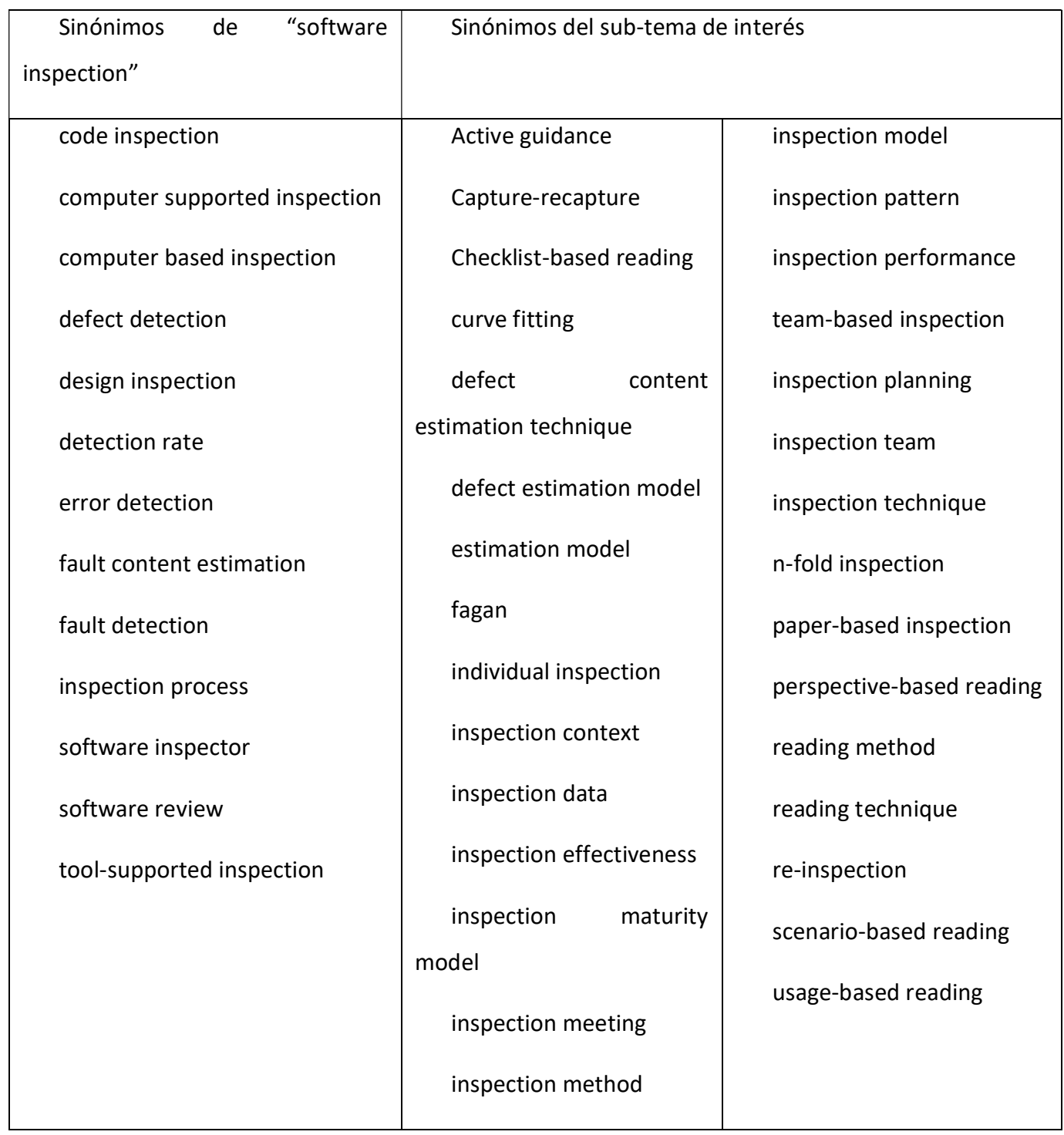




\subsubsection{Documentar estrategia de búsqueda (segunda iteración)}

La tabla A.6 presenta la cadena de búsqueda realizada en Scopus con base en los términos extraídos previamente.

Tabla A.6. Cadena de búsqueda para Scopus (2da iteración)

\begin{tabular}{|c|c|}
\hline Repositori & Cadena de búsqueda \\
\hline Scopus & $\begin{array}{l}\text { TITLE-ABS-KEY(("active guidance" OR "active guidances" OR capture-recapture } \\
\text { OR "checklist-based reading" OR "code inspection" OR "code inspections" OR } \\
\text { "computer supported inspection" OR "computer supported inspections" OR } \\
\text { "computer-based inspection" OR "computer-based inspections" OR "curve fitting" } \\
\text { OR "defect content estimation technique" OR "defect content estimation } \\
\text { techniques" OR "defect data" OR "defect density" OR "defect detection" OR } \\
\text { "defect detections" OR "defect estimation model" OR "defect estimation models" } \\
\text { OR "design inspection" OR "design inspections" OR "detection rate" OR "error } \\
\text { detection" OR "estimation model" OR "estimation models" OR fagan OR "fault } \\
\text { content estimation" OR "fault content estimations" OR "fault detection" OR "fault } \\
\text { detections" OR "individual inspection" OR "individual inspections" OR "inspection } \\
\text { context" OR "inspection contexts" OR "inspection data" OR "inspection } \\
\text { effectiveness" OR "inspection maturity model" OR "inspection maturity models" } \\
\text { OR "inspection meeting" OR "inspection meetings" OR "inspection method" OR } \\
\text { "inspection methods" OR "inspection model" OR "inspection models" OR } \\
\text { "inspection pattern" OR "inspection patterns" OR "inspection performance" OR } \\
\text { "inspection planning" OR "inspection process" OR "inspection processes" OR } \\
\text { "inspection team" OR "inspection teams" OR "inspection technique" OR } \\
\text { "inspection techniques" OR "n-fold inspection" OR "n-fold inspections" OR "paper- } \\
\text { based inspection" OR "paper-based inspections" OR "perspective-based reading" } \\
\text { OR "reading method" OR "reading methods" OR "reading technique" OR "reading }\end{array}$ \\
\hline
\end{tabular}

Caso de estudio 


\begin{tabular}{|l|l|}
\hline techniques" OR reinspection OR "scenario-based reading" OR "software \\
inspector" OR "software inspectors" OR "software review" OR "software reviews" \\
OR "team-based inspection" OR "team-based inspections" OR "tool-supported \\
inspection" OR "tool-supported inspections" OR "usage-based reading") AND \\
$\begin{array}{l}\text { (experiment OR "experimental study" OR "experimental comparison" OR "experimental } \\
\text { analysis" OR "experimental evidence" OR "experimental setting")) }\end{array}$
\end{tabular}

\subsubsection{Ejecutar búsqueda (segunda iteración)}

Como muestra la tabla A.7, luego de ejecutar la cadena de búsqueda se obtuvieron más de 900 artículos, los cuales fueron registrados a través de una herramienta automática de gestión de referencias. Por razones de espacio, sólo se reporta un listado de los títulos.

\section{Tabla A.7. Resultado de la búsqueda (2da iteración)}

\begin{tabular}{|l|c|}
\hline Cadena de búsqueda & No. \\
recuperados \\
\hline TITLE-ABS-KEY("active guidance" OR "active guidances" OR capture-recapture OR & 905 \\
"checklist-based reading" OR "code inspection" OR "code inspections" OR "computer & \\
supported inspection" OR "computer supported inspections" OR "computer-based & \\
inspection" OR "computer-based inspections" OR "curve fitting" OR "defect content & \\
estimation technique" OR "defect content estimation techniques" OR "defect data" OR & \\
"defect density" OR "defect detection" OR "defect detections" OR "defect estimation & \\
model" OR "defect estimation models" OR "design inspection" OR "design inspections" OR & \\
"detection rate" OR "error detection" OR "estimation model" OR "estimation models" OR & \\
fagan OR "fault content estimation" OR "fault content estimations" OR "fault detection" OR & \\
"fault detections" OR "individual inspection" OR "individual inspections" OR "inspection & \\
context" OR "inspection contexts" OR "inspection data" OR "inspection effectiveness" OR & \\
"inspection maturity model" OR "inspection maturity models" OR "inspection meeting" OR \\
"inspection meetings" OR "inspection method" OR "inspection methods" OR "inspection
\end{tabular}




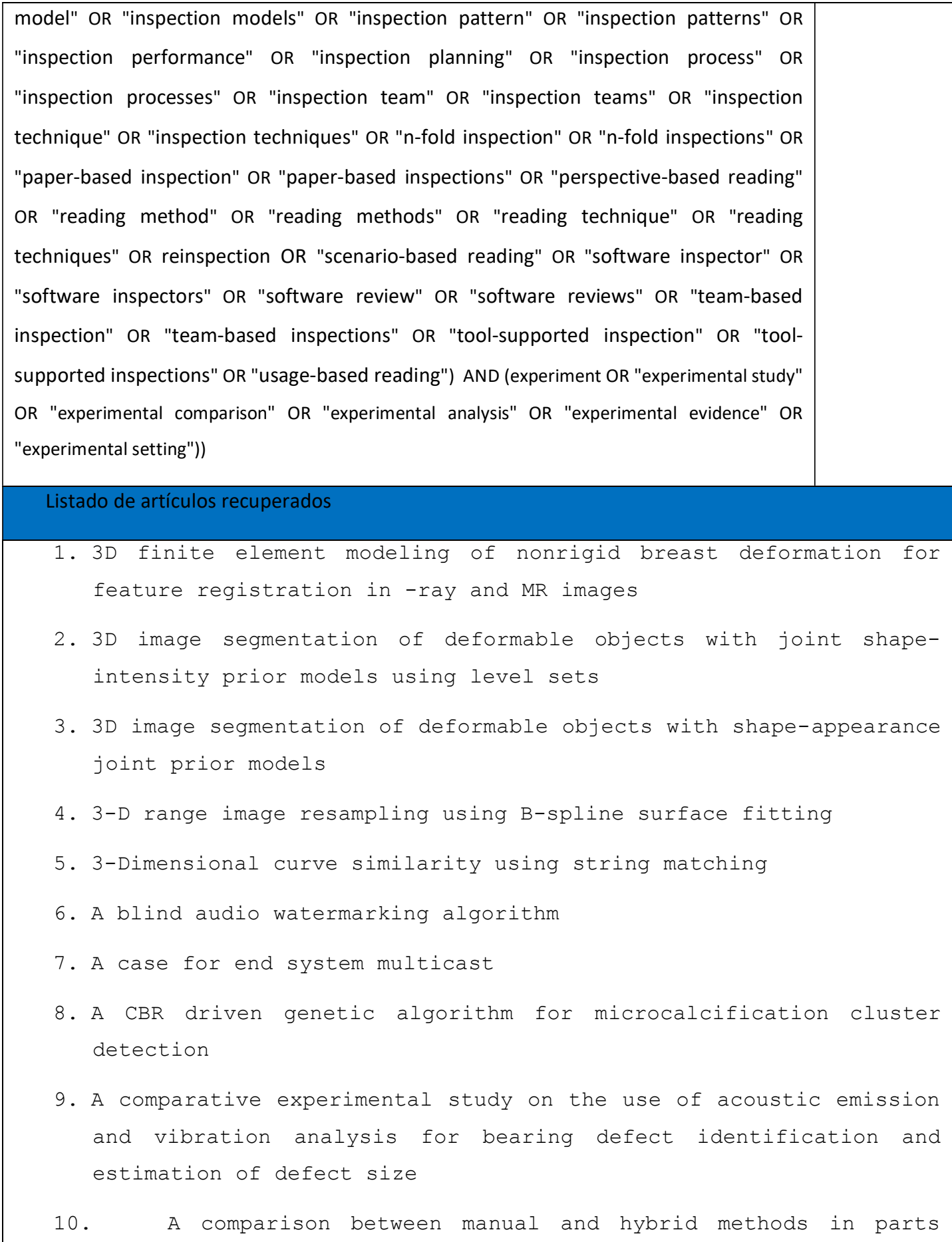

Caso de estudio 


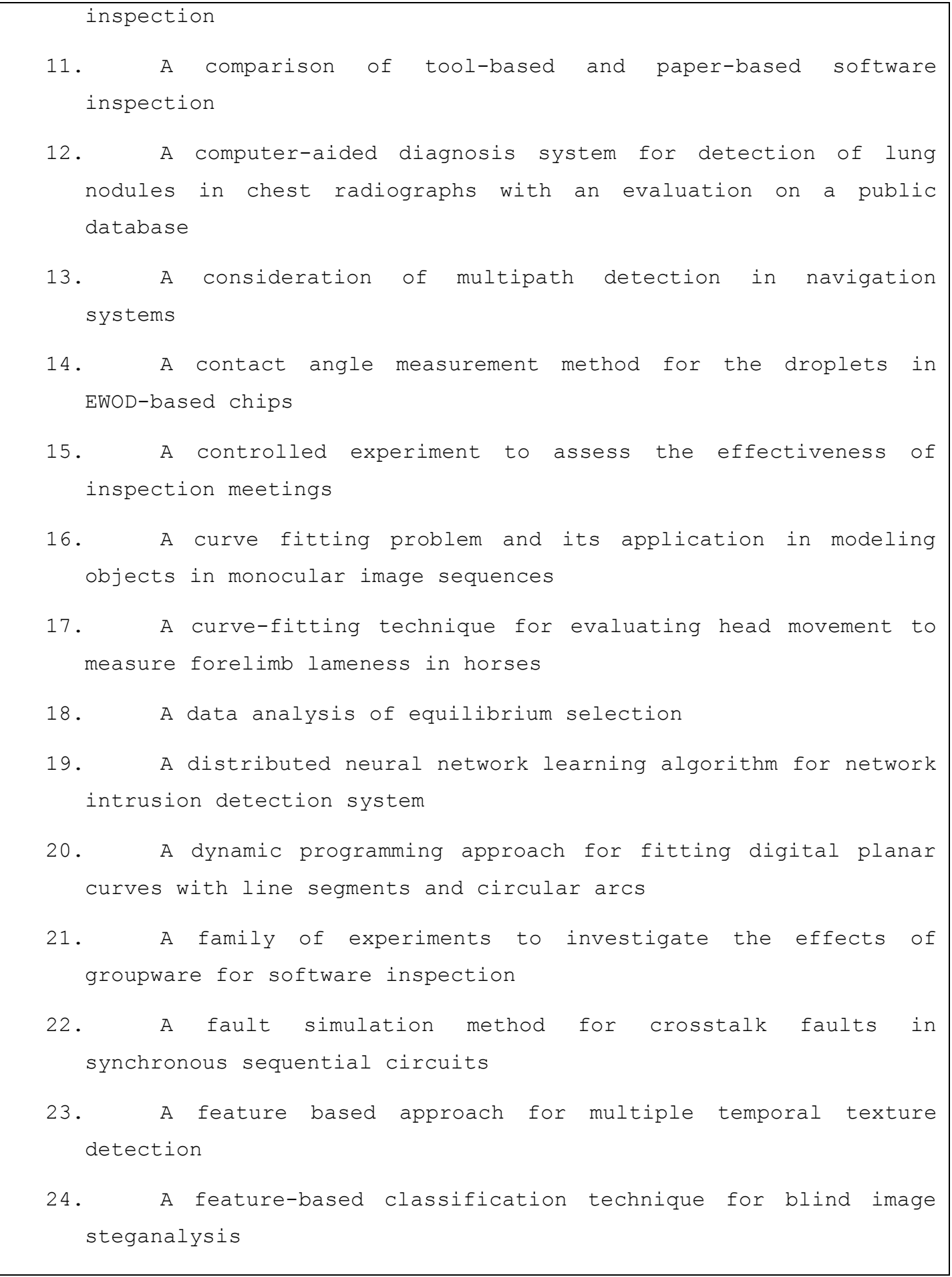




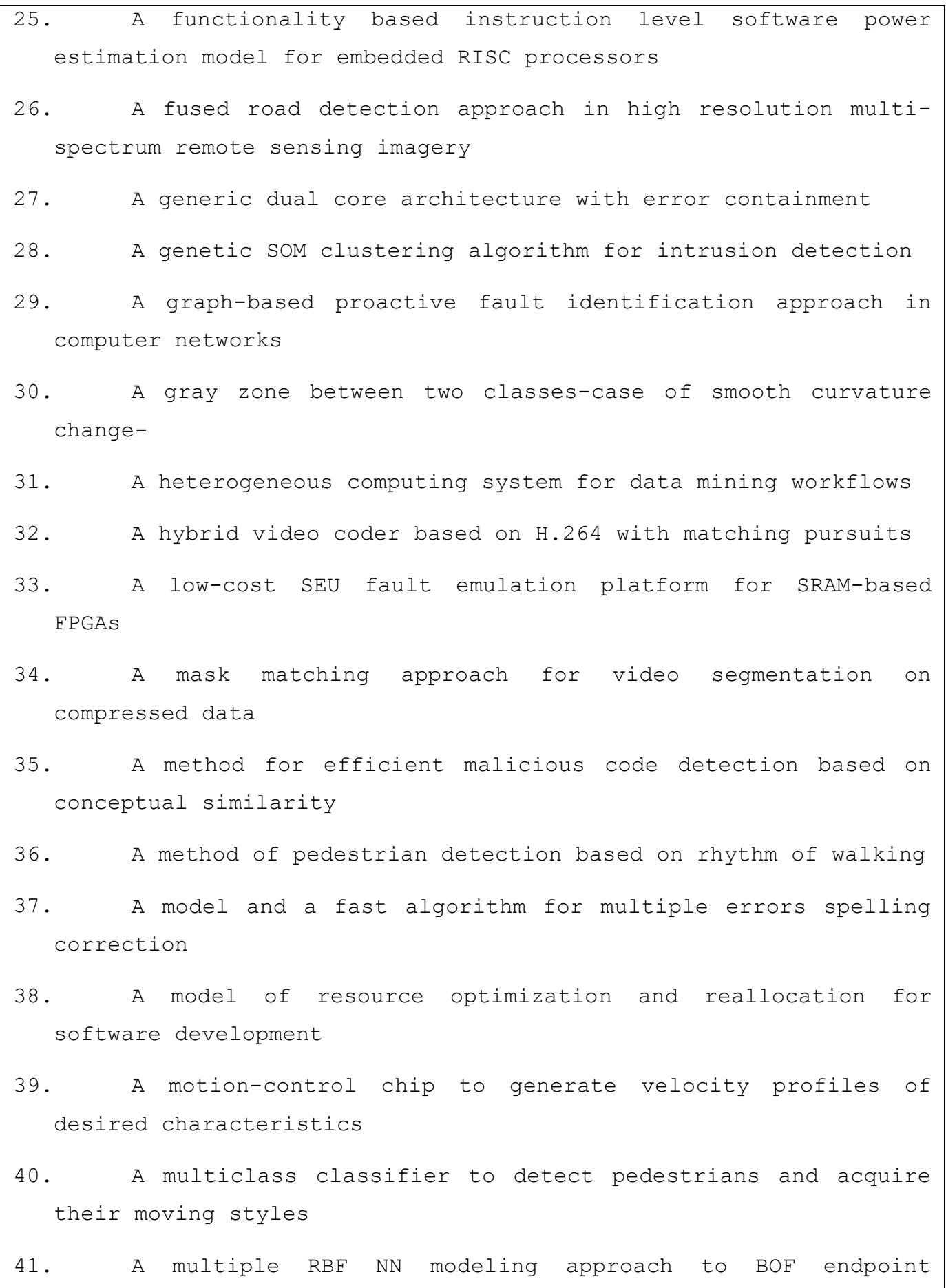

\section{Caso de estudio}


estimation in steelmaking process

42. A new intrusion detection model based on combination of order and frequency characters of system calls

43. A novel manufacturing defect detection method using data mining approach

44. A novel SVM decision tree and its application to face detection

45. A novel wavelet transform based transient current analysis for fault detection and localization

46. A novel wavelet transform-based transient current analysis for fault detection and localization

47. A numerical method for biphasic curve fitting with a programmable calculator

48. A pattern approach to software inspection process improvement

49. A PCI Interface with four 2 Gbit/s serial optical links

50. A promising approach to two-person software review in educational environment-

51. A real-time system-adapted anomaly detector

52. A region and data hiding based error concealment scheme for images

53. A Replicated Experiment to Assess Requirements Inspection Techniques

54. A replicated server architecture supporting survivable services

55. A robust analysis for unreplicated factorial experiments

56. A robust fingerprint matching method

57. A robust real-time pitch detector based on neural networks

58. A routine fitting of kinetic data to sums of exponentials with a programmable calculator

59. A segmentation-based multiple-baseline stereo (SMBS) scheme for 


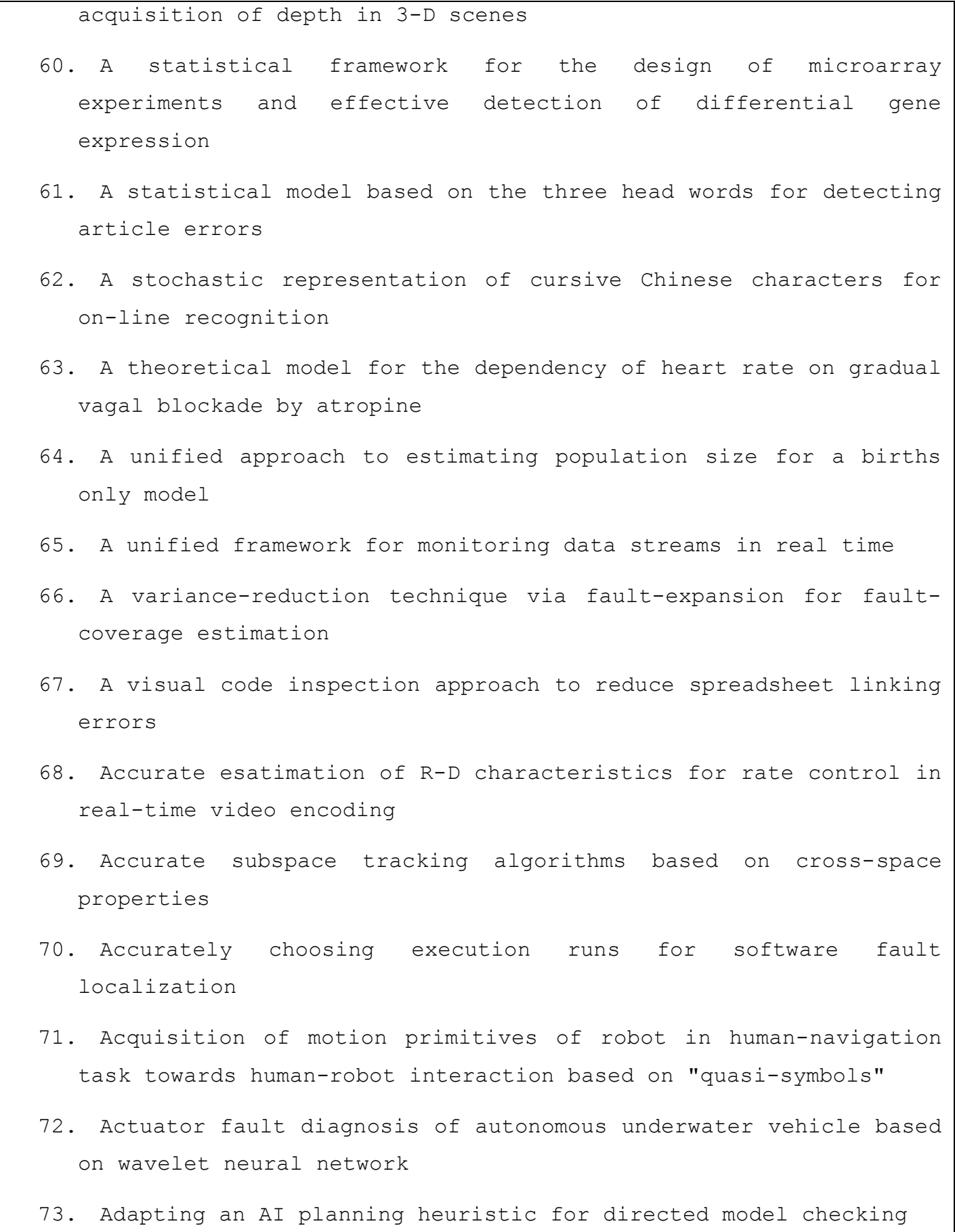

\section{Caso de estudio}


74. Adaptive $700 \hat{a}<-1350 \mathrm{ps} / \mathrm{nm}$ chromatic dispersion compensation in $1.6 \mathrm{Tbit} / \mathrm{s}(40 \tilde{\mathrm{A}}-40 \mathrm{Gbit} / \mathrm{s})$ DPSK and ASK transmission experiments over $44 \hat{a}<-81 \mathrm{~km}$ of $\mathrm{SSMF}$

75. Adaptive and distributed fault monitoring of grid by mobile agents

76. Adaptive anomaly detection with evolving connectionist systems

77. Adaptive B-splines and boundary estimation

78. Adaptive delay concealment for internet voice applications with packet-based time-scale modification

79. Adaptive normalization of handwritten characters using global/local affine transformation

80. Adaptive reconstruction of bone geometry from serial crosssections

81. ADAPTIVE SCHEDULED EXPERIMENTATION AND FAULT LOCATION IN LARGE COMBINATIONAL LOGIC NETWORKS

82. Algorithm based fault tolerance versus result-checking for matrix computations

83. Algorithm for non-parametric model identification and curve fitting

84. Algorithm of pipeline leak detection based on discrete incremental clustering method

85. ALGORITHMS FOR DESIGNING FAULT-DETECTION EXPERIMENTS FOR SEQUENTIAL MACHINES.

86. An active queue management scheme based on a capture-recapture model

87. An active search method for local individual features in offline signature verification

88. An adaptive level-selecting wavelet transform for texture defect detection 


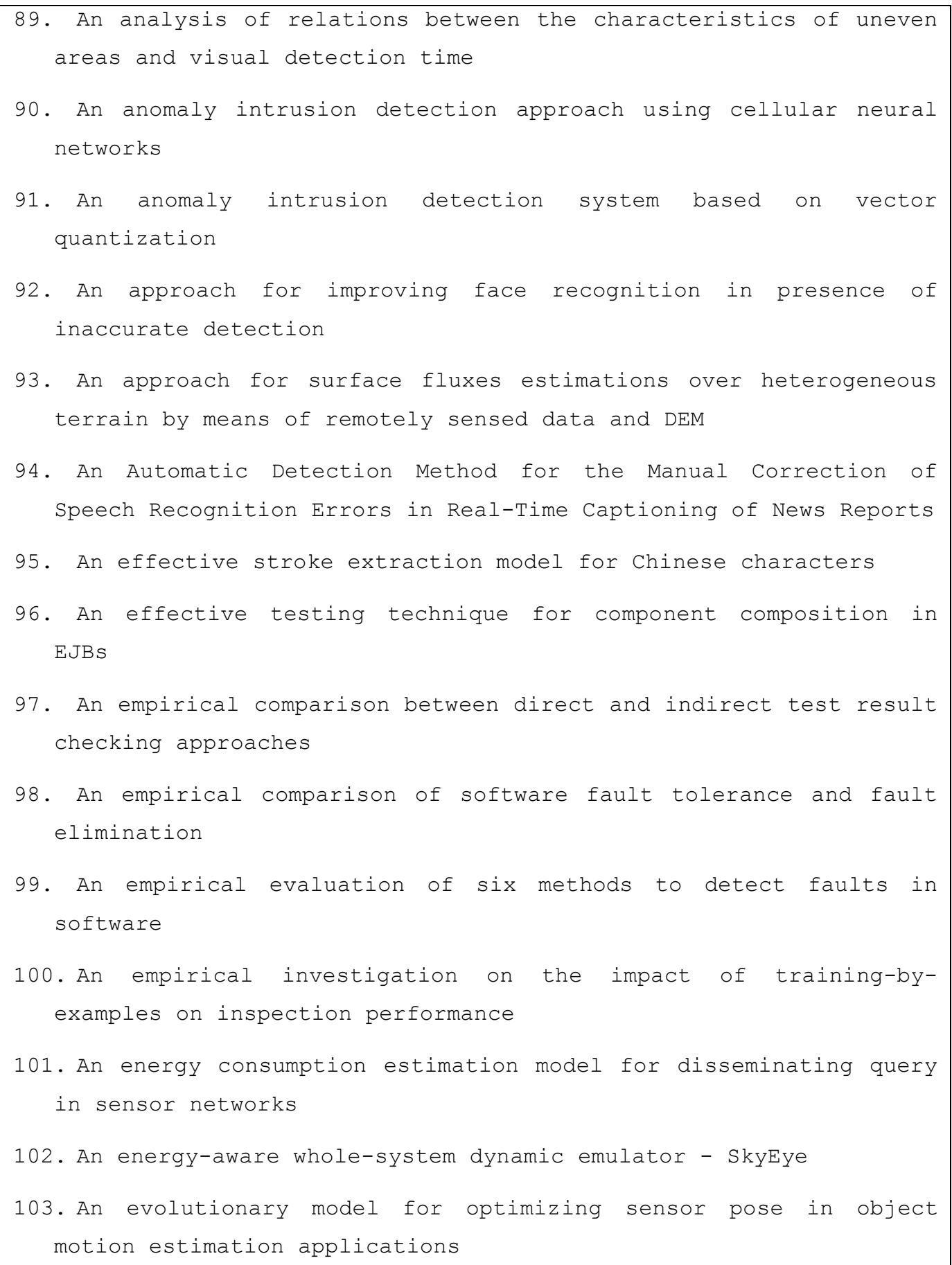

97. An empirical comparison between direct and indirect test result checking approaches

98. An empirical comparison of software fault tolerance and fault elimination

99. An empirical evaluation of six methods to detect faults in software

100. An empirical investigation on the impact of training-byexamples on inspection performance

101. An energy consumption estimation model for disseminating query in sensor networks

102. An energy-aware whole-system dynamic emulator - SkyEye

103. An evolutionary model for optimizing sensor pose in object motion estimation applications

\section{Caso de estudio}


104. An experiment to assess the cost-benefits of code inspections in large scale software development

105. An experimental comparison of usage-based and checklist-based reading

106. An experimental evaluation of an experience-based capturerecapture method in software code inspections

107. An experimental evaluation of data flow and mutation testing

108. An experimental investigation of formality in UML-based development

109. An experimental investigation of UML modeling conventions

110. An experimental study of security vulnerabilities caused by errors

111. An experimental study on software structural testing: Deterministic versus random input generation

112. An extended hyperbola model for road tracking for video-based personal navigation

113. An extended replication of an experiment for assessing methods for software requirements inspections

114. An immunity-based technique to characterize intrusions in computer networks

115. An immuno-fuzzy approach to anomaly detection

116. An improved cfcss control flow checking algorithm

117. An industrial example using one-way analysis of circular-linear data

118. An internally replicated quasi-experimental comparison of checklist and perspective-based reading of code documents

119. An investigation of the negative selection algorithm for fault detection in refrigeration systems 
120. An NN-based malicious exeİ cutables detection algorithm based on immune principles

121. An ultrasonic profiling method for sewer inspection

122. An ultrasonic profiling method for the inspection of tubular structures

123. An utterance verification algorithm in keyword spotting system

124. Analog self-test based on differential IDD monitoring supported by differential IOUT checking

125. Analysis of current waves and faults recognition in rare earth permanent magnet brushless DC motor

126. Analysis of watermarking systems in the frequency domain and its application to design of robust watermarking systems

127. Analysis of watermarking systems in the frequency domain and its application to design of robust watermarking systems

128. Anomaly detection model based on dynamic behavior and character patterns

129. Antibody generation and antigen detection component in immunebased network intrusion detection system

130. Application of a model-based fault detection and diagnosis using parameter estimation and fuzzy inference to a DC-servomotor

131. Application of an informal program verification method to Ada

132. Application of fuzzy logic for automatic shape control in stainless steel rolling process

133. Application of Holter ECG signal analysis based on wavelet and data mining technique

134. Application of support vector machines in reciprocating compressor valve fault diagnosis

135. Application of wavelet analysis on fault diagnosis of interturn

\section{Caso de estudio}


short circuit in rotor windings

136. Applications of fuzzy average to curve and surface fitting

137. Applying concept analysis to user-session-based testing of web applications

138. Applying design metrics to a large-scale software system

139. Applying design metrics to predict fault-proneness: A case study on a large-scale software system

140. Approach based on rough set theory in aggregating alerts of cooperative intrusion detection system

141. Approximating a set of points by a step function

142. Arc-length-based axial deformation and length preserved animation

143. Are software cost-estimation models accurate?

144. Area and delay estimation for FPGA implementation of coarsegrained reconfigurable architectures

145. Area and delay estimation for FPGA implementation of coarsegrained reconfigurable architectures

146. Assertion-oriented automated test data generation

147. Assessing and improving state-based class testing: A series of experiments

148. Assessing defect detection performance of interacting teams in object-oriented design inspection

149. Assessing inter-modular error propagation in distributed software

150. Assessing software review meetings: A controlled experimental study using CSRS

151. Assessing software review meetings: results of a comparative analysis of two experimental studies 


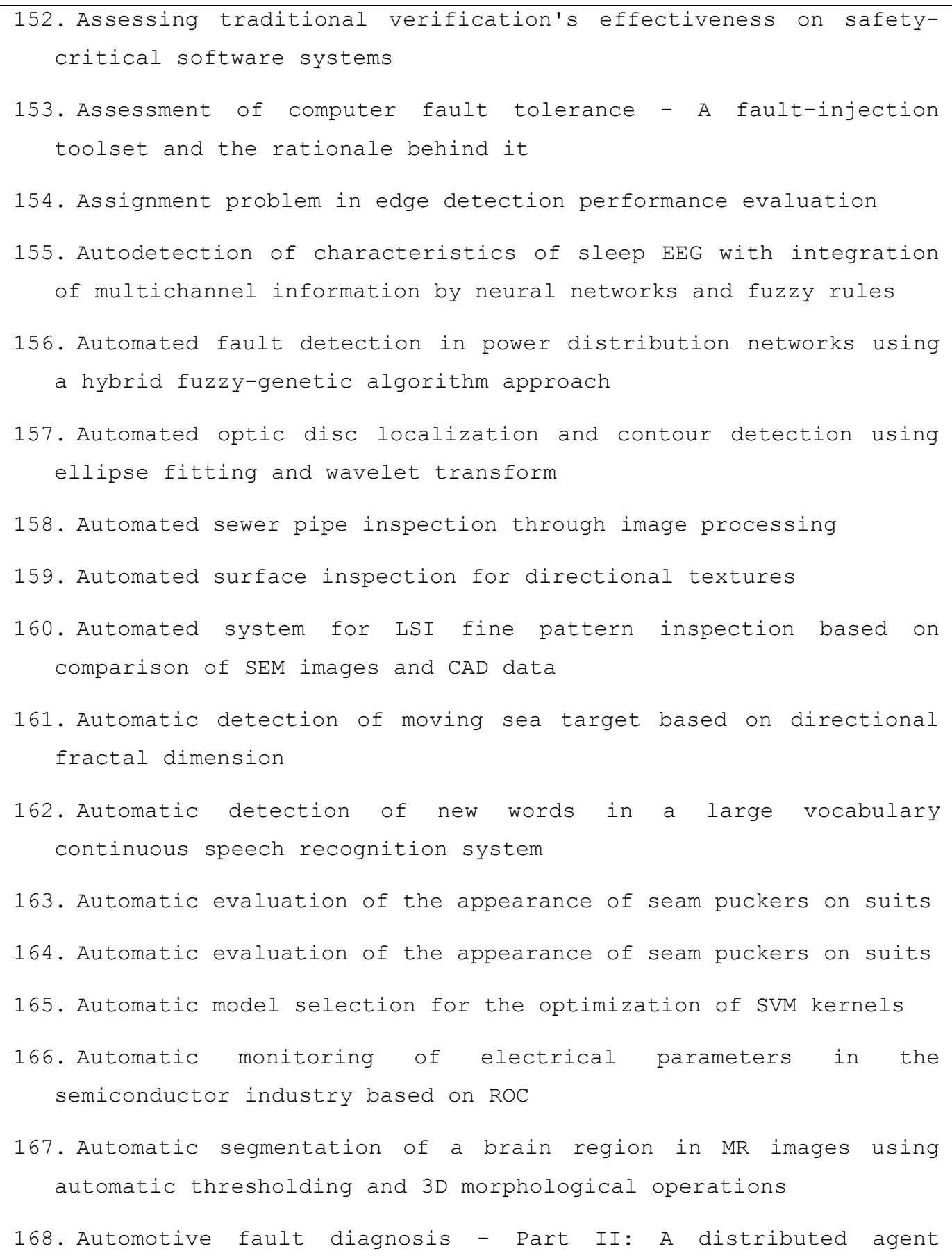

\section{Caso de estudio}


diagnostic system

169. Available bandwidth measurement, implementation and evaluation

170. BASIC program for non-parametric fitting of user-defined functions to experimental data with plotting of results

171. Bayesian curve estimation by model averaging

172. Bayesian estimation of survival and capture probabilities using logit link and photoidentification data

173. Black-box testing using flowgraphs: An experimental assessment of effectiveness and automation potential

174. Blind decentralized estimation for bandwidth constrained sensor networks

175. Blind source separation for classification and detection of flaws in impact-echo testing

176. Boundary-based corner detection using wavelet transform

177. Bounding error masking in linear output space compression schemes

178. Broad-side delay test

179. Bromosulphalein plasma kinetics after obstruction of the common bile duct in rats: Curve fitting with a programmable calculator

180. Building knowledge through families of experiments

181. Building recognition for augmented reality based navigation system

182. Cache interference phenomena

183. Can fault-exposure-potential estimates improve the fault detection abilities of test suites?

184. Can humans detect errors in data? impact of base rates, incentives, and goals

185. Can results from software engineering experiments be safely 


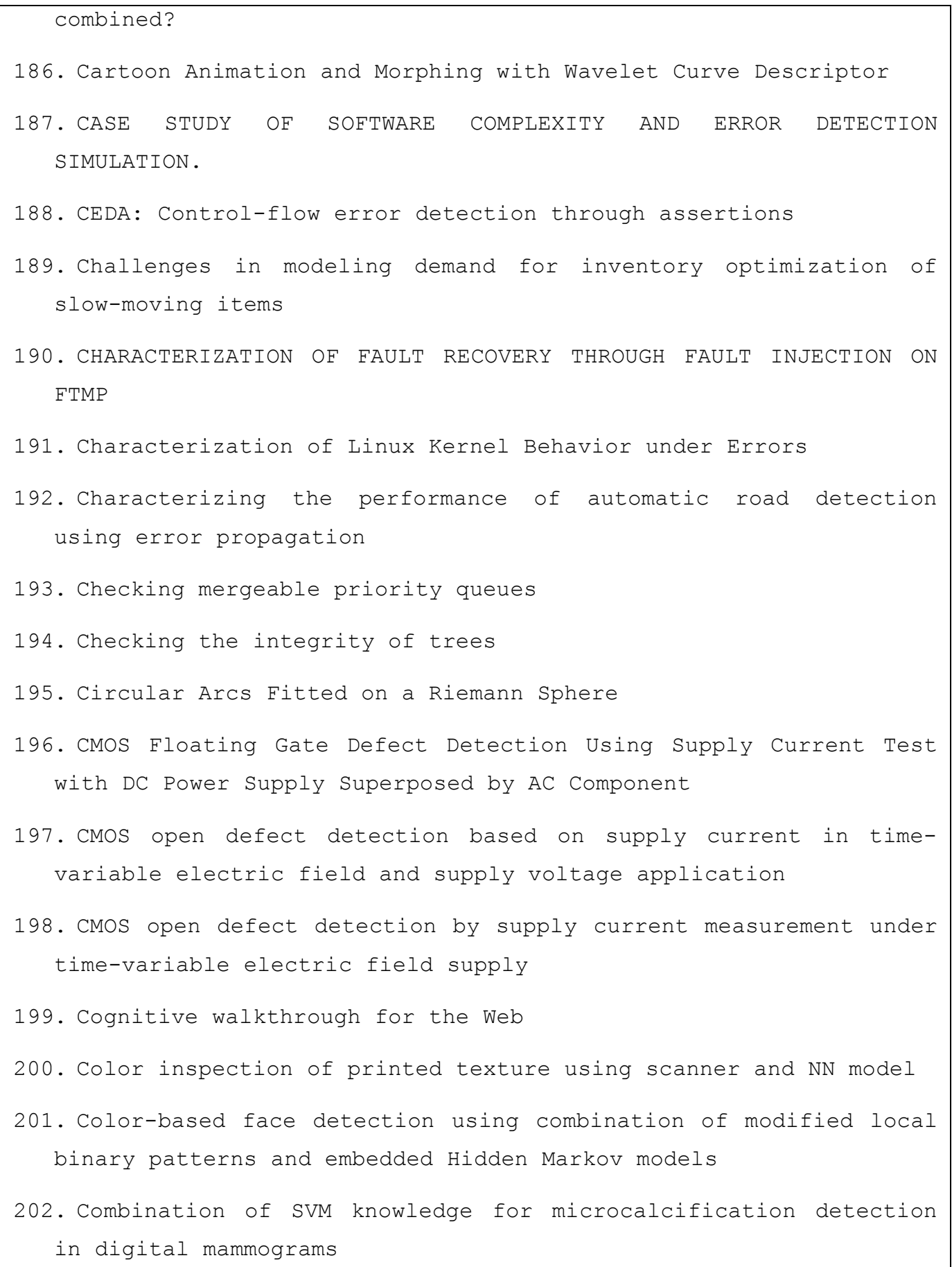

Caso de estudio 
203. Comparative study of structured and text-oriented analysis and design methodologies

204. Comparing detection methods for software requirements inspections: A replication using professional subjects

205. Comparing detection methods for software requirements inspections: a replicated experiment

206. Comparing reading techniques for object-oriented design inspection

207. Comparison of discriminative training criteria

208. Compilation of mosaics from separately scanned line drawings

209. Compiler-based multiple instruction retry

210. Computer-mediated group support, anonymity, and the software inspection process: An empirical investigation

211. Computing immune model based on poisson Procedure and rough inclusion

212. Concurrent detection of control flow errors by hybrid signature monitoring

213. Concurrent error detection in block ciphers

214. Concurrent error detection schemes for involution ciphers

215. Concurrent process monitoring with no reference signatures

216. Concurrent test for digital linear systems

217. Confidence intervals for capture-recapture estimations in software inspections

218. Confidence measures as a search guide in speech recognition

219. Confidence measures from local posterior probability estimates

220. Confidence score based unsupervised incremental adaptation for oOV words detection

221. Consideration on automatic defect detection algorithm for 


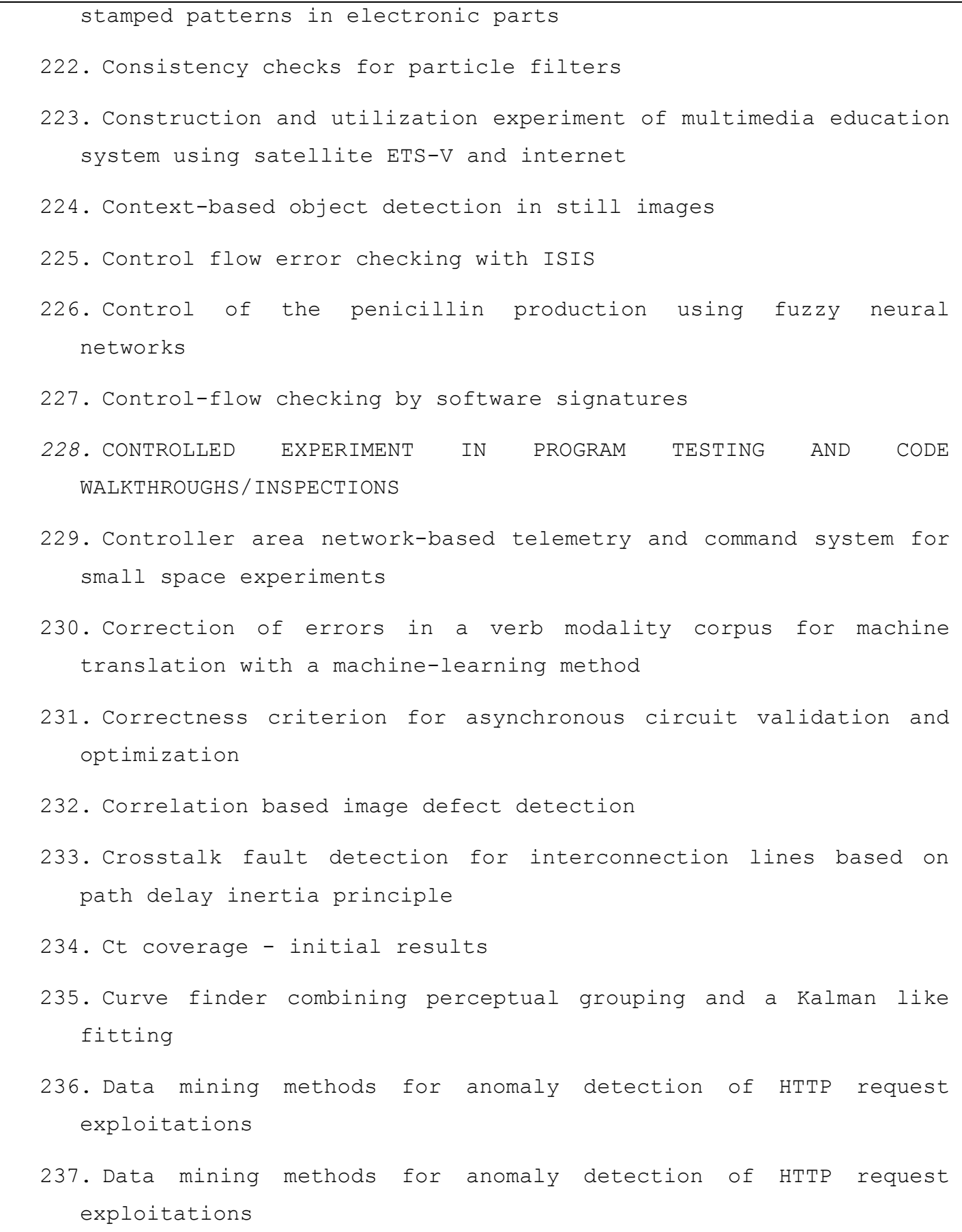

\section{Caso de estudio}


238. Data-driven fault management for TINA applications

239. Decay of UV-induced fiber Bragg gratings

240. Decisive differences and partial differences for stuck-at fault detection in MVL circuits

241. Deep submicron defect detection with the energy consumption ratio

242. Defect detection for executable specifications - An experiment Distributed software inspections - An experiment with Adobe Acrobat

243. Defect detection in textile materials based on aspects of the HVS

244. Defect detection in textured materials using optimized filters

245. Defect detection in textured surfaces using color ringprojection correlation

246. Defect detection using power supply transient signal analysis

247. Defect visibility and content importance implications for the design of an objective video fidelity metric

248. Defect visibility and content importance: Effects on perceived impairment

249. DEFINE: a distributed fault injection and monitoring environment

250. Dependability Evaluation with Fault Injection Experiments

251. Dependable flight control system using data diversity with error recovery

252. Depitch and the role of fundamental frequency in speaker recognition

253. Design and evaluation of system-level checks for on-line control flow error detection 


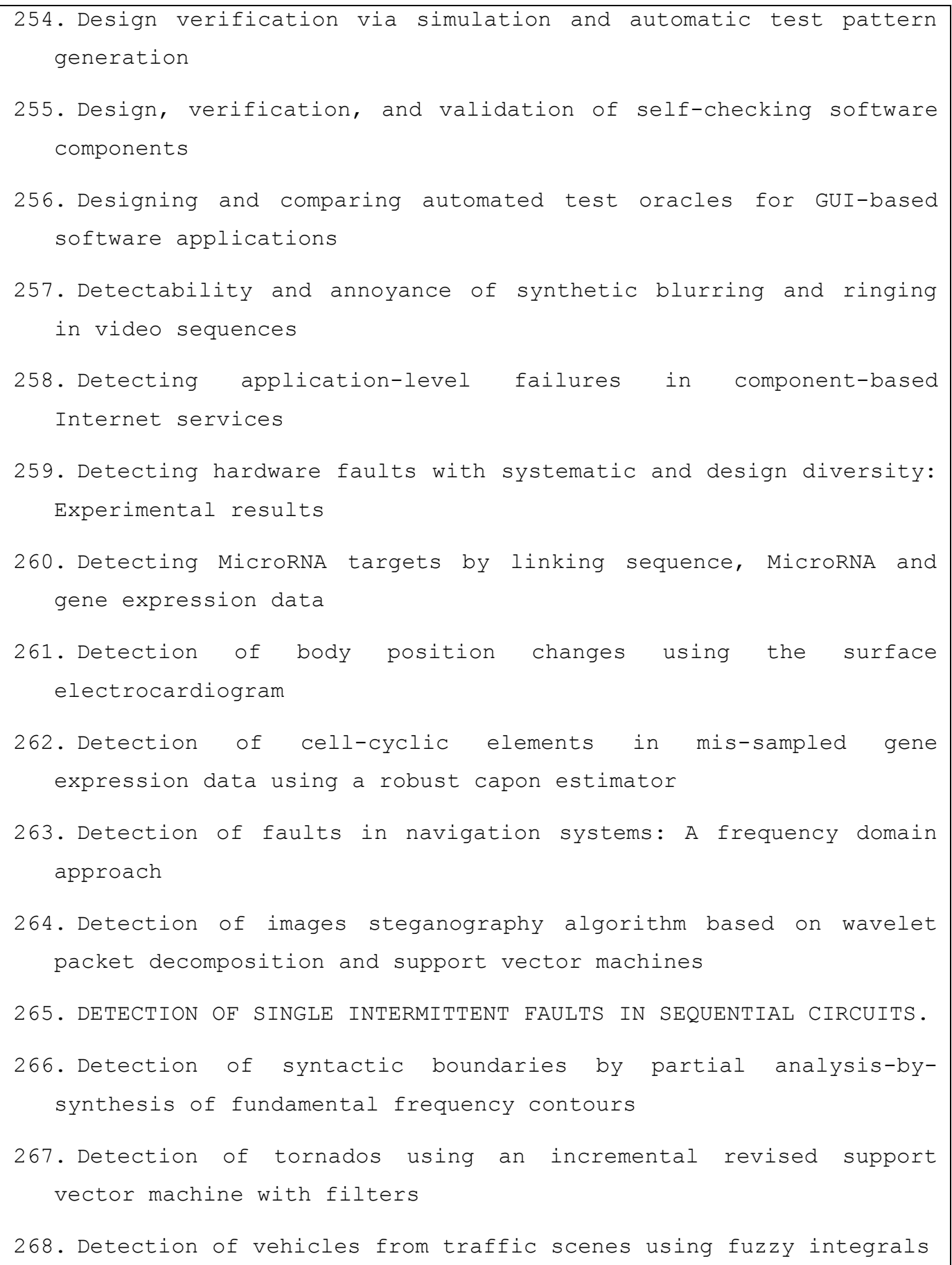

\section{Caso de estudio}




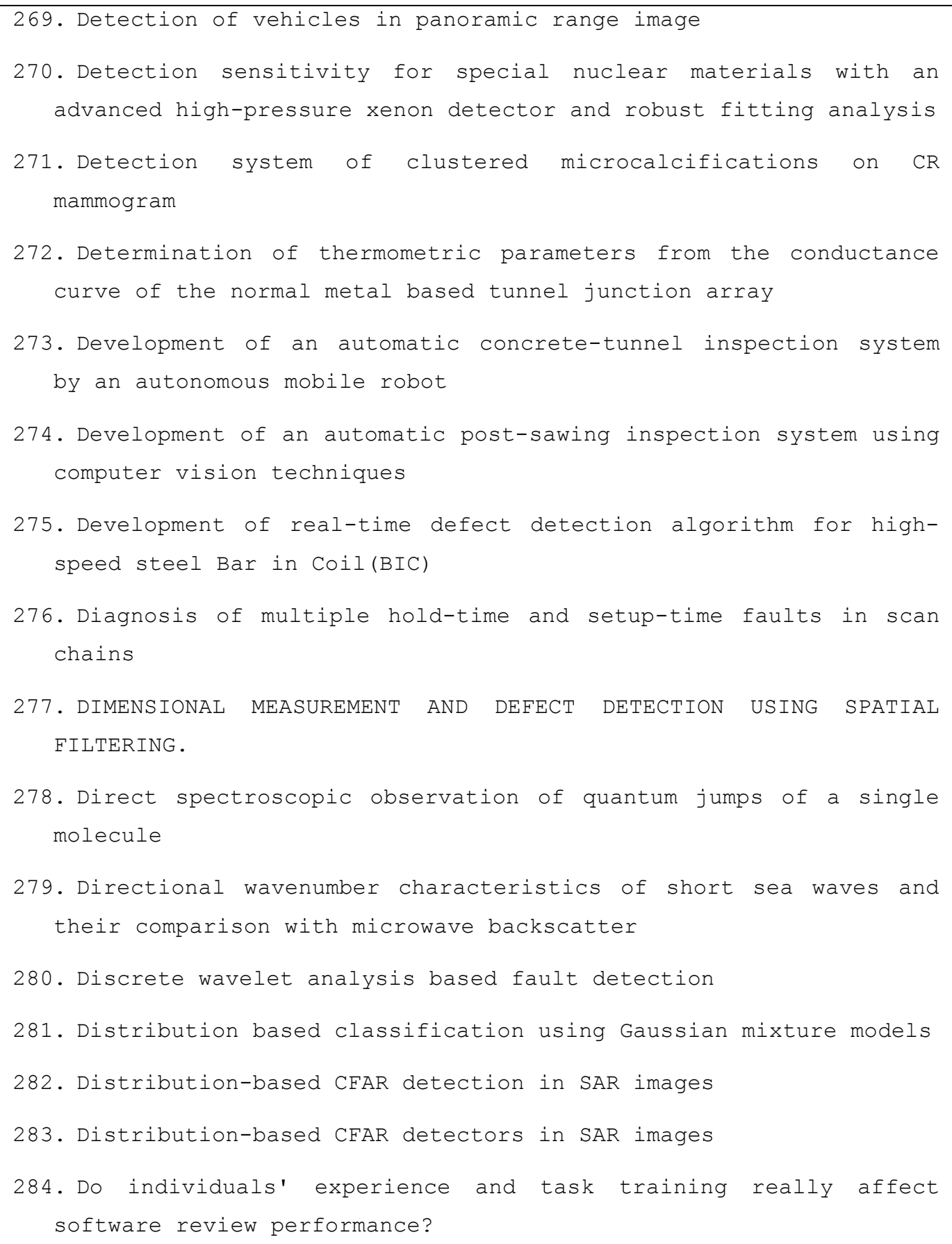
advanced high-pressure xenon detector and robust fitting analysis

285. Does Every Inspection Really Need a Meeting? 


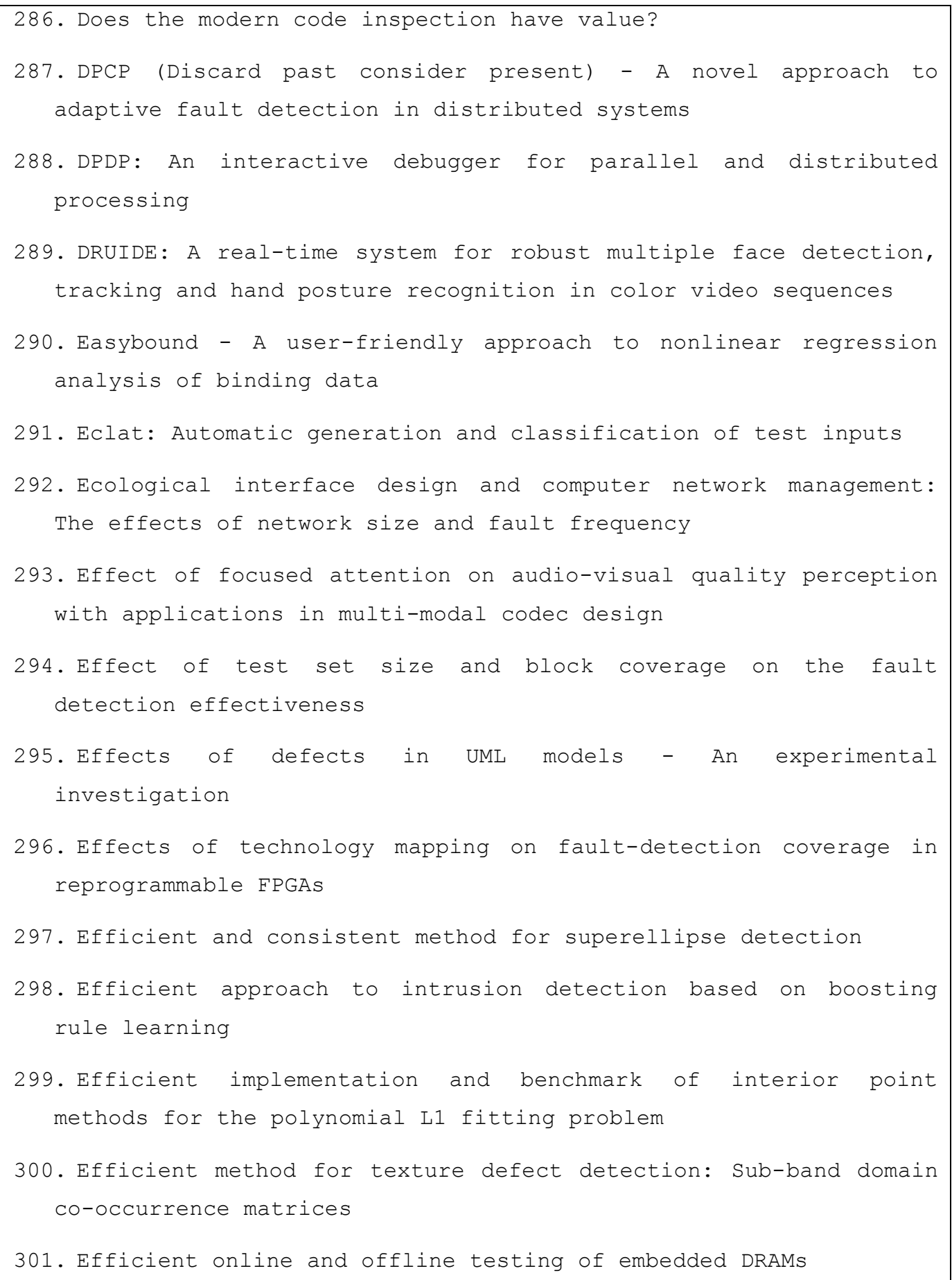

\section{Caso de estudio}




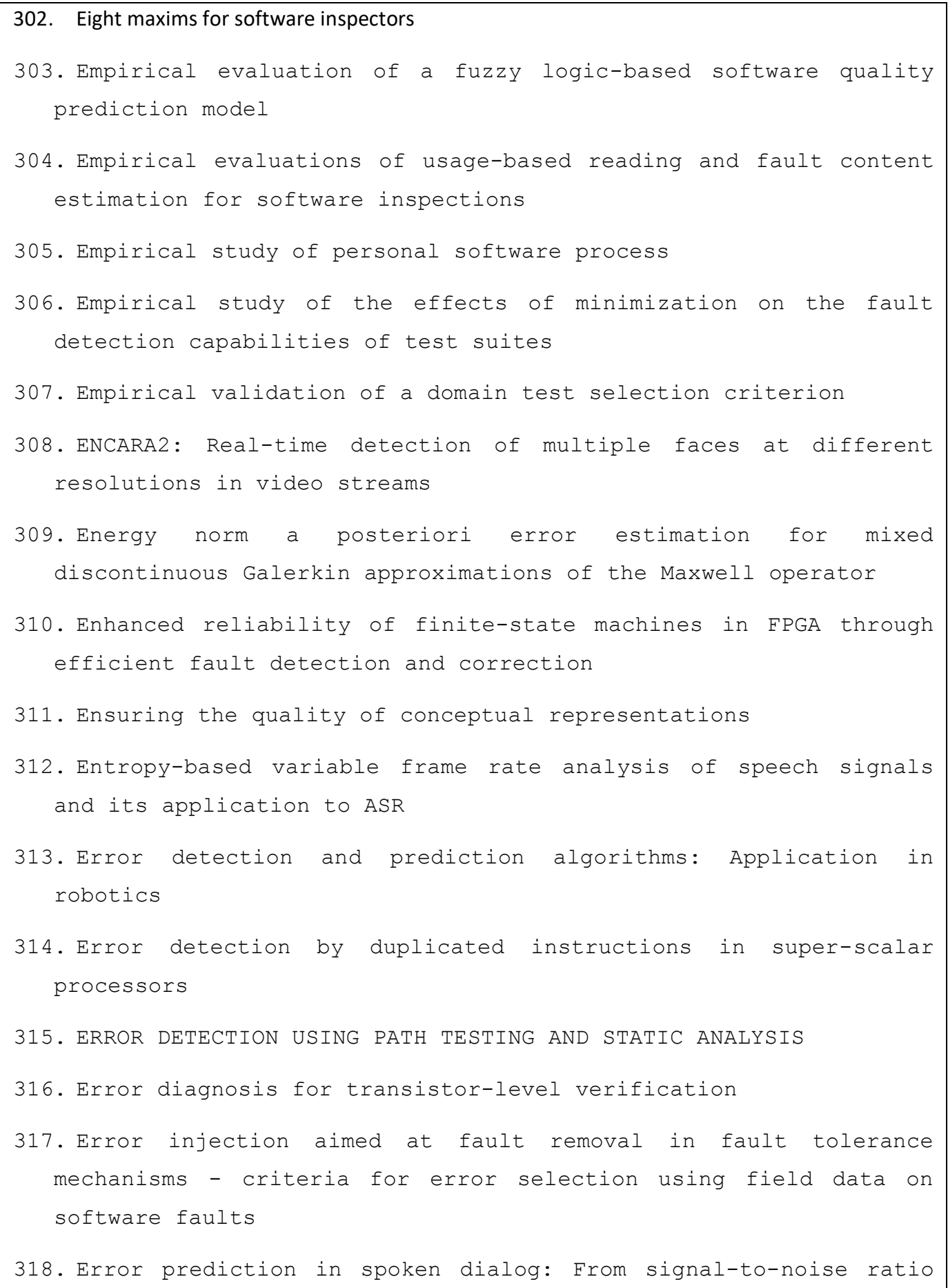




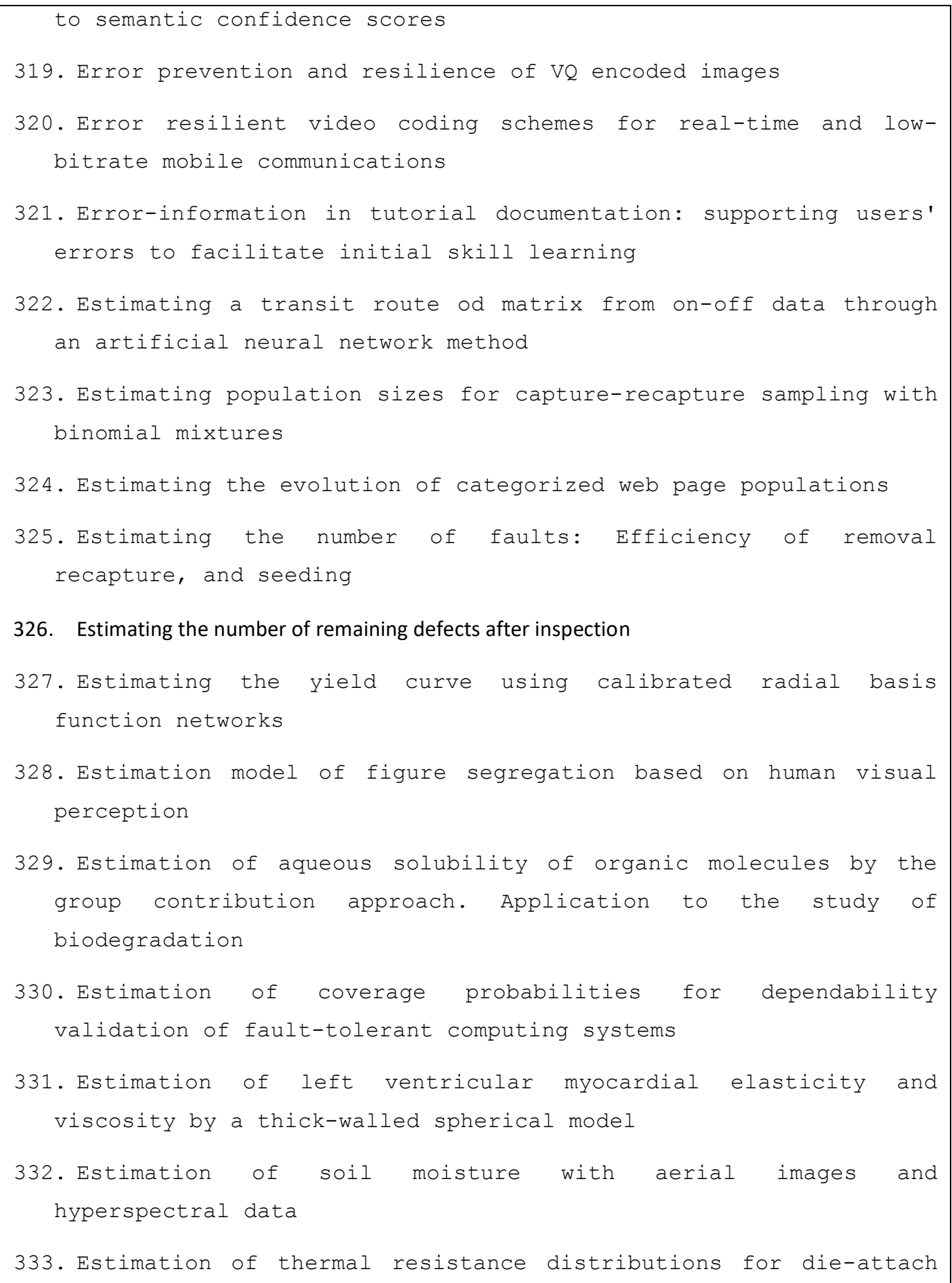

Caso de estudio 


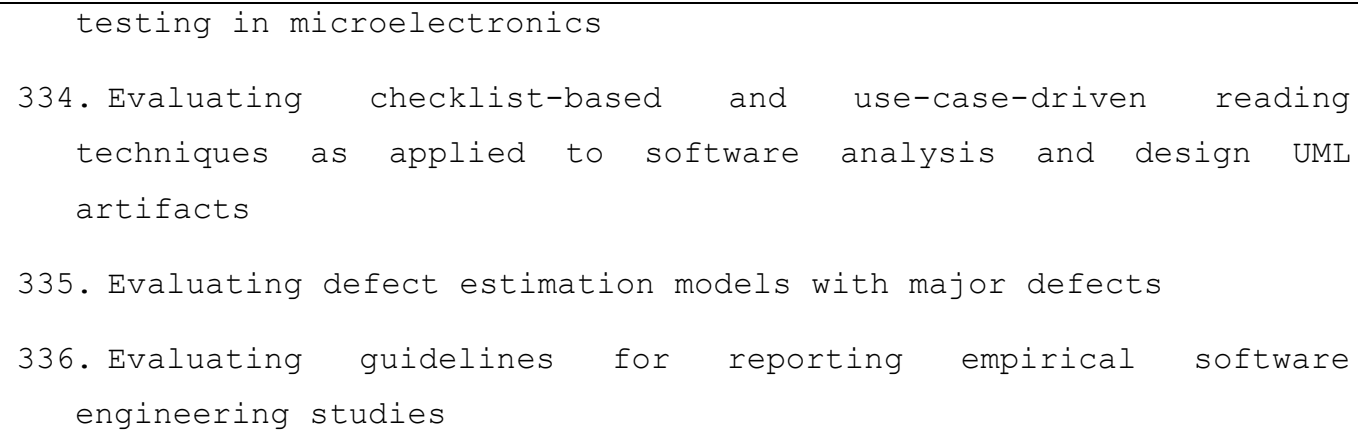

337. Evaluating the accuracy of defect estimation models based on inspection data

338. Evaluating the effectiveness of fault tolerance in replicated database management systems

339. Evaluating the usefulness and the ease of use of a web-based inspection data collection tool

340. Evaluation of a scenario-based reading technique for analysing process components

341. Evaluation of Fault Handling of the Time-Triggered Architecture with Bus and Star Topology

342. Evaluation of SAT-based bounded model checking of ACTL properties

343. Evaluation of the scaled maximum likelihood test statistic

344. Evaluation of Usage-Based Reading - Conclusions after Three Experiments

345. Evolving fuzzy rule-based classifiers

346. Evolving training model method for one-class SVM

347. EXPERIMENT IN SOFTWARE ERROR DATA COLLECTION AND ANALYSIS.

348. EXPERIMENT ON THE SIZE OF FAULT DETECTION TESTS FOR TESTABLE PLAS

349. Experiment to assess cost-benefits of inspection meetings and their alternatives: a pilot study 


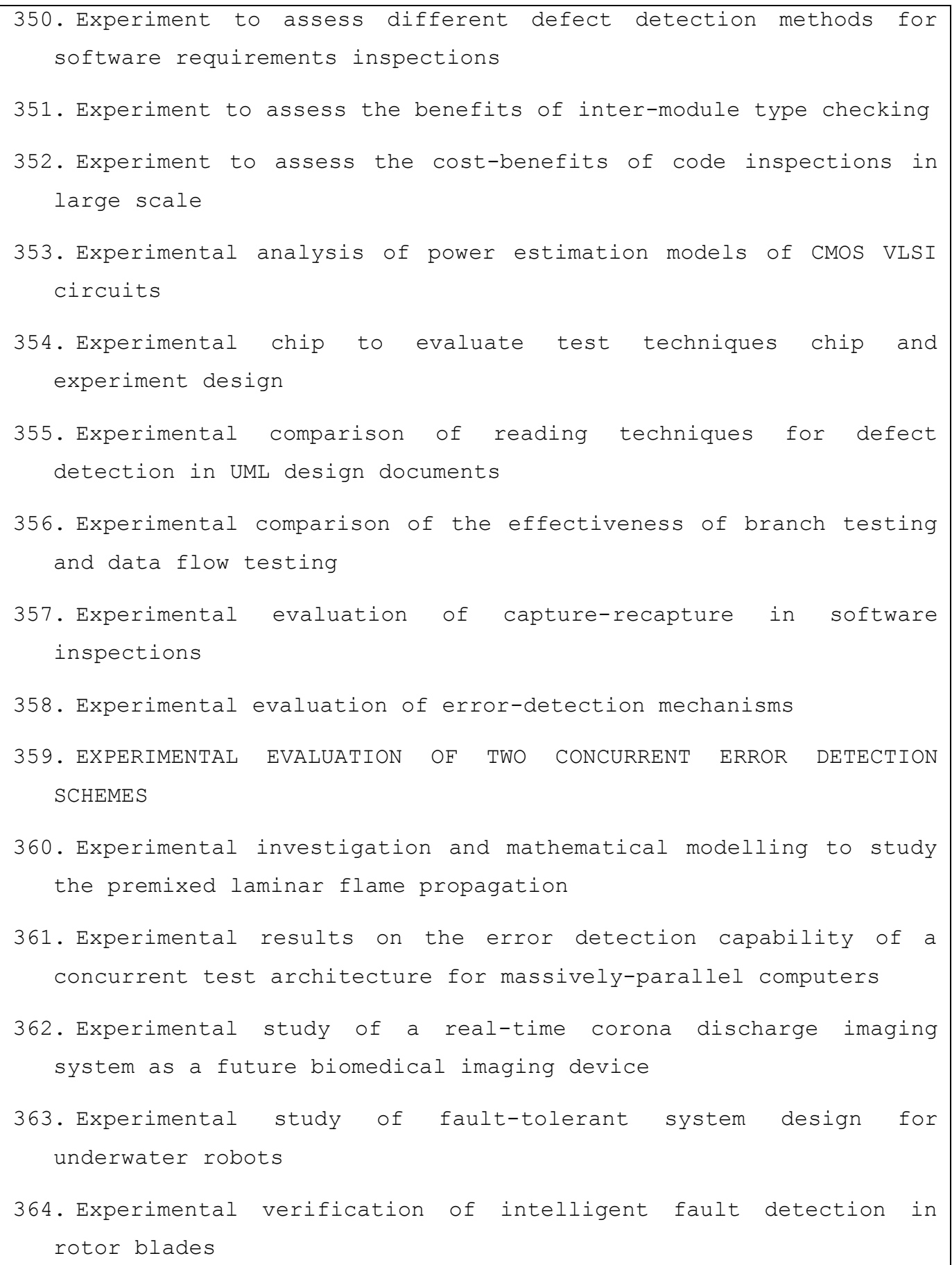

\section{Caso de estudio}


365. Experimentation with usage-based reading

366. Experimenting with error abstraction in requirements documents 367. EXPERIMENTS DETERMINING BEST PATHS FOR TESTING COMPUTER PROGRAM PREDICATES

368. EXPERIMENTS IN SOFTWARE RELIABILITY: LIFE-CRITICAL APPLICATIONS

369. Experiments on the effectiveness of dataflow- and controlflowbased test adequacy criteria

370. Experiments with a regular pulse CELP coder for the pan European half rate channel

371. Experiments with curvature-continuous patch-boundary fitting 372. Experiments with test case prioritization using relevant slices

373. EXPFIT: A program for simultaneous analysis of families of exponential decay curves

374. Exploiting instruction-level parallelism for integrated control-flow monitoring

375. Exploiting purity for atomicity

376. Exploring human error recovery strategies: Implications for spoken dialogue systems

377. Extracting circular road signs using specific color distinction and region limitation

378. Extracting structure from optical flow using the fast error search technique

379. Extracting the trajectory of writing brush in chinese character calligraphy

380. Extraction of text words in document images based on a statistical characterization

381. Fabric defect detection using adaptive wavelet

382. Face and head detection for a real-time surveillance system 


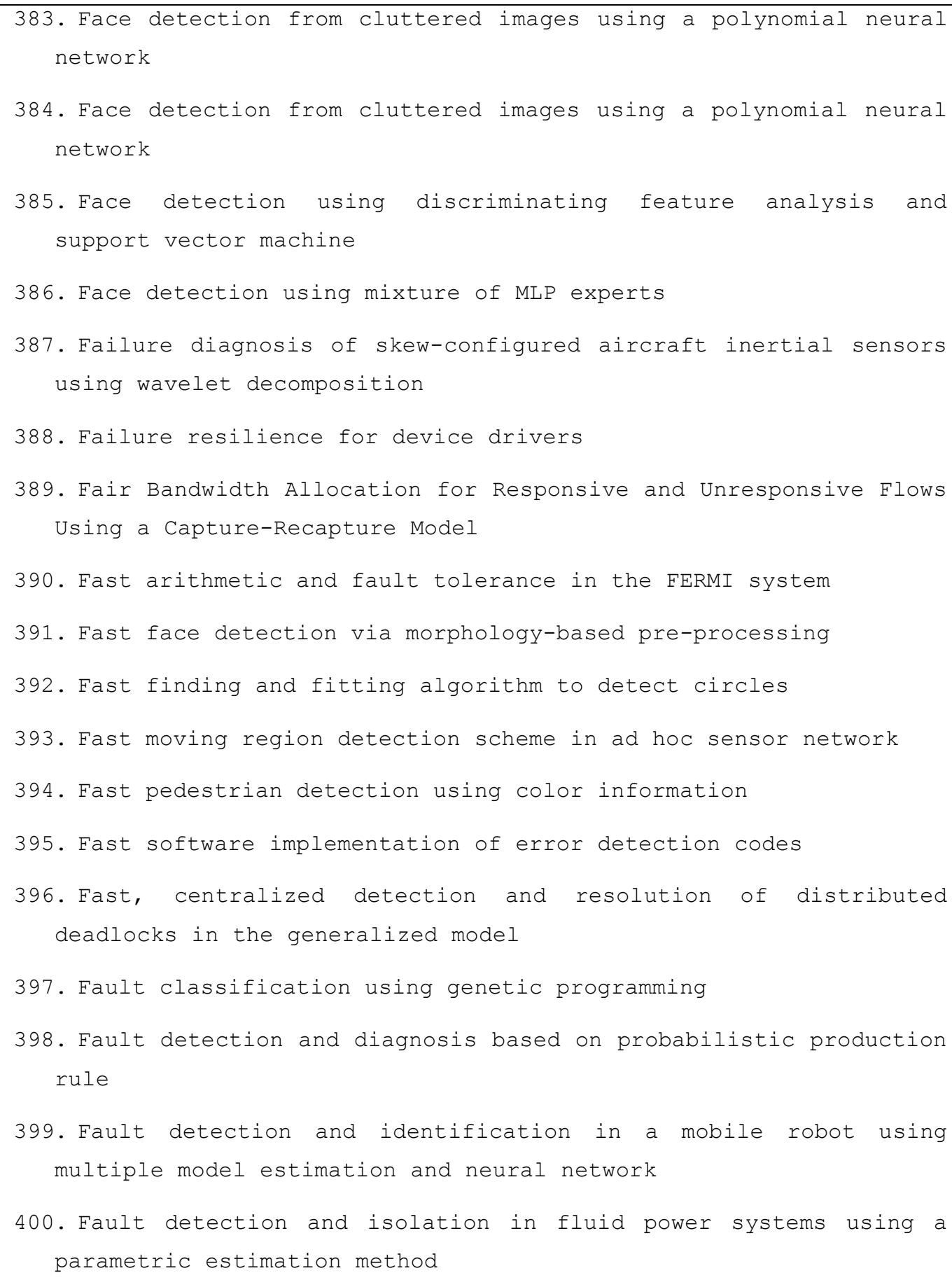

Caso de estudio 
401. Fault detection and isolation of systems with slowly varying parameters - Simulation with a simplified aircraft turbo engine model

402. Fault detection and prediction of clocks and timers based on computer audition and probabilistic neural networks

403. Fault Detection and Recovery Coverage Improvement by Optimal Clock Diversity

404. Fault detection based on evolving LVQ neural networks

405. Fault detection effectiveness of mutation and data flow testing

406. Fault detection filter design for networked control system with communication delays

407. Fault detection for robot manipulators with parametric uncertainty: a prediction error based approach

408. Fault detection in electro-hydraulic servo-positioning systems using sequential test of wald

409. FAULT DETECTION IN FANOUT-FREE COMBINATIONAL NETWORKS.

410. Fault detection in ink jet printers using neural networks

411. Fault detection in multi-threaded c++ server applications

412. Fault Detection in Multi-Threaded C++ Server Applications

413. Fault detection in Rule-based Software systems

414. Fault diagnose of rotating system based on ICA with reference and RBF networks

415. Fault diagnosis in gas turbine engines using fuzzy logic

416. Fault diagnosis methodology for the UltraSPARCTM-I microprocessor

417. Fault diagnosis of induction motor using linear discriminant analysis

418. Fault identification by passive testing 


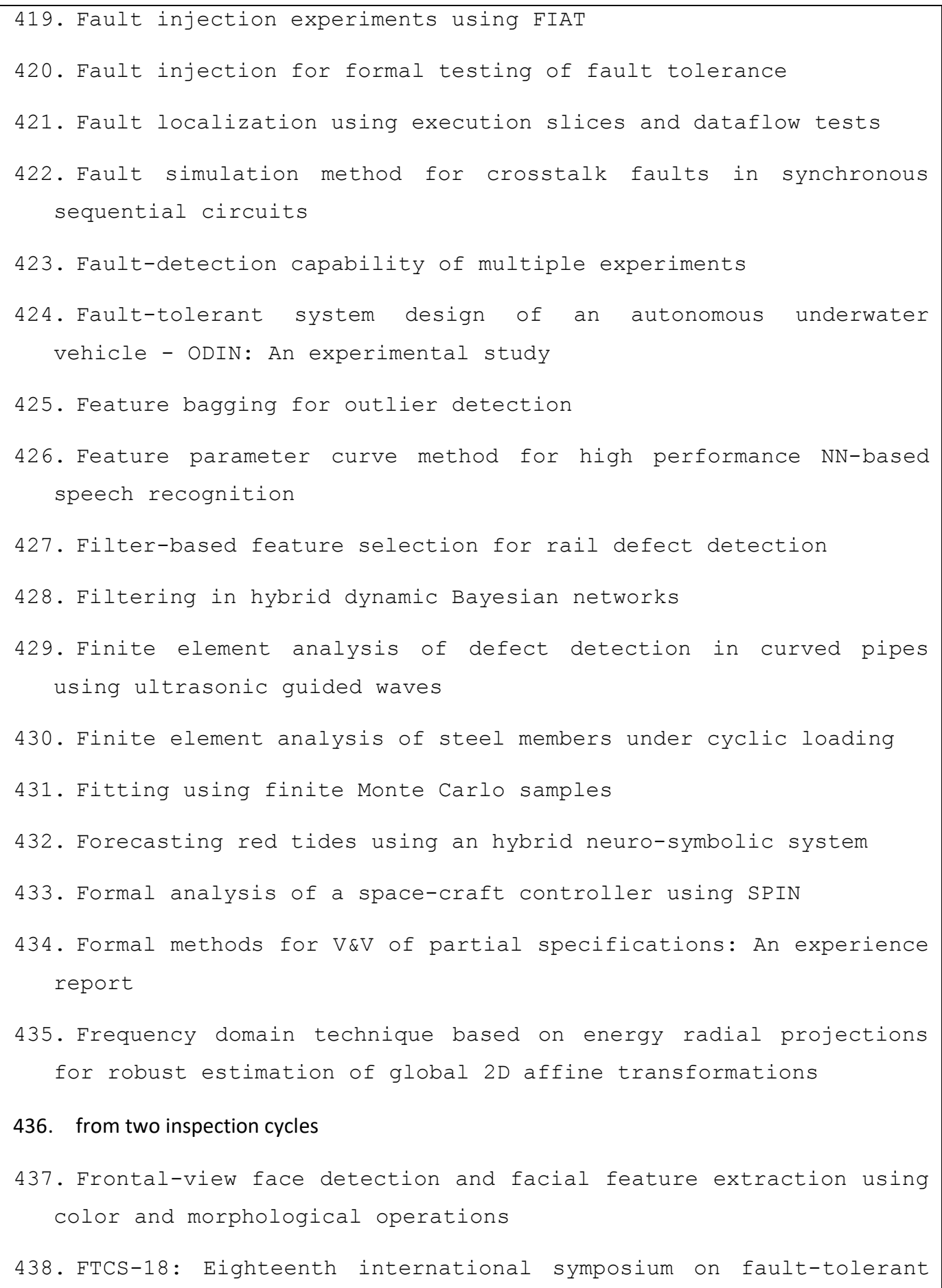


computing, digest of papers

439. Functional straight-line and circular paths control for robot with minimized via points

440. Further Experiences with Scenarios and Checklists

441. Further investigations into the development and evaluation of reading techniques for object-oriented code inspection -

442. Further investigations of reading techniques for objectoriented design inspection

443. Fusions of GA and SVM for anomaly detection in intrusion detection system

444. Fuzzy logic to assist the planning in adolescent idiopathic scoliosis instrumentation surgery

445. Fuzzy measures for vehicle detection

446. Fuzzy model based on-line stator winding turn fault detection for induction motors

447. Fuzzy reasoning based intra frame error concealment for block based images

448. Fuzzy set approach to cost estimation of software projects

449. Gabor wavelet-based eyes and mouth detection algorithm

450. Gate-level design diagnosis using a learning-based search strategy

451. Gaussian process latent variable models for fault detection

452. Generalized likelihood ratio tests for complex fMRI Data: A simulation study

453. Generalized training subset selection for statistical estimation of epicardial activation maps from intravenous catheter measurements

454. Generalizing perspective-based inspection to handle object- 


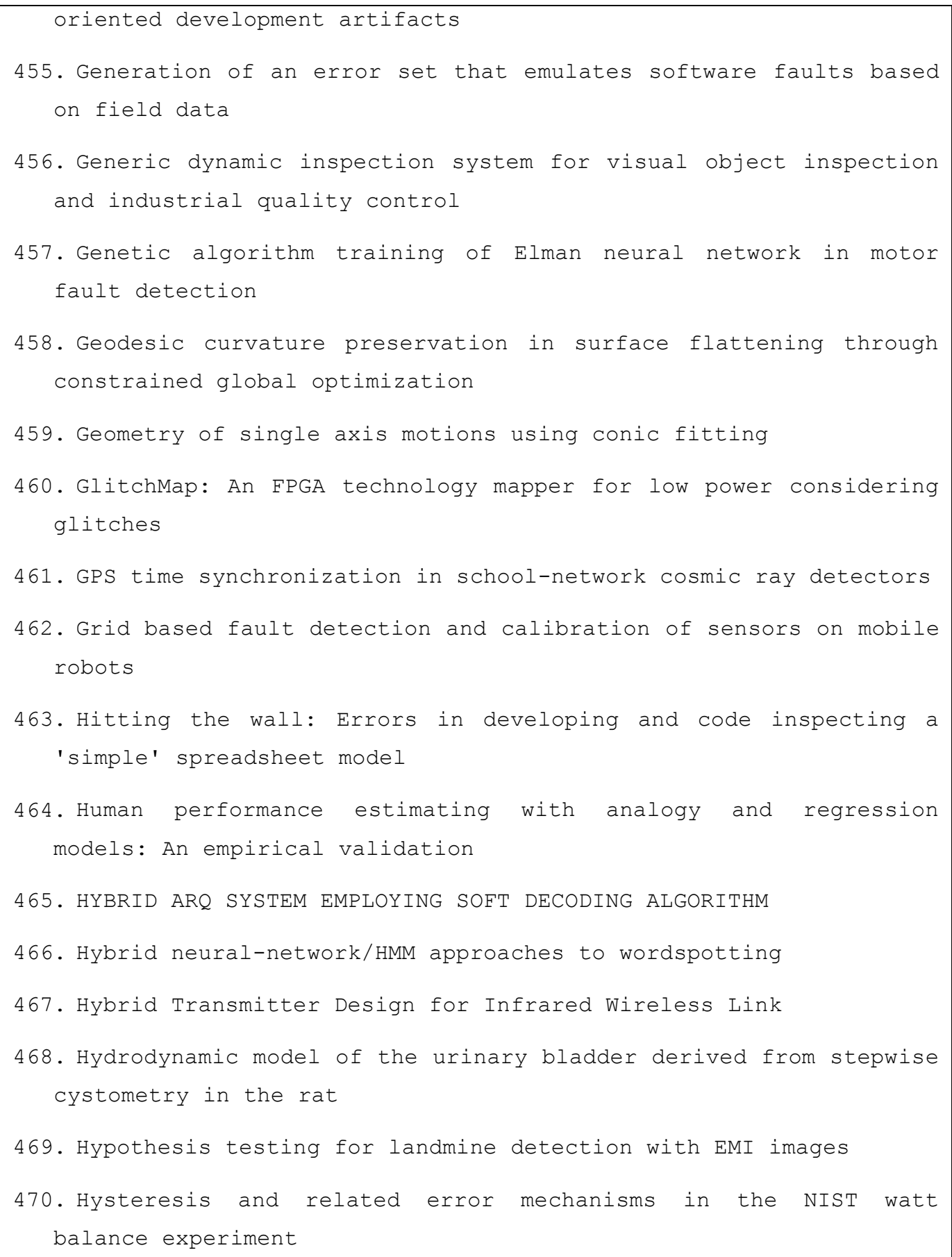

\section{Caso de estudio}




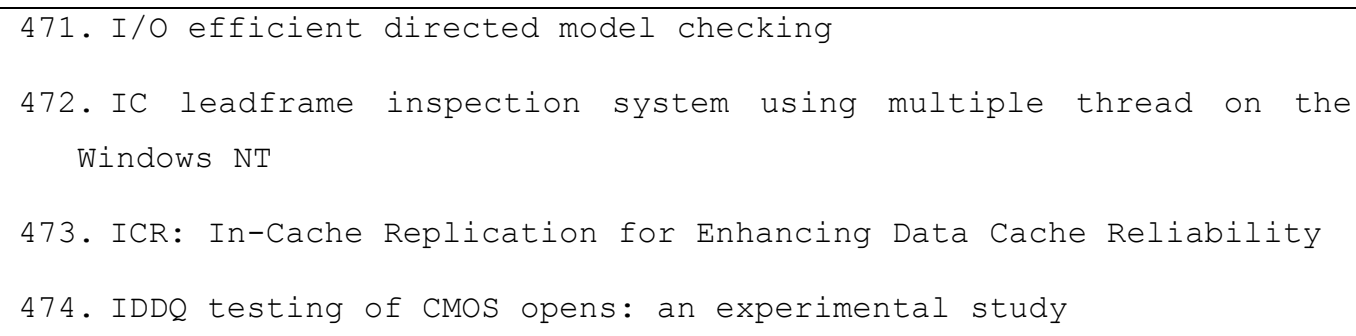




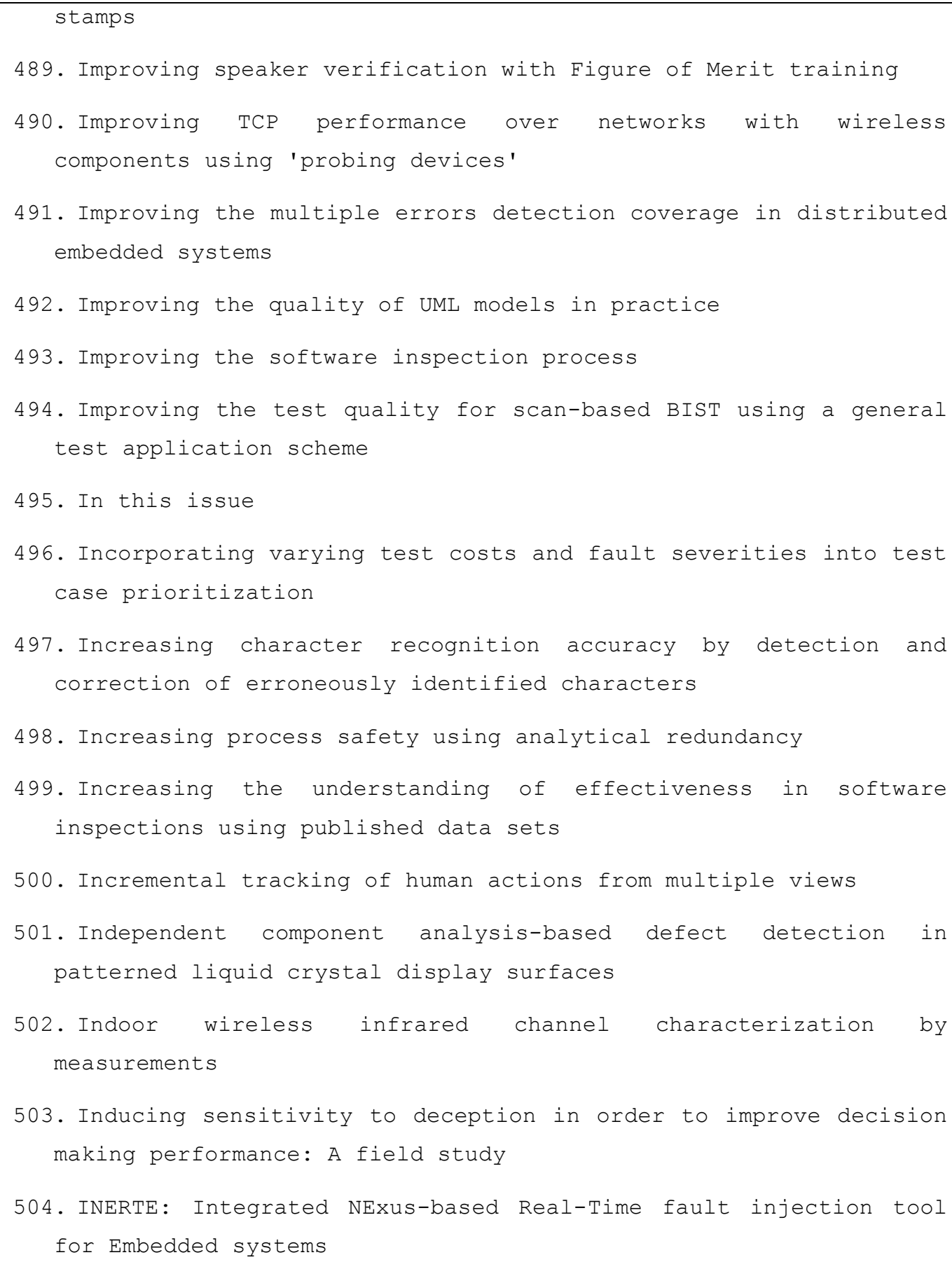

\section{Caso de estudio}


505. Influence of error correlations on the signature analysis aliasing

506. Influence of filter sphericity on the detection of singularities in synthetic images

507. Influence of team size and defect detection technique on inspection effectiveness

508. Injecting redundant instructions behind branches for a faulttolerant architecture

509. Inspection planning for mission-critical quality

510. Integrating communication protocol selection with hardware/software codesign

511. Integrating metrics and models for software risk assessment

512. Integration of multiple range and intensity image pairs using a volumetric method to create textured three-dimensional models

513. Integration testing using interface mutation

514. Intelligent mobile agents-based architecture for network fault detection

515. Interactive debugging tool for $\mathrm{C}$ based on dynamic slicing and dicing

516. Interactive design of constrained variational curves

517. Interactive model for human error detection in an e-learning environment

518. INTERMITTENT FAULTS: A MODEL AND A DETECTION PROCEDURE.

519. Internet traffic modeling and prediction using FARIMA models

520. Interpolation errors on gray gradations caused by the threedimensional lookup table method

521. Interpretation of circulatory shunt-dilution curves as bimodal distribution functions 


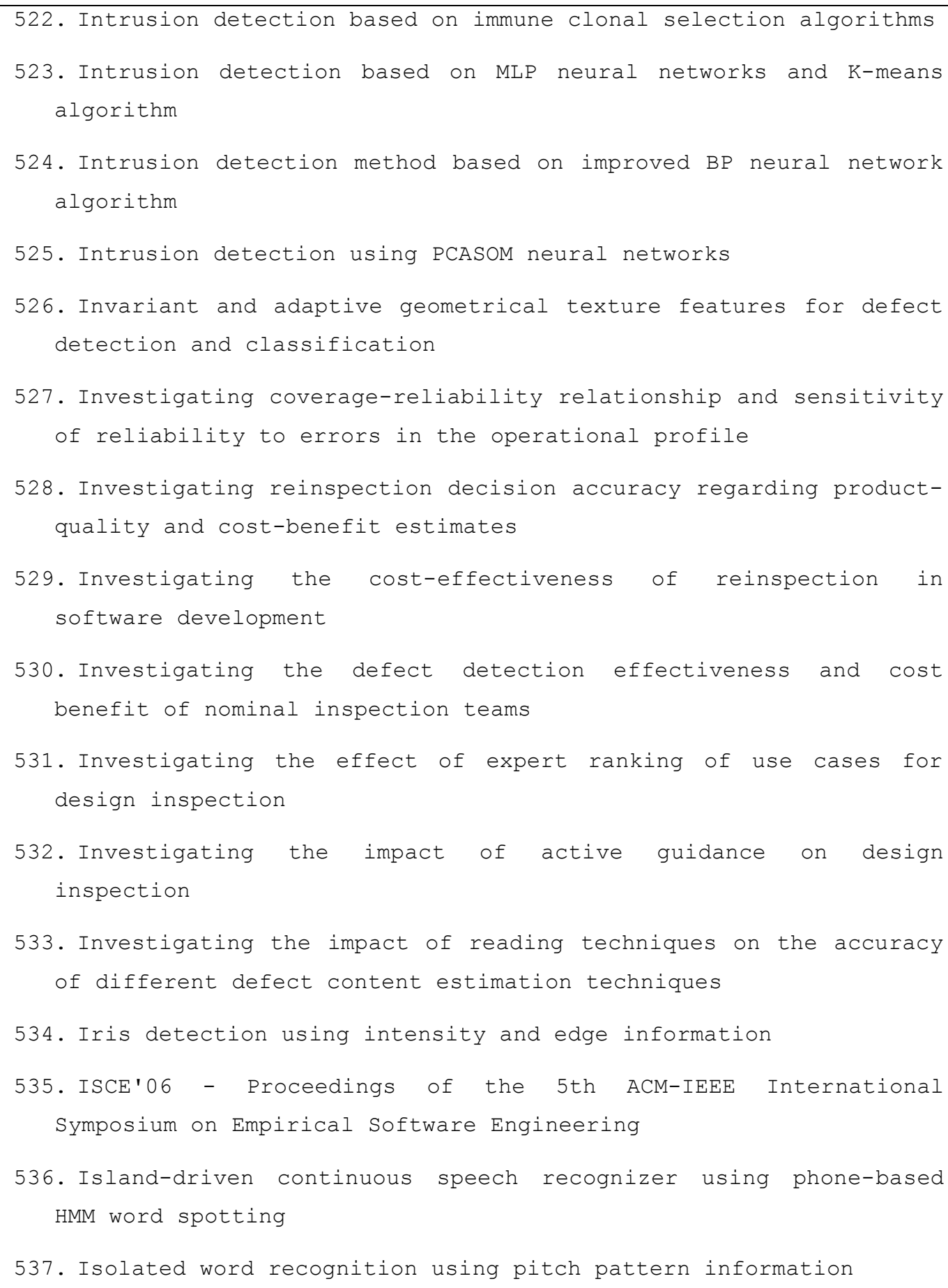

\section{Caso de estudio}


538. ITA, a portable program for the interactive analysis of data from tracer experiments

539. Joint prior models of neighboring objects for 3D image segmentation

540. Keyword spotting using FO contour information

541. Knowledge-based fault detection system using evolutive observer approach

542. Knowledge-Sharing Issues in Experimental Software Engineering

543. LADAR target detection using morphological shared-weight neural networks

544. LD2-ARMA identification algorithm

545. Leakage model and teeth clack removal for air- and boneconductive integrated microphones

546. Learning features from examples for face detection

547. Learning the compositional nature of visual objects

548. Learning-based building outline detection from multiple aerial images

549. Learning-based license plate detection using global and local features

550. Line structure extraction from line-drawing images

551. Lip reading using video and thermal images

552. Load impedance measurement on a coaxial cable via timefrequency domain reflectometry

553. Local concurrent error detection and correction in data structures using virtual backpointers

554. Local feature recognition for industrial radiation imaging with DWT and SVMS

555. Logic mapping on a microprocessor 


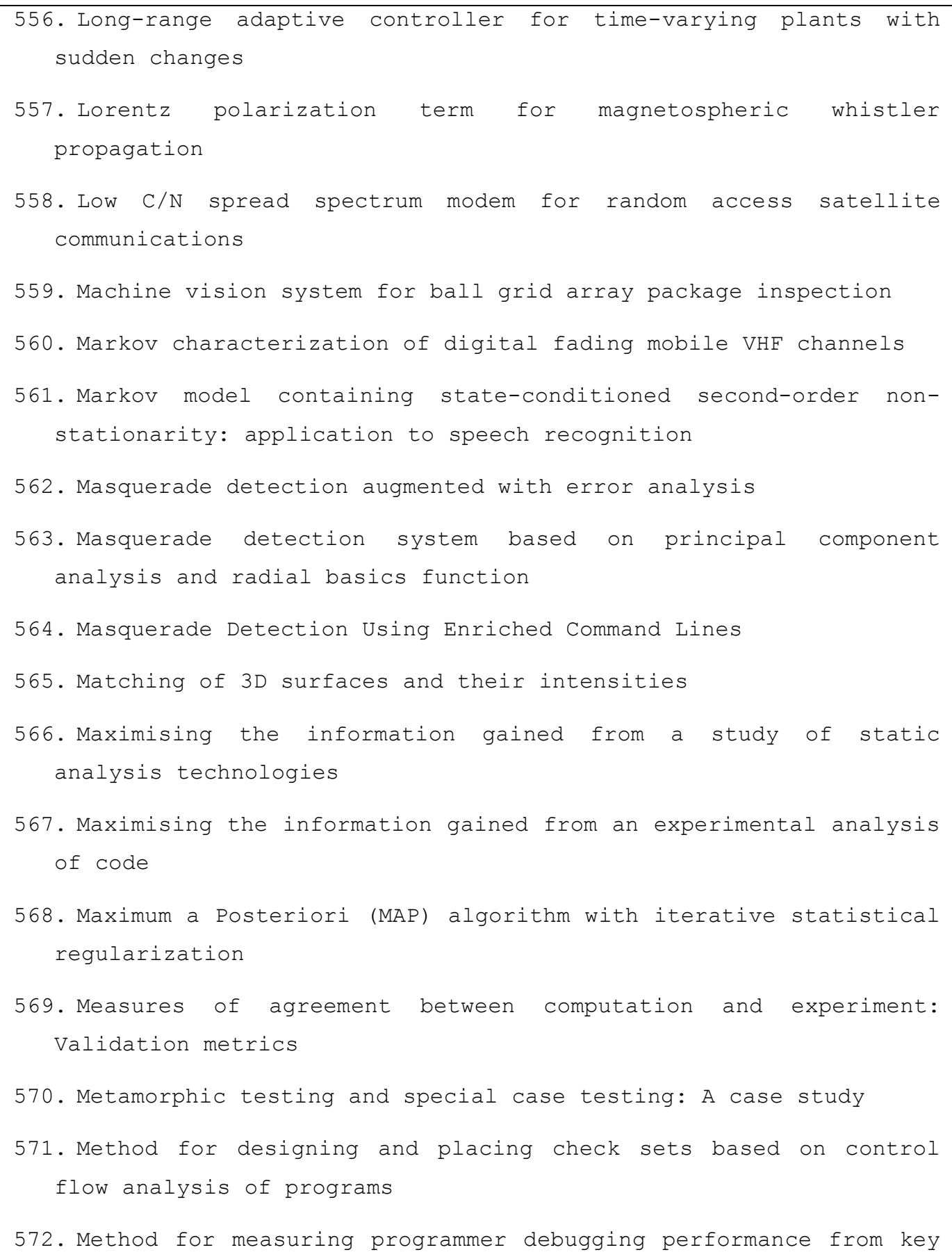

\section{Caso de estudio}


strokes

573. METHOD FOR THE DESIGN OF FAULT DETECTION EXPERIMENTS

574. Method to validate the correctness of test logic programs applied in a protocol conformance test system using petri nets

575. Microarchitecture-level power modelling and analyzing for highperformance microprocessors

576. Microprocessor error behavior modeling

577. Mining temporal specifications for error detection

578. Mobile Ad-hoc and Sensor Networks - First International Conference, MSN 2005, Proceedings

579. Mode matching based transformer chromatogram peaks identification algorithm

580. Model for the analysis of the fault injection process

581. Model-based diagnosis of hybrid systems

582. Modeling and evaluating the security threats of transient errors in firewall software

583. Modelling unknown words in spontaneous speech

584. Mondrix: Memory isolation for linux using mondriaan memory protection

585. Monitoring browsing behaviour and search services evolution adaptation with a capture-recapture Internet-based programming technique: A case-study over medical portals

586. Monitoring the evolution of cached content in Google and MSN

587. Monitoring the generic assembly operation for impact from gripping to finished insertion

588. Morphology-based front-view facial contour detection

589. Mouth detection based on interest point

590. Multi-band decomposition of the linear prediction error applied 


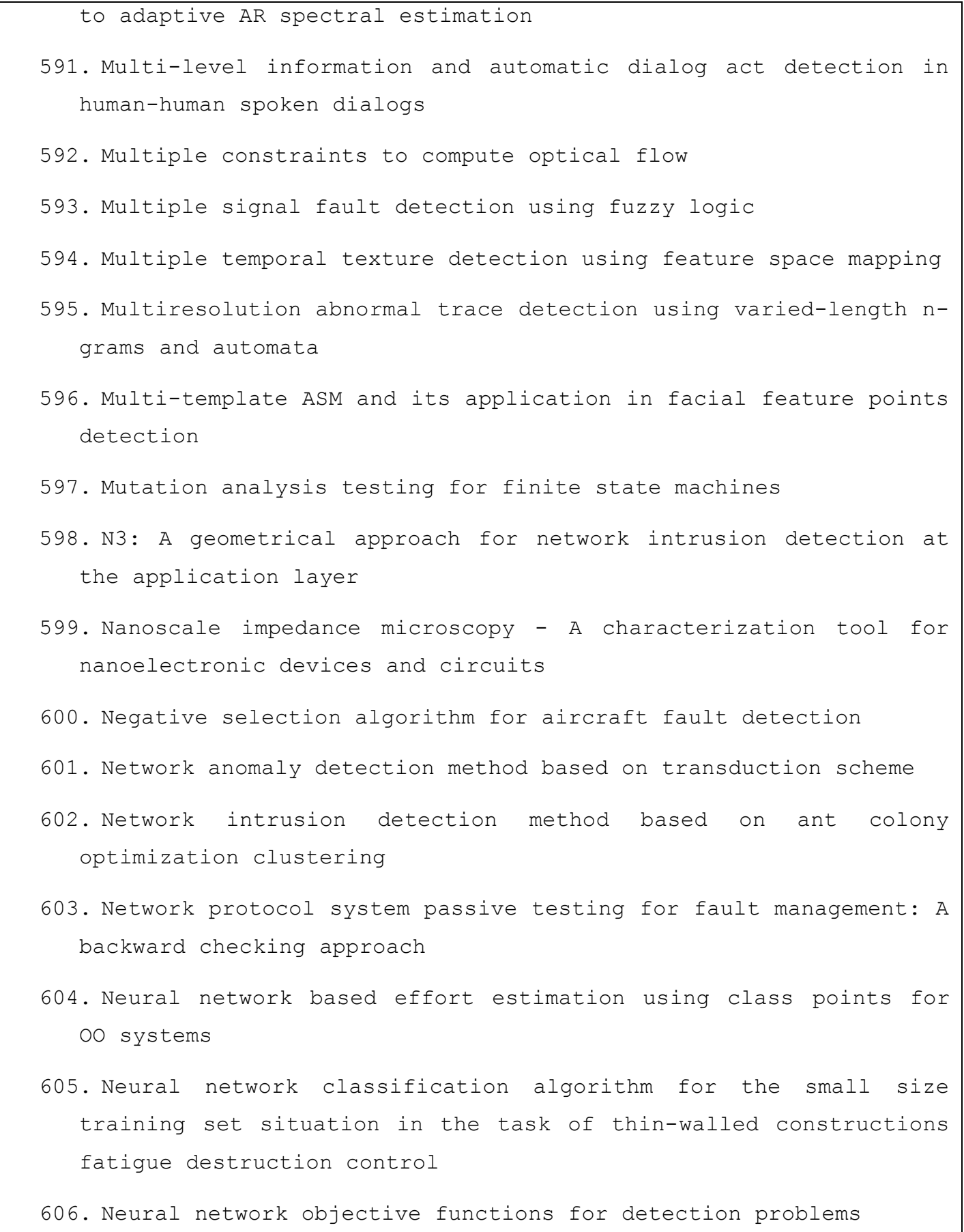

\section{Caso de estudio}


607. Neural networks applied to fault detection of a biotechnological process

608. Neutron ser characterization of microprocessors

609. New advance in the multi-beat body surface detection of his bundle waves

610. NEW APPROACH TO THE DESIGN OF TESTABLE PLA'S

611. New approaches for passive testing using an Extended Finite State Machine specification

612. New diagnosis approach for short faults in interconnects

613. New elasto-plastic constitutive model inserted into the usersupplied material model of ADINA

614. New measurements and corner-guidance for curve matching with probabilistic relaxation

615. New methods for detecting characters wrongly deleted and inserted in Japanese strings and their applicability to DNA chains

616. Noise-robust cellular phone speech recognition using CODECadapted speech and noise models

617. Non bit-exact approach for implementation verification of the CCITT LD-CELP speech coder

618. Non-destructive sensing and its inverse model for canopy parameters using texture analysis and artificial neural network

619. Novel adaptation scheme in the NLMS algorithm for echo cancellation

620. Novel multilayer neural networks training algorithm that minimizes the probability of classification error

621. Novel robust watermarking technique in dithering halftone images 


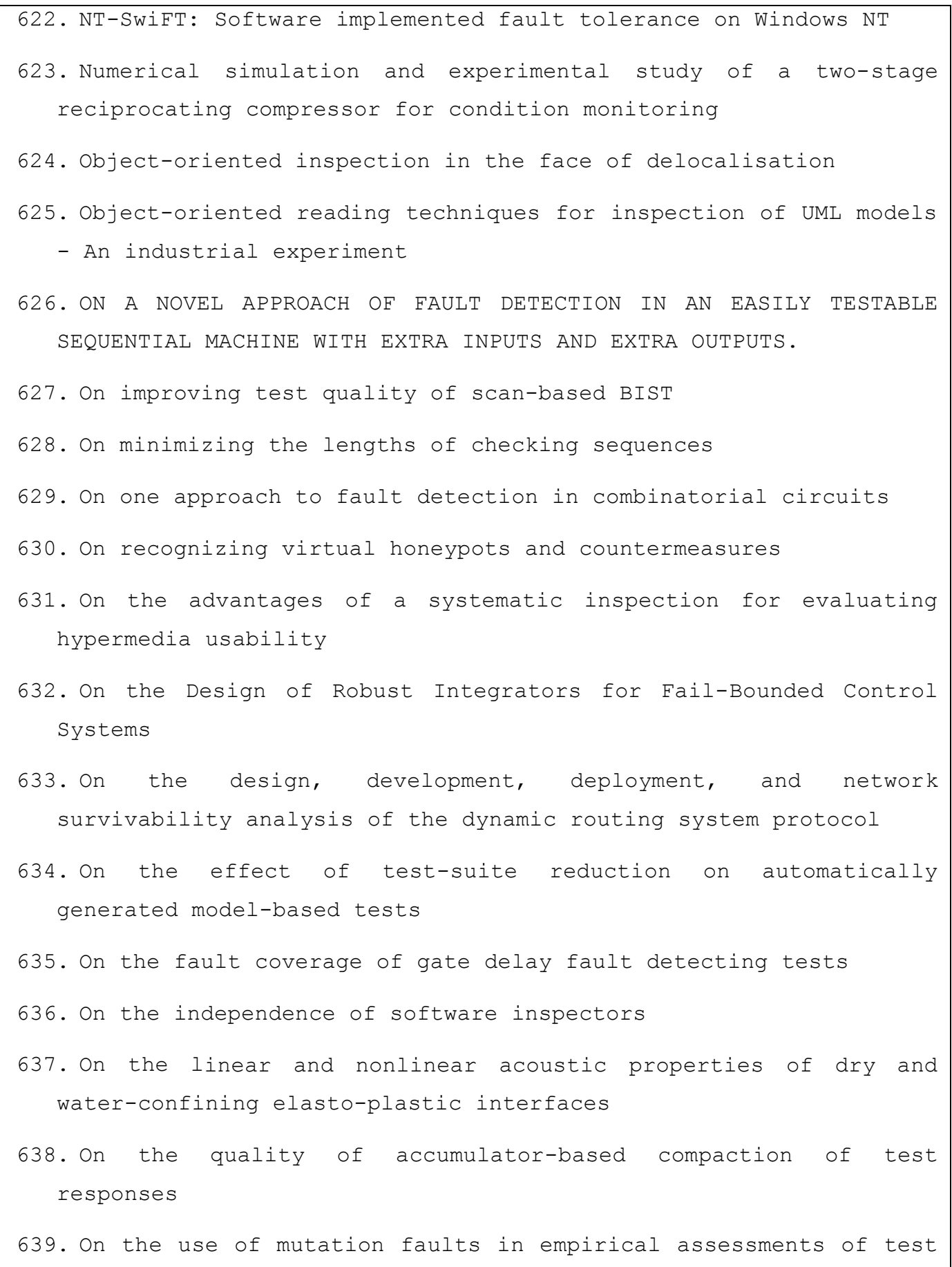

\section{Caso de estudio}


case prioritization techniques

640. On the utility of historical project statistics for cost and schedule estimation. Results from a simulation-based case study

641. On tolerating faults in naturally redundant algorithms

642. One step ahead to multisensor data fusion for DDos detection

643. One-class bearings fault detection model based on Lyapunov exponent spectrum

644. On-line boosting for car detection from aerial images

645. On-line fault detection and location for Noc interconnects

646. Online Internet traffic prediction models based on MMSE

647. On-line learning from search failures

648. Optical camera based pedestrian detection in rainy or snowy weather

649. OPTIMAL DETECTION OF BRIDGE FAULTS AND STUCK-AT FAULTS IN TWOLEVEL LOGIC.

650. Optimally distributed computation in augmented networks

651. Optimising the informativeness of test data used for computational model updating

652. Optimum polygonal approximation of digitized curves

653. Optimum threshold generation for automated visual inspection of large-scale integration wafer patterns

654. Out-of-Bounds Array Access Fault Model and Automatic Testing Method Study

655. Overcoming the NAH syndrome for inspection deployment

656. Parallel, self-organizing hierarchical neural networks

657. Parallel, self-organizing, hierarchical neural networks

658. Partial scan design based on state transition modeling 


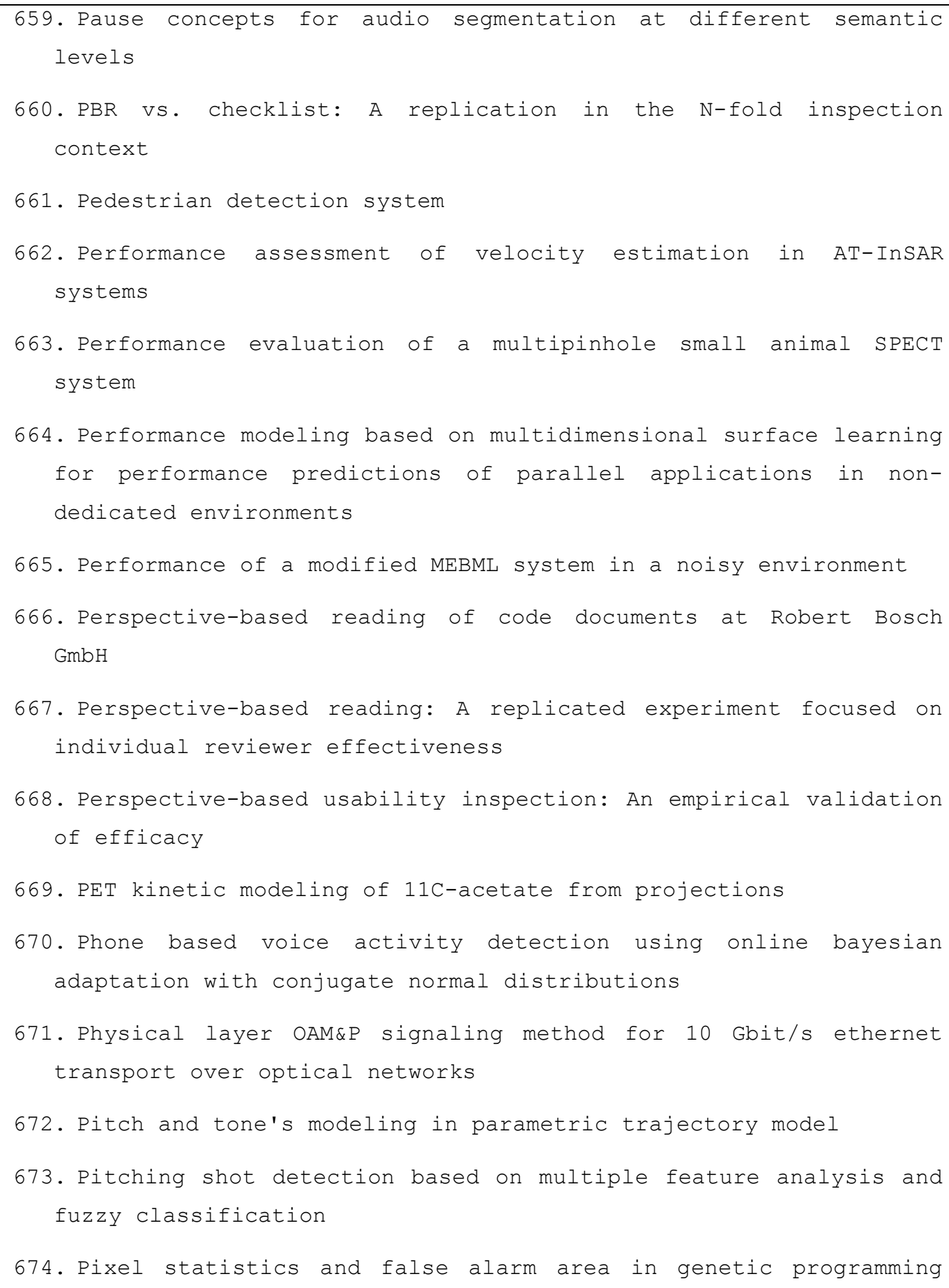

\section{Caso de estudio}


for object detection

675. Platinum silicide study for submicron CMOS application. Dielectric breakdown of gate oxide and correlation with yield models

676. Pocket computer program for fitting the Hill equation

677. Polarization modulation (PLM)/optical coherent detection system and its phase noise cancelling effect

678. POLYNOMIALLY COMPLETE FAULT DETECTION PROBLEMS.

679. Post global routing RLC crosstalk budgeting

680. Practical code inspection techniques for object-oriented systems: An experimental comparison

681. Practical experiences in the design and conduct of surveys in empirical software engineering

682. Practical rough image curve matching method based on accumulation of evidence

683. Preliminary study of behavioral and safety effects of driver dependence on a warning system in a driving simulator

684. Prevention of error propagation in dictionary compression with update and deletion

685. Prioritizing JUnit test cases: An empirical assessment and cost-benefits analysis

686. Prioritizing test cases for regression testing

687. Probabilistic classification between foreground objects and background

688. Problem detection in human-machine interactions based on facial expressions of users

689. Proceedings - ICSE 2007 Workshops: Fourth International Workshop on Mining Software Repositories, MSR 2007 
690. Proceedings of t1he 14th ACM SIGSOFT International Symposium on Foundations of Software Engineering

691. Proceedings of the 1998 ACM SIGPLAN/SIGSOFT Workshop on Program Analysis for Software Tools and Engineering

692. Process for asynchronous software inspection

693. PROCESSOR CONTROL FLOW MONITORING USING SIGNATURED INSTRUCTION STREAMS

694. Processor for calorimetry at the large hadron collider in the FERMI project

695. Processor-level selective replication

696. Prosodic word boundary detection using statistical modeling of moraic fundamental frequency contours and its use for continuous speech recognition

697. Quality Estimation Model of Monochrome Still Picture Based on Distortion Factors and Texture Features

698. Quantitative analysis of FTIR used in transformer on-line monitoring

699. Querying sensor networks by using dynamic task sets

700. Radial basis function support vector machine based softmagnetic ring core inspection

701. Range selectivity estimation for continuous attributes

702. Rank-aware query optimization

703. RankSQL: Query algebra and optimization for relational top-k queries

704. Rapid estimation for parameterized components in high-level synthesis

705. Rapid measurement of regional cerebral blood flow in the baboon using 150-labelled water and dynamic positron emission tomography

\section{Caso de estudio}


706. Rate control for real-time video network transmission on endto-end rate-distortion and application-oriented QoS

707. Rate of the reaction of $\mathrm{S}(3 \mathrm{p} 4 \mathrm{ID} 2)$ with OCS

708. Rational Filters for Passive Depth from Defocus

709. RBF nets, mixture experts, and Bayesian Ying-Yang learning

710. Rcapture: Loglinear models for capture-recapture in $\mathrm{R}$

711. RD optimization in JSCC-based error control on Internet multimedia layered multicast

712. Real-time detection of distributed denial-of-service attacks using RBF networks and statistical features

713. Real-time transcription system for simultaneous subtitling of Japanese broadcast news programs

714. Recognition confidence scoring and its use in speech understanding systems

715. Recognizing multitasked activities from video using stochastic context-free grammar

716. Reconstruction of textured urban 3D model by fusing groundbased laser range and CCD images

717. Recursive least absolute error algorithm: Analysis and simulations

718. Reducing critical failures for control algorithms using executable assertions and best effort recovery

719. Reducing hardware with fuzzy multiple signature analysis

720. Reducing inspection interval in large-scale software development

721. Reducing the cost of test pattern generation by information reusing

722. Region-based shape analysis with tracked locations 
723. Region-based shape analysis with tracked locations

724. Registration of multiple range data from real scenes using 3D contour features

725. Relationship among recognition rate, rejection rate and false alarm rate in a spoken word recognition system

726. RELATIONSHIP OF RAIN-INDUCED CROSS-POLARIZATION DISCRIMINATION TO ATTENUATION FOR 10 TO 30 GHz EARTH-SPACE RADIO LINKS.

727. Relative magnitude of Gaussian curvature from shading images using neural network

728. Reliability Microkernel: Providing application-aware reliability in the oS

729. Repeatable software engineering experiments for comparing defect-detection techniques

730. Replication cache: A small fully associative cache to improve data cache reliability

731. Representing OCRed documents in HTML

732. Research of the thruster fault diagnosis for open-frame underwater vehicles

733. Research on medical image clustering based on approximate density function

734. Research on supervised intrusion detection method

735. Research on test-platform and condition monitoring method for AUV

736. Research on the propagation characteristics of utrasonic guided waves in curved pippes

737. Research on the security audit model in intrusion prevention based on write-related support vector data description

738. Resolving motion correspondence for densely moving points

\section{Caso de estudio}


739. Response and excitation points selection for accurate rigidbody inertia properties identification

740. Robust adaptive-scale parametric model estimation for computer vision

741. Robust and adaptive OMR system including fuzzy modeling, fusion of musical rules, and possible error detection

742. Robust and secret data transmission over the noisy channel

743. Robust automated multiple view inspection

744. Robust end-of-utterance detection for real-time speech recognition applications

745. Robust estimation of adaptive tensors of curvature by tensor voting

746. Robust estimations of fault content with capture-recapture and detection profile estimators

747. Robust fault detection of robotic systems: New results and experiments

748. Robust least squares estimation for image geometric correction

749. Robust motion control for mobile manipulator using resolved acceleration and proportional-integral active force control

750. Robust spatial image watermarking using progressive detection

751. Role of comprehension in software inspection

752. Role of visual fidelity in computer-based instruction

753. Rolling bearing outside diameter inspection system based on machine vision

754. Rule based approach for detection of defects in microlithography patterns

755. Rule based approach for detection of defects in microlithography patterns 


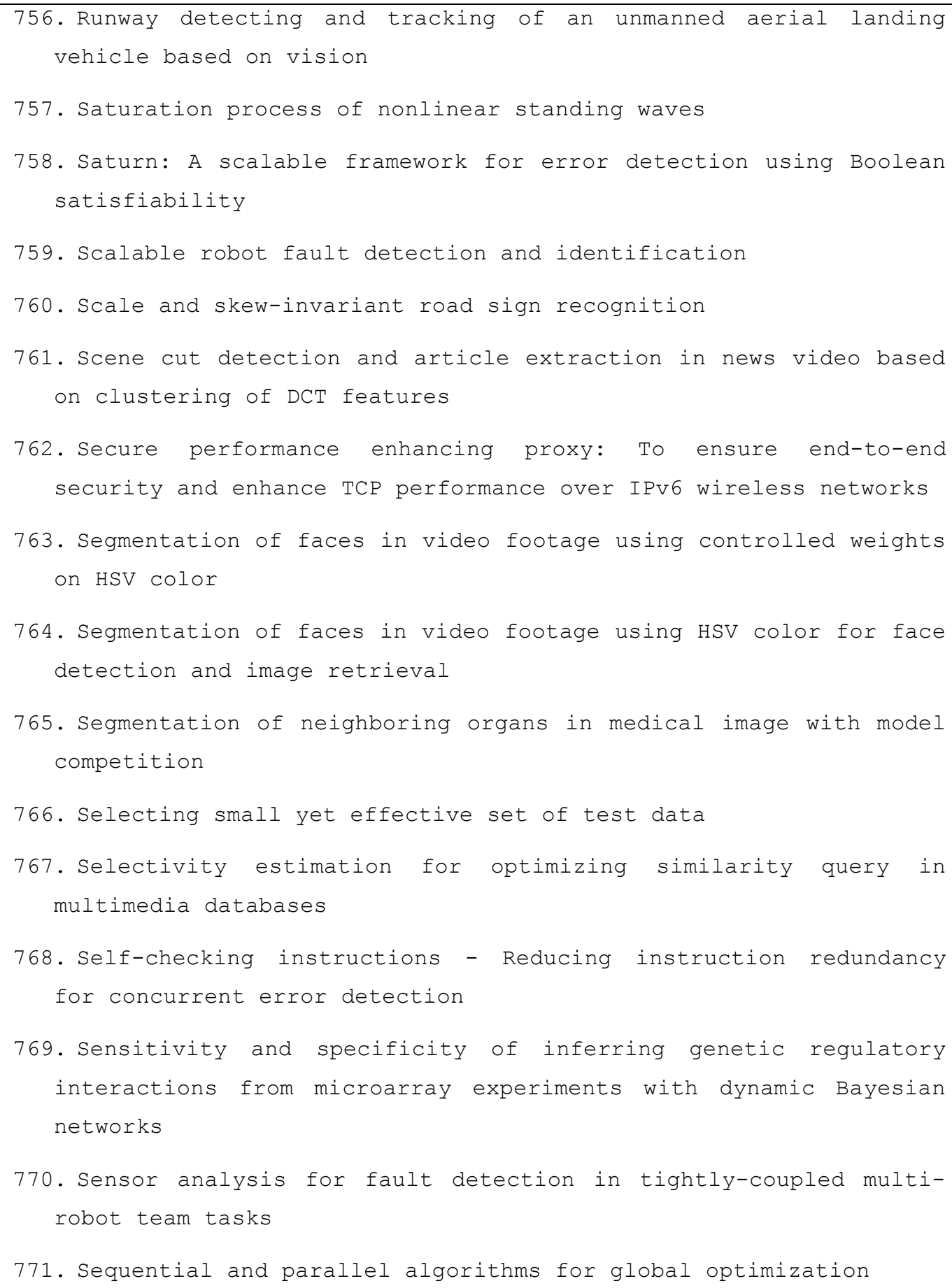

\section{Caso de estudio}


772. Shape classification by moment and autoregressive invariants

773. Shape reconstruction on a varying mesh

774. Ship detection experiments using RADARSAT/SAR images

775. Ship detection in SAR images using multipolarimetric information

776. Significance and attributes of subpixel estimation on areabased matching

777. Simulation-based testing of communication protocols for dependable embedded systems

778. Simulations of space-clamp errors in estimating parameters of voltage-gated conductances localized at different electrotonic distances

779. Simultaneous segmentation and approximation of complex patterns

780. Simultaneous surface approximation and segmentation of complex objects

781. Skew detection and correction in document images based on straight-line fitting

782. Skyeye: An instruction simulator with energy awareness

783. Smart debugging software architectural design in SDL

784. Software effort estimation by analogy and "regression toward the mean"

785. SOFTWARE ERRORS IN EXPERIMENTAL SYSTEMS HAVING ULTRARELIABILITY REQUIREMENTS

786. Software group reviews and the impact of procedural roles on defect detection performance

787. Software quality classification model based on McCabe's complexity measure

788. Software reliability growth model considering differences 


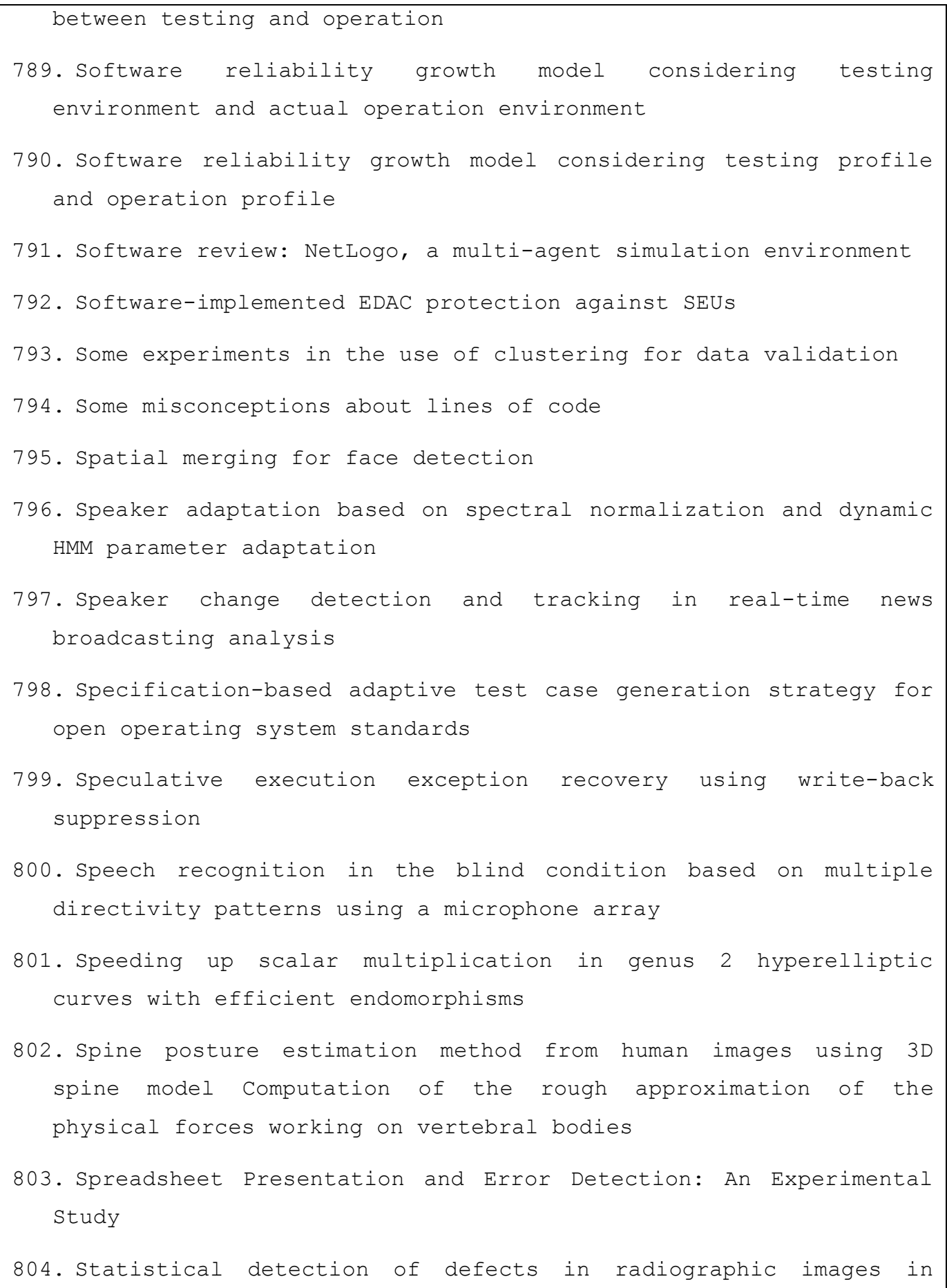

\section{Caso de estudio}




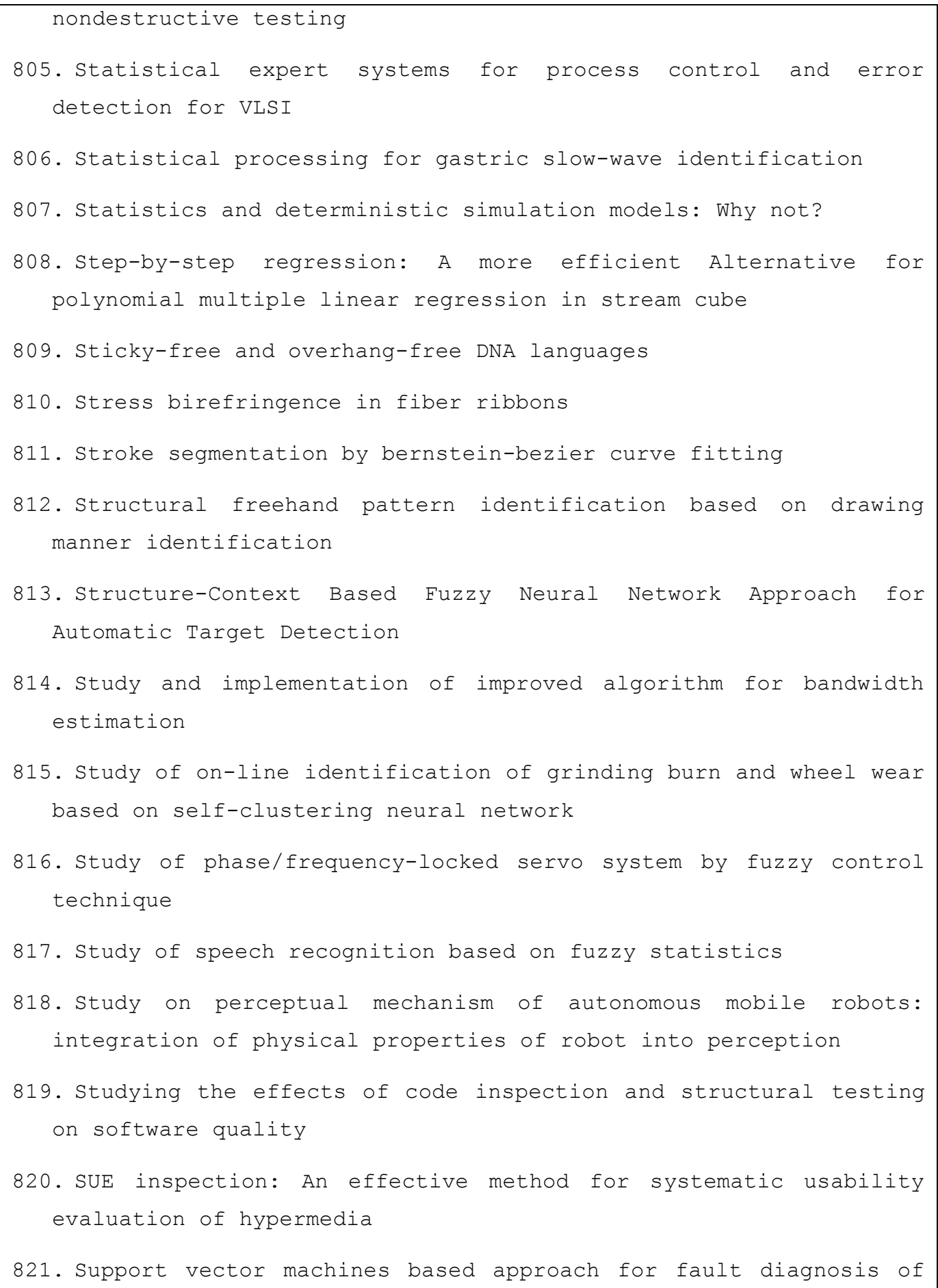




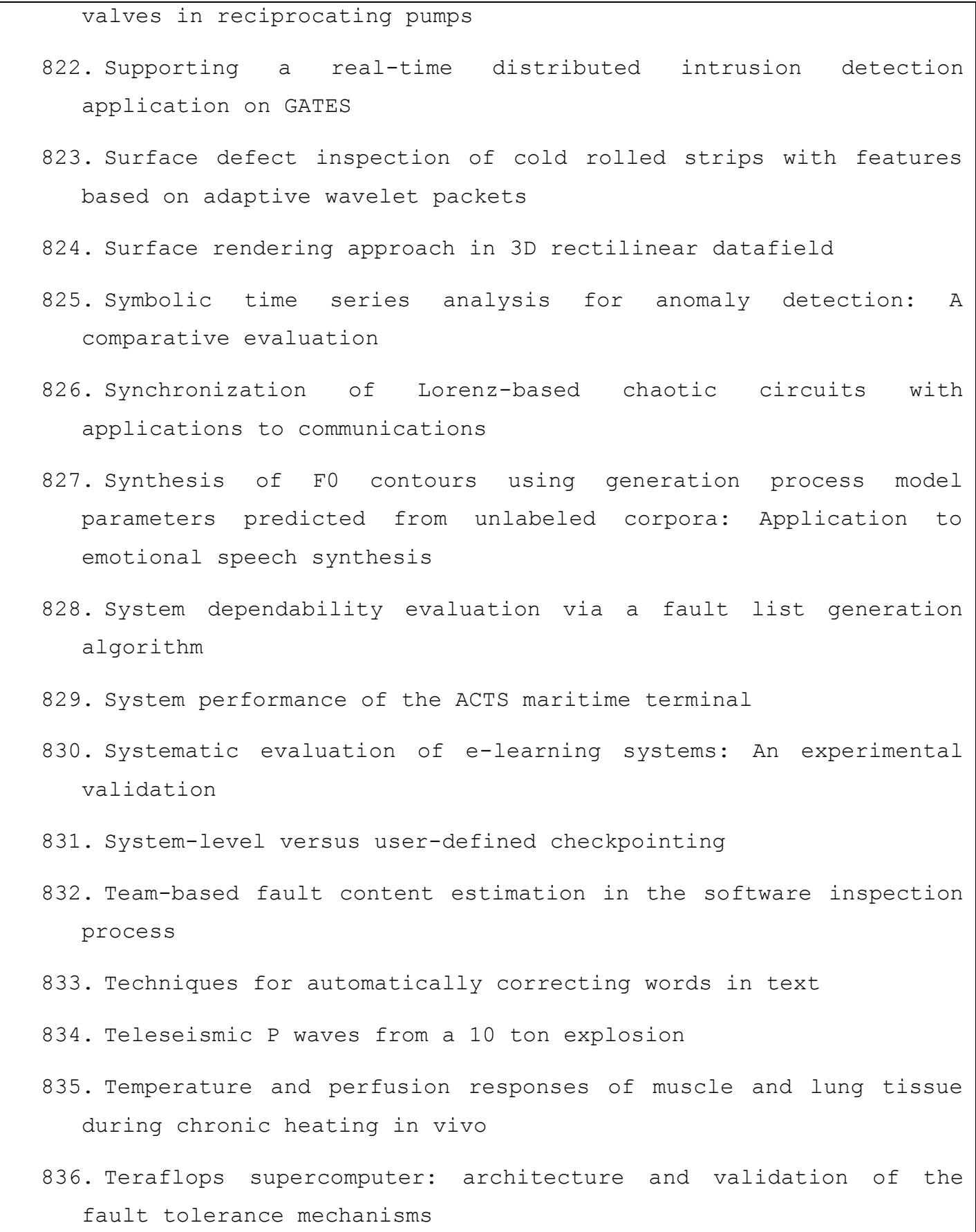

\section{Caso de estudio}


837. Test agent system

838. Test case prioritization for black box testing

839. Test case prioritization: A family of empirical studies

840. Test cases generation method for FSM with counters and its fault coverage evaluation using a mutant generator

841. Testing and inspecting reusable product line components: First empirical results

842. Testing from partial deterministic FSM specifications

843. Testing of fault-tolerant and real-time distributed systems via protocol fault injection

844. The analysis of heart rate variability in unrestrained rats. Validation of method and results

845. The application of fitting methods to chemical kinetics

846. The combinatorial design approach to automatic test generation

847. The conversion of a dynamic B-spline curve into piecewise polynomials in power form

848. The dual of denial: Two uses of disconfirmations in dialogue and their prosodic correlates

849. The effects of an ARMOR-based SIFT environment on the performance and dependability of user applications

850. The electric actuator's fault diagnosis based on information fusion

851. The empirical investigation of perspective-based reading

852. The estimation models of rape biomass yield using hyperspectral data

853. The feature vector selection for robust multiple face detection

854. The impact of training-by-examples on inspection performance using two laboratory experiments 


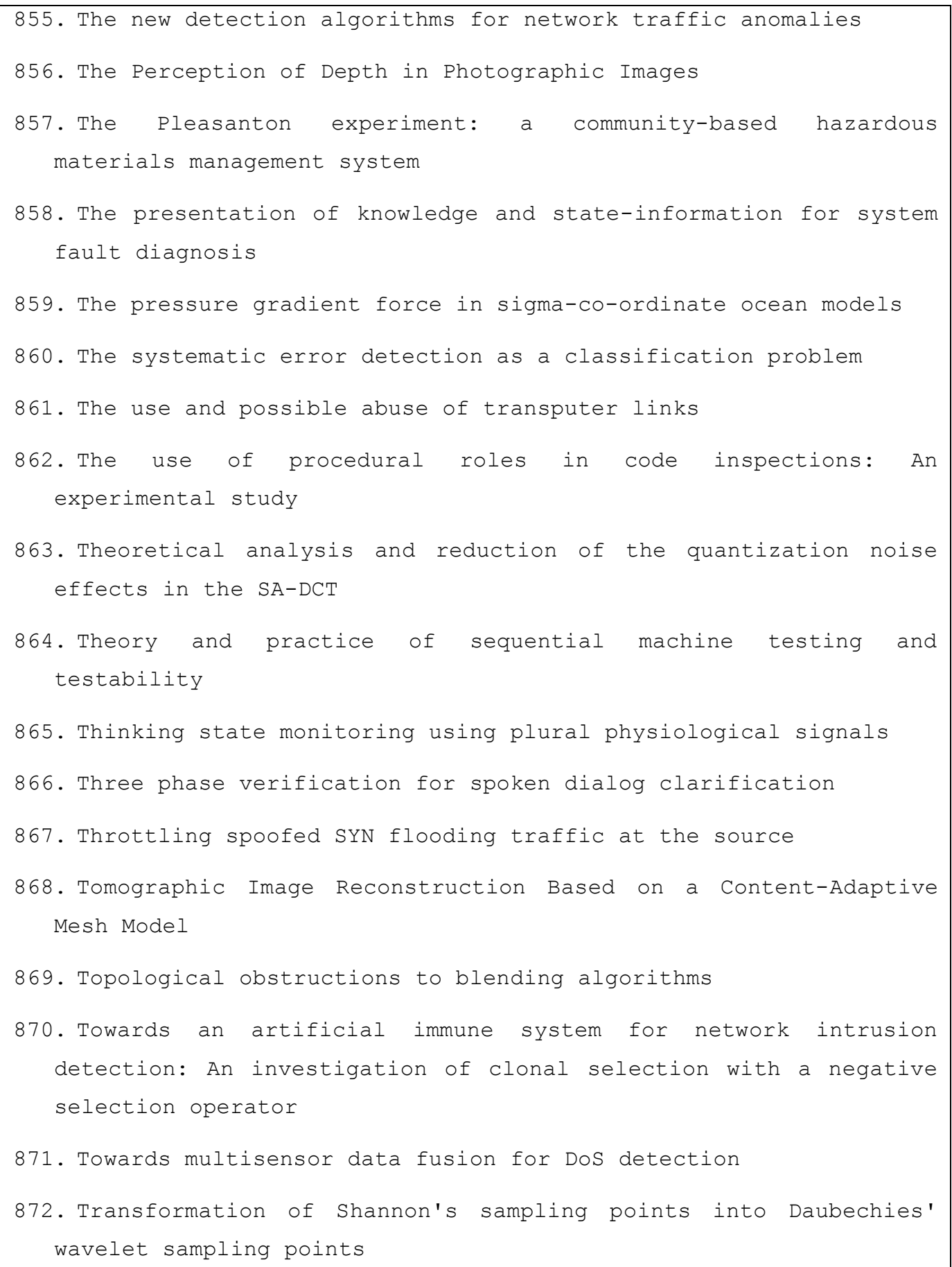

Caso de estudio 
873. Transient power supply current testing of digital CMOS circuits

874. Trend-resistant and cost-efficient cross-over designs for mixed models

875. T-S model based indirect adaptive fuzzy control using online parameter estimation

876. 'Two out of three': An alternative method for codon reading

877. Two-person inspection method to improve programming productivity

878. Unbiased estimation of ellipses by bootstrapping

879. Understanding and improving speech recognition performance through the use of diagnostic tools

880. Understanding and measuring the sources of variation in the prioritization of regression test suites

881. Understanding the effects of developer activities on inspection interval

882. Understanding the Sources of Variation in Software Inspections

883. Upset-tolerant CMOS SRAM using current monitoring: prototype and test experiments

884. Usability inspection by metaphors of human thinking compared to heuristic evaluation -

885. Usage-based reading - An experiment to guide reviewers with use cases

886. Use and possible abuse of transputer links

887. Use of k-nearest neighbor classifier for intrusion detection

888. Using a reliability growth model to control software inspection

889. Using boosting learning method for intrusion detection

890. Using eye movement parameters for evaluating human-machine interface frameworks under normal control operation and fault 


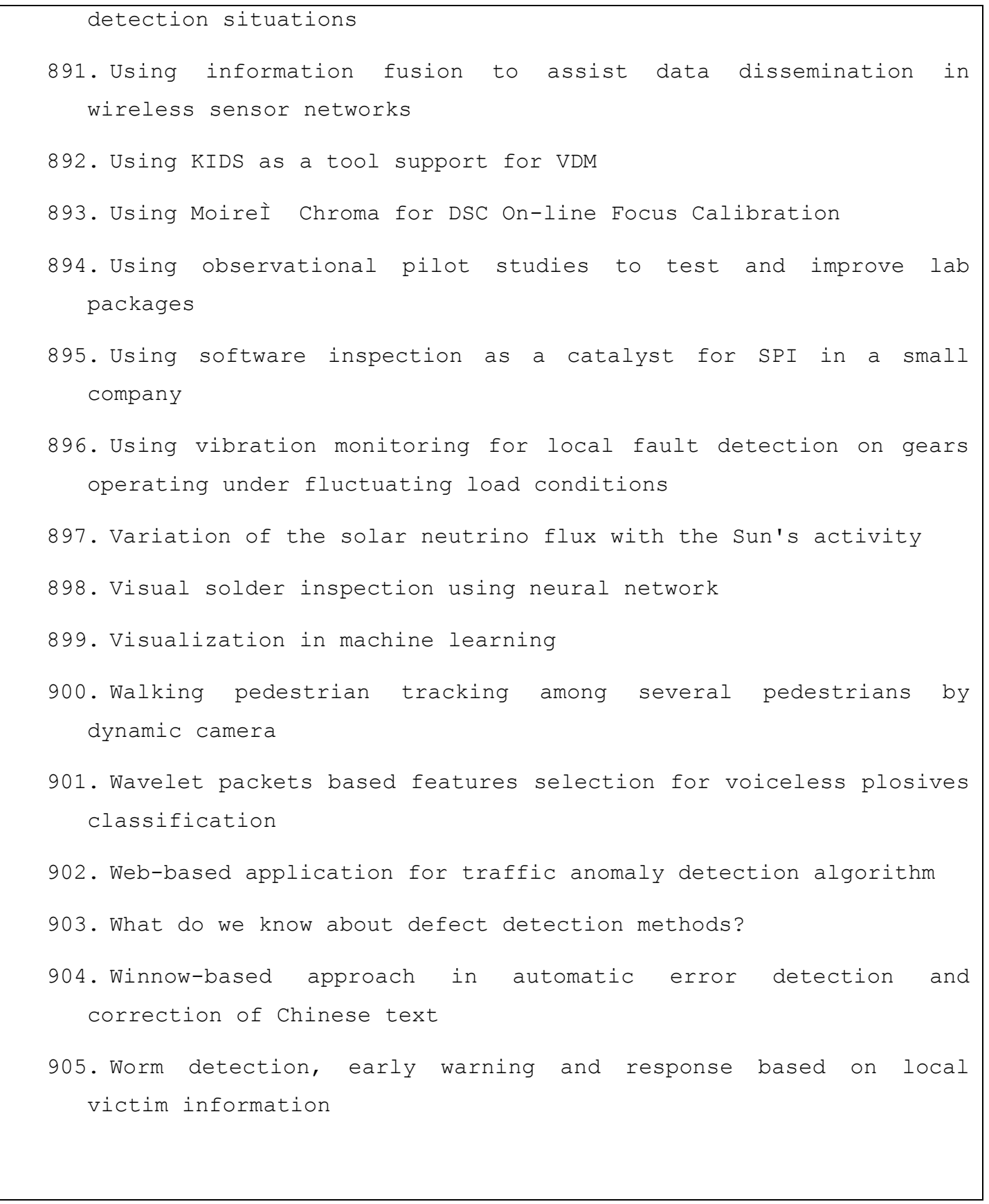

\section{Caso de estudio}




\subsubsection{Descarte de artículos irrelevantes (segunda iteración)}

Luego de analizar los resultados obtenidos en la actividad anterior, se encontraron 87 artículos considerados relevantes. Debido al solapamiento entre los artículos obtenidos en esta iteración y los obtenidos en la búsqueda preliminar, sólo 35 nuevos artículos son agregados al conjunto base (para un total de 112 artículos). De los nuevos artículos considerados relevantes sólo 9 se corresponde con el grupo seleccionado para la agregación (ST-1). A continuación, se muestran los artículos que resultaron relevantes en esta iteración. Sólo se reporta la información de los artículos relevantes que son nuevos para el conjunto base. 
Proceso de RS de experimentos en Ingeniería del Software

B03_Resumen de artículos relevantes

Realizado por: Anna Grimán

Fecha:

\begin{tabular}{|c|c|c|c|c|c|}
\hline D & Autores & 309. Referencia & Fichero & Resumen & $\begin{array}{l}\text { Observació } \\
\text { n }\end{array}$ \\
\hline 1 & $\begin{array}{l}\text { F. } \\
\text { MacDonald } \\
\text { and J. Miller, }\end{array}$ & $\begin{array}{l}\text { A comparison of tool- } \\
\text { based and paper-based } \\
\text { software inspection. } \\
\text { Empirical Software Engineering, } 3 \\
\text { (3), pp. 233-253. } 1998\end{array}$ & & & $\begin{array}{l}\text { Recuperad } \\
\text { o previamente } \\
\text { (iteración 1) }\end{array}$ \\
\hline 2 & $\begin{array}{l}\text { A. Bianchi, } \\
\text { F. Lanubile, } \\
\text { and G. } \\
\text { Visaggio, }\end{array}$ & $\begin{array}{l}\text { A controlled experiment } \\
\text { to assess the effectiveness } \\
\text { of inspection meetings. } \\
\text { International Software Metrics } \\
\text { Symposium, Proceedings, pp. } 42-50 \text {. } \\
2001 \text {. }\end{array}$ & & & $\begin{array}{l}\text { Recuperad } \\
\text { o previamente } \\
\text { (iteración 1) }\end{array}$ \\
\hline
\end{tabular}

Caso de estudio 


\begin{tabular}{|c|c|c|}
\hline $\begin{array}{l}\text { B. Stefan, } \\
\text { G. Paul, and } \\
\text { H. Michael, }\end{array}$ & $\begin{array}{l}\text { A family of experiments } \\
\text { to investigate the effects } \\
\text { of groupware for software } \\
\text { inspection. Automated } \\
\text { Software Engineering } 13 \\
\text { (3), pp. 373-394. } 2006\end{array}$ & $\begin{array}{l}\text { Recuperad } \\
\text { o previamente } \\
\text { (iteración 1) }\end{array}$ \\
\hline $\begin{array}{l}\text { C. Atiq } \\
\text { and L. Lesley } \\
\text { Pek Wee, }\end{array}$ & $\begin{array}{l}\text { An } \\
\text { investigation on the impact } \\
\text { of training-by-examples on } \\
\text { inspection performance. } \\
\text { Lecture Notes in Computer } \\
\text { Science (including } \\
\text { subseries Lecture Notes in } \\
\text { Artificial Intelligence and } \\
\text { Lecture Notes in } \\
\text { Bioinformatics) 3009, pp. } \\
\text { 203-219. 2004 }\end{array}$ & $\begin{array}{l}\text { Recuperad } \\
\text { o previamente } \\
\text { (iteración 1) }\end{array}$ \\
\hline $\begin{array}{l}\text { C. A. } \\
\text { Toman, and } \\
\text { L. G. Votta, }\end{array}$ & $\begin{array}{l}\text { An experiment to assess } \\
\text { the cost-benefits of code } \\
\text { inspections in large scale } \\
\text { software development. } \\
\text { IEEE Transactions on Software }\end{array}$ & $\begin{array}{l}\text { Recuperad } \\
\text { o previamente } \\
\text { (iteración 1) }\end{array}$ \\
\hline
\end{tabular}


Proceso de RS de experimentos en Ingeniería del Software

\begin{tabular}{|c|c|c|c|}
\hline & & Engineering 23 (6), pp. 329-346. 1997 & \\
\hline & $\begin{array}{l}\text { Thelin, T., } \\
\text { Runeson, P. } \\
\text { and Wohlin, } \\
\text { C. }\end{array}$ & $\begin{array}{l}\quad \text { An } \\
\text { comparison of usage-based } \\
\text { and checklist-based } \\
\text { reading. } \\
\quad \text { IEEE Transactions on Software } \\
\text { Engineering, } 29 \text { (8), pp. 687-704. } 2003\end{array}$ & $\begin{array}{l}\text { Recuperad } \\
\text { o previamente } \\
\text { (iteración 1) }\end{array}$ \\
\hline 0 & $\begin{array}{l}\text { R. Per and } \\
\text { W. Claes, }\end{array}$ & $\begin{array}{l}\text { An oxperimental } \\
\text { evaluation an } \\
\text { experience-based capture- } \\
\text { recapture method in } \\
\text { software code inspections. } \\
\text { Empirical Software Engineering, } 3 \\
\text { (4), pp.381-406.1998 }\end{array}$ & $\begin{array}{l}\text { Recuperad } \\
\text { o previamente } \\
\text { (iteración 1) }\end{array}$ \\
\hline 1 & $\begin{array}{l}\text { El Emam, } \\
\text { and T. G. } \\
\text { Harbich, }\end{array}$ & $\begin{array}{l}\text { An internally replicated } \\
\text { quasi-experimental } \\
\text { comparison of checklist and } \\
\text { perspective-based reading } \\
\text { of code documents. IEEE }\end{array}$ & $\begin{array}{l}\text { Recuperad } \\
\text { o previamente } \\
\text { (iteración 1) }\end{array}$ \\
\hline
\end{tabular}

Caso de estudio 


\begin{tabular}{|c|c|c|c|}
\hline & & 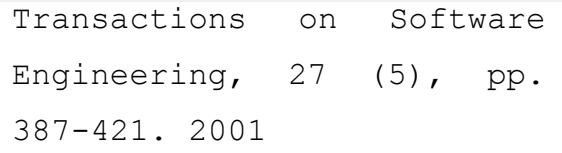 & \\
\hline 2 & $\begin{array}{l}\text { S. } \\
\text { Kusumoto, } \\
\text { and K. Inoue, }\end{array}$ & $\begin{array}{l}\text { Assessing defect } \\
\text { detection performance of } \\
\text { interacting teams in } \\
\text { object-oriented design } \\
\text { inspection. } \\
\text { Information and Software } \\
\text { Technology } 46 \text { (13), pp. 875-886. } 2004\end{array}$ & $\begin{array}{l}\text { Recuperad } \\
\text { o previamente } \\
\text { (iteración 1) }\end{array}$ \\
\hline 3 & $\begin{array}{l}\text { Philip M. } \\
\text { Johnson, } \\
\text { Danu } \\
\text { Tjahjono }\end{array}$ & 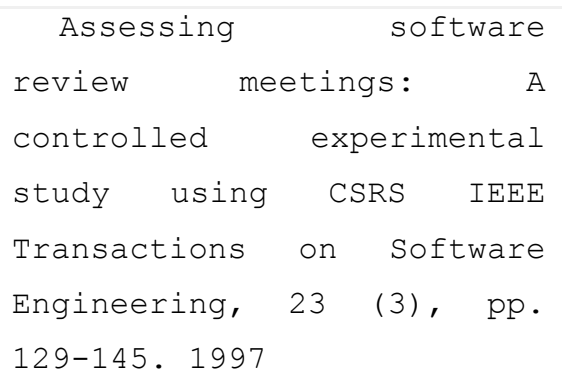 & $\begin{array}{l}\text { Recuperad } \\
\text { o previamente } \\
\text { (iteración 1) }\end{array}$ \\
\hline 9 & $\begin{array}{l}\text { A. Porter, } \\
\text { L. Votta, and } \\
\text { V. Basili }\end{array}$ & $\begin{array}{l}\text { Comparing detection } \\
\text { methods for software } \\
\text { requirements inspections: a } \\
\text { replicated experiment. } \\
\text { IEEE Transactions on Software }\end{array}$ & $\begin{array}{l}\text { Recuperad } \\
\text { o previamente } \\
\text { (iteración 1) }\end{array}$ \\
\hline
\end{tabular}


Proceso de RS de experimentos en Ingeniería del Software

\begin{tabular}{|c|c|c|c|}
\hline & & Engineering, 21 (6), pp. 563-575. 1995 & \\
\hline 0 & $\begin{array}{l}\text { Sabaliausk } \\
\text { aite, G., } \\
\text { Kusumoto, S., } \\
\text { Inoue, K. }\end{array}$ & $\begin{array}{l}\text { Comparing reading } \\
\text { techniques for object- } \\
\text { oriented design inspection. } \\
\text { Empirical Software Engineering, } 3 \\
\text { (4), pp.355-379.1998 }\end{array}$ & $\begin{array}{l}\text { Recuperad } \\
\text { o previamente } \\
\text { (iteración 1) }\end{array}$ \\
\hline 1 & $\begin{array}{l}\text { P. } \\
\text { Vitharana } \\
\text { and K. } \\
\text { Ramamurthy, }\end{array}$ & $\begin{array}{l}\text { Computer-mediated group } \\
\text { support, anonymity, and the } \\
\text { software inspection } \\
\text { process: An empirical } \\
\text { investigation. } \\
\text { IEEE Transactions on Software } \\
\text { Engineering } 29 \text { (2), pp.167-180.2003 }\end{array}$ & $\begin{array}{l}\text { Recuperad } \\
\text { o previamente } \\
\text { (iteración 1) }\end{array}$ \\
\hline 2 & $\begin{array}{l}\text { T. Thelin } \\
\text { and P. } \\
\text { Runeson, }\end{array}$ & $\begin{array}{l}\text { Confidence intervals for } \\
\text { capture-recapture } \\
\text { estimations in software } \\
\text { inspections. } \\
\text { Information and Software }\end{array}$ & $\begin{array}{l}\text { Recuperad } \\
\text { o previamente } \\
\text { (iteración 1) }\end{array}$ \\
\hline
\end{tabular}

Caso de estudio 


\begin{tabular}{|c|c|c|c|}
\hline & & Technology 44 (12), pp. 683-702. 2002 & \\
\hline 4 & $\begin{array}{l}\text { Harjumaa, } \\
\text { L. }\end{array}$ & $\begin{array}{l}\text { Distributed software } \\
\text { inspections - An experiment } \\
\text { with Adobe Acrobat. } \\
\text { Proceedings of the IASTED } \\
\text { International Conference on Computer } \\
\text { Science and Technology, pp. 26-31. } \\
2003\end{array}$ & $\begin{array}{l}\text { Recuperad } \\
\text { o previamente } \\
\text { (iteración 1) }\end{array}$ \\
\hline 6 & $\begin{array}{l}\text { S. S. So, S. } \\
\text { D. Cha, and Y. } \\
\text { R. Kwon, }\end{array}$ & $\begin{array}{l}\text { Empirical evaluation of } \\
\text { a fuzzy logic-based } \\
\text { software quality prediction } \\
\text { model. Fuzzy Sets and } \\
\text { Systems, } 127 \text { (2), pp. 199- } \\
\text { 208. } 2002\end{array}$ & $\begin{array}{l}\text { Recuperad } \\
\text { o previamente } \\
\text { (iteración 1) }\end{array}$ \\
\hline 7 & $\begin{array}{c}\text { T. } \\
\text { Thomas, }\end{array}$ & 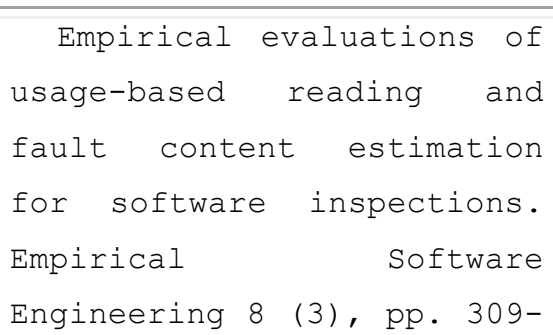 & $\begin{array}{l}\text { Recuperad } \\
\text { o previamente } \\
\text { (iteración 1) }\end{array}$ \\
\hline
\end{tabular}


Proceso de RS de experimentos en Ingeniería del Software

\begin{tabular}{|c|c|c|c|}
\hline & & 313.2003 & \\
\hline 8 & S. Biffl, & $\begin{array}{l}\text { Evaluating defect } \\
\text { estimation models with } \\
\text { major defects. Journal of } \\
\text { Systems and Software, } 65 \\
\text { (1), pp. 13-29. } 2003\end{array}$ & $\begin{array}{l}\text { Recuperad } \\
\text { o previamente } \\
\text { (iteración 1) }\end{array}$ \\
\hline 0 & $\begin{array}{l}\text { T. } \\
\text { Thomas, R. } \\
\text { Per, W. Claes, } \\
\text { O. Thomas, } \\
\text { and A. Carina, }\end{array}$ & $\begin{array}{l}\text { Evaluation of Usage- } \\
\text { Based Reading - Conclusions } \\
\text { after Three Experiments. } \\
\text { Empirical Software Engineering, } 9 \\
\text { (1-2), pp. 77-110. } 2004\end{array}$ & $\begin{array}{l}\text { Recuperad } \\
\text { o previamente } \\
\text { (iteración 1) }\end{array}$ \\
\hline 2 & $\begin{array}{l}\text { Porter, L. } \\
\text { G. Votta }\end{array}$ & $\begin{array}{l}\text { Experiment to assess } \\
\text { different defect detection } \\
\text { methods for software } \\
\text { requirements inspections. } \\
\text { Proceedings - International } \\
\text { Conference on Software Engineering, } \\
\text { pp.103-112.1994 }\end{array}$ & $\begin{array}{l}\text { Recuperad } \\
\text { o previamente } \\
\text { (iteración 1) }\end{array}$ \\
\hline
\end{tabular}

Caso de estudio 


\begin{tabular}{|c|c|c|c|}
\hline 3 & $\begin{array}{l}\text { A. Porter, } \\
\text { H. P. Siy, C. A. } \\
\text { Toman, and } \\
\text { L. G. Votta, }\end{array}$ & $\begin{array}{l}\text { Experiment to assess the } \\
\text { cost-benefits of code } \\
\text { inspections in large scale. } \\
\text { IEEE Transactions on Software } \\
\text { Engineering } 23(6), \text { pp. 329-346. } 1997\end{array}$ & $\begin{array}{l}\text { Recuperad } \\
\text { o previamente } \\
\text { (iteración 1) }\end{array}$ \\
\hline 4 & $\begin{array}{l}\text { O. } \\
\text { Laitenberger, } \\
\text { C. Atkinson, } \\
\text { M. Schlich, } \\
\text { and K. El } \\
\text { Emam, }\end{array}$ & $\begin{array}{l}\text { Experimental comparison } \\
\text { of reading techniques for } \\
\text { defect detection in UML } \\
\text { design documents. Journal } \\
\text { of Systems and Software, } 53 \\
\text { (2), pp. 183-204. } 2000\end{array}$ & $\begin{array}{l}\text { Recuperad } \\
\text { o previamente } \\
\text { (iteración 1) }\end{array}$ \\
\hline 5 & & 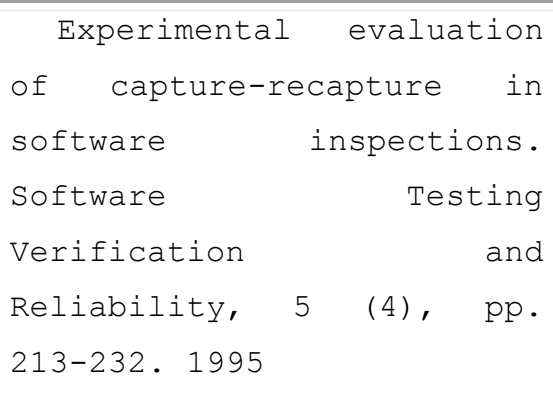 & $\begin{array}{l}\text { Recuperad } \\
\text { o previamente } \\
\text { (iteración 1) }\end{array}$ \\
\hline 6 & & $\begin{array}{l}\text { Experimentation } \text { with } \\
\text { usage-based } \\
\text { Lecture Notes in Computer } \\
\text { Science }\end{array}$ & $\begin{array}{l}\text { Recuperad } \\
\text { o previamente } \\
\text { (iteración 1) }\end{array}$ \\
\hline
\end{tabular}


Proceso de RS de experimentos en Ingeniería del Software

\begin{tabular}{|c|c|c|}
\hline & $\begin{array}{l}\text { subseries Lecture Notes in } \\
\text { Artificial Intelligence and } \\
\text { Lecture Notes in } \\
\text { Bioinformatics), 2765, pp. } \\
\text { 193-207. } 2003\end{array}$ & \\
\hline 8 & $\begin{array}{l}\text { Further Experiences with } \\
\text { Scenarios and Checklists. } \\
\text { Empirical Software Engineering, } 3 \\
\text { (1), pp.37-64.1998 }\end{array}$ & $\begin{array}{l}\text { Recuperad } \\
\text { o previamente } \\
\text { (iteración 1) }\end{array}$ \\
\hline 0 & $\begin{array}{l}\text { Further investigations } \\
\text { of reading techniques for } \\
\text { object-oriented design } \\
\text { inspection. } \\
\text { Information and Software } \\
\text { Technology, } 45 \text { (9), pp.571-585.2003 }\end{array}$ & $\begin{array}{l}\text { Recuperad } \\
\text { o previamente } \\
\text { (iteración 1) }\end{array}$ \\
\hline 2 & $\begin{array}{l}\text { Investigating } \\
\text { reinspection decision } \\
\text { accuracy regarding product- } \\
\text { quality and cost-benefit } \\
\text { estimates. Proceedings - } \\
\text { IEEE Computer Society's }\end{array}$ & $\begin{array}{l}\text { Recuperad } \\
\text { o previamente } \\
\text { (iteración 1) }\end{array}$ \\
\hline
\end{tabular}

Caso de estudio 


\begin{tabular}{|c|c|c|}
\hline & $\begin{array}{l}\text { International } \quad \text { Computer } \\
\text { Software and Applications } \\
\text { Conference, pp. 87-96. } 2001\end{array}$ & \\
\hline 3 & $\begin{array}{l}\text { Investigating the cost- } \\
\text { effectiveness } \\
\text { reinspection in software } \\
\text { development. } \\
\text { Proceedings - } \\
\text { Conference on Software Engineering, } \\
\text { pp.155-164. } 2001\end{array}$ & $\begin{array}{l}\text { Recuperad } \\
\text { o previamente } \\
\text { (iteración 1) }\end{array}$ \\
\hline 4 & $\begin{array}{l}\text { Investigating the defect } \\
\text { detection effectiveness and } \\
\text { cost benefit of nominal } \\
\text { inspection teams. } \\
\text { IEEE Transactions on Software } \\
\text { Engineering, } 29 \text { (5), pp. 385-397. } 2003\end{array}$ & $\begin{array}{l}\text { Recuperad } \\
\text { o previamente } \\
\text { (iteración 1) }\end{array}$ \\
\hline 5 & $\begin{array}{l}\text { Investigating the effect } \\
\text { of expert ranking of use } \\
\text { cases for } \\
\text { inspection. } \\
\text { Proceedings Conference } \\
\text { EUROMICRO, } 30 \text {, pp. 362-371. }\end{array}$ & $\begin{array}{l}\text { Recuperad } \\
\text { o previamente } \\
\text { (iteración 1) }\end{array}$ \\
\hline
\end{tabular}


Proceso de RS de experimentos en Ingeniería del Software

\begin{tabular}{|c|c|c|}
\hline & 2004 & \\
\hline 6 & $\begin{array}{l}\text { Investigating the impact } \\
\text { of active guidance on } \\
\text { design inspection. } \\
\text { Lecture Notes in Computer Science, } \\
\text { 3547, pp. } 458-473.2005\end{array}$ & $\begin{array}{l}\text { Recuperad } \\
\text { o previamente } \\
\text { (iteración 1) }\end{array}$ \\
\hline 7 & $\begin{array}{l}\text { Investigating the impact } \\
\text { of reading techniques on } \\
\text { the accuracy of different } \\
\text { defect content estimation } \\
\text { techniques. } \\
\text { International Software Metrics } \\
\text { Symposium, Proceedings, pp. 51-62. } \\
2001\end{array}$ & $\begin{array}{l}\text { Recuperad } \\
\text { o previamente } \\
\text { (iteración 1) }\end{array}$ \\
\hline 0 & $\begin{array}{l}\text { Object-oriented reading techniques } \\
\text { for inspection of UML models - An } \\
\text { industrial experiment. ISCE'06 - } \\
\text { Proceedings of the 5th ACM-IEEE } \\
\text { International Symposium on Empirical }\end{array}$ & $\begin{array}{l}\text { Recuperad } \\
\text { o previamente } \\
\text { (iteración 1) }\end{array}$ \\
\hline
\end{tabular}

Caso de estudio 


\begin{tabular}{|c|c|c|}
\hline & $\begin{array}{l}\text { Software Engineering, 2006, pp. 174- } \\
\text { 183. } 2006\end{array}$ & \\
\hline 2 & $\begin{array}{l}\text { On the independence of } \\
\text { software } \\
\text { Journal of Systems and } \\
\text { Software, } 60 \text { (1), pp. 5-10. }\end{array}$ & $\begin{array}{l}\text { Recuperad } \\
\text { o previamente } \\
\text { (iteración 1) }\end{array}$ \\
\hline 3 & $\begin{array}{l}\text { Overcoming the NAH } \\
\text { syndrome for inspection } \\
\text { deployment. Proceedings - } \\
\text { International Conference on } \\
\text { Software Engineering, pp. } \\
\text { 371-378. } 1998\end{array}$ & $\begin{array}{l}\text { Recuperad } \\
\text { o previamente } \\
\text { (iteración 1) }\end{array}$ \\
\hline 4 & $\begin{array}{l}\text { PBR vs. checklist: A } \\
\text { replication in the N-fold } \\
\text { inspection context. } \\
\text { ISCE-Proceedings of the 5th ACM- } \\
\text { IEEE International Symposium on } \\
\text { Empirical Software Engineering 2006, } \\
\text { pp.95-104.2006 }\end{array}$ & $\begin{array}{l}\text { Recuperad } \\
\text { o previamente } \\
\text { (iteración 1) }\end{array}$ \\
\hline
\end{tabular}


Proceso de RS de experimentos en Ingeniería del Software

\begin{tabular}{|c|c|c|}
\hline 5 & Perspective-based & Recuperad \\
\hline 6 & 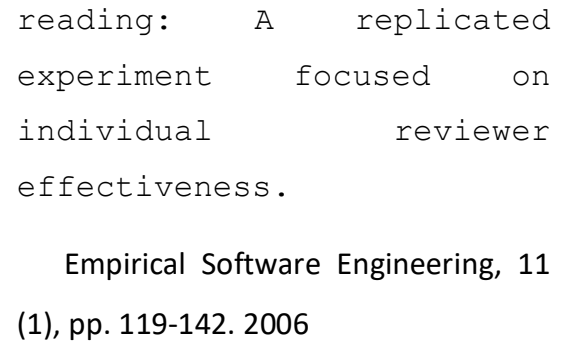 & $\begin{array}{l}\text { o previamente } \\
\text { (iteración 1) }\end{array}$ \\
\hline 8 & $\begin{array}{l}\quad \text { Practical } \\
\text { inspection techniques for } \\
\text { object-oriented systems: An } \\
\text { experimental comparison. } \\
\text { IEEE Software, } 20 \text { (4), pp. } \\
\text { 21-29. } 2003\end{array}$ & $\begin{array}{l}\text { Recuperad } \\
\text { o previamente } \\
\text { (iteración 1) }\end{array}$ \\
\hline 9 & $\begin{array}{l}\text { Process for asynchronous } \\
\text { software inspection. } \\
\text { Proceedings of the International } \\
\text { Workshop on Software Technology and } \\
\text { Engineering Practice, STEP, pp. 96-104. } \\
1997\end{array}$ & $\begin{array}{l}\text { Recuperad } \\
\text { o previamente } \\
\text { (iteración 1) }\end{array}$ \\
\hline
\end{tabular}

Caso de estudio 


\begin{tabular}{|c|c|c|}
\hline 0 & $\begin{array}{l}\text { Robust estimations of } \\
\text { fault content with capture- } \\
\text { recapture and detection } \\
\text { profile estimators. Journal } \\
\text { of Systems and Software, } 52 \\
\text { (2), pp. 139-148. } 2000\end{array}$ & $\begin{array}{l}\text { Recuperad } \\
\text { o previamente } \\
\text { (iteración 1) }\end{array}$ \\
\hline 1 & $\begin{array}{l}\text { Role of comprehension in } \\
\text { software inspection. } \\
\text { Journal of Systems and Software, } 52 \\
\text { (2), pp. 121-129. } 2000\end{array}$ & $\begin{array}{l}\text { Recuperad } \\
\text { o previamente } \\
\text { (iteración 1) }\end{array}$ \\
\hline 2 & 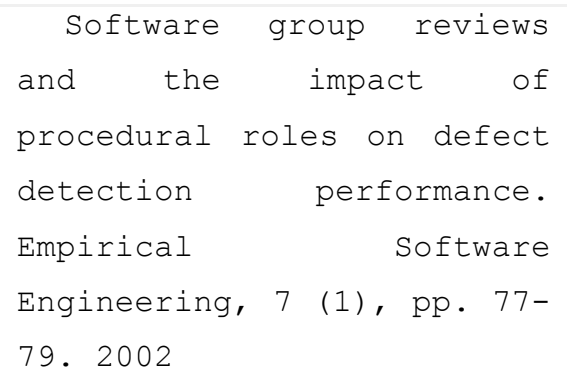 & $\begin{array}{l}\text { Recuperad } \\
\text { o previamente } \\
\text { (iteración 1) }\end{array}$ \\
\hline 6 & $\begin{array}{l}\text { Team-based fault content } \\
\text { estimation in the software } \\
\text { inspection process. } \\
\text { Proceedings - International } \\
\text { Conference on Software Engineering }\end{array}$ & $\begin{array}{l}\text { Recuperad } \\
\text { o previamente } \\
\text { (iteración 1) }\end{array}$ \\
\hline
\end{tabular}


Proceso de RS de experimentos en Ingeniería del Software

\begin{tabular}{|c|c|c|}
\hline & 26, pp. 263-272. 2004 & \\
\hline 7 & $\begin{array}{l}\text { Testing and inspecting } \\
\text { reusable product line } \\
\text { components: First empirical } \\
\text { results. } \\
\text { ISCE'06 - Proceedings of the 5th } \\
\text { ACM-IEEE International Symposium on } \\
\text { Empirical Software Engineering, 2006, } \\
\text { pp. 184-193. } 2006\end{array}$ & $\begin{array}{l}\text { Recuperad } \\
\text { o previamente } \\
\text { (iteración 1) }\end{array}$ \\
\hline 8 & $\begin{array}{l}\text { The impact of training- } \\
\text { by-examples on inspection } \\
\text { performance using two } \\
\text { laboratory experiments. } \\
\text { Proceedings of the Australian } \\
\text { Software Engineering Conference, } \\
\text { ASWEC 2004, pp. 279-288.2004 }\end{array}$ & $\begin{array}{l}\text { Recuperad } \\
\text { o previamente } \\
\text { (iteración 1) }\end{array}$ \\
\hline 9 & $\begin{array}{l}\text { The use of procedural } \\
\text { roles in code inspections: } \\
\text { An experimental study. }\end{array}$ & $\begin{array}{l}\text { Recuperad } \\
\text { o previamente } \\
\text { (iteración 1) }\end{array}$ \\
\hline
\end{tabular}

Caso de estudio 


\begin{tabular}{|c|c|c|}
\hline & $\begin{array}{l}\text { Empirical Software Engineering, } 5 \\
\text { (1), pp. 11-34. } 2000\end{array}$ & \\
\hline 2 & $\begin{array}{l}\text { Usage-based reading - An } \\
\text { experiment to guide } \\
\text { reviewers with use cases. } \\
\text { Information and Software } \\
\text { Technology, } 43 \text { (15), pp. } 925-938.2001\end{array}$ & $\begin{array}{l}\text { Recuperad } \\
\text { o previamente } \\
\text { (iteración 1) }\end{array}$ \\
\hline 3 & 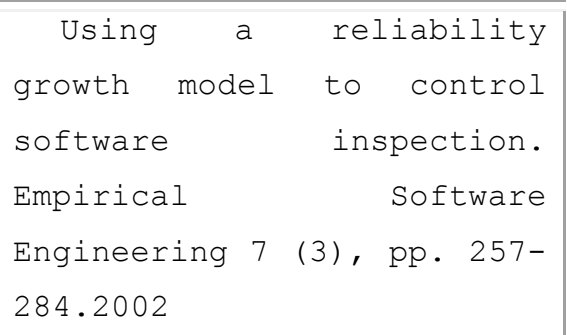 & $\begin{array}{l}\text { Recuperad } \\
\text { o previamente } \\
\text { (iteración } 1 \text { ) }\end{array}$ \\
\hline 4 & $\begin{array}{l}\text { Using software inspection as a } \\
\text { catalyst for SPI in a small company. } \\
\text { Lecture Notes in Computer Science } \\
\text { (including subseries Lecture Notes in } \\
\text { Artificial Intelligence and Lecture Notes } \\
\text { in Bioinformatics), } 3009 \text {, pp. } 62-75 .\end{array}$ & $\begin{array}{l}\text { Recuperad } \\
\text { o previamente } \\
\text { (iteración } 1 \text { ) }\end{array}$ \\
\hline
\end{tabular}


Proceso de RS de experimentos en Ingeniería del Software

\begin{tabular}{|c|c|c|}
\hline & 2004 & \\
\hline 4 & $\begin{array}{l}\text { Eight maxims for software } \\
\text { inspectors. Software Testing, } \\
\text { Verification and Reliability } 14(4) \text {, 243- } \\
\text { 256. } 2004\end{array}$ & $\begin{array}{l}\text { Recuperad } \\
\text { o previamente } \\
\text { (iteración 1) }\end{array}$ \\
\hline 5 & $\begin{array}{l}\text { Estimating the number of remaining } \\
\text { defects after inspection. Software } \\
\text { Testing, Verification and Reliability 9(3), } \\
\text { 167-189. } 1999\end{array}$ & $\begin{array}{l}\text { Recuperad } \\
\text { o previamente } \\
\text { (iteración 1) }\end{array}$ \\
\hline 7 & $\begin{array}{l}\text { Understanding the } \\
\text { Sources of Variation in } \\
\text { Software Inspections. } \\
\text { ACM Transactions on Software } \\
\text { Engineering and Methodology 7(1), 41- } \\
\text { 79. } 1998\end{array}$ & $\begin{array}{l}\text { Recuperad } \\
\text { o previamente } \\
\text { (iteración 1) }\end{array}$ \\
\hline
\end{tabular}

Caso de estudio 


\begin{tabular}{|c|c|c|c|}
\hline $\begin{array}{l}\text { Fusaro, P., } \\
\text { Lanubile, F., } \\
\text { Visaggio, G. }\end{array}$ & 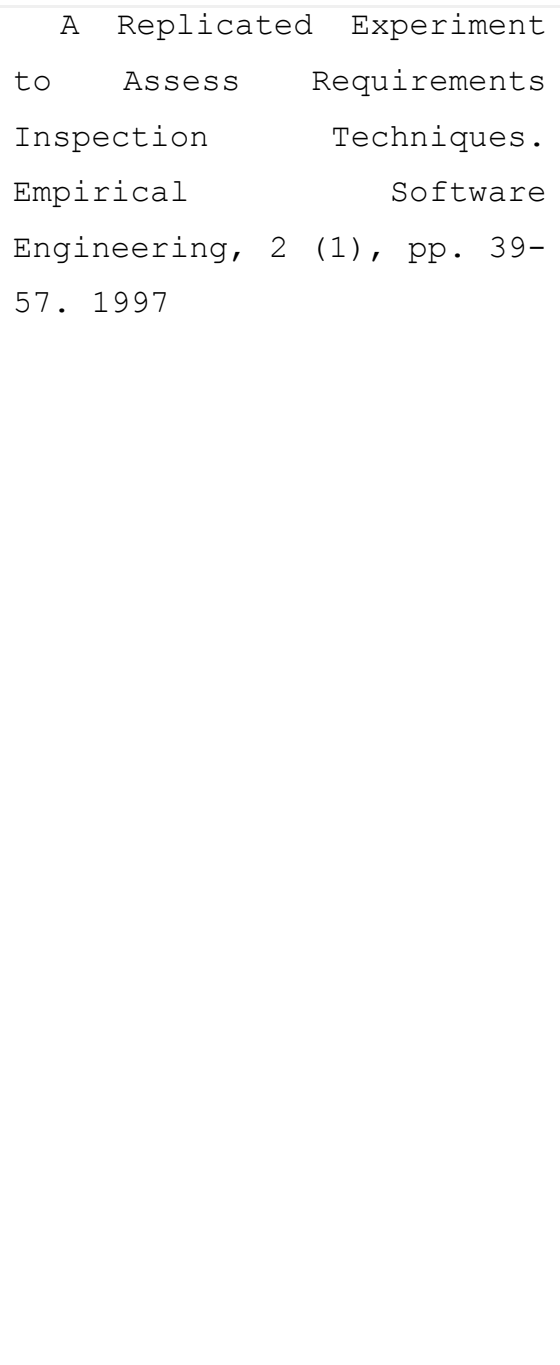 & $\begin{array}{l}\text { This paper presents the } \\
\text { independent replication of a } \\
\text { controlled experiment which } \\
\text { compared three defect detection } \\
\text { techniques (Ad Hoc, Checklist, and } \\
\text { Defect-based Scenario) for software } \\
\text { requirements inspections, and } \\
\text { evaluated the benefits of collection } \\
\text { meetings after individual reviews. } \\
\text { The results of our replication were } \\
\text { partially different from those of the } \\
\text { original experiment. Unlike the } \\
\text { original experiment, we did not find } \\
\text { any empirical evidence of better } \\
\text { performance when using scenarios. } \\
\text { To explain these negative findings } \\
\text { we provide a list of hypotheses. On } \\
\text { the other hand, the replication } \\
\text { confirmed one result of the original } \\
\text { experiment: the defect detection } \\
\text { rate is not improved by collection } \\
\text { meetings. The independent } \\
\text { replication was made possible by }\end{array}$ & ART_78 \\
\hline
\end{tabular}


Proceso de RS de experimentos en Ingeniería del Software

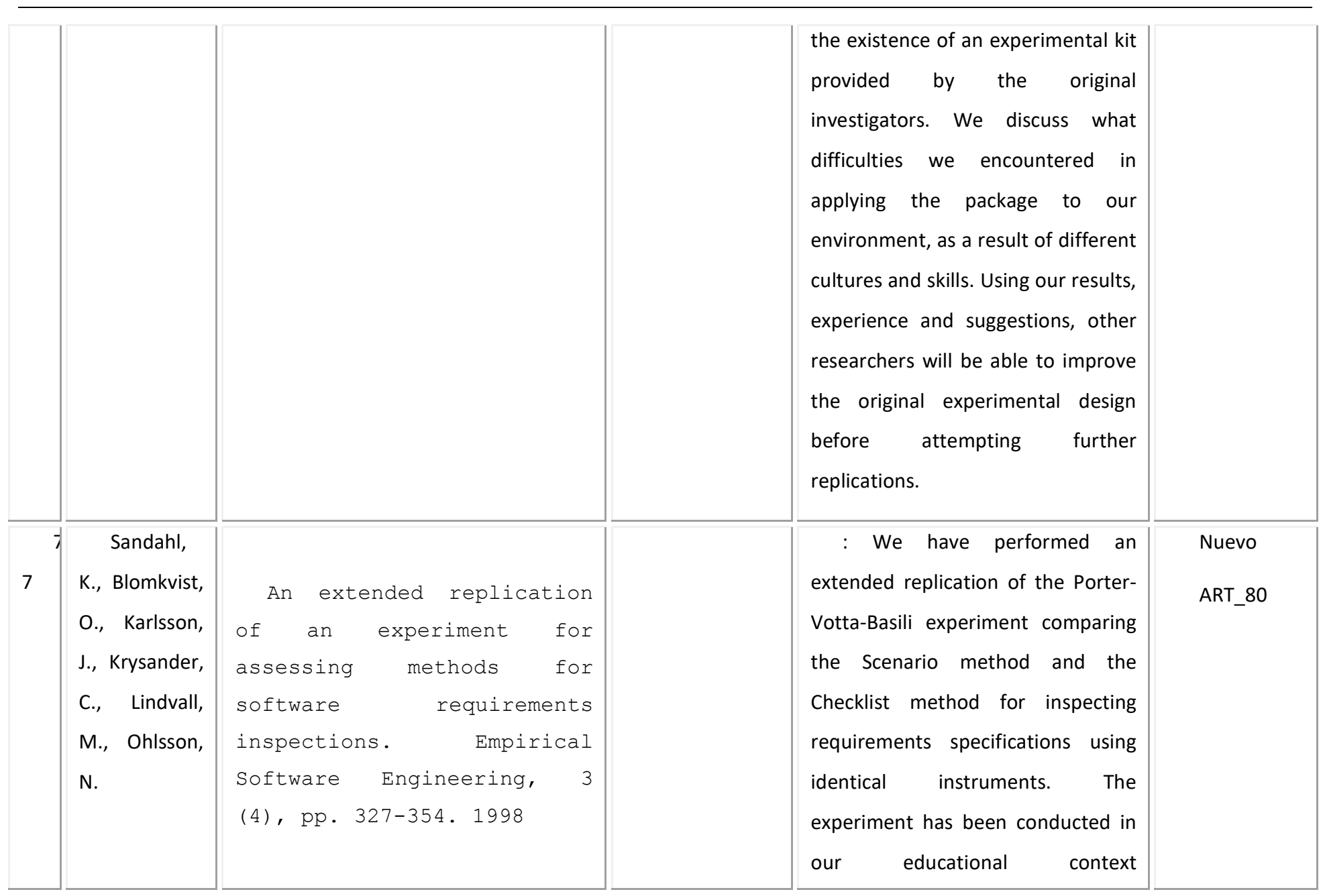

Caso de estudio 


\begin{tabular}{|l||l|l|}
\hline $\mid$ & $\begin{array}{l}\text { represented by a more general } \\
\text { definition of a defect compared to } \\
\text { the original defect list. Our study } \\
\text { involving } 24 \quad \text { undergraduate } \\
\text { students manipulated three } \\
\text { independent variables: detection } \\
\text { method, requirements specification, } \\
\text { and the order of the inspections. } \\
\text { The dependent variable measured is } \\
\text { the defect detection rate. We found } \\
\text { the requirements specification } \\
\text { inspected and not the detection } \\
\text { method to be the most probable } \\
\text { explanation for the variance in } \\
\text { defect detection rate. This suggests } \\
\text { that it is important to gather } \\
\text { knowledge of how a requirements } \\
\text { specification can convey an } \\
\text { understandable view of the product } \\
\text { and adapt inspection methods } \\
\text { accordingly. Contrary to the original } \\
\text { toxperiment, we can not significantly } \\
\text { support the superiority of the }\end{array}$ \\
\hline
\end{tabular}


Proceso de RS de experimentos en Ingeniería del Software

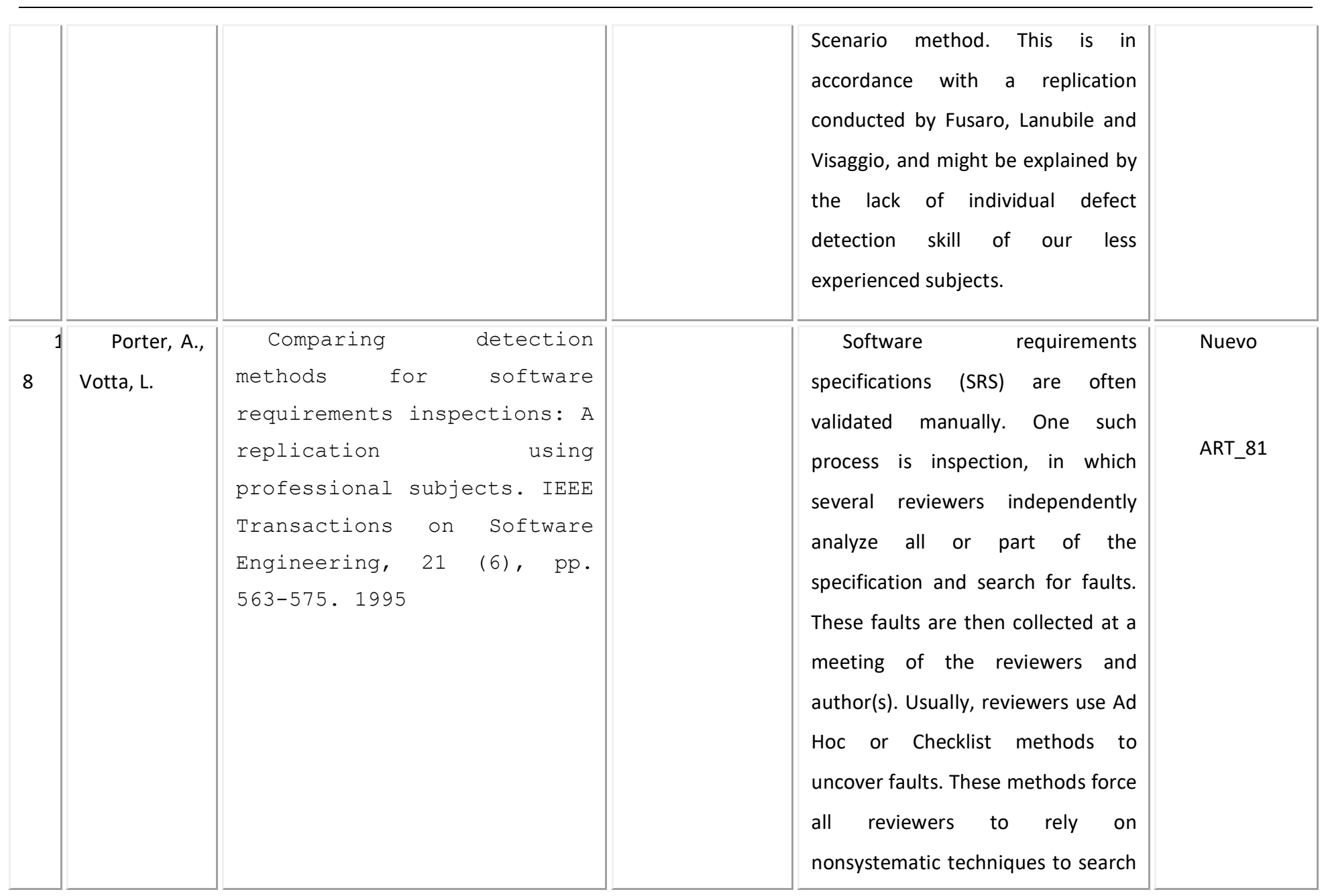

Caso de estudio 


\begin{tabular}{|l|l|l|}
\hline $\mid$ & $\mid \begin{array}{l}\text { for a wide variety of faults. We } \\
\text { hypothesize that a Scenario-based } \\
\text { method, in which each reviewer } \\
\text { uses different, systematic } \\
\text { techniques to search for different, } \\
\text { specific classes of faults, will have a } \\
\text { significantly higher success rate. In } \\
\text { previous work we evaluated this } \\
\text { hypothesis using 48 graduate } \\
\text { students in computer science as } \\
\text { subjects. We now have replicated } \\
\text { this experiment using 18 } \\
\text { professional developers from Lucent } \\
\text { Technologies as subjects. Our goals } \\
\text { were (1) extend the external } \\
\text { tredibility of our results by studying } \\
\text { professional developers, and to (2) } \\
\text { compare the performances of } \\
\text { professionals with that of the } \\
\text { graduate students to better } \\
\text { understand how generalizable the } \\
\text { results of the less expensive student } \\
\text { experiments were. For each }\end{array}$ \\
\hline
\end{tabular} \mid


Proceso de RS de experimentos en Ingeniería del Software

\begin{tabular}{|l|l|l|}
\hline $\mid$ & $\begin{array}{l}\text { inspection we performed four } \\
\text { measurements: (1) individual fault } \\
\text { detection rate, (2) team fault } \\
\text { detection rate, (3) percentage of } \\
\text { faults first identified at the } \\
\text { collection meeting (meeting gain } \\
\text { rate), and (4) percentage of faults } \\
\text { first identified by an individual, but } \\
\text { never reported at the collection } \\
\text { meeting (meeting loss rate). For } \\
\text { both the professionals and the } \\
\text { students the experimental results } \\
\text { are that (1) the Scenario method } \\
\text { had a higher fault detection rate } \\
\text { than either Ad Hoc or Checklist } \\
\text { methods, (2) Checklist reviewers } \\
\text { were no more effective than Ad Hoc } \\
\text { reviewers, (3) Collection meetings } \\
\text { produced no net improvement in } \\
\text { the fault, and detection rate - } \\
\text { meeting gains were offset by } \\
\text { meeting losses, Finally, although }\end{array}$ \\
\hline
\end{tabular}

Caso de estudio 


\begin{tabular}{|c|c|c|c|c|}
\hline & & & $\begin{array}{l}\text { specific measures differed between } \\
\text { the professional and student } \\
\text { populations, the outcomes of } \\
\text { almost all statistical tests were } \\
\text { identical. This suggests that the } \\
\text { graduate students provided an } \\
\text { adequate model of the professional } \\
\text { population and that the much } \\
\text { greater expense of conducting } \\
\text { studies with professionals may not } \\
\text { always be required. }\end{array}$ & \\
\hline 6 & \begin{tabular}{l}
\multicolumn{1}{c}{ Cantone, } \\
G., Colasanti, \\
L., Abdulnabi, \\
Z.A., \\
Lomartire, A., \\
Calavaro, G.
\end{tabular} & $\begin{array}{l}\text { Evaluating checklist- } \\
\text { based and use-case-driven } \\
\text { reading techniques as } \\
\text { applied to software } \\
\text { analysis and design UML } \\
\text { artifacts. Lecture Notes in } \\
\text { Computer Science (including } \\
\text { subseries Lecture Notes in } \\
\text { Artificial Intelligence and } \\
\text { Lecture Notes in } \\
\text { Bioinformatics), 2765, pp. } \\
\text { l42-165. } 2003\end{array}$ & $\begin{array}{l}\text { This chapter discusses the } \\
\text { experimental comparison of two } \\
\text { reading techniques, comparing their } \\
\text { effectiveness and detection rates } \\
\text { with respect to inspecting high-level } \\
\text { UML diagrams for defects. Artifact- } \\
\text { related checklists drive one } \\
\text { technique, and application use } \\
\text { cases drive the other. Our initial } \\
\text { idea was that the latter is more } \\
\text { effective than the former. This }\end{array}$ & $\begin{array}{l}\text { Nuevo } \\
\text { ART_82 }\end{array}$ \\
\hline
\end{tabular}


Proceso de RS de experimentos en Ingeniería del Software

\begin{tabular}{|l|l|l|}
\hline $\mid$ & $\mid \begin{array}{l}\text { experiment was developed at the } \\
\text { University of Rome "Tor Vergata". It } \\
\text { was conducted with junior and } \\
\text { senior students of object-oriented } \\
\text { analysis and design in the } \\
\text { university's Department of } \\
\text { Informatics, Systems and } \\
\text { Production. The data collected } \\
\text { shows that techniques performed } \\
\text { differently. Specifically, for } \\
\text { effectiveness, CBR in the average } \\
\text { performed + 41.6\% better than } \\
\text { UCDR. CBR detected 15.6\% more } \\
\text { seeded defects, and +149.3\% more } \\
\text { new faults, than UCDR. The latter } \\
\text { provided 11.6\% less false positives } \\
\text { than CBR. For detection rate, the } \\
\text { checklist-based reading technique's } \\
\text { peak value occurred 25\% later, and } \\
\text { was 66.7\% greater, than the use- } \\
\text { case driven reading's peak value. } \\
\text { However, the results were not }\end{array}$ \\
\hline
\end{tabular}

Caso de estudio 


\begin{tabular}{|c|c|c|c|c|}
\hline & & & $\begin{array}{l}\text { statistically significant. Because the } \\
\text { use-case-driven script turned out to } \\
\text { be much more complex than the } \\
\text { checklist-driven one, we decided to } \\
\text { restructure the former in multiple } \\
\text { layers and hence conducted further } \\
\text { experiments, the results of which } \\
\text { are forthcoming. }\end{array}$ & \\
\hline 2 & $\begin{array}{l}\text { Tortorella, } \\
\text { M., Visaggio, } \\
\text { G. }\end{array}$ & $\begin{array}{l}\text { Evaluation of a } \\
\text { scenario-based reading } \\
\text { technique for analysing } \\
\text { process Components. Journal } \\
\text { of Software Maintenance and } \\
\text { Evolution, } 13 \text { (3), pp. 149- } \\
\text { 166. } 2001\end{array}$ & $\begin{array}{l}\text { To improve a working process, } \\
\text { one or more process components } \\
\text { can be replaced by innovative ones. } \\
\text { The literature provides a possible } \\
\text { source of innovative process } \\
\text { components. However, it is often } \\
\text { difficult to evaluate whether a } \\
\text { particular innovative process } \\
\text { component satisfying an } \\
\text { improvement goal can be } \\
\text { introduced to replace a process } \\
\text { component in the working software } \\
\text { process to be improved. In previous } \\
\text { works, the authors of this paper }\end{array}$ & $\begin{array}{l}\text { Nuevo } \\
\text { ART_83 }\end{array}$ \\
\hline
\end{tabular}


Proceso de RS de experimentos en Ingeniería del Software

\begin{tabular}{|l|l|l|}
\hline $\mid$ & $\begin{array}{l}\text { proposed a characterization and } \\
\text { evaluation framework to address } \\
\text { the above problem. To improve the } \\
\text { usability of the framework, a } \\
\text { scenario was defined for each } \\
\text { question to help the user answer it } \\
\text { methodically. The experiment } \\
\text { presented in this paper aims to } \\
\text { verify if a scenario-based reading } \\
\text { technique improves the usability of } \\
\text { the framework. The results obtained } \\
\text { show that the technique proposed } \\
\text { makes assessment of which process } \\
\text { components of a working process } \\
\text { are candidates for making } \\
\text { innovation more reliable. Moreover, } \\
\text { the scenario-based reading } \\
\text { technique is user independent and } \\
\text { only a little training may be } \\
\text { sufficient to sensibly improve the } \\
\text { effectiveness of use of the } \\
\text { scenarios. The trustworthy results of }\end{array}$ \\
\hline
\end{tabular}

Caso de estudio 


\begin{tabular}{|c|c|c|c|c|}
\hline & & & $\begin{array}{l}\text { this technique and its independence } \\
\text { of the user's previous knowledge } \\
\text { and ability ensure that it can be } \\
\text { applied methodically. }\end{array}$ & \\
\hline 9 & $\begin{array}{l}\text { Dunsmore } \\
\text {, A., Roper, } \\
\text { M., Wood, M. }\end{array}$ & $\begin{array}{l}\text { Further } \\
\text { into the development and } \\
\text { evaluation of reading } \\
\text { techniques for object- } \\
\text { oriented code inspection. } \\
\text { Proceedings - International } \\
\text { Conference on Software } \\
\text { Engineering, pp. } 47-57 . \\
2002\end{array}$ & $\begin{array}{l}\text { This paper describes the } \\
\text { development and experimental } \\
\text { evaluation of a rigorous approach } \\
\text { for effective object-oriented (OO) } \\
\text { code inspection. Since their } \\
\text { development, inspections have } \\
\text { been shown to be powerful defect } \\
\text { detection strategies but little } \\
\text { research has been done to } \\
\text { investigate their application to oo } \\
\text { systems, which have very different } \\
\text { structural and execution models } \\
\text { compared to procedural systems. } \\
\text { Previous investigations have } \\
\text { demonstrated that the delocalised } \\
\text { nature of oo software - the } \\
\text { resolution of frequent non-local } \\
\text { references, and the incongruous }\end{array}$ & Nuevo \\
\hline
\end{tabular}


Proceso de RS de experimentos en Ingeniería del Software

\begin{tabular}{|l|l|l|}
\hline $\mid$ & $\mid \begin{array}{l}\text { relationship between its static and } \\
\text { dynamic representations, are } \\
\text { primary inhibitors to its effective } \\
\text { inspection. The experiment } \\
\text { investigates a set of three } \\
\text { complementary code reading } \\
\text { techniques devised specifically to } \\
\text { address these problems: one based } \\
\text { on a checklist adapted to address } \\
\text { the identified problems of oo } \\
\text { inspections, one focused on the } \\
\text { systematic construction of abstract } \\
\text { specifications, and the last centered } \\
\text { on the dynamic slice that a use-case } \\
\text { takes through a system. The analysis } \\
\text { shows that there is a significant } \\
\text { difference in the number of defects } \\
\text { found between the three reading } \\
\text { techniques. The checklist-based } \\
\text { technique emerges as the most } \\
\text { effective approach but the other } \\
\text { techniques also have noticeable }\end{array}$ \\
\hline
\end{tabular}

Caso de estudio 


\begin{tabular}{|c|c|c|c|c|}
\hline & & & $\begin{array}{l}\text { strengths and so for the best results } \\
\text { in a practical situation a } \\
\text { combination of techniques is } \\
\text { recommended. }\end{array}$ & \\
\hline 5 & Laitenber & Perspective-based & Despite dramatic changes in & Nuevo \\
\hline 5 & $\begin{array}{l}\text { ger, O., } \\
\text { DeBaud, J.-M. }\end{array}$ & $\begin{array}{l}\text { reading of code documents } \\
\text { at Robert Bosch GmbH. } \\
\text { Information and Software } \\
\text { Technology, } 39 \text { (11), pp. } \\
\text { 781-791. } 1997\end{array}$ & $\begin{array}{l}\text { software development in the two } \\
\text { decades since the term software } \\
\text { engineering was coined, software } \\
\text { quality deficiencies and cost } \\
\text { overruns continue to afflict the } \\
\text { software industry. Inspections, } \\
\text { developed at IBM by Fagan in the } \\
\text { early 1970s [1], can be used to } \\
\text { improve upon these problems } \\
\text { because they allow the detection } \\
\text { and removal of defects after each } \\
\text { phase of the software development } \\
\text { process. But, in most published } \\
\text { inspection processes, individuals } \\
\text { performing defect detection are not } \\
\text { systematically supported. There, } \\
\text { defect detection depends heavily }\end{array}$ & ART_86 \\
\hline
\end{tabular}


Proceso de RS de experimentos en Ingeniería del Software

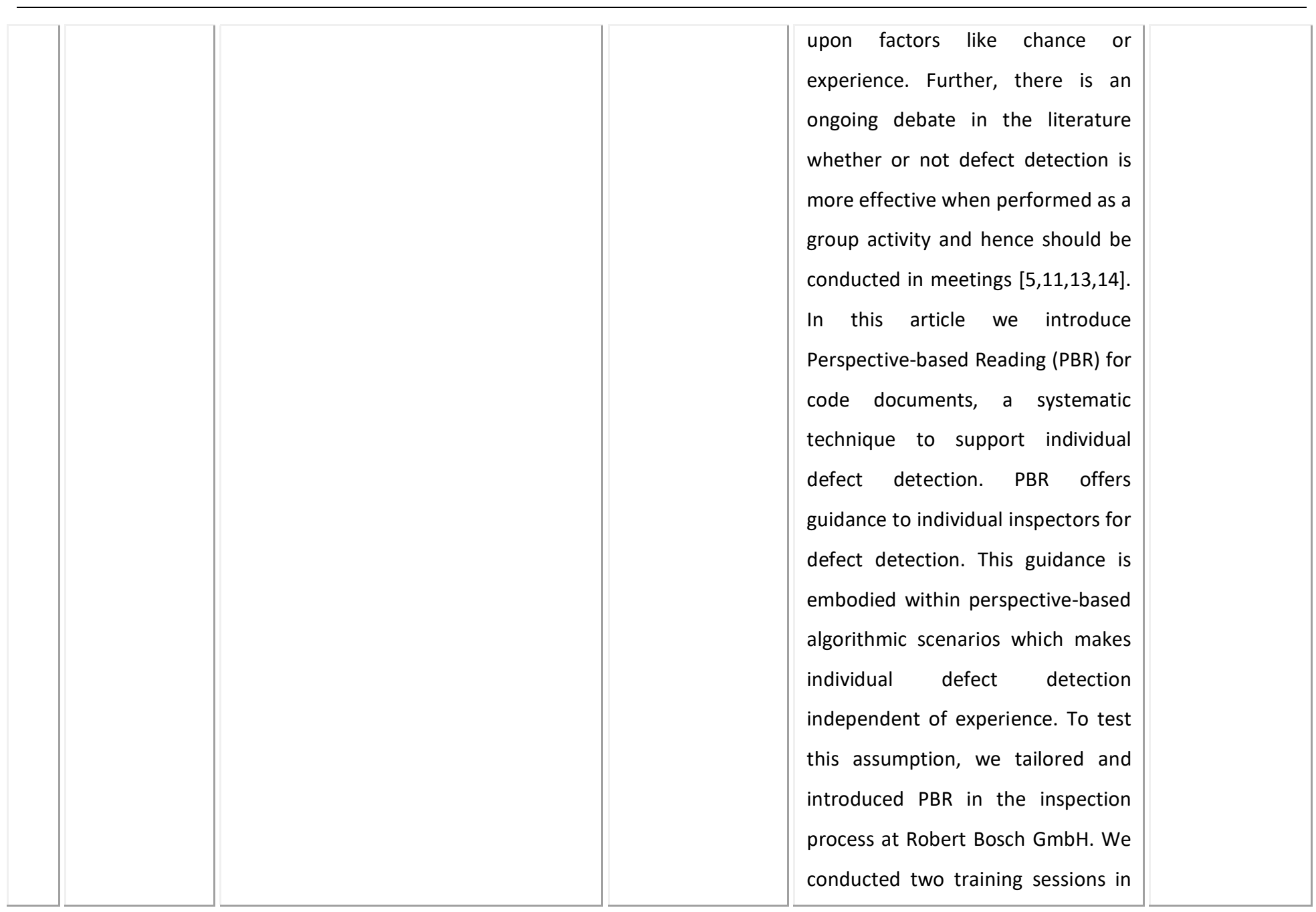

Caso de estudio 


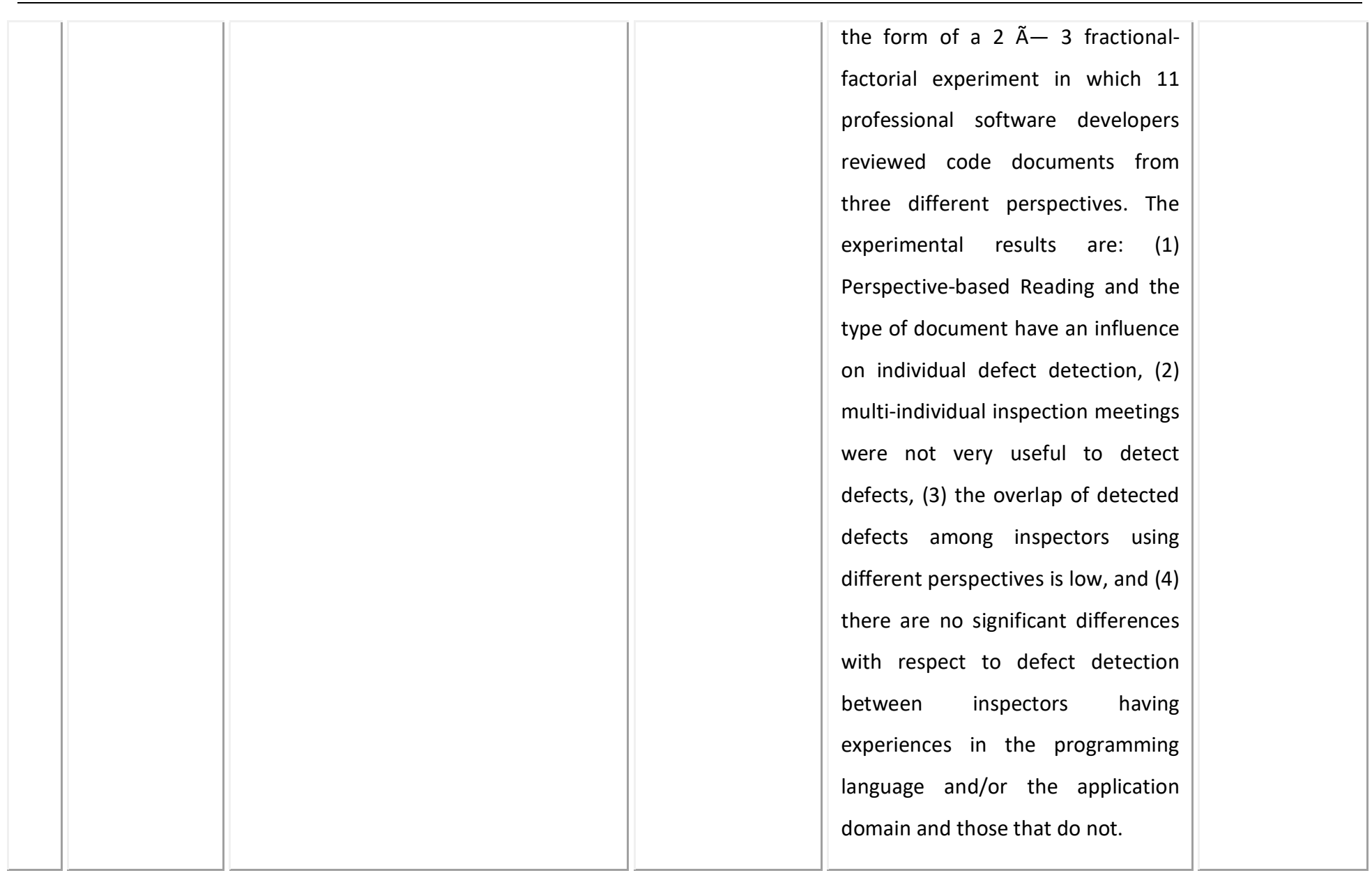


Proceso de RS de experimentos en Ingeniería del Software

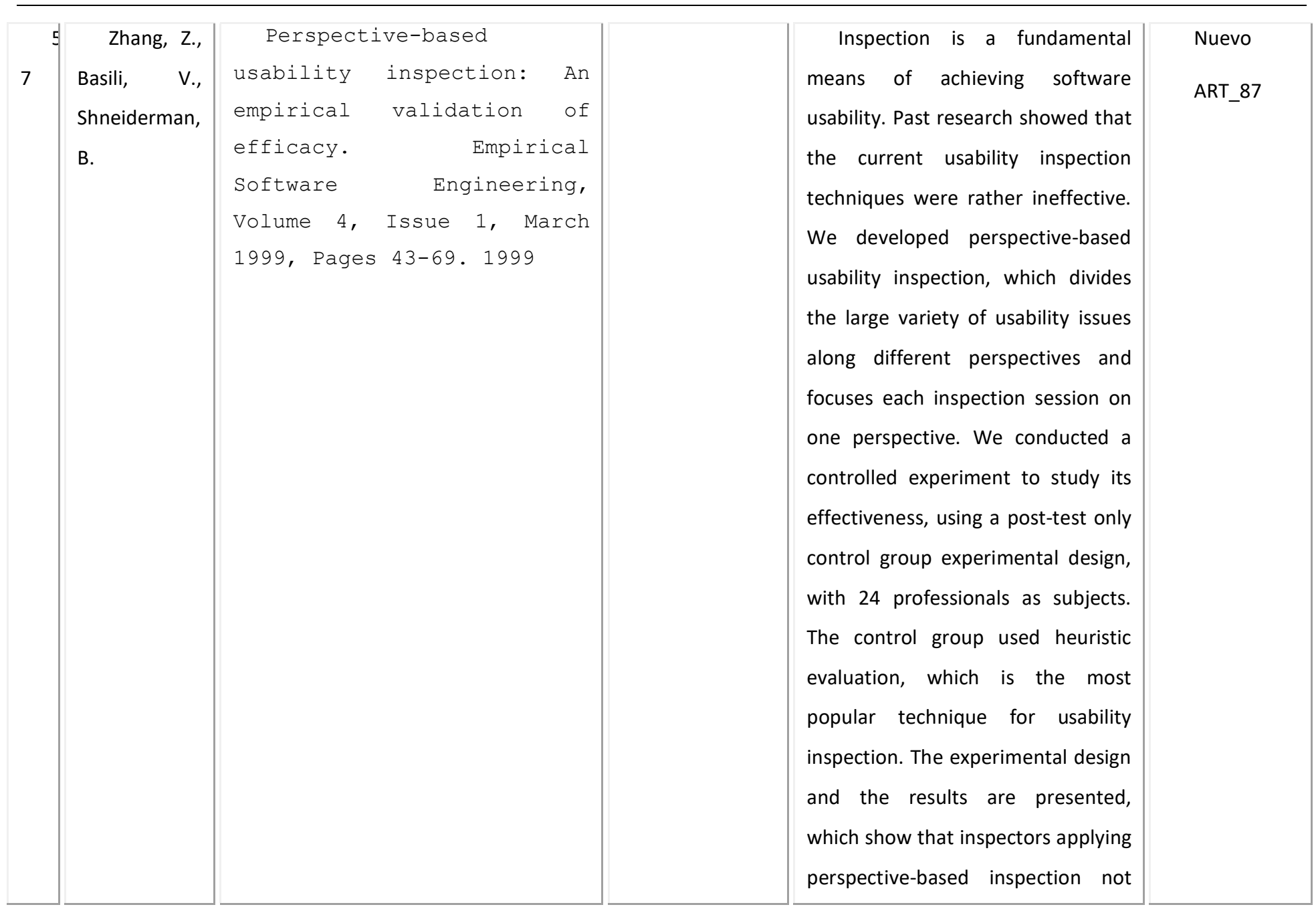

Caso de estudio 


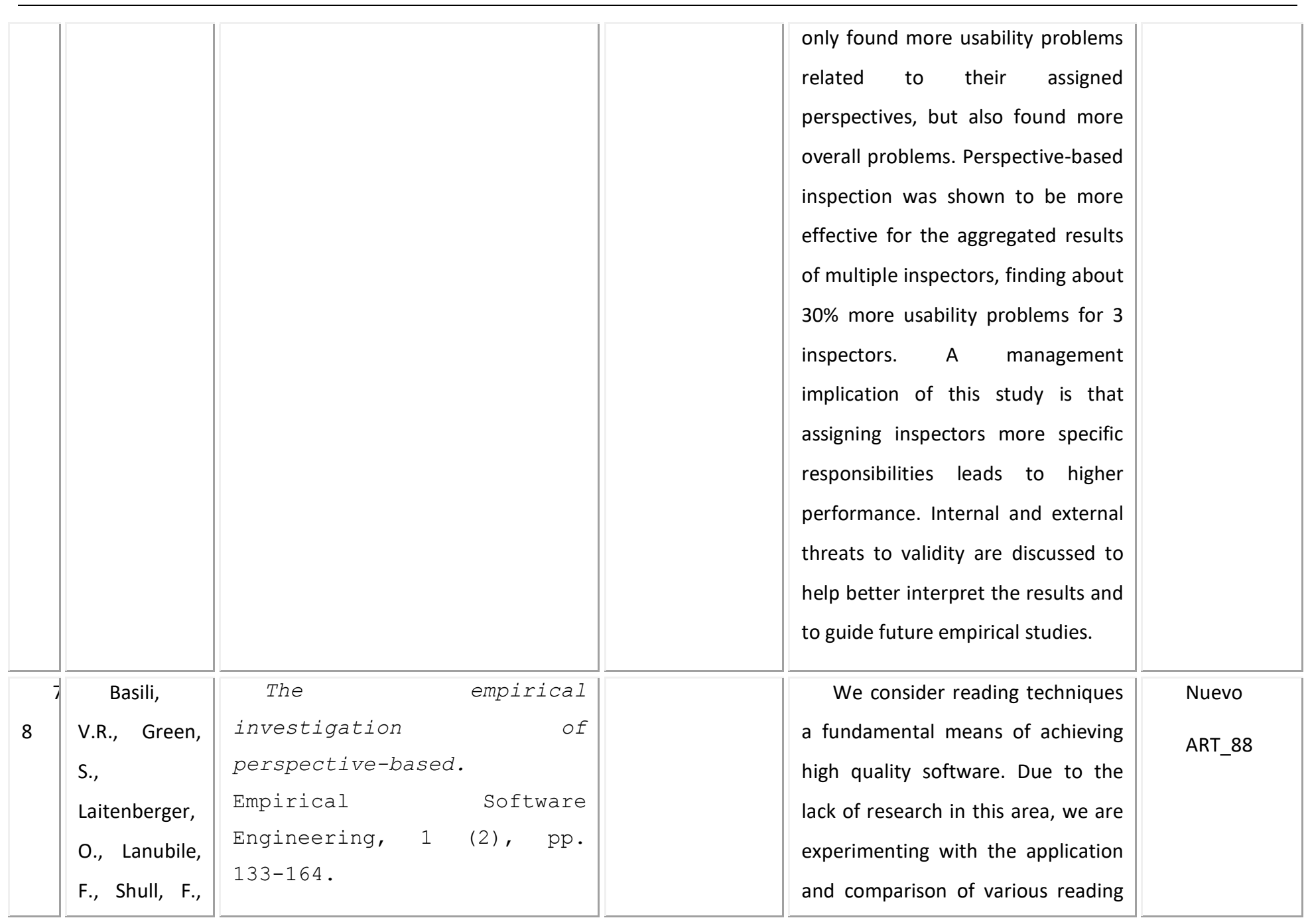


Proceso de RS de experimentos en Ingeniería del Software

\begin{tabular}{|c|c|}
\hline $\begin{array}{l}\text { Sørumgård, } \\
\text { S., Zelkowitz, } \\
\text { M.V. }\end{array}$ & $\begin{array}{l}\text { techniques. This paper deals with } \\
\text { our experiences with a family of } \\
\text { reading techniques known as } \\
\text { Perspective-Based Reading (PBR), } \\
\text { and its application to requirements } \\
\text { documents. The goal of PBR is to } \\
\text { provide operational scenarios } \\
\text { where members of a review team } \\
\text { read a document from a particular } \\
\text { perspective, e.g., tester, developer, } \\
\text { user. Our assumption is that the } \\
\text { combination of different } \\
\text { perspectives provides better } \\
\text { coverage of the document, i.e., } \\
\text { uncovers a wider range of defects, } \\
\text { than the same number of readers } \\
\text { using their usual technique. To test } \\
\text { the effectiveness of PBR, we } \\
\text { conducted a controlled experiment } \\
\text { with professional software } \\
\text { developers from the National } \\
\text { Aeronautics and Space }\end{array}$ \\
\hline
\end{tabular}

Caso de estudio 


\begin{tabular}{|l|l|l|}
\hline $\mid$ & $\mid \begin{array}{l}\text { Administration / Goddard Space } \\
\text { Flight Center (NASA/GSFC) Software } \\
\text { Engineering Laboratory (SEL). The } \\
\text { subjects read two types of } \\
\text { documents, one generic in nature } \\
\text { and the other from the NASA } \\
\text { domain, using two reading } \\
\text { techniques, a PBR technique and } \\
\text { their usual technique. The results } \\
\text { from these experiments, as well as } \\
\text { the experimental design, are } \\
\text { presented and analyzed. Teams } \\
\text { applying PBR are shown to achieve } \\
\text { significantly better coverage of } \\
\text { documents than teams that do not } \\
\text { apply PBR. We thoroughly discuss } \\
\text { the threats to validity so that } \\
\text { external replications can benefit } \\
\text { from the lessons learned and } \\
\text { improve the experimental design if } \\
\text { the constraints are different from } \\
\text { those posed by subjects borrowed }\end{array}$ \\
\hline
\end{tabular}


Proceso de RS de experimentos en Ingeniería del Software

\begin{tabular}{|c|c|c|c|}
\hline & & from a development organization. & \\
\hline $\begin{array}{l}\text { Morrison, } \\
\text { M., Morrison, } \\
\text { J., Melrose, J., } \\
\text { Wilson, E.V. }\end{array}$ & $\begin{array}{l}\text { A visual code inspection } \\
\text { approach to reduce } \\
\text { spreadsheet linking errors. } \\
\text { Journal of End User } \\
\text { Computing, } 14 \text { (3), pp. 51- } \\
\text { 63. } 2002\end{array}$ & $\begin{array}{l}\text { Spreadsheet programs are } \\
\text { deceptively simple tools that are } \\
\text { widely used by end-user developers } \\
\text { in organizations. However, recent } \\
\text { studies have shown that } \\
\text { spreadsheets often contain } \\
\text { significant, decision-affecting errors. } \\
\text { One study that addressed "linking } \\
\text { errors," i.e., incorrect references to } \\
\text { spreadsheet cell values on separate } \\
\text { work areas, found these errors to be } \\
\text { a major error source in complex } \\
\text { spreadsheets that use distinct work } \\
\text { areas spread across multiple } \\
\text { worksheets. This paper describes a } \\
\text { code inspection approach that } \\
\text { visually represents the structure of } \\
\text { a linked spreadsheet and graphically } \\
\text { identifies linked cells and their } \\
\text { sources. We tested this approach in }\end{array}$ & $\begin{array}{l}\text { Nuevo } \\
\text { No se } \\
\text { corresponde } \\
\text { con el GCA }\end{array}$ \\
\hline
\end{tabular}

Caso de estudio 


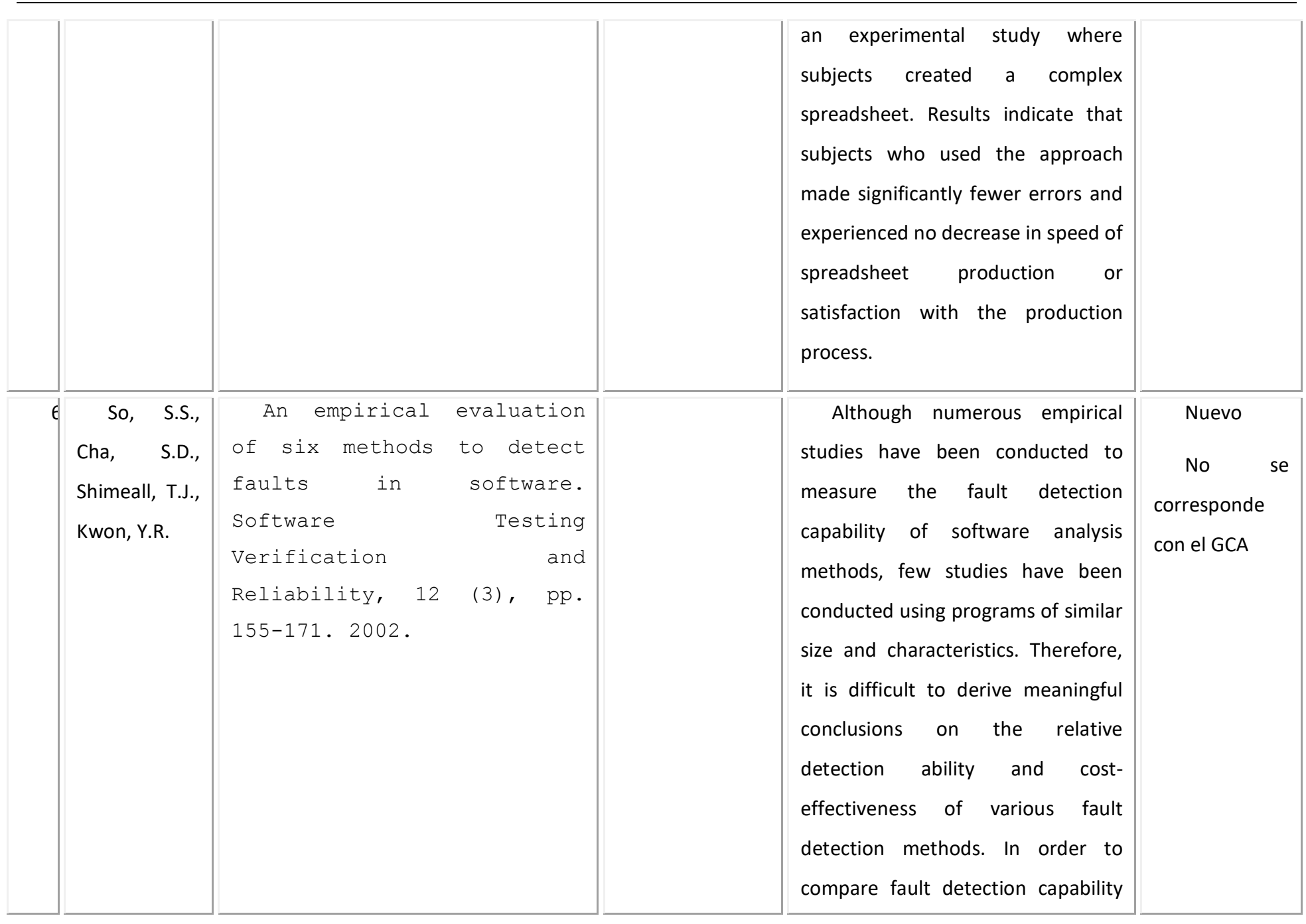


Proceso de RS de experimentos en Ingeniería del Software

\begin{tabular}{|l|l|l|}
\hline $\mid$ & $\begin{array}{l}\text { objectively, experiments must be } \\
\text { conducted using the same set of } \\
\text { programs to evaluate all methods } \\
\text { and must involve participants who } \\
\text { possess comparable levels of } \\
\text { technical expertise. One such } \\
\text { experiment was 'Conflict1', which } \\
\text { compared voting, a testing method, } \\
\text { self-checks, code reading by } \\
\text { stepwise refinement and data-flow } \\
\text { analysis methods on eight versions } \\
\text { of a battle simulation program. } \\
\text { Since an inspection method was not } \\
\text { included in the comparison, the } \\
\text { authors conducted a follow-up } \\
\text { experiment 'Conflict2', in which five } \\
\text { of the eight versions from Conflict1 } \\
\text { were subjected to Fagan inspection. } \\
\text { Conflict2 examined not only the } \\
\text { number of types of faults detected } \\
\text { by each method, but also the cost- } \\
\text { effectiveness of each method, by }\end{array}$ \\
\hline
\end{tabular}

Caso de estudio 


\begin{tabular}{|c|c|c|c|c|}
\hline & & & $\begin{array}{l}\text { comparing the average amount of } \\
\text { effort expended in detecting faults. } \\
\text { The primary findings of the Conflict2 } \\
\text { experiment are the following. First, } \\
\text { voting detected the largest number } \\
\text { of faults, followed by the testing } \\
\text { method, Fagan inspection, self- } \\
\text { checks, code reading and data-flow } \\
\text { analysis. Second, the voting, testing } \\
\text { and inspection methods were } \\
\text { largely complementary to each } \\
\text { other in the types of faults } \\
\text { detected. Third, inspection was far } \\
\text { more cost-effective than the testing } \\
\text { method studied. }\end{array}$ & \\
\hline 1 & $\begin{array}{l}\text { Porter, } \\
\text { A.A., } \\
\text { Johnson, P.M. }\end{array}$ & $\begin{array}{l}\text { Assessing software } \\
\text { review meetings: results of } \\
\text { a comparative analysis of } \\
\text { two experimental studies. } \\
\text { IEEE Transactions on } \\
\text { Software Engineering, } 23 \\
\text { (3), pp. 129-145. } 1997\end{array}$ & $\begin{array}{l}\text { Software review is a } \\
\text { fundamental tool for software } \\
\text { quality assurance. Nevertheless, } \\
\text { there are significant controversies } \\
\text { as to the most efficient and } \\
\text { effective review method. One of the } \\
\text { most important questions currently }\end{array}$ & $\begin{array}{l}\text { Nuevo } \\
\text { No se } \\
\text { corresponde } \\
\text { con el GCA }\end{array}$ \\
\hline
\end{tabular}


Proceso de RS de experimentos en Ingeniería del Software

\begin{tabular}{|l|l|l|}
\hline $\mid$ & $\begin{array}{l}\text { being debated is the utility of } \\
\text { meetings. Although almost all } \\
\text { industrial review methods are } \\
\text { centered around the inspection } \\
\text { meeting, recent findings call their } \\
\text { value into question. In prior } \\
\text { research the authors of this paper } \\
\text { separately and independently } \\
\text { conducted controlled experimental } \\
\text { studies to explore this issue. This } \\
\text { paper presents new research to } \\
\text { understand the broader } \\
\text { implications of these two studies. } \\
\text { To do this, we designed and carried } \\
\text { out a process of "reconciliation" in } \\
\text { which we established a common } \\
\text { framework for the comparison of } \\
\text { the two experimental studies, } \\
\text { reanalyzed the experimental data } \\
\text { with respect to this common } \\
\text { framework, and compared the } \\
\text { results. Through this process we }\end{array}$ \\
\hline
\end{tabular}

Caso de estudio 


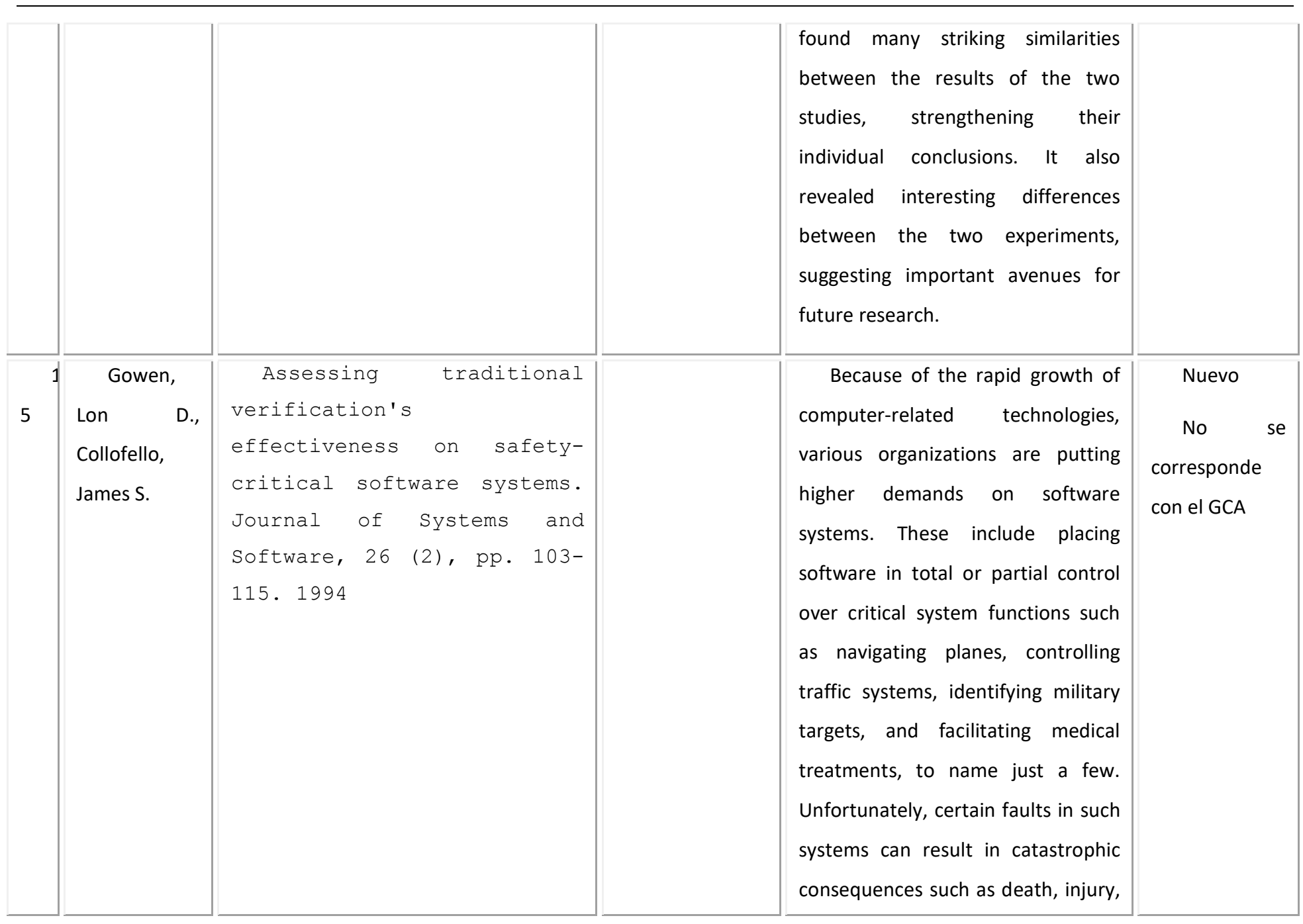


Proceso de RS de experimentos en Ingeniería del Software

\begin{tabular}{|l|l|l|}
\hline $\mid$ & $\begin{array}{l}\text { or environmental harm. To detect } \\
\text { these faults, various standards state } \\
\text { that these software systems must } \\
\text { undergo verification by specific } \\
\text { verification techniques, both static } \\
\text { and dynamic. However, some of } \\
\text { these techniques are traditional in } \\
\text { nature and do not focus on } \\
\text { detecting safety-critical faults. } \\
\text { Instead, these traditional } \\
\text { techniques focus on all classes of } \\
\text { faults. To determine the } \\
\text { effectiveness of such techniques at } \\
\text { detecting safety-critical faults, we } \\
\text { conducted an experiment that } \\
\text { measured hazardous-fault leakage } \\
\text { (i.e., the number of safety-critical } \\
\text { faults that these traditional } \\
\text { techniques failed to detect). This } \\
\text { article discusses this experiment, } \\
\text { presents the results, and proposes } \\
\text { some new ideas that show promise }\end{array}$ \\
\hline
\end{tabular}

Caso de estudio 


\begin{tabular}{|c|c|c|c|c|}
\hline & & & $\begin{array}{l}\text { at reducing hazardous-fault leakage. } \\
\text { Additionally, this article discusses } \\
\text { traditional verification and how it is } \\
\text { inadequate for verifying safety- } \\
\text { critical software systems. }\end{array}$ & \\
\hline 6 & $\begin{array}{l}\text { Klein, } \\
\text { B.D., } \\
\text { Goodhue, } \\
\text { D.L., Davis, } \\
\text { G.B. }\end{array}$ & $\begin{array}{l}\text { Can humans detect errors } \\
\text { in data? impact of base } \\
\text { rates, incentives, and } \\
\text { goals. MIS Quarterly: } \\
\text { Management } \\
\begin{array}{llll}\text { Systems, } 21 & \text { (2), pp. 169- } \\
\text { 190. } 1997 & & \end{array}\end{array}$ & $\begin{array}{l}\text { There is strong evidence that } \\
\text { data items stored in organizational } \\
\text { databases have a significant rate of } \\
\text { errors. If undetected in use, those } \\
\text { errors in stored data may } \\
\text { significantly affect business } \\
\text { outcomes. Published research } \\
\text { suggests that users of information } \\
\text { systemstend to be ineffective in } \\
\text { detecting data errors. However, in } \\
\text { this paper it is argued that, rather } \\
\text { than accepting poor human error } \\
\text { detection performance, MIS } \\
\text { researchers need to develop better } \\
\text { theories of human error detection } \\
\text { and to improve their understanding } \\
\text { of the conditions for improving }\end{array}$ & $\begin{array}{l}\text { Nuevo } \\
\text { No se } \\
\text { corresponde } \\
\text { con el GCA }\end{array}$ \\
\hline
\end{tabular}


Proceso de RS de experimentos en Ingeniería del Software

\begin{tabular}{|l|l|l|}
\hline $\mid$ & $\mid \begin{array}{l}\text { performance. This paper applies } \\
\text { several theory bases (primarily } \\
\text { signal detection theory but also a } \\
\text { theory of individual task } \\
\text { performance, theories of effort and } \\
\text { accuracy in decision making, and } \\
\text { theories of goals and incentives) to } \\
\text { develop a set of propositions about } \\
\text { successful human error detection. } \\
\text { These propositions are tested in a } \\
\text { laboratory setting. The results } \\
\text { present a strong challenge to earlier } \\
\text { assertions that humans are poor } \\
\text { detectors of data errors. The } \\
\text { findings of the two laboratory } \\
\text { experiments show that explicit error } \\
\text { detection goals and incentives can } \\
\text { modify error detection } \\
\text { performance. These findings } \\
\text { provide an improved understanding } \\
\text { of conditions under which users } \\
\text { detect data errors. They indicate it }\end{array}$ \\
\hline
\end{tabular}

Caso de estudio 


\begin{tabular}{|c|c|c|c|c|}
\hline & & & $\begin{array}{l}\text { is possible to influence detection } \\
\text { behavior in organizational settings } \\
\text { through managerial directives, } \\
\text { training, and incentives. }\end{array}$ & \\
\hline 1 & $\begin{array}{l}\quad \text { Blackmon, } \\
\text { M.H., Polson, } \\
\text { P.G., Kitajima, } \\
\text { M., Lewis, C. }\end{array}$ & $\begin{array}{l}\text { Cognitive walkthrough } \\
\text { for the Web. Conference on } \\
\text { Human Factors in Computing } \\
\text { Systems - Proceedings, } 4 \\
\text { (1), pp. 463-470. } 2002\end{array}$ & $\begin{array}{l}\text { This paper proposes a } \\
\text { transformation of the Cognitive } \\
\text { Walkthrough (CW), a theory-based } \\
\text { usability inspection method that has } \\
\text { proven useful in designing } \\
\text { applications that support use by } \\
\text { exploration. The new Cognitive } \\
\text { Walkthrough for the Web (CWW) is } \\
\text { superior for evaluating how well } \\
\text { websites support users' navigation } \\
\text { and information search tasks. The } \\
\text { CWW uses Latent Semantic Analysis } \\
\text { to objectively estimate the degree } \\
\text { of semantic similarity (information } \\
\text { scent) between representative user } \\
\text { goal statements (100-200 words) } \\
\text { and heading/link texts on each web } \\
\text { page. Using an actual website, the }\end{array}$ & $\begin{array}{l}\text { Nuevo } \\
\text { No se } \\
\text { corresponde } \\
\text { con el GCA }\end{array}$ \\
\hline
\end{tabular}


Proceso de RS de experimentos en Ingeniería del Software

\begin{tabular}{|c|c|c|c|c|}
\hline & & & $\begin{array}{l}\text { paper shows how the CWW } \\
\text { identifies three types of problems in } \\
\text { web page designs. Three } \\
\text { experiments test CWW predictions } \\
\text { of users' success rates in } \\
\text { accomplishing goals, verifying the } \\
\text { value of CWW for identifying these } \\
\text { usability problems. }\end{array}$ & \\
\hline 2 & $\begin{array}{l}\text { Houdek, } \\
\text { F., Schwinn, } \\
\text { T., Ernst, D. }\end{array}$ & $\begin{array}{l}\text { Defect detection for } \\
\text { executable specifications - } \\
\text { An experiment. } \\
\text { International Journal of } \\
\text { Software Engineering and } \\
\text { Knowledge Engineering, } 12 \\
\text { (6), pp. 637-655. } 2002\end{array}$ & $\begin{array}{l}\text { The deployment of executable } \\
\text { specifications has increased } \\
\text { significantly in the last few years. } \\
\text { Just as with any other specification } \\
\text { documents, these specifications } \\
\text { must be examined to ensure the } \\
\text { necessary degree of quality. A } \\
\text { common and successful technique } \\
\text { used for examining traditional } \\
\text { specifications is inspection. Now the } \\
\text { question has arisen whether } \\
\text { inspections on executable } \\
\text { specification are the best choice, or }\end{array}$ & $\begin{array}{l}\text { Nuevo } \\
\text { No se } \\
\text { corresponde } \\
\text { con el GCA }\end{array}$ \\
\hline
\end{tabular}

Caso de estudio 


\begin{tabular}{|c|c|c|c|c|}
\hline & & & $\begin{array}{l}\text { if other techniques which use the } \\
\text { execution capabilities of the models } \\
\text { perform better. In this paper, we } \\
\text { empirically compare several defect } \\
\text { detection techniques for executable } \\
\text { specifications. In particular, we } \\
\text { examine inspections, testing, and } \\
\text { ad-hoc simulation. Here, we use the } \\
\text { specification languages Statemate } \\
\text { and Matlab/Simulink. Also, we take } \\
\text { a closer look at the inspection } \\
\text { process itself and try to quantify the } \\
\text { benefits of an inspection meeting } \\
\text { for executable specifications. }\end{array}$ & \\
\hline 2 & $\begin{array}{l}\quad \text { Lange, } \\
\text { C.F.J., } \\
\text { Chaudron, } \\
\text { M.R.V. }\end{array}$ & $\begin{array}{l}\text { Effects of defects in } \\
\text { UML models }- \text { An } \\
\text { experimental investigation. } \\
\text { Proceedings - International } \\
\text { Conference on Software } \\
\text { Engineering, 2006, pp. } 401- \\
410.2006\end{array}$ & $\begin{array}{l}\text { The Unified Modeling Language } \\
\text { (UML) is the de facto standard for } \\
\text { designing and architecting software } \\
\text { systems. UML offers a large number } \\
\text { of diagram types that can be used } \\
\text { with varying degree of rigour. As a } \\
\text { result UML models may contain } \\
\text { consistency defects. Previous }\end{array}$ & $\begin{array}{l}\text { Nuevo } \\
\text { No se } \\
\text { corresponde } \\
\text { con el GCA }\end{array}$ \\
\hline
\end{tabular}


Proceso de RS de experimentos en Ingeniería del Software

\begin{tabular}{|l|l|l|}
\hline $\mid$ & $\begin{array}{l}\text { research has shown that industrial } \\
\text { UML models that are used as basis } \\
\text { for implementation and } \\
\text { maintenance contain large numbers } \\
\text { of defects. This study investigates to } \\
\text { what extent implementers detect } \\
\text { defects and to what extent defects } \\
\text { cause different interpretations by } \\
\text { different readers. We performed } \\
\text { two controlled experiments with a, } \\
\text { large group of students (111) and a } \\
\text { group of industrial practitioners } \\
\text { (48). The experiment's results show } \\
\text { that defects often remain } \\
\text { undetected and cause } \\
\text { misinterpretations. We present a } \\
\text { classification of defect types based } \\
\text { on a ranking of detection rate and } \\
\text { risk for misinterpretation. } \\
\text { Additionally we observed effects of } \\
\text { using domain knowledge to } \\
\text { compensate defects. The results are }\end{array}$ \\
\hline
\end{tabular}

Caso de estudio 


\begin{tabular}{|c|c|c|c|c|}
\hline & & & $\begin{array}{l}\text { generalizable to industrial UML } \\
\text { users and can be used for improving } \\
\text { quality assurance techniques for } \\
\text { UML-based development. }\end{array}$ & \\
\hline 1 & $\begin{array}{l}\text { McCarthy, } \\
\text { Patricia, } \\
\text { Porter, Adam, } \\
\text { Siy, Harvey, } \\
\text { Votta Jr., } \\
\text { Lawrence G. }\end{array}$ & $\begin{array}{l}\text { Experiment to assess } \\
\text { cost-benefits of inspection } \\
\text { meetings and their } \\
\text { alternatives: a pilot } \\
\text { study. International } \\
\text { Software Metrics Symposium, } \\
\text { Proceedings, pp. 100-111. } \\
1996\end{array}$ & $\begin{array}{l}\text { We hypothesize that inspection } \\
\text { meetings are far less effective than } \\
\text { many people believe and that } \\
\text { meetingless inspections are equally } \\
\text { effective. However, two of our } \\
\text { previous industrial case studies } \\
\text { contradict each other on this issue. } \\
\text { Therefore, we are conducting a } \\
\text { multi-trial, controlled experiment to } \\
\text { assess the benefits of inspection } \\
\text { meetings and to evaluate } \\
\text { alternative procedures. The } \\
\text { experiment manipulates four } \\
\text { independent variables: (1) the } \\
\text { inspection method used (two } \\
\text { methods involve meetings, one } \\
\text { method does not), (2) the } \\
\text { requirements specification to be }\end{array}$ & $\begin{array}{l}\text { Nuevo } \\
\text { No se } \\
\text { corresponde } \\
\text { con el GCA }\end{array}$ \\
\hline
\end{tabular}


Proceso de RS de experimentos en Ingeniería del Software

\begin{tabular}{|l|l|l|}
\hline $\mid$ & $\mid \begin{array}{l}\text { inspected (there are two), (3) the } \\
\text { inspection round (each team } \\
\text { participates in two inspections), and } \\
\text { (4) the presentation order (either } \\
\text { specification can be inspected first). } \\
\text { For each experiment we measure 3 } \\
\text { dependent variables: (1) the } \\
\text { individual fault detection rate, (2) } \\
\text { the team fault detection rate, and } \\
\text { (3) percentage of faults } \\
\text { the priginally discovered after the initial } \\
\text { inspection phase (during which } \\
\text { phase reviewers individually analyze } \\
\text { the document). So far we have } \\
\text { completed one run of the } \\
\text { experiment with 21 graduate } \\
\text { students in the computer science at } \\
\text { the University of Maryland as } \\
\text { subjects, but we do not yet have } \\
\text { enough data points to draw definite } \\
\text { conclusions. Rather than presenting } \\
\text { preliminary conclusions, this article }\end{array}$ \\
\hline
\end{tabular}

Caso de estudio 


\begin{tabular}{|c|c|c|c|c|}
\hline & & & $\begin{array}{l}\text { (1) describes the experiment's } \\
\text { design and the provocative } \\
\text { hypotheses we are evaluating, (2) } \\
\text { summarizes our observations from } \\
\text { the experiment's initial run, and (3) } \\
\text { discusses how we are using these } \\
\text { observations to verify our data } \\
\text { collection instruments and to refine } \\
\text { future experimental runs. }\end{array}$ & \\
\hline 7 & $\begin{array}{l}\text { Lanubile, } \\
\text { Filippo, Shull, } \\
\text { Forrest, } \\
\text { Basili, Victor } \\
\text { R. }\end{array}$ & $\begin{array}{l}\text { Experimenting with error } \\
\text { abstraction in requirements } \\
\text { documents. International } \\
\text { Software Metrics Symposium, } \\
\text { Proceedings, pp. 114-120. } \\
1998\end{array}$ & $\begin{array}{l}\text { In previous experiments we } \\
\text { showed that the Perspective-Based } \\
\text { Reading (PBR) family of defect } \\
\text { detection techniques was effective } \\
\text { at detecting faults in requirements } \\
\text { documents in some contexts. } \\
\text { Experiences from these studies } \\
\text { indicate that requirements faults } \\
\text { are very difficult to define, classify } \\
\text { and quantify. In order to address } \\
\text { these difficulties, we present an } \\
\text { empirical study whose main } \\
\text { purpose is to investigate whether }\end{array}$ & $\begin{array}{l}\text { Nuevo } \\
\text { No se } \\
\text { corresponde } \\
\text { con el GCA }\end{array}$ \\
\hline
\end{tabular}


Proceso de RS de experimentos en Ingeniería del Software

\begin{tabular}{|c|c|c|c|c|}
\hline & & & $\begin{array}{l}\text { defect detection in requirements } \\
\text { documents can be improved by } \\
\text { focusing on the errors (i.e., } \\
\text { underlying human misconceptions) } \\
\text { in a document rather than the } \\
\text { individual faults that they cause. In } \\
\text { the context of a controlled } \\
\text { experiment, we assess both benefits } \\
\text { and costs of the process of } \\
\text { abstracting errors from faults in } \\
\text { requirements documents. }\end{array}$ & \\
\hline 1 & \begin{tabular}{l}
\multicolumn{1}{c}{ van } \\
Solingen, \\
Rini, van \\
Genuchten, \\
Michiel, \\
Kusters, Rob
\end{tabular} & $\begin{array}{l}\text { Impact of EMS support on } \\
\text { inspections; Description of } \\
\text { an experiment. Proceedings } \\
\text { of the Hawaii International } \\
\text { Conference on System } \\
\text { Sciences, } 1 \text {, pp. } 575- \\
579.1998\end{array}$ & $\begin{array}{l}\text { Fagan inspections are a } \\
\text { structured review of development } \\
\text { documents that consists of } \\
\text { individual preparation, a meeting } \\
\text { and rework by the author of the } \\
\text { document. Industrial experience } \\
\text { shows that the inspection meeting } \\
\text { can be improved by EMS support. } \\
\text { The industrial results generate many } \\
\text { research questions, relevant for }\end{array}$ & $\begin{array}{l}\text { Nuevo } \\
\text { No se } \\
\text { corresponde } \\
\text { con el GCA }\end{array}$ \\
\hline
\end{tabular}

Caso de estudio 


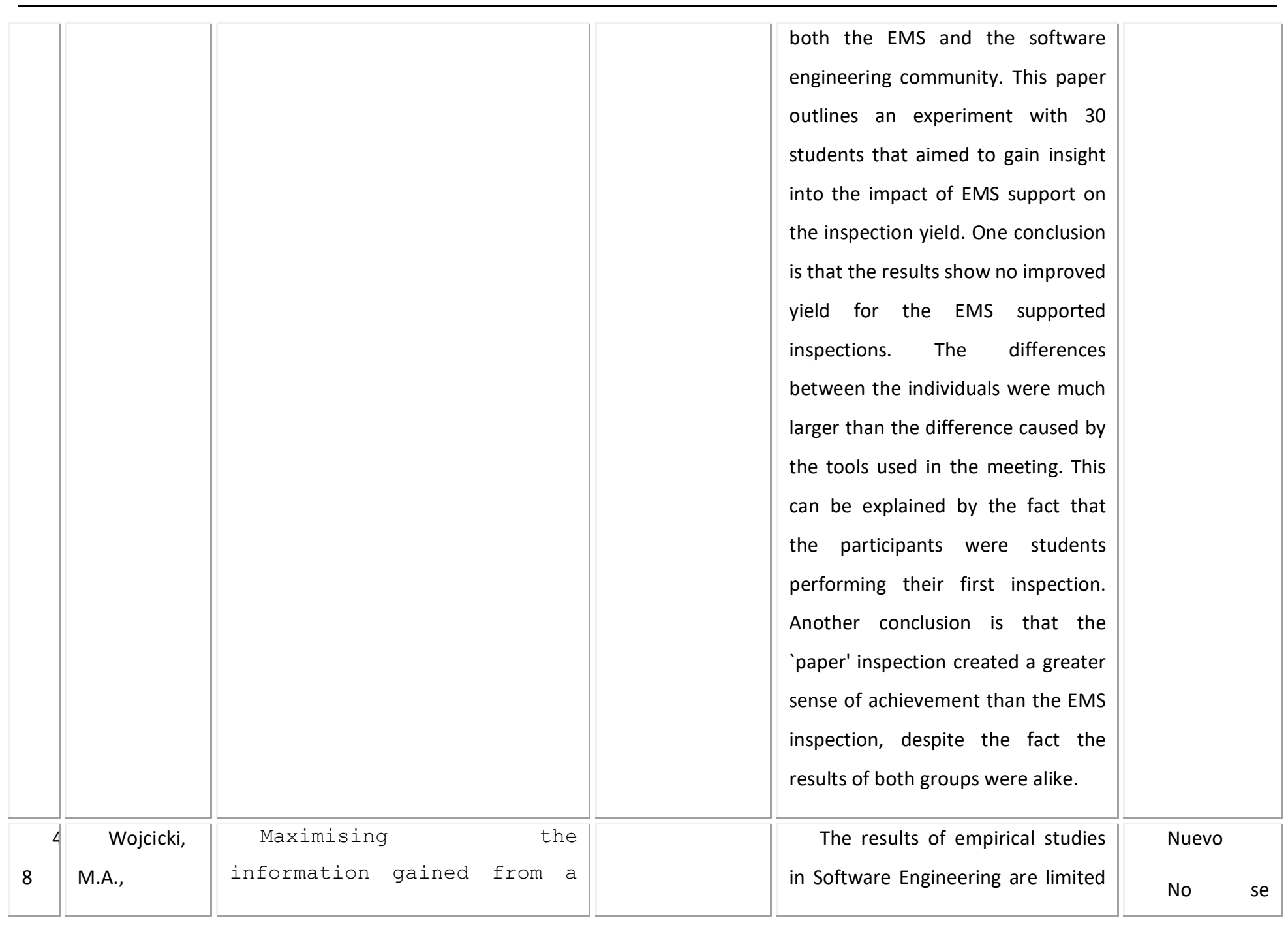


Proceso de RS de experimentos en Ingeniería del Software

\begin{tabular}{|c|c|c|c|}
\hline Strooper, P. & $\begin{array}{l}\text { study of static analysis } \\
\text { technologies for concurrent } \\
\text { software. } \\
\text { Software Enpirical } \\
\text { (6), pp. 617-645. } 2007\end{array}$ & $\begin{array}{l}\text { to particular contexts, difficult to } \\
\text { generalise and the studies } \\
\text { themselves are expensive to } \\
\text { perform. Despite these problems, } \\
\text { empirical studies can be made } \\
\text { effective and they are important to } \\
\text { both researchers and practitioners. } \\
\text { The key to their effectiveness lies in } \\
\text { the maximisation of the information } \\
\text { that can be gained by examining } \\
\text { and replicating existing studies and } \\
\text { using power analyses for an } \\
\text { accurate minimum sample size. This } \\
\text { approach was applied in a } \\
\text { controlled experiment examining } \\
\text { the combination of automated } \\
\text { static analysis tools and code } \\
\text { inspection in the context of the } \\
\text { verification and validation (V\&V) of } \\
\text { concurrent Java components. The } \\
\text { paper presents the results of this } \\
\text { controlled experiment and shows }\end{array}$ & $\begin{array}{l}\text { corresponde } \\
\text { con el GCA }\end{array}$ \\
\hline
\end{tabular}

Caso de estudio 


\begin{tabular}{|c|c|c|c|c|}
\hline & & & $\begin{array}{l}\text { that the combination of automated } \\
\text { static analysis and code inspection is } \\
\text { cost-effective. Throughout the } \\
\text { experiment a strategy to maximise } \\
\text { the information gained from the } \\
\text { experiment was used. As a result, } \\
\text { despite the size of the study, } \\
\text { conclusive results were obtained, } \\
\text { contributing to the research on } V \& V \\
\text { technology evaluation. }\end{array}$ & \\
\hline 9 & $\begin{array}{l}\text { Wojcicki, } \\
\text { M.A., } \\
\text { Strooper, P. }\end{array}$ & $\begin{array}{l}\text { Maximising the } \\
\text { information gained from an } \\
\text { experimental analysis of } \\
\text { code inspection and static } \\
\text { analysis for concurrent } \\
\text { Java components. ISCE'06 - } \\
\text { Proceedings of the 5th ACM- } \\
\text { IEEE. International } \\
\text { Symposium on Empirical } \\
\text { Software Engineering, 2006, } \\
\text { pp. 174-183. } 2006\end{array}$ & $\begin{array}{l}\text { The results of empirical studies } \\
\text { are limited to particular contexts, } \\
\text { difficult to generalise and the } \\
\text { studies themselves are expensive to } \\
\text { perform. Despite these problems, } \\
\text { empirical studies in software } \\
\text { engineering can be made effective } \\
\text { and they are important to both } \\
\text { researchers and practitioners. The } \\
\text { key to their effectiveness lies in the } \\
\text { maximisation of the information } \\
\text { that can be gained by examining }\end{array}$ & $\begin{array}{l}\text { Nuevo } \\
\text { No se } \\
\text { corresponde } \\
\text { con el GCA }\end{array}$ \\
\hline
\end{tabular}


Proceso de RS de experimentos en Ingeniería del Software

\begin{tabular}{|c|c|c|c|c|}
\hline & & & $\begin{array}{l}\text { existing studies, conducting power } \\
\text { analyses for an accurate minimum } \\
\text { sample size and benefiting from } \\
\text { previous studies through } \\
\text { replication. This approach was } \\
\text { applied in a controlled experiment } \\
\text { examining the combination of } \\
\text { automated static analysis tools and } \\
\text { code inspection in the context of } \\
\text { verification and validation (V\&V) of } \\
\text { concurrent Java components. The } \\
\text { combination of these V\&V } \\
\text { technologies was shown to be cost- } \\
\text { effective despite the size of the } \\
\text { study, which thus contributes to } \\
\text { research in V\&V technology } \\
\text { evaluation. }\end{array}$ & \\
\hline 5 & $\begin{array}{l}\text { De Angeli, } \\
\text { A., Matera, } \\
\text { M., Costabile, } \\
\text { M.F., }\end{array}$ & $\begin{array}{l}\text { On the advantages of a systematic } \\
\text { inspection for evaluating hypermedia } \\
\text { usability. International Journal of } \\
\text { Human-Computer Interaction, } 15 \text { (3), }\end{array}$ & $\begin{array}{l}\text { It is indubitable that usability } \\
\text { inspection of complex hypermedia } \\
\text { is still an "art," in the sense that a } \\
\text { great deal is left to the skills, }\end{array}$ & $\begin{array}{l}\text { Nuevo } \\
\text { No se } \\
\text { corresponde }\end{array}$ \\
\hline
\end{tabular}

Caso de estudio 


\begin{tabular}{|l|l|l|l|}
\hline Garzotto, F., & pp. 315-335. 2003 & $\begin{array}{l}\text { experience, and ability of the } \\
\text { inspectors. Training inspectors is } \\
\text { difficult and often quite expensive. } \\
\text { The Systematic Usability Evaluation } \\
\text { (SUE) }\end{array}$ & $\begin{array}{l}\text { inspection technique has been } \\
\text { proposed to help usability } \\
\text { inspectors share and transfer their } \\
\text { evaluation know-how, to simplify } \\
\text { the hypermedia inspection process } \\
\text { for newcomers, and to achieve } \\
\text { nore effective and efficient }\end{array}$ \\
& & $\begin{array}{l}\text { nevaluation results. SUE inspection is } \\
\text { based on the use of evaluation } \\
\text { patterns, called abstract tasks, } \\
\text { which precisely describe the } \\
\text { activities to be performed by } \\
\text { evaluators during inspection. This } \\
\text { article highlights the advantages of } \\
\text { this inspection technique by } \\
\text { presenting its empirical validation } \\
\text { through a controlled experiment. } \\
\text { Two groups of novice inspectors } \\
\text { were asked to evaluate a }\end{array}$ \\
\hline
\end{tabular}


Proceso de RS de experimentos en Ingeniería del Software

\begin{tabular}{|c|c|c|c|c|}
\hline & & & $\begin{array}{l}\text { commercial hypermedia CD-ROM by } \\
\text { applying the SUE inspection or } \\
\text { traditional heuristic evaluation. The } \\
\text { comparison was based on three } \\
\text { major dimensions: effectiveness, } \\
\text { efficiency, and satisfaction. Results } \\
\text { indicate a clear advantage of the } \\
\text { SUE inspection over the traditional } \\
\text { inspection on all dimensions, } \\
\text { demonstrating that abstract tasks } \\
\text { are efficient tools to drive the } \\
\text { evaluator's performance. }\end{array}$ & \\
\hline 3 & $\begin{array}{l}\text { Galletta, } \\
\text { D.F., Hartzel, } \\
\text { K.S., Johnson, } \\
\text { S.E., Joseph, } \\
\text { J.L., Rustagi, } \\
\text { S. }\end{array}$ & $\begin{array}{l}\text { Spreadsheet Presentation } \\
\text { and Error Detection: An } \\
\text { Experimental Study. Journal } \\
\text { of Management Information } \\
\text { Systems, } 13 \text { (3), pp. 45-63. } \\
1996\end{array}$ & $\begin{array}{l}\text { The pervasiveness and impact of } \\
\text { electronic spreadsheets have } \\
\text { generated serious concerns about } \\
\text { their integrity and validity when } \\
\text { used in significant decision-making } \\
\text { settings. Previous studies have } \\
\text { shown that few of the errors that } \\
\text { might exist in any given spreadsheet } \\
\text { are found, even when the reviewer }\end{array}$ & $\begin{array}{l}\text { Nuevo } \\
\text { No se } \\
\text { corresponde } \\
\text { con el GCA }\end{array}$ \\
\hline
\end{tabular}

Caso de estudio 


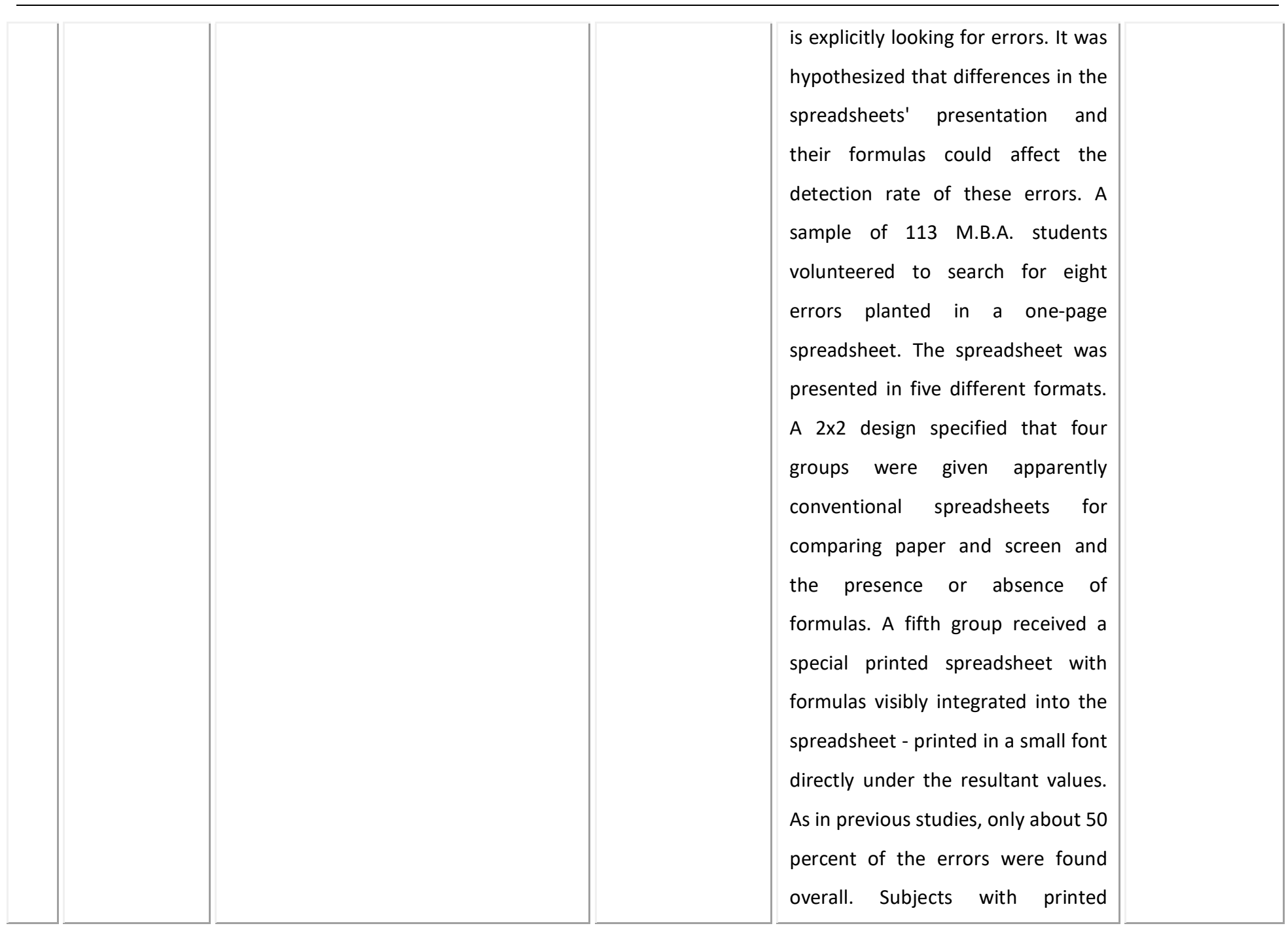


Proceso de RS de experimentos en Ingeniería del Software

\begin{tabular}{|l|l|l|}
\hline $\mid$ & $\mid \begin{array}{l}\text { spreadsheets found more errors } \\
\text { than their colleagues with screen- } \\
\text { only spreadsheets but they took } \\
\text { longer to do so. There was no } \\
\text { discernible formula effect; subjects } \\
\text { who were able to refer to formulas } \\
\text { did not outperform subjects with } \\
\text { access to only the final numbers. } \\
\text { The special format did not facilitate } \\
\text { error finding. Exploratory analysis } \\
\text { uncovered some interesting results. } \\
\text { The special experimental integrated } \\
\text { paper format appeared to diminish } \\
\text { the number of correct items falsely } \\
\text { identified as errors. There also } \\
\text { seemed to be differences in } \\
\text { performance that were accounted } \\
\text { for by the subjects' self-reported } \\
\text { error-finding strategy. Researchers } \\
\text { should focus on other factors that } \\
\text { might facilitate error finding, and } \\
\text { practitioners should be cautious }\end{array}$ \\
\hline
\end{tabular}

Caso de estudio 


\begin{tabular}{|c|c|c|c|c|}
\hline & & & $\begin{array}{l}\text { about relying on spreadsheets' } \\
\text { accuracy, even those that have been } \\
\text { "audited.". }\end{array}$ & \\
\hline 4 & $\begin{array}{l}\text { Laitenber } \\
\text { ger, Oliver }\end{array}$ & \begin{tabular}{l}
\multicolumn{1}{l}{ Studying the effects of } \\
code inspection and \\
structural testing on \\
software \\
Proceedings quality. \\
International Symposium on \\
Software \\
Engineering, \\
237-246. 1998
\end{tabular} & $\begin{array}{l}\text { This paper contributes a } \\
\text { controlled experiment to } \\
\text { characterize the effects of code } \\
\text { inspection and structural testing on } \\
\text { software quality. Twenty subjects } \\
\text { performed sequentially code } \\
\text { inspection and structural testing } \\
\text { using different coverage values as } \\
\text { test criteria on a C-code module. } \\
\text { The results of this experiment show } \\
\text { that inspection significantly } \\
\text { outperforms the defect detection } \\
\text { effectiveness of structural testing. } \\
\text { Furthermore, the experimental } \\
\text { results indicate little evidence to } \\
\text { support the hypothesis that } \\
\text { structural testing detects different } \\
\text { defects, that is, defects of a } \\
\text { particular class, that were missed by }\end{array}$ & $\begin{array}{l}\text { Nuevo } \\
\text { No se } \\
\text { corresponde } \\
\text { con el GCA }\end{array}$ \\
\hline
\end{tabular}


Proceso de RS de experimentos en Ingeniería del Software

\begin{tabular}{|c|c|c|c|c|}
\hline & & & $\begin{array}{l}\text { inspection and vice versa. These } \\
\text { findings suggest that inspection and } \\
\text { structural testing do not } \\
\text { complement each other well. Since } \\
39 \text { percent (on average) of the } \\
\text { defects were not detected at all, it } \\
\text { might be more valuable to apply } \\
\text { inspection together with other } \\
\text { testing techniques, such as } \\
\text { boundary value analysis, to achieve } \\
\text { a better defect coverage. We are } \\
\text { aware that a single experiment has } \\
\text { many limitations and, often, does } \\
\text { not provide conclusive evidence. } \\
\text { Hence, we consider this experiment } \\
\text { a starting point and encourage } \\
\text { other researchers to investigate the } \\
\text { optimal mix of defect detection } \\
\text { techniques. }\end{array}$ & \\
\hline$\epsilon$ & $\begin{array}{l}\text { Matera, } \\
\text { M., Costabile, }\end{array}$ & $\begin{array}{cc}\text { SUE } & \text { inspection: } \\
\text { effective } & \text { method }\end{array}$ & $\begin{array}{c}\text { SUE inspection is a novel } \\
\text { usability evaluation method for }\end{array}$ & $\begin{array}{l}\text { Nuevo } \\
\text { No }\end{array}$ \\
\hline
\end{tabular}

Caso de estudio 


\begin{tabular}{|c|c|c|c|}
\hline $\begin{array}{l}\text { M.F., } \\
\text { Garzotto, F., } \\
\text { Paolini, P. }\end{array}$ & $\begin{array}{l}\text { systematic usability } \\
\text { evaluation of hypermedia. } \\
\text { IEEE Transactions on } \\
\text { Systems, Man, and } \\
\text { Cybernetics Part A:Systems } \\
\text { and Humans., } 32 \text { (1), pp. } \\
\text { 93-103. } 2002\end{array}$ & $\begin{array}{l}\text { hypermedia, which falls into the } \\
\text { category of inspection methods. Its } \\
\text { primary goal is to favor a Systematic } \\
\text { Usability Evaluation (hence the } \\
\text { acronym SUE), for supplying } \\
\text { hypermedia usability inspectors } \\
\text { with a structured flow of activities, } \\
\text { allowing them to obtain more } \\
\text { reliable, comparable, and cost- } \\
\text { effective evaluation results. This is } \\
\text { obtained especially thanks to the } \\
\text { use of evaluation patterns, called } \\
\text { Abstract Tasks, which describe in } \\
\text { details the activities that evaluators } \\
\text { must carry out during inspection. } \\
\text { Abstract Tasks helps share and } \\
\text { transfer evaluation know-how } \\
\text { among different evaluators, thus } \\
\text { making it easier to learn the SUE } \\
\text { inspection method by newcomers. A } \\
\text { further notable advantage provided } \\
\text { by the sUE inspection over other } \\
\text { existent approaches is that it }\end{array}$ & $\begin{array}{l}\text { corresponde } \\
\text { con el GCA }\end{array}$ \\
\hline
\end{tabular}


Proceso de RS de experimentos en Ingeniería del Software

\begin{tabular}{|c|c|c|c|c|}
\hline & & & $\begin{array}{l}\text { focuses on navigation and } \\
\text { information structures, making } \\
\text { evident some problems that other } \\
\text { "surface-oriented" approaches } \\
\text { might not reveal. This paper } \\
\text { describes the SUE inspection for } \\
\text { hypermedia. It also reports on a } \\
\text { validation experiment, involving } 28 \\
\text { evaluators, that has shown the } \\
\text { major effectiveness and efficiency } \\
\text { of the SUE inspection for } \\
\text { hypermedia, with respect to } \\
\text { traditional heuristic evaluation } \\
\text { techniques. }\end{array}$ & \\
\hline 0 & $\begin{array}{l}\text { Bisant, } \\
\text { David B., Lyle, } \\
\text { James R. }\end{array}$ & $\begin{array}{l}\text { Two-person } \text { inspection } \\
\text { method to improve } \\
\text { programming productivity. } \\
\text { IEEE Transactions on } \\
\text { Software Engineering, } 15 \\
\text { (10), pp. 1294-1304. } 1989\end{array}$ & $\begin{array}{l}\text { The authors review current } \\
\text { research and investigate the effect } \\
\text { of a two-person inspection method } \\
\text { on programmer productivity. This } \\
\text { method is similar to the current } \\
\text { larger team method in stressing } \\
\text { fault detection but does not use a }\end{array}$ & $\begin{array}{l}\text { Nuevo } \\
\text { No se } \\
\text { corresponde } \\
\text { con el GCA }\end{array}$ \\
\hline
\end{tabular}

Caso de estudio 


\begin{tabular}{|l|l|l|}
\hline $\mid$ & $\begin{array}{l}\text { moderator. The experiment used a } \\
\text { Pretest-Protest Control Group } \\
\text { design. An experimental and control } \\
\text { group of novices each completed } \\
\text { two programming assignments. The } \\
\text { amount of time taken to complete } \\
\text { each program was recorded for } \\
\text { each subject. An analysis of variance } \\
\text { was performed, and the relationship } \\
\text { between the times was modeled for } \\
\text { both groups. The experimental } \\
\text { group improved significantly in } \\
\text { programming speed as a result of }\end{array}$ \\
using the two-person inspection, \\
and the method appeared to be \\
more effective at improving the \\
performance of the slower \\
programmers. The two-person \\
method could have its application in \\
those environments where access \\
to larger team resources is not \\
available.
\end{tabular} \mid


Proceso de RS de experimentos en Ingeniería del Software

\begin{tabular}{|c|c|c|c|c|}
\hline 1 & $\begin{array}{r}\text { HornbÃ }{ }_{1 k} \\
\text { K., } \\
\text { FrÃ, } k j \tilde{A}_{1}^{\prime} r, \text { E. }\end{array}$ & $\begin{array}{l}\text { Usability inspection by } \\
\text { metaphors of human thinking } \\
\text { compared to heuristic } \\
\text { evaluation. International } \\
\text { Journal of Human-Computer } \\
\text { Interaction, } 17 \text { (3), pp. } \\
\text { 357-374. } 2004\end{array}$ & $\begin{array}{l}\text { A new usability inspection } \\
\text { technique based on metaphors of } \\
\text { human thinking has been } \\
\text { experimentally compared to } \\
\text { heuristic evaluation (HE). The aim of } \\
\text { metaphors of thinking (MOT) is to } \\
\text { focus inspection on users' mental } \\
\text { activity and to make inspection } \\
\text { easily applicable to different devices } \\
\text { and use contexts. Building on } \\
\text { classical introspective psychology, } \\
\text { MOT bases inspection on } \\
\text { metaphors of habit formation, } \\
\text { stream of thought, awareness and } \\
\text { associations, the relation between } \\
\text { utterances and thought, and } \\
\text { knowing. An experiment was } \\
\text { conducted in which } 87 \text { novices } \\
\text { evaluated a large Web application, } \\
\text { and its key developer assessed the } \\
\text { problems found. Compared to HE, } \\
\text { MOT uncovered usability problems }\end{array}$ & $\begin{array}{l}\text { Nuevo } \\
\text { No se } \\
\text { corresponde } \\
\text { con el GCA }\end{array}$ \\
\hline
\end{tabular}

Caso de estudio 


\begin{tabular}{|c|c|c|c|c|}
\hline & & & $\begin{array}{l}\text { that were assessed as more severe } \\
\text { for users and also appeared more } \\
\text { complex to repair. The evaluators } \\
\text { using HE found more cosmetic } \\
\text { problems. The time spent learning } \\
\text { and performing an evaluation with } \\
\text { MOT was shorter. A discussion of } \\
\text { strengths and weaknesses of MOT } \\
\text { and HE is provided, which shows } \\
\text { how MOT can be an effective } \\
\text { alternative or supplement to HE. }\end{array}$ & \\
\hline 5 & $\begin{array}{l}\quad \text { Runeson, } \\
\text { P., } \\
\text { Andersson, } \\
\text { C., Thelin, T., } \\
\text { Andrews, A., } \\
\text { Berling, T. }\end{array}$ & $\begin{array}{l}\text { What do we know about } \\
\text { defect detection methods? } \\
\text { IEEE Software, } 23 \text { (3), pp. } \\
\text { 82-90. } 2006\end{array}$ & $\begin{array}{l}\text { efforts are spent on defect } \\
\text { detection during software } \\
\text { development. So, it's important to } \\
\text { use the most efficient and effective } \\
\text { defect detection methods. This } \\
\text { guide can help practitioners choose } \\
\text { efficient and effective defect } \\
\text { detection methods using the } \\
\text { evidence-based software } \\
\text { engineering (EBSE) approach. Using } \\
12 \text { empirical studies, including } 10\end{array}$ & $\begin{array}{l}\text { Nuevo } \\
\text { No se } \\
\text { corresponde } \\
\text { con el GCA }\end{array}$ \\
\hline
\end{tabular}


Proceso de RS de experimentos en Ingeniería del Software

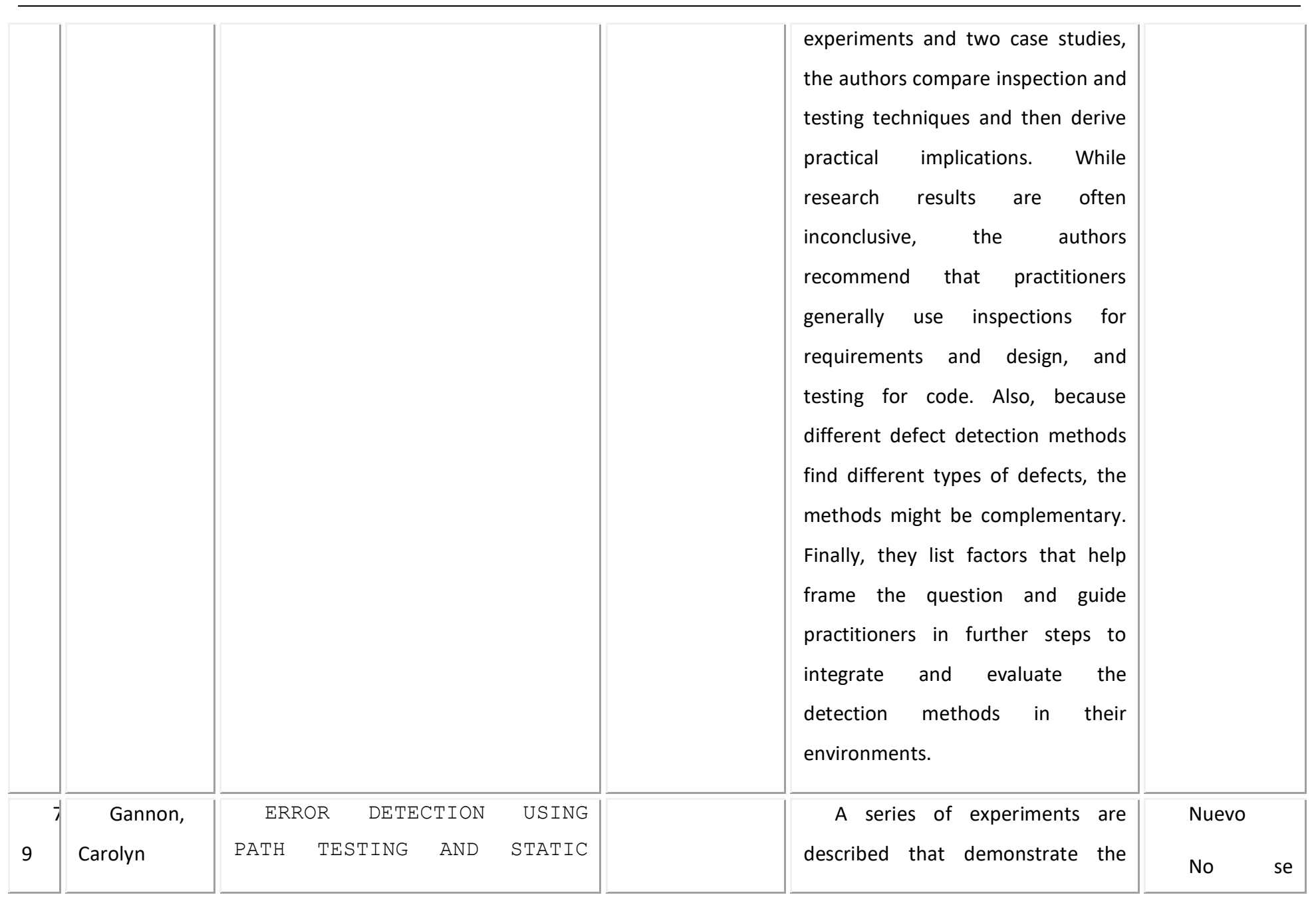

Caso de estudio 


\begin{tabular}{|c|c|c|c|c|}
\hline & & $\begin{array}{l}\text { ANALYSIS. Computer, } 12 \text { (8), } \\
\text { pp. p26-31. } 1979\end{array}$ & $\begin{array}{l}\text { kinds of errors which can be } \\
\text { uncovered in a systematic testing } \\
\text { and static analysis approach to } \\
\text { quality assurance of a computer } \\
\text { software. The program considered } \\
\text { was a } 5000 \text {-statement Fortran } \\
\text { system, into which errors were } \\
\text { "seeded" to determine how much } \\
\text { effort would be involved in finding } \\
\text { them using various techniques. }\end{array}$ & $\begin{array}{l}\text { corresponde } \\
\text { con el GCA }\end{array}$ \\
\hline$\varepsilon$ & Myers, & CONTROLLED EXPERIMENT IN & An experiment in program & Nuevo \\
\hline 0 & Glenford J. & $\begin{array}{l}\text { PROGRAM TESTING AND CODE } \\
\text { WALKTHROUGHS/INSPECTIONS. } \\
\text { Communications of the ACM, } \\
21 \text { (9), pp. 760-768. } 1978\end{array}$ & $\begin{array}{l}\text { testing is described that employs } 59 \\
\text { highly experienced data processing } \\
\text { professionals using seven methods } \\
\text { to test a small PL/I program. The } \\
\text { results show that the popular code } \\
\text { walkthrough/inspection method } \\
\text { was as effective as other computer- } \\
\text { based methods in finding errors and } \\
\text { that the most effective methods (in } \\
\text { terms of errors found and cost) } \\
\text { employed pairs of subjects who }\end{array}$ & $\begin{array}{l}\text { No se } \\
\text { corresponde } \\
\text { con el GCA }\end{array}$ \\
\hline
\end{tabular}


Proceso de RS de experimentos en Ingeniería del Software

\begin{tabular}{|c|c|c|c|c|}
\hline & & & $\begin{array}{l}\text { tested the program independently } \\
\text { and then pooled their findings. The } \\
\text { study also shows that there is a } \\
\text { tremendous amount of variability } \\
\text { among subjects and that the ability } \\
\text { to detect certain types of errors } \\
\text { varies from method to method. }\end{array}$ & \\
\hline 1 & $\begin{array}{l}\text { \& Harjumaa, } \\
\text { L. }\end{array}$ & $\begin{array}{l}\text { A pattern approach to } \\
\text { software inspection process } \\
\text { improvement. } \\
\text { Process: Improvement and } \\
\text { Practice } 10(4), \\
465.2005\end{array}$ & $\begin{array}{l}\text { Concrete guidelines are often } \\
\text { helpful when planning software } \\
\text { process improvement. Small } \\
\text { companies, in particular, need } \\
\text { detailed and unambiguous } \\
\text { instructions detailing what process } \\
\text { areas to improve, and how to } \\
\text { achieve the improvement. This } \\
\text { article introduces a set of patterns } \\
\text { to direct the improvement of the } \\
\text { software inspection process. The } \\
\text { pattern approach has been applied, } \\
\text { since it has been used very } \\
\text { successfully for knowledge-sharing }\end{array}$ & $\begin{array}{l}\text { Nuevo } \\
\text { No se } \\
\text { corresponde } \\
\text { con el GCA }\end{array}$ \\
\hline
\end{tabular}

Caso de estudio 


\begin{tabular}{|c|c|c|c|c|}
\hline & & & $\begin{array}{l}\text { purposes and other areas of } \\
\text { software engineering. The approach } \\
\text { involves an evaluation of the } \\
\text { inspection process capability, } \\
\text { setting an overall goal for the } \\
\text { improvement and updating the } \\
\text { process according to pre-defined } \\
\text { actions. Experiments with initial } \\
\text { patterns show that the method } \\
\text { provides a feasible and quick way of } \\
\text { making inspections more effective. } \\
\text { Using patterns may also be } \\
\text { beneficial when launching more } \\
\text { wide-ranging SPI activities, as } \\
\text { companies can run preliminary trials } \\
\text { of the improvement process on a } \\
\text { smaller scale first. }\end{array}$ & \\
\hline$\delta$ & $\begin{array}{l}\text { Kusumoto } \\
\text {, S., Chimura, } \\
\text { A., Kikuno, T., } \\
\text { Matsumoto, } \\
\text { K.-I., Mohri, }\end{array}$ & $\begin{array}{l}\text { A promising approach to } \\
\text { two-person software review } \\
\text { in educational environment. } \\
\text { Journal of Systems and } \\
\text { Software } 40(2) \text {, 115-123. }\end{array}$ & $\begin{array}{l}\text { Technical review is a type of } \\
\text { software review which effectively } \\
\text { reduces testing effort and detects } \\
\text { faults more effectively than testing. } \\
\text { Thus, it should be learned by all }\end{array}$ & $\begin{array}{l}\text { Nuevo } \\
\text { No se } \\
\text { corresponde } \\
\text { con el GCA }\end{array}$ \\
\hline
\end{tabular}


Proceso de RS de experimentos en Ingeniería del Software

\begin{tabular}{|l|l|l|l|l|}
\hline Y. & $\mid 2005$ & $\begin{array}{l}\text { persons that are engaged in } \\
\text { software development in } \\
\text { educational environments. In this } \\
\text { paper, we propose a new approach } \\
\text { which allows every person to } \\
\text { effectively learn the review } \\
\text { methods in educational } \\
\text { environments. In the proposed } \\
\text { approach, the review is done by a } \\
\text { pair of persons producer and } \\
\text { reviewer. For each product, first, } \\
\text { the producer explains the product } \\
\text { to the reviewer and receives } \\
\text { questions about it from the } \\
\text { reviewer; then, both the producer } \\
\text { and the reviewer jointly check the } \\
\text { product to detect faults by using a } \\
\text { checklist. Then, we have applied the } \\
\text { proposed method to an } \\
\text { experimental project in 1994. } \\
\text { Comparing the result of the } \\
\text { experiment to results of an }\end{array}$ \\
\hline
\end{tabular}

Caso de estudio 


\begin{tabular}{|c|c|c|c|c|}
\hline & & & $\begin{array}{l}\text { experimental project in } 1993 \text { in } \\
\text { which the conventional review } \\
\text { method was applied, the following } \\
\text { advantages were found: (1) } \\
\text { Contributions from each individual } \\
\text { increased, (2) Every person learned } \\
\text { the review methods easily, (3) } \\
\text { Percentage of unreviewed product } \\
\text { decreased, (4) Review effort } \\
\text { decreased by 30\%, and (5) } \\
\text { Completion rate increased by } 10 \% \text {. } \\
\text { Thus, the proposed approach is } \\
\text { useful for not only the educational } \\
\text { environment but also for actual } \\
\text { software development. }\end{array}$ & \\
\hline$\varepsilon$ & $\begin{array}{l}\text { Johnson, } \\
\text { P.M.a e f g } \\
\text { h i , } \\
\text { Tjahjono, D.a } \\
\text { b c d }\end{array}$ & \begin{tabular}{lr}
\multicolumn{1}{c}{ Does Every } & Inspection \\
Really Need a & Meeting? \\
Empirical & Software \\
Engineering 3(1), & $9-35.1998$
\end{tabular} & $\begin{array}{l}\text { Software review is a } \\
\text { fundamental component of the } \\
\text { software quality assurance process, } \\
\text { yet significant controversies } \\
\text { surround the most efficient and } \\
\text { effective review method. A central } \\
\text { question surrounds the use of }\end{array}$ & $\begin{array}{l}\text { Nuevo } \\
\text { No se } \\
\text { corresponde } \\
\text { con el GCA }\end{array}$ \\
\hline
\end{tabular}


Proceso de RS de experimentos en Ingeniería del Software

\begin{tabular}{|l|l|l|}
\hline $\mid$ & $\begin{array}{l}\text { meetings; traditional review } \\
\text { practice views them as essential, } \\
\text { while more recent findings question } \\
\text { their utility. To provide insight into } \\
\text { this question, we conducted a } \\
\text { controlled experiment to assess } \\
\text { several measures of cost and } \\
\text { effectiveness for a meeting and } \\
\text { non-meeting-based review method. } \\
\text { The experiment used cSRS, a } \\
\text { computer mediated collaborative } \\
\text { software review environment, and } \\
24 \text { three person groups. We found } \\
\text { that the meeting-based review } \\
\text { method studied was significantly } \\
\text { more costly than the non-meeting- } \\
\text { based method, but that meeting- } \\
\text { based review did not find } \\
\text { significantly more defects than the } \\
\text { non-meeting-based method. } \\
\text { However, the meeting-based review } \\
\text { method was significantly better at }\end{array}$ \\
\hline
\end{tabular}

Caso de estudio 


\begin{tabular}{|c|c|c|c|c|}
\hline & & & $\begin{array}{l}\text { reducing the level of false positives, } \\
\text { and subjects subjectively preferred } \\
\text { meeting-based review over non- } \\
\text { meeting-based review. This paper } \\
\text { presents the motivation for this } \\
\text { experiment, its design and } \\
\text { implementation, our empirical } \\
\text { findings, pointers to Internet } \\
\text { repositories for replication or } \\
\text { additional analysis of this } \\
\text { experiment, conclusions, and future } \\
\text { directions. }\end{array}$ & \\
\hline 6 & $\begin{array}{l}\text { Biffl, S., } \\
\text { Grossmann, } \\
\text { W. }\end{array}$ & $\begin{array}{l}\text { Evaluating the accuracy } \\
\text { of defect estimation models } \\
\text { based on inspection data } \\
\text { from two inspection cycles. } \\
\text { Proceedings of the } 23 r d \\
\text { International Conference on } \\
\text { Software Engineering, } \\
\text { Toronto, Canada, May 12-19. } \\
\text { Washington: IEEE Computer } \\
\text { Society, 145-154. } 2001\end{array}$ & $\begin{array}{l}\text { Defect content estimation } \\
\text { techniques (DCETs), based on defect } \\
\text { data from inspection, estimate the } \\
\text { total number of defects in a } \\
\text { document to evaluate the } \\
\text { development process. For } \\
\text { inspections that yield few data } \\
\text { points DCETs reportedly } \\
\text { underestimate the number of } \\
\text { defects. If there is a second }\end{array}$ & $\begin{array}{l}\text { Nuevo } \\
\text { No se } \\
\text { corresponde } \\
\text { con el GCA }\end{array}$ \\
\hline
\end{tabular}


Proceso de RS de experimentos en Ingeniería del Software

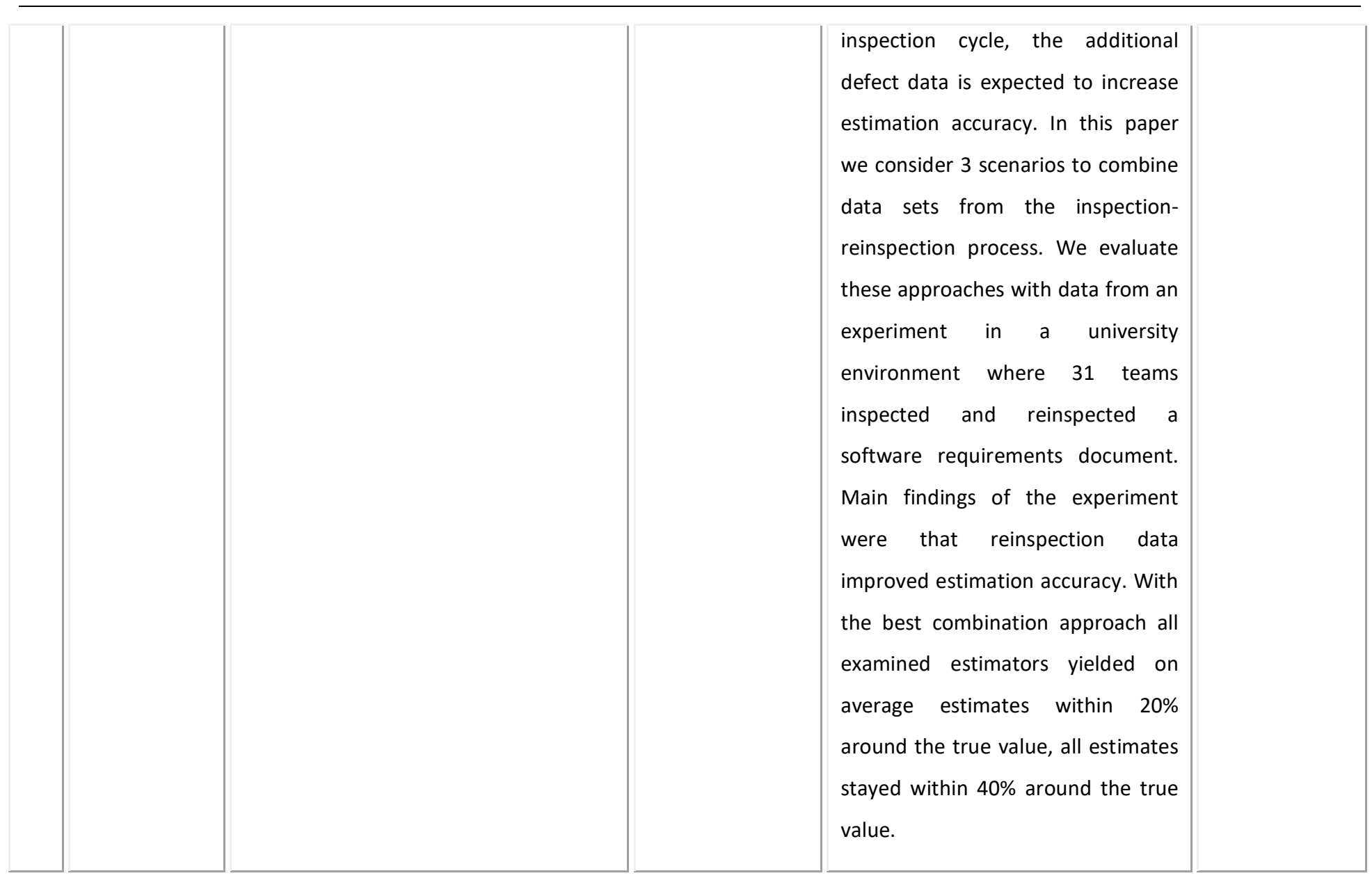

Caso de estudio 


\subsubsection{Documentar estadísticas de búsqueda (segunda iteración)}

A continuación se presentan los resultados de las búsquedas realizadas. El conjunto base se incrementa en 35 artículos para un total de 112 artículos.

B04 Formulario para Estadísticas de búsqueda

\begin{tabular}{|l|} 
Realizado por: Anna \\
Grimán \\
\hline Fecha: \\
\hline
\end{tabular}

\begin{tabular}{|l|l|l|l|}
\hline & $\begin{array}{l}310 . \quad \text { Artículos } \\
\text { Repositorio }\end{array}$ & Artículos relevantes \\
\hline Scopus & 907 & 87 \\
\hline & & & \\
\hline $312 . \quad$ Total artículos relevantes (distintos) & 87 \\
\hline $313 . \quad$ Total estudios (distintos) & 87 \\
\hline $314 . \quad$ Total replicaciones & \\
\hline
\end{tabular}




\subsubsection{Definir la cadena de búsqueda (tercera iteración)}

Para la tercera iteración los siguientes términos fueron extraídos de los artículos relevantes obtenidos en la iteración anterior:

ad-hoc reading

code reading

code walkthrough

code walkthroughs

defect finding potential

error-finding strategies

error-finding strategy

perspective-based inspection

perspective-based inspections

\author{
requirement inspection \\ requirements inspection \\ requirements inspections \\ static analysis \\ use-case-driven reading \\ verification technique \\ verification techniques
}

\subsubsection{Documentar la estrategia de búsqueda (tercera iteración)}

La tabla A.8 presenta la cadena de búsqueda realizada en Scopus con base en los términos extraídos previamente.

Tabla A.8. Cadena de búsqueda (3ra iteración)

\begin{tabular}{|l|l|}
\hline Reposito & Cadena de Búsqueda \\
rio & \\
\hline Scopus & TITLE-ABS-KEY(("code reading" OR "defect finding potential" OR "error-finding \\
\hline
\end{tabular}

Caso de estudio 


\begin{tabular}{|l|l|}
\hline strategy" OR "error-finding strategies" OR "requirement inspection" OR "requirements \\
inspection" OR " requirements inspections" OR "static analysis" OR "verification \\
techniques" OR "verification technique" OR "ad-hoc reading" OR "code walkthrough" OR \\
"code walkthrough" OR "perspective-based inspection" OR "perspective-based \\
inspections" OR "use-case-driven reading") AND (experiment OR "experimental study" \\
OR "experimental comparison" OR "experimental analysis" OR "experimental evidence" \\
OR "experimental setting"))
\end{tabular}

\subsubsection{Ejecutar la búsqueda (tercera iteración)}

La tabla A.9, resume el número de artículos recuperados utilizando la cadena anterior. Por razones de espacio, sólo se reporta un listado de los títulos.

Tabla A.9. Resultados de la búsqueda (3ra iteración)

\begin{tabular}{|l|c|}
\hline Cadena de búsqueda & $\begin{array}{c}\text { No. } \\
\text { recuperados }\end{array}$ \\
\hline TITLE-ABS-KEY(("code reading" OR "defect finding potential" OR "error-finding & 142 \\
strategy" OR "error-finding strategies" OR "requirement inspection" OR "requirements \\
inspection" OR " requirements inspections" OR "static analysis" OR "verification \\
techniques" OR "verification technique" OR "ad-hoc reading" OR "code walkthrough" \\
OR "code walkthrough" OR "perspective-based inspection" OR "perspective-based \\
inspections" OR "use-case-driven reading") AND (experiment OR "experimental study" \\
OR "experimental comparison" OR "experimental analysis" OR "experimental \\
evidence" OR "experimental setting"))
\end{tabular}




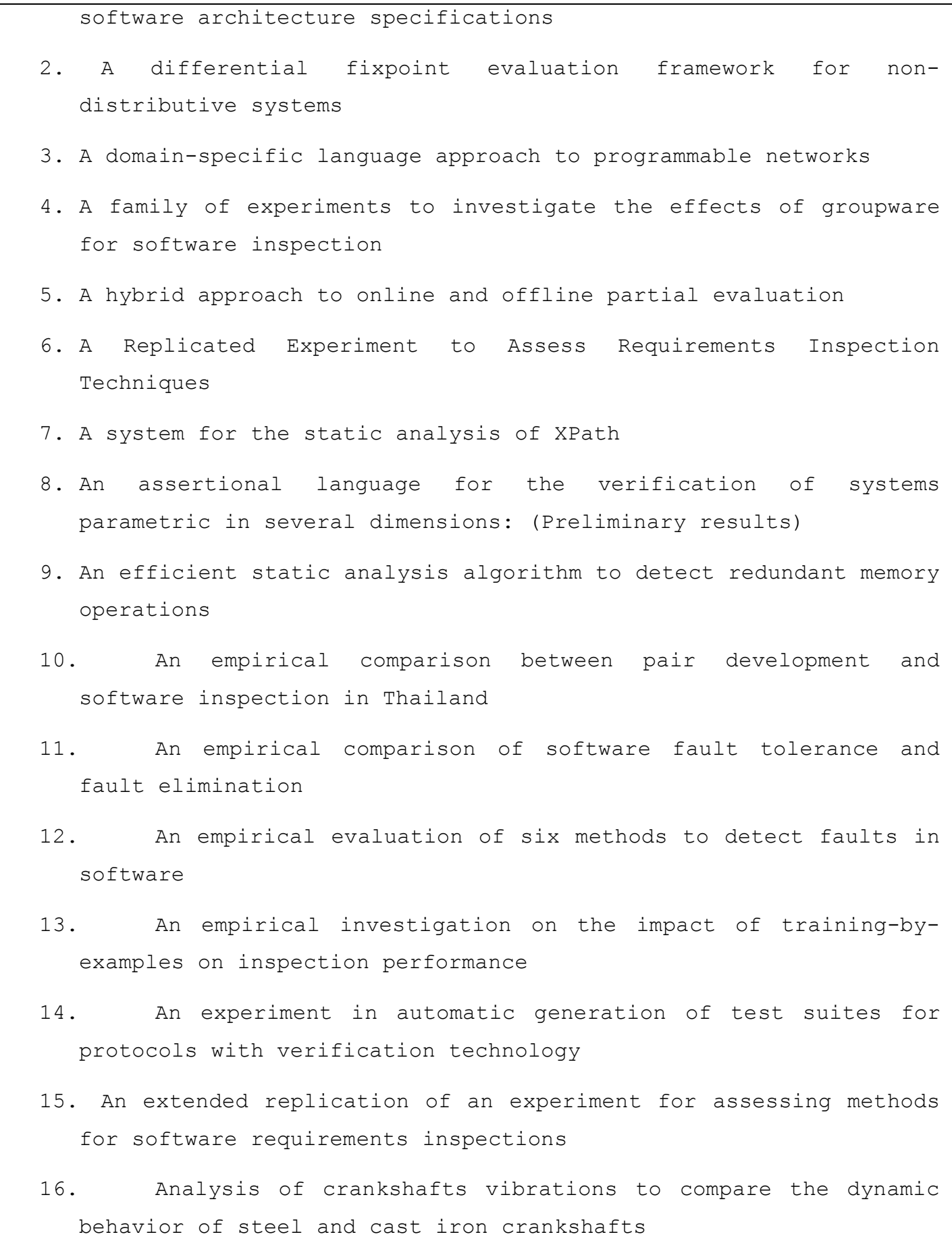

\section{Caso de estudio}




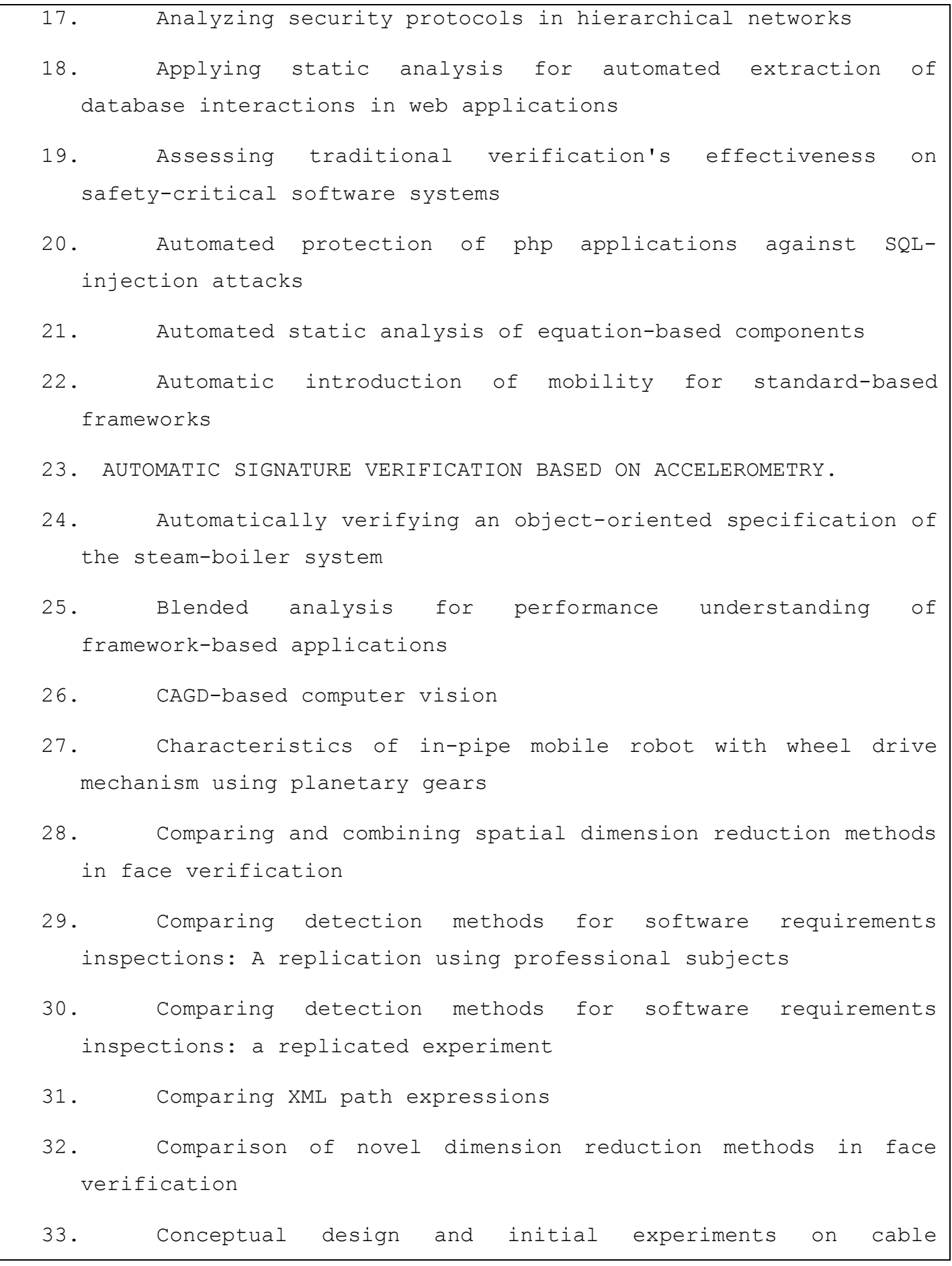




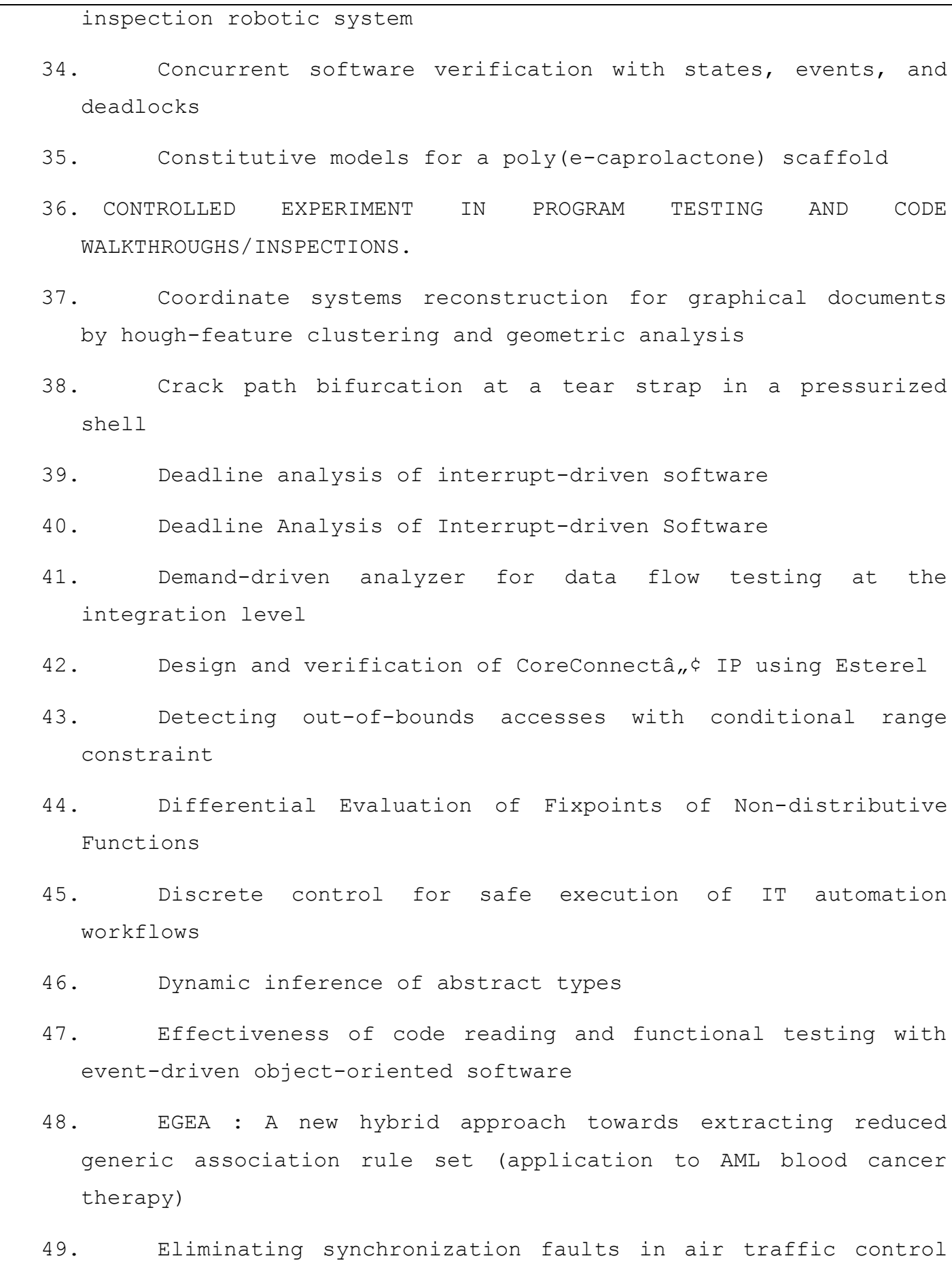

\section{Caso de estudio}




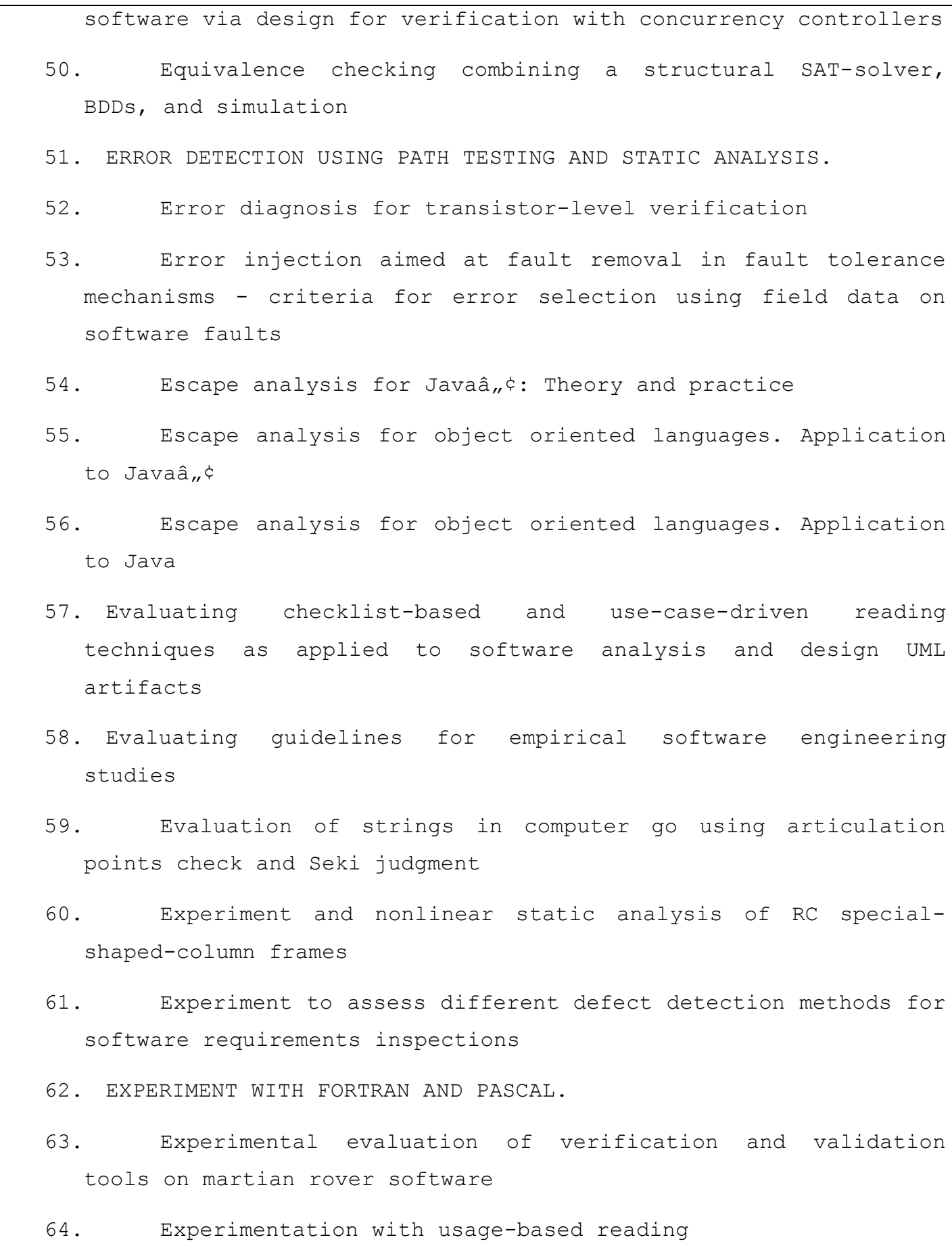




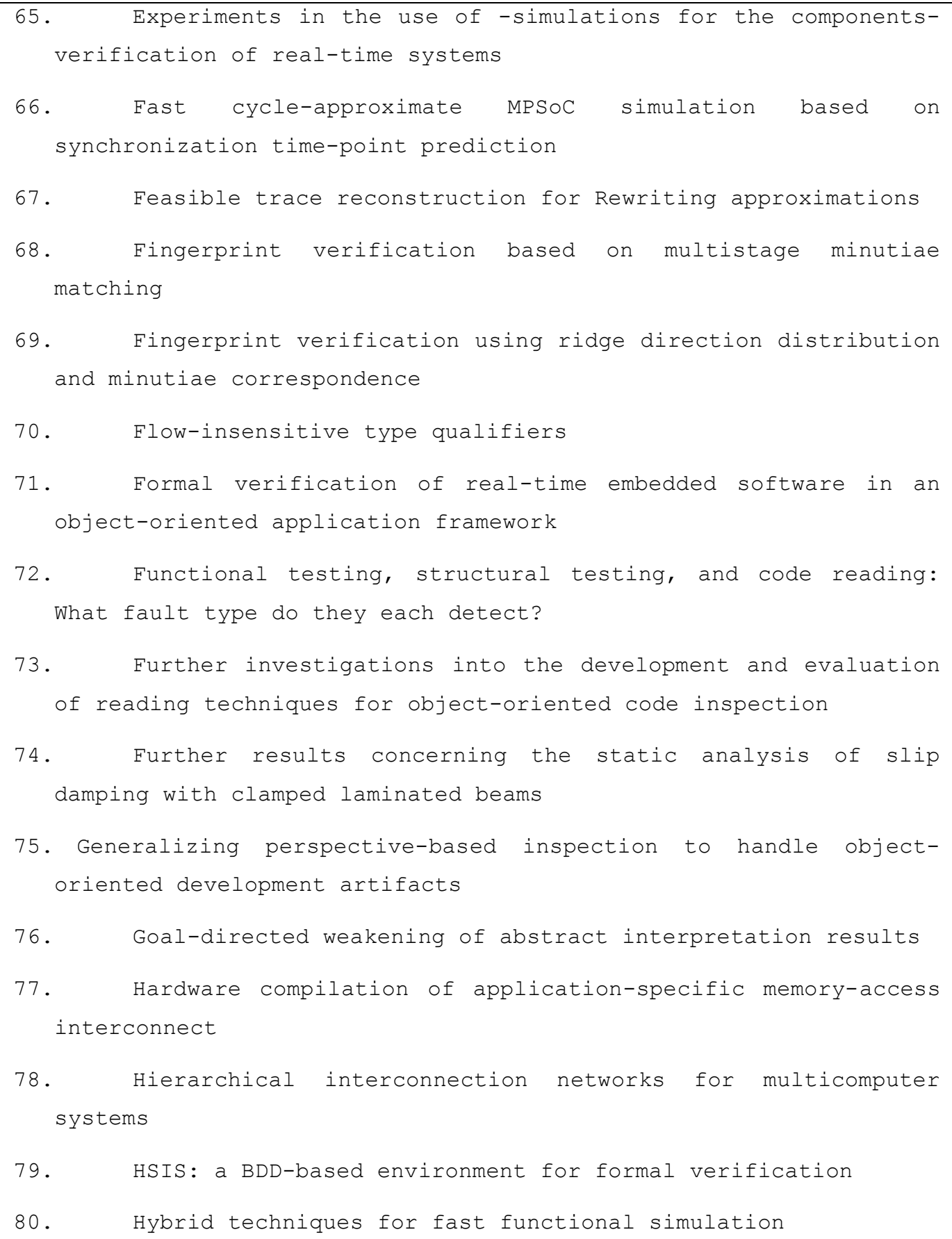

\section{Caso de estudio}




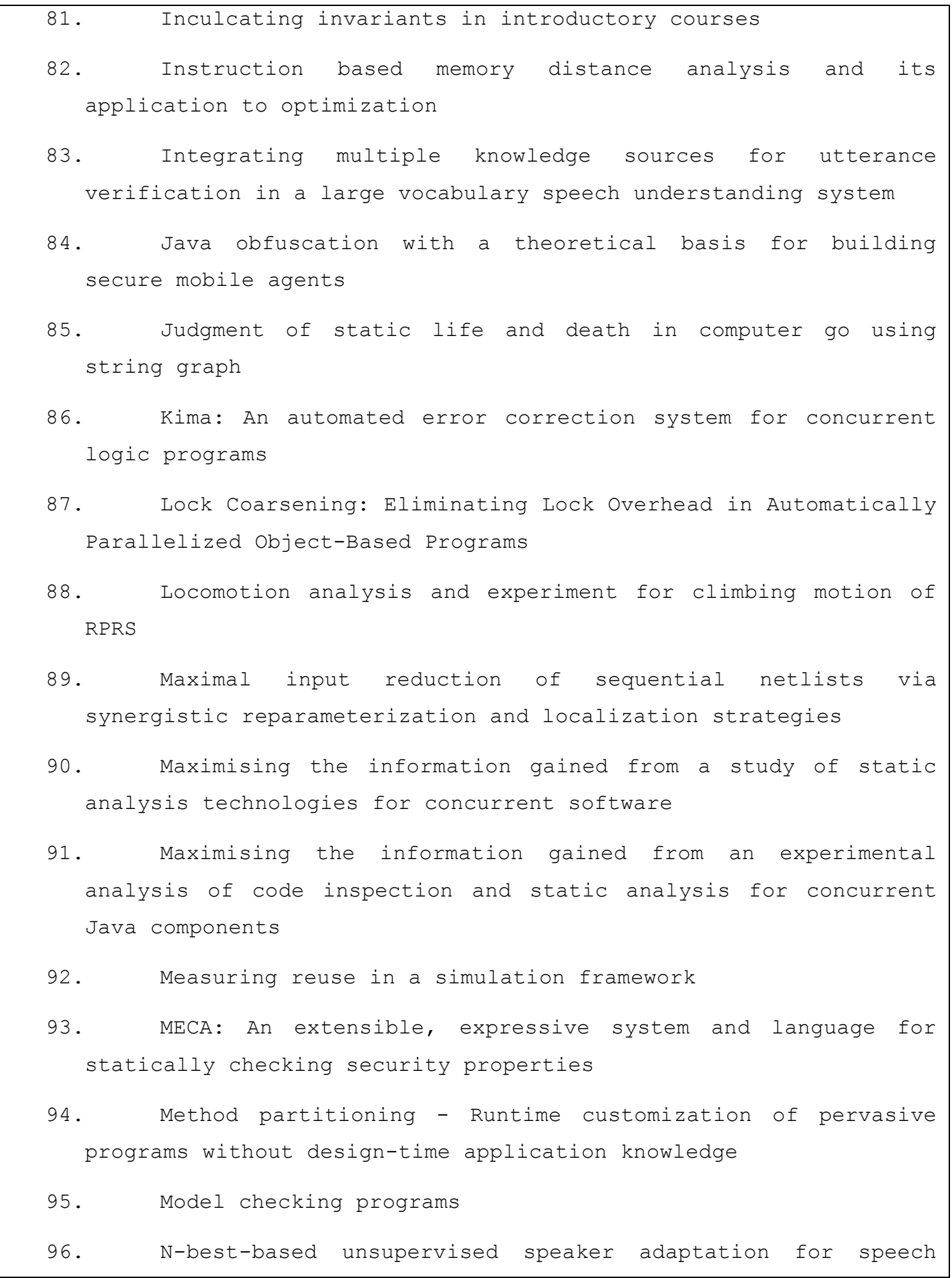




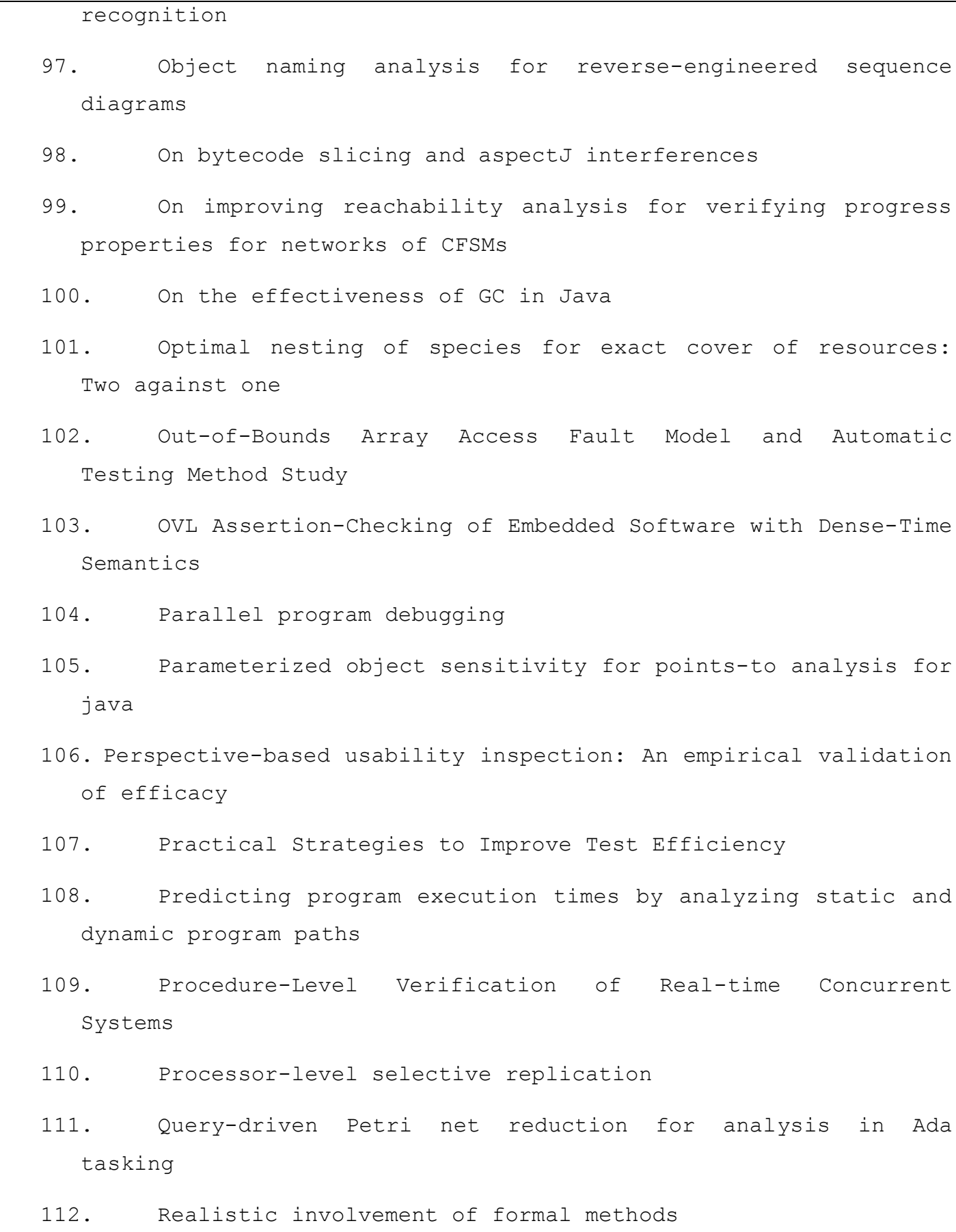

\section{Caso de estudio}


113. Recognition method for network script virus based on statistical analysis

114. Refining buffer overflow detection via demand-driven pathsensitive analysis

115. Reflection analysis for java

116. RELAY: Static race detection on millions of lines of code

117. Repeatable software engineering experiments for comparing defect-detection techniques

118. Robustness and security hardening of COTS software libraries

119. Safety verification of dynamic storage management in coq

120. Sequence-based abstract interpretation of Prolog

121. Simultaneous scalability and security for data-intensive web applications

122. SNIAFL: Towards a static noninteractive approach to feature location

123. Software engineering laboratory - an operational software experience factory

124. Software obfuscation on a theoretical basis and its implementation

125. Specification and model checking of temporal properties in time petri nets and timed automata

126. Spreadsheet Presentation and Error Detection: An Experimental Study

127. State/event-based software model checking

128. Static analysis by policy iteration on relational domains

129. Static analysis of string manipulations in critical embedded C programs 


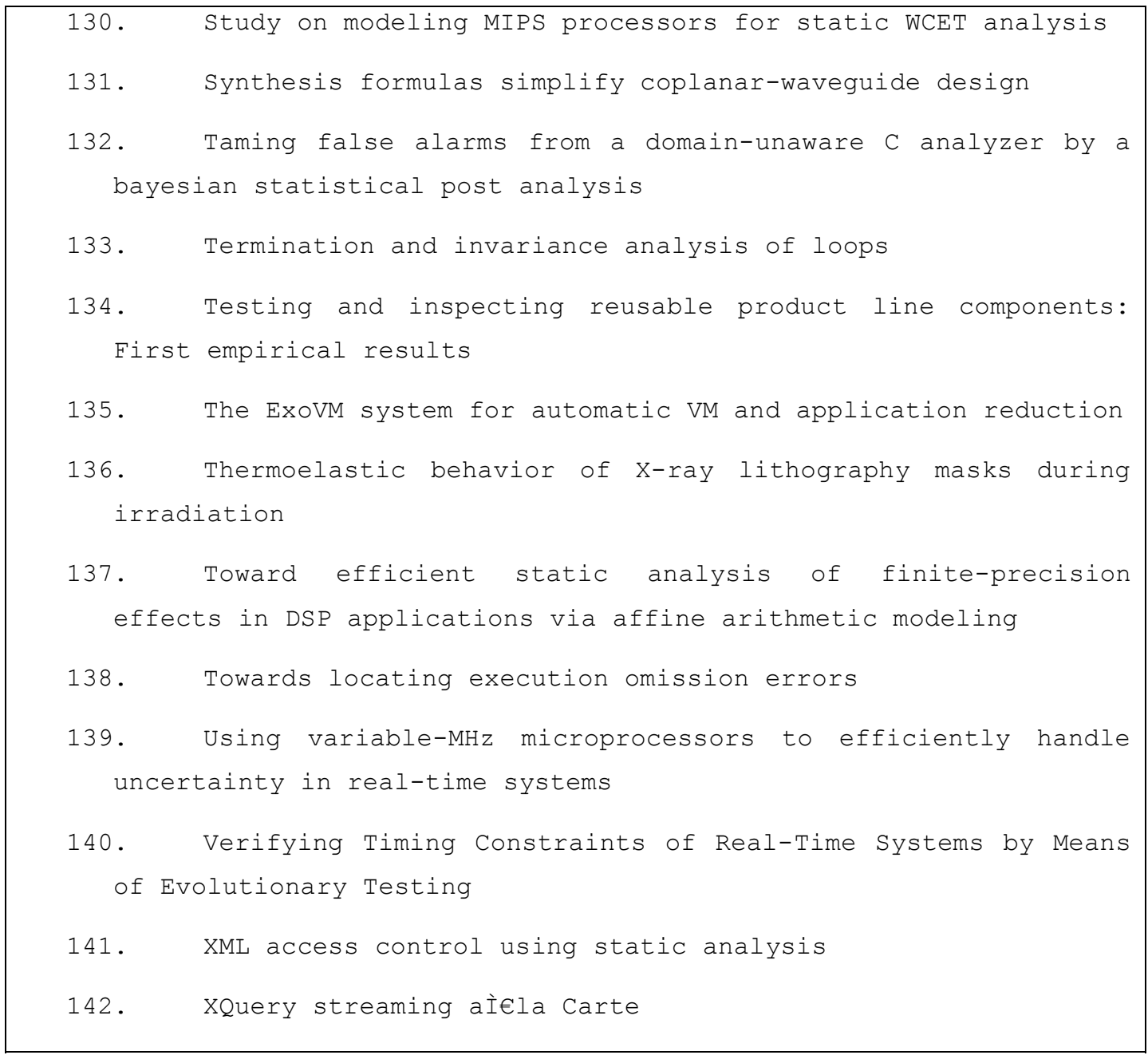

\subsubsection{Descarte de artículos irrelevantes (tercera iteración)}

Luego de analizar los resultados obtenidos en la actividad anterior, se encontraron 23 artículos considerados relevantes. Debido al solapamiento entre los artículos obtenidos en esta iteración y los obtenidos en las iteraciones anteriores, sólo 3 nuevos artículos son agregados al conjunto base (para un

Caso de estudio 
total de 115 artículos). De los nuevos artículos considerados relevantes ninguno corresponde con el grupo seleccionado para la agregación (ST-1). A continuación, se muestran los artículos que resultaron relevantes en esta iteración. Sólo se reporta la información de los artículos relevantes que son nuevos para el conjunto base. 
Proceso de RS de experimentos en Ingeniería del Software

B03_Resumen de artículos relevantes

Realizado por: Anna Grimán

Fecha:

\begin{tabular}{|c|c|c|c|c|c|}
\hline D & Autores & 315. Referencia & Fichero & Resumen & n Observació \\
\hline 1 & & $\begin{array}{l}\text { 316. A family of experiments to } \\
\text { investigate the effects of groupware for } \\
\text { software inspection, Automated } \\
\text { Software Engineering, vol. V13, pp. 373- } \\
394,2006 \text {. }\end{array}$ & & & $\begin{array}{l}\text { Recuperad } \\
\text { o previamente } \\
\text { (iteración 1) }\end{array}$ \\
\hline 2 & & $\begin{array}{l}\text { A Replicated Experiment } \\
\text { to Assess Requirements } \\
\text { Inspection Techniques. } \\
\text { Empirical Software Engineering, } 2 \\
\text { (1), pp. 39-57.1997 }\end{array}$ & & & $\begin{array}{l}\text { Recuperad } \\
\text { o previamente } \\
\text { (iteración 2) }\end{array}$ \\
\hline 3 & & $\begin{array}{l}\text { An empirical comparison } \\
\text { between pair development }\end{array}$ & & & Recuperad \\
\hline
\end{tabular}

Caso de estudio 


\begin{tabular}{|c|c|c|}
\hline & $\begin{array}{l}\text { and software inspection in } \\
\text { Thailand. Proceedings of the } \mathbf{2 0 0 6} \\
\text { ACM/IEEE international symposium on } \\
\text { International symposium on empirical } \\
\text { software engineering ISESE '06 }\end{array}$ & $\begin{array}{l}\text { o previamente } \\
\text { (iteración 1) }\end{array}$ \\
\hline 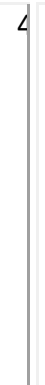 & $\begin{array}{lr}\quad \text { An empirical } & \text { evaluation } \\
\text { of six methods to detect } \\
\text { faults in } & \text { software. } \\
\text { Software } & \text { Testing } \\
\text { Verification } & \text { and } \\
\text { Reliability, 12 } & \text { (3), } p \text { p. } \\
\text { 155-171. 2002. } & \end{array}$ & $\begin{array}{l}\text { Recuperad } \\
\text { o previamente } \\
\text { (iteración 2) }\end{array}$ \\
\hline 5 & $\begin{array}{l}\text { An } \\
\text { investigation on the impact } \\
\text { of training-by-examples on } \\
\text { inspection performance. } \\
\text { Lecture Notes in Computer } \\
\text { Science (including } \\
\text { subseries Lecture Notes in } \\
\text { Artificial Intelligence and } \\
\text { Lecture Notes in } \\
\text { Bioinformatics) 3009, pp. } \\
\text { 203-219.2004 }\end{array}$ & $\begin{array}{l}\text { Recuperad } \\
\text { o previamente } \\
\text { (iteración 2) }\end{array}$ \\
\hline
\end{tabular}


Proceso de RS de experimentos en Ingeniería del Software

\begin{tabular}{|c|c|c|}
\hline$\epsilon$ & 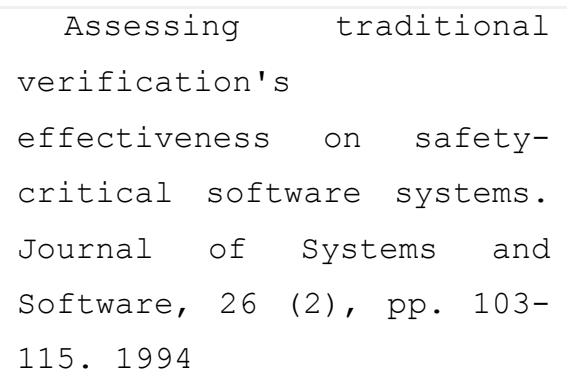 & $\begin{array}{l}\text { Recuperad } \\
\text { o previamente } \\
\text { (iteración 2) }\end{array}$ \\
\hline 7 & 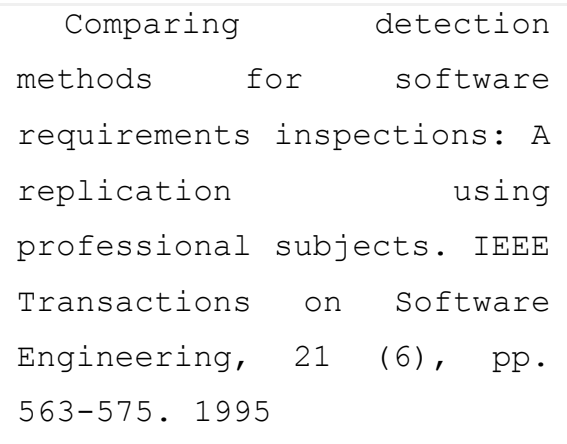 & $\begin{array}{l}\text { Recuperad } \\
\text { o previamente } \\
\text { (iteración 2) }\end{array}$ \\
\hline$\varepsilon$ & 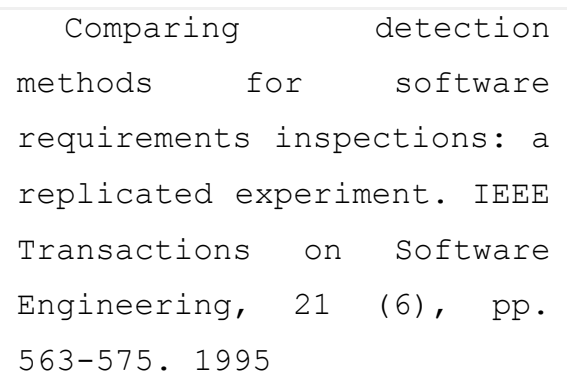 & $\begin{array}{l}\text { Recuperad } \\
\text { o previamente } \\
\text { (iteración 2) }\end{array}$ \\
\hline
\end{tabular}

Caso de estudio 


\begin{tabular}{|c|c|c|}
\hline$\Phi$ & $\begin{array}{l}\text { Experiment to assess } \\
\text { different defect detection } \\
\text { methods for software } \\
\text { requirements inspections, } \\
\text { Proceedings of the } \mathbf{1 6}^{\text {th }} \text { international } \\
\text { conference on Software engineering } \\
\text { ICSE'94 }\end{array}$ & $\begin{array}{l}\text { Recuperad } \\
\text { o previamente } \\
\text { (iteración 1) }\end{array}$ \\
\hline 0 & $\begin{array}{l}\text { Experimentation } \\
\text { usage-based } \\
\text { Lecture Notes in Computer } \\
\text { Science } \\
\text { subseries Lecture Notes in } \\
\text { Artificial Intelligence and } \\
\text { Lecture Notes in } \\
\text { Bioinformatics) 2765, pp. } \\
\text { 193-207, } 2003\end{array}$ & $\begin{array}{l}\text { Recuperad } \\
\text { o previamente } \\
\text { (iteración 1) }\end{array}$ \\
\hline 1 & $\begin{array}{l}\text { Further investigations } \\
\text { into the development and } \\
\text { evaluation of reading } \\
\text { techniques for object- } \\
\text { oriented code inspection. } \\
\text { Proceedings - International } \\
\text { Conference on Software }\end{array}$ & $\begin{array}{l}\text { Recuperad } \\
\text { o previamente } \\
\text { (iteración 2) }\end{array}$ \\
\hline
\end{tabular}


Proceso de RS de experimentos en Ingeniería del Software

\begin{tabular}{|c|c|c|}
\hline & $\begin{array}{l}\text { Engineering, pp. } 47-57 \text {. } \\
2002\end{array}$ & \\
\hline 2 & $\begin{array}{l}\text { Maximising the } \\
\text { information gained from a } \\
\text { study of static analysis } \\
\text { technologies for concurrent } \\
\text { software. Empirical } \\
\text { Software Engineering, } 12 \\
\text { (6), pp. 617-645. } 2007\end{array}$ & $\begin{array}{l}\text { Recuperad } \\
\text { o previamente } \\
\text { (iteración 2) }\end{array}$ \\
\hline 3 & $\begin{array}{l}\text { Maximising the } \\
\text { information gained from an } \\
\text { experimental analysis of } \\
\text { code inspection and static } \\
\text { analysis for concurrent } \\
\text { Java components. ISCE'06 - } \\
\text { Proceedings of the 5th ACM- } \\
\text { IEEE International } \\
\text { Symposium on Empirical } \\
\text { Software Engineering, 2006, } \\
\text { pp. 174-183. } 2006\end{array}$ & $\begin{array}{l}\text { Recuperad } \\
\text { o previamente } \\
\text { (iteración 2) }\end{array}$ \\
\hline 1 & $\begin{array}{l}\text { Spreadsheet Presentation } \\
\text { and Error Detection: An }\end{array}$ & Recuperad \\
\hline
\end{tabular}

Caso de estudio 


\begin{tabular}{|c|c|c|}
\hline 4 & $\begin{array}{l}\text { Experimental Study. Journal } \\
\text { of Management Information } \\
\text { Systems, } 13 \text { (3), pp. 45-63. } \\
1996\end{array}$ & $\begin{array}{l}\text { o previamente } \\
\text { (iteración 2) }\end{array}$ \\
\hline 5 & $\begin{array}{l}\quad \text { Testing and inspecting } \\
\text { reusable product line } \\
\text { components: First empirical } \\
\text { results. ISCE'06 - } \\
\text { Proceedings of the 5th ACM- } \\
\text { IEEE International } \\
\text { Symposium on Empirical } \\
\text { Software Engineering, 2006, } \\
\text { pp. 184-193. } 2006\end{array}$ & $\begin{array}{l}\text { Recuperad } \\
\text { o previamente } \\
\text { (iteración 2) }\end{array}$ \\
\hline 6 & $\begin{array}{l}\text { An extended replication } \\
\text { of an experiment for } \\
\text { assessing methods for } \\
\text { software requirements } \\
\text { inspections. } \\
\text { Software Engineering, } 3 \\
\text { (4), pp. 327-354. } 1998\end{array}$ & $\begin{array}{l}\text { Recuperad } \\
\text { o previamente } \\
\text { (iteración 2) }\end{array}$ \\
\hline 7 & $\begin{array}{l}\text { ERROR DETECTION USING } \\
\text { PATH TESTING AND STATIC } \\
\text { ANALYSIS. Computer, } 12 \text { (8), }\end{array}$ & $\begin{array}{c}\text { Recuperad } \\
\text { o previamente }\end{array}$ \\
\hline
\end{tabular}


Proceso de RS de experimentos en Ingeniería del Software

\begin{tabular}{|c|c|c|}
\hline & pp.p26-31. 1979 & (iteración 2) \\
\hline 8 & $\begin{array}{l}\text { Evaluating checklist- } \\
\text { based and use-case-driven } \\
\text { reading techniques as } \\
\text { applied to software } \\
\text { analysis and design UML } \\
\text { artifacts. Lecture Notes in } \\
\text { Computer Science (including } \\
\text { subseries Lecture Notes in } \\
\text { Artificial Intelligence and } \\
\text { Lecture Notes in } \\
\text { Bioinformatics), 2765, pp. } \\
\text { 142-165. } 2003\end{array}$ & $\begin{array}{l}\text { Recuperad } \\
\text { o previamente } \\
\text { (iteración 2) }\end{array}$ \\
\hline 9 & $\begin{array}{l}\text { CONTROLLED EXPERIMENT IN } \\
\text { PROGRAM TESTING AND CODE } \\
\text { WALKTHROUGHS/INSPECTIONS. } \\
\text { Communications of the ACM, } \\
21 \text { (9), pp. 760-768. } 1978\end{array}$ & $\begin{array}{l}\text { Recuperad } \\
\text { o previamente } \\
\text { (iteración 2) }\end{array}$ \\
\hline 0 & \begin{tabular}{l}
\multicolumn{2}{c}{ Perspective-based } \\
usability inspection: An \\
empirical validation of
\end{tabular} & $\begin{array}{c}\text { Recuperad } \\
\text { o previamente }\end{array}$ \\
\hline
\end{tabular}

Caso de estudio 


\begin{tabular}{|c|c|c|c|c|}
\hline & & 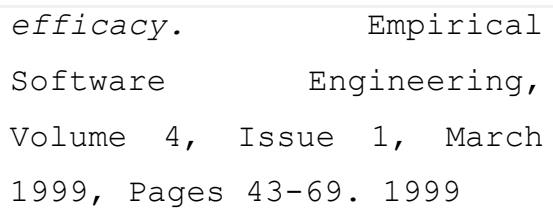 & & (iteración 2) \\
\hline 1 & $\begin{array}{l}\quad \text { Cantone, } \\
\text { G., } \\
\text { Abdulnabi, } \\
\text { Z.A., } \\
\text { Lomartire, A., } \\
\text { Calavaro, G. }\end{array}$ & $\begin{array}{l}\text { Effectiveness of code reading and } \\
\text { functional testing with event-driven } \\
\text { object-oriented software. (2003) } \\
\text { Lecture Notes in Computer Science } \\
\text { (including subseries Lecture Notes in } \\
\text { Artificial Intelligence and Lecture Notes } \\
\text { in Bioinformatics), 2765, pp. 166-192. }\end{array}$ & $\begin{array}{l}\text { This chapter is concerned with } \\
\text { experimental comparisons of code } \\
\text { reading and functional testing } \\
\text { (including fault identification) of } \\
\text { concurrent event-driven Java } \\
\text { software. Our initial idea was that } \\
\text { functional-testing is more effective } \\
\text { than code reading with respect to } \\
\text { concurrent event-driven oo } \\
\text { software. A controlled experiment } \\
\text { was initially conducted with } \\
\text { sophomore students (inexperienced } \\
\text { subjects). Subsequently, it was } \\
\text { replicated with some changes with } \\
\text { junior and senior students } \\
\text { (moderately experienced subjects). } \\
\text { We also conducted a further } \\
\text { replication with Master students, }\end{array}$ & $\begin{array}{l}\text { Nuevo } \\
\text { No } \\
\text { corresponde } \\
\text { con el GCA }\end{array}$ \\
\hline
\end{tabular}


Proceso de RS de experimentos en Ingeniería del Software

\begin{tabular}{|l|l|l|l|}
\hline $\mid$ & $\begin{array}{l}\text { which is not considered in this } \\
\text { Chapter. The experiment goal was } \\
\text { studied from different perspectives, } \\
\text { including effect of techniques on } \\
\text { the different types of faults. Results } \\
\text { can be overviewed as the following: } \\
\text { 1) Concerning the initial, basic } \\
\text { experiment: with inexperienced } \\
\text { subjects and a strict interval of } \\
\text { inspecting time of two hours, there } \\
\text { was no statistically significant } \\
\text { difference between the techniques } \\
\text { under consideration; subjects } \\
\text { performance indicator was 62\% for } \\
\text { code reading and 75\% for functional } \\
\text { testing. 2) Concerning the (first) } \\
\text { replication: with moderately expert } \\
\text { subjects, again a strict interval of } \\
\text { inspecting time of two hours, and } \\
\text { more than twice number of seeded } \\
\text { faults, there was no statistically } \\
\text { significant difference between the }\end{array}$ \\
\hline
\end{tabular}

Caso de estudio 


\begin{tabular}{|l|l|l|}
\hline $\mid$ & $\begin{array}{l}\text { techniques; subjects performance } \\
\text { indicator was 100\% for code reading } \\
\text { and } 92 \% \text { for functional testing; } \\
\text { subjects performance indicator } \\
\text { shows that more experienced } \\
\text { subjects were asking for more } \\
\text { inspecting time; however, } \\
\text { functional testing performed much } \\
\text { better than in the basic experiment. } \\
\text { Computation faults were the most } \\
\text { detectable for code reading while } \\
\text { control faults were the most } \\
\text { detectable for functional testing. } \\
\text { Moreover, moderately expert } \\
\text { subjects were more effective than } \\
\text { inexperienced ones in detecting } \\
\text { interface and event types of faults. } \\
\text { Furthermore moderately expert } \\
\text { functional testers detected many } \\
\text { preexistent (non-seeded) faults, } \\
\text { while both inexperienced subjects, } \\
\text { and moderately experienced code } \\
\text { readers could not detect non- }\end{array}$ \\
\hline
\end{tabular} \mid


Proceso de RS de experimentos en Ingeniería del Software

\begin{tabular}{|c|c|c|c|c|}
\hline & & & seeded faults. & \\
\hline 2 & $\begin{array}{c}\text { Juristo, } \\
\text { N., Vegas, S. }\end{array}$ & $\begin{array}{l}\text { Functional testing, structural } \\
\text { testing, and code reading: What fault } \\
\text { type do they each detect? (2003) } \\
\text { Lecture Notes in Computer Science } \\
\text { (including subseries Lecture Notes in } \\
\text { Artificial Intelligence and Lecture Notes } \\
\text { in Bioinformatics), 2765, pp. 208-232. }\end{array}$ & $\begin{array}{l}\text { The origin of the study described } \\
\text { here is the experiment performed } \\
\text { by Basili and Selby, further } \\
\text { replicated by Kamsties and Lott, and } \\
\text { once again by Wood et al. These } \\
\text { experiments investigated the } \\
\text { effectiveness and efficiency of } \\
\text { different code evaluation } \\
\text { techniques (functional and } \\
\text { structural testing and code reading). } \\
\text { The working hypotheses are the } \\
\text { same in all three experiments, } \\
\text { although some experimental } \\
\text { conditions were changed. The } \\
\text { experiments described here use the } \\
\text { experiment package elaborated by } \\
\text { Kamsties and Lott and examine } \\
\text { some of the questions posed as a } \\
\text { result of these experiments. Wood } \\
\text { et al. concluded in their replication }\end{array}$ & $\begin{array}{l}\text { Nuevo } \\
\text { No } \\
\text { corresponde } \\
\text { con el GCA }\end{array}$ \\
\hline
\end{tabular}

Caso de estudio 


\begin{tabular}{|c|c|c|c|c|}
\hline & & & $\begin{array}{l}\text { of the original study that the } \\
\text { relative effectiveness of the } \\
\text { techniques depends on the program } \\
\text { and fault type. In fact, they suggest } \\
\text { formulating a fault taxonomy based } \\
\text { on technique sensitivity. Our study } \\
\text { intends to compare the relative } \\
\text { effectiveness of the testing } \\
\text { techniques and to relate the testing } \\
\text { techniques to fault types. }\end{array}$ & \\
\hline 3 & $\begin{array}{l}\begin{array}{l}\text { Basili, } \\
\text { Caldiera, }\end{array} \\
\text { McGarry, } \\
\text { Pajerski, } \\
\text { Page, } \\
\text { Waligora, S. }\end{array}$ & $\begin{array}{l}\text { Software engineering laboratory - } \\
\text { an operational software experience } \\
\text { factory. (1992) Proceedings - } \\
\text { International Conference on Software } \\
\text { Engineering, (14), pp. } 370-381 .\end{array}$ & $\begin{array}{l}\text { For } 15 \text { years, the Software } \\
\text { Engineering Laboratory (SEL) has } \\
\text { been carrying out studies and } \\
\text { experiments for the purpose of } \\
\text { understanding, assessing, and } \\
\text { improving software and software } \\
\text { processes within a production } \\
\text { software development environment } \\
\text { at the National Aeronautics and } \\
\text { Space Administration/Goddard } \\
\text { Space Flight Center (NASA/GSFC). } \\
\text { The SEL comprises three major }\end{array}$ & $\begin{array}{l}\text { Nuevo } \\
\text { No } \\
\text { corresponde } \\
\text { con el GCA }\end{array}$ \\
\hline
\end{tabular}


Proceso de RS de experimentos en Ingeniería del Software

\begin{tabular}{|l|l|l|}
\hline $\mid$ & $\begin{array}{l}\text { organizations: NASA/GSFC, Flight } \\
\text { Dynamics Division; University of } \\
\text { Maryland, Department of Computer } \\
\text { Science; and Computer Sciences } \\
\text { Corporation, Flight Dynamics } \\
\text { Technology Group. These } \\
\text { organizations have jointly carried } \\
\text { out several hundred software } \\
\text { studies, producing hundreds of } \\
\text { reports, papers, and documents, all } \\
\text { of which describe some aspect of } \\
\text { the software engineering } \\
\text { technology that has been analyzed } \\
\text { in the flight dynamics environment } \\
\text { at NASA. The studies range from } \\
\text { small, controlled experiments (such } \\
\text { as analyzing the effectiveness of } \\
\text { code reading versus that of } \\
\text { functional testing) to large, } \\
\text { multiple-project studies (such as } \\
\text { assessing the impacts of Ada on a } \\
\text { production environment). The }\end{array}$ \\
\hline
\end{tabular}

Caso de estudio 


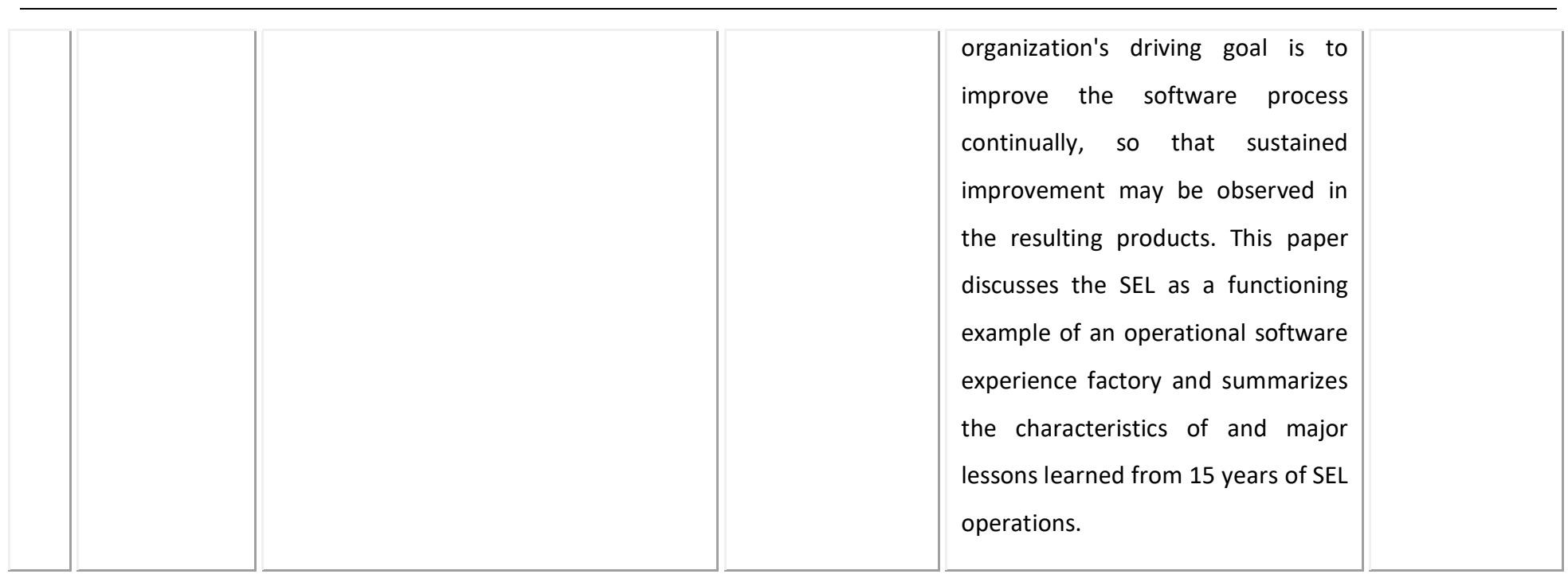




\subsubsection{Documentar las estadísticas de búsqueda (tercera iteración)}

A continuación se presentan los resultados de las búsquedas realizadas. El conjunto base se incrementa en 3 artículos para un total de 115 artículos.

B04 Formulario para Estadísticas de búsqueda

\begin{tabular}{|l|} 
Realizado por: Anna \\
Grimán \\
\hline Fecha: \\
\hline
\end{tabular}

\begin{tabular}{|c|c|c|c|}
\hline \multicolumn{2}{|c|}{ Repositorio } & $\begin{array}{l}\text { 317. Artículos } \\
\text { recuperados }\end{array}$ & Artículos relevantes \\
\hline \multicolumn{2}{|c|}{ Scopus } & 142 & 23 \\
\hline & & 318. & \\
\hline 319. & \multicolumn{2}{|c|}{ Total artículos relevantes (distintos) } & 23 \\
\hline 320. & \multicolumn{2}{|c|}{ Total estudios (distintos) } & 23 \\
\hline 321. & \multicolumn{2}{|c|}{ Total replicaciones } & - \\
\hline
\end{tabular}

Caso de estudio 


\section{- 1.8. BÚSQUEDA POR REFERENCIAS}

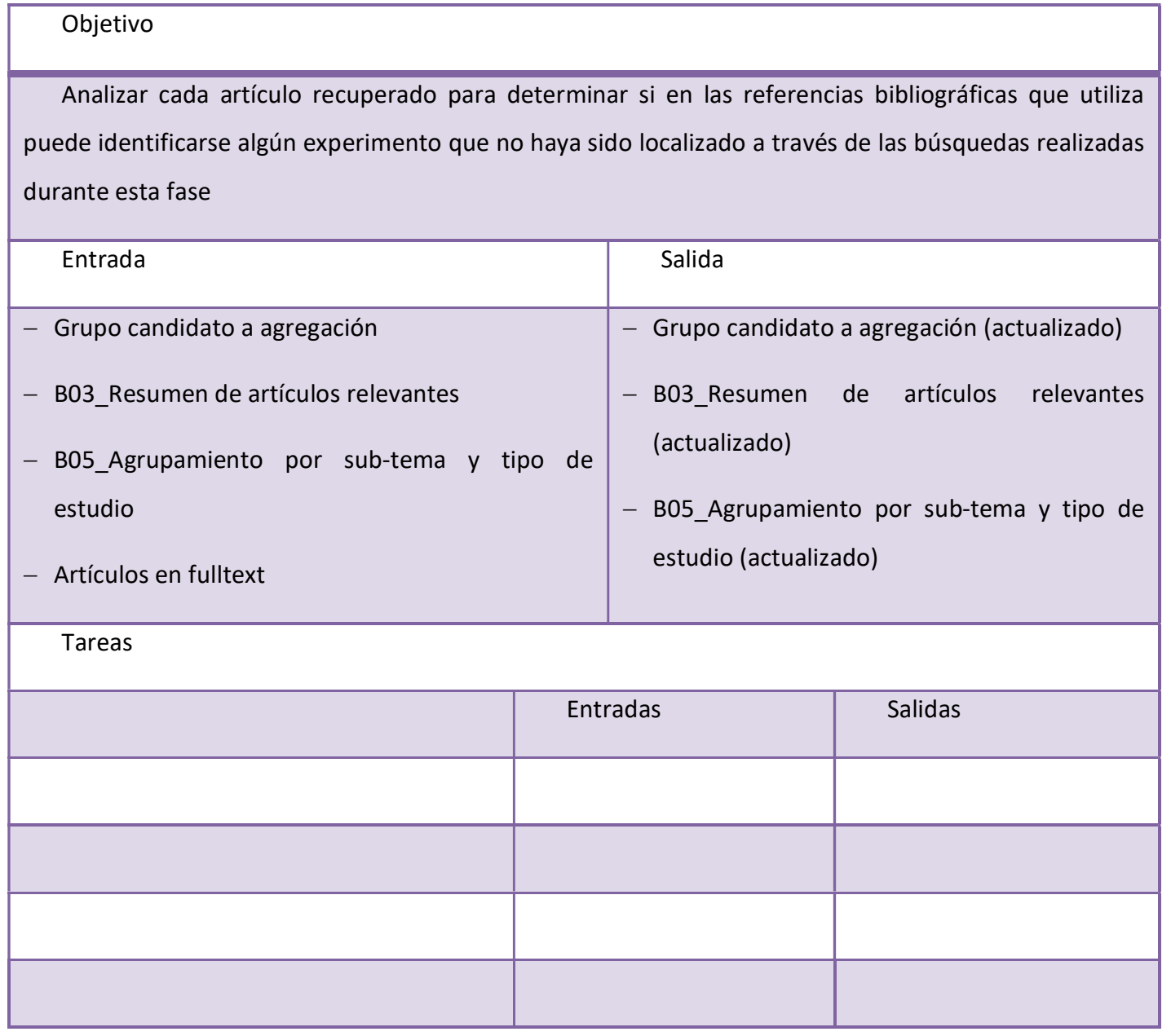

Esta actividad no recuperó nuevos artículos. 


\subsection{DEFINICIÓN/ACTUALIZACIÓN DE GRUPOS CANDIDATOS A AGREGACIÓN}

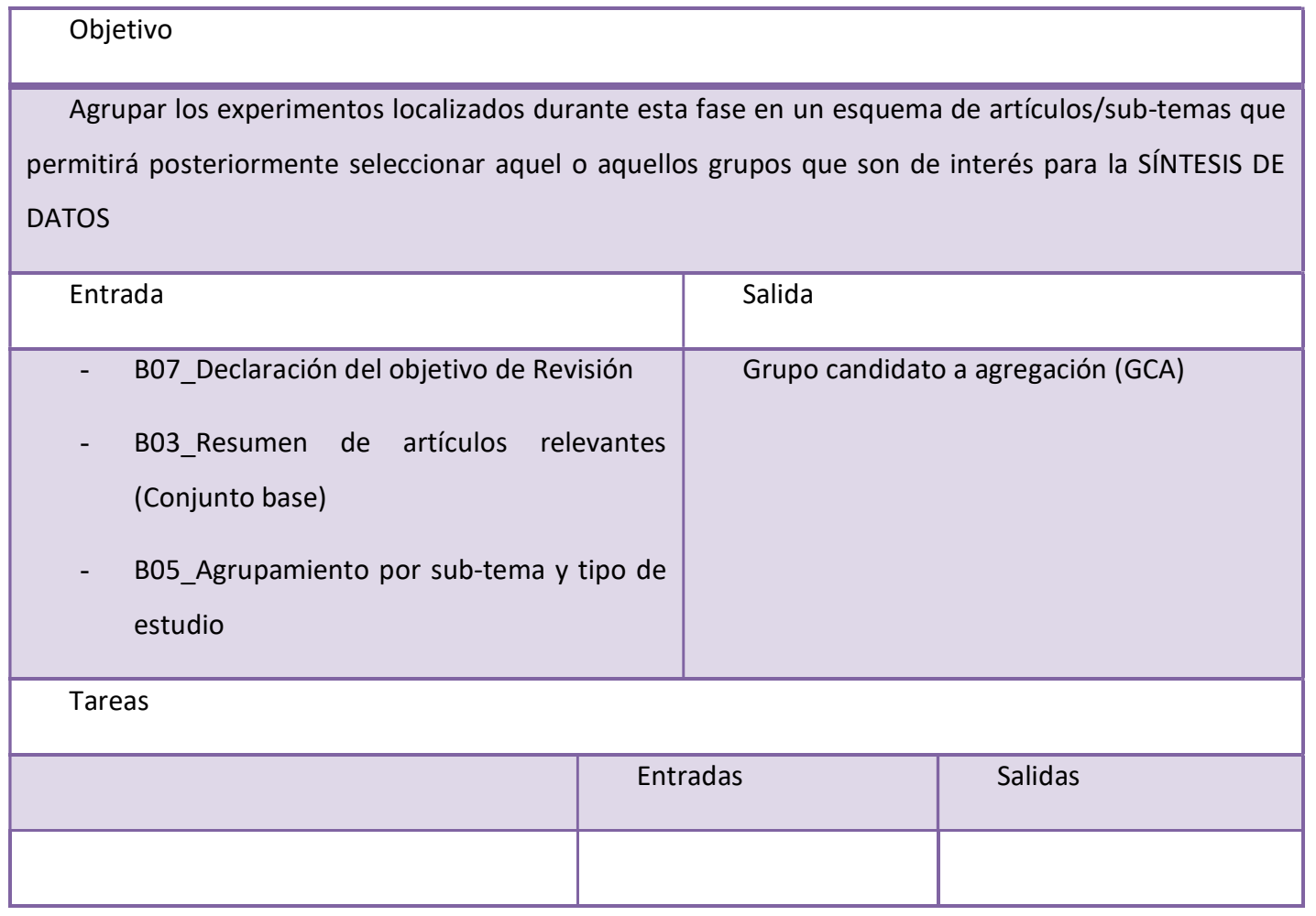

Sólo 9 de los artículos encontrados como relevantes en la actividad anterior incrementan el GCA. De esta manera el conjunto base se incrementa a 86 artículos, mientras que el GCA incluye $\mathbf{3 4}$ artículos, como se muestra en la siguiente tabla.

No obstante, algunos artículos son descartados por no estar disponibles o no corresponde efectivamente con el objetivo de revisión (ART_47, ART_52, ART_58, ART_59, ART_60, ART_88)

Tabla A.10 Grupo agregable

\begin{tabular}{|l|l|}
\hline Grupo agregable & Artículo \\
\hline
\end{tabular}

Caso de estudio 


\begin{tabular}{|c|c|}
\hline $\begin{array}{l}\text { ST1- Experimentos } \\
\text { controlados }\end{array}$ & $\begin{array}{l}\text { ART_01, ART_08, ART_11, ART_14, ART_17, ART_18, ART_19, ART_25, } \\
\text { ART_27, ART_28, ART_39, ART_40, ART_42, ART_44, ART_45, ART_46, } \\
\text { ART_47, ART_52, ART_54, ART_58, ART_59, ART_60, ART_73, ART_75, } \\
\text { ART_78, ART_80, ART_81, ART_82, ART_83, ART_85, ART_86, ART_87, } \\
\text { ART_88 }\end{array}$ \\
\hline $\begin{array}{r}\text { ST1-Quasi- } \\
\text { experimentos }\end{array}$ & ART_23 \\
\hline
\end{tabular}

Evaluación de la continuidad del proceso

Al final de esta fase se cuenta con:

- Pregunta de revisión bien definida y criterios de inclusión/exclusión claros

- $\quad$ Un GCA de interés para el equipo de RS y con 34 estudios 


\section{EXTRACCIÓN DE DATOS}

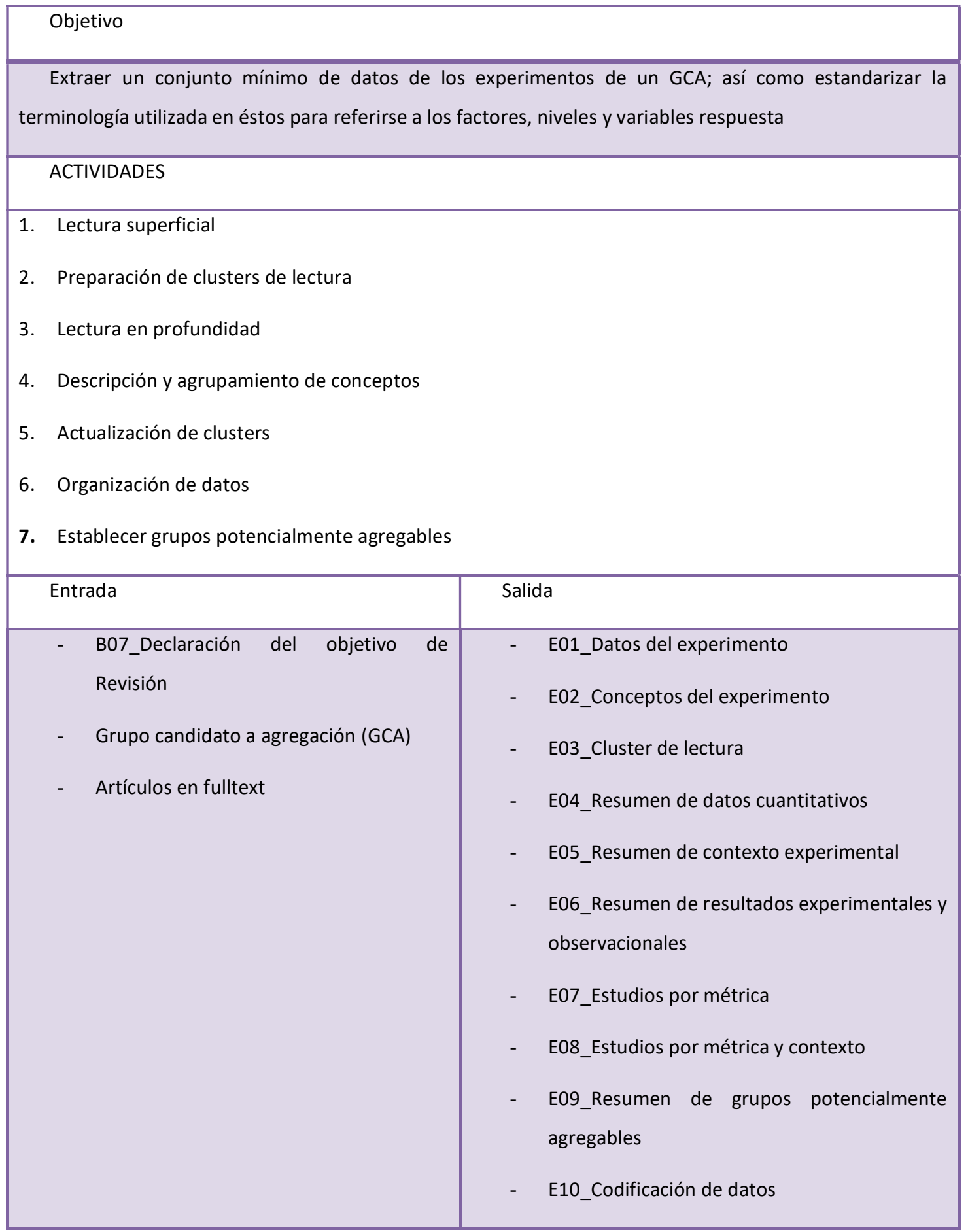




\section{- 2.1. LECTURA SUPERFICIAL}

\begin{tabular}{|l|l|l|}
\hline \multicolumn{2}{|c|}{ Objetivo } \\
terminología utilizada en éstos para referirse a los factores, niveles y variables respuesta \\
\hline Entrada & Salida \\
\hline - B07_Declaración del objetivo de Revisión & E01_Datos del Experimento (parcial) \\
\hline - Grupo candidato a agregación (GCA) & & Salidas \\
\hline Tartículos en fulltext & Entradas & \\
\hline
\end{tabular}

Durante esta actividad se extrajeron los datos básicos de cada uno de los $\mathbf{3 4}$ estudios seleccionados en la fase anterior; a fin de extraer los siguientes datos:

\begin{tabular}{|c|c|c|}
\hline - Identificación & - & Variables respuesta \\
\hline - Objetivo & - & Tipo de estudio \\
\hline Tópico & - & Tarea experimental \\
\hline - Factores & - & Sujetos experimentales \\
\hline - Niveles & - & Replicación \\
\hline
\end{tabular}

Por razones de restricciones de espacio, se mostrarán los formularios E01_Datos del experimento completamente llenos en la actividad Lectura en profundidad.

Como producto de este actividad, se eliminaron los siguientes artículos: 
Una vez que se ha realizado la lectura superficial de todos los experimentos de un GCA:

- Se cuenta con experimentos suficientes para continuar con el proceso.

- Se han excluido todos los experimentos del GCA en virtud de su baja calidad de reporte, lo cual hace imposible extraer al menos los datos más básicos y, en consecuencia, impedirá que un experimento pueda participar en la agregación. 


\section{- 2.2. PREPARACIÓN DE CLUSTERS DE LECTURA}

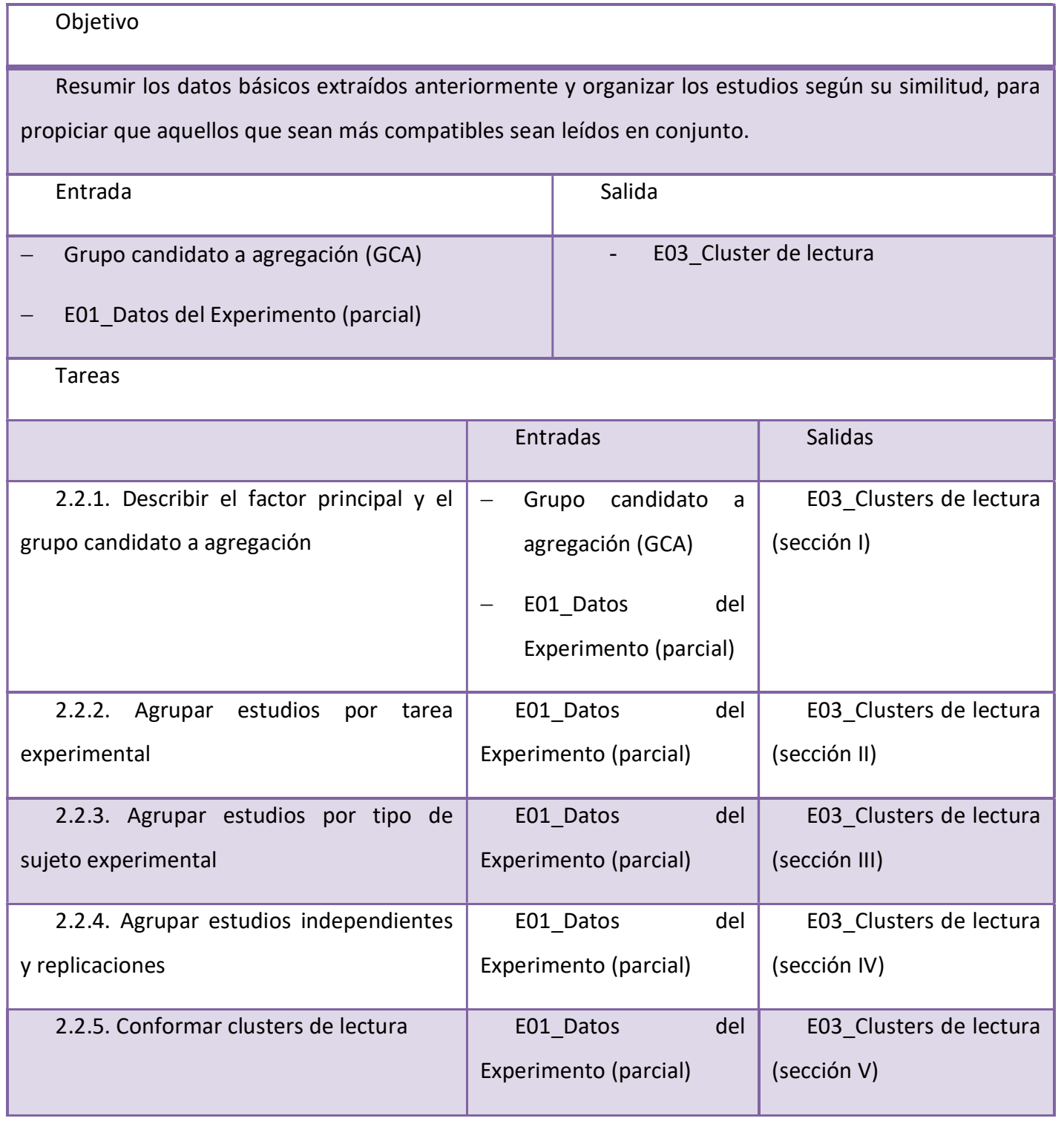

Para el GCA que fue seleccionado a partir del ST-1, se registro un formulario E03 con los agrupamientos correspondientes según las secciones indicadas. A continuación, cada una de las tareas realizadas para cumplimentar el formulario.

\subsubsection{Describir el factor principal y el grupo candidato a agregación}


El formulario E03 corresponde a un GCA, el cual es identificado al inicio del mismo, como se muestra a continuación.

CLUSTERS DE LECTURA

\begin{tabular}{|c|c|}
\hline \begin{tabular}{ll|} 
GRUPO CANDIDATO A \\
AGREGACIÓN:
\end{tabular} & ST1 \\
\hline FACTOR: & Técnicas de lectura/métodos de inspección \\
\hline
\end{tabular}

\subsubsection{Agrupar estudios por tarea experimental}

A continuación, se cumplimenta la sección I del formulario AGRUPAMIENTO POR TAREA EXPERIMENTAL.

Tabla A.11 Agrupamiento por tarea experimental

\begin{tabular}{|c|c|}
\hline TAREA & 322. ESTUDIOS \\
\hline Requisitos & $\begin{array}{l}\text { ART_01, ART_11, ART_14, ART_27, ART_39, ART_44, ART_45, ART_54, } \\
\text { ART_75, ART_78, ART_80, ART_81, ART_83 }\end{array}$ \\
\hline Diseño & ART_08, ART_17, ART_19, ART_25, ART_46 \\
\hline $\begin{array}{l}\text { Diseño con } \\
\text { UML }\end{array}$ & ART_18, ART_28, ART_82, \\
\hline Código & ART_23a, ART_23b, ART_23c, ART_85 \\
\hline Usabilidad & ART_87 \\
\hline
\end{tabular}




\subsubsection{Agrupar estudios por tipo de sujeto experimental}

A continuación, se cumplimenta la sección II del formulario AGRUPAMIENTO POR TIPO DE SUJETO EXPERIMENTAL.

Tabla A.12 Agrupamiento por tipo de sujeto

\begin{tabular}{|c|c|c|}
\hline \multicolumn{2}{|c|}{ GRUPO CANDIDATO A AGREGACIÓN: } & ST1 \\
\hline FACTOR: & & Técnicas de lectura/métodos de inspección \\
\hline TAREA & $\begin{array}{l}\text { 323. TIPO DE } \\
\text { SUJETO }\end{array}$ & 324. ESTUDIOS \\
\hline \multirow[t]{2}{*}{ Requisitos } & ESTUDIANTES & $\begin{array}{l}\text { ART_01, ART_11, ART_14, ART_27, ART_44, } \\
\text { ART_45, ART_54, ART_75, ART_78, ART_80, ART_39 }\end{array}$ \\
\hline & PROFESIONALES & ART_81 \\
\hline \multirow[t]{2}{*}{ Diseño } & ESTUDIANTES & ART_08, ART_17, ART_19, ART_25, ART_46 \\
\hline & PROFESIONALES & \\
\hline \multirow[t]{2}{*}{$\begin{array}{l}\text { Diseño con } \\
\text { UML }\end{array}$} & ESTUDIANTES & $\begin{array}{l}\text { ART_18, ART_28, ART_40, ART_42, ART_ 73, } \\
\text { ART_82 }\end{array}$ \\
\hline & PROFESIONALES & \\
\hline \multirow[t]{2}{*}{ Código } & ESTUDIANTES & ART_23a, ART_23b, ART_23c, ART_85, ART_86 \\
\hline & PROFESIONALES & \\
\hline
\end{tabular}

\subsubsection{Agrupar estudios independientes y replicaciones}

A continuación, se cumplimenta la sección III del formulario AGRUPAMIENTO POR REPLICACIONES y por NIVELES/VR - ESTUDIOS INDEPENDIENTES.

Tabla A.13. Agrupamiento por replicaciones 
Proceso de RS de experimentos en Ingeniería del Software

\begin{tabular}{|c|c|c|c|c|c|c|}
\hline \multicolumn{3}{|c|}{ GRUPO CANDIDATO A AGREGACIÓN: } & \multicolumn{4}{|l|}{ ST1 } \\
\hline \multicolumn{3}{|c|}{ FACTOR: } & \multicolumn{4}{|c|}{ Técnicas de lectura/métodos de inspección } \\
\hline \multicolumn{3}{|c|}{ TIPO DE SUJETO EXPERIMENTAL } & \multicolumn{4}{|c|}{ Estudiantes, Profesionales } \\
\hline \multicolumn{3}{|c|}{ TAREA EXPERIMENTAL } & \multicolumn{4}{|c|}{ Requisitos } \\
\hline $\begin{array}{l}\text { GR } \\
\text { UPO }\end{array}$ & $\begin{array}{l}\text { ESTUDIO } \\
\text { ORIGINAL }\end{array}$ & REP & ICACIONE & NIVELES & $\begin{array}{l}\text { VARIABLE } \\
\text { RESPUESTA }\end{array}$ & A \\
\hline \multirow[t]{4}{*}{$\mathrm{R} 1$} & \multirow[t]{4}{*}{ ART_27 } & \multirow{4}{*}{\multicolumn{2}{|c|}{$\begin{array}{l}\text { ART_78, ART_45, } \\
\text { ART_80, } \\
\text { (profes.) }\end{array}$}} & \multirow[t]{4}{*}{$\begin{array}{r}\text { CBR, } \\
A H, S B R\end{array}$} & \multirow[t]{2}{*}{$\begin{array}{l}\text { Efectivida } \\
\text { d método }\end{array}$} & $\begin{array}{l}\text { Tasa } \\
\text { individual } \\
\text { de } \\
\text { detección } \\
\text { de fallos }\end{array}$ \\
\hline & & & & & & $\begin{array}{l}\text { Tasa } \\
\text { grupal de } \\
\text { detección } \\
\text { de fallos }\end{array}$ \\
\hline & & & & & \multirow[t]{2}{*}{$\begin{array}{l}\text { Efectivida } \\
\text { d reunión }\end{array}$} & $\begin{array}{l}\text { Tasa de } \\
\text { ganancia de } \\
\text { reunions }\end{array}$ \\
\hline & & & & & & $\begin{array}{l}\text { Tasa de } \\
\text { pérdida de } \\
\text { reunions }\end{array}$ \\
\hline $\mathrm{R} 2$ & ART_39 & ART & 75 & $\begin{array}{l}\text { CBR, } \\
\text { SBR }\end{array}$ & Precisión & \\
\hline \multirow[t]{2}{*}{ R3 } & \multirow[t]{2}{*}{ ART_19 } & \multirow{2}{*}{\multicolumn{2}{|c|}{ ART_08 }} & $\begin{array}{l}\text { CBR, } \\
\text { UBR }\end{array}$ & $\begin{array}{l}\text { Efectivida } \\
\text { d método }\end{array}$ & \\
\hline & & & & & $\begin{array}{l}\text { Eficiencia } \\
\text { método }\end{array}$ & \\
\hline
\end{tabular}

Tabla A.14. Agrupamiento de estudios independientes 
Software

\begin{tabular}{|c|c|c|c|c|c|}
\hline \multicolumn{3}{|c|}{ AGREGACIÓN: } & \multicolumn{3}{|l|}{ ST1 } \\
\hline \multicolumn{3}{|c|}{ FACTOR: } & \multicolumn{3}{|c|}{ Técnicas de lectura/métodos de inspección } \\
\hline \multicolumn{3}{|c|}{ TIPO DE SUJETO EXPERIMENTAL } & \multicolumn{3}{|c|}{ Estudiantes } \\
\hline \multicolumn{3}{|c|}{ TAREA EXPERIMENTAL } & \multicolumn{3}{|c|}{ Diseño con UML } \\
\hline $\begin{array}{l}\text { GRUP } \\
\text { O }\end{array}$ & NIVELES & \multicolumn{2}{|c|}{$\begin{array}{l}\text { VARIABLE } \\
\text { RESPUESTA }\end{array}$} & MÉTRICA & ARTíCULOS \\
\hline G1 & CBR, PBR & \multicolumn{2}{|c|}{ EFECTIV. METODO } & & $\begin{array}{c}\text { ART_18, } \\
\text { ART_28, ART_42 }\end{array}$ \\
\hline
\end{tabular}

\begin{tabular}{|c|c|c|c|c|c|}
\hline \multicolumn{3}{|c|}{ AGREGACIÓN: } & \multicolumn{3}{|l|}{ ST1 } \\
\hline \multicolumn{3}{|c|}{ FACTOR: } & \multicolumn{3}{|c|}{ Técnicas de lectura/métodos de inspección } \\
\hline \multicolumn{3}{|c|}{ TIPO DE SUJETO EXPERIMENTAL } & \multicolumn{3}{|c|}{ Estudiantes } \\
\hline \multicolumn{3}{|c|}{ TAREA EXPERIMENTAL } & \multicolumn{3}{|l|}{ Diseño } \\
\hline $\begin{array}{ll} & \text { GRUP } \\
\mathrm{O} & \end{array}$ & NIVELES & & $\begin{array}{l}\text { BLE } \\
\text { TA }\end{array}$ & MÉTRICA & ARTÍCULOS \\
\hline \multirow[t]{3}{*}{ G2 } & \multirow[t]{3}{*}{ CBR, PBR } & \multicolumn{2}{|c|}{ EFECTIV. METODO } & & $\begin{array}{c}\text { ART_17, } \\
\text { ART_25, ART_46 }\end{array}$ \\
\hline & & \multicolumn{2}{|c|}{ COSTE } & & $\begin{array}{l}\text { ART_17, } \\
\text { ART_46 }\end{array}$ \\
\hline & & \multicolumn{2}{|c|}{ TIEMPO } & & $\begin{array}{l}\text { ART_17, } \\
\text { ART_46 }\end{array}$ \\
\hline G3 & CBR, UBR & \multicolumn{2}{|c|}{ EFECTIV. METODO } & & $\begin{array}{l}\text { ART_40, } \\
\text { ART_44 }\end{array}$ \\
\hline
\end{tabular}




\subsubsection{Conformar clusters de lectura}

A continuación, se cumplimenta la sección CLUSTERS DE LECTURA que surgen del agrupamiento anterior.

\begin{tabular}{|c|c|c|c|c|c|c|c|c|c|c|c|c|}
\hline \multicolumn{2}{|c|}{ REQUISITOS } & \multicolumn{5}{|c|}{ NIVELES ENSAYADOS } & \multicolumn{6}{|c|}{ VARIABLES RESPUESTA } \\
\hline 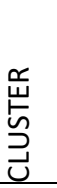 & 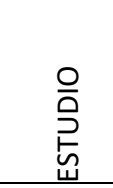 & $\stackrel{\mathscr{c}}{\mathscr{\cup}}$ & $\frac{\mathscr{c}}{\emptyset}$ & 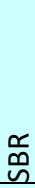 & $\begin{array}{l}\stackrel{\mathscr{m}}{\mathcal{I}} \\
\end{array}$ & $\frac{I}{<}$ & 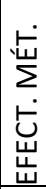 & 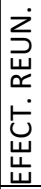 & $\begin{array}{l}z \underline{0} \\
\underline{\underline{n}} \\
\underline{u} \\
\underline{u} \\
\alpha\end{array}$ & 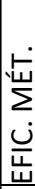 & 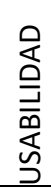 & 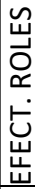 \\
\hline \multirow[t]{2}{*}{1.1} & $\mathrm{R} 1$ & $x$ & & $\mathrm{x}$ & & $x$ & $x$ & $x$ & & & & \\
\hline & ART_14 & $\mathrm{X}$ & & $x$ & & $\mathrm{x}$ & $x$ & & & & & \\
\hline \multirow[t]{2}{*}{1.2} & R2 & $x$ & & $x$ & & & & & $x$ & & & \\
\hline & ART_54 & $x$ & & $x$ & & & & & $x$ & & & \\
\hline \multirow[t]{2}{*}{1.3} & R3 & $\mathrm{X}$ & & & $x$ & & $\mathrm{X}$ & & & $x$ & & \\
\hline & ART_44 & $\mathrm{X}$ & & & $x$ & & $\mathrm{X}$ & & & & & \\
\hline 1.4 & ART_01 & $x$ & $\mathrm{X}$ & & & & $x$ & & & $x$ & & \\
\hline 1.5 & ART_11 & $\mathrm{x}$ & & & & $\mathrm{X}$ & & $\mathrm{X}$ & & & & $x$ \\
\hline 1.6 & ART_83 & & & $x$ & & & & & & & $x$ & \\
\hline
\end{tabular}

\begin{tabular}{|c|c|c|c|c|c|c|c|c|}
\hline \multicolumn{2}{|c|}{ CODIGO } & \multicolumn{4}{|c|}{ NIVELES ENSAYADOS } & \multicolumn{3}{|c|}{ VAR. RESPTA. } \\
\hline 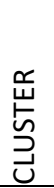 & 음 & $\frac{\mathscr{c}}{\mathscr{U}}$ & $\begin{array}{l}\frac{r}{0} \\
a\end{array}$ & $\begin{array}{l}\text { 号 } \\
\text { 号 } \\
\text { 号 }\end{array}$ & $\tilde{\mathscr{\alpha}}$ & 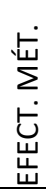 & 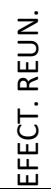 & 岕 \\
\hline 2.1 & ART_85 & $x$ & $x$ & & & $\mathrm{X}$ & $x$ & $x$ \\
\hline 2.2 & ART_23 & $x$ & & $x$ & $x$ & $X$ & & \\
\hline
\end{tabular}




\begin{tabular}{|l|l|l|l|l|l|l|l|l|l|}
\hline 2.3 & ART_86 & & $\mathrm{X}$ & & & & $\mathrm{X}$ & & \\
\hline
\end{tabular}

\begin{tabular}{|c|c|c|c|c|c|c|c|c|c|c|}
\hline \multicolumn{2}{|c|}{ UML } & \multicolumn{4}{|c|}{ NIVELES ENSAYADOS } & \multicolumn{5}{|c|}{ VAR. RESPTA } \\
\hline 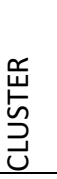 & $\begin{array}{c}\text { 음 } \\
\stackrel{5}{5} \\
\text { w }\end{array}$ & 恖 & $\begin{array}{l}\text { 商 } \\
\text { a }\end{array}$ & 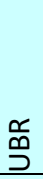 & $\begin{array}{l}\text { 品 } \\
\text { Q }\end{array}$ & 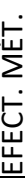 & 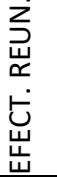 & 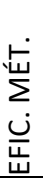 & 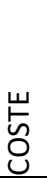 & $\sum_{\text {쓸 }}^{\circ}$ \\
\hline 3.1 & ART_82 & $x$ & & & $x$ & $\mathrm{x}$ & & & & \\
\hline \multirow[t]{3}{*}{3.2} & ART_18 & $x$ & $x$ & & & $\mathrm{x}$ & $x$ & & $\mathrm{x}$ & \\
\hline & ART_28 & $\mathrm{x}$ & $\mathrm{x}$ & & & $\mathrm{x}$ & $\mathrm{x}$ & & & \\
\hline & ART_42 & $\mathrm{x}$ & $\mathrm{x}$ & & & $\mathrm{x}$ & & & & \\
\hline 3.3 & ART_73 & & & $\mathrm{X}$ & & $\mathrm{x}$ & & $\mathrm{X}$ & & $x$ \\
\hline
\end{tabular}

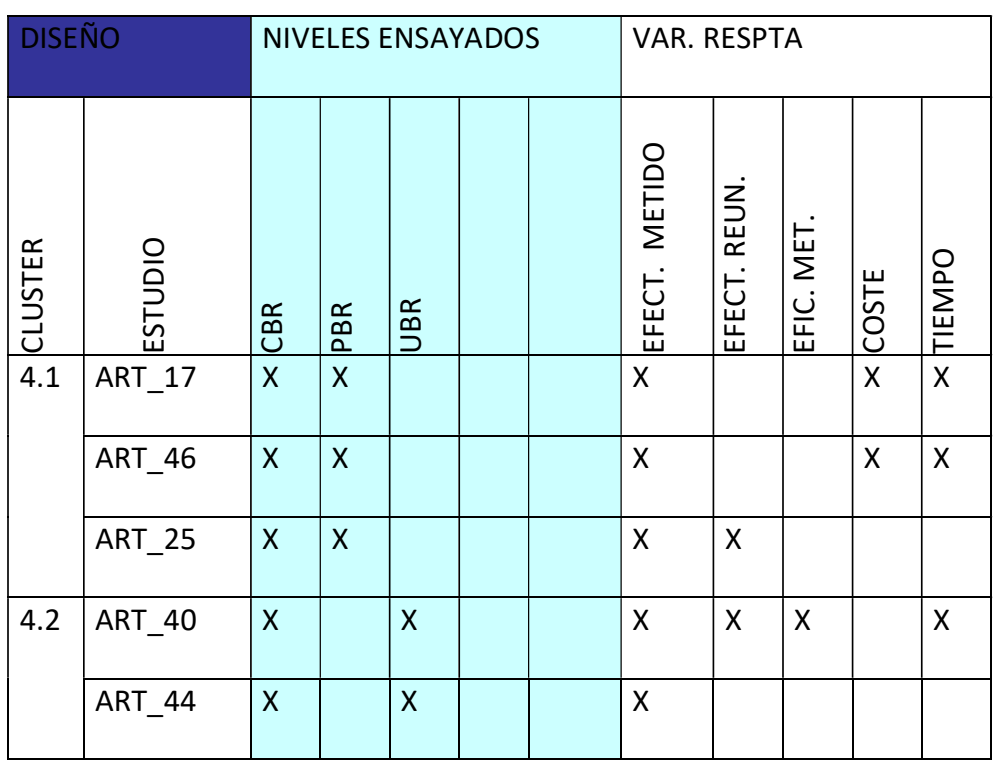

\begin{tabular}{|l|l|l|}
\hline USABILIDAD & NIVELES ENSAYADOS & VAR. RESPTA \\
\hline
\end{tabular}


Proceso de RS de experimentos en Ingeniería del Software

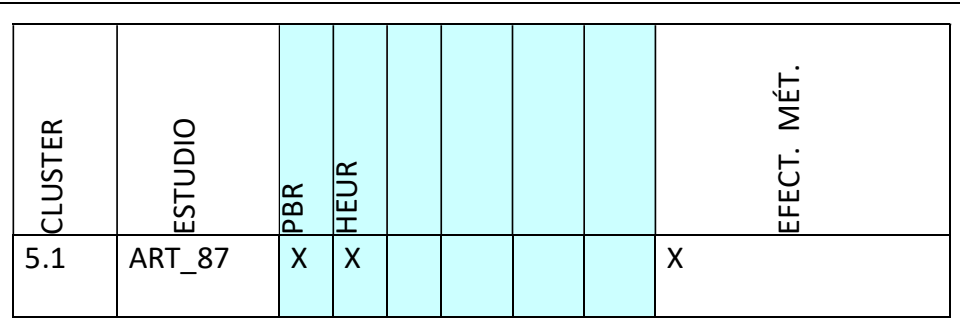




\section{- 2.3. LECTURA EN PROFUNDIDAD}

\begin{tabular}{|c|c|c|}
\hline \multicolumn{3}{|l|}{ Objetivo } \\
\hline \multicolumn{3}{|c|}{$\begin{array}{l}\text { Extraer el resto de las características relevantes de los experimentos seleccionados necesarios tanto } \\
\text { para valorar la calidad del estudio como para agregar sus resultados experimentales con los resultados } \\
\text { de otros experimentos similares. }\end{array}$} \\
\hline Entrada & \multicolumn{2}{|l|}{ Salida } \\
\hline E03_Clusters de lectura & \multicolumn{2}{|c|}{ E03_Clusters de lectura (actualizado) } \\
\hline Artículos en fulltext & \multicolumn{2}{|c|}{ E01_Datos del exprimento (actualizado) } \\
\hline \multicolumn{3}{|l|}{ Tareas } \\
\hline & Entradas & Salidas \\
\hline 2.3.1. Depurar los clusters de lectura & $\begin{array}{l}\text { E03_Clusters de } \\
\text { lectura }\end{array}$ & $\begin{array}{l}\text { E03_Clusters de lectura } \\
\text { (actualizados) }\end{array}$ \\
\hline 2.3.2. Planificar la lectura & $\begin{array}{c}\text { E03_Clusters de } \\
\text { lectura (actualizados) }\end{array}$ & Orden del lectura \\
\hline 2.3.3. Leer & $\begin{array}{l}\text { Orden del lectura } \\
\text { Fulltexts }\end{array}$ & $\begin{array}{l}\text { E01_Datos del } \\
\text { exprimento (actualizado) } \\
\text { E03_Clusters de lectura } \\
\text { (actualizados) }\end{array}$ \\
\hline
\end{tabular}

\section{- 2.3.1. Depurar clusters de lectura}

A continuación se eliminan a los artículos que aparecen en solitario tanto para una comparación de niveles como para una métrica o VR: ART_83, ART_86, ART_73, ART_87.

Tabla A.16. Clusters de lectura (depurado)

\begin{tabular}{|c|c|c|c|c|c|c|c|c|c|c|c|c|}
\hline \multicolumn{2}{|c|}{ CLUSTERS } & \multicolumn{5}{|c|}{ NIVELES ENSAYADOS } & \multicolumn{6}{|c|}{ VARIABLES RESPUESTA } \\
\hline 으 & $\begin{array}{l}\frac{0}{0} \\
\frac{5}{5} \\
\frac{5}{4}\end{array}$ & 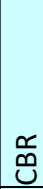 & 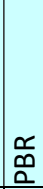 & $\begin{array}{l}\text { 咩 } \\
\text { w }\end{array}$ & $\begin{array}{l}\text { 哈 } \\
\end{array}$ & $\frac{\mathrm{T}}{\mathrm{L}}$ & 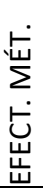 & 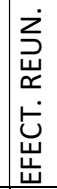 & 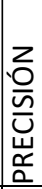 & $\begin{array}{l}\sum_{\mathbf{U}} \\
\underline{\underline{U}} \\
\vec{W}\end{array}$ & 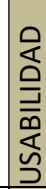 & 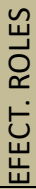 \\
\hline 1. & R1 & $x$ & & $x$ & & $\bar{x}$ & $x$ & $x$ & & & & \\
\hline
\end{tabular}



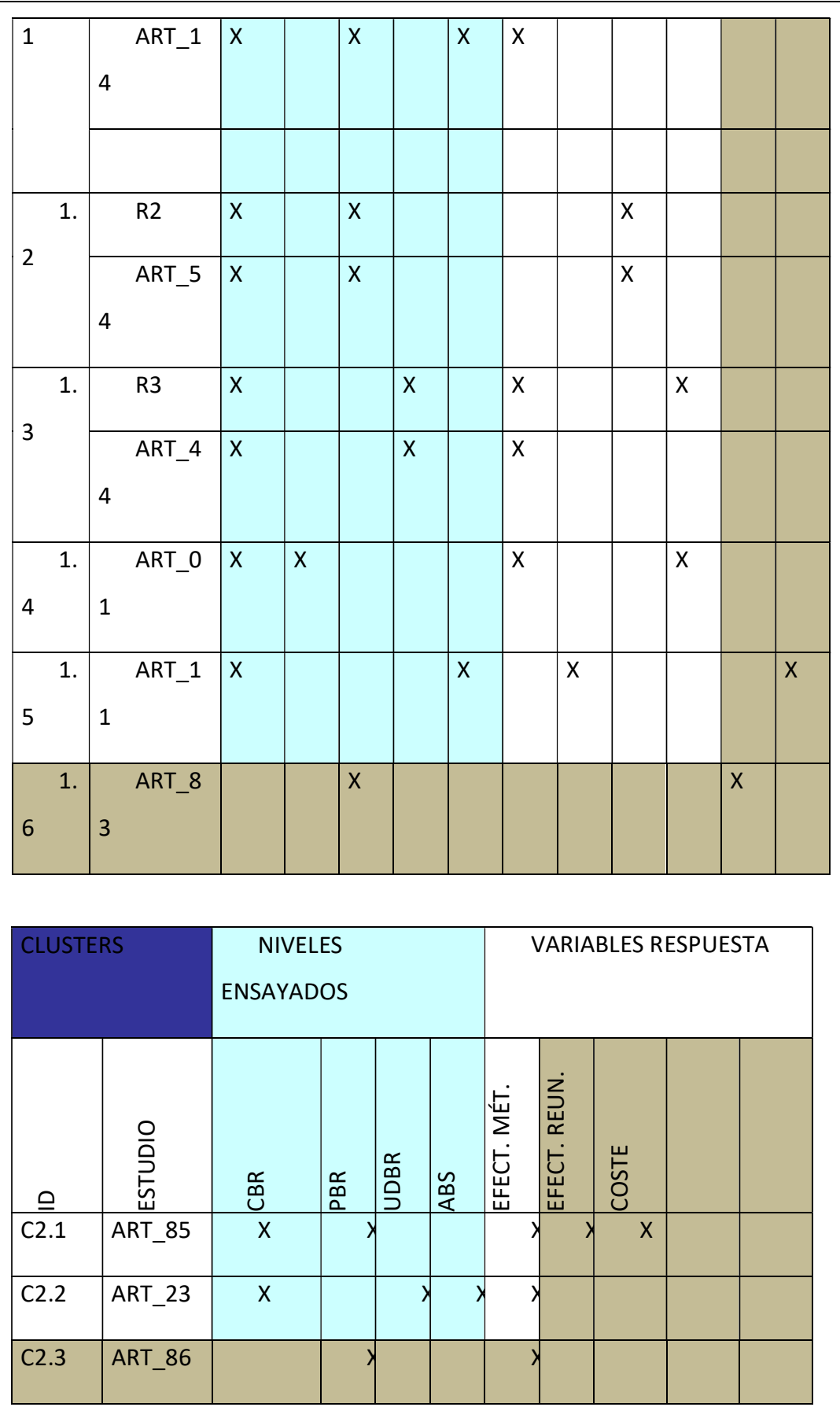

\begin{tabular}{|c|c|c|}
\hline CLUSTERS & NIVELES \\
ENSAYADOS & VARIABLES \\
& RESPUESTA \\
\hline
\end{tabular}



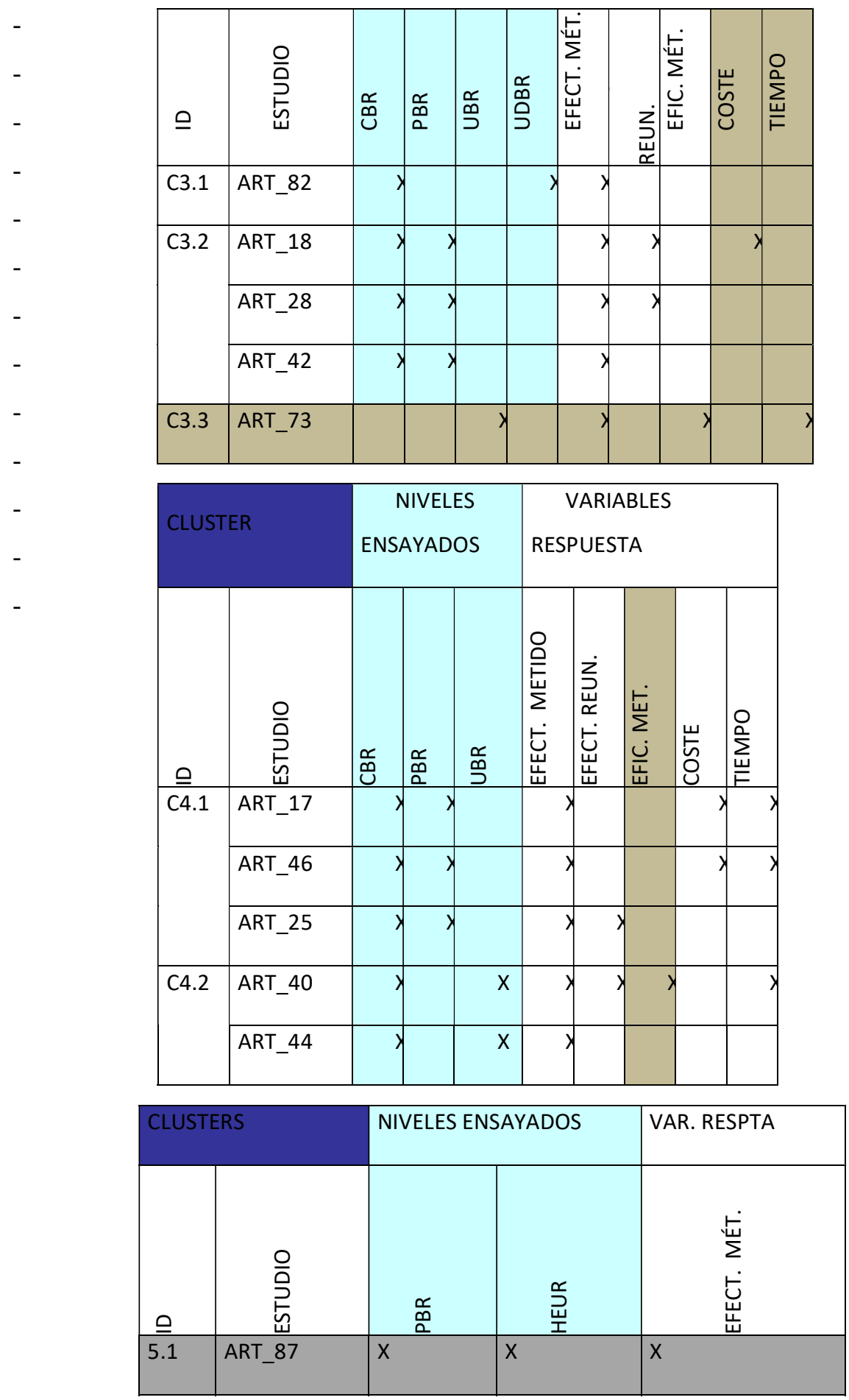
- 2.3.2. Planificar la lectura

La tabla A.17 muestra el orden de lectura propuesto con base en las similitudes de los estudios preseleccionados.

Tabla A.17. Orden de lectura propuesto

\begin{tabular}{|c|c|}
\hline Tarea & VR / Orden de lectura \\
\hline Requisitos & 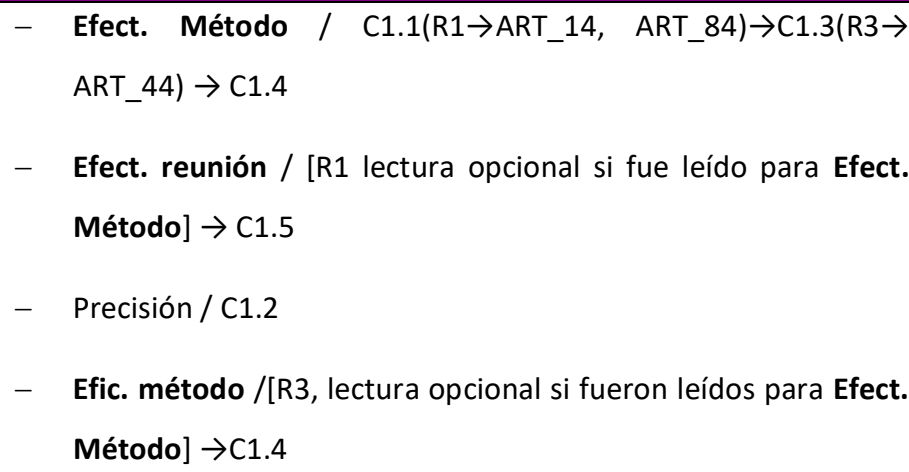 \\
\hline Código & Efect. Método / C2.1 $\rightarrow$ C2.2 \\
\hline Diseño & 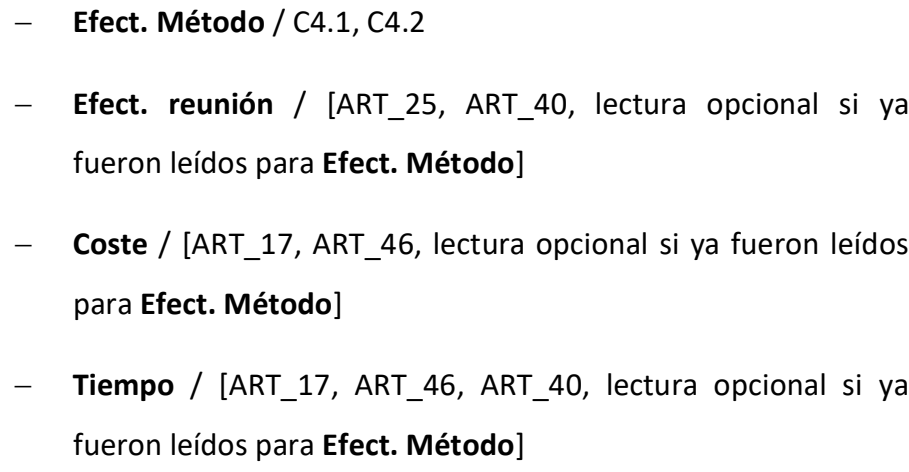 \\
\hline Diseño con UML & $\begin{array}{ll}- & \text { Efect. Método / C3.1 } \rightarrow \text { C3.2 } \\
\text { - } & \text { Efect. reunión / [ART_18, ART_48 lectura opcional si fueron } \\
& \text { leídos para Efect. Método] }\end{array}$ \\
\hline
\end{tabular}

\section{- 2.3.3. Leer}

En esta actividad se realizó la lectura de los estudios en el orden establecido en la actividad anterior, realizando al mismo tiempo la extracción de los datos necesarios para cumplimentar los modelos E01 para cada uno de los estudios. 
Extracción de Datos

Proceso de RS de experimentos en Ingeniería del

Software

Esta lectura permitió también descartar algunos artículos adicionales bien por presentar una calidad de reporte muy pobre, por estar duplicados o por no cumplir con los criterios de I/E. Éste es el caso de los artículos: ART_01, ART_40,ART_42, ART_46.

Los modelos E01 completados se encuentran al final de este apéndice 
Proceso de RS de experimentos en Ingeniería del Software

\subsection{Descripción y agrupamiento de conceptos}

Objetivo

\begin{tabular}{|l|l|l|}
\hline \multicolumn{2}{|l|}{} & Salida \\
\hline Entrada & \\
\hline Tareas & Entradas & Salidas \\
\hline & & \\
\hline & & \\
\hline & & \\
\hline & & \\
\hline
\end{tabular}

$-$ 


\subsection{ActualizaCIÓN de GRUPOS PARA LECTURA}

\begin{tabular}{|l|l|l|}
\hline \multicolumn{2}{|l|}{ Objetivo } & \multicolumn{2}{|c|}{ Salida } \\
\hline \multicolumn{2}{|c|}{ Revisar y modificar los clusters que han sido establecidos al comienzo de la FASE DE EXTRACCIÓN } \\
\hline Entrada & - E03_Clusters de lectura (actualizados) \\
\hline$-\quad$ E03_Clusters de lectura & - Orden de lectura & Salidas \\
\hline E01_Datos del experimento & Entradas & \\
\hline
\end{tabular}

A continuación se realizaron los cambios en los distintos clusters de lectura con base en los criterios de I/E y la lectura en profundidad. Fueron actualizadas varias secciones del modelo E03, incluyendo el agrupamiento de replicaciones y estudios independientes, además de los clusters de lectura.

\begin{tabular}{|c|c|c|c|c|c|}
\hline TAREA & \multicolumn{5}{|l|}{ Requisitos } \\
\hline SUJETOS & \multicolumn{5}{|l|}{ Estudiantes } \\
\hline FACTOR & \multicolumn{5}{|c|}{ Métodos de inspección de software } \\
\hline GRUPO & ESTUDIO ORIGINAL & REPLICACIONES & NIVELES & VR & Métrica \\
\hline \multirow[t]{2}{*}{ R1 } & \multirow[t]{2}{*}{ ART_27 } & \multirow[t]{2}{*}{$\begin{array}{l}\text { ART_78, ART_45, } \\
\text { ART_80 } \\
\text { (extensión), } \\
\text { ART_81 } \\
\text { (practitioners) }\end{array}$} & \multirow[t]{2}{*}{$\begin{array}{l}\text { CBR, } A H, \\
\text { SBR: } 27, \\
78,81\end{array}$} & $\begin{array}{l}\text { Efectividad } \\
\text { método: } 27,78,81\end{array}$ & $\begin{array}{l}\text { Tasa ind de } \\
\text { detección de } \\
\text { fallas x tipo de } \\
\text { falla } \\
\text { Tasa grupal de } \\
\text { detección de } \\
\text { fallas } x \text { tipo de } \\
\text { falla }\end{array}$ \\
\hline & & & & $\begin{array}{l}\text { Efectividad } \\
\text { reunión: } 27,78,81\end{array}$ & $\begin{array}{ll}\text { Ganancia de } \\
\text { reuniones }\end{array}$ \\
\hline
\end{tabular}


Proceso de RS de experimentos en Ingeniería del Software

\begin{tabular}{|c|c|c|c|c|c|}
\hline & & & & & $\begin{array}{l}\text { Pérdida de } \\
\text { reuniones }\end{array}$ \\
\hline & & & \multirow[t]{2}{*}{$\begin{array}{l}\text { CBR, SBR: } \\
45,80,\end{array}$} & $\begin{array}{l}\text { Eficiencia reunión: } \\
45,80\end{array}$ & \\
\hline & & & & $\begin{array}{l}\text { Efectividad } \\
\text { método: } 80,45\end{array}$ & \\
\hline \multirow[t]{2}{*}{ R2 } & \multirow[t]{2}{*}{ ART_39 } & \multirow[t]{2}{*}{ ART_75 } & \multirow[t]{2}{*}{$\begin{array}{l}\text { CBR } \\
\text { SBR }\end{array}$} & $\begin{array}{l}\text { Efectividad } \\
\text { método: } 39,75\end{array}$ & $\begin{array}{l}\text { Tasa ind de } \\
\text { detección de } \\
\text { fallas }\end{array}$ \\
\hline & & & & $\begin{array}{l}\text { Eficiencia método: } \\
75\end{array}$ & \\
\hline
\end{tabular}

\begin{tabular}{|c|c|c|c|c|c|}
\hline TAREA & \multicolumn{5}{|l|}{ Diseño } \\
\hline SUJETOS & \multicolumn{5}{|l|}{ Estudiantes } \\
\hline FACTOR & \multicolumn{5}{|c|}{ Métodos de inspección de software } \\
\hline GRUPO & ESTUDIO ORIGINAL & REPLICACIONES & NIVELES & VR & Métrica \\
\hline \multirow[t]{2}{*}{ R3 } & \multirow[t]{2}{*}{ ART_19 } & \multirow[t]{2}{*}{ ART_08 } & \multirow[t]{2}{*}{ CBR, UBR } & $\begin{array}{l}\text { Efectividad } \\
\text { método: 19, } 08\end{array}$ & $\begin{array}{l}\text { Number of } \\
\text { faults found }\end{array}$ \\
\hline & & & & $\begin{array}{l}\text { Eficiencia método: } \\
19,08\end{array}$ & $\begin{array}{l}\text { Time spent } \\
\text { Clock time }\end{array}$ \\
\hline
\end{tabular}

\begin{tabular}{|c|c|c|c|c|}
\hline TAREA & \multicolumn{4}{|l|}{ Requisitos } \\
\hline SUJETOS & \multicolumn{4}{|c|}{ Estudiantes } \\
\hline FACTOR & \multicolumn{4}{|c|}{ Métodos de inspección de software } \\
\hline GRUPO & NIVELES & VR & MÉTRICA & ARTÍCULOS \\
\hline G1 & $\begin{array}{ll}\mathrm{CBR}, & \mathrm{SBR}, \\
\mathrm{AH} & \end{array}$ & Efectividad método & $\begin{array}{l}\text { Tasa grupal de detección de } \\
\text { fallas / Tipo de falla }\end{array}$ & ART_14 \\
\hline G2 & SBR & Usabilidad & Usabilidad de un framework & ART_83 \\
\hline
\end{tabular}

Caso de estudio 


\begin{tabular}{|l|l|l|l|l|}
\hline G3 & AH, CBR & Efectividad roles & Efectividad roles & ART_11 \\
\cline { 3 - 5 } & & Efectividad método & $\begin{array}{l}\text { Tasa de detección de } \\
\text { defectos }\end{array}$ & ART_11 \\
\cline { 3 - 5 } & & Capacidad de detección & ART_11 \\
\hline G4 & CBR, UBR & Efectividad método & Efectividad individual & ART_44 \\
\cline { 4 - 6 } & & & Efectividad grupal & ART_44 \\
\hline
\end{tabular}

\begin{tabular}{|c|c|c|c|c|c|c|c|c|c|c|c|c|}
\hline \multicolumn{2}{|c|}{ REQUISITOS } & \multicolumn{5}{|c|}{ NIVELES ENSAYADOS } & \multicolumn{6}{|c|}{ VR } \\
\hline $\begin{array}{l}\text { 怠 } \\
\text { 号 } \\
\text { U. }\end{array}$ & $\begin{array}{l}\frac{0}{0} \\
\frac{5}{5} \\
\stackrel{5}{4}\end{array}$ & 吕 & 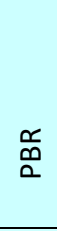 & 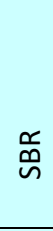 & 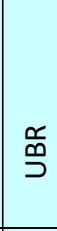 & 岳 & 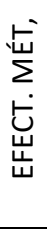 & 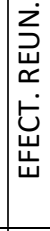 & 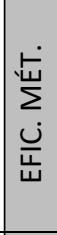 & 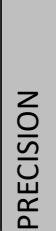 & 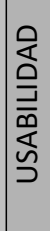 & 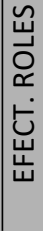 \\
\hline \multirow[t]{2}{*}{1.1} & R1 & $\mathrm{x}$ & & $\mathrm{x}$ & & $\mathrm{x}$ & $\mathrm{x}$ & $x$ & & & & \\
\hline & $4_{4}{ }^{\text {ART_1 }}$ & $\mathrm{x}$ & & $\mathrm{x}$ & & $\mathrm{x}$ & $\mathrm{x}$ & & & & & \\
\hline \multirow[t]{2}{*}{1.2} & R2 & $\mathrm{x}$ & & $\mathrm{X}$ & & & $\mathrm{X}$ & & & $\mathrm{X}$ & & \\
\hline & ART_54 & $\mathrm{X}$ & & $\mathrm{x}$ & & & & & & $\mathrm{X}$ & & \\
\hline 1.3 & ART_44 & $\mathrm{x}$ & & & $x$ & & $\mathrm{x}$ & & & & & \\
\hline 1.5 & ART_1 & $x$ & & & & $\mathrm{x}$ & & $x$ & & & & $\mathrm{x}$ \\
\hline & 1 & & & & & & & & & & & \\
\hline
\end{tabular}

\begin{tabular}{|c|c|c|c|c|c|c|c|c|}
\hline \multicolumn{2}{|c|}{ CODIGO } & \multicolumn{4}{|c|}{ NIVELES ENSAYADOS } & \multicolumn{3}{|c|}{ VR } \\
\hline 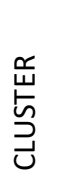 & 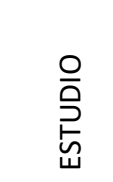 & $\begin{array}{l}\stackrel{\circ}{0} \\
\stackrel{0}{u}\end{array}$ & $\begin{array}{l}\frac{\mathfrak{c}}{0} \\
\frac{0}{a}\end{array}$ & $\begin{array}{l}\frac{\mathscr{c}}{0} \\
\text { ดे }\end{array}$ & 吕 & 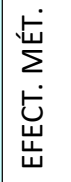 & $\begin{array}{l}\mathrm{w} \\
\text { Оू } \\
\text { Oे }\end{array}$ & 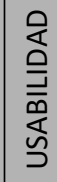 \\
\hline 2.1 & ART_85 & $x$ & & $x$ & $\mathrm{x}$ & $x$ & k & \\
\hline 2.2 & ART_23 & $x$ & $x$ & & & $x$ & K & $y$ \\
\hline
\end{tabular}




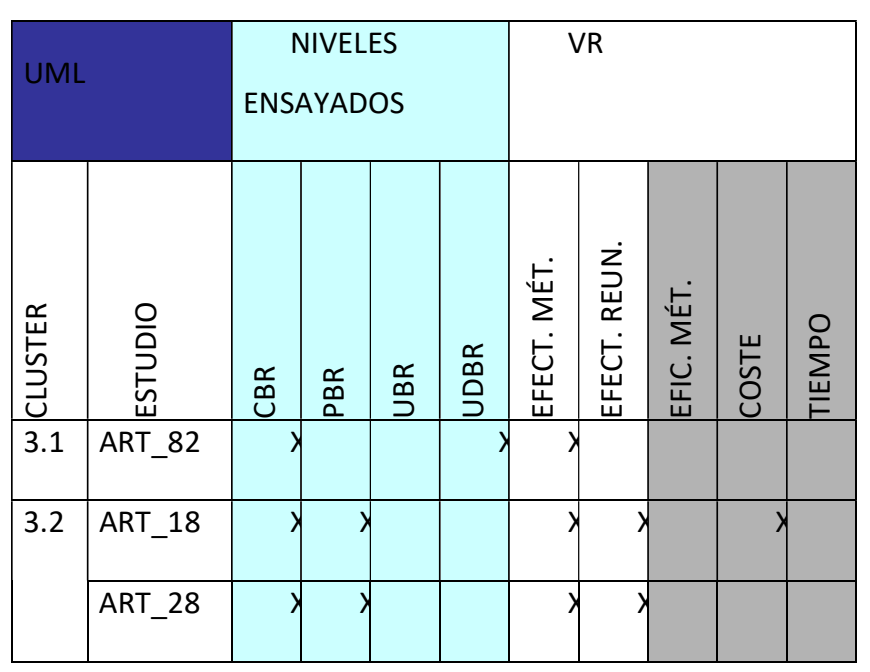

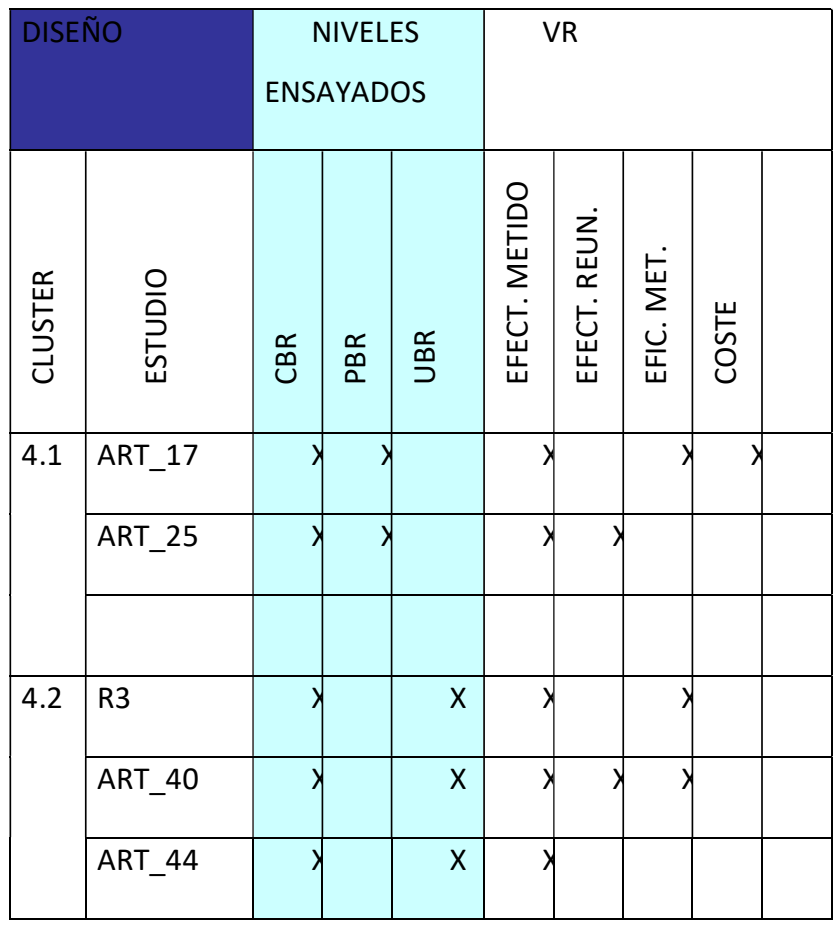

\begin{tabular}{|c|c|c|c|c|}
\hline \multicolumn{2}{|c|}{ USABILIDAD } & \multicolumn{2}{|c|}{$\begin{array}{l}\text { NIVELES } \\
\text { ENSAYADO }\end{array}$} & \\
\hline $\begin{array}{l}\text { 㟧 } \\
\text { 今 } \\
\text { U }\end{array}$ & $\begin{array}{l}\text { 음 } \\
\stackrel{5}{5} \\
\text { 山 }\end{array}$ & 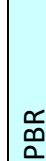 & 愛 & 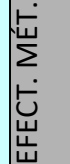 \\
\hline
\end{tabular}




\begin{tabular}{|l|l|l|l|l|l|l|l|l|}
\hline 5.1 & ART_87 & $X$ & $X$ & & & $X$ & & \\
\hline
\end{tabular}

En la tabla XX se resumen los artículos descartados junto con el criterio que justifica su eliminación.

\begin{tabular}{|c|c|c|c|c|c|c|c|c|c|c|c|c|c|c|c|c|c|}
\hline \multirow[b]{2}{*}{ ESTUDIO } & \multicolumn{6}{|c|}{ NIVELES ENSAYADOS } & \multicolumn{7}{|c|}{ VR } & \multicolumn{4}{|c|}{ CRITERIO I/E } \\
\hline & $\begin{array}{l}\frac{1}{\infty} \\
\frac{\infty}{\alpha}\end{array}$ & $\stackrel{\mathscr{c}}{\mathscr{O}}$ & $\frac{I}{<}$ & 号 & $\begin{array}{l}\stackrel{⿰}{\oplus} \\
\stackrel{一}{\supset}\end{array}$ & $\begin{array}{l}\stackrel{⿰}{\mathscr{D}} \\
\sim\end{array}$ & 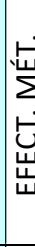 & 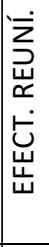 & 岕 & 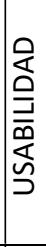 & 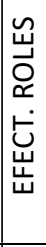 & 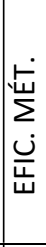 & 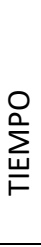 & 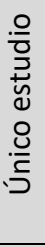 & 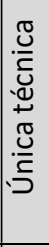 & 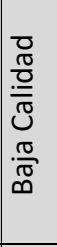 & 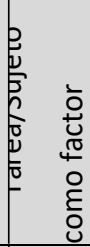 \\
\hline ART_01 & & & & & & & & & & & & & & & & & $x$ \\
\hline ART_40 & & $\mathrm{x}$ & & & $X$ & & & & & & & $\mathrm{x}$ & & $x$ & & & \\
\hline ART_73 & & & & & $x$ & & & & & & & $\mathrm{x}$ & $x$ & $\mathrm{x}$ & $x$ & & \\
\hline ART_83 & & & & & & $x$ & & & & $\mathrm{x}$ & & & & $x$ & $x$ & & \\
\hline ART_85 & $x$ & $\mathrm{X}$ & & & & & & $\mathrm{x}$ & $\mathrm{X}$ & & & & & $x$ & & & \\
\hline ART_86 & $x$ & & & & & & $\mathrm{X}$ & & & & & & & & $\mathrm{x}$ & & \\
\hline ART_87 & $x$ & & & $X$ & & & $X$ & & & & & & & $x$ & & & \\
\hline
\end{tabular}

A continuación es actualizado el orden en que debe realizarse la lectura para optimizar el esfuerzo de los revisores. 
Proceso de RS de experimentos en Ingeniería del Software

\begin{tabular}{|c|c|c|}
\hline Tarea & Cluster & Constructo / Orden de lectura \\
\hline Req. & 1 & $\begin{array}{l}\text { Efect. Método / G1.1(R1 } \rightarrow \text { ART_14 } \rightarrow \mathrm{G} 1.2 \rightarrow \mathrm{G} 1.3 \\
\text { Efect. reunión / [R1 lectura opcional si fue leído para Efect. Método] } \rightarrow \\
\text { G1.5 }\end{array}$ \\
\hline Código & 2 & Efect. Método / G2.1 $\rightarrow$ G2.2 \\
\hline UML & 3 & $\begin{array}{l}\text { Efect. Método / G3.1 } \rightarrow \text { G3.2 } \\
\text { Efect. reunión / [G3.2 lectura opcional si fueron leídos para Efect. } \\
\text { Método] }\end{array}$ \\
\hline Diseño & 4 & $\begin{array}{l}\text { Efect. Método / G4.1, G4.2 (R3 } \rightarrow \text { ART_44) } \\
\text { Efect. reunión / [ART_25, lectura opcional si ya fueron leídos para Efect. } \\
\text { Método] } \\
\text { Eflc. Método / [G4.1(ART_17) } \rightarrow \text { G4.2(R3 } \rightarrow \text { ART_44) opcional si ya fueron } \\
\text { leídos para Efect. Método ] } \\
\text { Coste / [ART_17, lectura opcional si ya fueron leídos para Efect. Método] }\end{array}$ \\
\hline
\end{tabular}




\subsection{Organización de datos}

\begin{tabular}{|c|c|c|}
\hline \multicolumn{3}{|l|}{ Objetivo } \\
\hline \multicolumn{3}{|c|}{$\begin{array}{l}\text { Preparar los datos experimentales extraídos en los formularios para que sean más fácilmente } \\
\text { manipulados y agregados a través del método seleccionado durante la fase de SíNTESIS DE DATOS }\end{array}$} \\
\hline Entrada & Salida & \\
\hline E01_Datos del experimento & \multicolumn{2}{|c|}{$\begin{array}{l}\text { - E10_Codificación de datos } \\
\text { - } \quad \text { E04_Resumen de datos cuantitativos } \\
\text { - E05_Resumen de características del contexto } \\
\text { - E06-Resumen de resultados experimentales y } \\
\text { observacionales }\end{array}$} \\
\hline \multicolumn{3}{|l|}{ Tareas } \\
\hline & Entradas & Salidas \\
\hline 2.6.1. Codificar datos & $\begin{array}{l}\text { E01_Datos } \\
\text { experimento }\end{array}$ & $\begin{array}{l}\text { E10_Codificación de } \\
\text { datos }\end{array}$ \\
\hline $\begin{array}{l}\text { 2.6.2. Resumir datos cuantitativos por } \\
\text { estudio }\end{array}$ & $\begin{array}{l}\text { E01_Datos } \\
\text { experimento }\end{array}$ & $\begin{array}{l}\text { E04_Resumen de datos } \\
\text { cuantitativos }\end{array}$ \\
\hline $\begin{array}{lll}\text { 2.6.3. Resumir características del } \\
\text { contexto }\end{array}$ & $\begin{array}{l}\text { E01_Datos } \\
\text { experimento }\end{array}$ & $\begin{array}{l}\text { E05_Resumen de } \\
\text { características del contexto }\end{array}$ \\
\hline $\begin{array}{c}\text { 2.6.4. Resumir resultados } \\
\text { experimentales y observacionales }\end{array}$ & $\begin{array}{l}\text { E01_Datos } \\
\text { experimento }\end{array}$ & $\begin{array}{l}\text { E06-Resumen de } \\
\text { resultados experimentales } \\
\text { y observacionales }\end{array}$ \\
\hline
\end{tabular}

Esta tarea permitió obtener los datos necesarios para la posterior agregación así como descartar algunos experimentos por presentar una calidad de reporte baja, al no reportar resultados de tipo experimental y observacional que pudieran ser utilizados para la obtención de evidencias secundarias. Tal fue el caso de ART_25, ART_28, ART_54 y ART_75.

\subsubsection{Codificar resultados}

Las tablas A.18 - A.21 presentan la codificación de los estudios seleccionados para la RS, así como los factores, variables respuesta y métricas. 
Tabla A.18. Estudios de la RS codificados

\begin{tabular}{|c|c|c|}
\hline COD & ARTICULO & Fulltext \\
\hline E01 & ART_27 & Xplore_16 \\
\hline E02 & ART_78 & springer_12 \\
\hline E03 & ART_45 & sco_16 \\
\hline E04 & ART_80 & springer_13 \\
\hline E05 & ART_81 & springer_15 \\
\hline E06 & ART_14 & ACM_2 \\
\hline E07 & ART_44 & springer_14 \\
\hline E08 & ART_11 & Xplore_7 \\
\hline E09 & ART_39 & sdirect_4 \\
\hline E10 & ART_75 & Xplore_27 \\
\hline E11 & ART_54 & Xplore_24 \\
\hline E12 & ART_85 & xplore_21 \\
\hline E13 & ART_23a & xplore_15 \\
\hline E14 & ART_23b & xplore_15 \\
\hline E15 & ART_23c & xplore_15 \\
\hline E16 & ART_82 & springer_16 \\
\hline E17 & ART_18 & sdirect_9 \\
\hline E18 & ART_28 & \\
\hline E19 & ART_19 & Xplore_30 \\
\hline E20 & ART_08 & Xplore_5 \\
\hline E21 & ART_17 & Xplore_29 \\
\hline E23 & ART_25 & sdirect_2 \\
\hline
\end{tabular}


Tabla A.19. Niveles del factor principal codificados

\begin{tabular}{|c|c|c|}
\hline FACTORES & CÓDIGO & NIVEL \\
\hline \multirow{8}{*}{$\begin{array}{r}\text { TÉCNICA } \\
\text { (PRINCIPAL) }\end{array}$} & T01 & $\mathrm{Ad} \mathrm{Hoc}(\mathrm{AH})$ \\
\hline & T02 & Checklist-based reading (CBR) \\
\hline & T03 & Scenario-based reading (SBR) \\
\hline & T04 & Usage-based reading (UBR) \\
\hline & T05 & $\begin{array}{l}\text { Abstraction-driven inspection } \\
\text { technique (ADIT) }\end{array}$ \\
\hline & T06 & Use-case Driven Reading (UCDR) \\
\hline & T07 & Perspectiva-based reading (PBR) \\
\hline & T08 & Use-case based reading (UCBR) \\
\hline \multirow[t]{2}{*}{$\mathrm{ROL}$} & R1 & Con rol \\
\hline & R2 & Sin rol \\
\hline \multirow{2}{*}{$\begin{array}{c}\text { CICLO } \\
\text { INSPECCIÓN }\end{array}$} & C1 & Inspección \\
\hline & $\mathrm{C} 2$ & Re-inspección \\
\hline \multirow[t]{2}{*}{ RONDA } & RD1 & Ronda 1 \\
\hline & RD2 & Ronda 2 \\
\hline \multirow[t]{4}{*}{ ESPECIFICACIÓN } & S1 & CRUISE \\
\hline & S2 & WLMS \\
\hline & S3 & ER \\
\hline & S4 & AIS \\
\hline
\end{tabular}

Tabla A.20. VR codificadas

\begin{tabular}{|c|c|}
\hline CÓDIGO & VARIABLE RESPUESTA \\
\hline V01 & Efectividad individual \\
\hline
\end{tabular}


Proceso de RS de experimentos en Ingeniería del Software

\begin{tabular}{|c|l|}
\hline V02 & Efectividad del equipo \\
\hline V03 & Eficiencia individual - Global \\
\hline V04 & Eficiencia individual - Inspección \\
\hline V05 & Eficiencia individual - Preparación \\
\hline V06 & Eficiencia equipo \\
\hline V07 & Habilidad del inspector \\
\hline V08 & Efectividad del método \\
\hline V09 & Eficiencia individual \\
\hline V10 & Eficiencia del método \\
\hline V11
\end{tabular}

Tabla A.21. Metricas codificadas

\begin{tabular}{|c|c|c|c|}
\hline $\begin{array}{l}\text { CÓDI } \\
\text { GO }\end{array}$ & MÉTRICAS & FORMULACIÓN & $\begin{array}{c}\text { VR } \\
\text { ASOCIADA }\end{array}$ \\
\hline M01 & $\begin{array}{l}\text { Tasa de detección de fallos } \\
\text { individual }\end{array}$ & $\begin{array}{l}\text { Número de defectos detectado } \\
\text { por un individuo / número total de } \\
\text { fallos conocidos en la especificación }\end{array}$ & \multirow{5}{*}{ V01 } \\
\hline M02 & $\begin{array}{l}\text { Número de defectos } \\
\text { encontrados por individuo }\end{array}$ & & \\
\hline M03 & $\begin{array}{l}\text { Número de falsos positivos } \\
\text { por individuo }\end{array}$ & & \\
\hline M13 & $\begin{array}{l}\text { Tasa de detección de fallos } \\
\text { individual (por tipo de fallo A, B, } \\
\text { C) }\end{array}$ & $\begin{array}{l}\text { Número de fallos del tipo } \mathrm{T} \\
\text { detectados por un individuo/número } \\
\text { de fallos del tipo } \mathrm{T} \text { conocidos }\end{array}$ & \\
\hline M14 & $\begin{array}{l}\text { Tasa de detección de fallos } \\
\text { individual (por tipo de fallo } \\
\text { SEMANTIC, } \\
\text { CONSISTENCY) }\end{array}$ & $\begin{array}{l}\text { Número de fallos del tipo } T \\
\text { detectados por un individuo/número } \\
\text { de fallos del tipo } T \text { conocidos }\end{array}$ & \\
\hline
\end{tabular}




\begin{tabular}{|c|c|c|c|}
\hline GO & MÉTRICAS & FORMULACIÓN & $\begin{array}{c}\text { VR } \\
\text { ASOCIADA }\end{array}$ \\
\hline M15 & $\begin{array}{l}\text { Tasa de detección de fallos } \\
\text { individual (por CALIFICACION del } \\
\text { inspector) e defectos } \\
\text { encontrados (por }\end{array}$ & $\begin{array}{l}\text { number of faults detected by an } \\
\text { individual with qualification Q / total } \\
\text { number of faults known to be in the } \\
\text { specification }\end{array}$ & \\
\hline M16 & $\begin{array}{l}\text { Número d HABILIDAD del } \\
\text { sujeto) }\end{array}$ & & \\
\hline M17 & $\begin{array}{l}\text { Tasa de detección de fallo } \\
\text { individual por tipo de diagrama } \\
\text { (CLASS, SEC, ACTV, COMPON) }\end{array}$ & & \\
\hline M18 & $\begin{array}{l}\text { Número de revisores que } \\
\text { encuentran cada fallo (por tipo } \\
\text { de fallo } A, B, C \text { ) }\end{array}$ & & \\
\hline M19 & \begin{tabular}{l}
\multicolumn{1}{c}{ Porcentaje de revisores que } \\
encuentran fallos con \\
características \\
DESLOCALIZACION
\end{tabular} & & \\
\hline M20 & $\begin{array}{l}\text { Tasa de detección de fallo } \\
\text { individual por tipo de } \\
\text { perspectiva }(U, D, I)\end{array}$ & & \\
\hline M21 & $\begin{array}{l}\text { Número de defectos } \\
\text { encontrados por un sujeto (por } \\
\text { tipo de perspectiva: } U, D, I \text { ) }\end{array}$ & & \\
\hline M32 & $\begin{array}{l}\text { Tasa individual de detección } \\
\text { de fallos (por tipo de fallos: DT, } \\
\text { MF, IF ) }\end{array}$ & & \\
\hline M04 & $\begin{array}{l}\text { Tasa de detección de fallos } \\
\text { por equipo }\end{array}$ & $\begin{array}{l}\text { Número de defectos detectado } \\
\text { por un equipo / número total de } \\
\text { fallos conocidos en la especificación }\end{array}$ & V02 \\
\hline M05 & Número de defectos & & \\
\hline
\end{tabular}


Proceso de RS de experimentos en Ingeniería del Software

\begin{tabular}{|c|c|c|c|}
\hline $\begin{array}{l}\text { CÓDI } \\
\text { GO }\end{array}$ & MÉTRICAS & FORMULACIÓN & $\begin{array}{c}\text { VR } \\
\text { ASOCIADA }\end{array}$ \\
\hline & encontrados por equipo & & \\
\hline M22 & $\begin{array}{l}\text { Tasa de detección de fallos } \\
\text { (por tamaño de equipo por tipo } \\
\text { de fallo A, B, C) } \\
\text { (OBSERVACIONAL) }\end{array}$ & & \\
\hline M23 & $\begin{array}{l}\text { Tasa de detección de fallos } \\
\text { por tamaño de equipo } \\
\text { (OBSERVACIONAL) }\end{array}$ & & \\
\hline M24 & $\begin{array}{l}\text { Número de defectos } \\
\text { encontrados por un equipo } \\
\text { durante la inspección (por tipo } \\
\text { de defecto Major, All) }\end{array}$ & & \\
\hline M25 & $\begin{array}{lrr}\text { Número } & \text { de } & \text { defectos } \\
\text { encontrados } & \text { (por grupo de } \\
\text { experimento) } & & \\
\end{array}$ & & \\
\hline M26 & $\begin{array}{l}\text { Número de defectos } \\
\text { encontrados por tamaño de } \\
\text { grupo (por tipo de fallo A, B, C) }\end{array}$ & & \\
\hline M06 & $\begin{array}{l}\text { Número de defectos } \\
\text { encontrados por un individuo } \\
\text { por unidad de tiempo }\end{array}$ & $\begin{array}{l}\text { Número de defectos positivos } \\
\text { encontrados/tiempo disponible para } \\
\text { el experimento }\end{array}$ & \\
\hline M07 & $\begin{array}{l}\text { Tiempo gastado por } \\
\text { individuo }\end{array}$ & $\begin{array}{l}\text { Tiempo gastado por cada } \\
\text { participante para las inspecciones } \\
\text { individuales }\end{array}$ & \\
\hline M08 & $\begin{array}{l}\text { Tiempo en el que es } \\
\text { encontrado un fallo }\end{array}$ & & \\
\hline M27 & $\begin{array}{l}\text { Número de defectos } \\
\text { encontrados por un individuo } \\
\text { por unidad de tiempo (por tipo } \\
\text { A, B, C) }\end{array}$ & $\begin{array}{l}\text { Número de fallos del tipo } \mathrm{T} \\
\text { detectados por un individuo/número } \\
\text { de horas de inspección }\end{array}$ & \\
\hline
\end{tabular}

Caso de estudio 


\begin{tabular}{|c|c|c|c|}
\hline $\begin{array}{l}\text { CÓDI } \\
\text { GO }\end{array}$ & MÉTRICAS & FORMULACIÓN & $\begin{array}{c}\text { VR } \\
\text { ASOCIADA }\end{array}$ \\
\hline M33 & $\begin{array}{l}\text { Tiempo gastado por un } \\
\text { individuo durante la inspección } \\
\text { (por perspectiva } U, D, I \text { ) }\end{array}$ & & \\
\hline $\mathrm{M} 28$ & $\begin{array}{l}\text { Tiempo gastado por } \\
\text { individuo durante la inspección } \\
\text { (OBSERVACIONAL) }\end{array}$ & & V04 \\
\hline M29 & $\begin{array}{c}\text { Tiempo gastado por } \\
\text { individuo durante la preparación }\end{array}$ & & V05 \\
\hline M10 & $\begin{array}{l}\text { Número de defectos } \\
\text { encontrados por un equipo por } \\
\text { unidad de tiempo }\end{array}$ & $\begin{array}{l}\text { Número de defectos positivos } \\
\text { encontrados/ tiempo disponible para } \\
\text { el experimento }\end{array}$ & \\
\hline M09 & $\begin{array}{l}\text { Tiempo máximo gastado por } \\
\text { un equipo durante la inspección }\end{array}$ & & \\
\hline M30 & $\begin{array}{l}\text { Número de defectos } \\
\text { encontrados por un equipo por } \\
\text { unidad de tiempo por tamaño de } \\
\text { equipo por tipo de fallo }(A, B, C)\end{array}$ & $\begin{array}{l}\text { the number of positive defects } \\
\text { found/ total duration time available } \\
\text { for the experiment run }\end{array}$ & V06 \\
\hline M31 & $\begin{array}{l}\text { Número de defectos } \\
\text { encontrados por un equipo por } \\
\text { unidad de tiempo por tamaño de } \\
\text { equipo }\end{array}$ & $\begin{array}{l}\text { the number of positive defects } \\
\text { found/ total duration time available } \\
\text { for the experiment run }\end{array}$ & \\
\hline M11 & $\begin{array}{l}\text { Cost per defect for the defect } \\
\text { detection phase por equipo }\end{array}$ & $\begin{array}{l}\text { Two-person Team Defect } \\
\text { detection effort (minutes) / Defects } \\
\text { found by a two-person team } \\
\text { (without meeting gains) }{ }^{+}\end{array}$ & V07 \\
\hline M34 & $\begin{array}{l}\text { Cost per defect for the defect } \\
\text { detection phase por individuo }\end{array}$ & & \\
\hline M12 & $\begin{array}{l}\text { Average academic } \\
\text { performance of each subject }\end{array}$ & $\begin{array}{l}\text { Habilidad de cada sujeto para } \\
\text { encontrar un defecto dado }\end{array}$ & V08 \\
\hline
\end{tabular}




\subsubsection{Resumir datos cuantitativos por estudio}

A continuación se presenta el modelo E04-Resumen de datos cuantitativos con los datos extraídos de los estudios seleccionados.

Caso de estudio 


\begin{tabular}{|c|c|c|c|c|c|c|c|c|c|c|}
\hline ID & METRICA & ESPECIF & $\mathrm{ROL}$ & RONDA & NIVEL & $M$ & SD & $\mathrm{N}$ & RESULTADOS & Observ. \\
\hline \multirow[t]{7}{*}{ EO } & \multirow{7}{*}{$\begin{array}{l}\text { M04- Tasa } \\
\text { de detección } \\
\text { de fallos por } \\
\text { equipo }\end{array}$} & \multirow[t]{3}{*}{$\begin{array}{l}\text { Promed } \\
\text { io }\end{array}$} & \multirow[t]{3}{*}{$S / R$} & \multirow[t]{3}{*}{ R1 } & T01-AH & 0.37 & 0.10 & $\begin{array}{c}13 \\
\text { equipos }\end{array}$ & \multirow{7}{*}{$\begin{array}{l}\text { M04/T03>T01> } \\
\text { T02 } \\
\text { M01/T03>T01> } \\
\text { T02 (CRUISE) } \\
\text { M01/T01>T03> } \\
\text { T02 (WLMS) }\end{array}$} & \multirow{3}{*}{\begin{tabular}{l}
\multicolumn{1}{c}{ Calculadas a } \\
partir de los datos \\
originales \\
considerar la \\
especificación (no \\
es significativa)
\end{tabular}} \\
\hline & & & & & $\begin{array}{l}\text { T02- } \\
\text { CBR }\end{array}$ & 0.325 & 0.123 & $\begin{array}{c}8 \\
\text { equipos }\end{array}$ & & \\
\hline & & & & & $\begin{array}{l}\text { T03- } \\
\text { SBR }\end{array}$ & 0.51 & 0.112 & $\begin{array}{c}12 \\
\text { equipos }\end{array}$ & & \\
\hline & & \multirow[t]{3}{*}{ CRUISE } & \multirow[t]{3}{*}{$S / R$} & \multirow[t]{3}{*}{ R1 } & T01-AH & 0.43 & 0.08 & $\begin{array}{c}6 \\
\text { equipos }\end{array}$ & & \\
\hline & & & & & $\begin{array}{l}\text { T02- } \\
\text { CBR }\end{array}$ & 0.42 & 0.12 & $\begin{array}{c}4 \\
\text { equipos }\end{array}$ & & \\
\hline & & & & & \begin{tabular}{l}
\multicolumn{1}{c}{ T03- } \\
SBR
\end{tabular} & 0.57 & 0.11 & $\begin{array}{c}6 \\
\text { equipos }\end{array}$ & & \\
\hline & & WLMS & $S / R$ & R1 & T01-AH & 0.31 & 0.09 & 7 & & \\
\hline
\end{tabular}


Proceso de RS de experimentos en Ingeniería del Software

\begin{tabular}{|c|c|c|c|c|c|c|c|c|}
\hline & & & & & & & equipos & \\
\hline & & & & $\begin{array}{l}\text { T02- } \\
\text { CBR }\end{array}$ & 0.24 & 0.05 & $\begin{array}{c}4 \\
\text { equipos }\end{array}$ & \\
\hline & & & & $\begin{array}{l}\text { T03- }^{\text {To3 }} \\
\text { SBR }\end{array}$ & 0.45 & 0.07 & $\begin{array}{c}5 \\
\text { equipos }\end{array}$ & \\
\hline \multirow{6}{*}{$\begin{array}{l}\text { M01- Tasa } \\
\text { de detección } \\
\text { de fallos } \\
\text { individual }\end{array}$} & \multirow[t]{3}{*}{ CRUISE } & \multirow[t]{3}{*}{$S / R$} & \multirow[t]{3}{*}{$\mathrm{R} 1$} & T01-AH & $s / i$ & $s / i$ & $\begin{array}{c}18 \\
\text { sujetos }\end{array}$ & \multirow{6}{*}{$\begin{array}{l}\text { No } \\
\text { proporcionan M } \\
\text { sino la mediana }\end{array}$} \\
\hline & & & & $\begin{array}{l}\text { T02- } \\
\text { CBR }\end{array}$ & $s / i$ & $s / i$ & $\begin{array}{c}12 \\
\text { sujetos }\end{array}$ & \\
\hline & & & & $\begin{array}{l}\text { T03- } \\
\text { SBR }\end{array}$ & $s / i$ & $s / i$ & $\begin{array}{c}18 \\
\text { sujetos }\end{array}$ & \\
\hline & \multirow[t]{3}{*}{ WLMS } & \multirow[t]{3}{*}{$S / R$} & \multirow[t]{3}{*}{$\mathrm{R} 1$} & T01-AH & $s / i$ & $s / i$ & $\begin{array}{c}21 \\
\text { sujetos }\end{array}$ & \\
\hline & & & & $\begin{array}{l}\text { T02- } \\
\text { CBR }\end{array}$ & $s / i$ & $s / i$ & $\begin{array}{c}12 \\
\text { sujetos }\end{array}$ & \\
\hline & & & & $\begin{array}{l}\text { T03- } \\
\text { SBR }\end{array}$ & $s / i$ & $s / i$ & $\begin{array}{c}15 \\
\text { sujetos }\end{array}$ & \\
\hline \multirow{2}{*}{$\begin{array}{c}\text { M32- } \\
\text { individual de }\end{array}$} & \multirow[t]{2}{*}{ CRUISE } & \multirow[t]{2}{*}{$S / R$} & \multirow[t]{2}{*}{ R1 } & \multirow[t]{2}{*}{ T01-AH } & $s / i$ & $s / i$ & \multirow{2}{*}{$\begin{array}{c}18 \\
\text { sujetos }\end{array}$} & $-\mathrm{H} 1$ \\
\hline & & & & & $s / i$ & $s / i$ & & No \\
\hline
\end{tabular}


Extracción de Datos

Proceso de RS de experimentos en Ingeniería del Software

\begin{tabular}{|c|c|c|c|c|c|c|c|c|}
\hline \multirow{13}{*}{$\begin{array}{l}\text { detección de } \\
\text { fallos (por tipo } \\
\text { de fallos: DT, } \\
\text { MF, IF ) }\end{array}$} & & & & TO2- & $s / i$ & $s / i$ & & \multirow[t]{13}{*}{$\begin{array}{l}\text { proporcionan } \mathrm{M} \\
\text { sino la mediana }\end{array}$} \\
\hline & & & & & & & \multirow{2}{*}{$\begin{array}{c}12 \\
\text { sujetos }\end{array}$} & \\
\hline & & & & & $\mathrm{s} / \mathrm{i}$ & $s / i$ & & \\
\hline & & & & \multirow[t]{3}{*}{$\begin{array}{l}{ }^{\text {T03- }} \\
\text { SBR }\end{array}$} & $\begin{array}{r}\text { DT } \\
\mathrm{s} / \mathrm{i}^{-}\end{array}$ & $\mathrm{s} / \mathrm{i}$ & $\begin{array}{c}6 \\
\text { sujetos }\end{array}$ & \\
\hline & & & & & $\begin{array}{l}\text { MF } \\
\mathrm{s} / \mathrm{i}^{\mathrm{N}}\end{array}$ & $\mathrm{s} / \mathrm{i}$ & $\begin{array}{c}6 \\
\text { sujetos }\end{array}$ & \\
\hline & & & & & $s /{ }^{\prime}$ & $\mathrm{s} / \mathrm{i}$ & $\begin{array}{c}6 \\
\text { sujetos }\end{array}$ & \\
\hline & \multirow[t]{7}{*}{ WLMS } & \multirow[t]{7}{*}{$S / R$} & \multirow[t]{7}{*}{ R1 } & \multirow[t]{3}{*}{ T01-AH } & $s / i$ & $\mathrm{~s} / \mathrm{i}$ & \multirow{3}{*}{$\begin{array}{c}21 \\
\text { sujetos }\end{array}$} & \\
\hline & & & & & $s / i$ & $\mathrm{~s} / \mathrm{i}$ & & \\
\hline & & & & & $s / i$ & $\mathrm{~s} / \mathrm{i}$ & & \\
\hline & & & & \multirow{3}{*}{$\begin{array}{l}\text { T02- } \\
\text { CBR }\end{array}$} & $s / i$ & $\mathrm{~s} / \mathrm{i}$ & \multirow{3}{*}{$\begin{array}{c}12 \\
\text { sujetos }\end{array}$} & \\
\hline & & & & & $s / i$ & $\mathrm{~s} / \mathrm{i}$ & & \\
\hline & & & & & $s / i$ & $\mathrm{~s} / \mathrm{i}$ & & \\
\hline & & & & $\begin{array}{l}\text { T03- } \\
\text { SBR }\end{array}$ & $\begin{array}{l}\text { DT } \\
\mathrm{s} / \mathrm{i}\end{array}$ & $\mathrm{s} / \mathrm{i}$ & $\begin{array}{c}5 \\
\text { sujetos }\end{array}$ & \\
\hline
\end{tabular}


Proceso de RS de experimentos en Ingeniería del Software

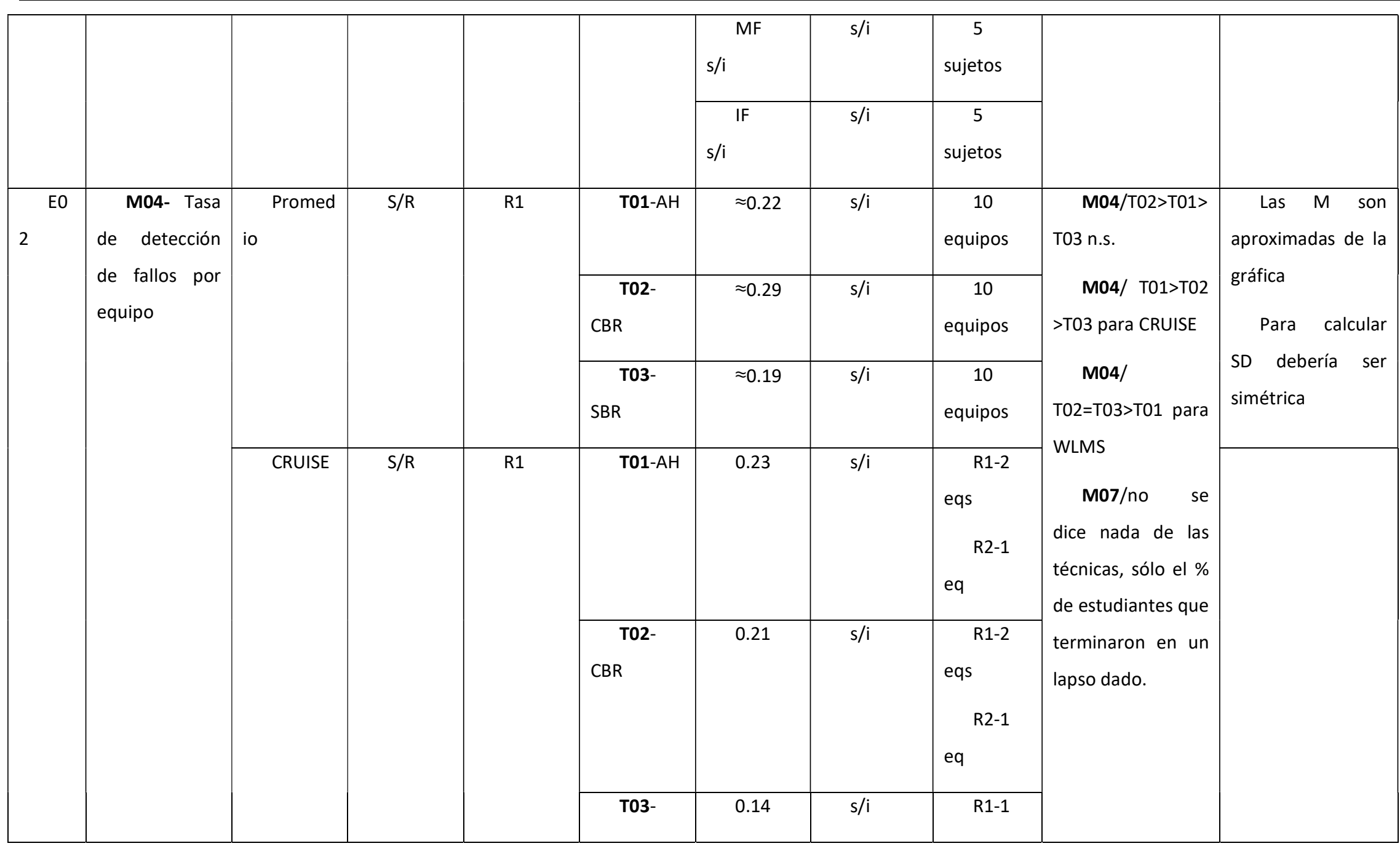


Extracción de Datos

\begin{tabular}{|c|c|c|c|c|c|c|c|c|}
\hline & & & & SBR & & & $\begin{array}{l}\text { eq } \\
\text { R2- } 3 \\
\text { eqs }\end{array}$ & \\
\hline & \multirow[t]{3}{*}{ WLMS } & \multirow[t]{3}{*}{$S / R$} & \multirow[t]{3}{*}{$\mathrm{R} 1$} & T01-AH & 0.27 & $\mathrm{~s} / \mathrm{i}$ & $\begin{array}{l}\text { R1-2 } \\
\text { eqs } \\
\text { R2- } 1 \\
\text { eq }\end{array}$ & \\
\hline & & & & $\begin{array}{l}\text { T02- } \\
\text { CBR }\end{array}$ & 0.33 & $s / i$ & $\begin{array}{l}\text { R1- } 1 \\
\text { eq } \\
\text { R2- } 2 \\
\text { eqs }\end{array}$ & \\
\hline & & & & $\begin{array}{l}\text { T03- } \\
\text { SBR }\end{array}$ & 0.33 & $\mathrm{~s} / \mathrm{i}$ & $\begin{array}{l}\text { R1- } 2 \\
\text { eqs } \\
\text { R2- } 2 \\
\text { eqs }\end{array}$ & \\
\hline \multirow[t]{2}{*}{$\begin{array}{l}\text { M07- } \\
\text { Tiempo } \\
\text { gastado por } \\
\text { individuo }\end{array}$} & & \multirow[t]{2}{*}{$S / R$} & \multirow[t]{2}{*}{$\mathrm{R} 1$} & \begin{tabular}{l} 
T01-AH \\
\multicolumn{1}{c}{${ }^{\text {T02- }}$} \\
CBR
\end{tabular} & & & & \multirow[t]{2}{*}{$\begin{array}{l}\text { No da nada de } \\
\text { inf. }\end{array}$} \\
\hline & & & & T03- & & & & \\
\hline
\end{tabular}


Proceso de RS de experimentos en Ingeniería del Software

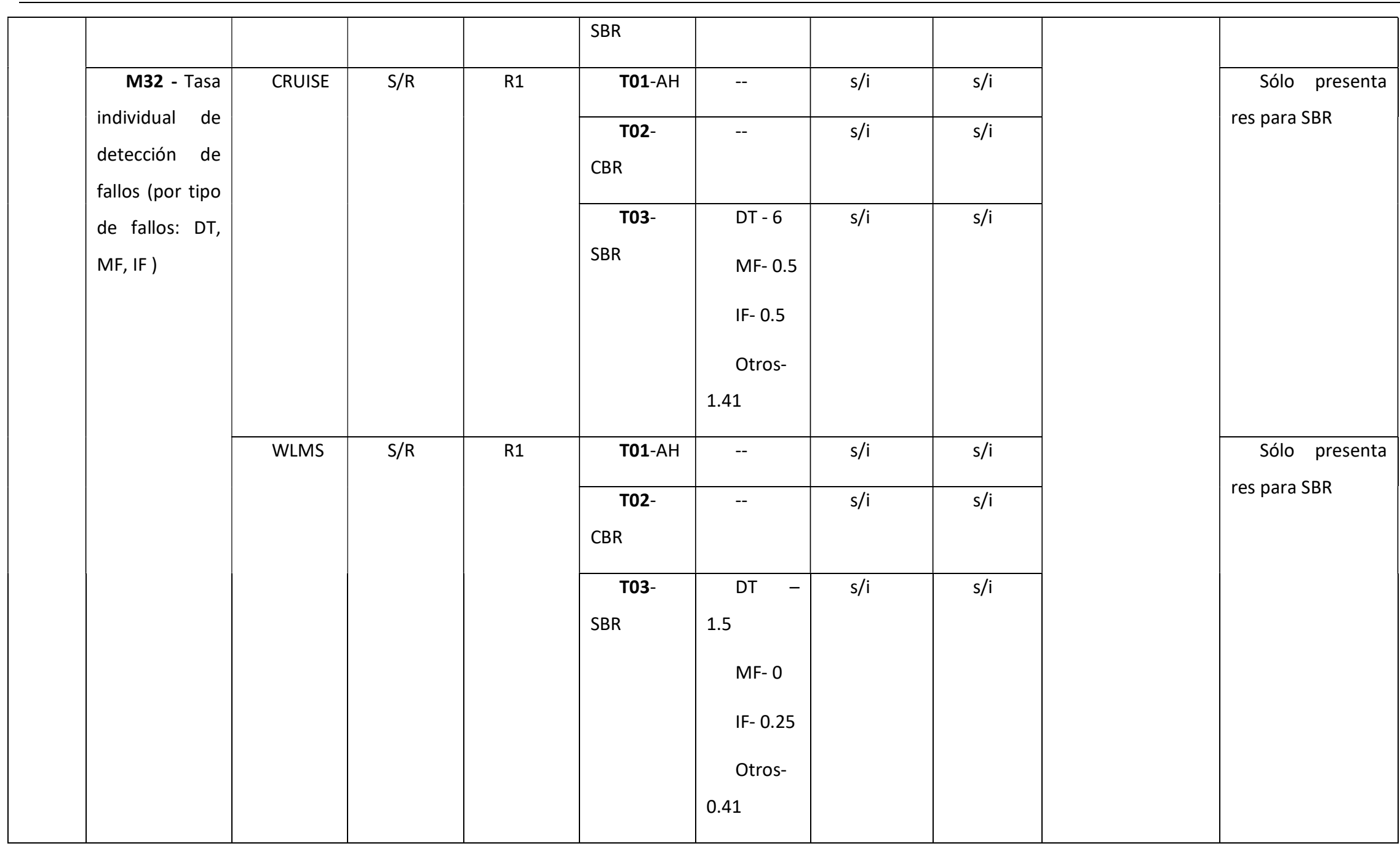


Extracción de Datos

Proceso de RS de experimentos en Ingeniería del Software

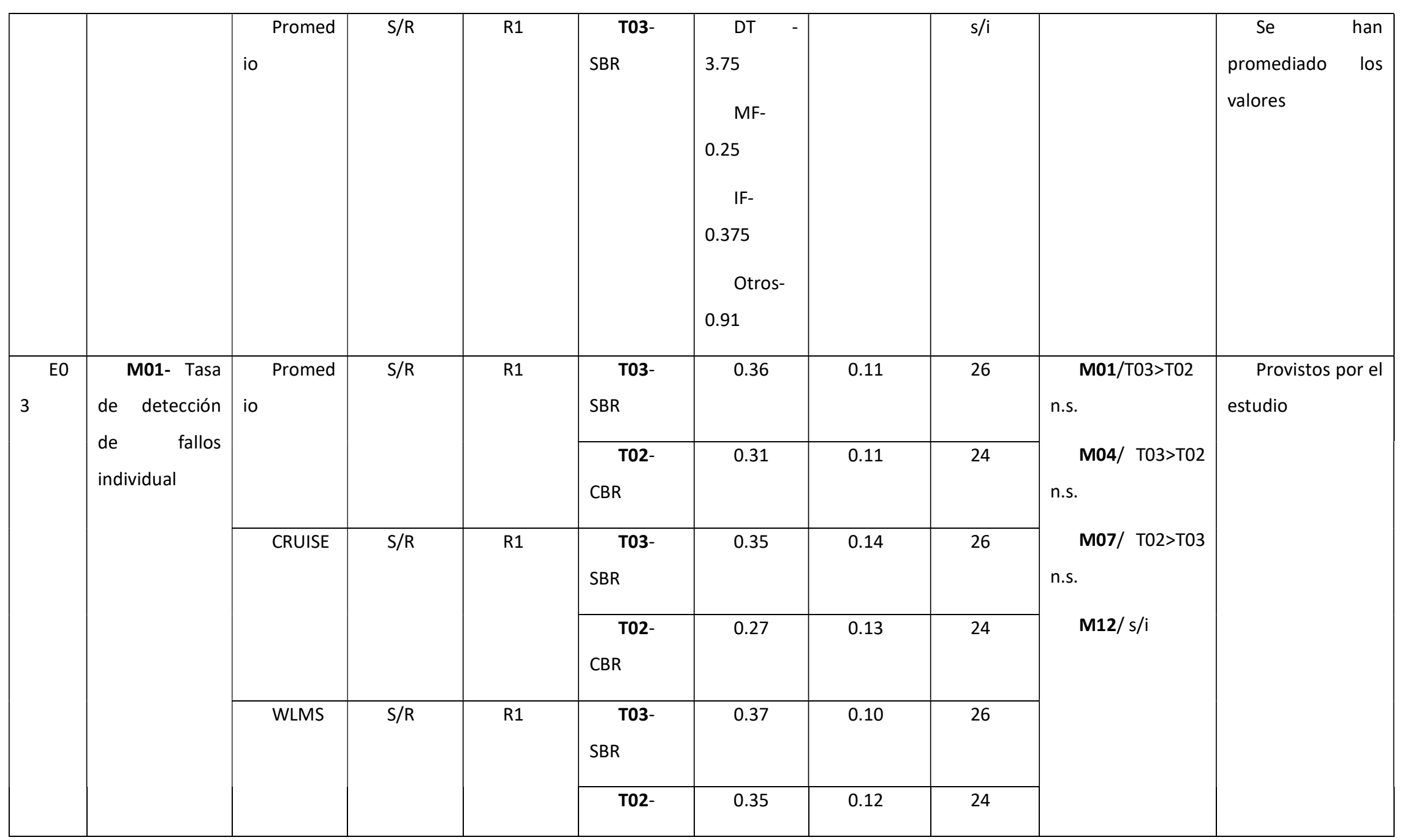


Proceso de RS de experimentos en Ingeniería del Software

\begin{tabular}{|c|c|c|c|c|c|c|c|c|}
\hline & & & & CBR & & & & \\
\hline \multirow{6}{*}{$\begin{array}{l}\text { M07- } \\
\text { Tiempo } \\
\text { indivildual }\end{array}$} & \multirow[t]{2}{*}{ CRUISE } & \multirow[t]{2}{*}{$S / R$} & \multirow[t]{2}{*}{ R1 } & $\begin{array}{l}\text { T03- } \\
\text { SBR }\end{array}$ & 403 & 168 & 23 & \\
\hline & & & & $\begin{array}{l}\text { T02- } \\
\text { CBR }\end{array}$ & 460 & 180 & 24 & \\
\hline & \multirow[t]{2}{*}{ WLMS } & \multirow[t]{2}{*}{$S / R$} & \multirow[t]{2}{*}{ R1 } & $\begin{array}{l}{ }^{\text {T03- }} \\
\text { SBR }\end{array}$ & 370 & 137 & 23 & \\
\hline & & & & $\begin{array}{l}\text { T02- } \\
\text { CBR }\end{array}$ & 379 & 158 & 24 & \\
\hline & \multirow[t]{2}{*}{$\begin{array}{l}\text { Promed } \\
\text { io }\end{array}$} & \multirow[t]{2}{*}{$S / R$} & \multirow[t]{2}{*}{ R1 } & \begin{tabular}{l}
\multicolumn{2}{c}{ T03- } \\
SBR
\end{tabular} & 391 & 150 & 23 & $\begin{array}{l}\text { Promediando } \\
\text { las } \\
\text { especificaciones }\end{array}$ \\
\hline & & & & $\begin{array}{l}\text { T02- } \\
\text { CBR }\end{array}$ & 420 & 166 & 24 & \\
\hline \multirow{3}{*}{$\begin{array}{l}\text { M04- Tasa } \\
\text { de detección } \\
\text { de fallos por } \\
\text { equipo }\end{array}$} & \multirow[t]{2}{*}{$\begin{array}{l}\text { Promed } \\
\text { io }\end{array}$} & \multirow[t]{2}{*}{$S / R$} & \multirow[t]{2}{*}{ R1 } & $\begin{array}{l}\text { T03- } \\
\text { SBR }\end{array}$ & 0.45 & 0.07 & $\begin{array}{c}8 \\
\text { grupos }\end{array}$ & \multirow{2}{*}{$\begin{array}{l}\text { Promediando } \\
\text { las } \\
\text { especificaciones }\end{array}$} \\
\hline & & & & $\begin{array}{l}\text { T02- } \\
\text { CBR }\end{array}$ & 0.44 & 0.09 & $\begin{array}{c}8 \\
\text { grupos }\end{array}$ & \\
\hline & CRUISE & $S / R$ & R1 & T03- & 0.42 & 0.08 & 8 & \\
\hline
\end{tabular}


Extracción de Datos

Proceso de RS de experimentos en Ingeniería del Software

\begin{tabular}{|c|c|c|c|c|c|c|c|c|c|c|}
\hline & & & & & SBR & & & grupos & & \\
\hline & & & & & $\begin{array}{l}\text { T02- } \\
\text { CBR }\end{array}$ & 0.39 & 0.09 & $\begin{array}{c}8 \\
\text { grupos }\end{array}$ & & \\
\hline & & \multirow[t]{2}{*}{ WLMS } & \multirow[t]{2}{*}{$S / R$} & \multirow[t]{2}{*}{ R1 } & $\begin{array}{l}\text { T03- } \\
\text { SBR }\end{array}$ & 0.49 & 0.07 & $\begin{array}{c}8 \\
\text { grupos }\end{array}$ & & \\
\hline & & & & & $\begin{array}{l}\text { T02- } \\
\text { CBR }\end{array}$ & 0.48 & 0.11 & $\begin{array}{c}8 \\
\text { grupos }\end{array}$ & & \\
\hline \multirow[t]{5}{*}{$\begin{array}{ll} & \text { EO } \\
4 & \end{array}$} & \multirow[t]{5}{*}{$\begin{array}{l}\text { M04- Tasa } \\
\text { de detección } \\
\text { de fallos por } \\
\text { equipo }\end{array}$} & \multirow[t]{3}{*}{$\begin{array}{l}\text { Promed } \\
\text { io }\end{array}$} & \multirow[t]{3}{*}{$S / R$} & R1 & $\begin{array}{l}\text { T03- } \\
\text { SBR } \\
\text { T02- } \\
\text { CBR }\end{array}$ & $\begin{array}{l}\text { R1- } \\
0.27 \\
\text { R1- } \\
0.23\end{array}$ & 0.03 & $\begin{array}{c}4 \\
\text { equipos } \\
4 \\
\text { equipos }\end{array}$ & \multirow[t]{5}{*}{$\begin{array}{l}\text { M04/T03>T02 } \\
\text { (RONDA1) } \\
\text { M04/T02>T03 } \\
\text { (RONDA2 }\end{array}$} & \multirow[t]{3}{*}{$\begin{array}{l}\text { Promediando } \\
\text { las } \\
\text { especificaciones }\end{array}$} \\
\hline & & & & \multirow[t]{2}{*}{$\mathrm{R} 2$} & $\begin{array}{l}\text { T03- } \\
\text { SBR }\end{array}$ & $\begin{array}{l}\text { R2- } \\
0.22\end{array}$ & 0.09 & $\begin{array}{c}4 \\
\text { equipos }\end{array}$ & & \\
\hline & & & & & $\begin{array}{l}\text { T02- } \\
\text { CBR }\end{array}$ & $\begin{array}{l}\text { R2- } \\
0.32\end{array}$ & 0.05 & $\begin{array}{c}4 \\
\text { equipos }\end{array}$ & & \\
\hline & & \multirow[t]{2}{*}{ CRUISE } & \multirow[t]{2}{*}{$S / R$} & \multirow[t]{2}{*}{ R1 } & $\begin{array}{l}\text { T03- } \\
\text { SBR }\end{array}$ & $\begin{array}{l}\text { R1- } \\
0.23\end{array}$ & 0.04 & & & \\
\hline & & & & & $\begin{array}{l}\text { T02- } \\
\text { CBR }\end{array}$ & $\begin{array}{l}\text { R1- } \\
0.19\end{array}$ & 0.06 & & & \\
\hline
\end{tabular}


Proceso de RS de experimentos en Ingeniería del Software

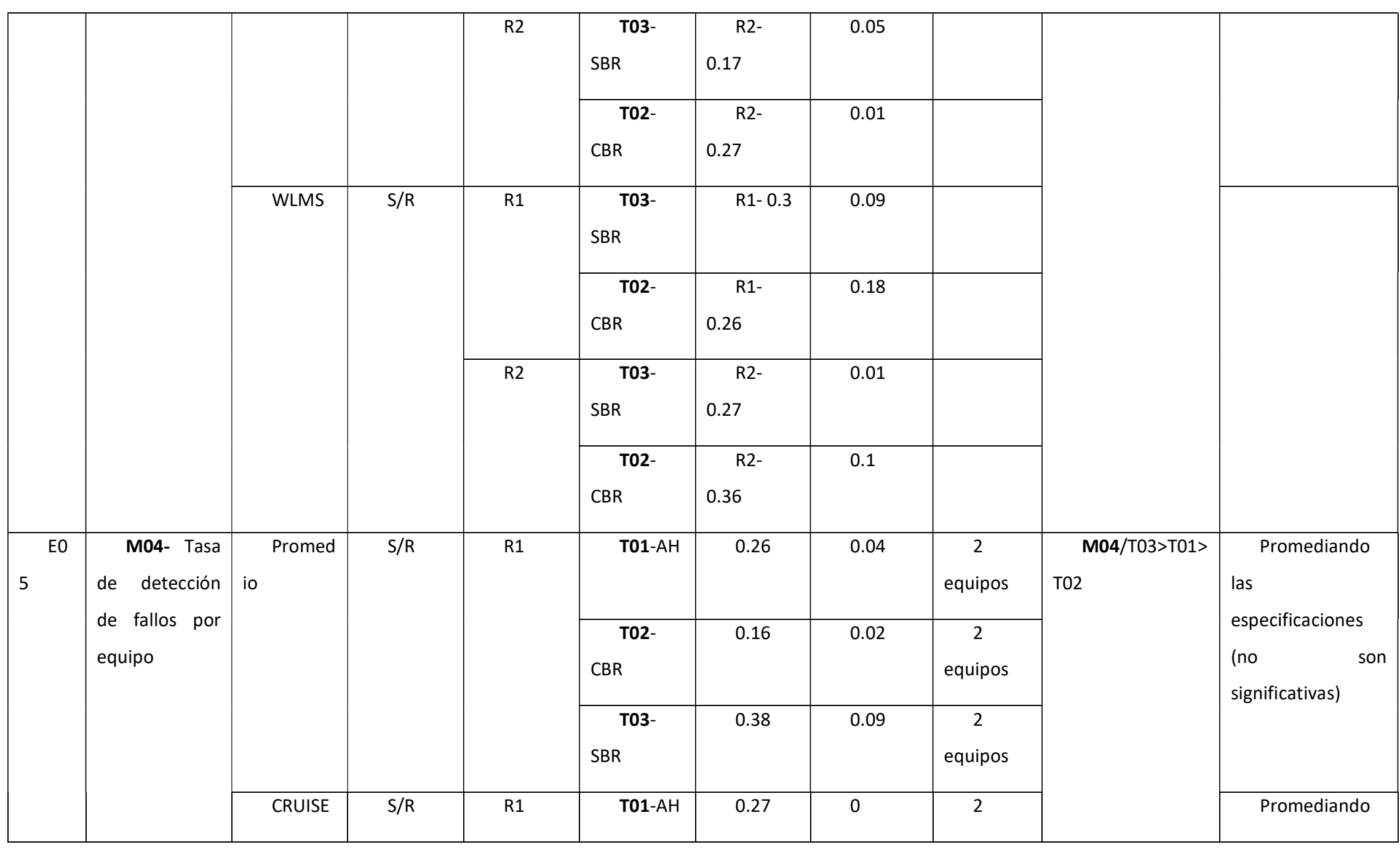


Extracción de Datos

Proceso de RS de experimentos en Ingeniería del Software

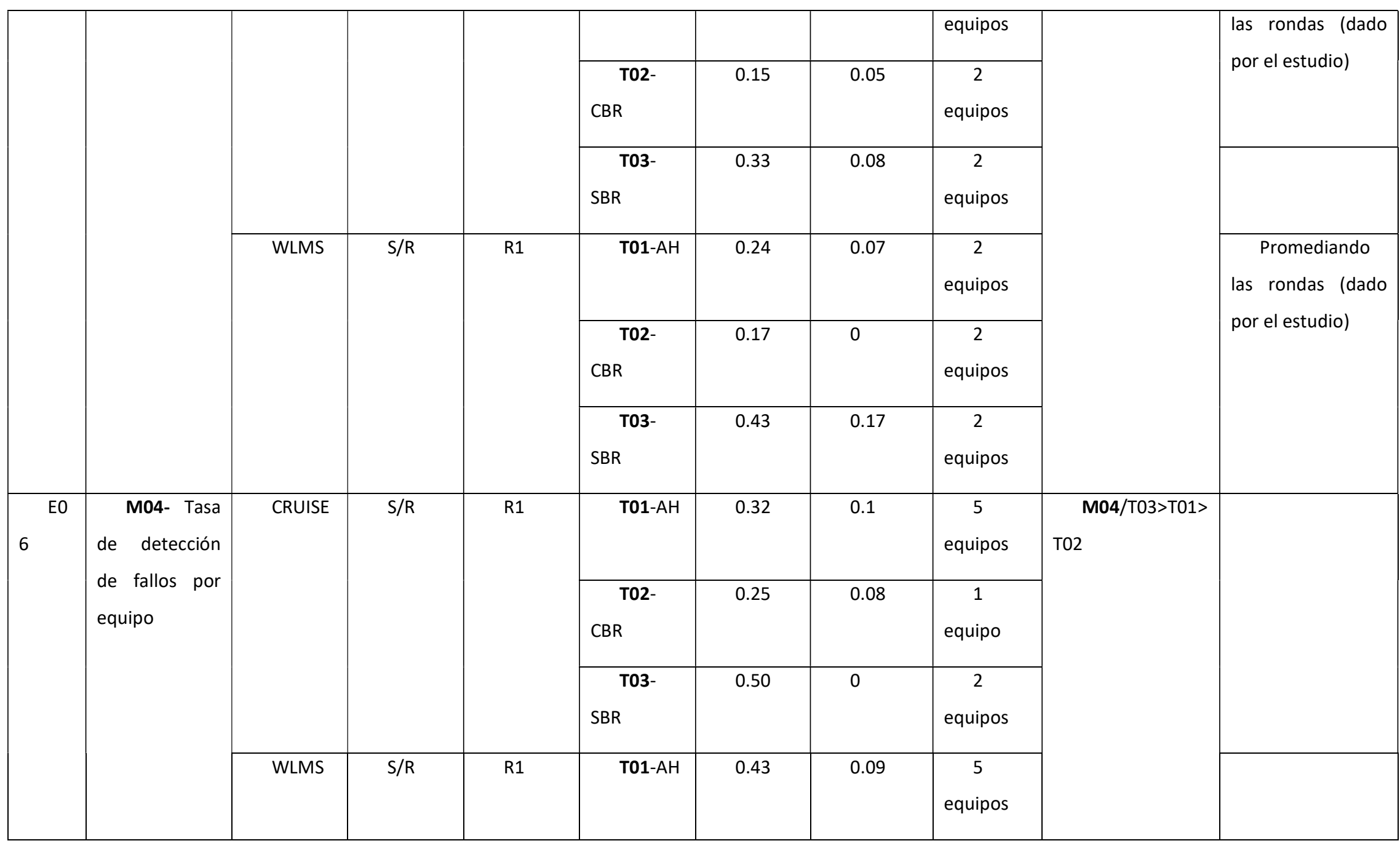


Proceso de RS de experimentos en Ingeniería del Software

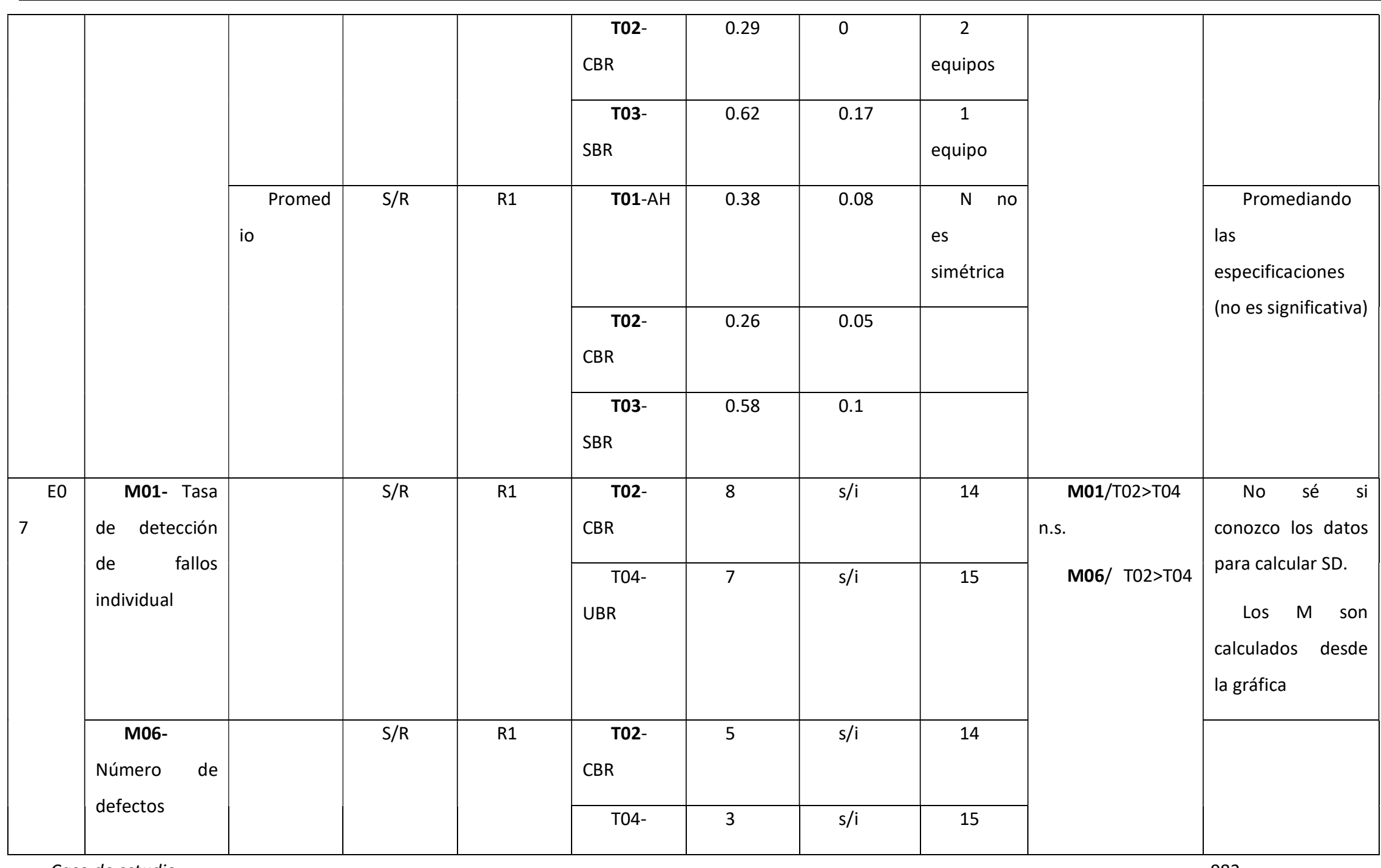




\begin{tabular}{|c|c|c|c|c|c|c|c|}
\hline \begin{tabular}{ll}
\multicolumn{2}{l}{ encontrados } \\
por & un \\
individuo por \\
unidad & de \\
tiempo &
\end{tabular} & & & UBR & & & & \\
\hline \multirow[t]{2}{*}{$\begin{array}{l}\text { M13- Tasa } \\
\text { de detección } \\
\text { der fallos } \\
\text { individual (por } \\
\text { tipo de fallo A, } \\
\text { B, C) }\end{array}$} & \multirow[t]{2}{*}{$S / R$} & \multirow[t]{2}{*}{ R1 } & $\begin{array}{l}\text { T02- } \\
\text { CBR }\end{array}$ & 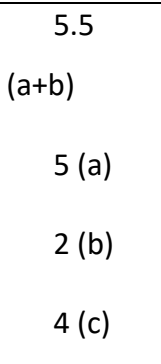 & $s / i$ & 14 & \multirow[t]{2}{*}{$\begin{array}{l}\text { No sé si } \\
\text { conozco los datos } \\
\text { para calcular SD. } \\
\text { Los M son } \\
\text { calculados desde } \\
\text { la gráfica }\end{array}$} \\
\hline & & & $\begin{array}{l}\text { T04- } \\
\text { UBR }\end{array}$ & $\begin{array}{l}7(a+b) \\
4(a) \\
4(b) \\
0(c)\end{array}$ & $s / i$ & 15 & \\
\hline \begin{tabular}{l}
\multicolumn{1}{c}{ M27- } \\
Número de \\
defectos \\
encontrados \\
por un
\end{tabular} & $S / R$ & R1 & $\begin{array}{l}\text { T02- } \\
\text { CBR }\end{array}$ & $\begin{array}{l}3(a+b) \\
2.5(a) \\
0.75(b) \\
2(c)\end{array}$ & $s / i$ & 14 & $\begin{array}{l}\text { No sé si } \\
\text { conozco los datos } \\
\text { para calcular SD. } \\
\text { Los M son } \\
\text { calculados desde }\end{array}$ \\
\hline
\end{tabular}


Proceso de RS de experimentos en Ingeniería del Software

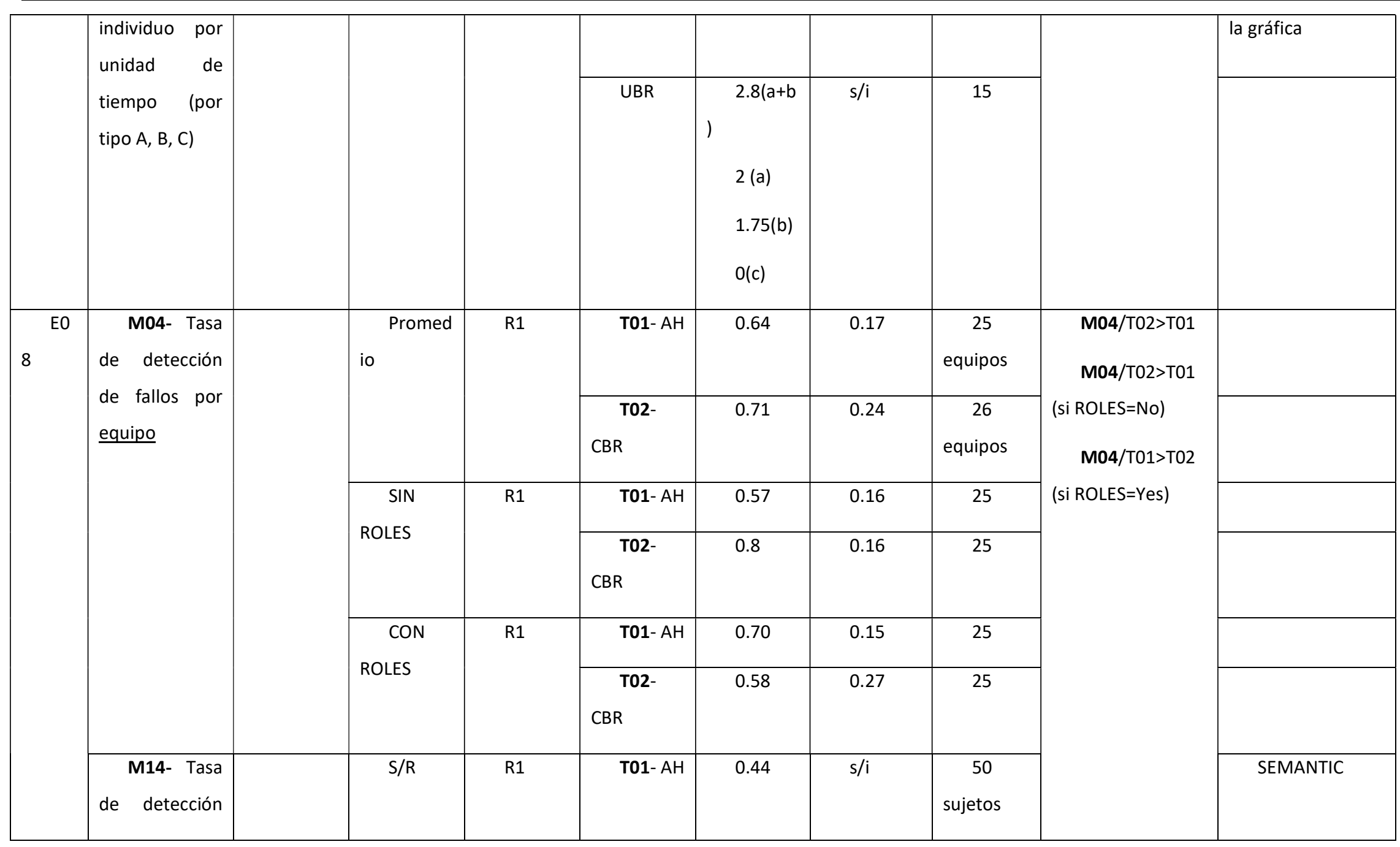


Extracción de Datos

Proceso de RS de experimentos en Ingeniería del Software

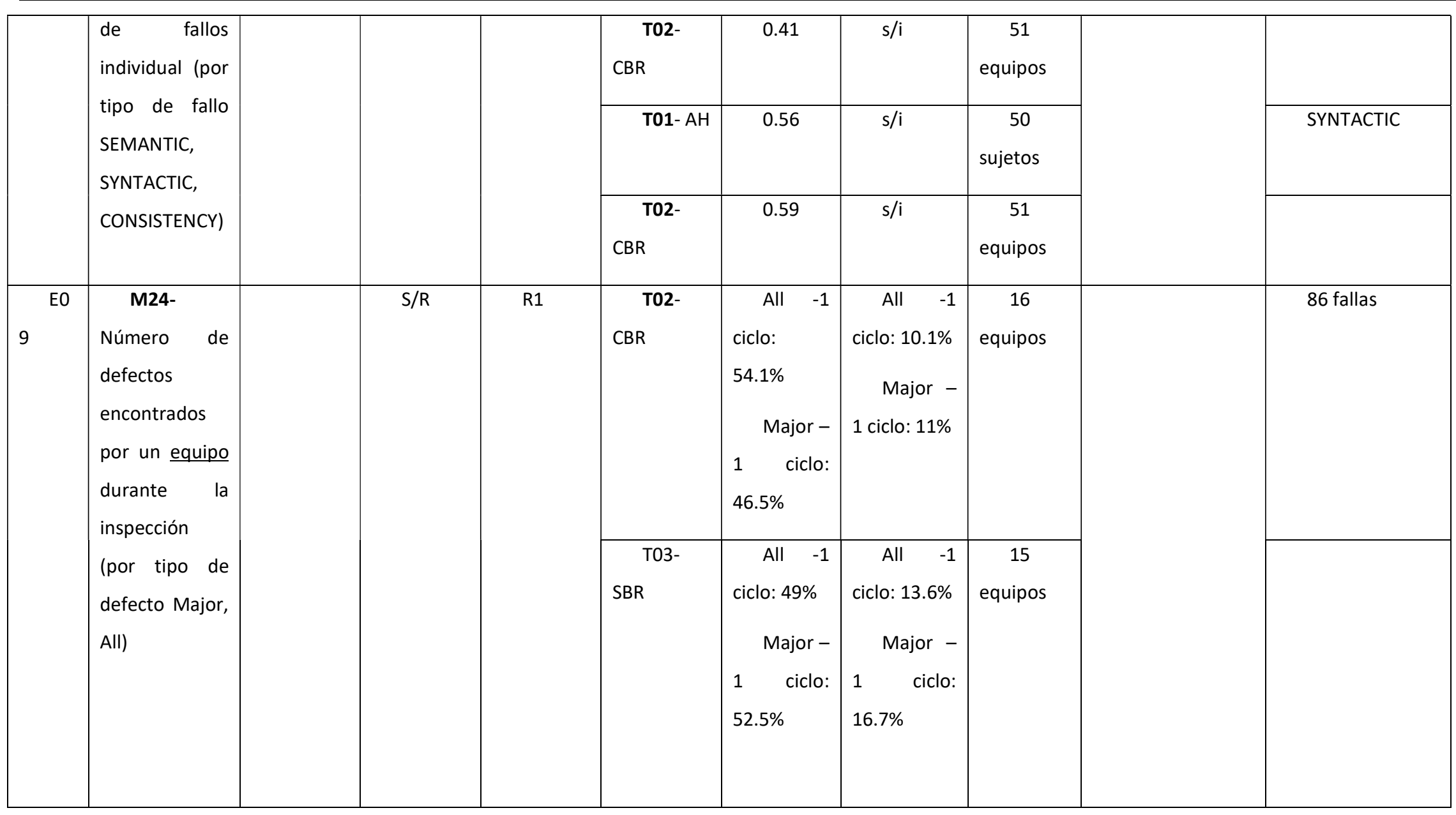


Proceso de RS de experimentos en Ingeniería del Software

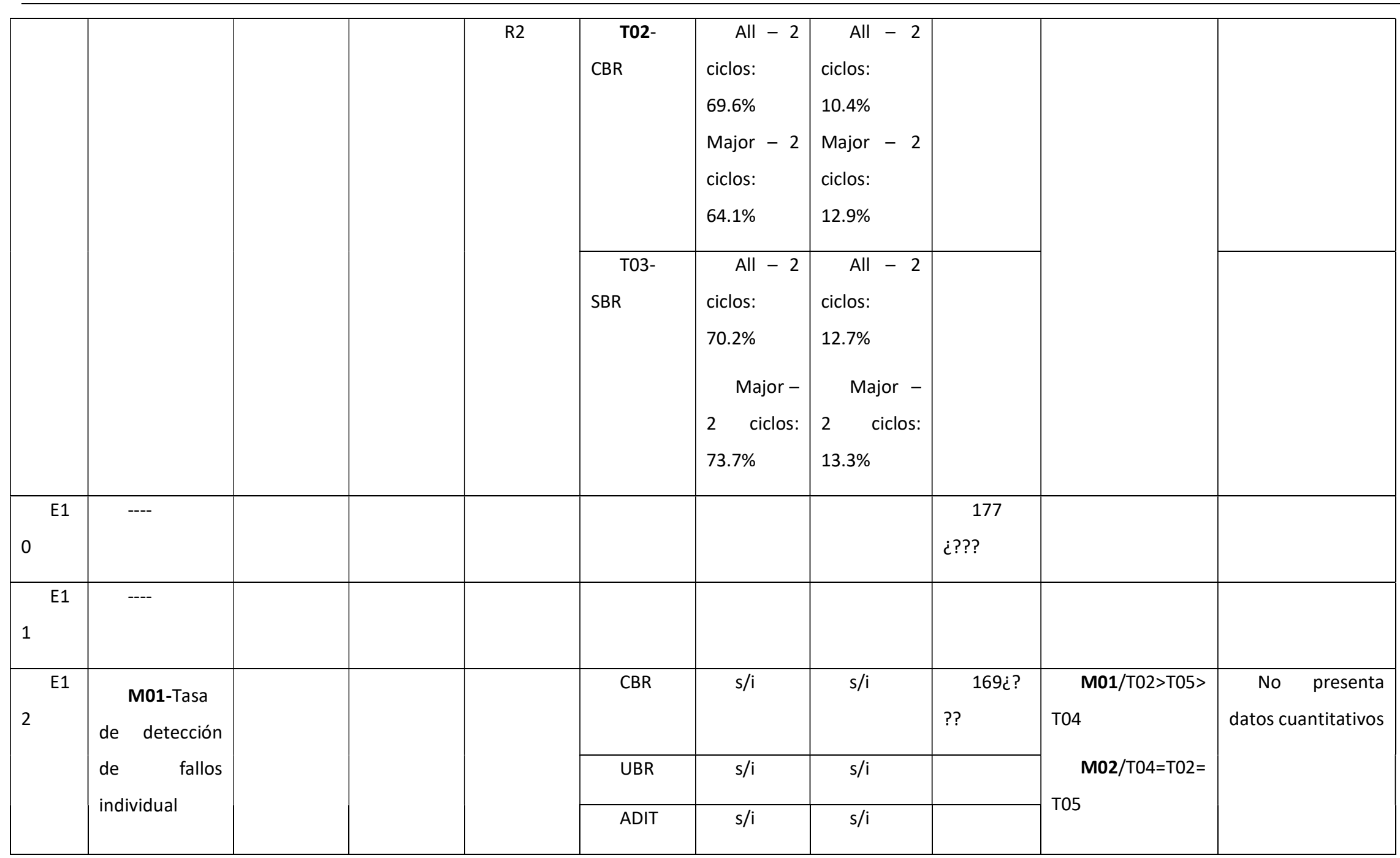

Caso de estudio 


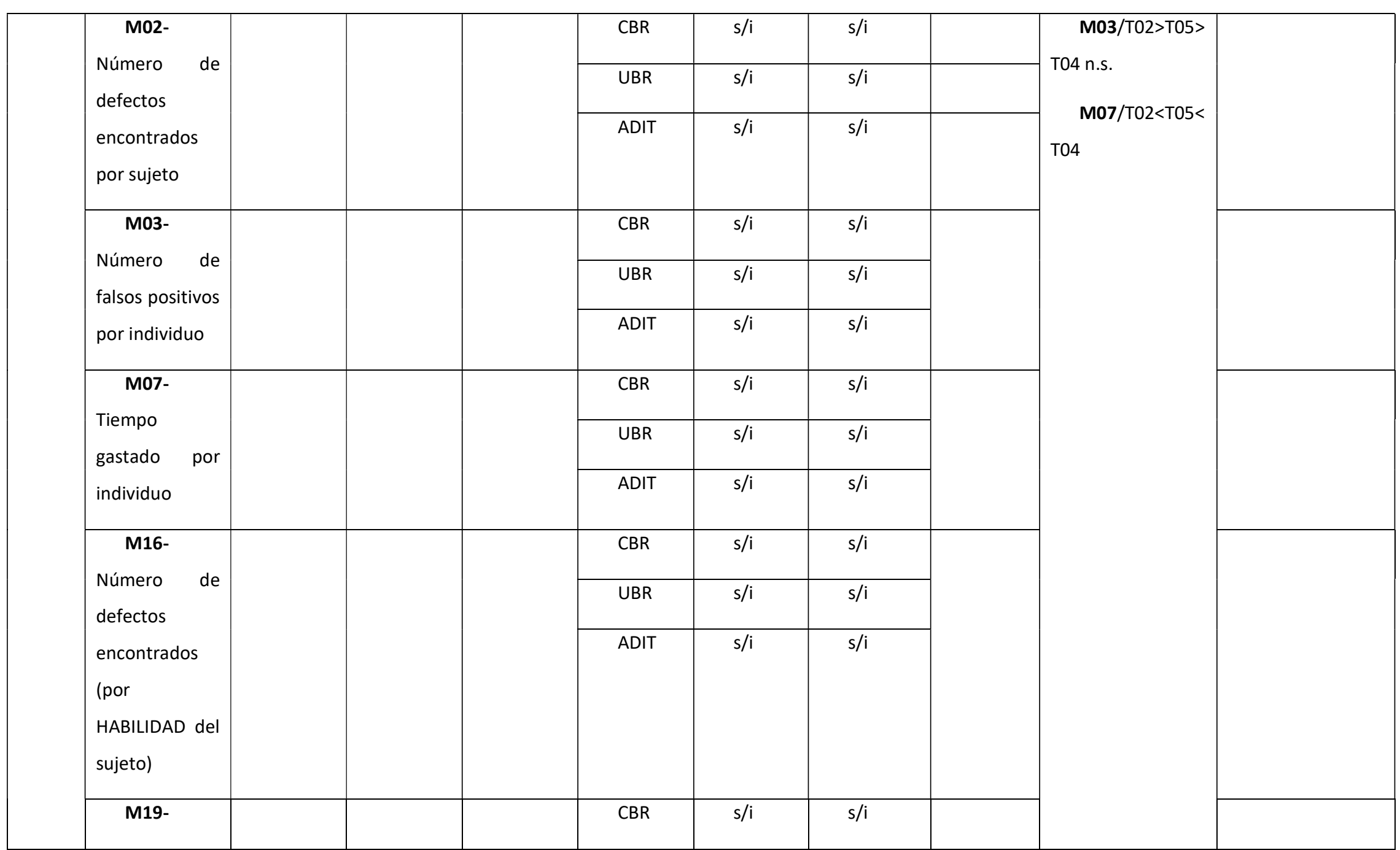


Proceso de RS de experimentos en Ingeniería del Software

\begin{tabular}{|c|c|c|c|c|c|c|c|}
\hline & $\begin{array}{l}\text { Porcentaje de } \\
\text { revisores que } \\
\text { encuentran } \\
\text { fallos con } \\
\text { características } \\
\text { de } \\
\text { DESLOCALIZAC } \\
\text { ION }\end{array}$ & $\begin{array}{l}\text { UBR } \\
\text { ADI }\end{array}$ & $\begin{array}{l}s / i \\
s / i\end{array}$ & $\mathrm{~s} / \mathrm{i}$ & & & \\
\hline \multirow[t]{4}{*}{ E1 } & \multirow[t]{2}{*}{$\begin{array}{l}\text { M04- Tasa } \\
\text { de detección } \\
\text { de fallos por } \\
\text { equipo }\end{array}$} & $\begin{array}{l}\text { T02- } \\
\text { CBR }\end{array}$ & 0.55 (a) & 0.13 & 9 & \multirow[t]{4}{*}{$\begin{array}{l}\text { M04/T07>T02 } \\
\text { M11/T07>T02 }\end{array}$} & $\begin{array}{l}\text { Los valores han } \\
\text { sido tomados de la } \\
\text { gráfica }\end{array}$ \\
\hline & & $\begin{array}{l}\text { T07- } \\
\text { PBR }\end{array}$ & $0.68(a)$ & 0.08 & 9 & & \\
\hline & \multirow{2}{*}{$\begin{array}{l}\text { M11- Cost } \\
\text { per defect for } \\
\text { the defect } \\
\text { detection } \\
\text { phase }\end{array}$} & $\begin{array}{l}\text { T02- } \\
\text { CBR }\end{array}$ & 60 & 22 & 9 & & \\
\hline & & $\begin{array}{l}\text { T07- } \\
\text { PBR }\end{array}$ & 49 & 8 & 9 & & \\
\hline $4^{\mathrm{E} 1}$ & $\begin{array}{c}\text { M04-Tasa } \\
\text { de detección } \\
\text { de fallos por }\end{array}$ & $\begin{array}{l}\text { T02- } \\
\text { CBR }\end{array}$ & 0.68 (a) & 0.2 & 10 & $\begin{array}{l}\text { M04/T07>T02 } \\
\text { n.s. } \\
\text { M11/T07>T02 }\end{array}$ & $\begin{array}{l}\text { Los valores han } \\
\text { sido tomados de la } \\
\text { gráfica }\end{array}$ \\
\hline
\end{tabular}


Extracción de Datos

Proceso de RS de experimentos en Ingeniería del Software

\begin{tabular}{|c|c|c|c|c|c|c|c|}
\hline & equipo & $\begin{array}{l}\text { T07- } \\
\text { PBR }\end{array}$ & $0.78(a)$ & 0.1 & 10 & \multirow[t]{3}{*}{ n.s. } & \\
\hline & \multirow{2}{*}{$\begin{array}{l}\text { M11- Cost } \\
\text { per defect for } \\
\text { the defect } \\
\text { detection } \\
\text { phase }\end{array}$} & $\begin{array}{l}\text { T02- } \\
\text { CBR }\end{array}$ & 45 & 21 & 10 & & \\
\hline & & $\begin{array}{l}\text { T07- } \\
\text { PBR }\end{array}$ & 29 & 5 & 10 & & \\
\hline \multirow[t]{4}{*}{$\begin{array}{ll} & \mathrm{E} 1 \\
5 & \end{array}$} & \multirow[t]{2}{*}{$\begin{array}{l}\text { M04-Tasa } \\
\text { de detección } \\
\text { de fallos por } \\
\text { equipo }\end{array}$} & $\begin{array}{l}\text { T02- } \\
\text { CBR }\end{array}$ & 0.55 (a) & 0.12 & 10 & \multirow[t]{4}{*}{$\begin{array}{l}\text { M04/T07>T02 } \\
\text { M11/T02>T07 } \\
\text { n.s. }\end{array}$} & $\begin{array}{l}\text { Los valores han } \\
\text { sido tomados de la } \\
\text { gráfica }\end{array}$ \\
\hline & & $\begin{array}{l}\text { T07- } \\
\text { PBR }\end{array}$ & $0.68(a)$ & 0.08 & 10 & & \\
\hline & \multirow{2}{*}{$\begin{array}{l}\text { M11-Cost } \\
\text { per defect for } \\
\text { the defect } \\
\text { detection } \\
\text { phase }\end{array}$} & $\begin{array}{l}\text { T02- } \\
\text { CBR }\end{array}$ & 51 & 8 & 10 & & \\
\hline & & $\begin{array}{l}\text { T07- } \\
\text { PBR }\end{array}$ & 48 & 8 & 10 & & \\
\hline 6 & $\begin{array}{l}\text { M02- } \\
\text { Número de } \\
\text { defectos } \\
\text { encontrados }\end{array}$ & CBR & 11 & 24 & 22 & $\begin{array}{l}\text { M02/T02>T06 } \\
\text { M03/T02>T06 } \\
\text { M10/T06>T02 }\end{array}$ & \begin{tabular}{l}
\multicolumn{1}{c}{ es aprox } \\
tomado de la \\
gráfica \\
SD=3/2(Q3-Q1)
\end{tabular} \\
\hline
\end{tabular}


Proceso de RS de experimentos en Ingeniería del Software

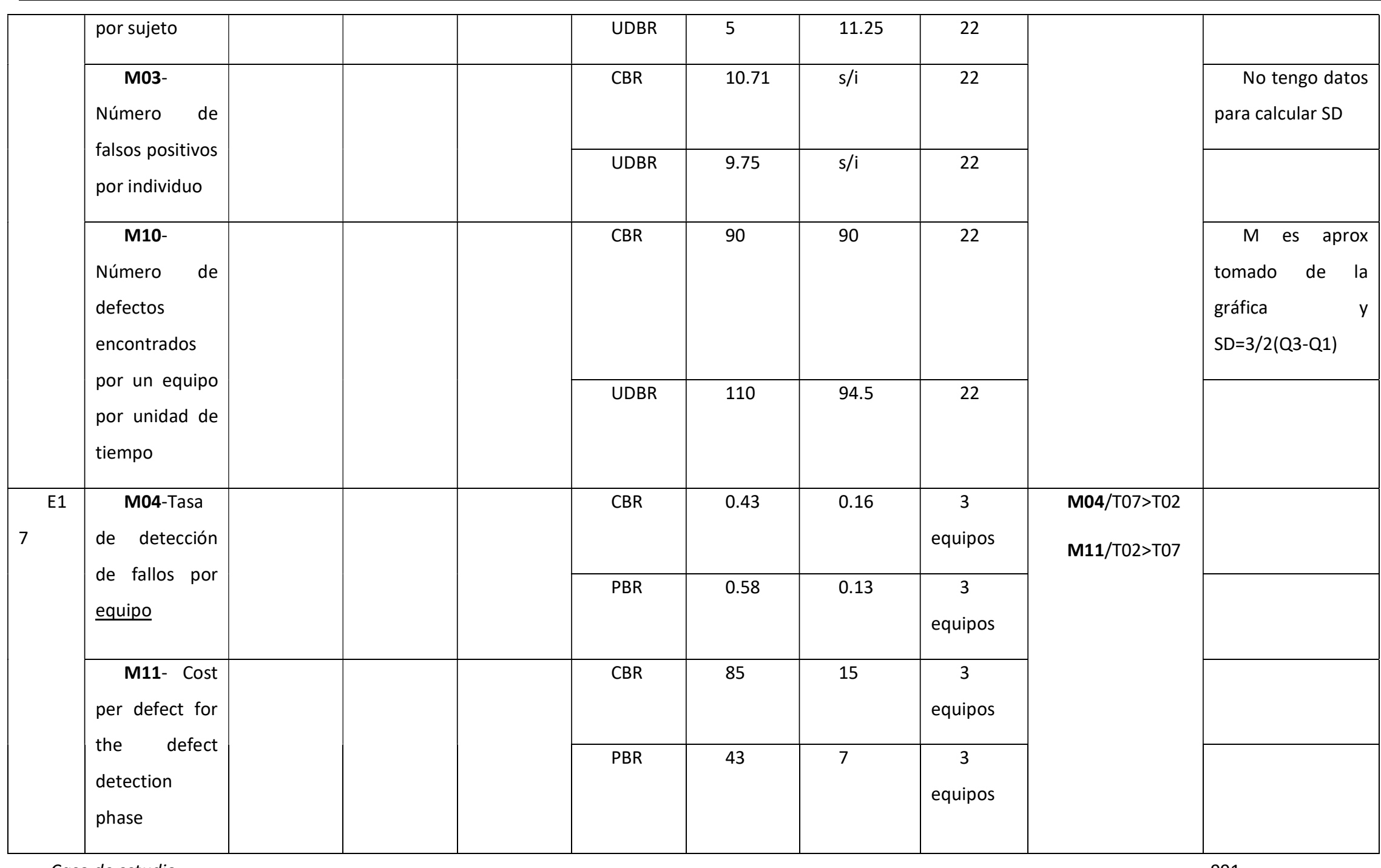


Extracción de Datos

Proceso de RS de experimentos en Ingeniería del Software

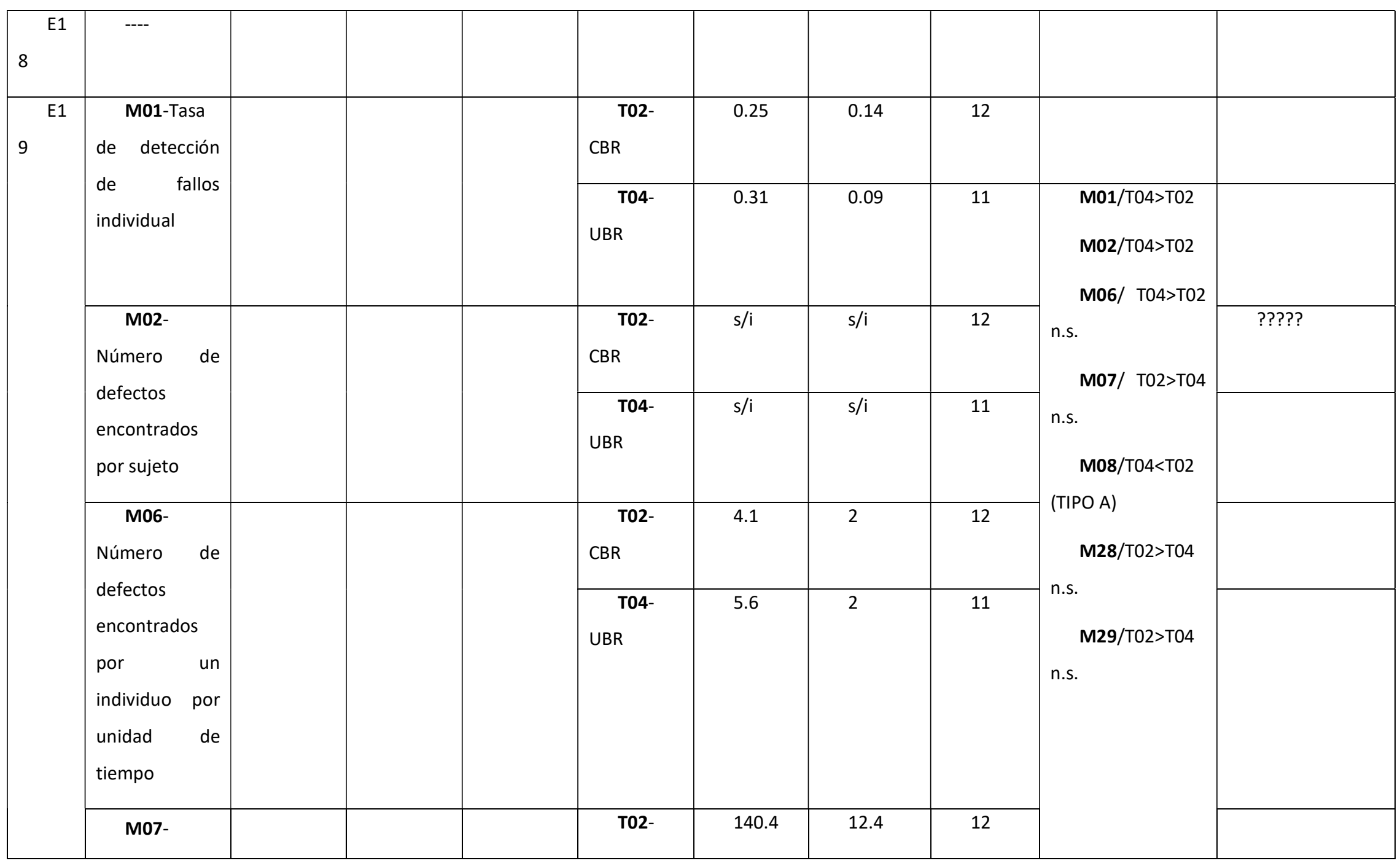


Proceso de RS de experimentos en Ingeniería del Software

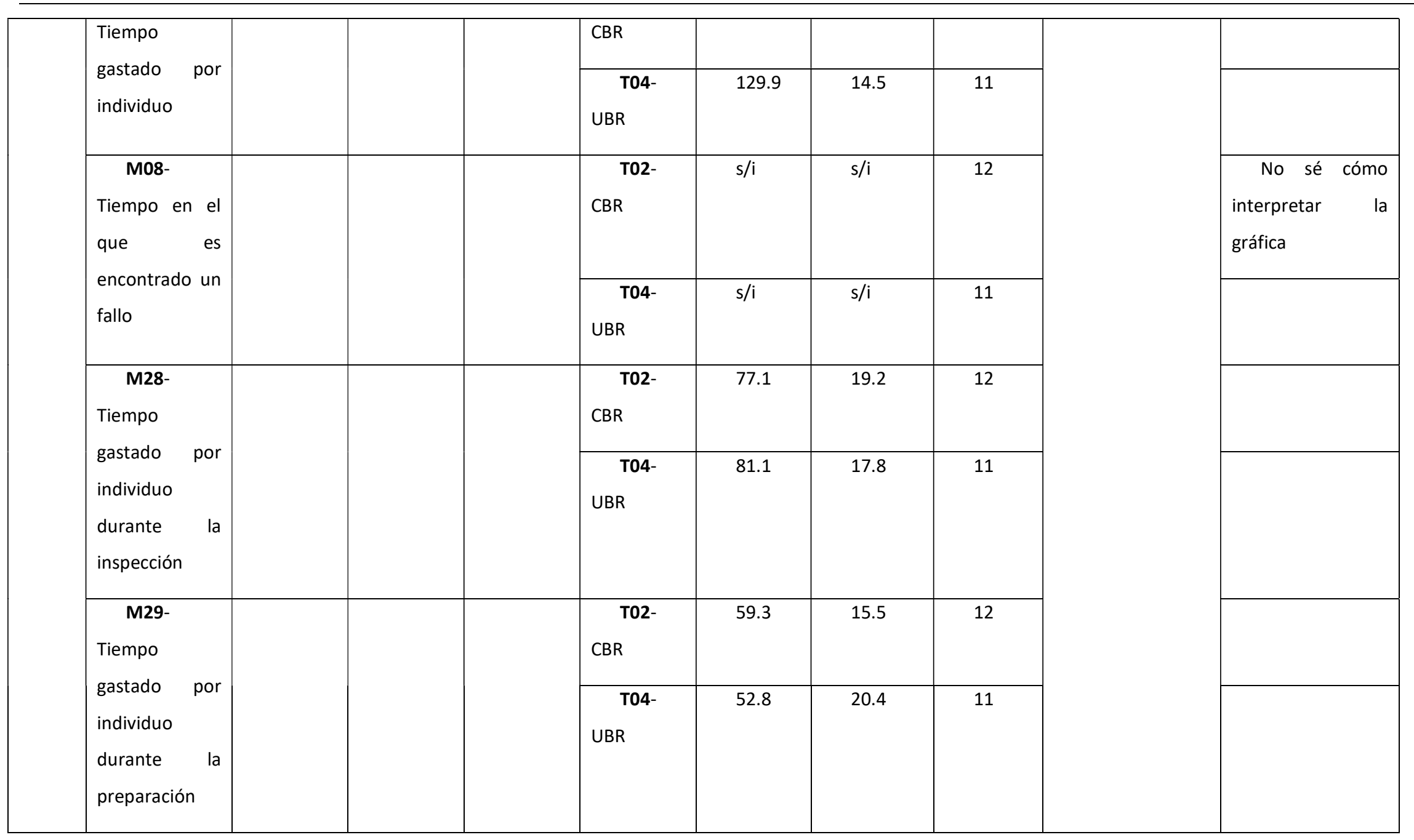


Extracción de Datos

Proceso de RS de experimentos en Ingeniería del Software

\begin{tabular}{|c|c|c|c|c|c|}
\hline $\begin{array}{l}\text { M13- Tasa } \\
\text { de detección } \\
\text { de fallos } \\
\text { individual (por } \\
\text { tipo de fallo A, } \\
\text { B, C) }\end{array}$ & $\begin{array}{l}\text { T02- } \\
\text { CBR }\end{array}$ & $\begin{array}{l}0.24(\mathrm{a}) \\
0.24(\mathrm{~b}) \\
0.3(\mathrm{c}) \\
0.24(\mathrm{a}+ \\
\text { b) }\end{array}$ & $\begin{array}{l}0.21 \\
0.13 \\
0.21 \\
0.16\end{array}$ & 12 & \\
\hline & $\begin{array}{l}\text { T04- } \\
\text { UBR }\end{array}$ & $\begin{array}{l}0.43(\mathrm{a}) \\
0.31(\mathrm{~b}) \\
0.18(\mathrm{c}) \\
0.37(\mathrm{a}+ \\
\text { b) }\end{array}$ & $\begin{array}{l}0.17 \\
0.15 \\
0.08 \\
0.12\end{array}$ & 11 & \\
\hline $\begin{array}{l}\text { M18- } \\
\text { Número de } \\
\text { revisores que }\end{array}$ & $\begin{array}{l}\text { T02- } \\
\text { CBR }\end{array}$ & $s / i$ & $s / i$ & 12 & $\begin{array}{l}\text { No sé cómo } \\
\text { interpretarlo } \\
\text { partir de la figs } 7-9\end{array}$ \\
\hline $\begin{array}{l}\text { cada fallo (por } \\
\text { tipo de fallo A, } \\
\text { B, C) }\end{array}$ & $\begin{array}{l}\text { T04- } \\
\text { UBR }\end{array}$ & $s / i$ & $s / i$ & 11 & \\
\hline $\begin{array}{l}\text { M31- } \\
\text { Número de }\end{array}$ & $\begin{array}{l}\text { T02- } \\
\text { CBR }\end{array}$ & $s / i$ & $s / i$ & 12 & $\begin{array}{l}\text { No sé cómo } \\
\text { interpretarlo }\end{array}$ \\
\hline
\end{tabular}


Proceso de RS de experimentos en Ingeniería del Software

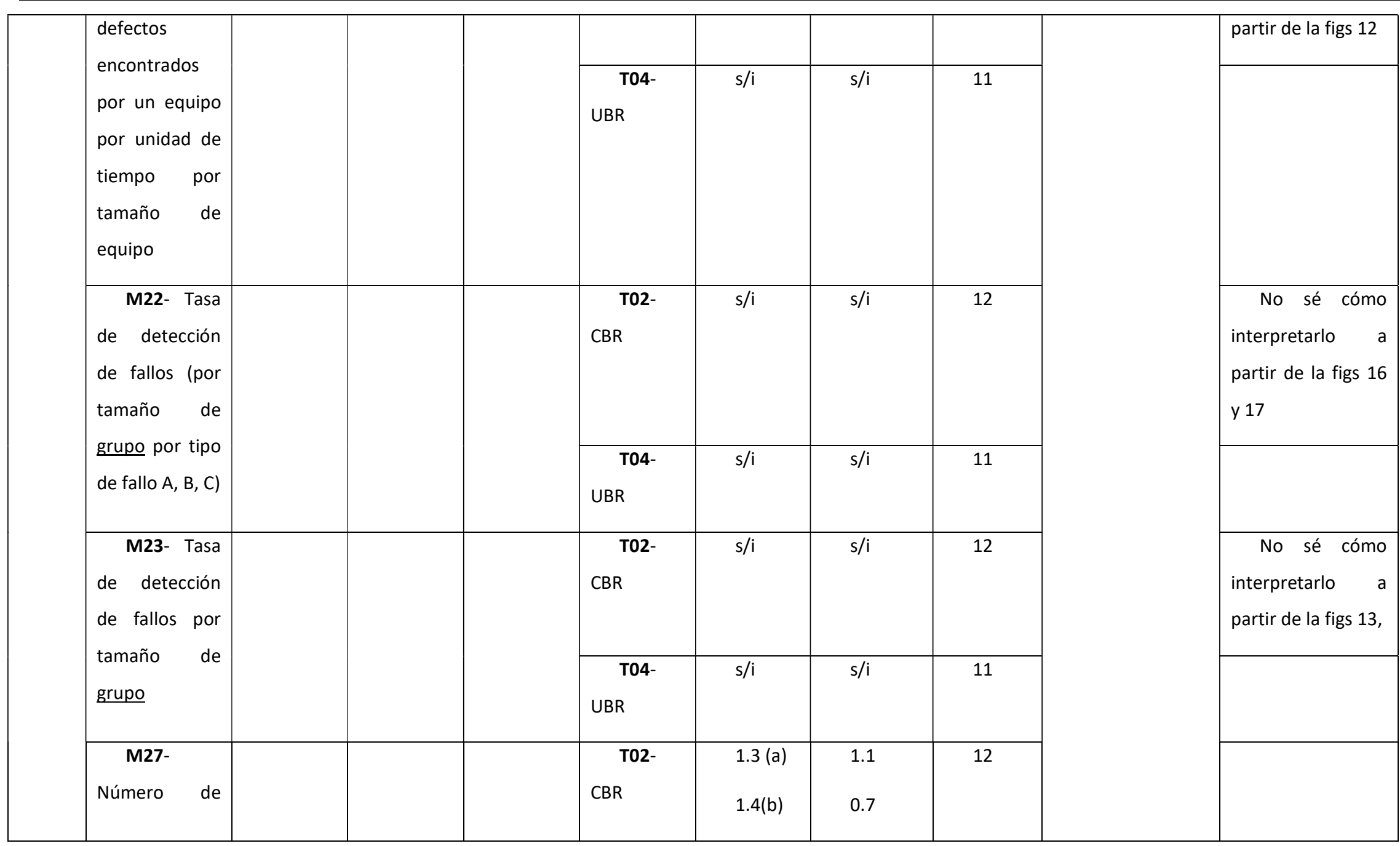




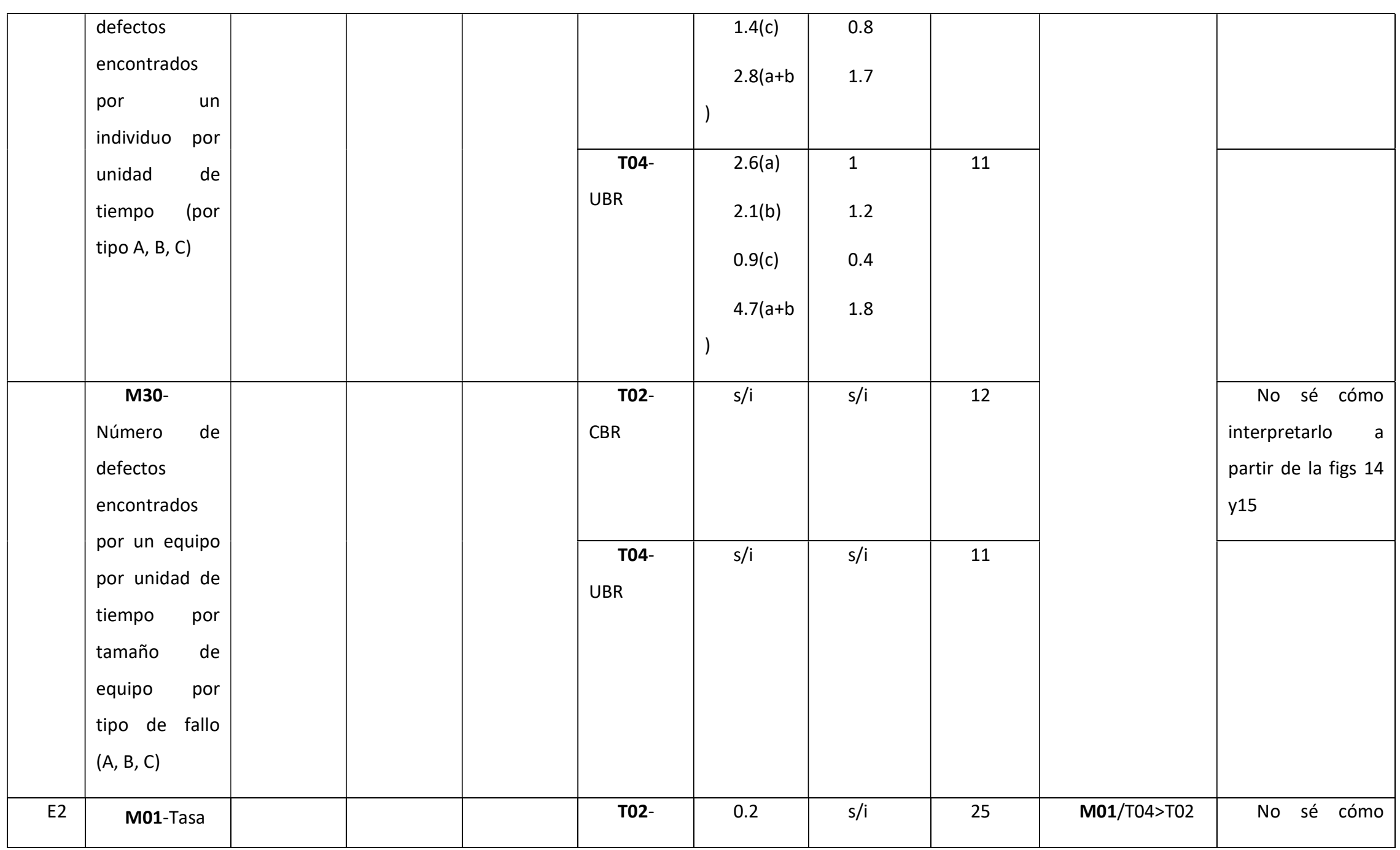


Proceso de RS de experimentos en Ingeniería del Software

\begin{tabular}{|c|c|c|c|c|c|c|c|}
\hline \multirow{2}{*}{\multicolumn{2}{|c|}{\begin{tabular}{|l|lr}
0 & de & detección \\
& de & fallos \\
& individual \\
\end{tabular}}} & CBR & & & & \multirow{8}{*}{$\begin{array}{l}\text { M06/T04>T02 } \\
\text { M07/ T04>T02 } \\
\text { M08/T02>T04 } \\
\text { M28/ T04>T02 }\end{array}$} & $\begin{array}{l}\text { interpretarlo } \\
\text { partir de la figs } 3\end{array}$ \\
\hline & & $\begin{array}{l}\text { T04- } \\
\text { UBR }\end{array}$ & 0.29 & $s / i$ & 27 & & \\
\hline & $\begin{array}{l}\text { M06- } \\
\text { Número de } \\
\text { defectos }\end{array}$ & $\begin{array}{l}\text { T02- } \\
\text { CBR }\end{array}$ & 3.4 & $s / i$ & 25 & & $\begin{array}{l}\text { No sé cómo } \\
\text { interpretarlo a } \\
\text { partir de la figs } 2\end{array}$ \\
\hline & \begin{tabular}{ll}
\multicolumn{2}{l}{ encontrados } \\
por & un \\
individuo & por \\
unidad & de \\
tiempo &
\end{tabular} & $\begin{array}{l}\text { T04- } \\
\text { UBR }\end{array}$ & 4.8 & $s / i$ & 27 & & \\
\hline & $\begin{array}{l}\text { M07- } \\
\text { Tiempo }\end{array}$ & $\begin{array}{l}\text { T02- } \\
\text { CBR }\end{array}$ & 132 & 25.1 & 25 & & \\
\hline & $\begin{array}{ll}\text { gastado } & \text { por } \\
\text { individuo } & \end{array}$ & \begin{tabular}{l}
\multicolumn{1}{c}{ T04- } \\
UBR
\end{tabular} & 144.9 & 28.8 & 27 & & \\
\hline & $\begin{array}{l}\text { M08- } \\
\text { Tiempo en el } \\
\text { que es }\end{array}$ & $\begin{array}{l}\text { T02- } \\
\text { CBR }\end{array}$ & $\mathrm{s} / \mathrm{i}$ & $s / i$ & $s / i$ & & $\begin{array}{l}\text { No sé cómo } \\
\text { interpretarlo a } \\
\text { partir de la figs } 1\end{array}$ \\
\hline & $\begin{array}{l}\text { encontrado un } \\
\text { fallo }\end{array}$ & T04- & $\mathrm{s} / \mathrm{i}$ & $s / i$ & $\mathrm{~s} / \mathrm{i}$ & & \\
\hline
\end{tabular}


Extracción de Datos

Proceso de RS de experimentos en Ingeniería del Software

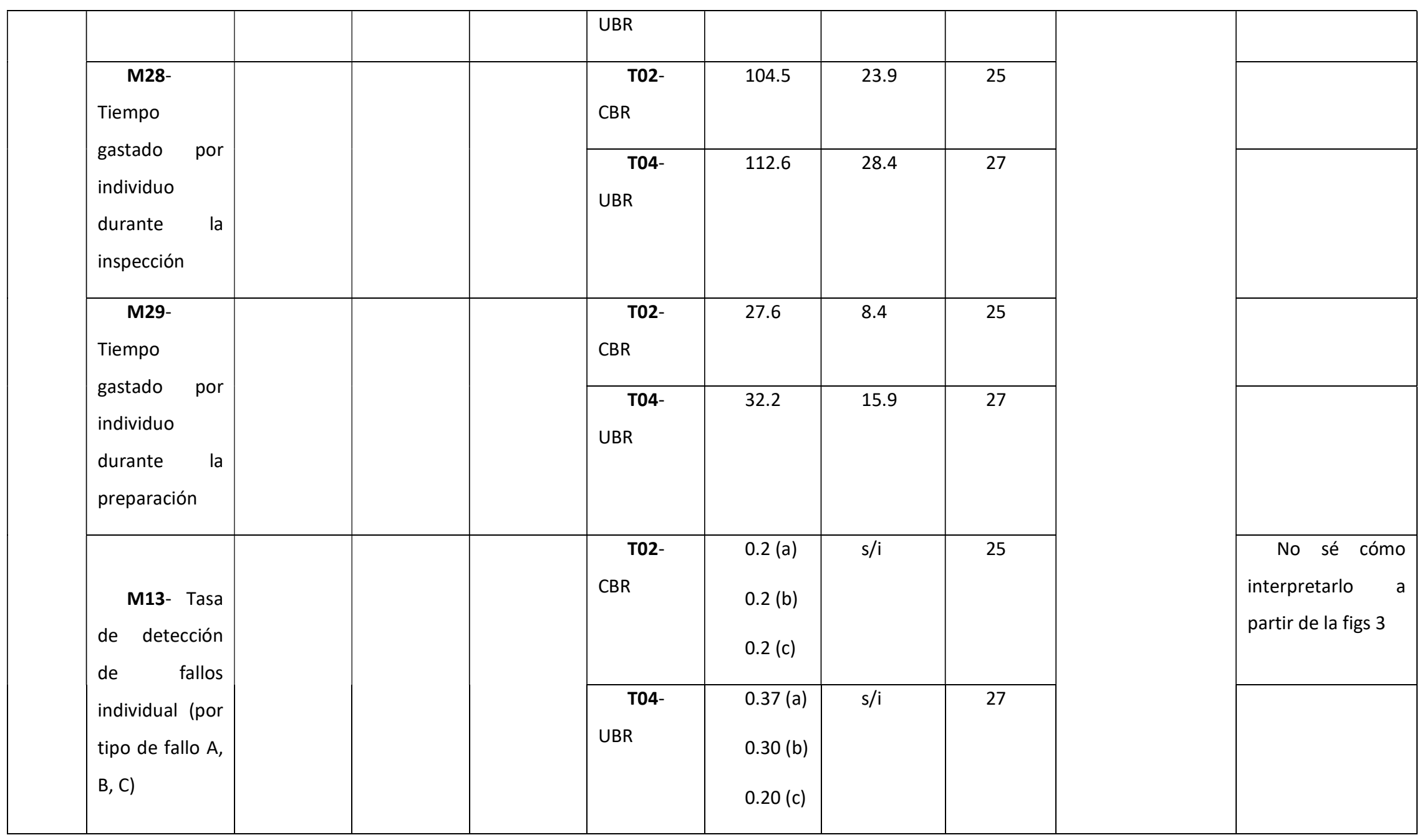


Proceso de RS de experimentos en Ingeniería del Software

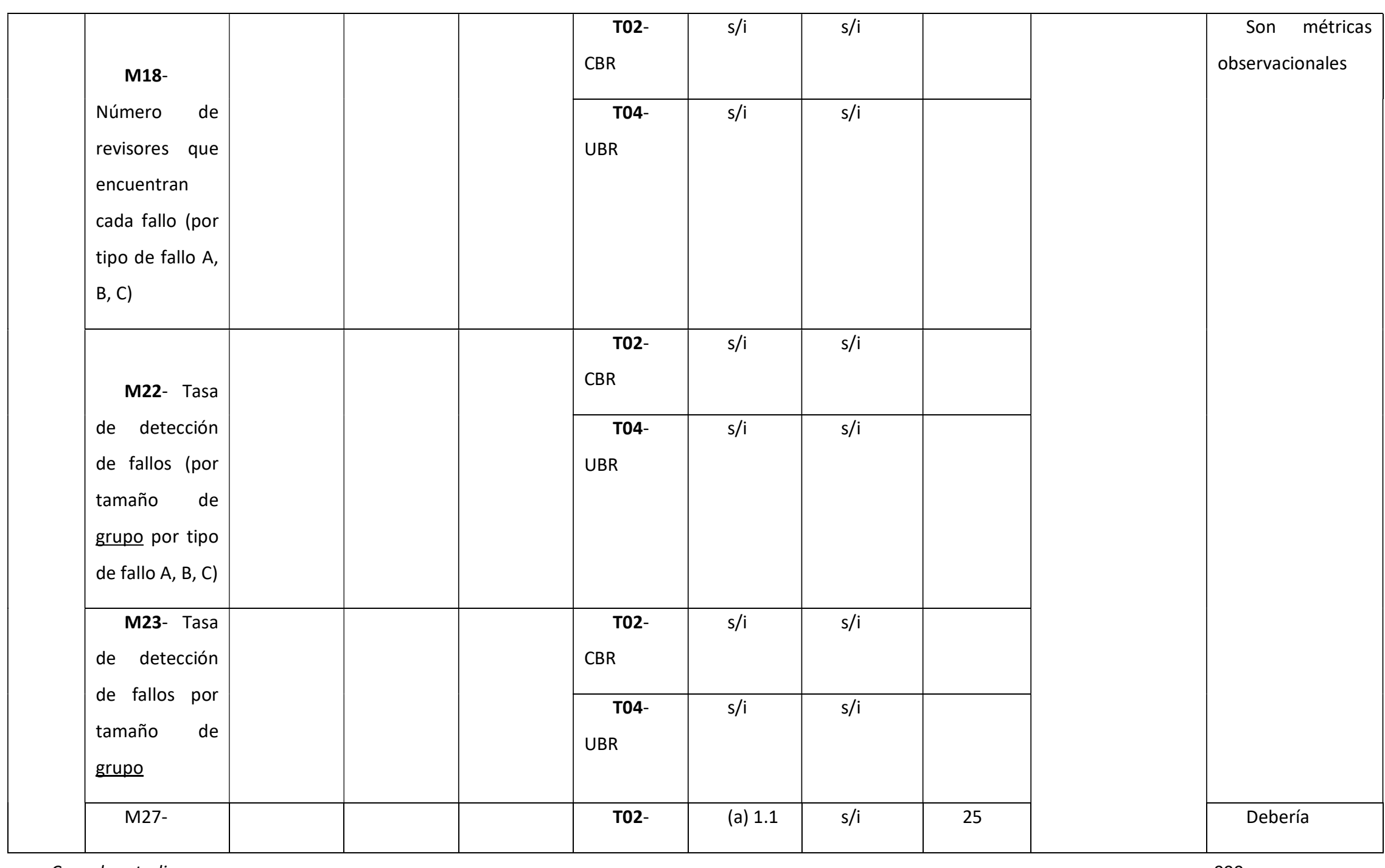


Extracción de Datos

Proceso de RS de experimentos en Ingeniería del Software

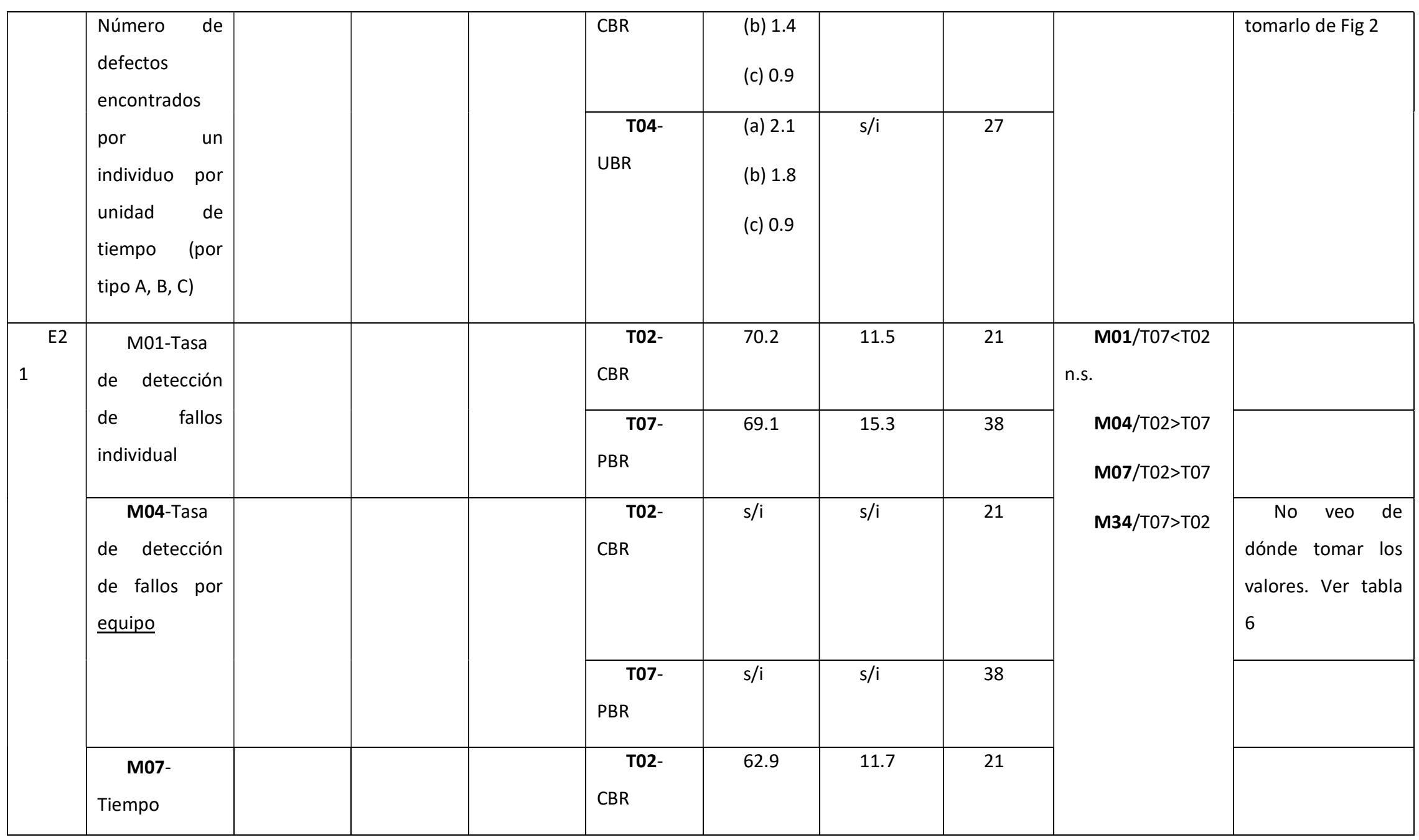


Proceso de RS de experimentos en Ingeniería del Software

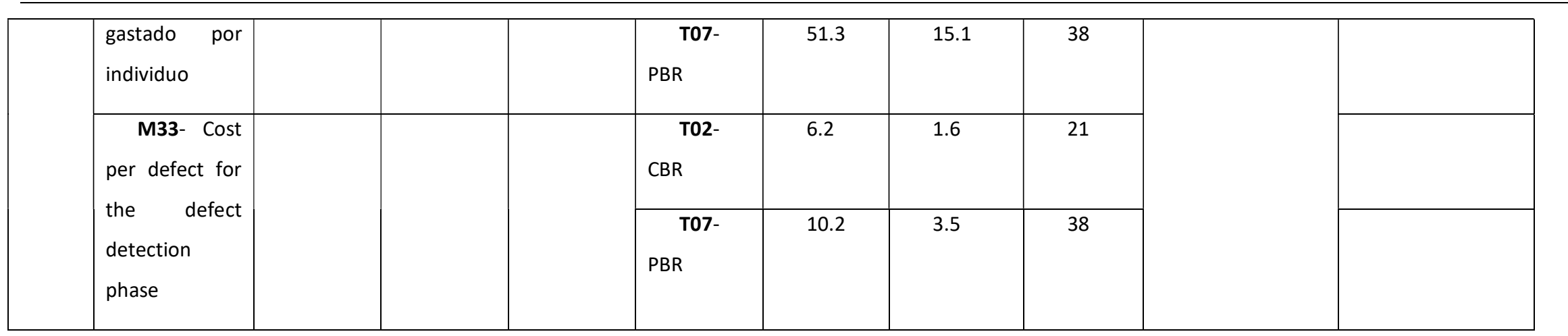




\subsubsection{Resumir características del contexto}

A continuación se presenta el modelo E05_Resumen del contexto organizacional.

\begin{tabular}{|c|c|c|c|c|c|}
\hline \multirow{2}{*}{ ST. } & \multirow[t]{2}{*}{ SUJETOS } & \multirow[t]{2}{*}{ AMBIENTE } & \multicolumn{3}{|c|}{ PROCESO EXPERIMENTAL } \\
\hline & & & TAREA & DURACIÓN & OBJETOS \\
\hline 01 & Estudiantes & $\begin{array}{l}\text { Laboratori } \\
\text { o }\end{array}$ & $\begin{array}{lr} & \text { Requisito } \\
\mathrm{s} & \end{array}$ & & \\
\hline 02 & Estudiantes & $\begin{array}{l}\text { Laboratori } \\
\text { o }\end{array}$ & $\begin{array}{ll} & \text { Requisito } \\
\mathrm{S} & \end{array}$ & & \\
\hline $03^{E}$ & Estudiantes & $\begin{array}{l}\text { Laboratori } \\
\text { o }\end{array}$ & $\begin{array}{lr} & \text { Requisito } \\
\mathrm{s} & \end{array}$ & & \\
\hline $\begin{array}{l}\mathrm{E} \\
04\end{array}$ & Estudiantes & $\begin{array}{l}\text { Laboratori } \\
\text { o }\end{array}$ & $\begin{array}{ll} & \text { Requisito } \\
\mathrm{s} & \end{array}$ & & \\
\hline $05^{E}$ & $\begin{array}{ll} & \text { Profesionale } \\
\mathrm{s} & \end{array}$ & Industria & $\begin{array}{ll} & \text { Requisito } \\
\mathrm{s} & \end{array}$ & & \\
\hline 09 & Estudiantes & $\begin{array}{l}\text { Laboratori } \\
\text { o }\end{array}$ & $\begin{array}{lr} & \text { Requisito } \\
\mathrm{s} & \end{array}$ & & \\
\hline $10^{E}$ & Estudiantes & $\begin{array}{l}\text { Laboratori } \\
\text { o }\end{array}$ & $\begin{array}{lr} & \text { Requisito } \\
\mathrm{s} & \end{array}$ & & \\
\hline $06^{E}$ & Estudiantes & $\begin{array}{l}\text { Laboratori } \\
\text { o }\end{array}$ & $\begin{array}{ll} & \text { Requisito } \\
\mathrm{S} & \end{array}$ & & \\
\hline $\begin{array}{l}\mathrm{E} \\
07\end{array}$ & Estudiantes & $\begin{array}{l}\text { Laboratori } \\
\text { o }\end{array}$ & $\begin{array}{lr} & \text { Requisito } \\
\mathrm{s} & \end{array}$ & & \\
\hline 08 & Estudiantes & $\begin{array}{ll} & \text { Laboratori } \\
& \end{array}$ & $\begin{array}{ll} & \text { Requisito } \\
\mathrm{S} & \end{array}$ & & \\
\hline$E$ & Estudiantes & Laboratori & Requisito & & \\
\hline
\end{tabular}

Caso de estudio 


\begin{tabular}{|c|c|c|c|c|c|}
\hline \multirow{2}{*}{$\begin{array}{l}\text { E } \\
\text { ST. }\end{array}$} & \multirow[t]{2}{*}{ SUJETOS } & \multirow[t]{2}{*}{ AMBIENTE } & \multicolumn{3}{|c|}{ PROCESO EXPERIMENTAL } \\
\hline & & & TAREA & DURACIÓN & OBJETOS \\
\hline 11 & & 0 & $\mathrm{~s}$ & & \\
\hline $12^{E}$ & Estudiantes & $\begin{array}{l}\text { Laboratori } \\
\text { o }\end{array}$ & Código & & \\
\hline $13^{E}$ & Estudiantes & $\begin{array}{l}\text { Laboratori } \\
\text { o }\end{array}$ & Código & & \\
\hline $14^{E}$ & Estudiantes & $\begin{array}{l}\text { Laboratori } \\
\text { o }\end{array}$ & Código & & \\
\hline $15^{E}$ & Estudiantes & $\begin{array}{l}\text { Laboratori } \\
\text { o }\end{array}$ & Código & & \\
\hline $16^{E}$ & Estudiantes & $\begin{array}{l}\text { Laboratori } \\
\text { o }\end{array}$ & UML & & \\
\hline $17^{E}$ & Estudiantes & $\begin{array}{l}\text { Laboratori } \\
\text { o }\end{array}$ & UML & & \\
\hline $18^{E}$ & Estudiantes & $\begin{array}{l}\text { Laboratori } \\
\end{array}$ & UML & & \\
\hline $19^{E}$ & Estudiantes & $\begin{array}{l}\text { Laboratori } \\
\end{array}$ & Diseño & & \\
\hline $20^{\mathrm{E}}$ & Estudiantes & $\begin{array}{l}\text { Laboratori } \\
\text { o }\end{array}$ & Diseño & & \\
\hline 21 & Estudiantes & $\begin{array}{l}\text { Laboratori } \\
\text { o }\end{array}$ & Diseño & & \\
\hline $22^{E}$ & Estudiantes & $\begin{array}{l}\text { Laboratori } \\
\end{array}$ & Diseño & & \\
\hline $23^{E}$ & Estudiantes & $\begin{array}{l}\text { Laboratori } \\
\end{array}$ & Diseño & & \\
\hline
\end{tabular}

\subsubsection{Resumir resultados experimentales y observacionales}




\section{Proceso de RS de experimentos en Ingeniería del Software}

A continuación se presenta el modelo E06_Resumen de resultados experimentales y observacionales para los estudios seleccionados en esta revisión. 


\begin{tabular}{|c|c|c|c|c|c|}
\hline ID & NIVELES & MÉTRICAS & $\begin{array}{c}\text { RESULTADOS } \\
\text { EXPERIMENTALES }\end{array}$ & RESULTADOS OBSERVACIONALES & NOTAS \\
\hline E01 & T01, T02, T03 & $\begin{array}{l}\text { M01, M04, } \\
\text { M32 }\end{array}$ & $\begin{array}{l}\text { M01/T03>T01>T02 } \\
\text { (CRUISE) } \\
\text { M01/T01>T03>T02 } \\
\text { (WLMS) } \\
\text { M04/T01>T02 } \\
\text { M04/T03>T01>T02 }\end{array}$ & $\begin{array}{l}\text { M32/T03> T01, T02 (para defectos del tipo } \\
\text { DT para los cuales fueron creados los } \\
\text { escenarios, CRUISE) } \\
\text { M32/T03> T01> T02 (para defectos del tipo } \\
\text { MF para los cuales fueron creados los } \\
\text { escenarios, CRUISE) } \\
\text { M32/ T01, T02> T03 (para defectos del tipo } \\
\text { IF para los cuales fueron creados los escenarios, } \\
\text { CRUISE) } \\
\text { M32/T03> T01> T02 (para defectos del tipo } \\
\text { DT para los cuales fueron creados los } \\
\text { escenarios, WLMS) } \\
\text { M32/T03=T01=T02 (para defectos del tipo } \\
\text { MF, IF para los cuales fueron creados los } \\
\text { escenarios, WLMS) }\end{array}$ & \\
\hline E02 & T01, T02, T03 & $\begin{array}{l}\text { M04, M07, } \\
\text { M32 }\end{array}$ & $\begin{array}{l}\text { M04/T02>T01>T03 } \\
\text { n.s. } \\
\text { M04/ T01>T02 >T03 }\end{array}$ & $\begin{array}{l}\text { M32/(T03,DT)>(T03,otras } \\
\text { fallas })>(T 03, M F)=(T 03, I F) \text { para CRUISE } \\
\text { M32/(T03,DT })>(T 03, \text { otras } \quad \text { fallas })>(T 03, I F)\end{array}$ & No hay información sobre M07 \\
\hline
\end{tabular}


Proceso de RS de experimentos en Ingeniería del Software

\begin{tabular}{|c|c|c|c|c|c|}
\hline & & & $\begin{array}{l}\text { para CRUISE } \\
\text { M04/ T02=T03>T01 } \\
\text { para WLMS } \\
\text { M07/no se dice nada } \\
\text { de las técnicas, sólo el \% } \\
\text { de estudiantes que } \\
\text { terminaron en un lapso } \\
\text { dado. }\end{array}$ & $\begin{array}{l}>(\mathrm{TO3}, \mathrm{MF}) \text { para WLMS } \\
\text { M32/(T03, otras fallas })>(T 03, \mathrm{DT})=(\mathrm{T03}, \mathrm{IF})> \\
(\mathrm{T} 03, \mathrm{MF})\end{array}$ & \\
\hline E03 & T02, T03 & $\begin{array}{cc}\text { M01, } & \text { M04, } \\
\text { M07, M12 }\end{array}$ & $\begin{array}{l}\text { M01/T03>T02 n.s. } \\
\text { M04/ T03>T02 n.s. } \\
\text { M07/ T02>T03 n.s. } \\
\text { M12/ }\end{array}$ & & No hay información sobre M12 \\
\hline E04 & T02, T03 & M04 & $\begin{array}{l}\text { M04/T03>T02 } \\
\text { (RONDA1) } \\
\text { M04/T02>T03 } \\
\text { (RONDA2) }\end{array}$ & & \\
\hline E05 & $\begin{array}{l}\text { T01, T02, T03 } \\
\text { PROFESIONALE }\end{array}$ & M04 & $\mathrm{M04/T03>T01>T02}$ & & \\
\hline
\end{tabular}




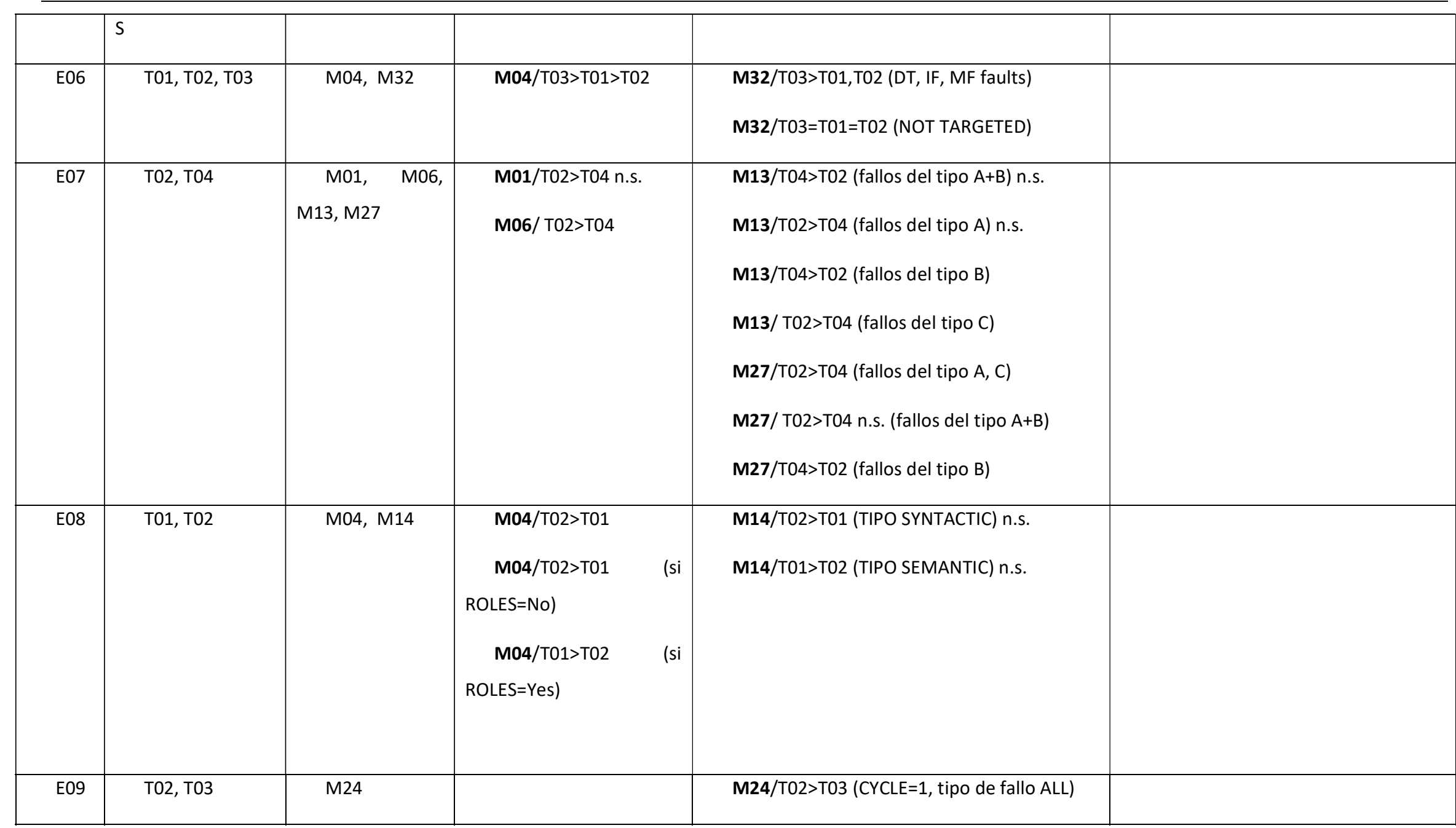


Proceso de RS de experimentos en Ingeniería del Software

\begin{tabular}{|c|c|c|c|c|}
\hline & & & & $\begin{array}{l}\text { M24/T03>T02 (CYCLE }=2 \text {, tipo de fallo ALL) } \\
\text { n.s. } \\
\text { M24/T03>T02 (tipo de fallo MAJOR) }\end{array}$ \\
\hline E10 & ????? & & & \\
\hline E11 & & $\begin{array}{l}\text { No presenta } \\
\text { nada }\end{array}$ & & \\
\hline E12 & T02, T04, T05 & $\begin{array}{l}\text { M01, M02, } \\
\text { M03, M07, M16, } \\
\text { M19, }\end{array}$ & 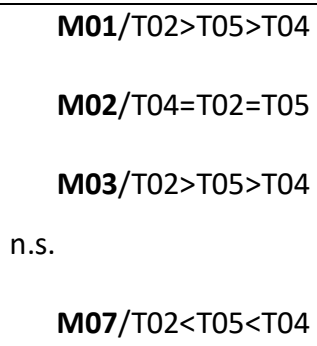 & 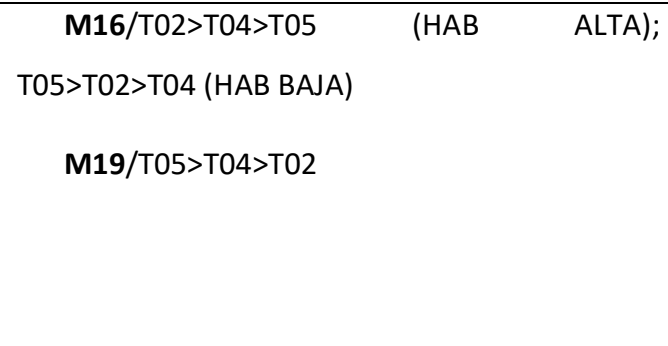 \\
\hline E13 & T02, T07 & M04, M11 & $\begin{array}{l}\text { M04/T07>T02 } \\
\text { M11/T07>T02 }\end{array}$ & \\
\hline E14 & T02, T07 & M04, M11 & $\begin{array}{l}\text { M04/T07>T02 n.s. } \\
\text { M11/T07>T02 n.s. }\end{array}$ & \\
\hline
\end{tabular}




\begin{tabular}{|c|c|c|c|c|c|}
\hline E16 & T02, T06 & $\begin{array}{l}\text { M02, M03, } \\
\text { M10 }\end{array}$ & $\begin{array}{l}\text { M02/T02>T06 } \\
\text { M03/T02>T06 } \\
\text { M10/T06>T02 }\end{array}$ & & \\
\hline E17 & T02, T07 & M04, M11 & $\begin{array}{l}\text { M04/T07>T02 } \\
\text { M11/T02>T07 }\end{array}$ & & \\
\hline
\end{tabular}


Proceso de RS de experimentos en Ingeniería del Software

\begin{tabular}{|c|c|c|c|c|c|}
\hline & & & M29/T02>T04 n.s. & $\begin{array}{l}\text { M23/T04>T02 } \\
\text { M27/T04>T02 (para fallos del tipo: A,B,A-B); } \\
\text { T02>T04 (para fallos del tipo C) } \\
\text { M30/ T04>T02 (para fallos del tipo A y A-B) } \\
\text { M31/T04>T02 }\end{array}$ & \\
\hline E20 & T02, T04 & $\begin{array}{l}\text { M01, M06, } \\
\text { M07, M08, M13, } \\
\text { M18, M22, M23, } \\
\text { M27, } \\
\text { M28, M29 }\end{array}$ & $\begin{array}{l}\text { M01/T04>T02 } \\
\text { M06/T04>T02 } \\
\text { M07/ T04>T02 } \\
\text { M08/T02>T04 } \\
\text { M28/ T04>T02 } \\
\text { M29/ T04>T02 }\end{array}$ & $\begin{array}{l}\text { M13/T04>T02 (para fallos del tipo A y B); } \\
\text { T04=T02 (para fallos del tipo C) } \\
\text { M18/T04>T02 (para fallos del tipo A, B); } \\
\text { T02>T04 (para fallos del tipo C) } \\
\text { M22/T04>T02 (para fallos del tipo A y B) } \\
\text { M23/T04>T02 } \\
\text { M27/T04>T02 (para fallos del tipo A y B); } \\
\text { T04=T02 (para fallos del tipo C) }\end{array}$ & \\
\hline E21 & T02, T07 & $\begin{array}{r}\text { M01, M04, } \\
\text { M07, M11, M34 }\end{array}$ & $\begin{array}{l}\text { M01/T07<T02 n.s. } \\
\text { M04/T02>T07 } \\
\text { M07/T02>T07 }\end{array}$ & & Falta M11 \\
\hline
\end{tabular}




\begin{tabular}{|c|c|c|c|c|c|}
\hline & & & M34/T07>T02 & & \\
\hline E22 & T02, T07 & $\begin{array}{l}\text { M01, M02, } \\
\text { M04, M07, M09, } \\
\text { M12 } \\
\text { M14, M17, } \\
\text { M20, M21, M33 }\end{array}$ & $\begin{array}{l}\text { M01/T02>T07 n.s. } \\
\text { M02/T07>T02 } \\
\text { M04/T02>T07 n.s. } \\
\text { M07/ T02>T07 } \\
\text { M12/T07>T02 }\end{array}$ & $\begin{array}{l}\text { M14/TO7>T02 n.s. (para fallos del tipo } \\
\text { SEMANTIC); T02>T07 n.s. (para fallos del tipo } \\
\text { SYNTACTIC); T07>T02 (para fallos del tipo } \\
\text { CONSISTENCY) } \\
\text { M17/T02>T07 n.s. (para diagramas del tipo } \\
\text { CLASS); T07>T02 n.s. (para diagramas del tipo } \\
\text { SEC Y ACTIV); T07>T02 (para diagramas del tipo } \\
\text { COMPONENTS) } \\
\text { M20/T02>T07 n.s. (para perspectiva del tipo } \\
\text { DESIGNER); T07>T02 n.s. (para perspectivas del } \\
\text { tipo USER, IMPLEMENTER) } \\
\text { M21/T02>T07 (para las perspectivas del tipo } \\
\text { USER, DESIGNER, IMPLEMENTER) } \\
\text { M33/T02>T07 (para perspectivas del tipo } \\
\text { USER, DESIGNER); T07>T02 (para perspectiva } \\
\text { del tipo IMPLEMENTER para la especificación } \\
\text { "Seminar"); T02>T07 (para perspectiva del tipo } \\
\text { IMPLEMENTER) para la especificación } \\
\text { “Hospital") }\end{array}$ & Falta M09 \\
\hline
\end{tabular}


Proceso de RS de experimentos en Ingeniería del Software

\begin{tabular}{|l|l|l|l|l|l|}
\hline E23 & & & & & \\
\hline
\end{tabular}


Extracción de Datos

Proceso de RS de experimentos en Ingeniería del

Software

\subsection{ESTABLECER GRUPOS POTENCIALMENTE AGREGABLES}

\begin{tabular}{|c|c|c|c|}
\hline \multicolumn{4}{|l|}{ Objetivo } \\
\hline \multicolumn{4}{|c|}{$\begin{array}{l}\text { Organizar los experimentos de un GCA de manera que se pueda establecer fácilmente cuáles de } \\
\text { ellos deberían ser agregados en la futura fase de SíNTESIS DE DATOS; tomando en cuenta para ello que } \\
\text { existan dos o más experimentos que midan la misma métrica para un mismo par de niveles }\end{array}$} \\
\hline \multicolumn{2}{|l|}{ Entrada } & \multicolumn{2}{|l|}{ Salida } \\
\hline \multicolumn{2}{|c|}{$\begin{array}{l}\text { - } \quad \text { E03_Clusters de lectura } \\
\text { - } \quad \text { E04_Resumen de datos cuantitativos } \\
\text { - } \quad \text { E05_Resumen de características del contexto } \\
\text { - E06-Resumen de resultados experimentales y } \\
\text { observacionales }\end{array}$} & \multicolumn{2}{|c|}{$\begin{array}{l}\text { E09_Resumen de grupos potencialmente } \\
\text { agregables }\end{array}$} \\
\hline \multicolumn{4}{|l|}{ Tareas } \\
\hline & \multicolumn{2}{|l|}{ Entradas } & Salidas \\
\hline $\begin{array}{l}\text { 2.7.1. Analizar densidad de } \\
\text { estudios por métrica }\end{array}$ & \multicolumn{2}{|c|}{$\begin{array}{l}\text { - } \text { E03_Clusters de lectura } \\
\text { - } \text { E04_Resumen de datos } \\
\text { cuantitativos } \\
\text { - E05_Resumen de } \\
\text { características del contexto } \\
-\quad \text { E06-Resumen de resultados } \\
\text { experimentales } \\
\text { observacionales }\end{array}$} & $\begin{array}{l}\text { E07_Densidad de estudios } \\
\text { por métrica }\end{array}$ \\
\hline $\begin{array}{l}\text { 2.7.2. Analizar densidad de } \\
\text { estudios por métrica y } \\
\text { contexto }\end{array}$ & $\begin{array}{l}\text { E07_Densida } \\
\text { métrica }\end{array}$ & de estudios por & $\begin{array}{l}\text { E08-Densidad de estudios } \\
\text { por métrica y contexto }\end{array}$ \\
\hline $\begin{array}{l}\text { 2.7.3. Establecer grupos } \\
\text { agregables }\end{array}$ & $\begin{array}{l}\text { - E07_Densida } \\
\text { métrica } \\
\text { - E08-Densida } \\
\text { métrica y co }\end{array}$ & $\begin{array}{l}\text { de estudios por } \\
\text { de estudios por } \\
\text { exto }\end{array}$ & $\begin{array}{l}\text { E09_Resumen de grupos } \\
\text { potencialmente agregables }\end{array}$ \\
\hline & & & \\
\hline
\end{tabular}




\subsubsection{Analizar densidad de estudios por métrica}

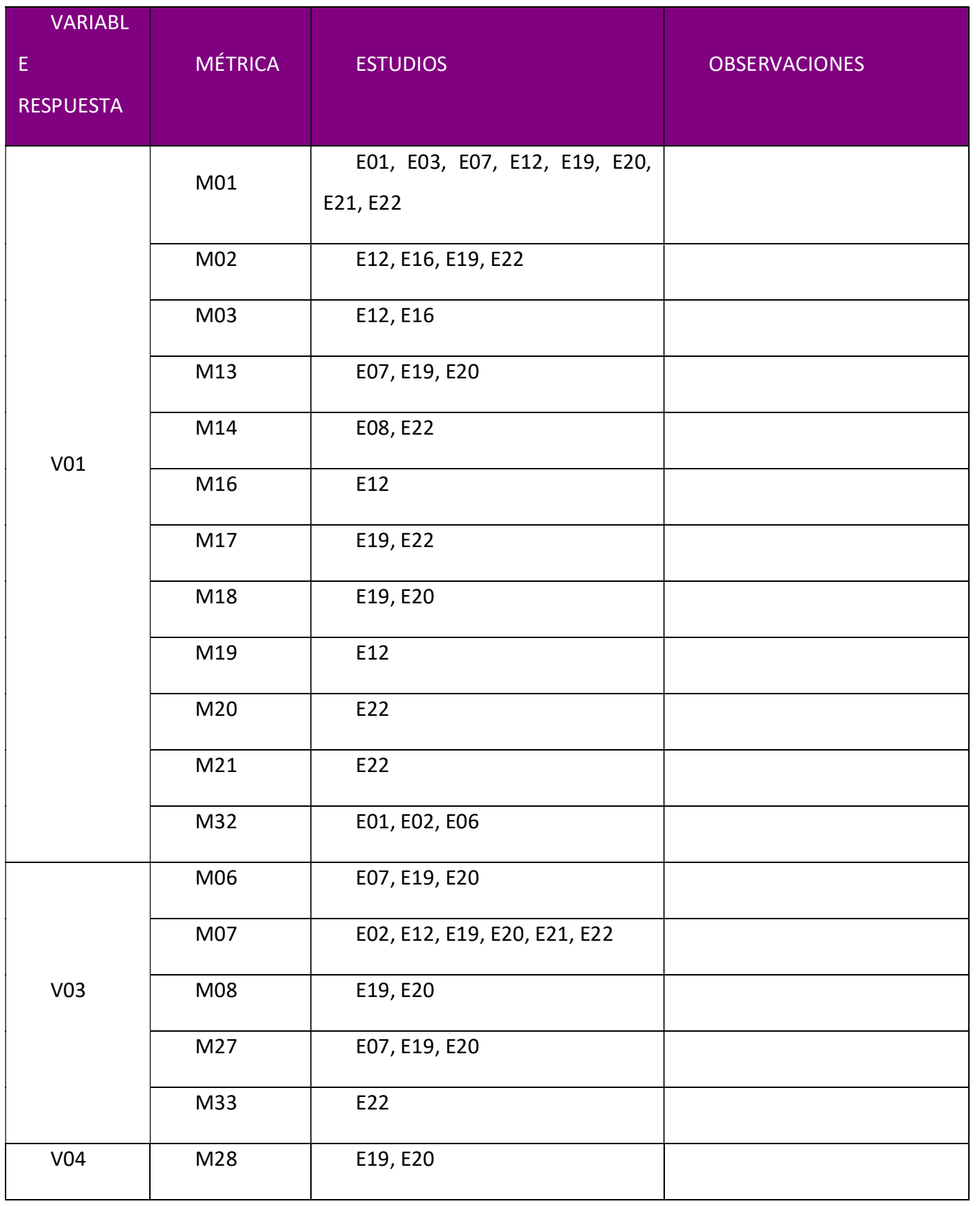

Caso de estudio 
Extracción de Datos

Proceso de RS de experimentos en Ingeniería del

Software

\begin{tabular}{|c|c|c|c|}
\hline \multicolumn{1}{|l|}{ VARIABL } & MÉTRICA & ESTUDIOS & OBSERVACIONES \\
RESPUESTA & & & \\
\hline V05 & M29 & E19, E20 & \\
\hline \multirow{2}{*}{ V07 } & M11 & E13, E14, E15, E17 & \\
\cline { 2 - 4 } & M34 & E21 & \\
\hline
\end{tabular}

2.7.2. Analizar densidad de estudios por métrica y contexto

TAREA: REQUISITOS

TIPO DE SUJETO: ESTUDIANTES

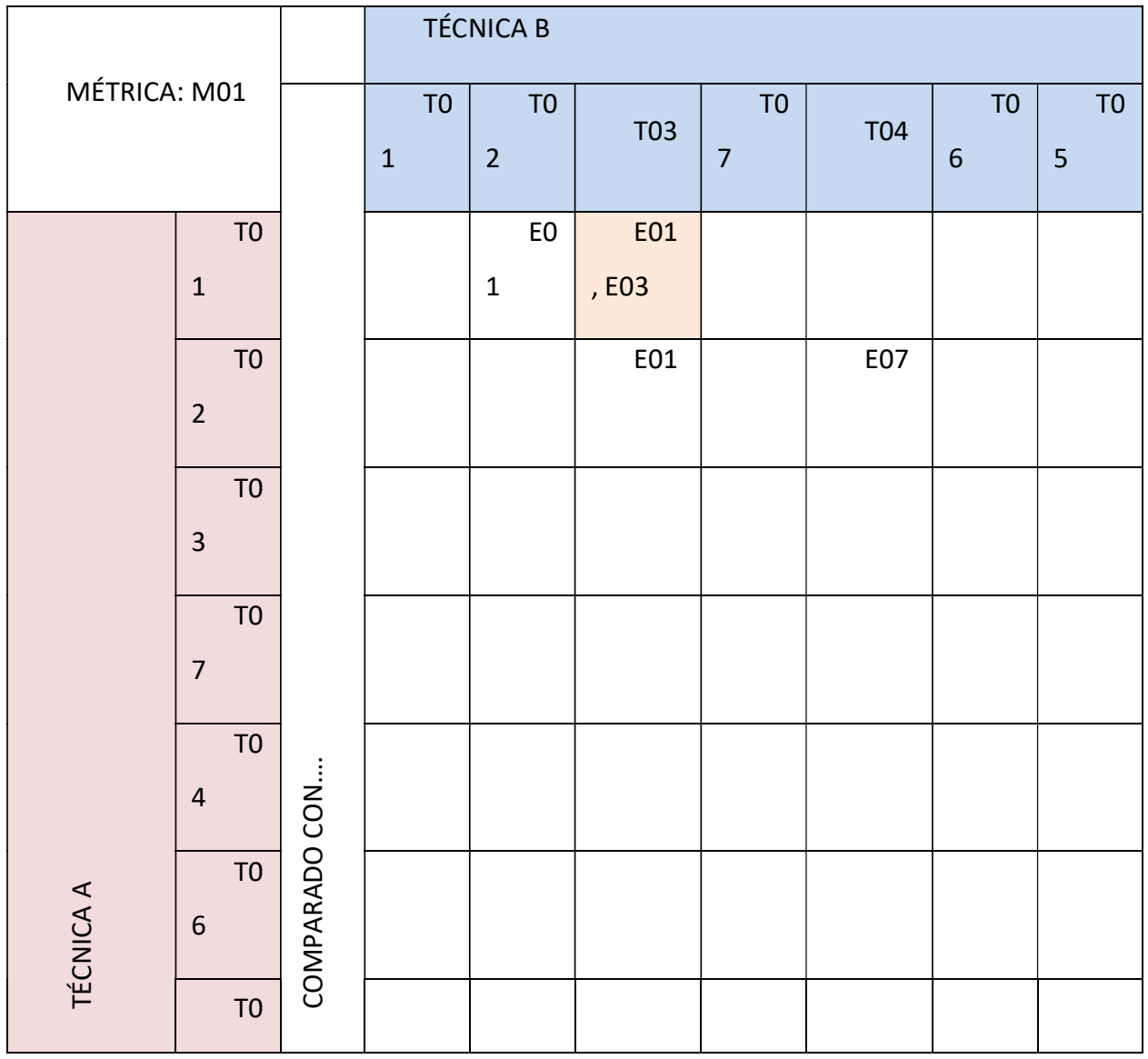




\begin{tabular}{|l|l|l|l|l|l|l|l|l|l|}
\hline & 5 & & & & & & & & \\
\hline
\end{tabular}

TAREA: REQUISITOS

TIPO DE SUJETO: ESTUDIANTES

\begin{tabular}{|c|c|c|c|c|c|c|c|c|c|}
\hline & & & \multicolumn{7}{|c|}{ TÉCNICA B } \\
\hline \multicolumn{2}{|c|}{ MÉTRICA: M04 } & & 1 & $T$ & & $\mathrm{~T}$ & $\mathrm{~T}$ & $T$ & TO \\
\hline \multirow{5}{*}{ 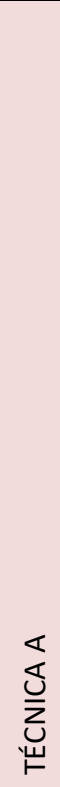 } & $\begin{array}{lr} & \text { T0 } \\
1 & \end{array}$ & & & $\begin{array}{l}\text { E01, E05, } \\
\text { E02, E06, } \\
\text { E08 }\end{array}$ & $\begin{array}{l}\text { E02; } \\
\text { E01; E05; } \\
\text { E06 }\end{array}$ & & & & \\
\hline & $2 \begin{array}{ll}\text { T0 } \\
2\end{array}$ & & & & $\begin{array}{l}\text { E02, } \\
\text { E04, E01, } \\
\text { E03, E05, } \\
\text { E06 }\end{array}$ & & & & \\
\hline & 3 & zo & & & & & & & \\
\hline & $\begin{array}{rr} & \text { T0 } \\
7 & \end{array}$ & 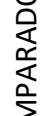 & & & & & & & \\
\hline & TO & U & & & & & & & \\
\hline
\end{tabular}

Caso de estudio 
Extracción de Datos

Proceso de RS de experimentos en Ingeniería del

Software

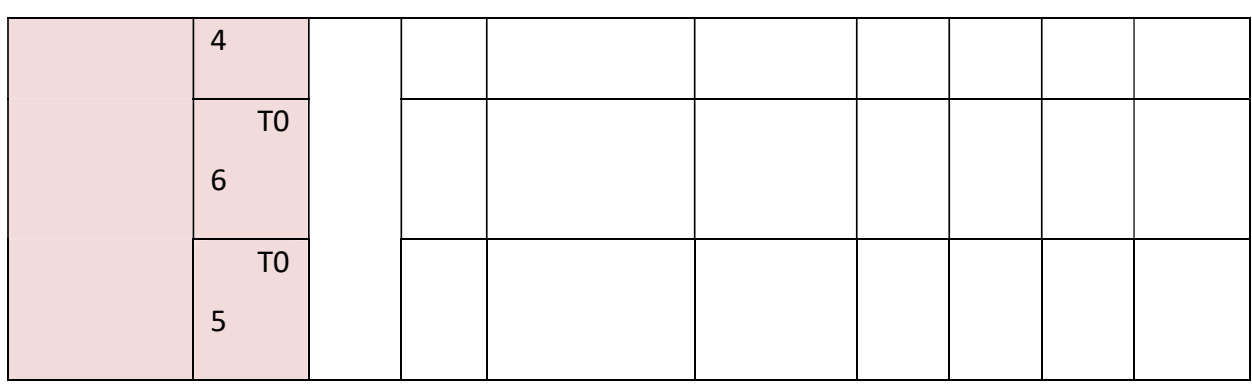

TAREA: REQUISITOS

TIPO DE SUJETO: ESTUDIANTES

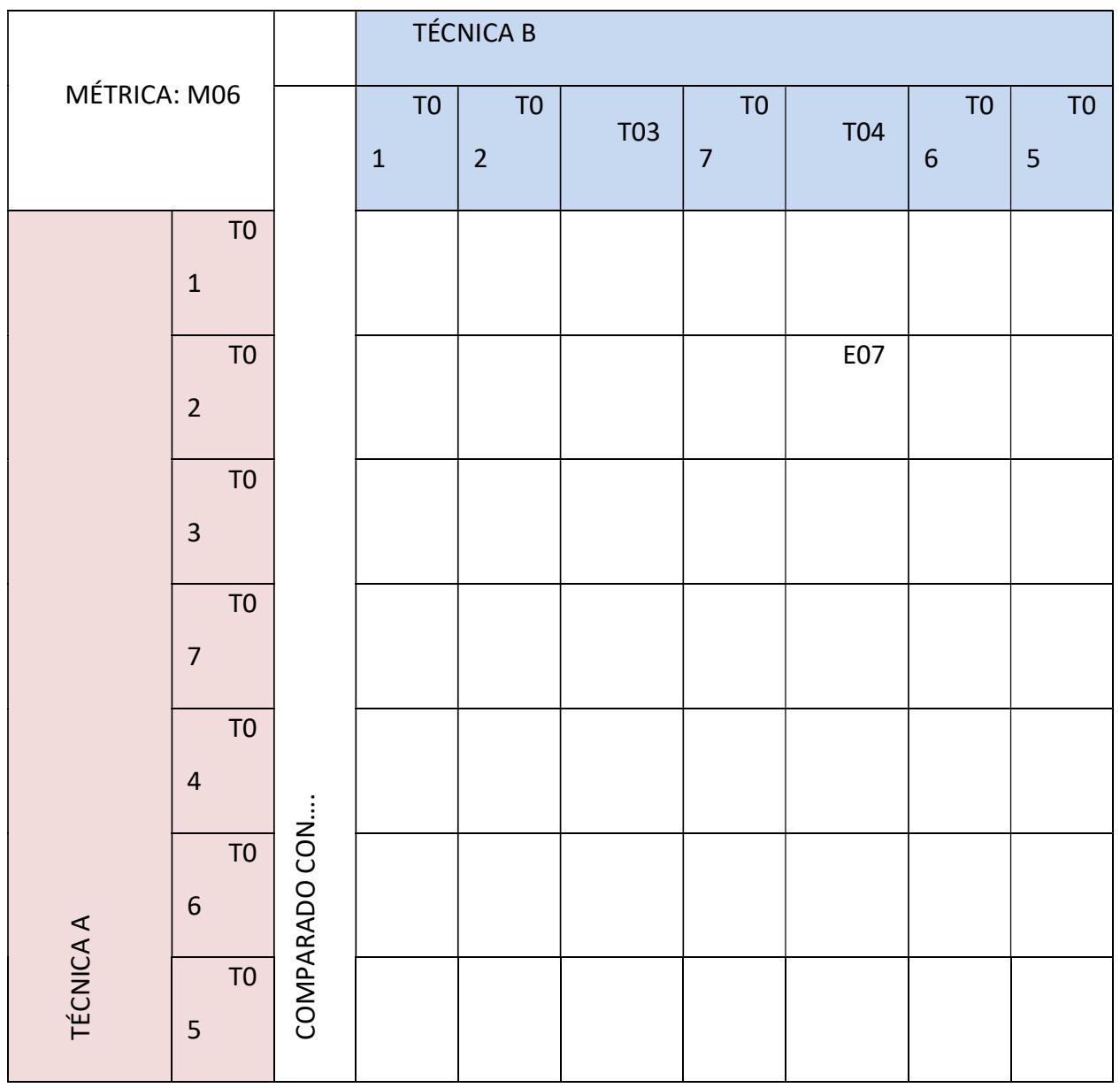


TAREA: REQUISITOS

TIPO DE SUJETO: ESTUDIANTES

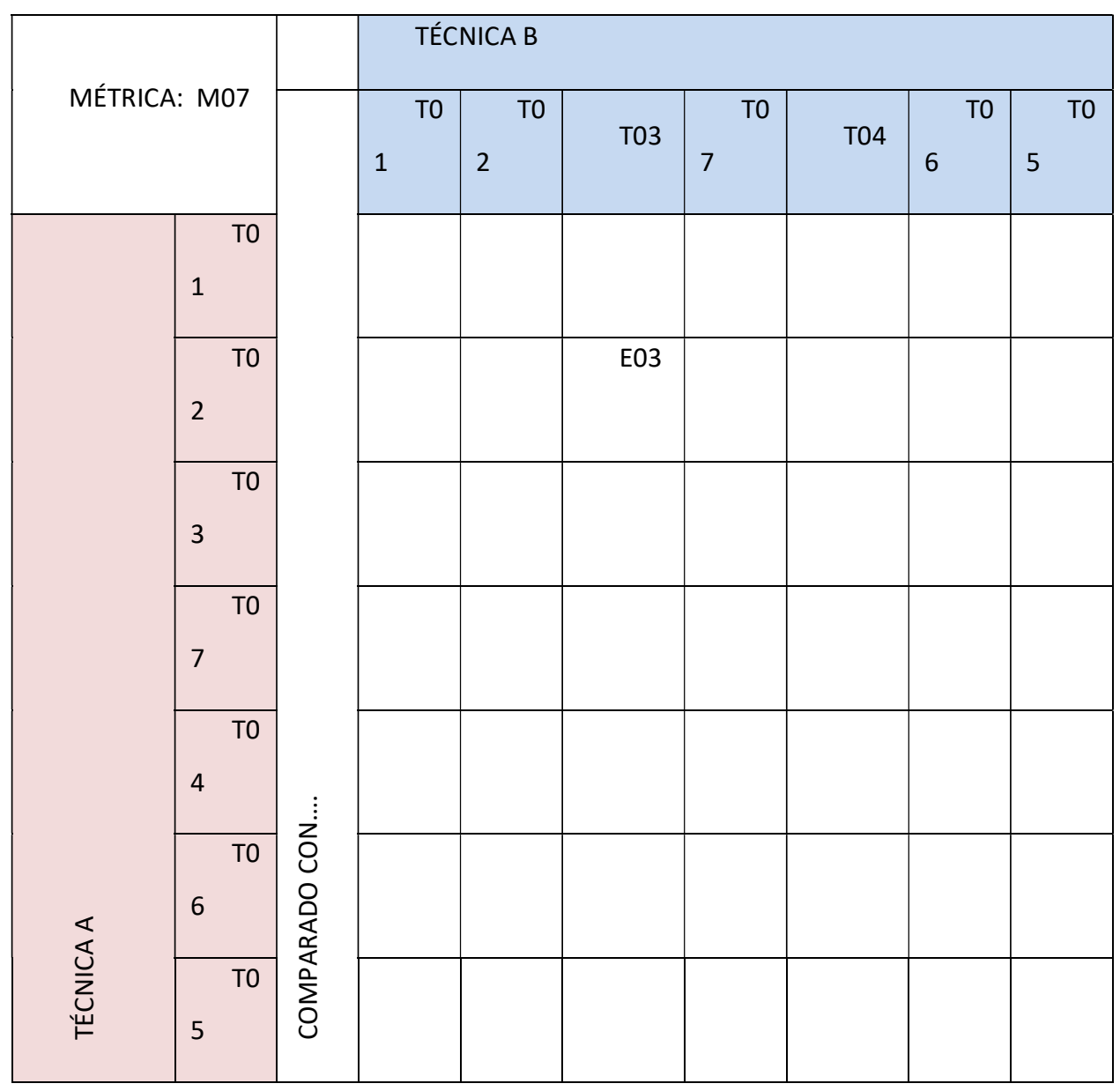

TAREA: REQUISITOS

TIPO DE SUJETO: ESTUDIANTES

Caso de estudio 
Extracción de Datos

Proceso de RS de experimentos en Ingeniería del

Software

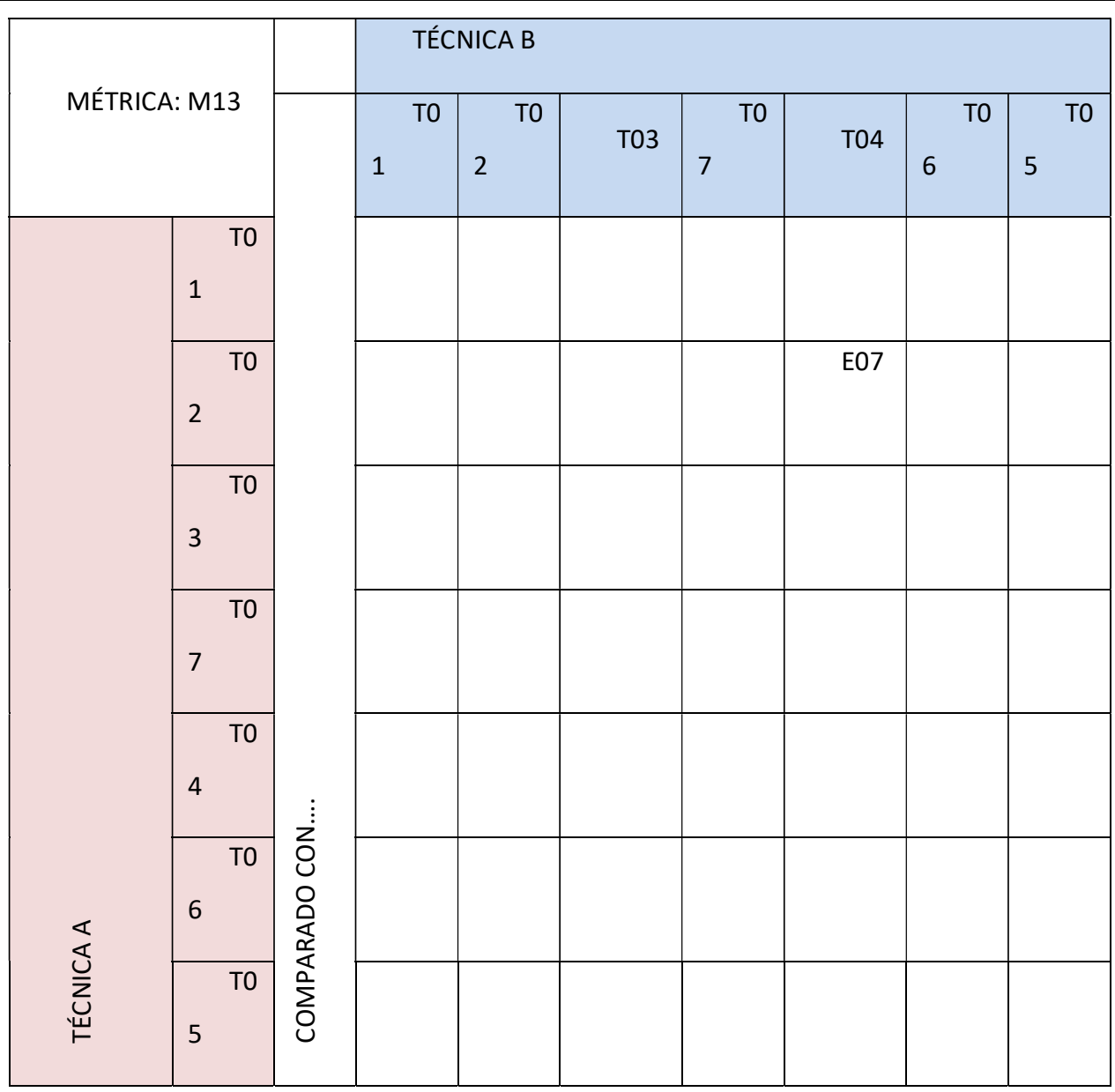

TAREA: REQUISITOS

TIPO DE SUJETO: ESTUDIANTES

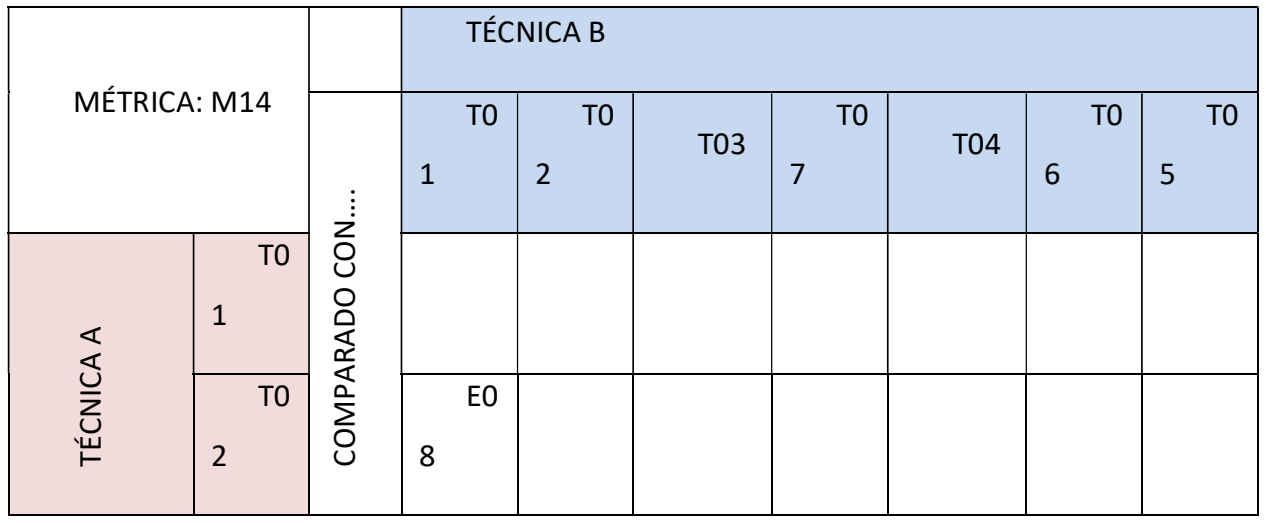


Proceso de RS de experimentos en Ingeniería del Software

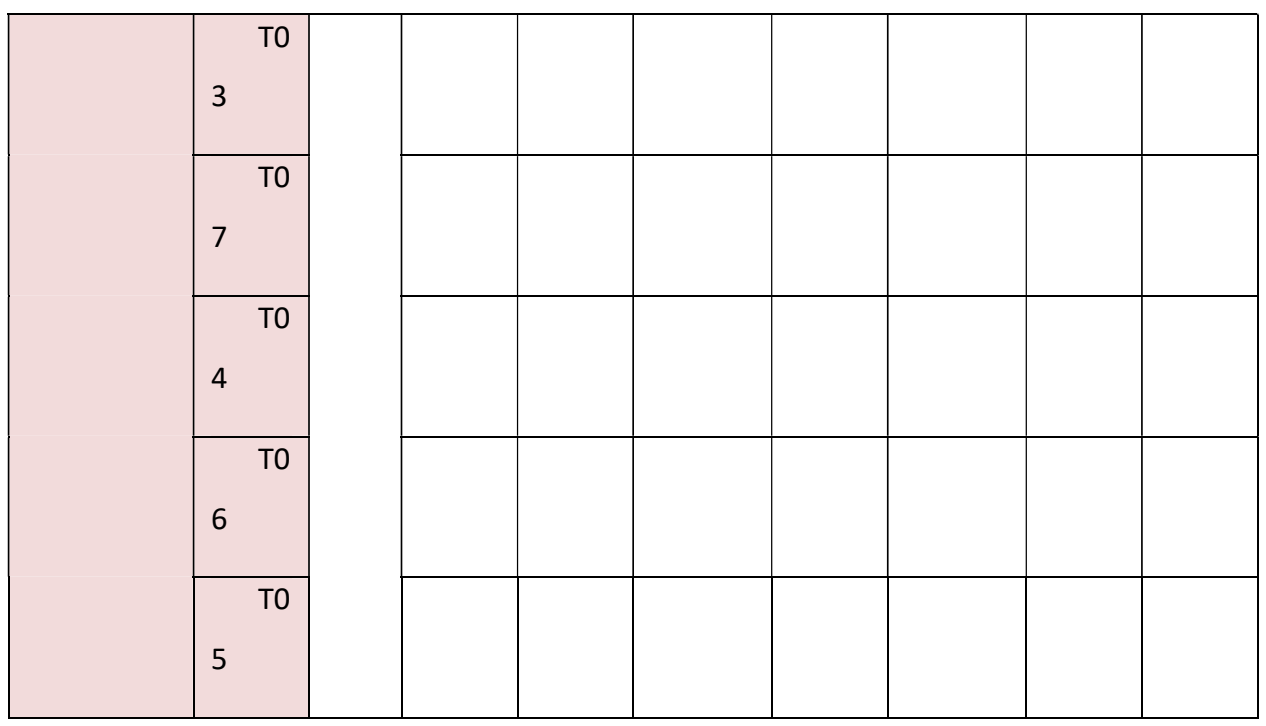

TAREA: REQUISITOS

TIPO DE SUJETO: ESTUDIANTES

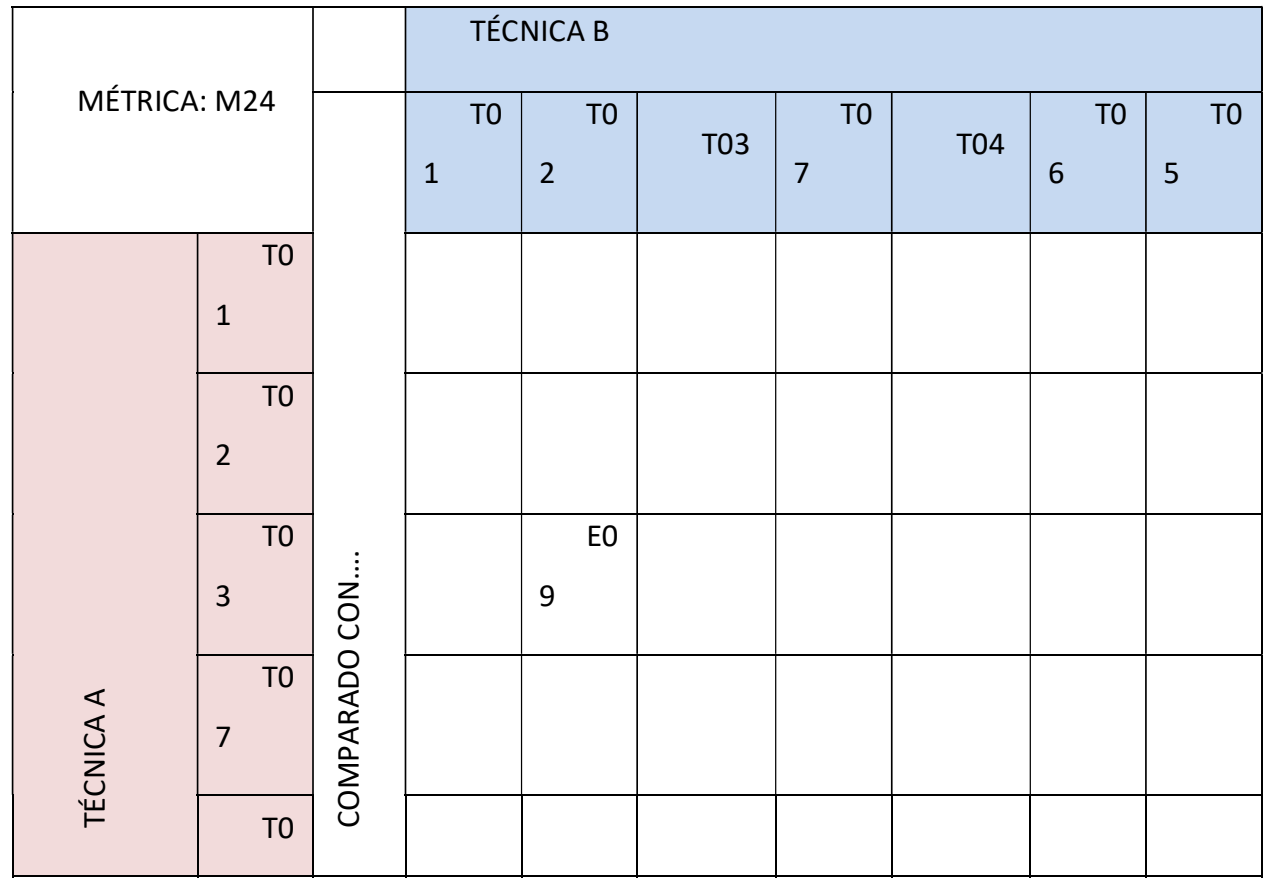

Caso de estudio 
Extracción de Datos

Proceso de RS de experimentos en Ingeniería del

Software

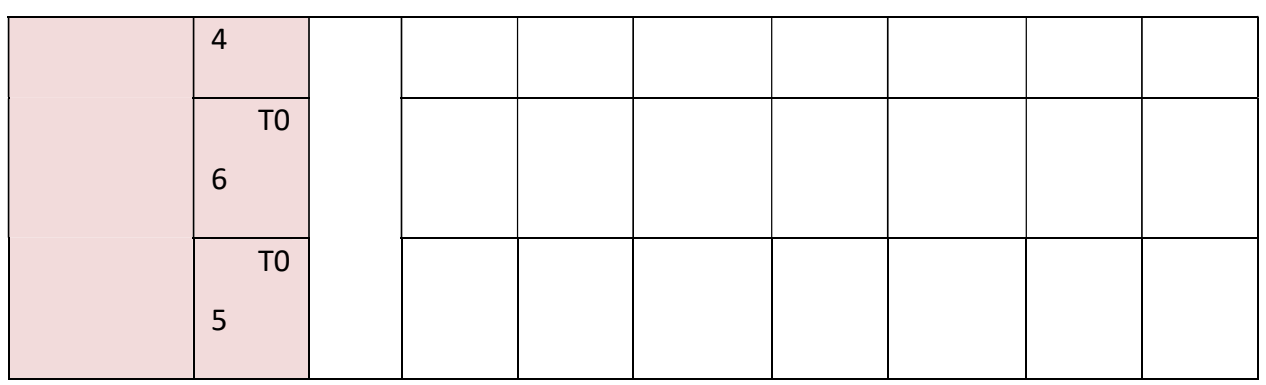
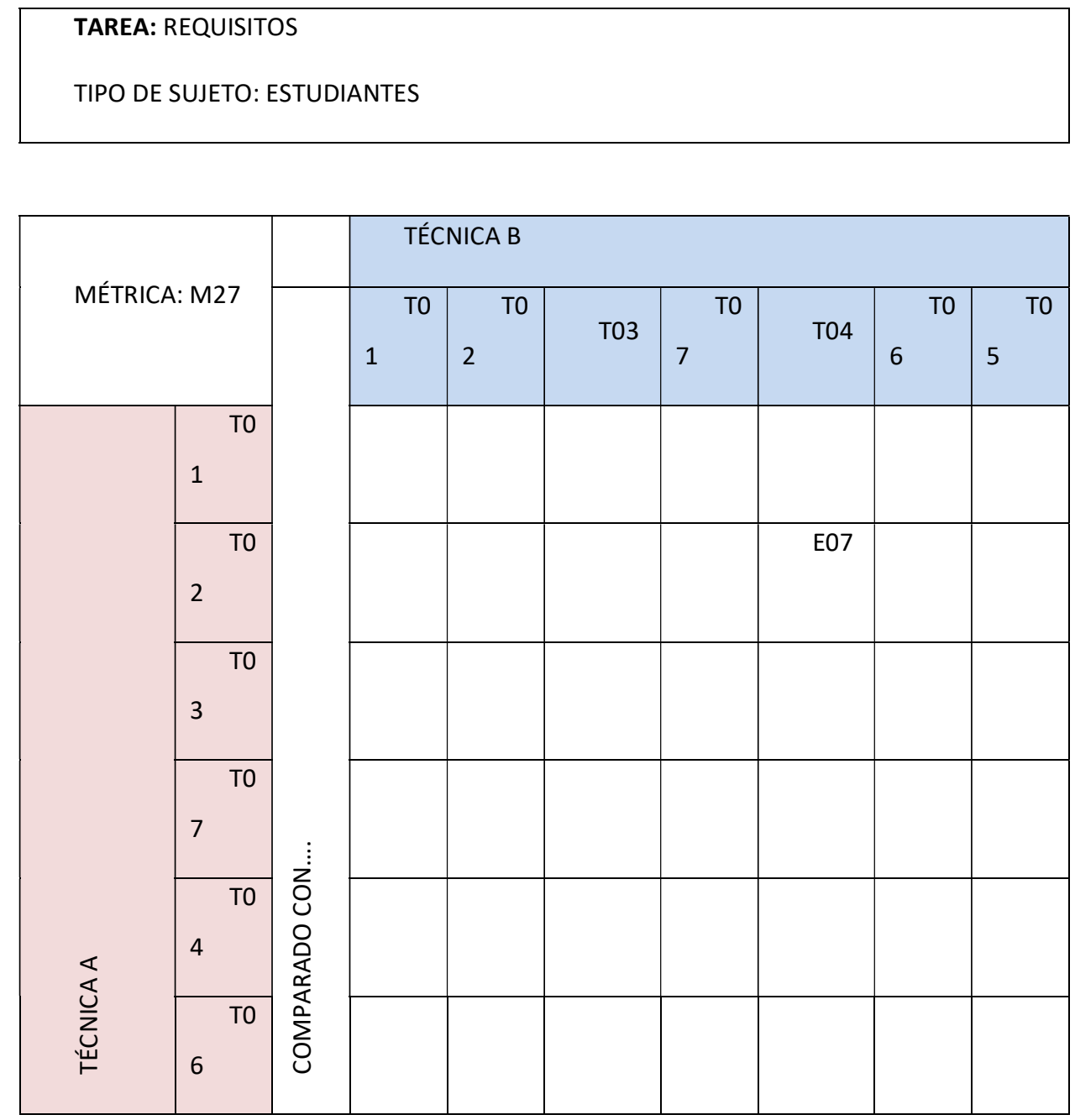
Proceso de RS de experimentos en Ingeniería del Software

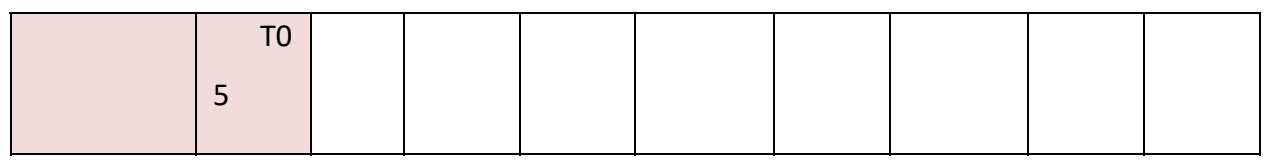

TAREA: REQUISITOS

TIPO DE SUJETO: ESTUDIANTES

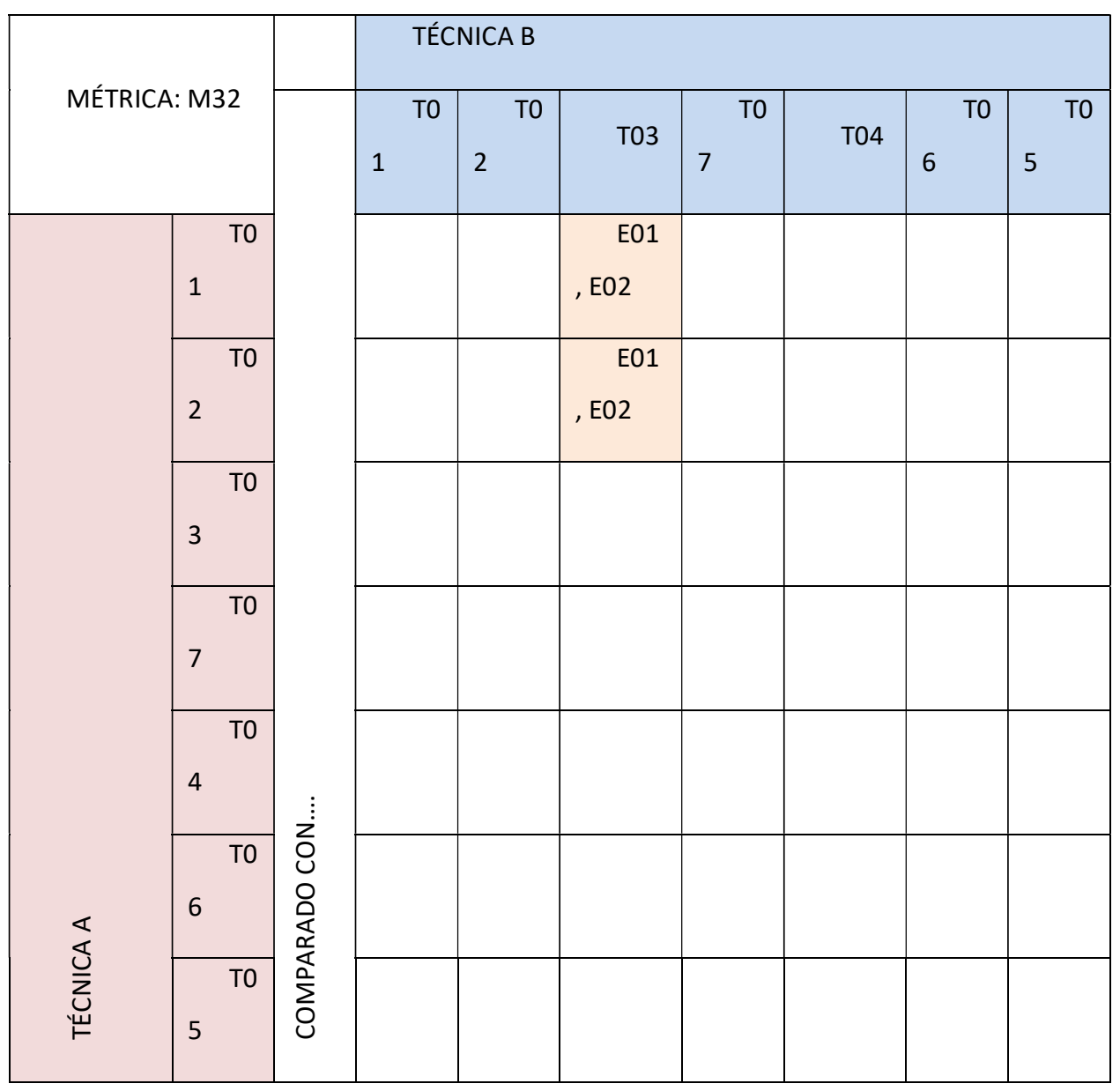

Caso de estudio 
Extracción de Datos

TAREA: CODIGO

TIPO DE SUJETO: ESTUDIANTES

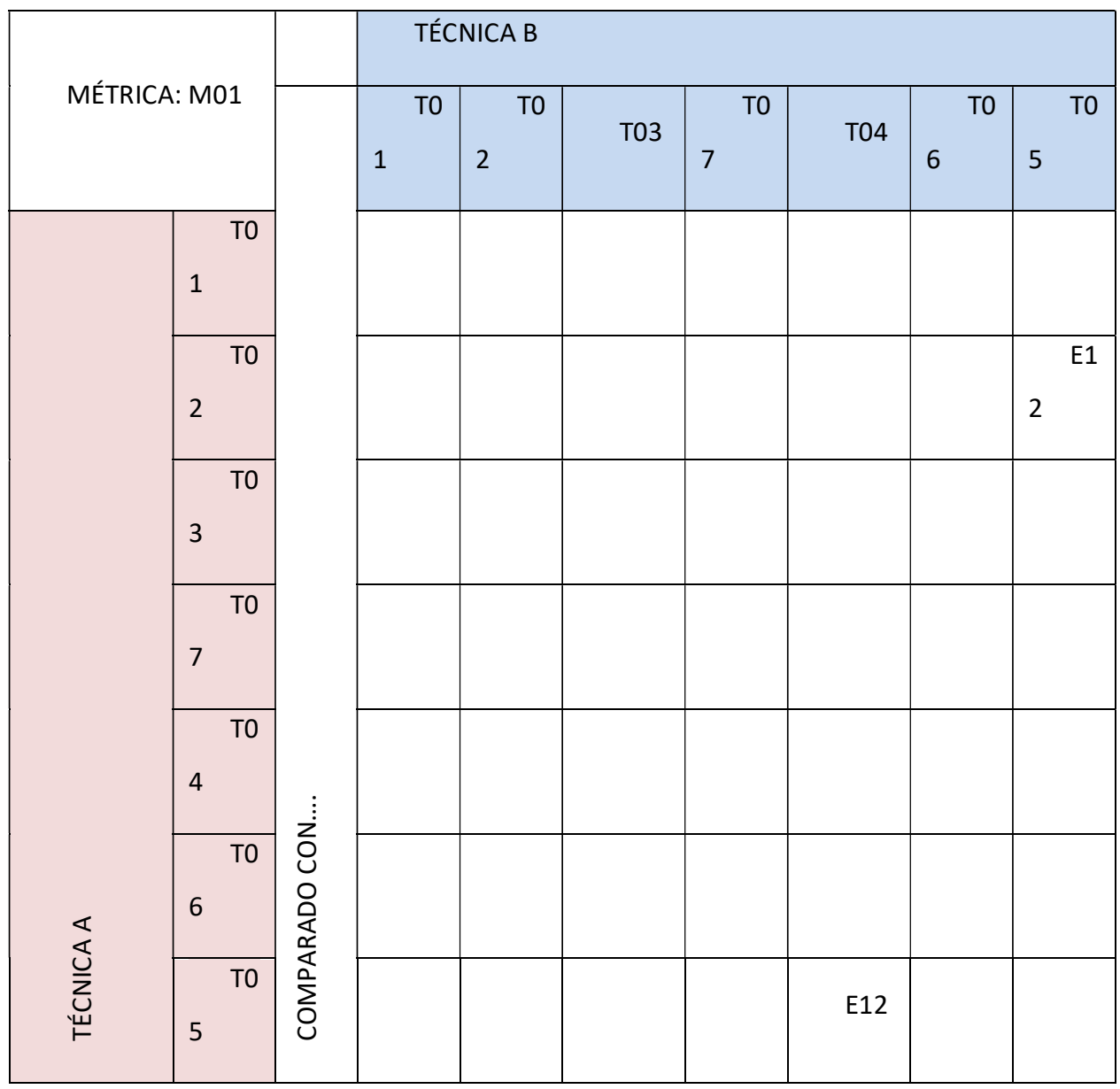

TAREA: CODIGO

TIPO DE SUJETO: ESTUDIANTES

\begin{tabular}{|l|l|l|}
\hline MÉTRICA: M03 & & TÉCNICA B \\
\hline
\end{tabular}


Proceso de RS de experimentos en Ingeniería del Software

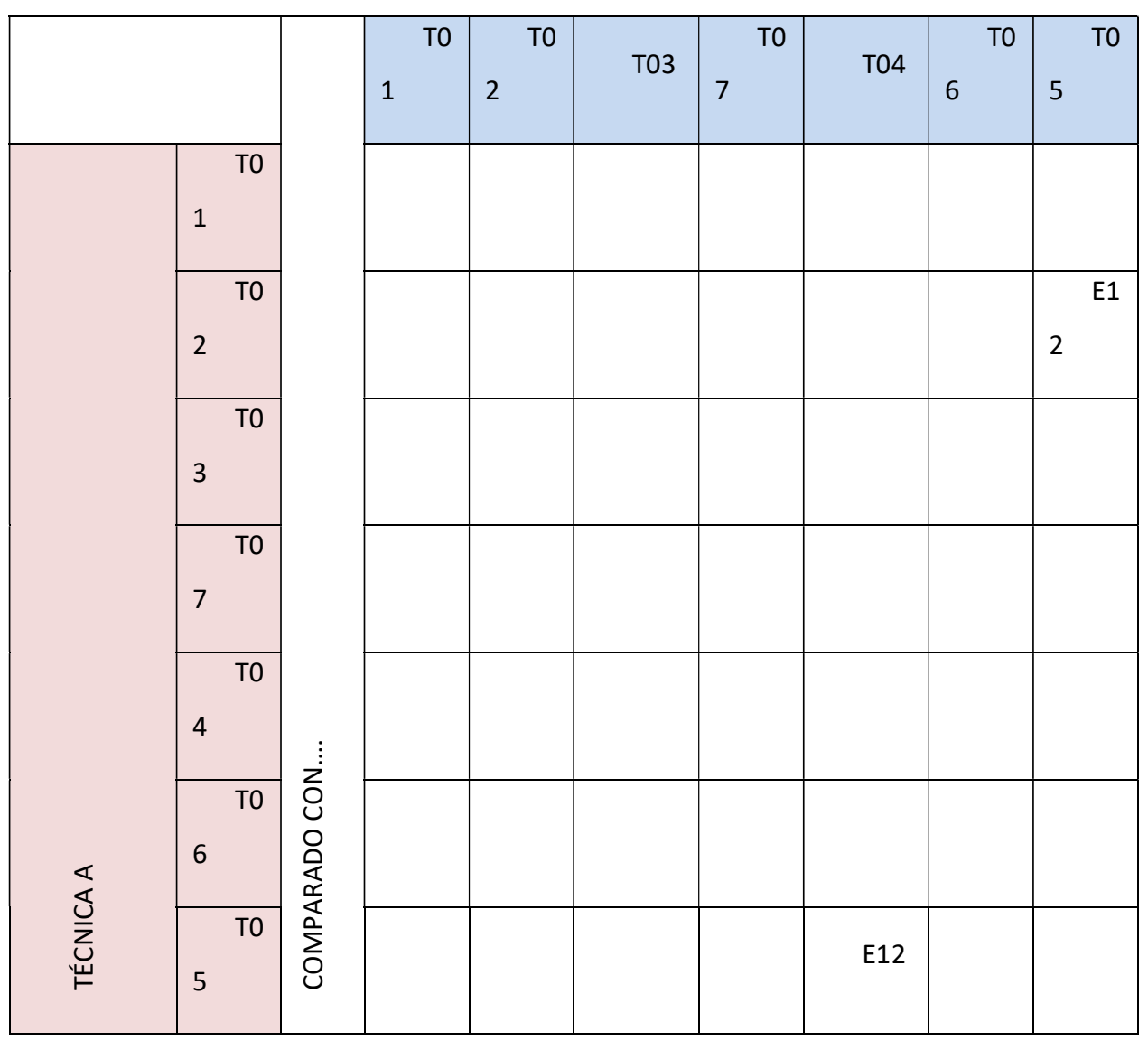

TAREA: CODIGO

TIPO DE SUJETO: ESTUDIANTES

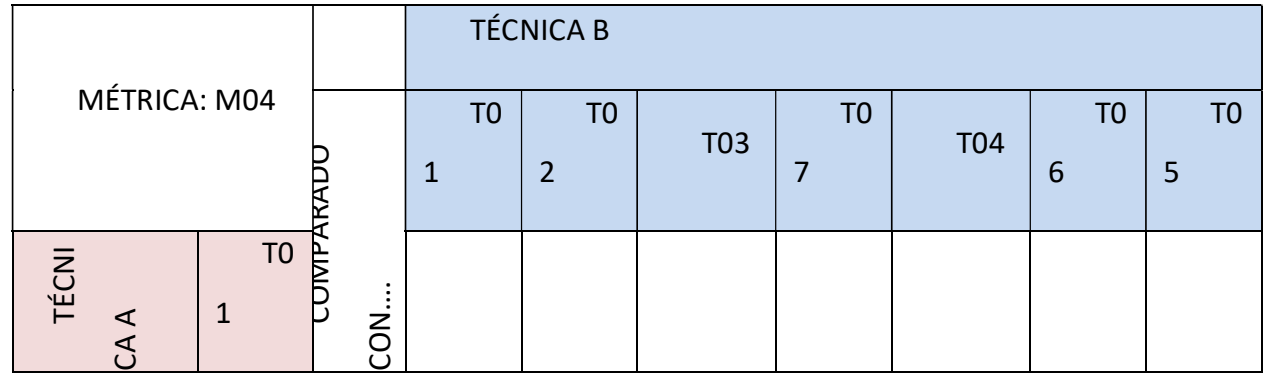

Caso de estudio 
Extracción de Datos

Proceso de RS de experimentos en Ingeniería del

Software

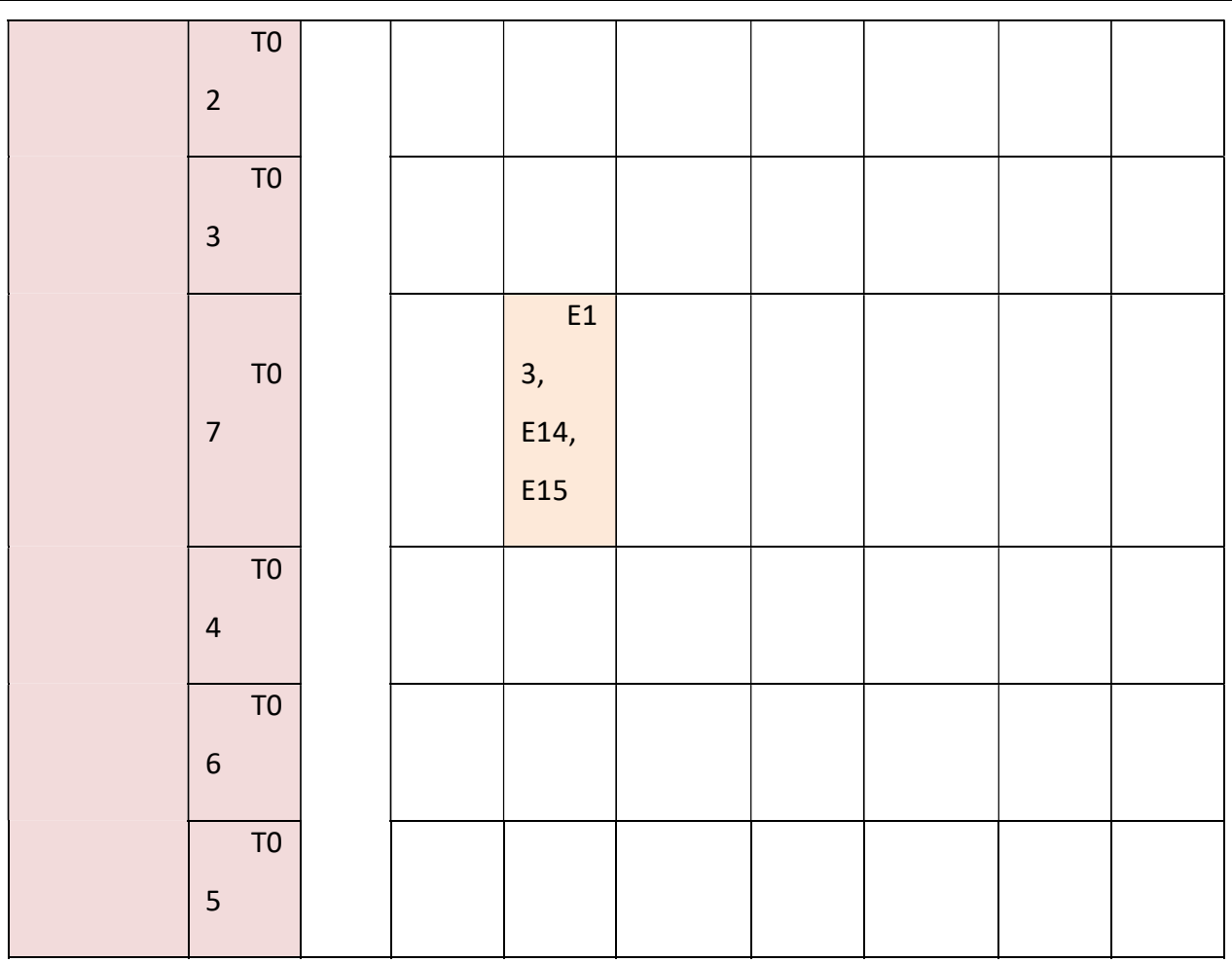

TAREA: CODIGO

TIPO DE SUJETO: ESTUDIANTES

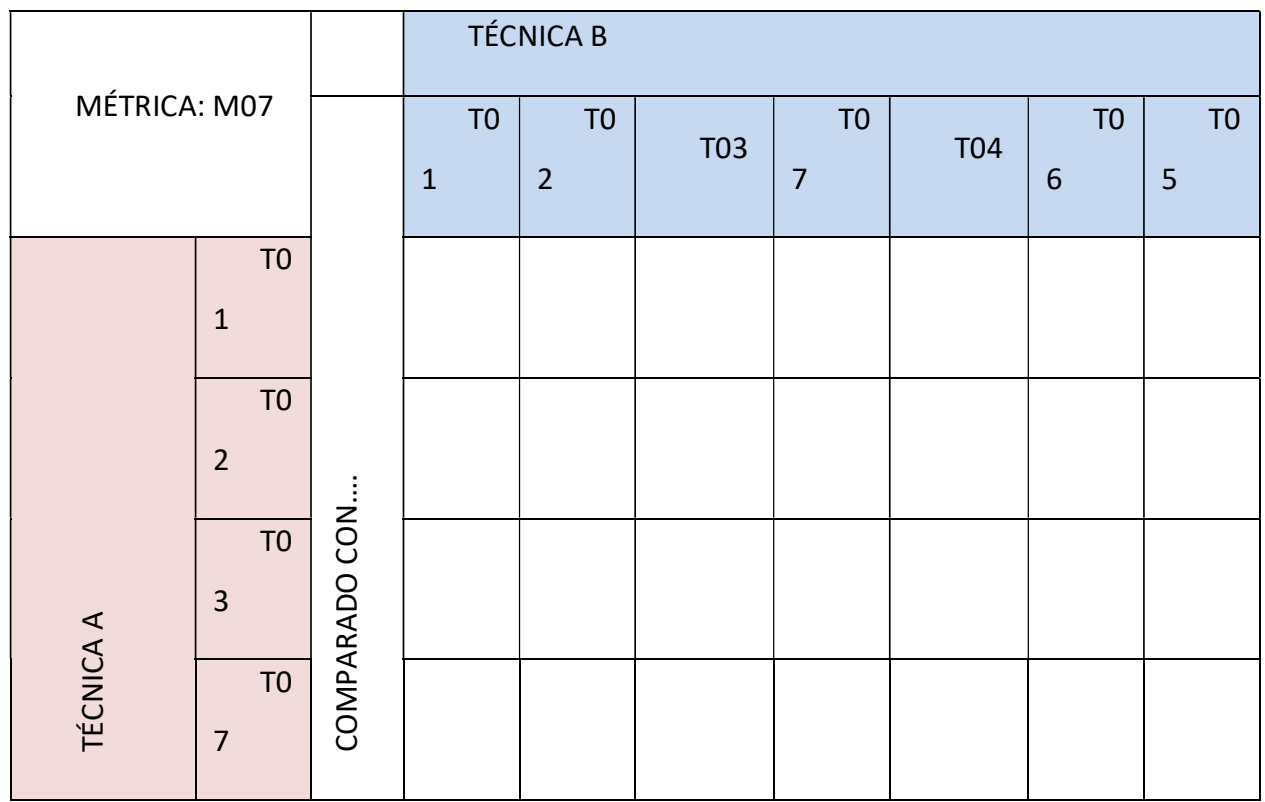


Proceso de RS de experimentos en Ingeniería del Software

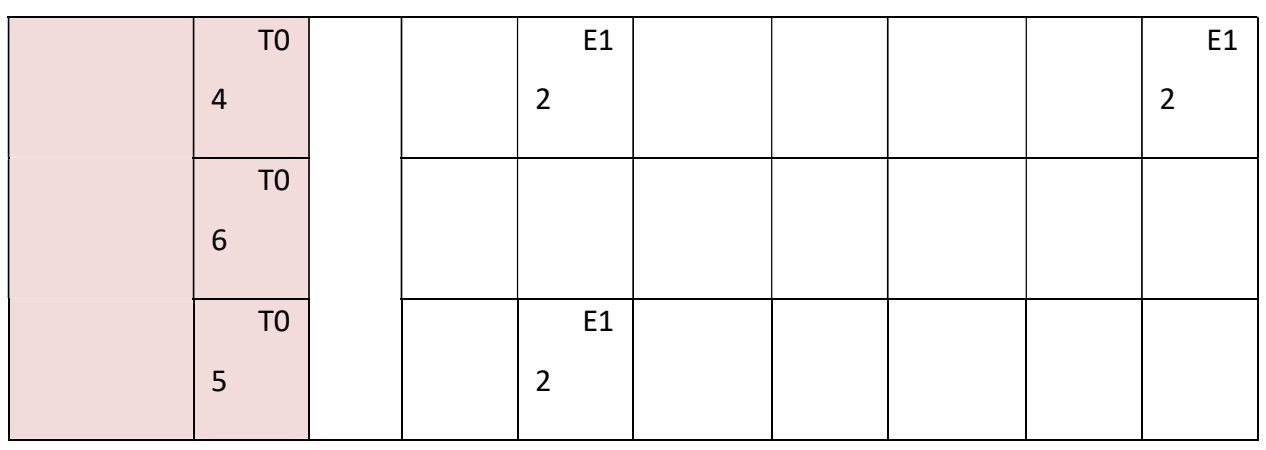

TAREA: CODIGO

TIPO DE SUJETO: ESTUDIANTES

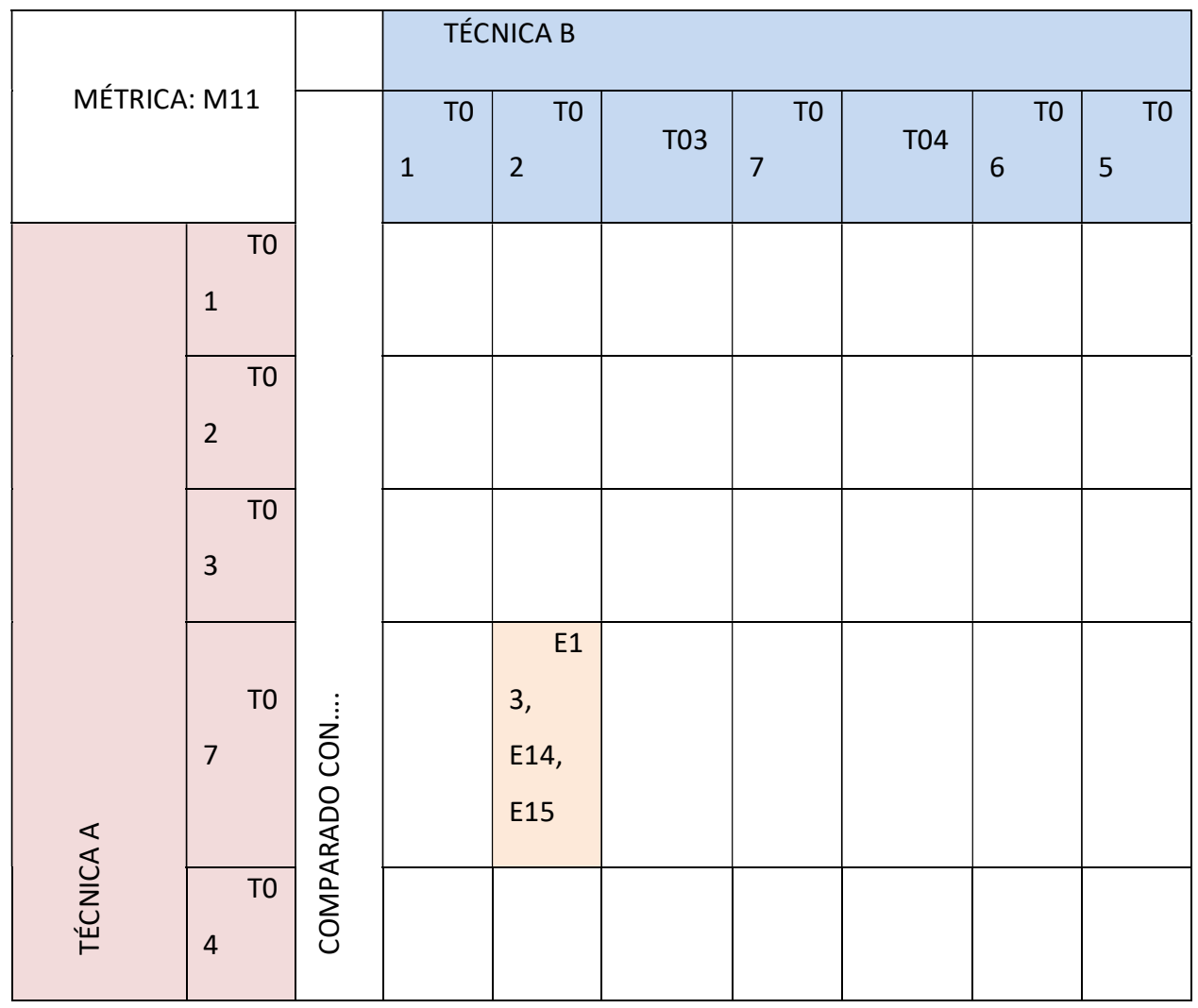

Caso de estudio 
Extracción de Datos

Proceso de RS de experimentos en Ingeniería del

Software

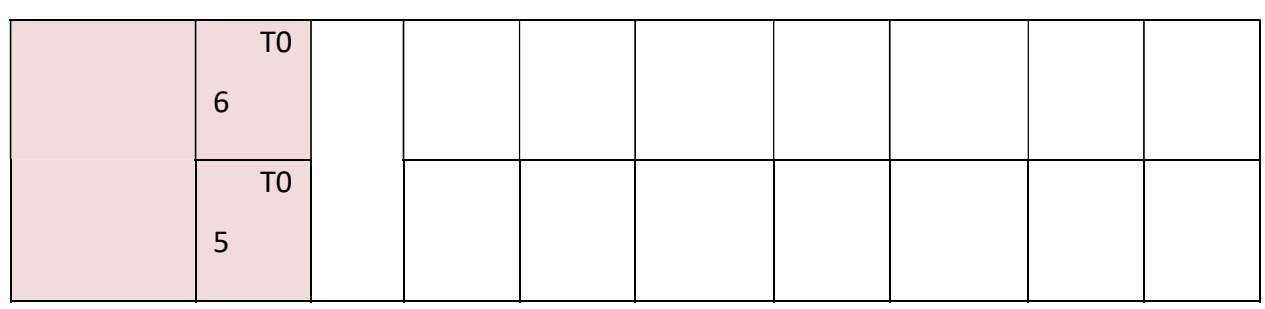

TAREA: CODIGO

TIPO DE SUJETO: ESTUDIANTES

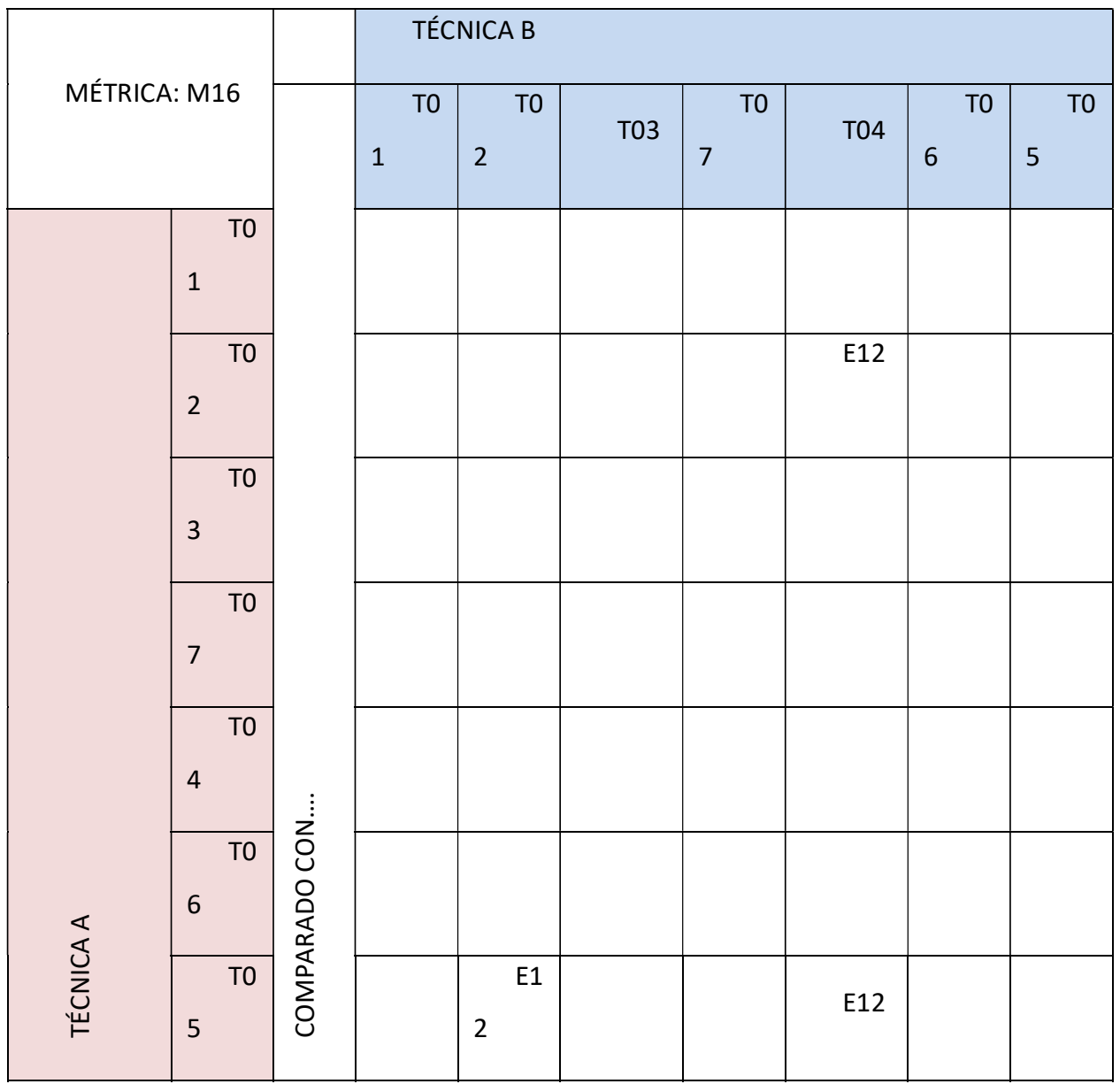


Proceso de RS de experimentos en Ingeniería del Software

TAREA: CODIGO

TIPO DE SUJETO: ESTUDIANTES

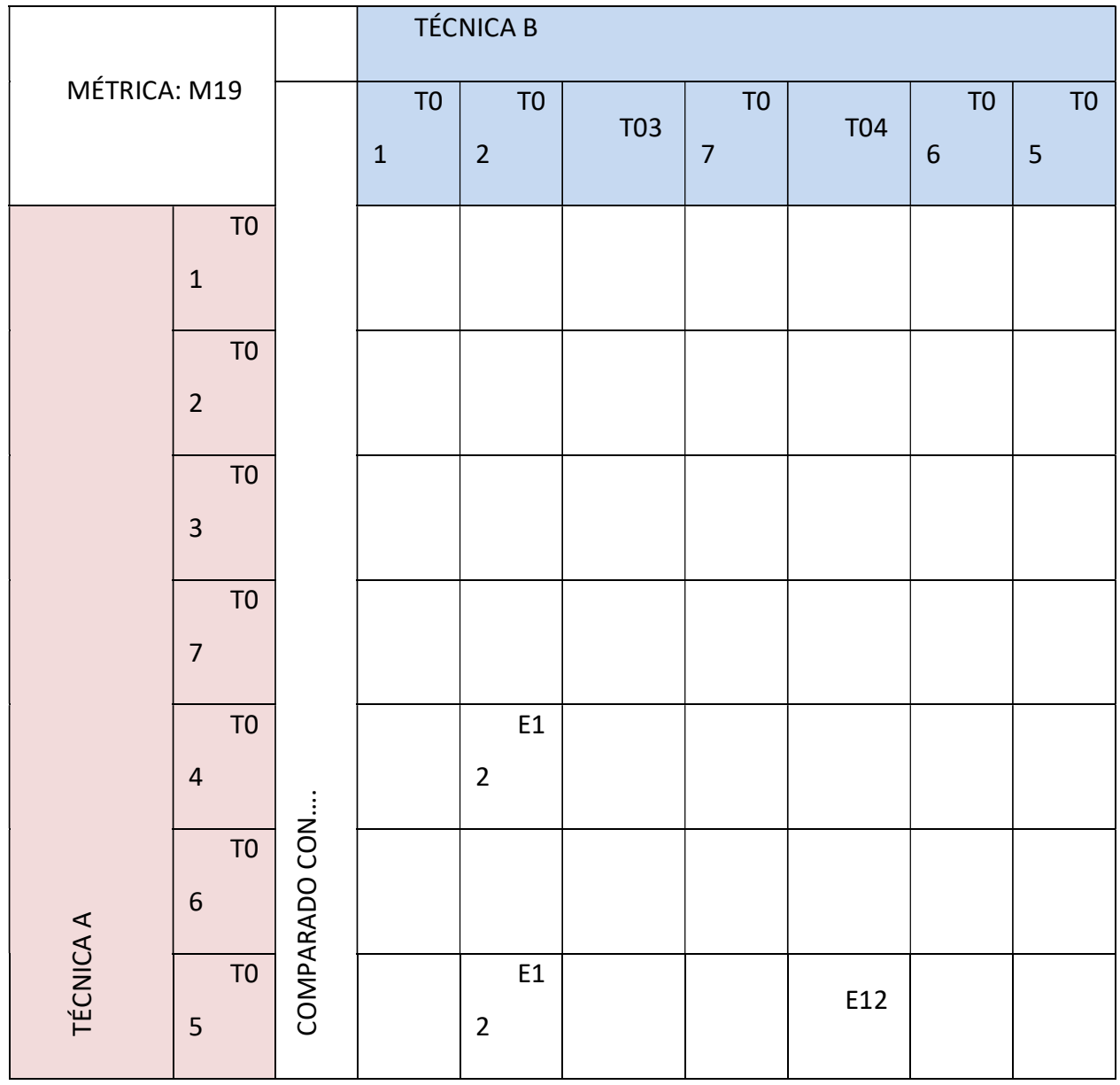

Caso de estudio 
TAREA: DISEÑO CON UML

TIPO DE SUJETO: ESTUDIANTES

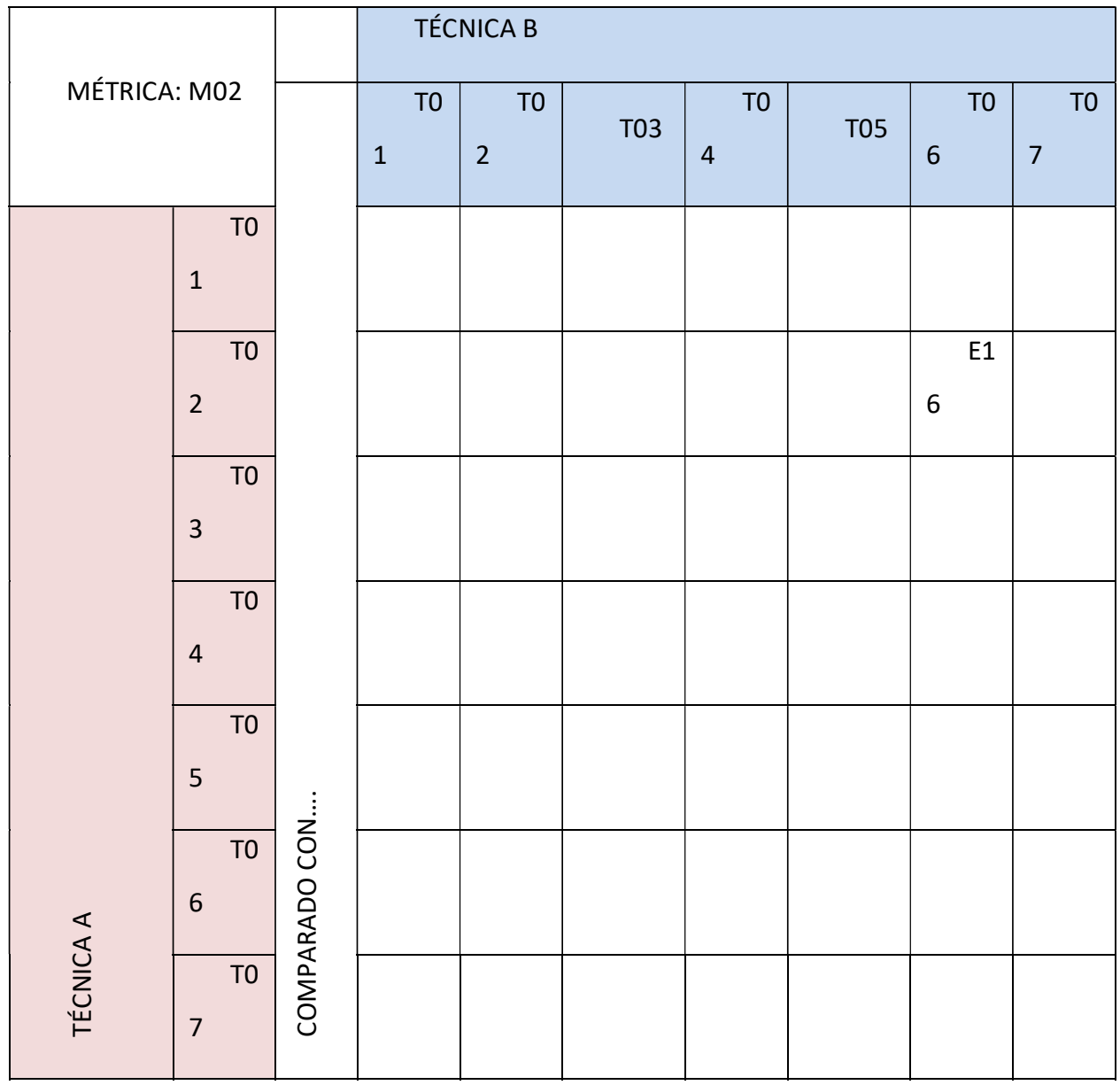

TAREA: DISEÑO CON UML

TIPO DE SUJETO: ESTUDIANTES

\begin{tabular}{|l|l|l|}
\hline MÉTRICA: M03 & & TÉCNICA B \\
\hline
\end{tabular}


Proceso de RS de experimentos en Ingeniería del Software

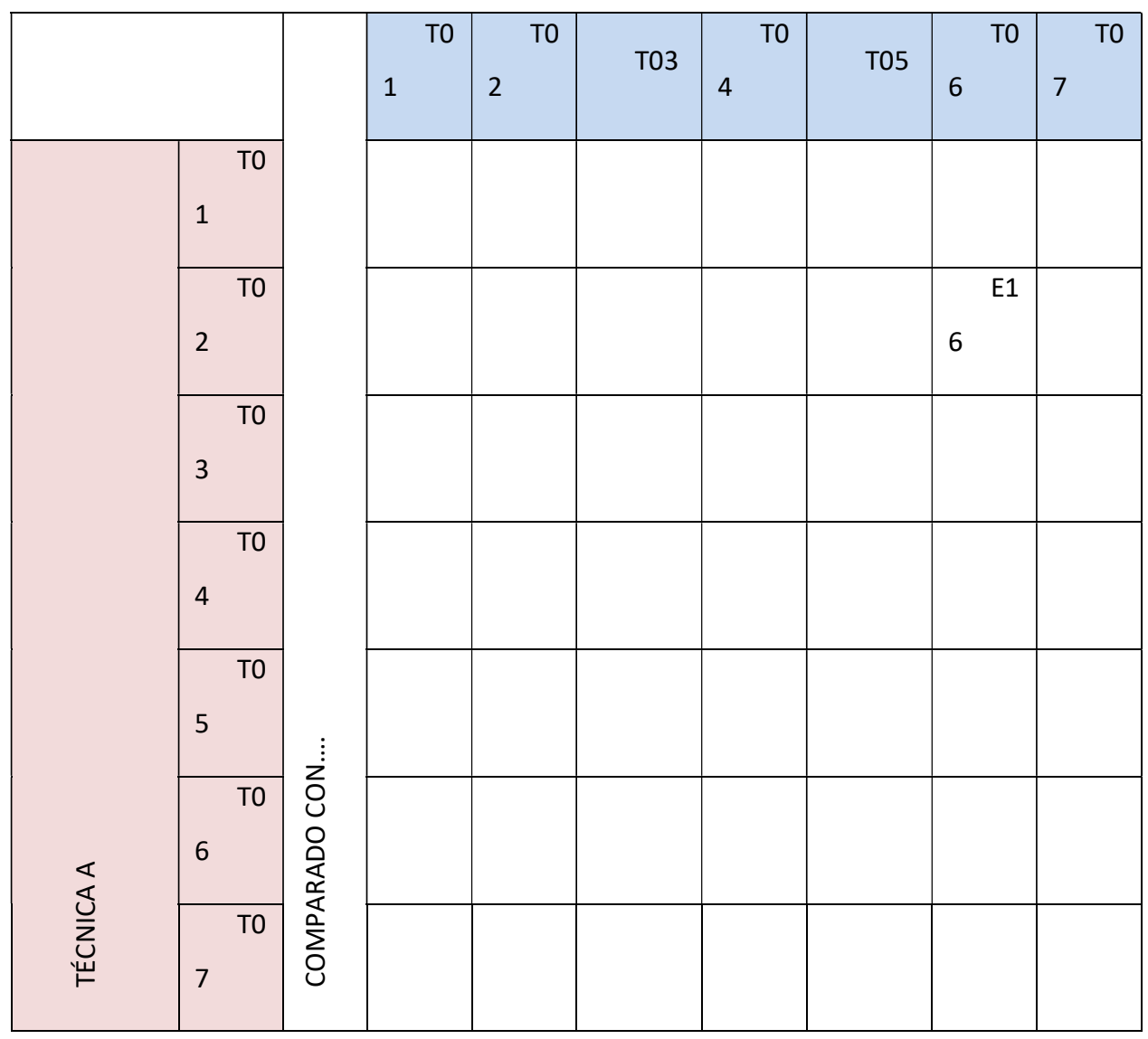

TAREA: DISEÑO CON UML

TIPO DE SUJETO: ESTUDIANTES

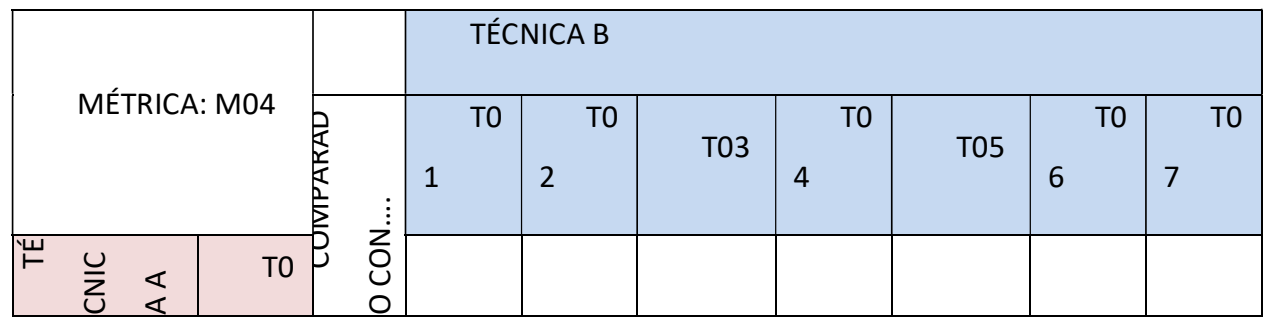

Caso de estudio 


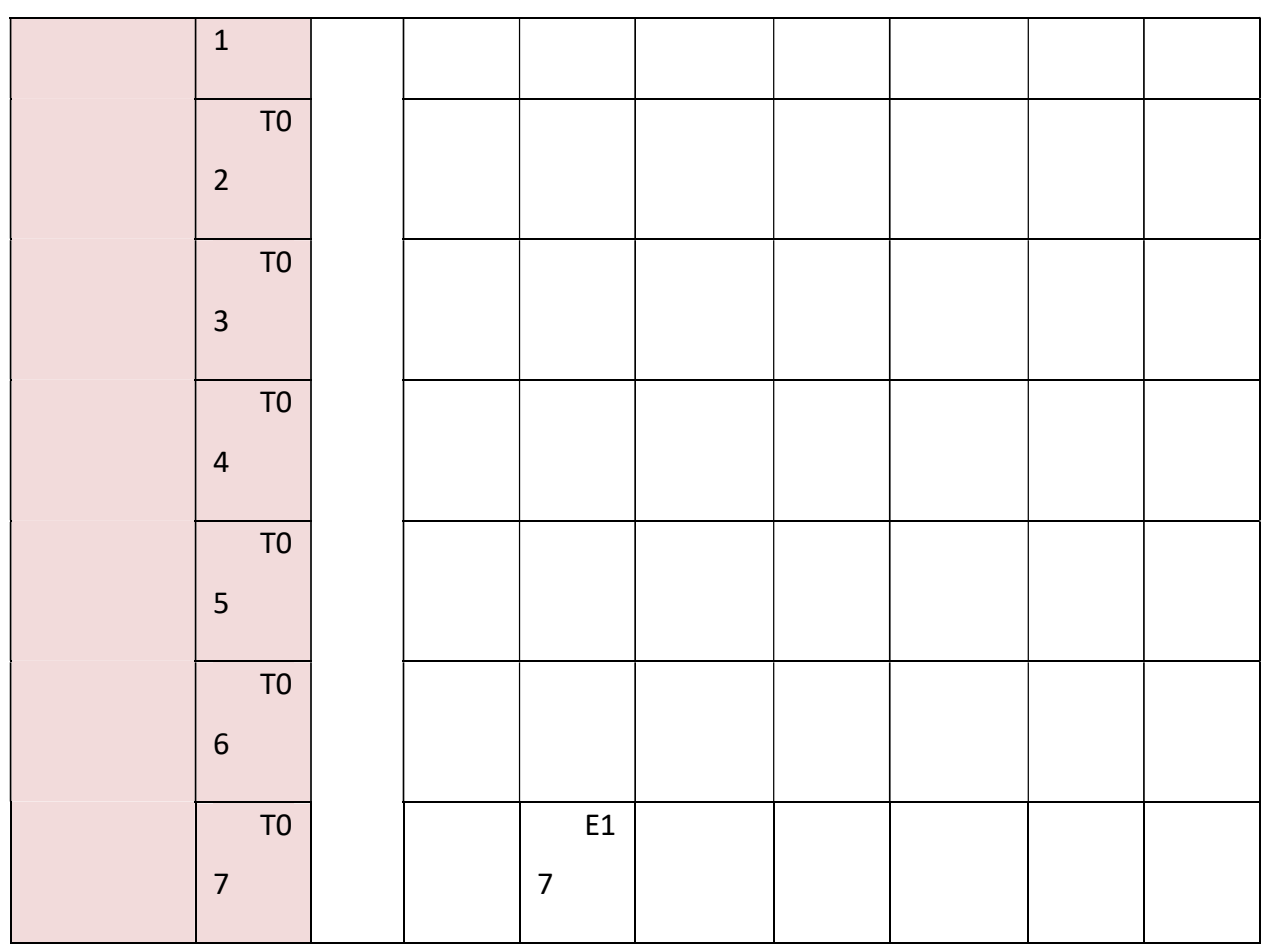

TAREA: DISEÑO CON UML

TIPO DE SUJETO: ESTUDIANTES

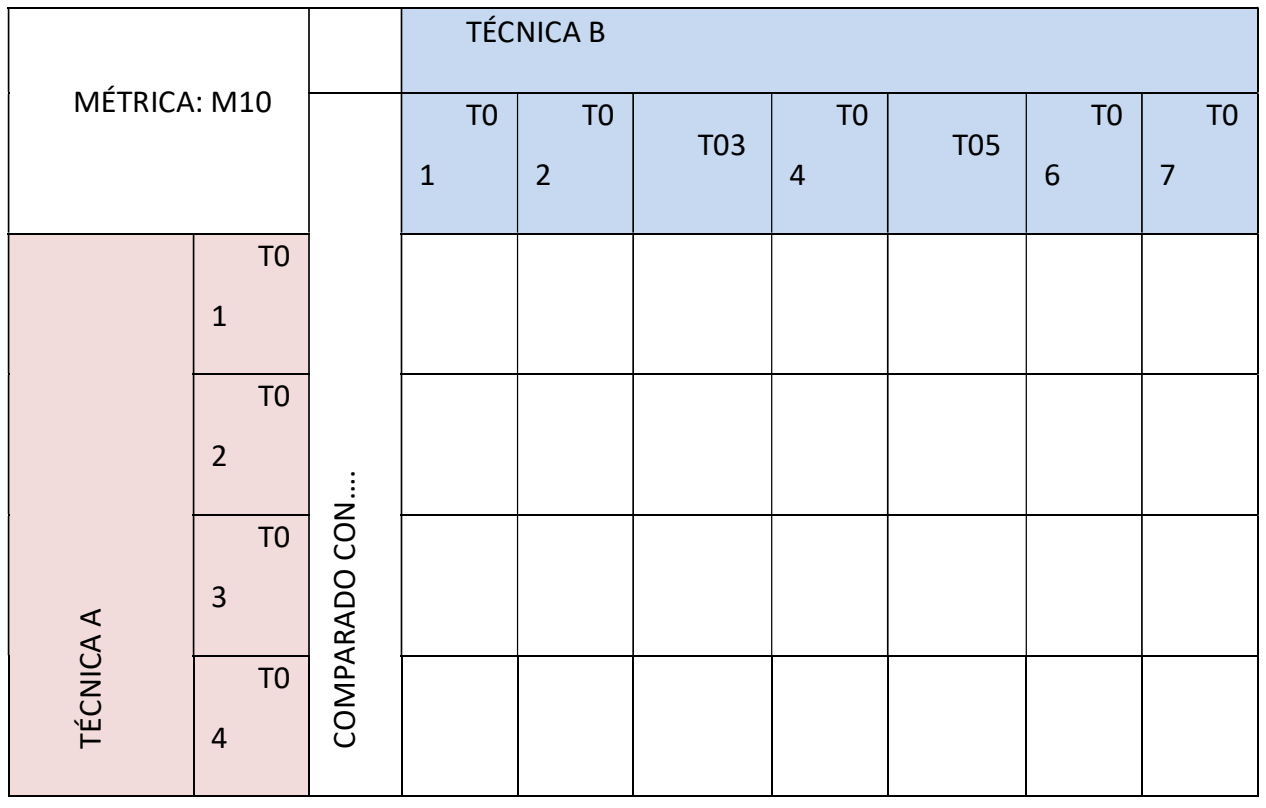


Proceso de RS de experimentos en Ingeniería del Software

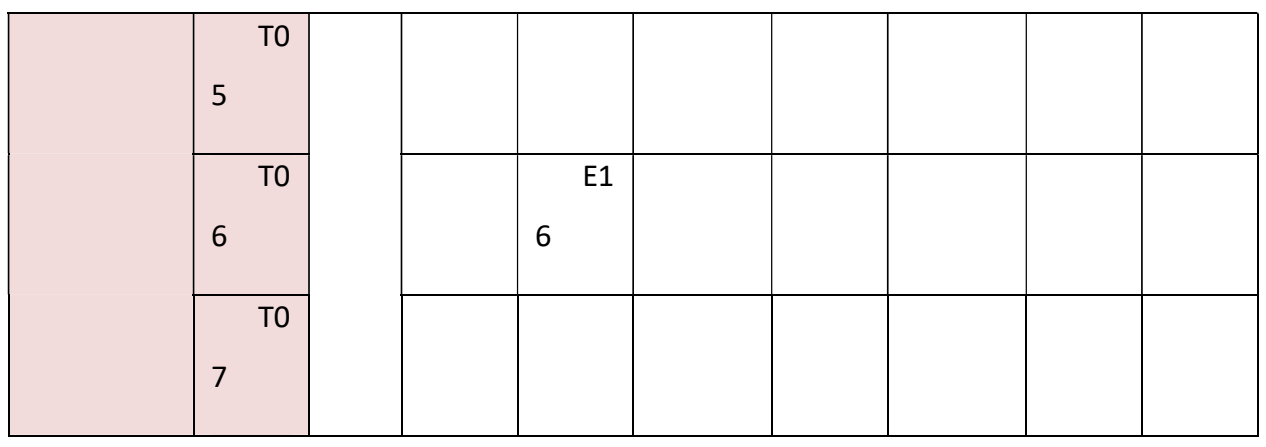

TAREA: DISEÑO CON UML

TIPO DE SUJETO: ESTUDIANTES

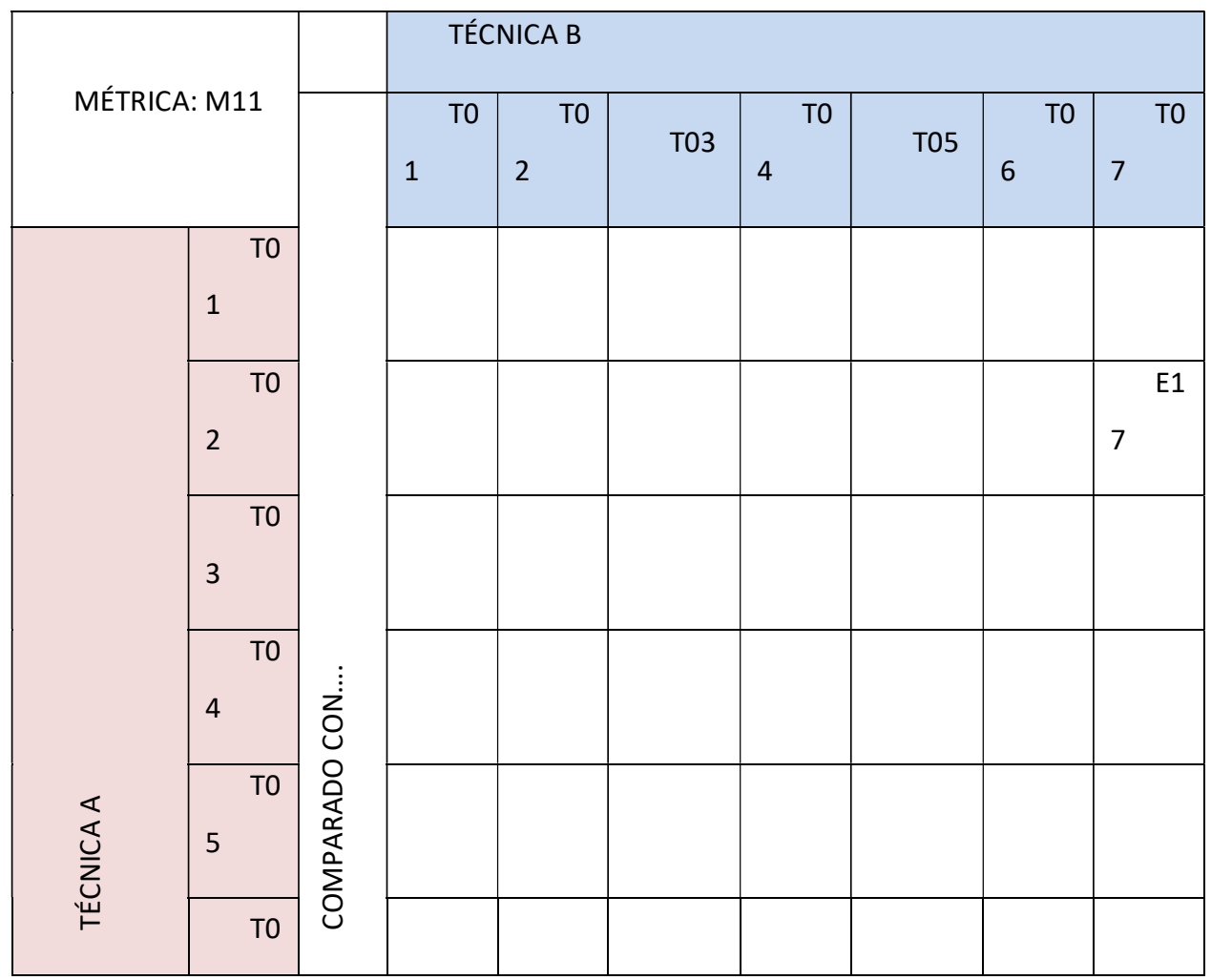

Caso de estudio 


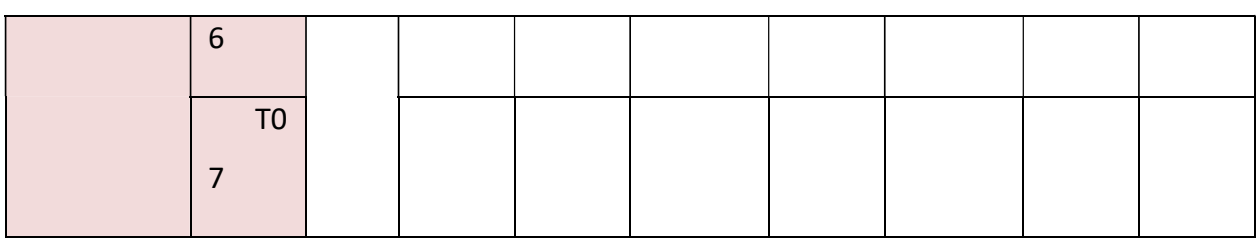




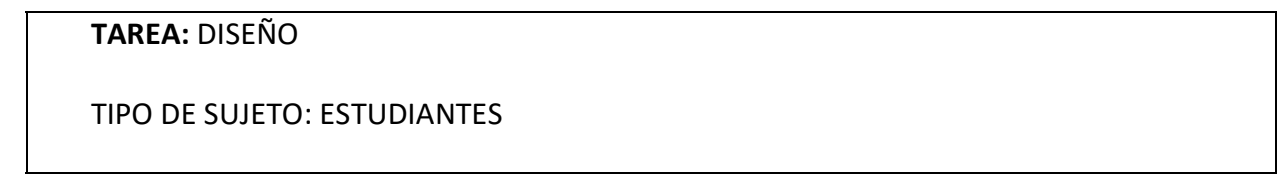

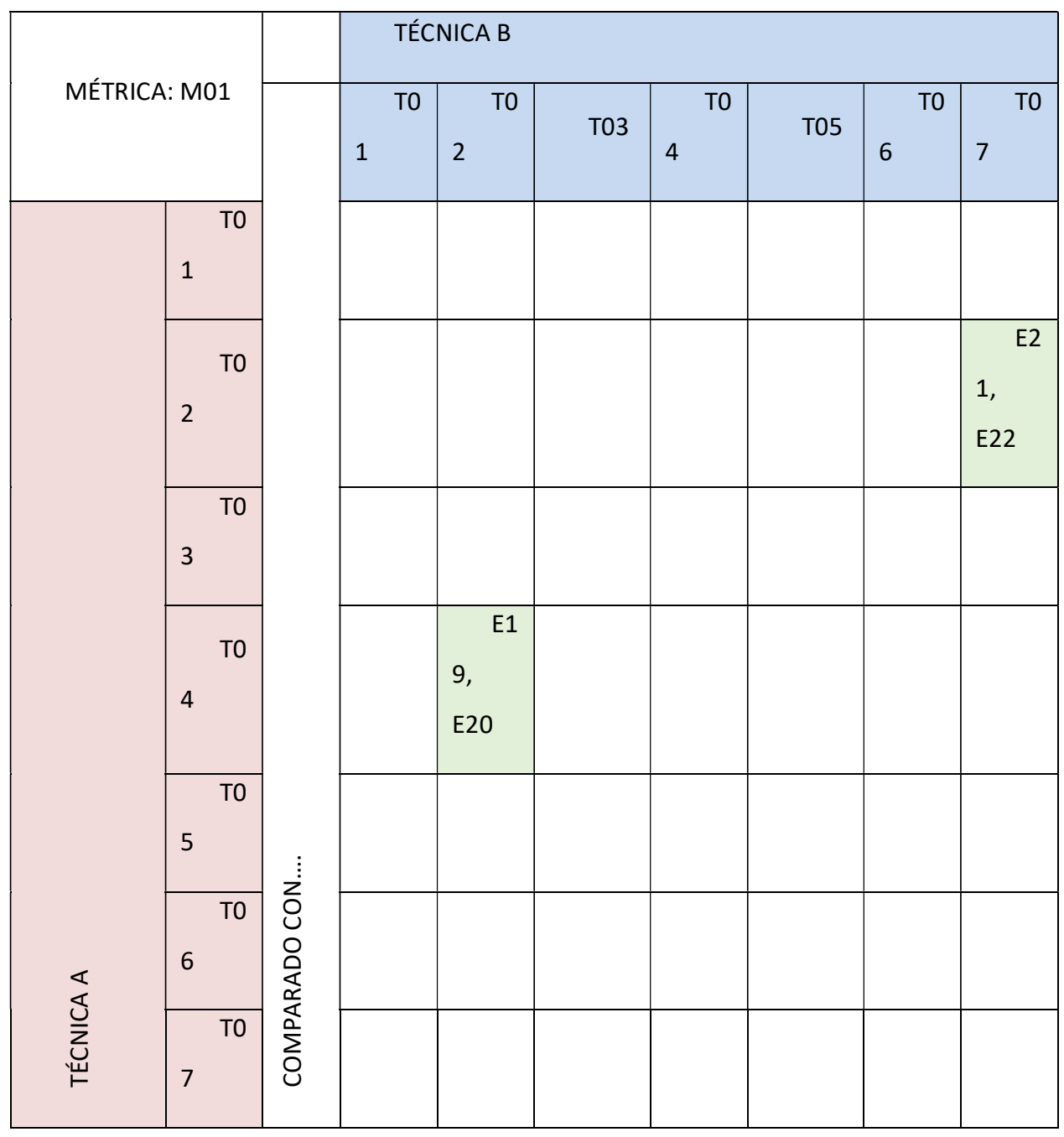

Caso de estudio 
Extracción de Datos

Proceso de RS de experimentos en Ingeniería del

Software

TAREA:

TIPO DE SUJETO:

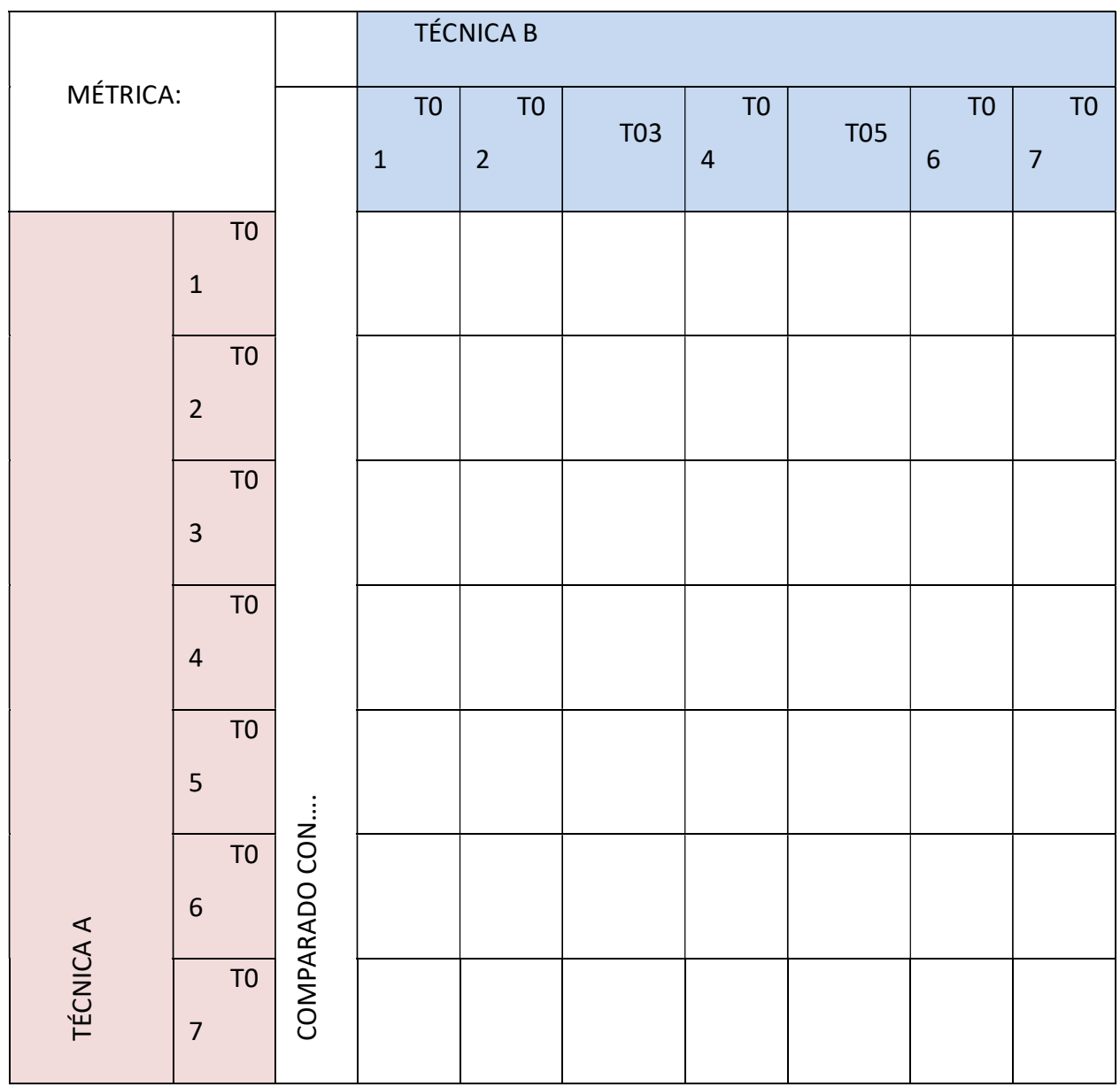

M02 - DISEÑO

\begin{tabular}{|l|l|l|l|l|l|l|l|}
\hline & T01 & T02 & T03 & T04 & T05 & T06 & T07 \\
\hline T01 & & & & & & & \\
\hline
\end{tabular}


Proceso de RS de experimentos en Ingeniería del Software

\begin{tabular}{|c|l|l|l|l|l|l|l|}
\hline T02 & & & & & & & \\
\hline T03 & & & & & & & \\
\hline T04 & & E19 & & & & & \\
\hline T05 & & & & & & & \\
\hline T06 & & & & & & & \\
\hline T07 & & E22 & & & & & \\
\hline
\end{tabular}

M04 - DISEÑO

\begin{tabular}{|c|c|c|c|c|c|c|c|}
\hline & T01 & T02 & T03 & T04 & T05 & T06 & T07 \\
\hline T01 & & & & & & & \\
\hline T02 & & & & & & & $\begin{array}{l}\text { E21, } \\
\text { E22 }\end{array}$ \\
\hline T03 & & & & & & & \\
\hline T04 & & & & & & & \\
\hline T05 & & & & & & & \\
\hline T06 & & & & & & & \\
\hline T07 & & & & & & & \\
\hline
\end{tabular}

M06 - DISEÑO

\begin{tabular}{|c|c|c|c|c|c|c|c|}
\hline & T01 & T02 & T03 & T04 & T05 & T06 & T07 \\
\hline T01 & & & & & & & \\
\hline T02 & & & & $\begin{array}{r}\text { E07 } \\
\text { E19 E20 }\end{array}$ & & & \\
\hline
\end{tabular}

Caso de estudio 
Extracción de Datos

Proceso de RS de experimentos en Ingeniería del

Software

\begin{tabular}{|c|l|l|l|l|l|l|l|}
\hline T03 & & & & & & & \\
\hline T04 & & & & & & & \\
\hline T05 & & & & & & & \\
\hline T06 & & & & & & & \\
\hline T07 & & & & & & & \\
\hline
\end{tabular}

M07 - DISEÑO

\begin{tabular}{|c|c|c|c|c|c|c|c|}
\hline & T01 & T02 & T03 & T04 & T05 & T06 & T07 \\
\hline T01 & & & & & & & \\
\hline T02 & & & & $\begin{array}{r}\text { E12 } \\
\text { E19 E20 }\end{array}$ & E12 & & $\begin{array}{l}\text { E21, } \\
\text { E22 }\end{array}$ \\
\hline T03 & & & & & & & \\
\hline T04 & & & & & E12 & & \\
\hline T05 & & & & & & & \\
\hline T06 & & & & & & & \\
\hline T07 & & & & & & & \\
\hline
\end{tabular}

M08 - DISEÑO

\begin{tabular}{|c|c|c|c|c|c|c|c|}
\hline & T01 & T02 & T03 & T04 & T05 & T06 & T07 \\
\hline T01 & & & & & & & \\
\hline T02 & & & & $\begin{array}{r}\text { E19 } \\
\text { E20 }\end{array}$ & & & \\
\hline T03 & & & & & & & \\
\hline T04 & & & & & & & \\
\hline T05 & & & & & & & \\
\hline
\end{tabular}


Proceso de RS de experimentos en Ingeniería del Software

\begin{tabular}{|c|l|l|l|l|l|l|l|}
\hline T06 & & & & & & & \\
\hline T07 & & & & & & & \\
\hline
\end{tabular}

M11 - DISEÑO

\begin{tabular}{|c|l|l|l|l|l|l|l|}
\hline & T01 & T02 & T03 & T04 & T05 & T06 & T07 \\
\hline T01 & & & & & & & \\
\hline T02 & & & & & & & \\
\hline T03 & & & & & & & \\
\hline T04 & & & & & & & \\
\hline T05 & & & & & & & \\
\hline T06 & & & & & & & \\
\hline T07 & & E17 & & & & & \\
\hline
\end{tabular}

M12- DISEÑO

\begin{tabular}{|c|l|l|l|l|l|l|l|}
\hline & T01 & T02 & T03 & T04 & T05 & T06 & T07 \\
\hline T01 & & & & & & & \\
\hline T02 & & & & & & & \\
\hline T03 & & & & & & & \\
\hline T04 & & & & & & & \\
\hline T05 & & & & & & & \\
\hline T06 & & & & & & & \\
\hline T07 & & E22 & & & & & \\
\hline
\end{tabular}

Caso de estudio 
Extracción de Datos

Proceso de RS de experimentos en Ingeniería del

Software

M13- DISEÑO

\begin{tabular}{|c|c|c|c|c|c|c|c|}
\hline & T01 & T02 & T03 & T04 & T05 & T06 & T07 \\
\hline T01 & & & & & & & \\
\hline T02 & & & & & & & \\
\hline T03 & & & & & & & \\
\hline T04 & & $\begin{array}{r}\text { E19 } \\
\text { E20 }\end{array}$ & & & & & \\
\hline T05 & & & & & & & \\
\hline T06 & & & & & & & \\
\hline T07 & & & & & & & \\
\hline
\end{tabular}

M14- DISEÑO

\begin{tabular}{|c|c|c|c|c|c|c|c|}
\hline & T01 & T02 & T03 & T04 & T05 & T06 & T07 \\
\hline T01 & & & & & & & \\
\hline T02 & & & & & & & E22 \\
\hline T03 & & & & & & & \\
\hline T04 & & & & & & & \\
\hline T05 & & & & & & & \\
\hline T06 & & & & & & & \\
\hline T07 & & & & & & & \\
\hline
\end{tabular}

M17- DISEÑO

\begin{tabular}{|c|c|c|c|c|c|c|c|}
\hline . & T01 & T02 & T03 & T04 & T05 & T06 & T07 \\
\hline T01 & & & & & & & \\
\hline T02 & & & & & & & \\
\hline T03 & & & & & & & \\
\hline
\end{tabular}


Proceso de RS de experimentos en Ingeniería del Software

\begin{tabular}{|c|l|l|l|l|l|l|l|}
\hline T04 & & & & & & & \\
\hline T05 & & & & & & & \\
\hline T06 & & & & & & & \\
\hline T07 & & E22 & & & & & \\
\hline
\end{tabular}

M20- DISEÑO

\begin{tabular}{|c|l|l|l|l|l|l|l|}
\hline & T01 & T02 & T03 & T04 & T05 & T06 & T07 \\
\hline T01 & & & & & & & \\
\hline T02 & & & & & & & \\
\hline T03 & & & & & & & \\
\hline T04 & & & & & & & \\
\hline T05 & & & & & & & \\
\hline T06 & & & & & & & \\
\hline T07 & & E22 & & & & & \\
\hline
\end{tabular}

M21- DISEÑO

\begin{tabular}{|c|c|c|c|c|c|c|c|}
\hline & T01 & T02 & T03 & T04 & T05 & T06 & T07 \\
\hline T01 & & & & & & & \\
\hline T02 & & & & & & & E22 \\
\hline T03 & & & & & & & \\
\hline T04 & & & & & & & \\
\hline T05 & & & & & & & \\
\hline T06 & & & & & & & \\
\hline T07 & & & & & & & \\
\hline
\end{tabular}

Caso de estudio 
Extracción de Datos

Proceso de RS de experimentos en Ingeniería del

Software

M22- DISEÑO

\begin{tabular}{|c|c|c|c|c|c|c|c|}
\hline & T01 & T02 & T03 & T04 & T05 & T06 & T07 \\
\hline T01 & & & & & & & \\
\hline T02 & & & & & & & \\
\hline T03 & & & & & & & \\
\hline T04 & & $\begin{array}{r}\text { E19 } \\
\text { E20 }\end{array}$ & & & & & \\
\hline T05 & & & & & & & \\
\hline T06 & & & & & & & \\
\hline T07 & & & & & & & \\
\hline
\end{tabular}

M23- DISEÑO

\begin{tabular}{|c|c|c|c|c|c|c|c|}
\hline & T01 & T02 & T03 & T04 & T05 & T06 & T07 \\
\hline T01 & & & & & & & \\
\hline T02 & & & & & & & \\
\hline T03 & & & & & & & \\
\hline T04 & & $\begin{array}{l}\text { E19, } \\
\text { E20 }\end{array}$ & & & & & \\
\hline T05 & & & & & & & \\
\hline T06 & & & & & & & \\
\hline T07 & & & & & & & \\
\hline
\end{tabular}

M27- DISEÑO

\begin{tabular}{|c|c|c|c|c|c|c|c|}
\hline & T01 & T02 & T03 & T04 & T05 & T06 & T07 \\
\hline T01 & & & & & & & \\
\hline T02 & & & & & & & \\
\hline T03 & & & & & & & \\
\hline
\end{tabular}


Proceso de RS de experimentos en Ingeniería del Software

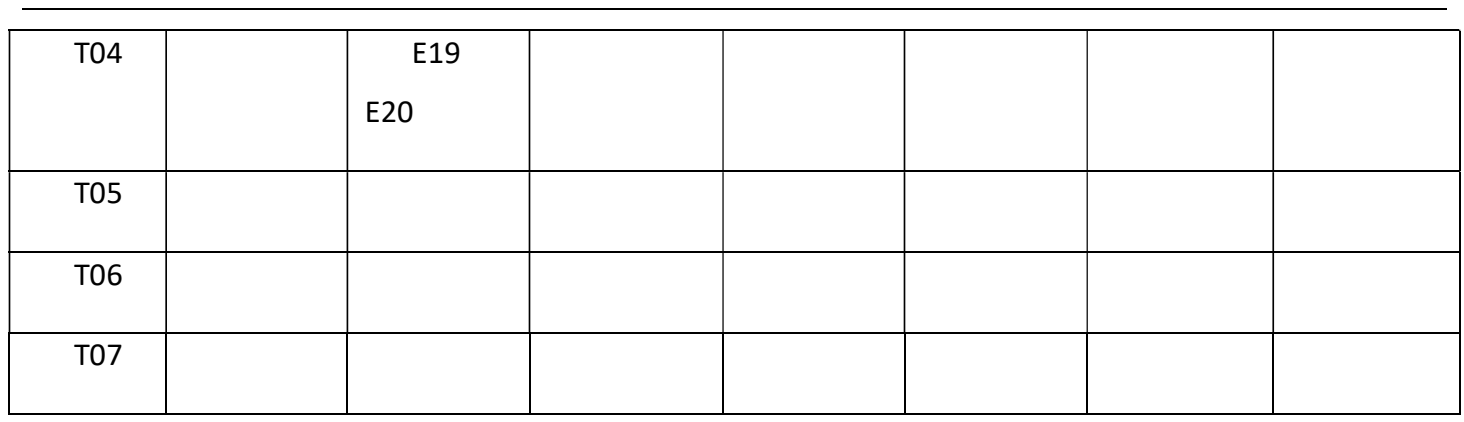

M28- DISEÑO

\begin{tabular}{|c|c|c|c|c|c|c|c|}
\hline & T01 & T02 & T03 & T04 & T05 & T06 & T07 \\
\hline T01 & & & & & & & \\
\hline T02 & & & & & & & \\
\hline T03 & & & & & & & \\
\hline T04 & & E19 & & & & & \\
\hline T05 & & & & & & & \\
\hline T06 & & & & & & & \\
\hline T07 & & & & & & & \\
\hline
\end{tabular}

M29- DISEÑO

\begin{tabular}{|c|c|c|c|c|c|c|c|}
\hline & T01 & T02 & T03 & T04 & T05 & T06 & T07 \\
\hline T01 & & & & & & & \\
\hline T02 & & & & & & & \\
\hline T03 & & & & & & & \\
\hline T04 & & E19 & & & & & \\
\hline T05 & & & & & & & \\
\hline
\end{tabular}

Caso de estudio 
Extracción de Datos

Proceso de RS de experimentos en Ingeniería del

Software

\begin{tabular}{|c|l|l|l|l|l|l|l|}
\hline T06 & & & & & & & \\
\hline T07 & & & & & & & \\
\hline
\end{tabular}

M30- DISEÑO

\begin{tabular}{|c|c|c|c|c|c|c|c|}
\hline & T01 & T02 & T03 & T04 & T05 & T06 & T07 \\
\hline T01 & & & & & & & \\
\hline T02 & & & & & & & \\
\hline T03 & & & & & & & \\
\hline T04 & & E19 & & & & & \\
\hline T05 & & & & & & & \\
\hline T06 & & & & & & & \\
\hline T07 & & & & & & & \\
\hline
\end{tabular}

M31- DISEÑO

\begin{tabular}{|c|l|l|l|l|l|l|l|}
\hline & T01 & T02 & T03 & T04 & T05 & T06 & T07 \\
\hline T01 & & & & & & & \\
\hline T02 & & & & & & & \\
\hline T03 & & & & & & & \\
\hline T04 & & E19 & & & & & \\
\hline T05 & & & & & & & \\
\hline T06 & & & & & & & \\
\hline T07 & & & & & & & \\
\hline
\end{tabular}

M33- DISEÑO

\begin{tabular}{|c|c|c|c|c|c|c|c|}
\hline & T01 & T02 & T03 & T04 & T05 & T06 & T07 \\
\hline T01 & & & & & & & \\
\hline
\end{tabular}


Proceso de RS de experimentos en Ingeniería del Software

\begin{tabular}{|c|l|l|l|l|l|l|l|}
\hline T02 & & & & & & & \\
\hline T03 & & & & & & & \\
\hline T04 & & & & & & & \\
\hline T05 & & & & & & & \\
\hline T06 & & & & & & & \\
\hline T07 & & E22 & & & & & \\
\hline
\end{tabular}

M34- DISEÑO

\begin{tabular}{|c|c|c|c|c|c|c|c|}
\hline & T01 & T02 & T03 & T04 & T05 & T06 & T07 \\
\hline T01 & & & & & & & \\
\hline T02 & & & & & & & E21 \\
\hline T03 & & & & & & & \\
\hline T04 & & & & & & & \\
\hline T05 & & & & & & & \\
\hline T06 & & & & & & & \\
\hline T07 & & & & & & & \\
\hline
\end{tabular}




\subsubsection{Establecer grupos agregables}

A continuación se presentan los GA propuestos para la agregación, una vez que se ha validado que los mismos presentan los datos mínimos para aplicacar algún método de síntesis. El criterio anterior obliga a descartar las siguientes entradas del análisis anterior:

- $\quad$ M32/T01+T03=E01, E02 (Requisitos)

- $\mathrm{M32/T02+T03=E01,} \mathrm{E02} \mathrm{(Requisitos)}$

- $\quad$ M07/T02+T04= E12, (E19, E20) (Diseño)

\begin{tabular}{|c|c|c|c|c|c|}
\hline \multirow{2}{*}{$\begin{array}{r}\text { ID } \\
\text { grupo }\end{array}$} & \multirow[b]{2}{*}{ Métrica / Técnicas } & \multicolumn{2}{|l|}{ Estudios } & \multirow[b]{2}{*}{ Tarea } & \multirow{2}{*}{$\begin{array}{l}\text { Observaci } \\
\text { ón }\end{array}$} \\
\hline & & Estudiantes & $\begin{array}{l}\text { Profesional } \\
\text { es }\end{array}$ & & \\
\hline $\begin{array}{rr} & \mathrm{A0} \\
1 & \end{array}$ & M01/T01+T03 & E01, E03 & & Requisitos & \\
\hline $\begin{array}{ll} & \mathrm{AO} \\
2 & \end{array}$ & M04 / T01+T02 & $\begin{aligned} & \text { (E01, E02, } \\
& \text { E06), E08 }\end{aligned}$ & E05 & Requisitos & -- \\
\hline $\begin{array}{ll} & \mathrm{AO} \\
3 & \end{array}$ & M04 / T01+T03 & $\begin{array}{l}\text { (E01, E02, } \\
\text { E06) }\end{array}$ & E05 & Requisitos & -- \\
\hline $\begin{array}{r}\mathrm{AO} \\
4\end{array}$ & M04/ T02+T03 & $\begin{array}{l}\text { (E01, E02, } \\
\text { E03, E04, E06) }\end{array}$ & E05 & Requisitos & \\
\hline${ }^{4} \quad A 0$ & M04/ T02+T07 & E13, E14, E15 & & Código & \\
\hline $\begin{aligned} & A 0 \\
6 & \end{aligned}$ & M11/ T02+T07 & E13, E14, E15 & & Código & \\
\hline $\begin{array}{ll} & \mathrm{A0} \\
7 & \end{array}$ & M07/T02+T04 & $\begin{array}{l}\text { E12,(E19, } \\
\text { E20) }\end{array}$ & & Diseño & \\
\hline $\begin{array}{ll} & A 0 \\
8 & \end{array}$ & M01/ T02+T04 & E19, E20 & & Diseño & \\
\hline $\begin{array}{ll} & A 0 \\
9 & \end{array}$ & M06/ T02+T04 & $\begin{array}{l}\text { E07, (E19, } \\
\text { E20) }\end{array}$ & & Diseño & \\
\hline A1 & $\mathrm{M} 28 / \mathrm{T} 02+\mathrm{T} 04$ & E19, E20 & & Diseño & \\
\hline
\end{tabular}


Proceso de RS de experimentos en Ingeniería del Software

\begin{tabular}{|c|c|c|c|c|c|}
\hline \multirow{2}{*}{$\begin{array}{r}\text { ID } \\
\text { grupo }\end{array}$} & \multirow[b]{2}{*}{ Métrica / Técnicas } & \multicolumn{2}{|l|}{ Estudios } & \multirow[b]{2}{*}{ Tarea } & \multirow{2}{*}{$\begin{array}{l}\text { Observaci } \\
\text { ón }\end{array}$} \\
\hline & & Estudiantes & $\begin{array}{l}\text { Profesional } \\
\text { es }\end{array}$ & & \\
\hline \multicolumn{6}{|l|}{0} \\
\hline${ }_{1} \quad \begin{array}{l}\text { A1 } \\
\end{array}$ & M29/ T02+T04 & E19, E20 & & Diseño & \\
\hline 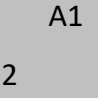 & M01/T02+T07 & E21, E22 & & Diseño & \\
\hline $3 \quad \mathrm{~A} 1$ & M04/T02+T07 & E21, E22 & & Diseño & \\
\hline $\begin{array}{l}\quad \text { A1 } \\
4\end{array}$ & M07/T02+T07 & E21, E22 & & Diseño & \\
\hline & & & & & \\
\hline
\end{tabular}




\section{VALORACIÓN DE LA CALIDAD}

Objetivo

Asegurar que los estudios incluidos en la RS, y en cuyos resultados se fundamentarán las conclusiones y recomendaciones que finalmente se generen, posean un nivel de calidad (validez) adecuado; asimismo, buscan facilitar la toma de decisiones durante la fase de SÍNTESIS DE DATOS.

ACTIVIDADES

1. Aplicar escala de evaluación

2. Clasificar el nivel de calidad del estudio 


\subsection{Aplicar escala de evaluación}

Objetivo

Determinar la calidad de cada estudio primario (experimentos y cuasi-experimentos) y permitir, de esta manera, ponderar su contribución a la agregación.

\begin{tabular}{|l|l|l|}
\hline \multicolumn{2}{|l|}{ Entrada } & \multicolumn{2}{|l|}{ Salida } \\
\hline- E01_Datos del experimento & - C01_Escala de calidad \\
\hline Tareas & \multicolumn{1}{|c|}{ Entradas } & Salidas \\
\hline & - & \\
\hline & - & \\
\hline
\end{tabular}

En esta actividad se aplicó la escala de calidad para los estudios finalmente incluídos en los GA anteriormente seleccionados: E01, E02, E03, E04, E05, E06, E07, E08, E13, E14, E15, E19, E20, E21, E22. Por razones de espacio, la aplicación del modelo C01 para los 15 estudios ha sido simplificado en una sola matriz, como se muestra más adelante en esta fase.

\subsection{Clasificar el nivel de calidad del estudio}

\begin{tabular}{|l|l|}
\hline \multicolumn{2}{|l|}{ Objetivo } \\
\hline \multicolumn{2}{|l|}{ Establecer el nivel de calidad de acuerdo a las respuestas obtenidas en la tarea anterior } \\
\hline Entrada & Salida \\
\hline- C01_Escala de calidad & $-\quad$ C01_Escala de calidad (actualizado) \\
\hline Tareas & \\
\hline
\end{tabular}

Caso de estudio 


\begin{tabular}{|l|l|l|}
\hline & \multicolumn{1}{|c|}{ Entradas } & Salidas \\
\hline & - & \\
\hline
\end{tabular}

El resultado de esta actividad se ha integrado con el producto de la actividad anterior en el modelo presentado a continuación. 
C01 ESCALA DE CALIDAD (resumen)

Nombre de la Revisión:

Comparación de técnicas de lectura

\section{Evaluador:}

Fecha:

\begin{tabular}{|c|c|c|c|c|c|c|c|c|c|c|c|c|c|c|c|}
\hline \multirow[t]{2}{*}{ Items del cuestionario } & \multicolumn{15}{|c|}{ Valor asignado (S/N) } \\
\hline & E01 & E02 & E03 & E04 & E05 & E06 & E07 & E08 & E13 & E14 & E15 & E19 & E20 & E21 & E22 \\
\hline $\begin{array}{l}\text { ¿Se establecen las hipótesis y se discute su relación con } \\
\text { el objetivo en un sección de Introducción? }\end{array}$ & $S$ & $\mathrm{~S}$ & $\mathrm{~S}$ & $\mathrm{~S}$ & $\mathrm{~S}$ & $S$ & $\mathrm{~S}$ & $\mathrm{~S}$ & $\mathrm{~S}$ & $S$ & $\mathrm{~S}$ & $\mathrm{~S}$ & $\mathrm{~S}$ & $\mathrm{~S}$ & $S$ \\
\hline $\begin{array}{l}\text { ¿El investigador define el proceso por el que se aplica el } \\
\text { tratamiento a los objetos y sujetos (por ejemplo, la } \\
\text { aleatorizaición)? }\end{array}$ & $S$ & $\mathrm{~S}$ & $\mathrm{~S}$ & $\mathrm{~S}$ & $\mathrm{~S}$ & $\mathrm{~S}$ & $\mathrm{~S}$ & $\mathrm{~S}$ & $\mathrm{~S}$ & $S$ & $\mathrm{~S}$ & $\mathrm{~S}$ & $\mathrm{~S}$ & $\mathrm{~S}$ & $S$ \\
\hline $\begin{array}{l}\text { ¿Se mencionan las amenazas a la validez y cómo éstas } \\
\text { afectan los resultados y los hallazgos? }\end{array}$ & $S$ & $\mathrm{~S}$ & $\mathrm{~S}$ & $\mathrm{~S}$ & $\mathrm{~S}$ & $\mathrm{~S}$ & $\mathrm{~S}$ & $S$ & $S$ & $S$ & $\mathrm{~S}$ & $\mathrm{~S}$ & $\mathrm{~S}$ & $S$ & $S$ \\
\hline ¿Se menciona la significancia estadística junto con los resultados? & $N$ & $N$ & $N$ & $N$ & $N$ & $N$ & $S$ & $S$ & $N$ & $N$ & $N$ & $N$ & $N$ & $S$ & $S$ \\
\hline Nivel de calidad asignado (M/A) & $A$ & A & $A$ & $A$ & A & $A$ & A & $A$ & $A$ & A & $A$ & A & A & $A$ & $A$ \\
\hline
\end{tabular}


Proceso de RS de experimentos en Ingeniería del Software

\section{SÍNTESIS DE DATOS}

Objetivo

ACTIVIDADES

1. Seleccionar grupos de estudios a agregar

2. Meta-análisis

3. Consolidar y clasificar evidencias

4. Combinar evidencias

Caso de estudio 


\subsection{Seleccionar grupos de estudios a agregar}

Los grupos seleccionados para la agregación están conformados por A01 a A14. No obstante, algunos de los grupos serán agregados por más de un método de meta-análisis por lo que se generan varios subgrupos distintos. Éste es el caso de A02, A03 y A04.

\begin{tabular}{|c|c|c|c|c|c|}
\hline \multirow{2}{*}{$\begin{array}{r}\text { ID } \\
\text { grupo }\end{array}$} & \multirow[b]{2}{*}{ Métrica / Técnicas } & \multicolumn{2}{|l|}{ Estudios } & \multirow[b]{2}{*}{ Tarea } & \multirow{2}{*}{$\begin{array}{l}\text { Observaci } \\
\text { ón }\end{array}$} \\
\hline & & Estudiantes & $\begin{array}{l}\text { Profesional } \\
\text { es }\end{array}$ & & \\
\hline $\begin{array}{ll} & \mathrm{AO} \\
1 & \end{array}$ & M01/T01+T03 & E01, E03 & & Requisitos & \\
\hline $\mathrm{AO}$ & M04 / T01+T02 & $\begin{array}{l}(E 01, \quad E 02, \\
\text { E06), E08 }\end{array}$ & E05 & Requisitos & $\begin{array}{l}\text { Genera } \\
\text { A02 (RR) y } \\
\text { A02 (Ind) }\end{array}$ \\
\hline $3 \begin{array}{ll} & \mathrm{AO} \\
3 & \end{array}$ & M04 / T01+T03 & $\begin{array}{l}\text { (E01, E02, } \\
\text { E06) }\end{array}$ & E05 & Requisitos & $\begin{array}{l}\text { Genera } \\
\text { A03 (RR) y } \\
\text { A03 (Ind) }\end{array}$ \\
\hline $\mathrm{AO}$ & M04/ T02+T03 & $\begin{array}{r}(E 01, E 02, \\
E 03, E 04, E 06)\end{array}$ & E05 & Requisitos & $\begin{array}{l}\text { Genera } \\
\text { A04 (RR) y } \\
\text { A04 (Ind) }\end{array}$ \\
\hline $\begin{array}{ll} & \text { A0 } \\
5 & \end{array}$ & M04/ T02+T07 & E13, E14, E15 & & Código & \\
\hline $\begin{aligned} & A 0 \\
6 & \end{aligned}$ & M11/ T02+T07 & E13, E14, E15 & & Código & \\
\hline $\begin{array}{ll} & \mathrm{A0} \\
7 & \end{array}$ & M07/T02+T04 & $\begin{array}{l}\text { E12,(E19, } \\
\text { E20) }\end{array}$ & & Diseño & \\
\hline $\begin{aligned} & A 0 \\
8 & \end{aligned}$ & M01/ T02+T04 & E19, E20 & & Diseño & $\begin{array}{l}\text { Sólo se } \\
\text { puede aplicar } \\
\text { RR }\end{array}$ \\
\hline
\end{tabular}


Proceso de RS de experimentos en Ingeniería del Software

\begin{tabular}{|c|c|c|c|c|c|}
\hline \multirow{2}{*}{$\begin{array}{r}\text { ID } \\
\text { grupo }\end{array}$} & \multirow[b]{2}{*}{ Métrica / Técnicas } & \multicolumn{2}{|l|}{ Estudios } & \multirow[b]{2}{*}{ Tarea } & \multirow{2}{*}{$\begin{array}{l}\text { Observaci } \\
\text { ón }\end{array}$} \\
\hline & & Estudiantes & $\begin{array}{l}\text { Profesional } \\
\text { es }\end{array}$ & & \\
\hline A0 & M06/ T02+T04 & $\begin{array}{l}\text { E07, (E19, } \\
\text { E20) }\end{array}$ & & Diseño & \\
\hline $\begin{array}{ll} & \mathrm{A} 1 \\
0 & \end{array}$ & M28/ T02+T04 & E19, E20 & & Diseño & \\
\hline $\begin{array}{ll} & \mathrm{A} 1 \\
1 & \end{array}$ & M29/ T02+T04 & E19, E20 & & Diseño & \\
\hline $2^{A 1}$ & M01/T02+T07 & E21, E22 & & Diseño & \\
\hline $3{ }^{A 1}$ & M04/T02+T07 & E21, E22 & & Diseño & \\
\hline $\begin{array}{r}\text { A1 } \\
4\end{array}$ & M07/T02+T07 & E21, E22 & & Diseño & \\
\hline & & & & & \\
\hline
\end{tabular}




\subsection{Meta-análisis}

Se presentan las agregaciones de los siguientes grupos utilizando WMD: A01 a A14. Donde algunos de los grupos han ameritado la separación, como es el caso A02 


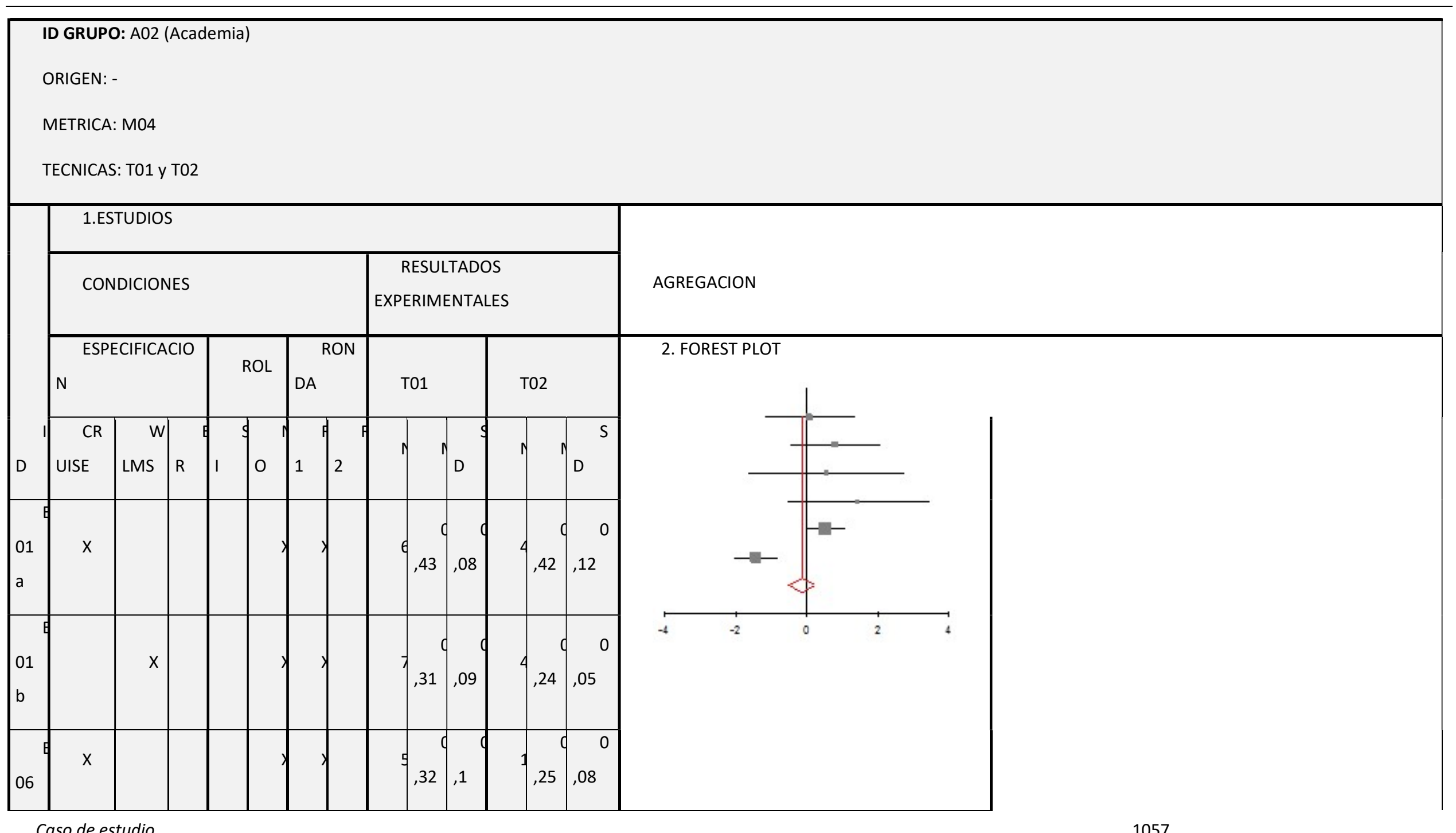




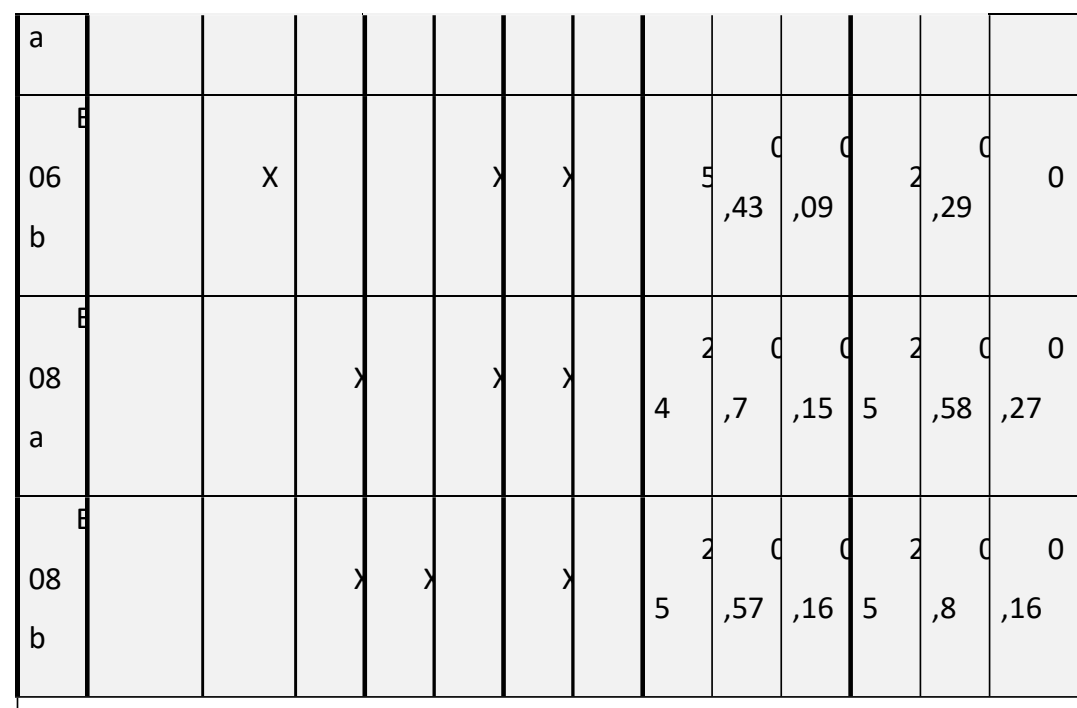

EFECTO GLOBAL: $-0,13$

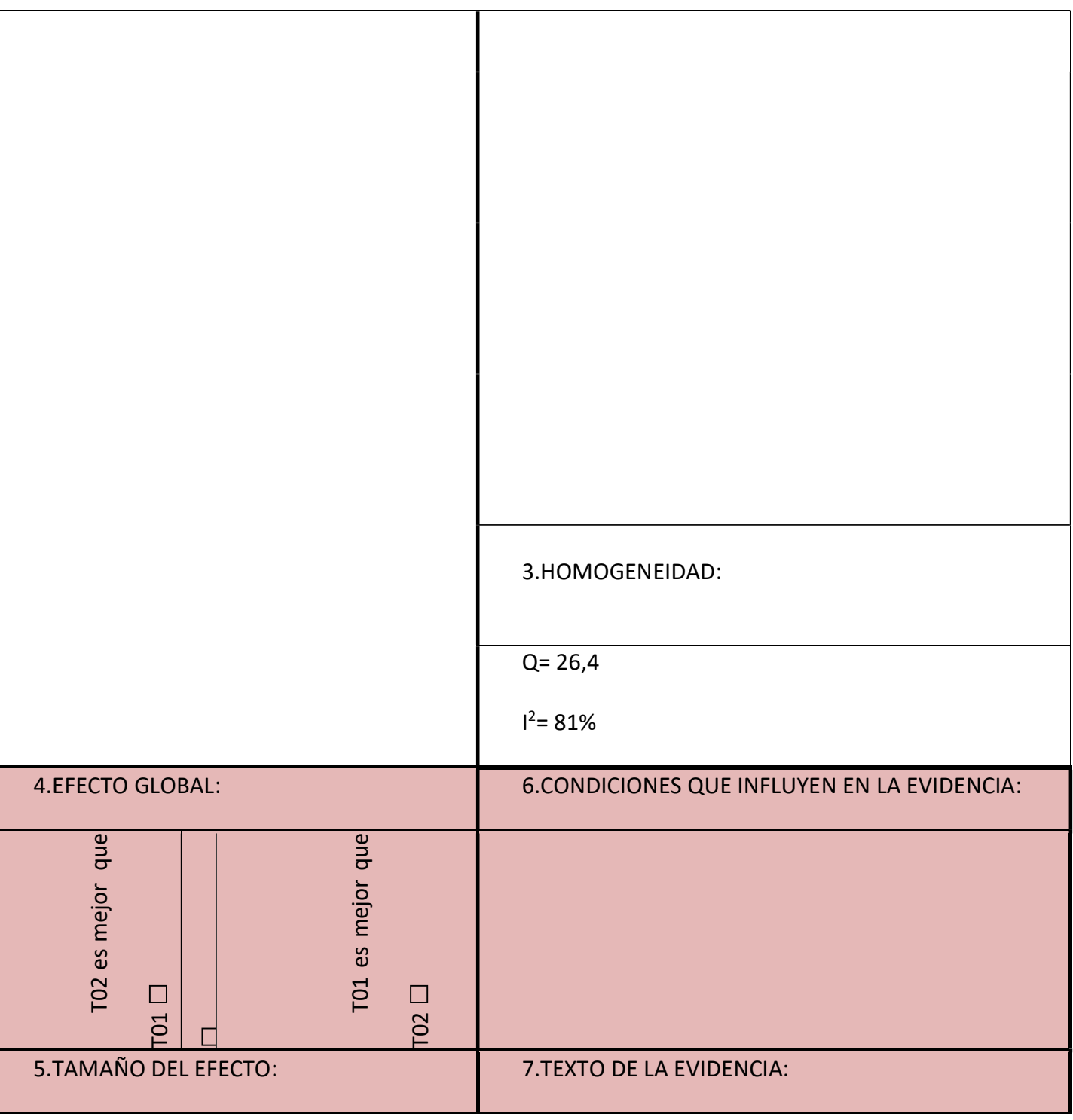


Proceso de RS de experimentos en Ingeniería del Software

\begin{tabular}{|l|l|l|}
\hline & $\bullet$ & \\
\hline OBSERVACIONES: & \\
\hline SE DECIDIO DESCOMPONER YA QUE SE OBSERVA QUE LOS EFECTOS SON INCOSISTENTES. \\
\hline
\end{tabular}




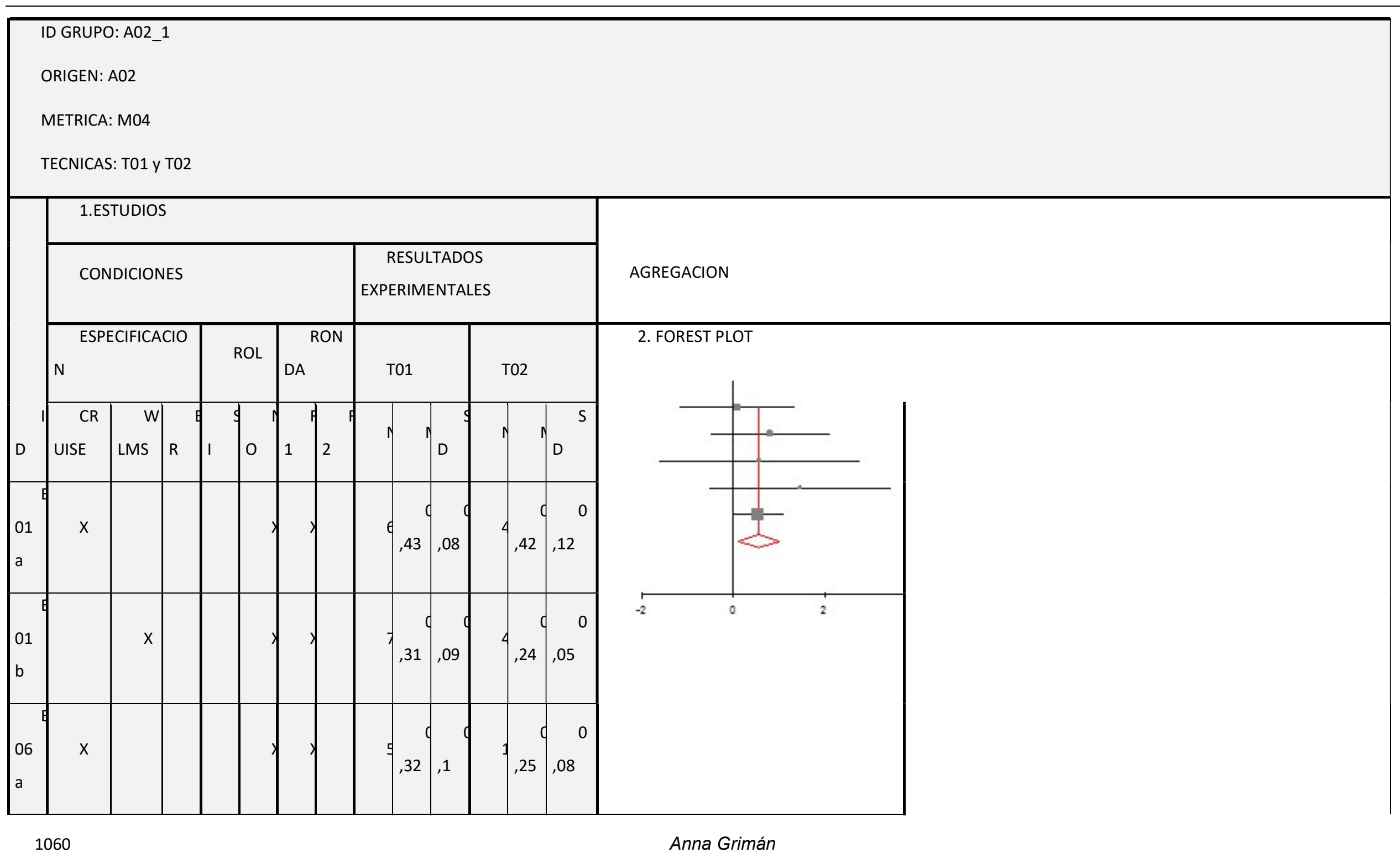


Proceso de RS de experimentos en Ingeniería del Software

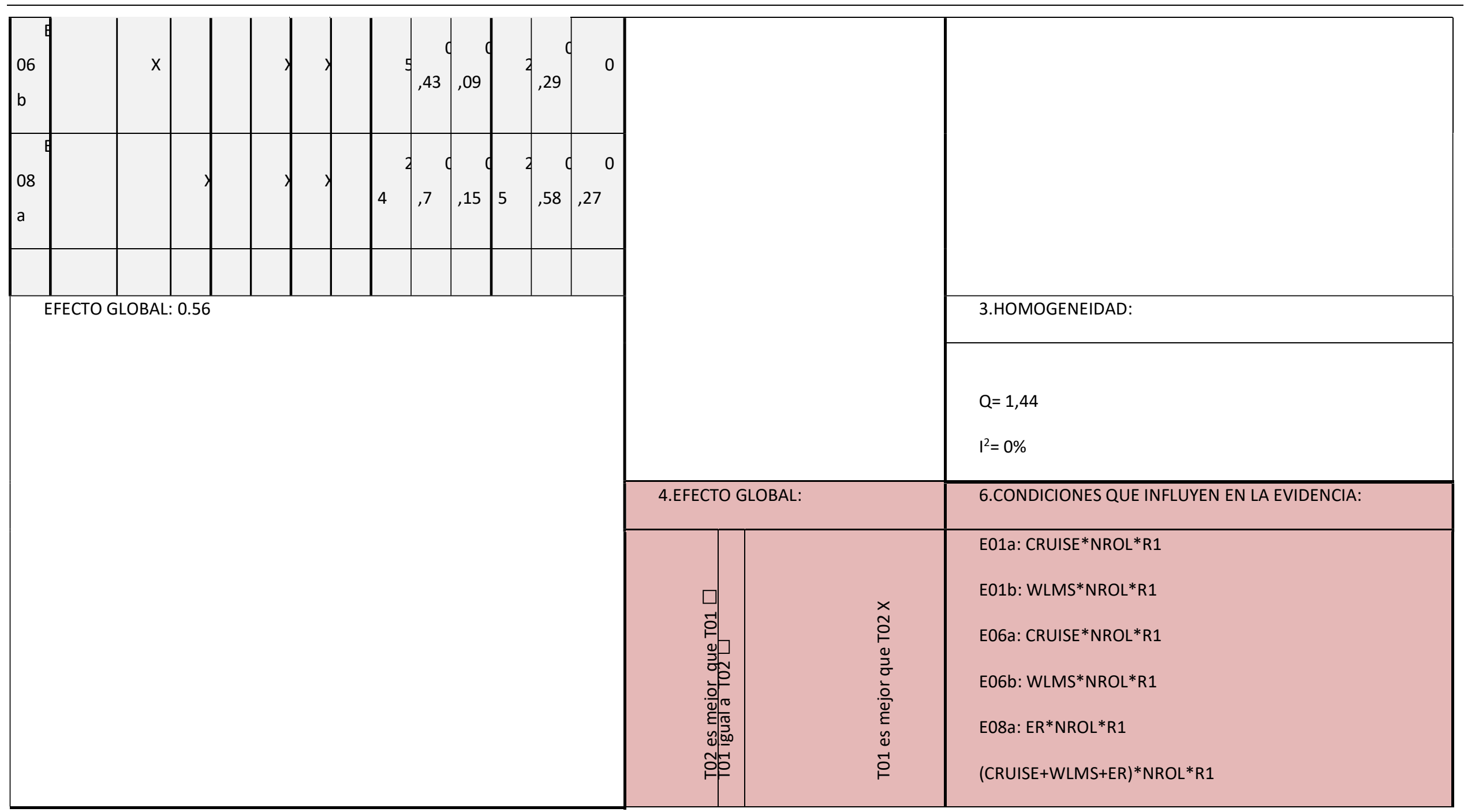




\begin{tabular}{|l|l|l|}
\hline & 5.TAMAÑO DEL EFECTO: & \multicolumn{1}{c|}{ 7.TEXTO DE LA EVIDENCIA: } \\
\cline { 2 - 3 } & & $\begin{array}{l}\text { "M04 parece ser mejor cuando se usa T01 que cuando se } \\
\text { usa T02 (con un tamaño del efecto de 0,56), esto se puede } \\
\text { afirmar con base en } 5 \text { estudios y con un 95\% de confianza. Esto } \\
\text { fue así para las especificaciones probadas (CRUISE, WLMS y ER); } \\
\text { cuando no se utilizó roles y la inspección se realizó en una } \\
\text { ronda" }\end{array}$ \\
\hline OBSERVACIONES: & 0,56 ->T01 es mejor que T02 & \\
\hline SUB-GRUPO DE A02 & \\
\hline
\end{tabular}




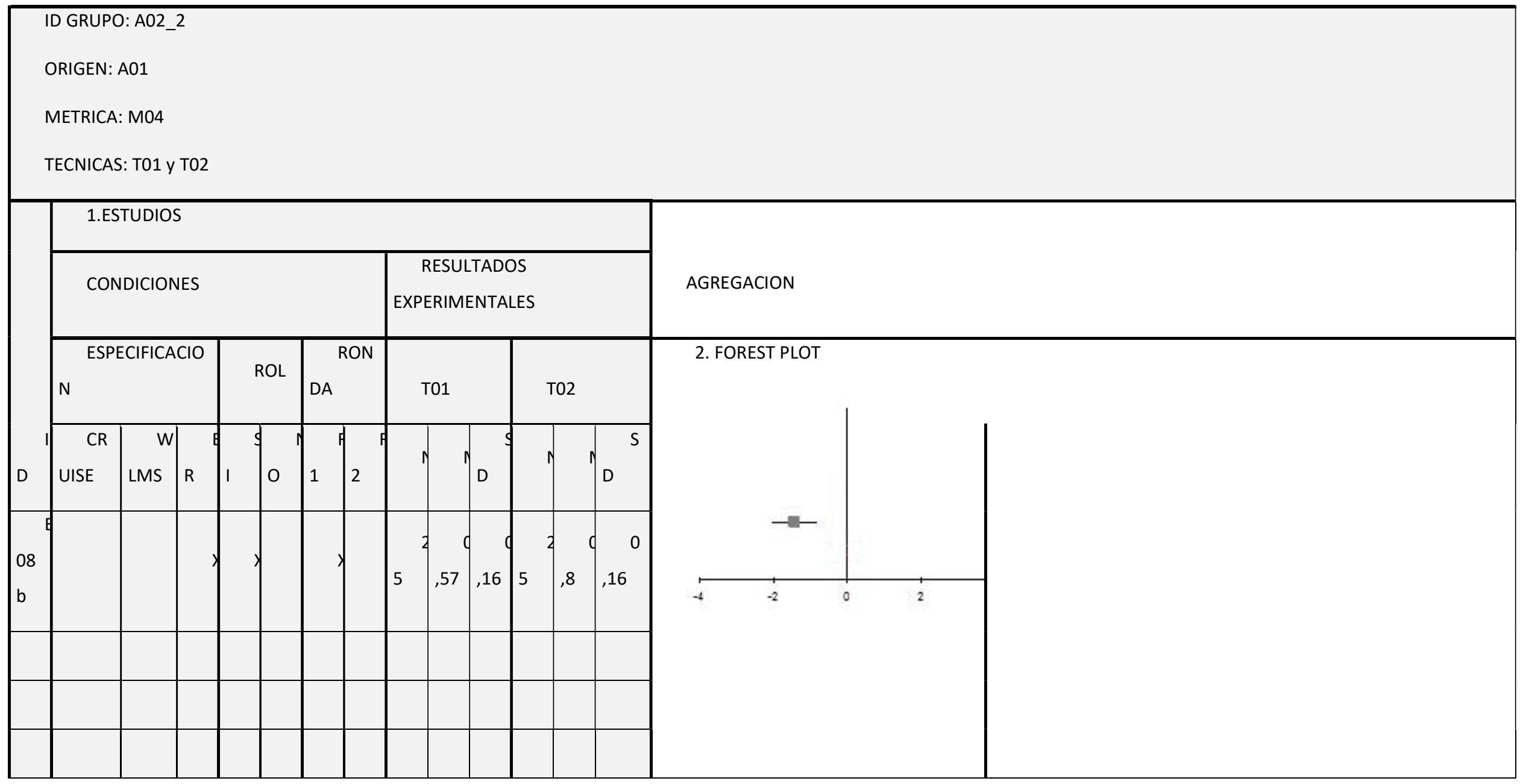




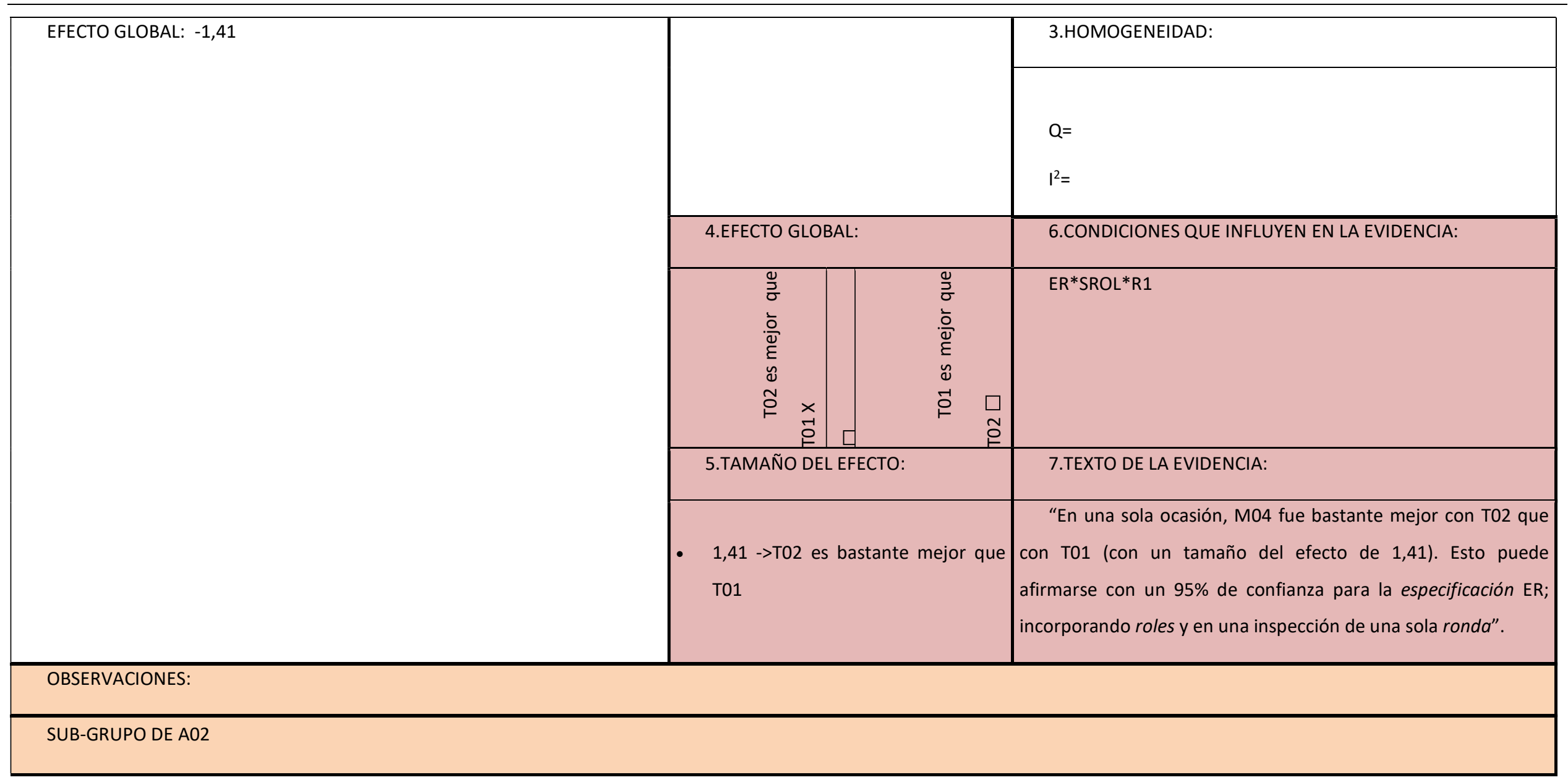




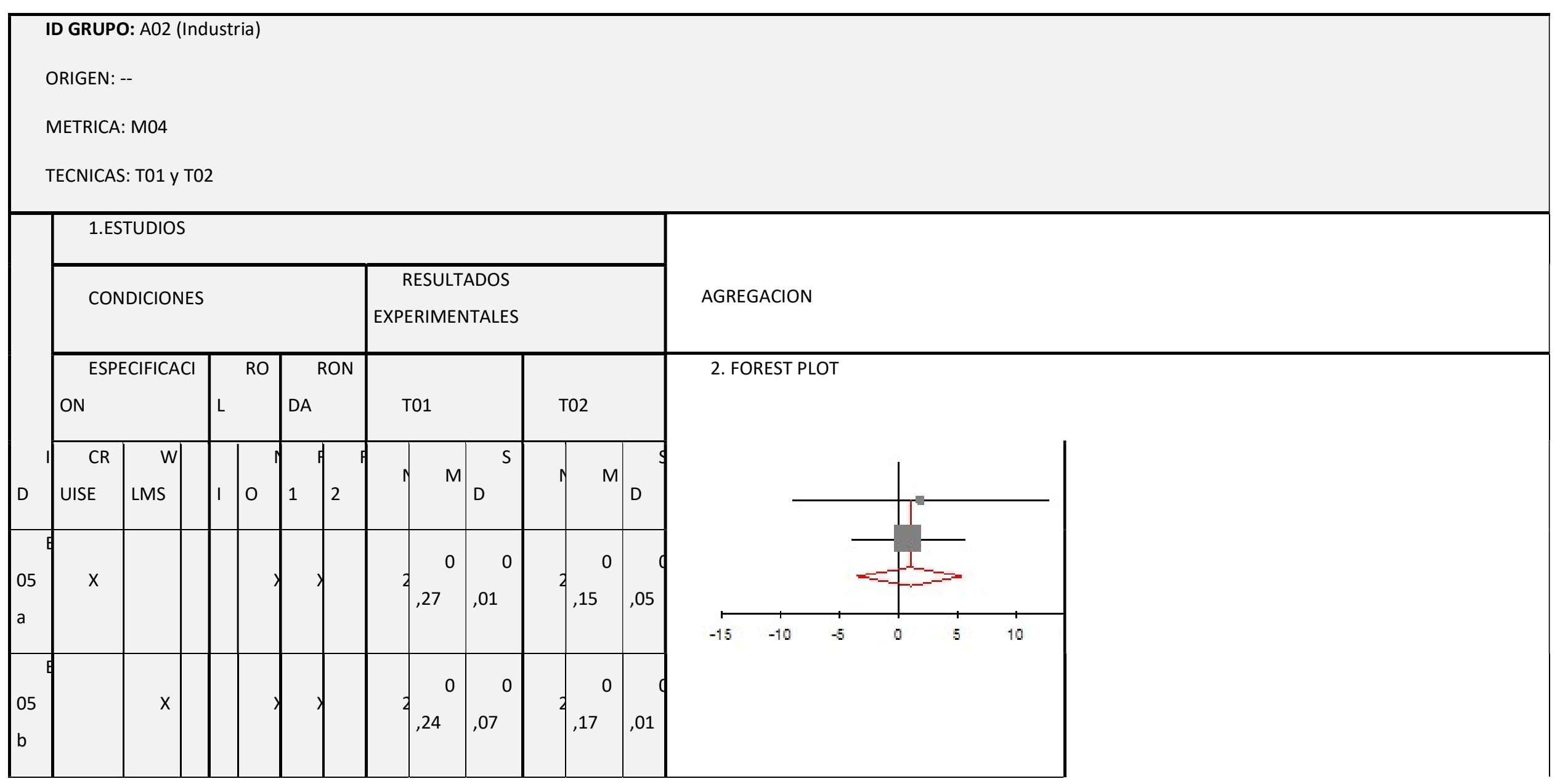




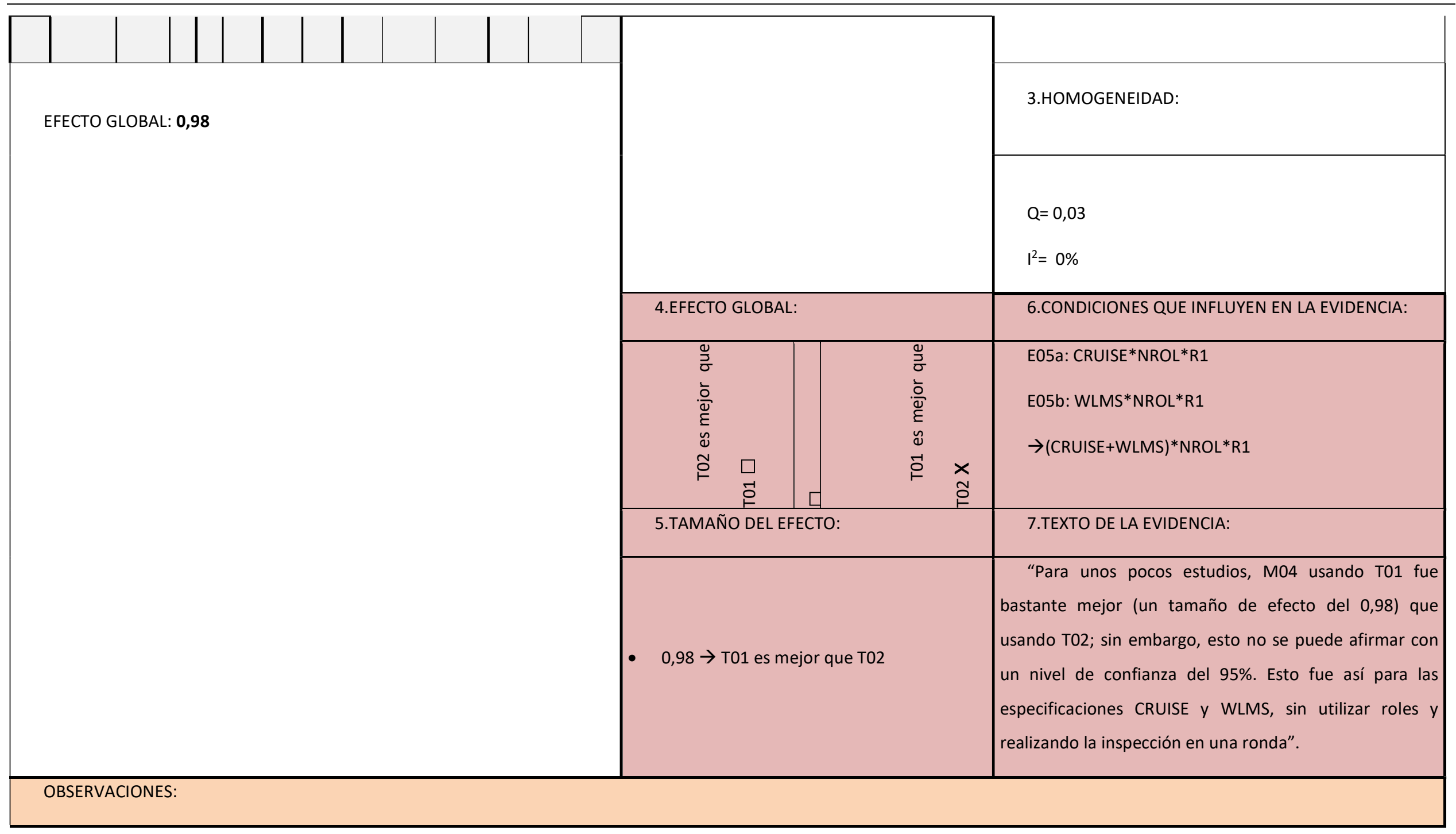




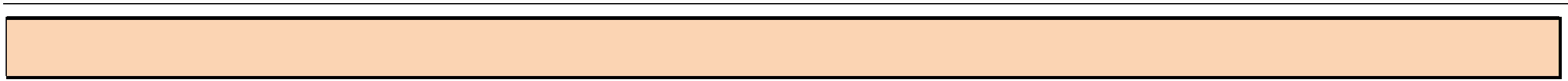




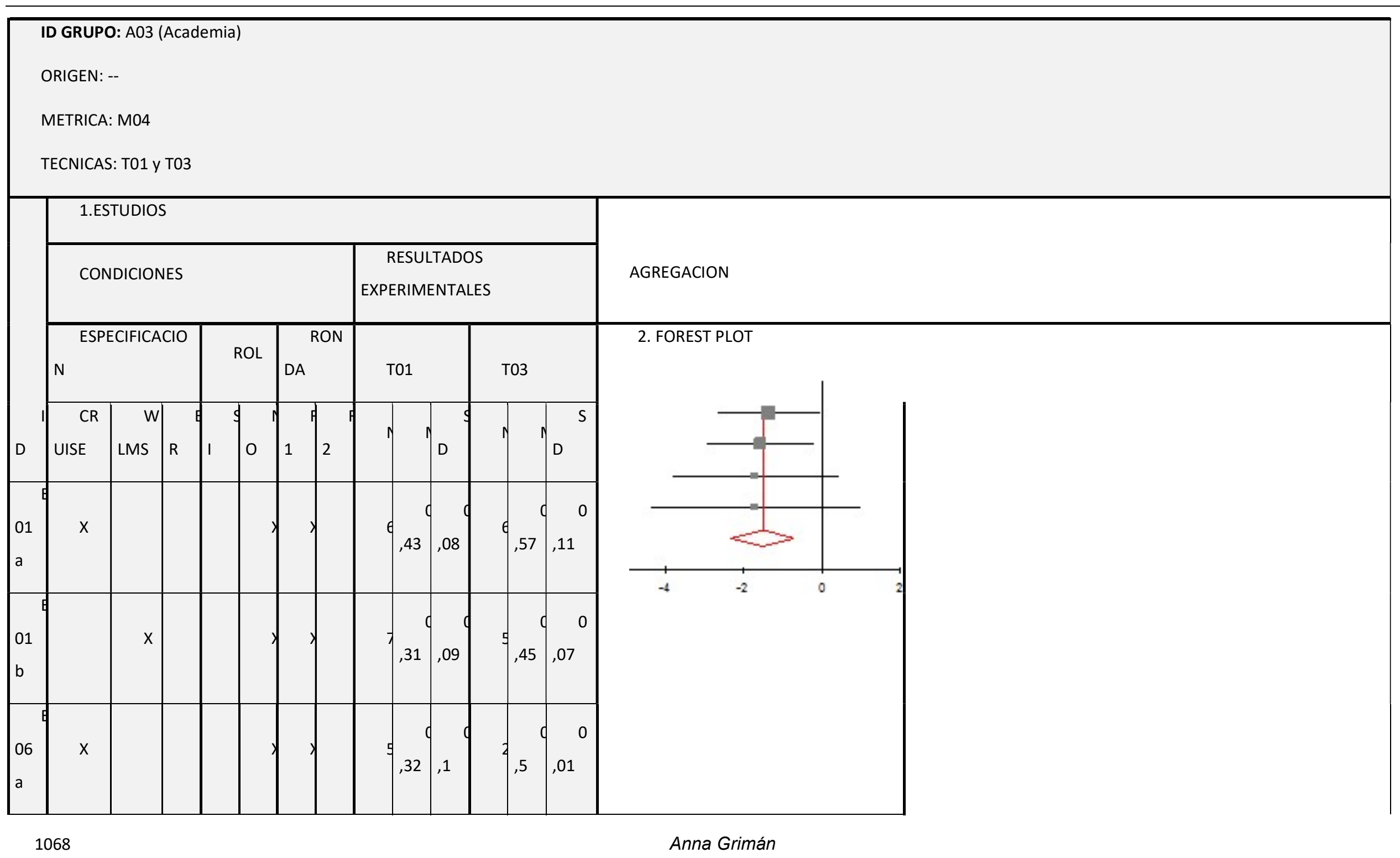


Proceso de RS de experimentos en Ingeniería del Software

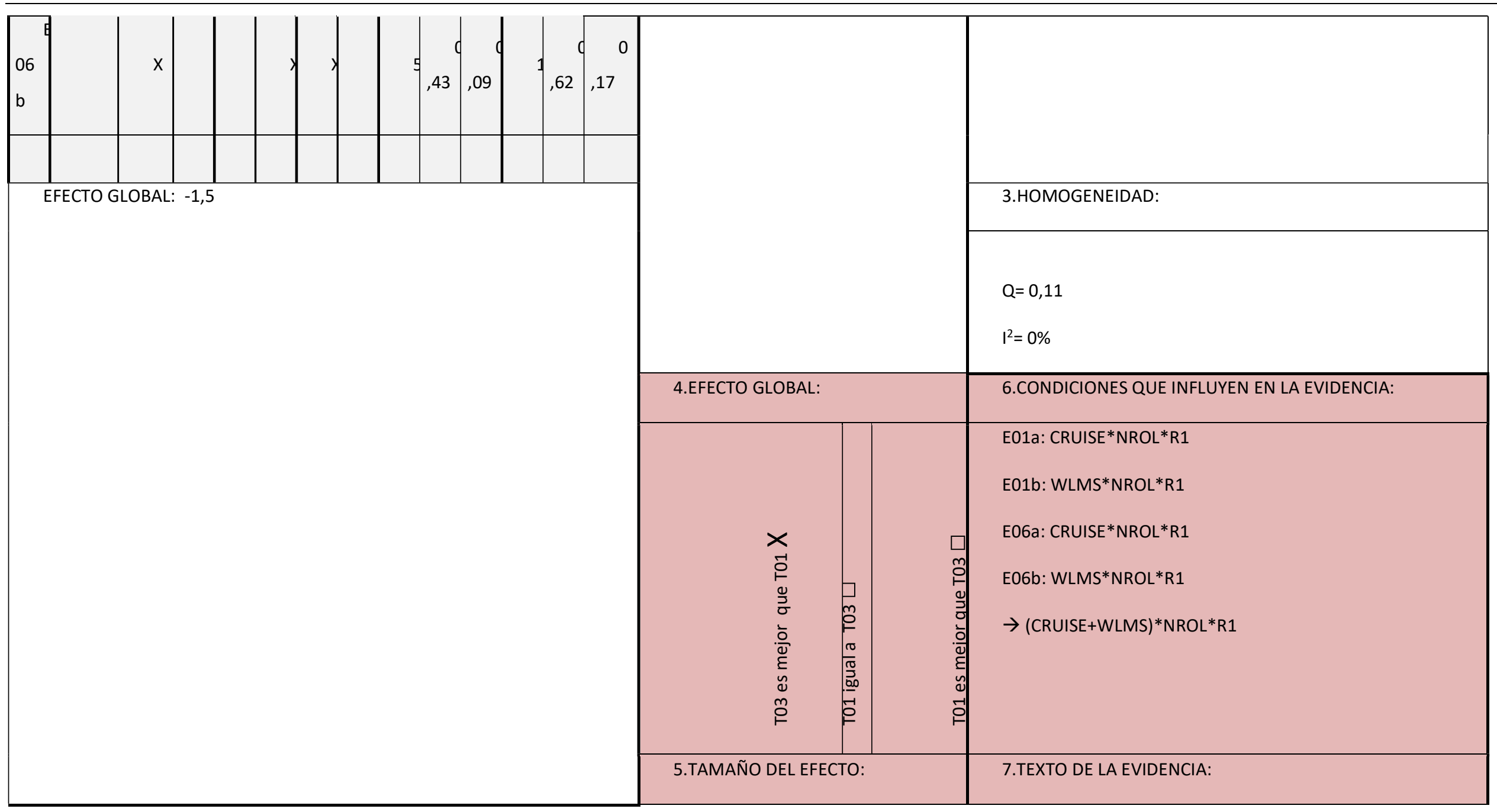




\begin{tabular}{|c|c|c|}
\hline & $\begin{array}{l}\text { - } 1,5 \text {-> T03 es bastante mejor que } \\
\text { T01 }\end{array}$ & $\begin{array}{l}\text { "En algunos casos (4 estudios) M04 fue bastante mejor } \\
\text { cuando se utilizó T03 que cuando se aplicó T01 (con un tamaño } \\
\text { del efecto de 1,5). Esto se puede afirmar con una confianza del } \\
95 \% \text { para las especificaciones CRUISE y WLMS; cuando no se } \\
\text { utilizó roles y la inspección se realizó en una ronda" }\end{array}$ \\
\hline OBSERVACIONES: & & \\
\hline
\end{tabular}

\section{ID GRUPO: A03 (Industria)}

ORIGEN: --

METRICA: M04

TECNICAS: T01 y T03

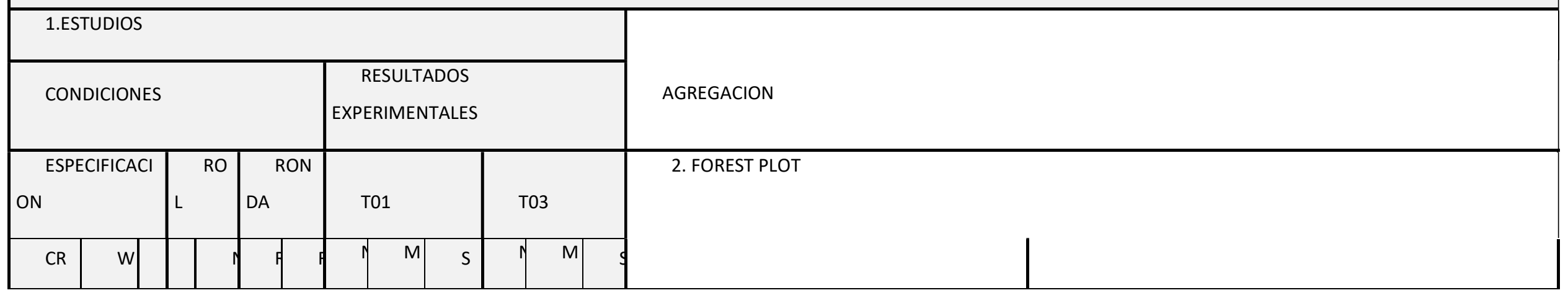


Proceso de RS de experimentos en Ingeniería del Software

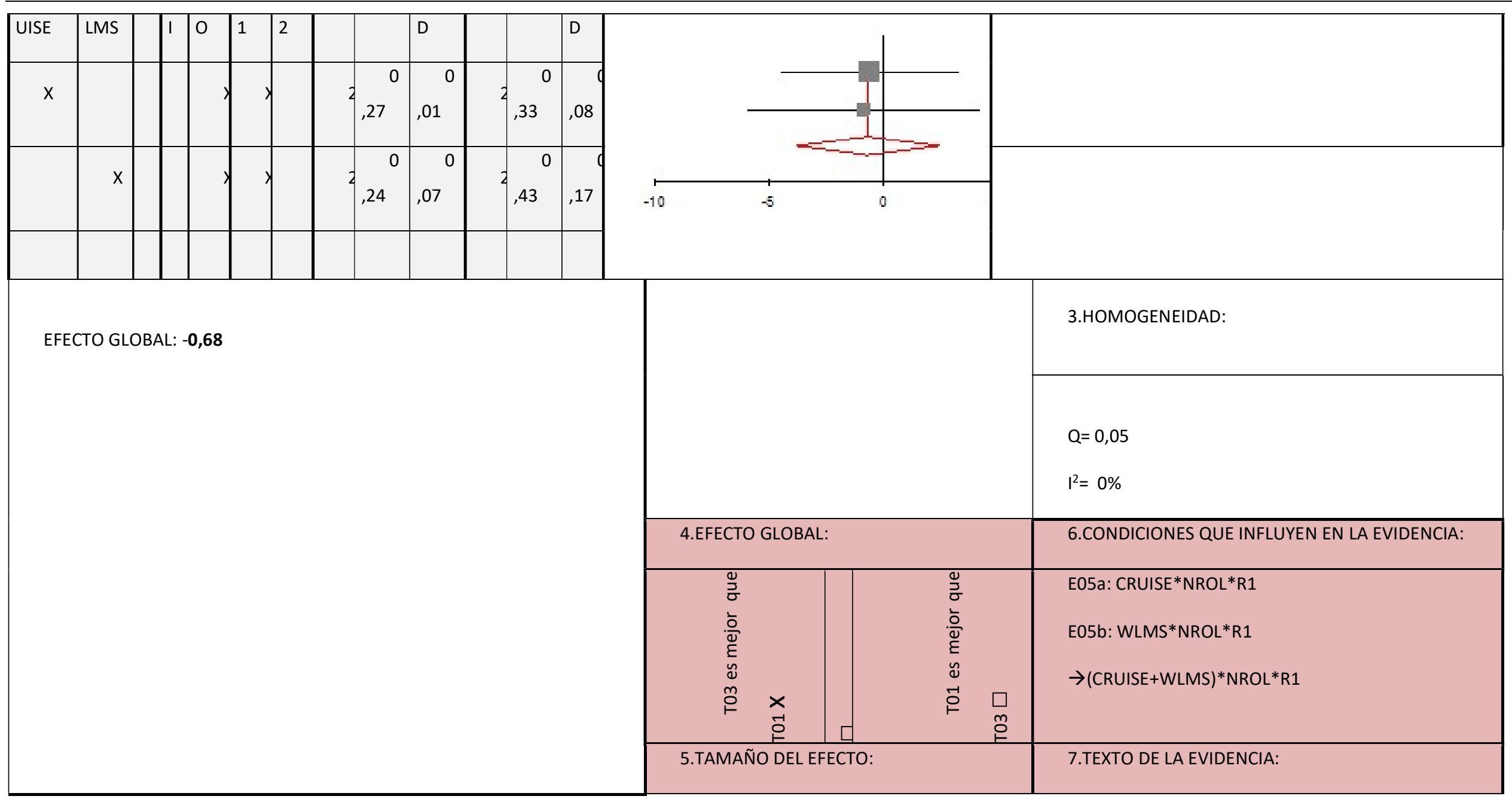




\begin{tabular}{|l|l|l|}
\hline & \multicolumn{1}{|c|}{$\begin{array}{l}\text { "Para unos pocos estudios, M04 usando T03 fue } \\
\text { mejor (un tamaño de efecto del 0,68) que usando T01; } \\
\text { sin embargo, esto no se puede afirmar con un nivel de } \\
\text { confianza del 95\%. Esto fue así para las especificaciones } \\
\text { CRUISE y WLMS, sin utilizar roles y realizando la } \\
\text { inspección en una ronda". }\end{array}$} \\
\hline OBSERVACIONES: & $0,68 \rightarrow$ T03 es mejor que T01 & \\
\hline
\end{tabular}




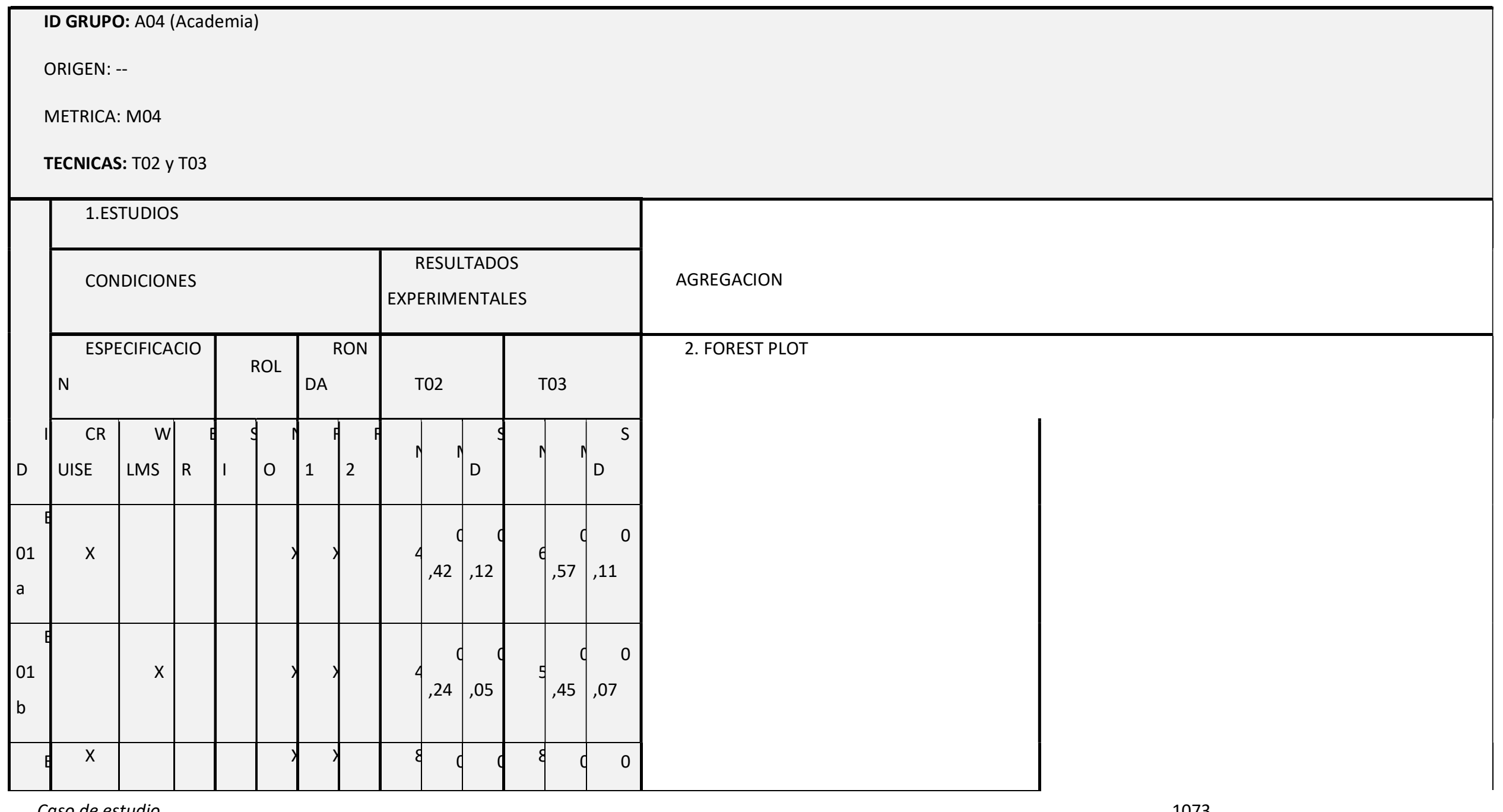




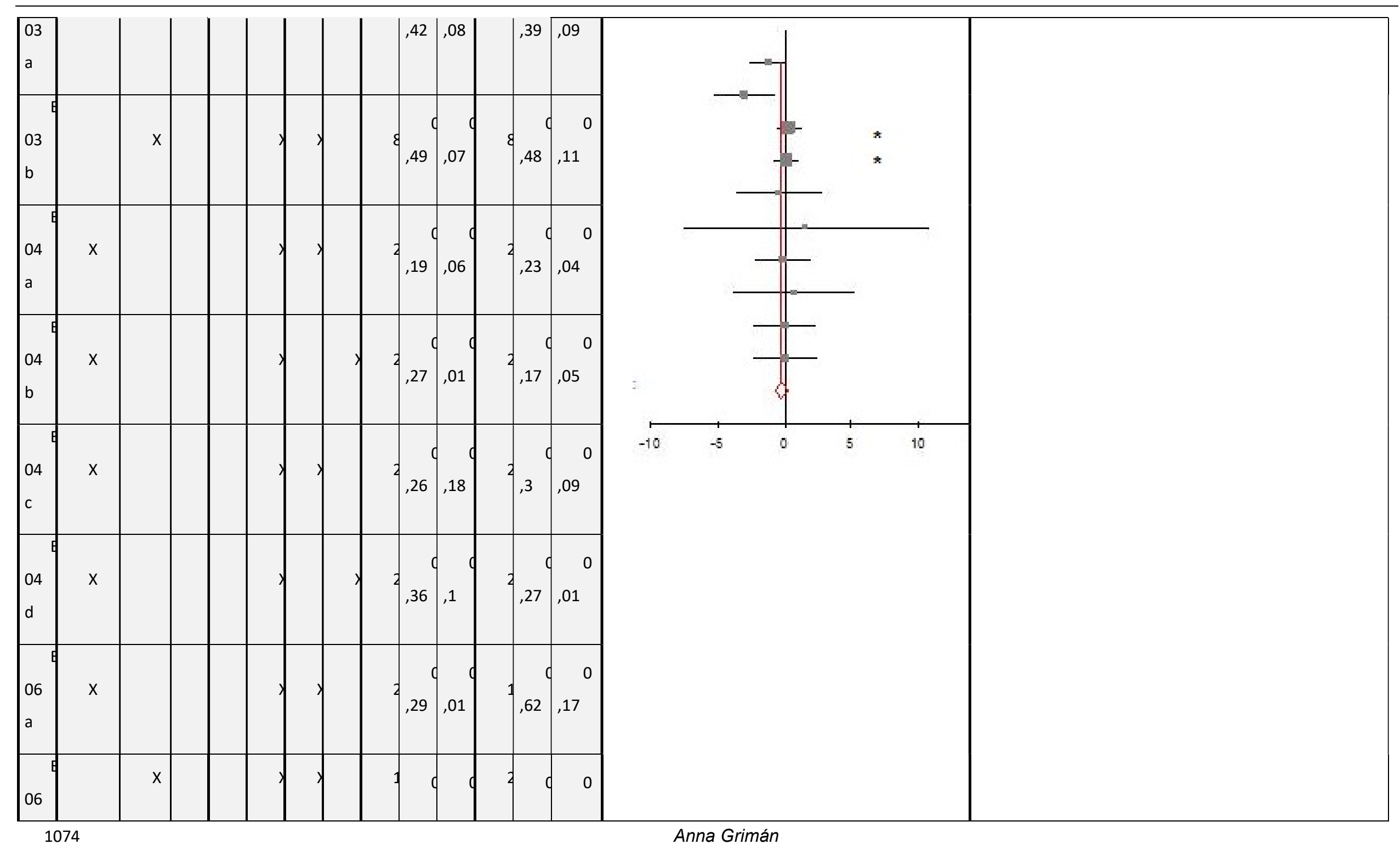


Proceso de RS de experimentos en Ingeniería del Software

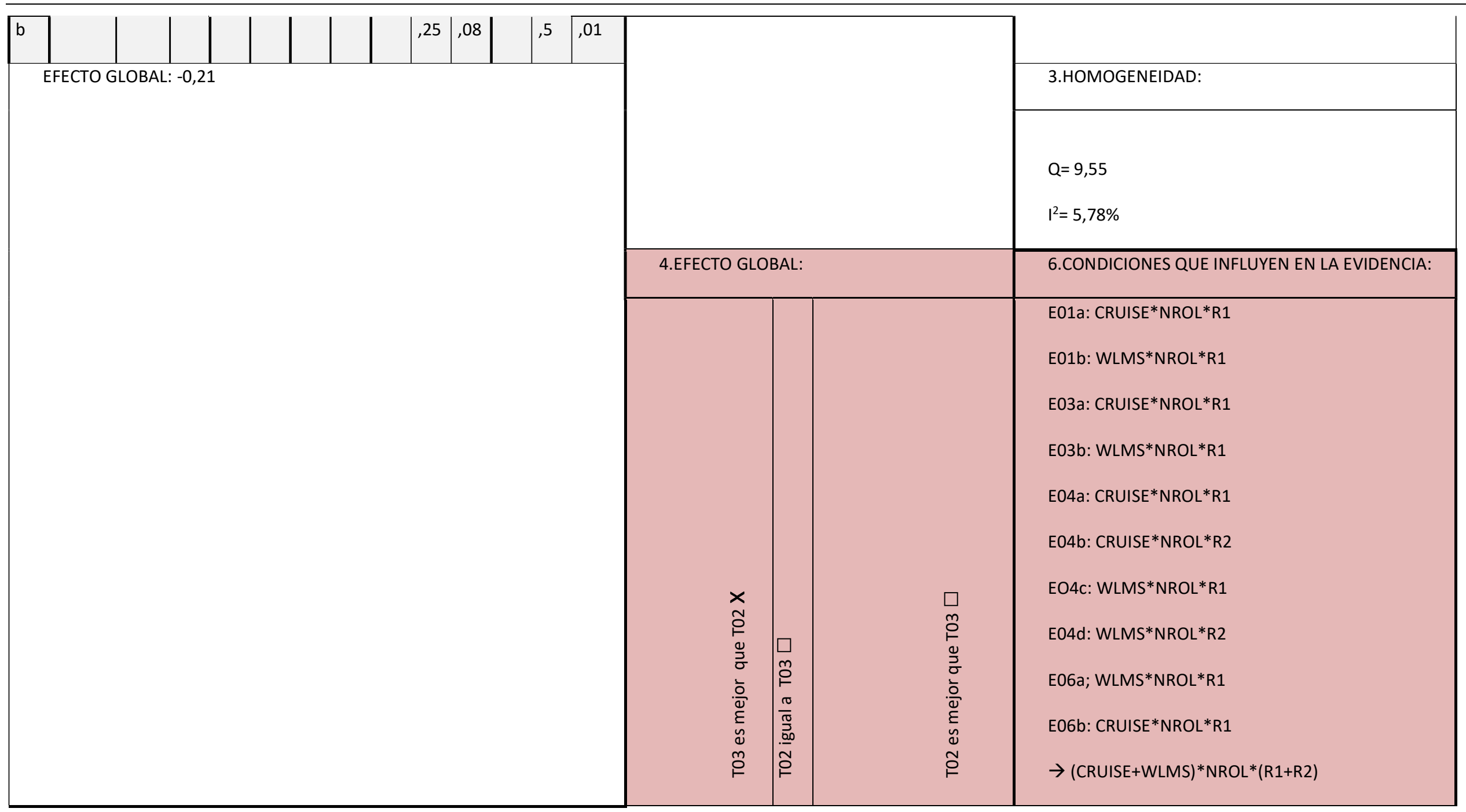




\begin{tabular}{|l|l|l|}
\hline & 5.TAMAÑO DEL EFECTO: & 7.TEXTO DE LA EVIDENCIA: \\
\cline { 2 - 3 } & $-0,21 \rightarrow$ T03 es un poco mejor que T02 & $\begin{array}{l}\text { "Para } 10 \text { estudios, M04 resultó un poco mejor con } \\
\text { T03 que con T02 (con un valor absoluto del tamaño del } \\
\text { efecto igual a } 0,21 \text { ). Sin embargo, esto no se puede } \\
\text { afirmar con un } 95 \% \text { de confianza. Esto fue así con las } \\
\text { especificaciones probadas (WLMS y CRUISE), sin utilizar } \\
\text { roles y, parece ser que, con independencia de que la } \\
\text { inspección se realice en una ronda o en dos rondas". }\end{array}$ \\
\hline OBSERVACIONES: & & \\
\hline EL VALOR DE I2 ES BAJO, POR LO QUE SE DECIDE NO DESCOMPONER. ADEMAS NO SE PODRÍA EXPLICAR LA DIFERENCIA ENTRE E01b Y EL RESTO DEL CONJUNTO DE ESTUDIOS.
\end{tabular}




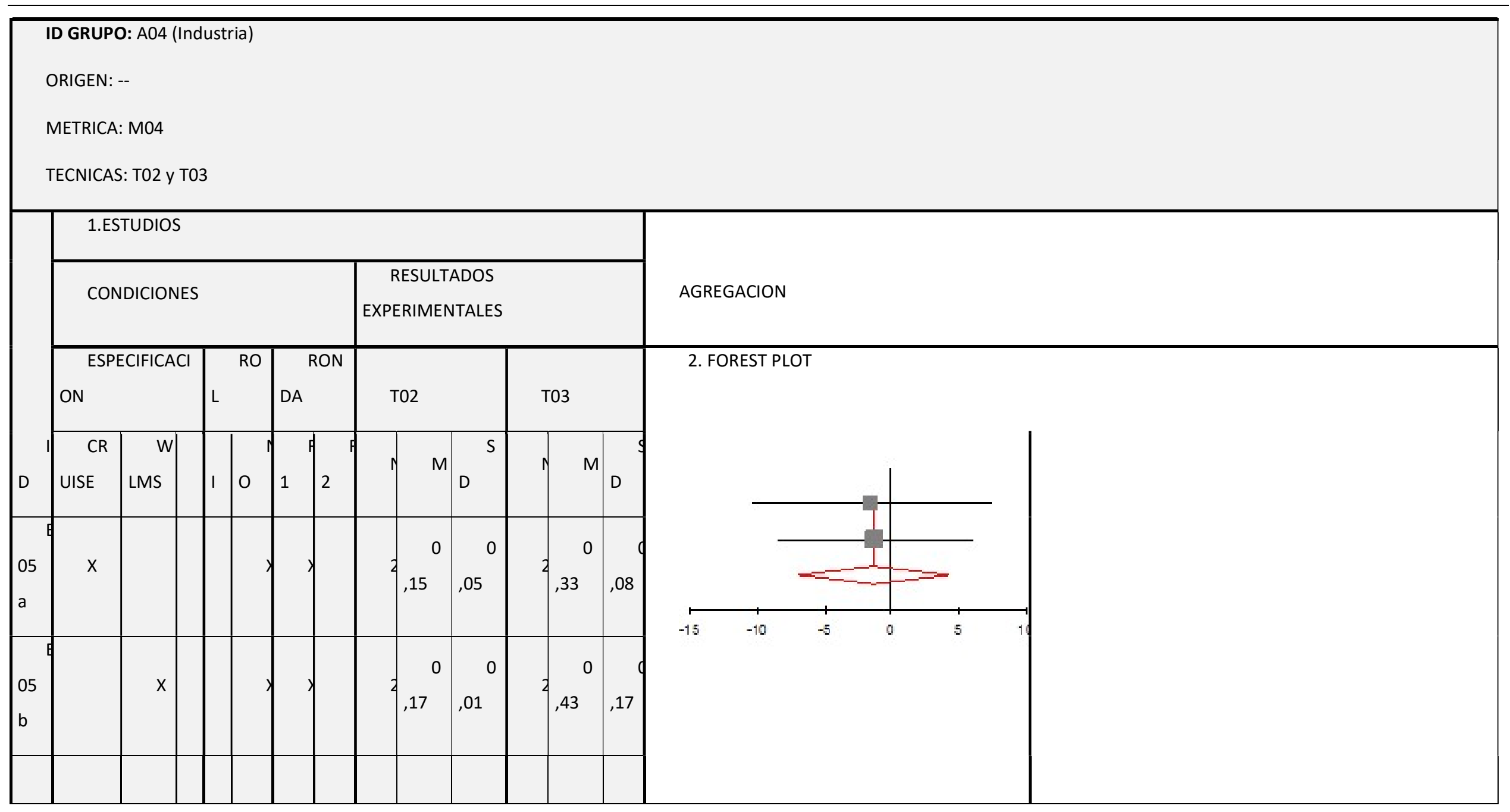




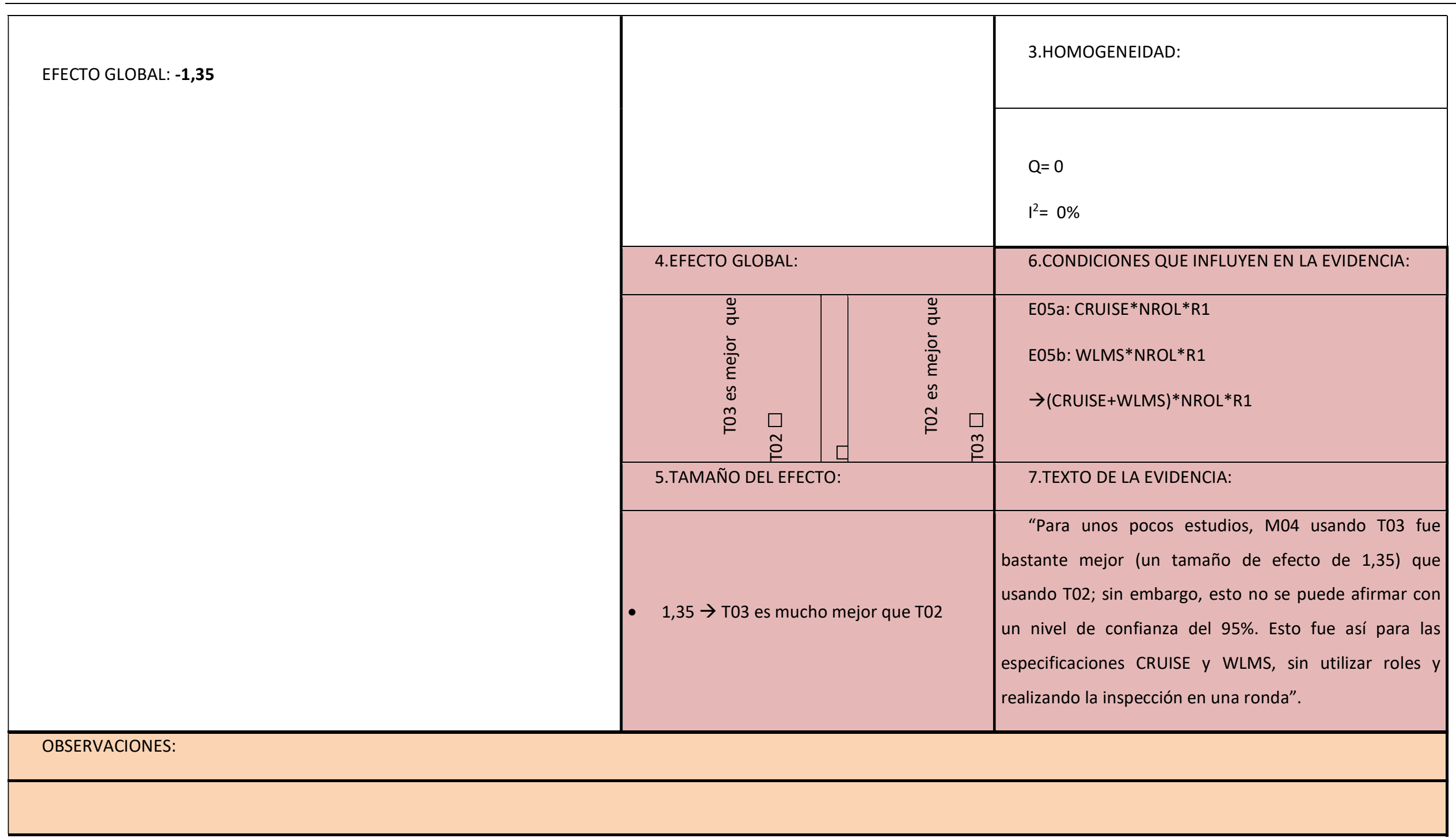




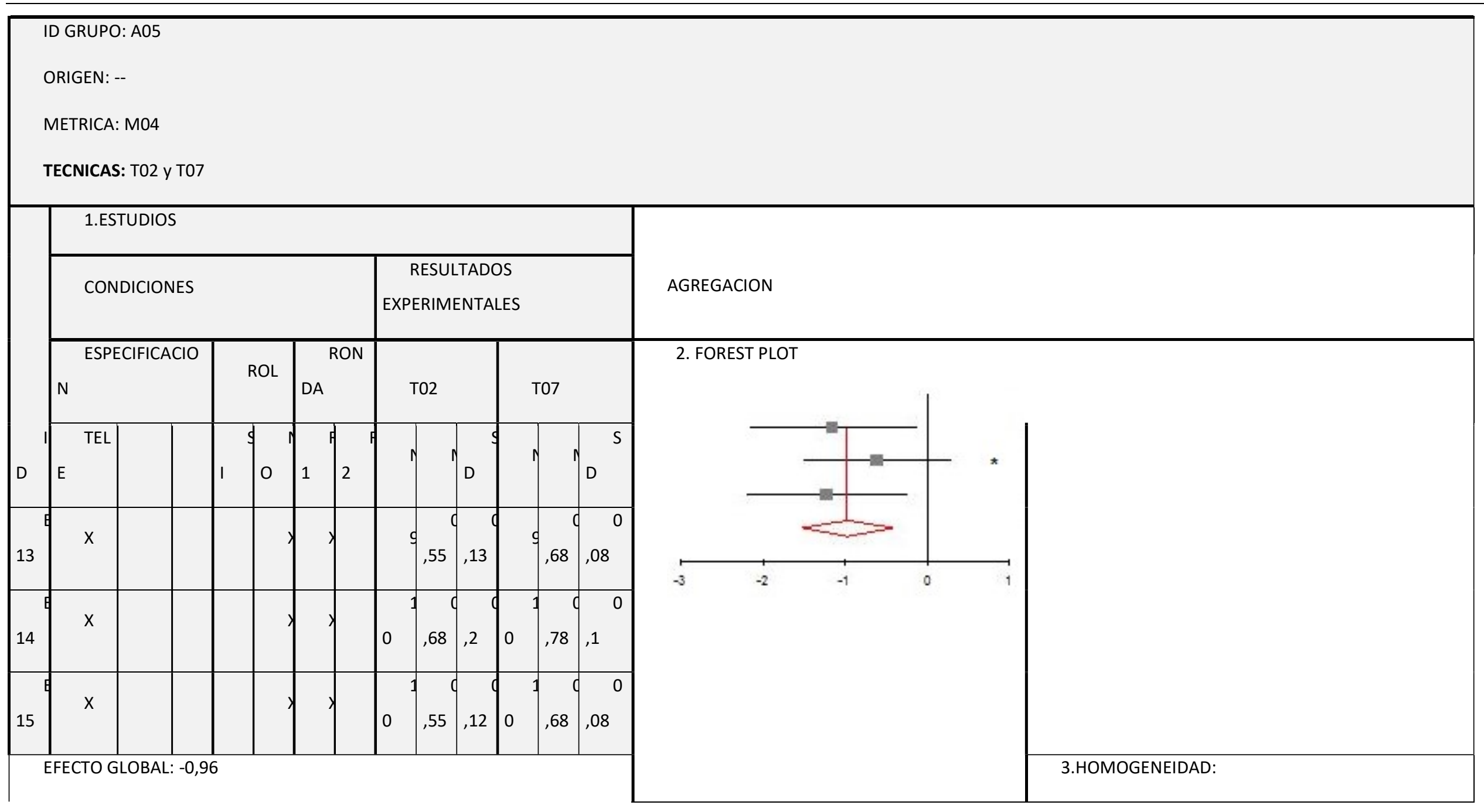




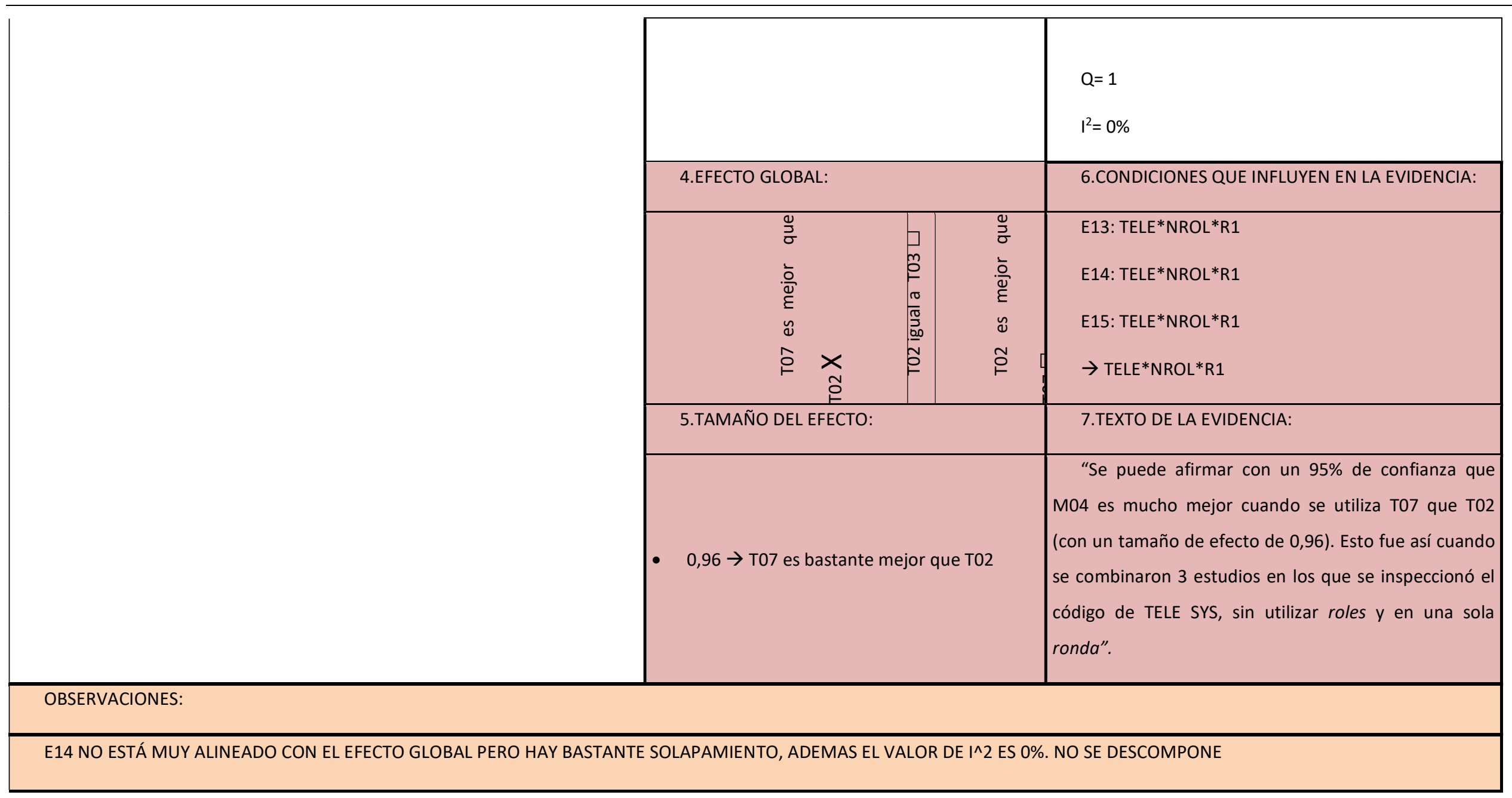




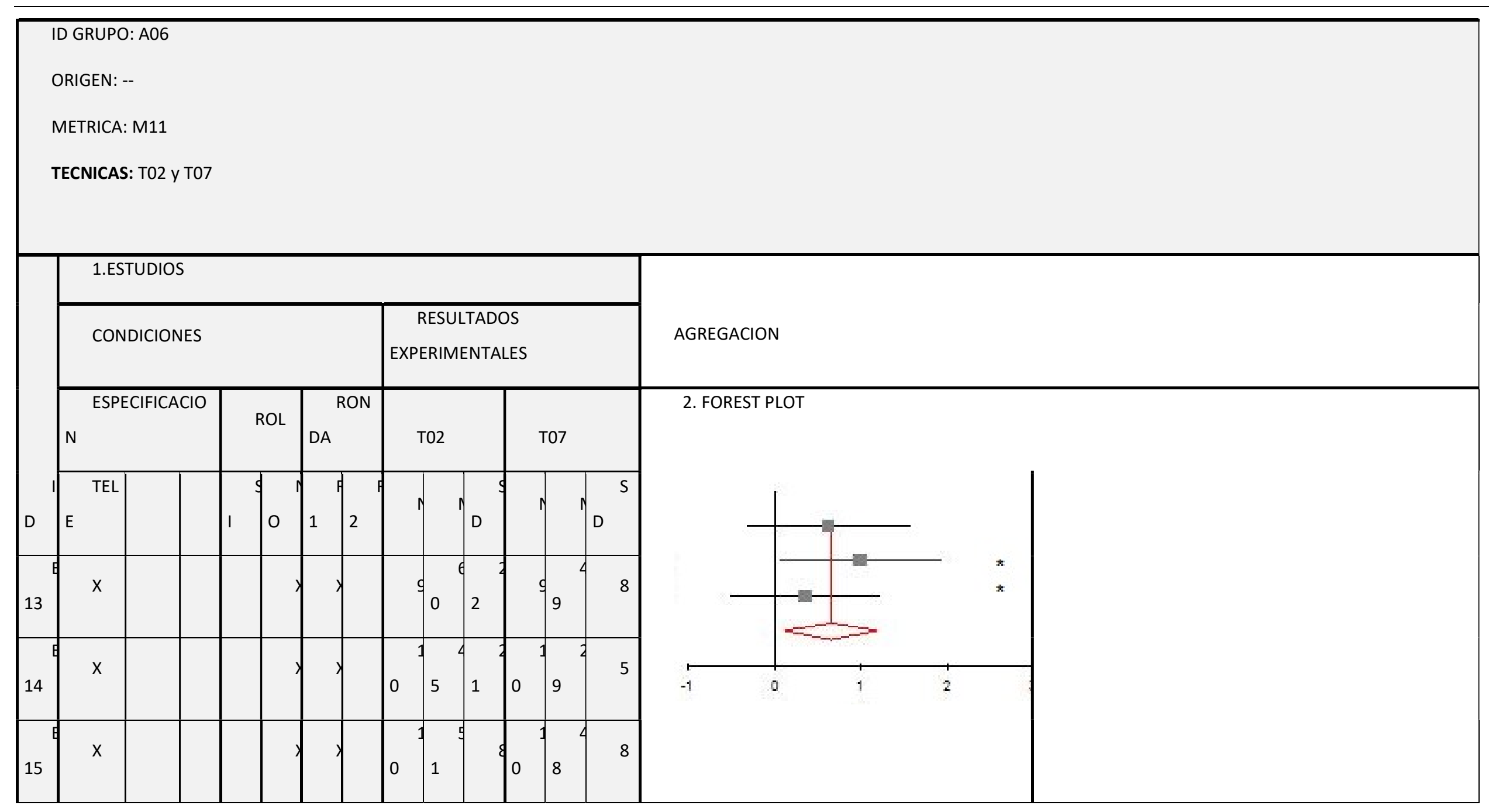




\begin{tabular}{|c|c|c|c|}
\hline \multirow[t]{6}{*}{ EFECTO GLOBAL: 0,65 } & & & 3.HOMOGENEIDAD: \\
\hline & & & $\begin{array}{l}Q=0,95 \\
I^{2}=0 \%\end{array}$ \\
\hline & \multicolumn{2}{|c|}{ 4.EFECTO GLOBAL: } & 6.CONDICIONES QUE INFLUYEN EN LA EVIDENCIA: \\
\hline & 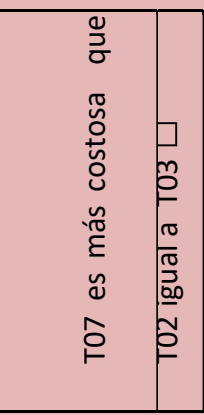 & 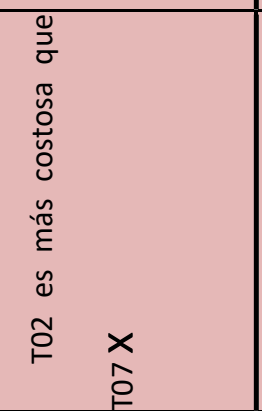 & $\begin{array}{l}\text { E13: TELE*NROL*R1 } \\
\text { E14: TELE*NROL*R1 } \\
\text { E15: TELE*NROL*R1 } \\
\rightarrow \text { TELE*NROL*R1 }\end{array}$ \\
\hline & \multicolumn{2}{|c|}{ 5.TAMAÑO DEL EFECTO: } & 7.TEXTO DE LA EVIDENCIA: \\
\hline & \multicolumn{2}{|c|}{$\begin{array}{l}\text { - } 0,65 \rightarrow \text { T02 es bastante más costosa que } \\
\text { T07 }\end{array}$} & $\begin{array}{l}\text { "M11 fue bastante más costosa cuando se usó T02 } \\
\text { que cuando se usó T07 (con un tamaño de efecto de } \\
\text { 0,65). Esto se probó solamente con la especificación } \\
\text { TELE, sin utilizar roles y con una sola ronda" }\end{array}$ \\
\hline \multicolumn{4}{|l|}{ OBSERVACIONES: } \\
\hline
\end{tabular}




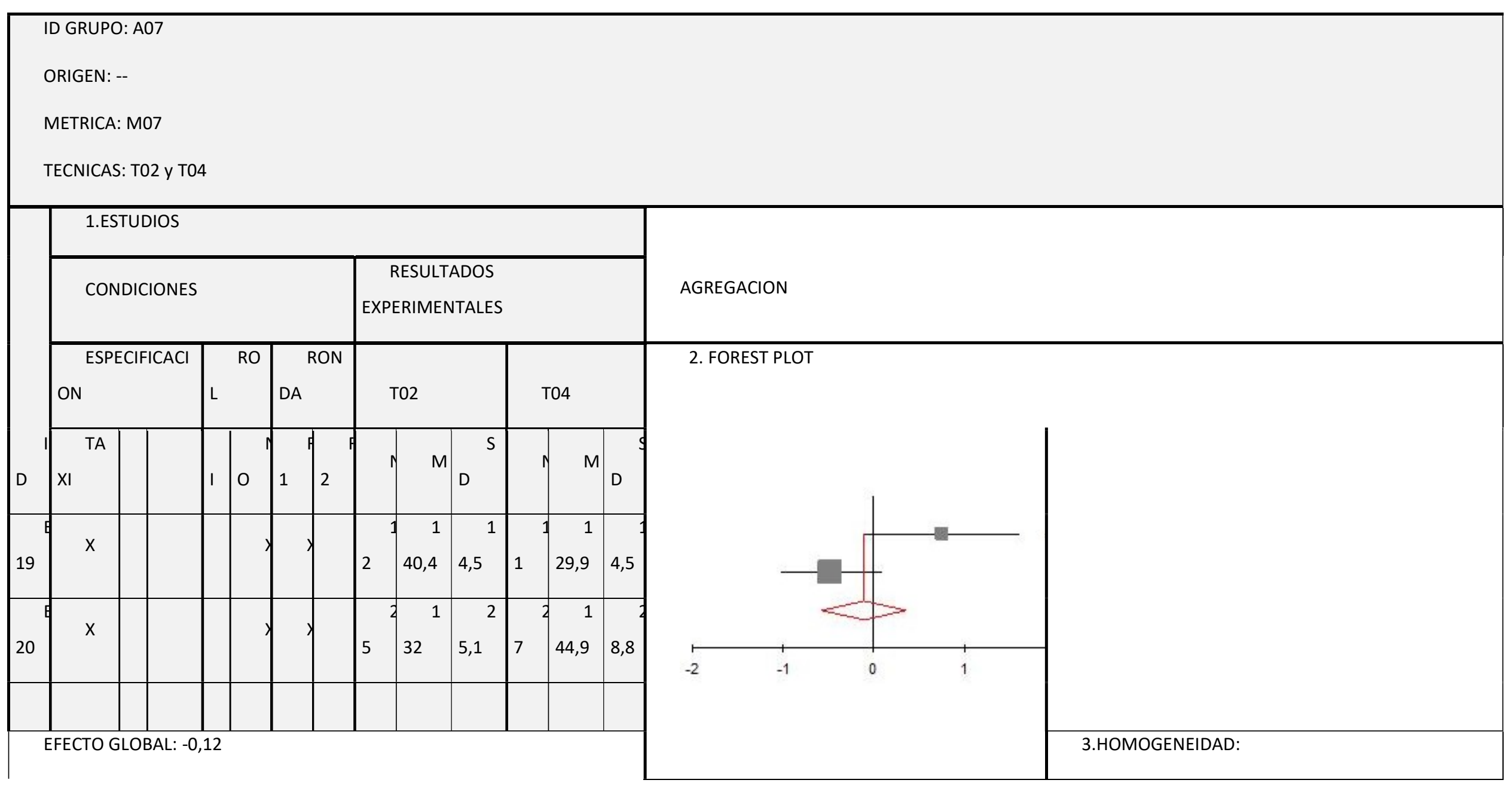




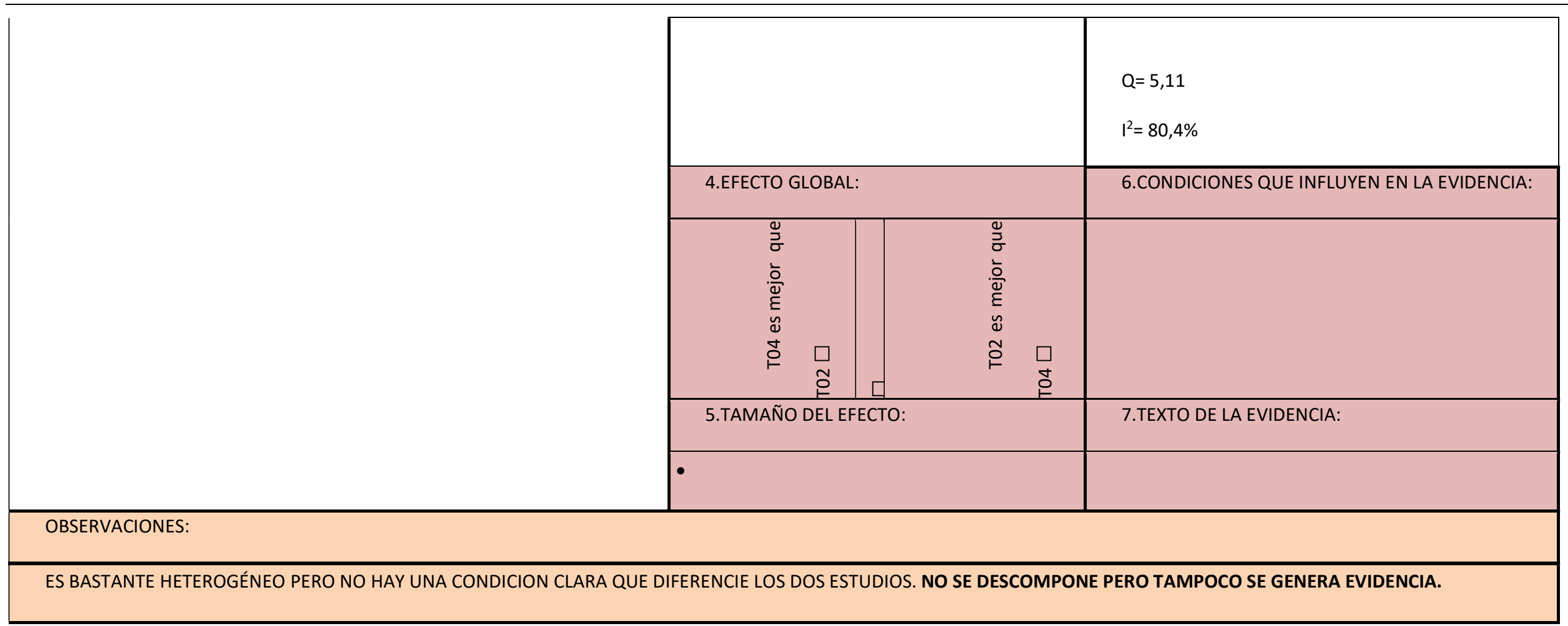




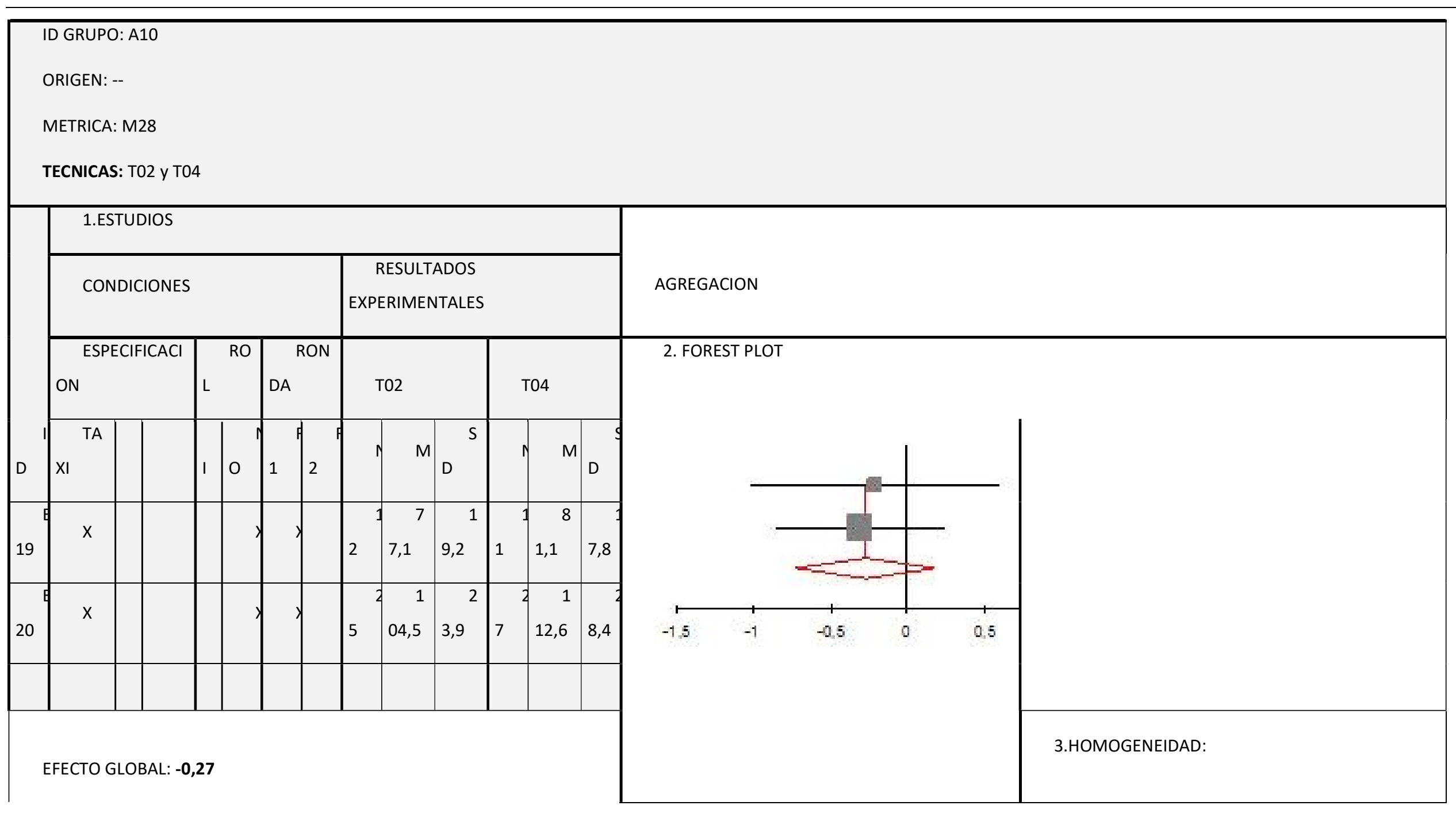




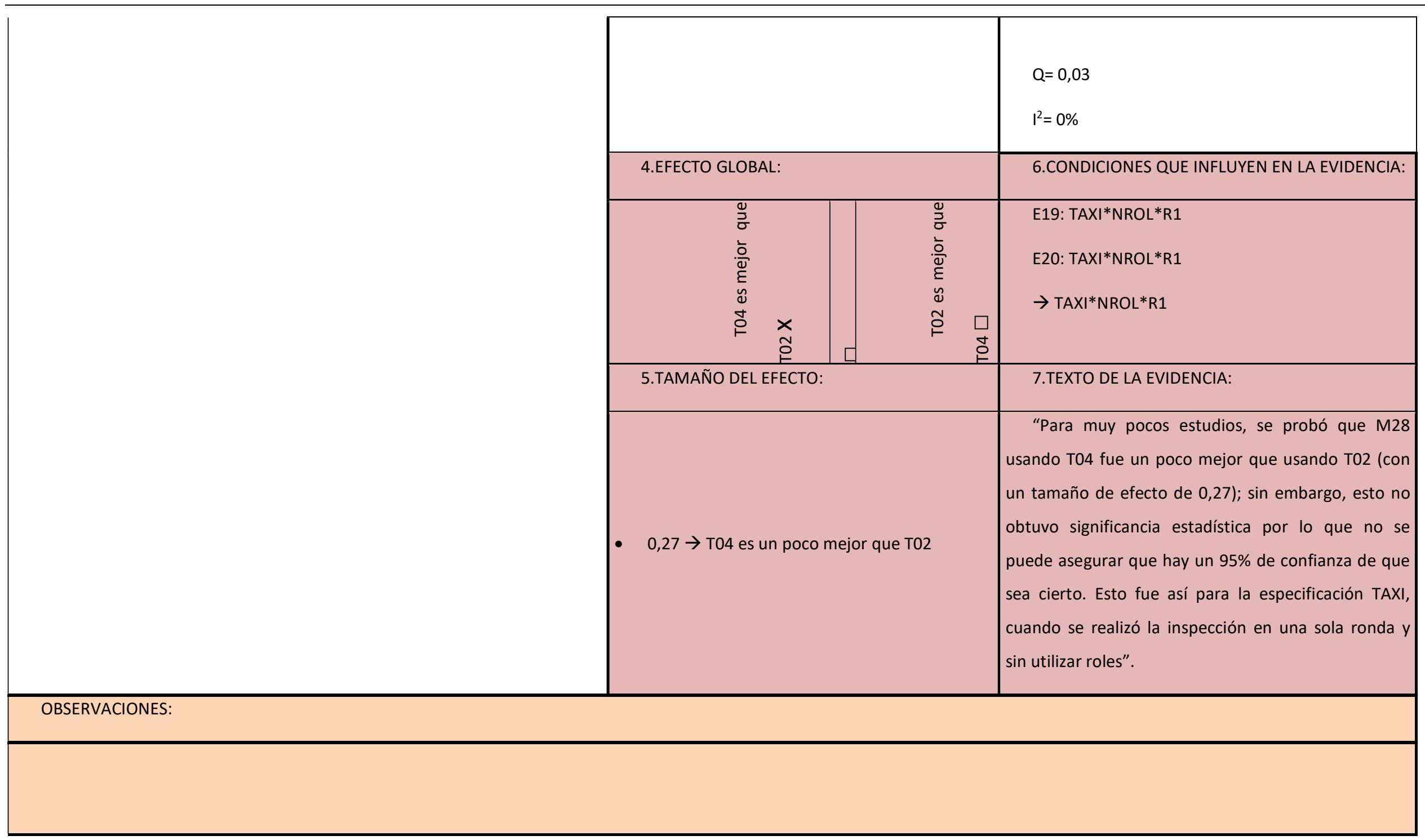




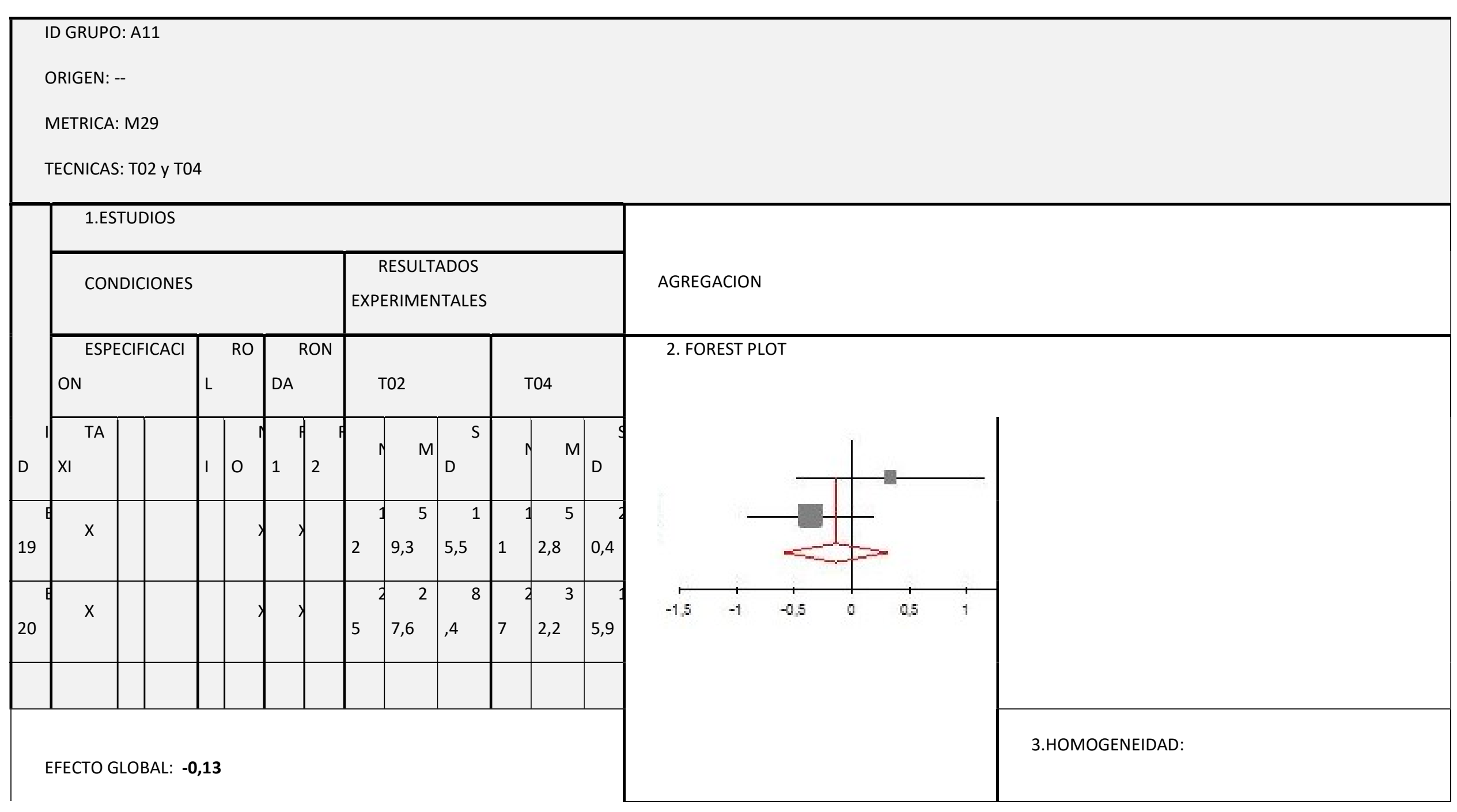


Proceso de RS de experimentos en Ingeniería del Software

\begin{tabular}{|c|c|c|c|}
\hline & & & $\begin{array}{l}Q=1,91 \\
I^{2}=47,8 \%\end{array}$ \\
\hline & \multicolumn{2}{|c|}{ 4.EFECTO GLOBAL: } & 6.CONDICIONES QUE INFLUYEN EN LA EVIDENCIA: \\
\hline & 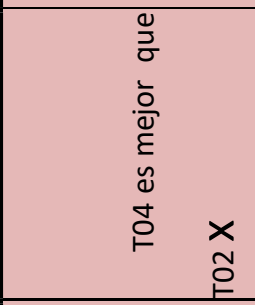 & 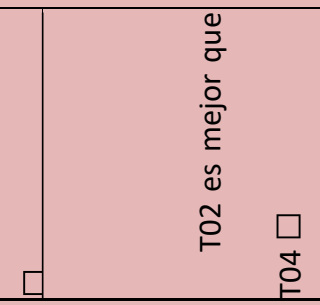 & $\begin{array}{l}\text { E19: TAXI*NROL*R1 } \\
\text { E20: TAXI*NROL*R1 } \\
\rightarrow \text { TAXI*NROL*R1 }\end{array}$ \\
\hline & \multicolumn{2}{|c|}{ 5.TAMAÑO DEL EFECTO: } & 7.TEXTO DE LA EVIDENCIA: \\
\hline & \multicolumn{2}{|c|}{ - $0,13 \rightarrow$ T04 es un poco mejor que T02 } & $\begin{array}{l}\text { "Para muy pocos estudios, M29 usando T4 fue un } \\
\text { poco mejor que T02 (con un tamaño de efecto de 0,13) } \\
\text { utilizando la especificación TAXI sin roles y con una sola } \\
\text { ronda. Sin embargo, esto no puede afirmarse con un } 95 \% \\
\text { de confianza". }\end{array}$ \\
\hline OINES: & & & \\
\hline
\end{tabular}


LA HETEROGENEIDAD ES MEDIA (POCO MENOS DEL 50\%) PERO NO HAY UNA CONDICION CLARA QUE DIFERENCIE LOS DOS ESTUDIOS POR LO TANTO NO SE DESCOMPONE; SIN EMBARGO, DEBIDO A QUE, AÚN SIENDO INCONSISTENTES, LOS EFECTOS SE ENCUENTRAN MUY CERCANOS Y EN TODOS LOS CASOS INCLUYEN AL CERO, SE PUEDE GENERAR UNA EVIDENCIA. 
META-ANALISIS DE GRUPOS

(RADIO DE RESPUESTA) 


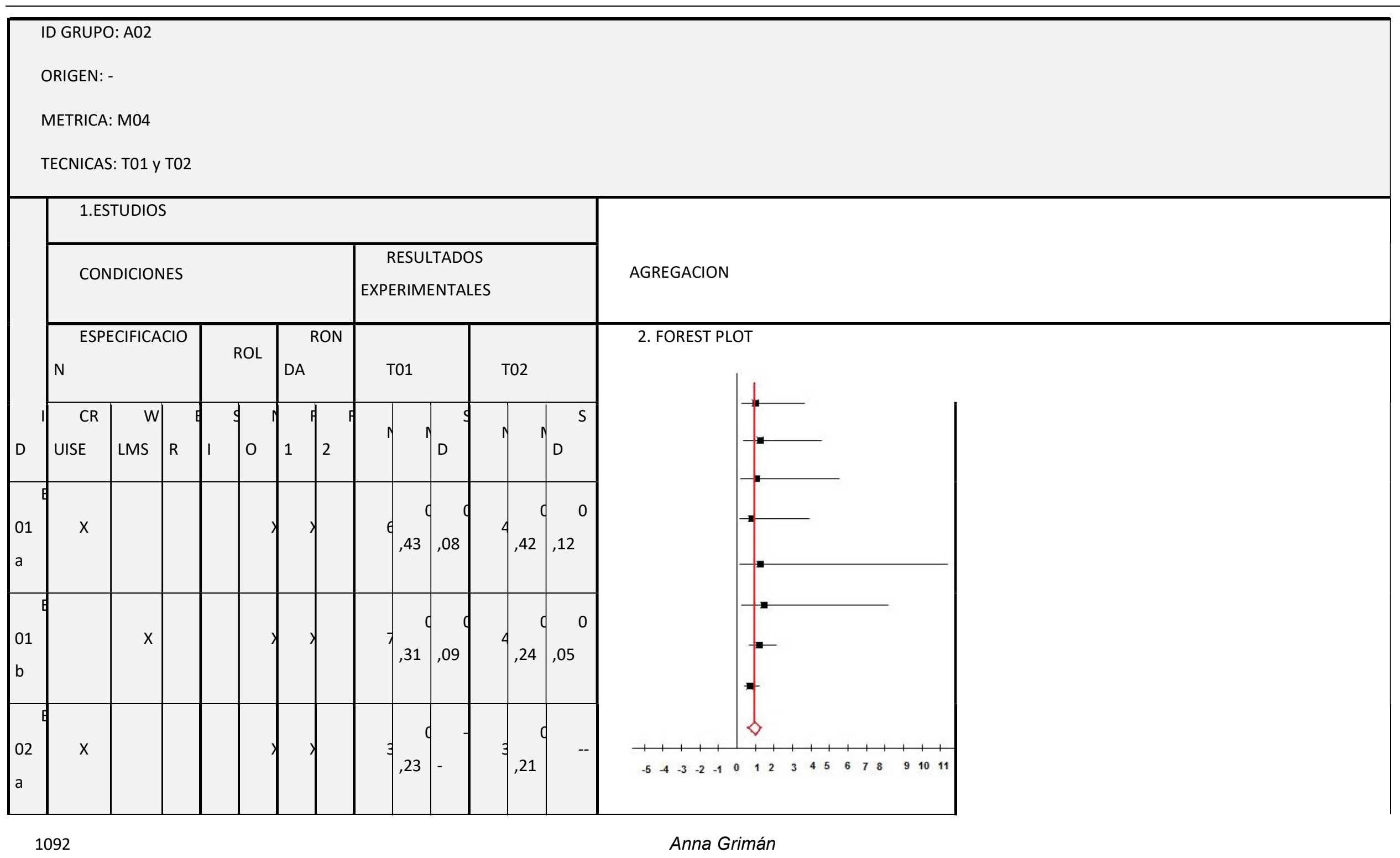




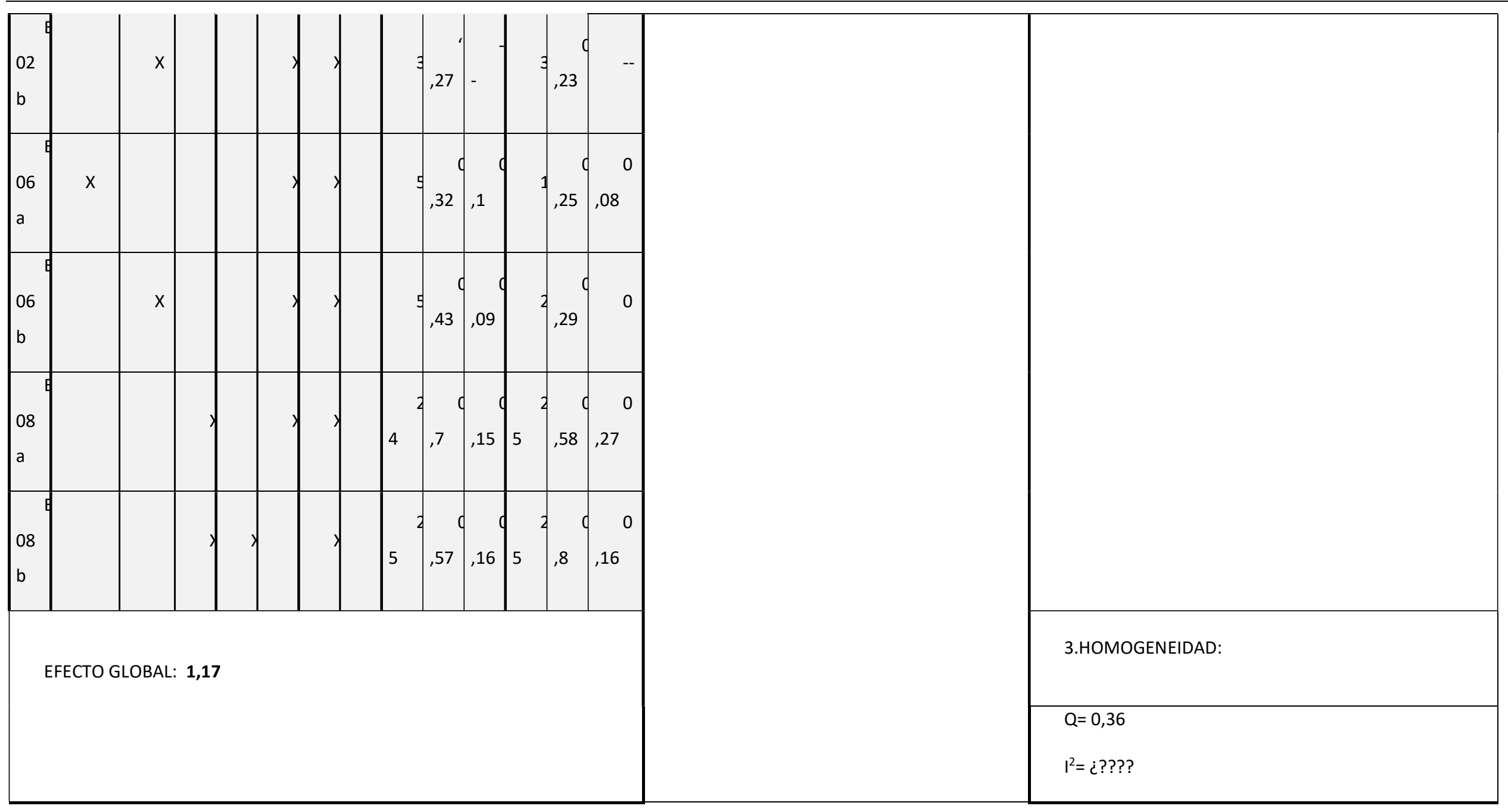




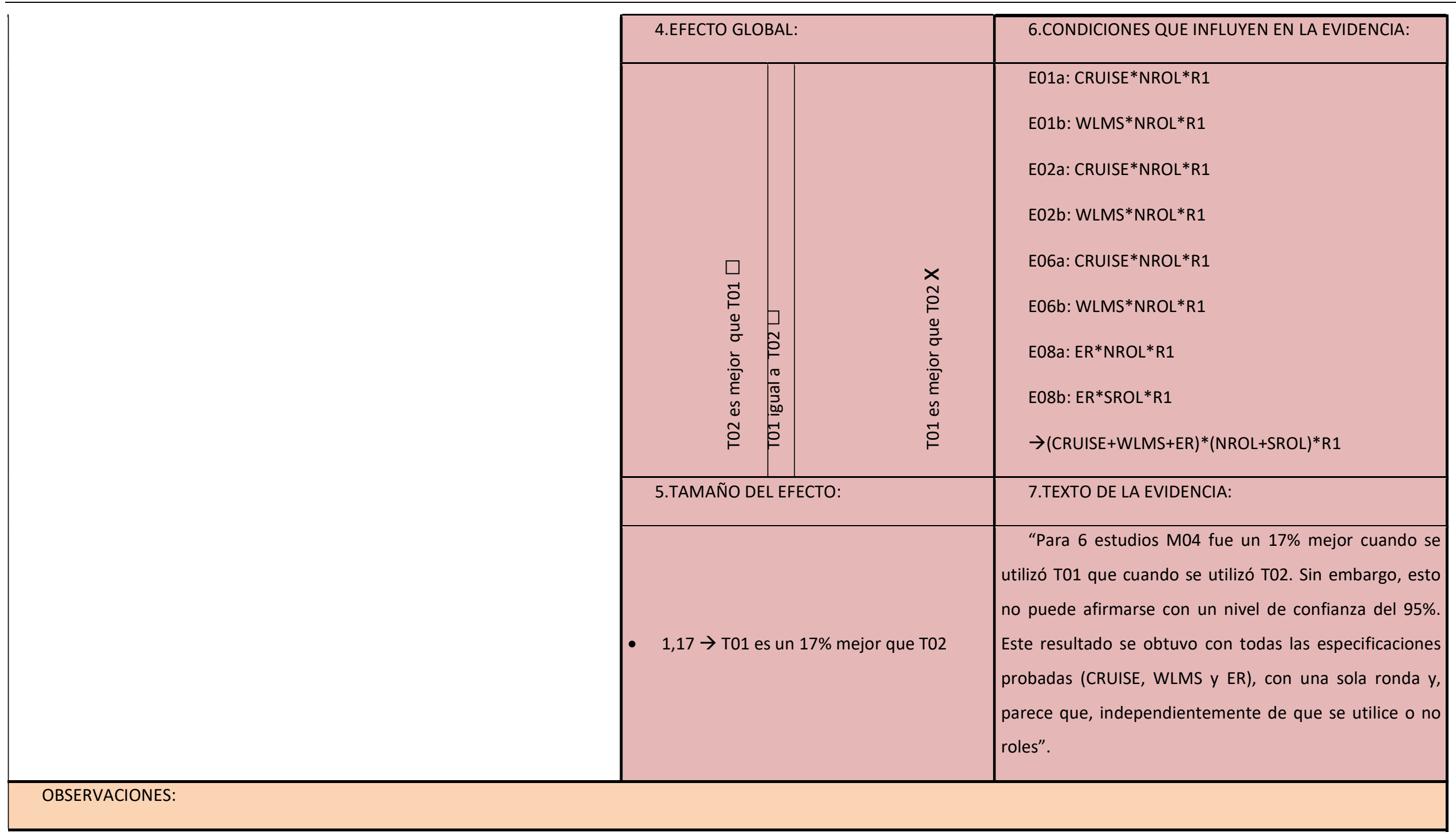


Proceso de RS de experimentos en Ingeniería del Software

LOS EFECTOS SON BASTANTES CONSISTENTES. AUN CUANDO ALGUNO ES OPUESTO AL RESTO, SE SOLAPAN BASTANTE Y TODOS INCLUYEN AL 1. 


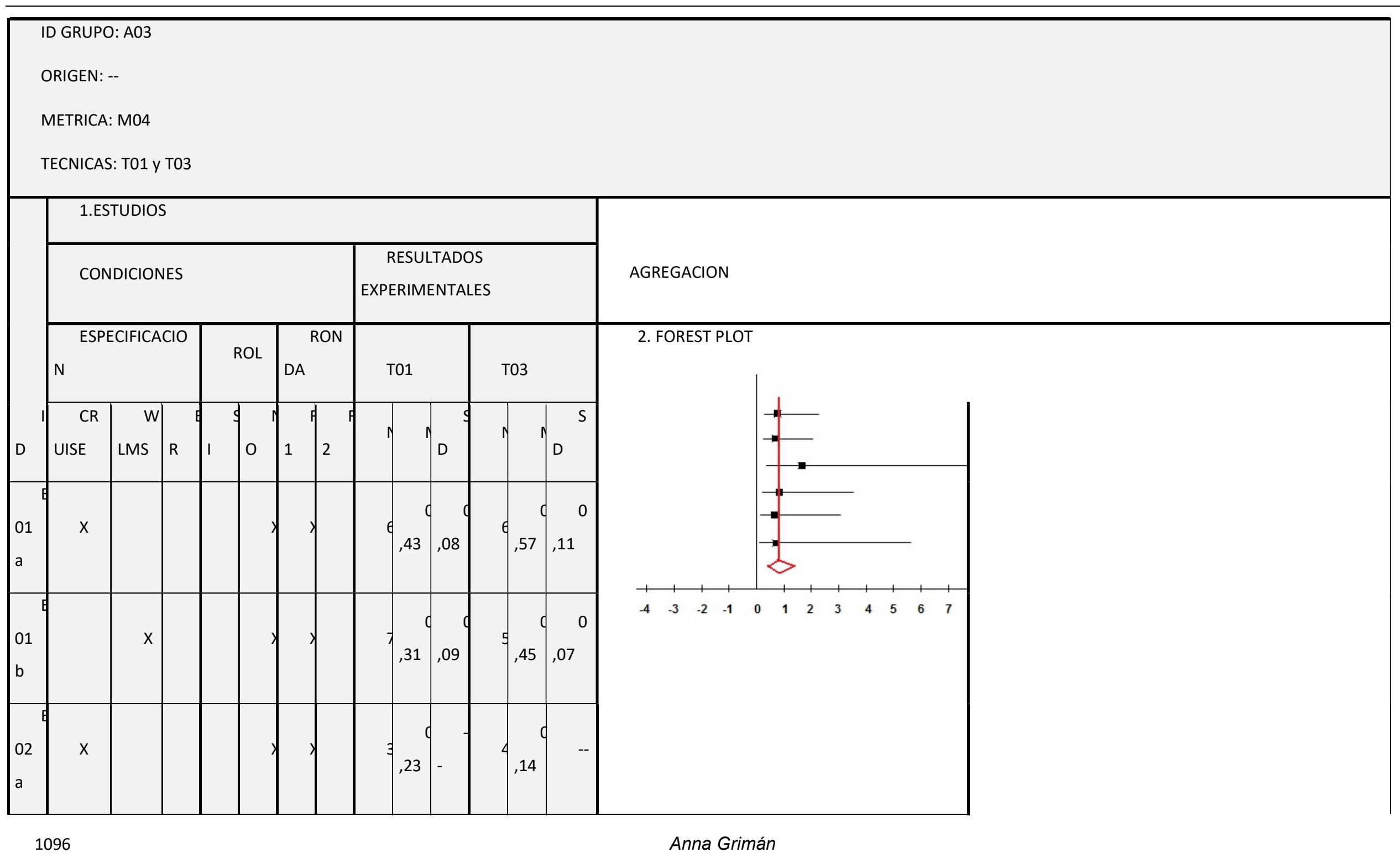




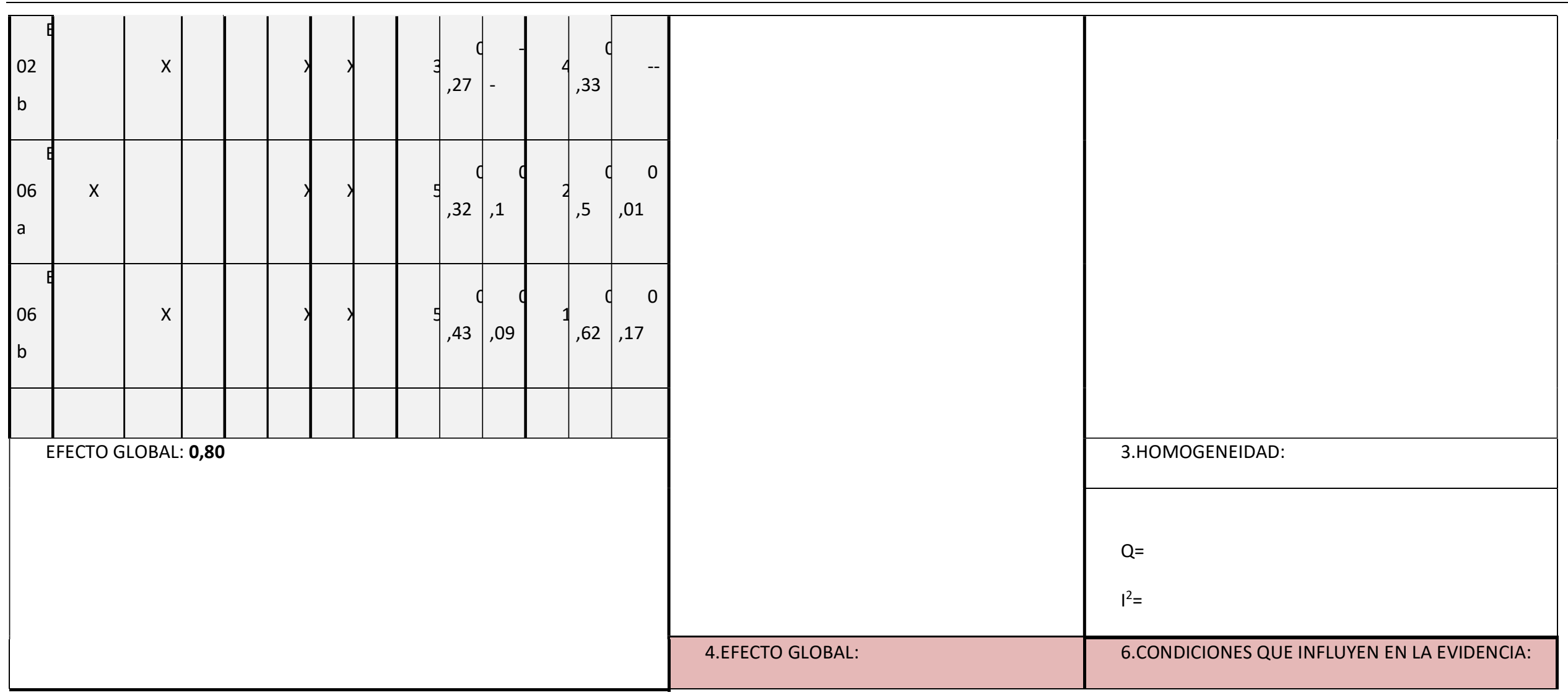




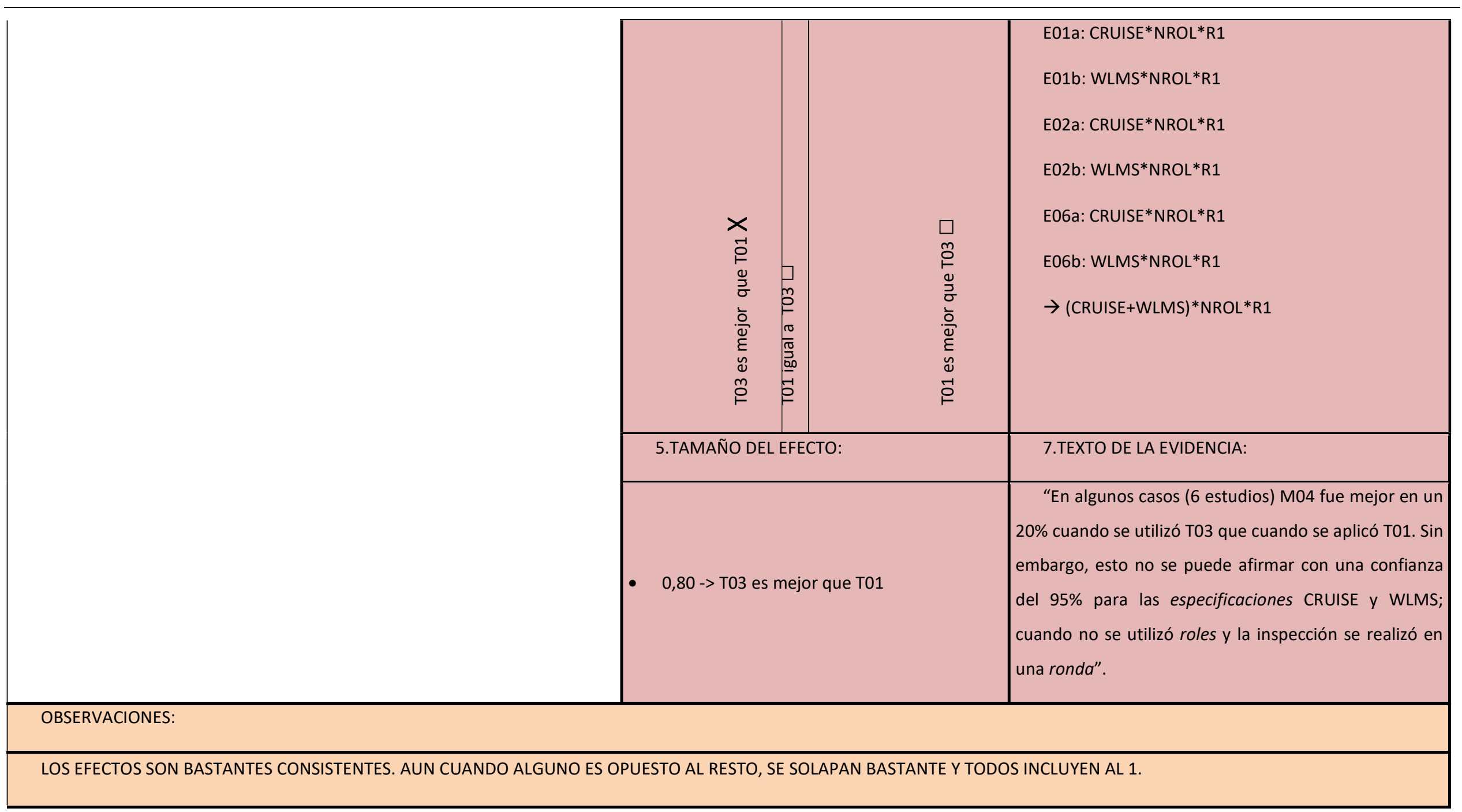




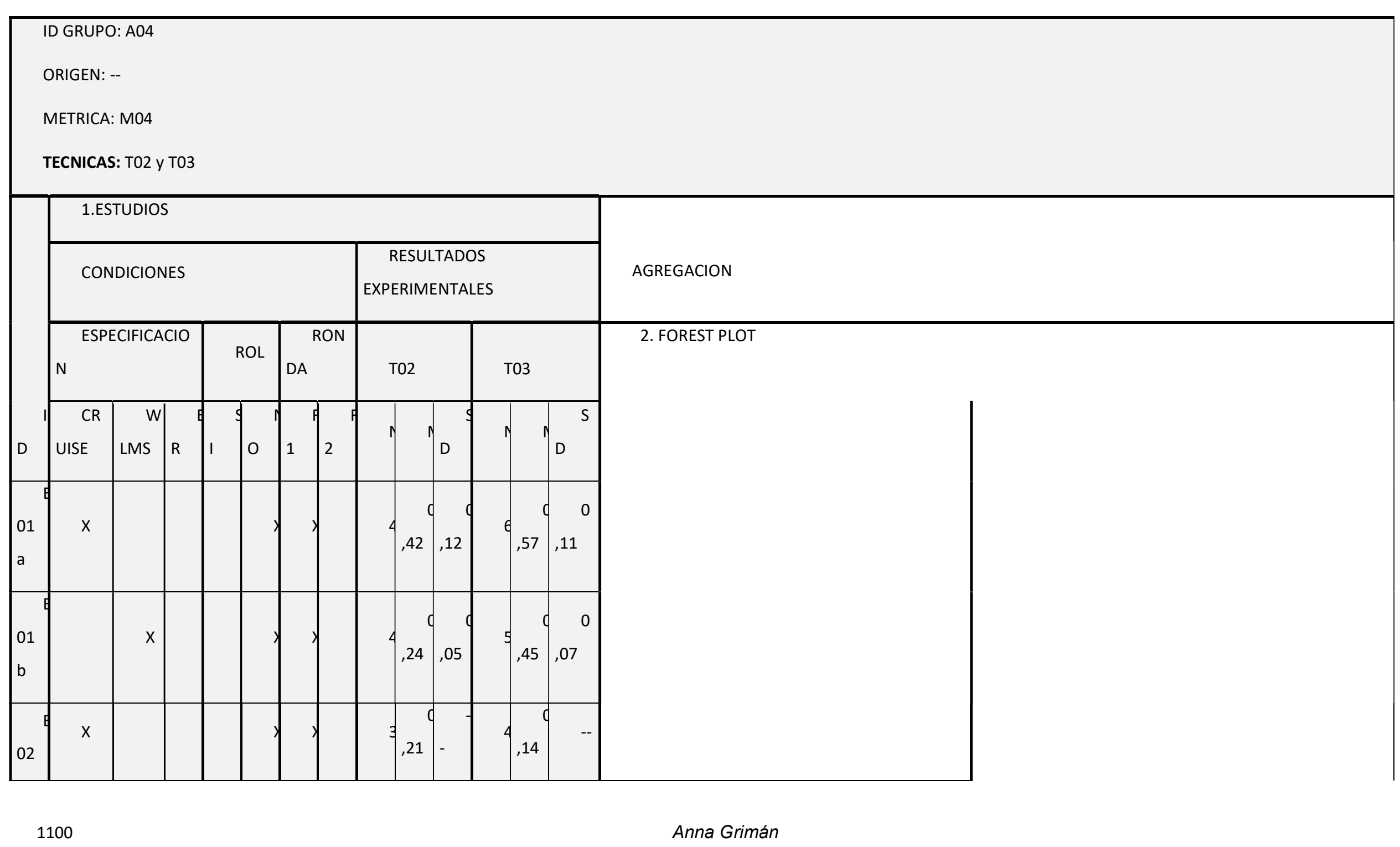


Proceso de RS de experimentos en Ingeniería del Software

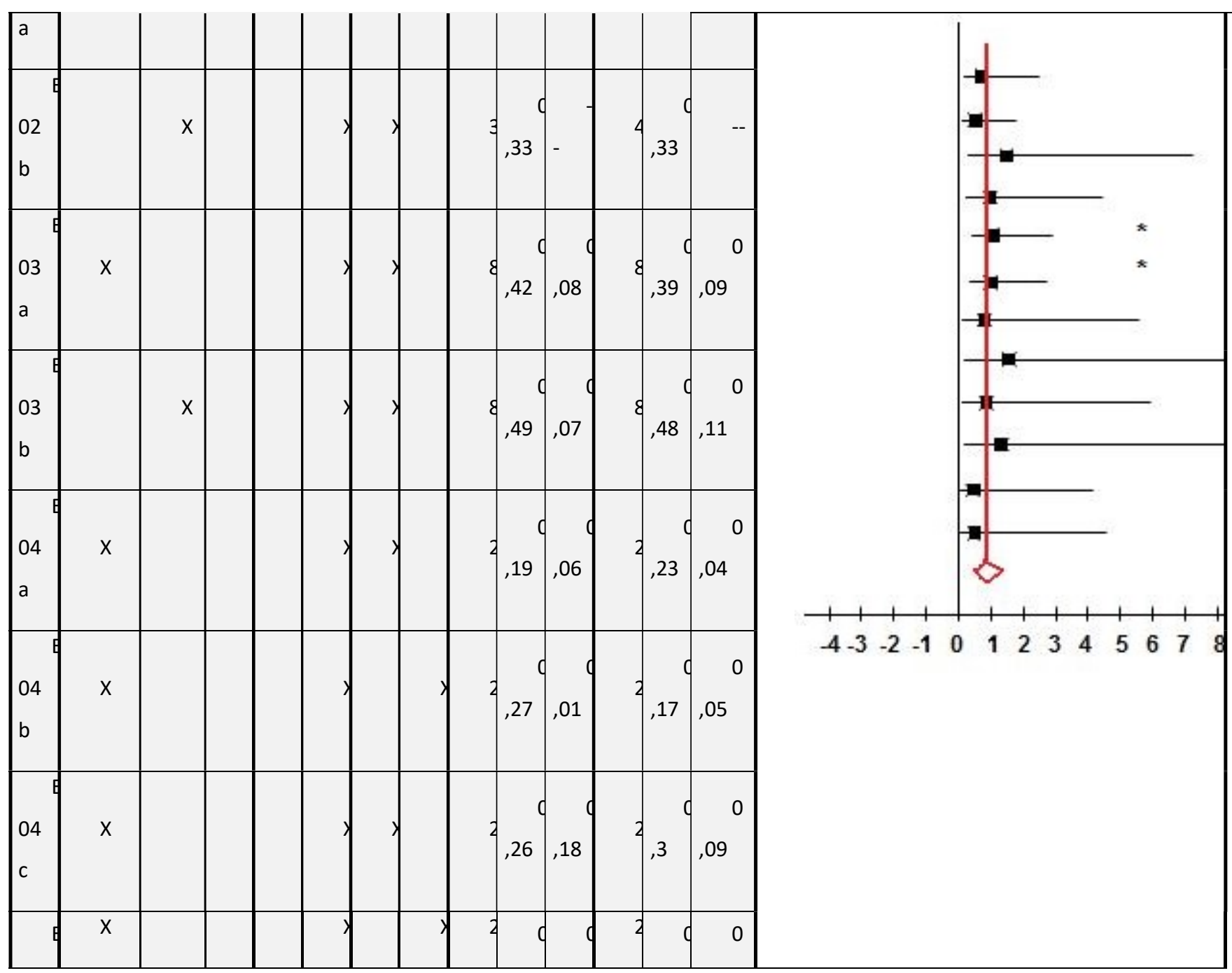

Caso de estudio

1101 


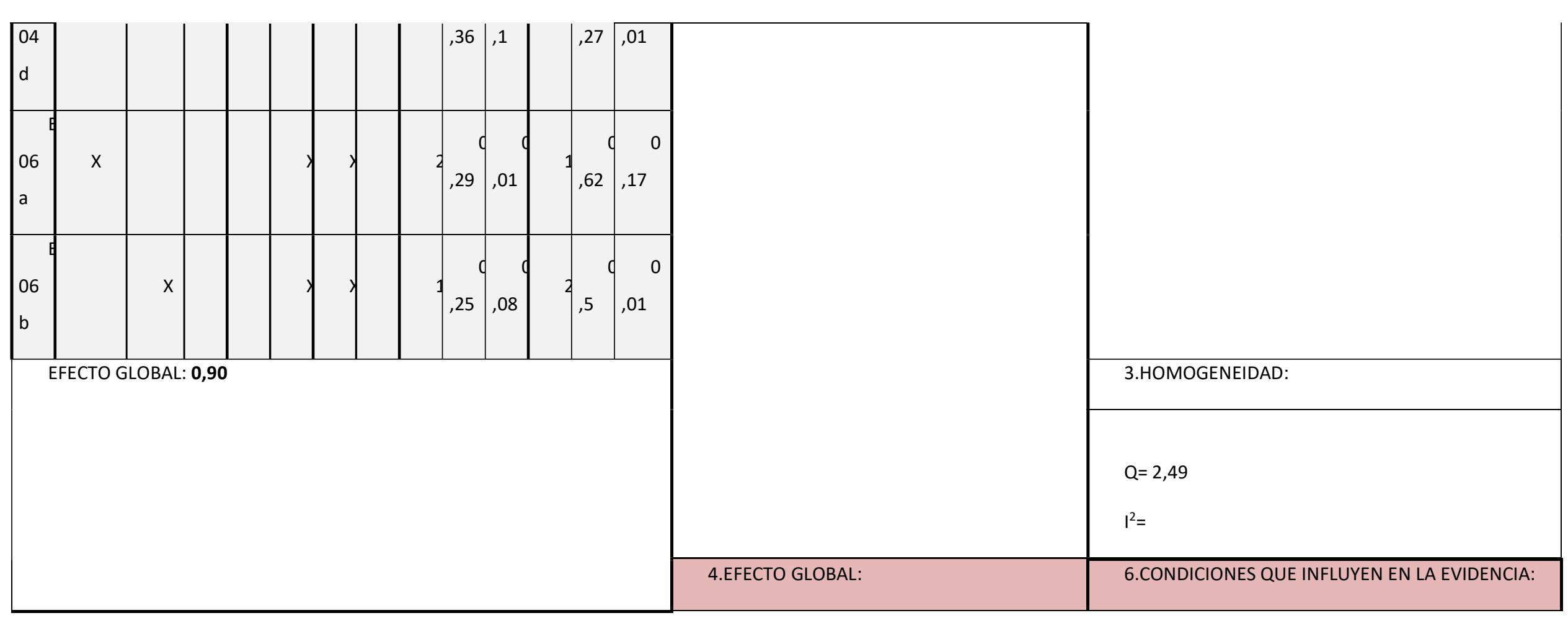


Proceso de RS de experimentos en Ingeniería del Software

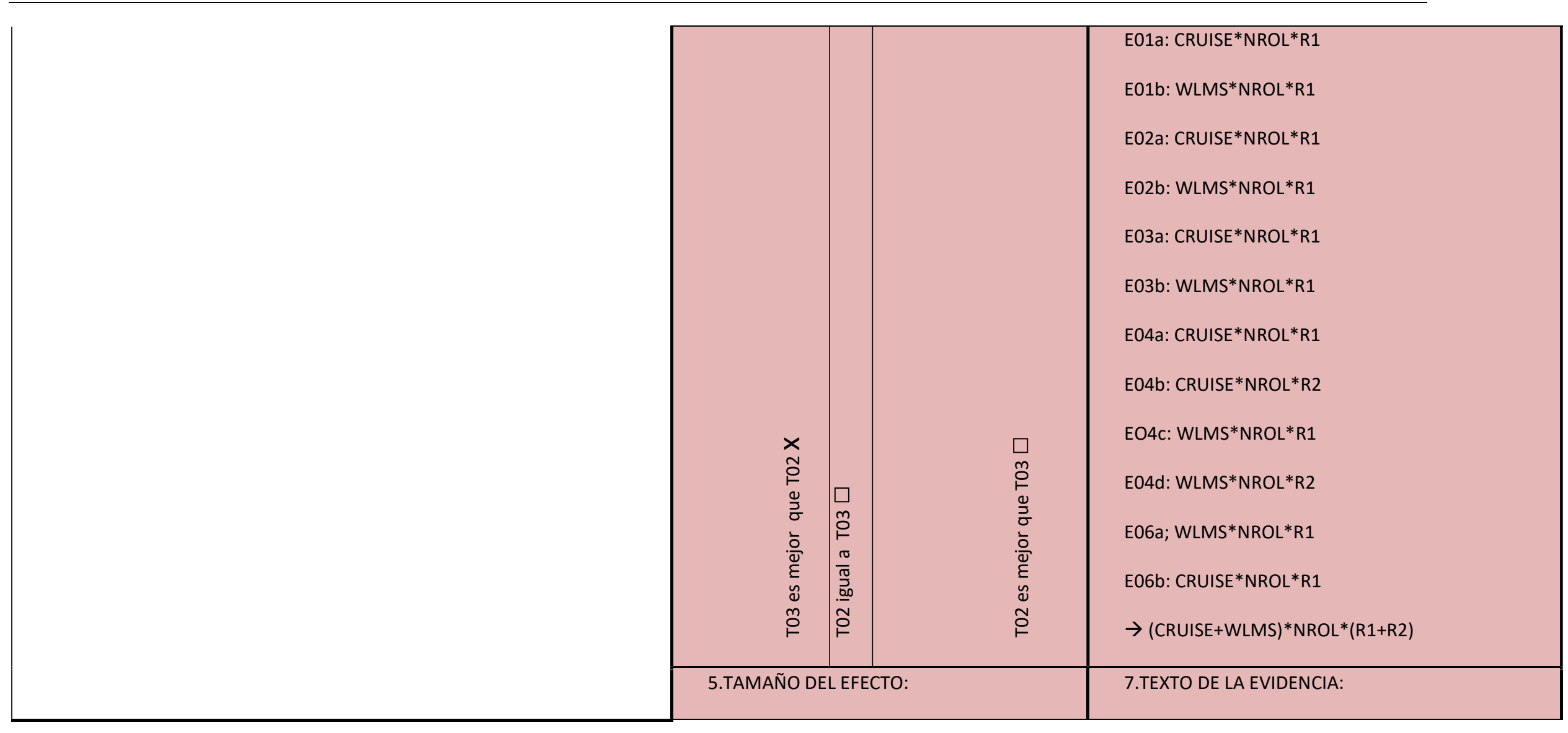




\begin{tabular}{|l|l|l|}
\hline & & $\begin{array}{l}\text { "Para un grupo grande de estudios (12 en total), } \\
\text { M04 resultó } 10 \% \text { mejor cuando se usó T03 que cuando } \\
\text { se usó T02. Esto fue asi con las especificaciones WLMS } \\
\text { y CRUISE, sin utilizar roles } \quad \text { y, parece ser que, con } \\
\text { independencia de que la inspección se realizara en una } \\
\text { ronda o en dos rondas. Sin embargo, esto no se puede } \\
\text { afirmar con un 95\% de confianza". }\end{array}$ \\
\hline OBSERVACIONES: & $0,90 \rightarrow$ T03 es mejor que T02 & \\
\hline LOS EFECTOS SON BASTANTES CONSISTENTES. AUN CUANDO ALGUNO ES OPUESTO AL RESTO, SE SOLAPAN BASTANTE Y TODOS INCLUYEN AL 1.
\end{tabular}




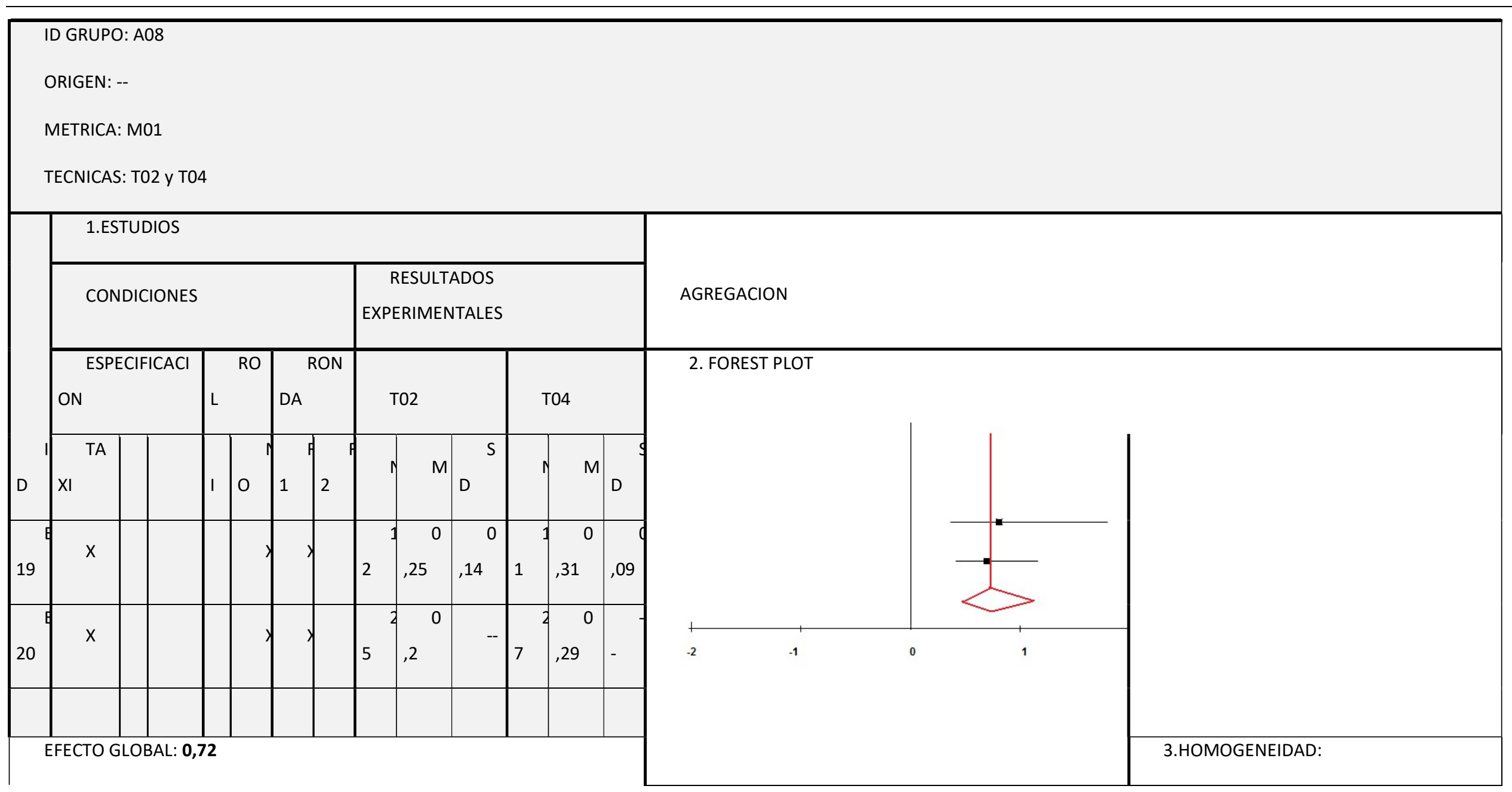




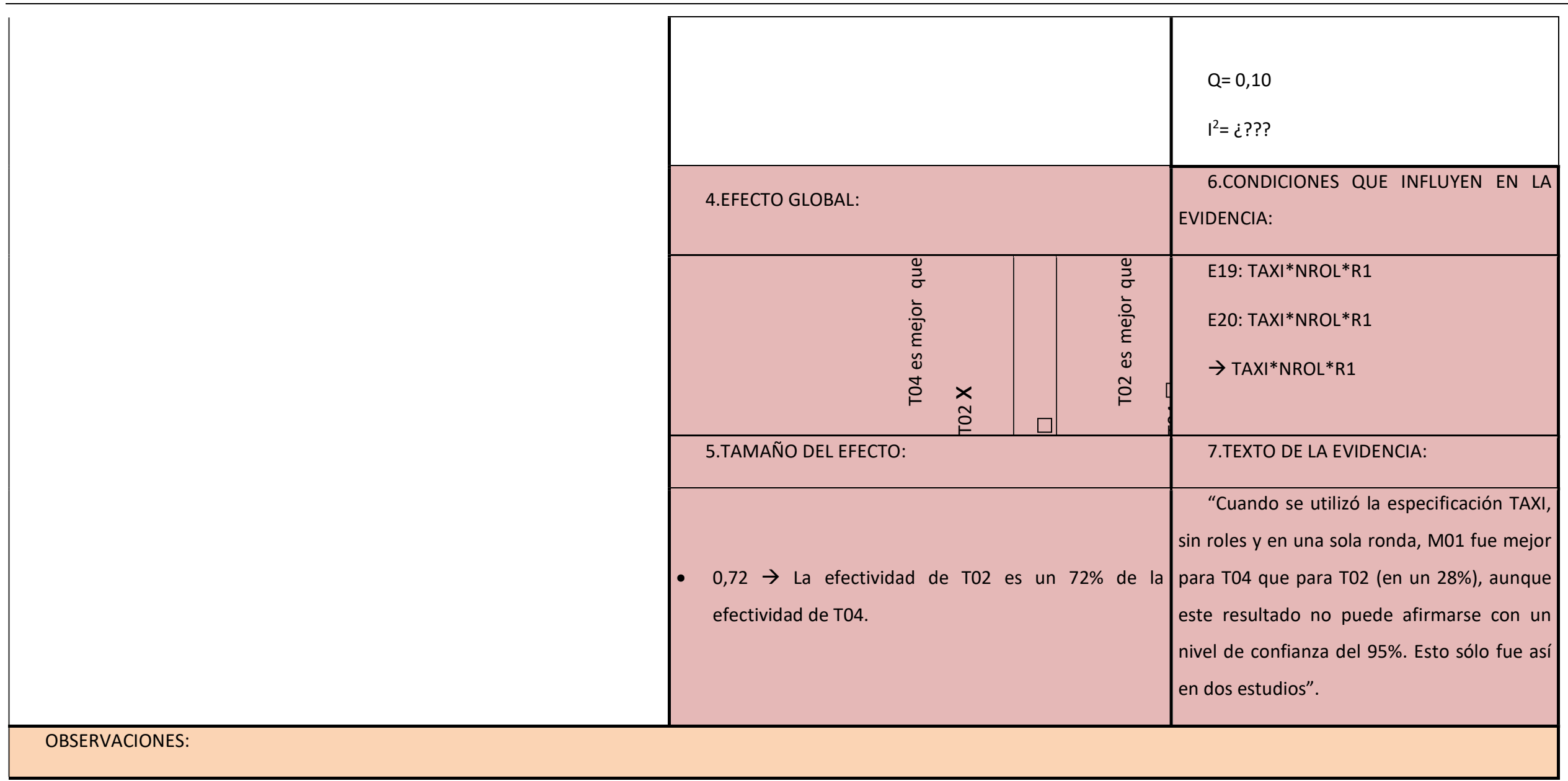


SE APLICA RR-NP PORQUE NO SE CUENTA CON TODAS LAS VARIANZAS. 


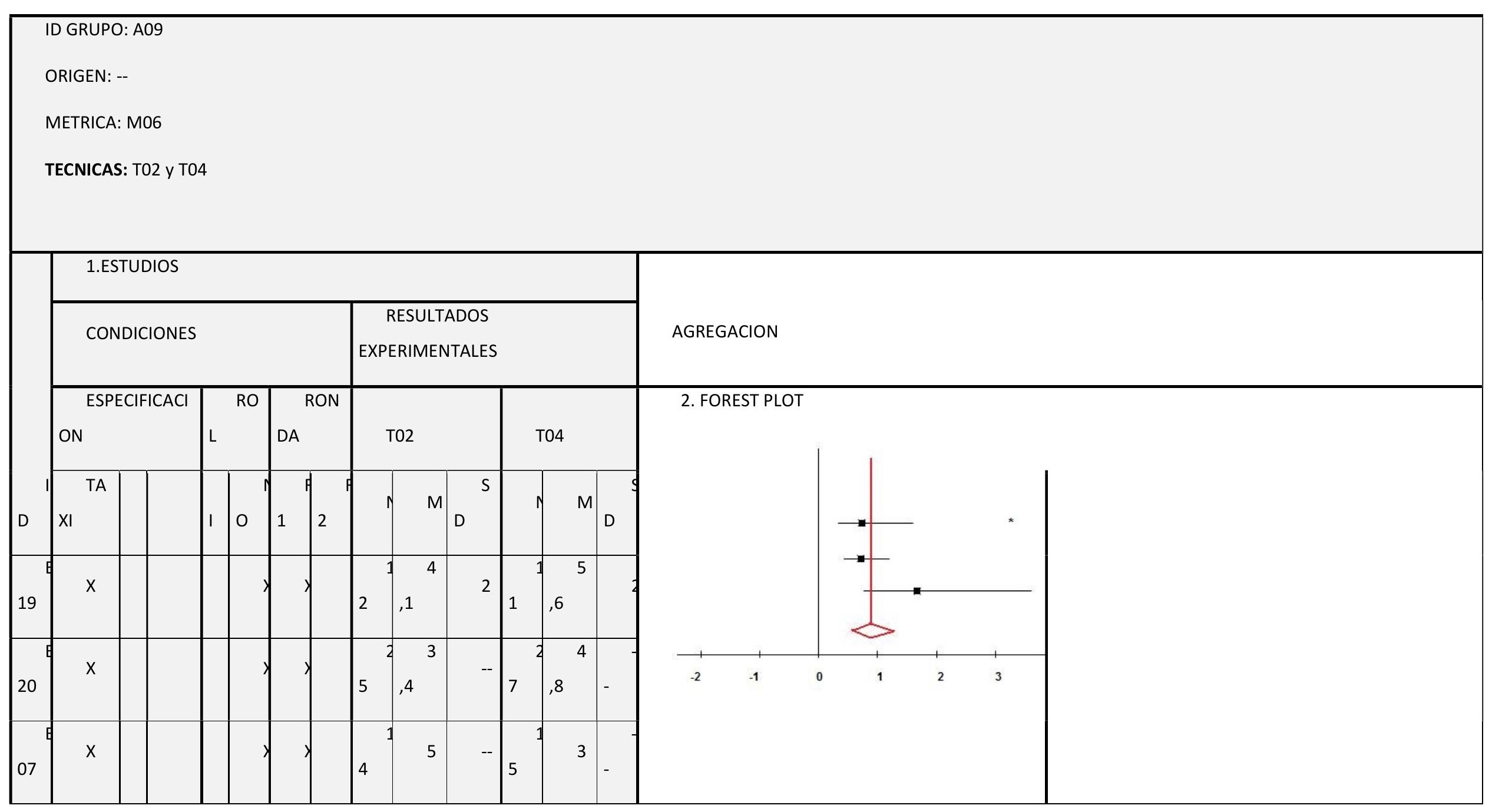


Proceso de RS de experimentos en Ingeniería del Software

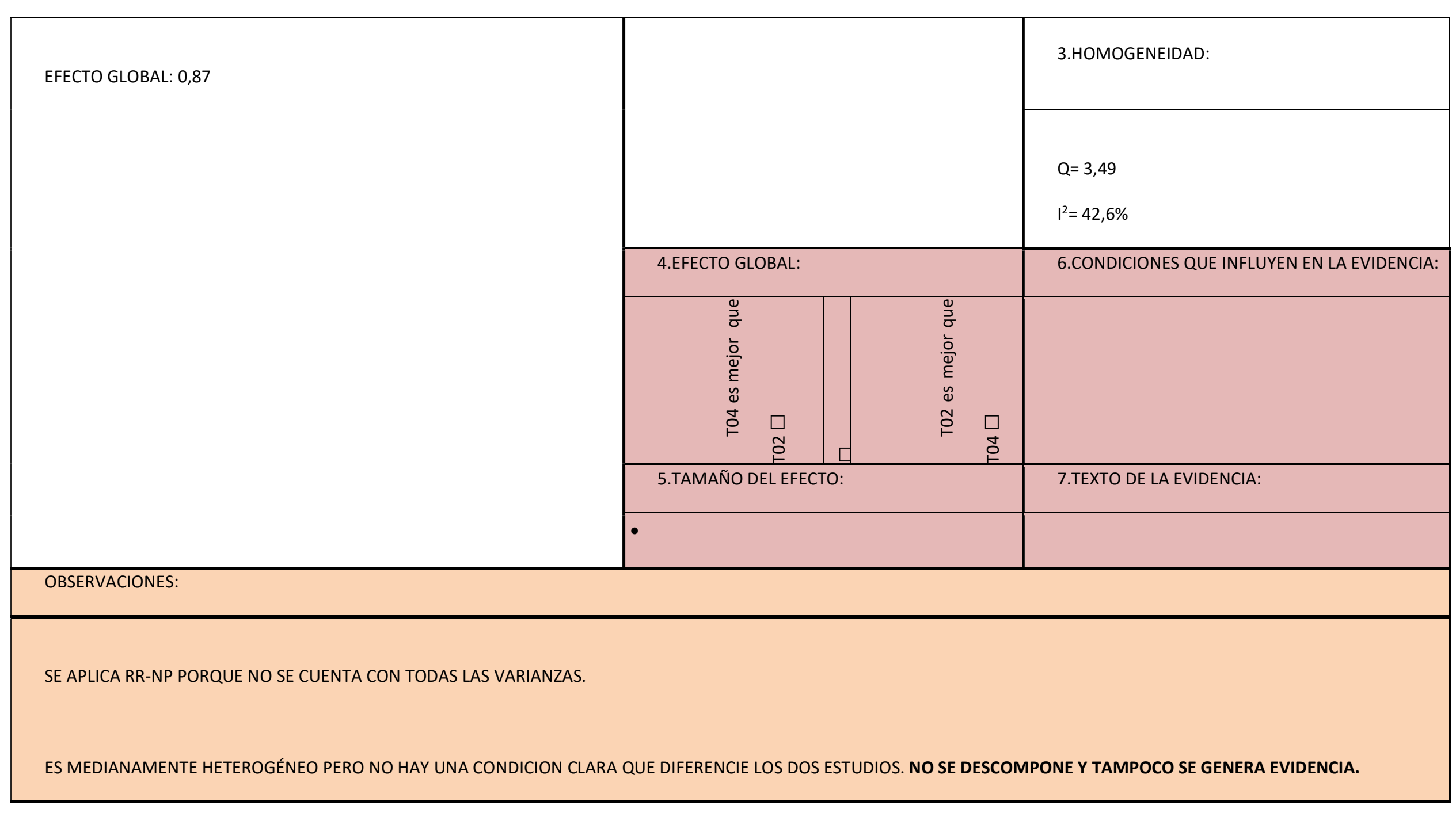




\subsection{Consolidar y clasificar evidencias}

A continuación se resumen las evidencias con el nivel

Tabla A.17. Resumen de evidencias

\begin{tabular}{|c|c|c|c|}
\hline $\mathrm{D}$ & Evidencia & Grupo & $\begin{array}{l}\text { Nivel } \\
\text { de } \\
\text { confianza }\end{array}$ \\
\hline $\mathrm{V} 2^{\mathrm{E}}$ & $\begin{array}{l}\text { "M04 parece ser mejor } \\
\text { cuando se usa T01 que } \\
\text { cuando se usa T02 (con un } \\
\text { tamaño del efecto de 0,56). } \\
\text { Esto fue estadísticamente } \\
\text { significativo, siendo probado } \\
\text { con cinco estudios, para tres } \\
\text { especificaciones (CRUISE, } \\
\text { WLMS y ER). Este resultado } \\
\text { se obtuvo sin utilizar roles y } \\
\text { realizando la inspección en } \\
\text { una ronda". }\end{array}$ & A02_1 & 1 \\
\hline $\begin{array}{l}E \\
V 3^{E}\end{array}$ & $\begin{array}{l}\text { "En una sola ocasión, } \\
\text { M04 fue bastante mejor (con } \\
\text { un tamaño del efecto de } \\
\text { 1,41) cuando se utilizó T02 } \\
\text { que cuando se utilizó T01. } \\
\text { Esto fue estadísticamente } \\
\text { significativo, siendo probado } \\
\text { para la especificación ER; } \\
\text { incorporando roles y en una } \\
\text { inspección de una sola } \\
\text { ronda". }\end{array}$ & A02_2 & 0 \\
\hline$E$ & “Para unos & A02 & 0 \\
\hline
\end{tabular}

Caso de estudio 


\begin{tabular}{|c|c|c|c|}
\hline V4 & $\begin{array}{l}\text { estudios, M04 usando T01 } \\
\text { fue bastante mejor (un } \\
\text { tamaño de efecto del 0,98) } \\
\text { que usando T02; sin } \\
\text { embargo, esto no se puede } \\
\text { afirmar con un nivel de } \\
\text { confianza del 95\%. Esto fue } \\
\text { así para las especificaciones } \\
\text { CRUISE y WLMS, sin utilizar } \\
\text { roles y realizando la } \\
\text { inspección en una ronda". } \\
\text { Esto fue probado en un } \\
\text { ambiente industrial. }\end{array}$ & (industria) & \\
\hline $\begin{array}{l}{ }^{2} \mathrm{E} \\
\mathrm{V} 5\end{array}$ & $\begin{array}{l}\text { "Para } 6 \text { estudios M04 fue } \\
\text { un } 17 \% \text { mejor cuando se } \\
\text { utilizó T01 que cuando se } \\
\text { utilizó T02. Sin embargo, } \\
\text { esto no puede afirmarse con } \\
\text { un nivel de confianza del } \\
95 \% \text {. Este resultado se } \\
\text { obtuvo con todas las } \\
\text { especificaciones probadas } \\
\text { (CRUISE, WLMS y ER), con } \\
\text { una sola ronda y, parece } \\
\text { que, independientemente de } \\
\text { que se utilice o no roles". }\end{array}$ & $\begin{array}{l}\mathrm{A} 02 \\
\text { (RR) }\end{array}$ & 1 \\
\hline $\begin{array}{l}{ }^{2} \\
\text { V6 }\end{array}$ & $\begin{array}{l}\text { "En algunos casos (4 } \\
\text { estudios) M04 fue bastante } \\
\text { mejor cuando se utilizó T03 } \\
\text { que cuando se aplicó T01 } \\
\text { (con un tamaño del efecto } \\
\text { de 1,5). Esto se puede } \\
\text { afirmar con una confianza } \\
\text { del } 95 \% \text { para las } \\
\text { especificaciones CRUISE y }\end{array}$ & $\mathrm{A} 03$ & 1 \\
\hline
\end{tabular}


Proceso de RS de experimentos en Ingeniería del Software

\begin{tabular}{|c|c|c|c|}
\hline & $\begin{array}{l}\text { WLMS; cuando no se utilizó } \\
\text { roles y la inspección se } \\
\text { realizó en una ronda" }\end{array}$ & & \\
\hline $\begin{array}{r}\quad E \\
V 7\end{array}$ & $\begin{array}{l}\text { "Para unos pocos } \\
\text { estudios, M04 usando T03 } \\
\text { fue mejor (un tamaño de } \\
\text { efecto del 0,68) que usando } \\
\text { T01; sin embargo, esto no se } \\
\text { puede afirmar con un nivel } \\
\text { de confianza del 95\%. Esto } \\
\text { fue así para las } \\
\text { especificaciones CRUISE y } \\
\text { WLMS, sin utilizar roles y } \\
\text { realizando la inspección en } \\
\text { una ronda". } \\
\text { Esto fue probado en un } \\
\text { ambiente industrial. }\end{array}$ & $\begin{array}{c}\mathrm{A} 03 \\
\text { (industria) }\end{array}$ & 0 \\
\hline V8 & $\begin{array}{l}\text { EV6 se confirma? } \\
\text { "En algunos casos (6 } \\
\text { estudios) M04 fue mejor en } \\
\text { un 20\% cuando se utilizó T03 } \\
\text { que cuando se aplicó T01. } \\
\text { Sin embargo, esto no se } \\
\text { puede afirmar con una } \\
\text { confianza del 95\% para las } \\
\text { especificaciones CRUISE y } \\
\text { WLMS; cuando no se utilizó } \\
\text { roles y la inspección se } \\
\text { realizó en una ronda”. }\end{array}$ & $\begin{array}{l}\mathrm{A} 03 \\
(\mathrm{RR})\end{array}$ & 1 \\
\hline V9 & $\begin{array}{l}\text { "Para diez estudios, M04 } \\
\text { resultó un poco mejor al }\end{array}$ & A04 & 0 \\
\hline
\end{tabular}

Caso de estudio 


\begin{tabular}{|c|c|c|c|}
\hline & $\begin{array}{l}\text { utilizar T03 que al utilizar } \\
\text { T02 (con un valor absoluto } \\
\text { del tamaño del efecto igual a } \\
\text { 0,21). Sin embargo, esto no } \\
\text { fue estadísticamente } \\
\text { significativo. Esto fue así } \\
\text { para dos especificaciones } \\
\text { (WLMS y CRUISE), sin utilizar } \\
\text { roles y, parece ser que, con } \\
\text { independencia de que la } \\
\text { inspección se realice en una } \\
\text { ronda o en dos rondas". }\end{array}$ & & \\
\hline $\begin{array}{r}E \\
V 10\end{array}$ & $\begin{array}{l}\text { "Para dos estudios, M04 } \\
\text { fue bastante mejor (un } \\
\text { tamaño de efecto de 1,35) al } \\
\text { utilizar T03 que al aplicar } \\
\text { T02; sin embargo, esto no } \\
\text { fue estadísticamente } \\
\text { significativo. Esto fue así } \\
\text { para dos especificaciones } \\
\text { (CRUISE y WLMS), sin utilizar } \\
\text { roles y realizando la } \\
\text { inspección en una ronda". } \\
\text { Esto fue probado en un } \\
\text { ambiente industrial. }\end{array}$ & $\begin{array}{c}\text { A04 } \\
\text { (industria) }\end{array}$ & 0 \\
\hline $\begin{array}{r}E \\
\text { V11 }\end{array}$ & $\begin{array}{l}\text { EV9 se confirmó cuando } \\
\text { se agregaron dos estudios } \\
\text { adicionales utilizando un } \\
\text { método menos riguroso: } \\
\text { "Para un grupo grande } \\
\text { de estudios (doce en total), } \\
\text { M04 resultó } 10 \% \text { mejor } \\
\text { cuando se usó T03 que } \\
\text { cuando se usó T02. Esto fue } \\
\text { así con las especificaciones }\end{array}$ & $\begin{array}{l}\text { A04 } \\
\text { (RR) }\end{array}$ & 1 \\
\hline
\end{tabular}


Proceso de RS de experimentos en Ingeniería del Software

\begin{tabular}{|c|c|c|c|}
\hline & $\begin{array}{l}\text { WLMS y CRUISE, sin utilizar } \\
\text { roles y, parece ser que, con } \\
\text { independencia de que la } \\
\text { inspección se realizara en } \\
\text { una ronda o en dos rondas". } \\
\text { Sin embargo, esto no fue } \\
\text { estadísticamente } \\
\text { significativo. }\end{array}$ & & \\
\hline $\begin{array}{r}E \\
V 12\end{array}$ & $\begin{array}{l}\text { "Se puede afirmar con un } \\
95 \% \text { de confianza que M04 } \\
\text { es mucho mejor cuando se } \\
\text { utiliza T07 que T02 (con un } \\
\text { tamaño de efecto de 0,96). } \\
\text { Esto fue así cuando se } \\
\text { combinaron } 3 \text { estudios en } \\
\text { los que se inspeccionó el } \\
\text { código de TELE SYS, sin } \\
\text { utilizar roles y en una sola } \\
\text { ronda". }\end{array}$ & A05 & 1 \\
\hline $\begin{array}{r}E \\
V 13\end{array}$ & $\begin{array}{l}\text { "M11 fue bastante más } \\
\text { costosa cuando se usó T02 } \\
\text { que cuando se usó T07 (con } \\
\text { un tamaño de efecto de } \\
0,65 \text { ). Esto se probó } \\
\text { solamente con la } \\
\text { especificación TELE, sin } \\
\text { utilizar roles y con una sola } \\
\text { ronda" }\end{array}$ & A06 & 1 \\
\hline $\begin{array}{r}E \\
V 14\end{array}$ & $\begin{array}{l}\text { “Cuando se utilizó la } \\
\text { especificación TAXI, sin roles } \\
\text { y en una sola ronda, M01 fue } \\
\text { mejor para T04 que para T02 }\end{array}$ & $\mathrm{A} 08$ & 1 \\
\hline
\end{tabular}

Caso de estudio 


\begin{tabular}{|c|c|c|c|}
\hline & $\begin{array}{l}\text { (en un } 28 \% \text { ), aunque este } \\
\text { resultado no puede } \\
\text { afirmarse con un nivel de } \\
\text { confianza del } 95 \% \text {. Esto sólo } \\
\text { fue así en dos estudios". }\end{array}$ & & \\
\hline $\begin{array}{r}E \\
\text { V15 }\end{array}$ & $\begin{array}{l}\text { “Para muy pocos } \\
\text { estudios, se probó que M28 } \\
\text { usando T04 fue un poco } \\
\text { mejor que usando T02 (con } \\
\text { un tamaño de efecto de } \\
\text { 0,27); sin embargo, esto no } \\
\text { obtuvo significancia } \\
\text { estadística por lo que no se } \\
\text { puede asegurar que hay un } \\
\text { 95\% de confianza de que sea } \\
\text { cierto. Esto fue así para la } \\
\text { especificación TAXI, cuando } \\
\text { se realizó la inspección en } \\
\text { una sola ronda y sin utilizar } \\
\text { roles". }\end{array}$ & A10 & 0 \\
\hline $\begin{array}{r}E \\
\text { V16 }\end{array}$ & $\begin{array}{l}\text { "Para muy pocos } \\
\text { estudios, M29 usando T4 fue } \\
\text { un poco mejor que T02 (con } \\
\text { un tamaño de efecto de } \\
0,13 \text { ) utilizando la } \\
\text { especificación TAXI sin roles } \\
\text { y con una sola ronda. Sin } \\
\text { embargo, esto no puede } \\
\text { afirmarse con un } 95 \% \text { de } \\
\text { confianza". }\end{array}$ & A11 & 0 \\
\hline
\end{tabular}




\section{Proceso de RS de experimentos en Ingeniería del Software}

Tabla A.18. Resumen de hipótesis

\begin{tabular}{|r|c|c|}
\hline D I & Hipótesis & $\begin{array}{c}\text { Grupos } \\
\text { involucrados }\end{array}$ \\
\hline 01 & El rol parece influir en M04; de manera que \\
& $\begin{array}{l}\text { cuando se aplica la técnica sin rol T01 es mejor que } \\
\text { T02 y cuando se aplica con rol T02 es mejor que T01, } \\
\text { esto se ha dado sólo para la especificación ER. }\end{array}$ & A02_2 \\
\hline
\end{tabular}

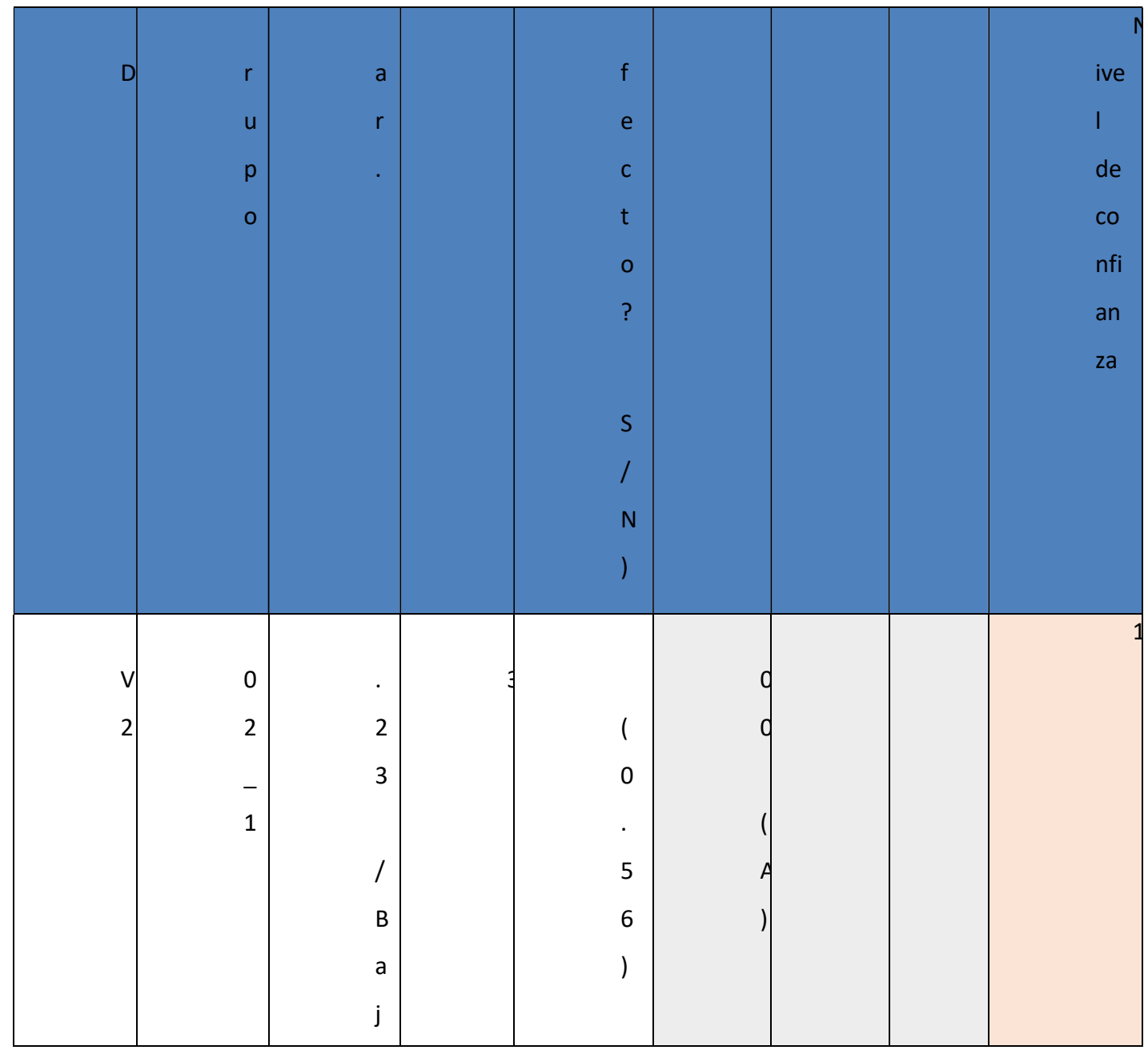

Caso de estudio 


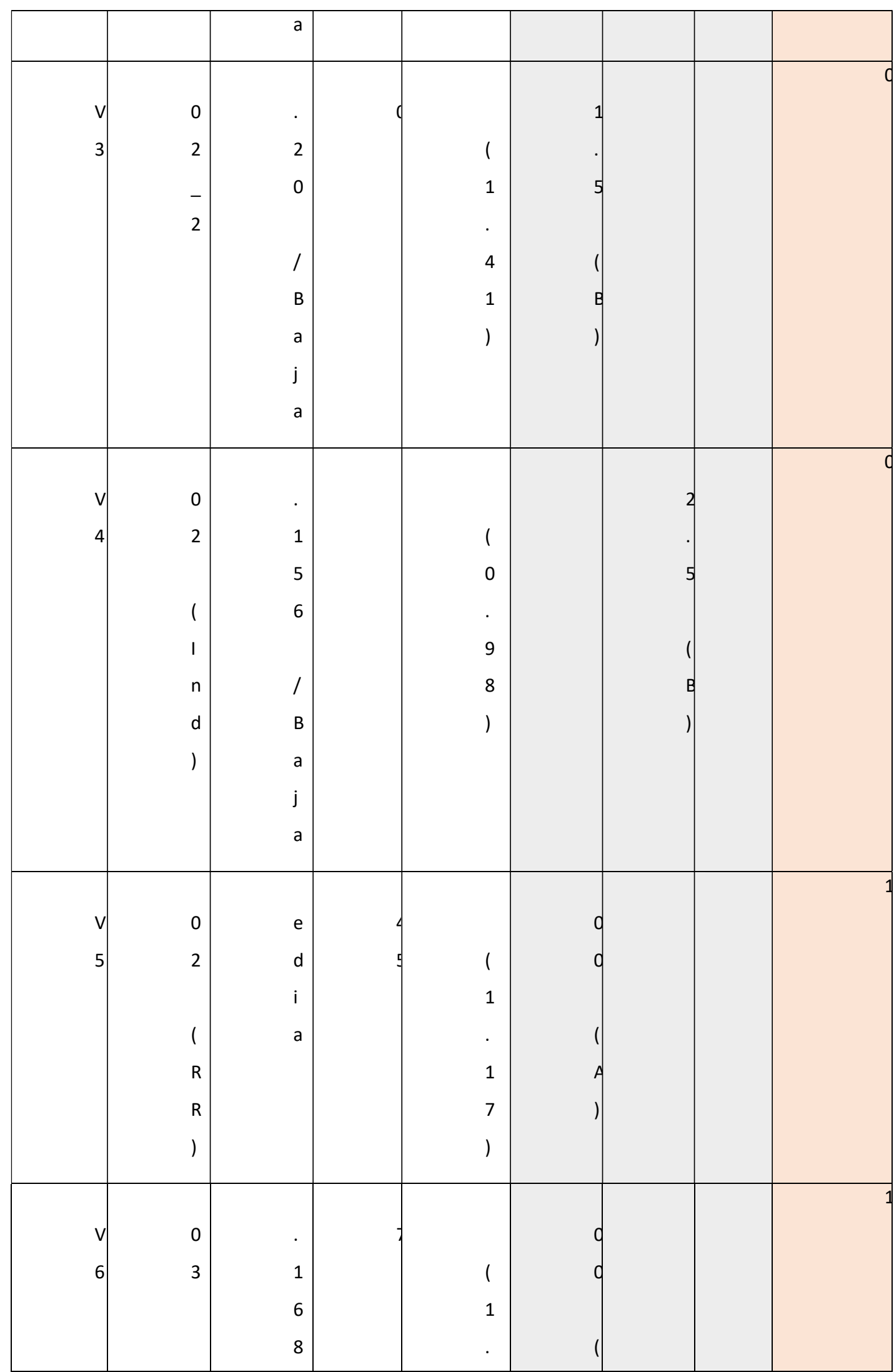


Proceso de RS de experimentos en Ingeniería del Software

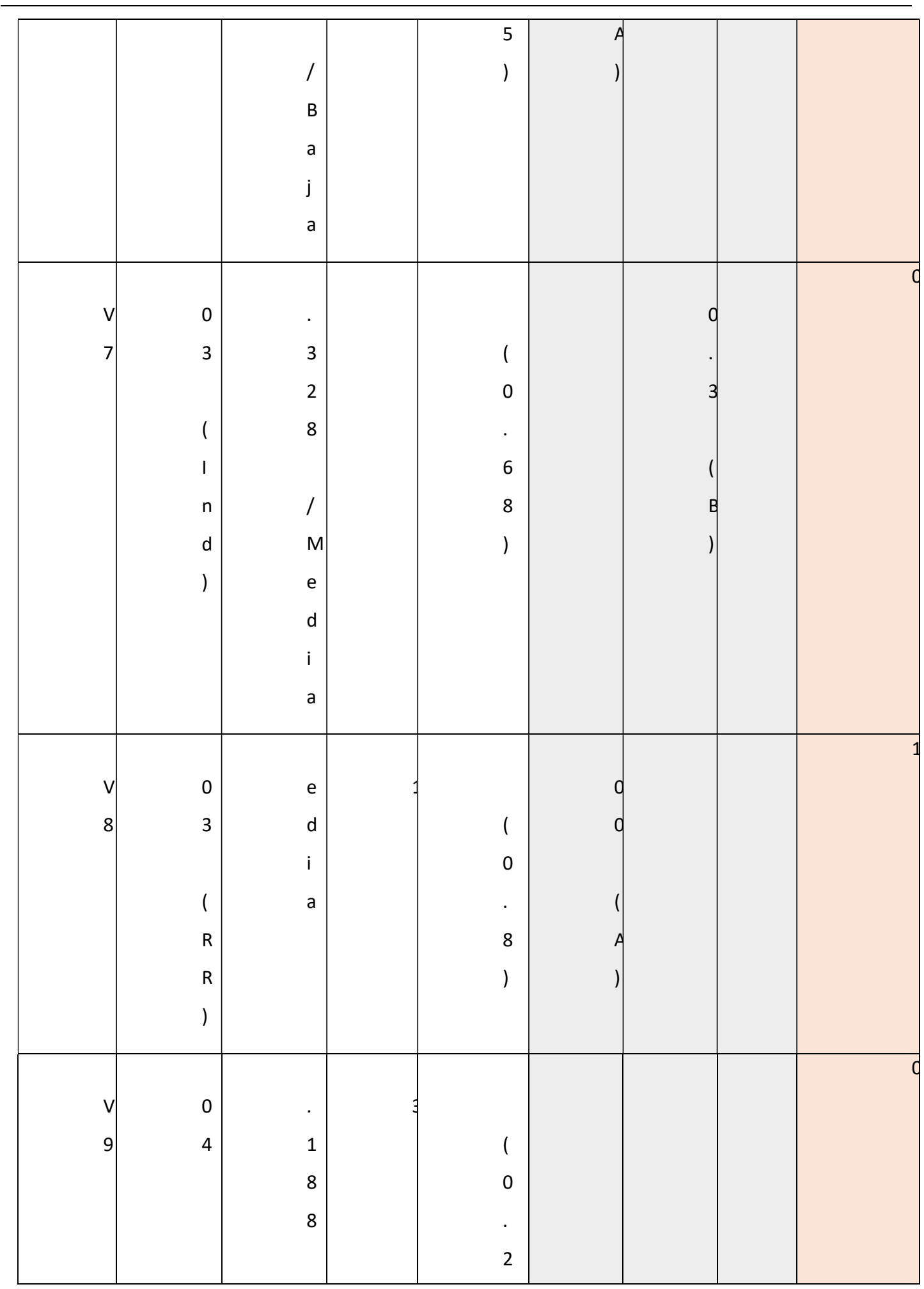

Caso de estudio 


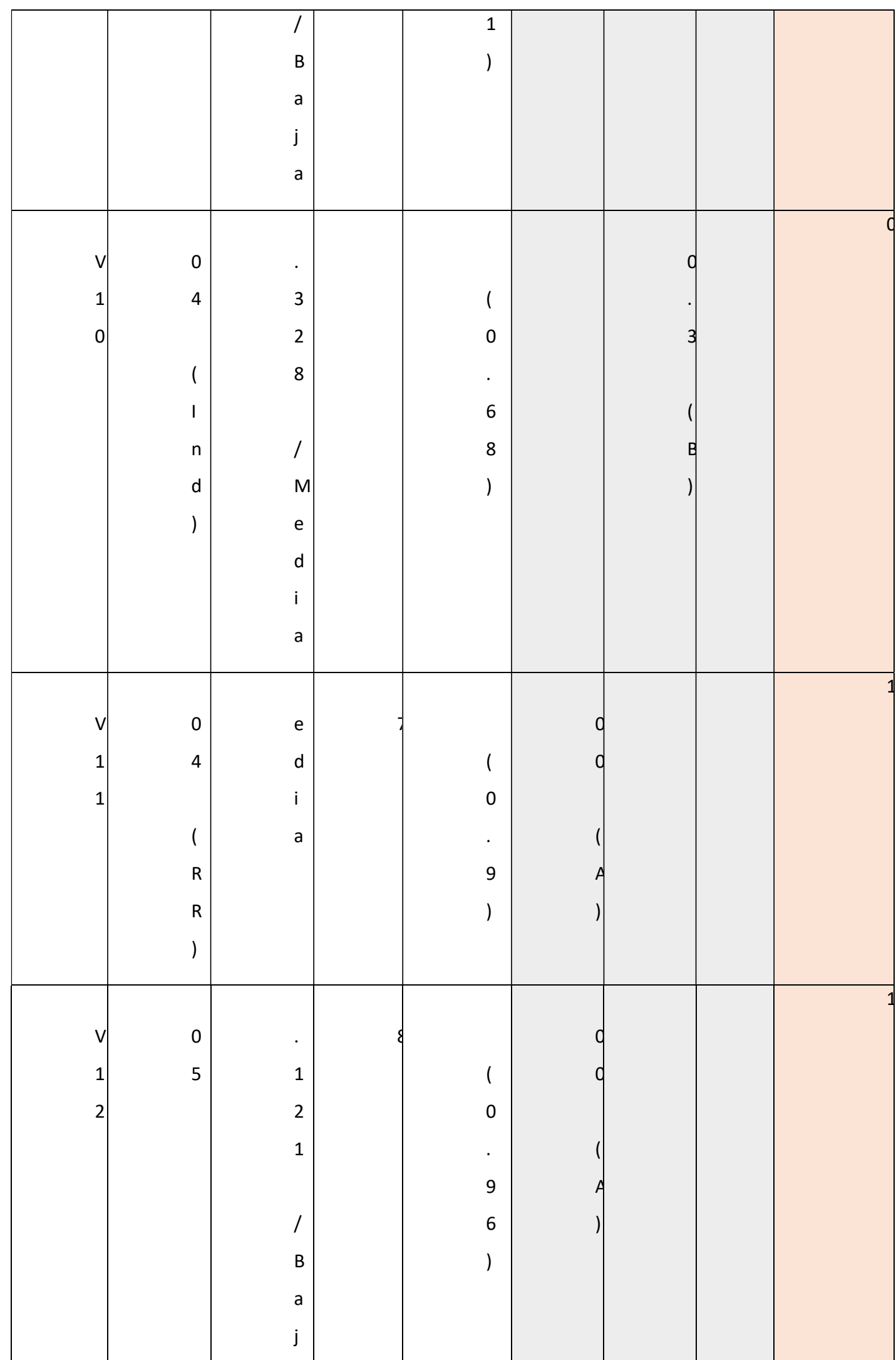


Proceso de RS de experimentos en Ingeniería del Software

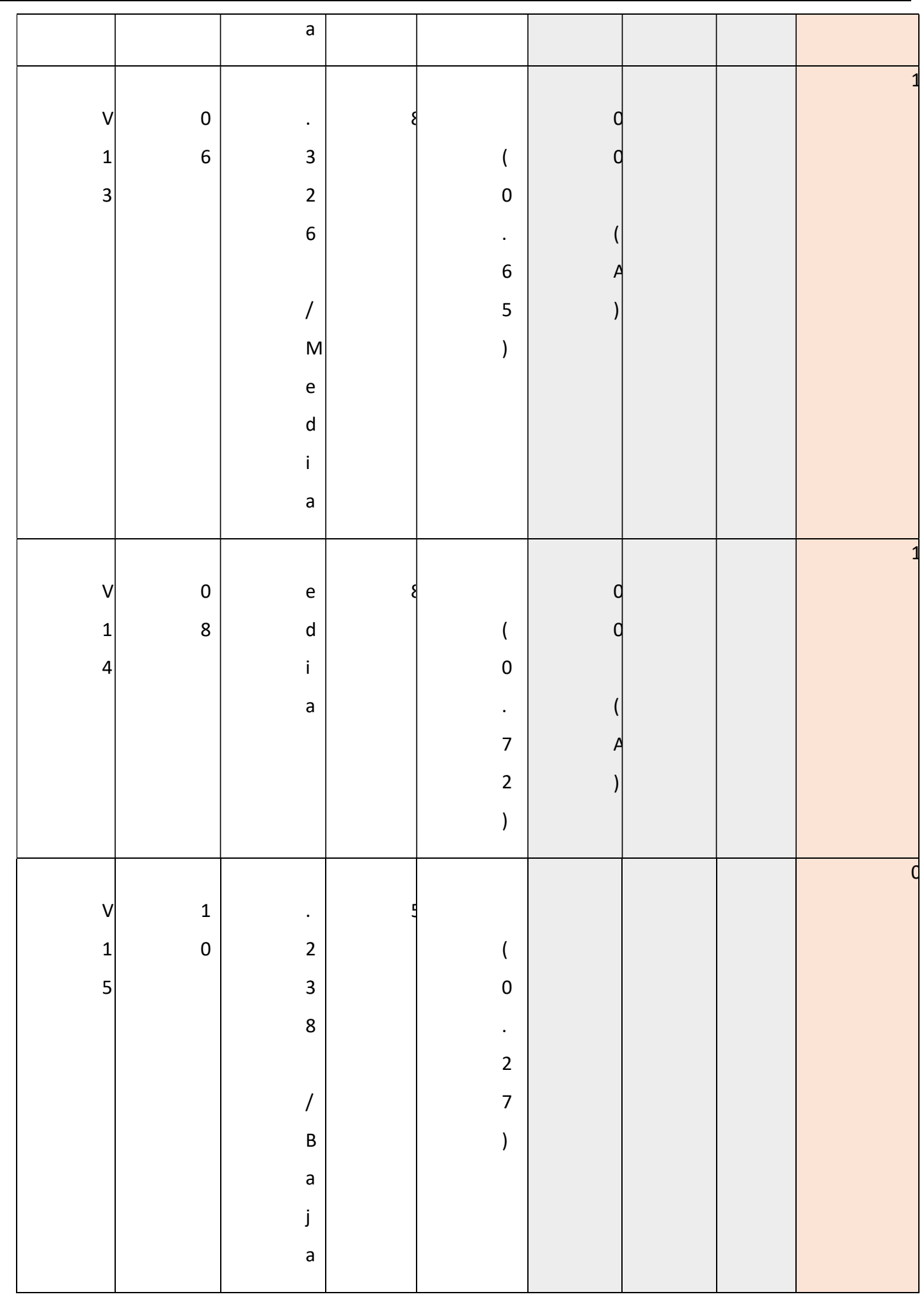

Caso de estudio

1121 
Extracción de Datos

Proceso de RS de experimentos en Ingeniería del

Software

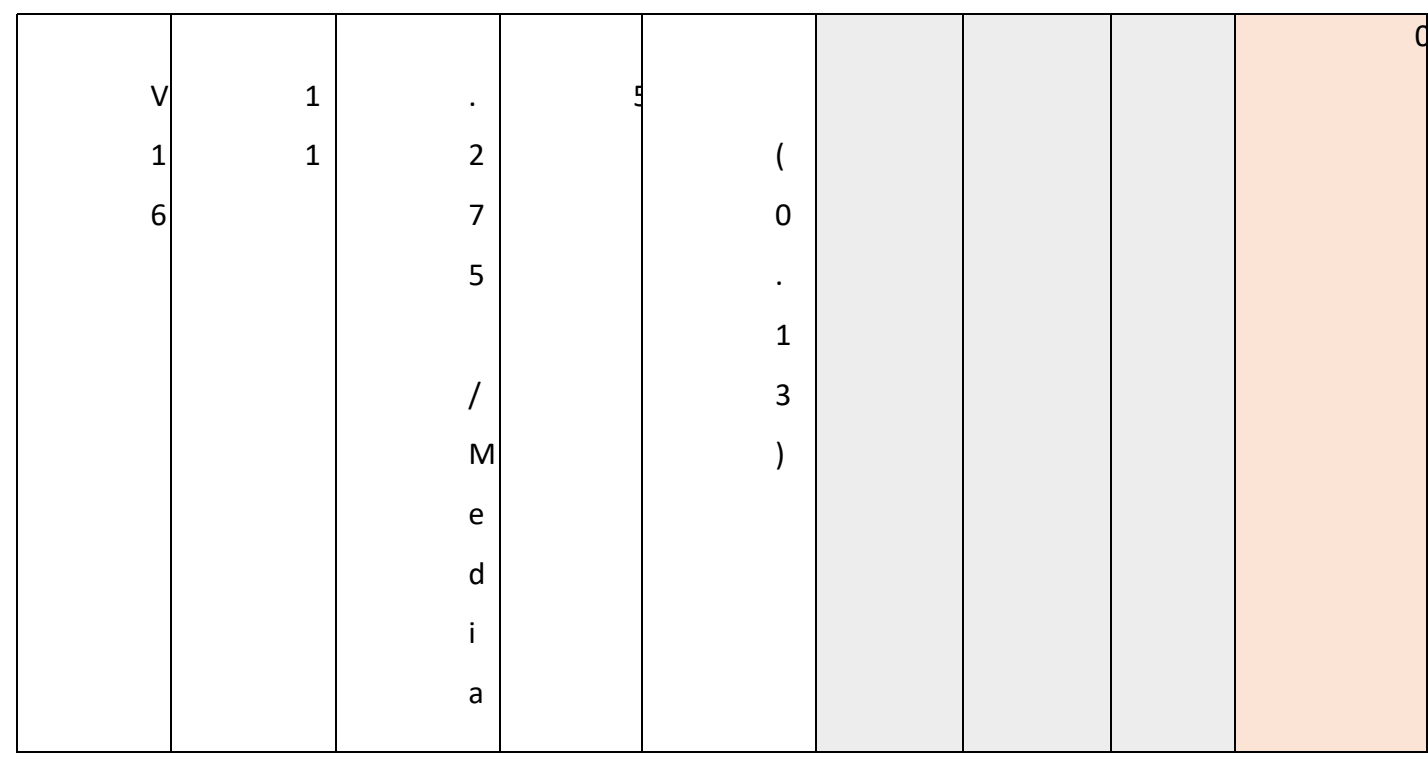


4.4. Combinar evidencias

4.4.1. Establcer jerarquías

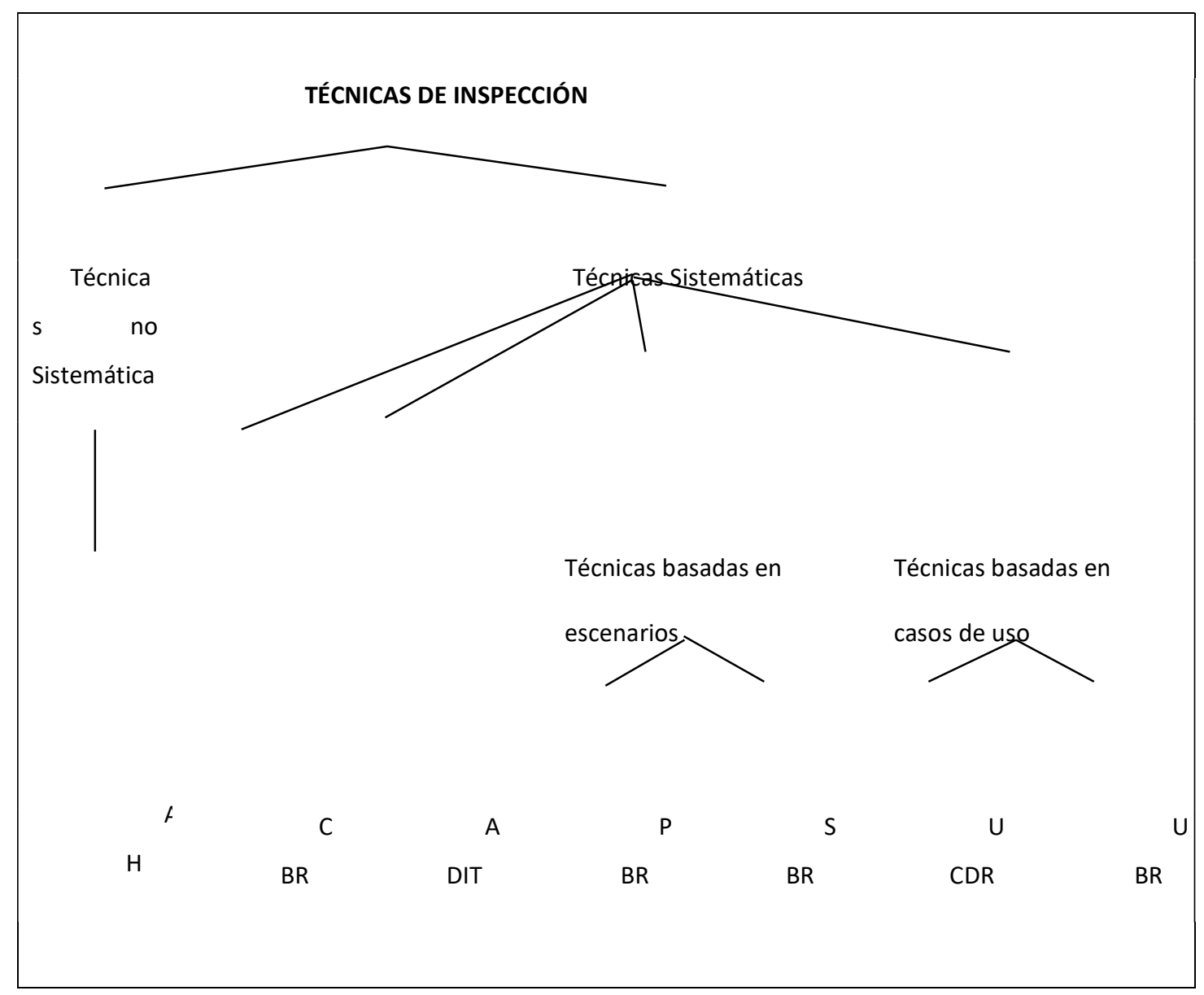

Figura A.1. Jerarquía de técnicas para la RS sobre inspección de software

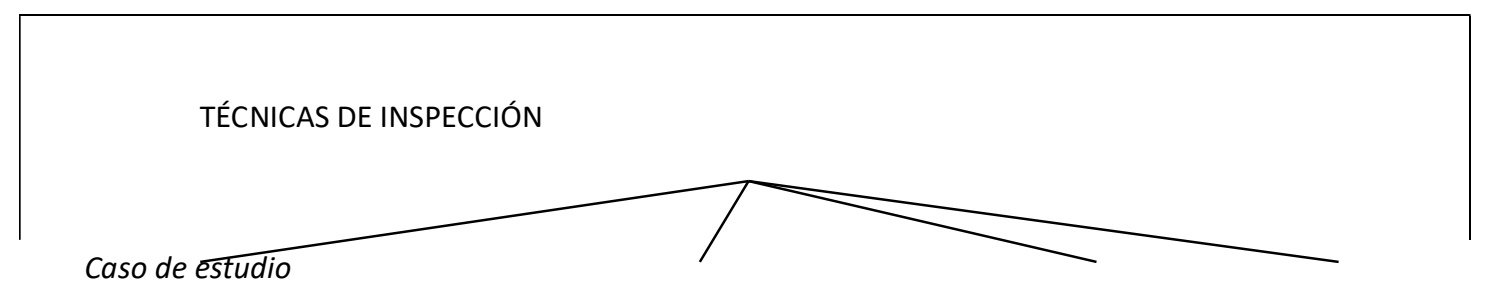




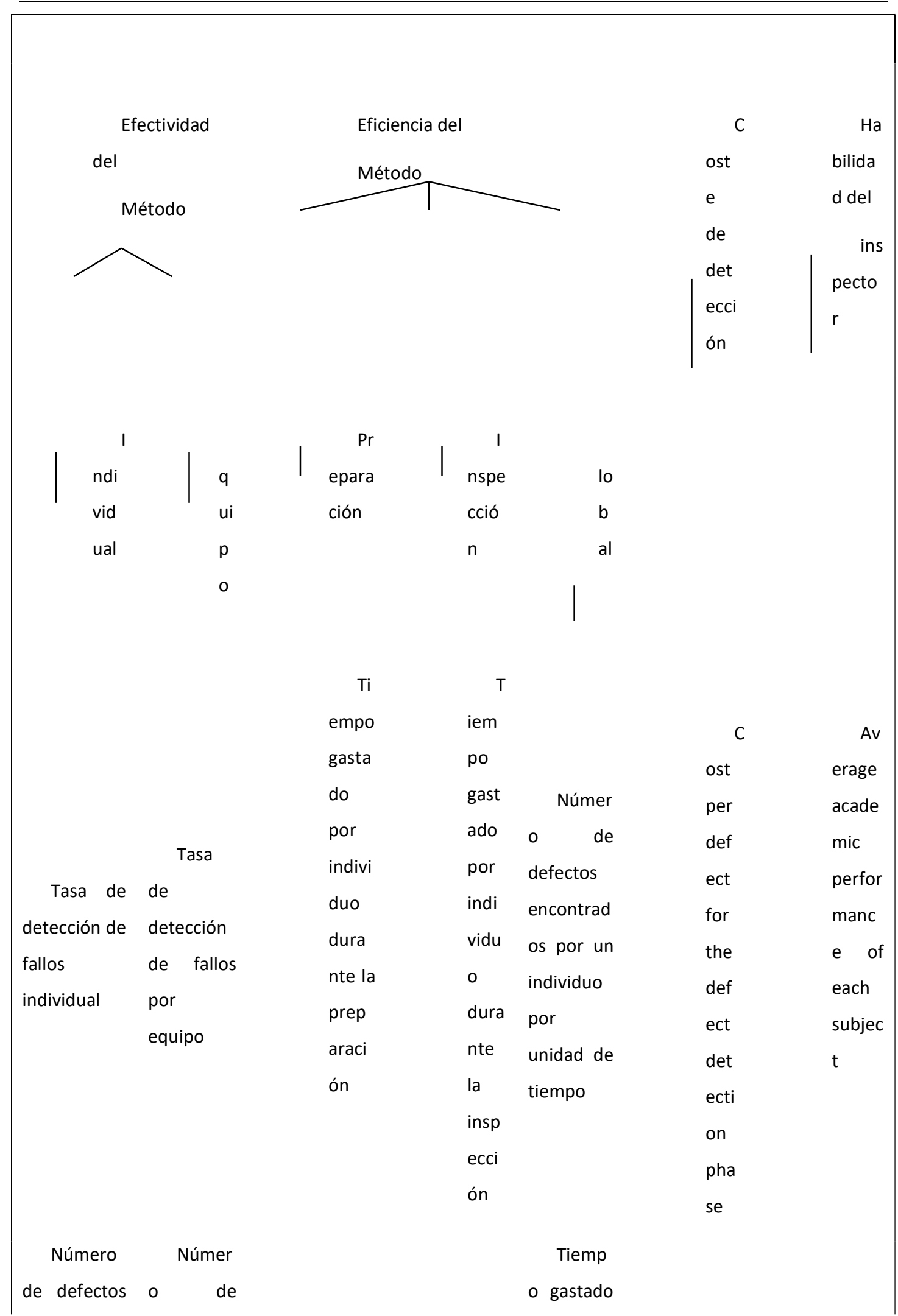


Proceso de RS de experimentos en Ingeniería del Software

\begin{tabular}{|lll|}
\hline encontrados & defectos & por \\
por sujeto & encontrad & individuo \\
& os por & \\
& equipo & Tiemp \\
& & o en el \\
Número & que es \\
de falsos & encontrad \\
positivos por & o un fallo \\
individuo & \\
\hline
\end{tabular}

Figura A.2. Jerarquía de VR y métricas para la RS sobre inspección de software

\subsubsection{Relacionar evidencias con la jerarquía de métricas y niveles}

Caso de estudio 


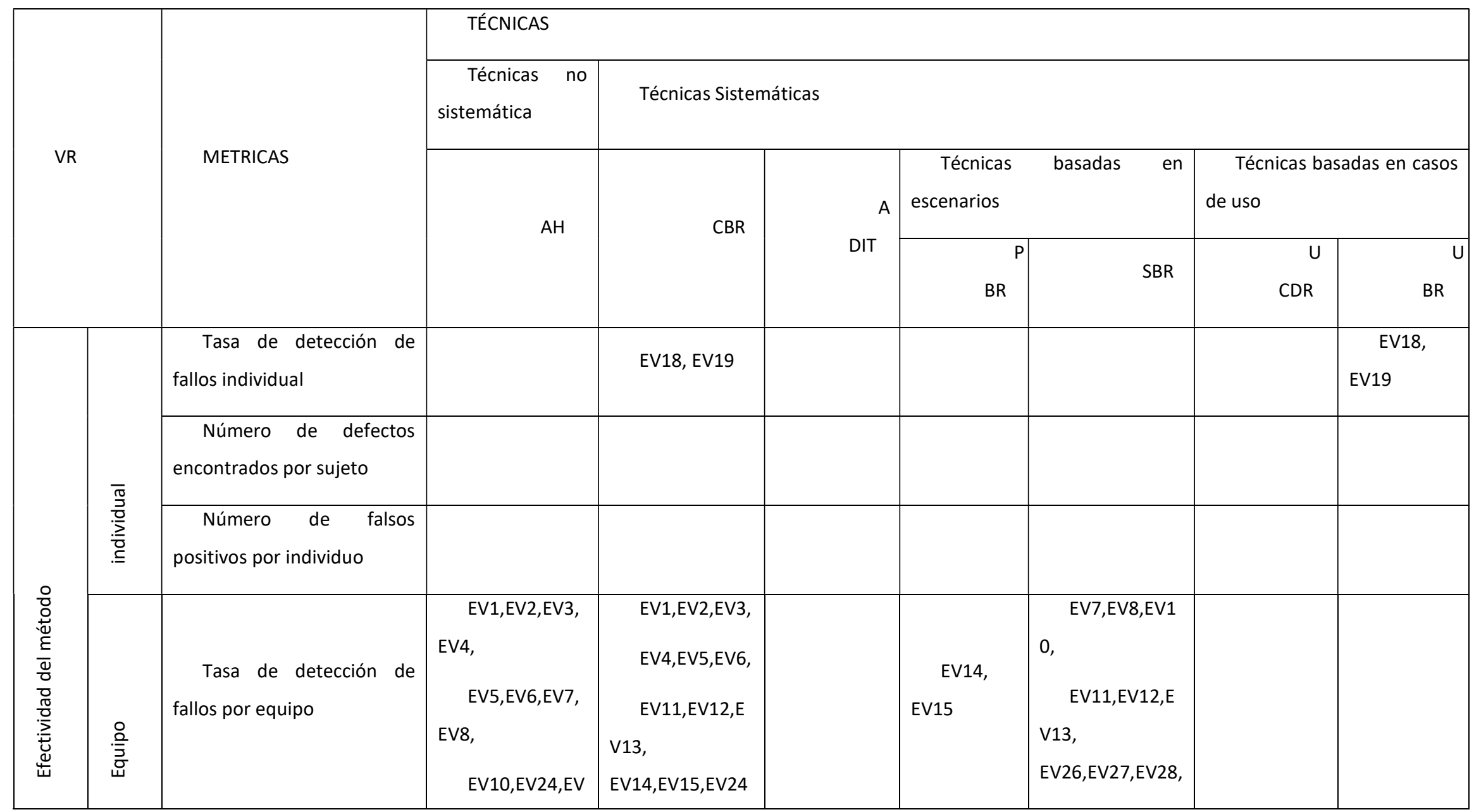


Proceso de RS de experimentos en Ingeniería del Software

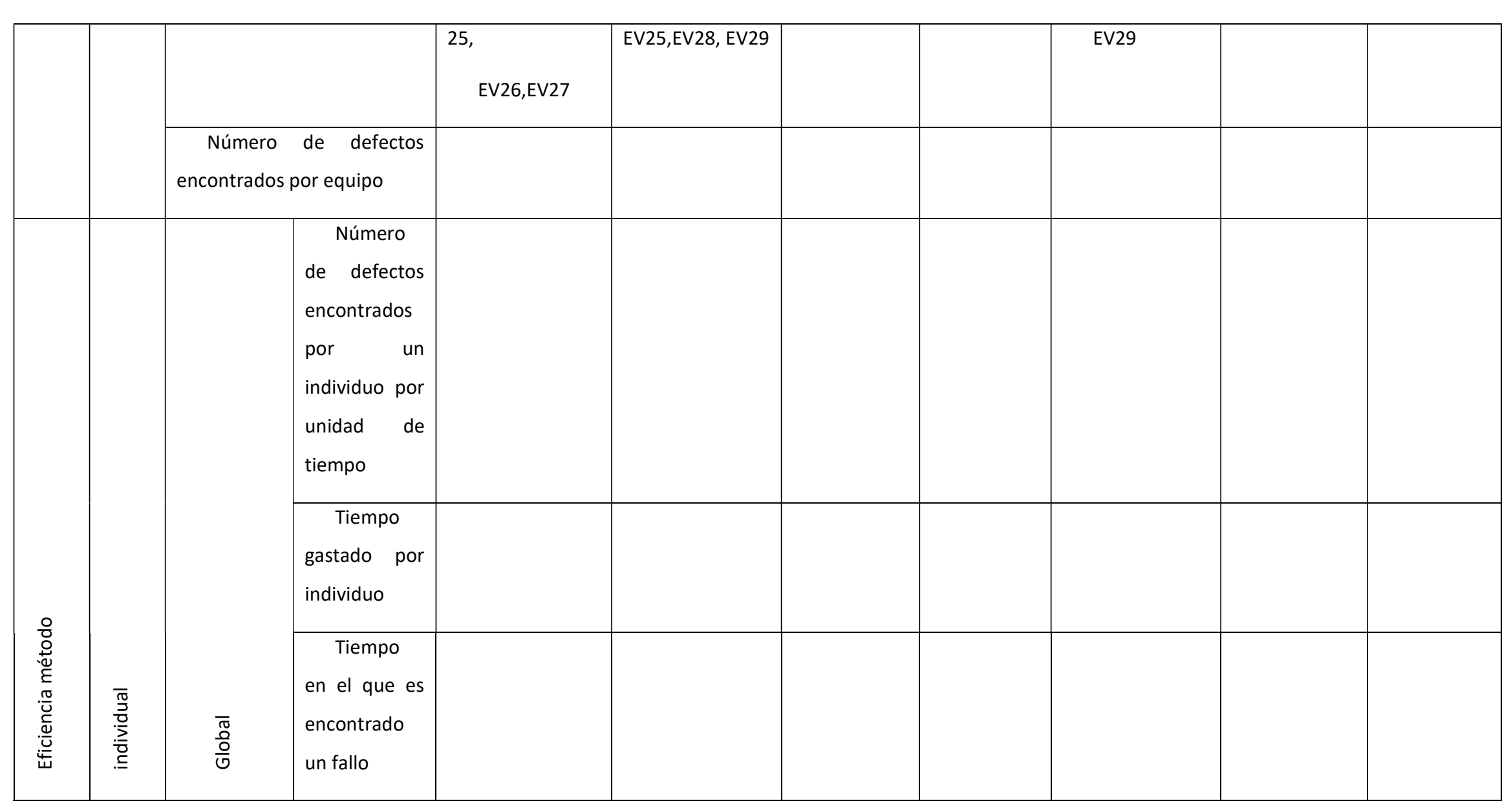




\begin{tabular}{|c|c|c|c|c|c|c|}
\hline & & 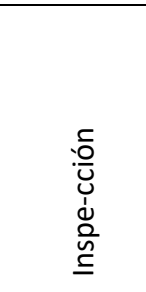 & \begin{tabular}{l}
\multicolumn{2}{c}{ Tiempo } \\
gastado por \\
individuo \\
durante la \\
inspección
\end{tabular} & EV20, EV21 & & $\begin{array}{l}\text { EV20, } \\
\text { EV21 }\end{array}$ \\
\hline & & 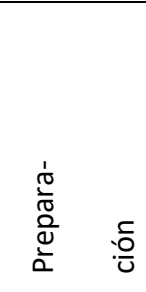 & \begin{tabular}{l}
\multicolumn{2}{c}{ Tiempo } \\
gastado por \\
individuo \\
durante la \\
preparación
\end{tabular} & EV22, EV23 & & $\begin{array}{l}\text { EV22, } \\
\text { EV23 }\end{array}$ \\
\hline & \multirow[b]{2}{*}{$\stackrel{\circ}{\frac{\circ}{7}}$} & \multicolumn{2}{|c|}{$\begin{array}{l}\text { Número de defectos } \\
\text { encontrados por un equipo } \\
\text { por unidad de tiempo }\end{array}$} & & & \\
\hline & & \multicolumn{2}{|c|}{$\begin{array}{l}\text { Tiempo máximo gastado } \\
\text { por un equipo durante la } \\
\text { inspección }\end{array}$} & & & \\
\hline 仓ัّ & $\frac{\square}{0.00}$ & \multicolumn{2}{|c|}{$\begin{array}{l}\text { Cost per defect for the } \\
\text { defect detection phase }\end{array}$} & EV16, EV17 & $\begin{array}{l}\text { EV16, } \\
\text { EV17 }\end{array}$ & \\
\hline
\end{tabular}


Proceso de RS de experimentos en Ingeniería del Software

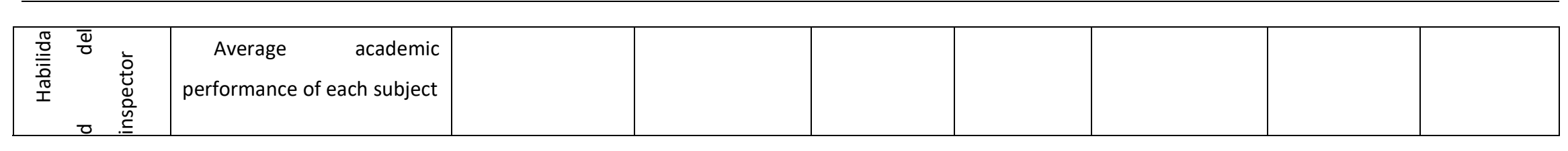




\subsubsection{Resumir evidencias}

\begin{tabular}{|c|c|}
\hline $\begin{array}{l}\quad \text { Nivel } \\
\text { o } \\
\text { tecnología }\end{array}$ & Evidencias obtenidas \\
\hline CBR & $\begin{array}{l}\text { - En relación a la efectividad de la técnica, existe una tendencia a que cuando } \\
\text { la inspección se realice en una sola ronda y sin incorporar roles, CBR sea } \\
\text { menos efectiva que AH en términos de la Tasa de detección de fallos por } \\
\text { equipo. En tales condiciones CBR fue también mucho menos efectiva que } \\
\text { PBR. } \\
\text { - Aunque no se puede afirmar con certeza, parece también haber una } \\
\text { tendencia a que CBR se comporte con menos efectividad que SBR, } \\
\text { independientemente de que la inspección se realice en una o dos rondas. } \\
\text { En algún caso, al incorporar roles, CBR ha demostrado ser más efectiva que } \\
\text { AH. Sin embargo, en la mayoría de los casos encontrados parece haber una } \\
\text { tendencia a que se mantenga la superioridad de AH frente a CBR. } \\
\text { En algunas ocasiones, cuando la efectividad de CBR ha sido medida en } \\
\text { términos de la Tasa de detección de fallos individual, CBR parece haber } \\
\text { tenido un peor comportamiento que UBR. } \\
\text { En cuanto a la eficiencia, es posible que en algunos casos el Tiempo gastado } \\
\text { roles durante la inspección, ni de la efectividad de CBR frente a AH/PBR/UBR } \\
\text { utilizando dos rondas. } \\
\text { al utilizar una técnica basada en casos de uso (UBR). Esto ha sido así cuando } \\
\text { la inspección no incorpora roles y se realiza en una sola ronda. De manera } \\
\text { - en que al utilizar UBR. }\end{array}$ \\
\hline
\end{tabular}




\section{Propuesta de un proceso de revisión de estudios empíricos en Ingeniería del Software}

\begin{tabular}{|l|l|}
\hline & $\begin{array}{l}\text { Por último, en relación al coste, se ha podido comprobar que en algunas } \\
\text { ocasiones el Coste por defecto para la fase de detección es mayor para CBR } \\
\text { que para PBR. Estos resultados corresponden a inspecciones en las que no se } \\
\text { han incorporado roles ni una segunda ronda. }\end{array}$ \\
\hline
\end{tabular}


